Universidade de São Paulo

Instituto de Astronomia, Geofisica e Ciências Atmosféricas

Departamento de Astronomia

Roberto Bertoldo Menezes

\title{
Espectroscopia 3D de núcleos ativos de galáxias: tratamento e análise de dados no óptico e infravermelho próximo.
}

São Paulo

2012 

Roberto Bertoldo Menezes

\section{Espectroscopia 3D de núcleos ativos de galáxias: tratamento e análise de dados no óptico e infravermelho próximo.}

Tese apresentada ao Departamento de Astronomia do Instituto de Astronomia, Geofísica e Ciências Atmosféricas da Universidade de São Paulo como parte dos requisitos para a obtenção do título de Doutor em Ciências

Área de Concentração: Astronomia

Orientador: Prof. Dr. João Evangelista Steiner

Versão corrigida. A versão original encontra-se disponível na biblioteca do Instituto de Astronomia, Geofísica e Ciências Atmosféricas da Universidade de São Paulo.

São Paulo

2012 

À minha mãe Lindete. 



\section{Agradecimentos}

$\mathrm{Eu}$ agradeço aos meus pais Lindete e Roberto por sempre me darem apoio em todas as minhas atividades.

Também gostaria de agradecer ao meu orientador João Evangelista Steiner por me guiar ao longo desse trabalho e me ajudar a superar as várias dificuldades encontradas.

Aos meus colegas Tiago Vecchi Ricci e Daniel May Nicolazzi por várias ajudas fornecidas durante a execução do trabalho.

Finalmente, gostaria de agradecer à FAPESP pelo apoio financeiro fornecido durante a execução do projeto. 



\section{Resumo}

Nesse trabalho, foram analisados os cubos de dados de oito AGNs próximos, no óptico e no infravermelho. O tratamento e a análise de todos os cubos de dados foram feitos utilizando-se uma série de metodologias específicas, muitas das quais foram desenvolvidas nos últimos anos pelo grupo de trabalho do autor. A utilização dessas metodologias permitiu a detecção de uma vasta fenomenologia que, de outra forma, não seria detectada ou seria observada não tão claramente. Dessa forma, pode-se dizer que esse trabalho teve um aspecto metodológico muito importante. A análise dos cubos de dados foi feita com quatro objetivos principais: análise da fenomenologia geral nos arredores do AGN, utilizando-se a Tomografia PCA; análise das populações estelares, da emissão térmica de poeira e do featureless continuum nos arredores do AGN, com o software Starlight; análise da cinemática das estrelas e do gás ao redor do buraco negro central e, em alguns casos, simulação com o objetivo de determinar a massa do buraco negro; análise dos mecanismos de excitação e ionização do gás ou da emissão molecular de $\mathrm{H}_{2}$.

A Tomografia PCA proporcionou uma visualização bastante detalhada da emissão proveniente do AGN central dos cubos de dados analisados. Além disso, essa metodologia detectou uma série de fenômenos cinemáticos associados ao gás e às estrelas, revelando, em alguns casos, discos em rotação ao redor do buraco negro central. A Tomografia PCA também mostrou existência de diferenciais de inclinação dos contínuos dos espectros dos cubos de dados. No infravermelho, foi possível separar regiões com o fluxo dominado pela emissão térmica de poeira (com espectros mais avermelhados) de áreas com o fluxo dominado, principalmente, por populações estelares (com espectros mais azulados). No óptico, por outro lado, os diferenciais de inclinação observados relaram a existência de possíveis nuvens de poeira (com espectros mais avermelhados). Por fim, a Tomografia PCA foi capaz de separar áreas nos cubos de dados com diferentes graus de ionização. No infravermelho, essa função da Tomografia PCA permitiu diferenciar regiões de mais alta ionização, geralmente associadas à NLR do AGN, de áreas com menor ionização, com espectros dominados pela emissão de $\mathrm{H}_{2}$. Essas últimas, em alguns casos, podiam estar associadas a um toro molecular ao redor do AGN.

A síntese espectral com o Starlight nos cubos de dados no infravermelho foi capaz de separar consideravelmente bem regiões com o fluxo dominado pelas populações estelares, pela emissão térmica de poeira e pelo featureless continuum. Em muitos casos, a emissão térmica de 
poeira observada podia estar associada a um toro de poeira ao redor do AGN, o que estaria de acordo com o Modelo Unificado. A síntese espectral dos cubos de dados no óptico, por outro lado, permitiu uma análise mais detalhada das populações estelares nos arredores do AGN.

O processo do pPXF revelou, de uma maneira bastante detalhada, a cinemática estelar nos cubos de dados. Em NGC 5643, M104 e M31, foi detectado um disco estelar em rotação ao redor do núcleo e, a partir disso, foi possível fazer simulações para se determinar a massa do buraco negro central nessas galáxias. Em M104 e NGC 5643, as simulações foram feitas com o método de Jeans e, em M31, essas simulações foram aplicadas utilizando-se apenas equações keplerianas básicas e desprezando-se a massa estelar ao redor do núcleo. Em M104, as simulações nos cubos de dados no óptico e no infravermelho resultaram em $M_{b h}=(2.0 \pm 0.8) \cdot 10^{8}$ $\mathrm{M}_{\odot}$ e $M_{b h}=(1.0 \pm 0.2) \cdot 10^{8} \mathrm{M}_{\odot}$, respectivamente, para a massa do buraco negro central. Em NGC 5643, a massa do buraco negro era muito menor do que a massa estelar ao seu redor, assim, foi possível calcular apenas um limite superior para $M_{b h}$. O valor obtido foi de $M_{b h_{-} \text {sup }}=$ $4.0 \cdot 10^{7} \mathrm{M}_{\odot}$. Em M31, as simulações com simples órbitas keplerianas resultaram em $M_{b h}=$ $4.5_{-1.1}^{+0.1} \cdot 10^{7} \mathrm{M}_{\odot}$

O ajuste de funções gaussianas nas linhas de emissão dos cubos de dados revelou uma considerável complexidade da cinemática do gás molecular e ionizado, com a presença de mais um fenômeno cinemático (como rotação e outflow) em vários casos. Em M31, foi detectado um disco emissor de $\mathrm{H} \alpha$ em rotação ao redor do núcleo. Esse disco jamais havia sido observado em estudos anteriores, logo, esse foi um achado de considerável importância. Uma simulação do mapa de velocidades de $\mathrm{H} \alpha$, utilizando órbitas keplerianas simples e desprezando-se a massa estelar ao redor do buraco negro, resultou em $M_{b h}=5.0_{-1.0}^{+0.3} \cdot 10^{7} \mathrm{M}_{\odot}$.

$\mathrm{O}$ estudo das razões de linhas de $\mathrm{H}_{2}$ no infravermelho revelou que a aproximação de ETL parece não ser válida na maior parte das regiões espaciais dos cubos de dados analisados. Nas áreas onde o ETL é uma boa aproximação, as temperaturas de excitação mais elevadas calculadas são compatíveis com um aquecimento das nuvens moleculares por raios-x, provavelmente emitidos pelo AGN central. Em M104 no óptico, simulações com o software Cloudy mostraram que a fotoionização por um AGN central é capaz de explicar as razões de linhas de emissão observadas. Os melhores modelos obtidos nessas simulações envolveram um featureless continuum com índice espectral de -1.5 , cortes inferiores de energia no contínuo entre $22 \mathrm{eV}$ e $26 \mathrm{eV}$ e parâmetros de ionização entre $10^{-3.9}$ e $10^{-3.6}$. 


\section{Abstract}

In this work, we analyzed data cubes of eight nearby AGNs, in the optical and infrared spectral regions. All data cube treatment and analysis were performed using a series of specific methodologies, many of which were developed in the last few years by the author's working group. The use of these methodologies allowed the detection of a significant phenomenology that, otherwise, would not be detected or would not be observed so clearly. This work has, therefore, an important methodological aspect. The analysis of the data cubes was performed with four main objectives: analysis of the general phenomenology of the AGN environment, using the PCA Tomography; analysis of the stellar populations, of the thermal emission from dust and of the featureless continuum in the vicinity of the AGN, using the Starlight software; analysis of the stellar and gas kinematics around the central black hole, and, in some cases, simulations with the purpose of determining the mass of the black hole; analysis of the excitation and ionization mechanisms of the gas or of the molecular emission of $\mathrm{H}_{2}$.

PCA Tomography allowed a very detailed visualization of the emission from the central AGN of the analyzed data cubes. Furthermore, this methodology detected a series of kinematic phenomena associated to the gas and to the stars, revealing, in some cases, rotating disks around

the central black holes. PCA Tomography also showed the existence of different inclinations of the spectral continua in the data cubes. In the infrared, it was possible to separate regions in which the flux was dominated by the thermal emission from dust (with redder spectra) from areas dominated, mainly, by stellar populations (with bluer spectra). In the optical, on the other hand, the different spectral inclinations revealed the existence of possible dust clouds (with redder spectra). Finally, the PCA Tomography was able to separate areas in the data cubes with different degrees of ionization. In the infrared, this use of the PCA Tomography allowed to differentiate between regions with higher ionization, usually associated to the NLR of the AGN, and areas with lower ionization, with spectra dominated by the emission of $\mathrm{H}_{2}$. The latter, in some cases, could be associated to a molecular torus around the AGN.

The spectral synthesis of the infrared data cubes with the Starlight separated considerably well regions in which the flux was dominated by the stellar populations, by the thermal emission from dust and by the featureless continuum. In many cases, the observed thermal emission from dust could be associated to a dust torus around the AGN, what would be 
in agreement with the Unified Model. The spectral synthesis in the optical data cubes, on the other hand, allowed a more detailed analysis of the stellar populations in the vicinity of the AGN.

The pPXF method revealed, in a very detailed way, the stellar kinematics of the data cubes. In NGC 5643, M104 and M31, it was detected a rotating stellar disk around the nucleus and, from that, it was possible to perform simulations in order to determine the mass of the central black hole in these galaxies. In M104 and NGC 5643, the simulations were performed with the Jeans method and, in M31, these simulations were made using only basic Keplerian equations and neglecting the stellar mass around the nucleus. In M104, the simulations in the data cubes in the optics and in the infrared resulted in $M_{b h}=(2.0 \pm 0.8) \cdot 10^{8} \mathrm{M}_{\odot}$ and $M_{b h}=$ $(1.0 \pm 0.2) \cdot 10^{8} \mathrm{M}_{\odot}$, respectively, for the mass of the central black hole. In NGC 5643, the mass of the black hole was much smaller than the stellar mass around it, therefore, it was possible to calculate only a superior limit for $M_{b h}$. The obtained value was $M_{b h_{-} s u p}=4.0 \cdot 10^{7} \mathrm{M}_{\odot}$. In M31, the simulations with simple Keplerian orbits resulted in $M_{b h}=4.5_{-1.1}^{+0.1} \cdot 10^{7} \mathrm{M}_{\odot}$.

The fitting of Gaussian functions to the emission lines in the data cubes revealed a considerable complexity of the kinematics of the molecular and ionized gas, with the presence of more than one kinematical phenomenon (like rotation plus outflow) in many cases. In M31, we detected a rotating $\mathrm{H} \alpha$ emitting disk around the nucleus. This disk had never been observed in previous studies, therefore, this is a finding of considerable importance. A simulation of the velocity map of $\mathrm{H \alpha}$, using simple Keplerian orbits and neglecting the stellar mass around the black hole, resulted in $M_{b h}=5.0_{-1.0}^{+0.3} \cdot 10^{7} \mathrm{M}_{\odot}$.

The study of the $\mathrm{H}_{2}$ line ratios in the infrared revealed that the approximation of ETL does not seem to be valid in most of the spatial regions of the analyzed data cubes. In the areas where the ETL is a good approximation, the highest calculated excitation temperatures are compatible with a heating of the molecular clouds by x-rays, probably emitted by the central AGN. For the optical data cube of M104, simulations with the Cloudy software showed that the photoionization by a central AGN can explain the observed emission line ratios. The best models obtained with these simulations involved a featureless continuum with a spectral index of -1.5 , lower energy cuts in the continuum between $22 \mathrm{eV}$ and $26 \mathrm{eV}$ and ionization parameters between $10^{-3.9}$ and $10^{-3.6}$. 


\section{Lista de Figuras}

2.1 - Distribuição de energia espectral (SED) média de um conjunto de quasares e QSOs........... 71

2.2 - Espectro médio de uma amostra de mais de 700 quasares e QSOs....................................... 81

2.3 - Espectro da galáxia Seyfert 1 Mrk 376 ................................................................................ 82

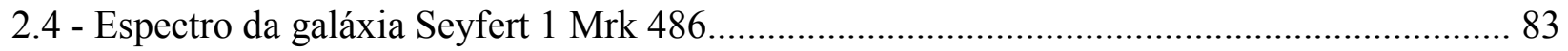

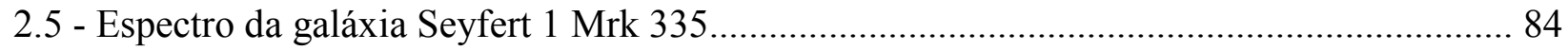

2.6 - Diagrama de diagnóstico com as razões de linhas [O III] $\lambda 5007 / \mathrm{H} \beta$ e [N II] $\lambda 6583 / \mathrm{H} \alpha \ldots \ldots . . .86$

2.7 - Diagramas de diagnóstico envolvendo as razões de linhas de $\mathrm{H}_{2} 2-1 \mathrm{~S}(1) / 1-0 \mathrm{~S}(1)$ e

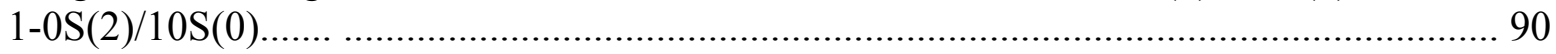

2.8 - Espectros nucleares de NGC 1068 com o fluxo total e com o fluxo polarizado.................... 95

2.9 - Esquema do cenário básico previsto pelo Modelo Unificado para os AGNs........................ 99

2.10 - Esquemas possíveis para a morfologia do toro de poeira dos AGNs assumindo-se uma distribuição contínua de densidade e uma distribuição clumpy de nuvens........................ 100

2.11 - Esquema mostrando o comportamento da temperatura da poeira no caso de uma distribuição clumpy de nuvens....................................................................................... 101

2.12 - Valores esperados de $f_{2}$ em função de $\sigma$ e $N_{0}$, considerando-se uma distribuição clumpy para a morfologia do toro.............................................................................................. 104

3.1 - Esquema do IFU dos espectrógrafos GMOS-N e GMOS-S............................................. 114

3.2 - Dados brutos da observação da estrela HD 26154 com o IFU do GMOS-S no modo two-slit e da observação da estrela ltt 4816 com o IFU do GMOS-S no modo one-slit................... 114

3.3 - Imagem de um intervalo espectral intermediário colapsado do cubo de dados de HD 26154, após a redução dos dados.

3.4 - Espectro extraído de uma região espacial (circular) centrada no objeto do cubo de dados de HD 26154, após a redução dos dados.

3.5 - Imagem de um intervalo espectral intermediário colapsado do cubo de dados de ltt 4816, após a redução dos dados.

3.6 - Espectro extraído de uma região espacial (circular) centrada no objeto do cubo de dados de ltt 4816, após a redução dos dados.

3.7 - Esquema com os principais componentes do NIFS do telescópio Gemini-Norte. 
3.8 - Dados brutos da observação da estrela GQ Lup, na banda K, com o NIFS.....

3.9 - Imagem de um intervalo espectral intermediário colapsado do cubo de dados de GQ Lup, após a redução dos dados

3.10 - Espectro extraído de uma região espacial (circular) centrada no objeto do cubo de dados de GQ Lup, após a redução dos dados 122

3.11 - Esquema com os principais componentes do SINFONI do VLT................................ 124

3.12 - Esquema mostrando o funcionamento básico de do image slicer do SINFONI............. 125

3.13 - Dados brutos da observação da estrela HIP 49220, na banda K, com o SINFONI......... 125

3.14 - Imagem de um intervalo espectral intermediário colapsado do cubo de dados de HIP 49220, após a redução dos dados.

3.15 - Espectro extraído de uma região espacial (circular) centrada no objeto do cubo de dados de HIP 49220, após a redução dos dados.

3.16 - Gráficos com as coordenadas $X_{c}$ e $Y_{c}$ dos centróides do cubo de dados de ltt 4816 em função do comprimento de onda, antes da correção da refração atmosférica diferencial, juntamente com as funções de terceiro grau ajustadas aos pontos................................ 130

3.17 - Composição RGB com imagens do cubo de dados de ltt 4816, antes da correção da refração atmosférica diferencial.

3.18 - Composição RGB com imagens do cubo de dados da estrela Cal 83, antes da correção da refração atmosférica diferencial.

3.19 - Gráficos com as coordenadas $X_{c}$ e $Y_{c}$ dos centróides do cubo de dados de ltt 4816 em função do comprimento de onda, após a correção da refração atmosférica diferencial.... 132

3.20 - Composição RGB com imagens do cubo de dados de ltt 4816, após a correção da refração atmosférica diferencial.

3.21 - Composição RGB com imagens do cubo de dados de Cal 83, após a correção da refração atmosférica diferencial.

3.22 - Gráficos com as coordenadas $X_{c}$ e $Y_{c}$ dos centróides do cubo de dados de GQ Lup em função do comprimento de onda, antes da correção da refração atmosférica diferencial, juntamente com as funções de terceiro grau ajustadas aos pontos.

3.23 - Gráficos com as coordenadas $X_{c}$ e $Y_{c}$ dos centróides do cubo de dados de GQ Lup em função do comprimento de onda, após a correção da refração atmosférica diferencial.... 136

3.24 - Gráficos com as coordenadas $X_{c}$ e $Y_{c}$ dos centróides do cubo de dados de HIP 49220 em função do comprimento de onda, antes da correção da refração atmosférica diferencial, juntamente com as funções de terceiro grau ajustadas aos pontos. 
3.25 - Composição RGB com imagens do cubo de dados de HIP 49220, antes da correção da refração atmosférica diferencial.

3.26 - Gráficos com as coordenadas $X_{c}$ e $Y_{c}$ dos centróides do cubo de dados de HIP $49220 \mathrm{em}$ função do comprimento de onda, após a correção da refração atmosférica diferencial... 138

3.27 - Composição RGB com imagens do cubo de dados de HIP 49220, após a correção da refração atmosférica diferencial.

3.28 - Perfil horizontal de brilho da imagem de um cubo de dados de uma estrela arbitrária, antes da reamostragem espacial, após uma reamostragem espacial simples e após uma reamostragem espacial seguida de uma interpolação dos valores.

3.29 - Imagem de um intervalo espectral intermediário colapsado do cubo de dados de GQ Lup, antes da aplicação da reamostragem espacial e após a aplicação da reamostragem espacial.

3.30 - Imagem do módulo da transformada de Fourier de um comprimento de onda intermediário do cubo de dados de GQ Lup, antes da aplicação da reamostragem espacial e após a aplicação da reamostragem espacial.

3.31 - Imagem de um intervalo espectral intermediário colapsado do cubo de dados de HIP 49220, antes da aplicação da reamostragem espacial e após a aplicação da reamostragem espacial.

3.32 - Imagem do módulo da transformada de Fourier de um comprimento de onda intermediário do cubo de dados de HIP 49220, antes da aplicação da reamostragem espacial e após a aplicação da reamostragem espacial.

3.33 - Imagens de um intervalo espectral intermediário colapsado dos cubos de dados $W_{0}, W_{l}$, $W_{2}, W_{3}, W_{4}$ e $W_{C}$, obtidas a partir do cubo de dados de ltt 4816 . 159

3.34 - Imagens de um intervalo espectral intermediário colapsado dos cubos de dados $W_{0}, W_{l}$, $W_{2}, W_{3}, W_{4}$ e $W_{C}$, obtidas a partir do cubo de dados de GQ Lup... 160

3.35 - Imagens de um intervalo espectral intermediário colapsado dos cubos de dados $W_{0}, W_{l}$, $W_{2}, W_{3}, W_{4}$ e $W_{C}$, obtidas a partir do cubo de dados de HIP 49220. 161

3.36 - Convolução das funções $f(m)$ e $h(m)$, sem periodicidade e com periodicidade. 167

3.37 - Convolução das funções $f(m)$ e $h(m)$, após a aplicação do procedimento do padding..... 168

3.38 - Imagem do módulo da transformada de Fourier de um comprimento de onda intermediário do cubo de dados de ltt 4816 .

3.39 - Imagens de um intervalo espectral intermediário colapsado do cubo de dados $W_{0}$ de ltt 4816, antes da filtragem espacial de Butterworth e após a filtragem com ordem $n=2$, $n=3, n=4, n=5$ e $n=6$.

3.40 - Módulos das transformadas de Fourier inversas de filtros de Butterworth com freqüência de corte de $0.15 \mathrm{Ny}$ e ordens $n=2, n=3, n=4, n=5$ e $n=6$. 
3.41 - Imagem de um intervalo espectral intermediário colapsado do cubo de dados $W_{0}$ de ltt 4816, após a aplicação da filtragem espacial de Butterworth com um filtro dado pela expressão (3.67) com $n=2$ e freqüência de corte de $0.18 \mathrm{Ny}$, e módulo da transformada de Fourier inversa do filtro utilizado na filtragem de Butterworth que originou a imagem anterior

3.42 - Imagem de um intervalo espectral intermediário colapsado do cubo de dados de ltt 4816, antes e após a filtragem espacial de Butterworth, e imagem de um intervalo espectral intermediário colapsado do cubo de dados de ltt 4816 correspondente à diferença entre o cubo não filtrado e o cubo filtrado.

3.43 - Imagens de um intervalo espectral intermediário colapsado do cubo de dados $W_{0}$ de GQ Lup, antes da filtragem espacial de Butterworth e após a filtragem com ordem $n=2$, $n=3, n=4, n=5$ e $n=6$.

3.44 - Módulos das transformadas de Fourier inversas de filtros de Butterworth com freqüência de corte de 0.32 Ny e ordens $n=2, n=3, n=4, n=5$ e $n=6$. 178

3.45 - Imagem de um intervalo espectral intermediário colapsado do cubo de dados de GQ Lup, antes e após a filtragem espacial de Butterworth, e imagem de um intervalo espectral intermediário colapsado do cubo de dados de GQ Lup correspondente à diferença entre o cubo não filtrado e o cubo filtrado.

3.46 - Imagens de um intervalo espectral intermediário colapsado do cubo de dados $W_{0}$ de GQ Lup, antes da filtragem espacial de Butterworth e após a filtragem com ordem $n=2$, $n=3, n=4, n=5$ e $n=6$.

3.47 - Módulos das transformadas de Fourier inversas de filtros de Butterworth com freqüência de corte de 0.25 Ny e ordens $n=2, n=3, n=4, n=5$ e $n=6$.

3.48 - Imagem de um intervalo espectral intermediário colapsado do cubo de dados $W_{0}$ de HIP 49220, após a aplicação da filtragem espacial de Butterworth com um filtro dado pela expressão (3.67) com $n=2$ e freqüência de corte de $0.28 \mathrm{Ny}$, e módulo da transformada de Fourier inversa do filtro utilizado na filtragem de Butterworth que originou a imagem anterior.

3.49 - Imagem de um intervalo espectral intermediário colapsado do cubo de dados de HIP 49220, antes e após a filtragem espacial de Butterworth, e imagem de um intervalo espectral intermediário colapsado do cubo de dados de HIP 49220 correspondente à diferença entre o cubo não filtrado e o cubo filtrado.

3.50 - Espectro extraído de uma região espacial (circular) centrada no objeto do cubo de dados de 1tt 4816, antes e após a aplicação do de-noising espectral. 187

3.51 - Espectro extraído de uma região espacial (circular) centrada no objeto do cubo de dados de GQ Lup, antes e após a aplicação do de-noising espectral.

3.52 - Espectro extraído de uma região espacial (circular) centrada no objeto do cubo de dados de HIP 49220, antes e após a aplicação do de-noising espectral. 
3.53 - Perfil horizontal de brilho da imagem de um intervalo espectral intermediário colapsado do cubo de dados de 1tt 4816, juntamente com o ajuste gaussiano, no formato da expressão (3.82), aplicado.

3.54 - Gráficos com os valores de $\log (F W H M)_{x}$ e $\log (F W H M)_{y}$ das imagens do cubo de dados de ltt 4816 em função de $\log \lambda$, juntamente com as funções lineares ajustadas aos pontos.

3.55 - Imagem de um intervalo espectral intermediário colapsado do cubo de dados de ltt 4816, antes e após a aplicação da deconvolução de Richardson-Lucy, utilizando-se 10 iterações

3.56 - Perfil horizontal de brilho da imagem de um intervalo espectral intermediário colapsado do cubo de dados de GQ Lup, juntamente com um ajuste gaussiano, no formato da expressão (3.82), e com um ajuste no formato da expressão (3.86).

3.57 - Imagem de um intervalo espectral intermediário colapsado do cubo de dados de GQ Lup, antes e após a aplicação da deconvolução de Richardson-Lucy, utilizando-se 10 iterações.

3.58 - Perfil vertical de brilho da imagem de um intervalo espectral intermediário colapsado do cubo de dados de HIP 49220, juntamente com um ajuste gaussiano, no formato da expressão (3.82), e com um ajuste no formato da expressão (3.86)...

3.59 - Imagem de um intervalo espectral intermediário colapsado do cubo de dados de HIP 49220, antes e após a aplicação da deconvolução de Richardson-Lucy, utilizando-se 10 iterações.

3.60 - Tomograma e auto-espectro correspondentes ao autovetor E4, resultante da aplicação da Tomografia PCA ao cubo de dados de M104, obtido com o IFU do GMOS, após a remoção das linhas espectrais, juntamente com o resultado encontrado após a subtração do spline do auto-espectro em questão.

3.61 - Tomograma e auto-espectro correspondentes ao autovetor E5, resultante da aplicação da Tomografia PCA ao cubo de dados de M104, obtido com o NIFS, após a remoção das linhas espectrais, juntamente com o resultado encontrado após a subtração do spline do auto-espectro em questão.

3.62 - Tomograma e auto-espectro correspondentes ao autovetor E3, resultante da aplicação da Tomografia PCA ao cubo de dados de NGC 5643, obtido com o SINFONI, após a remoção das linhas espectrais, juntamente com o resultado encontrado após a subtração do spline do auto-espectro em questão.

4.1 - Imagem na banda V das galáxias em interação NGC 2992 e NGC 2993, obtida com o

CTIO 225

4.2 - Mapa do contínuo em $6 \mathrm{~cm}$ da região central de NGC 2992, obtido pelo VLA................... 226

4.3 - Imagem na banda R+V da região central de NGC 2992, obtida com o HST. 227 
4.4 - Soma de todas as imagens do cubo de dados de NGC 2992, antes e após a aplicação da reamostragem espacial.

4.5 - Soma das imagens do cubo de dados de NGC 2992, antes e após a filtragem espacial de Butterworth, e soma das imagens do cubo de dados de NGC 2992 correspondente à diferença entre o cubo não filtrado e o cubo filtrado

4.6 - Tomograma e auto-espectro correspondentes ao autovetor E4, resultante da aplicação da Tomografia PCA ao cubo de dados de NGC 2992, após a remoção das linhas espectrais, juntamente com o resultado encontrado após a subtração do spline do auto-espectro em questão.

4.7 - Soma de todas as imagens e espectro médio do cubo de dados final de NGC 2992, obtido após todo o processamento.

4.8 - Tomograma e auto-espectro correspondentes ao autovetor E1, obtido com a Tomografia PCA do cubo de dados de NGC 2992 com o contínuo estelar.

4.9 - Tomograma correspondente ao autovetor E1, já mostrado na figura 4.8, com a LUT "exagerada".

4.10 - Tomograma e auto-espectro correspondentes ao autovetor E2, obtido com a Tomografia PCA do cubo de dados de NGC 2992 com o contínuo estelar.

4.11 - Tomograma e auto-espectro correspondentes ao autovetorE3, obtido com a Tomografia PCA do cubo de dados de NGC 2992 com o contínuo estelar.

4.12 - Tomograma e auto-espectro correspondentes ao autovetor E4, obtido com a Tomografia PCA do cubo de dados de NGC 2992 com o contínuo estelar.

4.13 - Tomograma e auto-espectro correspondentes ao autovetor E5, obtido com a Tomografia PCA do cubo de dados de NGC 2992 com o contínuo estelar. 234

4.14 - Tomograma e auto-espectro correspondentes ao autovetor E6, obtido com a Tomografia PCA do cubo de dados de NGC 2992 com o contínuo estelar. 234

4.15 - Ampliação na região espectral da linha $\mathrm{H}_{2} \lambda 21218$ dos auto-espectros correspondentes aos autovetores E5 e E6, obtidos com a Tomografia PCA do cubo de dados de NGC 2992 com o contínuo estelar. 235

4.16 - Scree test dos autovetores obtidos com a Tomografia PCA do cubo de dados de NGC 2992 com o contínuo estelar.

4.17 - Mapeamento dos valores do $\chi^{2} / n_{\text {eff }}$ dos ajustes obtidos pelo Starlight para os espectros do cubo de dados de NGC 2992.

4.18 - Mapeamento do fluxo total devido às populações estelares, obtido com a aplicação do Starlight ao cubo de dados de NGC 2992.

4.19 - Mapeamento do fluxo total devido à emissão térmica de poeira, obtido com a aplicação do Starlight ao cubo de dados de NGC 2992. 
4.20 - Mapeamento do fluxo atribuído ao featureless continuum do AGN, obtido com a aplicação do Starlight ao cubo de dados de NGC 2992.

4.21 - Gráfico representativo das frações de fluxo devidas às populações estelares, à emissão térmica de poeira e ao featureless continuum, considerando-se todo o campo visual do SINFONI, obtido com a aplicação do Starlight ao cubo de dados de NGC 2992............. 244

4.22 - Composição RGB contendo os mapeamentos do fluxo associado às populações estelares, à emissão térmica de poeira e ao featureless continuum, obtidos a partir da síntese espectral do cubo de dados de NGC 2992

4.23 - Mapeamentos dos valores da razão $S / N$, obtidos a partir da síntese espectral do cubo de dados de NGC 2992 com o Starlight.

4.24 - Tomograma e auto-espectro correspondentes ao autovetor E1, obtido com a Tomografia PCA do cubo de dados de NGC 2992 com o contínuo estelar subtraído.

4.25 - Tomograma e auto-espectro correspondentes ao autovetor E2, obtido com a Tomografia PCA do cubo de dados de NGC 2992 com o contínuo estelar subtraído.

4.26 - Tomograma e auto-espectro correspondentes ao autovetor E3, obtido com a Tomografia PCA do cubo de dados de NGC 2992 com o contínuo estelar subtraído.

4.27 - Tomograma e auto-espectro correspondentes ao autovetor E4, obtido com a Tomografia PCA do cubo de dados de NGC 2992 com o contínuo estelar subtraído.

4.28 - Ampliação na região espectral da linha $\mathrm{H}_{2} \lambda 21218$ do auto-espectro correspondente ao autovetor E4, obtido com a Tomografia PCA do cubo de dados de NGC 2992 com o contínuo estelar subtraído.

4.29 - Scree test dos autovetores obtidos com a Tomografia PCA do cubo de dados de NGC 2992 com o contínuo estelar subtraído.

4.30 - Mapeamentos dos valores da velocidade radial estelar, da dispersão de velocidades estelar, do coeficiente $h_{3}$ e do coeficiente $h_{4}$, obtidos com a aplicação do pPXF ao cubo de dados de NGC 2992.

4.31 - Mapeamento dos valores de velocidade radial do gás molecular, obtido com a linha de $\mathrm{H}_{2} \lambda 21218$ do cubo de dados de NGC 2992.

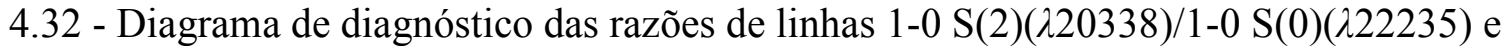
1-0 Q(1)(224066)/1-0 S(1)(221218) do cubo de dados de NGC 2992.

4.33 - Mapeamento dos valores da temperatura de excitação do cubo de dados de NGC 2992,

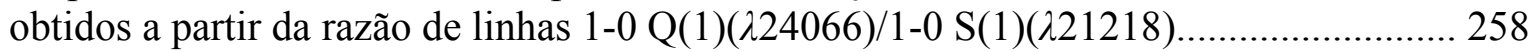

5.1 - Imagem da galáxia NGC 4151, obtida com o SDSS........................................................... 261

5.2 - Imagem em $21 \mathrm{~cm}$ da região central de NGC 4151........................................................... 262

5.3 - Imagem em [O III] $\lambda 5007$ da região central de NGC 4151, obtida com o HST.................. 263 
5.4 - Soma de todas as imagens do cubo de dados de NGC 4151, antes e após a aplicação da reamostragem espacial.

5.5 - Soma das imagens do cubo de dados de NGC 4151, antes e após a filtragem espacial de Butterworth, e soma das imagens do cubo de dados de NGC 4151 correspondente à diferença entre o cubo não filtrado e o cubo filtrado. 266

5.6 - Espectro extraído de uma região circular central do cubo de dados de NGC 4151, antes e após a aplicação do de-noising.....

5.7 - Soma de todas as imagens e espectro médio do cubo de dados final de NGC 4151, obtido após todo o processamento.

5.8 - Tomograma e auto-espectro correspondentes ao autovetor E1, obtido com a Tomografia PCA do cubo de dados de NGC 4151 com o contínuo estelar..

5.9 - Tomograma e auto-espectro correspondentes ao autovetor E2, obtido com a Tomografia PCA do cubo de dados de NGC 4151 com o contínuo estelar..

5.10 - Tomograma e auto-espectro correspondentes ao autovetor E3, obtido com a Tomografia PCA do cubo de dados de NGC 4151 com o contínuo estelar..

5.11 - Tomograma e auto-espectro correspondentes ao autovetor E4, obtido com a Tomografia PCA do cubo de dados de NGC 4151 com o contínuo estelar...

5.12 - Tomograma e auto-espectro correspondentes ao autovetor E5, obtido com a Tomografia PCA do cubo de dados de NGC 4151 com o contínuo estelar..

5.13 - Tomograma e auto-espectro correspondentes ao autovetor E6, obtido com a Tomografia PCA do cubo de dados de NGC 4151 com o contínuo estelar..

5.14 - Tomograma e auto-espectro correspondentes ao autovetor E7, obtido com a Tomografia PCA do cubo de dados de NGC 4151 com o contínuo estelar.

5.15 - Tomograma e auto-espectro correspondentes ao autovetor E8, obtido com a Tomografia PCA do cubo de dados de NGC 4151 com o contínuo estelar.

5.16 - Tomograma e auto-espectro correspondentes ao autovetor E9, obtido com a Tomografia PCA do cubo de dados de NGC 4151 com o contínuo estelar.

5.17 - Tomograma e auto-espectro correspondentes ao autovetor E10, obtido com a Tomografia PCA do cubo de dados de NGC 4151 com o contínuo estelar.

5.18 - Scree test dos autovetores obtidos com a Tomografia PCA do cubo de dados de NGC 4151 com o contínuo estelar.

5.19 - Sobreposição da imagem da emissão em $21 \mathrm{~cm}$ da região central de NGC 4151 ao tomograma da figura 5.10 .

5.20 - Mapeamento dos valores do $\chi^{2} / n_{\text {eff }}$ dos ajustes obtidos pelo Starlight para os espectros do cubo de dados de NGC 4151 . 
5.21 - Mapeamento do fluxo total devido às populações estelares, obtido com a aplicação do Starlight ao cubo de dados de NGC 4151.................................................................... 278

5.22 - Mapeamento do fluxo total devido à emissão térmica de poeira, obtido com a aplicação do Starlight ao cubo de dados de NGC 4151 ............................................................... 278

5.23 - Mapeamento do fluxo atribuído ao featureless continuum do AGN, obtido com a aplicação do Starlight ao cubo de dados de NGC 4151............................................................. 278

5.24 - Gráfico representativo das frações de fluxo devidas às populações estelares, à emissão térmica de poeira e ao featureless continuum, considerando-se todo o campo visual do NIFS, obtido com a aplicação do Starlight ao cubo de dados de NGC 4151

5.25 - Composição RGB contendo os mapeamentos do fluxo associado às populações estelares, à emissão térmica de poeira e ao featureless continuum, obtidos a partir da síntese espectral do cubo de dados de NGC 4151

5.26 - Mapeamentos dos valores da razão $S / N$, obtidos a partir da síntese espectral do cubo de dados de NGC 4151 com o Starlight.

5.27 - Tomograma e auto-espectro correspondentes ao autovetor E1, obtido com a Tomografia PCA do cubo de dados de NGC 4151 com o contínuo estelar subtraído.

5.28 - Tomograma e auto-espectro correspondentes ao autovetor E3, obtido com a Tomografia PCA do cubo de dados de NGC 4151 com o contínuo estelar subtraído.

5.29 - Tomograma e auto-espectro correspondentes ao autovetor E5, obtido com a Tomografia PCA do cubo de dados de NGC 4151 com o contínuo estelar subtraído.

5.30 - Tomograma e auto-espectro correspondentes ao autovetor E6, obtido com a Tomografia PCA do cubo de dados de NGC 4151 com o contínuo estelar subtraído.

5.31 - Tomograma e auto-espectro correspondentes ao autovetor E8, obtido com a Tomografia PCA do cubo de dados de NGC 4151 com o contínuo estelar subtraído.

5.32 - Tomograma e auto-espectro correspondentes ao autovetor E9, obtido com a Tomografia PCA do cubo de dados de NGC 4151 com o contínuo estelar subtraído.

5.33 - Tomograma e auto-espectro correspondentes ao autovetor E10, obtido com a Tomografia PCA do cubo de dados de NGC 4151 com o contínuo estelar subtraído.

5.34 - Tomograma e auto-espectro correspondentes ao autovetor E11, obtido com a Tomografia PCA do cubo de dados de NGC 4151 com o contínuo estelar subtraído.

5.35 - Tomograma e auto-espectro correspondentes ao autovetor E12, obtido com a Tomografia PCA do cubo de dados de NGC 4151 com o contínuo estelar subtraído.

5.36 - Scree test dos autovetores obtidos com a Tomografia PCA do cubo de dados de NGC 4151 com o contínuo estelar subtraído. 
5.37 - Imagem correspondente à média ponderada das imagens das linhas de $\mathrm{H}_{2}$ do cubo de dados I' de NGC 4151, juntamente com o RGB associado. 290

5.38 - Imagem da linha de Bry do cubo de dados I' de NGC 4151, juntamente com o RGB associado e com a imagem em [O III] da região central de NGC 4151, obtida com o HST.

5.39 - Mapeamentos dos valores da velocidade radial estelar, da dispersão de velocidades estelar, do coeficiente $h_{3}$ e do coeficiente $h_{4}$, obtidos com a aplicação do pPXF ao cubo de dados de NGC 4151 292

5.40 - Mapeamentos dos valores de velocidade radial do gás, obtidos com as linhas de $\mathrm{H}_{2} \lambda 21218$

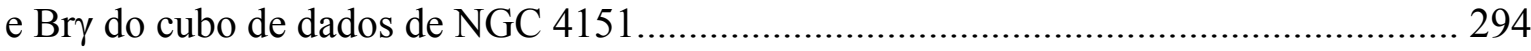

5.41 - Esquema do outflow bi-cônico a partir do AGN de NGC 4151......................................... 295

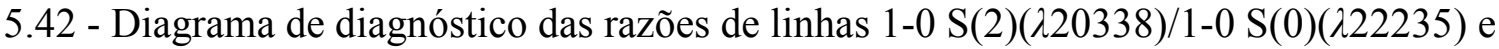

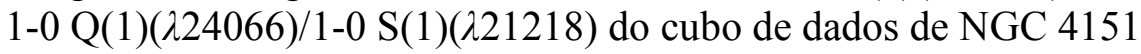

5.43 - Mapeamento dos valores da temperatura de excitação do cubo de dados de NGC 4151,

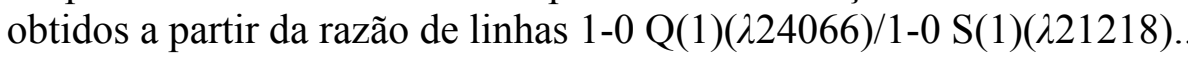

6.1 - Imagem da galáxia NGC 3227, obtida com o SDSS............................................................. 301

6.2 - Imagens da emissão de H I (em 21 cm) e de CO na região central de NGC 3227.............. 303

6.3 - Modelo de disco distorcido para o gás molecular ao redor do AGN central de NGC 3227.

6.4 - Imagem de um intervalo espectral intermediário colapsado do cubo de dados de NGC 3227 obtido com o GMOS, antes e após a filtragem espacial de Butterworth, e imagem de um intervalo espectral intermediário colapsado do cubo de dados de NGC 3227 obtido com o GMOS, correspondente à diferença entre o cubo não filtrado e o cubo filtrado.

6.5 - Tomograma e auto-espectro correspondentes ao autovetor E4, resultante da aplicação da Tomografia PCA ao cubo de dados de NGC 3227 obtido com o GMOS, após a remoção das linhas espectrais, juntamente com o resultado encontrado após a subtração do spline do autoespectro em questão. 307

6.6 - Soma de todas as imagens e espectro médio do cubo de dados de NGC 3227 obtido com o GMOS, após todo o processamento. 308

6.7 - Soma de todas as imagens do cubo de dados de NGC 3227 obtido com o SINFONI, antes e após a aplicação da reamostragem espacial. 309

6.8 - Soma das imagens do cubo de dados de NGC 3227 obtido com o SINFONI, antes e após a filtragem espacial de Butterworth, e soma das imagens do cubo de dados de NGC 3227 obtido com o SINFONI, correspondente à diferença entre o cubo não filtrado e o cubo filtrado. 
6.9 - Tomograma e auto-espectro correspondentes ao autovetor E6, resultante da aplicação da Tomografia PCA ao cubo de dados de NGC 3227 obtido com o SINFONI, após a remoção das linhas espectrais, juntamente com o resultado encontrado após a subtração do spline do auto-espectro em questão.

6.10 - Soma de todas as imagens e espectro médio do cubo de dados de NGC 3227 obtido com o SINFONI, após todo o processamento.

6.11 - Tomograma e auto-espectro correspondentes ao autovetor E1, resultante da Tomografia PCA do cubo de dados de NGC 3227 obtido com o GMOS, com o contínuo estelar...... 313

6.12 - Ampliação na região espectral azul do auto-espectro correspondente ao autovetor E1, resultante da Tomografia PCA do cubo de dados de NGC 3227 obtido com o GMOS, com o contínuo estelar.

6.13 - Tomograma e auto-espectro correspondentes ao autovetor E2, resultante da Tomografia PCA do cubo de dados de NGC 3227 obtido com o GMOS, com o contínuo estelar...... 314

6.14 - Tomograma e auto-espectro correspondentes ao autovetor E3, resultante da Tomografia PCA do cubo de dados de NGC 3227 obtido com o GMOS, com o contínuo estelar...... 314

6.15 - Ampliação na região espectral azul do auto-espectro correspondente ao autovetor E3, resultante da Tomografia PCA do cubo de dados de NGC 3227 obtido com o GMOS, com o contínuo estelar.

6.16 - Tomograma e auto-espectro correspondentes ao autovetor E4, resultante da Tomografia PCA do cubo de dados de NGC 3227 obtido com o GMOS, com o contínuo estelar...... 315

6.17 - Ampliação na região espectral azul do auto-espectro correspondente ao autovetor E4, resultante da Tomografia PCA do cubo de dados de NGC 3227 obtido com o GMOS, com o contínuo estelar.

6.18 - Scree test dos autovetores encontrados com a Tomografia PCA do cubo de dados de NGC 3227 obtido com o GMOS, com o contínuo estelar.

6.19 - Tomograma e auto-espectro correspondentes ao autovetor E1, resultante da Tomografia PCA do cubo de dados de NGC 3227 obtido com o SINFONI, com o contínuo estelar.. 319

6.20 - Tomograma e auto-espectro correspondentes ao autovetor E2, resultante da Tomografia PCA do cubo de dados de NGC 3227 obtido com o SINFONI, com o contínuo estelar.. 319

6.21 - Tomograma e auto-espectro correspondentes ao autovetor E3, resultante da Tomografia PCA do cubo de dados de NGC 3227 obtido com o SINFONI, com o contínuo estelar.. 319

6.22 - Tomograma e auto-espectro correspondentes ao autovetor E7, resultante da Tomografia PCA do cubo de dados de NGC 3227 obtido com o SINFONI, com o contínuo estelar.. 320

6.23 - Tomograma e auto-espectro correspondentes ao autovetor E9, resultante da Tomografia PCA do cubo de dados de NGC 3227 obtido com o SINFONI, com o contínuo estelar.. 320 
6.24 - Tomograma e auto-espectro correspondentes ao autovetor E11, resultante da Tomografia PCA do cubo de dados de NGC 3227 obtido com o SINFONI, com o contínuo estelar.. 320

6.25 - Scree test dos autovetores encontrados com a Tomografia PCA do cubo de dados de NGC 3227 obtido com o SINFONI, com o contínuo estelar.

6.26 - Mapeamento dos valores do $\chi^{2} / n_{\text {eff }}$ dos ajustes do Starlight para os espectros do cubo de dados de NGC 3227 obtido com o SINFONI.............................................................. 325

6.27 - Mapeamento do fluxo total devido às populações estelares, resultante da aplicação do Starlight ao cubo de dados de NGC 3227 obtido com o SINFONI.............................. 326

6.28 - Mapeamento do fluxo devido à emissão térmica de poeira com temperaturas entre $700 \mathrm{~K}$ e $1000 \mathrm{~K}$, resultante da aplicação do Starlight ao cubo de dados de NGC 3227 obtido com o SINFONI.

6.29 - Mapeamento do fluxo devido à emissão térmica de poeira com temperaturas entre $1100 \mathrm{~K}$ e 1400 K, resultante da aplicação do Starlight ao cubo de dados de NGC 3227 obtido com o SINFONI 327

6.30 - Mapeamento do fluxo atribuído ao featureless continuum do AGN, resultante da aplicação do Starlight ao cubo de dados de NGC 3227 obtido com o SINFONI.....

6.31 - Gráfico representativo das frações de fluxo devidas às populações estelares, à emissão térmica de poeira e ao featureless continuum, considerando-se todo o campo visual do SINFONI, resultante da aplicação do Starlight ao cubo de dados de NGC 3227 obtido com o SINFONI 328

6.32 - Composição RB contendo os mapeamentos do fluxo associado à emissão térmica de poeira com temperaturas entre $1100 \mathrm{~K}$ e $1400 \mathrm{~K}$ e entre $700 \mathrm{~K}$ e $1000 \mathrm{~K}$, resultantes da síntese espectral do cubo de dados de NGC 3227 obtido com o

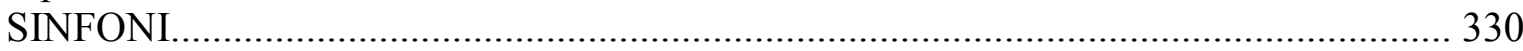

6.33 - Composição RGB contendo os mapeamentos do fluxo associado às populações estelares, à emissão térmica de poeira com temperaturas entre $1100 \mathrm{~K}$ e $1400 \mathrm{~K}$ e ao featureless continuum, resultantes da síntese espectral do cubo de dados de NGC 3227 obtido com o SINFONI.

6.34 - Composição RGB contendo os mapeamentos do fluxo associado à emissão térmica de poeira com temperaturas entre $1100 \mathrm{~K}$ e $1400 \mathrm{~K}$, ao featureless continuum e à emissão de $\mathrm{H}_{2}$, resultantes da síntese espectral do cubo de dados de NGC 3227 obtido com o SINFONI.

6.35 - Mapeamentos dos valores da razão $S / N$, resultantes da aplicação do Starlight ao cubo de dados de NGC3227 obtido com o SINFONI.

6.36 - Tomograma e auto-espectro correspondentes ao autovetor E1, resultante da Tomografia PCA do cubo de dados de NGC 3227 obtido com o GMOS, com o contínuo estelar subtraído 
6.37 - Ampliação na região espectral azul do auto-espectro correspondente ao autovetor E1, resultante da Tomografia PCA do cubo de dados de NGC 3227 obtido com o GMOS, com o contínuo estelar subtraído.

6.38 - Tomograma e auto-espectro correspondentes ao autovetor E2, resultante da Tomografia PCA do cubo de dados de NGC 3227 obtido com o GMOS, com o contínuo estelar subtraído.

6.39 - Ampliação na região espectral azul do auto-espectro correspondente ao autovetor E2, resultante da Tomografia PCA do cubo de dados de NGC 3227 obtido com o GMOS, com o contínuo estelar subtraído.

6.40 - Tomograma e auto-espectro correspondentes ao autovetor E3, resultante da Tomografia PCA do cubo de dados de NGC 3227 obtido com o GMOS, com o contínuo estelar subtraído.

6.41 - Ampliação na região espectral azul do auto-espectro correspondente ao autovetor E3, resultante da Tomografia PCA do cubo de dados de NGC 3227 obtido com o GMOS, com o contínuo estelar subtraído.

6.42 - Scree test dos autovetores encontrados com a Tomografia PCA do cubo de dados de NGC 3227 obtido com o GMOS, com o contínuo estelar subtraído.

6.43 - Tomograma e auto-espectro correspondentes ao autovetor E1, resultante da Tomografia PCA do cubo de dados de NGC 3227 obtido com o SINFONI, com o contínuo estelar subtraído.

6.44 - Tomograma e auto-espectro correspondentes ao autovetor E8, resultante da Tomografia PCA do cubo de dados de NGC 3227 obtido com o SINFONI, com o contínuo estelar subtraído.

6.45 - Tomograma e auto-espectro correspondentes ao autovetor E9, resultante da Tomografia PCA do cubo de dados de NGC 3227 obtido com o SINFONI, com o contínuo estelar subtraído.

6.46 - Scree test dos autovetores encontrados com a Tomografia PCA do cubo de dados de NGC 3227 obtido com o SINFONI, com o contínuo estelar subtraído.

6.47 - Imagem da linha de $\mathrm{H}_{2} \lambda 21218$ do cubo de dados de NGC 3227 obtido com o SINFONI, com o contínuo estelar subtraído.

6.48 - Mapeamentos dos valores da velocidade radial estelar, da dispersão de velocidades estelar, do coeficiente $h_{3}$ e do coeficiente $h_{4}$, resultantes da aplicação do PPXF ao cubo de dados de NGC 3227, obtido com o GMOS. 344

6.49 - Mapeamentos dos valores da velocidade radial estelar, da dispersão de velocidades estelar, do coeficiente $h_{3}$ e do coeficiente $h_{4}$, resultantes da aplicação do pPXF ao cubo de dados de NGC 3227, obtido com o SINFONI. 
6.50 - Mapeamento dos valores da velocidade radial do gás, construído com base na linha de [N II] $\lambda 6583$ do cubo de dados de NGC 3227 obtido com o GMOS.

6.51 - Mapeamento dos valores da velocidade radial do gás, construído com base na linha de $\mathrm{H}_{2} \lambda 21218$ do cubo de dados de NGC 3227 obtido com o SINFONI..

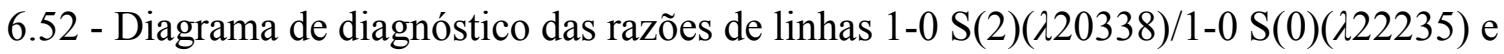

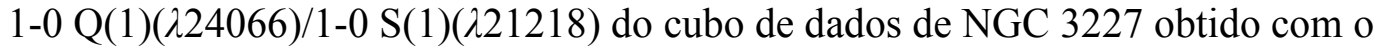
SINFONI.

6.53 - Mapeamento dos valores da temperatura de excitação do cubo de dados de NGC3227 obtido com o SINFONI, construído a partir da razão de linhas

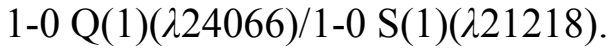

7.1 - Imagem da galáxia NGC 5643 na banda V, obtida com o HST .......................................... 355

7.2 - Mapa do contínuo em $6 \mathrm{~cm}$ da região central de NGC 5643, obtido pelo VLA................... 356

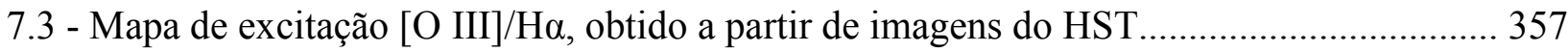

7.4 - Soma de todas as imagens do cubo de dados de NGC 5643, antes e após a aplicação da

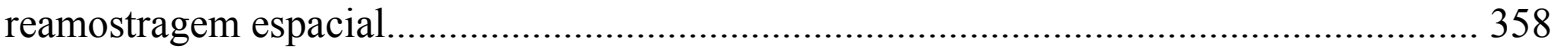

7.5 - Soma das imagens do cubo de dados de NGC 5643, antes e após a filtragem espacial de Butterworth, e soma das imagens do cubo de dados de NGC 5643 correspondente à diferença entre o cubo não filtrado e o cubo filtrado.

7.6 - Tomograma e auto-espectro correspondentes ao autovetor E3, resultante da aplicação da Tomografia PCA ao cubo de dados de NGC 5643, após a remoção das linhas espectrais, juntamente com o resultado encontrado após a subtração do spline do auto-espectro em

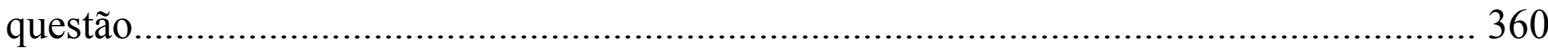

7.7 - Soma de todas as imagens e espectro médio do cubo de dados final de NGC 5643, obtido após todo o processamento.

7.8 - Tomograma e auto-espectro correspondentes ao autovetor E1, obtido com a Tomografia PCA do cubo de dados de NGC 5643 com o contínuo estelar.

7.9 - Tomograma e auto-espectro correspondentes ao autovetor E2, obtido com a Tomografia PCA do cubo de dados de NGC 5643 com o contínuo estelar.

7.10 - Tomograma e auto-espectro correspondentes ao autovetor E3, obtido com a Tomografia PCA do cubo de dados de NGC 5643 com o contínuo estelar.

7.11 - Ampliação do intervalo espectral entre $21000 \AA$ e $22750 \AA$ do auto-espectro correspondente ao autovetor E3, obtido com a Tomografia PCA do cubo de dados de NGC 5643 com o contínuo estelar.

7.12 - Tomograma e auto-espectro correspondentes ao autovetor E4, obtido com a Tomografia PCA do cubo de dados de NGC 5643 com o contínuo estelar. 
7.13 - Tomograma e auto-espectro correspondentes ao autovetor E5, obtido com a Tomografia PCA do cubo de dados de NGC 5643 com o contínuo estelar...

7.14 - Ampliação do intervalo espectral entre $21000 \AA$ e $22750 \AA$ do auto-espectro correspondente ao autovetor E5, obtido com a Tomografia PCA do cubo de dados de NGC 5643 com o contínuo estelar.

7.15 - Scree test dos autovetores obtidos com a Tomografia PCA do cubo de dados de NGC 5643 com o contínuo estelar......

7.16 - Mapeamento dos valores do $\chi^{2} / n_{\text {eff }}$ dos ajustes obtidos pelo Starlight para os espectros do cubo de dados de NGC 5643

7.17 - Mapeamento do fluxo total devido às populações estelares, obtido com a aplicação do Starlight ao cubo de dados de NGC 5643.

7.18 - Mapeamento do fluxo total devido à emissão térmica de poeira, obtido com a aplicação do Starlight ao cubo de dados de NGC 5643.

7.19 - Mapeamento do fluxo atribuído ao featureless continuum do AGN, obtido com a aplicação do Starlight ao cubo de dados de NGC 5643.

7.20 - Gráfico representativo das frações de fluxo devidas às populações estelares, à emissão térmica de poeira e ao featureless continuum, considerando-se todo o campo visual do SINFONI, obtido com a aplicação do Starlight ao cubo de dados de NGC 5643............ 370

7.21 - Mapeamentos dos valores da razão $S / N$, obtidos a partir da síntese espectral do cubo de dados de NGC 5643 com o Starlight.

7.22 - Tomograma e auto-espectro correspondentes ao autovetor E1, obtido com a Tomografia PCA do cubo de dados de NGC 5643 com o contínuo estelar subtraído.

7.23 - Tomograma e auto-espectro correspondentes ao autovetor E2, obtido com a Tomografia PCA do cubo de dados de NGC 5643 com o contínuo estelar subtraído.

7.24 - Ampliação do intervalo espectral entre $21000 \AA \AA$ e $22700 \AA$ do auto-espectro correspondente ao autovetor E2, obtido com a Tomografia PCA do cubo de dados de NGC 5643 com o contínuo estelar subtraído.

7.25 - Tomograma e auto-espectro correspondentes ao autovetor E3, obtido com a Tomografia PCA do cubo de dados de NGC 5643 com o contínuo estelar subtraído

7.26 - Tomograma e auto-espectro correspondentes ao autovetor E4, obtido com a Tomografia PCA do cubo de dados de NGC 5643 com o contínuo estelar subtraído

7.27 - Ampliação do intervalo espectral entre $21000 \AA$ e $22700 \AA$ do auto-espectro correspondente ao autovetor E4, obtido com a Tomografia PCA do cubo de dados de NGC 5643 com o contínuo estelar subtraído.

7.28 - Scree test dos autovetores obtidos com a Tomografia PCA do cubo de dados de NGC 5643 com o contínuo estelar subtraído. 
7.29 - Imagem da linha de Bry do cubo de dados de NGC 5643 com o contínuo estelar subtraído.

7.30 - Mapeamentos dos valores da velocidade radial estelar, da dispersão de velocidades estelar, do coeficiente $h_{3}$ e do coeficiente $h_{4}$, obtidos com a aplicação do pPXF ao cubo de dados de NGC 5643. 380

7.31 - Mapa dos valores da velocidade radial estelar observado, obtido a partir da aplicação do processo do pPXF ao cubo de dados de NGC 5643, juntamente com o resultado do melhor modelo obtido com as simulações feitas com o método de Jeans 384

7.32 - Curva de rotação extraída ao longo da linha de nodos do mapa dos valores da velocidade radial estelar observado, juntamente com o resultado do melhor modelo obtido com as simulações feitas com o método de Jeans 384

7.33 - Curva de rotação extraída ao longo da linha de nodos do mapa dos valores da velocidade radial estelar observado, juntamente com o modelo obtido, com o método de Jeans, utilizando-se os mesmos parâmetros dados na tabela 7.3 e $M_{b h}=M_{b h_{-} \text {sup }}=4 \cdot 10^{7} \mathrm{M}_{\odot} \ldots . .386$

7.34 - Mapeamento dos valores de velocidade radial do gás molecular, obtido com a linha de $\mathrm{H}_{2} \lambda 21218$ do cubo de dados de NGC 5643

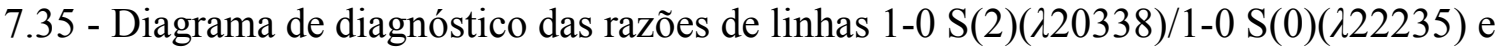

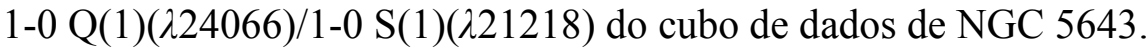

7.36 - Mapeamento dos valores da temperatura de excitação do cubo de dados de NGC5643,

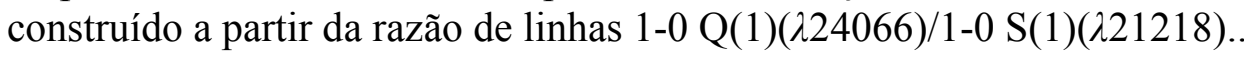
389

8.1 - Imagem da galáxia NGC 1068, obtida com o SDSS

8.2 - Mapa em $4.9 \mathrm{GHz}$ da região central de NGC 1068, juntamente com algumas ampliações correspondentes a observações em $15.0 \mathrm{GHz}$.

8.3 - Imagem em [O III] da região central de NGC 1068.......................................................... 395

8.4 - Mapeamento da linha de CO (1-0) da região central de NGC 1068.................................... 397

8.5 - Mapeamento em 0.25 - $7.50 \mathrm{keV}$ da região central de NGC 1068, obtido com o Chandra. 398

8.6 - Soma das imagens do cubo de dados de NGC 1068, antes e após a filtragem espacial de Butterworth, e soma das imagens do cubo de dados de NGC 1068 correspondente à diferença entre o cubo não filtrado e o cubo filtrado.

8.7 - Soma de todas as imagens e espectro médio do cubo de dados final de NGC 1068, obtido após todo o processamento.

8.8 - Ampliações do espectro médio do cubo de dados de NGC 1068 mostrado na figura 8.7.. 401

8.9 - Tomograma e auto-espectro correspondentes ao autovetor E1, obtido com a Tomografia PCA do cubo de dados de NGC 1068 com o contínuo estelar. 
8.10 - Ampliações do auto-espectro correspondente ao autovetor E1, obtido com a Tomografia PCA do cubo de dados de NGC 1068 com o contínuo estelar..

8.11 - Tomograma e auto-espectro correspondentes ao autovetor E2, obtido com a Tomografia PCA do cubo de dados de NGC 1068 com o contínuo estelar.

8.12 - Ampliação na região espectral azul do auto-espectro correspondente ao autovetor E2, obtido com a Tomografia PCA do cubo de dados de NGC 1068 com o contínuo estelar.

8.13 - Tomograma e auto-espectro correspondentes ao autovetor E3, obtido com a Tomografia PCA do cubo de dados de NGC 1068 com o contínuo estelar.

8.14 - Ampliação na região espectral azul do auto-espectro correspondente ao autovetor E3, obtido com a Tomografia PCA do cubo de dados de NGC 1068 com o contínuo estelar.

8.15 - Tomograma e auto-espectro correspondentes ao autovetor E4, obtido com a Tomografia PCA do cubo de dados de NGC 1068 com o contínuo estelar.

8.16 - Ampliação na região espectral azul do auto-espectro correspondente ao autovetor E4, obtido com a Tomografia PCA do cubo de dados de NGC 1068 com o contínuo estelar.

8.17 - Scree test dos autovetores obtidos com a Tomografia PCA do cubo de dados de NGC 1068 com o contínuo estelar...... 405

8.18 - Mapeamento dos valores do $\chi^{2} / n_{\text {eff }}$ dos ajustes obtidos pelo Starlight para os espectros do cubo de dados de NGC 1068

8.19 - Mapeamentos dos valores da velocidade radial estelar e da dispersão de velocidades estelar, resultantes da aplicação do Starlight ao cubo de dados de NGC 1068.

8.20 - Composições RGB das populações estelares com diferentes idades, obtidas a partir dos resultados da síntese espectral do cubo de dados de NGC 1068.

8.21 - Composições RGB das populações estelares com diferentes metalicidades, obtidas a partir dos resultados da síntese espectral do cubo de dados de NGC 1068.

8.22 - Mapeamento do fluxo atribuído ao featureless continuum do AGN, obtido com a aplicação do Starlight ao cubo de dados de NGC 1068

8.23 - Gráficos representativos das frações de fluxo e de massa devidas às populações estelares (e ao featureless continuum), considerando-se todo o campo visual do IFU do GMOS, obtidos com a aplicação do Starlight ao cubo de dados de NGC 1068 413

8.24 - Mapeamento dos valores de $A_{V}$, obtido a partir da síntese do cubo de dados de NGC 1068 com o Starlight.

8.25 - Mapeamentos dos valores da razão $S / N$, obtidos a partir da síntese espectral do cubo de dados de NGC 1068 com o Starlight. 
8.26 - Tomograma e auto-espectro correspondentes ao autovetor E1, obtido com a Tomografia PCA do cubo de dados de NGC 1068 com o contínuo estelar subtraído.

8.27 - Ampliações do auto-espectro correspondente ao autovetor E1, obtido com a Tomografia PCA do cubo de dados de NGC 1068 com o contínuo estelar subtraído.

8.28 - Tomograma e auto-espectro correspondentes ao autovetor E2, obtido com a Tomografia PCA do cubo de dados de NGC 1068 com o contínuo estelar subtraído.

8.29 - Ampliação na região espectral azul do auto-espectro correspondente ao autovetor E2, obtido com a Tomografia PCA do cubo de dados de NGC 1068 com o contínuo estelar subtraído.

8.30 - Tomograma e auto-espectro correspondentes ao autovetor E3, obtido com a Tomografia PCA do cubo de dados de NGC 1068 com o contínuo estelar subtraído.

8.31 - Ampliação na região espectral azul do auto-espectro correspondente ao autovetor E3, obtido com a Tomografia PCA do cubo de dados de NGC 1068 com o contínuo estelar subtraído.

8.32 - Tomograma e auto-espectro correspondentes ao autovetor E4, obtido com a Tomografia PCA do cubo de dados de NGC 1068 com o contínuo estelar subtraído.

8.33 - Ampliação na região espectral azul do auto-espectro correspondente ao autovetor E4, obtido com a Tomografia PCA do cubo de dados de NGC 1068 com o contínuo estelar subtraído

8.34 - Scree test dos autovetores obtidos com a Tomografia PCA do cubo de dados de NGC 1068 com o contínuo estelar subtraído

8.35 - Espectro extraído de uma região circular, centrada no AGN, do cubo de dados de NGC 1068, após a subtração do contínuo estelar.

8.36 - Mapeamentos dos valores da velocidade radial estelar, da dispersão de velocidades estelar, do coeficiente $h_{3}$ e do coeficiente $h_{4}$, obtidos com a aplicação do pPXF ao cubo de dados de NGC 1068. 425

8.37 - Mapeamento dos valores de velocidade radial do gás, obtido com a linha de [O III] $\lambda 5007$ do cubo de dados de NGC 1068.

8.38 - Espectro extraído de uma região circular no extremo nordeste do cubo de dados de NGC 1068, após a subtração do contínuo estelar.

8.39 - Espectro extraído de uma região circular no extremo sudoeste do cubo de dados de NGC 1068, após a subtração do contínuo estelar.

8.40 - Espectro extraído de uma região circular mais próxima ao AGN (correspondente à área clara dos tomogramas das figuras 8.11 e 8.28) do cubo de dados de NGC 1068, após a subtração do contínuo estelar. 
8.41 - Mapeamentos dos valores da velocidade radial estelar obtidos a partir dos intervalos $4978 \AA-5010 \AA$ e $5009 \AA-5027 \AA$ do cubo de dados de NGC 1068, após a subtração do contínuo estelar.

8.42 - Esquema do "outflow" bi-cônico a partir do AGN de NGC 1068...................................... 431

9.1 - Imagem da galáxia M87, obtida com o SDSS.................................................................. 435

9.2 - Imagem na banda V da galáxia M87, obtida com o HST.................................................... 436

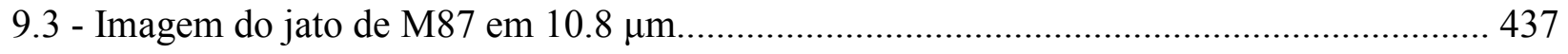

9.4 - Soma de todas as imagens do cubo de dados de M87, antes e após a aplicação da reamostragem espacial.

9.5 - Soma das imagens do cubo de dados de M87, antes e após a filtragem espacial de Butterworth, e soma das imagens do cubo de dados de M87 correspondente à diferença entre o cubo não filtrado e o cubo filtrado.

9.6 - Espectro extraído de uma região circular central do cubo de dados de M87, antes e após a aplicação do de-noising.

9.7 - Soma de todas as imagens e espectro médio do cubo de dados final de M87, obtido após todo o processamento

9.8 - Tomograma e auto-espectro correspondentes ao autovetor E1, obtido com a Tomografia PCA do cubo de dados de M87 com o contínuo estelar.

9.9 - Tomograma e auto-espectro correspondentes ao autovetor E2, obtido com a Tomografia PCA do cubo de dados de M87 com o contínuo estelar.

9.10 - Tomograma e auto-espectro correspondentes ao autovetor E6, obtido com a Tomografia PCA do cubo de dados de M87 com o contínuo estelar.

9.11 - Scree test dos autovetores obtidos com a Tomografia PCA do cubo de dados de M87 com o contínuo estelar.

9.12 - Mapeamento dos valores do $\chi^{2} / n_{\text {eff }}$ dos ajustes obtidos pelo Starlight para os espectros do cubo de dados de M87.

9.13 - Mapeamento do fluxo total devido às populações estelares, obtido com a aplicação do Starlight ao cubo de dados de M87.

9.14 - Mapeamento do fluxo total devido à emissão térmica de poeira, obtido com a aplicação do Starlight ao cubo de dados de M87.

9.15 - Mapeamento do fluxo atribuído ao featureless continuum do AGN, obtido com a aplicação do Starlight ao cubo de dados de M87. 
9.16 - Gráfico representativo das frações de fluxo devidas às populações estelares, à emissão térmica de poeira e ao featureless continuum, considerando-se todo o campo visual do NIFS, obtido com a aplicação do Starlight ao cubo de dados de M87.

9.17 - Mapeamentos dos valores da razão $S / N$, obtidos a partir da síntese espectral do cubo de dados de M87 com o Starlight.

9.18 - Tomograma e auto-espectro correspondentes ao autovetor E1, obtido com a Tomografia PCA do cubo de dados de M87 com o contínuo estelar subtraído.

9.19 - Tomograma e auto-espectro correspondentes ao autovetor E2, obtido com a Tomografia PCA do cubo de dados de M87 com o contínuo estelar subtraído.

9.20 - Scree test dos autovetores obtidos com a Tomografia PCA do cubo de dados de M87 com o contínuo estelar subtraído.

9.21 - Imagem do intervalo espectral correspondente à região emissora da suposta linha de Bry em blueshift; Espectro extraído de uma região circular, com raio igual a 0.105 ", centrada na região emissora em questão; Composição RB contendo o tomograma mostrado na figura 9.18 e a imagem da região emissora da suposta linha de Br $\gamma$ em blueshift............ 456

9.22 - Mapeamentos dos valores da velocidade radial estelar, da dispersão de velocidades estelar, do coeficiente $h_{3}$ e do coeficiente $h_{4}$, obtidos com a aplicação do pPXF ao cubo de dados de M87....... 459

10.1 - Imagem da galáxia M104 na banda V, obtida com o HST. 463

10.2 - Mapa do contínuo em $1.49 \mathrm{GHz}$ de M104, sobreposto a uma imagem óptica dessa Galáxia.

10.3 - Imagem de 1'x1' da região central de M104, obtida com o Chandra, na região espectral $0.3-7 \mathrm{keV}$. 465

10.4 - Imagem da região central da galáxia M104, obtida com o HST.. 466

10.5 - Soma das imagens do cubo de dados de M104 obtido com o GMOS, antes e após a filtragem espacial de Butterworth, e soma das imagens do cubo de dados de M104 obtido com o GMOS, correspondente à diferença entre o cubo não filtrado e o cubo filtrado. 467

10.6 - Tomograma e auto-espectro correspondentes ao autovetor E4, resultante da aplicação da Tomografia PCA ao cubo de dados de M104 obtido com o GMOS, após a remoção das linhas espectrais, juntamente com o resultado encontrado após a subtração do spline do auto-espectro em questão. 468

10.7 - Soma de todas as imagens e espectro médio do cubo de dados de M104 obtido com o GMOS, após todo o processamento.

10.8 - Soma de todas as imagens do cubo de dados de M104 obtido com o NIFS, antes e após a aplicação da reamostragem espacial. 
10.9 - Soma das imagens do cubo de dados de M104 obtido com o NIFS, antes e após a filtragem espacial de Butterworth, e soma das imagens do cubo de dados de M104 obtido com o NIFS, correspondente à diferença entre o cubo não filtrado e o cubo filtrado.

10.10 - Tomograma e auto-espectro correspondentes ao autovetor E5, resultante da aplicação da Tomografia PCA ao cubo de dados de M104 obtido com o GMOS, após a remoção das linhas espectrais, juntamente com o resultado encontrado após a subtração do spline do auto-espectro em questão.

10.11 - Soma de todas as imagens e espectro médio do cubo de dados de M104 obtido com o NIFS, após todo o processamento.

10.12 - Tomograma e auto-espectro correspondentes ao autovetor E1, resultante da Tomografia PCA do cubo de dados de M104 obtido com o GMOS, com o contínuo estelar.

10.13 - Tomograma e auto-espectro correspondentes ao autovetor E2, resultante da Tomografia PCA do cubo de dados de M104 obtido com o GMOS, com o contínuo estelar.

10.14 - Ampliação na região espectral vermelha do auto-espectro correspondente ao autovetor E2, resultante da Tomografia PCA do cubo de dados de M104 obtido com o GMOS, com o contínuo estelar.

10.15 - Tomograma e auto-espectro correspondentes ao autovetor E3, resultante da Tomografia PCA do cubo de dados de M104 obtido com o GMOS, com o contínuo estelar. 475

10.16 - Ampliação na região espectral vermelha do auto-espectro correspondente ao autovetor E3, resultante da Tomografia PCA do cubo de dados de M104 obtido com o GMOS, com o contínuo estelar.

10.17 - Tomograma e auto-espectro correspondentes ao autovetor E4, resultante da Tomografia PCA do cubo de dados de M104 obtido com o GMOS, com o contínuo estelar. 475

10.18 - Ampliação na região espectral vermelha do auto-espectro correspondente ao autovetor E4, resultante da Tomografia PCA do cubo de dados de M104 obtido com o GMOS, com o contínuo estelar.

10.19 - Tomograma e auto-espectro correspondentes ao autovetor E5, resultante da Tomografia PCA do cubo de dados de M104 obtido com o GMOS, com o contínuo estelar.

10.20 - Ampliação na região espectral vermelha do auto-espectro correspondente ao autovetor E5, resultante da Tomografia PCA do cubo de dados de M104 obtido com o GMOS, com o contínuo estelar.

10.21 - Scree test dos autovetores encontrados com a Tomografia PCA do cubo de dados de M104 obtido com o GMOS, com o contínuo estelar.

10.22 - Tomograma e auto-espectro correspondentes ao autovetor E1, resultante da Tomografia PCA do cubo de dados de M104 obtido com o NIFS, com o contínuo estelar. 
10.23 - Tomograma e auto-espectro correspondentes ao autovetor E2, resultante da Tomografia PCA do cubo de dados de M104 obtido com o NIFS, com o contínuo estelar. 481

10.24 - Tomograma e auto-espectro correspondentes ao autovetor E3, resultante da Tomografia PCA do cubo de dados de M104 obtido com o NIFS, com o contínuo estelar. 481

10.25 - Tomograma e auto-espectro correspondentes ao autovetor E5, resultante da Tomografia PCA do cubo de dados de M104 obtido com o NIFS, com o contínuo estelar. 481

10.26 - Tomograma e auto-espectro correspondentes ao autovetor E7, resultante da Tomografia PCA do cubo de dados de M104 obtido com o NIFS, com o contínuo estelar. 482

10.27 - Scree test dos autovetores encontrados com a Tomografia PCA do cubo de dados de M104 obtido com o NIFS, com o contínuo estelar..

10.28 - Mapeamento dos valores do $\chi^{2} / n_{\text {eff }}$ dos ajustes do Starlight para os espectros do cubo de dados de M104 obtido com o GMOS.

10.29 - Mapeamentos dos valores da velocidade radial estelar e da dispersão de velocidades estelar, resultantes da aplicação do Starlight ao cubo de dados de M104 obtido com o GMOS.

10.30 - Composições RGB das populações estelares com diferentes idades, resultantes da síntese espectral do cubo de dados de M104 obtido com o GMOS

10.31 - Composições RGB das populações estelares com diferentes metalicidades, resultantes da síntese espectral do cubo de dados de M104 obtido com o GMOS.

10.32 - Mapeamento do fluxo atribuído ao featureless continuum do AGN, resultante da aplicação do Starlight ao cubo de dados de M104 obtido com o GMOS.

10.33 - Gráfico representativo das frações de fluxo devidas às populações estelares e ao featureless continuum, considerando-se todo o campo visual do IFU do GMOS, resultante da aplicação do Starlight ao cubo de dados de M104 obtido com o GMOS.

10.34 - Gráfico representativo das frações de massa devidas às populações estelares, considerando-se todo o campo visual do IFU do GMOS, resultante da aplicação do Starlight ao cubo de dados de M104 obtido com o GMOS. 491

10.35 - Mapeamento dos valores de $A_{V}$, resultante da aplicação do Starlight ao cubo de dados de M104 obtido com o GMOS 493

10.36 - Mapeamentos dos valores da razão $S / N$, resultante da aplicação do Starlight ao cubo de dados de M104 obtido com o GMOS. 494

10.37 - Tomograma e auto-espectro correspondentes ao autovetor E1, resultante da Tomografia PCA do cubo de dados de M104 obtido com o GMOS, com o contínuo estelar subtraído. 
10.38 - Ampliação na região espectral vermelha do auto-espectro correspondente ao autovetor E1, resultante da Tomografia PCA do cubo de dados de M104 obtido com o GMOS, com o contínuo estelar subtraído. 496

10.39 - Tomograma e auto-espectro correspondentes ao autovetor E2, resultante da Tomografia PCA do cubo de dados de M104 obtido com o GMOS, com o contínuo estelar subtraído. 496

10.40 - Ampliação na região espectral vermelha do auto-espectro correspondente ao autovetor E2, resultante da Tomografia PCA do cubo de dados de M104 obtido com o GMOS, com o contínuo estelar subtraído. 496

10.41 - Tomograma e auto-espectro correspondentes ao autovetor E3, resultante da Tomografia PCA do cubo de dados de M104 obtido com o GMOS, com o contínuo estelar subtraído. 497

10.42 - Ampliação na região espectral vermelha do auto-espectro correspondente ao autovetor E3, resultante da Tomografia PCA do cubo de dados de M104 obtido com o GMOS, com o contínuo estelar subtraído.

10.43 - Tomograma e auto-espectro correspondentes ao autovetor E6, resultante da Tomografia PCA do cubo de dados de M104 obtido com o GMOS, com o contínuo estelar subtraído. 497

10.44 - Ampliação na região espectral vermelha do auto-espectro correspondente ao autovetor E6, resultante da Tomografia PCA do cubo de dados de M104 obtido com o GMOS, com o contínuo estelar subtraído. 498

10.45 - Scree test dos autovetores encontrados com a Tomografia PCA do cubo de dados de M104 obtido com o GMOS, com o contínuo estelar subtraído.

10.46 - Tomograma e auto-espectro correspondentes ao autovetor E1, resultante da Tomografia PCA do cubo de dados de M104 obtido com o NIFS, com o contínuo estelar subtraído. 502

10.47 - Tomograma e auto-espectro correspondentes ao autovetor E2, resultante da Tomografia PCA do cubo de dados de M104 obtido com o NIFS, com o contínuo estelar subtraído. 502

10.48 - Scree test dos autovetores encontrados com a Tomografia PCA do cubo de dados de M104 obtido com o NIFS, com o contínuo estelar subtraído

10.49 - Mapeamentos dos valores da velocidade radial estelar, da dispersão de velocidades estelar, do coeficiente $h_{3}$ e do coeficiente $h_{4}$, resultantes da aplicação do pPXF ao cubo de dados de M104, obtido com o GMOS. 505 
10.50 - Mapa dos valores da velocidade radial estelar observado, resultante da aplicação do processo do pPXF ao cubo de dados de M104 obtido com o GMOS, juntamente com o resultado do melhor modelo obtido com as simulações feitas com o método de Jeans....... 508

10.51 - Curva de rotação extraída ao longo da linha de nodos do mapa dos valores da velocidade radial estelar na figura $10.49-a$, juntamente com o resultado do melhor modelo obtido com as simulações feitas com o método de Jeans. 509

10.52 - Mapeamentos dos valores da velocidade radial estelar, da dispersão de velocidades estelar, do coeficiente $h_{3}$ e do coeficiente $h_{4}$, resultantes da aplicação do pPXF ao cubo de dados de M104, obtido com o NIFS. 510

10.53 - Mapa dos valores da velocidade radial estelar observado, resultante da aplicação do processo do pPXF ao cubo de dados de M104 obtido com o NIFS, juntamente com o resultado do melhor modelo obtido com as simulações feitas com o método de Jeans. 512

10.54 - Curva de rotação extraída ao longo da linha de nodos do mapa dos valores da velocidade radial estelar na figura $10.52-a$, juntamente com o resultado do melhor modelo obtido com as simulações feitas com o método de Jeans.

10.55 - Mapeamento dos valores da velocidade radial do gás, construído com base na linha de [N II] $\lambda 6583$ do cubo de dados de M104 obtido com o GMOS.

10.56 - Diagrama de diagnóstico de [N II] $\lambda 6583 / \mathrm{H} \alpha \times$ [S II] $(\lambda 6716+\lambda 6731) / \mathrm{H} \alpha$, construído a partir do cubo de dados de M104 obtido com o GMOS, após a subtração do contínuo estelar, juntamente com os ajustes feitos com o software Cloudy em função dos diferentes cortes inferiores de energia do contínuo e parâmetros de ionização. 515

10.57 - Diagrama de diagnóstico de [O III] $\lambda 5007 / \mathrm{H} \beta \times[\mathrm{O}$ I] $(\lambda 6300) / \mathrm{H} \alpha$, construído a partir do cubo de dados de M104 obtido com o GMOS, após a subtração do contínuo estelar, juntamente com os ajustes feitos com o software Cloudy em função dos diferentes cortes inferiores de energia do contínuo e parâmetros de ionização...................................... 516

11.1 - Imagem da galáxia M31, obtida com o SDSS ........................................................ 519

11.2 - Imagem na banda V do núcleo duplo de M31, obtida com o HST............................... 520

11.3 - Imagem, obtida com o Chandra, da região nuclear de M31......................................... 522

11.4 - Soma das imagens do cubo de dados de M31, antes e após a filtragem espacial de Butterworth, e soma das imagens do cubo de dados de M31 correspondente à diferença entre o cubo não filtrado e o cubo filtrado.

11.5 - Soma de todas as imagens e espectro médio do cubo de dados final de M31, obtido após todo o processamento.

11.6 - Tomograma e auto-espectro correspondentes ao autovetor E1, obtido com a Tomografia PCA do cubo de dados de M31 com o contínuo estelar. 
11.7 - Tomograma e auto-espectro correspondentes ao autovetor E2, obtido com a Tomografia PCA do cubo de dados de M31 com o contínuo estelar.

11.8 - Tomograma e auto-espectro correspondentes ao autovetor E3, obtido com a Tomografia PCA do cubo de dados de M31 com o contínuo estelar.

11.9 - Tomograma e auto-espectro correspondentes ao autovetor E4, obtido com a Tomografia PCA do cubo de dados de M31 com o contínuo estelar. 526

11.10 - Tomograma e auto-espectro correspondentes ao autovetor E6, obtido com a Tomografia PCA do cubo de dados de M31 com o contínuo estelar. 526

11.11 - Scree test dos autovetores obtidos com a Tomografia PCA do cubo de dados de M31 com o contínuo estelar.

11.12 - Mapeamento dos valores do $\chi^{2} / n_{\text {eff }}$ dos ajustes obtidos pelo Starlight para os espectros do cubo de dados de M31.

11.13 - Mapeamentos dos valores da velocidade radial estelar e da dispersão de velocidades estelar, resultantes da aplicação do Starlight ao cubo de dados de M31.

11.14 - Composições RGB das populações estelares com diferentes idades, obtidas a partir dos resultados da síntese espectral do cubo de dados de M31.

11.15 - Composições RGB das populações estelares com diferentes metalicidades, obtidas a partir dos resultados da síntese espectral do cubo de dados de M31.

11.16 - Gráfico representativo das frações de fluxo devidas às populações estelares e ao, considerando-se todo o campo visual do IFU do GMOS, resultante da aplicação do Starlight ao cubo de dados de M31

11.17 - Gráfico representativo das frações de massa devidas às populações estelares, considerando-se todo o campo visual do IFU do GMOS, resultante da aplicação do Starlight ao cubo de dados de M31

11.18 - Mapeamento dos valores de $A_{V}$, obtido a partir da síntese do cubo de dados de M31 com o Starlight.

11.19 - Mapeamentos dos valores da razão $S / N$, obtidos a partir da síntese espectral do cubo de dados de M31 com o Starlight.

11.20 - Tomograma e auto-espectro correspondentes ao autovetor E1, obtido com a Tomografia PCA do cubo de dados de M31 com o contínuo estelar subtraído.

11.21 - Ampliação do auto-espectro correspondente ao autovetor E1, obtido com a Tomografia PCA do cubo de dados de M31 com o contínuo estelar subtraído.

11.22 - Tomograma e auto-espectro correspondentes ao autovetor E2, obtido com a Tomografia PCA do cubo de dados de M31 com o contínuo estelar subtraído. 
11.23 - Ampliação do auto-espectro correspondente ao autovetor E2, obtido com a Tomografia PCA do cubo de dados de M31 com o contínuo estelar subtraído.

11.24 - Tomograma e auto-espectro correspondentes ao autovetor E3, obtido com a Tomografia PCA do cubo de dados de M31 com o contínuo estelar subtraído. 538

11.25 - Ampliações nas regiões espectrais azul e vermelha do auto-espectro correspondente ao autovetor E3, obtido com a Tomografia PCA do cubo de dados de M31 com o contínuo estelar subtraído. 538

11.26 - Scree test dos autovetores obtidos com a Tomografia PCA do cubo de dados de M31 com o contínuo estelar subtraído. 539

11.27 - Imagem da linha de [O III] $\lambda 5007$ do cubo de dados de M31, após a subtração do contínuo estelar e espectro extraído de uma região circular, com 0.45 " de raio, centrada na área clara da figura à esquerda. 540

11.28 - Mapeamentos dos valores da velocidade radial estelar, da dispersão de velocidades estelar, do coeficiente $h_{3}$ e do coeficiente $h_{4}$, obtidos com a aplicação do pPXF ao cubo de dados de M31 543

11.29 - Mapa dos valores da velocidade radial estelar observado, obtido a partir da aplicação do processo do pPXF ao cubo de dados de M31, juntamente com o resultado do melhor modelo obtido com as simulações

11.30 - Curva de rotação extraída ao longo da linha de nodos do mapa dos valores da velocidade radial estelar na figura $11.28-a$, juntamente com o resultado do melhor modelo obtido com as simulações 546

11.31 - Mapeamento dos valores de velocidade radial, obtido com a linha de emissão H $\alpha$ do cubo de dados de M31, após a subtração do contínuo estelar. 548

11.32 - Mapa dos valores da velocidade radial da linha Ha observado, obtido a partir do cubo de dados de M31, após a subtração do contínuo estelar, juntamente com o resultado do melhor modelo obtido com as simulações. 550

11.33 - Curva de rotação extraída ao longo da linha de nodos do mapa dos valores da velocidade radial estelar na figura 11.31, juntamente com o resultado do melhor modelo obtido com as simulações. 550

C.1 - Modelo considerado para um raio de luz S atravessando a atmosfera terrestre (formada por $n+1$ camadas)

I.1 - Esquema com os parâmetros orbitais levados em conta nas simulações das seções 11.6 e 11.7. 


\section{Lista de Tabelas}

1.1 - Densidades espaciais de diferentes categorias de AGNs e de galáxias sem atividade nuclear......

1.2 - Objetos analisados nesse trabalho.

2.1 - Principais linhas de emissão permitidas e proibidas detectadas nos espectros dos AGNs no óptico/ultravioleta.

2.2 - Principais linhas de emissão permitidas e proibidas detectadas nos espectros dos AGNs no infravermelho próximo.

2.3 - Principais linhas de $\mathrm{H}_{2}$ detectadas nos espectros dos AGNs no infravermelho próximo.... 91

2.4 - Principais linhas de emissão detectadas nos espectros dos AGNs na região dos raios-X moles

2.5 - Principais previsões do Modelo Unificado para as diferentes categorias de AGNs.

3.1 - Idades e metalicidades das populações estelares utilizadas nas sínteses espectrais dos cubos de dados analisados nesse trabalho

4.1 - Autovalores obtidos com a Tomografia PCA do cubo de dados de NGC 2992 com o contínuo estelar.

4.2 - Autovalores obtidos com a Tomografia PCA do cubo de dados de NGC 2992 com o contínuo estelar subtraído.

5.1 - Autovalores obtidos com a Tomografia PCA do cubo de dados de NGC 4151 com o contínuo estelar.

5.2 - Autovalores obtidos com a Tomografia PCA do cubo de dados de NGC 4151 com o contínuo estelar subtraído.

6.1 - Autovalores encontrados com a Tomografia PCA do cubo de dados de NGC 3227 obtido com o GMOS, com o contínuo estelar.

6.2 - Autovalores encontrados com a Tomografia PCA do cubo de dados de NGC 3227 obtido com o SINFONI, com o contínuo estelar.

6.3 - Autovalores encontrados com a Tomografia PCA do cubo de dados de NGC 3227 obtido com o GMOS, com o contínuo estelar subtraído......

6.4 - Autovalores encontrados com a Tomografia PCA do cubo de dados de NGC 3227 obtido com o GMOS, com o contínuo estelar subtraído...

7.1 - Autovalores obtidos com a Tomografia PCA do cubo de dados de NGC 5643 com o contínuo estelar. 
7.2 - Autovalores obtidos com a Tomografia PCA do cubo de dados de NGC 5643 com o contínuo estelar subtraído.

7.3 - Parâmetros do melhor modelo obtido com as simulações do mapa dos valores da velocidade radial estelar de NGC 5643, utilizando-se o método de Jeans.

8.1 - Autovalores obtidos com a Tomografia PCA do cubo de dados de NGC 1068 com o contínuo estelar.

8.2 - Autovalores obtidos com a Tomografia PCA do cubo de dados de NGC 1068 com o contínuo estelar subtraído.

8.3 - Identificação das linhas de emissão presentes no auto-espectro E1, mostrado nas figuras 8.25 e 8.26 .

9.1 - Autovalores obtidos com a Tomografia PCA do cubo de dados de M87 com o contínuo estelar.

9.2 - Autovalores obtidos com a Tomografia PCA do cubo de dados de M87 com o contínuo estelar subtraído.

10.1 - Autovalores encontrados com a Tomografia PCA do cubo de dados de M104 obtido com o GMOS, com o contínuo estelar.

10.2 - Autovalores encontrados com a Tomografia PCA do cubo de dados de M104 obtido com o NIFS, com o contínuo estelar.

10.3 - Autovalores encontrados com a Tomografia PCA do cubo de dados de M104 obtido com o GMOS, com o contínuo estelar subtraído.

10.4 - Autovalores encontrados com a Tomografia PCA do cubo de dados de M104 obtido com o NIFS, com o contínuo estelar subtraído.

10.5 - Parâmetros do melhor modelo resultante das simulações do mapa dos valores da velocidade radial estelar do cubo de dados de M104, obtido com o GMOS, utilizando-se o método de Jeans

10.6 - Parâmetros do melhor modelo resultante das simulações do mapa dos valores da velocidade radial estelar do cubo de dados de M104, obtido com o NIFS, utilizando-se o método de Jeans.

11.1 - Autovalores obtidos com a Tomografia PCA do cubo de dados de M31 com o contínuo estelar.

11.2 - Autovalores obtidos com a Tomografia PCA do cubo de dados de M31 com o contínuo estelar subtraído.

11.3 - Parâmetros do melhor modelo obtido com as simulações do mapa dos valores da velocidade radial estelar de M31 
11.4 - Parâmetros do melhor modelo obtido com as simulações do mapa dos valores da

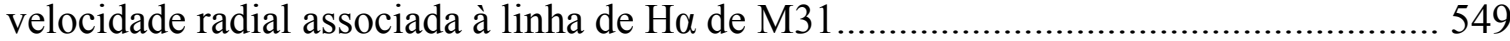





\section{Sumário}

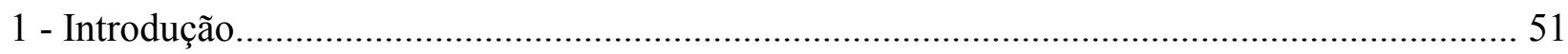

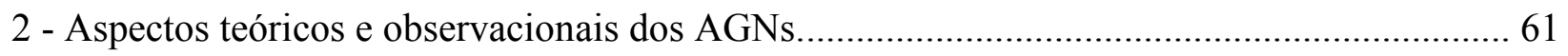

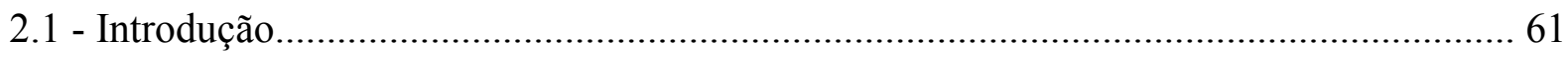

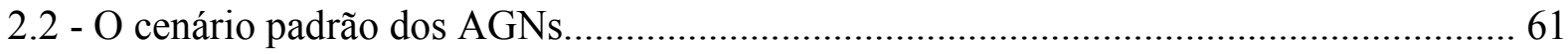

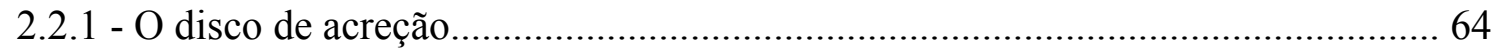

2.2.2 - A Região de Linhas Largas - BLR.................................................................... 66

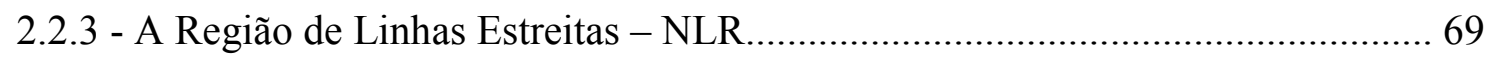

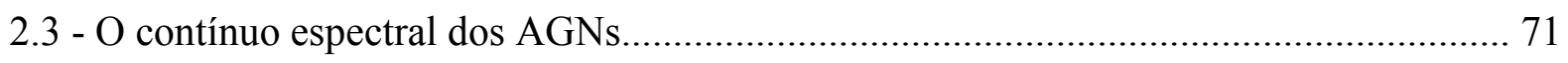

2.3.1 - O featureless continuum no óptico e ultravioleta.................................................... 74

2.3.2 - O featureless continuum nas regiões de altas energias....................................... 75

2.3.3 - O featureless continuum no infravermelho........................................................ 76

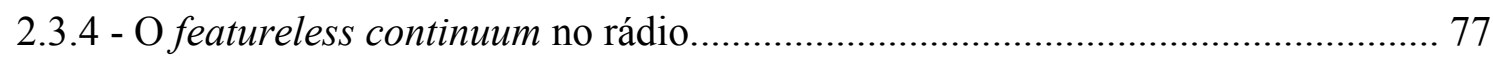

2.4 - O espectro de emissão dos AGNs........................................................................... 79

2.4.1 - As linhas de emissão dos AGNs no óptico e ultravioleta..................................... 79

2.4.2 - As linhas de emissão dos AGNs no infravermelho............................................. 86

2.4.3 - As linhas de emissão dos AGNs em raios-x....................................................... 91

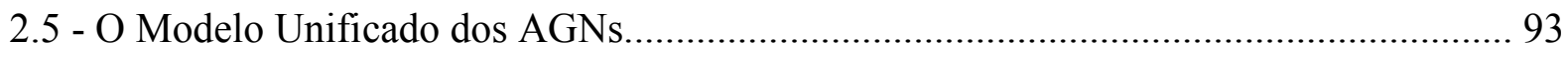

2.5.1 - O Modelo Unificado para os AGNs radio-quiet.................................................. 93

2.5.2 - O Modelo Unificado para os AGNs radio-loud................................................... 97

2.5.3 - Os toros de poeira.......................................................................................... 100

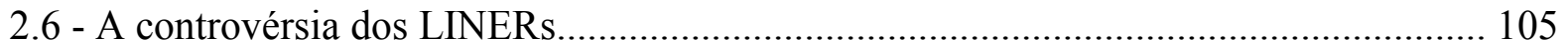

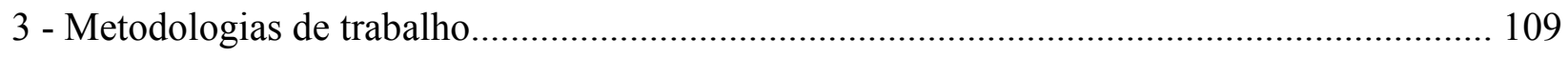

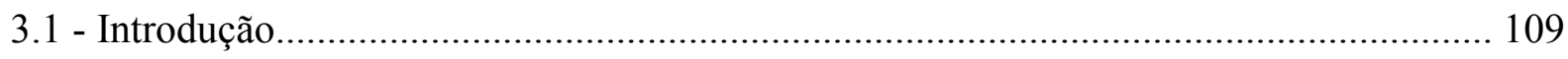




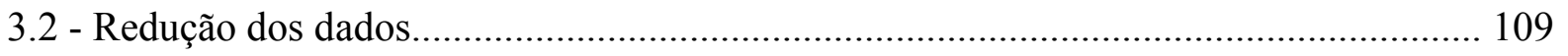

3.2.1 - Redução de dados do GMOS........................................................................ 113

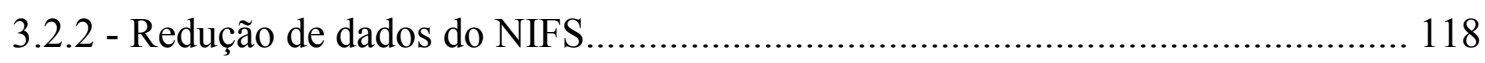

3.2.3 - Redução de dados do SINFONI........................................................................ 123

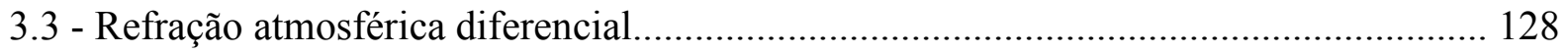

3.3.1 - Correção da refração atmosférica diferencial em cubos de dados do GMOS... 130

3.3.2 - Correção da refração atmosférica diferencial em cubos de dados do NIFS...... 134

3.3.3 - Correção da refração atmosférica diferencial em cubos de dados do

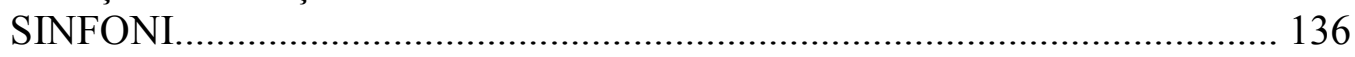

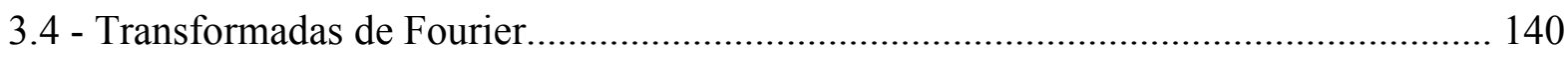

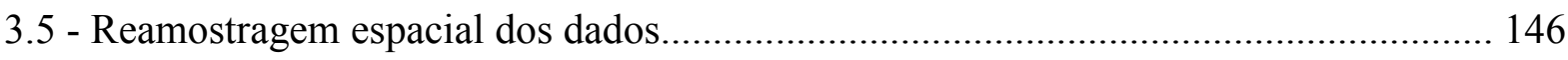

3.5.1 - Reamostragem espacial de cubos de dados do NIFS....................................... 149

3.5.2 - Reamostragem espacial de cubos de dados do SINFONI.................................. 150

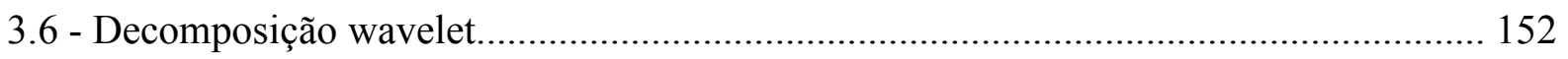

3.6.1 - Decomposição espacial wavelet em cubos de dados do GMOS........................ 159

3.6.2 - Decomposição espacial wavelet em cubos de dados do NIFS............................. 160

3.6.3 - Decomposição espacial wavelet em cubos de dados do SINFONI..................... 161

3.7 - Filtragem espacial de Butterworth.............................................................................. 162

3.7.1 - Filtragem espacial de Butterworth em cubos de dados do GMOS................... 170

3.7.2 - Filtragem espacial de Butterworth em cubos de dados do NIFS...................... 176

3.7.3 - Filtragem espacial de Butterworth em cubos de dados do SINFONI................ 181

3.8 - De-noising espectral.......................................................................................... 185

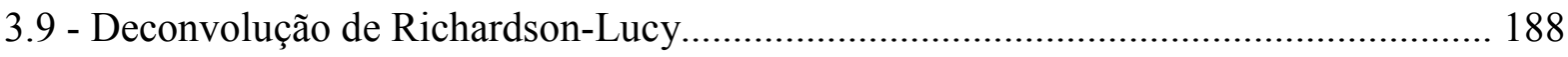

3.9.1 - Deconvolução de Richardson-Lucy em cubos de dados do GMOS.................. 191

3.9.2 - Deconvolução de Richardson-Lucy em cubos de dados do NIFS...................... 196

3.9.3 - Deconvolução de Richardson-Lucy em cubos de dados do SINFONI.............. 200

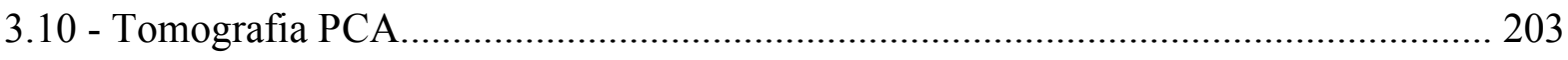

3.11 - Remoção de fingerprints instrumentais................................................................. 210 
3.12 - Síntese espectral com o Starlight ………………................................................ 214

3.13 - Determinação da cinemática estelar com o Penalized Pixel Fitting............................ 218

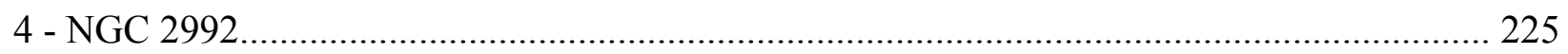

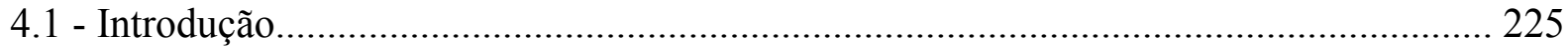

4.2 - Preparação do cubo de dados de NGC 2992 ……………………………………........ 228

4.3 - Aplicação da Tomografia PCA ao cubo de dados de NGC 2992 com o contínuo

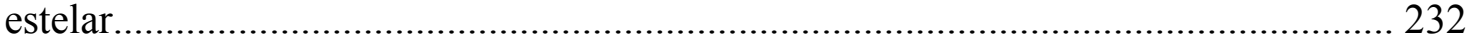

4.4 - Síntese espectral do cubo de dados de NGC 2992 com o Starlight ............................... 240

4.4.1 - Qualidade dos ajustes................................................................................. 241

4.4.2 - Populações estelares, poeira e featureless continuum......................................... 242

4.4.3 - Valores da razão $S / N$ dos espectros analisados................................................ 246

4.5 - Aplicação da Tomografia PCA ao cubo de dados de NGC 2992 com o contínuo estelar subtraído ............................................................................................................. 247

4.6 - Cinemática estelar do cubo de dados de NGC 2992 .................................................. 252

4.7 - Cinemática do gás do cubo de dados de NGC 2992 ..................................................... 254

4.8 - Espectro de emissão de $\mathrm{H}_{2}$ do cubo de dados de NGC 2992: razões de linhas e temperaturas de excitação....................................................................................... 255

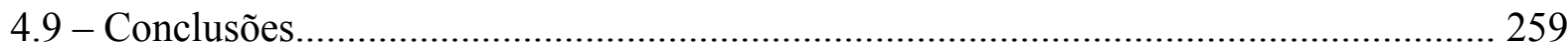

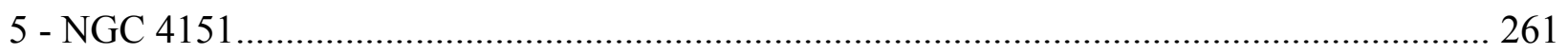

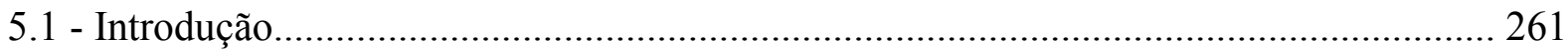

5.2 - Preparação do cubo de dados de NGC 4151 …………………………………............ 264

5.3 - Aplicação da Tomografia PCA ao cubo de dados de NGC 4151 com o contínuo

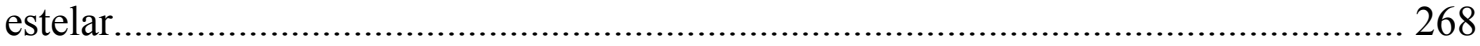

5.4 - Síntese espectral do cubo de dados de NGC 4151 com o Starlight t............................... 276

5.4.1 - Qualidade dos ajustes.................................................................................. 276

5.4.2 - Populações estelares, poeira e featureless continuum......................................... 277

5.4.3 - Valores da razão $S / N$ dos espectros analisados.................................................. 280 
5.5 - Aplicação da Tomografia PCA ao cubo de dados de NGC 4151 com o contínuo estelar subtraído.

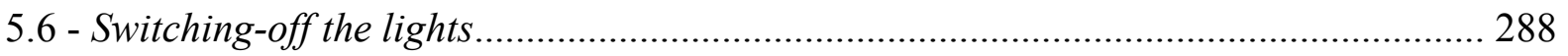

5.7 - Cinemática estelar do cubo de dados de NGC 4151 .................................................... 292

5.8 - Cinemática do gás do cubo de dados de NGC 4151 _................................................ 294

5.9 - Espectro de emissão de $\mathrm{H}_{2}$ do cubo de dados de NGC 4151: razões de linhas e

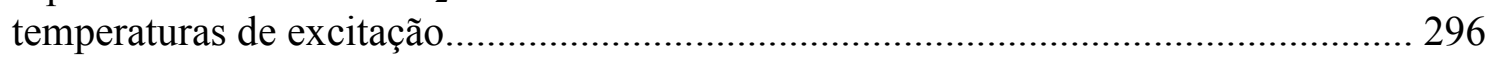

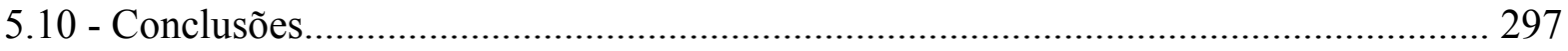

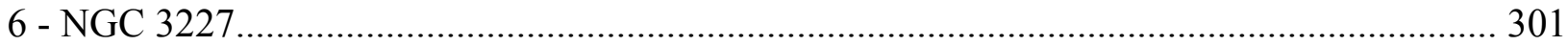

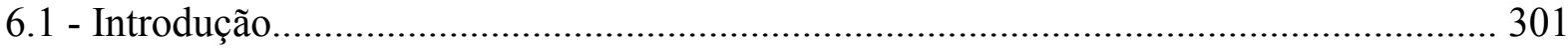

6.2 - Preparação dos cubos de dados de NGC 3227........................................................... 305

6.2.1 - Redução e tratamento dos cubos de dados obtidos com o GMOS..................... 305

6.2.2 - Redução e tratamento dos cubos de dados obtidos com SINFONI..................... 308

6.3 - Aplicação da Tomografia PCA aos cubos de dados de NGC 3227 com o contínuo

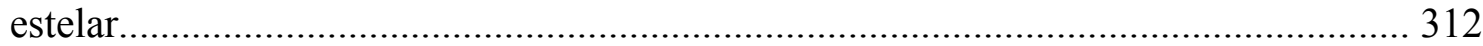

6.3.1 - Resultados da Tomografia PCA do cubo de dados de NGC 3227 obtido com o GMOS, com o contínuo estelar...................................................................... 313

6.3.2 - Resultados da Tomografia PCA do cubo de dados de NGC 3227 obtido com o SINFONI, com o contínuo estelar...................................................................... 318

6.4 - Síntese espectral do cubo de dados de NGC 3227 com o Starlight ................................ 324

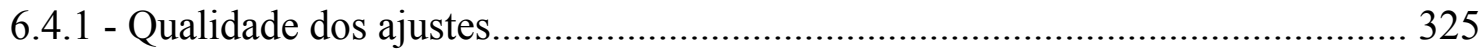

6.4.2 - Populações estelares, poeira e featureless continuum.......................................... 326

6.4.3 - Valores da razão $S / N$ dos espectros analisados................................................ 331

6.5 - Aplicação da Tomografia PCA aos cubos de dados de NGC 3227 com o contínuo estelar

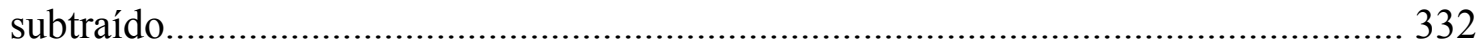

6.5.1 - Resultados da Tomografia PCA do cubo de dados de NGC 3227 obtido com o GMOS, com o contínuo estelar subtraído......................................................... 333

6.5.2 - Resultados da Tomografia PCA do cubo de dados de NGC 3227 obtido com o SINFONI, com o contínuo estelar subtraído....................................................... 338

6.6 - Cinemática estelar dos cubos de dados de NGC 3227................................................. 343 
6.6.1 - Resultados da aplicação do pPXF ao cubo de dados de NGC 3227 obtido com o GMOS

6.6.2 - Resultados da aplicação do pPXF ao cubo de dados de NGC 3227 obtido com o SINFONI.

6.7 - Cinemática do gás dos cubos de dados de NGC 3227.

6.7.1 - Mapeamentos da velocidade radial do gás do cubo de dados de NGC 3227 obtido com o GMOS. 348

6.7.2 - Mapeamentos da velocidade radial do gás do cubo de dados de NGC 3227 obtido com o SINFONI.

6.8 - Espectro de emissão de $\mathrm{H}_{2}$ do cubo de dados de NGC 3227 obtido com o SINFONI:

razões de linhas e temperaturas de excitação.

6.9 - Conclusões.

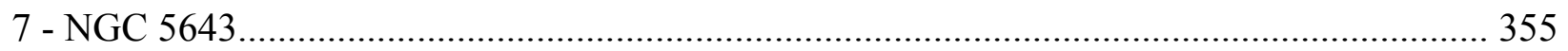

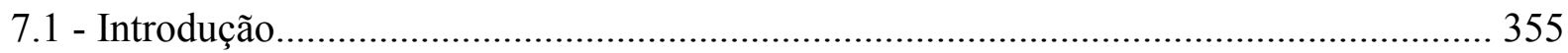

7.2 - Preparação do cubo de dados de NGC 5643 .............................................................. 357

7.3 - Aplicação da Tomografia PCA ao cubo de dados de NGC 5643 com o contínuo estelar.

7.4 - Síntese espectral do cubo de dados de NGC 5643 com o Starlight................................ 367

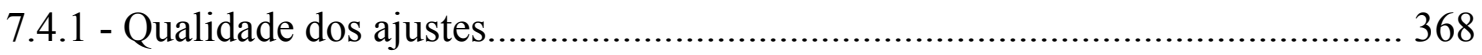

7.4.2 - Populações estelares, poeira e featureless continuum......................................... 369

7.4.3 - Valores da razão $S / N$ dos espectros analisados................................................ 372

7.5 - Aplicação da Tomografia PCA ao cubo de dados de NGC 5643 com o contínuo estelar

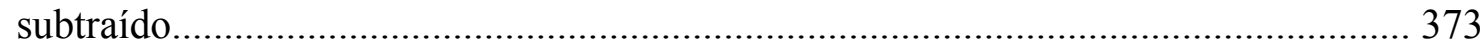

7.6 - Cinemática estelar do cubo de dados de NGC 5643................................................... 380

7.7 - Cinemática do gás do cubo de dados de NGC 5643 ..................................................... 386

7.8 - Espectro de emissão de $\mathrm{H}_{2}$ do cubo de dados de NGC 5643: razões de linhas e temperaturas de excitação......................................................................................... 388

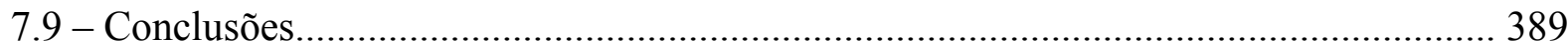

8 - NGC 1068 


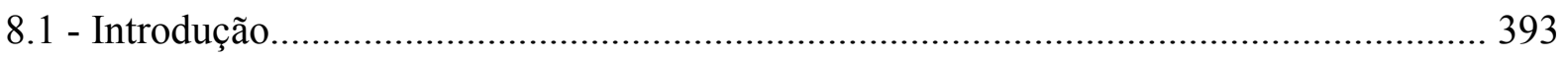

8.2 - Preparação do cubo de dados de NGC 1068................................................................. 399

8.3 - Aplicação da Tomografia PCA ao cubo de dados de NGC 1068 com o contínuo

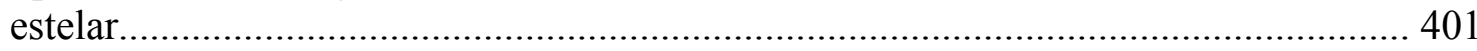

8.4 - Síntese espectral do cubo de dados de NGC 1068 com o Starlight ............................... 408

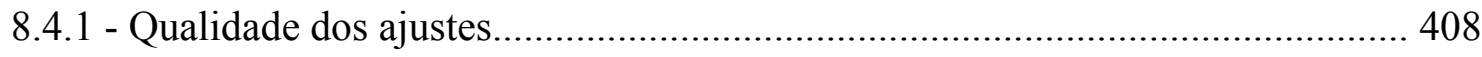

8.4.2 - Parâmetros cinemáticos................................................................................... 410

8.4.3 - Populações estelares e featureless continuum...................................................... 411

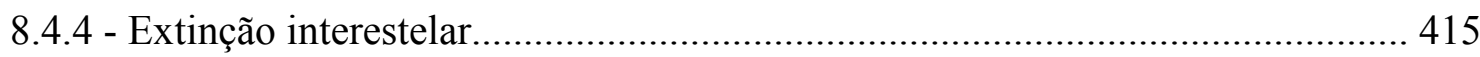

8.4.5 - Valores da razão $S / N$ dos espectros analisados................................................. 417

8.5 - Aplicação da Tomografia PCA ao cubo de dados de NGC 1068 com o contínuo estelar

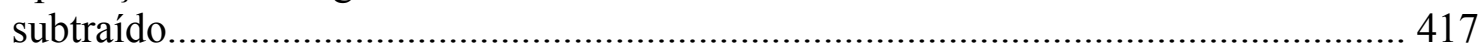

8.6 - Cinemática estelar do cubo de dados de NGC 1068 ................................................... 424

8.7 - Cinemática do gás do cubo de dados de NGC 1068.................................................. 427

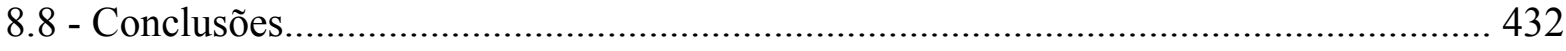

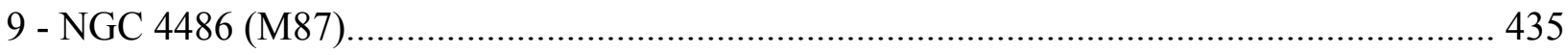

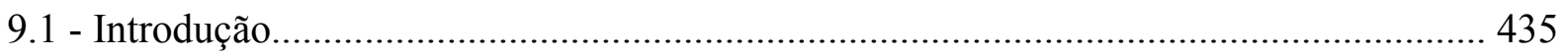

9.2 - Preparação do cubo de dados de M87................................................................................ 437

9.3 - Aplicação da Tomografia PCA ao cubo de dados de M87 com o contínuo estelar...... 442

9.4 - Síntese espectral do cubo de dados de M87 com o Starlight .......................................... 447

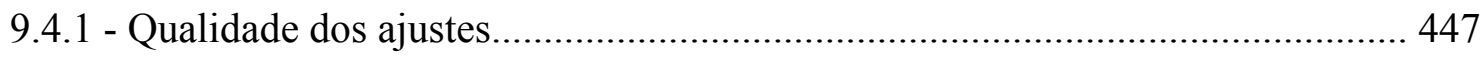

9.4.2 - Populações estelares, poeira e featureless continuum......................................... 448

9.4.3 - Valores da razão $S / N$ dos espectros analisados................................................. 452

9.5 - Aplicação da Tomografia PCA ao cubo de dados de M87 com o contínuo estelar

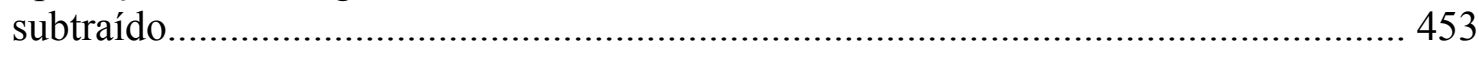

9.6 - Cinemática estelar do cubo de dados de M87 ............................................................ 458

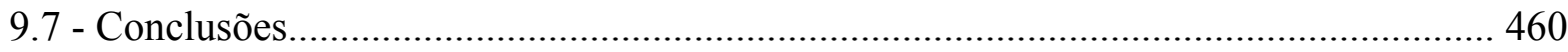


10.1 - Introdução 463

10.2 - Preparação dos cubos de dados de M104.

10.2.1 - Redução e tratamento dos cubos de dados obtidos com o GMOS

10.2.2 - Redução e tratamento dos cubos de dados obtidos com o NIFS.

10.3 - Aplicação da Tomografia PCA aos cubos de dados de M104 com o contínuo estelar.

10.3.1 - Resultados da Tomografia PCA do cubo de dados de M104 obtido com o GMOS, com o contínuo estelar.

10.3.2 - Resultados da Tomografia PCA do cubo de dados de M104 obtido com o NIFS, com o contínuo estelar.

10.4 - Síntese espectral do cubo de dados de M104 com o Starlight. 486

10.4.1 - Qualidade dos ajustes.

10.4.2 - Parâmetros cinemáticos.

10.4.3 - Populações estelares e featureless continuum.

10.4.4 - Extinção interestelar.

10.4.5 - Valores da razão $S / N$ dos espectros analisados.

10.5 - Aplicação da Tomografia PCA aos cubos de dados de M104 com o contínuo estelar subtraído.

10.5.1 - Resultados da Tomografia PCA do cubo de dados de M104 obtido com o GMOS, com o contínuo estelar subtraído.

10.5.2 - Resultados da Tomografia PCA do cubo de dados de M104 obtido com o NIFS, com o contínuo estelar subtraído. 501

10.6 - Cinemática estelar dos cubos de dados de M104.

10.6.1 - Resultados da aplicação do pPXF ao cubo de dados de M104 obtido com o GMOS.

10.6.2 - Resultados da aplicação do pPXF ao cubo de dados de M104 obtido com o NIFS

10.7 - Cinemática do gás do cubo de dados de M104.

10.8 - Espectro de emissão do cubo de dados de M104 obtido com o GMOS: ajustes com o software Cloudy. 


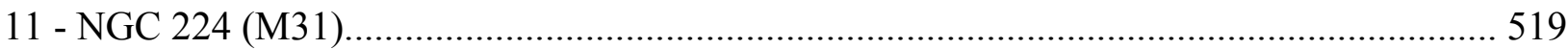

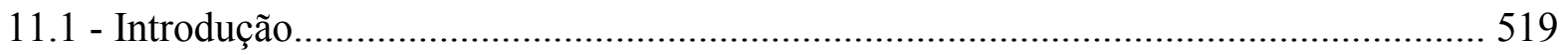

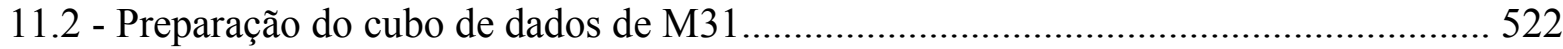

11.3 - Aplicação da Tomografia PCA ao cubo de dados de M31 com o contínuo estelar... 524

11.4 - Síntese espectral do cubo de dados de M31 com o Starlight ........................................ 529

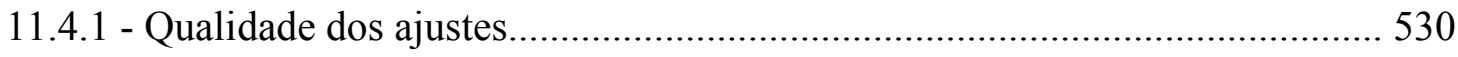

11.4.2 - Parâmetros cinemáticos............................................................................... 530

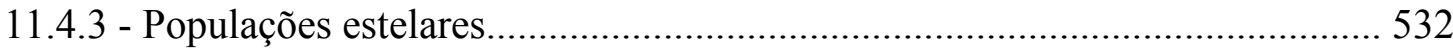

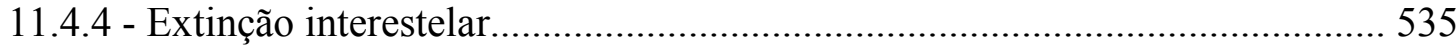

11.4.5 - Valores da razão $S / N$ dos espectros analisados............................................ 536

11.5 - Aplicação da Tomografia PCA ao cubo de dados de M31 com o contínuo estelar

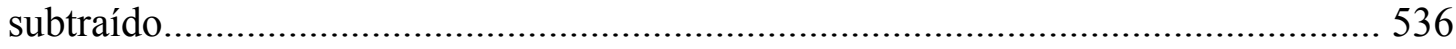

11.6 - Cinemática estelar do cubo de dados de M31 ............................................................ 542

11.7 - Cinemática da linha $\mathrm{H} \alpha$ do cubo de dados de M31.................................................... 548

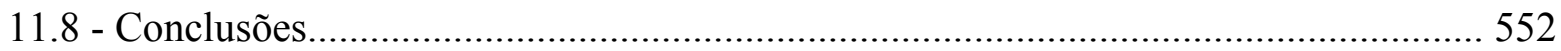

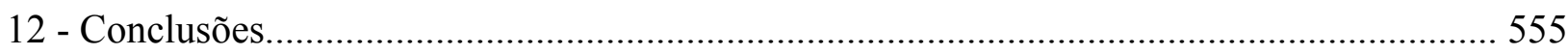

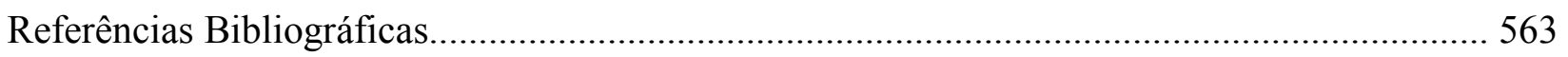

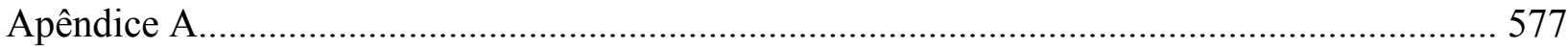

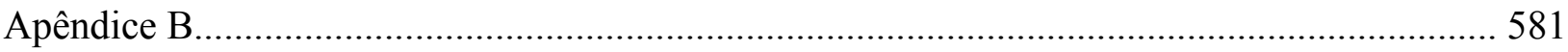

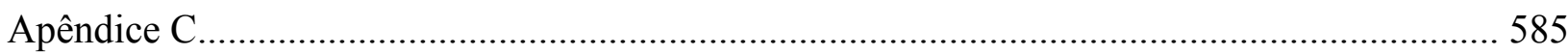

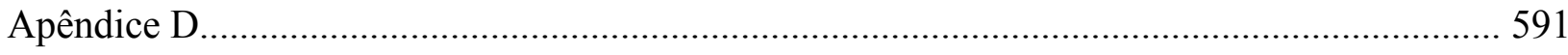

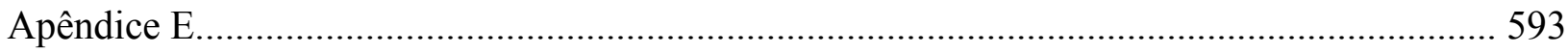

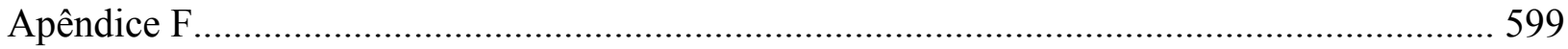




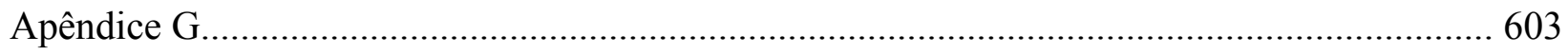

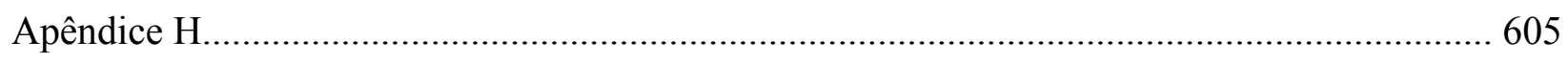

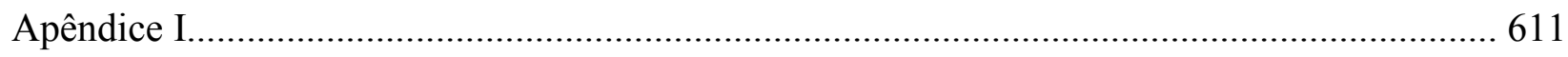





\section{1 - Introdução}

Núcleos ativos de galáxias (active galactic nuclei - $A G N$ ) estão localizados na região central de galáxias e apresentam uma emissão espectral que não pode ser atribuída, somente, a estrelas. Esses objetos são divididos nas seguintes categorias, de acordo com as suas características espectrais e fotométricas: quasares, QSOs, galáxias Seyfert, rádio-galáxias, LINERs, objetos BL Lac e OVVs.

Os quasares e os QSOs compreendem as categorias mais luminosas dos AGNs, com magnitudes absolutas nucleares dadas por $M_{B}<-21.5+5 \log h_{0}$, de acordo com um critério estabelecido por Schmidt \& Green (1983) para diferenciar quasares e QSOs de galáxias Seyfert. Visualmente, esses objetos apresentam uma aparência estelar não resolvida, entretanto, muitos membros dessas categorias também possuem uma emissão difusa ao seu redor, que parece ser devida a populações estelares presentes. Isso sugere que boa parte dos QSOs e quasares, senão todos, possuem uma galáxia ao seu redor, que geralmente não é visível, devido ao forte ofuscamento causado por esses AGNs muito luminosos. A diferença essencial entre os QSOs e os quasares, que justifica a divisão desses objetos em duas categorias distintas, é que os primeiros não apresentam emissão em rádio muito significativa (radio-quiet), ao passo que os últimos são fortes emissores em rádio (radio-loud). Com exceção da emissão em rádio, os QSOs e os quasares apresentam características espectrais bastante similares, dentre as quais pode-se destacar:

- Forte contínuo não térmico, variável no tempo, na forma de uma lei de potência

- Intenso fluxo na região espectral do ultravioleta (big blue bump)

- Linhas de emissão bastante largas, cobrindo uma ampla faixa de ionização

Nos quasares, é bastante freqüente que a emissão em rádio venha de dois lobos diametralmente opostos, localizados em regiões consideravelmente afastadas do AGN central. Em alguns casos,

uma fraca emissão óptica também pode ser detectada nesses lobos. Cobrindo uma faixa de ionização tão alta, conforme mencionado nas características anteriores, é freqüente que linhas de emissão de bastante alta ionização, como OVI $\lambda 1035$, NV $\lambda 1240$ e [Ne V] $\lambda 3426$, por exemplo, 
sejam detectadas nos espectros desses objetos. Apesar da diferença no que se refere à emissão em rádio, atualmente é bastante comum que quasares e QSOs sejam chamados, unicamente, de quasares.

As galáxias Seyfert são AGNs de menor luminosidade, com $M_{B}>-21.5+5 \log h_{0}$, de acordo com o critério estabelecido por Schmidt \& Green (1983), já mencionado anteriormente. Esses objetos possuem núcleos com aparências similares às de quasares, mas, nesses casos, a galáxia ao redor é claramente detectável. Morfologicamente, os membros dessa categoria possuem a aparência de galáxias espirais comuns, com um núcleo bastante brilhante, que apresenta fortes linhas de emissão de alta ionização. Diversos estudos (Adams 1977; Heckman 1978) mostraram que a maior parte das galáxias Seyfert, senão todas, são espirais. As características espectrais das Seyferts são bastante similares às do QSOs, embora menos intensas e com linhas de emissão com grau de ionização ligeiramente menor. Essa categoria engloba, apenas, AGNs do tipo radio-quiet. As galáxias Seyfert se subdividem em dois grandes grupos, de acordo com uma divisão primeiramente estabelecida por Khachikian \& Weedman (1974): as Seyferts de tipo 1 e as Seyferts de tipo 2. Os objetos de tipo 1 apresentam linhas de emissão permitidas bastante alargadas, com valores típicos de $F W H M$ da ordem de $5000 \mathrm{~km} / \mathrm{s}$, e linhas proibidas mais estreitas, com valores de $F W H M$ na faixa de $200 \mathrm{~km} / \mathrm{s}<F W H M<900 \mathrm{~km} / \mathrm{s}$, sendo que, na maioria dos casos, $F W H M=350-400 \mathrm{~km} / \mathrm{s}$. Os objetos de tipo 2, por outro lado, apresentam, apenas, linhas estreitas com valores de FWHM comparáveis aos das linhas estreitas dos objetos de tipo 1. Dessa forma, pode-se dizer que, embora as linhas estreitas dessa categoria de AGNs apresentem valores de FWHM consideravelmente menores do que os das linhas mais alargadas, elas ainda são mais largas do que as vistas em vários outros tipos de objetos, como galáxias starburst ou regiões HII. Baseando-se na aparência dos espectros ópticos, Osterbrock (1981) introduziu as subcategorias Seyfert 1.5, 1.8 e 1.9 para esse tipo de AGNs. As galáxias Seyfert 1.9 apresentam uma fraca componente alargada, apenas, na linha H $\alpha$. Nas galáxias Seyfert 1.8, as componentes largas também são bastante fracas, mas detectadas tanto em H $\alpha$ quanto em H $\beta$. Por fim, as galáxias Seyfert 1.5 apresentam componentes largas e estreitas das linhas de emissão com intensidades comparáveis.

As rádio-galáxias costumam ser consideradas como as análogas radio loud das galáxias Seyfert. A luminosidade e as características espectrais desses objetos são bastante similares às das Seyferts, com a diferença de que essas galáxias são fortes emissoras em rádio. Assim como 
no caso das Seyferts, as rádio-galáxias se dividem em duas subcategorias, de acordo com a largura das linhas de emissão visíveis em seus espectros: as broad-line radio galaxies (BLRG), que apresentam linhas permitidas mais alargadas e linhas proibidas estreitas em seus espectros, e as narrow-line radio galaxies (NLRG), que possuem apenas linhas estreitas em seus espectros. Apesar das semelhanças espectrais e fotométricas em relação às galáxias Seyfert, existem algumas diferenças entre essas duas categorias de AGNs, além da questão relacionada à emissão em rádio. Uma dessas diferenças é que quase todas as BLRGs possuem perfis de H I compostos (com componentes largas e estreitas com intensidades similares). Esse padrão é geralmente encontrado em galáxias Seyfert 1.5, mas outras Seyferts com linhas largas (como Seyferts 1, 1.8 e 1.9) não apresentam tal característica. As componentes largas das linhas das galáxias Seyfert 1 também costumam ser menos alargadas do que as das BLRGs. Além disso, as Seyferts 1 tendem a apresentar linhas largas, razoavelmente intensas, de Fe II em seus espectros, ao passo que, nas BLRGs, tais linhas costumam ser muito menos intensas. Por fim, a razão das intensidades das componentes largas das linhas $\mathrm{H} \alpha$ e $\mathrm{H} \beta$ é, em média, maior em BLRGs do que em Seyferts 1. As rádio-galáxias e as Seyferts também apresentam uma diferença fundamental no que se refere às propriedades da galáxia ao redor do AGN central. Enquanto as galáxias Seyfert costumam ser espirais, conforme mencionado anteriormente, as rádio-galáxias, geralmente, são elípticas. Algumas dessas, inclusive, podem ser classificadas como elípticas gigantes de tipo cD, que costumam ser encontradas nos centros de aglomerados de galáxias. Assim como os quasares, as rádio-galáxias podem apresentar estruturas estendidas emissoras em rádio. Tais estruturas podem ser divididas em duas classes de luminosidade (Fanaroff \& Riley 1974). A classe FR I engloba fontes em rádio mais fracas, que são mais brilhantes no centro e apresentam um decréscimo no brilho superficial em direção às bordas. A classe FR II, por outro lado, inclui fontes em rádio mais intensas, com as bordas brilhantes, e que também podem apresentar regiões de maior brilho imersas na própria estrutura da emissão estendida.

Os OVVs (Optically Violent Variables) são AGNs que apresentam uma variabilidade no contínuo em todos os comprimentos de onda nos quais eles são observados. Tal variabilidade é anormalmente grande (com $\Delta m \geq 0.1 \mathrm{mag}$, por exemplo, na região espectral do visível) e ocorre em escalas de tempo bastante curtas (em alguns casos, tão curtas quanto 1 dia, por exemplo). Todos os OVVs são emissores em rádio, ou seja, são radio-loud. Os objetos BL Lac são uma outra categoria de AGNs que apresentam, essencialmente, as mesmas propriedades dos OVVs, 
mas com uma diferença marcante: a ausência de fortes linhas de absorção ou de emissão em seus espectros. Fracas absorções estelares e linhas de emissão nebulares podem, entretanto, ser ocasionalmente observadas em espectros com alta razão $S / N$. Frequentemente, os OVVs e os objetos BL Lac são coletivamente chamados de blazares.

Os LINERs (Low Ionization Nuclear Emission-Line Regions) formam uma classe de objetos que apresentam linhas de emissão em seus espectros com mais baixa ionização do que no caso dos quasares e das galáxias Seyfert. Heckman (1980) foi o primeiro a identificar tal classe de objetos e estabeleceu que, para um objeto ser classificado como LINER, ele deve possuir linhas de emissão de [O I] $\lambda 6300$, [O II] $\lambda 3727$ e [O III] $\lambda 5007$ que satisfaçam os seguintes critérios:

$$
\frac{[O I I] \lambda 3727}{[O I I] \lambda 5007}>1 \quad \frac{[O I] \lambda 6300}{[O I I I] \lambda 5007}>\frac{1}{3}
$$

Devido às dificuldades em se comparar as intensidades de linhas em um intervalo tão grande de comprimentos de onda (de $3727 \AA$ a $6300 \AA$ ) e também ao fato de a linha de [O II] $\lambda 3727$ poder ser bastante afetada pela extinção interestelar, outras definições da classe dos LINERs mais utilizadas atualmente são (Osterbrock \& Ferland 2006):

$$
\frac{[O I I] \lambda 5007}{H \beta}<3 \quad \frac{[O I] \lambda 6300}{H \alpha}>0.05
$$

e

$$
\frac{([S I I] \lambda 6716+\lambda 6731)}{H \alpha}>0.4 \quad \frac{[N I I] \lambda 6583}{H \alpha}>0.5
$$

As luminosidades dos LINERs costumam ser baixas $\left(L_{b o l}<10^{44} \mathrm{erg} / \mathrm{s}\right)$ e muitos deles são emissores em rádio (radio-loud). As larguras das linhas de emissão desses objetos são comparáveis àquelas das linhas estreitas das galáxias Seyfert, entretanto, em alguns casos, podem ser detectadas componentes largas em algumas dessas linhas (como $\mathrm{H} \alpha$ e $\mathrm{H} \beta$, por exemplo). Por essa razão, costuma-se dividir esses objetos (analogamente ao que é feito no caso das galáxias Seyfert e das rádio-galáxias) em LINERs de tipo 1, mostrando algumas linhas com componentes 
largas em seus espectros, e LINERs de tipo 2, com apenas linhas estreitas em seus espectros. Os LINERs são bastante comuns. Acredita-se que eles estejam presentes em cerca de 1/3 das galáxias próximas. Mais especificamente, estudos têm mostrado que aproximadamente $20 \%$ das galáxias próximas contêm LINERs "puros", ao passo que $13 \%$ delas possuem objetos de transição, que também devem apresentar alguma emissão do tipo LINER (Ho 2008). Os LINERs tendem a ocorrer com maior freqüência em galáxias early type (estudos têm mostrado que o máximo da ocorrência de LINERs se dá em galáxias do tipo S0/Sa). Ao contrário de quasares e galáxias Seyfert, os LINERs, em geral, não apresentam o chamado big blue bump em seus espectros, mas possuem um big red bump, ou seja, um máximo de emissão na região infravermelha do espectro.

Os AGNs liberam uma grande quantidade de energia a partir de uma região consideravelmente pequena. Isso faz com que tal energia não possa ser atribuída a processos estelares comuns, já que a quantidade de estrelas necessária para liberar toda a energia observada não seria compatível com o pequeno espaço envolvido. Atualmente, o modelo mais aceito para explicar o mecanismo dos AGNs prevê a existência de um buraco negro supermassivo central e um disco de acreção ao redor deste. O material existente nesse disco de acreção espirala e cai na direção do buraco negro central e, durante esse processo, a sua energia potencial é convertida em energia radiativa, que é emitida, dando origem aos fenômenos energéticos observados. Esse modelo pode ser aplicado a todas as categorias de AGNs mencionadas anteriormente, entretanto, no caso dos LINERs, a situação é um pouco mais controversa. O espectro de baixa ionização desses objetos, inicialmente, foi tomado como sendo gerado por aquecimento devido a ondas de choque (Heckman 1980). Entretanto, trabalhos posteriores (Halpern \& Steiner 1983 e Ferland \& Netzer 1983) mostraram que tais características espectrais também poderiam ser reproduzidas por modelos envolvendo fotoionização com parâmetros de ionização até uma ordem de grandeza menores do que aqueles apresentados pelas galáxias Seyfert e utilizando, como fonte ionizante, um contínuo na forma de lei de potência. Esses trabalhos revelaram, consequentemente, que os LINERs poderiam ser movidos por autênticos AGNs, ou seja, que sua energia poderia ser produzida pela acreção de matéria em um buraco negro central. O único detalhe, nesse caso, é que o processo envolveria parâmetros de ionização consideravelmente baixos. Com o passar do tempo, entretanto, outros modelos também foram propostos para explicar o mecanismo dos LINERs, como fotoionização por estrelas quentes associadas a algum starburst recente 
(Terlevich \& Melnick 1985; Shields 1992), fotoionização por estrelas "velhas" (Taniguchi et al. 2000; Binette et al. 1994) e o próprio modelo de aquecimento por ondas de choque, primeiramente proposto por Heckman (1980), também foi bastante aprimorado (Dopita et al. 1996). Todos esses modelos são bastante diferentes em termos de origem física e, por isso mesmo, a natureza dos LINERs tem sido motivo de muitos debates ao longo dos anos. Hoje parece claro que os LINERs constituem uma classe de objetos bastante heterogênea, ou seja, não existe um modelo único capaz de explicar as características de todos os LINERs observados e cada objeto diferente pode ser explicado por um dos diversos modelos citados ou por combinações dos mesmos. Entretanto, acredita-se que a maioria desses objetos sejam movidos por autênticos AGNs (Ho 2008).

Do ponto de vista histórico, o estudo observacional dos AGNs começou em 1908 com o trabalho de Edward A. Fath no Observatório Lick. Fath estava estudando os espectros dos núcleos das "nebulosas espirais" mais brilhantes, que hoje nós sabemos que são galáxias. A maioria delas apresentou espectros com linhas de absorção, que eram devidas às populações estelares presentes nas galáxias, entretanto, no espectro de uma galáxia, NGC 1068, foram detectadas seis linhas de emissão conhecidas: H $\beta$, [O II] $\lambda 3727$, [Ne III] $\lambda 3869$ e

[O III] 24363,4959,5007. Em 1917, V. M. Slipher obteve espectros muito melhores de NGC 1068 e, em 1926, Edwin Hubble, em seu grande estudo de "nebulosas extragalácticas", notou a presença de espectros similares aos de nebulosas planetárias nos núcleos de três galáxias: NGC 1068, NGC 4051 e NGC 4151. Finalmente, Seyfert (1943) estabeleceu que uma fração pequena das galáxias observadas apresentava núcleos brilhantes com espectros com linhas de emissão largas e de alta ionização. Tais objetos ficaram conhecidos, posteriormente, como galáxias Seyfert. Após a Segunda Guerra Mundial, avanços na radio astronomia provocaram um aumento no número de fontes em rádio detectadas. Além disso, o número de identificações de fontes em rádio no óptico também aumentou. Walter Baade e Rudolph Minkowski, por exemplo, identificaram a fonte em rádio Cygnus A com uma galáxia fraca, em um redshift $z=0.057$, cujo espectro era bastante similar ao das galáxias Seyfert. Outras identificações similares a essa se seguiram com o passar dos anos e esses objetos passaram a ser chamados de rádio-galáxias. Uma fração das fontes em rádio identificadas apresentava uma aparência estelar não resolvida. Seus espectros apresentavam um forte contínuo com linhas de emissão largas, cuja identificação era desconhecida até então. Durante muito tempo, várias hipóteses foram propostas para tentar 
explicar essas linhas de emissão desconhecidas, até que, em 1963, Maarten Schmidt descobriu que as linhas de emissão detectadas no objeto 3C 273, um forte emissor em rádio, na verdade, correspondiam a linhas nebulares bastante conhecidas, mas com um redshift de $z=0.158$, que era um valor de $z$ anormalmente grande para a época. Após isso, Jesse Greenstein identificou linhas similares em 3C 48, com um redshift de $z=0.367$. Tal valor de $z$ era maior do que qualquer outro observado até então. Esses objetos ficaram conhecidos, então, como quasistellar radio sources ou quasares. Analogamente, também foram identificados objetos de aparência estelar e com propriedades espectrais similares, mas que não eram emissores em rádio (radio-quiet). Tais objetos ficaram conhecidos como quasistellar objects ou QSOs.

Considerando o grupo dos AGNs como um todo, pode-se dizer que eles são consideravelmente mais raros de serem encontrados do que galáxias sem atividade nuclear. Entretanto, comparando-se as diferentes categorias de AGNs, nota-se que a densidade espacial de objetos varia bastante de uma categoria para a outra, ou seja, certos tipos de AGNs são muito mais raros do que outros. A tabela 1.1 mostra as densidades espaciais dos diferentes tipos de AGNs e de galáxias sem atividade nuclear. Observando-se os valores, pode-se notar, claramente, que os quasares são os AGNs mais raros de serem encontrados, possuindo uma densidade espacial muito menor do que as galáxias Seyfert, por exemplo.

\begin{tabular}{|c|c|}
\hline Tipo do objeto & Densidade espacial $\left(\mathrm{Mpc}^{-1}\right)$ \\
\hline Galáxias de campo & $10^{-1}$ \\
\hline Galáxias luminosas & $10^{-2}$ \\
\hline Galáxias Seyfert & $10^{-4}$ \\
\hline Rádio-galáxias & $10^{-6}$ \\
\hline QSOs & $10^{-7}$ \\
\hline Quasares & $10^{-8}$ \\
\hline
\end{tabular}

Tabela 1.1 - Densidades espaciais de diferentes categorias de AGNs e de galáxias sem atividade nuclear. Tabela adaptada de Osterbrock \& Ferland (2006).

O estudo dos AGNs e do ambiente ao seu redor é um dos assuntos mais importantes da astronomia e envolve diferentes tópicos como: os diferentes modelos para acreção de material no buraco negro central, mecanismos de excitação e ionização do gás, populações estelares nas vizinhanças e em áreas mais afastadas do $\mathrm{AGN}$, cinemática estelar e do gás nas áreas próximas ao AGN (no caso de movimentos keplerianos, tal estudo pode ser utilizado para a determinação da massa do buraco negro central), etc. 
Nesse trabalho, foram analisados cubos de dados de 8 AGNs próximos de diferentes categorias, obtidos com o IFU (Integral Field Unity) do GMOS (Gemini Multi-Object Spectrograph) dos telescópios Gemini-Norte e Gemini-Sul, com o NIFS (Near-Infrared Integral Field Spectrograph) do telescópio Gemini-Norte e com o SINFONI (Spectrograph for Integral Field Observations in the Near Infrared) do VLT (Very Large Telescope). É importante mencionar que os telescópios Gemini-Norte, Gemini-Sul e VLT possuem 8 metros de abertura. O tratamento e a análise de todos os cubos de dados foram feitos utilizando-se uma série de metodologias específicas, muitas das quais foram desenvolvidas nos últimos anos pelo grupo de trabalho do autor. Em vários cubos de dados, o uso dessas metodologias foi o que possibilitou a detecção de uma série de fenômenos. Além disso, mesmo nos casos em que foram obtidos resultados já encontrados em estudos anteriores, os procedimentos aqui utilizados proporcionaram uma melhora significativa da qualidade de todos esses resultados. Dessa forma, pode-se dizer que o aspecto metodológico teve um peso significativo em todo esse trabalho. A tabela 1.2 contém os nomes de todos os objetos analisados, juntamente com o instrumento utilizado para se obter os cubos de cada um deles. Como apenas AGNs próximos foram selecionados para esse trabalho, certas categorias de objetos, geralmente encontradas em redshifts mais elevados, não foram consideradas aqui, como quasares e QSOs, por exemplo. O principal objetivo de se utilizar AGNs próximos nesse estudo foi obter espectros com grandes razões $S / N$ e, ao mesmo tempo, imagens com ótimas resoluções espaciais, o que proporcionou uma análise bastante detalhada.

\begin{tabular}{|c|c|c|c|}
\hline Objeto & $\begin{array}{c}\text { Instrumento } \\
\text { utilizado na } \\
\text { observação }\end{array}$ & Classificação & Distância \\
\hline NGC 4151 & NIFS & Seyfert 1 & $13.3 \mathrm{Mpc}$ \\
\hline M 31 & GMOS-N & LINER & $778 \mathrm{kpc}$ \\
\hline M 87 & NIFS & $\begin{array}{c}\text { LINER/rádio- } \\
\text { galáxia }\end{array}$ & $16.0 \mathrm{Mpc}$ \\
\hline NGC 1068 & GMOS-S & Seyfert 2 & $14.4 \mathrm{Mpc}$ \\
\hline NGC 2992 & SINFONI & Seyfert 1 & $32.5 \mathrm{Mpc}$ \\
\hline NGC 5643 & SINFONI & Seyfert 2 & $16.9 \mathrm{Mpc}$ \\
\hline NGC 3227 & GMOS-N/SINFONI & Seyfert 1 & $18.0 \mathrm{Mpc}$ \\
\hline M 104 & GMOS-S/NIFS & LINER & $9.2 \mathrm{Mpc}$ \\
\hline
\end{tabular}

Tabela 1.2 - Objetos analisados nesse trabalho.

A análise dos cubos de dados desses 8 AGNs foi feita com 4 focos principais: 
- Análise da fenomenologia geral nos arredores do AGN, utilizando-se a Tomografia PCA (Steiner et al. 2009)

- Análise das populações estelares, da emissão térmica de poeira e do featureless continuum existentes nas proximidades do AGN, utilizando-se o software Starlight (Cid Fernandes et al. 2005)

- Análise da cinemática estelar e do gás ao redor do buraco negro central. Em alguns casos, foi possível fazer uma modelagem com o objetivo principal de determinar a massa do buraco negro central

- Análise dos mecanismos de excitação e ionização do gás existente ou da emissão molecular de $\mathrm{H}_{2}$. 


\section{2 - Aspectos teóricos e observacionais dos AGNs}

\section{1 - Introdução}

O tema dos AGNs é bastante vasto e, conforme já foi mencionado anteriormente, envolve uma grande variedade de tópicos. Um exemplo disso é o estudo da forma como a acreção de material no buraco negro central ocorre e as conseqüências disso no espectro resultante emitido. Outro tópico bastante importante é a determinação das populações estelares nos arredores e também em regiões mais afastadas do AGN. O estudo da cinemática estelar e do gás nos arredores do buraco negro central também possui uma considerável importância, pois permite uma análise de estruturas como jatos ou outflows e, no caso da existência de movimentos keplerianos, uma modelagem pode permitir a determinação da massa do buraco negro central existente. Além de tudo isso, uma análise dos linhas de emissão detectadas pode permitir uma determinação dos prováveis mecanismos de excitação e ionização do gás existentes. Quando dados de uma grande quantidade de objetos estão disponíveis, uma série de estudos estatísticos associados a AGNs podem ser realizados. Nas seções a seguir, são discutidos alguns dos aspectos teóricos relevantes no tema dos AGNs, que possuem uma grande importância no trabalho aqui desenvolvido.

\section{2 - O cenário padrão dos AGNs}

Atualmente, o modelo mais aceito para explicar os AGNs diz que a energia liberada por esses objetos vem da acreção de matéria em um buraco negro central. Fundamentalmente, nesse processo, a energia é liberada à medida que a matéria vai sendo acretada no buraco negro, de forma que é possível dizer que se trata de um processo de obtenção de energia a partir de uma certa quantidade de matéria (que é acretada no buraco negro). Tal processo possui uma eficiência $\eta$, logo, a energia disponível a partir da acreção de uma certa quantidade de massa $m$ pode ser dada pela expressão 


$$
E=\eta m c^{2}
$$

e a taxa em que a energia é liberada a partir da acreção pode ser dada por

$$
L=\eta \dot{m} c^{2}
$$

onde $\dot{m}=\frac{d m}{d t}=$ taxa de acreção de massa

Por outro lado, a energia potencial gravitacional de uma massa $m$ a uma distância $r$ do buraco negro central de massa $M$ pode ser dada pela fórmula

$$
U=\frac{G M m}{r}
$$

consequentemente, a taxa em que a energia potencial gravitacional do material que está sendo acretado no buraco negro central pode ser convertida em radiação e emitida fica dada pela expressão

$$
L=\frac{d U}{d t}=\frac{G M}{r} \cdot \frac{d m}{d t}=\frac{G M \dot{m}}{r}
$$

Igualando-se, então, as expressões (2.2) e (2.4), obtém-se:

$$
L=\frac{G M \dot{m}}{r}=\eta \dot{m} c^{2} \Rightarrow \eta=\frac{G M}{r c^{2}}
$$

Pode-se considerar que a escala característica do tamanho de um buraco negro é dada pelo raio de Schwarzschild, que corresponde ao horizonte de eventos para um buraco negro sem rotação. O valor do raio de Schwarzschild é dado por 


$$
R_{S}=\frac{2 G M}{c^{2}}
$$

Tomando-se, em seguida, o valor de $r$ como sendo igual a cerca de $5 R_{S}$ (já que se acredita que essa é a distância a partir do buraco negro central na qual boa parte da radiação no óptico e ultravioleta é gerada) e substituindo-se esse dado na fórmula (2.5), chega-se a

$$
\eta=\frac{G M}{5 R_{S} c^{2}}=\frac{G M}{5 \cdot \frac{2 G M}{c^{2}} \cdot c^{2}}=0.1
$$

Assim, esse cálculo bastante simplificado sugere que a eficiência na qual matéria pode ser convertida em energia é de $\eta=0.1$, o que é cerca de uma ordem de magnitude maior do que a eficiência do processo de fusão do hidrogênio em hélio $(\eta=0.007)$. Na verdade, o cálculo preciso do valor da eficiência do processo de acreção é bem mais complexo e depende dos detalhes de como ele de fato ocorre, entretanto, esse valor de $\eta=0.1$ já é suficiente para mostrar como a acreção de matéria pode ser eficiente na obtenção de energia nesse cenário do AGN (sendo, inclusive, mais eficiente do que a fusão de hidrogênio em hélio).

Se o material a ser acretado não possuísse nenhum valor de momento angular, ele simplesmente fluiria radialmente na direção do buraco negro central, entretanto, acredita-se que, em geral, esse cenário não seja muito comum. Assim, admitindo-se que esse material possua um determinado momento angular (que varia com o tempo, devido à dissipação causada pela viscosidade), ele deve se espiralar ao redor do buraco negro central, formando um disco de acreção, através do qual o material vai sendo acretado. Numa região mais externa ao disco de acreção, esse cenário padrão dos AGNs prevê a existência da chamada Região das Linhas Largas (BLR - Broad Line Region), onde seriam formadas as componentes largas das linhas de emissão que são visíveis nos espectros dos AGNs. Externamente à BLR, existiria, ainda, a chamada Região das Linhas Estreitas (NLR - Narrow Line Region), onde seriam formadas as linhas estreitas visíveis nos espectros dos AGNs. Cada um dos componentes previstos por esse cenário está descrito mais detalhadamente a seguir. 


\subsection{1 - O disco de acreção}

O disco de acreção corresponde à estrutura formada pela matéria ao redor do buraco negro central, que espirala e cai na direção do mesmo. A estrutura detalhada desse disco depende de uma grande variedade de parâmetros, como, por exemplo, a intensidade do campo magnético existente, a taxa de acreção de massa, a presença ou ausência de jatos e etc. Um dos modelos para a estrutura do disco de acreção é o do Disco Padrão, que assume que o meio é opticamente espesso e que a energia de qualquer partícula a uma certa distância do buraco negro central é dissipada localmente. Num cenário como esse, no qual o material pode se resfriar eficientemente, ocorre a formação de um disco geometricamente fino e a emissão local pode ser aproximada como sendo a de um corpo negro. A energia potencial gravitacional de uma partícula de massa $m$ a uma distância $r$ do buraco negro central pode ser dada pela equação (2.3). De acordo com o teorema de Virial, em sua forma mais simples,

$$
2 K+U=0
$$

onde $K=$ energia cinética

$$
U=\text { energia potencial gravitacional }
$$

metade da energia potencial gravitacional da partícula é transformada em energia cinética e é utilizada para aquecer o material, e o restante é irradiado a uma taxa dada por

$$
L=\frac{G M \dot{m}}{2 r}
$$

Considerando-se a emissão como sendo a de um corpo negro, tem-se que

$$
L=\frac{G M \dot{m}}{2 r}=2 \pi r^{2} \sigma T^{4}
$$

onde $\sigma=$ constante de Stefan-Boltzman

$T=$ temperatura superficial do disco 
sendo que o fator 2 do lado direito da equação deve-se ao fato de o disco possuir dois lados com área $\pi r^{2}$. A partir da expressão (2.10), obtém-se que a temperatura superficial do disco de acreção pode ser dada por

$$
T(r)=\left(\frac{G M \dot{m}}{4 \pi \sigma r^{3}}\right)^{\frac{1}{4}}
$$

A derivação mais completa da temperatura superficial, de acordo com o modelo do Disco Padrão (Shakura \& Sunyaev 1973) leva em conta como a energia é dissipada no disco pela viscosidade, e fornece o seguinte resultado (válido em ETL):

$$
T(r)=\left\{\frac{3 G M m}{8 \pi \sigma r^{3}}\left[1-\left(\frac{R_{i n}}{r}\right)^{\frac{1}{2}}\right]\right\}^{\frac{1}{4}}
$$

onde $R_{i n}=$ raio interno do disco de acreção

A freqüência correspondente ao máximo da emissão do disco de acreção (obtida considerando-se uma emissão de corpo negro e fazendo-se $d B_{v} / d T=0$ ) pode ser dada por

$$
v_{\max }=\frac{2.8 k T}{h}
$$

onde $k=$ constante de Boltzmann

$$
h=\text { constante de Planck }
$$

Utilizando-se as expressões anteriores, verifica-se que o máximo da emissão dos discos de acreção dos AGNs, considerando um buraco negro central de massa $10^{8} \mathrm{M}_{\odot}$ e uma taxa de acreção de Eddington (ver apêndice A), se situa por volta dos $100 \mathrm{eV}$, ou seja, na região espectral do ultravioleta extremo ou dos raios-X moles. Assim, o cenário do AGN prevê emissões de contínuo consideravelmente fortes na região do ultravioleta e raios-X. 
O modelo do Disco Padrão, entretanto, só pode ser aplicado considerando-se um meio opticamente espesso e que pode se resfriar eficientemente. Se, por outro lado, o meio for opticamente fino e não puder se resfriar com boa eficiência, a acreção não irá tomar a forma de um disco geometricamente fino, mas sim uma configuração quase esférica, cuja dinâmica poderá ser dominada por advecção, convecção ou fluxos de material. O processo dominado por advecção, por exemplo, é chamado de ADAF, Advection-Dominated Accretion Flow (Narayan \& Yi 1994). A teoria prevê que esses modos de acreção quase esférica devem ocorrer em ambientes de pouca densidade e com pouco material disponível para ser acretado. Todos eles tendem a possuir uma baixa eficiência para a produção de energia e, por isso mesmo, costumam ser chamados de LRAFs, Low-Radiative Efficiency Accretion Flows. Atualmente, acredita-se que esses modos de acreção com baixa eficiência estão associados a núcleos ativos de baixa luminosidade, como LINERs, por exemplo.

\subsection{2 - A Região de Linhas Largas - BLR}

A Região de Linhas Largas (Broad Line Region - BRL) localiza-se ao redor do disco de acreção e é a área na qual, de acordo com o cenário padrão dos AGNs, as componentes largas das linhas de emissão visíveis nos espectros desses objetos são formadas. Em média, a largura dessas linhas é de $F W H M=5000 \mathrm{~km} / \mathrm{s}$. Uma característica fundamental a ser mencionada é que apenas linhas permitidas e de intercombinação são geradas nessa região, já que não são observadas linhas proibidas com componentes tão largas quanto essas. A única explicação para isso é que a BLR corresponda a uma área contendo nuvens de gás com elevada densidade. Dessa forma, as linhas proibidas, que são originadas por transições a partir de níveis energéticos dos átomos com menores valores de densidade crítica, não podem ser geradas, já que a desexcitação colisional impede que tais transições ocorram. As linhas permitidas e de intercombinação, por outro lado, podem ser emitidas nessa região sem problemas, já que os níveis de energia a partir dos quais ocorrem as transições que dão origem a elas possuem valores de densidade crítica mais elevados.

A determinação dos valores de densidade da BLR é difícil, pois as linhas permitidas de H I, He I e He II, que são bastante emitidas nessa região, não são boas para se fazer esse tipo de cálculo, entretanto, algumas estimativas podem ser feitas. As linhas proibidas 
[O III] ג4363, 4959, 5007, evidentemente, não apresentam asas largas nos espectros dos AGNs, já que, conforme foi explicado acima, não podem ser originadas na BLR. Como a densidade crítica do nível ${ }^{1} \mathrm{~S}_{0}$ do íon $\mathrm{O}$ III, que dá origem à transição correspondente à linha [O III] $\lambda 4363$, é de cerca de $10^{8} \mathrm{~cm}^{-3}$, conclui-se que esse é um valor adequado para o limite inferior da densidade da BLR. Por outro lado, uma componente larga da linha de C III] $\lambda 1909$ tem sido observada em diversos AGNs. Como a densidade crítica do nível ${ }^{3} \mathrm{P}_{1}$ do íon C III é de cerca de $10^{10} \mathrm{~cm}^{-3}$, podese dizer que esse é um valor aceitável para o limite superior da densidade da BLR. Um valor intermediário de $10^{9} \mathrm{~cm}^{-3}$, portanto, pode ser tomado como sendo representativo da densidade da BLR.

Da mesma forma que no caso dos valores de densidade, não é possível obter informações diretas sobre a temperatura da BLR, pois as linhas permitidas de H I, He I e He II não são úteis para se fazer estimativas de temperatura. Entretanto, a presença abundante de linhas largas de Fe II nos espectros de AGNs indica que a temperatura da BLR deve ser inferior a $35000 \mathrm{~K}$, pois, para temperaturas maiores do que essa, os íons de Fe II estariam totalmente ionizados na forma de Fe III. Assim, pode-se concluir que $T=10^{4} \mathrm{~K}$ corresponde a uma estimativa razoável para a temperatura da BLR.

A dispersão de velocidades de um gás na linha de visada, devida ao movimento térmico, pode ser estimada pela expressão

$$
v \approx\left(\frac{k T}{m_{p}}\right)^{\frac{1}{2}},
$$

onde $m_{p}=$ massa do próton

assim, se as larguras das linhas originadas na BLR fossem devidas, apenas, a movimentos térmicos, a temperatura do gás (estimada pela expressão 2.14 ) deveria ser superior a $10^{9} \mathrm{~K}$, o que, obviamente, não está de acordo com a estimativa de temperatura feita anteriormente. Na verdade, atualmente acredita-se que o alargamento das linhas provenientes da BLR seja devido a deslocamentos Doppler diferenciais causados pelos movimentos individuais das nuvens.

Variações no contínuo ionizante gerado pelos discos de acreção dos AGNs são muito comuns e, conforme o esperado, são sentidas pela BLR. Assim, monitorando-se essas variações e 
o intervalo de tempo decorrido até que as linhas originadas na BLR manifestem alguma "resposta" a essa variação, pode-se obter informações sobre o tamanho e a estrutura dessa região. Estudos sobre esse assunto têm sido bastante realizados nos últimos anos e um resultado obtido, por exemplo, é que linhas de emissão diferentes respondem às variações no contínuo ionizante em intervalos de tempo diferentes (Peterson 1997). Em geral, o que se nota é que as linhas de mais elevada ionização (como, por exemplo, He II $\lambda 1640$, N V $\lambda 1240$ e C IV 21549 ) respondem às variações no contínuo mais rapidamente do que as linhas de mais baixa ionização (como as linhas de Balmer, por exemplo). Isso indica claramente que a BLR deve possuir uma estrutura estratificada. Outro resultado importante, obtido com esses estudos, revela que a BLR possui um tamanho bastante reduzido, apresentando, geralmente, um diâmetro de cerca de 0.1 pc.

Algumas das linhas emitidas na BLR são simétricas, outras possuem uma asa vermelha (maiores comprimentos de onda) mais pronunciada e outras ainda apresentam uma asa azul (menores comprimentos de onda) mais acentuada. Assim, pode-se dizer que não há uma assimetria ou simetria comum entre essas linhas de emissão. Um campo de velocidades capaz de explicar essa ausência de padrões dominantes nos perfis das linhas emitidas pela BLR é o de uma rotação ao redor do buraco negro central. Nesse caso, as assimetrias nos perfis de algumas linhas seriam devidas a desvios na simetria na própria BLR, como, por exemplo, na distribuição da poeira ou do gás. Um ponto importante a ser mencionado, entretanto, é que a velocidade radial média de linhas de baixa ionização como Mg II $\lambda 2798$ não é a mesma que a de linhas de mais alta ionização, como C IV $\lambda 1549$, o que não está de acordo com um modelo de nuvens em rotação ao redor do buraco negro central. Além disso, as asas vermelhas dessas linhas de mais alta ionização, em geral, costumam estar suprimidas em relação às asas vermelhas das linhas de mais baixa ionização.

A explicação mais simples para esse fato é que exista, além de um movimento rotacional ao redor do buraco negro central, uma expansão radial do gás mais altamente ionizado (que deve estar localizado mais próximo da fonte ionizante, onde o fluxo de fótons ionizantes é maior). Nesse caso, considerando-se a existência de poeira em meio ao gás ionizado, a emissão vinda das nuvens que estão se afastando do observador (e que, consequentemente, dá origem às asas vermelhas das linhas) são mais afetadas pela extinção interestelar devida à poeira do que a emissão vinda das nuvens que estão se aproximando do observador, o que faz com que as asas vermelhas dessas linhas fiquem suprimidas em relação às azuis. Esse movimento de expansão 
radial do material mais altamente ionizado pode ser originado devido ao fato de as regiões mais internas da BLR (onde as nuvens estão mais altamente ionizadas) receberem campos de radiação mais intensos, podendo ser aceleradas radialmente para fora.

\subsection{3 - A Região de Linhas Estreitas - NLR}

A Região de Linhas Estreitas (Narrow-Line Region - NLR) se localiza em uma área externa à BLR e é o local no qual as linhas de emissão estreitas (incluindo as linhas proibidas) visíveis nos espectros dos AGNs são formadas. As larguras típicas dessas linhas são tais que $200 \mathrm{~km} / \mathrm{s} \leq F W H M \leq 900 \mathrm{~km} / \mathrm{s}$, sendo que, na maioria dos casos, $F W H M=350-400 \mathrm{~km} / \mathrm{s}$. Como as linhas proibidas visíveis nos espectros somente são produzidas nessa região (já que jamais apresentam componentes largas), pode-se concluir que se trata de uma área na qual as densidades são inferiores às da BLR. Dessa forma, os níveis de energia dos átomos a partir dos quais ocorrem as transições que dão origem às linhas proibidas (que possuem valores de densidade crítica inferiores aos dos níveis de energia relacionados às transições correspondentes às linhas permitidas e de intercombinação) não sofrem, de maneira considerável, o processo de desexcitação colisional.

Razões de linhas como [O III] $(\lambda 4959+\lambda 5007) /[\mathrm{O}$ III] $\lambda 4363 \mathrm{e}$

[N II] $(\lambda 6548+\lambda 6583) /[\mathrm{N} \mathrm{II}] \lambda 5755$ (que são bastante sensíveis à temperatura do gás) revelam que a temperatura da NLR nos AGNs deve ser próxima a $10^{4} \mathrm{~K}$.

A razão de linhas [O II] $\lambda 3726 /[\mathrm{O}$ II] $\lambda 3729$ é frequentemente usada para se estimar as densidades de regiões H II e nebulosas planetárias, entretanto, ela não pode ser utilizada em AGNs, pois, nesse caso, as larguras dessas linhas, em geral, são comparáveis ou superiores à separação existente entre elas (que é de cerca de $2.8 \AA$ ). A razão [S II] $\lambda 6716 /[\mathrm{S}$ II] $\lambda 6731$, entretanto, revela densidades com valores entre $10^{2} \mathrm{~cm}^{-3}$ e $10^{4} \mathrm{~cm}^{-3}$ para a NLR dos AGNs, assim, um valor intermediário razoável para a densidade é de $10^{3} \mathrm{~cm}^{-3}$.

Ao contrário da BLR, a NLR pode, geralmente, ser espacialmente resolvida com telescópios. As observações mostram que essa região é bem mais extensa do que a BLR, se estendendo até distâncias de cerca de $10^{2}$ pc do buraco negro central. Imageamentos da NLR (feitos, por exemplo, através de filtros de banda estreita centrados em linhas de emissão) revelam que, em geral, a morfologia dessa área tende a ser mais assimétrica do que simétrica. $\mathrm{O}$ eixo da 
NLR costuma coincidir com o eixo da região emissora de rádio (nos objetos onde emissão em rádio estendida foi detectada), o que parece indicar alguma conexão entre essas duas áreas. Em algumas fontes, a região emissora de rádio mostra indícios da existência de ondas de choque, sobretudo na região divisória entre o plasma emissor de rádio e o meio interestelar da galáxia. Isso parece indicar que esse plasma que está fluindo radialmente para fora cria ondas de choque ao colidir com o ambiente da NLR. Sabe-se que pode haver forte emissão de radiação ionizante a partir da região pós-choque de uma onde de choque (onde as temperaturas costumam ser bastante elevadas) e, além disso, em um cenário como esse, excitação colisional e até mesmo ionização colisional podem ter um papel relevante. Assim, pode-se concluir que, na NLR de alguns objetos, outros processos além da radiação ionizante emitida pelo disco de acreção podem ter um papel relevante.

Os perfis das linhas de emissão emitidas na NLR costumam apresentar uma assimetria em comum: as suas asas azuis tendem a ser mais intensas do que as vermelhas. Isso é um indício de que o campo de velocidades dessa região deve apresentar um fluxo radial de material para fora. Com isso, se houver poeira em meio ao gás presente, o cenário resultante será o mesmo que aquele utilizado para explicar o fato de as asas azuis das linhas de mais alta ionização da BLR (como C IV 21549 ) serem mais intensas do que as vermelhas: a emissão vinda do material que está se afastando do observador sofre uma extinção maior do que aquela proveniente do material que está se aproximando, o que faz com que as asas azuis das linhas fiquem mais intensas do que as vermelhas.

Algumas estruturas comumente vistas nos AGNs são os cones de ionização, que possuem uma forma de cunha com ângulos de abertura entre $30^{\circ}$ e $100^{\circ}$, e correspondem a regiões nas quais pode ser detectada emissão vinda de espécies de mais elevada ionização. A razão

[O III] $\lambda 5007 / \mathrm{H} \alpha$, por exemplo, apresenta valores mais elevados dentro desses cones (indicando uma provável ionização devida ao $\mathrm{AGN}$ ) do que em áreas próximas (nas quais a ionização, provavelmente, deve estar associada às populações estelares presentes). Em geral, a região contendo esses cones de ionização é chamada de Região de Linhas Estreitas Estendida (Extended Narrow-Line Region - ENLR), que se diferencia da NLR clássica pelo fato de possuir menor brilho superficial, estar mais afastada do núcleo e, em geral, apresentar menores graus de ionização. Os cones de ionização mostram que a emissão de radiação é anisotrópica ou que, pelo menos, ela se torna anisotrópica a distâncias de kiloparsecs da fonte de radiação central. De fato, 
não é possível saber, com certeza, se a radiação já é emitida (na região do disco de acreção) de maneira anisotrópica ou se essa anisotropia é introduzida em escalas menores do que a NLR por um possível toro de poeira, por exemplo (que pode existir nesses tipos de objetos, conforme estudos atuais têm mostrado).

\section{3 - O contínuo espectral dos AGNs}

Uma das principais características dos AGNs é um intenso contínuo espectral, que se estende desde a região espectral do rádio até a dos raios-gama. Tal contínuo espectral é geralmente chamado de featureless continuum. A figura 2.1 mostra a distribuição de energia espectral (spectral energy distribution - SED) média de um conjunto de quasares e QSOs e permite uma boa visualização desse featureless continuum dos AGNs.

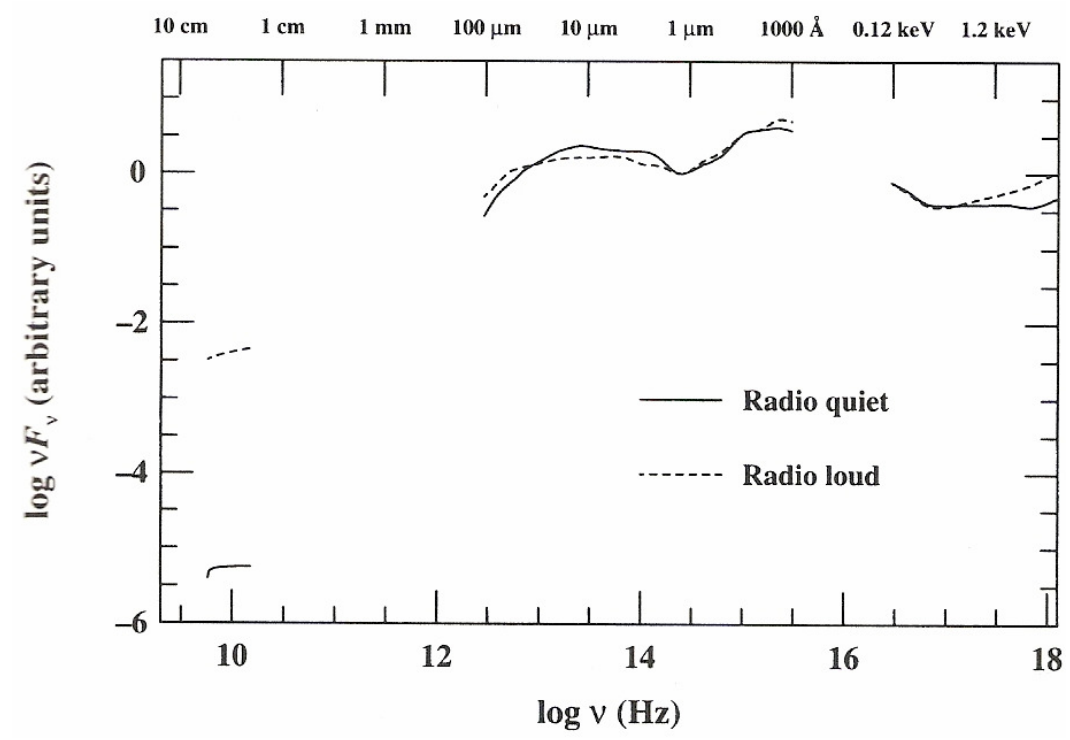

Figura 2.1 - Distribuição de energia espectral (SED) média de um conjunto de quasares e QSOs. Figura obtida de Elvis et al. (1994).

Em uma primeira aproximação, o featureless continuum dos AGNs pode ser tomado como tendo a forma de uma lei de potência,

$$
F_{v} \propto v^{-\alpha}
$$


onde $\alpha$ é chamado de índice espectral e, geralmente, assume valores no intervalo $0 \leq \alpha \leq 1.5$. Uma análise mais detalhada do featureless continuum mostra que ele apresenta uma série de desvios em relação a uma simples lei de potência, como depressões e protuberâncias. Algumas das principais características do featureless continuum dos AGNs que o diferenciam de uma simples lei de potência são:

- Uma protuberância bastante alargada que domina o espectro em comprimentos de onda menores do que $4000 \AA$, se estendendo até a região dos raios-x moles. Essa estrutura bastante proeminente, geralmente, é chamada de big blue bump.

- Um mínimo local próximo a $1 \mu \mathrm{m}$, seguido por uma suave protuberância em comprimentos de onda maiores, que costuma ser chamada de IR bump.

- Um rápido e acentuado decrescimento na região espectral de menores energias. O ponto no qual esse decréscimo abrupto ocorre, geralmente, é chamado de submillimeter break.

O fato de o featureless continuum dos AGNs se estender por um intervalo tão grande de freqüências sugere que ele deve ser gerado por mais de um mecanismo físico e acredita-se que elétrons relativísticos tenham um papel muito importante nesse cenário. Atualmente, acredita-se que os elétrons relativísticos nos AGNs são gerados por uma aceleração Fermi de primeira ordem em choques, que, provavelmente, são formados por fluxos de material supersônicos próximo ao buraco negro central. A aceleração de Fermi é definida como sendo aquela sofrida por partículas carregadas quando são refletidas por um campo magnético interestelar em movimento (Fermi 1949). Esse processo é especialmente eficaz em choques. Nesses casos, uma partícula carregada à frente do choque pode passar pela região do choque e ser espalhada por inhomogeneidades magnéticas atrás do choque. Após esse espalhamento, a partícula ganha energia e atravessa novamente a região do choque, podendo ser, após isso, novamente espalhada por inhomogeneidades magnéticas à frente do choque. Esse processo no qual a partícula é impulsionada para frente e para trás do choque pode se repetir sucessivamente, fazendo com que ela ganhe energia em cada uma das vezes. Como o ganho médio de energia tem uma dependência linear para com a velocidade do choque, esse processo é chamado de aceleração de Fermi de primeira ordem e, geralmente, dá origem a uma distribuição na forma de lei de potência para as energias das partículas aceleradas (Blandford \& Eichler 1987; Jones \& Ellison 1991). A presença 
de elétrons relativísticos com uma distribuição de energia na forma de lei de potência pode gerar dois mecanismos de emissão de radiação, que, de acordo com consenso atual, devem ter um importante papel para a formação do featureless continuum dos AGNs: a emissão synchrotron e o espalhamento Compton inverso.

A emissão synchrotron corresponde à radiação emitida por elétrons relativísticos acelerados por um campo magnético. Em um ambiente opticamente fino e com elétrons relativísticos com uma distribuição de energias dada pela expressão

$$
N(E) d E=C E^{-p} d E
$$

onde $C=$ constante

$N(E) d E=$ número de elétrons com energia entre $E$ e $E+\mathrm{d} E$

a emissividade correspondente à radiação synchrotron apresenta a seguinte dependência para com a freqüência:

$$
\begin{aligned}
\varepsilon_{v} \propto v^{-s} & \\
& \operatorname{com} s=(p-1) / 2
\end{aligned}
$$

Por outro lado, quando o meio é opticamente espesso, a emissão synchrotron sofre o processo de auto-absorção, ou seja, parte da radiação emitida pode ser absorvida pelo material existente no meio. Nesse caso, a emissividade associada à radiação synchrotron (ainda considerando-se elétrons com uma distribuição de energias na forma de uma lei de potência) possui a seguinte dependência para com a freqüência:

$$
\varepsilon_{v} \propto v^{\frac{5}{2}}
$$


O espalhamento Compton inverso, por sua vez, corresponde a um processo no qual fótons são espalhados por elétrons relativísticos. Nesse caso, os fótons menos energéticos podem ganhar energia, dando origem a fótons altamente energéticos de raios-x ou raios-gamma, por exemplo.

A seguir é dada uma descrição mais detalhada do featureless continuum dos AGNs em diferentes regiões espectrais, assim como dos prováveis mecanismos responsáveis por originá-lo.

\subsection{1 - O featureless continuum no óptico e ultravioleta}

A região espectral do ultravioleta se estende desde $100 \AA$ até $4000 \AA$, enquanto que a região do óptico vai desde $4000 \AA$ até $7500 \AA$. A estrutura dominante do featureless continuum no óptico e ultravioleta é o big blue bump. Acredita-se que essa intensa protuberância no contínuo espectral dos AGNs é devida a uma emissão térmica com uma temperatura de $10^{5 \pm 1} \mathrm{~K}$. Conforme mencionado na seção 2.2.1, o fluxo emitido pelo disco de acreção ao redor de um buraco negro de $10^{8} \mathrm{M}_{\odot}$ apresenta um máximo próximo a $100 \mathrm{eV}$, que corresponde à região espectral do ultravioleta extremo ou dos raios-x moles. Isso parece sugerir que o big blue bump pode ser originado pela emissão proveniente do disco de acreção, entretanto, esse é ainda um ponto bastante controverso. Assumindo-se uma emissão de corpo negro para o disco de acreção, é possível mostrar (apêndice B) que a sua luminosidade apresenta uma dependência para com freqüência dada por

$$
L_{v} \propto v^{1 / 3} .
$$

Entretanto, o featureless continuum na região do óptico/ultravioleta dos AGNs, em média, apresenta a forma $F_{v} \propto v^{-0.3}$, que é incompatível com o que é dado na expressão (2.19). Para tentar resolver essa discrepância, vários modelos foram propostos levando em conta o efeito conjunto da emissão térmica do disco de acreção e de outros mecanismos físicos. Malkan (1989), por exemplo, mostrou que a combinação de um espectro térmico frio na região do infravermelho com o espectro de um disco de acreção pode reproduzir bem o featureless continuum dos AGNs nessa região espectral. 
Apesar de alguns estudos terem reproduzido, com sucesso, o featureless continuum dos AGNs no óptico/ultravioleta, utilizando o efeito conjunto da emissão térmica do disco de acreção e de outros mecanismos físicos, ainda restam muitas dúvidas sobre a real origem do big blue bump. Mais detalhes sobre esse tópico podem ser encontrados em Peterson (1997).

\subsection{2 - O featureless continuum nas regiões de altas energias}

A região espectral dos raios-x se estende desde $0.01 \AA$ até $100 \AA$ ( $1 \mathrm{MeV}$ até $124 \mathrm{eV})$, enquanto que a região dos raios-gamma abrange comprimentos de onda inferiores a $0.01 \AA$ (energias superiores a $1 \mathrm{MeV}$ ). $\mathrm{O}$ espectro de altas energias dos AGNs é de grande importância para se entender o mecanismo físico desses objetos. A emissão em raios-x representa cerca de $10 \%$ da luminosidade bolométrica dos AGNs e, além disso, a sua rápida variabilidade indica que observações nessa região espectral podem revelar detalhes importantes sobre as áreas mais centrais desses objetos.

Um problema com as observações nessa região espectral é a baixa resolução espectral geralmente obtida. Entretanto, satélites para a observação em raios-X atuais, como o Chandra, por exemplo, têm melhorado bastante essa situação. Os primeiros satélites em raios-x possuíam

resoluções espectrais da ordem de $R=\frac{\lambda}{\Delta \lambda} \leq 10$, entretanto, o satélite Chandra pode atingir resoluções de $40 \leq R \leq 2000$, o que representa uma enorme melhoria. Observações iniciais de AGNs em raios-x (Mushotzky et al. 1980, por exemplo) mostraram que o featureless continuum na região espectral 2-20 keV podia ser bem ajustado por uma lei de potência com índice espectral $\alpha \approx 0.7 \pm 0.2$. Entretanto, estudos posteriores (Nandra \& Pounds 1994) mostraram que uma única lei de potência não ajusta bem toda a região espectral dos raios-x e que, na região de menores energias (raios-x moles), o espectro geralmente é mais íngreme, com $\alpha \approx 0.9-1$.

Observações em raios-gamma com resolução razoável somente se tornaram possíveis a partir da invenção do Compton Gamma-Ray Observatory (CGRO). Johnson et al. (1994) mostraram que o featureless continuum na região espectral dos raios-gamma é bem ajustado por uma lei de potência com índice espectral $\alpha \approx 1.2 \pm 0.2$.

A quantidade relativa de energia entre as regiões espectrais do óptico/ultravioleta e raios$\mathrm{x}$ é muitas vezes expressa em termos do índice espectral de uma lei de potência que une essas 
duas regiões. Entretanto, tal índice não é obtido a partir de um real ajuste de uma lei de potência, mas sim de um simples cálculo que quantifica os fluxos de relativos da região do óptico/ultravioleta e dos raios-X. Geralmente, esse índice espectral é chamado de $\alpha_{o x}$ e é definido da seguinte maneira (Tananbaum et al. 1979):

$$
\alpha_{o x}=\frac{-\log \left[\frac{F_{v}(2 k e V)}{F_{v}(2500 A)}\right]}{\log \left[\frac{v(2 k e V)}{v(2500 A)}\right]}=-0.384 \log \left[\frac{F_{v}(2 k e V)}{F_{v}(2500 A)}\right] .
$$

É bastante comum encontrarem-se valores da ordem de $\alpha_{o x} \approx 1.4$ em boa parte dos AGNs.

Com relação à origem da emissão em raios-x e raios-gamma dos AGNs, ainda há muitas dúvidas e controvérsias. Muitos modelos reproduzem essas emissões em altas energias utilizando o espalhamento Compton inverso de fótons de menor energia por elétrons altamente energéticos. No cenário adotado por Haardt \& Maraschi (1993), por exemplo, o contínuo no óptico/ultravioleta emitido pelo disco de acreção sofre um espalhamento Compton inverso por elétrons energéticos (provavelmente relativísticos) em uma coroa ao redor do disco, dando origem a fótons de mais altas energias. Esse cenário sofre várias modificações de acordo com o modelo adotado, mas o processo básico envolvido é conhecido como Comptonização. Uma outra variação possível para esse modelo envolve o espalhamento Compton inverso de fótons resultantes da emissão synchrotron gerada por elétrons relativísticos. Tal processo é chamado de Synchrotron Self-Compton (SSC) e somente pode ser utilizado em casos nos quais a radiação synchrotron é significativa.

\subsection{3 - O featureless continuum no infravermelho}

A região espectral do infravermelho se estende desde $7500 \AA$ até $1 \mathrm{~mm}$. Conforme já foi mencionado anteriormente, as principais características do featureless continuum no infravermelho são um mínimo próximo a $1 \mu \mathrm{m}$ seguido por uma suave protuberância em comprimentos de onda maiores, que costuma ser chamada de IR bump. Tal protuberância foi notada pela primeira vez por Neugebauer et al. (1979), que a descreveram como um excesso de 
emissão em $3.5 \mu \mathrm{m}$. Posteriormente, Robson et al. (1986) e Edelson \& Malkan (1986) chamaram novamente a atenção para essa componente do featureless continuum dos AGNs. Barvainis (1987) mostra que o IR bump pode ser explicado como sendo originado pela emissão térmica de poeira existente nas regiões ao redor do disco de acreção. De acordo com esse modelo, a poeira é aquecida pelo contínuo no óptico/ultravioleta (provavelmente emitido pelo disco de acreção) e emite no infravermelho. Atualmente, muitos AGNs já foram observados nessa região espectral (Riffel et al. 2006) e tudo parece indicar que o cenário da emissão térmica de poeira está correto. Três importantes evidências a favor disso são:

- O mínimo espectral próximo a $1 \mu \mathrm{m}$ seguido pelo IR bump em maiores comprimentos de onda, que parecem ser claros indicativos de emissão termal

- A variabilidade no contínuo no infravermelho, que apresenta um atraso em relação à variabilidade no óptico/ultravioleta. Esse atraso parece ser um efeito causado pelo tempo necessário para a luz viajar desde a região emissora de óptico/ultravioleta até a área emissora de infravermelho. Essa situação parece estar de acordo com o modelo que prevê a presença de poeira em áreas um pouco mais afastadas da região emissora de óptico/ultravioleta (presumivelmente o disco de acreção). Essa poeira seria, então, aquecida pelo contínuo recebido e emitiria no infravermelho

- O rápido decréscimo do featureless continuum na região espectral do infravermelho distante e submilimétrica. Estudos mostraram que um espectro térmico originado pela emissão de poeira poderia dar origem a esse comportamento (Draine \& Lee 1984)

\subsection{4 - O featureless continuum no rádio}

A região espectral do rádio se estende desde $10 \mathrm{~mm}$ até $30 \mathrm{~m}$. O featureless continuum dos AGNs no rádio teve uma enorme importância no contexto histórico desses objetos, já que, conforme foi mencionado anteriormente, muitas categorias de AGNs (como quasares e rádiogaláxias) foram, inicialmente, observadas como fontes de rádio. Entretanto, mesmo no caso de objetos do tipo radio- loud, a emissão em rádio detectada, geralmente, contribui pouco para a luminosidade bolométrica. Ainda assim, como se acredita que o contínuo em rádio dos AGNs seja, sobretudo, não térmico (ou seja, provavelmente originado a partir da emissão de partículas 
carregadas aceleradas), estudos nessa região espectral podem ser considerados como uma importante ferramenta para se avaliar os mecanismos de aceleração de partículas existentes.

O contínuo em rádio emitido pelos AGNs apresenta um formato compatível com o que se esperaria de uma emissão synchrotron. Normalmente, os índices espectrais encontrados nessa região espectral são próximos a 0.7 , o que, de acordo com a expressão (2.17) para a radiação syncrotron, equivale a $p=2.5$. Isso está de acordo com o esperado, considerando-se a radiação emitida por elétrons submetidos a uma aceleração de Fermi de primeira ordem em choques. Em regiões espectrais de menores freqüências, é comum observar-se um espectro mais íngreme, o que é compatível com o efeito da auto-absorção synchrotron (expressão 2.18). O índice espectral observado nessas regiões, entretanto, não costuma ser tão alto quanto o dado pela expressão (2.18). Esse comportamento, geralmente, é explicado como sendo devido à complexidade da fonte, com diferentes regiões se tornando opticamente espessas em diferentes freqüências.

Uma outra evidência importante que mostra que o featureless continuum dos AGNs em rádio tem uma origem não térmica está relacionada à temperatura de brilho detectada. Esses objetos costumam apresentar temperaturas de brilho bastante altas (na faixa de $10^{11}-10^{12} \mathrm{~K}$ ), mas que raramente ultrapassam o valor máximo de $10^{12} \mathrm{~K}$. Isso pode ser explicado considerando-se os valores relativos da densidade do campo magnético $\left(U_{m a g}=B^{2} / 8 \pi\right)$ e da densidade de radiação $\left(U_{\text {rad }}=4 \pi J / c\right)$. Quando o valor de $U_{\text {rad }}$ cresce a ponto de ultrapassar $U_{\text {mag, os fótons }}$ provenientes da emissão synchrotron começam a sofrer espalhamento Compton inverso, o que dá origem a fótons muito mais energéticos (raios-x e raios-gamma). Esse processo, entretanto, faz com que a temperatura de brilho jamais ultrapasse o valor de $10^{12} \mathrm{~K}$, pois estudos mostraram que é nesse valor que tem início o espalhamento Compton inverso (Kellermann \& Pauliny-Toth 1969). Em outras palavras, pode-se dizer que o desencadeamento do espalhamento Compton inverso é o que regula a temperatura de brilho desses objetos, impedindo que ela ultrapasse $10^{12}$ K.

No trabalho aqui realizado, foram utilizadas, apenas, observações de AGNs no óptico e no infravermelho próximo, logo, apenas o featureless continuum nessas duas regiões espectrais pôde ser analisado com maiores detalhes. 


\section{4 - O espectro de emissão dos AGNs}

As linhas de emissão detectadas nos espectros dos AGNs representam uma característica bastante marcante desses objetos, não apenas pelas suas grandes larguras, mas também pelo grande intervalo de ionização observado. Além disso, as razões de intensidade dessas linhas podem ser utilizadas para diferenciar os AGNs de outros tipos de objetos, assim como para diferenciar diferentes categorias de AGNs. As características do espectro de emissão desses objetos em diferentes regiões espectrais estão descritas com mais detalhes a seguir.

\subsection{1 - As linhas de emissão dos AGNs no óptico e ultravioleta}

As linhas de emissão nas regiões espectrais do óptico e ultravioleta foram as primeiras a serem detectadas nos AGNs e, consequentemente, possuem uma relevância histórica. Conforme já foi mencionado anteriormente, Edward A. Fath deu início ao estudo dos AGNs ao observar, pela primeira vez, seis linhas de emissão no espectro do núcleo de NGC 1068.

Linhas intensas provenientes tanto da BLR (extremamente alargadas) quanto da NLR (mais estreitas) costumam ser detectadas no espectro óptico e ultravioleta dos AGNs. Conforme foi dito em 2.2.2 e 2.2.3, apenas linhas permitidas e de intercombinação são emitidas pela BLR, enquanto que tanto linhas proibidas quanto permitidas e de intercombinação podem ser geradas na NLR.

Com relação aos processos que dão origem às linhas de emissão, pode-se dizer que as linhas permitidas, normalmente, são geradas a partir de um nível energético superior no átomo com uma energia vários elétron-volts acima da do nível inferior. Dessa forma, tais linhas raramente são geradas por excitação colisional dos átomos, já que isso exigiria colisões com partículas altamente energéticas. Ao invés disso, essas linhas, usualmente, são geradas a partir de processos de recombinação de elétrons (nos quais elétrons em estados não ligados se recombinam aos átomos, passando para estados ligados), seguidos de um decaimento em cascata para níveis mais baixos de energia. As principais linhas de recombinação detectadas no espectro óptico/ultravioleta dos AGNs são as de H I, He I e He II. Por outro lado, pode-se dizer que as linhas proibidas detectadas, geralmente, são originadas a partir de processos de excitação colisional. Isso porque tais linhas, normalmente, são geradas por transições nas quais o nível 
energético superior possui uma energia apenas poucos elétron-volts acima da do nível inferior, ou seja, o processo de excitação colisional é possível. O fato de quase todas as linhas no óptico/ultravioleta excitadas colisionalmente serem proibidas pode ser explicado da seguinte maneira: como os níveis energéticos superiores das transições possuem apenas poucos elétronvolts a mais do que os níveis inferiores, as suas configurações eletrônicas, geralmente, também são iguais às dos níveis inferiores, logo, as transições entre esses níveis são proibidas, de acordo com a regra de seleção da paridade. Entretanto, em certos comprimentos de onda no ultravioleta, algumas linhas permitidas excitadas colisionalmente costumam ser detectadas nos espectros dos AGNs: Mg II $\lambda \lambda 2796,2803$, C IV $\lambda \lambda$ 1548, 1551 e Si IV $\lambda \lambda$ 1394, 1403. A tabela 2.1 mostra as mais intensas linhas de emissão permitidas e proibidas frequentemente detectadas nos AGNs, juntamente com as blendagens geralmente formadas por linhas próximas.

\begin{tabular}{|c|c|c|}
\hline Linhas & $\begin{array}{l}\text { Comprimento de onda no } \\
\text { referencial de repouso }\end{array}$ & $\begin{array}{c}\text { Estrutura formada por } \\
\text { blendagens }\end{array}$ \\
\hline Ly $\beta$ & 1025.7 & \multirow[t]{3}{*}{ Ly $\beta+$ O VI $\lambda 1035$} \\
\hline O VI $\lambda 1032$ & 1031.9 & \\
\hline O VI $\lambda 1038$ & 1037.6 & \\
\hline Ly $\alpha$ & 1215.67 & \multirow[t]{3}{*}{ Ly $\alpha+N$ V } \\
\hline N V $\lambda 1239$ & 1238.82 & \\
\hline $\mathrm{N} V \lambda 1243$ & 1242.80 & \\
\hline Si IV $\lambda 1394$ & 1393.75 & \multirow[t]{3}{*}{ Si IV + O IV] } \\
\hline Si IV $\lambda 1403$ & 1402.77 & \\
\hline O IV] $\lambda 1401$ & 1401.16 & \\
\hline $\mathrm{C}$ IV $\lambda 1548$ & 1548.20 & \multirow[t]{2}{*}{ C IV $\lambda 1549$} \\
\hline C IV $\lambda 1551$ & 1550.78 & \\
\hline He II $\lambda 1640$ & 1640.42 & \multirow[t]{2}{*}{ He II + O III] } \\
\hline O III] $\lambda 1666$ & 1666.15 & \\
\hline Al III $\lambda 1855$ & 1854.72 & \multirow[t]{3}{*}{$\mathrm{C}$ III] $+\mathrm{Si}$ III] } \\
\hline Si III] $\lambda 1892$ & 1892.03 & \\
\hline C III] $\lambda 1909$ & 1908.70 & \\
\hline Mg II $\lambda 2796$ & 2795.53 & \multirow[t]{2}{*}{ Mg II $\lambda 2798$} \\
\hline Mg II $\lambda 2803$ & 2802.71 & \\
\hline$[\mathrm{Ne} \mathrm{V}] \lambda 3426$ & 3425.50 & \\
\hline$[\mathrm{O}$ II] $\lambda 3726$ & 3726.03 & \\
\hline$[\mathrm{O}$ II] $\lambda 3729$ & 3728.82 & \\
\hline$[\mathrm{Ne}$ III] $\lambda 3869$ & 3869.07 & \\
\hline$[\mathrm{O}$ III] $\lambda 4363$ & 4363.21 & \\
\hline He II $\lambda 4686$ & 4685.71 & \\
\hline
\end{tabular}

Tabela 2.1 - Principais linhas de emissão permitidas e proibidas detectadas nos espectros dos AGNs no óptico/ultravioleta. As blendagens mais comuns formadas por linhas próximas também são mostradas. Tabela adaptada de Peterson (1997). 


\begin{tabular}{|c|c|c|}
\hline Linhas & $\begin{array}{c}\text { Comprimento de onda no } \\
\text { referencial de repouso }\end{array}$ & \multirow{3}{*}{$\begin{array}{c}\text { Estrutura formada por } \\
\text { blendagens }\end{array}$} \\
\hline $\mathrm{H} \beta$ & 4861.33 & \\
\hline$[\mathrm{O} \mathrm{III}] \lambda 4959$ & 4958.91 & \\
\hline$[\mathrm{O} \mathrm{III}] \lambda 5007$ & 5006.84 & \\
\hline$[\mathrm{N} \mathrm{I}] \lambda 5198$ & 5197.90 & \\
\hline$[\mathrm{N} \mathrm{I}] \lambda 5200$ & 5200.26 & \\
\hline $\mathrm{He} \mathrm{I} \lambda 5876$ & 5875.6 & \\
\hline$[\mathrm{Fe} \mathrm{VII}] \lambda 6086$ & 6086.29 & \\
\hline$[\mathrm{O} \mathrm{I}] \lambda 6300$ & 6300.30 & \\
\hline$[\mathrm{Fe} \mathrm{X}] \lambda 6375$ & 6374.50 & \\
\hline$[\mathrm{N} \mathrm{II}] \lambda 6548$ & 6548.04 & \\
\hline $\mathrm{H} \alpha$ & 6562.80 \\
\hline$[\mathrm{N} \mathrm{II}] \lambda 6583$ & 6583.46 \\
\hline$[\mathrm{S} \mathrm{II}] \lambda 6716$ & 6716.44 \\
\hline$[\mathrm{S} \mathrm{II}] \lambda 6731$ & 6730.82 \\
\hline$[\mathrm{Ar}$ III $] \lambda 7136$ & 7135.80 \\
\hline
\end{tabular}

Tabela 2.1 (continuação).

A figura 2.2 mostra o espectro médio obtido a partir de uma amostra de mais de 700 QSOs e quasares. Nele podem ser observadas as principais linhas de emissão detectadas nessa região espectral dos AGNs.

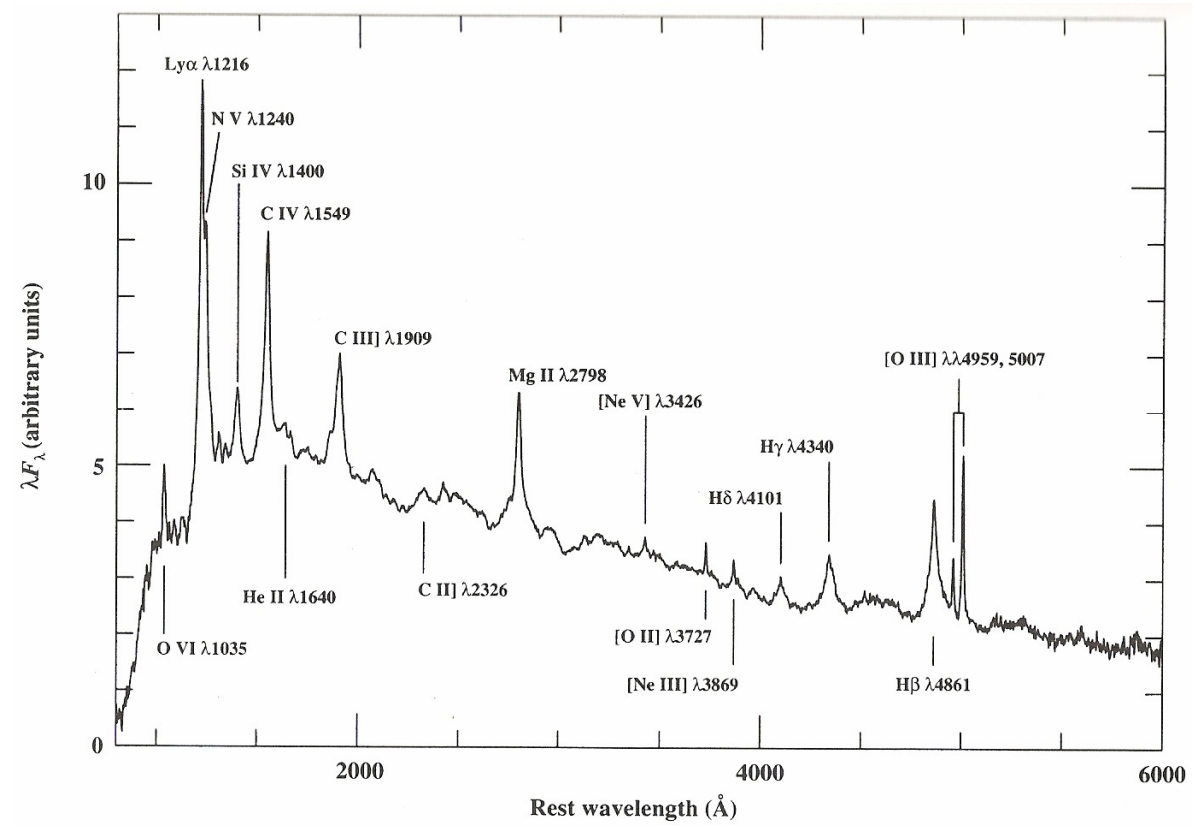

Figura 2.2 - Espectro médio de uma amostra de mais de 700 quasares e QSOs. Figura obtida de Francis et al. (1991). 
Além do que foi citado na tabela 2.1, várias linhas permitidas largas de Fe II, formadas por uma série de multipletos desse íon, também são comumente encontradas nos espectros de QSOs e Seyferts 1. Essas linhas, geralmente, sofrem uma série de blendagens, por estarem localizadas muito próximas umas das outras, dando origem a vários estruturas alargadas nos espectros desses objetos. A figura 2.3 mostra o espectro da galáxia Seyfert 1 Mrk 376 e é possível notar a presença de algumas dessas estruturas alargadas formadas por linhas de Fe II blendadas.

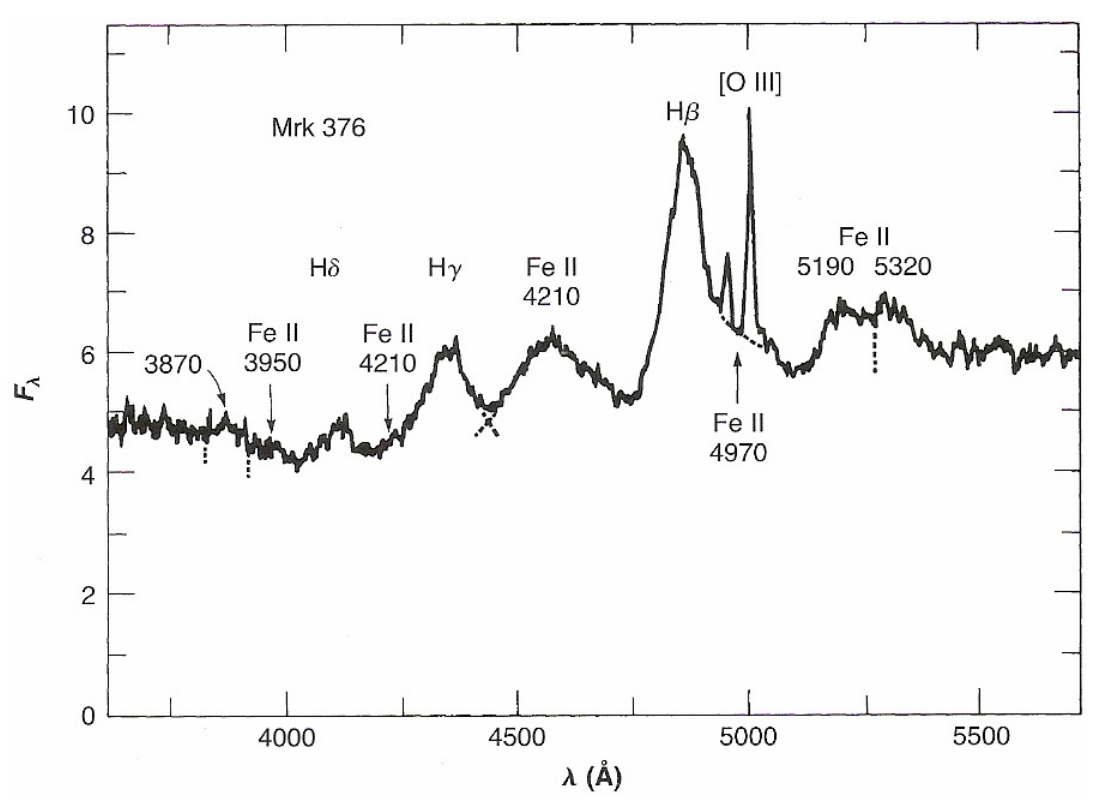

Figura 2.3 - Espectro da galáxia Seyfert 1 Mrk 376. Figura obtida de Osterbrock \& Ferland (2006).

A figura 2.4, por sua vez, mostra os espectros das galáxias Seyfert 1 Mrk 486 e I Zw 1. Esses dois objetos possuem linhas de Fe II consideravelmente mais estreitas, o que faz com que algumas delas possam ser resolvidas individualmente, ao contrário do que ocorre no caso de Mrk 376. Pode-se notar que, embora as estruturas formadas por blendagens de linhas de Fe II sejam bastante largas, as linhas de Fe II individuais possuem larguras comparáveis à da linha H $\beta$. 


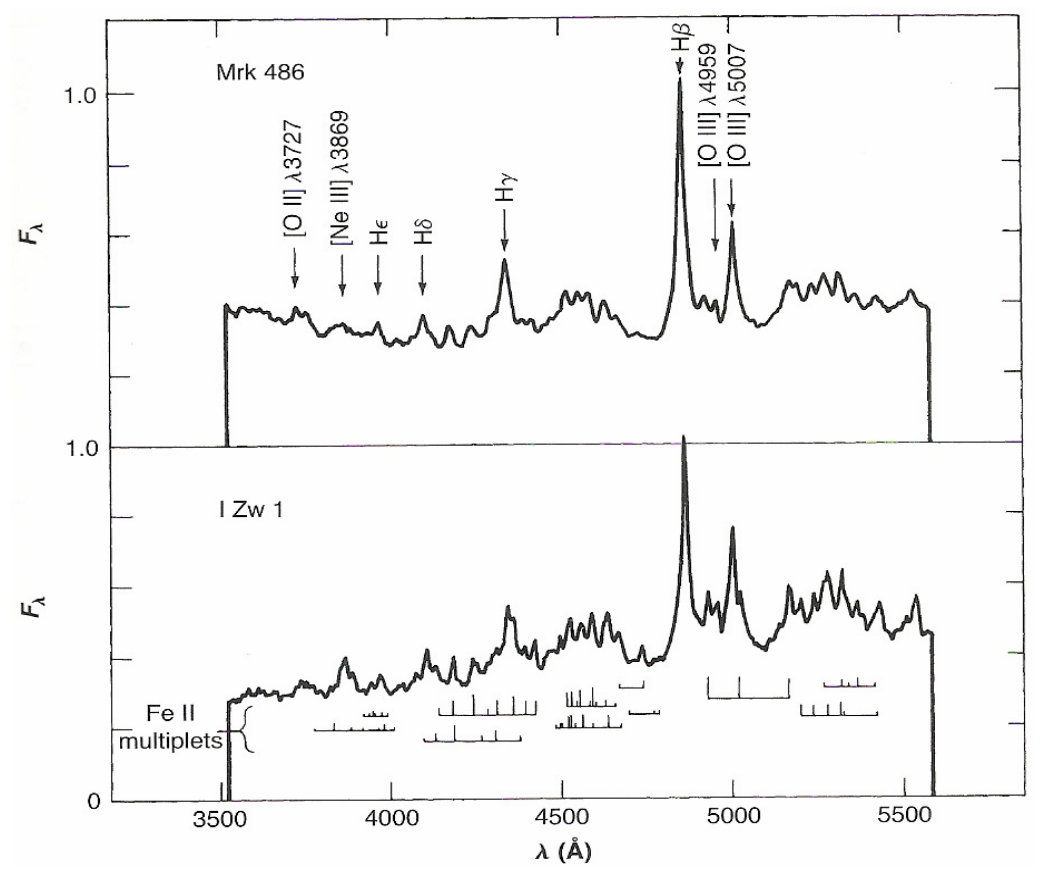

Figura 2.4 - Espectro da galáxia Seyfert 1 Mrk 486. Figura obtida de Osterbrock \& Ferland (2006).

As linhas de Fe II são produzidas por uma combinação de processos de excitação colisional e de ressonância fluorescente. A excitação colisional pode provocar transições entre níveis de energia separados por poucos eV, entretanto, as mais fortes linhas de Fe II observadas são geradas por transições entre níveis de energias separados por 5-10 eV. A excitação colisional não poderia provocar essas transições, pois seriam necessárias temperaturas superiores a 50000 K. A ressonância fluorescente, por outro lado, pode provocar transições entre níveis separados por vários $\mathrm{eV}$ e, consequentemente, pode originar as mais intensas linhas de Fe II observadas. Nesse processo, um fóton do contínuo pode ser absorvido e provocar uma transição que, posteriormente, resulta na emissão de uma linha. Além desses dois processos, a absorção de um fóton Ly $\alpha$ também pode provocar transições entre níveis de energia separados por muitos $\mathrm{eV}$ e, consequentemente, também é capaz de gerar alguma intensas linhas de Fe II. Mais detalhes sobre os mecanismos capazes de gerar as principais linhas permitidas e proibidas na região espectral do óptico/ultravioleta dos AGNs podem ser obtidos em Osterbrock \& Ferland (2006).

Uma outra característica frequentemente notada no espectro ultravioleta de vários AGNs é a presença do chamado small blue bump, que corresponde a uma protuberância entre $2000 \AA$ e 4000 Å. Acredita-se que essa estrutura seja causada por uma blendagem de várias linhas de Fe II, juntamente com o contínuo de Balmer (que corresponde ao contínuo gerado por fótons emitidos a 
partir da recombinações de elétrons livres para o segundo nível de energia do átomo de $\mathrm{H}$ ). A figura 2.5 mostra um espectro da galáxia Seyfert 1 Mrk 335, no qual é possível ver claramente o small blue bump.

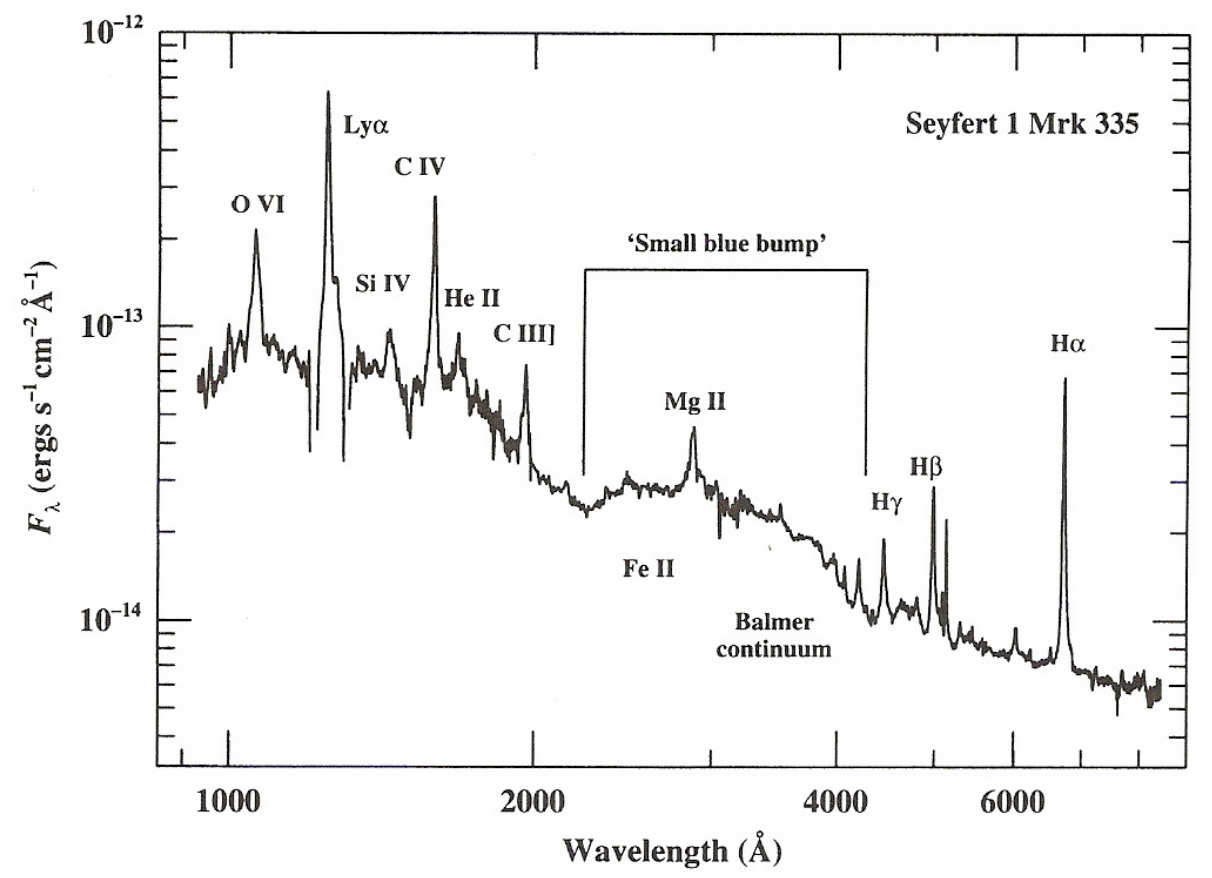

Figura 2.5 - Espectro da galáxia Seyfert 1 Mrk 335. Figura obtida de Zheng et al. (1995).

Uma grande utilidade dos espectros de emissão dos AGNs é que as razões de intensidade das suas linhas de emissão podem ser utilizadas para separá-los de outras categorias de objetos. Baldwin et al. (1981) mostraram que, utilizando gráficos com cada um dos eixos representando os valores da razão de intensidades de duas linhas de emissão, é possível separar objetos fotoionizados por estrelas jovens (regiões H II) dos AGNs. Esses gráficos contendo os valores de razões de intensidade de pares de linhas de emissão são chamados de diagramas de diagnóstico. No trabalho de Baldwin et al. (1981), foram utilizados gráficos de [N II] $\lambda 6583 / \mathrm{H \alpha}$ vs [O III] $\lambda 5007 / \mathrm{H} \beta$, [O II] $\lambda 3727 /[\mathrm{O}$ III] $\lambda 5007$ vs [O III] $\lambda 5007 / \mathrm{H} \beta$, [O II] $\lambda 3727 /[\mathrm{O}$ III] $\lambda 5007$ vs [N II] $\lambda 6583 / \mathrm{H} \alpha$ e [O II] $\lambda 3727 /[\mathrm{O}$ III] $\lambda 5007$ vs [O I] $\lambda 6300 / \mathrm{H \alpha}$ (após o trabalho de Baldwin et al. (1981), esses gráficos também ficaram conhecidos como diagramas de BPT), entretanto, atualmente, diagramas de diagnóstico envolvendo as linhas [S II] $\lambda \lambda 6716,6731$ também costumam ser utilizados. Para se entender a eficácia desses diagramas em separar os AGNs de outras categorias de objetos, uma comparação entre o contínuo espectral dos AGNs e de outros objetos precisa ser feita. Conforme foi mencionado na seção 2.3, os AGNs possuem um 
featureless continuum que se estende por um grande intervalo de freqüências (desde o rádio até os raios-gamma). Os contínuos emitidos pelas estrelas, por outro lado, não se estendem até freqüências tão altas (como raios-x e raios-gamma) com intensidades comparáveis às dos AGNs. Os fótons altamente energéticos associados ao contínuo dos AGNs produzem forte ionização próximo à fonte (íons como $\mathrm{Ne} \mathrm{V}, \mathrm{Fe}$ VII e até mesmo Fe X podem ser encontrados) e, devido ao seu grande livre caminho médio, penetram muito mais no meio gasoso ao redor, dando origem a uma zona de ionização parcial, na qual espécies como H I, H II, O I e S II podem coexistir. Dessa forma, intensas linhas de [O I] e [S II] costumam ser emitidas por essa região. Os fótons do contínuo menos energéticos das estrelas, por outro lado, não são capazes de causar tão alta ionização próximo à fonte e nem de gerar uma zona de ionização parcial como a dos AGNs. A razão de linhas [O III] $\lambda 5007 / \mathrm{H} \beta$ é um bom indicador do grau de ionização da fonte, ao passo que razões como [O I] $\lambda 6300 / \mathrm{H} \alpha$, [S II] $\lambda \lambda 6716,6731 / \mathrm{H} \alpha$ e $\left[\begin{array}{ll}\mathrm{N} & \mathrm{II}\end{array}\right] \lambda 6583 / \mathrm{H} \alpha$ são sensíveis à importância relativa da zona de ionização parcial da fonte. Dessa forma, em diagramas de diagnóstico, objetos com altos valores de [O III] $\lambda 5007 / \mathrm{H} \beta$ (alta ionização) e de como [O I] $\lambda 6300 / \mathrm{H} \alpha$, [S II] $\lambda \lambda 6716,6731 / \mathrm{H} \alpha$ ou [N II] $\lambda 6583 / \mathrm{H} \alpha$ (grande região de ionização parcial) são, provavelmente, AGNs. Por outro lado, objetos com baixos valores de razões como [O I] $\lambda 6300 / \mathrm{H} \alpha$, [S II] $\lambda \lambda 6716,6731 / \mathrm{H} \alpha$ ou [N II] $\lambda 6583 / \mathrm{H \alpha}$ (pequena região de ionização parcial) devem ser regiões H II. A razão [O III] $\lambda 5007 / \mathrm{H} \beta$, apenas, não separa bem AGNs de regiões H II, já que essas últimas também podem apresentar valores consideravelmente elevados para essa razão. Finalmente, objetos com baixos valores de [O III] $\lambda 5007 / \mathrm{H} \beta$ (baixa ionização) e altos valores de [O I] $\lambda 6300 / \mathrm{H} \alpha$, [S II] $\lambda \lambda 6716,6731 / \mathrm{H} \alpha$ ou [N II] $\lambda 6583 / \mathrm{H} \alpha$ (grande região de ionização parcial) devem se enquadrar na categoria dos LINERs, que será discutida mais à frente. A figura 2.6 mostra um diagrama de diagnóstico com as razões de linhas [O III] $\lambda 5007 / \mathrm{H} \beta$ e [N II] $\lambda 6583 / \mathrm{H} \alpha$. Na figura estão destacadas as divisões entre as diferentes categorias de objetos. 


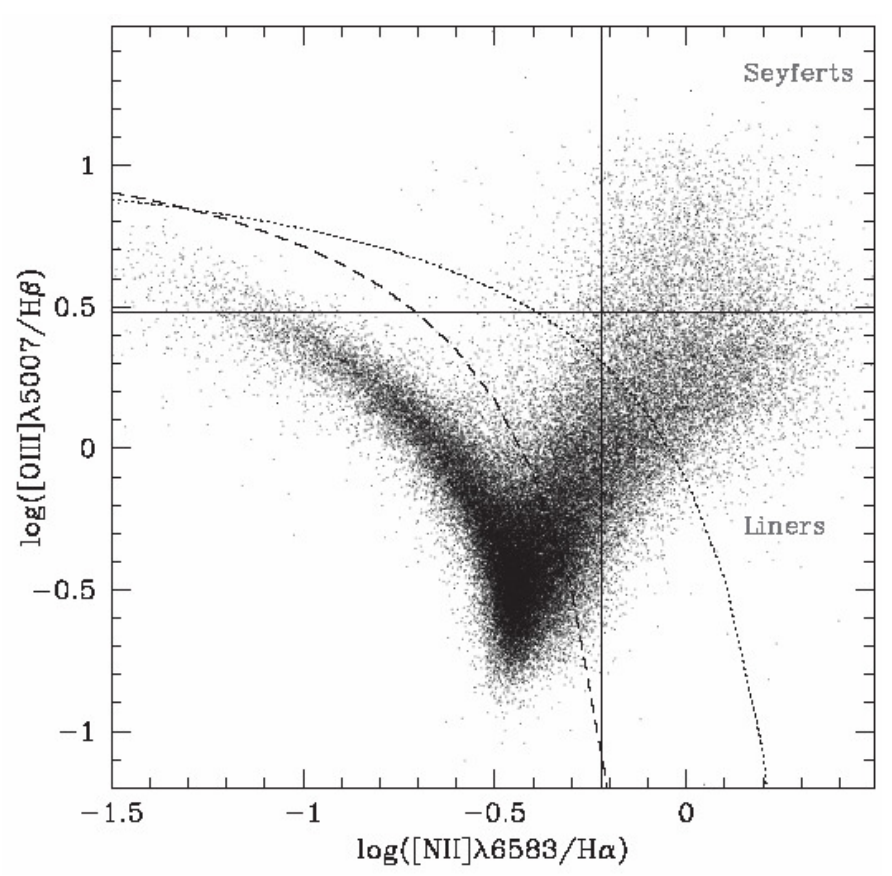

Figura 2.6 - Diagrama de diagnóstico com as razões de linhas [O III] $\lambda 5007 / H \beta$ e [N II] $\lambda 6583 / H \alpha$. A linha tracejada representa o limite de pura formação estelar definido por Kauffmann et al. (2003). A linha pontilhada corresponde ao limite de starburst extremo dado por Kewley et al. (2001). Figura adaptada de Kauffmann et al. (2003).

\subsection{2 - As linhas de emissão dos AGNs no infravermelho}

Conforme já foi mencionado anteriormente, a região espectral do infravermelho se estende desde $7500 \AA$ até $1 \mathrm{~mm}$. Entretanto, atualmente, o espectro de emissão dos AGNs é melhor estudado na região do infravermelho próximo, que se vai desde $7500 \AA$ até $25000 \AA$, assim, apenas esse intervalo espectral está discutido em detalhes aqui. As bandas J (de $11000 \AA$ até $14000 \AA), H(15000 \AA$ até $18000 \AA)$ e K (20000 A até $24000 \AA$ ) são as principais observadas nessa região espectral. Riffel et al. (2006) mostraram que os espectros dos AGNs no infravermelho próximo costumam apresentar fortes linhas de emissão de H I, He I, He II e [S III]. A tabela 2.2 mostra as principais linhas de emissão geralmente detectadas nos espectros dos AGNs no infravermelho próximo.

\begin{tabular}{|c|c|}
\hline Linha & $\begin{array}{c}\text { Comprimento de onda no referencial de } \\
\text { repouso }\end{array}$ \\
\hline$[\mathrm{S} \mathrm{III}] \lambda 9069$ & 9068.60 \\
\hline$[\mathrm{S} \mathrm{III}] \lambda 9531$ & 9530.60 \\
\hline He I $\lambda 10830$ & 10830.30 \\
\hline
\end{tabular}

Tabela 2.2 - Principais linhas de emissão permitidas e proibidas detectadas nos espectros dos AGNs no infravermelho próximo. Tabela adaptada de Riffel et al. (2006). 


\begin{tabular}{|c|c|}
\hline Linha & $\begin{array}{c}\text { Comprimento de onda no referencial de } \\
\text { repouso }\end{array}$ \\
\hline Pa $\gamma$ & 10938.10 \\
\hline $\mathrm{O} \mathrm{I} \lambda 11287$ & 11287.10 \\
\hline$[\mathrm{P} \mathrm{II}] \lambda 11883$ & 11882.85 \\
\hline$[\mathrm{Fe} \mathrm{II}] \lambda 12567$ & 12566.80 \\
\hline $\mathrm{Pa} \beta$ & 12818.08 \\
\hline$[\mathrm{Fe} \mathrm{II}] \lambda 13206$ & 13205.54 \\
\hline$[\mathrm{Si} \mathrm{X}] \lambda 14301$ & 14301.00 \\
\hline$[\mathrm{Fe} \mathrm{II}] \lambda 16435$ & 16435.49 \\
\hline $\mathrm{Pa} \alpha$ & 18751.01 \\
\hline$[\mathrm{Si} \mathrm{VI}] \lambda 19640$ & 19640.00 \\
\hline $\mathrm{He} \mathrm{I} \lambda 20581$ & 20581.28 \\
\hline $\mathrm{Br} \gamma$ & 21655.29 \\
\hline$[\mathrm{Ca} \mathrm{VIII}] \lambda 23210$ & 23210.00 \\
\hline
\end{tabular}

Tabela 2.2 (continuação).

Além das linhas de emissão geradas por átomos ionizados, um outro conjunto de linhas comumente observadas nos espectros dos AGNs no infravermelho próximo são as provenientes de moléculas de $\mathrm{H}_{2}$. Tais linhas de emissão já foram analisadas por vários estudos envolvendo a espectroscopia de AGNs no infravermelho próximo (Kawara, Nishida \& Gregory 1990; Moorwood \& Oliva 1990) e representam uma característica muito importante dos espectros dos AGNs nessa região espectral.

A molécula de $\mathrm{H}_{2}$ é a mais abundante dentre as espécies moleculares em nebulosas e matéria interestelar. Trata-se de uma molécula homonuclear, ou seja, formada por dois núcleos idênticos (dois prótons), cada um com spin $I=1 / 2$. Esses dois núcleos podem se combinar de duas maneiras diferentes: com spins anti-paralelos ou paralelos, o que dá origem a estados nucleares com spin total $T=0$ ou $T=1$, respectivamente. As moléculas com número quântico rotacional $J$ ímpar estão no chamado estado ortho, ao passo que as com $J$ par estão no estado para. Um ponto importante a ser mencionado aqui é que todas as moléculas no estado ortho possuem spins nucleares anti-paralelos e todas no estado para possuem spins nucleares paralelos. Colisões com troca de spin com H I ou H II, assim como um processo no qual o $\mathrm{H}_{2}$ é capturado na superfície de um grão de poeira, podem causar conversões ortho-para nessas moléculas.

As moléculas de $\mathrm{H}_{2}$ não podem se formar a partir da colisão entre dois átomos de $\mathrm{H}$, pois, para permanecerem em um estado ligado, esses átomos precisariam perder energia suficiente. Ao invés disso, em ambientes de maior densidade, como a atmosfera de uma estrela fria, o $\mathrm{H}_{2}$, 
geralmente, é formado a partir de colisões envolvendo três átomos, nas quais o terceiro átomo age como um catalisador, removendo o excesso de energia. Por outro lado, em ambientes de menor densidade, como o meio interestelar, por exemplo, tais processos com três átomos envolvidos apresentam taxas de ocorrência desprezíveis. Nesses casos, o $\mathrm{H}_{2}$ se forma, principalmente, da seguinte maneira: um átomo de $\mathrm{H}$ colide com um grão de poeira e adere à sua superfície. Nessa situação, ele poderá colidir com outro átomo e formar uma molécula de $\mathrm{H}_{2}$, já que a energia de formação (que precisa ser liberada da molécula) é absorvida pelo grão de poeira.

As linhas de $\mathrm{H}_{2}$ no infravermelho próximo são geradas por transições de quadrupolo elétrico dentro do estado fundamental $X^{1} \Sigma_{g}^{+}$e são nomeadas como $v_{\mathrm{u}}-v_{1} \mathrm{~S}\left(\mathrm{~J}_{1}\right), \mathrm{Q}\left(\mathrm{J}_{1}\right) e \mathrm{O}\left(\mathrm{J}_{1}\right)$, para $J_{u}-J_{l}=+2,0$ e -2 , respectivamente. Nessa notação, $v$ representa o número quântico vibracional.

Existem dois tipos de mecanismos de excitação da molécula de $\mathrm{H}_{2}$ que podem originar linhas de emissão: a excitação colisional (o processo térmico) e o decaimento radiativo a partir dos estados excitados $B^{1} \Sigma_{u}^{+}$e $C^{1} \Pi_{u}$ (o processo não térmico). Esses processos produzem espectros diferentes, que, frequentemente, podem ser observados juntos em um único objeto, ou seja, as observações têm mostrado que mecanismos térmicos e não térmicos de excitação da molécula de $\mathrm{H}_{2}$ podem estar presentes em um mesmo objeto. No caso térmico, as nuvens moleculares são aquecidas por ondas de choque, raios-x ou fótons UV (Brand et al. 1989; Lepp \& McCray 1983; Sternberg \& Dalgarno 1989). Esse aquecimento resulta, então, na excitação colisional das moléculas. Nessa situação, a razão ortho/para do $\mathrm{H}_{2}$ é constante e aproximadamente igual a 3 (Shull \& Beckwith 1982). Além disso, o gás pode ser tomado, em uma primeira aproximação, como estando em equilíbrio termodinâmico local (ETL) (Tanaka et al. 1989) e, consequentemente, o seu espectro pode ser caracterizado por uma única temperatura de excitação. No caso não térmico, por outro lado, a excitação eletrônica resulta da absorção de fótons UV na banda de Lyman-Werner (912 $\AA$ - $1108 \AA$ ) ou da colisão com elétrons bastante velozes, resultantes da fotoionização por raios-x (Black \& van Dishoeck 1987; Lepp \& McCray 1983). Nesse cenário, a excitação do gás ocorre em gás frio e a razão ortho/para não possui mais um valor constante, ficando entre 1 e 2 (Tanaka et al. 1989). Tudo isso indica que o espectro de emissão do $\mathrm{H}_{2}$ é caracterizado por três parâmetros principais (Mouri 1994; Tanaka et al. 1989): a temperatura de excitação da componente térmica, a razão ortho/para da componente não térmica e a intensidade relativa dessas duas componentes. 
$\mathrm{O}$ fato de o espectro de $\mathrm{H}_{2}$ ser mais intenso em galáxias Seyfert do que em galáxias starburst parece indicar que esse tipo de emissão está associado à atividade nuclear dos AGNs (Kawara et al. 1987). Nas galáxias starburst, é provável que a componente térmica da emissão de $\mathrm{H}_{2}$ seja devida à excitação das moléculas resultante do aquecimento das nuvens moleculares pela emissão de fótons UV de estrelas de tipos $\mathrm{O}$ e B e da ocorrência de ondas de choque movidas por explosões de supernovas. Nos AGNs, por outro lado, essa componente térmica da emissão de $\mathrm{H}_{2}$ deve ser uma conseqüência do aquecimento das nuvens moleculares pela forte emissão UV e de raios-x pelo núcleo. Também não se pode descartar que haja aquecimento por ondas de choque geradas por outflows, por exemplo.

A temperatura de excitação da componente térmica da emissão de $\mathrm{H}_{2}$ devida a choques, emissão de raios-x e emissão de UV não é a mesma, o que faz com que o cálculo desse valor seja um bom modo de se determinar o provável mecanismo de aquecimento presente. Mouri (1994) utiliza diagramas de diagnóstico envolvendo razões de intensidade de linhas de $\mathrm{H}_{2}$ para determinar os prováveis mecanismos de aquecimento das nuvens moleculares presentes em uma variedade de objetos (galácticos e extragalácticos). O autor preferiu utilizar, em cada uma das razões de linhas, apenas moléculas ortho ou apenas moléculas para. Dessa forma, as componentes não térmicas presentes, que dependem da razão ortho/para, ficam aproximadamente constantes. A figura 2.7 mostra alguns desses diagramas de diagnóstico utilizados no trabalho de Mouri (1994). 

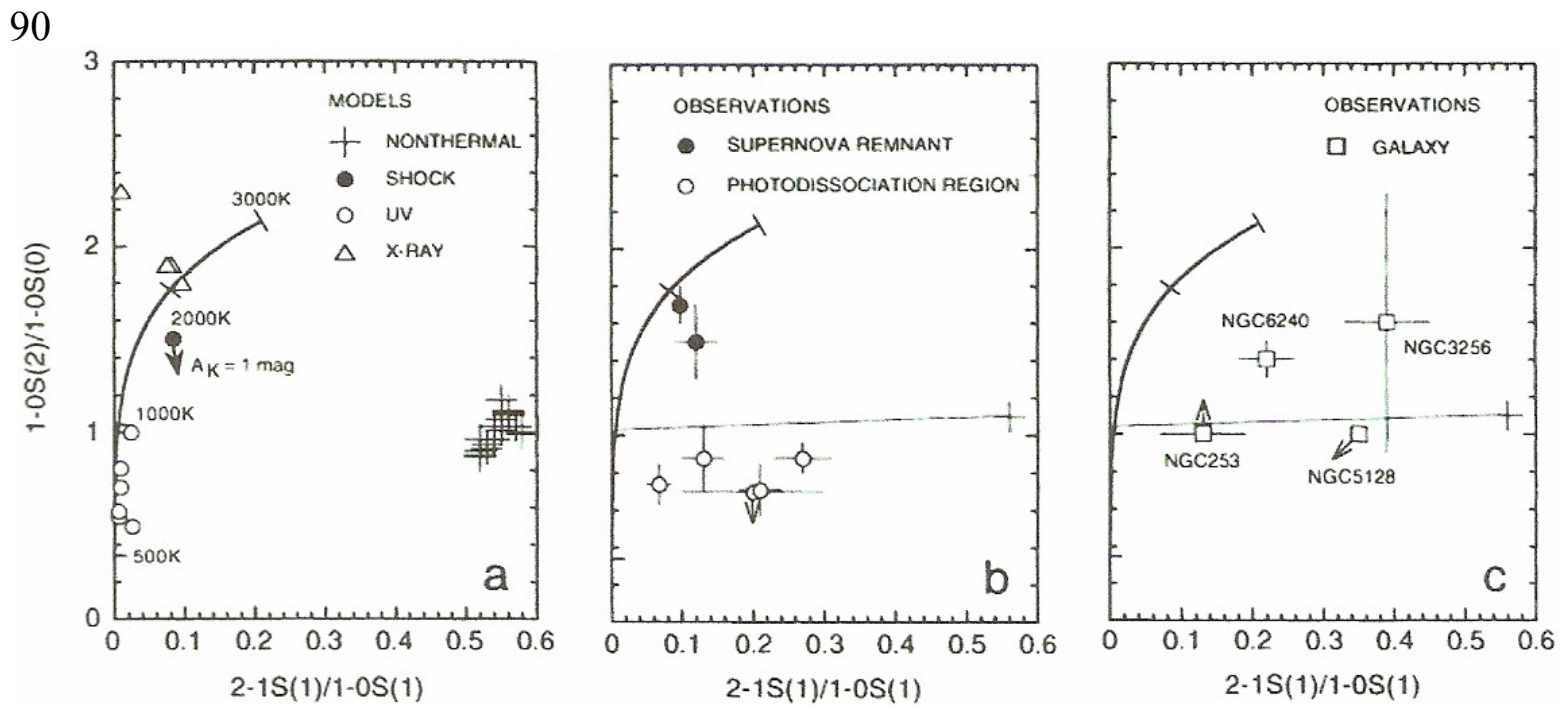

Figura 2.7 - Diagramas de diagnóstico envolvendo as razões de linhas de $\mathrm{H}_{2}$ 2-1S(1)/1-0S(1) e 1-0S(2)/1-0S(0). As curvas representam a emissão térmica entre $500 \mathrm{~K}$ e 3000

$K$. No diagrama da esquerda, as cruzes correspondem aos modelos de excitação UV não térmicos de Black \& van Dishoeck (1987), os círculos preenchidos representam o modelo de aquecimento por ondas de choque de Brand et al. (1989), os círculos vazios correspondem aos modelos de excitação UV térmica de Sternberg \& Dalgarno (1989) e os triângulos representam os modelos de aquecimento por raios-x de Lepp \& McCray (1983) e Draine \& Woods (1990). No

diagrama do centro são mostrados dados observacionais de remanescentes de supernovas (círculos preenchidos) e regiões de fotodissociação (círculos vazios). Uma cruz indica um típico espectro não térmico (modelo 14 de Black \& van Dishoeck 1987) e a reta conecta a região de emissão térmica em $1000 \mathrm{~K}$ e a área de emissão não térmica. No diagrama da direita são mostrados dados observacionais de galáxias (quadrados vazios). A cruz e a reta possuem o mesmo significado que no diagrama do centro. Figura obtida de Mouri (1994).

Observando-se a figura 2.7, pode-se notar que esses diagramas de diagnóstico separam consideravelmente bem objetos com emissão térmica de objetos com emissão não térmica. Além disso, considerando-se a componente térmica da emissão, esses gráficos também diferenciam de maneira eficaz objetos com diferentes temperaturas de excitação e, consequentemente, com diferentes mecanismos de aquecimento presentes. A figura 2.7 mostra, ainda, que os pontos correspondentes a galáxias apresentam um grande espalhamento ao longo do diagrama de diagnóstico, podendo se afastar bastante da linha correspondente ao caso térmico. Isso indica que processos não térmicos devem estar presentes e, no que se refere à componente térmica, o mecanismos de aquecimento desses objetos não deve ser universal, ou seja, galáxias diferentes devem apresentar formas diferentes de aquecimento das nuvens moleculares.

A tabela 2.3 mostra as principais linhas de $\mathrm{H}_{2}$ detectadas nos espectros no infravermelho próximo dos AGNs. 


\begin{tabular}{|c|c|}
\hline Linha & $\begin{array}{c}\text { Comprimento de onda no referencial de } \\
\text { repouso }\end{array}$ \\
\hline $\mathrm{H}_{2} \lambda 20338$ & 20337.6 \\
\hline $\mathrm{H}_{2} \lambda 21218$ & 21218.3 \\
\hline $\mathrm{H}_{2} \lambda 22234$ & 22234.4 \\
\hline $\mathrm{H}_{2} \lambda 22478$ & 22477.6 \\
\hline $\mathrm{H}_{2} \lambda 24085$ & 24084.7 \\
\hline $\mathrm{H}_{2} \lambda 24137$ & 24136.7 \\
\hline
\end{tabular}

Tabela 2.3 - Principais linhas de $\mathrm{H}_{2}$ detectadas nos espectros dos AGNs no infravermelho próximo. Tabela adaptada de Riffel et al. (2006).

\subsection{3 - As linhas de emissão dos AGNs em raios-X}

Quando fótons de regiões menos energéticas do espectro são absorvidos por átomos e provocam fotoionizações, em geral, removem os elétrons de valência desses átomos. Posteriormente, tais elétrons podem passar pelo processo de recombinação, seguido por um decaimento em cascata, dando origem a uma série de emissões. Entretanto, quando uma fotoionização é provocada por um fóton com energia significativamente maior do que a da camada de valência, é mais provável que ele remova um elétron de uma camada mais interna. Isso deixa uma "vaga" nessa camada, que pode ser preenchida por um elétron que "desça" de uma camada superior. Quando tal processo ocorre, a energia é conservada com a emissão de um fóton (fluorescência) ou com a ejeção de um elétron de uma camada mais externa (efeito Auger).

Geralmente, as três camadas eletrônicas mais internas são chamadas de $K\left(1 s^{2}\right), L\left(2 s^{2}, 2 p^{6}\right)$ e $\mathrm{M}\left(3 \mathrm{~s}^{2}, 3 \mathrm{p}^{6}, 3 \mathrm{~d}^{10}\right)$, onde os números e letras entre parêntesis se referem às subcamadas presentes. Então, por uma analogia com a nomenclatura utilizada no caso do átomo de hidrogênio, uma transição da camada $L$ para a camada $K$ é chamada de $K \alpha$, da $M$ para a $K$ é chamada de $K \beta$ e assim por diante. Para muitos átomos e íons, os fótons emitidos por transições entre essas camadas internas são altamente energéticos, pertencendo à região espectral dos raios-X. Tais fótons dão origem a várias linhas de emissão que podem ser detectadas nos espectros em raios-X de vários objetos (inclusive dos AGNs).

No caso dos AGNs, acredita-se que boa parte das fotoionizações responsáveis por remover elétrons das camadas internas dos átomos devem ser causadas por fótons associados ao featureless continuum desses objetos na região dos raios-x, por exemplo (seção 2.3.2). 
A região espectral dos raios-x costuma ser dividida em raios-X moles, que vai desde $6.2 \AA$ até $100 \AA$ ( $2 \mathrm{keV}$ até $124 \mathrm{eV})$, e raios-x duros, que vai desde $0.01 \AA$ até $6.2 \AA$ ( $1 \mathrm{MeV}$ até $2 \mathrm{keV})$. A tabela 2.4 mostra algumas das principais linhas de emissão detectadas nos espectros de AGNs na região dos raios-X moles.

\begin{tabular}{|c|c|}
\hline Linha & $\begin{array}{c}\text { Comprimento de onda no referencial de } \\
\text { repouso }\end{array}$ \\
\hline Ne X K $\alpha$ & 12.134 \\
\hline Ne IX r & 13.447 \\
\hline Ne IX i & 13.552 \\
\hline Ne IX f & 13.698 \\
\hline O VIII K $\beta$ & 16.006 \\
\hline O VIII K $\alpha$ & 18.969 \\
\hline O VII K $\beta$ & 18.627 \\
\hline O VII r & 21.602 \\
\hline O VII i & 21.803 \\
\hline O VII f & 22.101 \\
\hline N VII K $\alpha$ & 24.781 \\
\hline N VI r & 28.787 \\
\hline N VI i & 29.083 \\
\hline N VI f & 29.534 \\
\hline C VI K $\beta$ & 28.466 \\
\hline C V K $\beta$ & 34.973 \\
\hline
\end{tabular}

Tabela 2.4 - Principais linhas de emissão detectadas nos espectros dos AGNs na região dos raios-x moles. Tabela adaptada de Kinkhabwala et al. (2002). As letras $r$, i e findicam linhas de ressonância, intercombinação e proibidas (forbidden), respectivamente.

Na região de raios-x duros, por outro lado, as estruturas mais proeminentes são aquelas associadas a linhas de $\mathrm{Fe} \mathrm{K} \alpha$ em diferentes estágios de ionização. As mais intensas são as de Fe XXV e Fe XXVI localizadas entre $1.854 \AA$ e $1.874 \AA$ (entre $6.7 \mathrm{keV}$ e $6.629 \mathrm{keV}$ ) (Decaux et al. 1997).

Conforme já foi mencionado anteriormente, nesse trabalho foram utilizadas, apenas, observações de AGNs no óptico e no infravermelho próximo, logo, apenas o espectro de emissão nessas duas regiões espectrais pôde ser analisado com maiores detalhes. 


\section{5 - O Modelo Unificado dos AGNs}

A idéia de um Modelo Unificado para os AGNs se baseia na hipótese de que as diferentes categorias observadas desses objetos são devidas a uma combinação de diferenças reais em um pequeno número de parâmetros físicos (como luminosidade ou emissão em rádio) e de diferenças aparentes, causadas pela orientação sob a qual os diferentes objetos são observados.

Os Modelos Unificados são divididos em "fortes" e "fracos" dependendo da quantidade de parâmetros intrínsecos que são tomados como sendo variáveis de um objeto para outro. Os modelos fracos permitem uma maior diversidade física entre os AGNs, já que uma quantidade maior de parâmetros intrínsecos variáveis é considerada. Um Modelo Unificado fraco bastante utilizado é o que considera dois parâmetros intrínsecos: a luminosidade no óptico e a luminosidade em rádio. De acordo com esse modelo, existem dois tipos de AGNs, os radio-loud e os radio-quiet. Em cada um desses dois grupos, são observadas diferentes categorias de AGNs, originadas por variações nos parâmetros intrínsecos e na orientação sob a qual os objetos são observados. Os modelos fortes, por outro lado, admitem uma menor quantidade de parâmetros intrínsecos, o que resulta em uma menor diversidade física entre os AGNs. Um modelo forte usualmente utilizado é o que considera, apenas, um parâmetro intrínseco: a luminosidade total. Nesse cenário, todas as diferenças observadas nas diferentes categorias de AGNs são devidas a variações na luminosidade total e na orientação sob a qual os objetos são observados.

A maior parte dos Modelos Unificados fortes propostos, entretanto, ainda não conseguiu reproduzir bem as propriedades individuais e estatísticas dos AGNs, logo, tais modelos não são discutidos em detalhes aqui. A seguir, são dadas as principais características de um Modelo Unificado fraco para os AGNs de tipo radio-loud e radio-quiet. Também são descritas as principais propriedades dos toros de poeira, que são estruturas essenciais no contexto dos Modelos Unificados.

\subsection{1 - O Modelo Unificado para os AGNs radio-quiet}

No conjunto dos AGNs radio-quiet, uma das principais perguntas que precisa ser respondida pelo Modelo Unificado é: por que existem objetos de tipo 1 e de tipo 2 (como ocorre 
no caso das galáxias Seyfert e dos LINERs) ? As principais diferenças observadas entre as galáxias Seyfert 1 e Seyfert 2 são:

- As Seyferts 1 possuem tanto linhas largas quanto estreitas em seus espectros, enquanto que as Seyferts 2 possuem, apenas, linhas estreitas

- O featureless continuum é mais fraco em relação ao contínuo estelar nas Seyferts 2 do que nas Seyferts 1

Para explicar tais diferenças, o Modelo Unificado propõe que existem apenas galáxias Seyfert 1, entretanto, ao redor da BLR desses objetos, existe um toro de poeira obscurecedor. Quando o toro é observado próximo a face-on, as linhas largas provenientes da BLR são visíveis e a galáxia é classificada como Seyfert 1. Entretanto, quando o toro é visto próximo a edge-on, a emissão proveniente da BLR é obscurecida e, consequentemente, apenas as linhas estreitas originadas pela NLR (que fica em uma área externa ao toro de poeira) são visíveis. Nessas circunstâncias, a galáxia é classificada como Seyfert 2. Osterbrock (1978) foi o primeiro a propor esse tipo de modelo para explicar as diferenças entre Seyferts 1 e 2, no entanto, a simples hipótese da presença de um toro de poeira apresenta as seguintes falhas:

- O contínuo das galáxias Seyfert 2 ainda se assemelha razoavelmente a uma lei de potência. Entretanto, isso não deveria ocorrer se ele tivesse sofrido um forte avermelhamento, já que uma lei de potência após o avermelhamento não é mais uma lei de potência.

- Uma galáxia Seyfert 2 comum é, apenas, cerca de uma magnitude mais fraca do que uma Seyfert 1. Isso não seria o esperado, pois um avermelhamento capaz de extinguir totalmente as linhas largas da BLR deveria fazer com que as Seyferts 2 ficassem bem mais fracas do que apenas uma magnitude em relação às Seyferts 1 .

Para resolver essas falhas, o Modelo Unificado sugere que existe um meio "espalhador" acima da abertura do toro de poeira. Nesse caso, o featureless continuum emitido nas regiões internas à BLR é espalhado por esse meio na direção do observador, podendo, assim, ser detectado. Essa hipótese explica muito bem porque as Seyferts 2 ainda apresentam um featureless 
continuum detectável e são, em geral, apenas uma magnitude mais fracas dos que as Seyferts 1. Em princípio, o espalhamento nesse meio poderia ser causado por poeira ou elétrons. Esse modelo, entretanto, prevê que também seria possível detectar, em objetos de tipo 2, a emissão da BLR, que, nesse caso, deveria apresentar um certo grau de polarização (devido ao espalhamento por poeira ou elétrons). De fato, Antonucci \& Miller (1985) detectaram a presença de componentes largas de linhas de emissão no espectro com polarização linear da galáxia Seyfert 2 NGC 1068. O grau de polarização do contínuo desse objeto chega a $16 \%$ e apresenta uma dependência para com o comprimento de onda até a região espectral do ultravioleta (cerca de $1500 \AA$ ) (Code et al. 1993), o que indica que o espalhamento deve ser devido a elétrons e não poeira. A detecção de linhas largas no espectro polarizado de NGC 1068 representou uma importante evidência a favor do Modelo Unificado. Estudos posteriores fizeram detecções similares nos espectros polarizados de outras galáxias Seyfert 2 (Tran et al. 1992). A figura 2.8 mostra o espectro total (sem linhas largas aparentes) e o espectro polarizado (com algumas linhas alargadas visíveis) de NGC 1068.

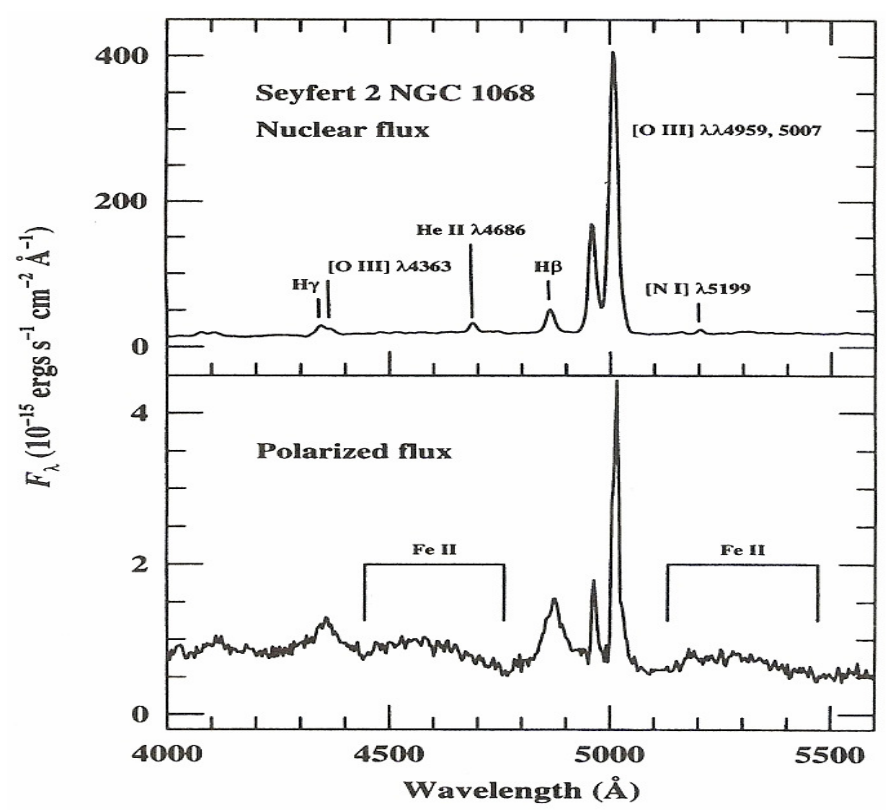

Figura 2.8 - (acima) Espectro nuclear com o fluxo total de NGC 1068; (em baixo) Espectro nuclear com o fluxo linearmente polarizado de NGC 1068, no qual se pode notar o surgimento de algumas linhas alargadas. Figura obtida de Miller et al. (1991).

O Modelo Unificado prevê que o mesmo cenário utilizado para as galáxias Seyfert também deveria ser aplicável a LINERs e QSOs. De fato, são observados LINERs de tipo 1 e 2, 
entretanto, a situação é mais complicada no que se refere aos QSOs. Por muito tempo, acreditouse que tais objetos apresentavam, unicamente, espectros com linhas largas presentes. Entretanto, observações mostraram que várias galáxias classificadas como Far-Infrared galaxies (FIR), que apresentam fortes emissões no infravermelho, possuem luminosidades comparáveis às dos QSOs, espectros com, apenas, linhas estreitas e índices espectrais comparáveis aos dos AGNs (Jannuzi et al. 1994). Com base nisso, atualmente, muitos já aceitam que as galáxias FIR são, na verdade, QSOs de tipo 2. Nesse caso, a forte emissão contínua e em linhas provenientes das regiões mais internas desses objetos deve ser absorvida pelo toro de poeira existente. Isso faz com que as linhas emitidas pela BLR não sejam detectadas e, ao mesmo tempo, a grande quantidade de energia absorvida pelo toro seja re-emitida no infravermelho, dando origem à forte emissão nessa região espectral desses objetos. Zakamska et al. (2003) e Reyes et al. (2008) apresentaram as observações de centenas de QSOs de tipo 2, sendo que a grande maior parte deles, senão todos, são também classificados como galáxias FIR.

O fato de linhas largas terem sido detectadas no espectro polarizado de algumas galáxias Seyfert 2, sem dúvida, sustenta a hipótese do Modelo Unificado. Além disso, Cohen (1983) verificou que as propriedades das linhas estreitas das galáxias Seyfert 1 e 2 são estatisticamente idênticas. Isso também é uma evidência a favor do Modelo Unificado, já que a similaridade entre tais linhas faz com que haja razão para acreditar que sejam provenientes de fontes intrinsicamente indistintas. Apesar disso, Cohen (1983) também afirma que as linhas estreitas de mais alta ionização tendem a ser encontradas, apenas, em Seyferts 1.

Existem evidências, entretanto, que não estão de acordo com o que é previsto pelo Modelo Unificado. Um exemplo disso é o fato de uma grande parte das galáxias Seyfert 2 não apresentar um espectro polarizado. Isso poderia significar, apenas, a ausência de um meio espalhador nesses objetos, entretanto, o featureless continuum ainda é detectado, apesar da ausência do espectro polarizado, o que não está de acordo com o previsto pelo Modelo Unificado. Além disso, em galáxias com o toro visto edge-on, são previstas polarizações no contínuo de até 50 \% (Miller \& Goodrich 1990). Entretanto, jamais foram observadas galáxias Seyfert 2 com valores tão altos de polarização. 


\subsection{2 - O Modelo Unificado para os AGNs radio-loud}

AGNs do tipo radio-loud, geralmente, são constituídos por duas componentes emissoras: um núcleo compacto e uma região estendida, geralmente apresentando o formato de dois lobos diametralmente opostos. Além disso, estruturas na forma de jatos são comumente vistas saindo do núcleo compacto. Entretanto, os jatos (ao contrário do que ocorre com a região emissora extensa) geralmente não apresentam estruturas diametralmente opostas, ou seja, apenas um jato é visível em cada galáxia, estando, normalmente, alinhado com o eixo dos lobos. Essa assimetria apresentada pelos jatos costuma ser explicada como sendo devida ao fato de a radiação emitida por eles ser fortemente afetada pelo efeito do beaming relativístico (com fatores de Lorentz consideravelmente grandes), o que favorece mais a detecção do jato com velocidade de aproximação do que do jato com velocidade de afastamento. Todas essas características, geralmente encontradas nos AGNs radio-loud, costumam gerar certas dificuldades para a aplicação do Modelo Unificado. Mesmo assim, com as devidas adaptações, esse modelo pode ser aplicado para essas categorias de AGNs.

Primeiramente, o Modelo Unificado pode ser aplicado a BLRGs e NLRGs de uma maneira inteiramente análoga à utilizada no caso de galáxias Seyfert 1 e 2: quando o toro de poeira existente em uma rádio-galáxia é visto próximo a face-on, as linhas largas provenientes da BLR são detectadas e a galáxia é classificada como BLRG. Por outro lado, quando o toro é observado próximo a edge-on, a emissão da BLR é obscurecida e apenas linhas estreitas são detectadas, fazendo com que a galáxia seja classificada como NLRG.

No caso dos quasares, se o modelo com duas componentes emissoras de rádio descrito anteriormente estiver correto, os jatos devem apresentar uma orientação aleatória e, consequentemente, deveria ser freqüente encontrar quasares nos quais os dois jatos estão próximos ao plano do céu. Nesses casos, ambos deveriam ser detectados com intensidades similares. Entretanto, isso não é observado, o que representa um problema para esse modelo. Phinney (1985) supôs que esses quasares sem o efeito do beaming (nos quais os jatos estão próximos ao plano do céu) não são classificados como quasares ao serem observados. Barthel (1989) propôs que quasares com os jatos próximos ao plano do céu são detectados como rádiogaláxias de tipo FR II. Se for assumido que o toro de poeira é o responsável por colimar os jatos emitidos, então o toro deverá estar em posição edge-on quando os jatos estiverem no plano do 
céu. O argumento de Barthel (1989) tem sido bastante aceito nos últimos anos. Considerando-se isso, então, pode-se dizer que o Modelo Unificado prevê que, quando esses objetos são observados com o toro de poeira estando próximo a face-on, eles são classificados como quasares, ao passo que, quando são observados com o toro de poeira próxima à posição edge-on, são classificados como rádio-galáxias FR II.

Urry et al. (1991) propuseram a unificação dos objetos BL Lac com as rádio-galáxias FR I. Nesse caso, quando o toro de poeira desses objetos é visto com o seu eixo praticamente coincidente com a linha de visada, eles são classificados com BL Lac e, quando o toro é observado mais próximo à posição edge-on, eles são classificados como rádio-galáxias FR I. Por fim, Padovani \& Urry (1992) postularam a unificação entre os OVVs e as rádio-galáxias FR II. Da mesma forma que no caso dos objetos BL Lac e as rádio-galáxias FR I, quando o toro de poeira desses objetos é observado com o seu eixo quase coincidente com a linha de visada, eles são classificados como OVVs, ao passo que, quando o toro é observado mais próximo à posição de edge-on, eles são classificados como rádio-galáxias FR II. É importante mencionar aqui que os blazares (objetos BL Lac e OVVs) somente são observados quando a linha de visada é praticamente coincidente com o eixo do toro, ou seja, com o jato existente. A diferença entre eles é que os OVVs são objetos de alta luminosidade e os objetos BL Lac possuem menor luminosidade.

O cenário geral proposto pelo Modelo Unificado pode ser, então, resumido da seguinte maneira: no caso de AGNs radio-quiet, quando os toros de poeira existentes forem observados próximos à posição face-on, os objetos detectados serão classificados como de tipo 1, sendo que as possíveis categorias a serem detectadas, em ordem crescente de luminosidade, são LINERs 1, Seyferts 1 e QSOs. Por outro lado, quando os toros de poeira forem observados próximos à posição edge-on, os objetos serão classificados como de tipo 2, sendo que as possíveis categorias a serem detectadas, em ordem crescente de luminosidade, são LINERs 2, Seyferts 2 e galáxias FIR. No caso de AGNs radio-loud, pode-se dizer que as BLRGs e as NLRGs são as análogas emissoras de rádio das galáxias Seyfert 1 e 2, respectivamente, ou seja, nas primeiras o toro de poeira é observado próximo à posição face-on e, nas últimas, o toro é observado próximo à posição edge-on. Nos objetos radio-loud de alta luminosidade, se a linha de visada for suficientemente próxima ao eixo do toro (que também corresponde ao jato), o objeto será 
classificado como OVV. Se o ângulo entre a linha de visada e o eixo do toro for um pouco maior (de modo que a linha de visada não seja mais englobada pelo jato), então o objeto será classificado como quasar. Se o toro for visto próximo à posição edge-on, o objeto será classificado como rádio-galáxia FR II. No caso de objetos de menor luminosidade, se a linha de visada for suficientemente próxima ao eixo do toro, o objeto será classificado como BL Lac, ao passo que, se o toro for visto mais próximo à posição edge-on, o objeto será classificado como rádio-galáxia FR I. Mais detalhes sobre o Modelo Unificado dos AGNs podem ser encontrados em Antonucci (1993) e Urry \& Padovani (1995). A tabela 2.5 resume as principais previsões do Modelo Unificado dos AGNs.

\begin{tabular}{|c|c|c|}
\hline \multirow{2}{*}{ Propriedades em rádio } & \multicolumn{2}{|c|}{ Orientação do toro } \\
\cline { 2 - 3 } & Face-on & Edge-on \\
\hline \multirow{2}{*}{ Radio-quiet } & Seyfert 1 & Seyfert 2 \\
\cline { 2 - 3 } & QSO & FR I \\
\hline Radio-loud & $\begin{array}{c}\text { BL Lac (se a linha de visada } \\
\text { for quase coincidente com o } \\
\text { eixo do toro) }\end{array}$ \\
\cline { 2 - 3 } & $\begin{array}{c}\text { BLRG } \\
\text { OVV (se a linha de visada } \\
\text { for quase coincidente com o } \\
\text { eixo do toro)/Quasar }\end{array}$ & FLRG II \\
\hline
\end{tabular}

Tabela 2.5 - Principais previsões do Modelo Unificado para as diferentes categorias de AGNs.

A figura 2.9 mostra um esquema básico do cenário previsto pelo modelo Unificado dos AGNs.

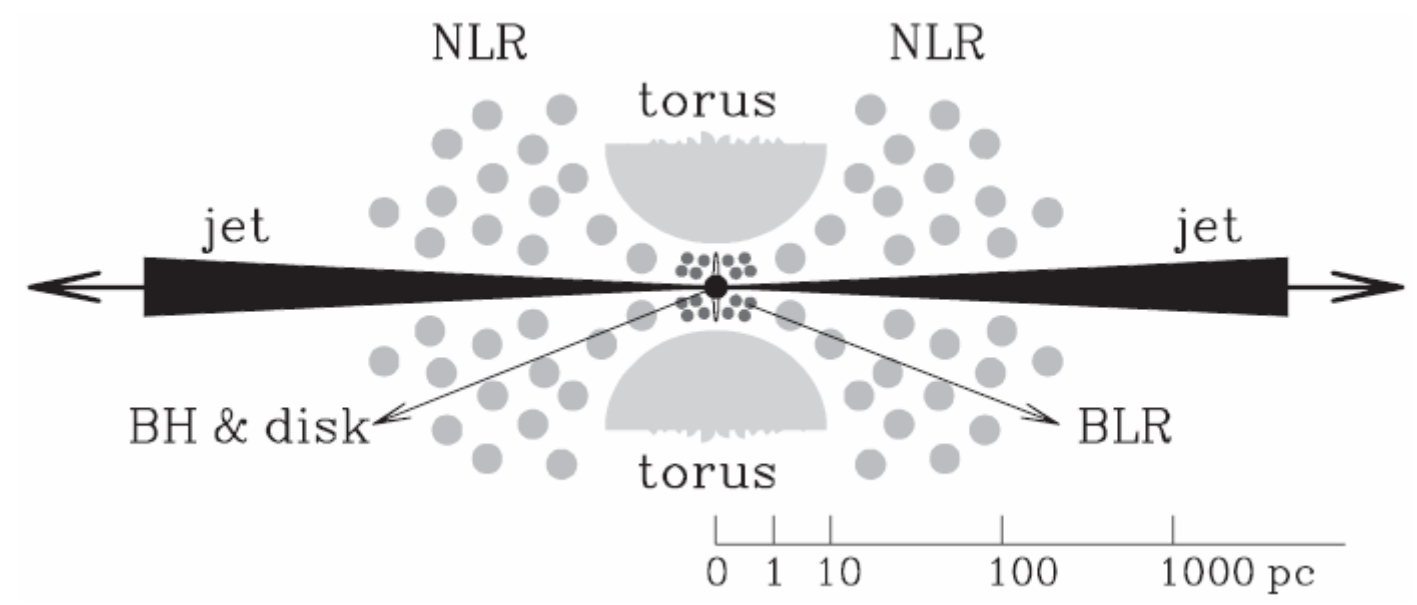

Figura 2.9 - Esquema do cenário básico previsto pelo Modelo Unificado para os AGNs. Figura obtida de Mo et al. (2010). 


\subsection{3 - Os toros de poeira}

Por tudo o que foi dito até aqui, pode-se notar que a presença de um toro de poeira em uma área ao redor da BLR de um AGN é um elemento essencial do Modelo Unificado. Por essa razão, muitos estudos relacionados a toros de poeira têm sido feitos nos últimos anos.

Apesar do termo "toro de poeira" ser comumente utilizado no contexto do Modelo Unificado, a real morfologia da distribuição de poeira ao redor da BLR dos AGNs foi motivo de vários debates ao longo dos anos. A hipótese mais simples para essa morfologia supõe que a poeira está realmente disposta ao longo de um toro em uma área externa à BLR, apresentando uma distribuição aproximadamente contínua de densidade (provavelmente em função do raio). Por outro lado, Krolik \& Begelman (1988) formularam a hipótese de que a poeira, na verdade, deve estar distribuída na forma de um grande número de nuvens individuais opticamente espessas, com um certo espaçamento entre elas (distribuição clumpy). A figura 2.10 mostra os esquemas correspondentes a essas duas morfologias possíveis para a distribuição de poeira ao redor da BLR dos AGNs.
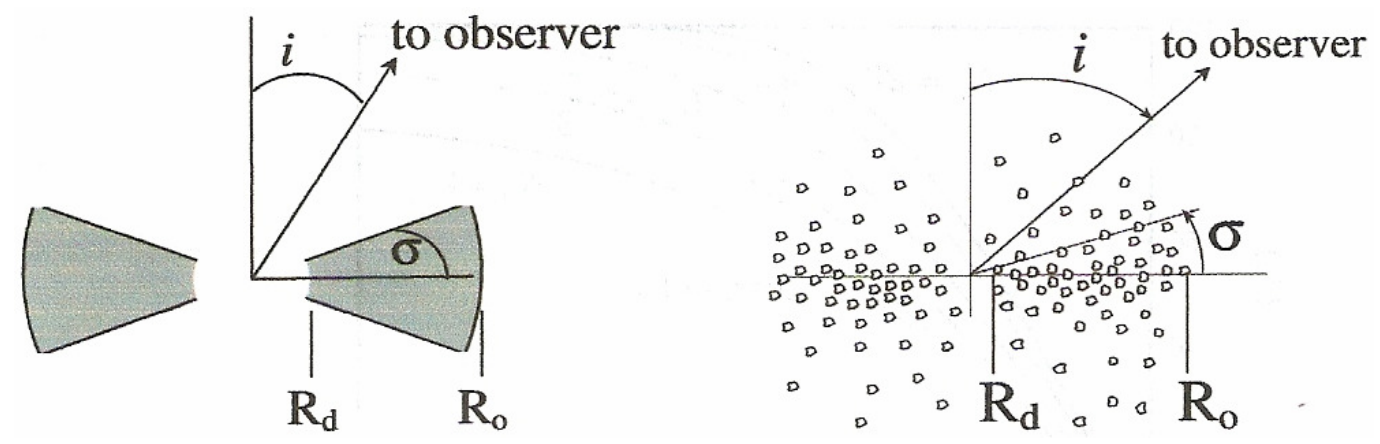

Figura 2.10 - Esquemas possiveis para a morfologia do toro de poeira dos AGNs assumindo-se (esquerda) uma distribuição contínua de densidade e (direita) uma distribuição "clumpy" de nuvens. Na figura, $R_{d}$ é o raio de sublimação da poeira e $R_{0}$ é o raio externo do toro. Figura obtida de Elitzur (2007).

Essas duas morfologias apresentam uma série de diferenças, como, por exemplo, nos valores esperados para a temperatura da poeira em função do raio. No caso da morfologia com uma distribuição contínua de densidade, a temperatura e o raio possuem uma relação unívoca, ou seja, dado o raio, a temperatura da poeira fica automaticamente determinada. Por outro lado, para a morfologia com distribuição clumpy, a situação é bastante diferente. Nesse caso, uma nuvem 
aquecida por uma fonte distante terá uma temperatura maior na sua face iluminada e temperaturas menores em outras áreas. O resultado final disso é que, em um meio com distribuição clumpy, a poeira pode apresentar temperaturas diferentes a uma mesma distância da fonte de energia e uma mesma temperatura a distâncias diferentes. Um exemplo disso é que a face escura de uma nuvem próxima ao AGN pode ser tão quente quanto a face iluminada de uma nuvem mais distante. $\mathrm{O}$ esquema da figura 2.11 mostra esse comportamento da temperatura da poeira na distribuição clumpy. Essas diferenças nos valores da temperatura em função do raio fazem com que a emissão infravermelha esperada dessas duas possíveis morfologias da distribuição de poeira apresente diferenças consideráveis.

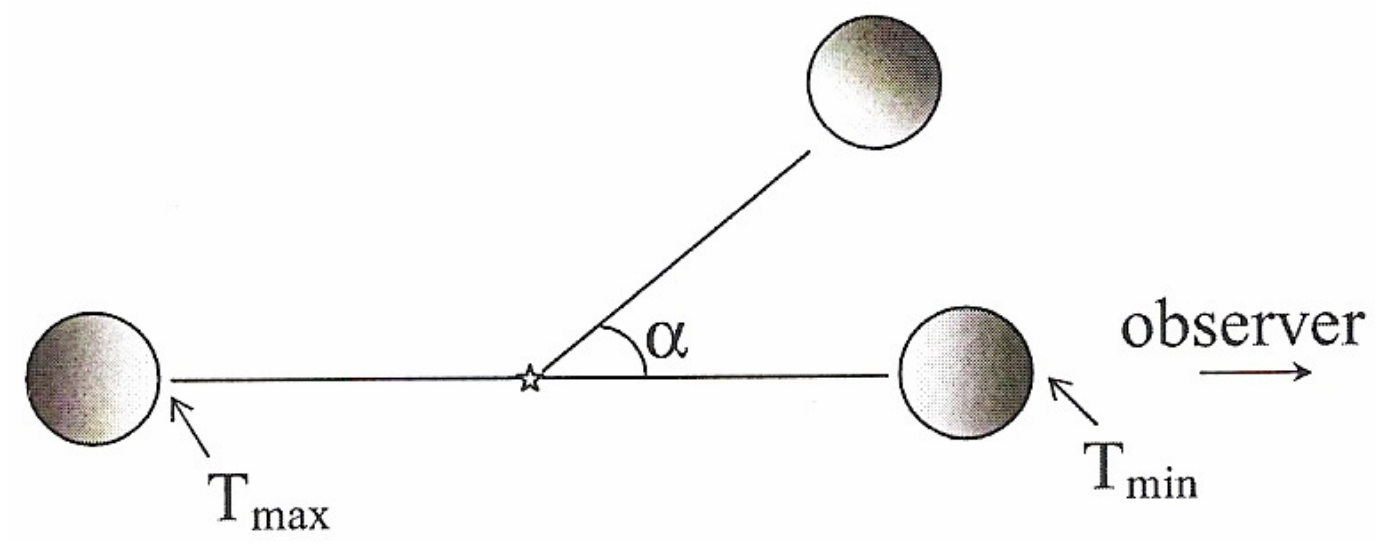

Figura 2.11 - Esquema mostrando o comportamento da temperatura da poeira no caso de uma distribuição “clumpy” de nuvens. Figura obtida de Elitzur (2008).

A primeira evidência detectada da existência de toros ao redor da BLR de um AGN veio da observação de linhas alargadas nos espectros polarizados de AGNs de tipo 2 (Antonucci \& Miller 1985; Tran et al. 1992). Apesar de possuir uma grande relevância, tal evidência é, apenas, indireta. Como o Modelo Unificado prevê que esses toros devem absorver boa parte da radiação incidente e re-emití-la no infravermelho, a forma mais simples de se obter uma evidência direta de sua existência seria a observação da radiação infravermelha emitida por essas estruturas. De fato, conforme foi mencionado anteriormente, o featureless continuum dos AGNs apresenta um excesso na região espectral com comprimentos de onda maiores do que $1 \mu \mathrm{m}$ (o IR bump), que é atribuída à emissão térmica de poeira. Entretanto, a primeira observação direta de um toro de poeira em um AGN foi feita por Jaffe et al. (2004), por meio de interferometria na faixa de 8-13 $\mu \mathrm{m}$, na galáxia NGC 1068. A segunda observação de um toro foi feita, utilizando essa mesma técnica, por Tristram et al. (2007) na galáxia Circinus. Nesse segundo trabalho, os autores 
encontraram evidências de que o toro apresentava uma morfologia com distribuição clumpy, já que foi detectada uma grande proximidade entre áreas com poeira quente (com temperaturas superiores a $800 \mathrm{~K}$ ) e fria (com temperaturas entre $200 \mathrm{~K}$ e $300 \mathrm{~K}$ ). Tal comportamento é muito difícil de ser explicado considerando-se uma distribuição contínua de densidade, mas é uma conseqüência natural da distribuição clumpy.

Os grãos de poeira sublimam a temperaturas muito altas, logo, o toro (independentemente da morfologia apresentada) não pode existir em raios muito pequenos. Assumindo um valor de $1500 \mathrm{~K}$ para a temperatura de sublimação da poeira, Nenkova et al. (2008a) determinaram a seguinte expressão para o raio de sublimação:

$$
\begin{array}{r}
R_{d} \cong 0.4\left(\frac{L}{10^{45} \operatorname{erg} \cdot s^{-1}}\right)^{\frac{1}{2}}\left(\frac{1500 K}{T_{\text {sub }}}\right)^{2.6} p c . \\
\text { onde } L=\text { luminosidade do AGN } \\
T_{\text {sub }}=\text { temperatura de sublimação }
\end{array}
$$

Observando-se a figura 2.10 e considerando-se que a altura do toro de poeira em relação ao plano equatorial seja dada por $H$, tem-se a seguinte relação:

$$
\frac{H}{R_{0}}=\tan \sigma
$$

Antes da existência de observações de alta resolução no infravermelho, as estimativas do tamanho do toro de poeira dos AGNs eram feitas com base em uma análise teórica das SEDs desses objetos. Pier \& Krolik (1992) fizeram os primeiros cálculos a respeito, utilizando uma densidade uniforme, e chegaram à conclusão de que o raio externo do toro deveria ser da ordem de $R_{0} \approx 5-10$ pc. Em um trabalho posterior (Pier \& Krolik 1993), esses mesmos autores especularam que esse toro compacto poderia estar embebido em um outro muito maior e mais difuso, como $R_{0} \approx 30-100 \mathrm{pc}$. Granato \& Danese (1994) fizeram novas estimativas, utilizando geometrias toroidais mais elaboradas e um perfil de densidade constante, e chegaram à conclusão 
de que $R_{0} \geq 300-1000$ pc. Após isso, Granato et al. (1997) estabeleceram que o tamanho do toro deve ser da ordem de centenas de parsecs. Desde então, tornou-se bastante comum considerar $R_{0} \geq 100 \mathrm{pc}$.

Com o surgimento das observações de alta resolução espacial no infravermelho, verificou-se que não há qualquer evidência que indique que nuvens de poeira do toro situadas em raios maiores do que $R_{0} \approx 20-30 R_{d}$ precisam ser consideradas.

Considerando-se o Modelo Unificado com um toro de poeira apresentando uma distribuição de densidade contínua e se estendendo até um ângulo $\sigma$ acima do plano equatorial, então, é previsto que AGNs vistos sob um ângulo $0 \leq i<\frac{\pi}{2}-\sigma$ serão classificados como de tipo 1, enquanto que os observados sob um ângulo $\frac{\pi}{2}-\sigma \leq i \leq \frac{\pi}{2}$ serão classificados como de tipo 2 . Sendo $f_{2}$ a fração de AGNs de tipo 2 observados, então, de acordo com esse modelo, tem-se que

$$
f_{2}=\operatorname{sen} \sigma
$$

Fazendo uma estatística de galáxias Seyfert, Schmitt et al. (2001) determinaram que $f_{2} \cong 70 \%$, o que, de acordo com a expressão (2.23) implica que $\sigma \cong 45^{\circ}$. Substituindo esse resultado na expressão (2.22), obtém-se $\frac{H}{R_{0}} \cong 1$. O valor de $f_{2}$, entretanto, ainda é muito incerto. Hao et al. (2005), por exemplo, determinaram que $f_{2} \cong 50 \%$, o que, de acordo com (2.23) implica que $\sigma \cong 30^{\circ}$. Substituindo, então, esse resultado em (2.22), obtém-se $\frac{H}{R_{0}} \cong 0.58$.

A análise relativa ao valor $\operatorname{de} f_{2}$, entretanto, muda significativamente quando se considera para a poeira uma morfologia com distribuição clumpy. Parametrizando-se o perfil angular da distribuição de nuvens como sendo uma gaussiana de largura $\sigma$ e a distribuição radial como uma lei de potência decrescente com índice $q$, tem-se que o número de nuvens por unidade de comprimento pode ser dado por (Nenkova et al. 2008a): 


$$
N_{C}(r, \beta)=\frac{C}{R_{d}} N_{0} e^{-\frac{\beta^{2}}{\sigma^{2}}}\left(\frac{R_{d}}{r}\right)^{q}
$$

onde $N_{0}=$ média do número de nuvens ao longo de um eixo radial no plano equatorial

$$
\beta=\text { ângulo a partir do plano equatorial }
$$

Se o toro possuísse um contorno bem definido mesmo com essa morfologia (ou seja, se houvesse um término abrupto das nuvens ao se atingir um ângulo $\sigma$ acima do plano equatorial), então o valor de $f_{2}$ seria dado por

$$
f_{2}=\left(1-e^{-N_{0}}\right) \operatorname{sen} \sigma
$$

Nesse caso, a situação praticamente seria a mesma que no caso de uma distribuição contínua de densidade (expressão 2.23) se $N_{0}$ excedesse o valor de 3 ou 4. Entretanto, Nenkova et al. (2008a) mostraram que, se o toro não tiver um contorno bem definido e se o cenário for equivalente ao correspondente à expressão (2.24), então o valor de $f_{2}$ irá depender não apenas de $\sigma$, mas também de $N_{0}$. A figura 2.12 mostra os valores esperados de $f_{2}$ em função de $\sigma$ e $N_{0}$, considerando que a morfologia com distribuição clumpy seja válida.

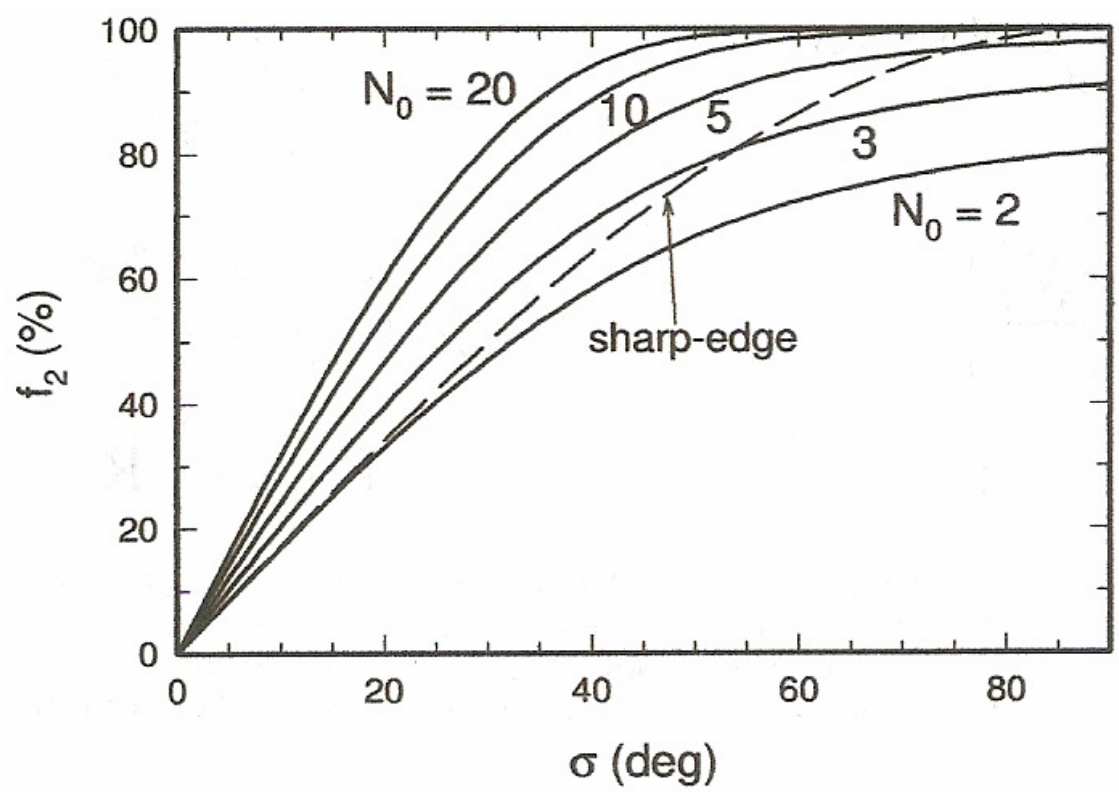

Figura 2.12 - Valores esperados de $f_{2}$ em função de $\sigma$ e $N_{0}$, considerando-se uma distribuição “clumpy” para a morfologia do toro. Figura obtida de Elitzur (2007). 
Observando-se a figura 2.12, pode-se notar que, se $f_{2} \cong 70 \%$ (Schmitt et al. 2001), então $\sigma \cong 33^{\circ}$, o que é consideravelmente diferente do resultado obtido admitindo-se um toro com distribuição contínua de densidade ( $\sigma \cong 45^{\circ}$ para $f_{2} \cong 70 \%$ ). Mais detalhes sobre o tratamento matemático de toros com morfologia apresentando uma distribuição clumpy de nuvens podem ser obtidos em Nenkova et al. (2008a; 2008b).

Muitos estudos têm encontrado evidências de que o toro de poeira pode ser uma simples continuação da BLR (Suganuma et al. 2006; Risaliti et al. 2002), sem que haja uma clara divisão entre essas duas regiões, que formariam, assim, uma distribuição contínua de nuvens. De acordo com esse cenário, o que delimitaria o tamanho da BLR seria o raio de sublimação da poeira e a única diferença essencial entre essas duas áreas seria o fato de a BLR não possuir poeira (por estar dentro do raio de sublimação) e o toro ser uma mistura de gás e poeira.

Um ponto importante a ser mencionado aqui é que, na literatura, pode haver uma certa confusão entre os termos toro de poeira e toro molecular. O Modelo Unificado prevê a existência de uma região obscurecedora com poeira, com formato toroidal, ao redor da BLR. Nesse trabalho, essa é a região que será chamada de toro de poeira. Por absorver boa parte da radiação emitida pelas áreas mais internas do AGN e re-emití-la no infravermelho, esse toro pode ser visualizado nessa região espectral, se houver resolução espacial suficiente para isso. Vale salientar, entretanto, que, dependendo da banda espectral específica no infravermelho utilizada, é possível que apenas parte do toro de poeira (com certos valores de temperatura) seja observada claramente. O termo toro molecular, por outro lado, pode se referir a uma região contendo moléculas como $\mathrm{H}_{2}, \mathrm{CO}$ e etc, que não necessariamente corresponde ao toro de poeira obscurecedor previsto pelo Modelo Unificado. É evidente, entretanto, que a poeira também pode existir em toros moleculares.

\section{6 - A controvérsia dos LINERs}

Os LINERs formam uma classe de objetos que foram motivo de várias controvérsias ao longo dos anos. Embora, inicialmente, tenha se suposto que o espectro de baixa ionização desses objetos fosse devido a ondas de choque (Heckman 1980), trabalhos como o de Halpern \& Steiner (1983) e de Ferland \& Netzer (1983) mostraram que as características espectrais dos LINERs 
também poderiam ser geradas por fotoionização a partir de AGNs, com parâmetros de ionização até uma ordem de grandeza menores do aqueles geralmente apresentados pelas galáxias Seyfert. É importante lembrar que o parâmetro de ionização, que é uma grandeza definida como sendo a razão entre a densidade de fótons ionizantes e a densidade de átomos de hidrogênio, pode ser dado por:

$$
U=\frac{1}{4 \pi r^{2} c n_{H}} \int_{v_{0}}^{\infty} \frac{L_{v}}{h v} d v
$$

onde $L_{v}=$ luminosidade da fonte em uma determinada frequência $v$

$n_{H}=$ densidade numérica de átomos de hidrogênio

$v_{0}=$ freqüência de ionização do $\mathrm{H}$

A aparente continuidade entre LINERs e Seyferts em diagramas de diagnóstico (Baldwin et al. 1981) parece indicar que, de fato, essas duas classes de objetos apresentam o mesmo tipo de fenômeno físico, ou seja, são todos AGNs.

Um dos problemas inicialmente encontrados para se considerar os LINERs autênticos AGNs foram as altas temperaturas eletrônicas derivadas a partir da razão de linhas [O III] $(\lambda 4959+\lambda 5007) /[\mathrm{O}$ III] $\lambda 4363$, o que não era previsto pelo cenário dos AGNs. Entretanto, estudos de razões de linhas como [S II] $\lambda 6716 /[\mathrm{S}$ II] $\lambda 6731$ mostraram a existência de uma grande faixa de densidades nesses objetos, o que, por sua vez, revelou a presença de regiões com maiores densidades do que o esperado. Nessas regiões, a desexcitação colisional diminuiu os valores deduzidos das temperaturas eletrônicas, o que tornou o modelo do AGN mais compatível com o cenário observado.

Existem outras características observacionais que favorecem a aplicação do modelo do AGN em muitos LINERs. Um exemplo disso é a linha de Ha larga, que foi detectada em $24 \%$ dos LINERs e é um indicativo da presença da BLR. Além disso, a detecção de um contínuo não estelar em muitos LINERs também é um fator que favorece o modelo do AGN; $25 \%$ dos LINERs têm uma fonte ultravioleta compacta e muitos também foram identificados como sendo fontes emissoras de rádio e de raios-x. 
Atualmente, o modelo do AGN parece ser capaz de explicar as características observacionais da maior parte dos LINERs, o que faz com que esse cenário seja o mais aceito para esses objetos. Apesar disso, outros modelos ainda são utilizados para explicar os espectros de baixa ionização de, pelo menos, alguns LINERs. Um deles é o que considera ondas de choque como sendo a fonte da ionização do gás existente nesses objetos. Esse modelo costuma envolver choques com velocidades entre $200 \mathrm{~km} / \mathrm{s}$ e $500 \mathrm{~km} / \mathrm{s}$ e foi bastante aprimorado nos últimos anos (Dopita \& Sutherland 1995; Dopita \& Sutherland 1996), sendo capaz de explicar as características espectrais de vários LINERs. Apesar desse aparente sucesso, o modelo das ondas de choque possui alguns problemas, como, por exemplo, o fato de muitos LINERs apresentarem linhas de emissão com valores de $F W H M$ muito pequenos (entre $100 \mathrm{~km} / \mathrm{s}$ e $200 \mathrm{~km} / \mathrm{s}$ ) para serem compatíveis com cenários envolvendo choques relevantes. A presença de uma estrutura puntual ionizante identificada em muitos desses objetos também não pode ser explicada por esse modelo. Além disso, alguns LINERs simplesmente apresentam razões de linhas de emissão incompatíveis com esse cenário.

Existem, ainda, modelos que explicam os espectros de baixa ionização dos LINERs como sendo devidos à fotoionização por estrelas. Tais modelos se dividem em dois grandes grupos, de acordo com a fonte específica de ionização levada em conta. O primeiro grupo considera a fotoionização por estrelas "jovens" como sendo o mecanismo responsável por originar as características espectrais dos LINERs. Terlevich \& Melnick (1985) mostraram que os espectros de galáxias Seyfert 2 e de LINERs poderiam ser gerados pela fotoionização a partir de estrelas Wolf-Rayet, que são chamadas pelos autores de Warmers. Shields (2000), por sua vez, verificou que os espectros dos LINERs também poderiam ser reproduzidos pela fotoionização a partir de estrelas O. O segundo grupo de modelos admite a fotoionização por estrelas "velhas" como sendo o mecanismo responsável por gerar as características gerais dos espectros desses objetos. Taniguchi et al. (2000) mostraram que a fotoionização a partir de núcleos de nebulosas planetárias poderia dar origem aos espectros dos LINERs. Binette et al. (1994), por sua vez, verificaram que as principais características espectrais de várias galáxias elípticas (inclusive LINERs) poderiam ser geradas pela fotoionização a partir de estrelas pós-AGB.

A partir de tudo o que foi dito, pode-se notar que uma grande variedade de modelos já foram propostos para explicar os espectros de baixa ionização dos LINERs. Hoje, entretanto, parece claro que não existe um modelo único capaz de explicar as características de todos os 
LINERs observados e cada objeto diferente pode ser explicado por um dos diversos modelos citados ou por combinações dos mesmos. Isso faz com que os LINERs constituam uma classe de objetos bastante heterogênea.

O estudo de populações estelares nos arredores dos AGNs é difícil de ser realizado em objetos de alta luminosidade, já que a emissão nuclear tende a "ofuscar" as assinaturas espectrais provenientes de populações estelares próximas. Os casos extremos desse cenário são os QSOs e os quasares, nos quais o "ofuscamento" causado pela emissão nuclear é tão grande que mesmo a galáxia ao redor do AGN é pouco detectada (e, em vários casos, nem sequer é detectada). Essa situação é bastante diferente, entretanto, no caso dos LINERs. Como a emissão nuclear é bem menos intensa nesses objetos, um estudo das populações estelares presentes nas proximidades dos AGNs centrais é mais viável. Além disso, como boa parte dos LINERs são objetos consideravelmente próximos, observações com elevados valores de $S / N$ e altas resoluções espaciais também são possíveis. Cid Fernandes et al. (2004) fizeram um estudo sobre as populações estelares presentes em núcleos ativos de baixa luminosidade e concluíram que cerca de um terço desses objetos apresentam populações com idades intermediárias (entre $10^{8}-10^{9}$ anos). Populações jovens (com idades inferiores a $10^{7}$ anos) provavelmente associadas a starbursts, por outro lado, contribuem muito pouco para o espectro óptico desses objetos. Mesmo nos objetos nos quais foi detectada a presença de estrelas jovens, por meio de observações em UV, tais populações contribuem com, apenas, cerca de $30 \%$ do contínuo óptico detectado. 


\section{3 - Metodologias de trabalho}

\section{1 - Introdução}

Os cubos de dados analisados nesse trabalho foram obtidos com o IFU (Integral Field Unity) do GMOS (Gemini Multi-Object Spectrograph) dos telescópios Gemini-Norte e GeminiSul, com o NIFS (Near-Infrared Integral Field Spectrograph) do telescópio Gemini-Norte e com o SINFONI (Spectrograph for Integral Field Observations in the Near Infrared) do VLT (Very Large Telescope). O trabalho com esses cubos de dados envolveu a utilização de uma série de metodologias, tanto para o tratamento dos dados, quanto para a sua análise. Em primeiro lugar, foi necessário fazer a redução de todos esses dados, que envolveu a utilização de diferentes softwares, dependendo do instrumento utilizado na observação. Após isso, as principais metodologias utilizadas no tratamento dos dados foram: a correção da refração atmosférica diferencial, a reamostragem espacial, a filtragem espacial de Butterworth, o de-noising espectral, a remoção de fingerprints instrumentais e a deconvolução de Richardson-Lucy. É importante mencionar, entretanto, que o tratamento de cada um dos cubos de dados analisados não envolveu, necessariamente, todas essas técnicas. As metodologias mais apropriadas para cada caso foram escolhidas levando-se em conta o instrumento utilizado na observação e, em alguns casos, a própria qualidade dos dados. Por outro lado, as principais técnicas utilizadas para a análise dos cubos de dados foram: a Tomografia PCA, a síntese espectral com o software Starlight e a determinação de parâmetros cinemáticos com o processo do Penalized Pixel Fitting. Algumas outras metodologias de análise (descritas nos capítulos seguintes) também foram usadas em certos casos específicos. As técnicas mencionadas acima estão descritas a seguir. Mais detalhes também podem ser encontrados em Gonzalez \& Woods (2002) e Starck \& Murtagh (2006).

\section{2 - Redução dos dados}

O primeiro tratamento aplicado nos dados a fim de se poder analisá-los foi, obviamente, o processo da redução. Esse procedimento costuma apresentar várias diferenças dependendo do 
tipo de dados envolvidos e do instrumento utilizado na observação. Mesmo assim, pode-se dizer que as principais etapas geralmente envolvidas na redução de cubos de dados são as seguintes:

- Determinação do trim

- Subtração do bias

- Rejeição de raios cósmicos

- Extração dos espectros

- Correção de flat-field

- Calibração em comprimento de onda

- Subtração do céu

- Remoção das absorções telúricas

- Calibração em fluxo

- Montagem dos cubos de dados

- Determinação do trim: Geralmente, todas as imagens possuem uma ou duas colunas de pixeis nas suas laterais que não apresentam dados que possam ser utilizados, assim sendo, essas regiões devem ser excluídas. A determinação do trim nada mais é do que a identificação de quais partes da imagem contêm dados que podem ser aproveitados. As demais regiões são, então, excluídas.

- Subtração do bias: O bias consiste em um número não nulo de contagens de fótons, que é obtido com uma exposição de 0 segundos. Em outras palavras, pode-se dizer que é um número de contagens na imagem independente do tempo de exposição e do objeto observado. Esse efeito é uma assinatura da eletrônica do instrumento e, consequentemente, precisa ser subtraído. Para isso, em cada observação, costuma-se fazer algumas exposições de 0 segundos, tirar uma média dessas exposições e, em seguida, subtrair essa média da imagem original.

- Rejeição de raios cósmicos: A Terra está constantemente sendo "bombardeada" pelos chamados raios cósmicos, que são partículas energéticas que podem penetrar na atmosfera e chegar na superfície. Quando essas partículas atingem o detector CCD do telescópio utilizado, pequenos "pontos" são gerados. A etapa da rejeição de raios cósmicos consiste na eliminação de tais "pontos", o que, geralmente, é feito através da comparação de diferentes imagens de um mesmo 
campo. Com essa comparação, é possível identificar a presença dos raios cósmicos e eliminá-los, fazendo-se uma interpolação com os pixeis adjacentes. Atualmente, entretanto, existem técnicas matemáticas para se localizar e eliminar raios cósmicos sem que qualquer comparação com outras imagens do mesmo campo seja necessária.

- Extração dos espectros: Quando um espectro é obtido por um espectrógrafo, ele encontra-se, inicialmente, bidimensional. A extração do espectro consiste, então, em passá-lo da forma bidimensional para a unidimensional, que nada mais é do que um gráfico do fluxo detectado em função do comprimento de onda.

- Correção de flat-field: Geralmente, existem variações de ganho entre os pixeis da imagem. Para igualar todos esses ganhos, deve-se "dividir" a imagem obtida pelo flat-field, que nada mais é do que uma imagem de calibração que tem por função revelar as variações de ganho entre os pixeis do CCD. Uma imagem de flat-field pode ser obtida apontando-se o telescópio durante algum tempo para uma tela iluminada por uma luz branca (imagem de GCAL-flat) ou para o céu do crepúsculo (imagem de twilight). No caso de cubos de dados, entretanto, o procedimento de correção de flat-field, geralmente, é um pouco mais complicado e costuma envolver a obtenção de curvas de resposta. Uma estratégia frequentemente utilizada (em dados do GMOS, por exemplo) consiste em calcular a média de todos os espectros da imagem de GCAL-flat, ajustar um polinômio a esse espectro médio e, em seguida, dividir cada espectro pelo polinômio encontrado. Com isso, são obtidas as curvas de resposta, que indicam as variações de ganho pixel a pixel em cada um dos espectros. Após isso, para se obter uma estimativa de padrões de iluminação da lâmpada de GCAL-flat e também variações de ganho fibra a fibra, primeiramente, os espectros da imagem de twilight são divididos pelas curvas de resposta do GCAL-flat. Em seguida, é calculada a média, ao longo do eixo espectral, de cada um dos espectros da imagem de twilight, obtendo-se, portanto, um mapa de resposta com valores representativos da razão céu/lâmpada (que indicam padrões de iluminação da lâmpada de GCAL-flat e variações de ganho fibra a fibra). Finalmente, multiplica-se o mapa de resposta do twilight pelas curvas de resposta correspondentes do GCAL-flat, chegando-se ao mapa de resposta final. Dividindo-se os espectros do objeto de ciência por esse mapa de resposta, são corrigidas variações de ganho pixel a pixel e fibra a fibra, assim como possíveis padrões de iluminação da lâmpada de GCAL-flat. 
- Calibração em comprimento de onda: Um espectro obtido, inicialmente, não possui valores de comprimento de onda associados. Assim sendo, essa etapa consiste em atribuir alguns valores de comprimentos de onda conhecidos a um espectro de calibração e, em seguida, aplicar essa calibração no espectro observado. Em geral, o espectro de calibração pode ser obtido apontandose o telescópio para uma lâmpada com espectro conhecido.

- Subtração do céu: É sabido que a atmosfera terrestre emite em certos comprimentos de onda e tal emissão pode aparecer nos espectros (na forma de linhas de emissão) e nas imagens dos objetos observados. A subtração do céu consiste na remoção dessa emissão, o que, geralmente, é feito tomando-se uma exposição em uma região do céu livre de objetos celestes e subtraindo-se a imagem obtida dos dados de ciência.

- Remoção das absorções telúricas: A atmosfera terrestre também absorve em certos comprimentos de onda, gerando as chamadas linhas de absorção telúricas, que são claramente visíveis em espectros tomados em algumas bandas espectrais. Para se corrigir esse efeito, é utilizado um espectro de referência obtido a partir da observação de uma estrela padrão apropriada. Esse espectro é normalizado e quaisquer linhas espectrais próprias da estrela que o originou são removidas, de modo que o resultado final é um espectro com contínuo de valor aproximadamente igual a 1 e contendo como linhas espectrais, apenas, as absorções telúricas. Dividindo-se, então, o espectro de ciência por esse espectro da estrela padrão telúrica, pode-se remover as linhas de absorção telúricas existentes.

- Calibração em fluxo: O espectro até esse momento consiste em um gráfico do número de contagens (que é dependente da sensibilidade do instrumento) em função do comprimento de onda. Essa etapa da redução tem por função transformar esse espectro em um gráfico de fluxo em função do comprimento de onda. Para isso, obtém-se uma relação entre o número de contagens e o fluxo correspondente a partir do espectro de uma estrela padrão espectrofotométrica e aplica-se essa relação no espectro que está sendo reduzido. 
- Montagem do cubo de dados: Um cubo de dados consiste num conjunto de dados com informações em três dimensões $(x, y, z)$. Nesse caso, $x$ e $y$ correspondem às dimensões espaciais do objeto e z representa o comprimento de onda. Dessa maneira, ao se analisar um cubo de dados, pode-se obter as imagens do objeto em vários comprimentos de onda, assim como os espectros de diferentes regiões espaciais dele. Essa etapa da redução consiste em organizar corretamente os espectros obtidos com a observação, obtendo-se, ao final, um cubo de dados.

\subsection{1 - Redução de dados do GMOS}

Os espectrógrafos GMOS dos telescópios Gemini-Norte e Gemini-Sul permitem que sejam feitas observações, no intervalo espectral de $3600 \AA$ até $9400 \AA$, nos modos long-slit e multi-slit. Além disso, cada um desses instrumentos também possuem uma unidade de campo integrado (IFU), que realiza espectroscopia 3D. O detector do GMOS (tanto do Gemini-Norte quanto do Gemini-Sul) consiste em três CCDs de 2048 x 4608 pixeis dispostos em uma linha, com $0.5 \mathrm{~mm}$ de gap entre eles, o que resulta em um detector final de 6144 x 4608 pixeis.

Conforme mencionado anteriormente, nesse trabalho foram analisados dados obtidos com o IFU do GMOS dos telescópios Gemini-Norte e Gemini-Sul. Nesse instrumento, há dois campos de visão, sendo um destinado à observação de ciência e o outro à observação do céu. $\mathrm{O}$ campo de visão da ciência possui uma dimensão de 5" x 7" e é amostrado por um conjunto de 1000 lenslets. A luz ali incidente passa por essas lenslets e é conduzida por um total de 1000 fibras (cada uma ligada a uma lenslet) a um grupo de fendas, onde será dispersada e dará origem aos espectros que serão registrados no detector. O processo é inteiramente análogo no caso do campo de visão do céu, entretanto, sua dimensão é de 5" x 3.5" e há, apenas, 500 lenslets e fibras para amostrar e conduzir a luz, respectivamente. É importante mencionar que, quando o IFU do GMOS opera com esse campo visual e com essa quantidade de lenslets e fibras, a extensão espectral obtida é de cerca de 1500 Å. Esse é o chamado modo two-slit. Existe, entretanto, um segundo modo de operação chamado de one-slit, no qual é tomado um campo de ciência com metade do tamanho (5" x 3.5”) e apenas 500 lenslets e fibras são utilizadas. Correspondentemente, nesse caso, o campo do céu também possui metade do tamanho ( 5 " $\mathrm{x}$ 1.75”) e somente 250 lenslets e fibras são utilizadas. A grande vantagem do modo one-slit é que ele permite que seja obtida uma extensão espectral de cerca de $3000 \AA$. Em resumo, pode-se dizer 
que o modo two-slit apresenta um maior campo visual, às custas de uma menor extensão espectral, ao passo que o modo one-slit possui um menor campo visual, porém com uma maior extensão espectral. Nesse trabalho, foram utilizados dados obtidos apenas com o modo one-slit. A figura 3.1 mostra um esquema do IFU do GMOS dos telescópios Gemini-Norte (GMOS-N) e Gemini-Sul (GMOS-S).

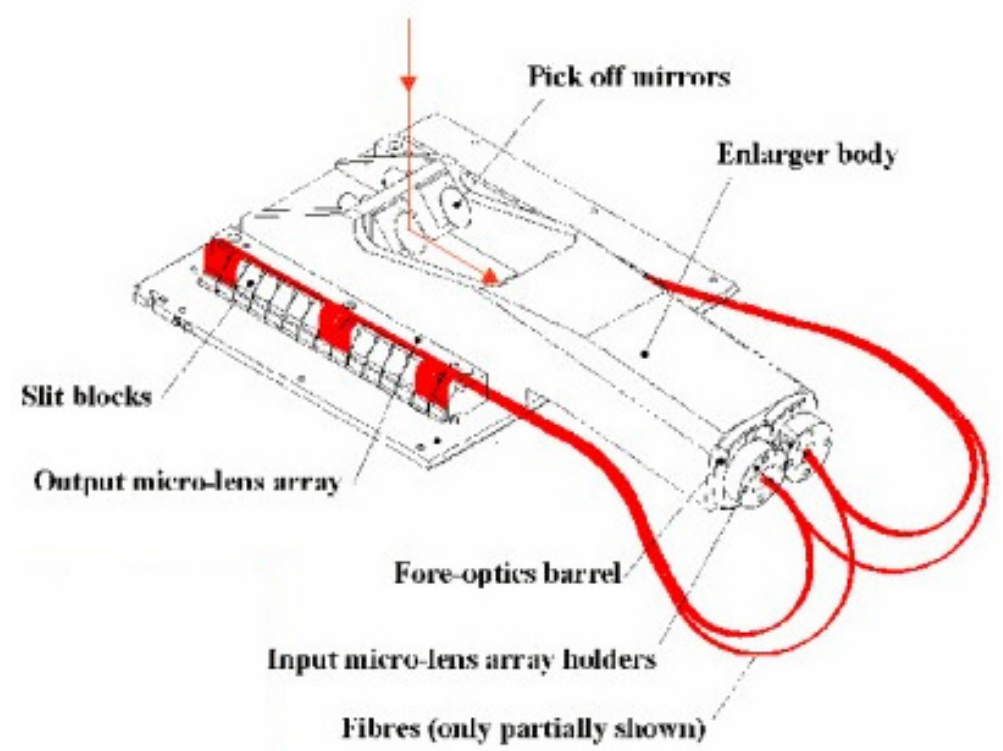

Figura 3.1 - Esquema do IFU dos espectrógrafos GMOS-N e GMOS-S.

A figura 3.2 mostra os dados brutos das observações das estrelas HD 26154 e ltt 4816 com o IFU do GMOS-S, sendo que a primeira foi observada no modo two-slit e a segunda no modo one-slit.
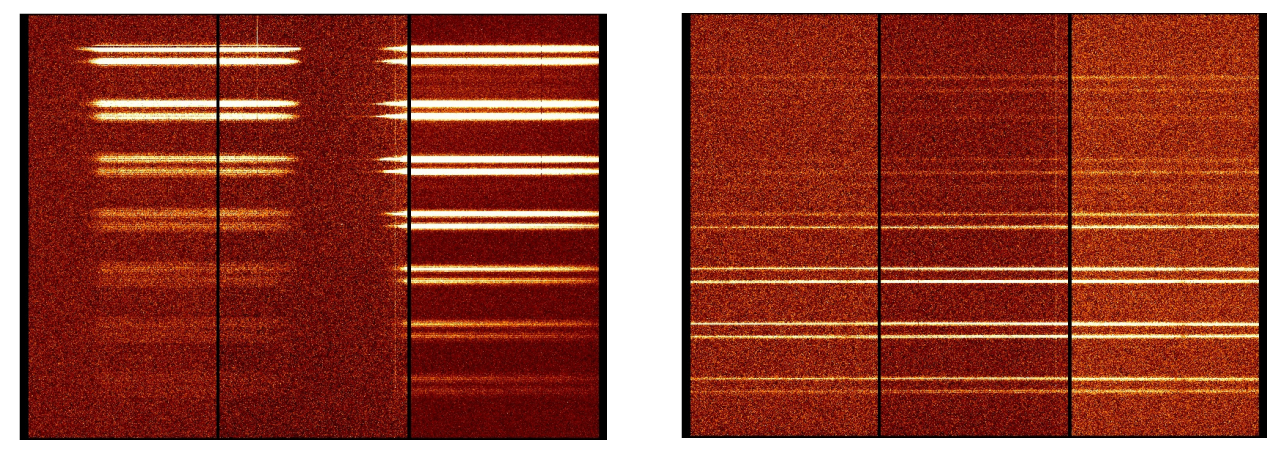

Figura 3.2 - (esquerda) Dados brutos da observação da estrela HD 26154 com o IFU do GMOS-S no modo "two-slit"; (direita) Dados brutos da observação da estrela ltt 4816 com o IFU do GMOS-S no modo "one-slit". 
Observando-se a figura 3.2, pode-se notar que os espectros brutos (bidimensionais) obtidos com o IFU do GMOS aparecem dispostos horizontalmente em várias linhas adjacentes. No caso do modo two-slit, pode-se notar a existência de dois espectros de menor extensão espectral por linha, ao passo que, no modo one-slit, verifica-se a presença de um espectro de maior extensão espectral por linha. Isso é uma conseqüência do fato de o modo two-slit apresentar um maior campo (e, consequentemente, um maior número de espectros) com uma menor cobertura espectral e do modo one-slit possuir um menor campo (e, portanto, um menor número de espectros) com uma maior cobertura espectral.

A redução dos dados do IFU do GMOS utilizados nesse trabalho foi feita em ambiente IRAF, utilizando-se o pacote de tarefas Gemini e envolveu as seguintes etapas: determinação do trim da imagem, subtração do bias, correção de flat-field, rejeição de raios cósmicos, extração dos espectros, calibração em comprimento de onda, subtração do céu, calibração em fluxo e montagem do cubo de dados. Inicialmente, foi utilizada a tarefa GPREPARE em todos os dados brutos a serem reduzidos. Essa é uma etapa necessária para essa redução e, essencialmente, durante a sua execução, são incluídas informações nos headers dos dados, inclusive a respeito das posições relativas dos espectros no cubo de dados que será gerado no final. Após essa etapa inicial, foi feita a determinação do trim e a subtração do bias de todas as imagens, utilizando-se a rotina GIREDUCE. Com a tarefa GFEXTRACT, foram extraídos os espectros de flat-field (incluindo os GCAL-flats e os twilights) e de lâmpada (para a calibração em comprimento de onda). A partir dos espectros de flat-field (tanto os GCAL-flats quanto os twilights) foi possível construir um mapa de resposta, utilizando-se a rotina GFRESPONSE. Esse mapa de resposta, conforme explicado anteriormente, permite que sejam corrigidas as variações de ganho pixel a pixel (nos pixeis espectrais de cada um dos espectros) e fibra a fibra, assim como possíveis padrões de iluminação da lâmpada de GCAL-flat. Para se determinar os valores dos comprimentos de onda corretos para o espectro da lâmpada de calibração, foi utilizada a tarefa GSWAVELENGTH.

Para poder aplicar uma calibração de fluxo nos dados, primeiramente, foi feita uma redução típica nos dados da estrela padrão a ser utilizada. Nesse caso, após a aplicação da tarefa GPREPARE e da determinação do trim e subtração do bias com a rotina GIREDUCE, fez-se a extração dos espectros e a correção de flat-field (utilizando-se o mapa de resposta obtido previamente) por meio da tarefa GFEXTRACT. Em seguida, aplicou-se a calibração em 
comprimento de onda (obtida com a rotina GSWAVELENGTH utilizada anteriormente) nesses dados da estrela padrão por meio da tarefa GFTRANSFORM. Somaram-se, então, todos os espectros da estrela padrão, por meio da rotina GFAPSUM, e, utilizando-se o espectro resultante dessa soma, determinou-se uma curva de sensibilidade dos dados por meio da tarefa GSSTANDARD.

Finalmente, para se fazer a redução dos dados de ciência, primeiramente, tomaram-se os dados após a aplicação da tarefa GPREPARE e da determinação do trim e da subtração do bias (por meio da rotina GIREDUCE), e aplicou-se uma rejeição de raios cósmicos por meio da tarefa GSCRREJ (que, por sua vez, utiliza a rotina LACOS para a remoção de raios cósmicos). Após isso, utilizou-se a tarefa GFEXTRACT para a extração dos espectros e para a correção de flatfield. A calibração em comprimento de onda foi, então, aplicada por meio da rotina GFTRANSFORM e, em seguida, foi feita uma subtração da emissão de céu com a tarefa GFSKYSUB. Finalmente, a calibração em fluxo foi aplicada (utilizando-se a curva de sensibilidade obtida com a rotina GSSTANDARD) por meio da tarefa GSCALIBRATE.

$\mathrm{Na}$ verdade, todo esse procedimento de redução dos dados obtidos com o IFU do GMOS não foi feito utilizando-se cada uma das tarefas anteriores separadamente, mas, ao invés disso, utilizou-se uma rotina mais abrangente chamada GFREDUCE, que aplicava cada uma das tarefas anteriores na seqüência desejada.

Por fim, foram montados os cubos de dados, utilizando-se a tarefa GFCUBE. Nesse trabalho, optou-se por aplicar essa rotina de modo a obter, em todos os casos, cubos de dados com pixeis espaciais de 0.05 " de lado. As figuras 3.3, 3.4, 3.5 e 3.6 mostram as imagens de um intervalo espectral intermediário colapsado e o espectro extraído de uma região espacial (circular) centrada no objeto dos cubos de dados de HD 26154 e ltt 4816, após a redução dos dados. 

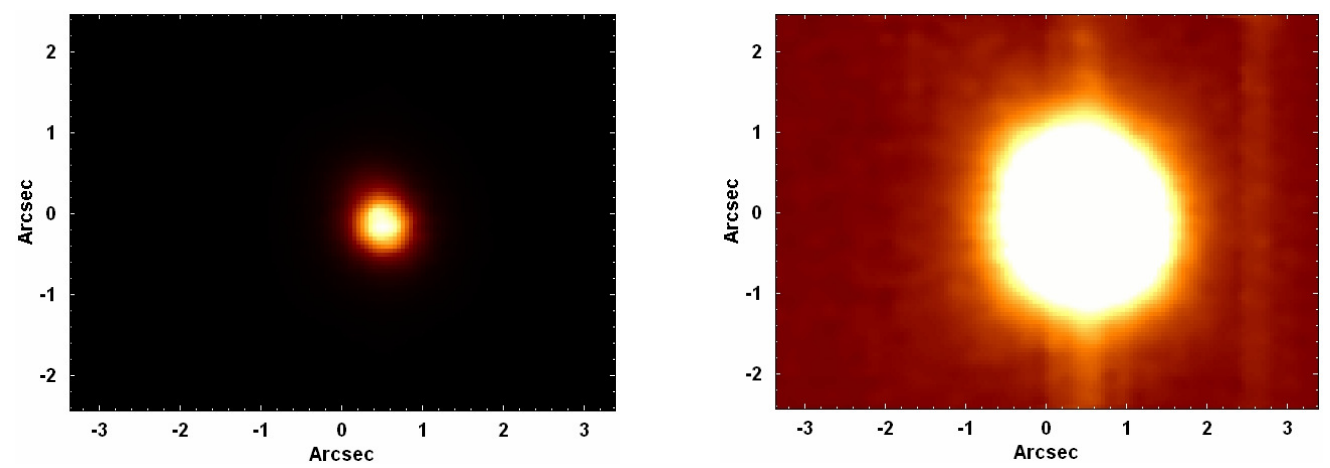

Figura 3.3 - (esquerda) Imagem de um intervalo espectral intermediário colapsado do cubo de dados de HD 26154, após a redução dos dados; (direita) Mesma imagem que à esquerda, mas com a LUT "exagerada”.

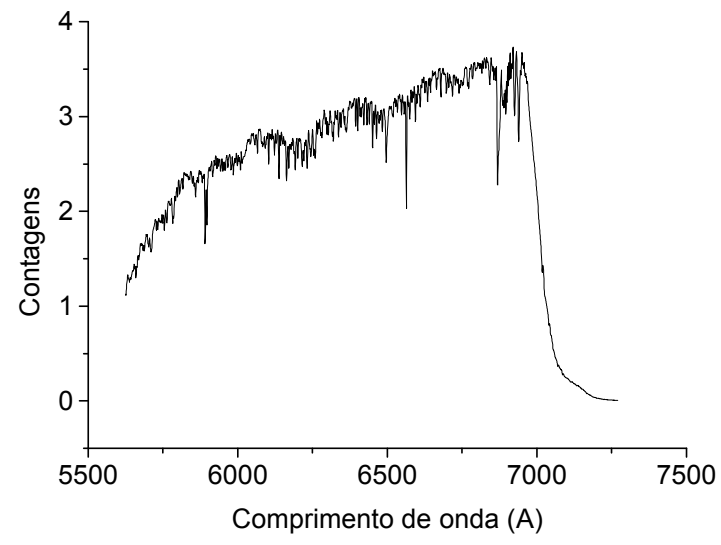

Figura 3.4 - Espectro extraído de uma região espacial (circular) centrada no objeto do cubo de dados de HD 26154, após a redução dos dados. Nesse caso, não foi aplicada a calibração em fluxo.
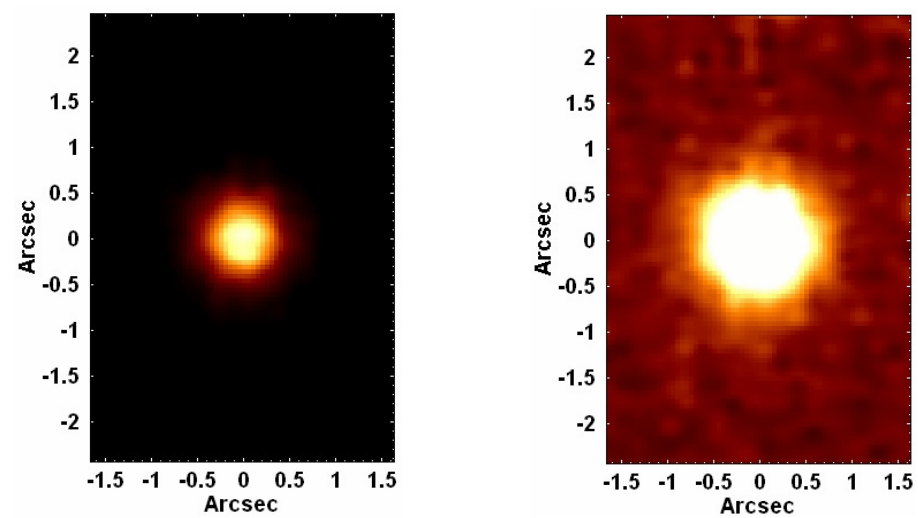

Figura 3.5 - (esquerda) Imagem de um intervalo espectral intermediário colapsado do cubo de dados de ltt 4816, após a redução dos dados; (direita) Mesma imagem que à esquerda, mas com a LUT "exagerada". 


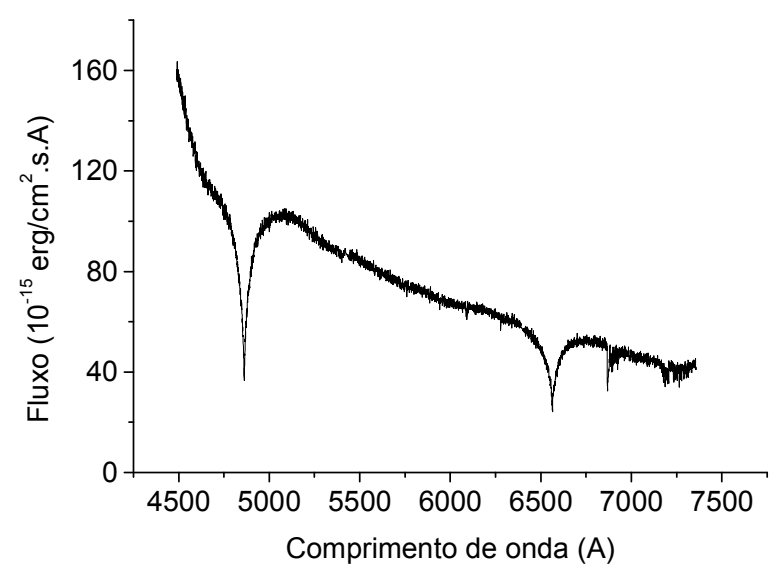

Figura 3.6 - Espectro extraído de uma região espacial (circular) centrada no objeto do cubo de dados de ltt 4816, após a redução dos dados.

As imagens com a LUT exagerada das figuras 3.3 e 3.5 revelam a presença de uma considerável quantidade de ruídos de alta freqüência espacial. Além disso, no caso da figura 3.3, também se pode notar a existência de uma faixa vertical, que, provavelmente, corresponde a algum tipo de fingerprint instrumental. Os procedimentos de tratamento de dados descritos nas próximas sessões têm como função remover boa parte desses efeitos indesejáveis visíveis nas imagens dos cubos de dados após a redução. Os espectros das figuras 3.4 e 3.6 mostram que, conforme já mencionado anteriormente, a extensão espectral obtida com observações no modo one-slit (pouco mais de $3000 \AA$ A ) é aproximadamente o dobro da fornecida por observações no modo two-slit (pouco mais de $1500 \AA$ ). O espectro da figura 3.4 também apresenta uma forte queda nos valores de contagens (lembrando que não foi feita calibração em fluxo nesse caso) em comprimentos de onda maiores do que cerca de $7000 \AA$ A . Isso pode ser explicado pelo fato de a rede de difração utilizada nessa observação possuir pouca sensibilidade nessa região espectral de maiores comprimentos de onda.

\subsection{2 - Redução de dados do NIFS}

O NIFS é um espectrógrafo de campo integrado no infravermelho próximo do telescópio Gemini-Norte. Com esse instrumento, é possível fazer espectroscopia 3D em um intervalo espectral de $9500 \AA$ até $24000 \AA$ (que inclui as bandas espectrais Z, J, H e K). O NIFS possui um campo com tamanho de 3" x 3" e foi projetado para funcionar em conjunto com o módulo de óptica adaptativa ALTAIR (usando estrelas guias naturais ou de laser), o que permite que 
resoluções espaciais da ordem de 0.1 " sejam obtidas. O detector do NIFS é composto por apenas um CCD com 2048 x 2048 pixeis.

A luz incidente no campo de visão do NIFS é passada para o image slicer, onde 29 pequenos espelhos côncavos direcionam toda a luz incidente para um outro conjunto de espelhos côncavos, chamados espelhos de pupila (pupil mirrors). Esse segundo arranjo de espelhos redireciona toda a luz para um terceiro grupo de espelhos, chamados espelhos de campo (field mirrors). Entretanto, além de redirecionar a luz, os espelhos de pupila também a reconfiguram, de modo que, ao atingir os espelhos de campo, toda a luz proveniente do plano focal está disposta num formato similar ao de uma fenda fina e longa. Com essa nova configuração, a luz passa pelo colimador, por um corretor do colimador, pela rede de difração (que dá origem aos espectros) e, finalmente, é encaminhada para o detector. O produto final de todas essas propriedades ópticas e geométricas do NIFS é a obtenção de pixeis espaciais retangulares, com dimensões 0.103 ” x 0.043". A figura 3.7 mostra um esquema com os principais componentes do NIFS.

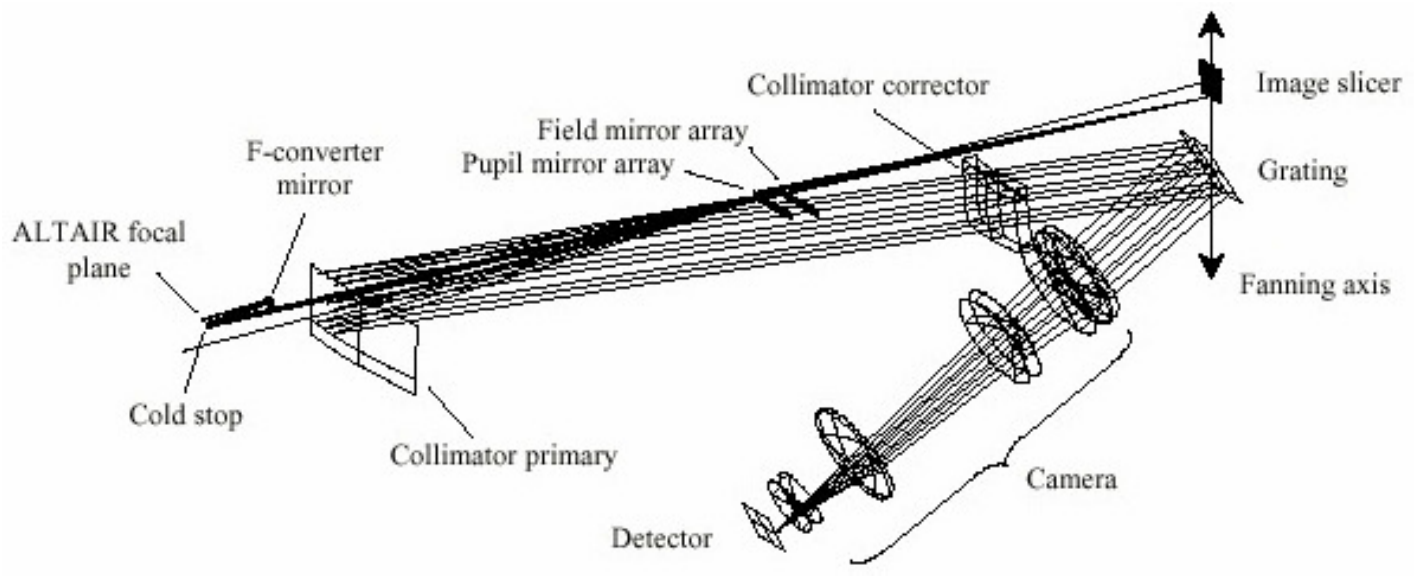

Figura 3.7 - Esquema com os principais componentes do NIFS do telescópio Gemini-Norte.

A figura 3.8 mostra os dados brutos da observação da estrela GQ Lup, na banda K, com o NIFS. 


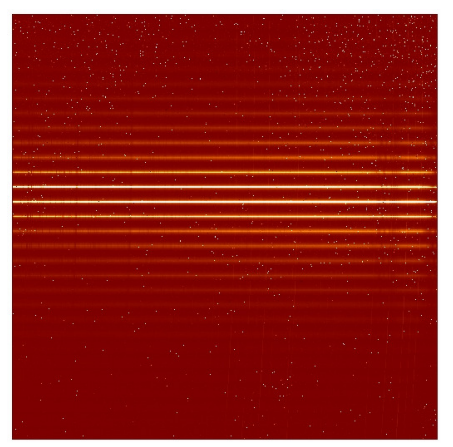

Figura 3.8 - Dados brutos da observação da estrela GQ Lup, na banda K, com o NIFS.

Observando-se a figura 3.8, pode-se notar que os espectros brutos (bidimensionais) obtidos com o NIFS, assim como no caso do IFU do GMOS, são dispostos horizontalmente em várias linhas adjacentes.

A redução dos dados do NIFS também foi feita em ambiente IRAF, utilizando-se o pacote de tarefas Gemini e envolveu as seguintes etapas: determinação do trim (nesse caso, os espectros eram "cortados" da imagem original e colocados em diferentes extensões), subtração do céu, correção de bad pixeis, correção de flat-field, retificação espacial, calibração em comprimento de onda, remoção de absorções telúricas, calibração em fluxo e montagem do cubo de dados. Inicialmente, foi utilizada a tarefa NFPREPARE em uma das imagens de flat-field para que fossem feitas atualizações em seu header, referentes à posição relativa dos espectros no cubo de dados que será gerado. As informações obtidas com esse procedimento foram utilizadas em todas as etapas seguintes nas quais a rotina NFPREPARE foi utilizada. Procedeu-se, então, com a redução das imagens de flat-field. Para isso, primeiramente, foi aplicada a tarefa NFPREPARE em cada uma dessas imagens. Em seguida, utilizou-se a rotina NSREDUCE para "cortar" os espectros existentes na imagem e colocá-los em diferentes extensões (na verdade, a tarefa NSREDUCE utiliza a sub-rotina NSCUT para realizar o corte dos espectros). Após isso, utilizouse a rotina NSFLAT para gerar uma imagem de flat-field normalizada. Essa mesma tarefa também realizou a subtração da corrente escura (a estimativa da corrente escura pôde ser feita porque, para cada imagem de flat-field obtida com o telescópio exposto à luz, havia uma outra obtida com o telescópio não exposto à luz). A imagem final de flat-field foi, então, produzida utilizando-se a tarefa NSSLITFUNCTION, que corrige a imagem obtida anteriormente com a rotina NSFLAT devido a variações de sensibilidade entre os diferentes image slices do NIFS.

Para se obter uma calibração em comprimento de onda, primeiramente, aplicou-se a tarefa NFPREPARE nas imagens de lâmpada e fez-se o "corte" dos espectros (colocando-os em 
diferentes extensões) com a rotina NSREDUCE. Nessa aplicação da tarefa NSREDUCE, entretanto, também foi feita uma correção de flat-field nas imagens de lâmpada (utilizando-se a imagem de flat-field obtida anteriormente). A calibração em comprimento de onda foi, então, obtida utilizando-se a rotina NSWAVELENGTH.

Para se fazer uma calibração espacial dos dados (mapeando efeitos de curvatura e distorções), primeiramente, aplicou-se, nas imagens de Ronchi-flat, a tarefa NFPREPARE e, em seguida, fez-se o "corte" dos espectros e a correção de flat-field utilizando-se a rotina NSREDUCE. Em seguida, o mapeamento espacial necessário foi feito com a tarefa NFSDIST. A etapa da calibração espacial é bastante importante para se obter o correto alinhamento dos espectros obtidos com os diferentes image slices.

Para se obter um espectro de template das absorções telúricas da atmosfera terrestre, primeiramente, foi aplicada a tarefa NFPREPARE nos dados da estrela padrão telúrica observada. Em seguida, uma imagem de céu foi obtida a partir de uma mediana das imagens da estrela padrão, que foi calculada com a rotina GEMCOMBINE. Isso foi possível porque essas imagens foram observadas utilizando-se o recurso de dithering. Essa imagem de céu foi subtraída da imagem original e, após isso, fez-se o "corte" dos espectros e a correção de flat-field utilizando-se a tarefa NSREDUCE. Uma correção de bad pixeis foi aplicada utilizando-se a rotina NFFIXBAD. Em seguida, utilizando-se a calibração em comprimento de onda, obtida com a tarefa NSWAVELENGTH, e a calibração espacial, obtida com a rotina NFSDIST, aplicou-se a tarefa NFFITCOORDS para se determinar o mapeamento dos dados no cubo de dados final. Após isso, as calibrações espacial e de comprimento de onda foram aplicadas nos dados utilizando-se a rotina NFTRANSFORM. Finalmente, utilizando-se a tarefa NFEXTRACT, extraiu-se um espectro da estrela telúrica.

Por fim, para se fazer a redução dos dados de ciência, primeiramente, repetiram-se as etapas iniciais aplicadas na redução dos dados da estrela telúrica, ou seja: aplicação da tarefa NFPREPARE, subtração do céu, corte dos espectros e aplicação da correção de flat-field com a rotina NSREDUCE, correção de bad pixeis com a tarefa NFFIXBAD, determinação do mapeamento do cubo de dados final com a rotina NFFITCOORDS e aplicação das calibrações espacial e de comprimento de onda com a tarefa NFTRANSFORM. Após isso, utilizando-se o template das absorções telúricas obtido anteriormente, foi feita a remoção dessas absorções por meio da rotina NFTELLURIC. Aplicaram-se, então, as tarefas STANDARD e SENSFUNC nos 
dados reduzidos da estrela padrão para se obter uma calibração em fluxo. Essa calibração foi feita ajustando-se um corpo negro ao espectro dessa estrela padrão (foi necessário fornecer a magnitude e o tipo espectral da estrela telúrica utilizada). A calibração em fluxo foi, em seguida, aplicada nos dados de ciência por meio da rotina CALIBRATE. Finalmente, o cubo de dados foi construído utilizando-se a tarefa NIFCUBE. Nesse trabalho, optou-se por aplicar essa rotina de modo a se obter, em todos os casos, cubos de dados com pixeis espaciais de 0.05" de lado As figuras 3.9 e 3.10 mostram, respectivamente, a imagem de um intervalo espectral intermediário colapsado e o espectro extraído de uma região espacial (circular) centrada no objeto do cubo de dados de GQ Lup, após a redução dos dados.
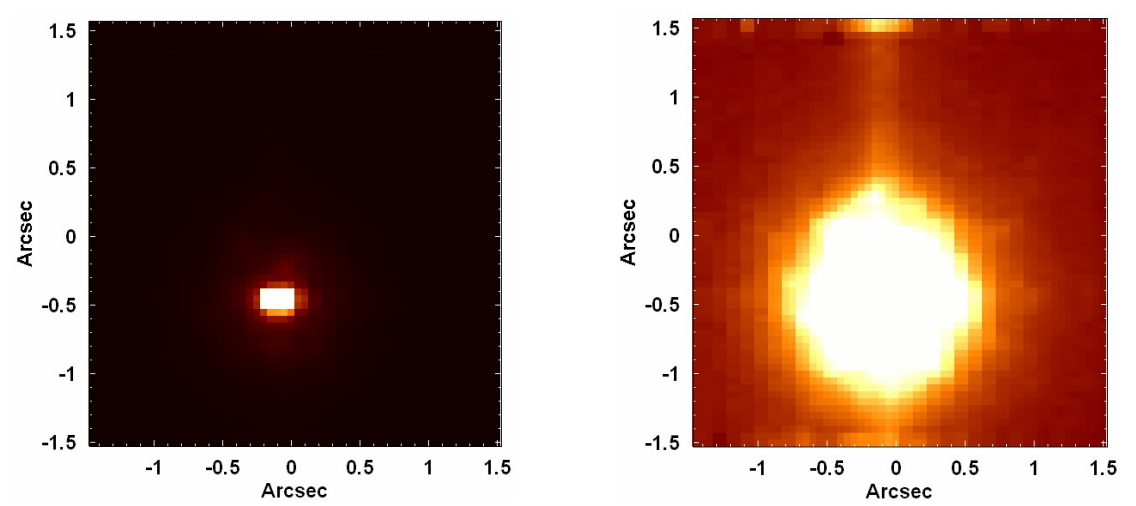

Figura 3.9 - (esquerda) Imagem de um intervalo espectral intermediário colapsado do cubo de dados de GQ Lup, após a redução dos dados; (direita) Mesma imagem que à esquerda, mas com a LUT "exagerada".

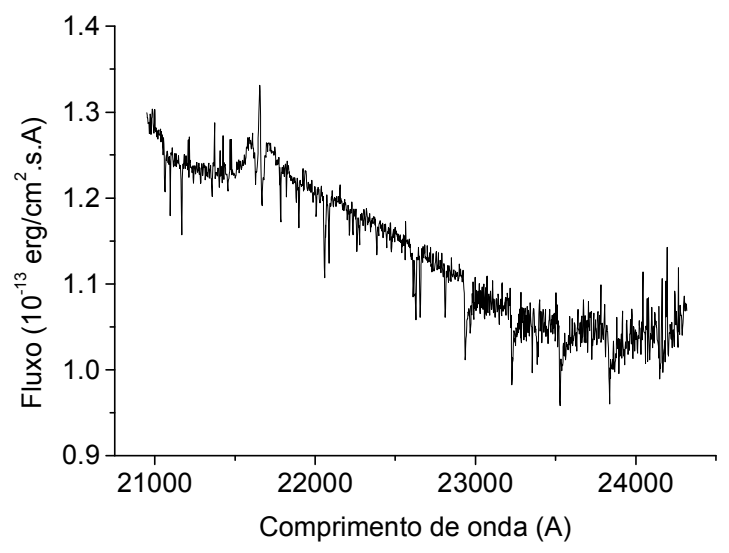

Figura 3.10 - Espectro extraído de uma região espacial (circular) centrada no objeto do cubo de dados de GQ Lup, após a redução dos dados.

A imagem com a LUT exagerada da figura 3.9 revela uma grande quantidade de ruídos de alta freqüência espacial e bad pixeis. Além disso, também sem pode notar a presença de várias "texturas" ao longo da imagem. Assim como foi mencionado no caso do IFU do GMOS, os 
procedimentos de tratamento de dados descritos nas próximas sessões podem remover boa parte dessas estruturas visíveis nas imagens do cubo de dados após a redução.

\subsection{3 - Redução de dados do SINFONI}

O SINFONI é um espectrômetro de campo integrado no infravermelho próximo do VLT, que fornece observações no intervalo espectral de $10500 \AA$ até $24500 \AA$ (que inclui as bandas J, H e K). Esse instrumento, na verdade, consiste em uma combinação do módulo de Óptica Adaptavia (Adaptive Optics Module - AO-Module), desenvolvido pelo ESO, e do espectrômetro SPIFFI (SPectrometer for Infrared Faint Field Imaging), desenvolvido pela MPE. O SINFONI possui três fore-optics diferentes, que proporcionam campos de visão de 8" x 8", 3.2" x 3.2" e 0.8 " x 0.8 ", o que equivale a pixeis espaciais com dimensões de 0.250 ” x 0.125 ”, 0.10 ” x 0.05 ” e $0.0250 "$ x 0.0125 ”, respectivamente. A óptica adaptativa aplicada com o fore-optics com campo de $0.8 "$ x $0.8 "$ (e pixeis espaciais de $0.025 "$ x 0.0125 "de lado) permite que sejam obtidas resoluções espaciais de até $0.056 "$ em um comprimento de onda $22000 \AA$. O detector do SINFONI é composto por apenas um CCD com 2048 x 2048 pixeis.

A luz incidente no campo de visão do SINFONI passa, primeiramente, pelo chamado $s k y$ spider, que possui três pares de espelhos motorizados que refletem a luz de um campo de céu (que pode estar a 15", 30" ou 45" do campo de ciência) para o image slicer. Esse artefato permite que sejam feitas observações de céu simultaneamente com as de ciência, sem a necessidade de deslocar o telescópio. Após isso, a luz passa para a região da pré-óptica, que possui três sub-áreas principais. Na primeira delas, ocorre a supressão da emissão térmica de fundo. A segunda subárea é uma roda de filtros motorizada, que seleciona um dos quatro filtros de banda larga disponíveis para serem utilizados, que representam as bandas $\mathrm{J}, \mathrm{H}, \mathrm{K}$ e $\mathrm{H}+\mathrm{K}$. O filtro $\mathrm{H}+\mathrm{K}$ proporciona uma maior extensão espectral (já que corresponde às bandas $\mathrm{H}$ e K juntas) às custas de uma menor resolução espectral. Por fim, a terceira sub-área é a roda de ópticas (optics wheel) motorizada, que seleciona uma das três lentes correspondentes aos fore-optics disponíveis (campos de 8 " x 8", 3.2" x 3.2" e $0.8 ”$ x $0.8 ”$ ). Após passar pela região da pré-óptica, a luz é encaminhada para o image-slicer, onde incide, inicialmente, em um grupo de 32 pequenos espelhos (o chamado small slicer), que dividem a luz incidente em várias partes (chamadas de slitlets). Em seguida, a luz (já dividida) atinge um segundo grupo de grandes espelhos (o 
chamado big slicer), que reconfigura todos os slitlets de modo que fiquem dispostos em um formato similar ao de uma fenda. Após isso, a luz atinge o colimador, que a direciona para a região contendo as redes difração, onde os espectros são gerados. Por fim, a luz chega ao detector do instrumento. A figura 3.11 mostra um esquema com os principais componentes do SINFONI.

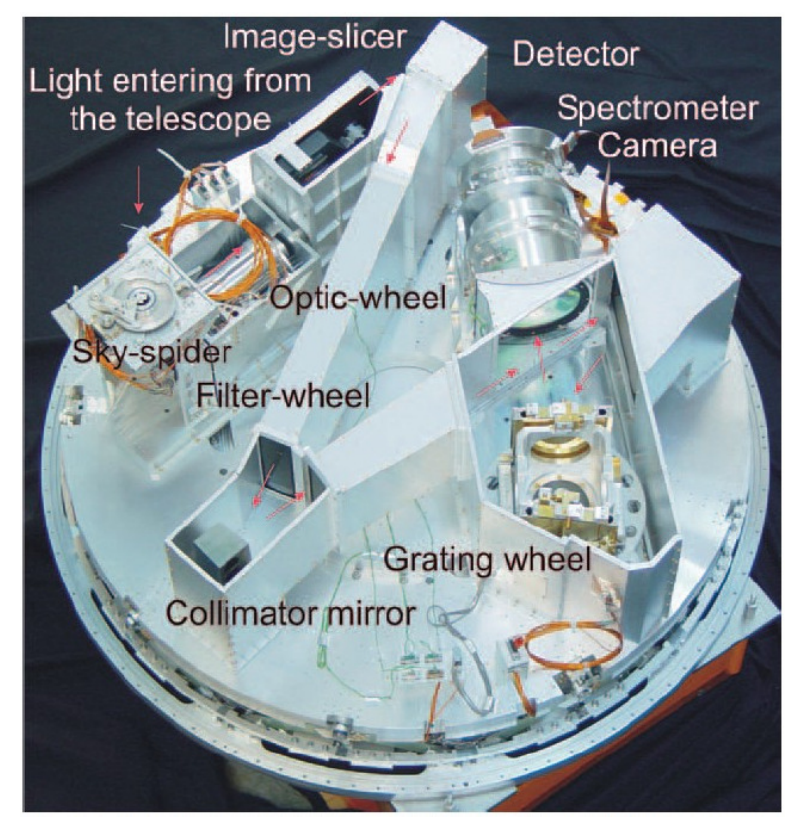

Figura 3.11 - Esquema com os principais componentes do SINFONI do VLT.

O esquema da figura 3.12 mostra o funcionamento básico do image slicer do SINFONI. O mecanismo é inteiramente análogo no caso do NIFS. 


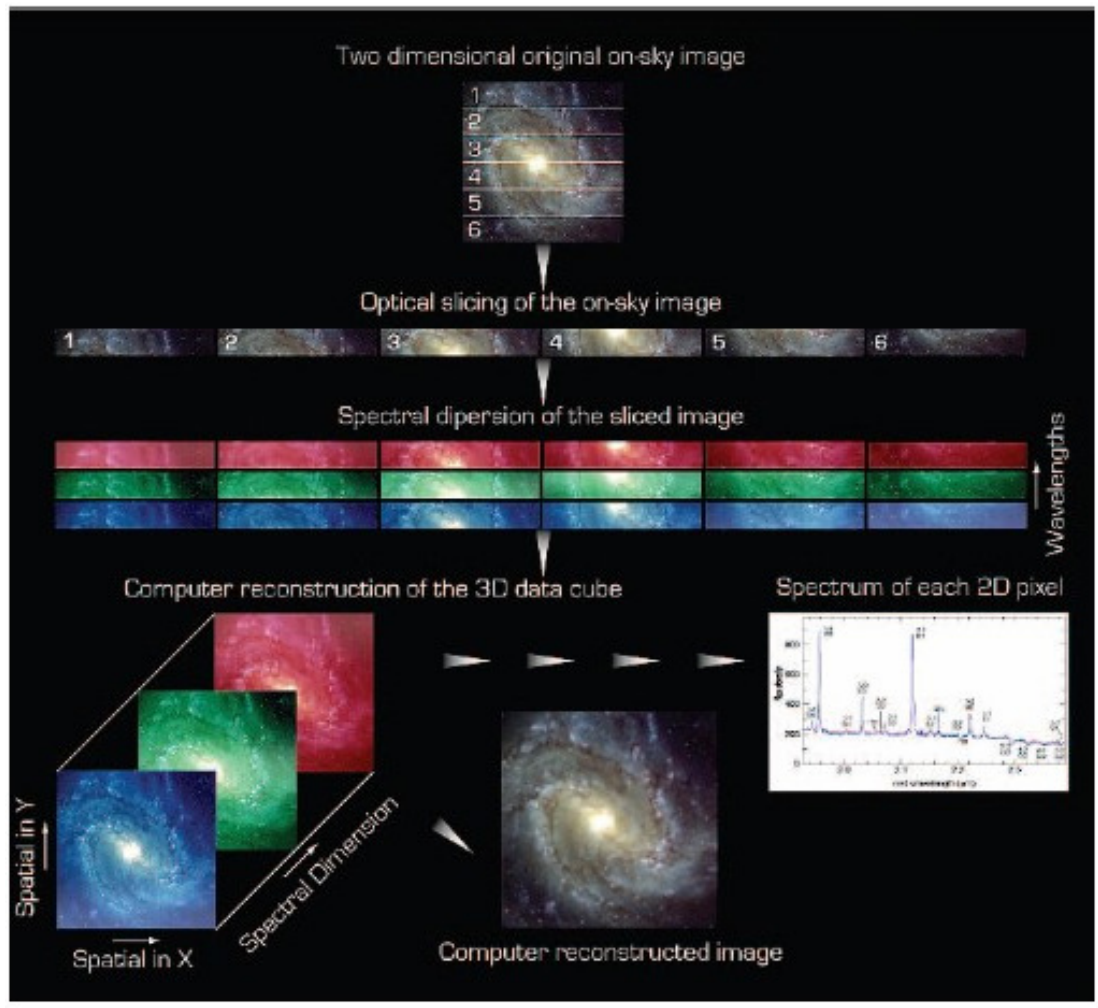

Figura 3.12 - Esquema mostrando o funcionamento básico do "image slicer" do SINFONI. O mesmo princípio é válido no caso do NIFS.

A figura 3.13 mostra os dados brutos da observação da estrela HIP 49220, na banda K, como o SINFONI.

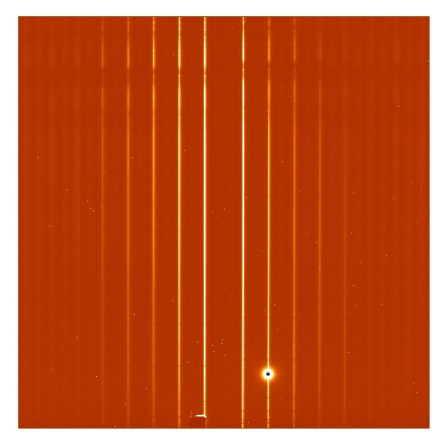

Figura 3.13 - Dados brutos da observação da estrela HIP 49220, na banda K, com o SINFONI.

Observando-se a figura 3.13, pode-se notar que os espectros brutos (bidimensionais) obtidos com o SINFONI são dispostos em colunas adjacentes e não em linhas, como ocorre com os dados do IFU do GMOS e do NIFS.

A redução dos dados do SINFONI foi feita utilizando-se o software Gasgano, desenvolvido pela própria equipe do SINFONI e envolveu as seguintes etapas: determinação do trim, subtração do céu, correção de bad pixeis, correção de flat-field, retificação espacial, 
calibração em comprimento de onda, correção de distorções espaciais e montagem do cubo de dados. Inicialmente, utilizou-se a tarefa sinfo_rec_detlin nas calibrações necessárias (obtidas juntamente com as observações dos dados de ciência) para se construir um mapa dos pixeis de resposta não linear. Para se obter um mapeamento das distorções espaciais, assim como as posições espaciais relativas dos espectros (informação que é essencial para a construção do cubo de dados), foi aplicada a rotina sinfo_rec_distortion nas calibrações apropriadas. Em seguida, para se construir um mapa final de bad pixeis e uma imagem de flat-field, aplicou-se a tarefa sinfo_rec_mflat utilizando-se o mapa de pixeis não lineares (obtido anteriormente) e as calibrações (imagens de flat-field) adequadas. Após isso, para se obter uma calibração em comprimento de onda, aplicou-se a rotina sinfo_rec_wavecal, utilizando-se a imagem de flatfield, o mapa de bad pixeis, o mapa de distorção espacial (todos obtidos anteriormente) e as calibrações (imagens de lâmpada) necessárias. Ou seja, para se chegar a uma calibração em comprimento de onda com a tarefa sinfo_rec_wavecal, são feitas correções de flat-field e de bad pixeis antes da calibração em comprimento de onda poder ser obtida. Essa tarefa também fornece uma tabela com as posições relativas dos espectros (que serão necessárias para a construção do cubo de dados), e é por isso que, para a sua execução, é necessário o fornecimento do mapa de distorção espacial (obtido anteriormente). Finalmente, a redução dos dados de ciência foi feita utilizando-se a rotina sinfo_rec_jitter. Os procedimentos executados por essa tarefa incluíram: subtração do céu (a partir de uma imagem de céu observada), correção de bad pixeis (a partir do mapa de bad pixeis construído previamente), correção de flat-field (a partir da imagem de flatfield obtida anteriormente), calibração em comprimento de onda (utilizando-se a calibração também já determinada) e a montagem do cubo de dados (levando-se em conta o mapa de distorção e a tabela com as posições relativas dos espectros, obtidos anteriormente). Nesse trabalho, cubos de dados resultantes de observações com campos de visão de 8" x 8", 3.2" x 3.2" e 0.8 " x 0.8 " foram construídos (com a rotina sinfo_rec_jitter) com pixeis espaciais de 0.125 ", 0.05 " e 0.0125 " de lado, respectivamente.

Ao contrário do procedimento de redução de dados do NIFS, o processo de redução no caso do SINFONI, executado com o software Gasgano, não realiza a calibração em fluxo e nem a remoção das absorções telúricas. Entretanto, como uma estrela padrão é, em geral, observada junto com os dados de ciência, escreveu-se um algoritmo em linguagem IRAF, que utiliza tarefas básicas desse software, para se aplicar esses procedimentos nos cubos de dados do SINFONI. As 
figuras 3.14 e 3.15 mostram, respectivamente, a imagem de um intervalo espectral intermediário colapsado e o espectro extraído de uma região espacial (circular) centrada no objeto do cubo de dados de HIP 49220, após a redução dos dados.
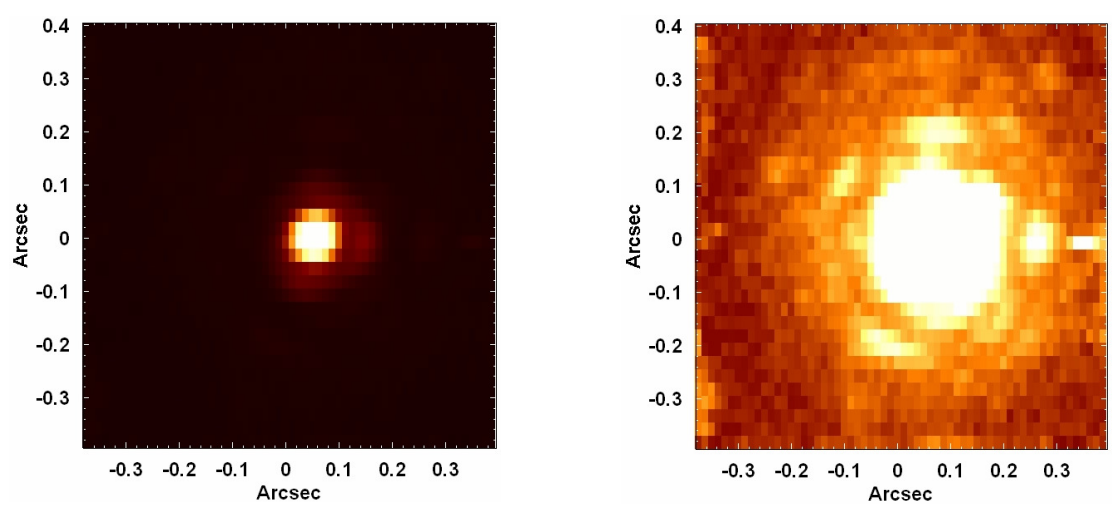

Figura 3.14 - (esquerda) Imagem de um intervalo espectral intermediário colapsado do cubo de dados de HIP 49220, após a redução dos dados; (direita) Mesma imagem que à esquerda, mas com a LUT exagerada.

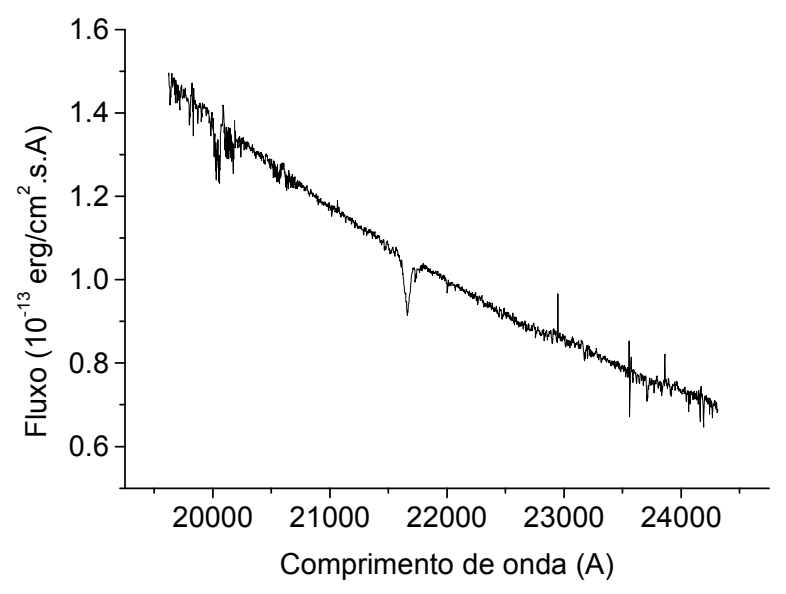

Figura 3.15 - Espectro extraído de uma região espacial (circular) centrada no objeto do cubo de dados de HIP 49220, após a redução dos dados.

A imagem com a LUT exagerada da figura 3.14 revela a presença de uma grande quantidade de ruídos de alta freqüência espacial, bad pixeis e também "texturas", o que é bastante similar ao observado no caso de cubos de dados obtidos com o NIFS. Além disso, no espectro da figura 3.15, pode-se notar alguns prováveis raios cósmicos ao longo da extensão espectral dos dados. Novamente, boa parte desses efeitos e estruturas indesejáveis pode ser removida com os procedimentos descritos nas seções a seguir. 


\section{3 - Refração atmosférica diferencial}

É sabido que a luz emitida por qualquer objeto celeste sofre o efeito da refração ao penetrar na atmosfera da Terra e, consequentemente, tem a sua direção de propagação original alterada. Esse efeito (que depende do comprimento de onda da luz) pode afetar significativamente as observações astronômicas realizadas a partir da superfície terrestre.

A refração atmosférica faz com que a distância zenital z na qual a luz de um determinado objeto celeste incide na parte superior da atmosfera terrestre seja diferente da distância zenital observada desse objeto. $\mathrm{O}$ ângulo $R=z-\zeta$ é chamado de ângulo de refração e pode ser dado, em segundos de arco, pela seguinte expressão (que está demonstrada detalhadamente no Apêndice C):

$$
R=206265 \cdot\left(\mu_{0}-1\right) \cdot \tan \zeta
$$

$$
\begin{gathered}
\text { onde } \mu_{0}=\text { índice de refração próximo à } \\
\text { superfície da Terra }
\end{gathered}
$$

$\mathrm{O}$ índice de refração $\mu_{0}$ possui uma dependência para com o comprimento de onda (Apêndice C), assim, a variação sofrida pelo ângulo de refração quando o comprimento de onda varia de $\lambda_{1}$ e $\lambda_{2}$ (mantendo-se $\zeta$ constante) pode ser dada por

$$
\begin{gathered}
\Delta R=R\left(\lambda_{2}\right)-R\left(\lambda_{1}\right) \\
\Delta R=206265 \cdot\left[\mu_{0}\left(\lambda_{2}\right)-\mu_{0}\left(\lambda_{1}\right)\right] \tan \zeta .
\end{gathered}
$$

A equação (3.2) mostra que os dois parâmetros que influenciam mais diretamente o fenômeno da refração atmosférica são a distância zenital e o comprimento de onda.

Em geral, durante a observação de um determinado objeto celeste, pode-se assumir que a distância zenital e outros parâmetros como temperatura e pressão são, aproximadamente, constantes (desde que o tempo de exposição não seja muito longo). Entretanto, o comprimento de onda é um parâmetro variável em um cubo de dados, já que a imagem do objeto pode ser vista 
em diferentes regiões espectrais. Devido à dependência de $\Delta R$ para com o comprimento de onda, pode-se concluir, portanto, que o ângulo de refração atmosférica varia ao longo de um cubo de dados, dando origem à chamada refração atmosférica diferencial. Esse efeito faz com que a posição de um determinado objeto em um cubo de dados mude conforme se observam imagens dele em diferentes comprimentos de onda. Em outras palavras, pode-se dizer que a refração atmosférica diferencial faz com que a posição de um objeto no cubo de dados varie ao longo do eixo espectral.

A refração atmosférica diferencial é significativamente maior no óptico do que no infravermelho. Entretanto, conforme está mostrado no apêndice C, outros parâmetros (distância zenital do objeto, temperatura, pressão atmosférica e pressão do vapor de água), além do comprimento de onda, possuem uma influência considerável nesse efeito. Assim, a refração atmosférica diferencial também tende a ser maior, por exemplo, em objetos com maior distância zenital.

Após o processo de redução, a etapa seguinte no tratamento dos cubos de dados analisados nesse trabalho foi a remoção do efeito da refração atmosférica diferencial. Para se aplicar esse procedimento, utilizou-se um algoritmo desenvolvido pelo professor João E. Steiner (apêndice D). A partir desse algoritmo, foi implementado um programa, a ser utilizado com o software IDL, para efetuar a correção em todos os cubos de dados. O procedimento de correção foi feito da seguinte maneira: primeiramente, foram determinados intervalos apropriados no espectro do objeto nos quais não houvesse nenhuma linha espectral proeminente. Em seguida, as imagens nesses intervalos foram somadas, obtendo-se, ao final, um total de cerca de 20 ou 25 imagens. Foram determinadas, então, as coordenadas $x$ e $y$ do centróide do objeto em cada uma dessas imagens (utilizando-se a tarefa imexamine do software IRAF) e traçaram-se gráficos das coordenadas $x$ e $y$ do centróide em função do comprimento de onda (é importante lembrar que, como cada imagem resultou da soma de várias outras em cada um dos intervalos espectrais utilizados, os gráficos construídos associaram as coordenadas $x$ e $y$ dos centróides aos comprimentos de onda médios correspondentes a cada imagem). Em seguida, para cada um dos gráficos construídos, foi ajustada uma função de terceiro grau. Inserindo-se, então, os parâmetros dos ajustes dos gráficos no programa implementado para ser utilizado com o software IDL, foi possível fazer-se a correção da refração atmosférica diferencial nos cubos de dados. As sessões 
seguintes mostram detalhes da aplicação desse procedimento em cubos de dados obtidos com o IFU do GMOS, com o NIFS e com o SINFONI.

\subsection{1 - Correção da refração atmosférica diferencial em cubos de dados do GMOS}

Como os cubos de dados do IFU do GMOS cobrem a região espectral do óptico, o efeito da refração atmosférica diferencial tende a ser consideravelmente maior do que nos cubos do NIFS ou do SINFONI (que cobrem a região espectral do infravermelho próximo). A figura 3.16 mostra os gráficos com as coordenadas dos centróides do cubo de dados de ltt 4816 em função do comprimento de onda, antes da correção da refração atmosférica diferencial. Nos mesmos gráficos, são mostradas as funções de terceiro grau ajustadas aos pontos.
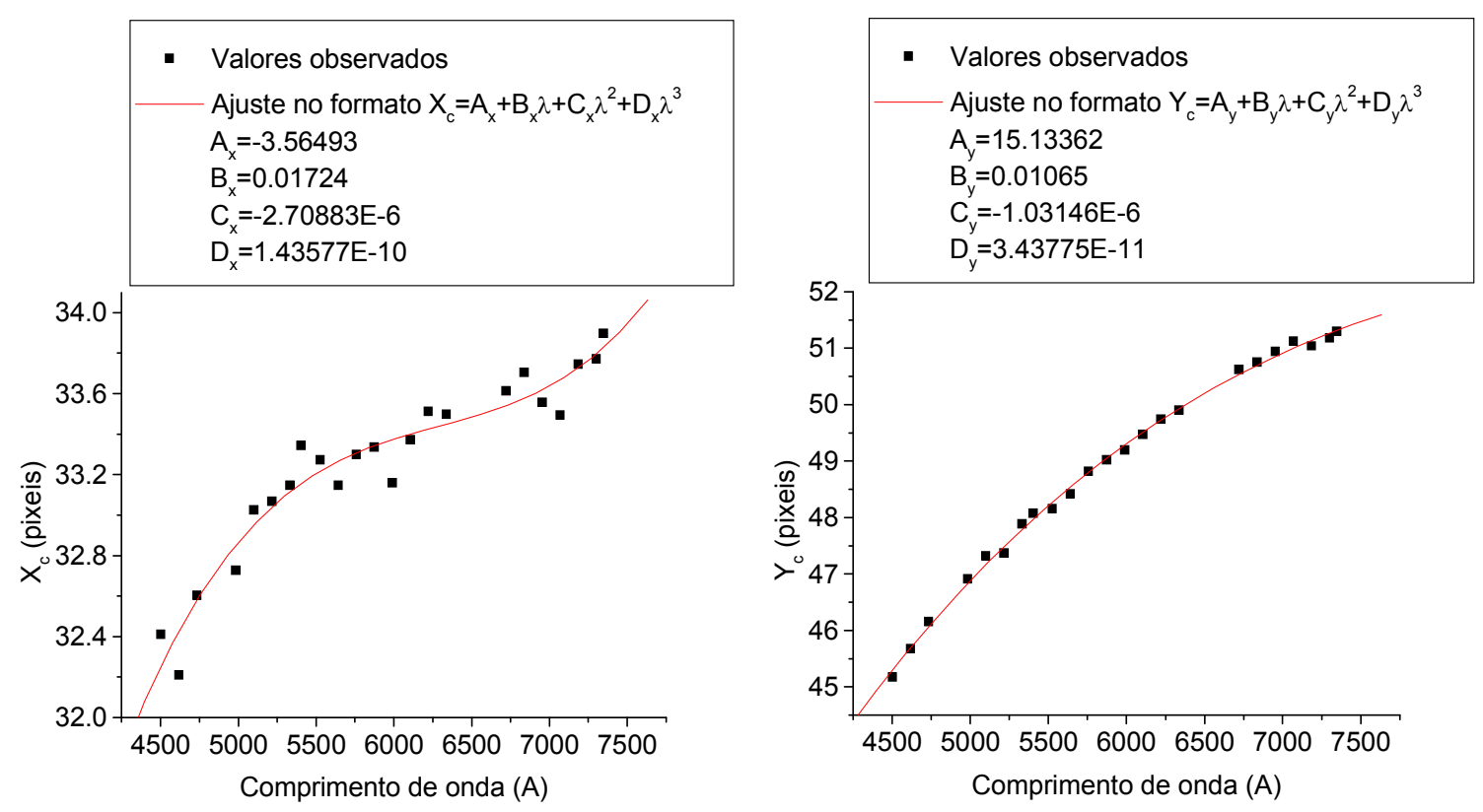

Figura 3.16 - Gráficos com as coordenadas $X_{c}$ e $Y_{c}$ dos centróides do cubo de dados de ltt 4816 em função do comprimento de onda, antes da correção da refração atmosférica diferencial. Nos gráficos também são mostradas as funções de terceiro grau ajustadas aos pontos.

A figura 3.17 mostra uma composição RGB com imagens do cubo de dados de ltt 4816 obtidas a partir da região de menores comprimentos de onda (azul), de comprimentos de onda intermediários (verde) e de maiores comprimentos de onda (vermelho). 


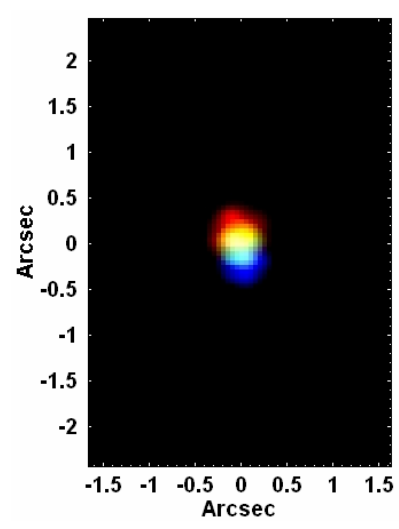

Figura 3.17 - Composição RGB com imagens do cubo de dados de ltt 4816 na região espectral de menores comprimentos de onda (azul), de comprimentos de onda intermediários (verde) e de maiores comprimentos de onda (vermelho), antes da correção da refração atmosférica diferencial.

Observando-se as figuras 3.16 e 3.17, pode-se notar que a refração atmosférica diferencial afeta consideravelmente o cubo de dados de ltt 4816, sendo que o deslocamento da imagem da estrela ao longo do eixo $y$ chega a cerca de 7 pixeis espaciais. Sem dúvida, muitas análises a serem feitas nesse cubo de dados poderiam ser seriamente prejudicadas se esse efeito não fosse removido. É importante mencionar, entretanto, que a refração atmosférica em cubos de dados do IFU do GMOS pode ser ainda mais intensa, dependendo da distância zenital apresentada pelo objeto observado. A figura 3.18 mostra uma composição RGB análoga à da figura 3.17, mas feita com imagens do cubo de dados da estrela Cal 83 (que não é tratado em detalhes aqui). Esse objeto, assim como ltt 4816, foi observado com o IFU do GMOS-S, mas apresentava uma maior distância zenital no dia de sua observação.

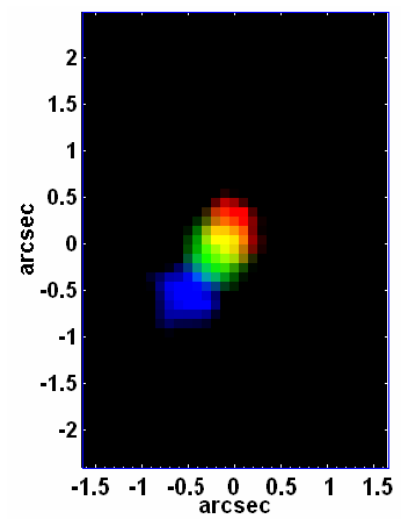

Figura 3.18 - Composição RGB com imagens do cubo de dados da estrela Cal 83 na região espectral de menores comprimentos de onda (azul), de comprimentos de onda intermediários (verde) e de maiores comprimentos de onda (vermelho), antes da correção da refração atmosférica diferencial. 
A figura 3.18 deixa claro que o efeito da refração atmosférica diferencial no cubo de dados de Cal 83 é significativamente mais intenso do que no caso de ltt 4816, podendo, portanto, afetar consideravelmente qualquer análise a ser aplicada, caso não seja removido.

A figura 3.19 mostra os gráficos com as coordenadas dos centróides do cubo de dados de ltt 4816 em função do comprimento de onda, após a correção da refração atmosférica diferencial.
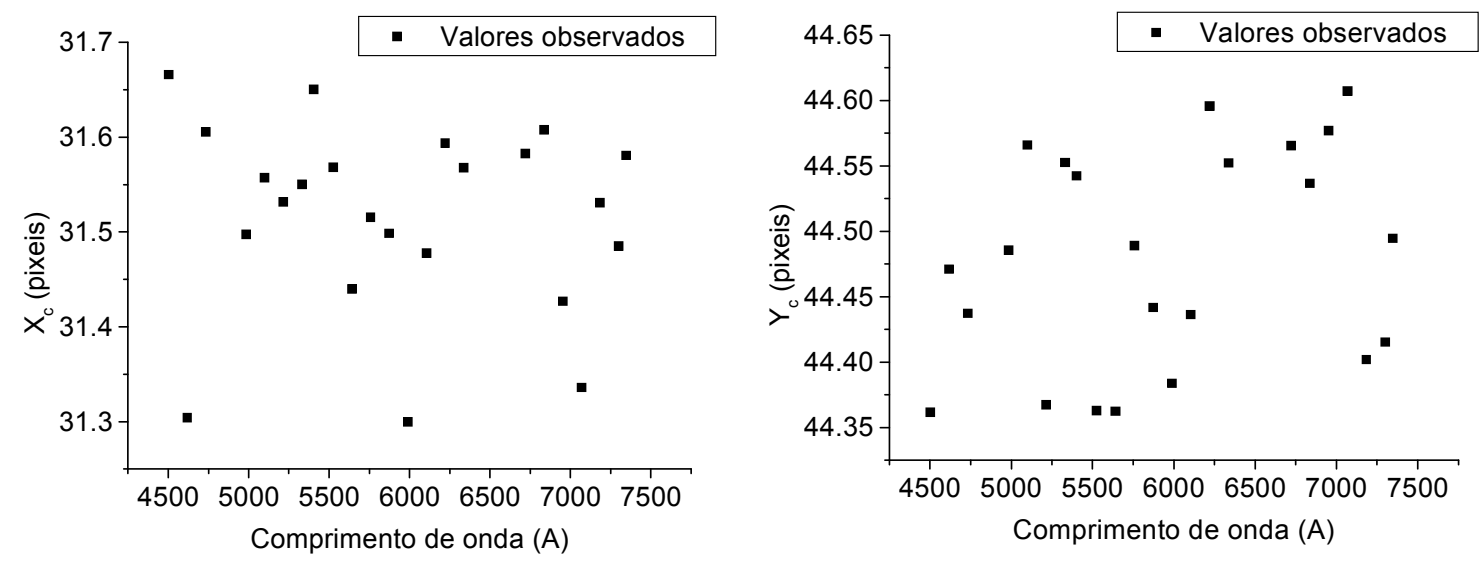

Figura 3.19 - Gráficos com as coordenadas $X_{c}$ e $Y_{c}$ dos centróides do cubo de dados de ltt 4816 em função do comprimento de onda, após a correção da refração atmosférica diferencial.

A figura 3.20 mostra uma composição RGB com imagens em diferentes comprimentos de onda do cubo de dados de ltt 4816, após a correção da refração atmosférica diferencial.

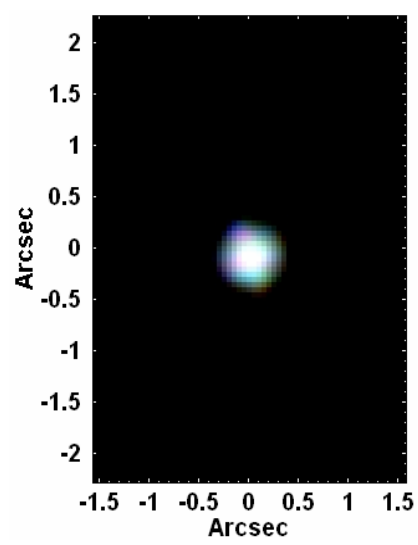

Figura 3.20 - Composição RGB com imagens do cubo de dados de ltt 4816 na região espectral de menores comprimentos de onda (azul), de comprimentos de onda intermediários (verde) e de maiores comprimentos de onda (vermelho), após a correção da refração atmosférica diferencial.

Observando-se as figuras 3.19 e 3.20 , pode-se notar que o procedimento aplicado removeu consideravelmente bem o efeito da refração atmosférica diferencial. Os valores esperados para $X_{c}$ e $Y_{c}$, após a correção, eram de 31.5 e 44.5, respectivamente. Os gráficos da 
figura 3.19 mostram que as medições de $X_{c}$ e $Y_{c}$ do cubo corrigido ficaram estáveis nos valores esperados com precisões $(1-\sigma)$ de cerca de 0.1 pixeis. Toda essa precisão fica bem ilustrada com o RGB da figura 3.20. Esse método foi testado em vários outros cubos de dados e sempre foram obtidas precisões entre 0.1 e 0.3 pixeis para as coordenadas finais dos centróides das estruturas. $\mathrm{O}$ procedimento aqui descrito funciona igualmente bem com cubos de dados nos quais o efeito da refração atmosférica diferencial é mais intenso. Isso fica claro com a figura 3.21, que mostra uma RGB com imagens em diferentes comprimentos de onda do cubo de dados de Cal 83, após a correção desse efeito.

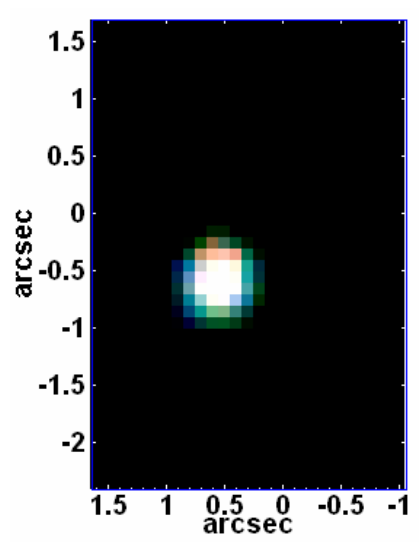

Figura 3.21 - Composição RGB com imagens do cubo de dados de Cal 83 na região espectral de menores comprimentos de onda (azul), de comprimentos de onda intermediários (verde) e de maiores comprimentos de onda (vermelho), após a correção da refração atmosférica diferencial.

Comparando-se as figuras 3.18 e 3.21, nota-se que a correção da refração atmosférica diferencial no cubo de dados de Cal 83 também foi altamente eficaz.

Como a classe de objetos tratada nesse trabalho tende a apresentar núcleos puntiformes brilhantes, a determinação de seus centróides não costuma ser um problema. Entretanto, em casos em que essa determinação não é possível, pode-se utilizar as equações de refração atmosférica mostradas anteriormente para prever o deslocamento dos centróides ao longo do eixo espectral do cubo de dados. A partir disso, pode-se, então, fazer a correção desse efeito com o programa escrito em linguagem IDL mencionado anteriormente.

A vantagem de se fazer um mapeamento manual das coordenadas dos centróides (desde que esse mapeamento seja confiável) é que, com esse procedimento, pode-se detectar não apenas o efeito da refração atmosférica diferencial, mas também outros efeitos instrumentais que, eventualmente, podem provocar algum deslocamento das estruturas ao longo do eixo espectral do cubo de dados. Isso não pode ser feito quando o deslocamento dos centróides é previsto 
utilizando-se as equações de refração atmosférica. No caso do GMOS, entretanto, esse tipo de efeito instrumental só foi detectado em comprimentos de onda elevados, geralmente próximos a $9000 \AA$.

\subsection{2 - Correção da refração atmosférica diferencial em cubos de dados do NIFS}

O procedimento utilizado para remover o efeito da refração atmosférica diferencial em cubos de dados obtidos com o NIFS foi exatamente o mesmo que o aplicado nos cubos do IFU do GMOS. Entretanto, como o NIFS cobre a região espectral do infravermelho próximo, esse efeito tende a ser bem menor. A figura 3.22 mostra os gráficos com as coordenadas dos centróides do cubo de dados de GQ Lup em função do comprimento de onda, antes da correção da refração atmosférica diferencial. Nos mesmos gráficos, são mostradas as funções de terceiro grau ajustadas aos pontos.
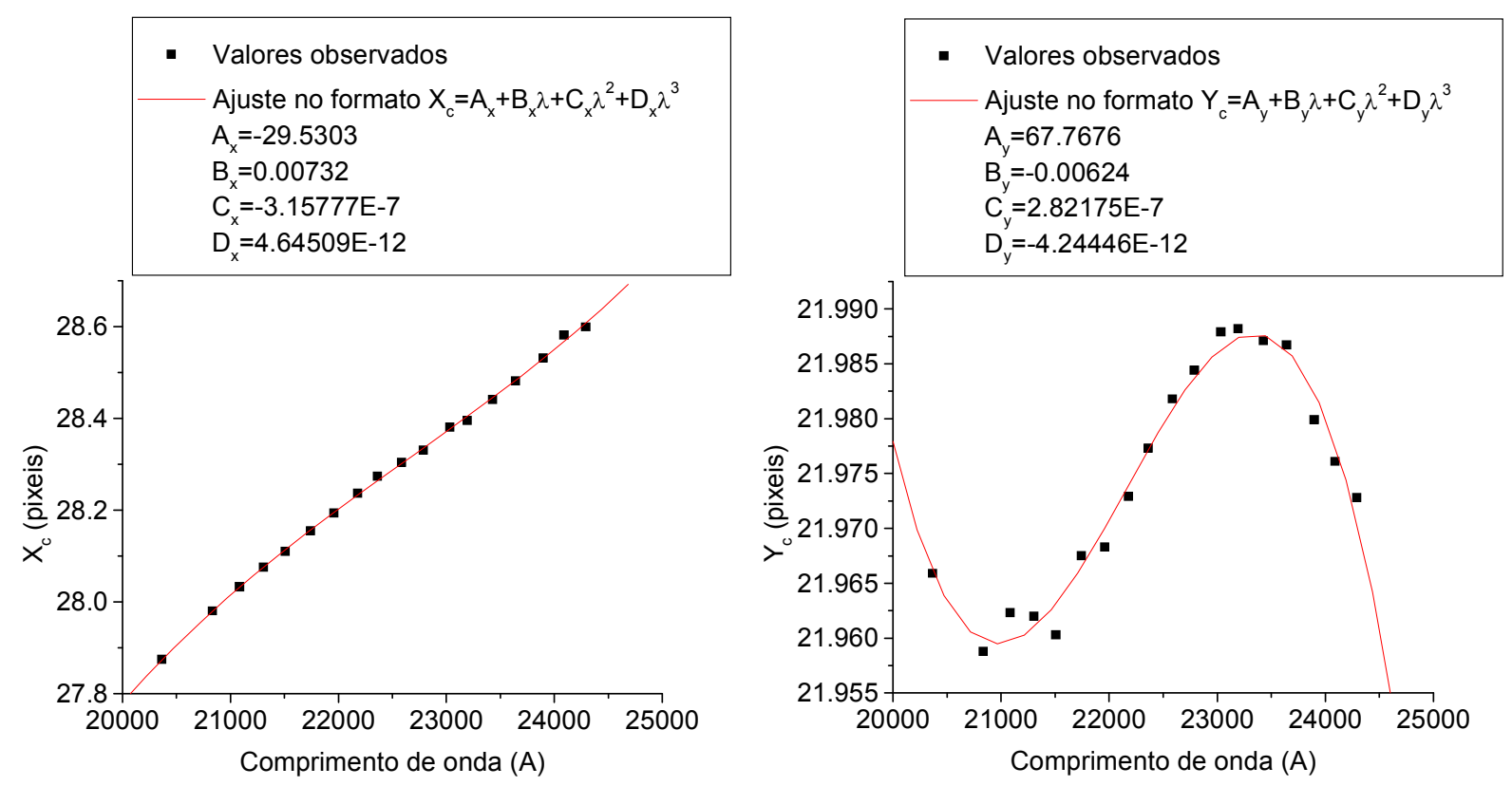

Figura 3.22 - Gráficos com as coordenadas $X_{c}$ e $Y_{c}$ dos centróides do cubo de dados de GQ Lup em função do comprimento de onda, antes da correção da refração atmosférica diferencial. Nos gráficos também são mostradas as funções de terceiro grau ajustadas aos pontos.

Ao se observar os gráficos da figura 3.22, a primeira coisa que pode ser notada é que o deslocamento máximo sofrido pelo centróide da imagem é de cerca de 0.7 pixeis ao longo do 
eixo $x$ e 0.03 pixeis ao longo do eixo $y$. Isso mostra o quanto o efeito da refração atmosférica diferencial é menor nos dados do NIFS do que naqueles obtidos com o IFU do GMOS. Entretanto, uma outra característica importante que pode ser observada na figura 3.22 é que os valores da coordenada $Y_{c}$ crescem com o comprimento de onda em certas regiões espectrais e decrescem em outras, ou seja, a função de terceiro grau ajustada a esses pontos muda de sinal ao longo da extensão espectral. Isso não é o que se esperaria se somente a refração atmosférica diferencial estivesse presente, pois, nesse caso, os valores das coordenadas dos centróides apresentariam um comportamento apenas crescente ou decrescente com o comprimento de onda, sem variações ao longo da extensão espectral. Assim, pode-se concluir que, no caso de dados do NIFS, deve haver algum tipo de "efeito instrumental", além da refração atmosférica diferencial, que provoca esse deslocamento dos centróides das estruturas com o comprimento de onda. Devido à presença desse suposto "efeito instrumental", as coordenadas dos centróides ao longo da extensão espectral do cubo de dados devem ser determinadas diretamente a partir das imagens (por meio da tarefa imexamine, por exemplo) e não por meio das equações teóricas da refração atmosférica.

O procedimento de correção da refração atmosférica diferencial foi aplicado no cubo de dados de GQ Lup. Entretanto, como a variação máxima observada de $Y_{c}$ com o comprimento de onda foi de cerca de 0.03 pixeis e, em geral, não são obtidas precisões superiores a 0.1 pixeis para as coordenadas finais dos centróides das estruturas, não era esperada a obtenção de melhorias significativas no que se refere ao comportamento dessa coordenada em função do comprimento de onda. Os gráficos com as coordenadas dos centróides obtidas após a correção estão mostrados na figura 3.23 . 

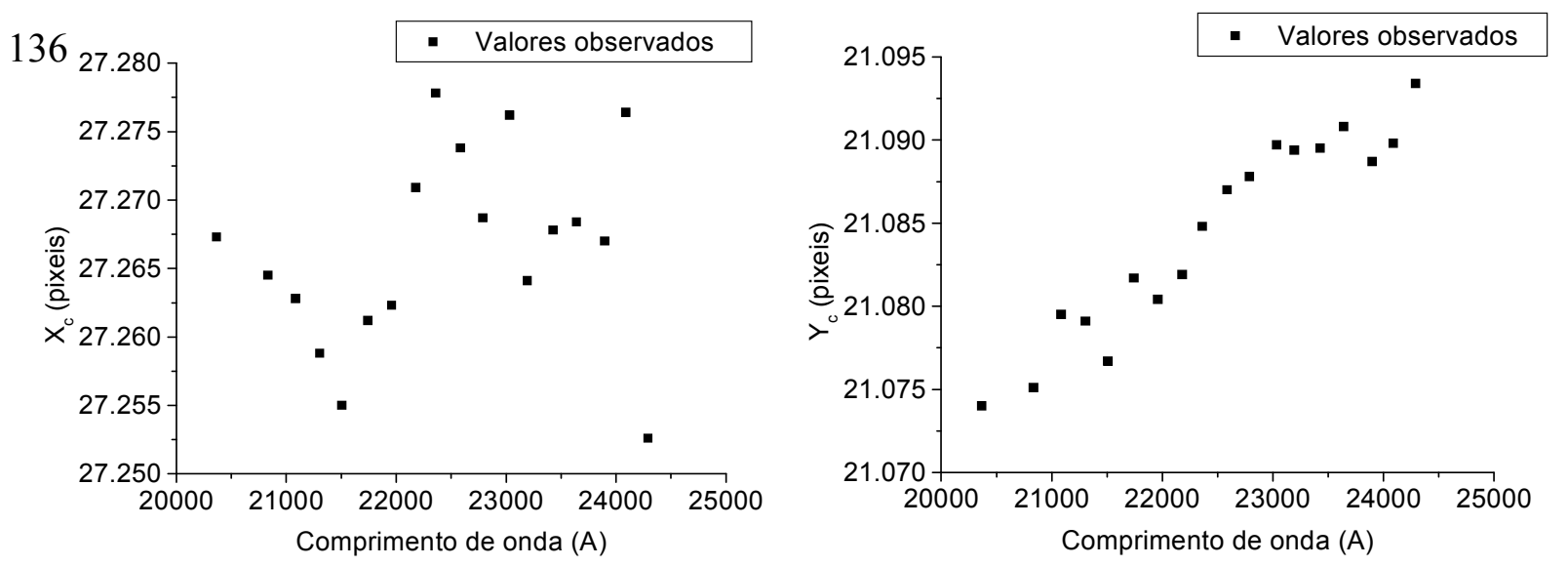

Figura 3.23 - Gráficos com as coordenadas $X_{c}$ e $Y_{c}$ dos centróides do cubo de dados de GQ Lup em função do comprimento de onda, após a correção da refração atmosférica diferencial.

Observando-se a figura 3.23, pode-se notar que a aplicação do procedimento no cubo de dados de GQ Lup foi eficaz na remoção do efeito detectado nas coordenadas $X_{c}$ dos centróides. Por outro lado, no caso das coordenadas $Y_{c}$, nota-se que houve uma mudança no padrão detectado, entretanto, ainda se percebe uma certa tendência de crescimento dos valores com o comprimento de onda. De qualquer forma, como a variação máxima detectada para $Y_{c}$ foi de cerca de 0.02 pixeis, é pouco provável que essa tendência remanescente possa causar qualquer problema durante a análise dos dados. Os valores esperados, após a correção, para $X_{c}$ e $Y_{c}$ eram de 27.2 e 21.0, respectivamente, assim, pode-se concluir que a precisão $(1-\sigma)$ obtida, nesse caso, foi próxima a 0.1 pixeis.

\subsection{3 - Correção da refração atmosférica diferencial em cubos de dados do SINFONI}

O SINFONI, assim como o NIFS, cobre a região espectral do infravermelho próximo, logo, a refração atmosférica diferencial detectada tende a ser pequena. Mesmo assim, optou-se por aplicar a correção descrita anteriormente nos cubos de dados obtidos com esse instrumento, devido à possibilidade da existência de efeitos instrumentais (similares aos que foram detectados no caso do NIFS) que possam causar deslocamentos dos centróides das estruturas ao longo da extensão espectral. O procedimento de remoção da refração atmosférica diferencial de cubos de dados do SINFONI é exatamente igual ao descrito anteriormente, sem quaisquer diferenças significativas. A figura 3.24 mostra os gráficos com as coordenadas dos centróides do cubo de dados de HIP 49220 em função do comprimento de onda, antes da correção da refração 
atmosférica diferencial. Nos mesmos gráficos, são mostradas as funções de terceiro grau ajustadas aos pontos.
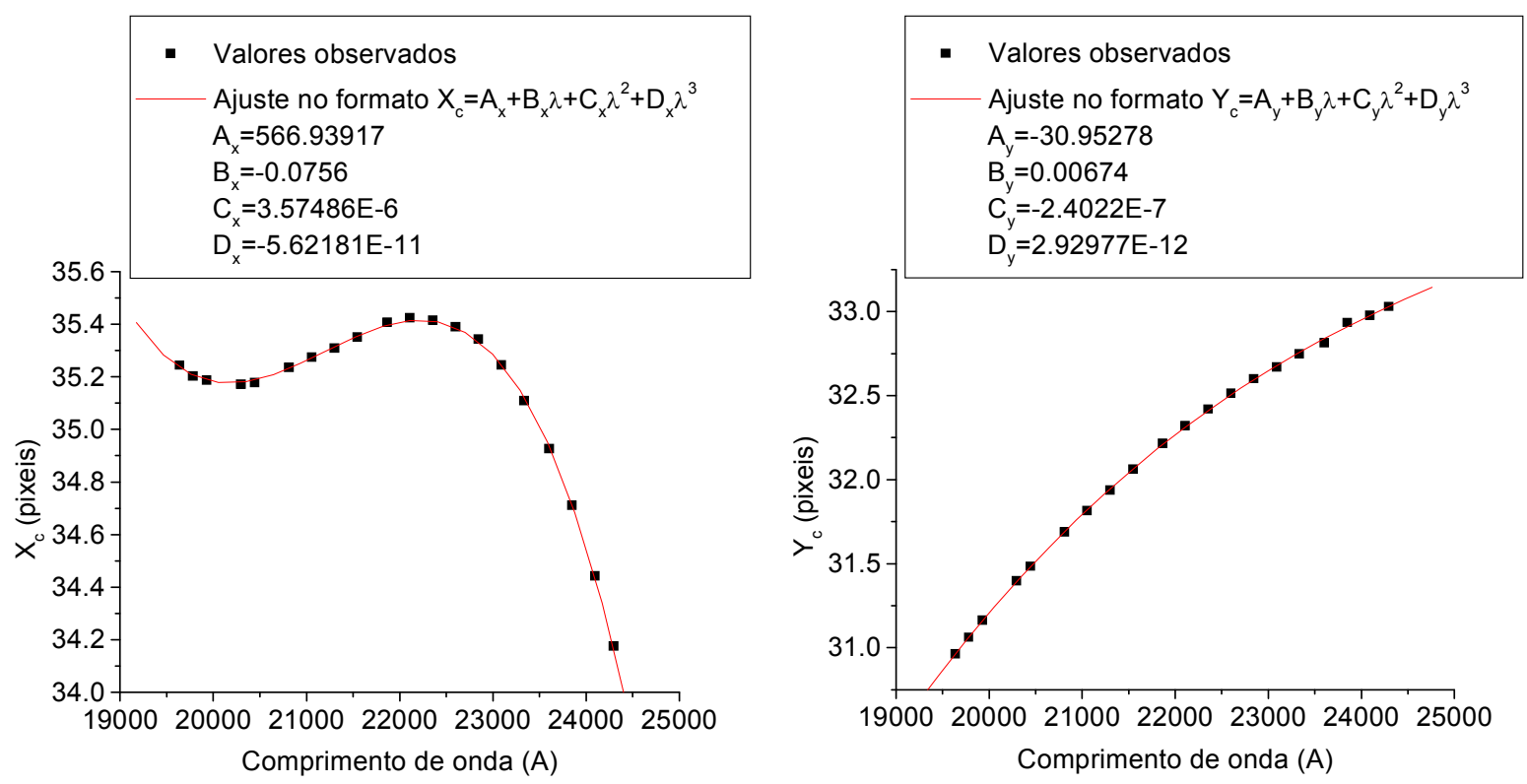

Figura 3.24 - Gráficos com as coordenadas $X_{c}$ e $Y_{c}$ dos centróides do cubo de dados de HIP 49220 em função do comprimento de onda, antes da correção da refração atmosférica diferencial. Nos gráficos também são mostradas as funções de terceiro grau ajustadas aos pontos.

A figura 3.25 mostra uma composição RGB com imagens em diferentes comprimentos de onda do cubo de dados de HIP 49220, antes da correção da refração atmosférica diferencial.

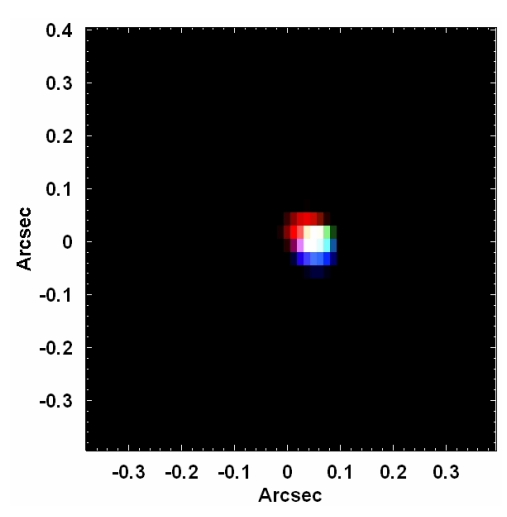

Figura 3.25 - Composição RGB com imagens do cubo de dados de HIP 49220 na região espectral de menores comprimentos de onda (azul), de comprimentos de onda intermediários (verde) e de maiores comprimentos de onda (vermelho), antes da correção da refração atmosférica diferencial. 
Observando-se as figuras 3.24 e 3.25 , pode-se notar que foram detectadas, ao longo da extensão espectral do cubo de dados de HIP 49220, variações consideráveis das coordenadas dos centróides, que chegaram a cerca de 1.2 pixeis ao longo do eixo $x$ e 2 pixeis ao longo do eixo $y$. Entretanto, como o tamanho de cada pixel espacial nessas imagens é de 0.0125 ", conclui-se que, em segundos de arco, o deslocamento máximo sofrido pelos centróides foi bastante pequeno. Isso está de acordo com o fato de a refração atmosférica diferencial prevista para a região do infravermelho próximo ser pequena. Por outro lado, a figura 3.24 também mostra que os valores da coordenada $X_{c}$ crescem com o comprimento de onda em certas regiões espectrais e decrescem em outras, ou seja, a função de terceiro grau ajustada a esses pontos muda de sinal ao longo da extensão espectral. Conforme já foi mencionado anteriormente, esse comportamento não é o que se esperaria se apenas a refração atmosférica diferencial estivesse presente, o que indica a presença de algum "efeito instrumental" que está causando, pelo menos em parte, o deslocamento observado dos centróides. Assim como no caso dos dados do NIFS, devido à presença desse aparente "efeito instrumental", as coordenadas dos centróides ao longo da extensão espectral do cubo de dados devem ser determinadas diretamente a partir das imagens e não por meio das equações teóricas da refração atmosférica. O procedimento de correção da refração atmosférica diferencial foi aplicado no cubo de dados de HIP 49220. Os gráficos com as coordenadas dos centróides obtidas após a correção estão mostrados na figura 3.26.
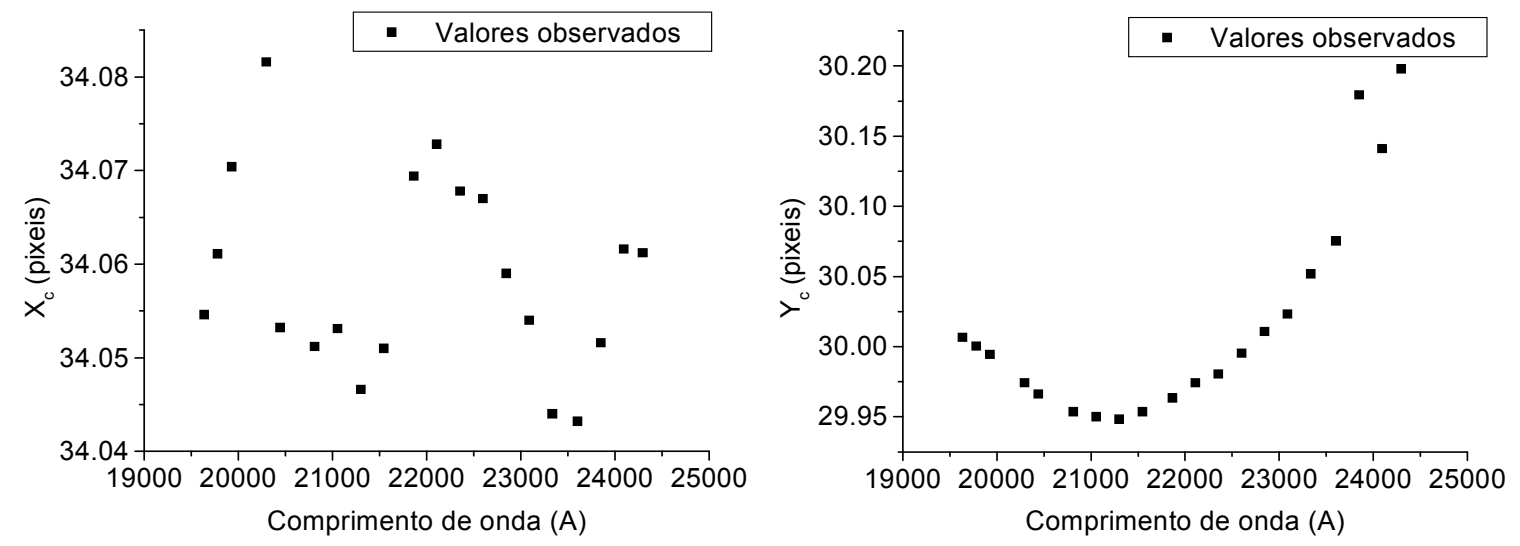

Figura 3.26 - Gráficos com as coordenadas $X_{c}$ e $Y_{c}$ dos centróides do cubo de dados de HIP 49220 em função do comprimento de onda, após a correção da refração atmosférica diferencial.

A figura 3.27 mostra uma composição RGB com imagens em diferentes comprimentos de onda do cubo de dados de HIP 49220, após da correção da refração atmosférica diferencial. 


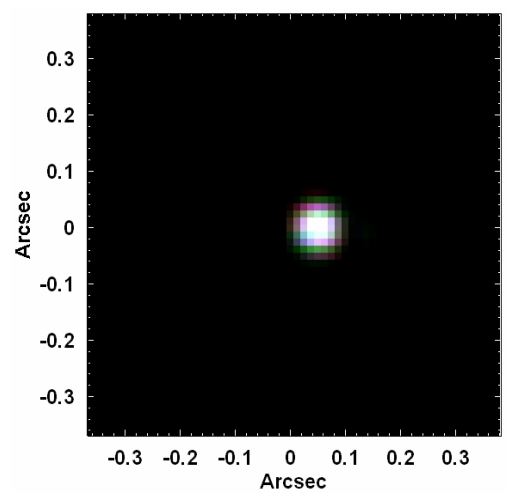

Figura 3.27 - Composição RGB com imagens do cubo de dados de HIP 49220 na região espectral de menores comprimentos de onda (azul), de comprimentos de onda intermediários (verde) e de maiores comprimentos de onda (vermelho), após a correção da refração atmosférica diferencial.

A figura 3.26 mostra que o procedimento aplicado no cubo de dados de HIP 49220 foi bastante eficaz na remoção do efeito detectado nas coordenadas $X_{c}$ dos centróides. No caso de $Y_{c}$, pode-se notar que houve uma mudança no comportamento dos valores em função do comprimento de onda, mas um certo padrão ainda é detectado. Mesmo assim, como a variação máxima detectada para essa coordenada foi de, apenas, 0.25 pixeis, é pouco provável que essa tendência remanescente possa causar qualquer problema durante a análise dos dados. Os valores esperados, após a correção, para $X_{c}$ e $Y_{c}$ eram de 34.0 e 30.0, respectivamente, assim, pode-se concluir que a precisão $(1-\sigma)$ obtida, nesse caso, também foi próxima a 0.1 pixeis.

Um detalhe que pode ser notado a partir do que foi exposto até aqui é que, apesar da eficácia das correções da refração atmosférica diferencial aplicadas nos cubos de dados de GQ Lup e HIP 49220, ambos os processos resultaram em um certo "comportamento" remanescente nos valores da coordenada $Y_{c}$ em função do comprimento de onda. Testes realizados em outros cubos de dados mostraram que isso parece ser uma tendência geral no caso de dados do NIFS ou do SINFONI. A causa disso ainda não está clara, mas, conforme foi mencionado anteriormente, é pouco provável que esse efeito cause qualquer prejuízo na análise dos dados, já que a amplitude máxima da variação de $Y_{c}$ causada por esse "comportamento" remanescente, em geral, não é superior a 0.3 pixeis.

Um ponto importante a ser mencionado é que, no caso de serem feitas várias exposições de um mesmo objeto, os cubos de dados resultantes somente podem ser combinados em um só (se esse for o objetivo) após a correção da refração atmosférica diferencial ser aplicada. A razão disso é que o deslocamento dos centróides das estruturas gerado por esse efeito pode sofrer 
variações entre as diferentes exposições, fazendo com que uma combinação dos cubos de dados envolvidos seja imprecisa. As reduções dos dados de ltt 4816 e de HIP 49220 resultaram, apenas, em um cubo de dados para cada objeto, já que não havia mais exposições disponíveis no banco de dados do Gemini. Entretanto, a redução de GQ Lup resultou em nove cubos de dados, que foram, após a correção da refração atmosférica diferencial, divididos em três grupos de três. Os integrantes de cada um desses grupos foram combinados em forma de mediana, resultando, portanto, em três cubos ao final desse processo. Por fim, calculou-se uma nova mediana para esses três últimos cubos, obtendo-se, assim, o cubo de dados combinado procurado.

\section{4 - Transformadas de Fourier}

Antes de prosseguir com a descrição das metodologias de tratamento e análise de cubos de dados, um conceito utilizado por vários desses procedimentos precisa ser discutido: a transformada de Fourier. Ela pode ser definida como uma operação matemática que passa uma determinada função para o domínio de frequências. Colocando isso de uma outra forma, pode-se

dizer que, calculando-se a transformada de Fourier de uma função, obtém-se o seu espectro de frequências, ou seja, obtém-se uma nova função que fornece as componentes em frequência da função original. A transformada de Fourier de uma função contínua de uma única variável, $f(x)$, pode ser dada pela equação:

$$
F(u)=\int f(x) \cdot e^{-i 2 \pi u x} d x
$$

onde $u=$ frequência

Uma vez calculada a transformada $F(u)$, a função original $f(x)$ pode ser obtida aplicandose a transformada de Fourier inversa em $F(u)$ :

$$
f(x)=\int_{-\infty}^{\infty} F(u) \cdot e^{i 2 \pi u x} d u .
$$


As equações (3.3) e (3.4) podem ser facilmente estendidas para funções de duas variáveis $f(x, y)$. A transformada de Fourier de uma função contínua $f(x, y)$ pode ser dada por

$$
F(u, v)=\int_{-\infty}^{\infty} \int_{-\infty}^{\infty} f(x, y) \cdot e^{-i 2 \pi(u x+v y)} d x d y
$$

onde $u=$ frequência ao longo do eixo $x$ $v=$ frequência ao longo do eixo $y$

e a transformada inversa de $F(u, v)$ pode ser dada por

$$
f(x, y)=\int_{-\infty}^{\infty} \int_{-\infty}^{\infty} F(u, v) \cdot e^{i 2 \pi(u x+v y)} d x d y
$$

Como o objetivo aqui, entretanto, é utilizar transformadas de Fourier em cubos de dados (ou seja, utilizá-las nas imagens bidimensionais dos cubos de dados), o interesse maior é nas transformadas de Fourier de funções discretas e não contínuas (já que uma imagem pode ser considerada uma função bidimensional discreta). A transformada de Fourier de uma função discreta $f(x)$, para $x=0,1,2, \ldots, M-1$, pode ser dada por

$$
\begin{gathered}
F(u)=\frac{1}{M} \sum_{x=0}^{M-1} f(x) \cdot e^{\frac{-i 2 \pi u x}{M}} . \\
\operatorname{para} u=0,1,2, \ldots M-1
\end{gathered}
$$

Similarmente, a transformada inversa de $F(u)$ pode ser dada por

$$
f(x)=\sum_{u=0}^{M-1} F(u) \cdot e^{\frac{i 2 \pi u x}{M}}
$$


Uma importante diferença da transformada de Fourier discreta para a transformada de Fourier contínua é que a última pode não existir para certas funções, enquanto que a primeira sempre existe.

Pelas equações anteriores, pode-se dizer que, em geral, transformadas de Fourier geram valores complexos. Dessa forma, uma transformada de Fourier $F(u)$ pode ser escrita como

$$
F(u)=|F(u)| \cdot e^{i \phi(u)}
$$

sendo que

$$
|F(u)|=\left(R^{2}(u)+I^{2}(u)\right)^{\frac{1}{2}}
$$

e

$$
\phi(u)=\tan ^{-1}\left(\frac{I(u)}{R(u)}\right)
$$

onde $I(u)=$ parte imaginária de $F(u)$

$$
\begin{aligned}
R(u) & =\text { parte real de } F(u) \\
|F(u)| & =\text { magnitude da transformada de Fourier } \\
\phi(u) & =\text { ângulo de fase da transformada de Fourier }
\end{aligned}
$$

Uma quantidade que é frequentemente utilizada para representar os resultados de uma transformada de Fourier é o espectro de potência, definido como

$$
P(u)=|F(u)|^{2}=R^{2}(u)+I^{2}(u)
$$


Assim como no caso de funções contínuas, a extensão da transformada de Fourier, e sua inversa, de uma função discreta para o caso bidimensional é bastante simples. A transformada de Fourier $F(u, v)$ de uma função discreta bidimensional $f(x, y)$, de tamanho $M \times 1$, pode ser dada por

$$
\begin{gathered}
F(u, v)=\frac{1}{M N} \sum_{x=0}^{M-1} \sum_{y=0}^{N-1} f(x, y) \cdot e^{-i 2 \pi(u x / M+v y / N)} . \\
\operatorname{para} u=0,1,2, \ldots, M-1 \\
v=0,1,2, \ldots, N-1
\end{gathered}
$$

A transformada inversa de $F(u, v)$, por sua vez, pode ser dada por

$$
f(x, y)=\sum_{u=0}^{M-1} \sum_{v=0}^{N-1} F(u, v) \cdot e^{i 2 \pi(u x / M+v y / N)} .
$$

Analogamente ao caso de uma transformada de Fourier discreta de uma função de uma única variável, a magnitude, o ângulo de fase e o espectro de potência da transformada de Fourier discreta de uma função de duas variáveis podem ser dadas, respectivamente, por

$$
\begin{gathered}
|F(u, v)|=\left(R^{2}(u, v)+I^{2}(u, v)\right)^{\frac{1}{2}}, \\
\phi(u, v)=\tan ^{-1}\left(\frac{I(u, v)}{R(u, v)}\right)
\end{gathered}
$$

e

$$
P(u, v)=|F(u, v)|^{2}=R^{2}(u, v)+I^{2}(u, v) .
$$


Uma propriedade importante das transformadas de Fourier é que, se $f(x, y)$ é uma função real, então, a sua transformada de Fourier é simétrica conjugada, ou seja,

$$
F(u, v)=F^{*}(-u,-v)
$$

onde $F^{*}$ corresponde ao complexo conjugado de $F$

A partir da equação (3.18), pode-se dizer que

$$
|F(u, v)|=|F(-u,-v)|
$$

A propriedade descrita pela equação anterior representa a simetria existente na transformada de Fourier. Entretanto, existem ainda outras propriedades importantes da transformada de Fourier bidimensional discreta que também devem ser mencionadas. Uma delas é a propriedade distributiva sobre a adição, que pode ser dada pela expressão

$$
F\left[f_{1}(x, y)+f_{2}(x, y)\right]=F\left[f_{1}(x, y)\right]+F\left[f_{2}(x, y)\right]
$$

Por outro lado, tem-se, em geral, que

$$
F\left[f_{1}(x, y) \cdot f_{2}(x, y)\right] \neq F\left[f_{1}(x, y)\right] \cdot F\left[f_{2}(x, y)\right]
$$

Ou seja, a transformada de Fourier é distributiva sobre a adição, mas não sobre a multiplicação. Outra propriedade importante se refere à multiplicação por escalares. Sendo $a$ e $b$ dois escalares, têm-se as seguintes igualdades:

$$
a \cdot f(x, y) \Leftrightarrow a F(u, v)
$$

e 


$$
f(a x, b y) \Leftrightarrow \frac{1}{|a b|} F(u / a, v / b) .
$$

onde $\Leftrightarrow$ indica um par formado pela função e sua respectiva transformada de Fourier

A periodicidade também é uma propriedade da transformada de Fourier de considerável importância. As equações a seguir revelam as propriedades periódicas da transformada de Fourier e de sua inversa, respectivamente:

$$
F(u, v)=F(u+M, v)=F(u, v+N)=F(u+M, v+N)
$$

$\mathrm{e}$

$$
f(x, y)=f(x+M, y)=f(x, y+N)=f(x+M, y+N) .
$$

Uma última propriedade muito importante é a da separabilidade da transformada de Fourier. Para se verificar a validade dessa propriedade, primeiramente, é preciso notar que a equação (3.13) pode ser escrita da seguinte maneira:

$$
F(u, v)=\frac{1}{M} \sum_{x=0}^{M-1} e^{\frac{-i 2 \pi u x}{M}} \frac{1}{N} \sum_{y=0}^{N-1} f(x, y) \cdot e^{\frac{-i 2 \pi v y}{N}}=\frac{1}{M} \sum_{x=0}^{M-1} F(x, v) \cdot e^{\frac{-i 2 \pi u x}{M}}
$$

onde

$$
F(x, v)=\frac{1}{N} \sum_{y=0}^{N-1} f(x, y) \cdot e^{\frac{-i 2 \pi v y}{N}}
$$

Associando-se $f(x, y)$ a uma matriz bidimensional, pode-se notar que a equação (3.27) corresponde à transformada de Fourier de uma linha dessa matriz. A equação (3.26), por sua vez, mostra que a transformada final $F(u, v)$ pode ser obtida tomando-se a matriz resultante das 
transformadas de Fourier de todas as linhas de $f(x, y)$ e fazendo-se uma nova transformada de Fourier, mas, dessa vez, das colunas. Em outras palavras, tomando-se $f(x, y)$ como sendo uma imagem por exemplo, então, a transformada de Fourier bidimensional dessa imagem pode ser obtida fazendo-se as transformadas de cada uma das suas linhas e, em seguida, tomando-se a imagem resultante e fazendo-se as transformadas de Fourier das suas colunas.

A transformada de Fourier bidimensional discreta se tornou uma importante ferramenta de análise de imagens nos últimos anos. Entretanto, a aplicação direta da equação (3.13) exige um grande esforço computacional e costuma levar bastante tempo, devido à grande quantidade de operações (adições e multiplicações) envolvidas. Para se calcular de maneira mais prática e rápida transformadas de Fourier de imagens, foi desenvolvido o algoritmo Fast Fourier Transform (FFT), descrito em maiores detalhes no apêndice E, que proporciona uma considerável economia de tempo nesse processo. Nesse trabalho, todas as transformadas de Fourier necessárias foram calculadas utilizando-se o algoritmo FFT.

\section{5 - Reamostragem espacial dos dados}

Após a redução e a correção da refração atmosférica diferencial, a etapa seguinte no tratamento dos dados foi a aplicação da reamostragem espacial em alguns cubos de dados, de modo a diminuir o tamanho dos pixeis espaciais. Isso foi feito porque, em alguns casos, foi constatado que esse procedimento permitia que as estruturas presentes nas imagens dos cubos de dados fossem melhor visualizadas.

De acordo com o critério de Nyquist, para que um sinal contínuo possa ser apropriadamente amostrado, ele não pode conter componentes de frequência acima da frequência de Nyquist, que é igual à metade da frequência de amostragem. Se essa condição for satisfeita, então, o sinal contínuo que foi amostrado poderá ser recomposto sem perda de informação. Dito de uma outra forma, o critério de Nyquist estabelece que, para que não haja nenhuma perda, um sinal contínuo deve ser amostrado com uma frequência igual ou maior do que o dobro da sua máxima frequência.

No caso de observações astronômicas, o critério de Nyquist estaria mais relacionado ao momento em que a luz emitida pelo objeto observado incide sobre o detector do telescópio. 
Nesse caso, o FWHM correspondente ao seeing da imagem deveria ser maior ou igual a dois pixeis do detector. Em geral, o design dos telescópios (inclusive aqueles cujos dados foram utilizados nesse trabalho) é tal que garante que esse critério seja satisfeito. Na verdade, a utilização do critério de Nyquist nesse cenário não é inteiramente correta, pois esse critério se aplica a situações em que funções contínuas são amostradas em pontos separados por certos intervalos, o que é diferente do CCD de um telescópio, que amostra a imagem em intervalos contíguos. Mesmo assim, a regra geral de que o FWHM do seeing de uma imagem deve ser maior do que 2 pixeis do detector gera bons resultados e, por essa razão, é sempre utilizada.

A reamostragem espacial dos cubos de dados, obviamente, não viola o critério de Nyquist, pois eles são reamostrados em pixeis menores do que os originais (sendo que a situação original já obedecia o critério de Nyquist). Assim, em princípio, a imagem inicial do objeto observado ainda pode ser recuperada após o processo de reamostragem (não há nenhuma perda de informação). Por outro lado, a reamostragem espacial dos cubos em pixeis menores introduz componentes de alta frequência espacial nas imagens. Isso, entretanto, não representa um problema, pois, conforme é explicado nas sessões seguintes, essas componentes de alta frequência espacial são eliminadas com a filtragem espacial de Butterworth, que também é aplicada aos dados. Dessa forma, pode-se dizer que a reamostragem espacial, em certos casos, é um procedimento vantajoso e que não causa prejuízos graves aos dados.

Para se aplicar a reamostragem espacial nos cubos de dados, elaborou-se um script em linguagem IDL que aumenta o número de pixeis espaciais de cada uma das imagens desses cubos, conservando o fluxo superficial. A aplicação desse processo apenas, entretanto, não proporciona uma melhoria considerável na qualidade das imagens, pois um efeito colateral desse procedimento é que a imagem final fica com grupos de pixeis adjacentes com valores iguais ou próximos. Um exemplo disso seria uma reamostragem feita de modo a duplicar o número de pixeis espaciais em cada eixo de uma imagem. Aplicando-se o procedimento descrito, cada pixel espacial daria origem a outros quatro, cada um com um valor igual a um quarto do valor do pixel original. O resultado final disso seria uma imagem sem grandes melhorias em relação à original, pois cada grupo de quatro pixeis espaciais adjacentes nela equivaleria, visualmente, a um pixel na imagem original. Para resolver esse problema, fez-se uma interpolação nos pixeis de cada uma das linhas e, em seguida, em cada uma das colunas da imagem. Esse procedimento foi aplicado ajustando-se uma função quadrática da forma $y=a+b x+c x^{2}$ a cada grupo de quatro pixeis 
adjacentes ao longo de uma linha (ou coluna). A figura 3.28 mostra os gráficos com os perfis horizontais com os valores dos pixeis de uma imagem sem reamostragem, com uma reamostragem simples e com uma reamostragem seguida de uma interpolação dos valores.
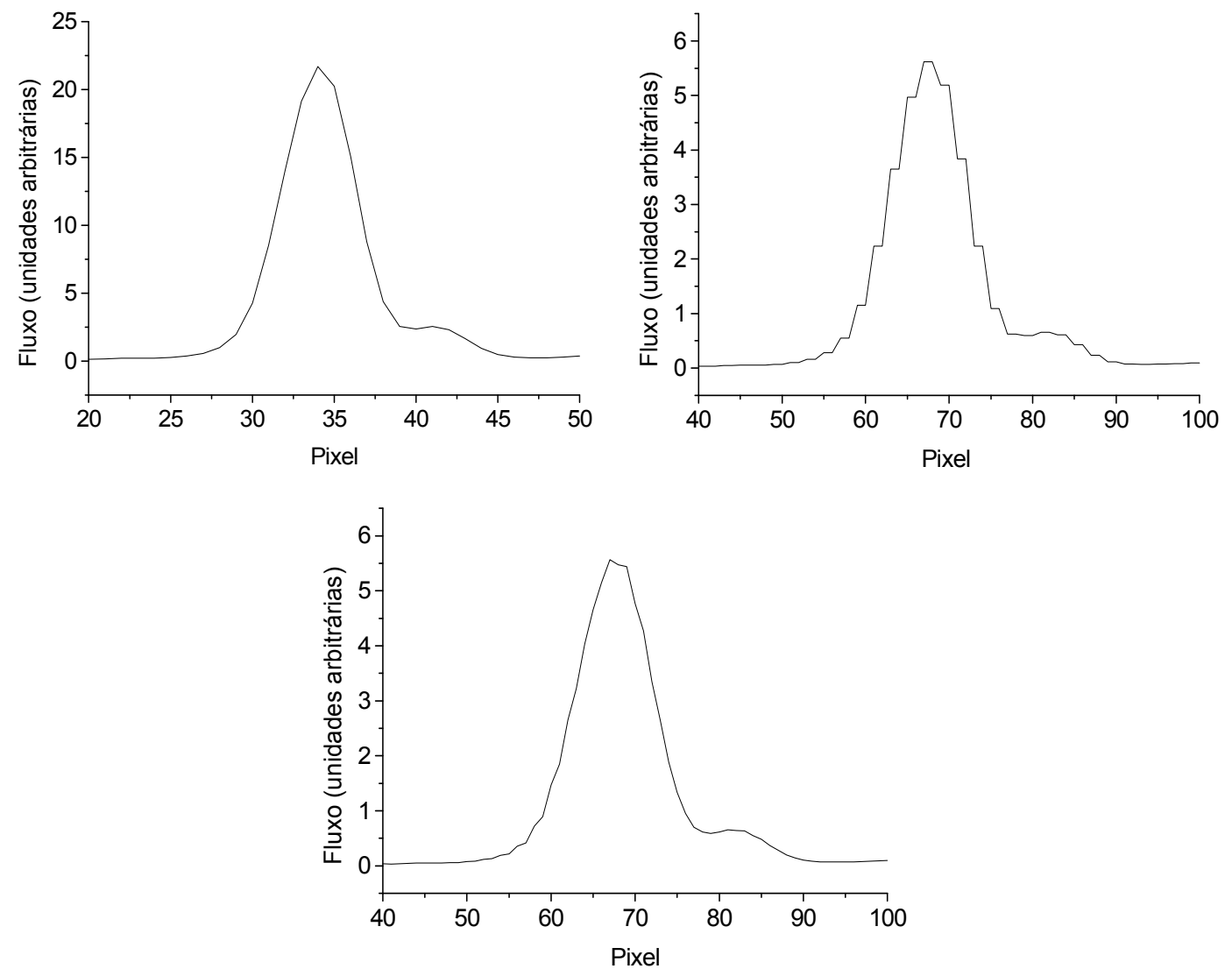

Figura 3.28 - (em cima à esquerda) Perfil horizontal de brilho da imagem de um cubo de dados de uma estrela arbitrária, antes da reamostragem espacial; (em cima à direita) Perfil horizontal da mesma imagem anterior, após uma reamostragem espacial simples; (abaixo) Perfil horizontal da mesma imagem anterior, após uma reamostragem espacial seguida de uma interpolação dos valores.

Observando-se a figura 3.28, pode-se notar que a reamostragem seguida de interpolação fornece resultados com uma melhor qualidade do que uma reamostragem simples. Assim, nesse trabalho, em todos os casos nos quais optou-se por fazer uma reamostragem espacial, esse procedimento foi seguido por uma interpolação dos valores.

O GMOS não possui nenhum sistema de óptica adaptativa. Isso, juntamente com os valores geralmente obtidos para o $F W H M$ do seeing das observações e o tamanho dos pixeis espaciais ( 0.05 " de lado) dos cubos de dados construídos, fizeram com que um processo de reamostragem espacial nos cubos de dados obtidos com esse intrumento não fosse vantajosa. De 
fato, muitos testes aplicados em dados do GMOS mostraram que esse procedimento não resultava em ganhos consideráveis. No caso dos cubos de dados obtidos com o NIFS e com o SINFONI, entretanto, a presença da óptica adaptativa, juntamente com os valores do FWHM do seeing normalmente obtidos durante as observações, tornaram vantajoso o processo da reamostragem espacial. Nesses casos, os testes mostraram claramente que a obtenção de imagens com pixeis menores fazia com que várias estruturas espaciais ficassem melhor definidas. Assim, nesse trabalho, a reamostragem espacial foi utilizada, apenas, em cubos de dados obtidos com o NIFS e com o SINFONI. Alguns exemplos da aplicação desse procedimento são mostrados nas sessões a seguir.

\subsection{1 - Reamostragem espacial de cubos de dados do NIFS}

A reamostragem espacial em cubos de dados do NIFS foi feita de modo a se chegar, no final do processo, a pixeis espaciais de 0.021 " de lado (lembrando que os pixeis espaciais dos cubos de dados após a redução eram de 0.05”). A razão para se executar esse procedimento dessa maneira foi obter pixeis espaciais quadrados com uma dimensão igual a um valor submúltiplo dos valores correspondentes às dimensões originais dos pixeis de hardware do NIFS (0.103" $\mathrm{x}$ 0.043”). A figura 3.29 mostra as imagens de um intervalo espectral intermediário colapsado do cubo de dados de GQ Lup antes e depois da aplicação da reamostragem espacial.
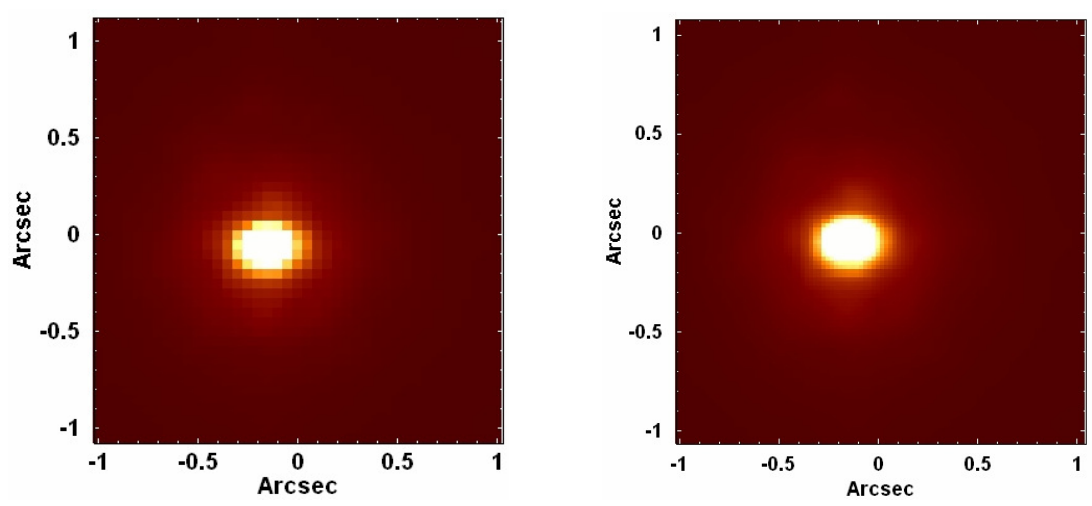

Figura 3.29 - (esquerda) Imagem de um intervalo espectral intermediário colapsado do cubo de dados de GQ Lup, antes da aplicação da reamostragem espacial; (direita) Imagem no mesmo intervalo espectral da imagem da direita do cubo de dados de GQ Lup, após a aplicação da reamostragem espacial. 
A figura 3.30 mostra os módulos das transformadas de Fourier das imagens de um comprimento de onda intermediário dos cubos de dados de GQ Lup, antes e depois da aplicação da reamostragem espacial.
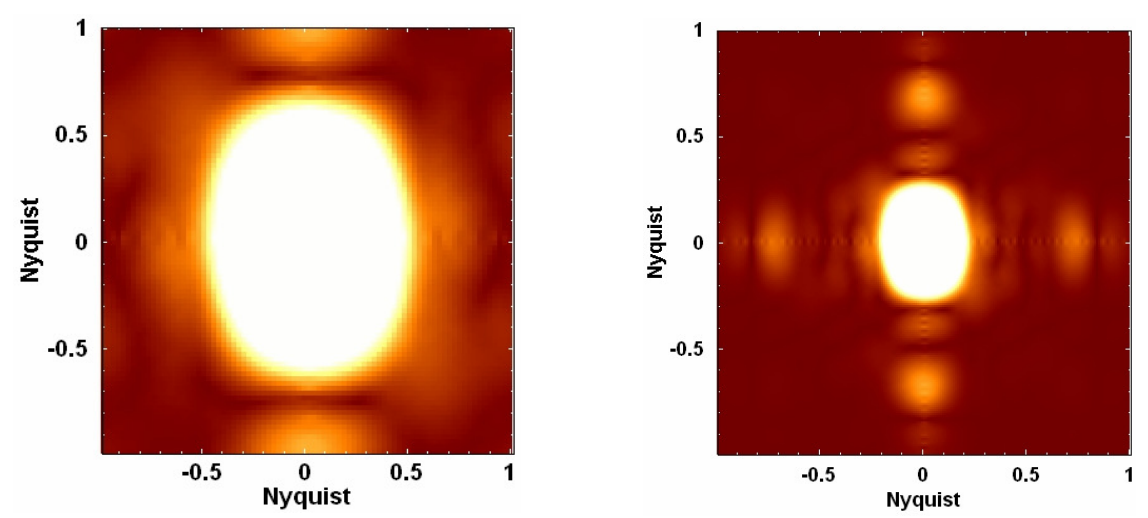

Figura 3.30 - (esquerda) Imagem do módulo da transformada de Fourier de um comprimento de onda intermediário do cubo de dados de GQ Lup, antes da aplicação da reamostragem espacial;

(direita) Imagem do módulo da transformada de Fourier do mesmo comprimento de onda da imagem à direita do cubo de dados de GQ Lup, após a aplicação da reamostragem espacial.

$\mathrm{Na}$ figura 3.29, pode-se notar que a aplicação da reamostragem espacial permitiu que as estruturas espaciais presentes no cubo de dados de GQ Lup ficassem melhor definidas, entretanto, conforme foi mencionado anteriormente, esse processo também introduziu componentes de alta freqüência espacial nas imagens, que podem ser vistas como estreitas faixas horizontais e verticais (essas estruturas aparecem de maneira tênue na figura 3.29). Na figura 3.30, entretanto, as componentes de alta freqüência espacial introduzidas com a reamostragem aparecem de maneira muito mais clara e correspondem às áreas claras mais afastadas do centro da imagem. Conforme está explicado nas sessões a seguir, essas componentes de alta freqüência introduzidas são quase totalmente removidas com aplicação da filtragem espacial de Butterworth, logo, não representam um problema sério.

\subsection{2 - Reamostragem espacial de cubos de dados do SINFONI}

A reamostragem espacial em cubos de dados do SINFONI foi feita de modo a se obter, para os fore-optics com campos de visão de 8" x 8", 3.2" x 3.2" e 0.8" x 0.8", pixeis espaciais de $0.0625 \%, 0.025 "$ e 0.00625 " de lado, respectivamente, que são submúltiplos dos valores correspondentes às dimensões originais dos pixeis de hardware do SINFONI $(0.250$ ” x 0.125 ”, 
$0.10 "$ × 0.05 " e $0.0250 "$ x 0.0125 ", respectivamente). A figura 3.31 mostra as imagens de um intervalo espectral intermediário colapsado do cubo de dados de HIP 49220 antes e depois da reamostragem espacial. Nesse caso, por se tratar do fore-optics com campo de visão de 0.8 " x 0.8 ", o procedimento foi aplicado de modo a se obter, ao final, pixeis espaciais de 0.00625 " de lado.
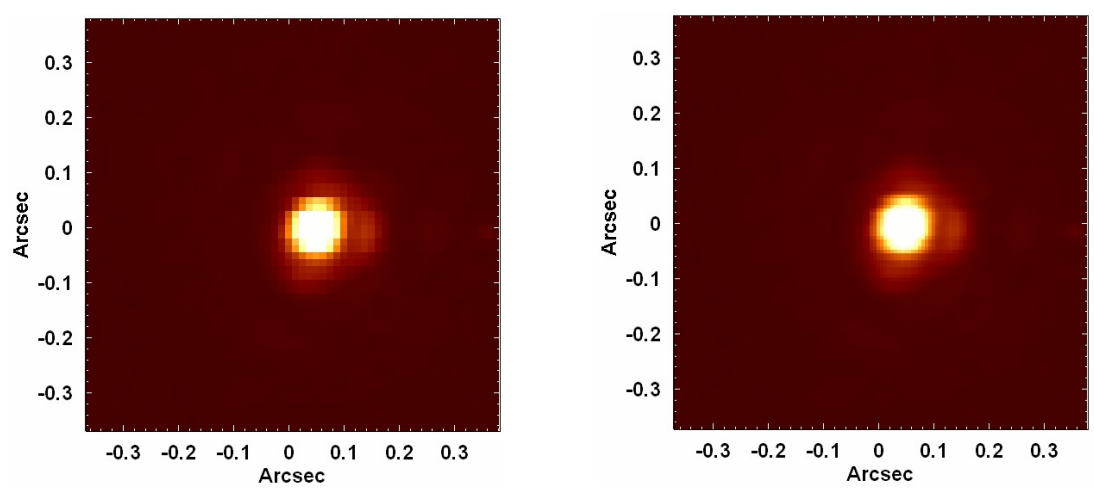

Figura 3.31 - (esquerda) Imagem de um intervalo espectral intermediário colapsado do cubo de dados de HIP 49220, antes da aplicação da reamostragem espacial; (direita) Imagem no mesmo intervalo espectral da imagem da direita do cubo de dados de HIP 49220, após a aplicação da reamostragem espacial.

A figura 3.32 mostra os módulos das transformadas de Fourier das imagens de um comprimento de onda intermediário dos cubos de dados de HIP 49220, antes e depois da aplicação da reamostragem espacial.
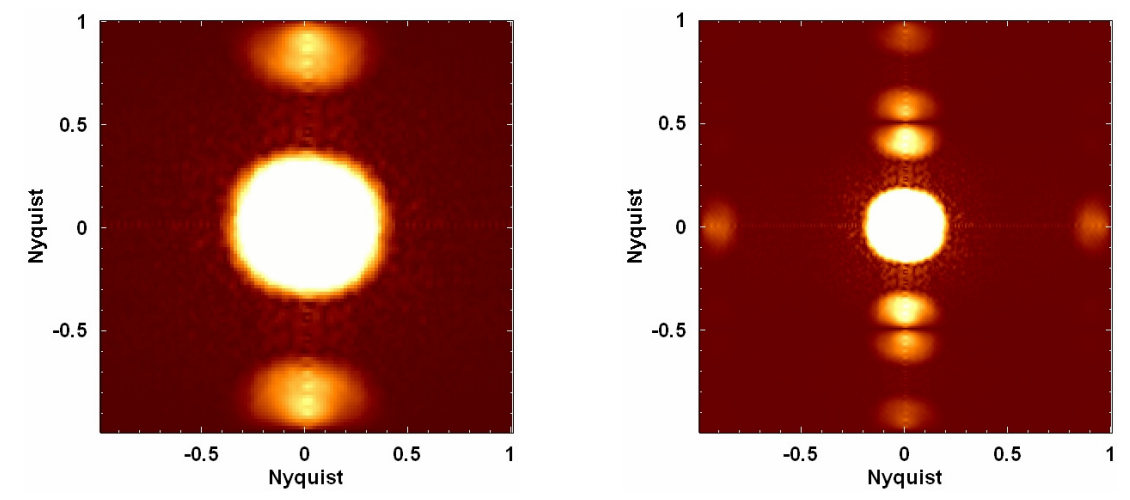

Figura 3.32 - (esquerda) Imagem do módulo da transformada de Fourier de um comprimento de onda intermediário do cubo de dados de HIP 49220, antes da aplicação da reamostragem espacial; (direita) Imagem do módulo transformada de Fourier do mesmo comprimento de onda da imagem à direita do cubo de dados de HIP 49220, após a aplicação da reamostragem espacial. 
Observando-se a figura 3.31, pode-se notar que a aplicação da reamostragem espacial no cubo de dados de HIP $49220 \mathrm{fez}$ com que as estruturas espaciais presentes ficassem melhor definidas. Entretanto, assim como no caso de GQ Lup, foram introduzidas componentes de alta freqüência espacial, que podem ser vistas, principalmente, como estreitas faixas horizontais (esse padrão é bastante tênue na figura 3.31). Por outro lado, na figura 3.32, as componentes de alta freqüência espacial introduzidas com a reamostragem aparecem de maneira muito mais clara e correspondem às áreas claras mais afastadas do centro da imagem. Novamente, conforme está explicado nas sessões a seguir, essas componentes de alta freqüência introduzidas são quase inteiramente removidas com aplicação da filtragem espacial de Butterworth.

\section{6 - Decomposição wavelet}

Após a aplicação da reamostragem espacial (exceto nos cubos de dados do IFU do GMOS), a etapa seguinte no tratamento dos cubos de dados foi a da decomposição wavelet. Essa técnica tem sido amplamente utilizada nos últimos anos para a análise de sinais e imagens. Em linhas gerais, o procedimento consiste em decompor um sinal em várias componentes com diferentes frequências características. Em outras palavras, pode-se dizer que a decomposição wavelet gera, a partir do sinal original, tanto componentes de alta frequência (representando as variações mais rápidas do sinal), quanto componentes de baixa frequência (representando as variações mais lentas do sinal). A partir dessa descrição, pode-se notar uma certa similaridade entre a transformada de Fourier e a decomposição wavelet, entretanto, esses procedimentos apresentam diferenças consideráveis. Enquanto a transformada de Fourier gera um espectro que indica as diferentes componentes em frequência presentes no sinal, a decomposição wavelet decompõe o sinal em componentes de alta e baixa frequência.

Existem alguns conceitos bastante importantes na teoria da decomposição wavelet. Primeiramente, uma função $f(x)$, geralmente, pode ser tomada como sendo a combinação linear de outras funções, da seguinte maneira:

$$
f(x)=\sum_{k} \alpha_{k} \phi_{k}(x)
$$


onde $k$ é o índice de uma soma finita ou infinita, $\alpha_{k}$ são os chamados coeficientes de expansão e $\phi_{k}(x)$ são as funções de expansão. Se a expansão for única, ou seja, se houver apenas um conjunto de coeficientes $\alpha_{k}$ para uma dada função $f(x)$, então as funções $\phi_{k}(x)$ são chamadas de funções base e o conjunto de funções $\left\{\phi_{k}(x)\right\}$ é chamado de base das funções que podem ser representadas por ele. As funções que podem ser representadas por essa base formam um espaço de funções, que é simbolizado por

$$
V=\underset{k}{\operatorname{Span}}\left\{\phi_{k}(x)\right\}
$$

Outro conceito importante é o de funções de escala. Tomando-se o conjunto de funções de expansão composto por translações e alterações de escala da função $\phi(x)$, tem-se que

$$
\phi_{j, l}(x)=2^{-j} \phi\left(2^{-j} x-l\right) .
$$

para $j, k \in \mathrm{Z}$

$\mathrm{Na}$ equação (3.30), $\phi$ é chamada de função de escala. Um ponto importante que pode ser notado facilmente observando-se a equação anterior é que o coeficiente $l$ determina a posição de $\phi_{j, l}$ e o coeficiente $j$ determina a largura de $\phi_{j, l}$ (ou seja, o quão larga ou estreita a função é ao longo do eixo $x$ ), assim sendo, pode-se dizer que j está relacionado à frequência apresentada pela função $\phi_{j, l}$. Nesse caso, quanto menor for o valor de $\mathrm{j}$, maior será a frequência associada a $\phi_{j, l}$. Analogamente ao que foi feito na equação (3.29), pode-se definir o espaço formado pelas funções que podem ser escritas como combinações lineares de $\phi_{j, l}$, para um determinado $j$, da seguinte maneira:

$$
V_{j}=\underset{l}{\operatorname{Span}}\left\{\phi_{j, l}(x)\right\}
$$


Uma propriedade importante a ser mencionada aqui é que uma função de expansão, com escala $j$, do espaço $V_{j}$ pode ser expressa como a combinação linear de funções de expansão de maiores escalas ( $j+1$, por exemplo). Assim,

$$
\phi_{j, l}(x)=\sum_{n} \alpha_{n} \phi_{j+1, n}(x)
$$

Substituindo-se (3.30) em (3.32) e mudando-se a variável de $\alpha_{n}$ para $h(n)$, obtém-se:

$$
\phi_{j, l}(x)=\sum_{n} h(n) 2^{-j+1} \phi\left(2^{-j+1} x-n\right) .
$$

Pela equação (3.30), pode-se notar que $\phi_{0,0}(x)=\phi(x)$, assim, a expressão (3.33) pode ser reescrita como

$$
\begin{gathered}
\phi_{0,0}(x)=\phi(x)=\sum_{n} h(n) 2 \phi(2 x-n) \rightarrow \\
\rightarrow \frac{1}{2} \phi\left(\frac{x}{2}\right)=\sum_{n} h(n) \phi(x-n) .
\end{gathered}
$$

A equação (3.34) é de grande importância e é chamada de equação de dilatação. Os coeficientes $h(n)$ são chamados de coeficientes da função de escala.

Uma função wavelet, $\psi(x)$, é definida de tal modo que uma combinação linear de funções de expansão obtidas a partir de translações e alterações de escala dela, $\psi_{j, l}(x)$, é capaz de reproduzir funções pertencentes à diferença entre dois espaços de escalas adjacentes $V_{j}$ e $V_{j+1}$. Em outras palavras, pode-se dizer que wavelets definidos como

$$
\psi_{j, l}(x)=2^{-j} \psi\left(2^{-j} x-l\right)
$$

são tais que 


$$
V_{j}-V_{j+1}=W_{j}=\underset{l}{\operatorname{Span}}\left\{\psi_{j, l}(x)\right\} .
$$

Seguindo-se um raciocínio similar àquele utilizado para demonstrar a equação de dilatação para $\phi(x)$ (equação 3.34), pode-se obter a equação de dilatação para $\psi(x)$ :

$$
\frac{1}{2} \psi\left(\frac{x}{2}\right)=\sum_{n} g(n) \psi(x-n),
$$

onde $g(n)$ são chamados de coeficientes da função de wavelet. A relação entre $g(n)$ e $h(n)$ (que não é demonstrada aqui) pode ser dada por

$$
g(n)=(-1)^{n} h(1-n) .
$$

Uma decomposição wavelet é obtida escrevendo-se uma determinada função como uma soma de wavelets, dados pela equação (3.35). Existem vários tipos de decomposições wavelet. A decomposição wavelet ortogonal, por exemplo, pode ser dada por

$$
f(x)=\sum_{l} c_{J, l} \phi_{J, l}(x)+\sum_{j=1}^{J} \sum_{l} w_{j, l} \psi_{j, l}(x),
$$

onde $J$ corresponde ao número de escalas utilizadas na decomposição, $w_{j, l}$ são os coeficientes de wavelet e $c_{J, l}$ são os coeficientes de aproximação. Na equação (3.39), $j=1$ corresponde à escala mais fina, ou seja, maiores frequências e a primeira das somatórias representa uma aproximação de $f(x)$ na escala $J$, ou seja, corresponde a uma versão "suavizada" de $f(x)$.

Nesse trabalho, a decomposição wavelet utilizada foi a baseada no algoritmo À Trous, que apresenta várias diferenças em relação a outros algoritmos comumente utilizados. Trata-se de uma decomposição wavelet, para dados discretos, não ortogonal, na qual os dados originais amostrados, $c_{0, k}$, são tomados como sendo produtos escalares, nos pixeis $k$, da função $f(x)$ com 
uma função de escala $\phi(x)$, que corresponde a um filtro passa-baixa. Os valores dos coeficientes de wavelet podem ser dados por

$$
w_{j+1, k}=c_{j, k}-c_{j+1, k},
$$

sendo que esses valores de $w_{j+1, k}$ também satisfazem a relação

$$
w_{j+1, k}=\sum_{n} g(n) c_{j, k+2^{j} n} .
$$

A função wavelet associada a esse algoritmo é tal que satisfaz a seguinte relação:

$$
\frac{1}{2} \psi\left(\frac{x}{2}\right)=\phi(x)-\frac{1}{2} \phi\left(\frac{x}{2}\right) .
$$

Os valores $\mathrm{c}_{\mathrm{j}+1, \mathrm{k}}$, por sua vez, podem ser dados pela equação:

$$
c_{j+1, k}=\sum_{n} h(n) c_{j, k+2^{j} n} .
$$

Os coeficientes $h(n)$ e $g(n)$ obedecem às equações de dilatação (3.34) e (3.37), respectivamente.

Uma característica importante da decomposição wavelet baseada no algoritmo À Trous é que a reconstrução do sinal original $c_{0, k}$ é bastante simples e pode ser dada por

$$
c_{0, k}=c_{J, k}+\sum_{j=1}^{J} w_{j, k}
$$

Outro aspecto importante a ser mencionado é que o conjunto $w_{j, k}$ apresenta média nula para um determinado $j$. 
As etapas a serem executadas para a aplicação do algoritmo À Trous podem ser resumidas da seguinte maneira:

1 - Inicialmente, tomam-se os dados amostrados $c_{0, k}$, ou seja, toma-se $j=0$.

2 - Faz-se uma convolução discreta dos dados $c_{j, k}$ com um filtro passa-baixa $h$, obtendo-se os dados $c_{j+1, k}$. Nessa convolução, a distância entre o pixel central e os adjacentes é $2^{j}$.

3 - O coeficiente $w_{j, k}$ pode, então, ser dado por $w_{j, k}=c_{j, k}-c_{j+1, k}$.

$4-\operatorname{Se} j$ for menor do que o número $J$ de escalas desejadas, deve-se acrescentar 1 ao valor de $j$ e voltar à etapa 2.

O conjunto $W=\left\{w_{1}, w_{2}, \ldots, w_{J}, c_{J}\right\}$ obtido é a decomposição wavelet dos dados procurada, sendo que $c_{J}$, por sua vez, representa o conjunto dos dados $c_{j, k}$ após a última convolução com o filtro $h$.

Diferentes funções de escala podem ser utilizadas com o algoritmo À Trous. Nesse trabalho, optou-se por utilizar uma função de escala do tipo $\mathrm{B}_{3}$-spline, que pode ser dada por

$$
\phi(x)=B_{3}(x)=\frac{1}{12}\left(|x-2|^{3}-4|x-1|^{3}+6|x|^{3}-4|x+1|^{3}+|x+2|^{3}\right) .
$$

Utilizando-se a equação de dilatação (3.34), pode-se mostrar que o filtro $h$ correspondente à função de escala dada por (3.45) é, no caso unidimensional,

$$
h=\left(\frac{1}{16}, \frac{1}{4}, \frac{3}{8}, \frac{1}{4}, \frac{1}{16}\right)
$$

No caso bidimensional, por outro lado, o filtro $h$ pode ser dado por 


$$
h=\left(\begin{array}{ccccc}
\frac{1}{256} & \frac{1}{64} & \frac{3}{128} & \frac{1}{64} & \frac{1}{256} \\
\frac{1}{64} & \frac{1}{16} & \frac{3}{32} & \frac{1}{16} & \frac{1}{64} \\
\frac{3}{128} & \frac{3}{32} & \frac{9}{64} & \frac{3}{32} & \frac{3}{128} \\
\frac{1}{64} & \frac{1}{16} & \frac{3}{32} & \frac{1}{16} & \frac{1}{64} \\
\frac{1}{256} & \frac{1}{64} & \frac{3}{128} & \frac{1}{64} & \frac{1}{256}
\end{array}\right) .
$$

Nos cubos de dados analisados nesse trabalho, a decomposição wavelet foi utilizada de duas maneiras diferentes: decomposição espacial e espectral. A decomposição espacial envolveu a aplicação do algoritmo À Trous bidimensional (utilizando a função de escala $\mathrm{B}_{3}$-spline) em cada uma das imagens do cubo de dados original. Esse procedimento gerou seis componentes de diferentes frequências espaciais a partir de cada uma dessas imagens. Nesse caso, utilizou-se o índice 0 para indicar a componente de maior freqüência e a notação $w_{c}$ para representar a componente obtida após a última convolução com o filtro $h$ (equação 3.47), assim, as componentes resultantes da decomposição wavelet de cada imagem foram $w_{0}, w_{1}, w_{2}, w_{3}, w_{4}$ e $w_{c}$ (foram utilizadas 5 escalas). Dessa forma, utilizando-se esse procedimento, foi possível obter seis cubos de dados, de diferentes frequências espaciais, a partir do original: $W_{0}, W_{1}, W_{2}, W_{3}, W_{4}$ e $W_{C}$. A decomposição espectral, por outro lado, foi utilizada para aplicar o processo do de-noising, que está explicado em detalhes na sessão 3.8 a seguir.

Nesse trabalho, utilizou-se, apenas, o cubo de dados $W_{0}$ para se determinar os melhores parâmetros da filtragem espacial de Butterworth a ser aplicada (os detalhes desse processo estão descritos na seção 3.7 a seguir). Nenhuma das componentes espaciais wavelet obtidas, entretanto, foi utilizada na análise dos dados. Alguns exemplos da aplicação da decomposição espacial wavelet em cubos de dados do IFU do GMOS, do NIFS e do SINFONI são mostrados nas sessões a seguir. 


\subsection{1 - Decomposição espacial wavelet em cubos de dados do GMOS}

A figura 3.33 mostra imagens de um intervalo espectral intermediário colapsado dos cubos de dados $W_{0}, W_{1}, W_{2}, W_{3}, W_{4}$ e $W_{C}$, obtidos a partir da decomposição espacial wavelet do cubo de ltt 4816.
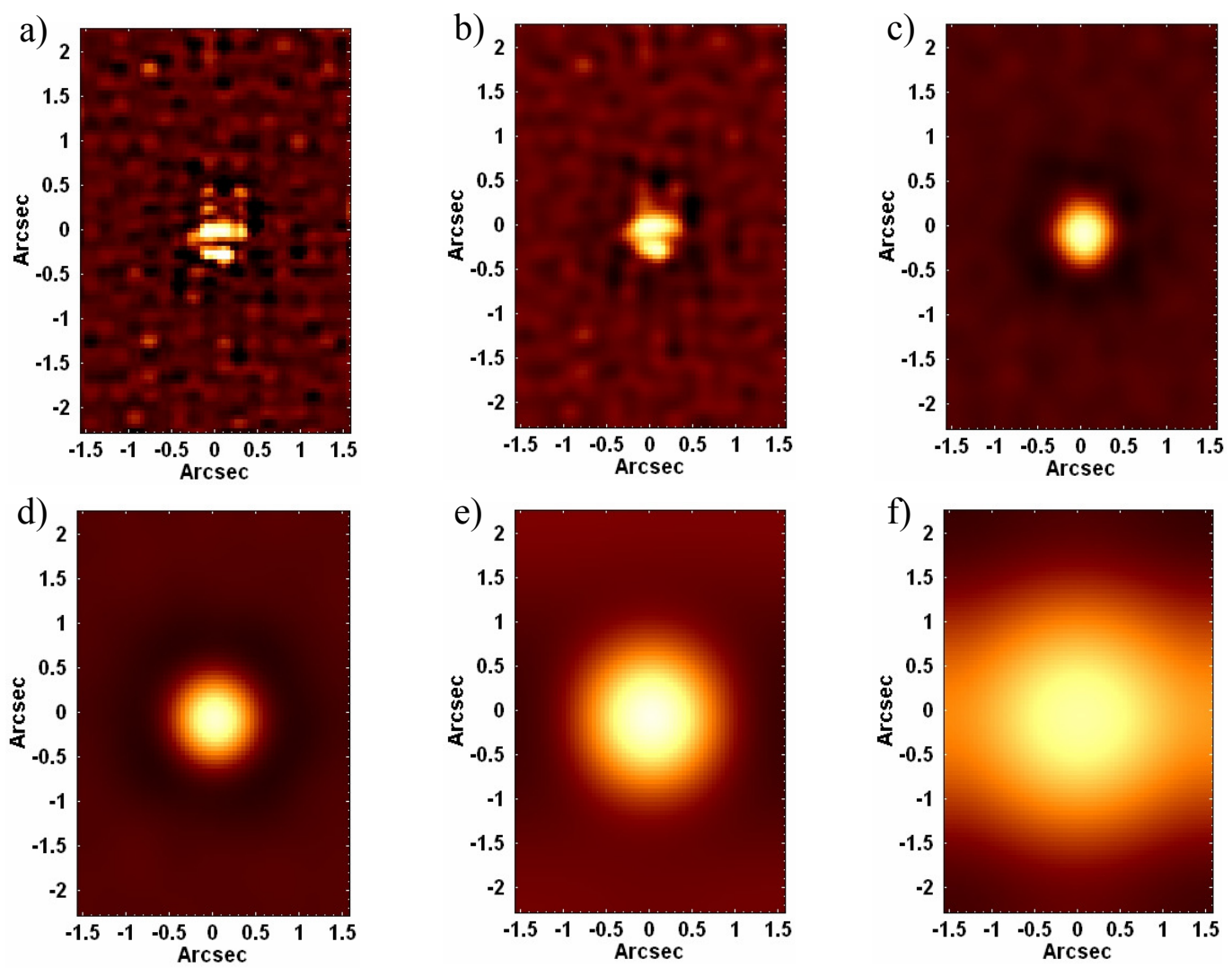

Figura 3.33 - Imagens de um intervalo espectral intermediário colapsado dos cubos de dados a) $W_{0}$, b) $W_{1}$, c) $W_{2}$, d) $W_{3}$, e) $W_{4}$ eff $W_{C}$, obtidas a partir do cubo de dados de ltt 4816.

A figura 3.33 revela a grande quantidade de ruído de alta freqüência espacial presente em $W_{0}$ e em $W_{1}$. Como nos cubos de dados do IFU do GMOS não foi aplicado o processo da reamostragem espacial (que poderia ter introduzido componentes de alta freqüência espacial), pode-se dizer que todo o ruído de alta freqüência visível em $W_{0}$ e $W_{l}$ é de natureza instrumental ou devido à baixa estatística de fótons. A aplicação do procedimento da filtragem espacial de Butterworth (descrita em detalhes na seção 3.7 a seguir) teve como objetivo remover essas componentes de alta freqüência espacial das imagens dos cubos de dados. Outra característica que pode ser notada na figura 3.33 é a presença de um anel escuro (com pixeis negativos) ao 
redor da estrutura brilhante central (isso pode ser notado, principalmente, nas imagens $c$ e $d$ da figura 3.33). Essa é uma conseqüência matemática da forma como a decomposição wavelet com o algoritmo À Trous é feita.

\subsection{2 - Decomposição espacial wavelet em cubos de dados do NIFS}

A figura 3.34 mostra imagens de um intervalo espectral intermediário colapsado dos cubos de dados $W_{0}, W_{1}, W_{2}, W_{3}, W_{4}$ e $W_{C}$, obtidos a partir da decomposição espacial wavelet do cubo de GQ Lup.
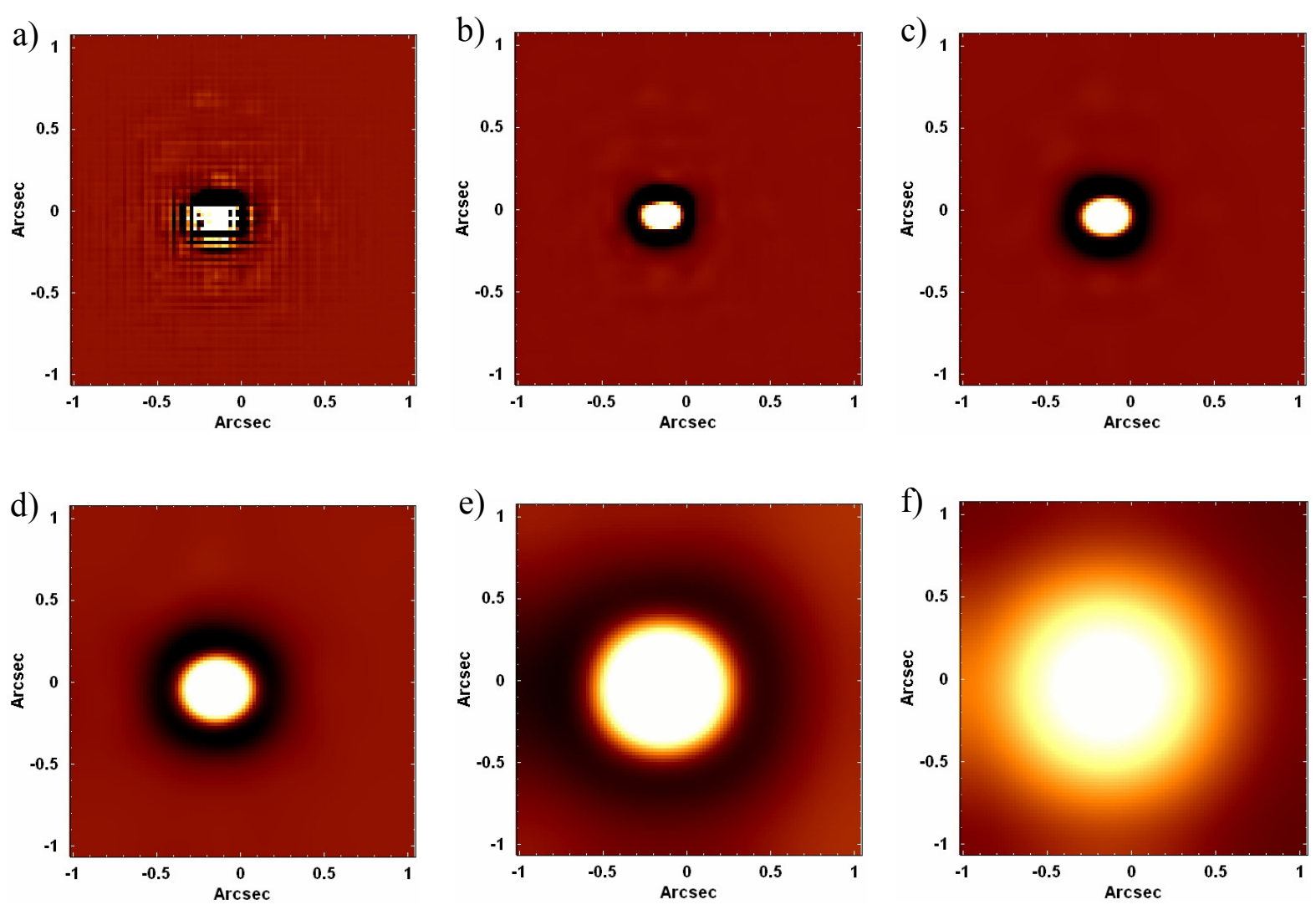

Figura 3.34 - Imagens de um intervalo espectral intermediário colapsado dos cubos de dados a) $W_{0}$, b) $W_{1}$, c) $W_{2}$, d) $W_{3}$, e) $W_{4}$ ef) $W_{C}$, obtidas a partir do cubo de dados de GQ Lup.

Observando-se a figura 3.34, pode-se notar a grande quantidade de ruído de alta freqüência espacial existente em $W_{0}$. Entretanto, ao contrário do que foi observado no caso de ltt 4816, as estruturas de alta freqüência espacial visíveis em $W_{0}$ tomam a forma de estreitas 
faixas horizontais e verticais. Essas aparecem em uma quantidade tão grande nas imagens que a estrela GQ Lup nem é visível claramente. Parte dessas estrias devem estar associadas a ruídos de natureza instrumental, entretanto, é provável que uma grande quantidade delas também correspondam a componentes de alta freqüência introduzidas pelo processo de reamostragem espacial. Independentemente da natureza dos ruídos de alta freqüência espacial, a filtragem espacial de Butterworth foi capaz de remover uma boa parte deles.

\subsection{3 - Decomposição espacial wavelet em cubos de dados do SINFONI}

A figura 3.35 mostra imagens de um intervalo espectral intermediário colapsado dos cubos de dados $W_{0}, W_{1}, W_{2}, W_{3}, W_{4}$ e $W_{C}$, obtidos a partir da decomposição espacial wavelet do cubo de HIP 49220.
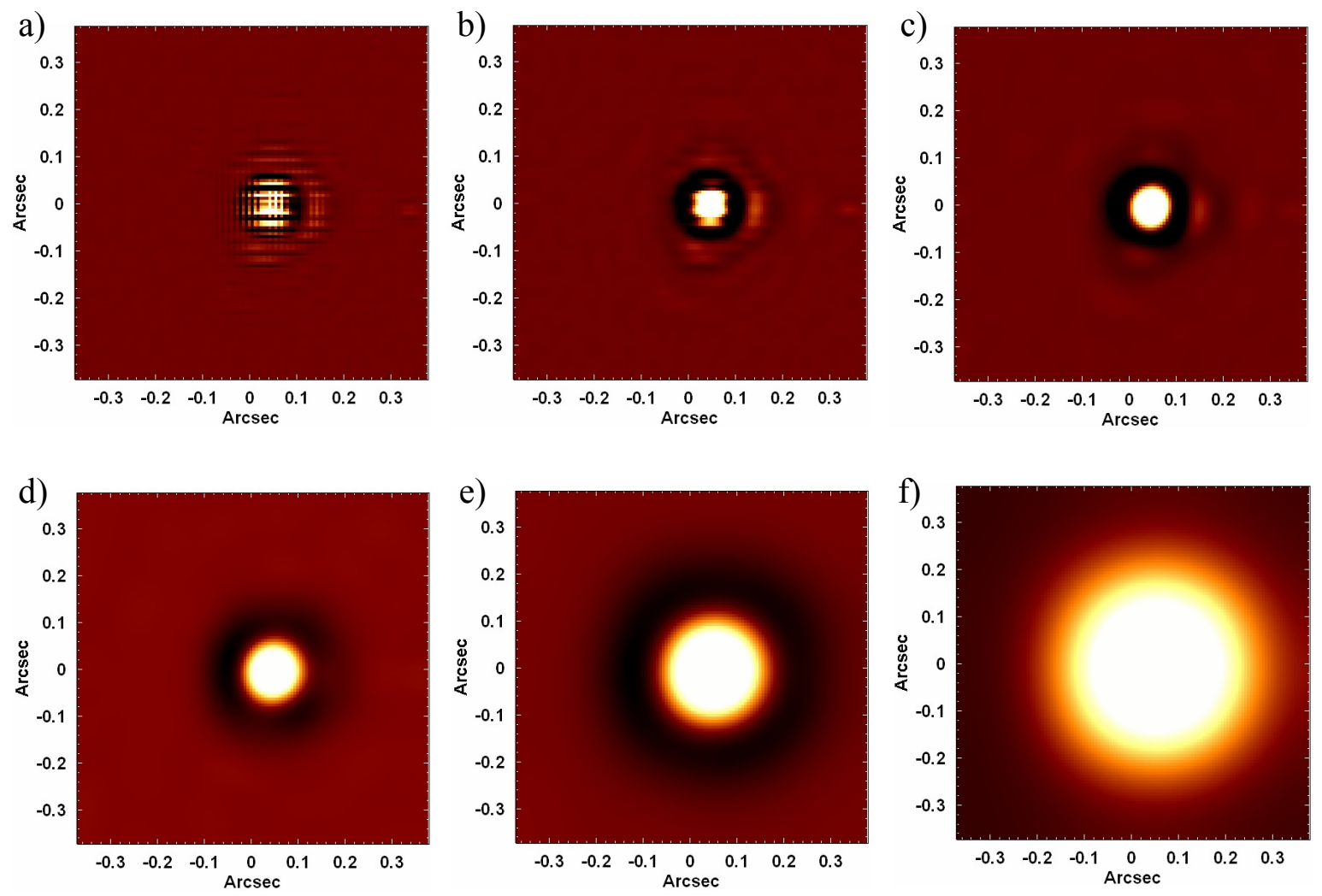

Figura 3.35 - Imagens de um intervalo espectral intermediário colapsado dos cubos de dados a) $W_{0}$, b) $W_{1}$, c) $\left.W_{2}, d\right) W_{3}$, e) $W_{4}$ ef) $W_{C}$, obtidas a partir do cubo de dados de HIP 49220. 
A figura 3.35 revela a existência de uma quantidade considerável de ruído de alta freqüência espacial em $W_{0}$ e $W_{l}$. Nesses dois cubos de dados, as principais estruturas de alta freqüência espacial visíveis apresentam a forma de estreitas faixas verticais e, sobretudo, horizontais. O número de estrias é tão alto em $W_{0}$ que a estrela HIP 49220 nem é visível claramente. Todas essas características são bastante similares ao que foi observado em GQ Lup e, da mesma forma, é provável que parte desse ruído seja de natureza instrumental e parte corresponda às componentes de alta freqüência introduzidas pelo processo de reamostragem espacial. Analogamente aos casos anteriores, uma grande quantidade dessas estruturas de alta freqüência espacial foi removida com a aplicação da filtragem espacial de Butterworth.

\section{7 - Filtragem espacial de Butterworth}

A etapa seguinte no tratamento dos cubos de dados analisados nesse trabalho foi a aplicação da filtragem espacial de Butterworth, que consiste em um processo de filtragem realizado diretamente no domínio de freqüências espaciais. Conforme foi mencionado anteriormente, a aplicação da transformada de Fourier permite que uma função seja analisada com relação às suas componentes em frequência, já que ela passa a função para o domínio de frequências. Uma consequência disso é que, com a transformada de Fourier, é possível fazer alterações diretamente nas componentes em freqüência existentes. A filtragem no domínio de frequências se baseia exatamente em passar uma determinada função para esse domínio (através da transformada de Fourier) e, em seguida, eliminar determinadas componentes presentes. Ao

final, a função é passada novamente para o domínio espacial, por meio da transformada de Fourier inversa. Como, nesse trabalho, o interesse foi aplicar a transformada de Fourier em imagens, a análise dessa seção envolve, apenas, transformadas de Fourier discretas de funções bidimensionais.

Em geral, antes de se aplicar a transformada de Fourier em uma imagem, costuma-se multiplicar cada pixel pelo fator $(-1)^{x+y}$, onde $x$ e $y$ correspondem às coordenadas espaciais (nos eixos horizontal e vertical, respectivamente) do pixel. Para se compreender o porquê disso, primeiramente, deve-se notar que a transformada de Fourier apresenta as seguintes propriedades translacionais: 


$$
f(x, y) \cdot e^{i 2 \pi\left(u_{0} x / M+v_{0} y / N\right)} \Leftrightarrow F\left(u-u_{0}, v-v_{0}\right)
$$

e

$$
f\left(x-x_{0}, y-y_{0}\right) \Leftrightarrow F(u, v) \cdot e^{-i 2 \pi\left(u x_{0} / M+v y_{0} / N\right)} .
$$

onde $\Leftrightarrow$ indica um par formado pela função e sua respectiva transformada de Fourier

Tomando-se $u_{0}=M / 2$ e $v_{0}=N / 2$, tem-se que:

$$
e^{i 2 \pi\left(u_{0} x / M+v_{0} y / N\right)}=e^{i 2 \pi\left(\frac{M x}{2 M}+\frac{N y}{2 N}\right)}=e^{i \pi(x+y)}=(-1)^{x+y} .
$$

A partir disso, conclui-se que as equações (3.48) e (3.49) podem ser reescritas como

$$
f(x, y) \cdot(-1)^{x+y} \Leftrightarrow F(u-M / 2, v-N / 2)
$$

e

$$
f(x-M / 2, y-N / 2) \Leftrightarrow F(u, v) \cdot(-1)^{u+v} .
$$

A partir da equação (3.51), pode-se concluir que a razão de se multiplicar cada pixel de uma imagem por $(-1)^{x+y}$ antes de se calcular a transformada de Fourier é fazer uma centralização da imagem da transformada, ou seja, ao se aplicar esse procedimento, o ponto $(0,0)$ no espaço de frequências fica no centro da imagem da transformada e as frequências mais elevadas ficam a distâncias maiores desse centro.

Após essa multiplicação pelo fator $(-1)^{x+y}$, a etapa seguinte no processo de filtragem consiste em se obter a transformada de Fourier $F(u, v)$ da imagem. Em seguida, deve-se multiplicar $F(u, v)$ por uma função filtro $H(u, v)$. Essa multiplicação tem como objetivo suprimir 
certas componentes em frequência presentes e é feita ponto a ponto, ou seja, o primeiro elemento da transformada de Fourier da imagem original é multiplicado pelo primeiro elemento do filtro, o segundo elemento da transformada é multiplicado pelo segundo elemento do filtro e assim por diante. Após isso, deve-se obter a transformada de Fourier inversa do produto $F(u, v) \cdot H(u, v)$, para que se possa voltar para o domínio espacial. Uma vez de volta a esse domínio, para se concluir o procedimento, deve-se extrair a parte real do resultado da transformada de Fourier inversa do produto $F(u, v) \cdot H(u, v)$ e multiplicar esse resultado por $(-1)^{x+y}$. No caso aqui considerado, tanto a imagem original quanto a função filtro $H(u, v)$ são reais, logo, é de se esperar que a imagem resultante da transformada de Fourier inversa de $F(u, v) \cdot H(u, v)$ também seja real. Entretanto, devido a incertezas computacionais, costuma haver componentes complexas de baixo módulo. Essas componentes são ignoradas quando se extrai a parte real da transformada de Fourier inversa. Por fim, o motivo de se multiplicar a imagem final, novamente, por $(-1)^{x+y}$ é apenas cancelar o efeito da multiplicação inicial.

Um ponto importante a ser mencionado aqui diz respeito ao teorema da convolução. Sendo $f(x, y)$ e $h(x, y)$ duas funções no domínio espacial de dimensões $M \times N$, a convolução dessas duas funções, $f(x, y)^{*} h(x, y)$, é dada pela expressão

$$
f(x, y) * h(x, y)=\frac{1}{M N} \sum_{m} \sum_{n} f(m, n) \cdot h(x-m, y-n) .
$$

Sendo $H(u, v)$ e $F(u, v)$ as transformadas de Fourier de $h(x, y)$ e $f(x, y)$, respectivamente, então o teorema da convolução diz que $f(x, y)^{*} h(x, y)$ e $F(u, v) \cdot H(u, v)$ constituem um par formado pela função e sua respectiva transformada de Fourier, ou seja,

$$
f(x, y) * h(x, y) \Leftrightarrow F(u, v) \cdot H(u, v)
$$

Dito de uma outra forma, o teorema da convolução afirma que uma multiplicação de duas funções no domínio de frequências equivale a uma convolução no domínio espacial.

De um modo similar, o teorema da convolução diz ainda que uma convolução no domínio de frequência corresponde a uma multiplicação no domínio espacial, ou seja, 


$$
f(x, y) \cdot h(x, y) \Leftrightarrow F(u, v) * H(u, v) .
$$

Assim sendo, pode-se concluir que o processo de filtragem descrito acima (com uma multiplicação do filtro pela transformada de Fourier da imagem no domínio de frequências) também poderia ser obtido com uma convolução entre a imagem original e a transformada de Fourier inversa do filtro no domínio espacial.

Diversos tipos de filtros são utilizados no tratamento de imagens e existem duas categorias principais que são bastante populares: os filtros passa-alta e passa-baixa. Os filtros passa-alta são aqueles que eliminam as componentes de frequência mais baixa da imagem, enquanto que os filtros passa-baixa eliminam as componentes de frequência mais alta. Nesse trabalho, apenas foram utilizados filtros passa-baixa, portanto, somente essa classe de filtros é discutida aqui.

Existem três filtros passa-baixa bastante famosos: o filtro ideal, o filtro de Butterworth e o filtro gaussiano (esses três filtros também possuem as suas versões passa-alta). O filtro ideal, basicamente, elimina completamente as frequências mais altas do que um certo valor e pode ser dado pela expressão

$$
H(u, v)= \begin{cases}1 & \text { para } \mathrm{D}(\mathrm{u}, \mathrm{v}) \leq \mathrm{D}_{0} \\ 0 & \text { para } \mathrm{D}(\mathrm{u}, \mathrm{v})>\mathrm{D}_{0}\end{cases}
$$

onde $D(u, v)$ é a distância entre os pontos $(u, v)$ e $(0,0)$ no domínio de frequências (o ponto $(0,0)$ está no centro da imagem correspondente à transformada de Fourier) e $D_{0}$ é a distância em relação ao ponto $(0,0)$ a partir da qual todas as componentes de frequência serão eliminadas. $\mathrm{O}$ filtro gaussiano, por sua vez, pode ser dado pela expressão

$$
H(u, v)=e^{\frac{-D^{2}(u, v)}{2 D_{0}^{2}}} .
$$

Nesse caso, quando $D(u, v)=D_{0}$, o valor do filtro cai para 0,607 (o valor máximo é 1).

Finalmente, o filtro de Butterworth de ordem $n$ pode ser dado pela expressão 


$$
H(u, v)=\frac{1}{1+\left[D(u, v) / D_{0}\right]^{2 n}}
$$

Pela equação (3.58), pode-se notar que quanto maior é o valor de $n$, mais abrupto é o corte feito pelo filtro, ao passo que quanto menor é o valor de $n$, mais suave é o corte. Nesse trabalho, optou-se por utilizar apenas o filtro de Butterworth, já que, nesse caso, há a vantagem de se poder alterar a ordem $n$ e, consequentemente, a rapidez com que os valores do filtro decrescem.

Utilizar um valor mais elevado de $n$ (como 6, por exemplo) apresenta a vantagem de que frequências mais altas são fortemente removidas, devido ao decaimento mais rápido do filtro. Entretanto, a aplicação de um filtro de Butterworth de ordem tão elevada possui a considerável desvantagem de que estruturas similares a anéis são introduzidas na imagem. Utilizar um valor mais baixo de $n$ (como 1 ou 2, por exemplo) apresenta a desvantagem de que o decaimento mais lento do filtro não elimina de maneira tão eficaz as mais altas frequências, entretanto, filtros de Butterworth de baixa ordem não geram anéis. Na prática, filtros de ordem 1 não introduzem anéis e os gerados por filtros de ordem 2 são praticamente imperceptíveis. Para ordens mais elevadas, os anéis introduzidos vão ficando cada vez mais fortes. Um fato que pode ser deduzido disso é que os filtros ideais (que apresentam um corte extremamente abrupto) geram vários anéis. Filtros gaussianos, por sua vez, não introduzem nenhum anel.

Conforme foi explicado anteriormente, a transformada de Fourier apresenta propriedades periódicas. Essa periodicidade é uma conseqüência do modo como a transformada de Fourier é definida e precisa ser levada em conta. Também já foi mencionado que uma multiplicação no domínio de frequências equivale a uma convolução no domínio espacial. Na figura 3.36, são mostrados exemplos de convoluções de duas funções, $f(m)$ e $h(m)$, com e sem periodicidade. Na coluna da esquerda é mostrada a convolução sem periodicidade e na coluna da direita é mostrada a convolução das funções com periodicidade. 
a)

$\mathrm{f}(\mathrm{m})$

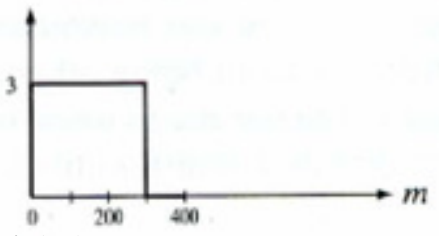

$\mathrm{h}(\mathrm{m})$

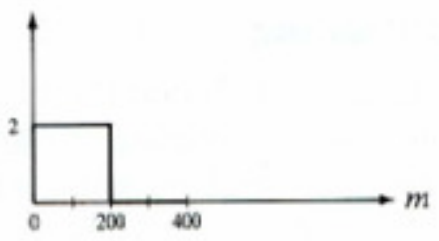

$\mathrm{f}(\mathrm{x})^{*} \mathrm{~h}(\mathrm{x})$

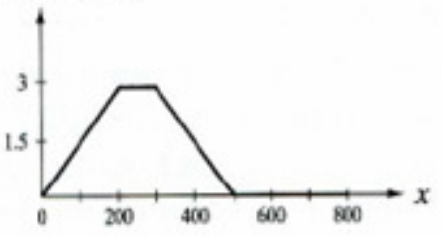

b)

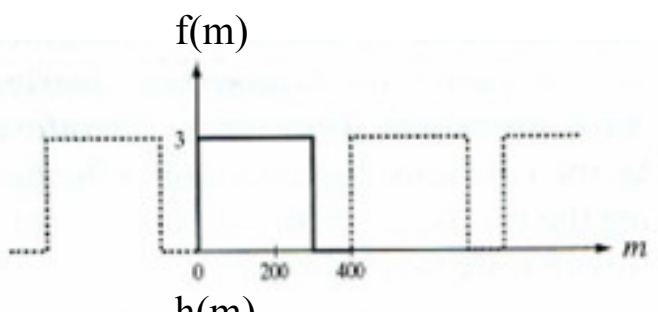

$\mathrm{h}(\mathrm{m})$
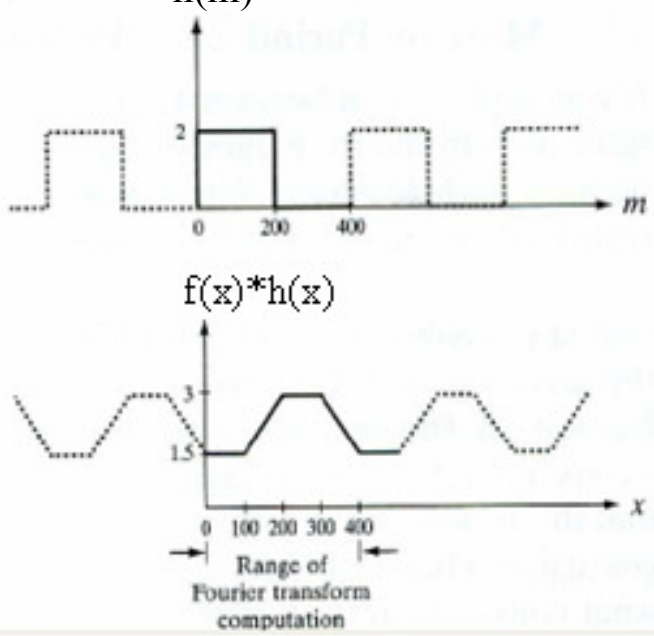

Figura 3.36 - Convolução das funções $f(m)$ e $h(m)$ (a) sem periodicidade e (b) com periodicidade.

Pode-se notar pela figura 3.36 que a convolução de duas funções periódicas gera um resultado diferente daquele obtido com a convolução de duas funções sem periodicidade. Para se resolver isso, pode-se aplicar o chamado padding, que consiste em adicionar zeros nas funções a serem convoluídas, de modo que elas fiquem com o mesmo período $P$. Tomando-se, por exemplo, as funções $f$ e $h$, com $A$ e $B$ pontos, respectivamente, o procedimento do padding faz com que elas apresentem a seguinte forma:

$$
f_{p}(m)=\left\{\begin{array}{cc}
f(m) & \text { para } 0 \leq \mathrm{x} \leq \mathrm{A}-1 \\
0 & \text { para } \mathrm{A} \leq \mathrm{x} \leq \mathrm{P}
\end{array}\right.
$$

e 
168

$$
g_{p}(m)=\left\{\begin{array}{cc}
g(m) & \text { para } 0 \leq \mathrm{x} \leq \mathrm{B}-1 \\
0 & \text { para } \mathrm{B} \leq \mathrm{x} \leq \mathrm{P},
\end{array}\right.
$$

onde

$$
P \geq A+B-1 \text {. }
$$

Nas equações (3.59) e (3.60), o índice $p$ indica que as funções passaram pelo procedimento do padding.

A figura 3.37 mostra a convolução das mesmas funções $f(m)$ e $h(m)$ da figura 3.36, após a aplicação do padding.
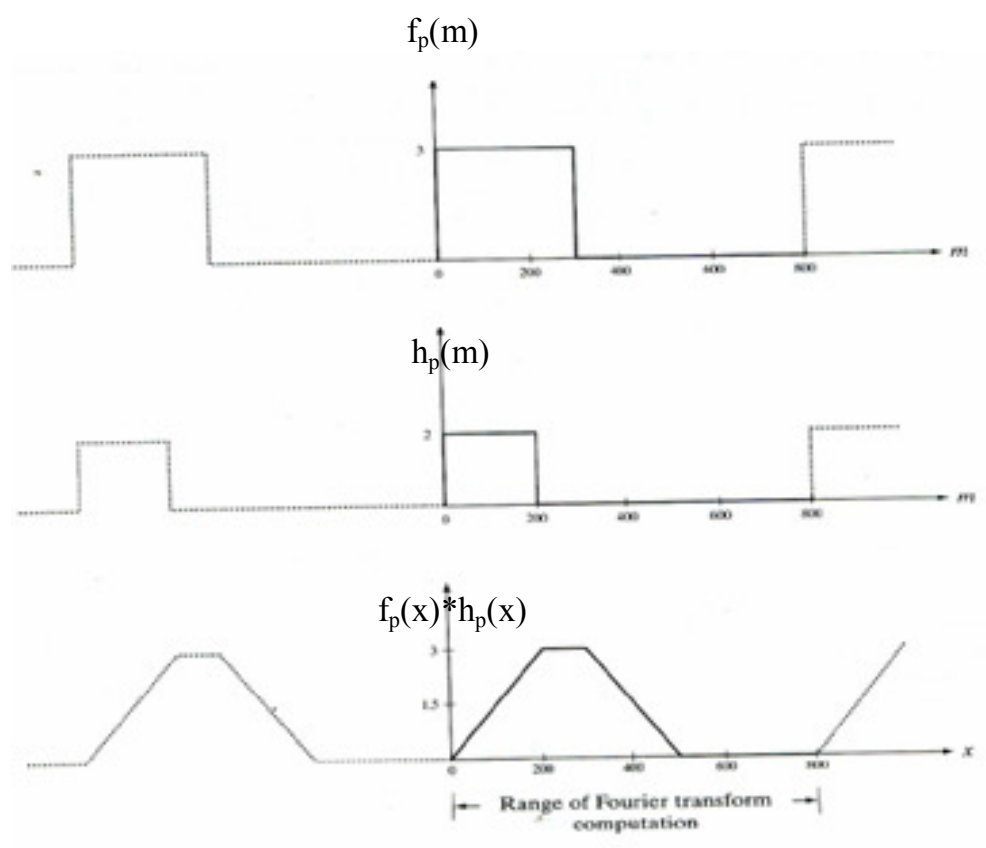

Figura 3.37 - Convolução das funções $f(m)$ e $h(m)$, após a aplicação do procedimento do "padding".

Observando-se a figura 3.37, pode-se notar que a aplicação do padding fez com que a convolução de $f_{p}(m)$ e $h_{p}(m)$ ficasse igual ao resultado mostrado na figura 3.36 - $a$, ou seja, podese concluir que a utilização desse procedimento evita que a convolução das duas funções gere resultados errôneos devido à sua periodicidade. 
A extensão desses conceitos para funções bidimensionais (imagens, por exemplo) é bastante simples. Tomando-se duas imagens $f(x, y)$ e $h(x, y)$ de tamanhos $A$ x $B$ e $C$ x $D$, respectivamente, o procedimento do padding deve fazer com que essas duas funções possuam os períodos $P$ e $Q$ nos eixos horizontal e vertical, respectivamente, dados por

$$
P \geq A+C-1
$$

$\mathrm{e}$

$$
Q \geq B+D-1 .
$$

As funções $f(x, y)$ e $h(x, y)$, após a aplicação do padding ficam dadas por

$$
f_{p}(x, y)=\left\{\begin{array}{cl}
f(x, y) & \text { para } 0 \leq \mathrm{x} \leq \mathrm{A}-1 \text { e } 0 \leq \mathrm{y} \leq \mathrm{B}-1 \\
0 & \text { para } \mathrm{A} \leq \mathrm{x} \leq \mathrm{P} \text { ou } \mathrm{B} \leq \mathrm{y} \leq \mathrm{Q}
\end{array}\right.
$$

e

$$
h_{p}(x, y)=\left\{\begin{array}{cc}
h(x, y) & \text { para } 0 \leq \mathrm{x} \leq \mathrm{C}-1 \text { e } 0 \leq \mathrm{y} \leq \mathrm{D}-1 \\
0 & \text { para } \mathrm{C} \leq \mathrm{x} \leq \mathrm{P} \text { ou } \mathrm{D} \leq \mathrm{y} \leq \mathrm{Q}
\end{array}\right.
$$

A utilização do padding é muito importante quando se realiza a filtragem de uma imagem no domínio de frequências. Isso porque, conforme diz o teorema da convolução, a multiplicação do filtro pela transformada de Fourier de uma imagem no domínio de frequências equivale a uma convolução da imagem original com a transformada inversa do filtro no domínio espacial. Como se trata de transformadas de Fourier, há uma periodicidade implícita e, dessa forma, se o padding não for aplicado, o resultado da filtragem irá conter dados errôneos.

Quando se pretende usar o padding, em geral, o filtro (que é construído no espaço de frequências) é gerado com um tamanho igual ao da imagem após a aplicação do padding. $\mathrm{O}$ restante do procedimento de filtragem deve ser feito conforme descrito anteriormente. 
Para se aplicar a filtragem espacial de Butterworth nos cubos de dados analisados nesse trabalho, foi elaborado um script em linguagem IDL, que executava uma série de procedimentos em cada uma das imagens dos cubos de dados. Primeiramente, o filtro a ser utilizado era criado. Após isso, aplicava-se o padding nas imagens e o fator $(-1)^{x+y}$ era multiplicado por cada um de seus pixeis. Em seguida, as transformadas de Fourier dessas imagens eram calculadas (ou seja, o cubo era passado para o domínio de freqüências espaciais) e, logo após, multiplicadas pelo filtro construído previamente (removendo, assim, as componentes de alta freqüência espacial presentes em todo o cubo de dados). Na seqüência, a transformada inversa de Fourier de cada uma das imagens era calculada e a sua parte real extraída (assim, componentes complexas originadas de imprecisões computacionais eram eliminadas). Por fim, todas as imagens do cubo eram multiplicadas, novamente, pelo fator $(-1)^{x+y}$, completando o procedimento. Alguns exemplos da aplicação da filtragem espacial de Butterworth em cubos de dados do IFU do GMOS, do NIFS e do SINFONI são mostrados nas sessões a seguir.

\subsection{1 - Filtragem espacial de Butterworth em cubos de dados do GMOS}

Conforme foi mencionado anteriormente, como a reamostragem espacial (que pode introduzir componentes de alta frequência espacial nas imagens) não foi aplicada nos cubos de dados do IFU do GMOS, todo o ruído de alta frequência espacial detectado nesses casos é de natureza instrumental ou devido à baixa estatística de fótons. A figura 3.38 mostra o módulo da transformada de Fourier da imagem de um comprimento de onda intermediário do cubo de dados de ltt 4816.

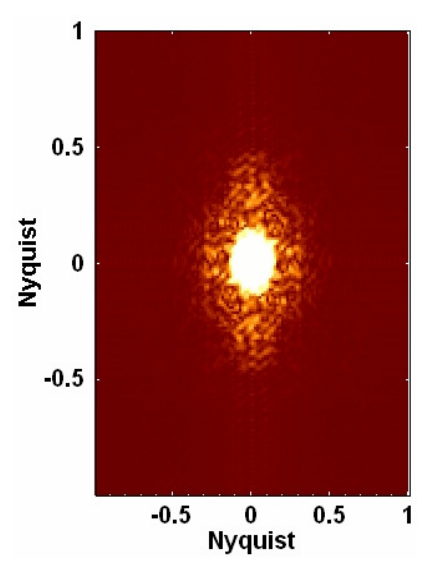

Figura 3.38 - Imagem do módulo da transformada de Fourier de um comprimento de onda intermediário do cubo de dados de ltt 4816. 
$\mathrm{Na}$ figura 3.38, a área brilhante mais uniforme próxima ao centro da imagem corresponde às componentes de baixa freqüência espacial presentes no cubo de dados de ltt 4816. Testes mostraram que essa região central representa as freqüências espaciais menores ou iguais à correspondente à PSF da observação (que, por sua vez, é a maior freqüência espacial que pode ser detectada, com exceção de ruídos, na imagem de um objeto celeste). Por outro lado, as áreas claras menores, de aspecto "floculento", afastadas do centro da imagem representam as componentes de mais alta freqüência espacial. A aplicação da filtragem espacial de Butterworth em todos os cubos de dados analisados nesse trabalho teve como objetivo remover as componentes com freqüência maior do que a da PSF da observação e preservar as demais. No caso de cubos de dados do IFU do GMOS, portanto, procurou-se eliminar as componentes em freqüência que, na figura 3.38, correspondem às áreas claras "floculentas" afastadas da região central.

Uma formulação simples do filtro de Butterworth, com formato elíptico, derivada diretamente da expressão (3.58) pode ser dada por

$$
H(u, v)=\frac{1}{1+\left[\sqrt{\left(\frac{u-u_{0}}{a}\right)^{2}+\left(\frac{v-v_{0}}{b}\right)^{2}}\right]^{2 n}} .
$$

onde $\left(u_{0}, v_{0}\right)=$ coordenadas do centro da imagem correspondente à transformada de Fourier $a=$ freqüência de corte (em pixeis) ao longo do eixo horizontal da imagem correspondente à transformada de Fourier $b=$ freqüência de corte (em pixeis) ao longo do eixo vertical da imagem correspondente à transformada de Fourier $n=$ ordem de filtragem

A figura 3.39 mostra as imagens de um intervalo espectral intermediário colapsado dos cubos de dados $W_{0}$ de ltt 4816, antes e após a aplicação do filtro de Butterworth (dado pela 
expressão 3.66) com diferentes ordens de filtragem. Em todos os casos, a freqüência de corte nos eixos horizontal e vertical utilizada no procedimento foi de $0.15 \mathrm{Ny}$, o que, geralmente, é um valor apropriado, considerando-se as condições de seeing frequentemente obtidas em observações com o GMOS nessa região espectral.
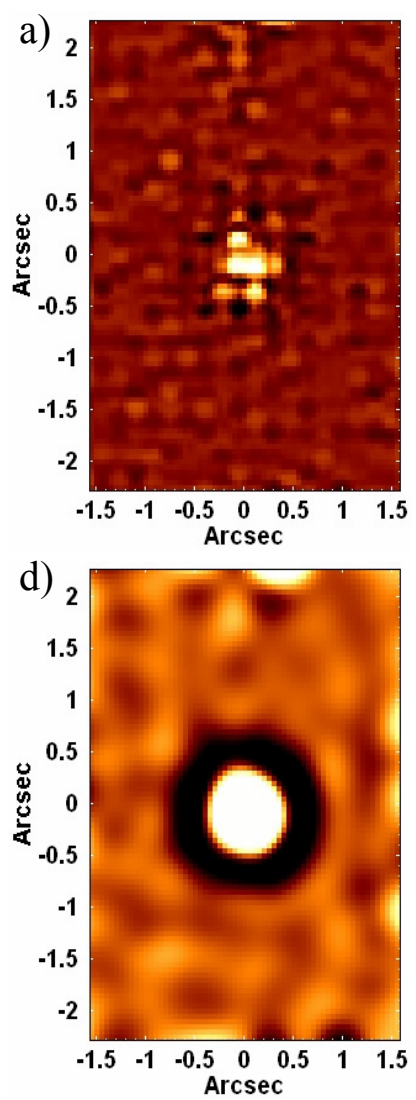
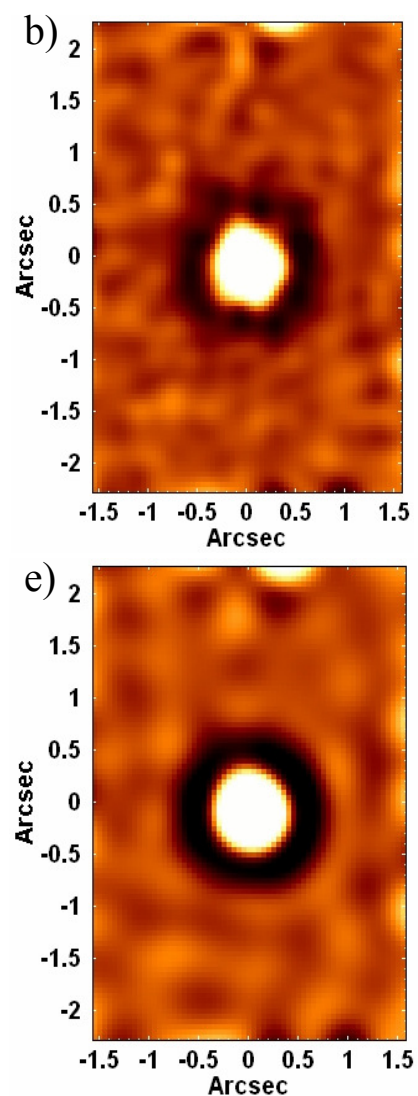
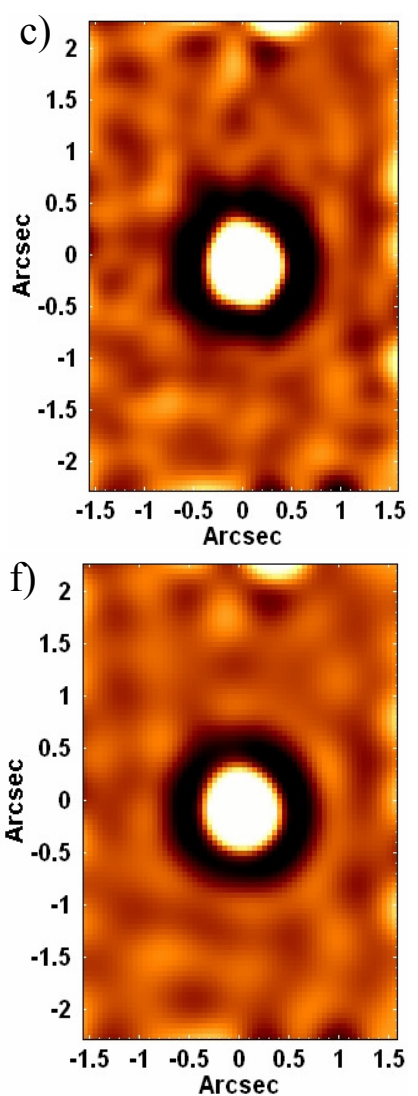

Figura 3.39 - Imagens de um intervalo espectral intermediário colapsado do cubo de dados $W_{0}$ de ltt 4816, a) antes da filtragem espacial de Butterworth e após a filtragem com ordem b) $n=2$, c) $n=3$, d) $n=4$, e) $n=5$ ef) $n=6$. Em todas as filtragens foi utilizada uma freqüencia de corte de $0.15 \mathrm{Ny}$.

Observando-se a figura 3.39, pode-se notar, primeiramente, que a aplicação da filtragem espacial de Butterworth permitiu que a estrela ltt 4816, que não era visível de maneira muito clara no cubo de dados $W_{0}$ original, se tornasse facilmente detectável. Por outro lado, as filtragens com ordem maior do que 2 introduziram uma estrutura em forma de anel ao redor da estrela, que começa a ser detectada quando $n=3$ e vai se tornando cada vez mais intensa à medida que $n$ cresce, ficando com uma intensidade considerável quando $n=6$. Essa é uma conseqüência esperada da aplicação da filtragem espacial de Butterworth com altas ordens. Para se explicar esse comportamento, primeiramente, é preciso lembrar que, de acordo com o teorema da 
convolução (mencionado anteriormente) uma multiplicação de duas imagens no domínio de freqüências equivale a uma convolução no domínio espacial. Assim, o procedimento da filtragem espacial de Butterworth dos cubos de dados (que corresponde à multiplicação do filtro pelas transformadas de Fourier das imagens dos cubos) equivale a uma convolução das imagens desses cubos com a transformada de Fourier inversa do filtro. A figura 3.40 mostra os módulos das transformadas de Fourier inversas dos filtros utilizados nas filtragens que deram origens às imagens da figura 3.39 .
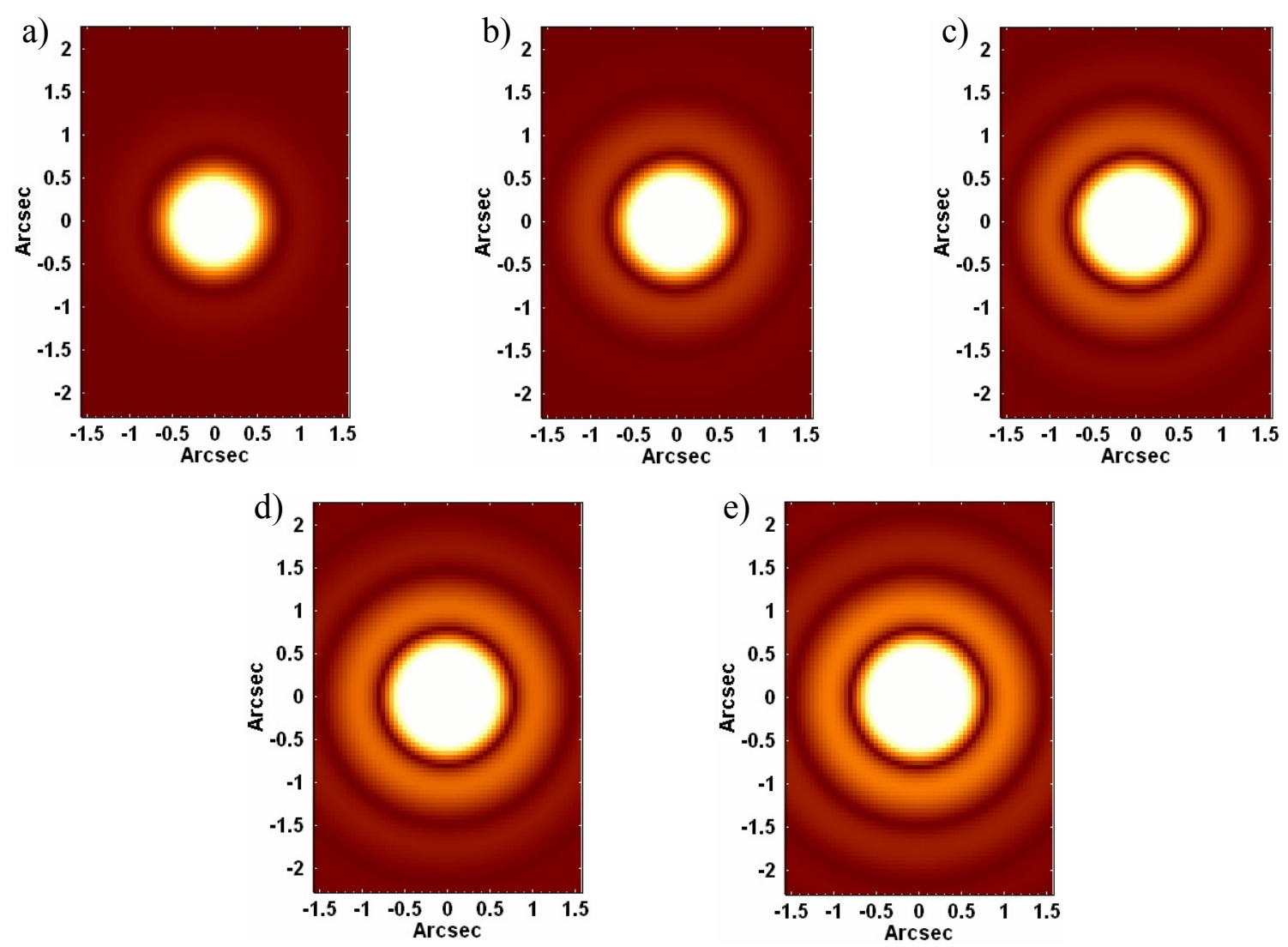

Figura 3.40 - Módulos das transformadas de Fourier inversas de filtros de Butterworth com freqüencia de corte de $0.15 \mathrm{Ny}$ e ordens a) $n=2$, b) $n=3$, c) $n=4$, d) $n=5$ e e) $n=6$. Todas as imagens foram feitas utilizando-se a mesma LUT.

A figura 3.40 mostra que a transformada de Fourier inversa do filtro com $n=6$ apresenta uma série de anéis concêntricos, que vão diminuindo em número e em intensidade à medida que $n$ diminui, restando, apenas, um fraco anel (que quase não é detectável) quando $n=2$. Como a filtragem espacial de Butterworth equivale à convolução desses filtros com as imagens dos cubos de dados, fica bastante claro porque aplicar o procedimento com altos valores de $n$ introduz anéis 
nas imagens filtradas. É importante mencionar, entretanto, que o anel visualizado na figura 3.39 é de baixa intensidade e somente pôde ser detectado porque foram analisadas imagens do cubo de dados $W_{0}$ de ltt 4816. Esse anel não é visível no cubo de dados original dessa estrela, pois, está imerso na componente de baixa freqüência espacial (que não aparece no cubo de dados $W_{0}$ ) da PSF desse objeto, ficando ofuscado pela mesma. Esse comportamento é bastante geral em cubos de dados obtidos com o IFU do GMOS, ou seja, é muito difícil detectar os anéis introduzidos por filtragens espaciais de Butterworth de alta ordem, a não ser que seja analisado o cubo de dados $W_{0}$ do objeto observado.

A figura 3.39 mostra que apenas filtragens espaciais de Butterworth com ordens menores ou iguais a 2 não introduzem anéis significativos nas imagens, o que parece indicar que a utilização de $n=2$ seria a melhor escolha. Entretanto, uma filtragem com essa ordem não remove de maneira tão eficaz o ruído espacial. Para se resolver esse problema, optou-se por aplicar, em cubos de dados do IFU do GMOS, uma filtragem espacial de Butterworth com um filtro de $n=2$ multiplicado por outro de mesma ordem, ou seja, o filtro final utilizado pode ser dado pela expressão

$$
H(u, v)=\left\{\frac{1}{1+\left[\sqrt{\left(\frac{u-u_{0}}{a}\right)^{2}+\left(\frac{v-v_{0}}{b}\right)^{2}}\right]^{2 n}}\right\}^{2},
$$

considerando-se $n=2$.

Ao se utilizar a expressão (3.67) $\operatorname{com} n=2$, entretanto, foi necessário aumentar o valor da freqüência de corte para que a PSF não fosse prejudicada. Verificou-se que, considerando-se as condições de seeing geralmente obtidas em observações com o GMOS, freqüências de corte de cerca de $0.18 \mathrm{Ny}$ ou $0.19 \mathrm{Ny}$ são apropriadas para a aplicação da fórmula (3.67) $\operatorname{com} n=2$. A figura 3.41 mostra a imagem de um intervalo espectral intermediário colapsado do cubo de dados $W_{0}$ de ltt 4816, após a aplicação da filtragem de Butterworth com um filtro dado pela expressão (3.67) com $n=2$ e freqüência de corte de $0.18 \mathrm{Ny}$. Na mesma figura também é mostrada a transformada de Fourier inversa do filtro utilizado no procedimento aplicado. 

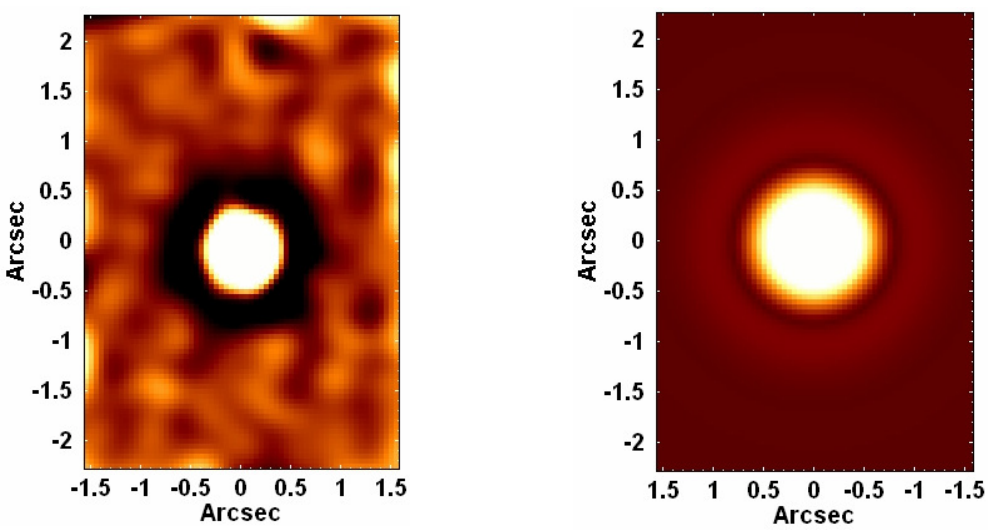

Figura 3.41 - (esquerda) Imagem de um intervalo espectral intermediário colapsado do cubo de dados $W_{0}$ de ltt 4816, após a aplicação da filtragem espacial de Butterworth com um filtro dado pela expressão (3.67) com $n=2$ e freqüencia de corte de $0.18 \mathrm{Ny}$; (direita) Módulo da transformada de Fourier inversa do filtro utilizado na filtragem de Butterworth que originou a imagem à esquerda.

Comparando-se as figuras 3.41 e 3.39 , pode-se notar que a filtragem espacial de Butterworth utilizando um filtro dado pela expressão (3.67) (uma multiplicação de dois filtros) com $n=2$ promoveu uma maior remoção de ruído do que quando foi usado o filtro dado pela equação (3.66) (um filtro simples) com mesma ordem. Além disso, o processo envolvendo a multiplicação de dois filtros não introduziu anéis nas imagens, o que mostra que esse procedimento é mais vantajoso do que a utilização de filtragens de alta ordem que, conforme mostrado na figura 3.39, introduzem estruturas de formato anelar nas imagens.

Nesse trabalho, os cubos de dados $W_{0}$ foram utilizados, apenas, para se determinar as melhores freqüências de corte para as filtragens espaciais de Butterworth a serem aplicadas nos cubos de dados originais dos objetos analisados. A razão disso é que, como $W_{0}$ contém, somente, as componentes de alta freqüência espacial existentes, a análise desse cubo torna mais simples avaliar a quantidade de ruído removido e detectar alguma possível introdução de anéis nas imagens (já que essas estruturas são mais facilmente detectáveis quando as estruturas de baixa freqüência espacial não estão presentes).

Em resumo, pode-se dizer que a filtragem espacial de Butterworth de cubos de dados do IFU do GMOS foi feita com filtros dados pela expressão (3.67) com $n=2$ e freqüências de corte determinadas pelos cubos de dados $W_{0}$ dos objetos analisados. A figura 3.42 mostra as imagens de um intervalo espectral intermediário colapsado do cubo de dados original de ltt 4816, antes e depois da filtragem espacial de Butterworth, assim como do cubo de dados correspondente à diferença entre esses dois. 

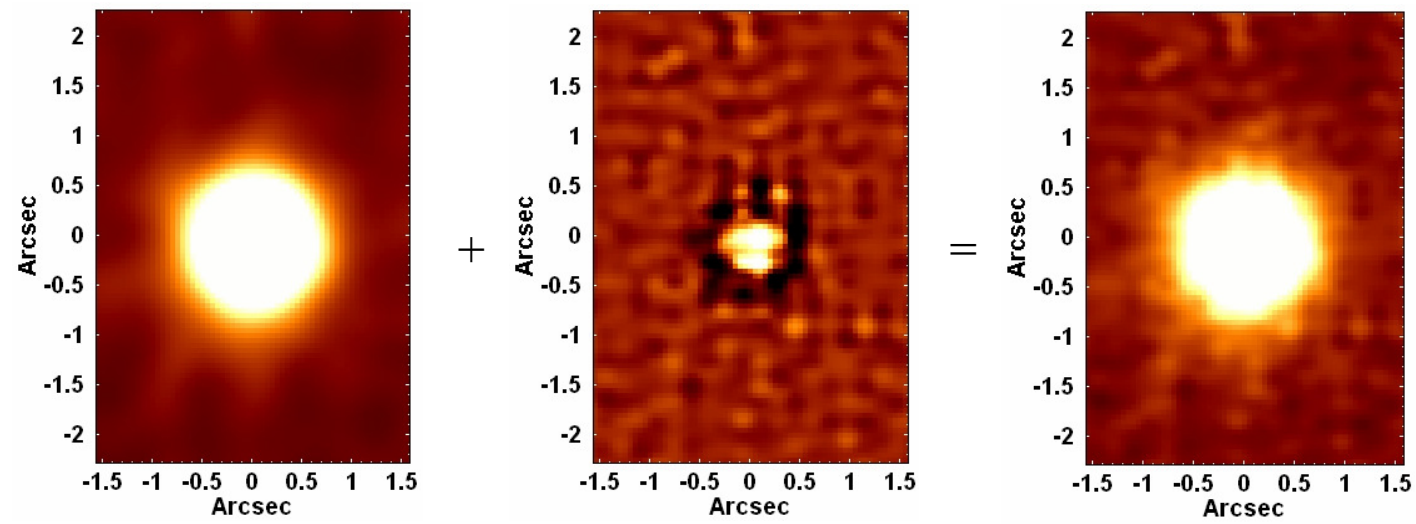

Figura 3.42 - (esquerda) Imagem de um intervalo espectral intermediário colapsado do cubo de dados de ltt 4816, após a filtragem espacial de Butterworth; (centro) Imagem de um intervalo espectral intermediário colapsado do cubo de dados de ltt 4816 correspondente à diferença entre o cubo não filtrado e o cubo filtrado; (direita) Imagem de um intervalo espectral intermediário colapsado do cubo de dados de ltt 4816, antes da filtragem espacial de Butterworth.

Observando-se a figura 3.42, pode-se notar a grande remoção de ruído de alta freqüência promovida pela filtragem espacial de Butterworth no cubo de dados de ltt 4816. A região central brilhante na imagem representativa do ruído na figura 3.42, entretanto, parece indicar que a PSF do objeto foi ligeiramente prejudicada, o que poderia sugerir que uma frequiência de corte maior seria mais adequada. Entretanto, testes mostraram que freqüências de corte maiores não removeriam tão eficientemente o ruído, além de que qualquer prejuízo sofrido pela PSF foi mínimo, assim, optou-se por manter esse valor de freqüência de corte.

\subsection{2 - Filtragem espacial de Butterworth em cubos de dados do NIFS}

A filtragem espacial de Butterworth em cubos de dados do NIFS teve como objetivo remover não apenas ruídos de alta freqüência espacial de natureza instrumental, mas também as componentes de alta freqüência introduzidas nas imagens pelo processo da reamostragem espacial, conforme mencionado anteriormente.

Devido à aparência da região de baixa freqüência espacial (que deve ser preservada nesse processo de filtragem) na transformada de Fourier de GQ Lup (figura 3.30), concluiu-se que o filtro mais apropriado para ser utilizado na filtragem espacial de Butterworth pode ser dado pela expressão 


$$
H(u, v)=\left\{\frac{1}{1+\left[\sqrt{\left(\frac{u-u_{0}}{a}\right)^{2}+\left(\frac{v-v_{0}}{b}\right)^{2}}\right]^{2 n}}\right\} \cdot\left\{\frac{1}{1+\left[\frac{\left|u-u_{0}\right|}{c}\right]^{2 n}} \cdot \frac{1}{1+\left[\frac{\left|v-v_{0}\right|}{d}\right]^{2 n}}\right\},
$$

que corresponde ao produto de um filtro com formato elíptico por outro com formato retangular. Vários testes mostraram que esse formato de filtro parece ser adequado para as filtragens em geral de cubos de dados obtidos com o NIFS. A figura 3.43 mostra as imagens de um intervalo espectral intermediário colapsado dos cubos de dados $W_{0}$ de GQ Lup, antes e após a aplicação do filtro de Butterworth (dado pela expressão 3.68) com diferentes ordens de filtragem. Em todos os casos, a freqüência de corte nos eixos horizontal e vertical utilizada no procedimento foi de 0.32 Ny.
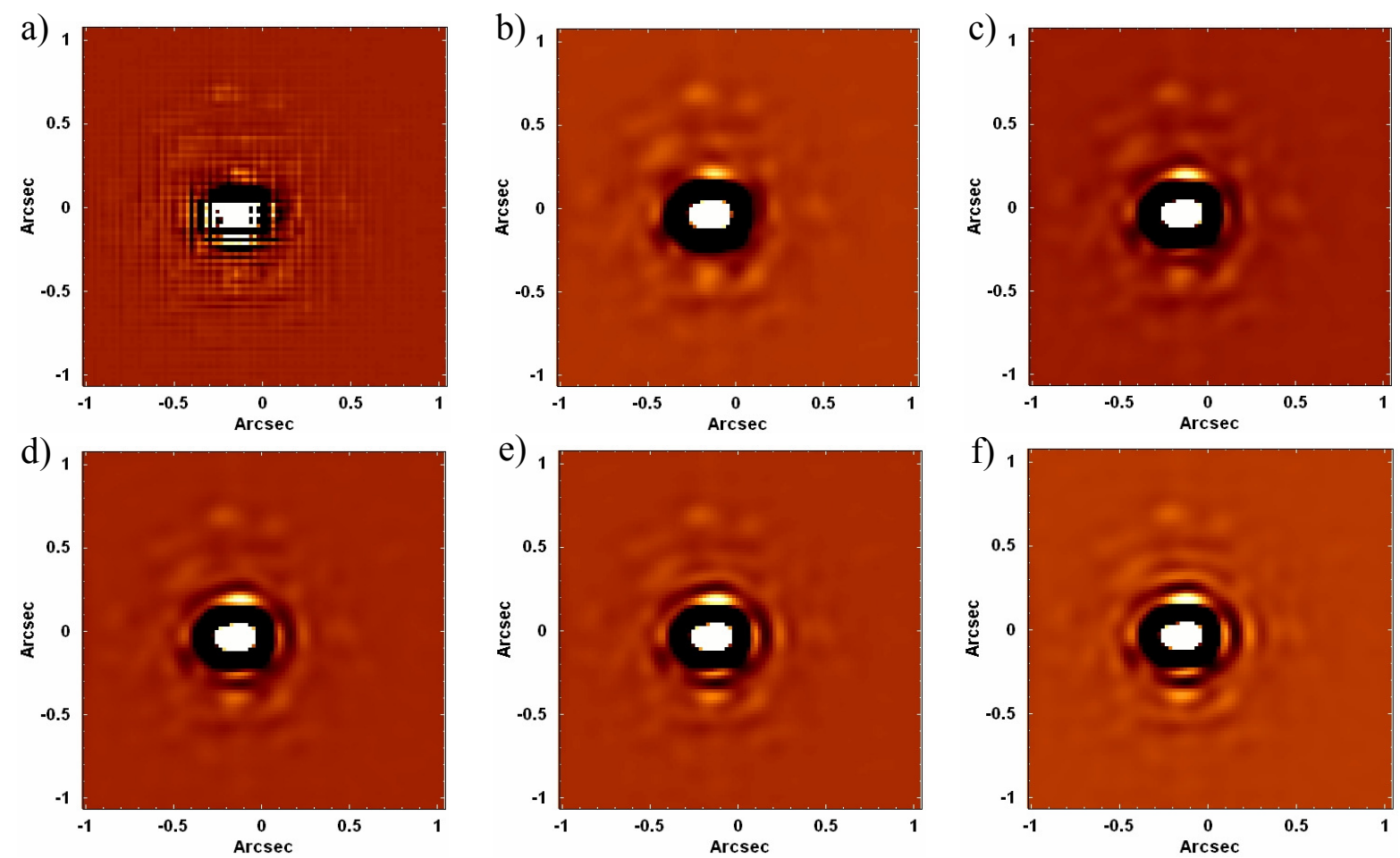

Figura 3.43 - Imagens de um intervalo espectral intermediário colapsado do cubo de dados $W_{0}$ de GQ Lup, a) antes da filtragem espacial de Butterworth e após a filtragem com ordem b) $n=2$, c) $n=3$, d) $n=4$, e) $n=5$ ef) $n=6$. Em todas as filtragens foi utilizada uma freqüencia de corte de $0.32 \mathrm{Ny}$. 
A figura 3.43 mostra que a aplicação da filtragem espacial de Butterworth melhorou muito a visualização da estrela GQ Lup, que aparecia de um modo muito distorcido no cubo de dados $W_{0}$ original. Entretanto, as filtragens com ordem maior do que 2 introduziram estruturas similares a anéis concêntricos nas imagens, que começam a ser detectados quando $n=3$ e vão se tornando mais intensos à medida que $n$ cresce. Um ponto importante a ser ressaltado é que, ao contrário do que ocorreu no caso de ltt 4816, as filtragens de alta ordem no cubo $W_{0}$ de GQ Lup introduziram mais de um anel nas imagens, provocando, assim, distorções consideráveis. A explicação para esse comportamento é inteiramente análoga à apresentada no caso de ltt $4816 \mathrm{e}$ se refere ao fato desse procedimento de filtragem espacial ser equivalente a uma convolução entre as imagens do cubo de dados e a transformada de Fourier inversa do filtro utilizado. A figura 3.44 mostra as transformadas de Fourier inversas dos filtros usados nas filtragens que deram origem às imagens da figura 3.43 .
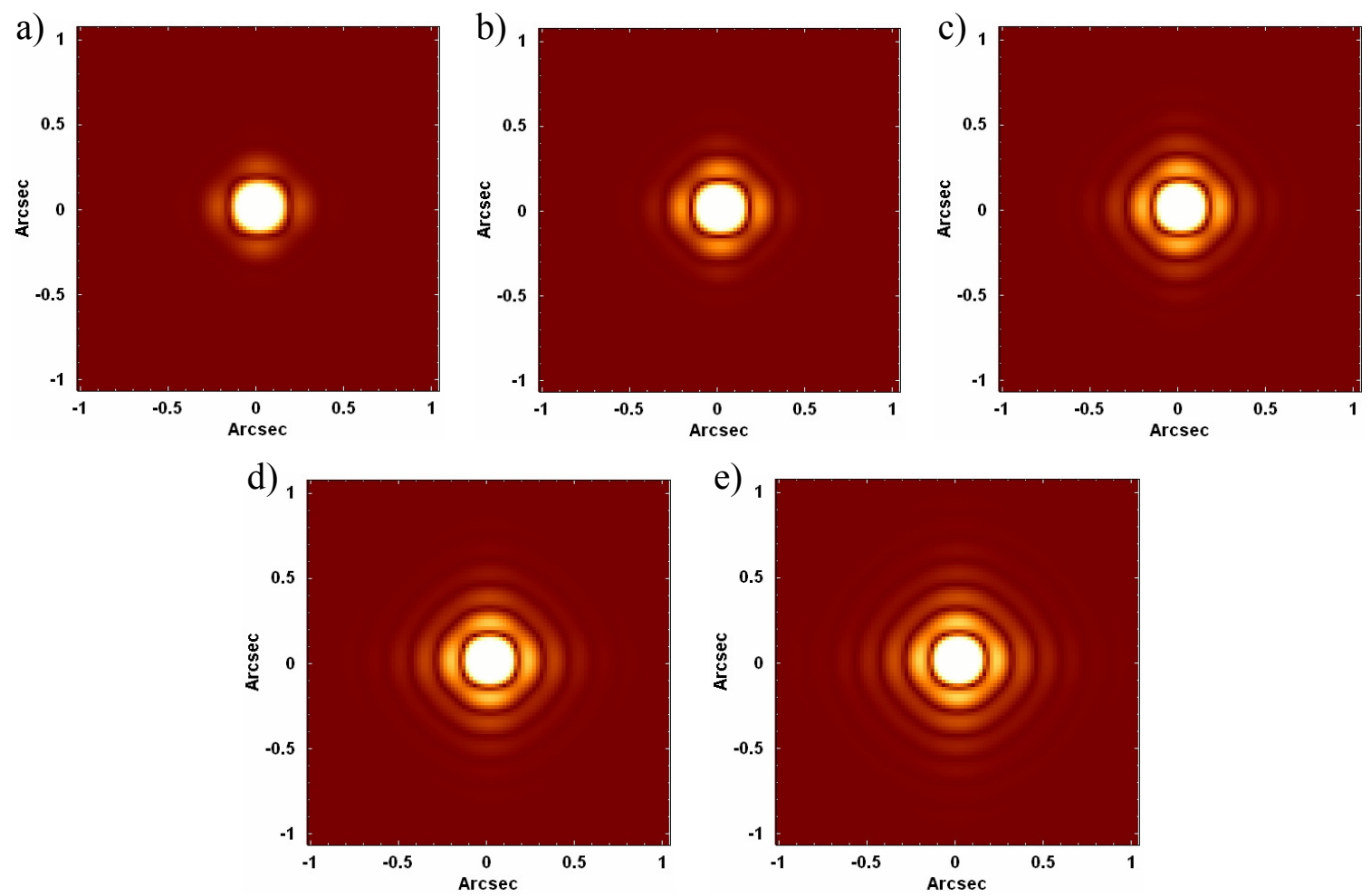

Figura 3.44 - Módulos das transformadas de Fourier inversas de filtros de Butterworth com freqüência de corte de 0.32 Ny e ordens a) $n=2$, b) $n=3$, c) $n=4$, d) $n=5$ e e) $n=6$. Todas as imagens foram feitas utilizando-se a mesma LUT.

Observando-se a figura 3.44, pode-se notar que a transformada de Fourier inversa do filtro com $n=6$ apresenta uma série de anéis concêntricos, que vão diminuindo em número e em 
intensidade à medida que n diminui, restando, apenas, um fraco anel (que quase não é detectável) quando $n=2$. Assim como foi mencionado no caso de ltt 4816, o fato da filtragem espacial de Butterworth ser equivalente à convolução dessas transformadas inversas dos filtros com as imagens dos cubos de dados deixa claro porque aplicar o procedimento com altos valores de $n$ introduz anéis nas imagens filtradas. Comparando-se as figuras 3.40 e 3.44, pode-se notar que o número de anéis no campo de visão é maior nas transformadas de Fourier inversas dos filtros utilizados em GQ Lup do que nas transformadas daqueles usados em ltt 4816. Esse comportamento está associado ao fato de as resoluções espaciais obtidas com o NIFS (levando em conta a região espectral envolvida e a óptica adaptativa do instrumento) serem maiores do que as resultantes de observações com o GMOS. Dessa forma, pode-se dizer que a diferença no número de anéis observados nas figuras 3.40 e 3.44 é uma tendência geral das filtragens espaciais de Butterworth aplicadas em dados desses dois instrumentos. Obviamente, esse comportamento também explica porque a quantidade de anéis introduzida por procedimentos de filtragem de alta ordem é maior em imagens do NIFS do que do GMOS.

Os anéis observados na figura 3.43 somente puderam ser observados tão claramente porque foram analisadas imagens do cubo de dados $W_{0}$ de GQ Lup. Nos cubos de dados originais obtidos com o NIFS é muito mais difícil observar tais estruturas, devido ao fato de estarem imersas nas componentes de baixa freqüência espacial das PSFs dos objetos, sendo "ofuscadas" pelas mesmas. Entretanto, ao contrário do que ocorre no caso de cubos de dados do IFU do GMOS, os anéis introduzidos por filtragens espaciais de Butterworth de alta ordem podem ser observados, de maneira tênue, em alguns cubos de dados originais do NIFS. A razão disso é que a região espectral coberta por esse instrumento e a óptica adaptativa envolvida permitem que sejam obtidos valores bem baixos para o FWHM das PSFs dos objetos, fazendo com que o "ofuscamento" dos anéis introduzidos pela filtragem espacial de Butterworth seja menor. Tal situação, evidentemente, não ocorre em cubos de dados do IFU do GMOS, já que não há óptica adaptativa nesse instrumento.

A figura 3.43 mostra que a filtragem espacial de Butterworth com $n=2$ removeu a maior parte do ruído de alta freqüência espacial existente, mas sem introduzir anéis de maneira perceptível, o que mostra que essa parece ser a ordem de filtragem mais apropriada para cubos de dados obtidos com o NIFS. Ao contrário do que ocorre no caso do GMOS, a freqüência de corte mais adequada para ser utilizada tende a variar bastante em dados do NIFS, devido ao fato de a 
óptica adaptativa nem sempre ser tão eficiente em todos os casos. Assim, utilizou-se o cubo de dados $W_{0}$ para se determinar a freqüência de corte mais apropriada.

Em resumo, pode-se dizer que a filtragem espacial de Butterworth de todos os cubos de dados do NIFS analisados nesse trabalho foi feita utilizando-se filtros dados pela expressão (3.68) com $n=2$ e freqüências de corte determinadas pelos cubos de dados $W_{0}$ dos objetos analisados. A figura 3.45 mostra as imagens de um intervalo espectral intermediário colapsado do cubo de dados original de GQ Lup, antes e depois da filtragem espacial de Butterworth, assim como do cubo de dados correspondente à diferença entre esses dois.
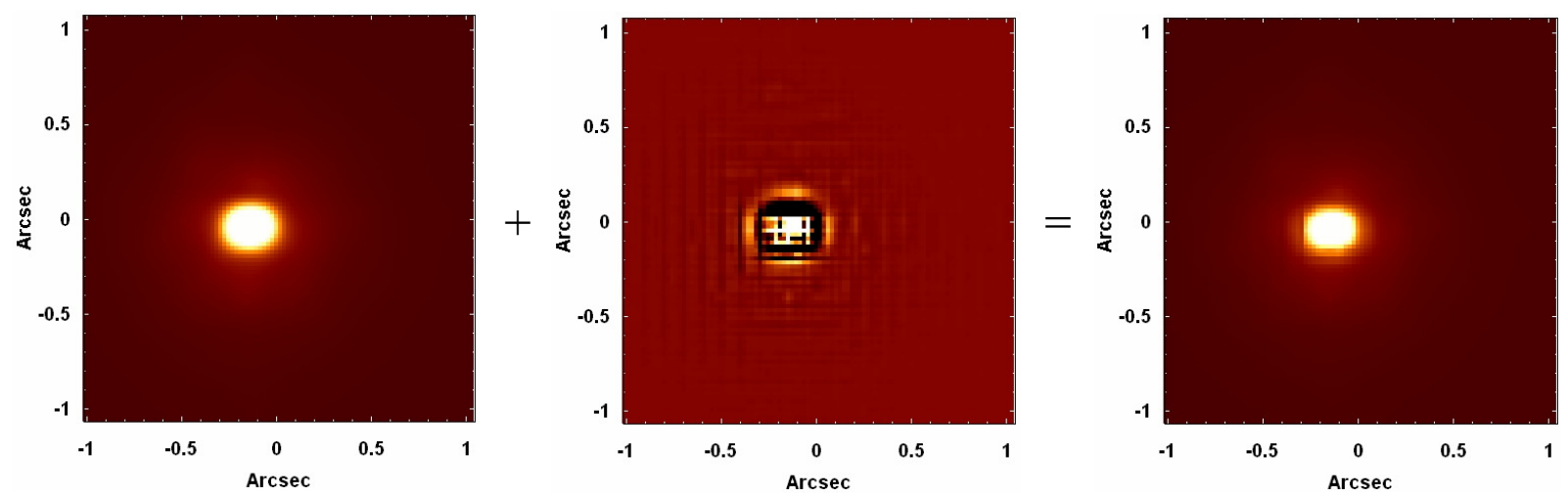

Figura 3.45 - (esquerda) Imagem de um intervalo espectral intermediário colapsado do cubo de dados de GQ Lup, após a filtragem espacial de Butterworth; (centro) Imagem de um intervalo espectral intermediário colapsado do cubo de dados de GQ Lup correspondente à diferença entre o cubo não filtrado e o cubo filtrado; (direita) Imagem de um intervalo espectral intermediário colapsado do cubo de dados de GQ Lup, antes da filtragem espacial de Butterworth.

Observando-se a figura 3.45, pode-se notar que a aplicação da filtragem espacial de Butterworth no cubo de dados de GQ Lup removeu boa parte do ruído de alta freqüência existente nas imagens (que aparece, sobretudo, como faixas horizontais e verticais na figura 3.45). Boa parte desse ruído corresponde às componentes de alta freqüência introduzidas pelo processo de reamostragem espacial. As estruturas visíveis na imagem representativa do ruído na figura 3.45 parecem indicar que a PSF do objeto foi ligeiramente prejudicada, o que poderia sugerir que uma freqüência de corte maior seria mais adequada. Entretanto, testes mostraram que freqüências de corte maiores não removeriam tão eficientemente o ruído, além de que qualquer prejuízo sofrido pela PSF foi bastante pequeno, assim, optou-se por manter esse valor de freqüência de corte. 


\subsection{3 - Filtragem espacial de Butterworth em cubos de dados do SINFONI}

Assim como no caso do NIFS, a filtragem espacial de Butterworth em cubos de dados do SINFONI teve como objetivo remover não apenas ruídos de alta freqüência espacial de natureza instrumental, mas também as componentes de alta freqüência introduzidas nas imagens pelo processo da reamostragem espacial.

Considerando-se a aparência da região de baixa freqüência espacial na transformada de Fourier de HIP 49220 (figura 3.32), optou-se por aplicar a filtragem espacial de Butterworth no cubo de dados desse objeto utilizando-se um filtro dado pela expressão (3.66). A figura 3.46 mostra as imagens de um intervalo espectral intermediário colapsado dos cubos de dados $W_{0}$ de HIP 49220, antes e após a aplicação do filtro de Butterworth (dado pela expressão 3.66) com diferentes ordens de filtragem. Em todos os casos, a freqüência de corte nos eixos horizontal e vertical utilizada no procedimento foi de $0.25 \mathrm{Ny}$.
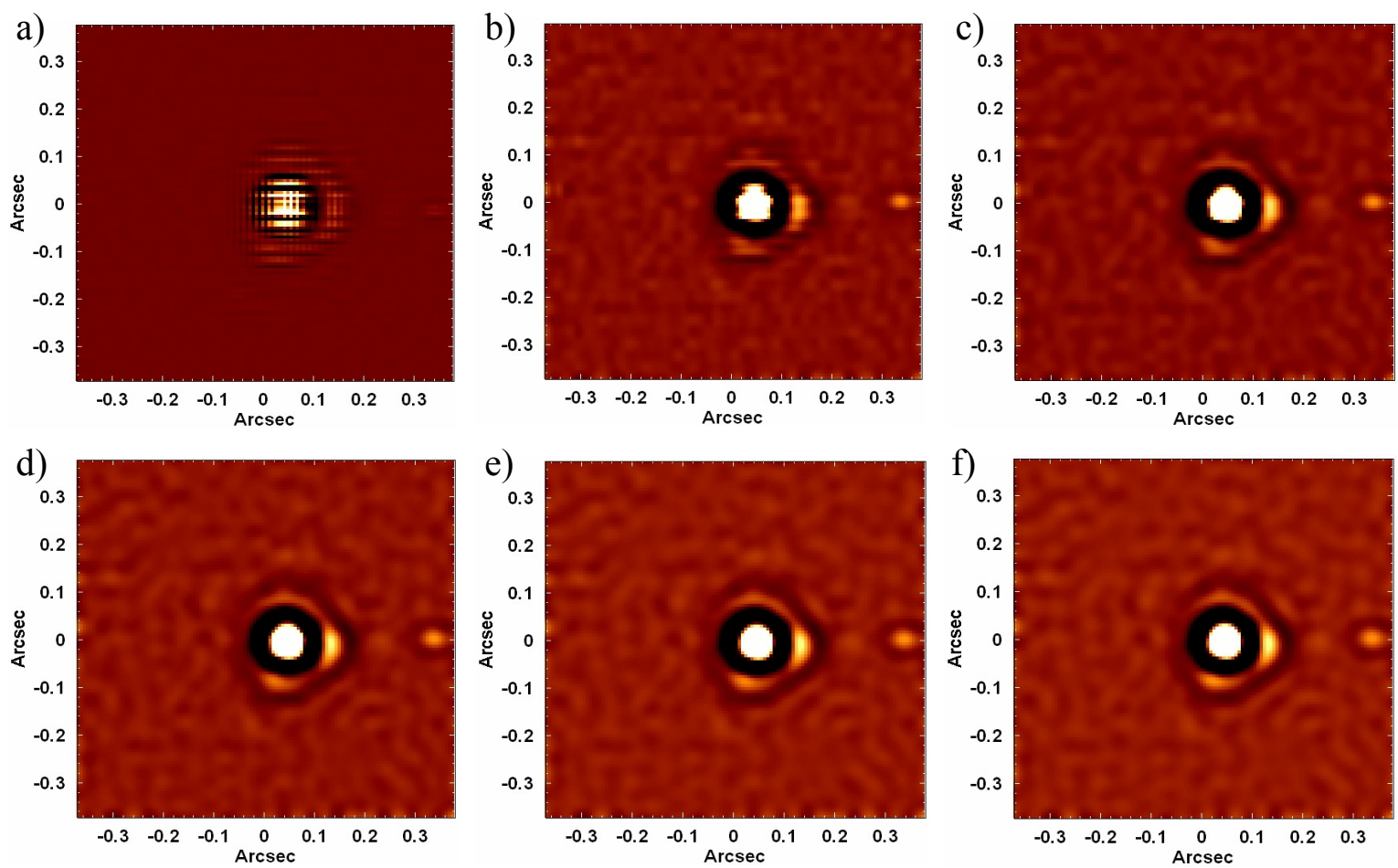

Figura 3.46 - Imagens de um intervalo espectral intermediário colapsado do cubo de dados $W_{0}$ de HIP 49220, a) antes da filtragem espacial de Butterworth e após a filtragem com ordem b) $n=2$, c) $n=3$, d) $n=4$, e) $n=5$ ef) $n=6$. Em todas as filtragens foi utilizada uma freqüência de corte de $0.25 \mathrm{Ny}$. 
A figura 3.46 mostra que o cubo de dados $W_{0}$ de HIP 49220 não filtrado apresenta algumas estruturas ao redor da estrela que se assemelham a um anel, mas que, na verdade, são uma conseqüência do efeito da óptica adaptativa. Tais estruturas ficam mais claras após a filtragem com $n=2$. Para ordens de filtragem maiores ou iguais a 3, entretanto, forma-se uma estrutura anelar mais inteiriça ao redor de HIP 49220, que possui a mesma natureza dos anéis detectados nas imagens resultantes de filtragens espaciais de Butterworth de alta ordem realizadas nos cubos de dados de ltt 4816 e GQ Lup. Dessa forma, o anel detectado nas imagens da figura 3.46 também resulta do fato do processo de filtragem ser equivalente a uma convolução das imagens do cubo de dados com as transformadas de Fourier inversa dos filtros utilizados, sendo que essas últimas apresentam anéis, se forem utilizados valores de $n$ elevados. A figura 3.47 mostra as transformadas de Fourier inversas dos filtros usados nas filtragens que deram origem às imagens da figura 3.46 .
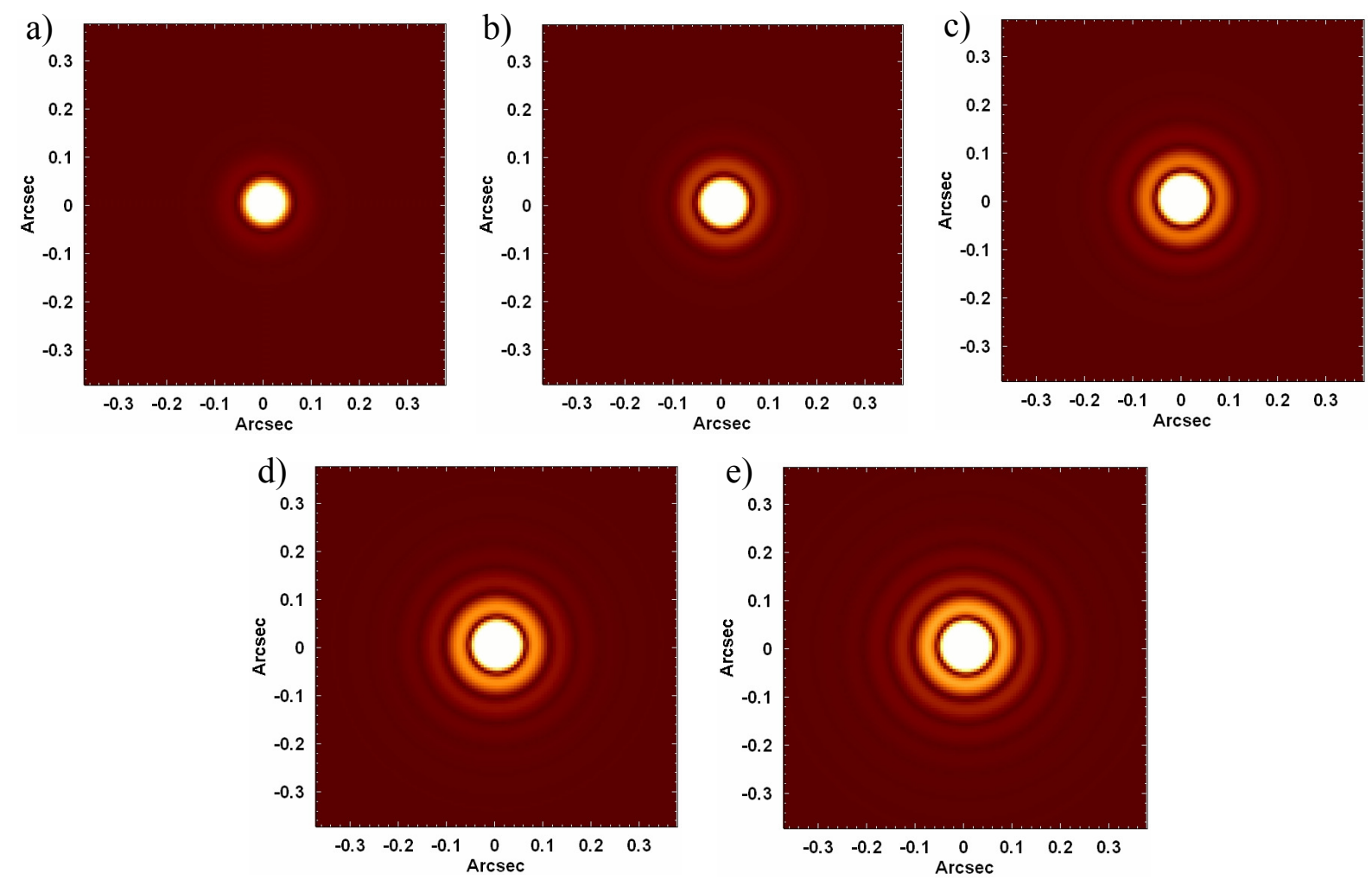

Figura 3.47 - Módulos das transformadas de Fourier inversas de filtros de Butterworth com freqüencia de corte de 0.25 Ny e ordens a) $n=2$, b) $n=3$, c) $n=4$, d) $n=5$ e e) $n=6$. Todas as imagens foram feitas utilizando-se a mesma LUT.

O comportamento das transformadas de Fourier inversas mostradas na figura 3.47 é bastante similar ao que foi observado na figura 3.44 e mostra claramente porque as filtragens 
espaciais de Butterworth de alta ordem em cubos de dados do SINFONI introduzem um anel nas imagens. O anel observado na figura 3.46 só pode ser observado tão claramente em cubos de dados $\mathrm{W}_{0}$, já que ele é fortemente "ofuscado" pelas componentes de baixa freqüência espacial da PSF dos objetos nos cubos de dados originais. Entretanto, assim como no caso do NIFS, em algumas situações, esse anel também pode visualizado, de maneira tênue, em cubos de dados originais, já que a região espectral coberta por esse instrumento e a óptica adaptativa envolvida permitem que sejam obtidos valores bem baixos para o FWHM das PSFs dos objetos, fazendo com que o "ofuscamento" gerado seja menor.

A figura 3.46 mostra que a filtragem espacial de Butterworth com ordens menores ou iguais a 2 não introduzem nenhum anel significativo nas imagens, o que parece indicar que a utilização de $n=2$ seria a melhor escolha. Entretanto, uma filtragem com essa ordem não remove de maneira tão eficaz o ruído espacial. Para se resolver esse problema, optou-se por aplicar o mesmo filtro utilizado nas filtragens de cubos de dados do IFU do GMOS, que é dado pela expressão (3.67) $\operatorname{com} n=2$.

Ao se utilizar a expressão (3.67) $\operatorname{com} n=2$, entretanto, foi necessário aumentar o valor da freqüência de corte para que a PSF não fosse prejudicada. Entretanto, assim como no caso dos dados do NIFS, a freqüência de corte mais adequada para ser utilizada tende a variar bastante em dados do SINFONI, devido ao fato de a óptica adaptativa nem sempre ser tão eficiente em todos os casos. Novamente, o cubo de dados $W_{0}$ foi utilizado para se determinar o valor da freqüência de corte mais apropriado para ser usado. No caso de HIP 49220, a análise do cubo de dados $W_{0}$ mostrou que a freqüência de corte mais adequada para ser utilizada na filtragem espacial de Butterworth envolvendo um filtro dado pela expressão (3.67) $\operatorname{com} n=2$ é de cerca de 0.28 Ny. A figura 3.48 mostra a imagem de um intervalo espectral intermediário colapsado do cubo de dados $W_{0}$ de HIP 49220 após a aplicação da filtragem de Butterworth com um filtro dado pela expressão (3.67) com $n=2$ e freqüência de corte de $0.28 \mathrm{Ny}$. Na mesma figura também é mostrada a transformada de Fourier inversa do filtro utilizado no procedimento aplicado. 

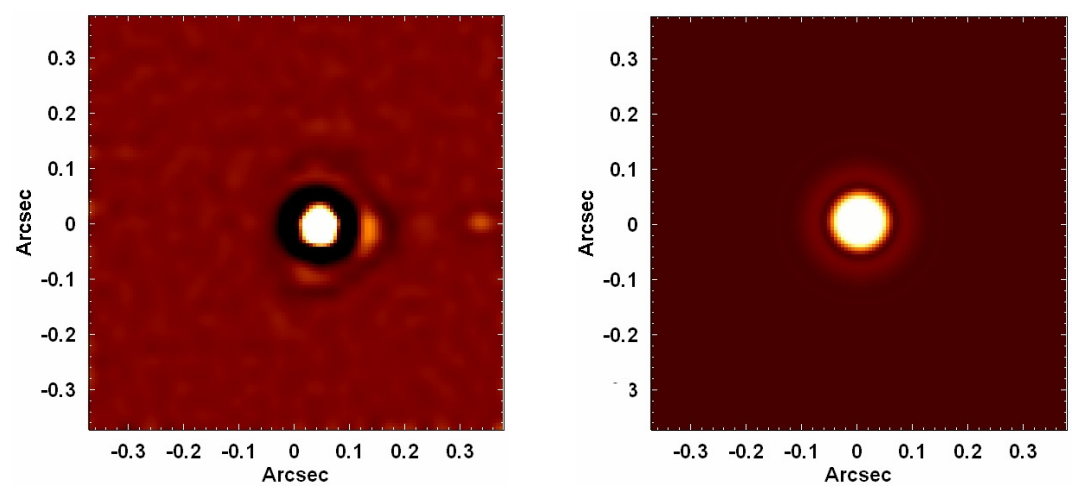

Figura 3.48 - (esquerda) Imagem de um intervalo espectral intermediário colapsado do cubo de dados $W_{0}$ de HIP 49220, após a aplicação da filtragem espacial de Butterworth com um filtro dado pela expressão (3.67) com $n=2$ e freqüencia de corte de $0.28 \mathrm{Ny}$; (direita) Tranformada de Fourier inversa do filtro utilizado na filtragem de Butterworth que originou a imagem à esquerda.

Comparando-se as figuras 3.48 e 3.46, pode-se notar que, assim como ocorreu no caso do IFU do GMOS, a filtragem espacial de Butterworth utilizando um filtro dado pela expressão (3.67) (uma multiplicação de dois filtros) $\operatorname{com} n=2$ promoveu uma maior remoção de ruído do que quando foi usado o filtro dado pela equação (3.66) (um filtro simples) com mesma ordem. As estruturas visíveis ao redor da estrela HIP 49220 na figura 3.48 são uma conseqüência do efeito da óptica adaptativa (assim como foi observado na imagem correspondente à filtragem com $n=2$ na figura 3.46) e não estão associadas a anéis introduzidos pela filtragem. Assim, como o processo envolvendo a multiplicação de dois filtros removeu uma maior quantidade de ruído do que do que quando foi usado um filtro simples e, ao mesmo tempo, não introduziu anéis nas imagens, conclui-se que ele é o mais vantajoso e, consequentemente, foi utilizado na filtragem espacial de Butterworth de cubos de dados do SINFONI.

Em suma, pode-se dizer que a filtragem espacial de Butterworth de todos os cubos de dados do NIFS analisados nesse trabalho foi feita utilizando-se filtros dados pela expressão (3.67) com $n=2$ e freqüências de corte determinadas pelos cubos de dados $\mathrm{W}_{0}$ dos objetos analisados. A figura 3.49 mostra as imagens de um intervalo espectral intermediário colapsado do cubo de dados original de HIP 49220, antes e depois da filtragem espacial de Butterworth, assim como do cubo de dados correspondente à diferença entre esses dois. 

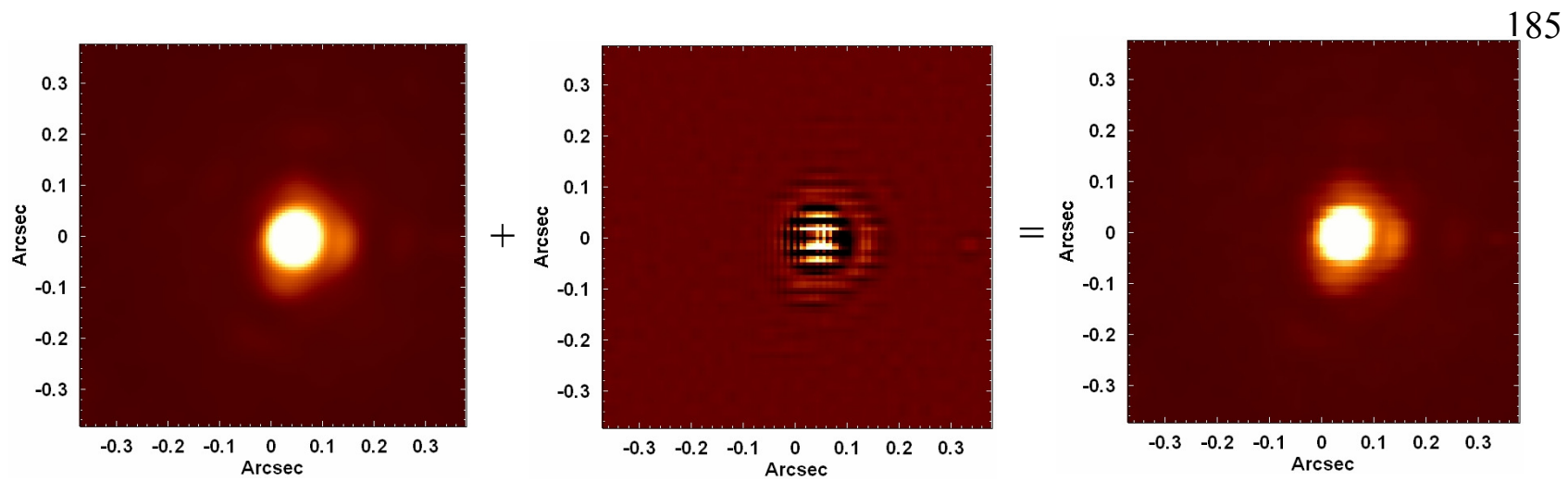

Figura 3.49 - (esquerda) Imagem de um intervalo espectral intermediário colapsado do cubo de dados de HIP 49220, após a filtragem espacial de Butterworth; (centro) Imagem de um intervalo espectral intermediário colapsado do cubo de dados de HIP 49220 correspondente à diferença entre o cubo não filtrado e o cubo filtrado; (direita) Imagem de um intervalo espectral intermediário colapsado do cubo de dados de HIP 49220, antes da filtragem espacial de Butterworth.

Observando-se a figura 3.49, pode-se notar que, assim como nos casos anteriores, a filtragem espacial de Butterworth no cubo de dados de HIP 49220 removeu uma quantidade considerável de ruído de alta freqüência existente nas imagens (que aparece, sobretudo, na forma de faixas horizontais na figura 3.49). Vale lembrar que boa parte desse ruído corresponde às componentes de alta freqüência introduzidas pelo processo de reamostragem espacial. Novamente, algumas das estruturas visíveis na imagem representativa do ruído na figura 3.49 sugerem que a PSF do objeto pode ter sido levemente afetada, o que poderia indicar que uma freqüência de corte maior seria mais adequada. Entretanto, assim como se constatou no caso dos cubos de dados de ltt 4816 e GQ Lup, freqüências de corte maiores não removeriam tão eficientemente o ruído, além de que qualquer prejuízo sofrido pela PSF foi bastante pequeno, assim, optou-se por manter esse valor de freqüência de corte.

\section{8 - De-noising espectral}

Após a filtragem espacial de Butterworth, a etapa seguinte no tratamento dos dados foi a aplicação do de-noising espectral, que tem como objetivo remover ruídos de alta freqüência dos espectros dos cubos de dados. Entretanto, devido a alguns possíveis efeitos colaterais, que são descritos a seguir, esse método somente foi aplicado em alguns casos. 
Para se aplicar o de-noising espectral, primeiramente, foi feita uma decomposição wavelet, utilizando o algoritmo À Trous unidimensional (com a função de escala $\mathrm{B}_{3}$-spline), em cada um dos espectros do cubo de dados. Com isso, foram obtidas as componentes $w_{0}, w_{1}, w_{2}, w_{3}$, $w_{4}, w_{5}, w_{6}$ e $w_{c}$ (foram utilizadas 7 escalas) para cada um desses espectros. Em seguida, para cada pixel espectral $\mathrm{k}$ de cada uma das componentes wavelet, foi calculado o desvio padrão dentro de um intervalo dado por $k-V \rightarrow k+V$, onde $V$ é um número inteiro a ser escolhido. Nesse trabalho, optou-se por utilizar $V=2$, já que esse valor originou resultados bastante satisfatórios. Após isso, a filtragem dessas componentes wavelet foi feita da seguinte maneira: tomando-se um certo valor $\delta$ apropriado (nesse trabalhou optou-se por utilizar $\delta=2$, já que esse foi o valor que gerou os resultados mais adequados), aplicou-se a seguinte condição para cada pixel espectral $k$ de cada componente wavelet:

$$
\begin{aligned}
& \text { se }\left|w_{j, k}\right| \geq \delta \cdot \sigma_{j, k} \text { então } w_{j, k} \text { é significativo } \\
& \text { se }\left|w_{j, k}\right|<\delta \cdot \sigma_{j, k} \text { então } w_{j, k} \text { não é significativo e toma-se } w_{j, k}=0 .
\end{aligned}
$$

onde $\sigma_{j, k}$ é o valor do desvio padrão calculado no intervalo $k-V \rightarrow k+V$

Após essa filtragem, os espectros originais foram reconstruídos, utilizando-se a equação (3.44). Esse procedimento eliminou ruídos espectrais de alta frequência, o que permitiu que uma análise mais precisa fosse feita. Entretanto, verificou-se que a aplicação do de-noising espectral pode gerar alguns efeitos colaterais, como alterações consideráveis no contínuo, deformações nas linhas de emissão (deixando-as mais alargadas, por exemplo) e etc. Por essa razão, essa metodologia somente foi utilizada em casos nos quais ela era extremamente necessária e não introduzia alterações significativas nos espectros.

$\mathrm{O}$ de-noising espectral foi aplicado nos cubos de dados utilizando-se um script escrito em linguagem IDL. O procedimento foi exatamente o mesmo para os cubos de dados obtidos com o IFU do GMOS, com o NIFS e com o SINFONI. As figuras 3.50, 3.51 e 3.52 mostram os espectros extraídos de regiões espaciais (de formato circular) centradas nos objetos dos cubos de dados de ltt 4816, GQ Lup e HIP 49220, antes e depois da aplicação do de-noising espectral. 

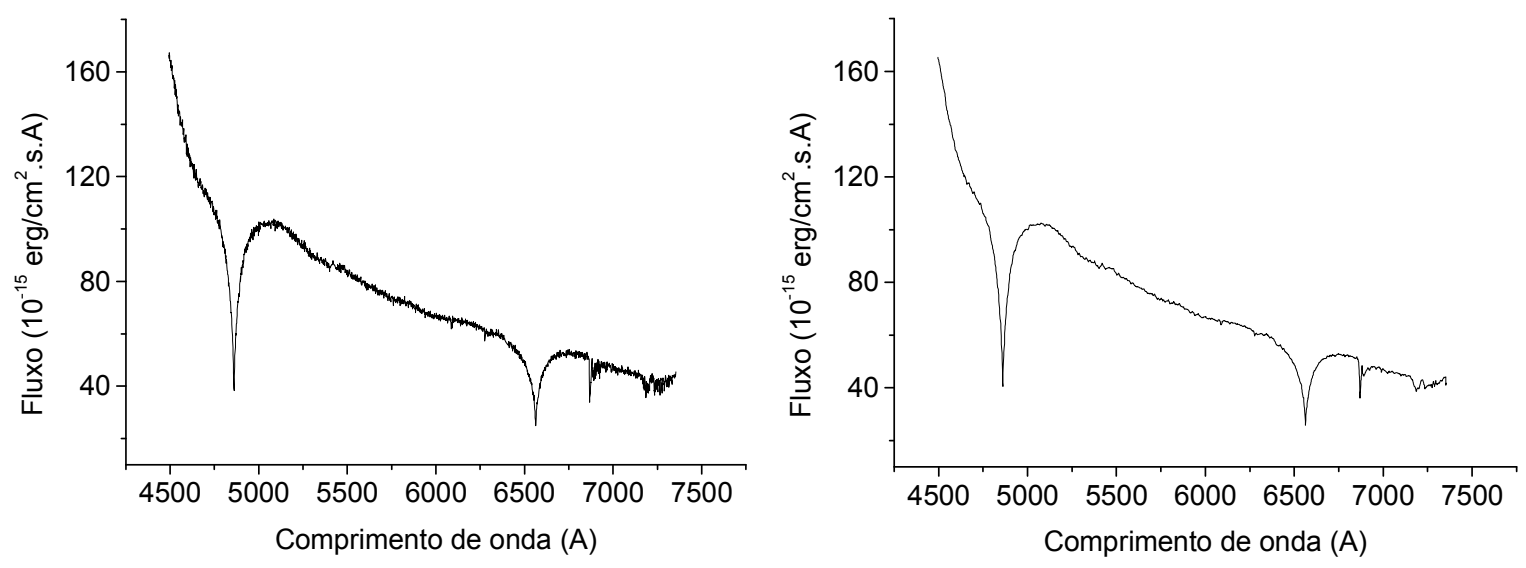

Figura 3.50 - (esquerda) Espectro extraído de uma região espacial (circular) centrada no objeto do cubo de dados de ltt 4816, antes da aplicação do "de-noising" espectral; (direita) Espectro extraído de uma região espacial (circular) centrada no objeto do cubo de dados de ltt 4816, depois da aplicação do "de-noising" espectral.
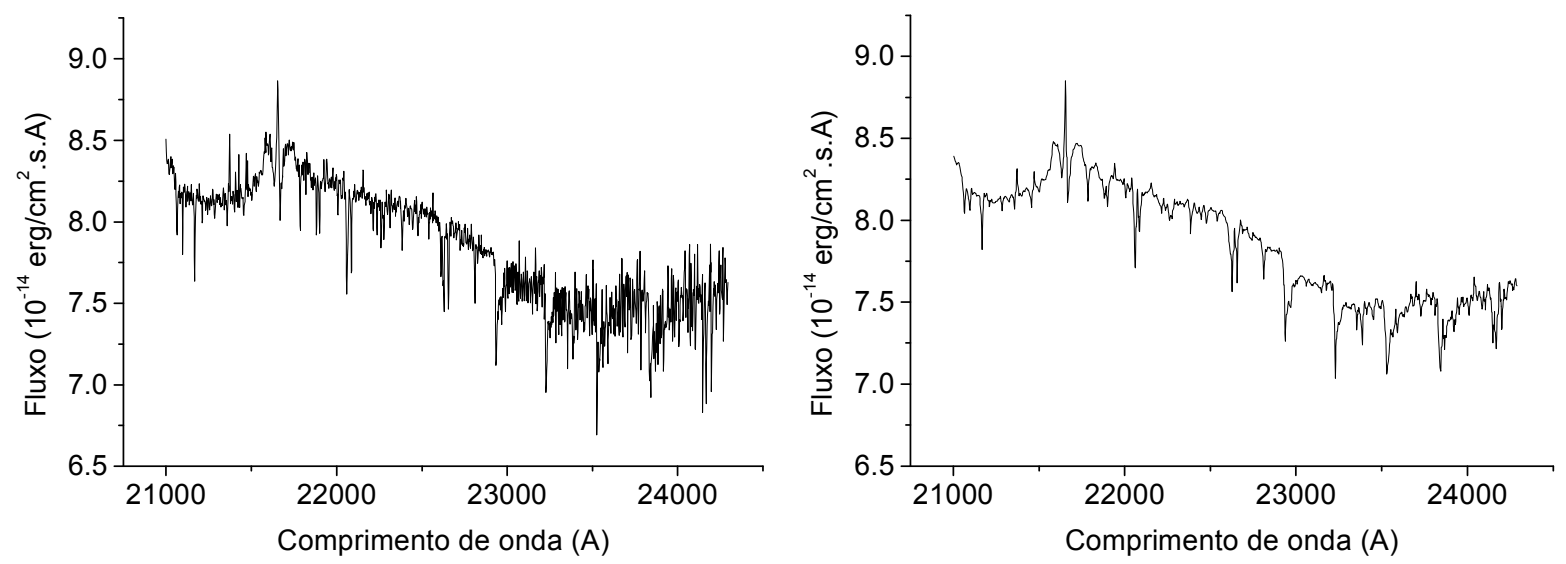

Figura 3.51 - (esquerda) Espectro extraído de uma região espacial (circular) centrada no objeto do cubo de dados de GQ Lup, antes da aplicação do "de-noising" espectral; (direita) Espectro extraído de uma região espacial (circular) centrada no objeto do cubo de dados de GQ Lup, depois da aplicação do "de-noising" espectral.
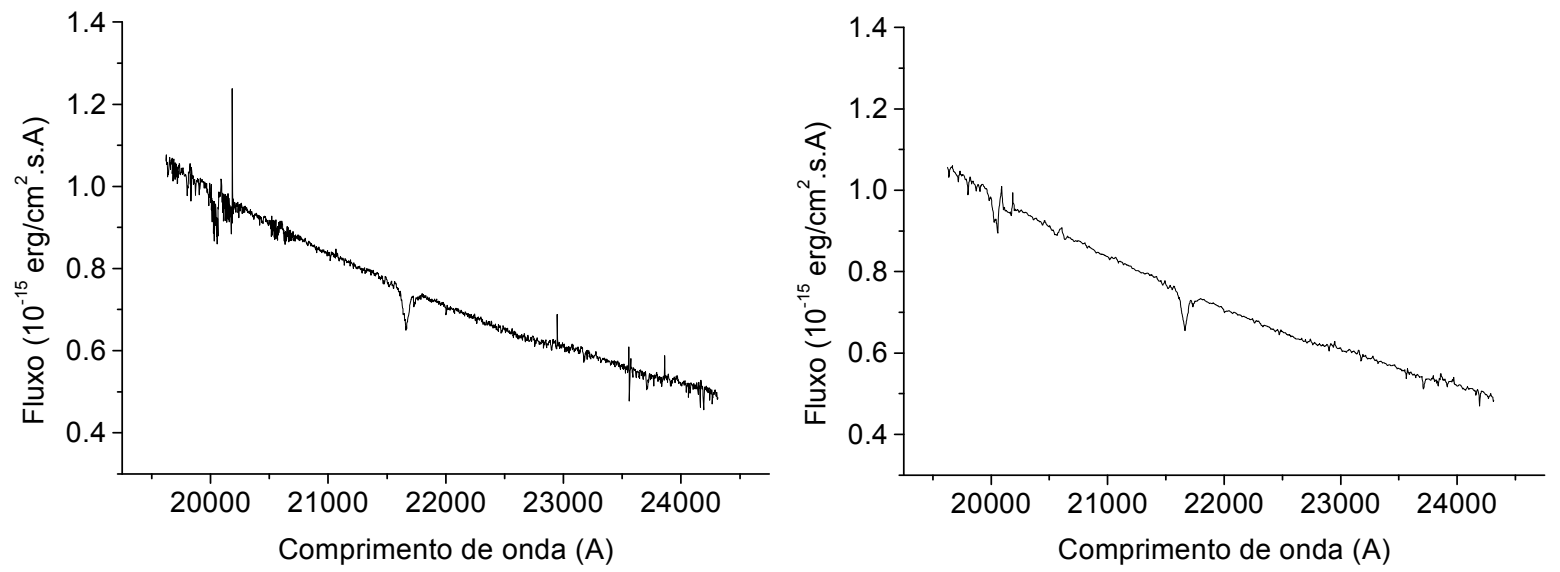

Figura 3.52 - (esquerda) Espectro extraído de uma região espacial (circular) centrada no objeto do cubo de dados de HIP 49220, antes da aplicação do "de-noising" espectral; (direita) Espectro extraído de uma região espacial (circular) centrada no objeto do cubo de dados de HIP 49220, depois da aplicação do "de-noising” espectral. 
As figuras 3.50, 3.51 e 3.52 deixam claro que a aplicação do de-noising espectral removeu boa parte do ruído de alta freqüência existente nos espectros dos cubos de dados de ltt 4816, GQ Lup e HIP 49220, permitindo que as estruturas espectrais presentes fossem visualizadas de uma maneira muito mais clara.

\section{9 - Deconvolução de Richardson-Lucy}

A metodologia seguinte no tratamento dos cubos de dados analisados nesse trabalho foi a deconvolução de Richardson-Lucy, que foi aplicada após o de-noising espectral (nos cubos em que esse procedimento foi utilizado) ou após a filtragem espacial de Butterworth (nos demais casos).

Matematicamente, a convolução de duas funções contínuas $f$ e $g$ é dada pela expressão

$$
\left(f^{*} g\right)(t)=\int_{0}^{t} f(\tau) g(t-\tau) d \tau
$$

Analogamente, a convolução de duas funções discretas $h$ e $j$, de $M$ pontos cada, pode ser dada pela fórmula

$$
\left(h^{*} j\right)(m)=\frac{1}{M} \sum_{n} h(n) j(m-n)
$$

Nesse trabalho, como era de se esperar, somente foram tratados casos relacionados a convoluções envolvendo funções discretas. A extensão da fórmula (3.71) para o caso bidimensional é dado pela equação (3.53).

Em astronomia, o conceito de convolução é bastante importante, pois é sabido que a imagem observada de qualquer objeto astronômico a partir da superfície da Terra corresponde à imagem original desse objeto convoluída com uma Point Spread Function (PSF), devida à atmosfera terrestre. É essa convolução que faz com que a imagem de um objeto puntual (como 
uma estrela, por exemplo) vista a partir da superfície da Terra apresente um diâmetro aparente, que é conhecido como seeing. Sendo $O(x, y)$ a imagem original do objeto observado e $P(x, y)$ a PSF da atmosfera terrestre, então, a imagem observada desse objeto pode ser dada por

$$
I(x, y)=(P * O)(x, y)+N(x, y)
$$

onde $N(x, y)$ é um ruído aditivo introduzido, por exemplo, pelo instrumento de observação

O procedimento de deconvolução consiste, basicamente, em um processo iterativo que visa reverter o efeito de uma convolução. No caso astronômico, em geral, o problema da deconvolução é colocado da seguinte maneira: conhecendo-se a imagem observada $I(x, y)$ e a PSF $P(x, y)$, deseja-se obter a imagem original $O(x, y)$.

De acordo com o teorema da convolução, explicado anteriormente, uma convolução no domínio espacial equivale a uma multiplicação no domínio de frequências. Assim, a equação (3.72) pode ser reescrita no domínio de frequências da seguinte maneira:

$$
I(u, v)=O(u, v) \cdot P(u, v)+N(u, v)
$$

Os principais problemas referentes à determinação de $O$, conhecendo-se $I$ e $P$, são a existência de uma frequência de "corte" na PSF e a presença do ruído aditivo. Uma possível solução simples poderia ser obtida, a partir da equação (3.73), dividindo-se $I(u, v)$ por $P(u, v)$. Nesse caso, a solução seria

$$
\tilde{O}(u, v)=\frac{I(u, v)}{P(u, v)}=O(u, v)+\frac{N(u, v)}{P(u, v)}
$$

Esse é o chamado método do quociente Fourier. Trata-se de um procedimento bastante rápido de ser aplicado, pois tudo o que é preciso fazer é calcular uma transformada de Fourier de $I(x, y)$, dividir o resultado pela transformada de Fourier de $P(x, y)$ e calcular a transformada de Fourier 
inversa do resultado. Entretanto, para frequências próximas da frequência de corte, pode-se notar, pela equação (3.74), que o termo de ruído $(N(u, v) / P(u, v))$ se torna significativo e até dominante. Assim sendo, pode-se concluir que, na presença de ruído, esse método não deve ser utilizado, pois ele causa uma amplificação do ruído.

Existem, entretanto, outros métodos mais apropriados para se executar uma deconvolução. Um desses métodos baseia-se no teorema de Bayes. De acordo com esse teorema, tem-se a seguinte relação:

$$
p(O / I)=\frac{p(I / O) \cdot p(O)}{p(I)},
$$

onde $p(O / I)$ corresponde à probabilidade de a imagem original do objeto observado ser $O$, dado que a imagem observada foi $I$ e $p(I / O)$ corresponde à probabilidade de a imagem observada ser $I$, dado que a imagem original é $O$. O método Bayesiano para se executar uma deconvolução baseia-se em maximizar o lado direito da equação (3.75). Uma solução bastante conhecida para esse problema é a de maximum likelihood (ML), que maximiza, apenas, $p(I / O)$ sobre $O$, ou seja,

$$
M L(O)=\max _{O} p(I / O) .
$$

Quando o ruído existente em uma determinada imagem é poissoniano, tem-se a seguinte expressão para $p(I / O)$ :

$$
p(I / O)=\prod_{x, y} \frac{\left(\left(P^{*} O\right)(x, y)\right)^{I(x, y)} e^{\left\{-\left(P^{*} O\right)(x, y)\right\}}}{I(x, y) !} .
$$

Para se determinar o máximo da expressão anterior, calcula-se a derivada do seu logaritmo e iguala-se o resultado a 0 , ou seja,

$$
\frac{\partial \ln p(I / O)(x, y)}{\partial O(x, y)}=0 .
$$


A aplicação da operação mostrada na equação (3.78) leva ao seguinte resultado (assumindo-se que a PSF esteja normalizada em 1):

$$
\frac{I(x, y)}{P^{*} O(x, y)} * P^{t}=1
$$

Multiplicando-se, então, ambos os lados de (3.79) por $O(x, y)$, obtém-se

$$
O(x, y)=\left[\frac{I(x, y)}{\left(P^{*} O\right)(x, y)} * P^{t}(x, y)\right] O(x, y) .
$$

Finalmente, utilizando-se uma iteração Picard (que não é discutida aqui), chega-se a

$$
O(x, y)^{n+1}=\left[\frac{I(x, y)}{\left(P^{*} O^{n}\right)(x, y)} * P^{t}(x, y)\right] O^{n}(x, y),
$$

que corresponde à expressão da deconvolução de Richardson-Lucy.

A deconvolução de Richardson-Lucy foi aplicada nos cubos de dados analisados nesse trabalho por meio de um script escrito em linguagem IDL. Nesses casos, o processo descrito pela expressão (3.81) foi aplicado sucessivamente em cada uma das imagens dos cubos de dados. Alguns exemplos da deconvolução de Richardson-Lucy em cubos de dados do IFU do GMOS, do NIFS e do SINFONI são mostrados nas sessões a seguir.

\subsection{1 - Deconvolução de Richardson-Lucy em cubos de dados do GMOS}

Para se aplicar o procedimento da deconvolução de Richardson-Lucy em cubos de dados, primeiramente, é necessário determinar-se uma estimativa da PSF durante a observação. Verificou-se que as PSFs obtidas em observações com o GMOS apresentam um perfil de brilho que pode ser bem ajustado por uma gaussiana na forma 


$$
A \cdot e^{-\frac{\left(x-x_{c}\right)^{2}}{2 \sigma^{2}}}
$$

A figura 3.53 mostra o perfil horizontal de brilho da imagem de um intervalo espectral intermediário colapsado do cubo de dados de $1 \mathrm{tt} 4816$, juntamente com o ajuste gaussiano feito com base na equação (3.82).

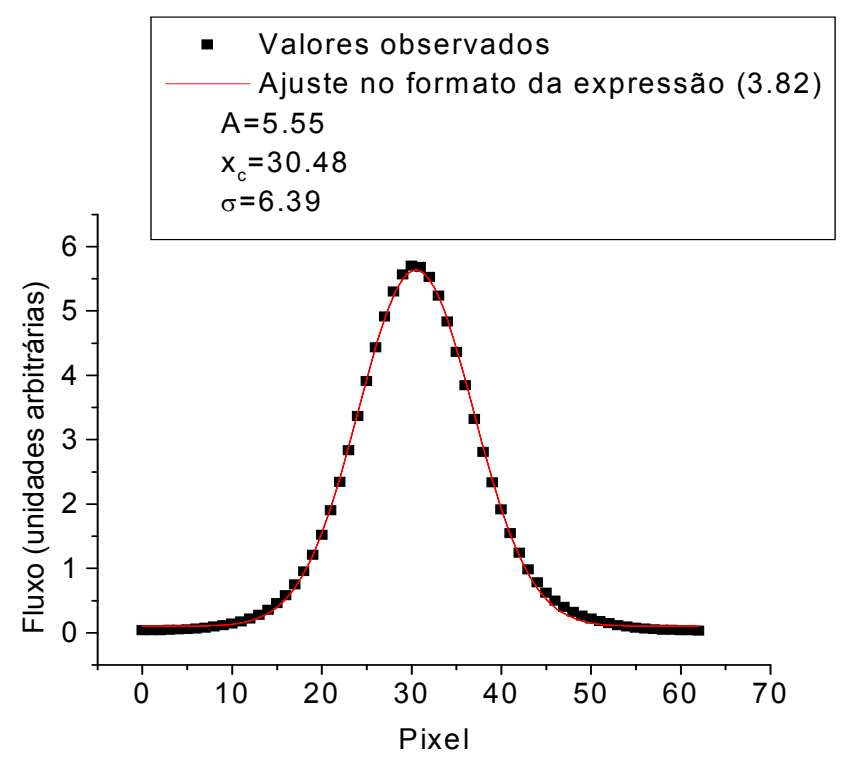

Figura 3.53 - Perfil horizontal de brilho da imagem de um intervalo espectral intermediário colapsado do cubo de dados de ltt 4816, juntamente com o ajuste gaussiano, no formato da expressão (3.82), aplicado.

Observando-se a figura 3.53, pode-se notar que a PSF da imagem analisada do cubo de dados de ltt 4816 pode ser bem ajustada por uma função gaussiana. Vários testes mostraram que esse é o comportamento geral em cubos de dados obtidos com o IFU do GMOS.

$\mathrm{Na}$ região espectral do óptico, entretanto, o valor do $F W H M$ da PSF tende a variar significativamente com o comprimento de onda. Assim, para se fazer a deconvolução de Richardson-Lucy em imagens de cubos de dados obtidos do IFU do GMOS, foi necessário não apenas encontrar uma estimativa da PSF em um determinado comprimento de onda, mas também foi preciso avaliar a variação do seu $F W H M$ ao longo do eixo espectral do cubo.

Constatou-se que a dependência do $F W H M$ da PSF para com o comprimento de onda pode ser bem expressa por uma função da forma 


$$
F W H M(\lambda)=\frac{(F W H M)_{r e f} \cdot \lambda^{-\alpha}}{\left(\lambda_{\text {ref }}\right)^{-\alpha}}
$$

onde $\lambda_{\text {ref }}=$ comprimento de onda no qual o

$$
(F W H M)_{\text {ref é medido }}
$$

Calculando-se o logaritmo de ambos os lados da expressão anterior, verifica-se que ela pode ser reescrita como

$$
\log (F W H M(\lambda))=\log \left(\frac{(F W H M)_{r e f}}{\left(\lambda_{\text {ref }}\right)^{-\alpha}}\right)-\alpha \log \lambda
$$

No caso de observações de estrelas, as estimativas da PSF podem ser feitas diretamente a partir das imagens da estrela no cubo de dados. Para se determinar a variação do FWHM da PSF de ltt 4816 com o comprimento de onda, procedeu-se da seguinte maneira: primeiramente, construíram-se imagens de certos intervalos espectrais colapsados ao longo de todo o contínuo do objeto e mediu-se o valor do FWHM, ao longo dos eixos horizontal e vertical, em cada uma dessas imagens. Após isso, construíram-se os gráficos de $\log (F W H M)_{x} \mathrm{x} \log \lambda \mathrm{e} \log (F W H M)_{y} \mathrm{x}$ $\log \lambda$ e ajustaram-se funções com a forma linear dada pela expressão (3.84). A figura 3.54 mostra os gráficos construídos, juntamente com as funções lineares ajustadas. 

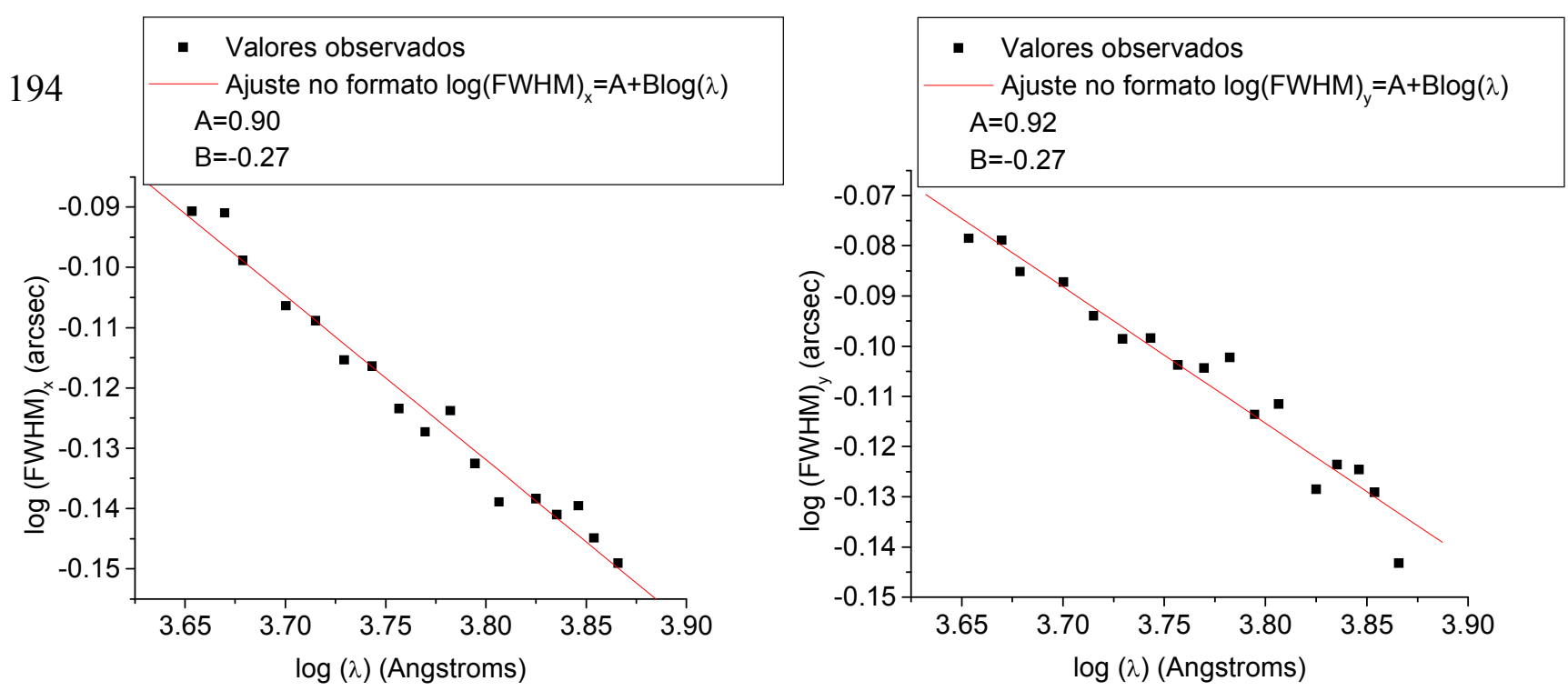

Figura 3.54 - Gráficos com os valores de log $(F W H M)_{x}$ e log $(F W H M)_{y}$ das imagens do cubo de dados de ltt 4816 em função de log $\lambda$. Nos gráficos também são mostradas as funções lineares ajustadas aos pontos.

A figura 3.54 mostra que os valores de $(F W H M)_{x}$ e $(F W H M)_{y}$ são bastante próximos, mas não exatamente iguais, o que indica que as PSFs do cubo de dados de ltt 4816 não são circulares, embora os desvios em relação a círculos perfeitos sejam pequenos A figura 3.54 revela, ainda, que a dependência de $(F W H M)_{x}$ e $(F W H M)_{y}$ para com o comprimento de onda é a mesma, como seria de se esperar. Verificou-se que todas essas características representam uma tendência geral das PSFs de cubos de dados do IFU do GMOS, embora o valor de $\alpha$ nas expressões (3.83) e (3.84) possa sofrer certas variações.

Vários testes mostraram que os melhores resultados nas deconvoluções de RichardsonLucy de cubos de dados do IFU do GMOS são obtidos usando-se PSFs gaussianas sintéticas, com valores de FWHM (ao longo dos eixos horizontal e vertical) apresentando dependências para com o comprimento de onda dadas pelas equações (3.83) e (3.84). O número de iterações utilizado nesses processos deve estar entre 6 e 10, para que sejam obtidos resultados otimizados.

Aplicou-se, então, a deconvolução de Richardson-Lucy no cubo de dados de 1tt 4816, utilizando-se PSFs gaussianas sintéticas construídas com base nos resultados mostrados na figura 3.54. A figura 3.55 mostra imagens de um intervalo espectral intermediário colapsado do cubo de ltt 4816, antes e depois da aplicação da deconvolução de Richardson-Lucy, com 10 iterações. Na mesma figura, são mostrados os valores medidos de $(F W H M)_{x} \mathrm{e}(F W H M)_{y}$. 


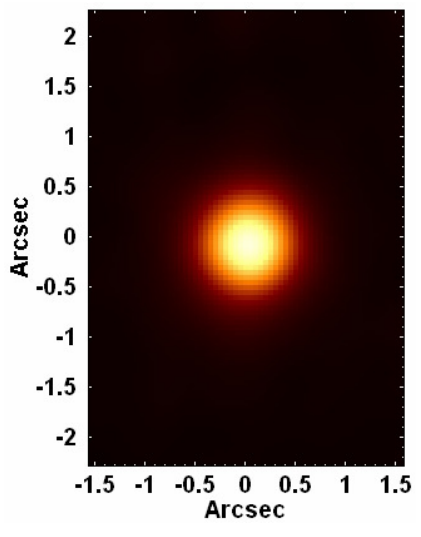

$$
\begin{aligned}
& (F W H M)_{x}=0.746 " \\
& (F W H M)_{y}=0.787 "
\end{aligned}
$$

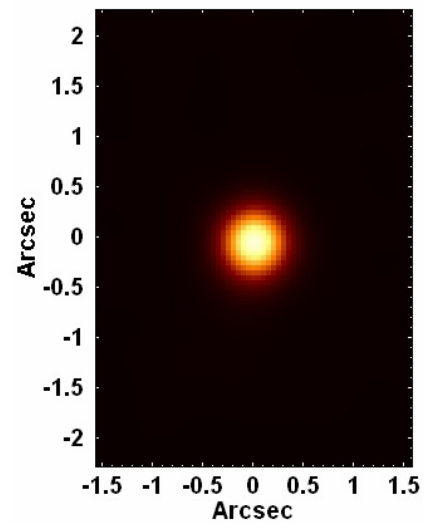

$$
\begin{aligned}
& (F W H M)_{x}=0.502 " \\
& (F W H M)_{y}=0.534 "
\end{aligned}
$$

Figura 3.55 - (esquerda) Imagem de um intervalo espectral intermediário colapsado do cubo de dados de ltt 4816, antes da aplicação da deconvolução de Richardson-Lucy; (direita) Imagem de um intervalo espectral intermediário colapsado do cubo de dados de ltt 4816, após a aplicação da deconvolução de Richardson-Lucy, com 10 iterações.

Observando-se a figura 3.55, pode-se notar que a aplicação da deconvolução de Richardson-Lucy com 10 iterações no cubo de dados de 1 tt 4816 provocou uma considerável diminuição dos valores de $(F W H M)_{x}$ e $(F W H M)_{y}$ da PSF desse objeto, melhorando, significativamente, a resolução espacial.

Como os objetos analisados nesse trabalho não são puntuais, mas sim extensos, não foi tão simples determinar estimativas das PSFs. A dependência para com o comprimento de onda dos valores de $(F W H M)_{x}$ e $(F W H M)_{y}$ pôde ser obtida a partir dos cubos de dados da estrelas padrão utilizadas, durante a redução, para a calibração em fluxo. Nos casos em que essas estrelas foram observadas com pouco tempo de diferença em relação ao objeto analisado, também foi possível utilizá-las para se estimar os valores de $(F W H M)_{\text {ref }}$ (ao longo dos eixos horizontal e vertical), que são necessários para a aplicação da equação (3.83) (ou 3.84) para a construção das PSFs gaussianas sintéticas nos diferentes comprimentos de onda. Entretanto, nos casos em que as estrelas padrão foram observadas com muito tempo de diferença em relação aos objetos analisados, foi necessário usar outra estratégia para a obtenção dos valores de $(F W H M)_{\text {ref }}$. Uma possibilidade foi utilizar as imagens de aquisição dos objetos. Nos casos de objetos com linhas espectrais com asas largas (tipo 1), entretanto, uma estimativa dos valores de (FWHM) ref pôde ser feita a partir de imagens construídas em intervalos espectrais correspondentes a essas asas. A razão disso é que as componentes largas das linhas de emissão são emitidas pelas BLRs dos AGNs, que, devido às suas pequenas dimensões, não podem ser resolvidas nas observações, 
196

apresentando, portanto, uma aparência puntual. Assim, a imagem da asa larga de uma linha de emissão de um AGN deve possuir um aspecto puntual e, consequentemente, pode ser utilizada na estimativa dos valores de $(F W H M)_{\text {ref. }}$.

\subsection{2 - Deconvolução de Richardson-Lucy em cubos de dados do NIFS}

Vários testes mostraram que, na região espectral do infravermelho, a variação da PSF com o comprimento de onda é pouco significativa. Assim, a deconvolução de Richardson-Lucy em cubos de dados do NIFS foi feita utilizando-se, apenas, uma PSF fixa, sem qualquer dependência para com o comprimento de onda.

O recurso da óptica adaptativa tem como objetivo fazer com que as resoluções espaciais obtidas com as observações se aproximem o máximo possível do limite de difração, que é dado pela função de Airy:

$$
I(\theta)=I(0) \cdot 4 \cdot\left[\frac{J_{1}(k a \operatorname{sen}(\theta))}{k \operatorname{kasen}(\theta)}\right]^{2} .
$$

onde $J_{l}=$ função de Bessel de ordem 1

$$
\begin{aligned}
a= & \text { raio da abertura circular que } \\
& \text { causou a difração } \\
k & =\text { número de onda }=\frac{2 \pi}{\lambda}
\end{aligned}
$$

Entretanto, essa técnica não é perfeita e o que se obtém, ao final do processo, é uma PSF com duas componentes: um spike central, com alta freqüência espacial, dado pela função de Airy e um halo ao redor, com baixa freqüência espacial, com o formato de uma função lorentziana. No caso do NIFS, entretanto, o que se obtém, na prática, são PSFs compostas por uma componente gaussiana e outra lorentziana, que podem ser bem ajustadas por funções na forma 


$$
A \cdot e^{-\frac{\left(x-x_{c}\right)^{2}}{2 \sigma_{g}^{2}}}+B \cdot\left(\frac{1}{\left(1+\left(\frac{x-x_{c}}{\sigma_{l}^{2}}\right)^{2}\right)}\right)
$$

A razão dessa componente gaussiana, ao invés de uma função de Airy, ainda não é totalmente clara, mas acredita-se que ela seja devida a vibrações instrumentais durante as observações. A figura 3.56 mostra gráficos com o perfil horizontal de brilho da imagem de um intervalo espectral intermediário colapsado do cubo de dados de GQ Lup, juntamente com ajustes feitos com base nas equações (3.82) e (3.86).
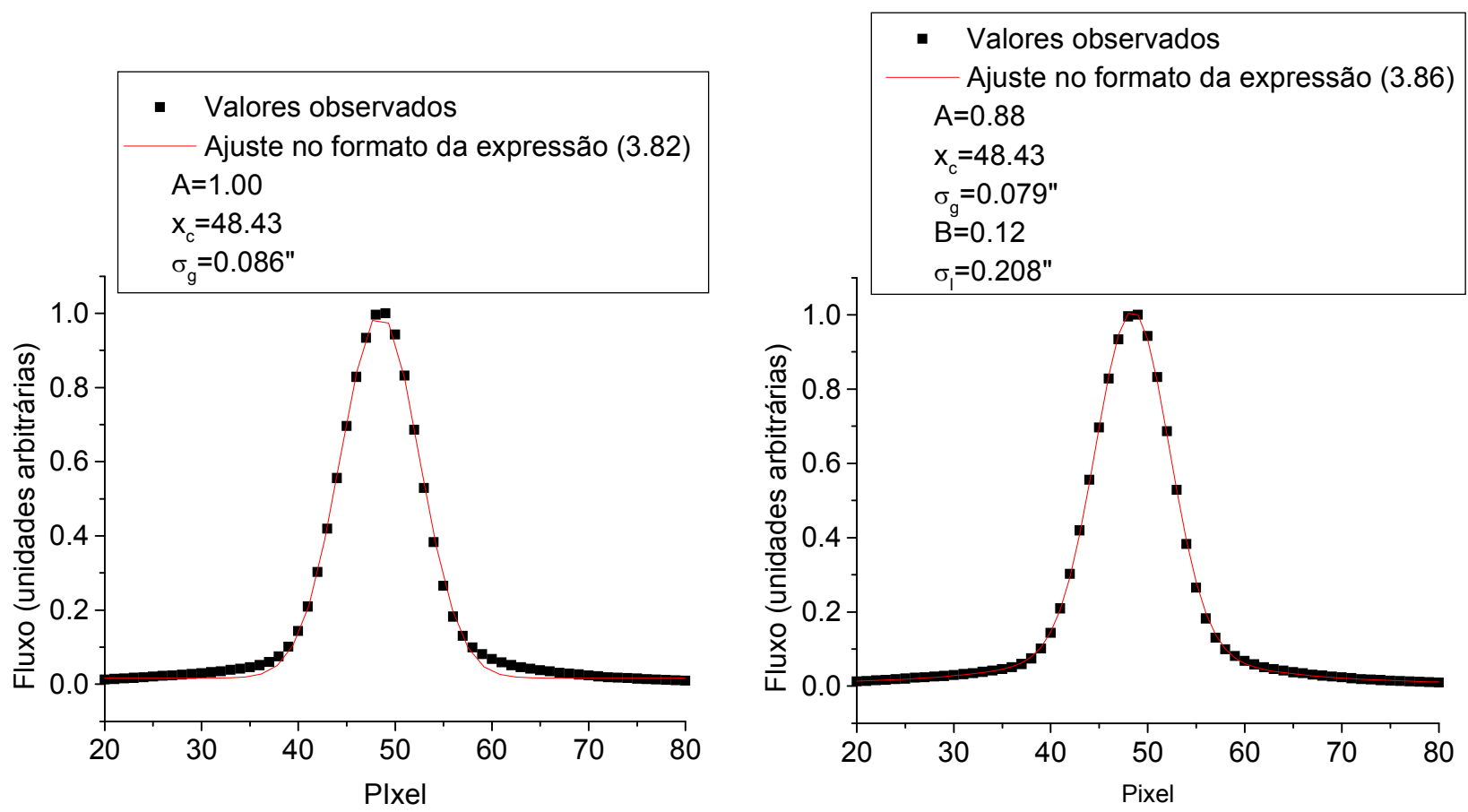

Figura 3.56 - (esquerda) Perfil horizontal de brilho da imagem de um intervalo espectral intermediário colapsado do cubo de dados de GQ Lup, juntamente com um ajuste gaussiano, no formato da expressão (3.82); (direita) Mesmo perfil de brilho mostrado à esquerda, com um ajuste no formato da expressão (3.86).

Uma análise da figura 3.56 deixa claro que o ajuste com duas componentes (gaussiana e lorentziana), dado pela expressão (3.86), reproduz melhor o perfil de brilho de uma imagem do cubo de dados de GQ Lup do que um simples ajuste gaussiano, dado pela equação (3.82). 
Conforme já foi mencionado anteriormente, isso se deve ao fato de o halo gerado pela óptica adaptativa ao redor da componente gaussiana possuir um formato não gaussiano, mas sim lorentziano.

Como as PSFs nos cubos de dados do NIFS são compostas por duas componentes, e não por uma simples gaussiana, a medição do valor do $F W H M$ não é uma técnica tão eficaz para se avaliar o efeito da óptica adaptativa na observação ou mesmo a melhoria obtida com a aplicação de uma deconvolução de Richardson-Lucy. Ao invés disso, um indicador muito mais robusto para ser utilizado é a razão de Strehl, que é definida da seguinte maneira:

$$
\text { Strehl }=\frac{I(0)_{P S F}}{I(0)_{\text {Airy }}}
$$

onde $I(0)_{P S F}=$ intensidade máxima da PSF da observação normalizada

$I(0)_{\text {Airy }}=$ intensidade máxima da Função de Airy normalizada

Como a óptica adaptativa não é uma técnica perfeita, o valor de $I(0)_{P S F}$ nunca se iguala ao de $I(0)_{A i r y}$, ou seja, embora esse procedimento melhore consideravelmente as resoluções espaciais obtidas nas observações, as razões de Strehl resultantes são sempre menores do que 1.

Verificou-se que os melhores resultados nas deconvoluções de Richardson-Lucy de cubos de dados do NIFS são conseguidos usando-se PSFs reais, obtidas diretamente a partir dos dados. No caso de observações de estrelas, obviamente, pode-se utilizar como PSF uma imagem em um comprimento de onda intermediário do cubo de dados. Caso não seja possível utilizar uma imagem real como PSF (o que pode acontecer se as imagens contiverem mais de um objeto no campo de visão, por exemplo), pode-se também construir uma PSF sintética com base na equação (3.86). O número de iterações utilizado nesses processos deve estar entre 6 e 10, para que sejam obtidos resultados otimizados.

A deconvolução de Richardson-Lucy foi aplicada no cubo de dados de GQ Lup, utilizando-se uma PSF real obtida a partir de uma imagem em um comprimento de onda intermediário desse cubo. A figura 3.57 mostra imagens de um intervalo espectral intermediário 
colapsado do cubo de dados de GQ Lup, antes e depois da aplicação da deconvolução de Richardson-Lucy, com 10 iterações. Na mesma figura, são mostrados os valores medidos da razão de Strehl.

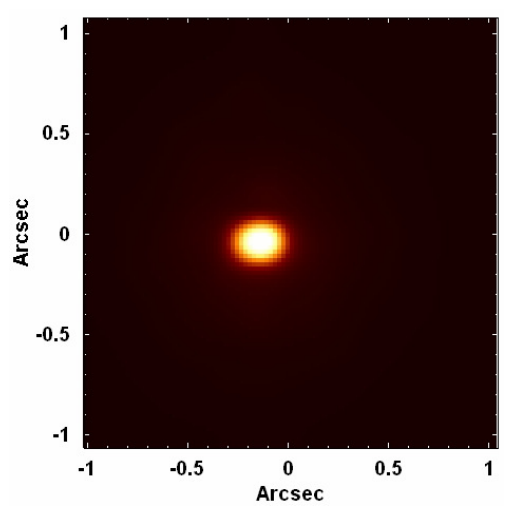

Strehl $=0.08$

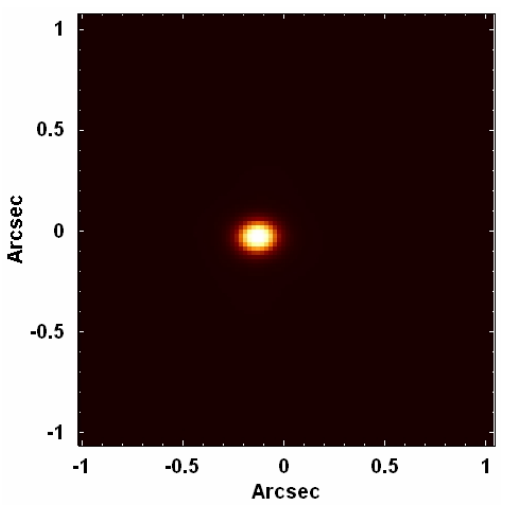

Strehl $=0.21$

Figura 3.57 - (esquerda) Imagem de um intervalo espectral intermediário colapsado do cubo de dados de GQ Lup, antes da aplicação da deconvolução de Richardson-Lucy; (direita) Imagem de um intervalo espectral intermediário colapsado do cubo de dados de GQ Lup, após a aplicação da deconvolução de Richardson-Lucy, com 10 iterações.

Observando-se a figura 3.57, pode-se notar que a aplicação da deconvolução de Richardson-Lucy no cubo de dados de GQ Lup provocou um aumento considerável do valor da razão de Strehl, o que indica que houve uma melhoria significativa na resolução espacial.

No caso dos objetos (extensos) analisados nesse trabalho, preferiu-se obter estimativas das PSFs a partir de imagens dos próprios cubos de dados analisados (o que pôde ser feito imageando a emissão proveniente da BLR, por exemplo), pois, dessa forma, pôde-se garantir que a PSF representaria, de maneira precisa, o efeito da óptica adaptativa nos dados. Caso não fosse possível utilizar essa estratégia, uma outra opção foi obter uma estimativa da PSF a partir do cubo de dados da estrela padrão utilizada, na redução dos dados, para a remoção das absorções telúricas e para a calibração em fluxo. Nos casos em que isso ocorreu, entretanto, não foi possível garantir que essa estimativa da PSF era precisa, já que a óptica adaptativa pode não ter sido igualmente eficaz nas observações dos dados de ciência e da estrela padrão. 


\subsection{3 - Deconvolução de Richardson-Lucy em cubos de dados do SINFONI}

O procedimento da deconvolução de Richardson-Lucy em cubos de dados do SINFONI apresentou uma série de semelhanças em relação ao utilizado em cubos do NIFS. Uma delas foi a utilização de uma PSF fixa sem dependência para com o comprimento de onda. A razão disso, conforme foi mencionado anteriormente, é que, na região espectral do infravermelho, a PSF varia muito pouco com o comprimento de onda. Além disso, no caso dos fore-optics com campos de visão de 3.2 × 3.2 " e 0.8 " x 0.8", as PSFs obtidas também são constituídas por uma componente gaussiana e outra lorentziana e, consequentemente, podem ser bem ajustadas pela expressão (3.86). A figura 3.58 mostra gráficos com o perfil vertical de brilho da imagem de um intervalo espectral intermediário colapsado do cubo de dados de HIP 49220, juntamente com ajustes feitos com base nas equações (3.82) e (3.86) (optou-se por não utilizar o perfil horizontal de brilho desse objeto, devido às fortes assimetrias presentes)
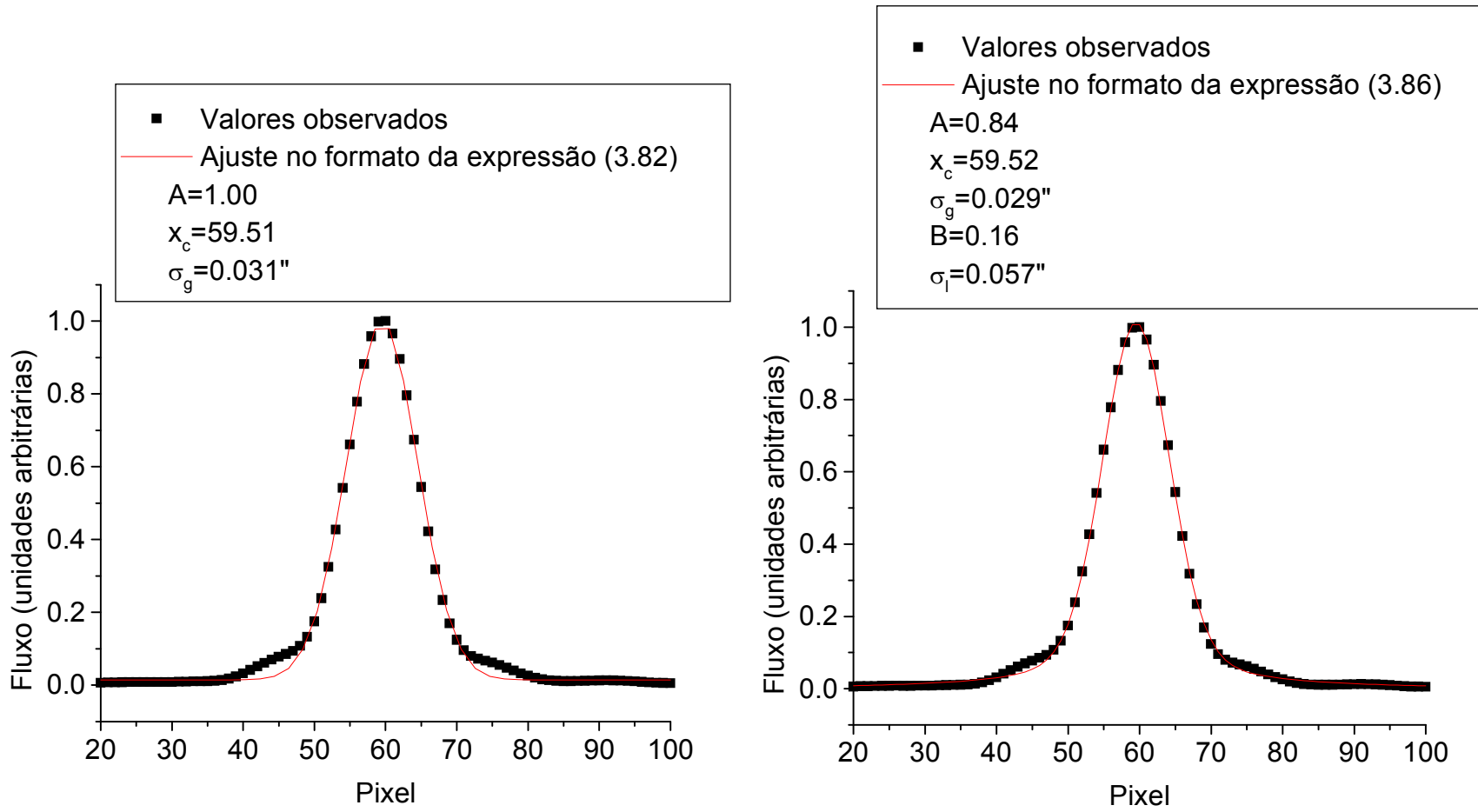

Figura 3.58 - (esquerda) Perfil vertical de brilho da imagem de um intervalo espectral intermediário colapsado do cubo de dados de HIP 49220, juntamente com um ajuste gaussiano, no formato da expressão (3.82); (direita) Mesmo perfil de brilho mostrado à esquerda, com um ajuste no formato da expressão (3.86). 
A figura 3.58 mostra que o ajuste com duas componentes (gaussiana e lorentziana), dado pela expressão (3.86), reproduz melhor o perfil de brilho de uma imagem do cubo de dados de HIP 49220 do que um simples ajuste gaussiano, dado pela equação (3.82). Conforme já foi mencionado anteriormente, isso se deve ao fato de o halo gerado pela óptica adaptativa ao redor da componente gaussiana possuir um formato não gaussiano, mas sim lorentziano. Entretanto, o ajuste com duas componentes não chegou a ser tão bom quanto no caso de GQ Lup. Isso se deveu ao fato de a PSF de HIP 49220 apresentar certas assimetrias, o que dificultou o ajuste.

Para o fore-optics com campo de visão de 8" x 8", entretanto, o grande tamanho dos pixeis espaciais $(0.250 " \mathrm{x} 0.125$ ”) faz com que o efeito da óptica adaptativa seja pouco perceptível. Nesses casos, em geral, as PSFs obtidas apresentam um aspecto gaussiano e podem ser bem ajustadas por funções na forma da expressão (3.82).

Testes mostraram que os melhores resultados nas deconvoluções de Richardson-Lucy de cubos de dados do SINFONI são encontrados usando-se PSFs reais, obtidas diretamente a partir dos dados. Nas observações de estrelas, obviamente, pode-se utilizar como PSF uma imagem em um comprimento de onda intermediário do cubo de dados. Caso não seja possível utilizar uma imagem real como PSF, pode-se, assim como foi mencionado no caso do NIFS, construir uma PSF sintética. Para observações com os fore-optics com campos de visão de 3.2" x 3.2" e 0.8" x 0.8" (nos quais a óptica adaptativa possui um efeito detectável), tal PSF sintética deve ser feita com base na equação (3.86). No caso de observações com o fore-optics com campo de visão de 8" x 8" (no qual a óptica adaptativa praticamente não gera melhorias perceptíveis), a PSF sintética pode ser construída com um formato gaussiano, dado pela expressão (3.82). O número de iterações utilizado nesses processos deve estar entre 6 e 10, para que sejam obtidos resultados otimizados.

A deconvolução de Richardson-Lucy foi aplicada no cubo de dados de HIP 49220, utilizando-se uma PSF real obtida a partir de uma imagem em um comprimento de onda intermediário desse cubo. A figura 3.59 mostra imagens de um intervalo espectral intermediário colapsado do cubo de dados de HIP 49220, antes e depois da aplicação da deconvolução de Richardson-Lucy, com 10 iterações. Na mesma figura, são mostrados os valores medidos da razão de Strehl. 


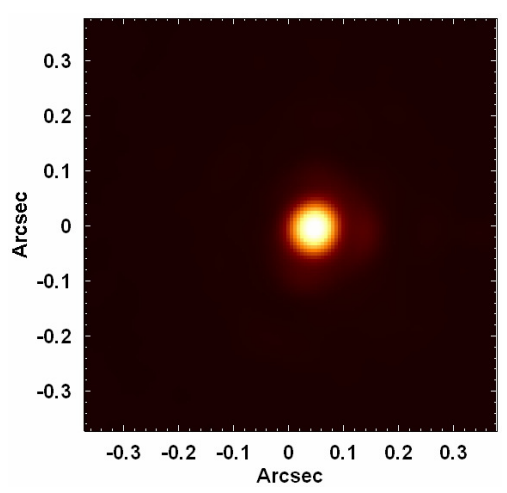

Strehl $=0.478$

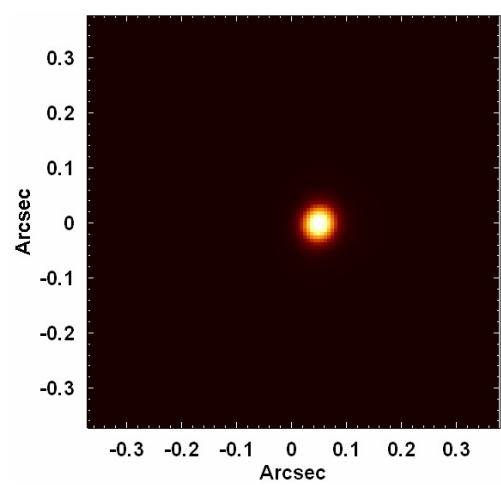

Strehl $=1.251$

Figura 3.59 - (esquerda) Imagem de um intervalo espectral intermediário colapsado do cubo de dados de HIP 49220, antes da aplicação da deconvolução de Richardson-Lucy; (direita) Imagem de um intervalo espectral intermediário do cubo de dados de HIP 49220, após a aplicação da deconvolução de Richardson-Lucy, com 10 iterações.

Observando-se a figura 3.59, pode-se notar que a aplicação da deconvolução de Richardson-Lucy no cubo de dados de HIP 49220 provocou um grande aumento na razão de Strehl, que chegou a atingir um valor maior do que 1. É importante mencionar, entretanto, que esses valores elevados da razão de Strehl somente foram encontrados nos dados do SINFONI com o fore-optics com campo de visão de 0.8 " x 0.8 ". Vários testes revelaram que valores de Strehl similares aos observados no NIFS foram obtidos em dados do SINFONI com o fore-optics com campo de 3.2" x 3.2". No caso do fore-optics com campo de 8" x 8", conforme já foi dito anteriormente, a óptica adaptativa não produziu melhorias consideráveis e os valores de Strehl obtidos foram muito inferiores a todos esses.

Assim como foi feito no caso do NIFS, para se aplicar a deconvolução de RicahrdsonLucy nos objetos (extensos) observados com o SINFONI analisados nesse trabalho, preferiu-se obter estimativas das PSFs a partir de imagens dos próprios cubos de dados analisados (o que pôde ser feito imageando a emissão proveniente da BLR, por exemplo). A razão disso é que, procedendo-se dessa forma, pôde-se garantir que a PSF representaria, de maneira precisa, o efeito da óptica adaptativa nos dados. Caso não fosse possível utilizar essa estratégia, uma outra opção foi obter uma estimativa da PSF a partir do cubo de dados da estrela padrão utilizada na redução dos dados. Nessas circunstâncias, entretanto, para os fore-optics com campo de visão de 3.2" x 3.2 " e 0.8 " x 0.8 ", não foi possível garantir a precisão da PSF utilizada, já que a óptica adaptativa pode não ter sido igualmente eficaz nas observações dos dados de ciência e da estrela padrão 


\subsection{0 - Tomografia PCA}

Após a aplicação de todos os procedimentos de tratamento de dados descritos anteriormente, a primeira metodologia de análise usada nos cubos de dados nesse trabalho foi a Tomografia PCA (Steiner et al. 2009), que consiste na aplicação do robusto método estatístico da Análise em Componentes Principais (Principal Component Analysis - PCA) a cubos de dados.

O PCA é uma técnica utilizada para analisar conjuntos de dados multidimensionais. Trata-se de um método bastante eficiente para se extrair informações de conjuntos de dados muito amplos, pois, com ele, é possível identificar padrões e correlações que, de outro modo, dificilmente poderiam ser notados. Uma outra grande vantagem do PCA consiste no fato de que essa técnica é capaz de reduzir a dimensionalidade inicial dos dados sem grande perda de informação, o que é muito útil quando se lida com conjuntos de dados de dimensões bastante elevadas.

O PCA é definido, matematicamente, como uma transformação linear ortogonal, que passa os dados para um novo sistema de coordenadas (não correlacionadas), tal que a primeira dessas novas coordenadas (o autovetor E1) seja capaz de explicar a maior parte da variância, a segunda coordenada (o autovetor E2) seja capaz de explicar a segunda maior parte da variância e assim por diante. Em outras palavras, pode-se dizer que a projeção dos dados sobre E1 é capaz de explicar a maior parte da variância existente. A projeção dos dados sobre E2 é capaz de explicar a segunda maior parte da variância e assim por diante. Essas novas coordenadas geradas pelo PCA também são chamadas de Componentes Principais e é importante mencionar que, por construção, todas elas são ortogonais entre si (para maiores detalhes ver Murtagh \& Heck 1987; Fukunaga 1990; Smith 2002).

Matricialmente, a transformação correspondente ao PCA pode ser representada da seguinte maneira 


$$
T=E \cdot X
$$

onde $X=$ matriz contendo os dados originais

$E=$ matriz cujas linhas correspondem aos autovetores (ou

Componentes Principais) mencionados anteriormente

$T=$ matriz contendo os dados no novo sistema de

coordenadas

$\mathrm{Na}$ fórmula anterior, cada linha da matriz $X$ corresponde a uma variável diferente (ou seja, a uma dimensão diferente) e cada coluna a um observável diferente. Além disso, a matriz $E$, que passa os dados para o novo sistema de coordenadas, é definida de modo que suas linhas correspondam aos autovetores da matriz de covariância, que pode ser dada pela expressão

$$
C_{X}=\frac{X \cdot X^{T}}{n-1}
$$

A variância explicada por cada um dos autovetores da matriz de covariância (que correspondem aos eixos do novo sistema de coordenadas) é dada pelos seus respectivos autovalores, que podem ser expressos por

$$
\Lambda_{k}=\frac{T(k) \cdot[T(k)]^{T}}{n-1} .
$$

onde $\Lambda_{k}=$ autovalor correspondente ao autovetor $k$

$$
T(k)=\text { linha da matriz } T \text { correspondente à projeção }
$$
dos dados sobre o autovetor $k$

Para se fazer o PCA, inicialmente, é conveniente subtraírem-se os valores médios das variáveis. Em seguida, deve-se construir a matriz de covariância e calcular os seus autovetores e respectivos autovalores. Esses autovetores devem ser ordenados de tal modo que o primeiro deles seja capaz de explicar a maior parte da variância (ou seja, E1 deve possuir o maior autovalor), o 
segundo seja capaz de explicar a segunda maior parte da variância e etc. É importante mencionar que, nessa etapa, pode-se desprezar os autovetores que apresentem autovalores muito baixos, ou seja, que expliquem uma variância muito pequena dos dados. Trata-se, portanto, de uma etapa de grande importância, pois permite que seja feita uma redução na dimensionalidade dos dados sem grande perda de informação. Após isso, deve-se construir a matriz $E$, considerando cada uma de suas linhas como sendo os autovetores obtidos anteriormente. Por fim, deve-se aplicar a equação (3.88) para passar os dados iniciais para o novo sistema de coordenadas obtido. Uma descrição detalhada de toda a matemática envolvida no PCA (incluindo uma demonstração da expressão 3.88) é mostrada no apêndice F.

Conforme foi mencionado anteriormente, a Tomografia PCA nada mais é do que a aplicação do método estatístico do PCA a cubos de dados. A primeira etapa dessa metodologia consiste na transformação do cubo de dados $I$ a ser analisado em uma matriz, que deve ser organizada de modo que as suas colunas correspondam a pixeis espaciais e suas linhas a pixeis espectrais. Em outras palavras, pode-se dizer que esse cubo deve ser convertido em uma matriz análoga a $X$ (mostrada na equação 3.88), na qual os observáveis correspondem aos pixeis espaciais e as variáveis aos pixeis espectrais. Em seguida, todo o procedimento mostrado anteriormente deve ser aplicado (inclusive a subtração dos valores médios de $X$ ), de modo que, ao final, deve-se obter (analogamente à equação 3.88) uma matriz $E$, cujas linhas correspondem aos autovetores $E_{k}$, e a matriz $T$, cujas linhas representam a projeção dos dados sobre os autovetores (ou seja, a matriz $T$ contém os dados no novo sistema de coordenadas obtido).

Os autovetores, nesse caso, são obtidos em função do comprimento de onda, apresentando um aspecto similar a espectros. Por essa razão esses autovetores são chamados, daqui para frente, de auto-espectros. Por outro lado, como os observáveis tomados nessa análise correspondem a pixeis espaciais, conclui-se que as projeções dos dados sobre os autovetores (que compõem o novo sistema de coordenadas) representam imagens, que, daqui para frente, são chamadas de tomogramas.

Pelo que foi dito acima, pode-se concluir que os auto-espectros, nessa análise, podem ser obtidos diretamente a partir das linhas da matriz $E$, assim como os tomogramas podem ser obtidos a partir das linhas da matriz $T$.

A análise simultânea de auto-espectros e tomogramas permite obter uma grande quantidade de informações que, de outra forma, talvez não fossem detectáveis. Algumas 
características espectrais, por exemplo, podem ser identificadas com estruturas nas imagens e vice-versa. Além disso, observando-se os autovalores $\Lambda_{k}$, pode-se ter uma idéia da relevância dos respectivos autovetores $E_{k}$ para explicar a variância dos dados.

É possível, também, reconstruir o cubo de dados a partir dos auto-espectros e tomogramas encontrados. Para se fazer isso utilizando-se todos os autovetores obtidos com o PCA, deve-se, primeiramente, inverter a equação (3.88):

$$
X=E^{-1} \cdot T
$$

Levando-se em conta, então, que $E^{-1}=E^{T}$ (teorema 1 do apêndice $\mathrm{G}$ ), tem-se que

$$
X=E^{T} \cdot T
$$

A partir da matriz $X$, pode-se reconstruir o cubo de dados original $I$, lembrando que é preciso somar novamente a média dos dados, que foi subtraída no início do processo. Essa soma é necessária para que a calibração em fluxo (no caso de dados calibrados) seja recuperada. Entretanto, o processo de reconstrução do cubo de dados também pode ser feito levando-se em conta apenas alguns autovetores. Em geral, o que se faz é considerar apenas os autovetores que contêm informações relevantes e desprezar aqueles que representam apenas ruído. Nesse caso, a equação (3.92) fica

$$
X^{\prime}(\leq r)=[E(\leq r)]^{T} \cdot T(\leq r)
$$

onde $E(\leq r)=$ matriz $E$ obtida levando-se em conta os autovetores até $k=r$

$T(\leq r)=$ matriz $T$ obtida levando-se em conta as projeções dos dados sobre todos os autovetores até $k=r$

A partir da matriz $X^{\prime}(\leq r)$, então, pode-se obter o cubo de dados $I^{\prime}(\leq r)$, que contem os dados correspondentes a todos os autovetores até $k=r$. Mais uma vez, seria preciso somar a média dos dados para recuperar a calibração em fluxo, entretanto, essa soma somente seria 
correta se todos os autovetores estivessem sendo considerados. Contudo, como apenas os autovetores que representam ruído estão sendo eliminados, o erro cometido ao somar a média, nesse caso, é bastante pequeno e esse processo, normalmente, pode ser executado.

Em geral, é bastante difícil saber precisamente em qual autovetor o sinal relevante do cubo de dados termina e o ruído se torna dominante. O critério de Kayser sugere que isso ocorre no autovetor que possui um autovalor igual ao valor médio dos autovalores. É possível também usar o scree test, no qual se adota que os autovetores deixam de ser relevantes a partir do momento em que seus autovalores se tornam praticamente constantes. No caso da Tomografia PCA, o critério de Kayser costuma selecionar muito poucos autovetores como relevantes. O scree test, por outro lado, parece ser bem mais adequado.

Considerando-se que o cubo de dados original possua um número $m$ de pixeis espectrais, então, pela maneira como é executado, o PCA também gera m autovetores. Somando-se, então, as variâncias associadas a todos os autovetores desde $r+1$ até $m$, obtém-se um valor do $\sigma$, no sentido de rms, entre os cubos $I$ e $I^{\prime}(\leq r)$. Assim, tem-se que

$$
\sigma^{2}=\sum_{k=r+1}^{k=m} \Lambda_{k}
$$

A equação (3.93) também pode ser aplicada para obter o cubo de dados de apenas um autovetor. Nesse caso, tem-se que

$$
X^{\prime}(k)=[E(k)]^{T} \cdot T(k)
$$

onde $E(k)=$ matriz $E$ contendo, apenas, a linha correspondente ao autovetor $k$

A partir de $X^{\prime}(k)$, pode-se, então, obter o cubo $I^{\prime}(k)$, que apresenta as mesmas dimensões do cubo original $I$, mas contém apenas as informações referentes ao autovetor $k$.

A reconstrução do cubo de dados levando-se em conta somente alguns dos autovetores possui muitas utilidades. Uma delas, conforme mencionado anteriormente, consiste na eliminação do ruído existente no cubo de dados original. Além disso, problemas como hot/cold 
pixeis ou raios cósmicos também podem aparecer como um ou mais autovetores. Nesse caso, esses defeitos, em princípio, também podem ser eliminados, excluindo-se os autovetores em questão.

Existe ainda mais uma utilidade da Tomografia PCA: o chamado Feature Supression and Enhancement, que consiste na supressão ou enfatização de uma determinada estrutura ou característica $A$, através de uma reconstrução apropriada do cubo de dados. Nesse processo, primeiramente, deve-se definir, para cada autovetor $k$, o que pode ser chamado de fator característico $\Gamma_{k}(A)$ :

$$
\Gamma_{k}(A)=1 ; 0
$$

Esse fator deve assumir o valor 1, para que o autovetor em questão seja considerado no processo de reconstrução, ou o valor 0 , para que ele seja desconsiderado. Nesse procedimento, o cubo de dados reconstruído pode ser dado por

$$
I^{\prime}(A)=\sum_{k}\left[I^{\prime}(k) \cdot \Gamma_{k}(A)\right]
$$

Esse método do Feature Supression and Enhacement também pode ser aplicado sem a construção dos cubos de dados $I^{\prime}(k)$ para cada um dos autovetores $k$. Nesse caso, tem-se que

$$
X^{\prime}(A)=\left[E_{\Gamma}\right]^{T} \cdot T
$$

onde $E_{\Gamma}=$ matriz $E$ que teve cada uma de suas linhas (que correspondem a cada um dos autovetores) multiplicadas pelos respectivos fatores característicos $\Gamma_{k}(A)$

A partir da matriz $X^{\prime}(A)$ pode-se, evidentemente, obter o cubo de dados $I^{\prime}(A)$. É importante lembrar que a estrutura $A$ mencionada nas equações anteriores pode ser, por exemplo, uma estrela, um núcleo galáctivo, a BLR de um núcleo ativo e etc. 
Existe uma outra estratégia, entretanto, para se fazer o Feature Supression and Enhancement. Ao invés de simplesmente se adicionar as intensidades dos autovetores (conforme foi feito na equação 3.97), pode-se adicionar a intensidade de cada autovetor dividida pela sua variância. Nesse caso, o processo de Feature Supression and Enhancement é dado pela expressão

$$
W^{\prime}(A)=\left[E_{\Gamma}\right]^{T} \cdot T_{N}
$$

sendo que $T_{N}$ corresponde à matriz $T$ com cada uma de suas linhas (que correspondem a cada um dos tomogramas) multiplicadas pelos respectivos fatores $N_{k}$, dados por

$$
N_{k}=\frac{1}{\left(\Lambda_{k}\right)^{\frac{1}{2}} \cdot(n-1)} .
$$

$\mathrm{N}_{\mathrm{k}}$ corresponde a um fator de normalização construído de tal modo que a soma quadrática de todos os pixeis espaciais de um tomograma multiplicado por ele é igual a 1. De maneira análoga ao que foi feito anteriormente, pode-se montar o cubo de dados $V^{\prime}(A)$ a partir da matriz $W^{\prime}(A)$. A grande diferença entre $I^{\prime}(A)$ e $V^{\prime}(A)$ é que o primeiro resulta de uma combinação de autovetores enfatizando a intensidade associada a cada autovetor, enquanto o segundo resulta de uma combinação que considera todos os autovetores com o mesmo peso. O cubo $V^{\prime}(A)$, em geral, possui a grande vantagem de ressaltar muitas características que, muitas vezes, não são tão visíveis em I'(A), entretanto, ele também pode acabar ressaltando o ruído existente em autovetores de ordem mais elevada, o que corresponde a uma desvantagem considerável.

A Tomografia PCA, assim como os processos de reconstrução do cubo de dados e do Feature Supression and Enhancement, foram aplicados aos cubos de dados analisados nesse trabalho utilizando-se scripts escritos em linguagem IDL. 


\subsection{1 - Remoção de fingerprints instrumentais}

Verificou-se que muitos dos cubos de dados analisados nesse trabalho apresentavam certos fingerprints instrumentais, que, normalmente, tomavam a forma de largas faixas horizontais ou verticais nas imagens. Tais estruturas também possuíam assinaturas espectrais bastante características.

O procedimento aqui utilizado para remover os fingerprints instrumentais foi exatamente o mesmo para os cubos de dados obtidos com o IFU do GMOS, com o NIFS e com o SINFONI: primeiramente, excluíram-se as linhas de emissão e absorção do cubo de dados tratado, de modo que apenas o contínuo espectral permanecesse. A razão disso é que as assinaturas espectrais dos fingerprints encontrados, em geral, estão associadas apenas ao contínuo e não a linhas espectrais, assim, a remoção de tais linhas facilitou a visualização do problema. Em seguida, aplicou-se a Tomografia PCA ao cubo de dados sem as linhas espectrais e selecionaram-se os autovetores obtidos que estavam relacionados ao fingerprint existente (se a Tomografia PCA tivesse sido aplicada ao cubo de dados com as linhas espectrais, é provável que os autovetores relacionados ao fingerprint também possuíssem alguma relação com fenômenos associados às linhas espectrais, ou seja, seria mais difícil isolar o fingerprint em autovetores específicos sem a "contaminação" dos mesmos por linhas espectrais). A fim de se remover a assinatura espectral do fingerprint, ajustaram-se e subtraíram-se splines dos auto-espectros selecionados. Fez-se, então, uma reconstrução do cubo de dados utilizando-se os autovetores relacionados ao fingerprint e, em seguida, uma nova reconstrução, utilizando-se os mesmos autovetores após a subtração dos splines dos respectivos auto-espectros. Dessa forma, obtiveram-se dois cubos de dados, sendo que o primeiro deles (cubo 1) foi construído a partir dos autovetores relacionados ao fingerprint e o segundo (cubo 2) a partir dos mesmos autovetores, mas após a eliminação da assinatura espectral do fingerprint neles detectado. Após isso, subtraiu-se o cubo 2 do cubo 1, de maneira a se obter um cubo contendo, exclusivamente, o fingerprint instrumental (cubo_fingerprint). A razão de se ter procedido dessa maneira foi que os autovetores identificados como estando relacionados ao fingerprint também poderiam estar "contaminados" por outros fenômenos, possivelmente não associados ao contínuo espectral. Uma possibilidade seria a existência de resquícios de linhas espectrais não totalmente removidas do cubo de dados original. Nesse caso, fenômenos associados a tais resquícios poderiam "contaminar" os autovetores relacionados ao 
fingerprint. Entretanto, a subtração dos splines dos auto-espectros não eliminaria tais fenômenos não associados ao contínuo espectral. Assim, a subtração entre os dois cubos de dados mencionada acima iria, em princípio, remover outros possíveis fenômenos que estivessem "contaminando" os autovetores, restando, apenas, o fingerprint instrumental. Finalmente, subtraiu-se o cubo fingerprint do cubo original (com as linhas espectrais presentes), eliminandose, assim, o problema existente. As figuras seguintes mostram alguns exemplos da aplicação da remoção de fingerprints instrumentais de cubos de dados de objetos observados com o IFU do GMOS, com o NIFS e com o SINFONI.

A figura 3.60 mostra o tomograma e o auto-espectro correspondentes ao autovetor E4, obtido com a Tomografia PCA do cubo de dados do LINER M104 (analisado nesse trabalho), observado com o IFU do GMOS, após a remoção das linhas espectrais. Na mesma figura, também é mostrado o resultado encontrado após a subtração do spline do auto-espectro.

a)
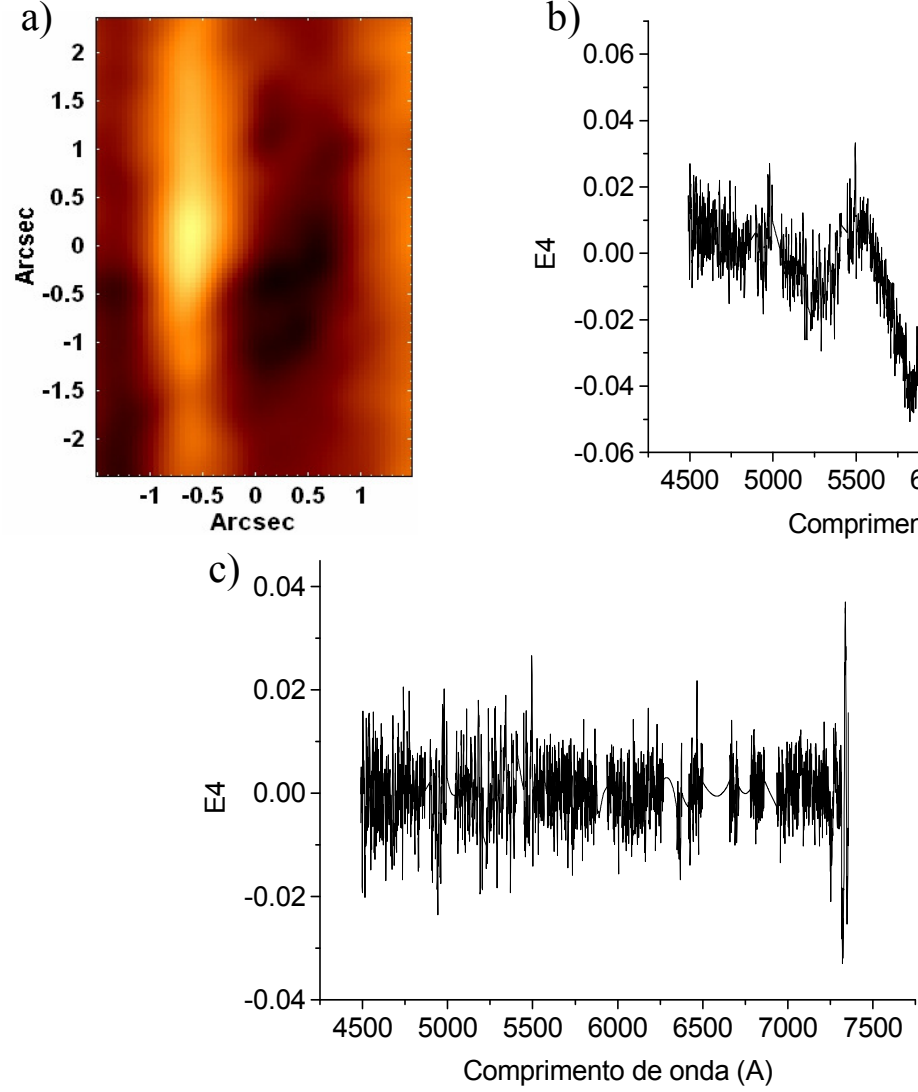

b)

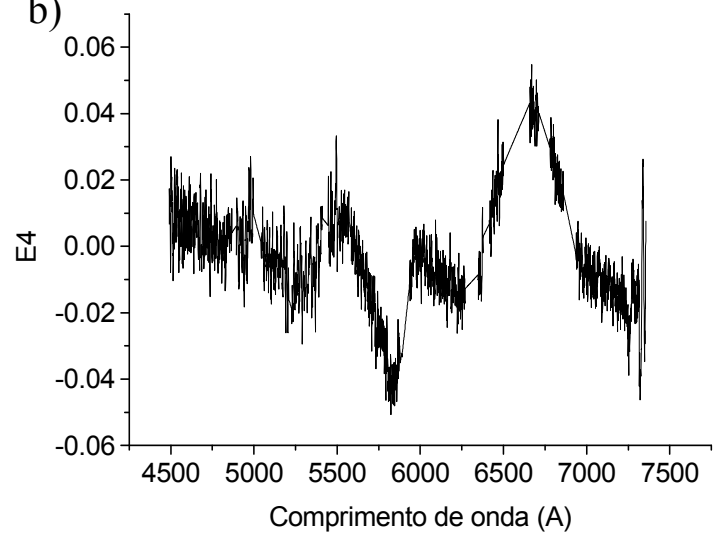

Figura 3.60 - (a) Tomograma correspondente ao autovetor E4, resultante da aplicação da Tomografia PCA ao cubo de dados de M104, obtido com o IFU do GMOS, após a remoção das linhas espectrais; (b) Auto-espectro correspondente ao autovetor E4, resultante da aplicação da Tomografia PCA do cubo de dados de M104, obtido com o IFU do GMOS, após a remoção das linhas espectrais; (c) Mesmo auto-espectro mostrado em (b), após a subtração do "spline" ajustado. 
A figura 3.61 mostra o tomograma e o auto-espectro correspondentes ao autovetor E5, obtido com a Tomografia PCA do cubo de dados do LINER M104, observado com o NIFS, após a remoção das linhas espectrais. Na mesma figura, também é mostrado o resultado encontrado após a subtração do spline do auto-espectro.
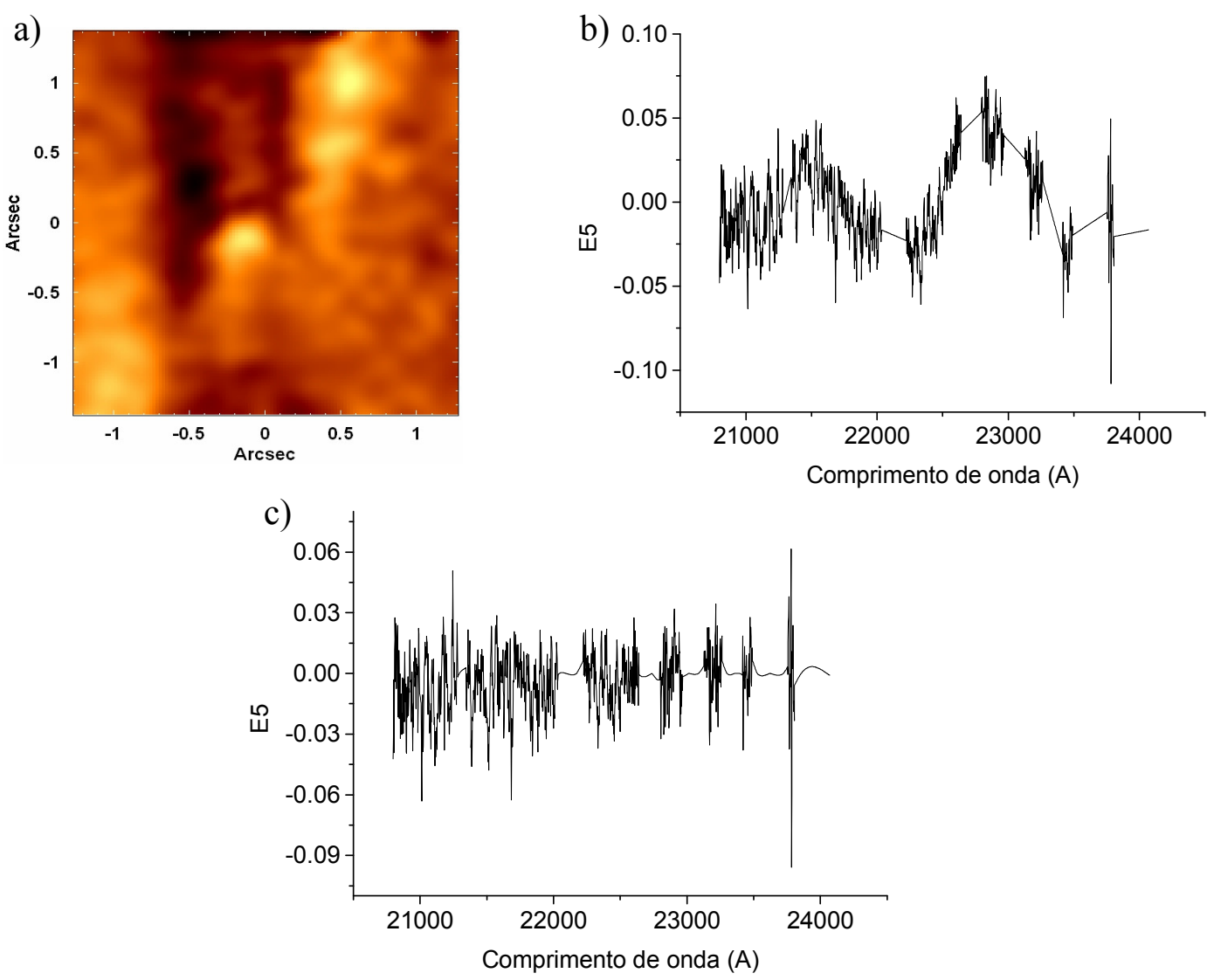

Figura 3.61 - (a) Tomograma correspondente ao autovetor E5, resultante da aplicação da Tomografia PCA no cubo de dados de M104, obtido com o NIFS, após a remoção das linhas espectrais; (b) Auto-espectro correspondente ao autovetor E5, resultante da aplicação da Tomografia PCA do cubo de dados de M104, obtido com o NIFS, após a remoção das linhas espectrais; (c) Mesmo auto-espectro mostrado em (b), após a subtração do "spline" ajustado.

A figura 3.62 mostra o tomograma e o auto-espectro correspondentes ao autovetor E3, obtido com a Tomografia PCA do cubo de dados da galáxia Seyfert 2 NGC 5643, observada com o SINFONI, após a remoção das linhas espectrais. Na mesma figura, também é mostrado o resultado encontrado após a subtração do spline do auto-espectro. 

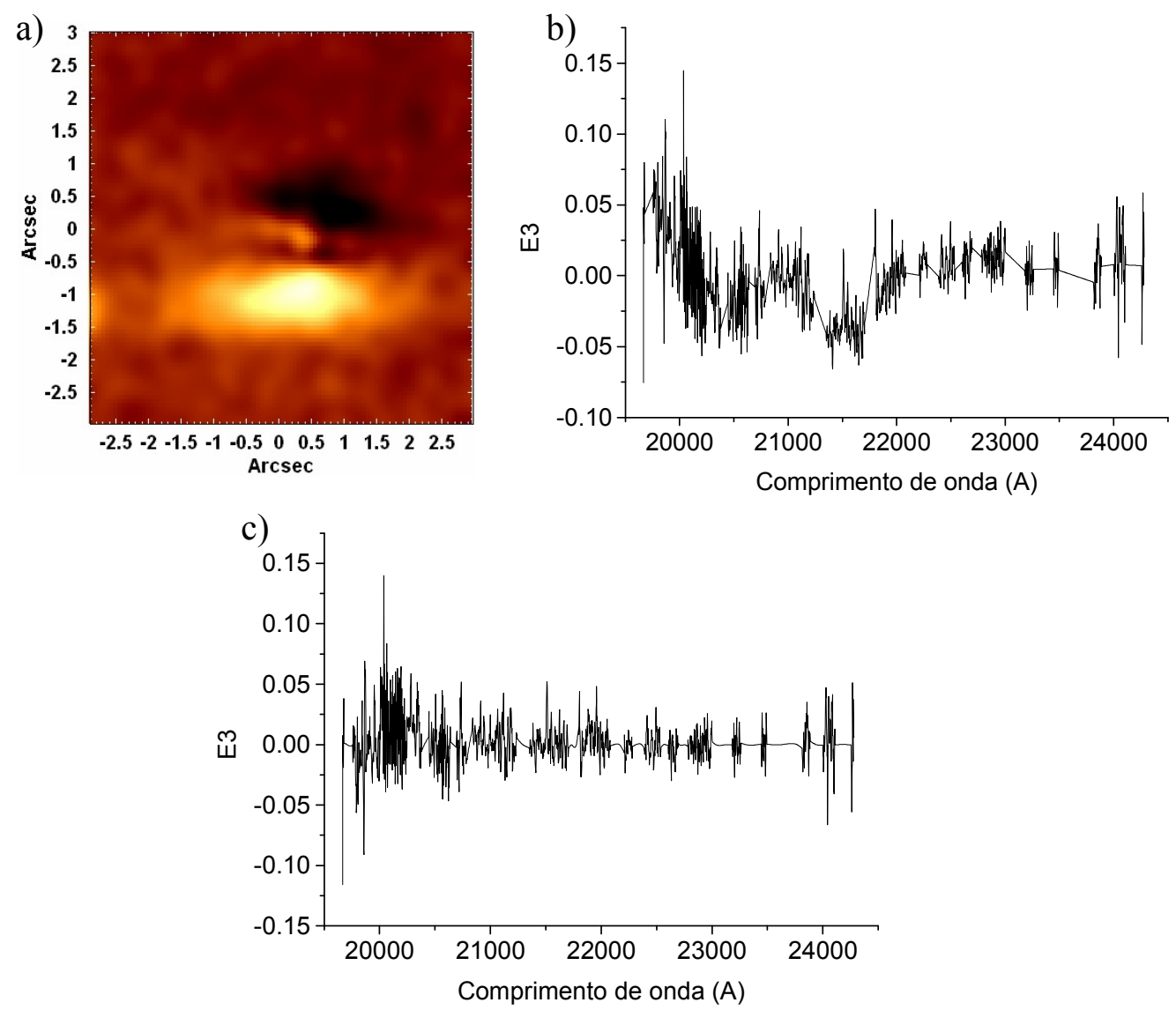

Figura 3.62 - (a) Tomograma correspondente ao autovetor E3, resultante da aplicação da Tomografia PCA no cubo de dados de NGC 5643, obtido com o SINFONI, após a remoção das linhas espectrais; (b) Auto-espectro correspondente ao autovetor E3, resultante da aplicação da Tomografia PCA do cubo de dados de NGC 5643, obtido com o SINFONI, após a remoção das linhas espectrais; (c) Mesmo auto-espectro mostrado em (b), após a subtração do "spline" ajustado.

Os fingerprints mostrados nas figuras 3.60, 3.61 e 3.62 são característicos dos instrumentos envolvidos na observação de cada objeto. Pode-se notar algumas semelhanças entre os fingerprints apresentados pelo IFU do GMOS e pelo NIFS, tanto nas suas características espaciais, na forma de faixas largas verticais, quanto nas suas assinaturas espectrais, com protuberâncias e depressões. O fingerprint de dados obtidos com o SINFONI, por sua vez, possui certas diferenças, já que, espacialmente, ele toma a forma de uma larga faixa horizontal e, espectralmente, a sua principal característica é uma depressão acentuada, facilmente detectável.

É importante mencionar, entretanto, que o fingerprint detectado em dados do SINFONI também costuma ter uma segunda característica importante: os espectros na região espacial da faixa brilhante mostrada na figura 3.62 - a tendem a apresentar inclinações ligeiramente diferentes das dos demais. A técnica descrita anteriormente não é capaz de remover essa segunda 
característica desse fingerprint. Entretanto, vários testes mostraram que é possível atenuar, ou mesmo eliminar esse problema, aplicando-se (após o procedimento de remoção de fingerprints) uma deconvolução de Richardson-Lucy com uma PSF real contaminada com a mesma faixa detectada na figura $3.62-a$.

Nos cubos de dados analisados nesse trabalho, o procedimento de remoção de fingerprints foi aplicado após a filtragem espacial de Butterworth e antes da deconvolução de RichardsonLucy (ou antes da aplicação do de-noising, nos casos em que esse método foi utilizado).

\subsection{2 - Síntese espectral com o Starlight}

O Starlight é um software que tem como função ajustar o espectro de um determinado objeto com um modelo formado pela soma de espectros de diferentes populações estelares (que constituem os espectros de base). Em outras palavras, o Starlight realiza uma síntese espectral a partir de um conjunto de espectros de base (que podem ser observados ou obtidos a partir de modelos teóricos) a fim de ajustar um dado espectro (para maiores detalhes ver Cid Fernandes et al. 2005). A síntese espectral com esse software foi utilizada na análise de todos os cubos de dados nesse trabalho.

Supondo-se que o número de espectros de base disponíveis para o ajuste com o Starlight seja igual a $N_{*}$, então, o modelo $M_{\lambda}$ obtido por esse software pode ser dado por

$$
M_{\lambda}=\sum_{j=1}^{N_{*}} L_{\lambda, j}=\sum_{j=1}^{N_{*}} L_{\lambda, j}^{0} * G\left(v_{*}, \sigma_{*}\right) \cdot 10^{-0.4 A_{\lambda, j}}
$$

onde $L_{\lambda, j}=$ espectro observado da população estelar $j$

$$
\begin{aligned}
L_{\lambda, j}^{0}= & \text { espectro da população estelar } j \text { sem } \\
& \text { nenhuma extinção ou efeito cinemático } \\
A_{\lambda, j}= & \text { extinção no comprimento de onda } \lambda \text { sofrido } \\
& \text { pela população estelar } j \\
G\left(v_{*}, \sigma_{*}\right)= & \text { distribuição gaussiana centrada em } v_{*} \\
& \text { e com dispersão de velocidades igual a } \sigma *
\end{aligned}
$$


Na equação (3.101), o símbolo * representa o processo de convolução. Entretanto, essa expressão também pode ser escrita como

$$
M_{\lambda}=\sum_{j=1}^{N_{*}} L_{\lambda_{0}, j}^{0} b_{\lambda, j} * G\left(v_{*}, \sigma_{*}\right) \cdot 10^{-0.4 A_{\lambda, j}}
$$

sendo que

$$
b_{\lambda, j}=\left(\frac{L_{\lambda, j}^{0}}{L_{\lambda_{0}, j}^{0}}\right)
$$

Nas equações anteriores, $L_{\lambda_{0}, j}^{0}$ representa a emissão da população estelar $j$ no comprimento de onda $\lambda_{0}$, assim, pode-se dizer que $b_{\lambda, j}$ corresponde ao espectro da população estelar j normalizado em $\lambda_{0}$.

Em seguida, definindo-se o espectro base da população estelar $j$ normalizado e convoluído com a distribuição gaussiana $G$ como

$$
\gamma_{\lambda, j}=b_{\lambda, j} * G\left(v_{*}, \sigma_{*}\right)
$$

e tomando-se

$$
A_{\lambda}=A_{V} q_{\lambda}
$$

tem-se que a equação (3.102) pode ser escrita como

$$
M_{\lambda}=\sum_{j=1}^{N_{*}}\left[L_{\lambda_{0}, j}^{0} \cdot 10^{-0.4 A_{V, j} q_{\lambda 0}} b_{j, \lambda} \cdot 10^{-0.4 A_{V, j}\left(q_{\lambda}-q_{\lambda 0}\right)}\right.
$$

Pela equação (3.106), pode-se notar que o termo entre colchetes corresponde à emissão da população estelar $j$ em $\lambda_{0}$, extinta por $A_{V, j}$, e antes da convolução com $G$. Definindo-se esse termo como 


$$
x_{j}=L_{\lambda_{0}, j}^{0} \cdot 10^{-0.4 A_{V, j} q_{\lambda 0}}
$$

então, a equação final do modelo obtido pela síntese espectral feita pelo Starlight pode ser dada por

$$
M_{\lambda}=\sum_{j=1}^{N_{*}} x_{j} \gamma_{j, \lambda} \cdot 10^{-0.4 A_{V, j}\left(q_{\lambda}-q_{\lambda 0}\right)}
$$

Como todos os espectros de base são normalizados em $\lambda_{0}$, pode-se dizer que, na prática, $\mathrm{x}_{\mathrm{j}}$ corresponde aproximadamente à fração de luz em $\lambda_{0}$ devida à população $j$. Entretanto, esse valor não é exatamente uma fração de luz, pois, como o Starlight não impõe que o modelo e o espectro observado devam coincidir em $\lambda_{0}$, em geral, a soma dos $\mathrm{x}_{\mathrm{j}}$ não será igual a $1(100 \%)$.

Pode-se dizer que o software Starlight, ao final dos ajustes, tem como objetivo determinar os valores de $x_{j}$ (ou seja, as frações de luz em $\lambda_{0}$ associadas a cada população estelar $j$ ), $A_{V}, \sigma$ e $v_{*}$.

Para encontrar o modelo mais adequado para ajustar o espectro observado, o Starlight utiliza métodos numéricos (que não são discutidos aqui) buscando determinar o menor valor de

$$
\begin{gathered}
\chi^{2}=\sum_{\lambda}\left[\left(O_{\lambda}-M_{\lambda}\right) w_{\lambda}\right]^{2} \\
\text { onde } O_{\lambda}=\text { espectro observado } \\
w_{\lambda}=1 / e_{\lambda}, \text { sendo que } e_{\lambda} \text { correspondem aos erros } \\
\text { associados ao espectro observado }
\end{gathered}
$$

No caso de o espectro observado não possuir erros associados aos diferentes comprimentos de onda, o Starlight define um com base no rms do espectro em um intervalo de comprimentos de onda determinado pelo usuário.

Para se aplicar a síntese espectral do software Starlight em cubos de dados, foram necessárias algumas etapas de preparação preliminares. Primeiramente, foi feita uma correção da extinção Galáctica, com base na lei de extinção de Cardelli et al. (1989), em todos os espectros de cada cubo, utilizando-se um programa escrito em linguagem IDL. Em seguida, todos esses espectros foram extraídos do cubo e corrigidos em relação ao redshift (ou seja, os espectros foram passados para um referencial de repouso). Essa correção foi feita utilizando-se a tarefa 
"dopcor" do software IRAF. Finalmente, foi feita uma reamostragem dos espectros em intervalos de 1 Á, através da tarefa "dispcor" do software IRAF. Todas essas etapas são necessárias para que o software Starlight possa funcionar corretamente.

As sínteses espectrais de todos os cubos de dados analisados nesse trabalho foram feitas utilizando-se espectros de base da MILES, Medium resolution INT Library of Empirical Spectra (Sánchez-Blázquez et al. 2006), envolvendo populações estelares de 25 idades e 6 metalicidades diferentes. A tabela 3.1 mostra os valores das idades e metalicidades das populações estelares utilizadas nas sínteses espectrais dos cubos de dados.

\begin{tabular}{|c|c|}
\hline Idades (anos) & Metalicidades \\
\hline $1.00 \cdot 10^{6}$ & 0.0001 \\
$3.16 \cdot 10^{6}$ & 0.0004 \\
$5.01 \cdot 10^{6}$ & 0.004 \\
$6.61 \cdot 10^{6}$ & 0.008 \\
$8.71 \cdot 10^{6}$ & 0.02 \\
$1.00 \cdot 10^{7}$ & 0.05 \\
$1.45 \cdot 10^{7}$ & \\
$2.51 \cdot 10^{7}$ & \\
$4.00 \cdot 10^{7}$ & \\
$5.50 \cdot 10^{7}$ & \\
$1.02 \cdot 10^{8}$ & \\
$1.61 \cdot 10^{8}$ & \\
$2.86 \cdot 10^{8}$ & \\
$5.09 \cdot 10^{8}$ & \\
$9.05 \cdot 10^{8}$ & \\
$1.28 \cdot 10^{9}$ & \\
$1.43 \cdot 10^{9}$ & \\
$2.50 \cdot 10^{9}$ & \\
$4.25 \cdot 10^{9}$ & \\
$6.25 \cdot 10^{9}$ & \\
$7.50 \cdot 10^{9}$ & \\
$1.00 \cdot 10^{10}$ & \\
$1.30 \cdot 10^{10}$ & \\
$1.50 \cdot 10^{10}$ & \\
$1.80 \cdot 10^{10}$ & \\
\hline
\end{tabular}

Tabela 3.1: Idades e metalicidades das populações estelares utilizadas nas sínteses espectrais dos cubos de dados analisados nesse trabalho.

Como os objetos analisados nesse trabalho são AGNs, foi preciso considerar, na síntese espectral, a presença de um featureless continuum. Para isso, foi adicionado ao conjunto de espectros de populações estelares da base um arquivo contendo uma lei de potência, com índice 
espectral igual a 1.5, para simular o featureless continuum do AGN central. Além disso, no caso de cubos de dados na região espectral do infravermelho (obtidos com o NIFS ou com o SINFONI), a emissão térmica de poeira também precisou ser levada em conta na síntese espectral. Por essa razão, nesses casos, foram adicionados, ainda, ao conjunto de espectros de populações estelares da base arquivos contendo curvas de corpo negro em diferentes temperaturas, que foram usados para simular a emissão térmica proveniente da poeira. Optou-se por utilizar 8 curvas de corpo negro, com temperaturas de $700 \mathrm{~K}, 800 \mathrm{~K}, 900 \mathrm{~K}, 1000 \mathrm{~K}, 1100 \mathrm{~K}$, $1200 \mathrm{~K}, 1300 \mathrm{~K}$ e $1400 \mathrm{~K}$.

A partir dos resultados obtidos com as sínteses espectrais dos cubos de dados, foi possível fazer mapeamentos de uma série de parâmetros como: dispersão de velocidades, velocidade radial das estrelas, fluxo emitido por cada população estelar, fluxo emitido por poeira quente em diferentes temperaturas, fluxo associado ao featureless continuum e extinção. Além disso, a síntese espectral com o Starlight também possibilitou a obtenção de contínuos estelares sintéticos, que foram subtraídos de todos os espectros originais dos cubos de dados, resultando, assim, em cubos contendo apenas linhas de emissão. A partir disso, foi possível fazer uma análise mais detalhada dos espectros de emissão de todos os objetos analisados nesse trabalho.

\subsection{3 - Determinação da cinemática estelar com o Penalized Pixel Fitting}

Análises da cinemática estelar de galáxias observadas requerem, primeiramente, determinações precisas da distribuição de velocidades ao longo da linha de visada (line-of-sight velocity distribution - LOSVD). Atualmente, muitas técnicas são utilizadas para se fazer isso e algumas das mais eficazes envolvem parametrizações de Gauss-Hermite.

Uma possível metodologia para se obter a LOSVD de um espectro de uma galáxia, utilizando-se parametrizações de Gauss-Hermite, começa com a criação de um modelo para esse espectro através da convolução de um espectro template com uma função representativa da LOSVD. Nesse caso, tem-se que 


$$
G_{\mathrm{mod}}(x)=\sum_{k=1}^{K} w_{k}\left[B^{*} T_{k}\right](x)+\sum_{l=0}^{L} b_{l} P_{l}(x), \quad w_{k} \geq 0
$$

onde $T_{k}=$ espectro template de uma biblioteca contendo $K$ espectros de populações estelares

$$
\begin{aligned}
B(x)= & L(c x), \operatorname{com} L(v) \text { correspondendo à função } \\
& \text { que descreve a LOSVD } \\
c= & \text { velocidade da luz } \\
P_{l}= & \text { polinômio de Legendre de ordem } l
\end{aligned}
$$

sendo que tanto o espectro observado quanto o template são reamostrados para uma escala linear em $x=\ln \lambda$. A função $L$ (que descreve a LOSVD) na expressão (3.110) é dada por uma série de Gauss-Hermite (van der Marel \& Franx 1993; Gerhard 1993):

$$
\begin{aligned}
L(v)=\frac{e^{-(1 / 2) y^{2}}}{\sigma \sqrt{2 \pi}}\left[1+\sum_{m=3}^{M} h_{m} H_{m}(y)\right] . \\
\text { onde } y=\frac{(v-V)}{\sigma} \\
H_{m}=\text { polinômio de Hermite de ordem } m
\end{aligned}
$$

Os parâmetros mais adequados para a LOSVD são determinados minimizando-se o $\chi^{2}$, que mede a concordância entre o modelo criado e o espectro observado $G(x)$, ao longo dos $N$ pixeis espectrais considerados no ajuste:

$$
\chi^{2}=\sum_{n=1}^{N} r_{n}^{2},
$$

onde

$$
r_{n}=\frac{G_{\mathrm{mod}}\left(x_{n}\right)-G\left(x_{n}\right)}{\Delta G\left(x_{n}\right)} .
$$


As expressões anteriores mostram que, para uma dada $L(v)$, a otimização do $\chi^{2}$ é um problema de mínimos quadrados linear para as variáveis $w_{1}, \ldots, w_{K}, b_{0}, \ldots$ e $b_{L}$, que pode ser resolvido, por exemplo, pelo algoritmo BVLS (bounded-variables linear least-squares) desenvolvido por Lawson \& Hanson (1995). Por outro lado, as equações também revelam que, para um dado conjunto de valores de $w_{1}, \ldots, w_{K}, b_{0}, \ldots$. e $b_{L}$, a otimização do $\chi^{2}$ é um problema de mínimos quadrados não linear, que pode ser resolvido, por exemplo, pelo método de LevenberMarquardt. Uma implementação bastante utilizada desse método é a MINPACK, desenvolvida por Moré et al. (1980).

A determinação da LOSVD, utilizando parametrizações de Gauss-Hermite, pode apresentar problemas em espectros com baixas razões $S / N$. Isso ocorre porque, nessas situações, as estruturas mal definidas dos espectros costumam gerar instabilidades nos ajustes, o que, consequentemente, resulta em parâmetros finais pouco confiáveis. Nessas circunstâncias, é preferível utilizar ajustes gaussianos nas linhas para se determinar a LOSVD. O processo do Penalized Pixel Fitting - pPXF (Cappellari \& Emsellem 2004) consiste na aplicação de um termo de penalização na expressão do $\chi^{2}$, de modo que, em espectros com altas razões $S / N$, a solução do ajuste mantenha todos os detalhes da expansão de Gauss-Hermite, mas, em espectros com baixas razões $S / N$, a solução tenda a um formato gaussiano. Um formato genérico para o $\chi^{2}$ penalizado pode ser dado por

$$
\chi_{p}^{2}=\chi^{2}+\alpha P
$$

onde $P=$ função de penalização

A partir do que foi dito anteriormente, um formato natural para a função $P$ é dado pelo desvio quadrático integrado entre $L(v)$ e o melhor ajuste gaussiano obtido $G(v)$ :

$$
D^{2}=\frac{\int_{-\infty}^{\infty}[L(v)-G(v)]^{2} d v}{\int_{-\infty}^{\infty} G(v)^{2} d v}
$$


Entretanto, van der Marel \& Franx (1993) mostraram que, quando $L(v)$ é dada pela expressão (3.111), a equação (3.115) pode ser bem aproximada por

$$
D^{2} \approx \sum_{m=3}^{M} h_{m}^{2}
$$

Em princípio, pareceria intuitivo tomar $P=D^{2}$, entretanto, esse processo apresenta duas desvantagens: em primeiro lugar, computacionalmente, é muito mais eficiente minimizar os resíduos, dados pela expressão (3.113), do que calcular explicitamente os valores do $\chi^{2}$. Além disso, seria preciso ajustar automaticamente o fator $\alpha$ de acordo com o $\chi^{2}$ do ajuste obtido. Para se resolver esses problemas, Cappellari \& Emsellem (2004) propuseram a aplicação da seguinte perturbação nos valores dos resíduos:

$$
r_{n}^{\prime}=r_{n}+\lambda \sigma(r) D
$$

onde

$$
\sigma^{2}(r)=\frac{1}{N} \sum_{n=1}^{N} r_{n}^{2}
$$

A interpretação qualitativa da expressão (3.117) pode ser dada da seguinte maneira: um desvio $D$ na LOSVD a partir de um formato gaussiano somente é aceito como uma melhoria no ajuste se ele diminui o espalhamento $\sigma(r)$ em um valor da ordem de $D$. A partir das equações (3.112) e (3.117), verifica-se que o $\chi^{2}$ penalizado pode ser dado por

$$
\chi_{p}^{2}=\sum_{n=1}^{N} r_{n}^{2}+2 \lambda \sigma(r) D \sum_{n=1}^{N} r_{n}+N[\lambda \sigma(r) D]^{2}
$$

Entretanto, a soma dos resíduos no segundo termo da expressão (3.119) é zero por construção, devido ao fato de os pesos utilizados na equação (3.110) serem otimizados para um dado $L(v)$. Assim, levando-se em conta isso e as expressões (3.112) e (3.118), obtém-se que 


$$
\chi_{p}^{2}=\chi^{2}\left(1+\lambda^{2} D^{2}\right)
$$

Pode-se notar que a equação (3.120) possui o mesmo formato da (3.114), $\operatorname{com} \alpha=\lambda^{2} \chi^{2}$. Dessa forma, utilizando-se a estratégia de penalização dada pela expressão (3.117), obtém-se um coeficiente $\alpha$ para a equação (3.114) que fica automaticamente definido pelo $\chi^{2}$ do ajuste, bastando apenas determinar um valor de $\lambda$ apropriado. Nesse trabalho, optou-se por utilizar o $\lambda$ padrão fornecido por Cappellari \& Emsellem (2004):

$$
\lambda=0.7 \sqrt{\frac{500.0}{N}} .
$$

Em resumo, o processo do pPXF proposto por Cappellari \& Emsellem (2004) consiste nas seguintes etapas:

1 - é dado um palpite inicial para os parâmetros $V$ e $\sigma$ e os demais parâmetros de Gauss-Hermite $\left(h_{3}, \ldots, h_{M}\right)$ são tomados com iguais a 0 ;

2 - obtêm-se os parâmetros $w_{1}, \ldots, w_{K}, b_{0}, \ldots$ e $b_{L}$ da equação (3.110), utilizando-se o algoritmo BVLS (apropriado para a solução de problemas de mínimos quadrados lineares), desenvolvido por Lawson \& Hanson (1995);

3 - calculam-se os resíduos $r_{n}$ dados pela expressão (3.113);

4 - aplicam-se as perturbações dadas pela equação (3.117) nos resíduos $r_{n}$, a fim de se obter os valores de $r_{n}$;

5 - partindo-se dos valores calculados de $r_{n}$ ' e utilizando-se os coeficientes $w_{1}, \ldots, w_{K}, b_{0}, \ldots$ e $b_{L}$ encontrados na etapa 2, aplica-se um procedimento iterativo na equação (3.110) com a rotina MINPACK (para a solução de problemas de mínimos quadrados não lineares) a fim de se obter os parâmetros $V, \sigma, h_{3}, \ldots$ e $h_{M}$. A cada iteração são calculados novos valores de $r_{n}$ e $r_{n}$ ' por meio das equações (3.113) e (3.117), respectivamente. 
Nos cubos de dados analisados nesse trabalho, o processo do pPXF foi aplicado utilizando-se um script escrito em linguagem IDL, obtido de http://www.strw.leidenuniv.nl/ mcappell/idl/. Para os cubos de dados no óptico, a base de espectros utilizada nos ajustes com o pPXF foi a MILES, que também foi usada para a síntese espectral com o Starlight. Para os cubos de dados no infravermelho, por outro lado, o pPXF foi aplicado utilizando-se uma base de espectros de estrelas observadas com o NIFS, que é descrita com detalhes em Winge et al. (2009). 


\section{4 - NGC 2992}

\section{1 - Introdução}

NGC 2992 é uma galáxia espiral de tipo morfológico Sa altamente inclinada $\left(i \sim 70^{\circ}\right)$, estando, portanto, quase edge-on. Trata-se de um sistema em interação com a galáxia próxima NGC 2993, sendo que os dois objetos estão, inclusive, conectados por uma cauda de maré com um tamanho projetado de 2.9'. A figura 4.1 mostra as galáxias em interação NGC 2992 e NGC 2993, assim como a cauda de maré que as conecta. NGC 2992 possui uma faixa de poeira ao longo de seu plano equatorial, que cruza o centro da galáxia aproximadamente do norte para o sul, dividindo a região nuclear em dois.

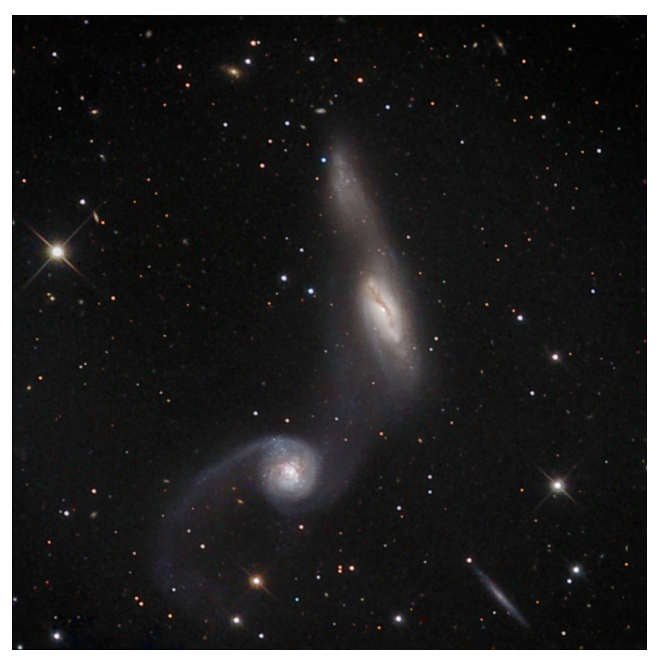

Figura 4.1 - Imagem na banda V das galáxias em interação NGC 2992 e NGC 2993, obtida com o CTIO. A orientação é norte para cima e leste para a esquerda.

Essa galáxia foi classificada, inicialmente, como Seyfert 2, entretanto, Ward et al. (1980) mudaram a sua classificação para Seyfert 1 intermediária, devido ao fato de terem observado uma componente larga da linha espectral $\mathrm{H} \alpha$, sem nenhuma correspondente em H $\beta$. Glass (1997) sugeriu que esse objeto pode ser um híbrido entre uma galáxia Seyfert intermediária e uma galáxia Starburst, sendo que o surto de formação estelar pode ter sido induzido pela interação com NGC 2993. 
Analisando mapas do contínuo em $6 \mathrm{~cm}$ e em 20cm, Ulvestad \& Wilson (1984) verificaram que NGC 2992 apresenta loops para noroeste e sudeste, que tomam a forma de um número 8 . O mapa do contínuo em $6 \mathrm{~cm}$ na figura 4.2 mostra a emissão na forma de um número 8 detectada. Existem vários modelos propostos para explicar a morfologia apresentada pela emissão em rádio: bolhas de gás em expansão (Wehrle \& Moris 1988), que poderiam estar associadas a um AGN existente; superventos movidos por starbursts (Heckman et al. 1990) e campos magnéticos toroidais (Wehrle \& Morris 1988). A emissão em raios-x em contínua diminuição foi interpretada como um AGN morrendo por Bassani et al. (1999), o que parecer favorecer o primeiro modelo proposto. Chapman et al. (2000) analisaram dados no infravermelho do CFHT (Canadian-France-Hawaii Telescope), no óptico do HST (Hubble Space Telescope) e no rádio do VLA (Very Large Array) e propuseram que componentes em rádio podem estar sendo superpostas, dando origem à figura com forma de 8. Os autores também concluíram que o melhor modelo para explicar essa morfologia é o de bolhas de gás em expansão sendo movidas por um AGN.

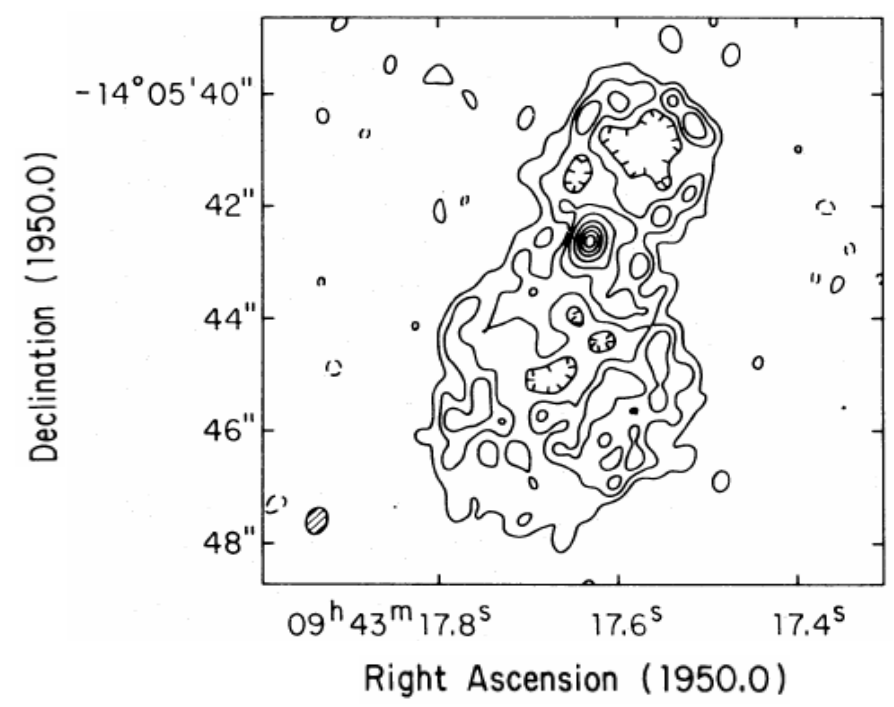

Figura 4.2 - Mapa do contínuo em $6 \mathrm{~cm}$ da região central de NGC 2992, obtido pelo VLA, retirado do trabalho de Ulvestad \& Winson (1984). 


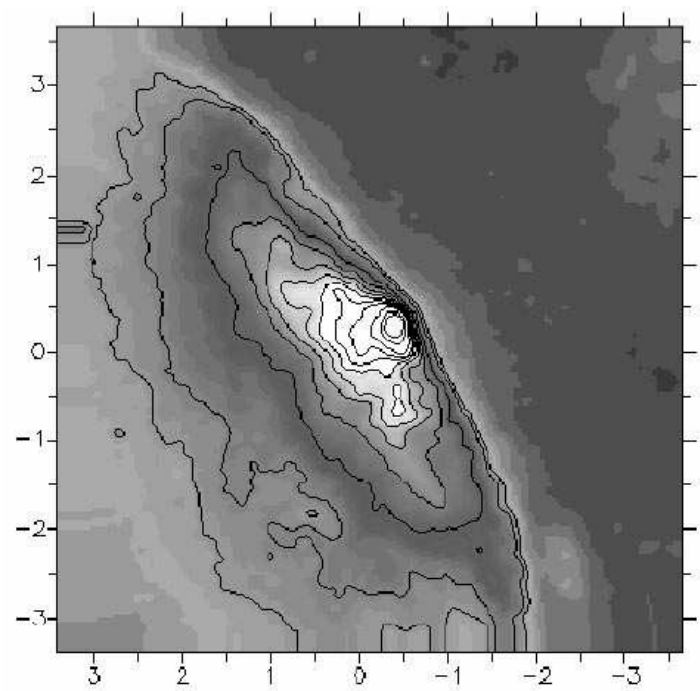

Figura 4.3 - Imagem na banda $R+V$ da região central de NGC 2992, obtida com o HST, retirada do trabalho de Chapman et al. (2000). A orientação é norte para cima e leste para a esquerda.

Heckman et al. (1981) detectaram uma cinemática complexa nessa galáxia, a partir da análise de espectros ópticos long slit obtidos em um ângulo de posição $P A=120^{\circ}$. Colina et al. (1987) realizaram uma extensão desse trabalho, também com espectroscopia óptica log slit, e acharam evidências de um outflow em um plano altamente inclinado em relação ao plano da galáxia. Ainda utilizando espectros ópticos long slit, mas dessa vez em nove ângulos de posição diferentes, Márquez et al. (1998) modelaram a cinemática do gás em NGC 2992 como um disco gasoso em rotação ao qual foi adicionado um outflow radial constante. Friedrich et al. (2010) analisaram dados desse objeto obtidos com o SINFONI do VLT e também chegaram à conclusão de que as curvas de rotação do gás são o resultado de uma superposição de um disco em rotação e de um outflow com velocidade constante.

Por ser um dos AGNs mais brilhantes em raios-x, NGC 2992 já foi observada pelos principais satélites de raios-x existentes, como ASCA, Einstein, ROSAT, BeppoSAX e Chandra. Colbert et al. (1998) analisaram dados obtidos com o ROSAT e detectaram uma emissão em raios-X estendida ao longo do ângulo de posição $P A=112^{\circ}$ nessa galáxia. Beckmann et al. (2007) analisaram dados de NGC 2992 obtidos com o INTEGRAL, com o Swift e com o BeppoSAX e detectaram uma luminosidade variável em $20-100 \mathrm{keV}$, indo de $1.2 \cdot 10^{43} \mathrm{erg} / \mathrm{s}$ a $3.9 \cdot 10^{43} \mathrm{erg} / \mathrm{s}$.

Friedrich et al. (2010) encontraram evidências de um curto surto de formação estelar há 4-5 $10^{7}$ anos atrás na região nuclear dessa galáxia, entretanto, a luminosidade é ainda dominada pelo AGN, sendo que apenas 10-20\% da luz é devida à formação estelar nuclear. 


\section{2 - Preparação do cubo de dados de NGC 2992}

Foram analisados cubos de dados da região central de NGC 2992 obtidos, na banda K do infravermelho próximo, com o SINFONI do VLT. Esses dados são os mesmos analisados por Friedrich et al. (2010), no entanto, aqui foram utilizadas diferentes metodologias de análise. A redução dos cubos de dados foi feita com o software Gasgano. Entretanto, como a remoção de absorções telúricas e a calibração em fluxo não são feitas com esse software, essas duas etapas da redução foram aplicadas utilizando-se algoritmos escritos em linguagem IRAF. Todo esse procedimento está descrito em maiores detalhes em 3.2.3. Ao final da redução, foram obtidos 9 cubos de dados com pixeis espaciais de 0.05 " de lado.

Após isso, foi aplicado o processo de correção da refração atmosférica diferencial em cada um dos cubos de dados, conforme descrito em 3.3. Em seguida, a fim de se combinar todos esses cubos em um só, primeiramente, eles foram separados em três grupos. Nomeando-se os cubos como 1, 2, 3, 4,..,9 (de acordo com a ordem de observação), a separação nos três grupos foi feita da seguinte maneira:

- Grupo 1: cubos 1, 5 e 6

- Grupo 2: cubos 2, 8 e 9

- Grupo 3: cubos 3, 4 e 7

Os integrantes de cada um desses três grupos foram combinados na forma de mediana, resultando, assim, em três cubos ao final do processo. Foi calculada, então, uma nova mediana desses três cubos de dados para se obter o cubo combinado procurado. Em seguida, aplicou-se o processo de reamostragem espacial no cubo de dados encontrado, a fim de se obter pixeis espaciais de 0.025 " de lado. A figura 4.4 mostra a soma de todas as imagens do cubo de dados de NGC 2992, antes e depois do processo de reamostragem. 

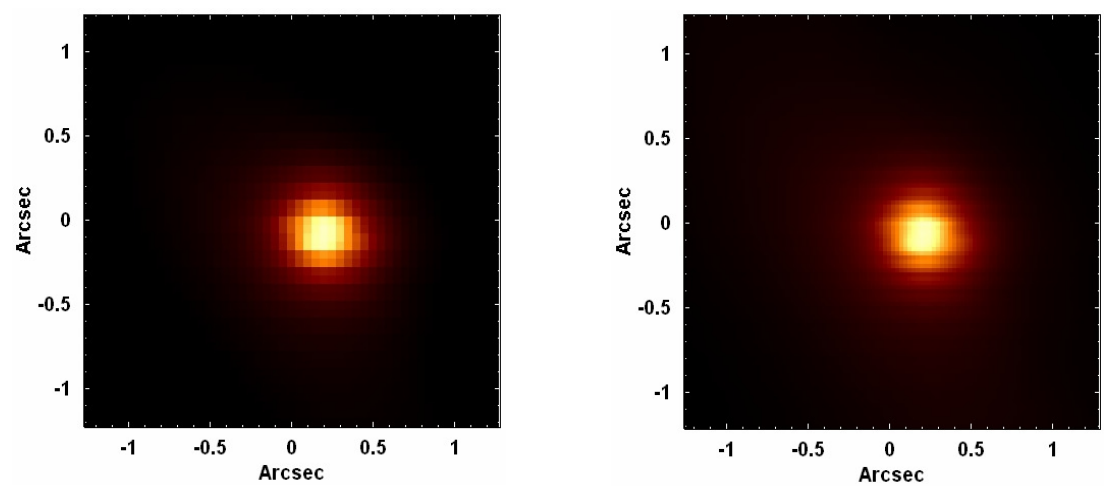

Figura 4.4 - (esquerda) Soma de todas as imagens do cubo de dados de NGC 2992, antes da aplicação da reamostragem espacial; (direita) Soma de todas as imagens do cubo de dados de NGC 2992, após a aplicação da reamostragem espacial.

Observando-se a figura 4.4, pode-se notar que a aplicação da reamostragem espacial permitiu que as estruturas espaciais presentes no cubo de dados ficassem definidas de uma maneira mais clara, no entanto, esse procedimento também introduziu componentes de alta freqüência espacial, que aparecem, sobretudo, na forma de faixas horizontais escuras e estreitas na imagem, conforme explicado em 3.5.2.

Após isso, aplicou-se uma decomposição wavelet no cubo de dados reamostrado, o que resultou na obtenção dos cubos $W_{0}, W_{1}, W_{2}, W_{3}, W_{4}$ e $W_{C}$, de acordo com o que está explicado em 3.6. Utilizou-se, então, $W_{0}$ para se determinar os parâmetros mais adequados para o filtro de Butterworth e, a seguir, esses parâmetros foram utilizados na filtragem espacial de todas as outras componentes wavelet e também do cubo de dados original (a partir do qual foram obtidas as componentes wavelet). No caso desse objeto, todas as filtragens foram feitas utilizando-se um filtro com forma dada pela expressão (3.67), $n=2$ e freqüência de corte ao longo dos eixos horizontal e vertical de $v_{c}=0.27 \mathrm{Ny}$. A figura 4.5 mostra as somas das imagens do cubo de dados, antes e depois da filtragem espacial de Butterworth, assim como a soma das imagens do cubo correspondente à diferença entre esses dois. 

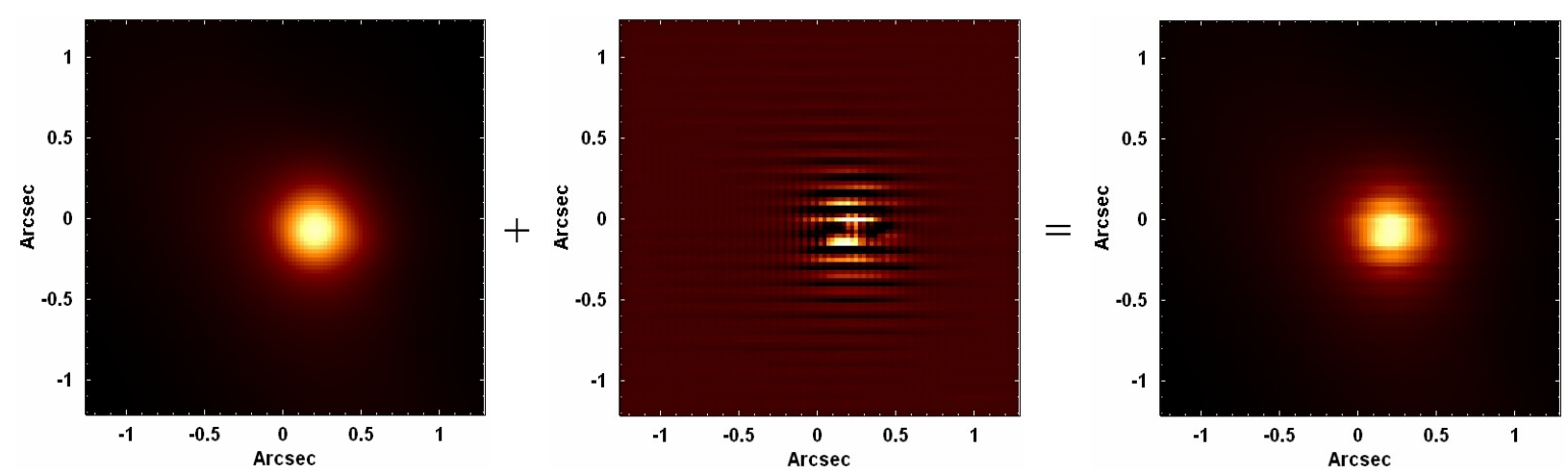

Figura 4.5 - (esquerda) Soma das imagens do cubo de dados de NGC 2992, após a filtragem espacial de Butterworth; (centro) Soma das imagens do cubo de dados de NGC 2992 correspondente à diferença entre o cubo não filtrado e o cubo filtrado; (direita) Soma das imagens do cubo de dados de NGC 2992, antes da filtragem espacial de Butterworth.

A figura 4.5 revela que a aplicação da filtragem espacial de Butterworth removeu grande parte dos ruídos de alta freqüência (inclusive as componentes de alta freqüência introduzidas pela reamostragem espacial), o que proporcionou uma considerável melhoria na qualidade das imagens do cubo de dados.

Após a aplicação da filtragem espacial de Butterworth, verificou-se que o cubo de dados de NGC 2992 ainda apresentava um fingerprint instrumental de baixa freqüência espacial, que tomava a forma de largas faixas horizontais na imagem. Tal fingerprint também possuía uma assinatura espectral bastante característica. A fim de se remover essa estrutura do cubo de dados, aplicou-se o procedimento descrito em 3.11. A figura 4.6 mostra o tomograma e o auto-espectro correspondentes ao autovetor E4 (que é o que revela o fingerprint existente de maneira mais clara), resultante da Tomografia PCA do cubo de dados de NGC 2992, após a remoção das linhas espectrais, assim como o resultado encontrado após o ajuste e a subtração de um spline do auto-espectro. 

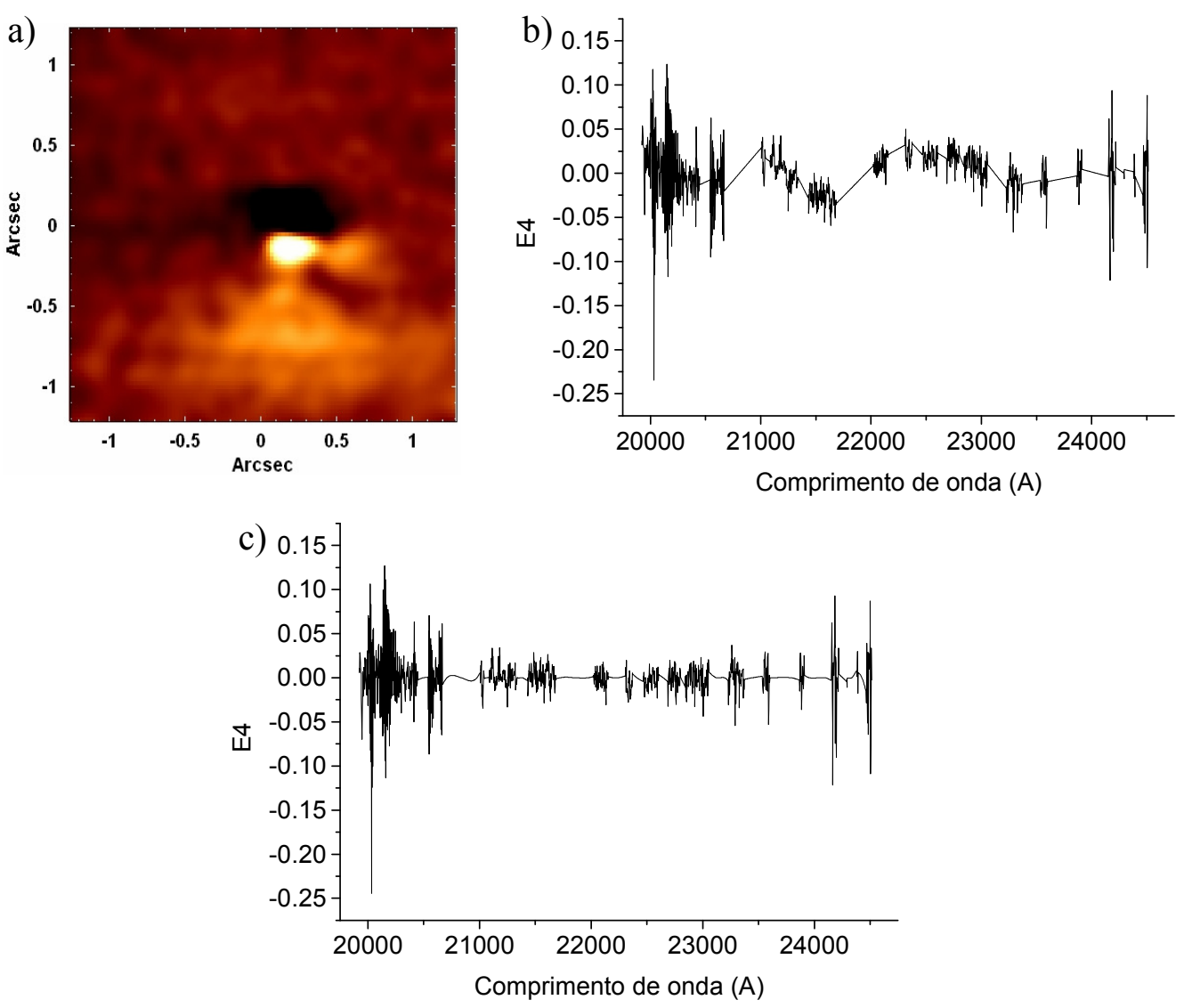

Figura 4.6 - (a) Tomograma correspondente ao autovetor E4, obtido com a Tomografia PCA aplicada ao cubo de dados de NGC 2992, após a remoção das linhas espectrais; (b) Autoespectro correspondente ao autovetor E4, obtido com a Tomografia PCA aplicada ao cubo de dados de NGC 2992, após a remoção das linhas espectrais; (c) Mesmo auto-espectro mostrado em (b), após a subtração do "spline" ajustado.

Por fim, passou-se para a etapa da deconvolução de Richardson-Lucy. Para se aplicar esse procedimento, entretanto, foi necessário obter uma imagem representativa da PSF dessa observação. No caso desse objeto, utilizou-se como PSF uma imagem do cubo de dados de NGC 2992, obtida a partir da região espectral correspondente à asa larga da linha de emissão de Bry. Conforme explicado em 3.9, essa é uma estimativa muito boa da PSF da observação, já que a emissão correspondente a essa região espectral é proveniente da BLR desse objeto, que, devido ao seu tamanho reduzido, não pôde ser resolvida nessa observação e apresentou, portanto, um aspecto puntual. A deconvolução de Richardson-Lucy foi aplicada utilizando-se 10 iterações. A figura 4.7 mostra a soma de todas as imagens e o espectro médio do cubo de dados final, obtido após a aplicação da deconvolução de Richardson-Lucy. 

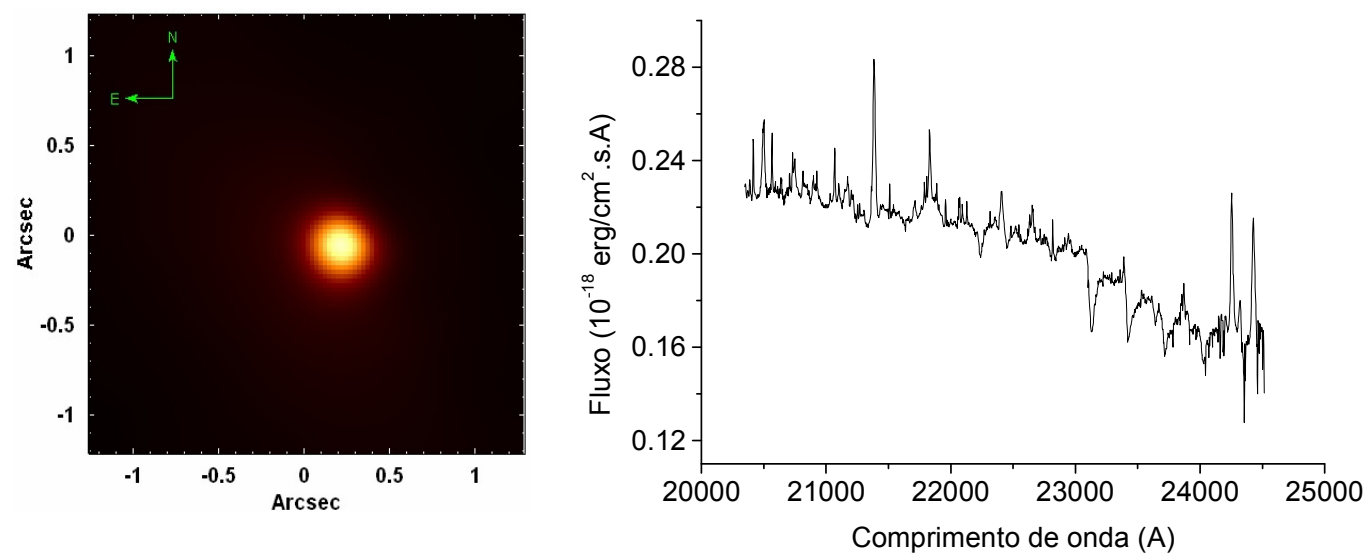

Figura 4.7 - (esquerda) Soma de todas as imagens do cubo de dados final de NGC 2992, obtido após todo o processamento; (direita) Espectro médio do cubo de dados final de NGC 2992, obtido após todo o processamento.

\section{3 - Aplicação da Tomografia PCA ao cubo de dados de NGC 2992 com o contínuo estelar}

Após todo o processamento descrito na seção 4.2, aplicou-se a Tomografia PCA ao cubo de dados de NGC 2992. Nessa primeira análise não foi feita nenhuma subtração do contínuo estelar. Os auto-espectros e respectivos tomogramas mais relevantes obtidos encontram-se a seguir.
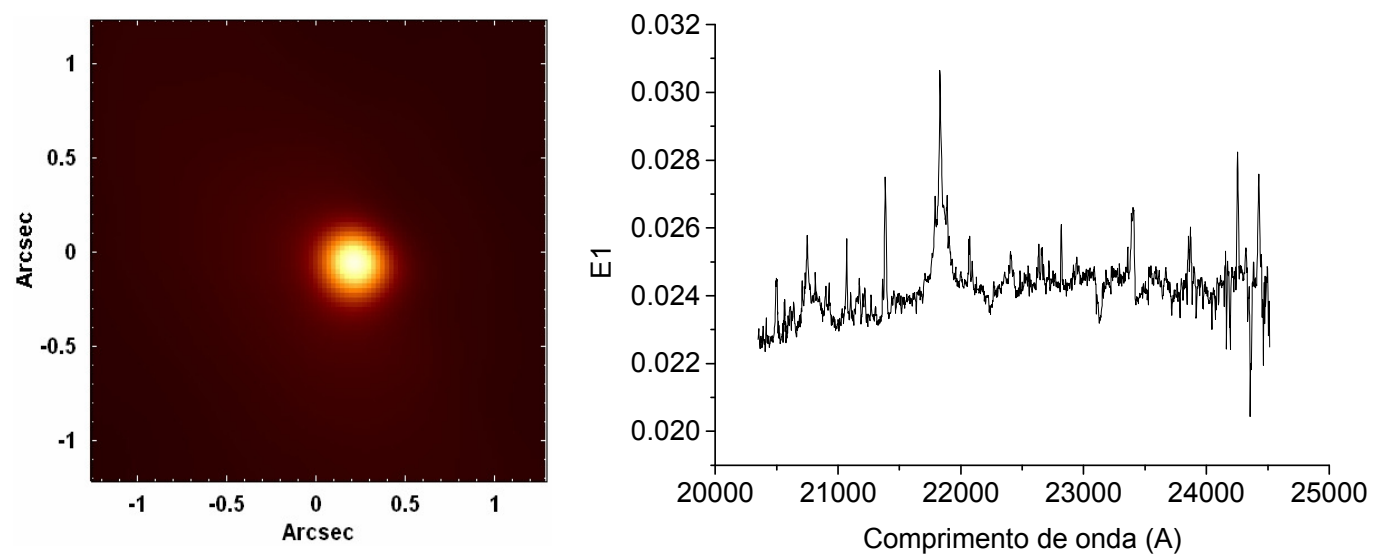

Figura 4.8 - Tomograma e auto-espectro correspondentes ao autovetor E1, obtido com a Tomografia PCA do cubo de dados de NGC 2992 com o contínuo estelar. 


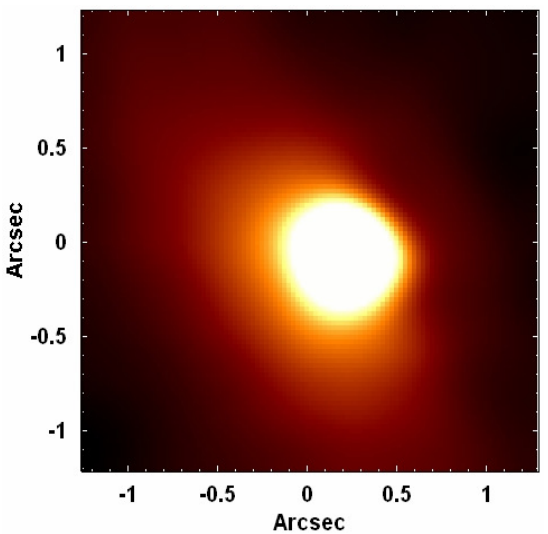

Figura 4.9 - Tomograma correspondente ao autovetor E1, já mostrado na figura 4.8, com a LUT "exagerada".
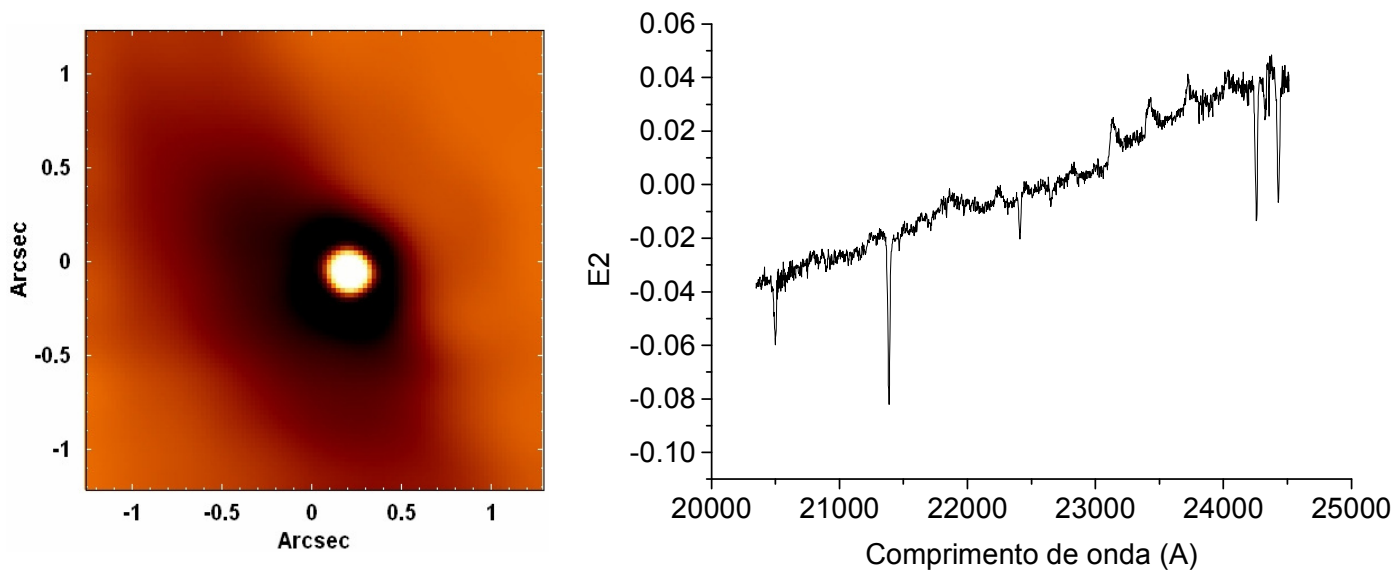

Figura 4.10 - Tomograma e auto-espectro correspondentes ao autovetor E2, obtido com a Tomografia PCA do cubo de dados de NGC 2992 com o contínuo estelar.
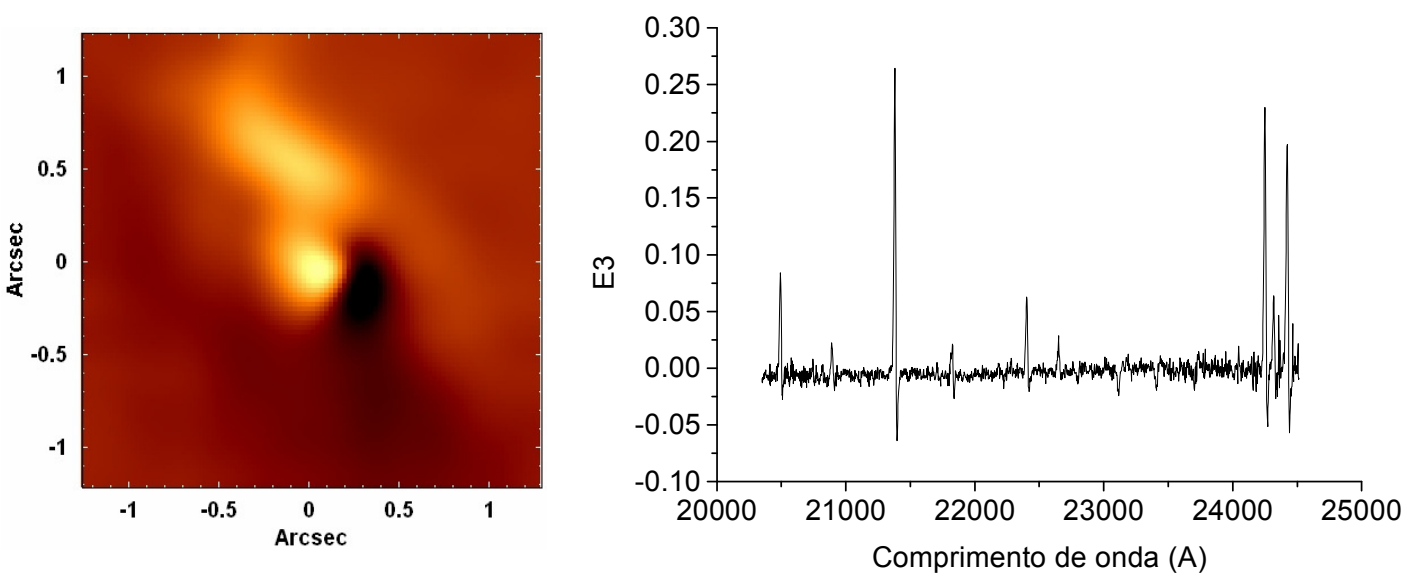

Figura 4.11 - Tomograma e auto-espectro correspondentes ao autovetorE3, obtido com a Tomografia PCA do cubo de dados de NGC 2992 com o contínuo estelar. 

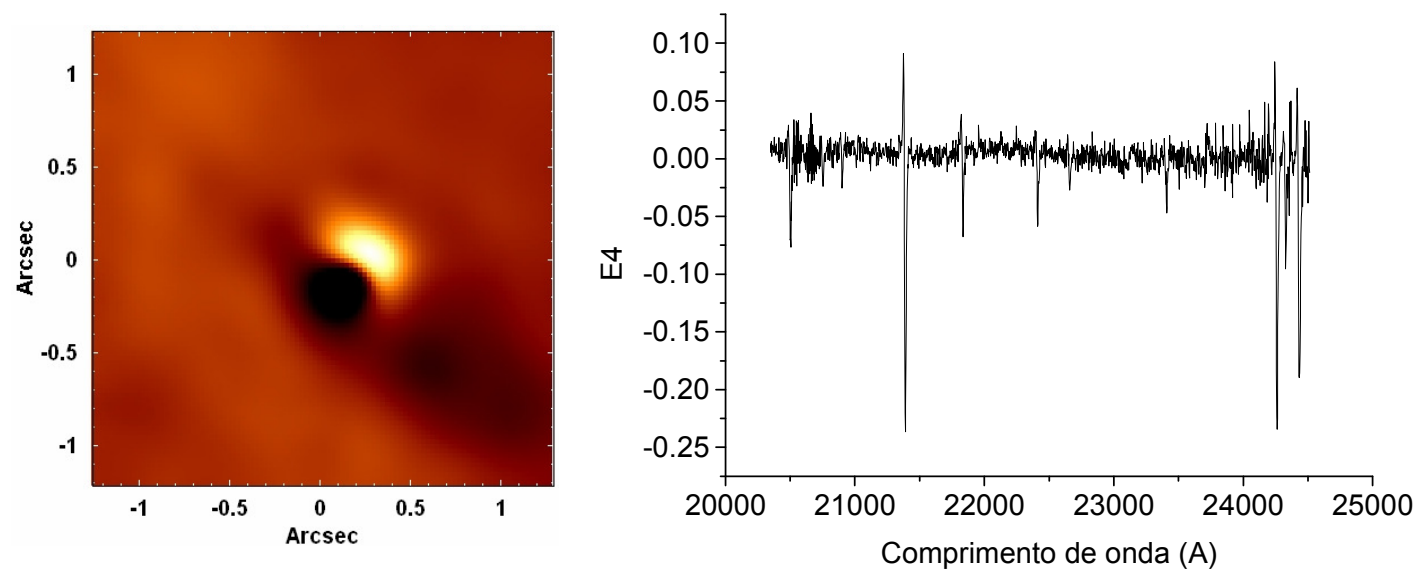

Figura 4.12 - Tomograma e auto-espectro correspondentes ao autovetor E4, obtido com a Tomografia PCA do cubo de dados de NGC 2992 com o contínuo estelar.
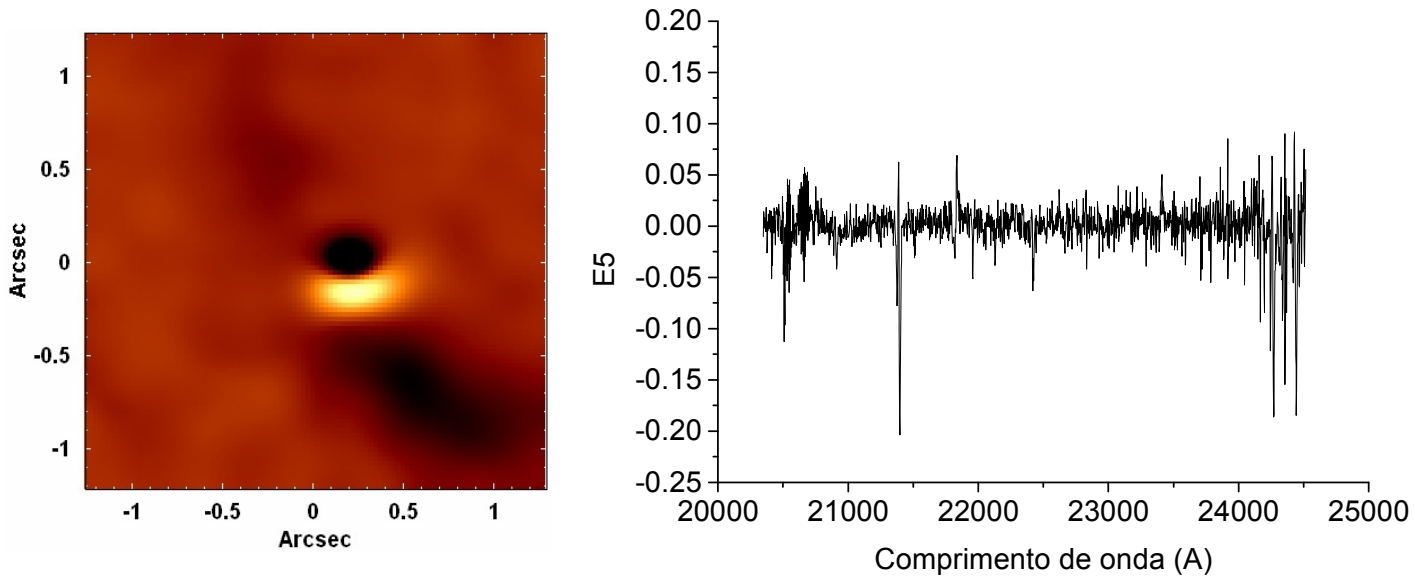

Figura 4.13 - Tomograma e auto-espectro correspondentes ao autovetor E5, obtido com a Tomografia PCA do cubo de dados de NGC 2992 com o contínuo estelar.
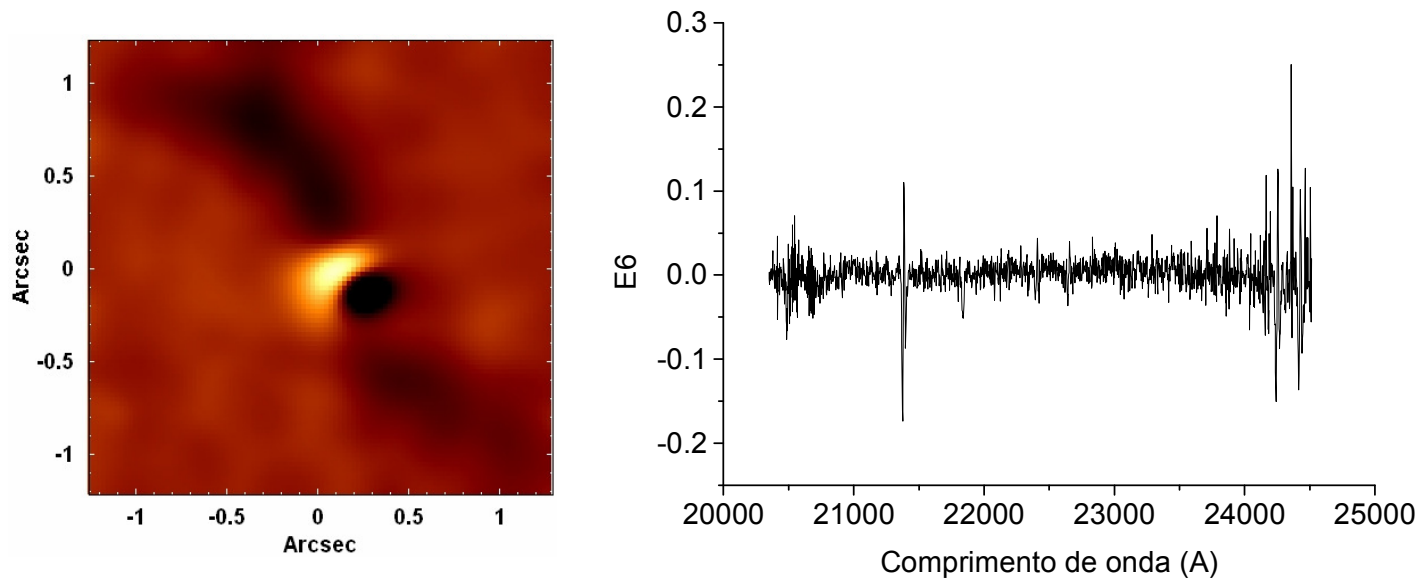

Figura 4.14 - Tomograma e auto-espectro correspondentes ao autovetor E6, obtido com a Tomografia PCA do cubo de dados de NGC 2992 com o contínuo estelar. 

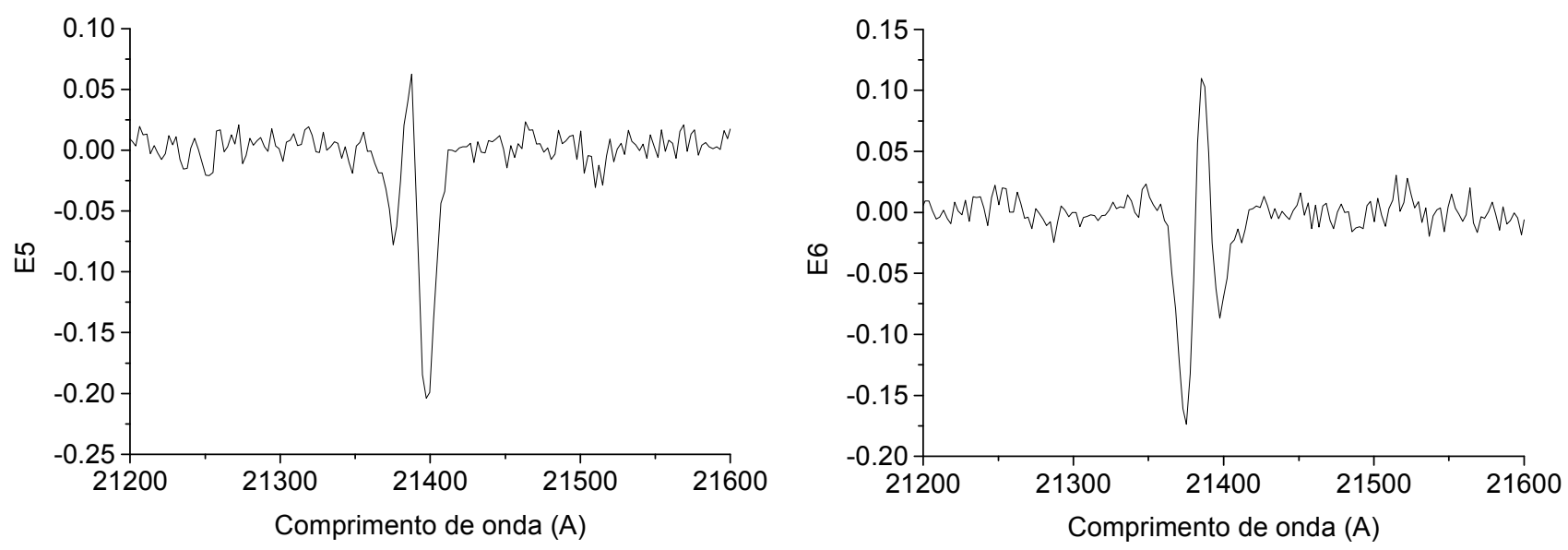

Figura 4.15 - Ampliação na região espectral da linha $\mathrm{H}_{2} \lambda 21218$ dos auto-espectros correspondentes aos autovetores E5 e E6, obtidos com a Tomografia PCA do cubo de dados de NGC 2992 com o contínuo estelar.

\begin{tabular}{|c|c|}
\hline Autovetor & Fração da variância explicada (\%) \\
\hline E1 & 99.6974 \\
\hline E2 & 0.2361 \\
\hline E3 & 0.0178 \\
\hline E4 & 0.0127 \\
\hline E5 & 0.0041 \\
\hline E6 & 0.0031 \\
\hline
\end{tabular}

Tabela 4.1 - Autovalores obtidos com a Tomografia PCA do cubo de dados de NGC 2992 com o contínuo estelar.

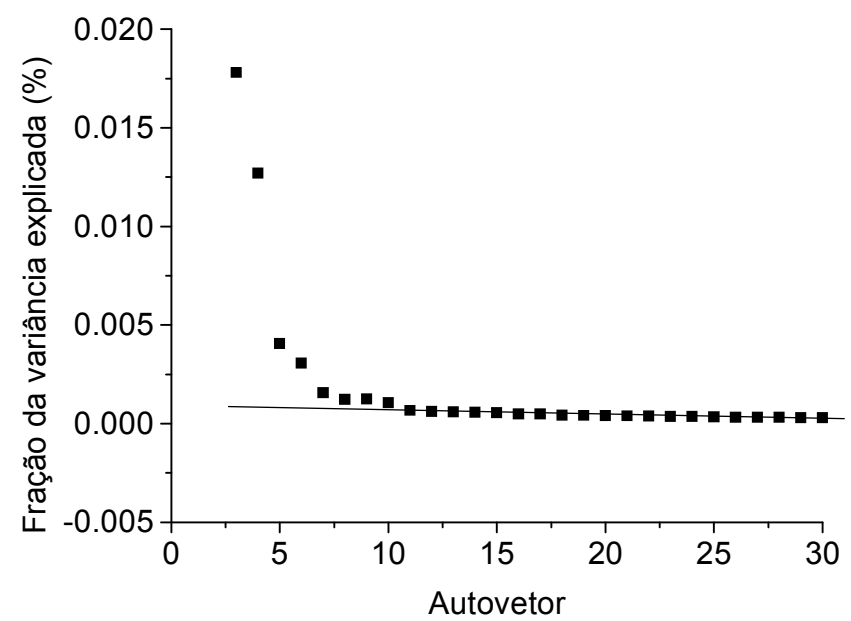

Figura 4.16 - "Scree test" dos autovetores obtidos com a Tomografia PCA do cubo de dados de NGC 2992 com o contínuo estelar. 
A figura 4.8 mostra que o auto-espectro E1 apresenta correlações com os comprimentos de onda correspondentes às linhas de Bry, [Ca VIII] e a uma linha de He I 220587. Além disso, pode-se notar, ainda, que esse auto-espectro possui correlações com comprimentos de onda associados às componentes largas das linhas de $\mathrm{Br} \gamma$ e He I. Isso indica que esse autovetor está correlacionado com a emissão proveniente do AGN existente nessa galáxia. Nesse caso, a localização desse AGN corresponderia à área mais clara (correlacionada com o auto-espectro) do tomograma associado. O fato da emissão do AGN desse objeto aparecer no autovetor E1 pode ser considerado como estando de acordo com o esperado, pois esse autovetor explica a maior parte da variância dos dados $(99.6974$ \%) e é sabido que o AGN dessa galáxia é de grande intensidade e, consequentemente, facilmente detectável. O auto-espectro E1, entretanto, também apresenta outras características relevantes. Podem ser notadas correlações com comprimentos de onda correspondentes a algumas linhas de $\mathrm{H}_{2}$, o que mostra que algumas das áreas claras do tomograma associado podem corresponder a regiões emissoras de $\mathrm{H}_{2}$. Além disso, esse autoespectro também apresenta estruturas correspondentes às bandas de absorção de $\mathrm{CO}$, o que mostra que esse autovetor também está correlacionado com a absorção estelar existente na região central de NGC 2992. A imagem do tomograma associado a E1 com a LUT "exagerada" (figura 4.9) revela a presença de uma área clara ao longo da diagonal da imagem. Essa região pode englobar áreas emissoras de $\mathrm{H}_{2}$ ou com absorções estelares, que foram evidenciadas pelas estruturas (linhas de $\mathrm{H}_{2}$ e bandas de $\mathrm{CO}$ ) visíveis em E1. A morfologia apresentada pelo tomograma mostrado na figura 4.9 também é facilmente visível, por exemplo, em imagens obtidas com o HST desse objeto (figura 4.3). Por fim, o auto-espectro E1 possui uma série de correlações e anti-correlações, ao longo de toda a extensão espectral, associadas a resquícios de absorções telúricas não completamente removidas durante a redução dos dados.

A figura 4.10 revela, primeiramente, que o auto-espectro E2 apresenta uma correlação com a região vermelha do espectro e uma anti-correlação com a região azul do mesmo. Isso indica que esse autovetor estabelece um diferencial entre espectros mais avermelhados e espectros mais azulados existentes no cubo de dados desse objeto. Observando-se o tomograma associado, pode-se concluir que a região clara mais próxima ao núcleo apresenta um contínuo mais vermelho do que as áreas escuras ao redor (anti-correlacionadas com o auto-espectro). Outro fato a ser mencionado é que esse auto-espectro também está anti-correlacionado com a emissão de $\mathrm{H}_{2}$ e com as bandas de absorção de CO. Todas essas características indicam que, na 
região mais próxima ao núcleo, a emissão parece ser devida, principalmente, à poeira quente ao redor do AGN (o que é evidenciado pelo contínuo mais avermelhado dessa área) e, nas regiões mais afastadas, o contínuo parece ser dominado por populações estelares, além de haver uma considerável emissão de $\mathrm{H}_{2}$ (o que é evidenciado pelo contínuo azul, pelas bandas de $\mathrm{CO}$ e pelas linhas de $\mathrm{H}_{2}$ existentes). $\mathrm{O}$ auto-espectro E2 apresenta, ainda, correlações com comprimentos de onda correspondentes à linha de Bry com uma considerável componente larga. Isso indica que esse autovetor também está correlacionado com a emissão proveniente do AGN, cuja posição corresponde à área central clara do tomograma associado. Isso está de acordo com o que foi observado no autovetor E1. O autovetor E2 explica cerca de 0.2361 \% da variância dos dados.

Observando-se a figura 4.11, pode-se notar que a principal característica do autoespectro E3 são correlações com os comprimentos de onda associados às asas azuis das principais linhas de emissão visíveis no espectro e anti-correlações com os comprimentos de onda correspondentes às asas vermelhas das mesmas. Esse comportamento parece indicar que o autovetor E3 está relacionado a algum fenômeno cinemático do gás (tanto molecular quanto ionizado) existente na região central de NGC 2992. Nesse caso, as áreas claras do tomograma associado correspondem a regiões com o gás apresentando uma componente radial de velocidade no sentido do observador (blueshift) e as áreas escuras são regiões com o gás possuindo uma componente radial de velocidade no sentido oposto ao do observador (redshift). A morfologia apresentada por esse tomograma parece indicar uma considerável complexidade da cinemática do gás na região central de NGC 2992, que poderia ser compatível com a existência de dois fenômenos cinemáticos, como uma rotação e um outflow, por exemplo. Entretanto, esse autovetor não permite que tais fenômenos sejam diferenciados claramente. Uma característica interessante do auto-espectro E3 é que as amplitudes das correlações com os comprimentos de onda associados às asas azuis das linhas são consideravelmente maiores do que as amplitudes das anti-correlações com os comprimentos de onda correspondentes às asas vermelhas das mesmas, o que parece indicar que regiões com blueshift estão mais associadas a esse autovetor do que as com redshift. O autovetor E3 explica cerca de 0.0178 \% da variância dos dados.

Uma análise da figura 4.12 mostra que o auto-espectro E4, assim como o E3, apresenta correlações com os comprimentos de onda associados às asas azuis das principais linhas de emissão visíveis no espectro e anti-correlações com os comprimentos de onda correspondentes 
às asas vermelhas das mesmas, o que parece indicar que esse autovetor também está associado a algum fenômeno cinemático do gás existente na região central de NGC 2992. Entretanto, uma diferença importante em relação a E3 é que, em E4, as amplitudes das anti-correlações com os comprimentos de onda correspondentes às asas vermelhas das linhas são consideravelmente maiores do que as amplitudes das correlações com os comprimentos de onda associados às asas azuis das mesmas (o comportamento em E3 é exatamente o oposto). Assim, analogamente ao que foi proposto no caso de E3, as regiões com redshift parecem estar mais associadas a esse autovetor do que as com blueshift. O tomograma correspondente também parece sugerir uma complexidade da cinemática envolvida, que pode indicar a presença de mais de um fenômeno cinemático, sendo que, assim como para E3, as áreas claras correspondem a regiões com a emissão do gás em blueshift e as áreas escuras representam regiões com a emissão do gás em redshift. O motivo de a Tomografia PCA ter dividido os fenômenos cinemáticos do gás existentes entre os autovetores E3 e E4 não está clara, entretanto, é provável que as características mostradas em ambos sejam complementares. O autovetor E4 explica cerca de $0.0127 \%$ da variância dos dados.

As figuras 4.13 e 4.14, assim como as ampliações mostradas na figura 4.15, revelam que os auto-espectros E5 e E6 apresentam anti-correlações com os comprimentos de onda associados às asas azuis e vermelhas de algumas linhas de emissão (sobretudo $\mathrm{H}_{2}$ 221218) visíveis no espectro e correlações com os comprimentos de onda correspondentes às regiões centrais das mesmas. Isso, juntamente com a aparência apresentada pelos tomogramas associados, parece indicar que esses autovetores estão estabelecendo um contraste entre regiões com o gás possuindo alguma componente radial considerável de velocidade (redshift ou blueshift) e regiões com o gás apresentando apenas baixos valores para a componente radial de velocidade. Nesse caso, as áreas escuras dos tomogramas correspondem a regiões com componentes radiais de velocidade significativas no sentido ou no sentido oposto ao do observador (blueshift ou redshift, respectivamente) e as áreas claras representam regiões com baixos valores para a componente radial de velocidade. A grande diferença entre os autovetores E5 e E6 é que, no auto-espectro E5, as amplitudes das anti-correlações com os comprimentos de onda associados às asas vermelhas das linhas de emissão são maiores do que as amplitudes das anti-correlações com os comprimentos de onda correspondentes às asas azuis das mesmas, entretanto, no auto-espectro E6, tem-se exatamente o oposto. Isso parece indicar que o autovetor 
E5 está mais associado a regiões com redshift do que a áreas com blueshift, ao passo que, no caso do autovetor E6, tem-se o contrário. Essa é uma situação inteiramente análoga à que foi observada no caso dos autovetores E3 e E4. Novamente, o motivo de a Tomografia PCA ter divido esse fenômeno cinemático do gás entre os autovetores E5 e E6 não está claro, entretanto, é provável que eles possuam características complementares. Os autovetores E5 e E6 explicam, respectivamente, cerca de $0.0041 \%$ e $0.0031 \%$ da variância dos dados.

O Scree test da figura 4.16 mostra que os valores das variâncias explicadas pelos autovetores decaem bastante até, aproximadamente, o autovetor E7. A partir daí, a taxa de decaimento diminui bastante, ficando praticamente constante a partir do autovetor E11. Isso indica que autovetores de ordem maior ou igual a 11 representam, sobretudo, ruído e, consequentemente, não possuem relevância nessa análise. Entretanto, a análise mostrou que apenas os autovetores com ordem menor do que 7 possuíam uma interpretação mais clara e, por essa razão, apenas eles foram mostrados aqui. É provável que a diminuição da taxa de decaimento dos autovalores a partir do autovetor E7 (mesmo que ela ainda não tenha atingido um valor constante) represente um indicativo da diminuição da significância dos autovetores com ordem maior ou igual a essa.

Por tudo o que foi dito até aqui, pode-se concluir que essa análise inicial com a Tomografia PCA, primeiramente, permitiu uma visualização bastante clara da emissão proveniente do AGN dessa galáxia. Além disso, ela também mostrou que as regiões mais próximas ao AGN apresentam espectros com um contínuo bem mais avermelhado do que as áreas ao redor, o que, provavelmente, deve ser uma conseqüência da emissão térmica de poeira ao redor do AGN. Tal poeira pode, inclusive, estar associada a um toro existente nessa região. As áreas mais afastadas do AGN apresentam espectros com um contínuo mais azulado e com a presença de bandas de absorção de $\mathrm{CO}$, o que indica que, nessas regiões, a maior parte da luz parece ser proveniente de populações estelares. Essas áreas mais afastadas também parecem apresentar uma emissão considerável de $\mathrm{H}_{2}$. Por fim, a Tomografia PCA revelou, ainda, a existência do que aparenta ser uma complexa cinemática do gás na região central de NGC 2992, que pode envolver mais de um fenômeno cinemático, como uma rotação e um outflow, por exemplo. 


\section{4 - Síntese espectral do cubo de dados de NGC 2992 com o Starlight}

Depois da análise inicial com a Tomografia PCA, foi feita uma síntese espectral no cubo de dados de NGC 2992 com o software Starlight. Para isso, primeiramente, foi aplicada toda a preparação descrita em 3.12. Nesse caso, a correção da extinção devido à Via Láctea foi feita tomando-se $A_{V}=0.2$ e a passagem dos espectros para o referencial de repouso foi aplicada considerando-se $z=0.00771$.

Como o cubo de dados de NGC 2992 foi obtido na região espectral do infravermelho próximo e há um intenso AGN nessa galáxia, foi preciso levar em conta a emissão térmica de poeira e um featureless continuum na síntese espectral, conforme foi explicado em 3.12. Ainda de acordo com o que foi mencionado em 3.12, os resultados obtidos com o Starlight permitem que se façam mapeamentos de vários parâmetros resultantes da síntese espectral. Entretanto, a base utilizada apresentava sérias limitações nessa região espectral, o que tornou impossível a determinação precisa de alguns desses parâmetros. Primeiramente, verificou-se que a base possuía uma resolução ruim nessa região espectral e, consequentemente, as determinações de parâmetros cinemáticos como a velocidade radial e a dispersão de velocidades foram consideravelmente imprecisas e não puderam ser levadas em conta aqui. Além disso, a própria inclinação dos contínuos dos espectros da base apresentava uma incerteza considerável. Isso fez com que os principais resultados da síntese espectral derivados diretamente da base de populações utilizada ficassem bastante imprecisos, como as idades e as metalicidades das diferentes populações estelares detectadas. $\mathrm{O}$ valor calculado de $\mathrm{A}_{\mathrm{V}}$, que depende fortemente da inclinação dos espectros da base, também ficou muito impreciso. Assim, nenhum desses resultados imprecisos pôde ser considerado aqui. Os espectros da base representativos da emissão térmica de poeira e do featureless continuum, por outro lado, não apresentavam grandes incertezas em relação às inclinações de seus contínuos, logo, os resultados derivados diretamente desses espectros de base puderam ser levados em conta aqui. Existe, entretanto, uma outra fonte de incertezas relacionada à aplicação do Starlight nessa região espectral que precisou levada em conta: a curta extensão espectral. Espectros obtidos apenas na banda K apresentam uma extensão espectral muito pequena para que se possa fazer uma síntese espectral 
altamente confiável e isso também precisou ser considerado, mesmo no caso de resultados obtidos diretamente a partir dos espectros de base mais confiáveis (representativos da emissão térmica de poeira e do featureless continuum). Considerando-se tudo isso, os mapeamentos mais confiáveis obtidos com a síntese espectral do cubo de dados de NGC 2992 são mostrados nas sessões a seguir.

\subsection{1 - Qualidade dos ajustes}

O mapeamento dos valores do $\chi^{2} / n_{\text {eff }}$ (onde $n_{\text {eff }}$ corresponde ao número de pixeis espectrais levados em conta na síntese espectral) dos ajustes obtidos com a síntese espectral do cubo de dados de NGC 2992 encontra-se a seguir.

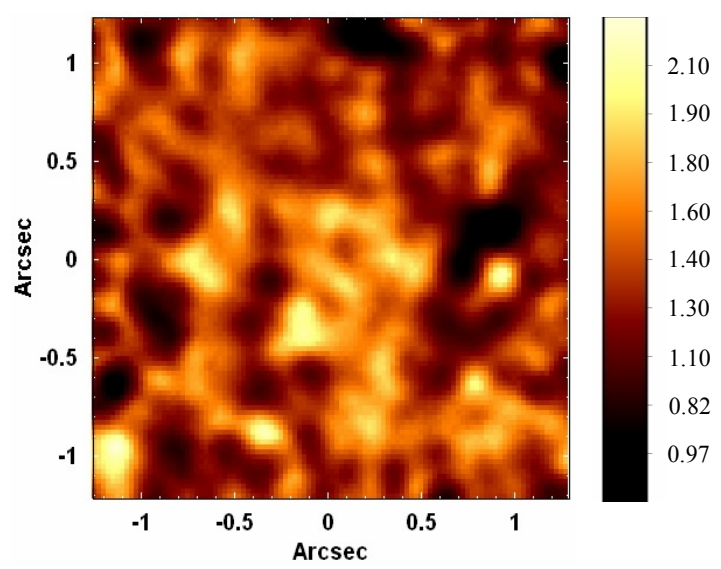

Figura 4.17: Mapeamento dos valores do $\chi^{2} / n_{\text {eff }}$ dos ajustes obtidos pelo "Starlight" para os espectros do cubo de dados de NGC 2992.

Observando-se a figura 4.17, pode-se notar que os melhores ajustes obtidos com o Starlight apresentaram $\chi^{2} / n_{\text {eff }}$ de cerca de 0.7 , ao passo que os piores ajustes tiveram $\chi^{2} / n_{\text {eff }}$ de cerca de 2.2, o que ainda pode ser tomado como um indicativo de ajustes com boa qualidade. Assim, conclui-se que todos os ajustes feitos com o Starlight nos espectros do cubo de dados desse objeto foram bastante razoáveis. O mapeamento da figura 4.17 não revelou, claramente, estruturas ou configurações que indicassem áreas com ajustes tendenciosamente melhores do que outras. 


\subsection{2 - Populações estelares, poeira e featureless continuum}

Conforme foi mencionado anteriormente, certos parâmetros obtidos com a síntese espectral com o Starlight na região espectral do infravermelho próximo, como a fração de fluxo atribuída a populações estelares de diferentes idades e metalicidades, não são confiáveis, devido às incertezas da base utilizada. Por essa razão, esses mapeamentos não são mostrados aqui. Por outro lado, conforme também já foi dito anteriormente, os espectros de base representativos da emissão térmica de poeira e do featureless continuum não apresentam esse tipo de incerteza e os resultados derivados diretamente deles puderam ser levados em conta. Mesmo assim, a curta extensão espectral do cubo de dados analisado (apenas a banda $\mathrm{K}$ ) representa uma fonte a mais de incertezas e poderia gerar problemas, inclusive, nos resultados derivados dos espectros de base mais confiáveis. Com base nisso tudo, pode-se dizer que o resultado mais confiável que se pôde obter a partir da síntese espectral com o Starlight (utilizando essa base) de cada um dos espectros do cubo de dados de NGC 2992 foi a determinação do fluxo total devido às populações estelares, à emissão térmica de poeira e ao featureless continuum, sem que se tente estabelecer quaisquer diferenciações entre populações estelares de diferentes idades e metalicidades ou emissões térmicas de poeira com diferentes temperaturas. Assim, construíramse três mapeamentos de fluxo a partir dos resultados do Starlight para esse objeto: o mapeamento do fluxo total devido às populações estelares, o mapeamento do fluxo total devido à emissão térmica de poeira e o mapeamento do fluxo devido ao featureless continuum. Para isso, primeiramente, construíram-se os mapeamentos das frações de fluxo associadas a cada um dos espectros de base incluídos na síntese espectral. Após isso, construiu-se um cubo de dados com os espectros estelares sintéticos fornecidos pelo Starlight. Em seguida, integrou-se todo esse cubo de dados de maneira a se obter uma imagem representativa do fluxo total (incluindo o featureless continuum, a emissão térmica de poeira e a emissão proveniente de populações estelares) emitido. Finalmente, multiplicou-se cada um dos mapeamentos das frações de fluxo por essa imagem correspondente ao fluxo total, obtendo-se, assim, os mapeamentos do fluxo associados a todos os componentes (populações estelares, poeira quente e featureless continuum) envolvidos na síntese espectral. Essas imagens foram combinadas, resultando nos três mapeamentos mencionados anteriormente, que são mostrados a seguir. 


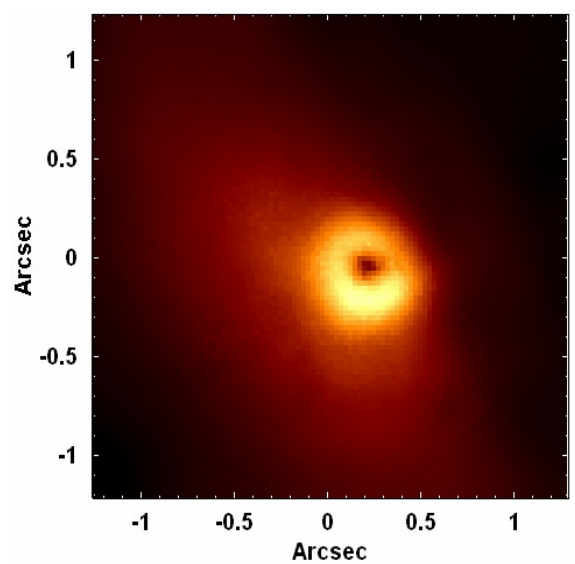

Figura 4.18: Mapeamento do fluxo total devido às populações estelares, obtido com a aplicação do "Starlight" ao cubo de dados de NGC 2992.

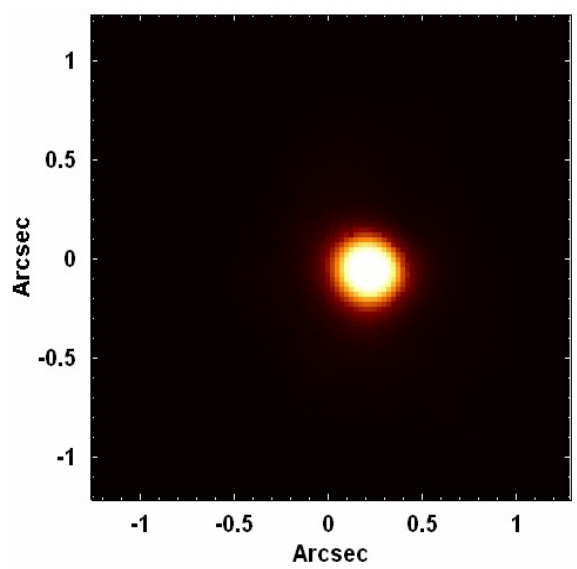

Figura 4.19: Mapeamento do fluxo total devido à emissão térmica de poeira, obtido com a aplicação do "Starlight" ao cubo de dados de NGC 2992.

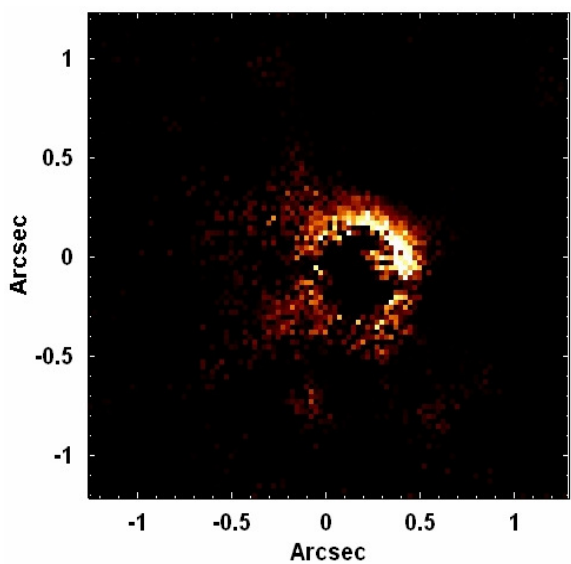

Figura 4.20: Mapeamento do fluxo atribuído ao "featureless continuum" do AGN, obtido com a aplicação do "Starlight" ao cubo de dados de NGC 2992. 
Em seguida, construiu-se um gráfico em colunas contendo as frações de fluxo atribuídas às populações estelares, à emissão térmica de poeira e ao featureless continumm do AGN, considerando-se todo o campo visual do SINFONI. O gráfico obtido encontra-se a seguir.

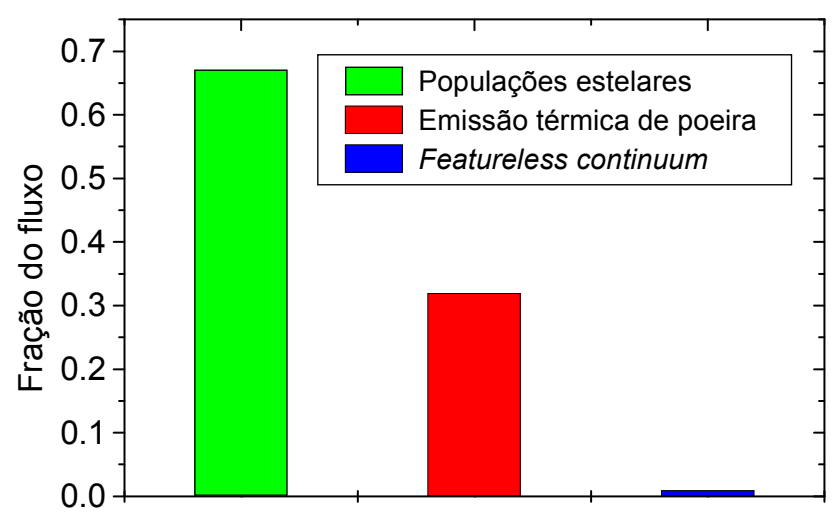

Figura 4.21: Gráfico representativo das frações de fluxo devidas às populações estelares, à emissão térmica de poeira e ao "featureless continuum", considerando-se todo o campo visual do SINFONI, obtido com a aplicação do "Starlight" ao cubo de dados de NGC 2992.

As figuras 4.18 e 4.19 mostram que a emissão térmica de poeira está bastante concentrada na região correspondente ao $\mathrm{AGN}$, onde praticamente não foi detectada luz proveniente de populações estelares. Isso está de acordo com os resultados obtidos anteriormente com a Tomografia PCA, sendo que é possível que a emissão térmica de poeira detectada esteja associada a algum toro de poeira existente nos arredores do AGN central, o que seria compatível com o previsto pelo Modelo Unificado. Nas regiões mais afastadas do AGN, o fluxo parece ser essencialmente devido a populações estelares, com uma forte concentração ao longo de uma região similar a uma faixa diagonal na imagem. Tal morfologia também foi observada em imagens dessa galáxia obtidas com o HST (figura 4.3) e no tomograma (com LUT exagerada) associado ao autovetor E1 obtido com a Tomografia PCA (figura 4.9). O fato de não se ter detectado fluxo proveniente de populações estelares nas regiões próximas ao AGN não significa que tais populações não estejam presentes nessas áreas, mas sim que elas, possivelmente, não foram observadas devido ao fato de a emissão próxima ao AGN ser totalmente dominada pela poeira, o que tornou difícil a detecção de qualquer emissão proveniente de populações estelares.

Observando-se a figura 4.20, pode-se notar que não foi detectado fluxo atribuído ao featureless continuum do $\mathrm{AGN}$ na região correspondente ao $\mathrm{AGN}$, mas apenas em áreas mais 
afastadas. Três possíveis explicações podem ser propostas para isso: a primeira é que o fluxo detectado esteja, de fato, associado ao featureless continuum do AGN, que sofreu algum tipo de espalhamento, sendo detectado, por fim, em áreas mais afastadas. Na região correspondente ao AGN, tal featureless continuum pode não estar sendo detectado ou devido a um obscurecimento por poeira ou mesmo devido a um ofuscamento pela forte emissão térmica de poeira nessa área (um efeito combinado entre esses dois fatores também é uma possibilidade aqui). A segunda explicação possível é que não tenha sido detectado nenhum featureless continuum emitido pelo AGN e o Starlight tenha utilizado o arquivo de base representativo do featureless continuum (que tem a forma de uma lei de potência com índice espectral igual a 1.5) para compensar possíveis falhas de ajuste, eventualmente provocadas por falhas na calibração em fluxo. A terceira explicação é que o fluxo detectado na figura 4.20, na verdade, seja devido a populações estelares (possivelmente sob o efeito de um valor de $A_{V}$ considerável) com um espectro apresentando um contínuo com formato similar ao de uma lei de potência. Nesse caso, as limitações da base utilizada podem ter feito com que nenhum dos espectros de base representativos de populações estelares tenha conseguido reproduzir bem o fluxo detectado, restando, apenas, o arquivo com a lei de potência representando o featureless continuum do AGN. Para se obter uma melhor visualização geral da morfologia das regiões com espectros dominados pela emissão associada às populações estelares, à poeira e ao featureless continuum, construiu-se uma imagem RGB, que é mostrada na figura 4.22.

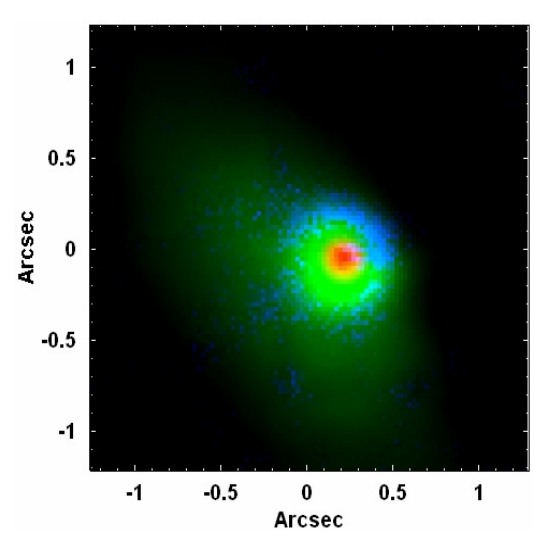

Figura 4.22 - Composição RGB contendo os mapeamentos do fluxo associado às populações estelares (verde), à emissão térmica de poeira (vermelho) e ao "featureless continuum" (azul), obtidos a partir da sintese espectral do cubo de dados de NGC 2992.

O gráfico na figura 4.21 mostra que, embora o fluxo proveniente de populações estelares (cerca de $67.1 \%$ do total) seja dominante no campo visual do SINFONI, a fração de fluxo 
devida à emissão térmica de poeira também é bastante significativa (cerca de $31.9 \%$ ). Isso está de acordo com o esperado, já que o intenso AGN existente nessa galáxia, sem dúvida, pode aquecer uma quantidade significativa de poeira ao redor, resultando na emissão térmica detectada. A fração de fluxo correspondente ao featureless continuum é bastante pequena (cerca de $1.0 \%$ ), o que pode ser devido a obscurecimento ou ofuscamento pela emissão térmica de poeira, por exemplo.

\subsection{3 - Valores da razão $S / N$ dos espectros analisados}

O mapeamento dos valores da razão $S / N$ obtidos pelo Starlight no intervalo espectral de $22308 \AA$ até $22403 \AA$ encontra-se a seguir.

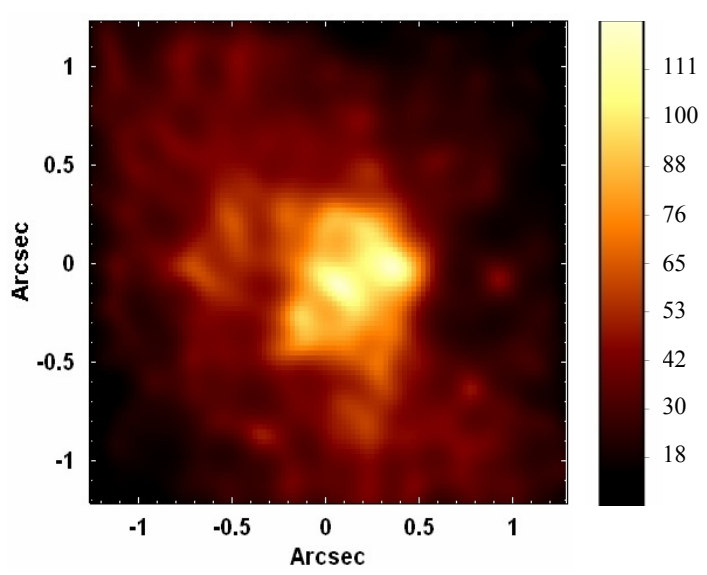

Figura 4.23 - Mapeamentos dos valores da razão $S / N$, obtidos a partir da síntese espectral do cubo de dados de NGC 2992 com o "Starlight".

Observando-se a figura 4.23, pode-se verificar que os valores mais altos (até cerca de 123) para a razão $S / N$ foram encontrados nas regiões mais centrais do campo visual do SINFONI, ao passo que os menores valores (até cerca de 7) foram obtidos nas áreas mais afastadas do centro, o que está de acordo com o esperado. Outra característica que pode ser observada é que os valores da razão $S / N$ na região correspondente à estrutura similar a uma faixa alargada ao longo da diagonal da imagem, que foi observada em várias imagens citadas anteriormente (figuras 4.3, 4.9 e 4.18), é tendenciosamente maior do que nos arredores. Isso também já era esperado, já que o mapeamento mostrado na figura 4.18 revelou que o fluxo proveniente de populações estelares é realmente maior nessa região. 


\section{5 - Aplicação da Tomografia PCA ao cubo de dados de NGC 2992 com o contínuo estelar subtraído}

Além de todos os parâmetros mencionados na seção anterior, o Starlight também fornece os espectros contínuos sintéticos obtidos com os seus ajustes. Assim, utilizando-se tais espectros, foi possível fazer uma subtração do contínuo em todos os espectros de NGC 2992, obtendo-se, no final, um cubo de dados contendo, apenas, linhas de emissão. Aplicou-se, então, a Tomografia PCA a esse cubo de dados resultante, a fim de se obter uma análise mais detalhada dos espectros de linhas de emissão dessa galáxia. Os principais auto-espectros e respectivos tomogramas obtidos encontram-se a seguir.
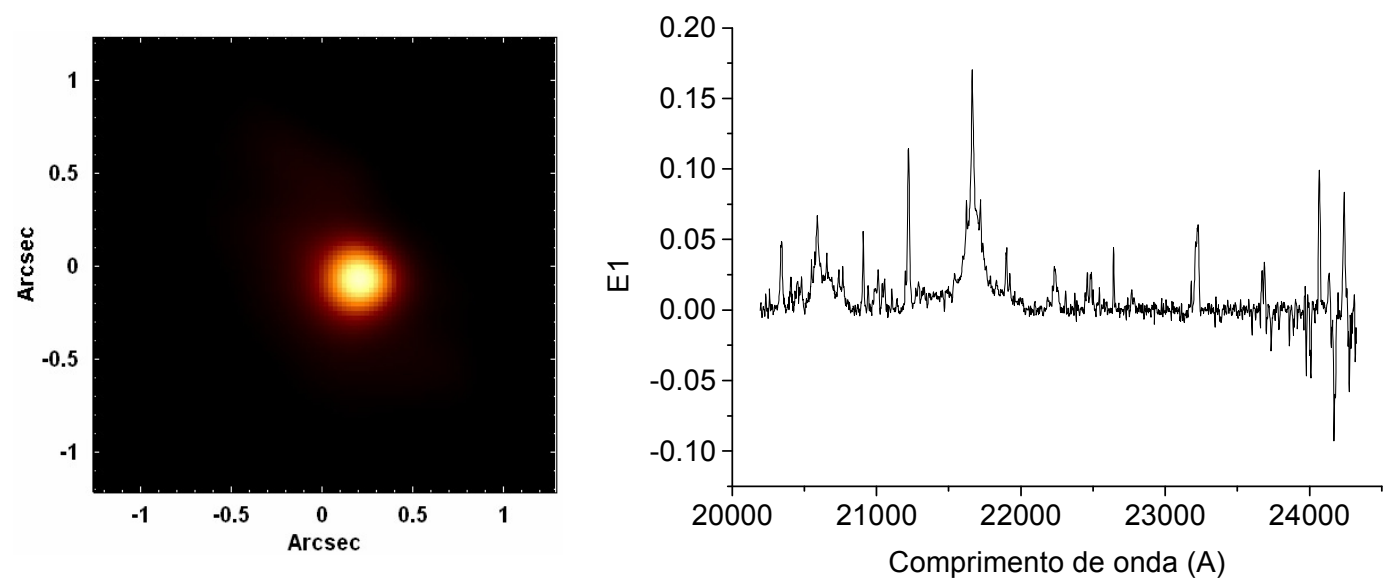

Figura 4.24 - Tomograma e auto-espectro correspondentes ao autovetor E1, obtido com a

Tomografia PCA do cubo de dados de NGC 2992 com o contínuo estelar subtraído.
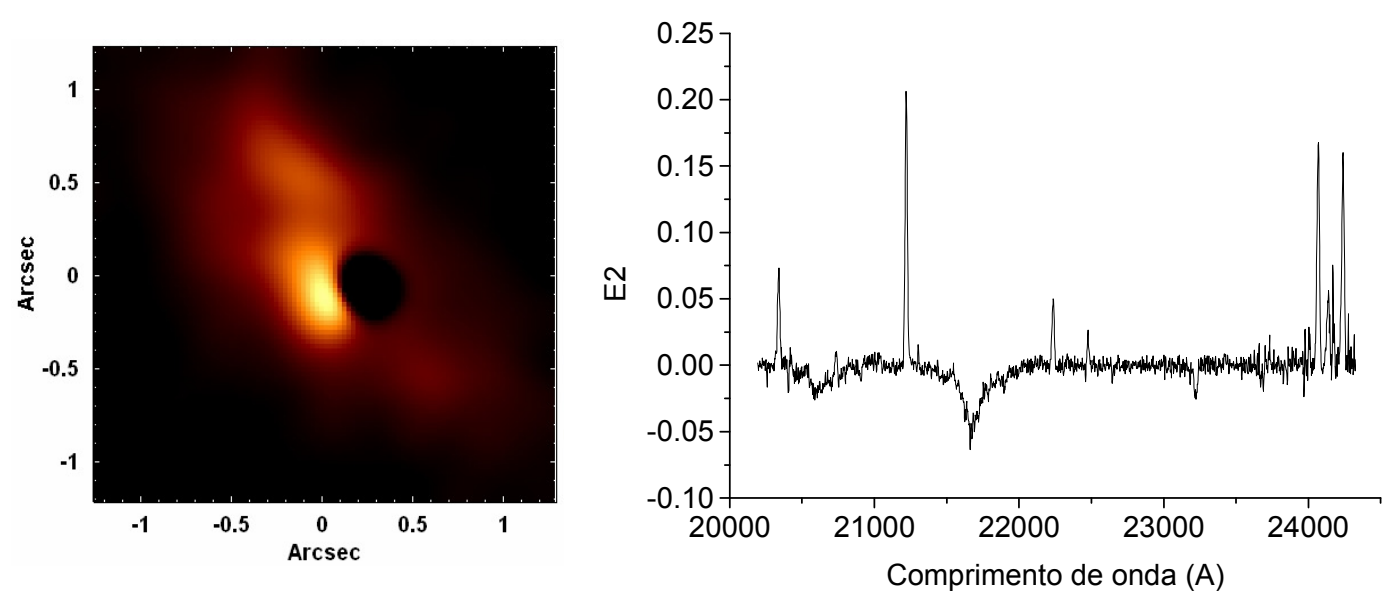

Figura 4.25 - Tomograma e auto-espectro correspondentes ao autovetor E2, obtido com a Tomografia PCA do cubo de dados de NGC 2992 com o contínuo estelar subtraído. 

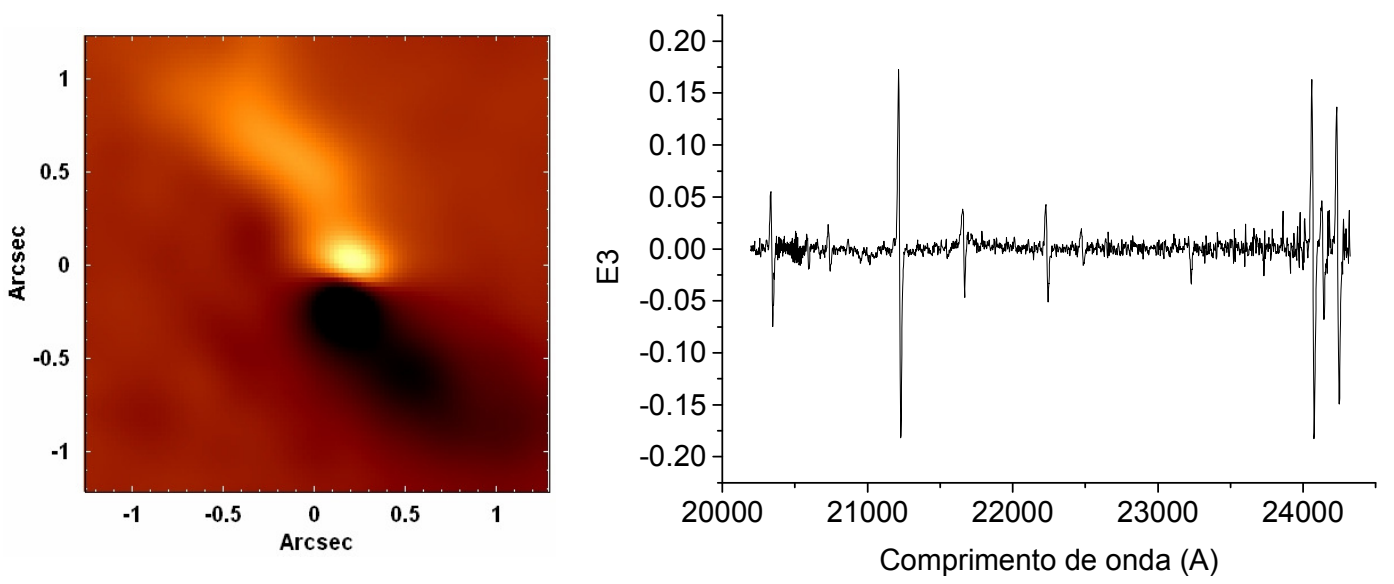

Figura 4.26 - Tomograma e auto-espectro correspondentes ao autovetor E3, obtido com a Tomografia PCA do cubo de dados de NGC 2992 com o contínuo estelar subtraído.
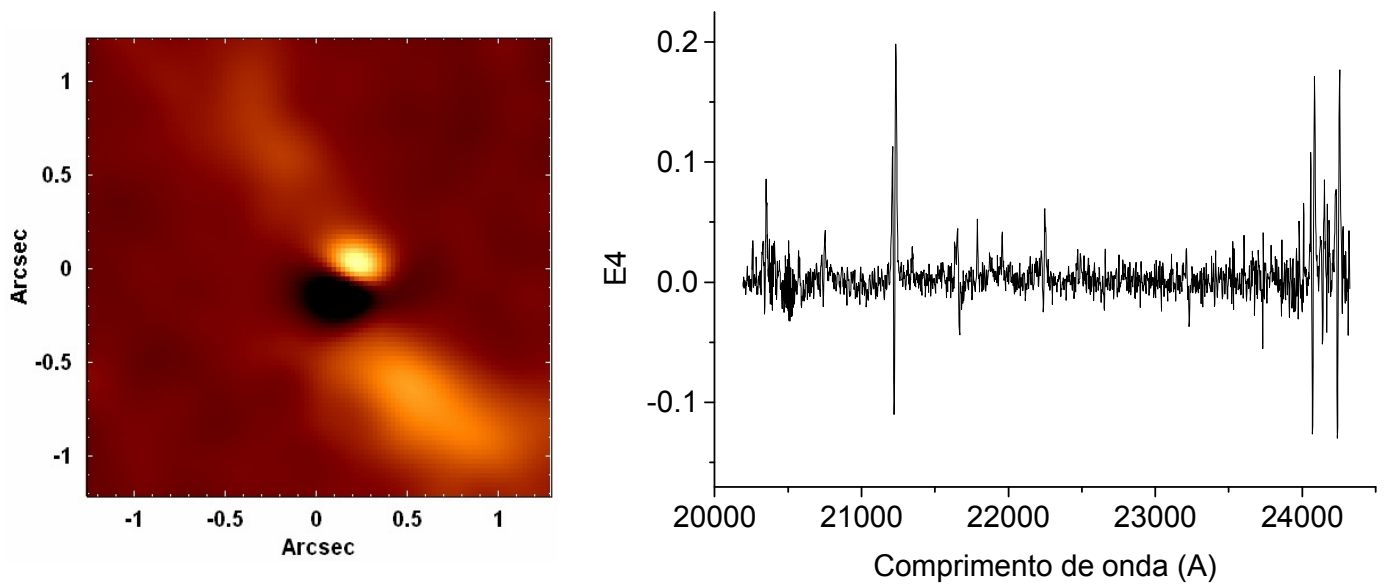

Figura 4.27 - Tomograma e auto-espectro correspondentes ao autovetor E4, obtido com a Tomografia PCA do cubo de dados de NGC 2992 com o contínuo estelar subtraído.

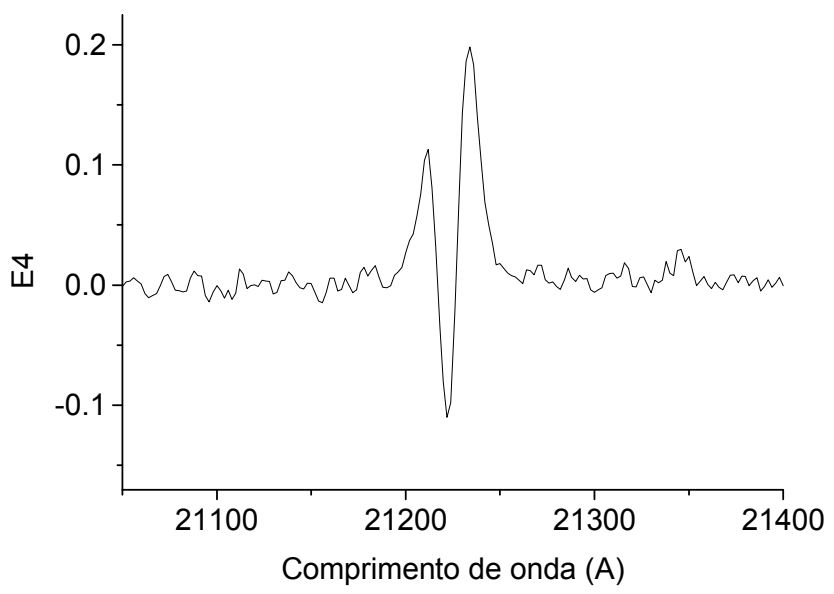

Figura 4.28 - Ampliação na região espectral da linha $\mathrm{H}_{2} \lambda 21218$ do auto-espectro correspondente ao autovetor E4, obtido com a Tomografia PCA do cubo de dados de NGC 2992 com o contínuo estelar subtraído. 


\begin{tabular}{|c|c|}
\hline Autovetor & Fração da variância explicada (\%) \\
\hline E1 & 66.3772 \\
\hline E2 & 12.6799 \\
\hline E3 & 6.8812 \\
\hline E4 & 1.8615 \\
\hline
\end{tabular}

Tabela 4.2 - Autovalores obtidos com a Tomografia PCA do cubo de dados de NGC 2992 com o contínuo estelar subtraído.

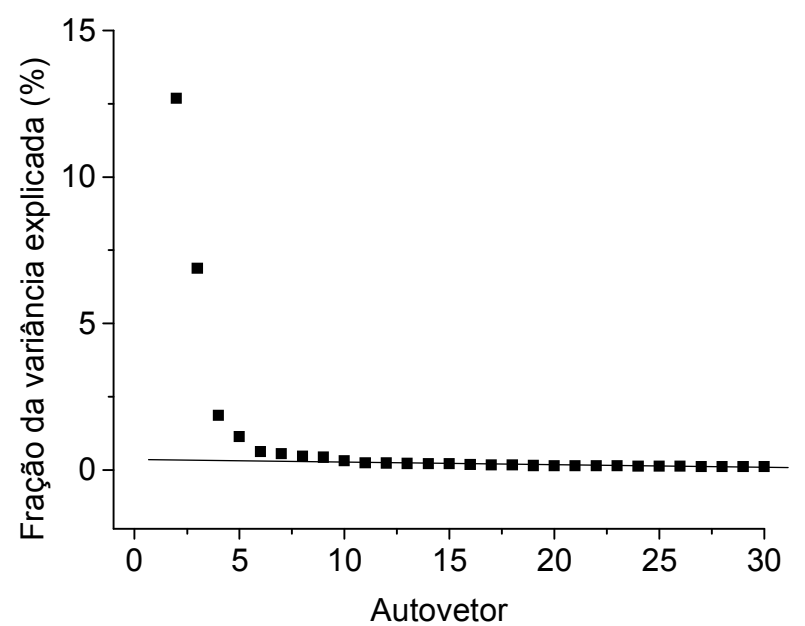

Figura 4.29 - "Scree test" dos autovetores obtidos com a Tomografia PCA do cubo de dados de NGC 2992 com o contínuo estelar subtraído.

A figura 4.24 mostra que o auto-espectro E1 apresenta correlações com os comprimentos de onda correspondentes às linhas de Bry, [Ca VIII] e a uma linha de He I 220587 . Pode-se notar, inclusive, a existência de correlações com os comprimentos de onda associados às componentes largas das linhas de Bry e He I. Isso indica que esse autovetor, assim como o autovetor E1 obtido com o Tomografia PCA do cubo de dados de NGC 2992 com o contínuo estelar (figuras 4.8 e 4.9), está correlacionado com a emissão proveniente do AGN existente em NGC 2992. Nesse caso, a posição do AGN corresponde à área mais clara do tomograma. O auto-espectro E1 apresenta, ainda, correlações com os comprimentos de onda correspondentes a linhas de emissão de $\mathrm{H}_{2}$, o que indica que esse autovetor está correlacionado com regiões emissoras de $\mathrm{H}_{2}$. Tais regiões também estariam entre as áreas claras do tomograma. $\mathrm{O}$ autovetor E1 obtido com a aplicação anterior da Tomografia PCA (figuras 4.8 e 4.9 da seção 4.3) também apresentava uma correlação com regiões emissoras de $\mathrm{H}_{2}$ e as informações reveladas por esses dois autovetores podem ser consideradas bastante compatíveis. O fato de o AGN existente nessa galáxia ser revelado pelo autovetor E1 (assim como ocorreu no caso do autovetor E1 mostrado 
nas figuras 4.8 e 4.9) está de acordo com o esperado, já que esse autovetor explica a maior parte da variância dos dados (66.3772 \%) e é sabido que o AGN desse objeto é bastante intenso e, por conseqüência, facilmente detectável. Por fim, assim como no caso do autovetor E1 da figura 4.8, o auto-espectro E1 na figura 4.24 possui uma série de correlações e anti-correlações, ao longo de toda a extensão espectral, associadas a resquícios de absorções telúricas não completamente removidas durante a redução dos dados.

Observando-se a figura 4.25, pode-se notar que o auto-espectro E2 apresenta correlações com os comprimentos de onda correspondentes às principais linhas de $\mathrm{H}_{2}$ existentes no espectro, o que mostra que esse autovetor está correlacionado com regiões emissoras de $\mathrm{H}_{2}$. Nesse caso, tais regiões são representadas pelas áreas claras do tomograma associado. Além disso, o autoespectro E2 também possui anti-correlações com os comprimentos de onda correspondentes às linhas de Bry, [Ca VIII] e He I, sendo que podem ser notadas, inclusive, anti-correlações com comprimentos de onda associados às componentes largas das linhas de Bry e He I. Isso indica que esse autovetor está anti-correlacionado com a emissão proveniente do AGN. Nesse caso, a posição do AGN corresponde à área escura mais próxima ao centro do tomograma, o que é compatível com tudo o que foi mostrado até aqui relativo à posição do AGN central. O autovetor E2 explica cerca de 12.6799 \% da variância dos dados.

A figura 4.26 revela que o auto-espectro E3 apresenta correlações com os comprimentos de onda associados às asas azuis das principais linhas de emissão do espectro e anti-correlações com os comprimentos de onda correspondentes às asas vermelhas das mesmas. Isso parece indicar que o autovetor E3 está relacionado a algum fenômeno cinemático do gás existente na região central de NGC 2992. Nesse caso, as áreas claras do tomograma associado correspondem a regiões com o gás apresentando emissão em blueshift e as áreas escuras representam regiões com o gás possuindo uma emissão em redshift. A morfologia apresentada por esse tomograma parece indicar uma complexidade cinemática do gás na região central de NGC 2992, que poderia ser compatível com a existência de dois fenômenos cinemáticos, como uma rotação e um outflow. Isso também foi constatado na análise dos autovetores E3 e E4, obtidos com a Tomografia PCA do cubo de dados de NGC 2992 com o contínuo estelar (figuras 4.11 e 4.12). O autovetor E3 explica cerca de 6.8812 \% da variância dos dados.

Finalmente, analisando-se a figura 4.27 e a ampliação da figura 4.28, pode-se notar que o auto-espectro E4 apresenta correlações com os comprimentos de onda associados às asas azuis e 
vermelhas das principais linhas de emissão visíveis no espectro e anti-correlações com os comprimentos de onda correspondentes às regiões centrais das mesmas. Isso, juntamente com a aparência apresentada pelo tomograma associado parece indicar que esse autovetor está estabelecendo um contraste entre regiões com o gás apresentando alguma componente radial de velocidade (blueshift ou redshift), que correspondem às áreas claras do tomograma, e regiões com o gás com pouca ou nenhuma componente radial de velocidade, que correspondem às áreas escuras do tomograma. As informações reveladas por esse autovetor são compatíveis não apenas com o autovetor E3 mostrado na figura 4.26, mas também com vários autovetores obtidos com a aplicação da Tomografia PCA ao cubo de dados de NGC 2992 com o contínuo estelar (seção 4.3). Uma característica interessante do autovetor E4 é que as amplitudes das correlações com os comprimentos de onda correspondentes às asas vermelhas das linhas de emissão são maiores do que as amplitudes das correlações com os comprimentos de onda associados às asas azuis das mesmas. Isso parece indicar que esse autovetor está mais relacionado a regiões com redshift do que com blueshift. Um comportamento análogo foi observado no autovetor E5 obtido com a aplicação anterior da Tomografia PCA (figuras 4.13 e 4.15 da seção 4.3). Embora alguns autovetores de ordem maior do que E4 tenham apresentado um comportamento similar, porém oposto ao de E4, nesse caso não ocorreu o mesmo que na seção 4.3, na qual os autovetores E5 e E6 apresentaram um comportamento exatamente análogo e oposto. Os autovetores aqui obtidos com ordem maior do que E4 e que se aproximavam desse comportamento apresentaram também características relacionadas a outros fenômenos, possuindo, portanto, uma interpretação mais difícil. Por essa razão, tais autovetores não foram mostrados aqui. O autovetor E4 explica cerca de $1.8615 \%$ da variância dos dados.

O Scree test mostrado na figura 4.29 revela que os valores das variâncias explicadas pelos autovetores decaem bastante até, aproximadamente, o autovetor E5. A partir daí, a taxa de decaimento diminui consideravelmente, ficando praticamente constante a partir do autovetor E10. Isso indica que autovetores de ordem maior ou igual a 10 representam essencialmente ruído e, portanto, não possuem relevância nessa análise. Entretanto, verificou-se que apenas os autovetores com ordem menor do que 5 possuíam uma interpretação mais clara e, por isso mesmo, apenas eles foram mostrados aqui. É provável que a diminuição da taxa de decaimento dos autovalores a partir do autovetor E5 represente um indicativo da diminuição da significância dos autovetores com ordem maior ou igual a essa. 
Pode-se concluir, assim, que essa segunda análise com a Tomografia PCA apresentou resultados compatíveis com a primeira análise (seção 4.3) e, ao mesmo tempo, possibilitou que certos fenômenos fossem mais claramente detectados. Primeiramente, essa segunda análise permitiu que a emissão proveniente do AGN fosse visualizada de uma maneira mais clara do que na primeira análise. Também foi possível estabelecer uma diferenciação entre as regiões mais próximas ao AGN, com uma emissão dominada por este, e as áreas mais afastadas, nas quais a emissão de $\mathrm{H}_{2}$ prevalece. A primeira análise com a Tomografia PCA gerou resultados bastante similares. Por fim, a segunda análise com a Tomografia PCA revelou, assim como a primeira, a provável existência de mais de um fenômeno cinemático do gás na região central de NGC 2992 (possivelmente uma rotação e um outflow). Isso está de acordo com o esperado, já que Márquez et al. (1998) e Friedrich et al. (2010) mostraram que as curvas de rotação do gás na região central dessa galáxia são o resultado de uma superposição de um disco em rotação e de um outflow com velocidade constante, conforme mencionado anteriormente.

\section{6 - Cinemática estelar do cubo de dados de NGC 2992}

A fim de se obter dados a respeito da cinemática estelar, aplicou-se o processo do pPXF no cubo de dados de NGC 2992. Esse procedimento forneceu, conforme explicado em 3.13, os seguintes parâmetros: velocidade radial estelar, dispersão de velocidades estelar e os coeficientes de Gauss-Hermite $h_{3}$ e $h_{4}$. Os mapeamentos obtidos para os valores desses parâmetros são mostrados na figura 4.30 .
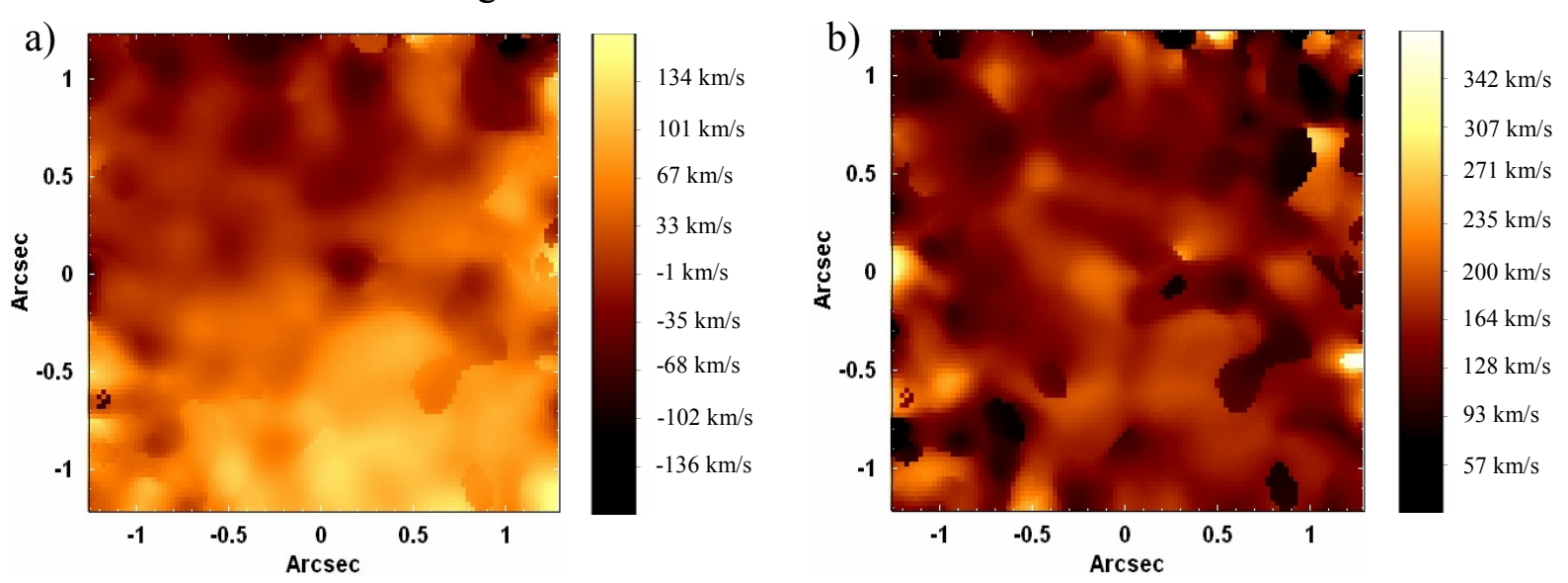

Figura 4.30 - Mapeamentos dos valores (a) da velocidade radial estelar, (b) da dispersão de velocidades estelar, (c) do coeficiente $h_{3} e(d)$ do coeficiente $h_{4}$, obtidos com a aplicação do pPXF ao cubo de dados de NGC 2992. 

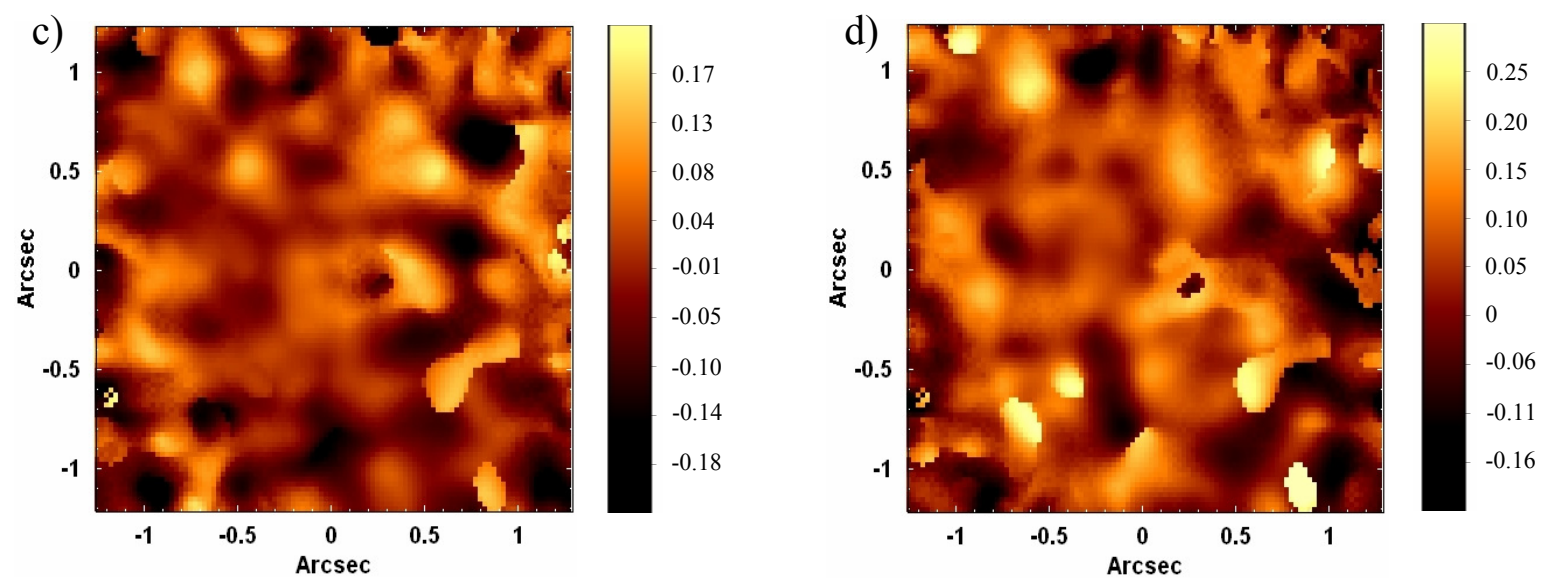

Figura 4.30 (continuação).

Observando-se a figura 4.30 - $a$, nota-se a presença de um padrão rotacional estelar, embora a imagem seja ruidosa e apresente irregularidades. Esse movimento rotacional estelar parece ser compatível com o padrão rotacional detectado (juntamente com um outflow) para o gás nos resultados obtidos com a aplicação da Tomografia PCA (seções 4.3 e 4.5). A figura 4.30 - $b$ mostra que o mapeamento dos valores da dispersão de velocidades estelar não apresentou padrões ou configurações espaciais claramente visíveis. Entretanto, comparando-se as figuras $4.30-a$ e $4.30-b$, pode-se notar que ambas revelaram um decréscimo dos valores na posição correspondente ao AGN. Esse comportamento pode ser explicado pelo fato de que, nessa área do cubo, o contínuo era dominado pela emissão térmica de poeira e as bandas de $\mathrm{CO}$ praticamente não eram detectáveis. Como os ajustes com o pPXF se basearam, essencialmente, nas bandas de CO (que são as estruturas espectrais provenientes de absorção estelar mais relevantes nessa faixa espectral), eles foram prejudicados nessa região do cubo, gerando resultados não confiáveis. Assim é bem provável que esse decréscimo de valores na área correspondente ao AGN não seja real, mas sim um produto de problemas de ajuste. Os mapeamentos mostrados nas figuras $4.30-a$ e $4.30-b$ são compatíveis com os obtidos por Friedrich et al. (2010) (lembrando que esses autores analisaram esse mesmo cubo de dados em seu trabalho, mas com um tratamento dos dados bastante diferente). Os mapeamentos das figuras $4.30-c$ e $4.31-d$ não revelaram comportamentos ou configurações dominantes que possam ser facilmente identificado.

Devido ao fato de a rotação estelar detectada na imagem 4.30 - $a$ ser relativamente tênue e considerando-se ainda que tanto esse mapeamento quanto o dos valores da dispersão de 
velocidades estelar (figura $4.30-b$ ) apresentaram várias irregularidades e possíveis zonas com valores não confiáveis (como a posição correspondente ao AGN, que teve uma diminuição de valores em ambos os mapeamentos), optou-se por não aplicar nenhum tipo modelagem com o intuito de se determinar a massa do buraco negro central existente nesse objeto.

\section{7 - Cinemática do gás do cubo de dados de NGC 2992}

Para se obter informações sobre a cinemática do gás molecular na região central de NGC 2992, construiu-se o mapa de velocidades da linha de emissão $\mathrm{H}_{2}$ ג21218. Para se fazer tal mapeamento, primeiramente, ajustou-se uma gaussiana nessa linha em cada um dos espectros do cubo de dados, após a subtração do contínuo estelar. Em seguida, os valores das velocidades foram calculados tomando-se o comprimento de onda central das gaussianas ajustadas. A linha de $\mathrm{H}_{2} \lambda 21218$ foi utilizada por ser uma das mais intensas do espectro. Linhas mais fracas forneceram mapas de velocidades menos precisos, que, por essa razão, não são mostrados aqui. A linha de Bry é de grande intensidade na região correspondente ao AGN, entretanto, em áreas mais afastadas, sua intensidade diminui bastante, fazendo com que um mapa de velocidades feito a partir dessa linha apresente grandes imprecisões. Assim, um mapeamento de velocidades baseado na linha de $\mathrm{Br} \gamma$ também não é mostrado aqui. $\mathrm{O}$ mapa feito a partir da linha de $\mathrm{H}_{2}$ $\lambda 21218$ encontra-se a seguir.

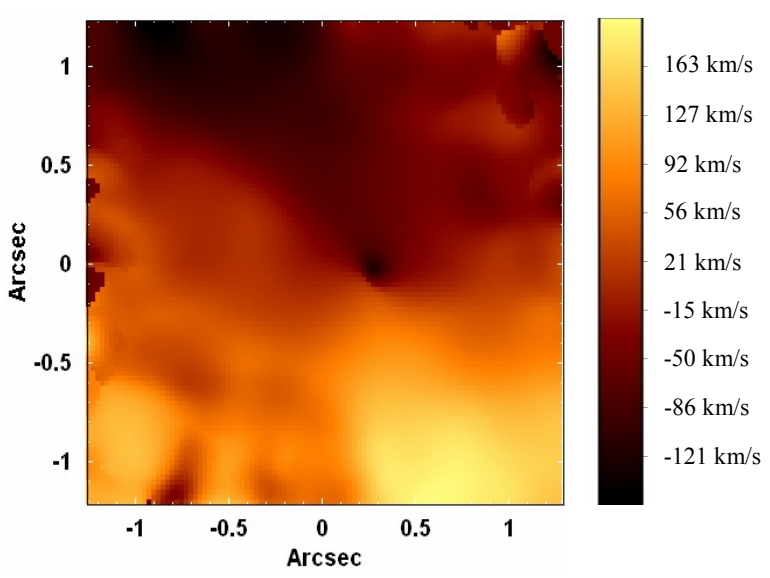

Figura 4.31 - Mapeamento dos valores de velocidade radial do gás molecular, obtido com a linha de $\mathrm{H}_{2} \lambda 21218$ do cubo de dados de NGC 2992. 
Observando-se o mapa de velocidades mostrado na figura 4.31, pode-se notar que ele está de acordo com vários resultados obtidos com as duas aplicações da Tomografia PCA ao cubo de dados de NGC 2992 (figuras 4.11, 4.12, 4.13, 4.14 e 4.15 da seção 4.3 e figuras 4.26, 4.27 e 4.28 da seção 4.5). Ele também é compatível com o que foi encontrado por Márquez et al. (1998) e Friedrich et al. (2010), que confirmaram a existência de uma rotação do gás e de um outflow na região central dessa galáxia. Logo, a sobreposição desses dois fenômenos cinemáticos foi o que deu origem à morfologia apresentada pela mapa de velocidades da figura 4.31 .

Para se tentar modelar o mapa de velocidades do gás mostrado na figura 4.31, seria preciso sobrepor uma curva de rotação a um outflow. Entretanto, como o objetivo desse trabalho envolve, apenas, a simulação de movimentos keplerianos, visando a determinação da massa do buraco negro central presente, e, nesse caso, não foi possível separar com precisão a rotação e o outflow existentes no mapeamento de velocidades, optou-se por não se fazer essa modelagem aqui.

\section{8 - Espectro de emissão de $\mathrm{H}_{2}$ do cubo de dados de NGC 2992: razões de linhas e temperaturas de excitação}

Conforme foi explicado em 2.4.2, a análise de diagramas de diagnóstico de razões de

linhas de emissão de $\mathrm{H}_{2}$ permite que se diferencie regiões com emissão de $\mathrm{H}_{2}$ com origem térmica e não térmica. Se for assumido que a área emissora está em equilíbrio termodinâmico local - ETL (o que implica em uma origem térmica para a emissão de $\mathrm{H}_{2}$ ), também é possível determinar a temperatura do gás molecular a partir dos valores das razões das linhas de emissão de $\mathrm{H}_{2}$.

Definindo-se duas linhas de emissão de $\mathrm{H}_{2}$ como sendo originadas por transições entre os níveis de energia arbitrários $2 \rightarrow 1$ e $4 \rightarrow 3$, tem-se que a razão entre as luminosidades por unidade de volume dessas linhas (e, consequentemente, a razão entre os fluxos dessas linhas) pode ser dada por 


$$
\frac{I_{21}}{I_{43}}=\frac{n_{2} A_{21} h v_{21}}{n_{4} A_{43} h v_{43}} .
$$

onde $n_{2}=$ número de moléculas por unidade de volume no nível de energia 2

$n_{4}=$ número de moléculas por unidade de volume no nível de energia 4 $A_{21}=$ probabilidade de transição entre os níveis de energia 2 e 1

$A_{43}=$ probabilidade de transição entre os níveis de energia 4 e 3

$v_{21}=$ freqüência da radiação emitida por transições entre os níveis de energia 2 e 1 $v_{43}=$ freqüência da radiação emitida por transições entre os níveis de energia 4 e 3 $h=$ constante de Planck

Em ETL, a razão $n_{2} / n_{4}$ pode ser dada pela equação de Boltzmann:

$$
\frac{n_{2}}{n_{4}}=\frac{g_{2}}{g_{4}} e^{\frac{-\left(E_{2}-E_{4}\right)}{k T}} .
$$

$$
\text { onde } \begin{aligned}
g_{2} & =\text { multiplicidade do nível } 2 \\
g_{4} & =\text { multiplicidade do nível } 4 \\
E_{2} & =\text { energia do nível } 2 \\
E_{4} & =\text { energia do nível } 4
\end{aligned}
$$

Substituindo-se (4.2) em (4.1), obtém-se:

$$
\frac{I_{21}}{I_{43}}=\frac{g_{2} A_{21} v_{21}}{g_{4} A_{43} v_{43}} e^{\frac{-\left(E_{2}-E_{4}\right)}{k T}},
$$


logo, calculando-se o logaritmo de ambos os lados da equação (4.3) e rearranjando os termos, obtém-se

$$
T=\frac{E_{4}-E_{2}}{k \ln \left(\frac{I_{21} A_{43} v_{43} g_{4}}{I_{43} A_{21} v_{21} g_{2}}\right)} .
$$

Por ter sido determinada a partir da equação de Boltzmann, a temperatura obtida é denominada temperatura de excitação.

Para se determinar as razões de algumas linhas de emissão de $\mathrm{H}_{2}$ do cubo de dados de NGC 2992, ajustaram-se funções gaussianas (dadas pela equação 3.82) nessas linhas em todos os espectros do cubo, após a subtração do contínuo estelar. Em seguida, calcularam-se, então, as razões dos picos dessas gaussianas. A figura 4.32 mostra o diagrama de diagnóstico obtido a

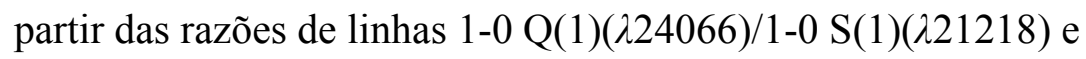

1-0 S(2)(220338)/1-0 S(0)(222235). Valores espúrios gerados por imprecisões nos ajustes das funções gaussianas (sobretudo em espectros com baixos valores da razão $S / N$ ) foram excluídos do diagrama.

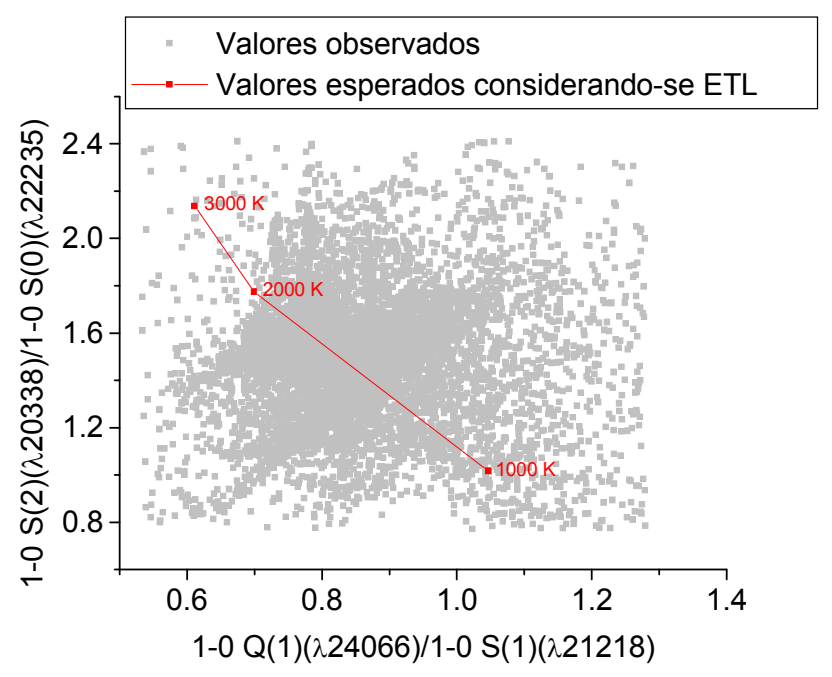

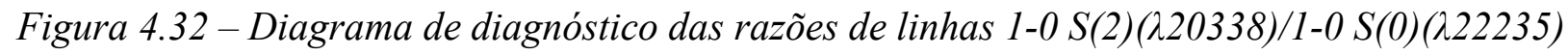

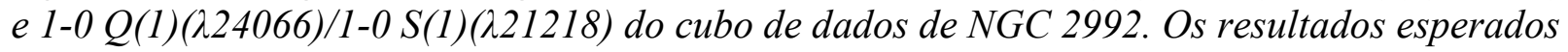
considerando-se ETL são mostrados em vermelho.

Uma análise do diagrama de diagnóstico da figura 4.32 deixa bastante claro que a aproximação de ETL parece não ser válida em várias regiões espaciais do cubo de dados de 
NGC 2992. Isso sugere uma origem não térmica para a emissão de $\mathrm{H}_{2}$ nessas áreas. Para se determinar a temperatura em regiões nas quais o ETL parece ser válido, primeiramente, estimou-se, com base nas flutuações do contínuo nas regiões espectrais próximas às linhas de emissão medidas, uma incerteza de $11 \%$ para as razões de linhas. Vale lembrar que essas medições foram feitas no cubo de dados após a subtração do contínuo estelar, logo, as flutuações observadas deviam ser devidas a resquícios do contínuo não removidos pela subtração ou mesmo ao ruído. Após isso, delimitou-se, no diagrama de diagnóstico mostrado na figura 4.32, uma região com valores dentro de um intervalo de até $11 \%$ a partir da curva vermelha representando o ETL. A aproximação de ETL foi considerada aproximadamente válida para todos os pontos dentro dessa região delimitada. Utilizando-se, então, a equação (4.4) (com as constantes obtidas do site http://www.jach.hawaii.edu/UKIRT/astronomy/calib/spec_cal_h2_s.html), calcularam-se as temperaturas de excitação para todos esses pontos em ETL. A figura 4.33 mostra o mapeamento dos valores obtidos para a temperatura, utilizando-se a razão

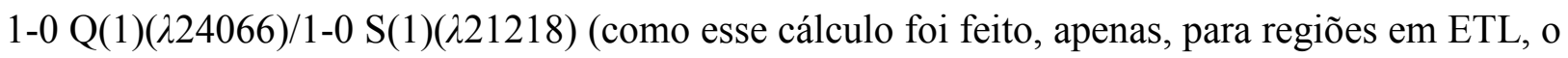
mapeamento com valores obtidos para a temperatura a partir da razão 1-0 S(2)(220338)/1-0 S(0)(222235) foi aproximadamente o mesmo, logo, ele não é mostrado aqui).

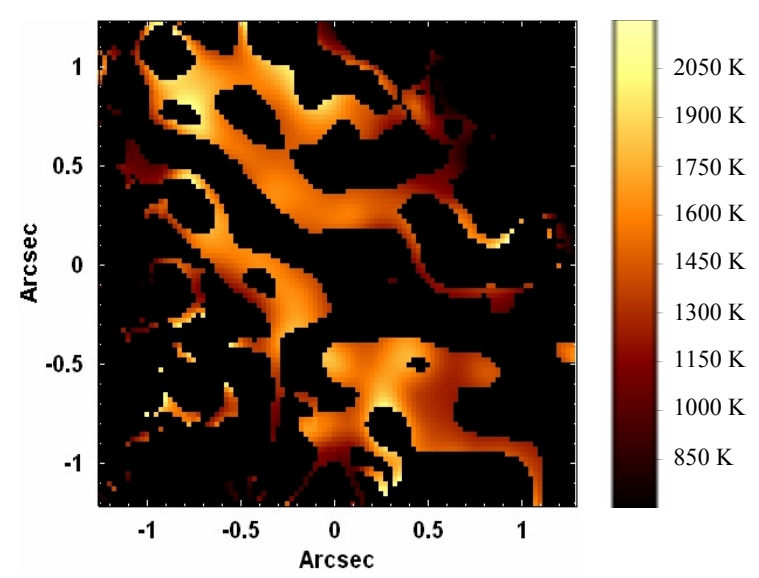

Figura 4.33 - Mapeamento dos valores da temperatura de excitação do cubo de dados de NGC 2992, obtidos a partir da razão de linhas 1-0 Q(1)(224066)/1-0 S(1)(221218). O mapeamento foi feito apenas para regiões nas quais a aproximação de ETL é válida.

Observando-se a figura 4.33, pode-se notar que a aparência do mapeamento de

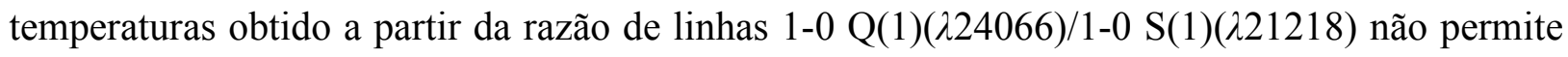
que sejam tiradas conclusões significativas a respeito da variação dos valores nas diferentes 
regiões espaciais, devido à grande quantidade de áreas não mapeadas (nas quais a aproximação de ETL não é válida). Apesar disso, percebe-se que a maior parte das regiões nas quais a temperatura pôde ser determinada se localiza ao longo da área correspondente à faixa diagonal que foi detectada pelas análises anteriores com a Tomografia PCA e com a síntese espectral com o Starlight (sessões 4.3 e 4.4, respectivamente). Isso está de acordo com o esperado, já que a aplicação da Tomografia PCA ao cubo de dados de NGC 2992 com o contínuo estelar (sessão 4.3) mostrou que a maior da emissão de $\mathrm{H}_{2}$ na região central dessa galáxia é proveniente dessa área. Os maiores valores obtidos para a temperatura de excitação (próximos a $2000 \mathrm{~K}$ ) são compatíveis com os encontrados por Mouri (1994) para objetos nos quais o aquecimento das nuvens moleculares emissoras de $\mathrm{H}_{2}$ é devido a raios-x. Isso sugere que o mecanismo responsável pelo aquecimento das nuvens em NGC 2992 é a emissão de raios-x pelo AGN central, o que está de acordo com o esperado.

\section{9 - Conclusões}

Em suma, pode-se dizer, primeiramente, que as análises com a Tomografia PCA, assim como a determinação do mapa de velocidades do gás molecular, do cubo de dados de NGC 2992 revelaram uma complexa cinemática do gás na região central de NGC 2992, que pode ser compatível com a existência de dois fenômenos cinemáticos, como uma rotação e um outflow. Esse resultado está de acordo com o que foi obtido por Márquez et al. (1998) e Friedrich et al. (2010). O ajuste com o processo do Penalized Pixel-Fitting também mostrou a existência de uma aparente rotação estelar mais tênue ao redor do núcleo dessa galáxia. Tanto a aplicação da Tomografia PCA ao cubo de dados de NGC 2992 com contínuo estelar quanto a síntese espectral realizada com o software Starlight evidenciaram a presença de uma provável emissão térmica de poeira na área correspondente ao AGN central. Um imageamento detalhado dessa região emissora não pôde ser feito, já que a resolução espacial aqui obtida não foi suficiente para isso. Entretanto, é possível que a emissão térmica de poeira detectada seja proveniente de um toro de poeira ao redor do AGN, o que seria compatível com as previsões do Modelo Unificado. As aplicações da Tomografia PCA e a síntese espectral com o Starlight revelaram que a maior parte da emissão estelar e molecular é proveniente de uma região ao longo da diagonal do 
campo de visão do SINFONI, que também foi detectada em imagens de NGC 2992 obtidas com o HST. A emissão devida do AGN pôde ser consideravelmente bem isolada pela Tomografia PCA, que revelou, claramente, a existência de componentes largas nas linhas de Bry e He I (220587). Os valores máximos da temperatura de excitação do gás obtidos a partir da razão de linhas 1-0 $\mathrm{Q}(1)(224066) / 1-0 \mathrm{~S}(1)(221218)$ para as áreas em ETL parecem indicar um aquecimento das nuvens moleculares por raios-x (Mouri 1994), provavelmente emitidos pelo AGN central. Entretanto, o mapa de temperaturas construído não permitiu que fossem tiradas conclusões claras a respeito da variação da temperatura nas diferentes regiões espaciais do campo visual do SINFONI. 


\section{5 - NGC 4151}

\section{1 - Introdução}

NGC 4151 é uma galáxia de tipo (R')SAB(rs)ab que se encontra a uma distância de 13.3 Mpc. Por se tratar da Seyfert 1 mais próxima, esse objeto também é um dos AGNs mais bem estudados. O fato de possuir tanto linhas permitidas largas quanto intensas linhas proibidas estreitas levou Osterbrock \& Koski (1976) a classificarem-na, mais especificamente, como uma Seyfert 1.5. Ela consta na lista de objetos analisados por Seyfert (1943), entretanto, o primeiro grande estudo do núcleo Seyfert dessa galáxia foi feito por Ulrich (1973), que demonstrou a existência de, pelo menos, 4 nuvens distintas nos 300 pc centrais.

Esse objeto possui uma distorção oval central com dimensões de $3.3^{\prime}$ x $2.1^{\prime}$, cujo eixo maior se estende ao longo de um ângulo de posição de $130^{\circ}$. Inicialmente, acreditava-se que essa galáxia era constituída, apenas, por essa distorção central, sendo, portanto, um objeto consideravelmente pequeno. Posteriormente, entretanto, foi comprovado que essa distorção oval é apenas a parte interna de uma galáxia maior. Davies (1973) detectou, com observações em H I, um disco que se estende até cerca de 6' do núcleo. Esse disco é bastante fraco no óptico, porém facilmente detectável em H I.

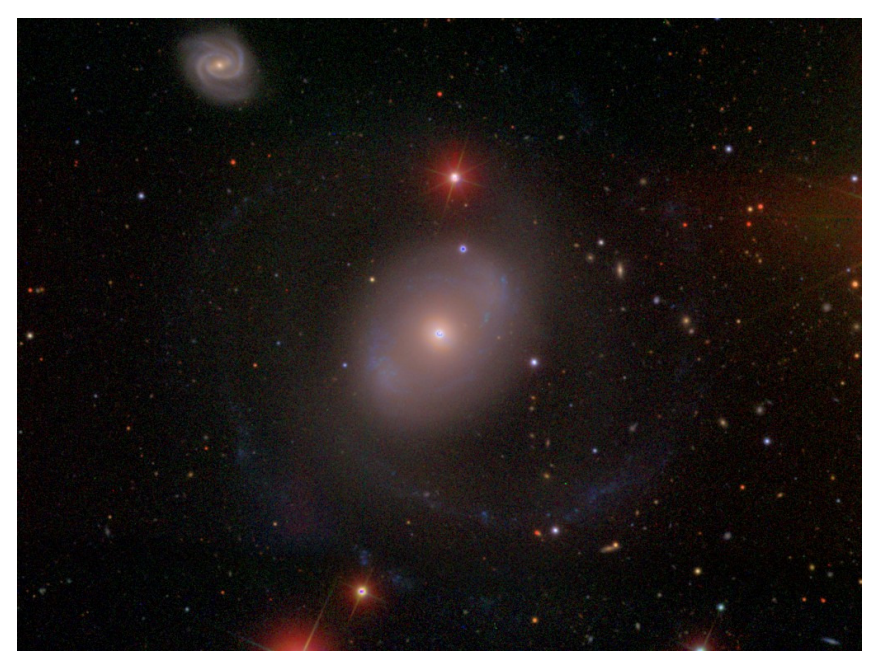

Figura 5.1 - Imagem da galáxia NGC 4151, obtida com o SDSS. A orientação é norte para cima e leste para a esquerda. 
Observando-se a imagem de NGC 4151 obtida com o SDSS (Figura 5.1), pode-se notar tanto a presença da distorção oval central mencionada anteriormente quanto a existência de um disco tênue (mais facilmente detectável em H I), que se estende até distâncias bem maiores do núcleo. Mundell et al. (1999) mostraram, utilizando imageamento espectral em H I, que essa distorção oval apresenta as características cinemáticas de uma barra.

Observações no contínuo em rádio de NGC 4151 mostraram a existência de uma estrutura linear compreendendo vários nós, se estendendo por 3.5" ao longo de um ângulo de posição médio de cerca de $77^{\circ}$ (Wilson \& Ulvestad 1982; Johnston et al. 1982; Carral et al. 1990; Pedlar et al. 1993; Mundell et al. 1995), a qual está embebida em uma emissão difusa se estendendo por mais de 10.5" (Johnston et al. 1982; Pedlar et al. 1993). Carral et al. (1990) identificaram cinco nós principais nessa emissão em rádio. Tal estrutura também foi observada por Mundell et al. (1995). Imageamentos em rádio feitos em trabalhos posteriores (Mundell et al. 2003) revelaram várias sub-estruturas presentes nesses cinco nós.

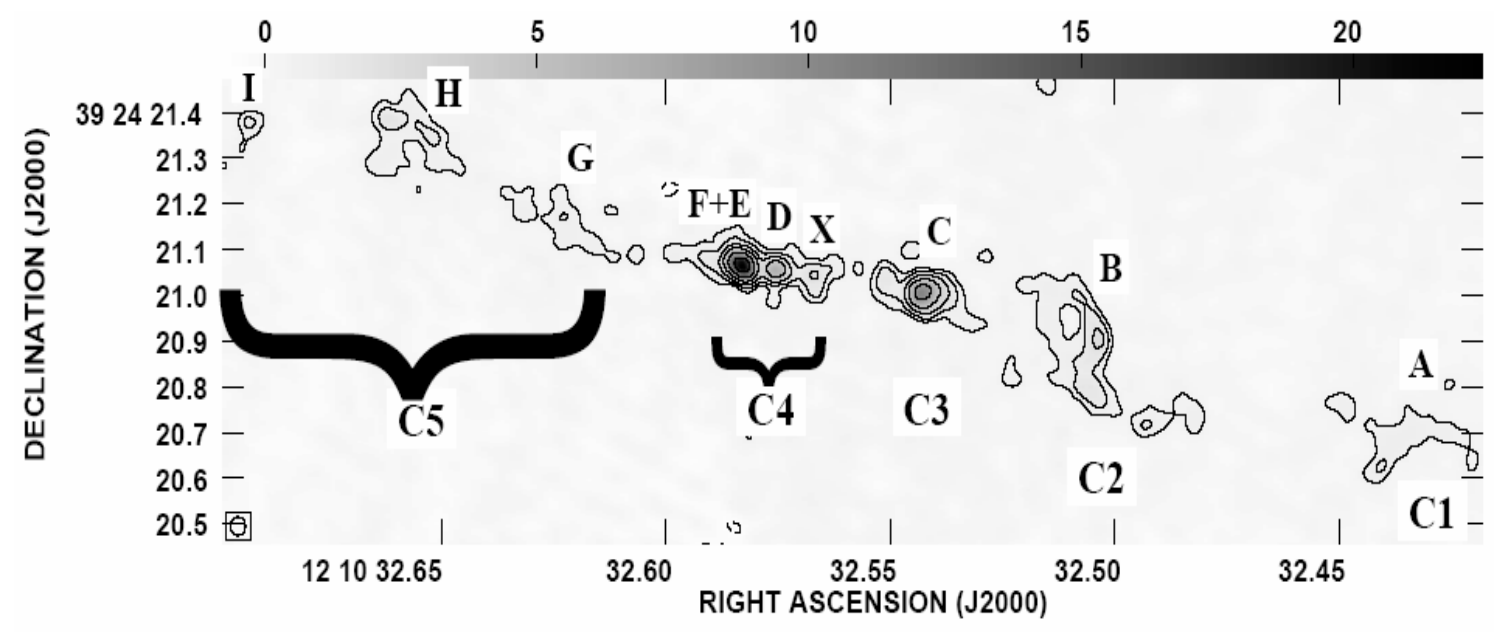

Figura 5.2 - Imagem em $21 \mathrm{~cm}$ da região central de NGC 4151, obtida a partir do trabalho de Mundell et al. (2003).

O mapeamento em $21 \mathrm{~cm}$ mostrado na figura 5.2 (Mundell et al. 2003) revela tanto os cinco nós principais (nomeados com a letra C) detectados por Carral et al. (1990) e Mundell et al. (1995) quanto outras sub-estruturas presentes. Em seu trabalho, Mundell et al. (2003) também detectaram um jato fraco em rádio por trás dos nós, que parecem ser estruturas produzidas pela interação do jato com as nuvens de gás ao redor.

Evans et al. (1993) analisaram imagens em [O III] $\lambda 5007$ e $\mathrm{H} \alpha+[\mathrm{N} \mathrm{II}] \lambda \lambda 6548,6583$, obtidas com o HST. Nesse trabalho, os autores concluíram que a emissão de $\mathrm{H} \alpha+$ 
[N II] $\lambda \lambda 6548,6583$ vem de uma fonte puntual nuclear não resolvida, provavelmente associada à BLR do AGN, ao passo que a emissão de [O III] 25007, associada à NLR, vem de nuvens distribuídas na forma de um bi-cone. Dessa forma, esse trabalho revelou que a NLR de NGC 4151 apresenta o formato de um bi-cone, cujo ângulo de abertura projetado é de $75^{\circ} \pm 10^{\circ}$ e que se estende ao longo de um ângulo de posição de $60^{\circ} \pm 5^{\circ}$.

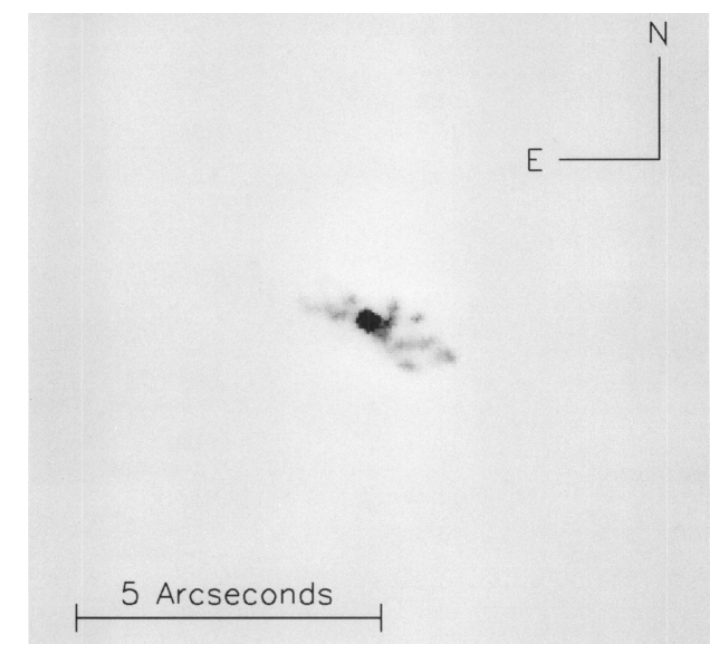

Figura 5.3 - Imagem em [O III] 25007 da região central de NGC 4151, obtida com o HST, retirada do trabalho de Evans et al. (1993).

A imagem em [O III] $\lambda 5007$ na figura 5.3 mostra as nuvens da NLR de NGC 4151 dispostas na forma de um bi-cone. Das et al. (2005) e Crenshaw et al. (2000) simularam outflows na forma de bi-cones e conseguiram reproduzir os aspectos gerais da cinemática detectada na região central de NGC 4151. Hutchings et al. (1998) também elaboraram modelos de outflows na forma de bi-cones e chegaram à conclusão de que esse é o modelo mais compatível com o observado, sendo que o limite do cone deve estar localizado próximo à linha de visada. Muitos trabalhos não encontraram correlações entre o jato em rádio e a emissão proveniente de boa parte das nuvens da NLR. No entanto, Winge et al. (1997) mostrou que o jato em rádio parece estar associado às nuvens de alta velocidade da NLR.

Knop et al. (1996) analisaram dados espectroscópicos de NGC 4151 no infravermelho próximo $(1.24 \mu \mathrm{m}-1.30 \mu \mathrm{m})$ e identificaram componentes de velocidade individuais para as linhas de $\mathrm{Pa} \beta$, [Fe II] $\lambda 12567$ e [SI X] $\lambda 12524$, o que é consistente com sistemas de nuvens individuais. Os autores também verificaram que os comportamentos cinemáticos das linhas de $\mathrm{Pa} \beta$ e [Fe II] $\lambda 12567$ concordavam bastante entre si e também concordavam com o comportamento de linhas de emissão no óptico, como H $\beta$ e [O III] $\lambda 5007$. Essa correspondência 
de [Fe II] $\lambda 12567$ com as demais linhas indica que a emissão de [Fe II] está associada diretamente à NLR. No entanto, as linhas estreitas de [Fe II] eram mais largas do que as linhas estreitas de $\mathrm{Pa} \beta$, o que parece sugerir que a emissão de [Fe II] tem uma fonte de excitação colisional. Tal fonte poderia ser, por exemplo, choques em alta velocidade associados a um outflow.

Storchi-Bergmann et al. (2009; 2010) analisaram cubos de dados no infravermelho próximo da região nuclear de NGC 4151, obtidos com o NIFS do telescópio Gemini-Norte. Nesse trabalho, foram identificadas três componentes cinemáticas do gás ionizado: uma emissão estendida com uma velocidade sistêmica em uma região circular ao redor do núcleo, uma componente de outflow ao longo do bi-cone e outra componente devido à interação do jato em rádio com o disco da galáxia. As distribuições de fluxo de várias linhas de emissão (como $\mathrm{H}$, He, [S III], [P II] e [Fe II]) apresentaram a morfologia de um bi-cone, conforme é o esperado

para essa galáxia. A distribuição de fluxo de $\mathrm{H}_{2}$, por outro lado, foi completamente diferente da do gás ionizado, sendo que praticamente não foi detectada emissão de $\mathrm{H}_{2}$ ao longo do bi-cone, possivelmente devido à destruição de moléculas de $\mathrm{H}_{2}$ nessa área. Os autores propuseram que as regiões de emissão de $\mathrm{H}_{2}$ nesse objeto demarcam um "reservatório" de gás que alimenta o AGN.

\section{2 - Preparação do cubo de dados de NGC 4151}

Foram analisados cubos de dados da região central de NGC 4151 obtidos, na banda K do infravermelho próximo, com o NIFS do telescópio Gemini-Norte. Esses dados são os mesmos estudados por Storchi-Bergmann et al. (2009; 2010), no entanto, aqui foram utilizadas diferentes metodologias de análise. A redução dos cubos de dados foi feita em ambiente IRAF, utilizandose o pacote de tarefas Gemini, conforme explicado em 3.2.2. Ao final desse processo, foram obtidos 8 cubos de dados com pixeis espaciais de 0.05 " de lado.

Após a redução dos dados, foi aplicada a correção da refração atmosférica diferencial em cada um dos cubos de dados. Em seguida, a fim de se combinar todos esses cubos em um só, primeiramente, eles foram separados em três grupos. Nomeando-se os cubos como 1, 2, 3, 4,..,8 (de acordo com a ordem de observação), a separação nos três grupos foi feita da seguinte maneira: 
- Grupo 1: cubos 1, 4 e 7

- Grupo 2: cubos 2, 5 e 8

- Grupo 3: cubos 2, 3 e 6

Os integrantes de cada um desses três grupos foram combinados na forma de mediana, resultando, portanto, em três cubos ao final do processo. Calculou-se, então, uma nova mediana para esses três últimos cubos, obtendo-se, assim, o cubo combinado procurado.

Em seguida, aplicou-se o processo de reamostragem espacial no cubo de dados encontrado, a fim de se obter pixeis espaciais de 0.021 " de lado. A figura 5.4 mostra as somas de todas as imagens do cubo de dados de NGC 4151, antes e depois do processo de reamostragem.
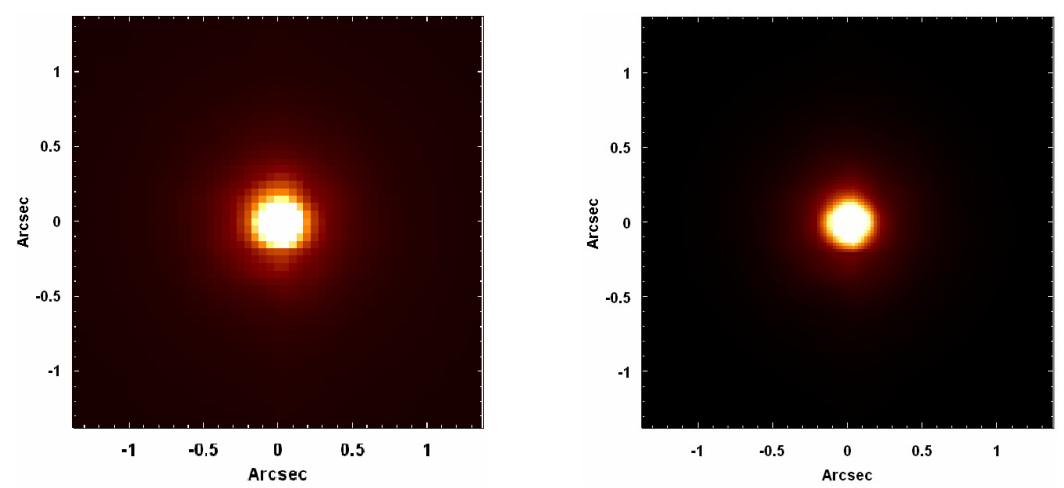

Figura 5.4 - (esquerda) Soma de todas as imagens do cubo de dados de NGC 4151, antes da aplicação da reamostragem espacial; (direita) Soma de todas as imagens do cubo de dados de NGC 4151, após a aplicação da reamostragem espacial.

Observando-se a figura 5.4, pode-se notar que a aplicação da reamostragem espacial permitiu que as estruturas espaciais presentes no cubo de dados fossem definidas de uma maneira mais clara. Esse procedimento, entretanto, também introduziu componentes de alta freqüência espacial, que aparecem tenuamente na forma de estreitas faixas escuras na imagem, conforme foi explicado em 3.5.1.

Após isso, aplicou-se uma decomposição wavelet no cubo de dados reamostrado, obtendo-se, ao final, os cubos $W_{0}, W_{1}, W_{2}, W_{3}, W_{4}$ e $W_{C}$, conforme explicado em 3.6. Utilizouse, então, $W_{0}$ para se determinar os parâmetros mais adequados para o filtro de Butterworth e, a seguir, esses parâmetros foram utilizados na filtragem espacial de todas as outras componentes wavelet e também do cubo de dados original. No caso desse objeto, todas as filtragens foram 
feitas utilizando-se um filtro com forma dada pela expressão (3.68), $n=2$ e freqüência de corte ao longo dos eixos horizontal e vertical de $v_{c}=0.40 \mathrm{Ny}$. A figura 5.5 mostra as somas das imagens do cubo de dados, antes e depois da filtragem espacial de Butterworth, assim como a soma das imagens do cubo correspondente à diferença entre esses dois.
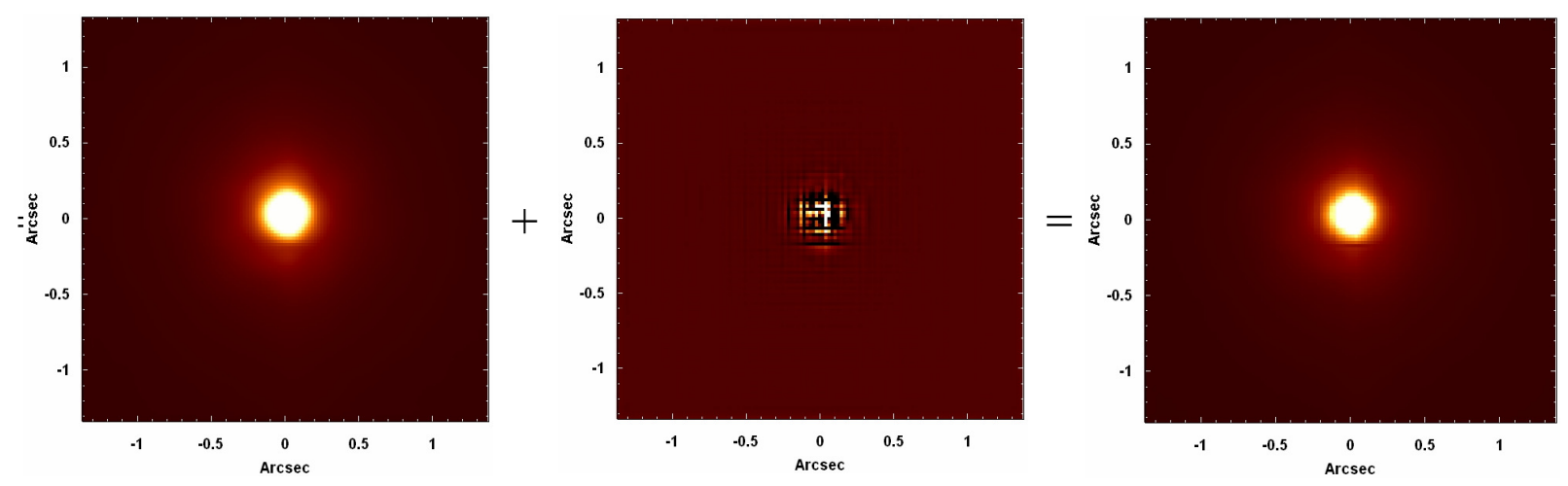

Figura 5.5 - (esquerda) Soma das imagens do cubo de dados de NGC 4151, após a filtragem espacial de Butterworth; (centro) Soma das imagens do cubo de dados de NGC 4151 correspondente à diferença entre o cubo não filtrado e o cubo filtrado; (direita) Soma das imagens do cubo de dados de NGC 4151, antes da filtragem espacial de Butterworth.

A figura 5.5 mostra que a aplicação da filtragem espacial de Butterworth removeu uma grande quantidade de ruídos de alta freqüência (inclusive as componentes de alta freqüência introduzidas pela reamostragem espacial), o que proporcionou uma melhoria na qualidade das imagens do cubo de dados.

Após a filtragem espacial de Butterworth, aplicou-se o processo de de-noising no cubo de dados, a fim de diminuir o ruído espectral existente. A utilização desse procedimento apresenta certos riscos, pois pode causar alterações indesejáveis nos espectros do cubo de dados, como, por exemplo, alargamento de linhas de emissão. No caso desse objeto, entretanto, notouse que os efeitos negativos desse processo eram mínimos e os ganhos consideráveis, assim, optou-se por aplicar o procedimento. A figura 5.6 mostra o espectro extraído de uma região circular central do cubo de dados de NGC 4151, antes e depois da aplicação do de-noising. 

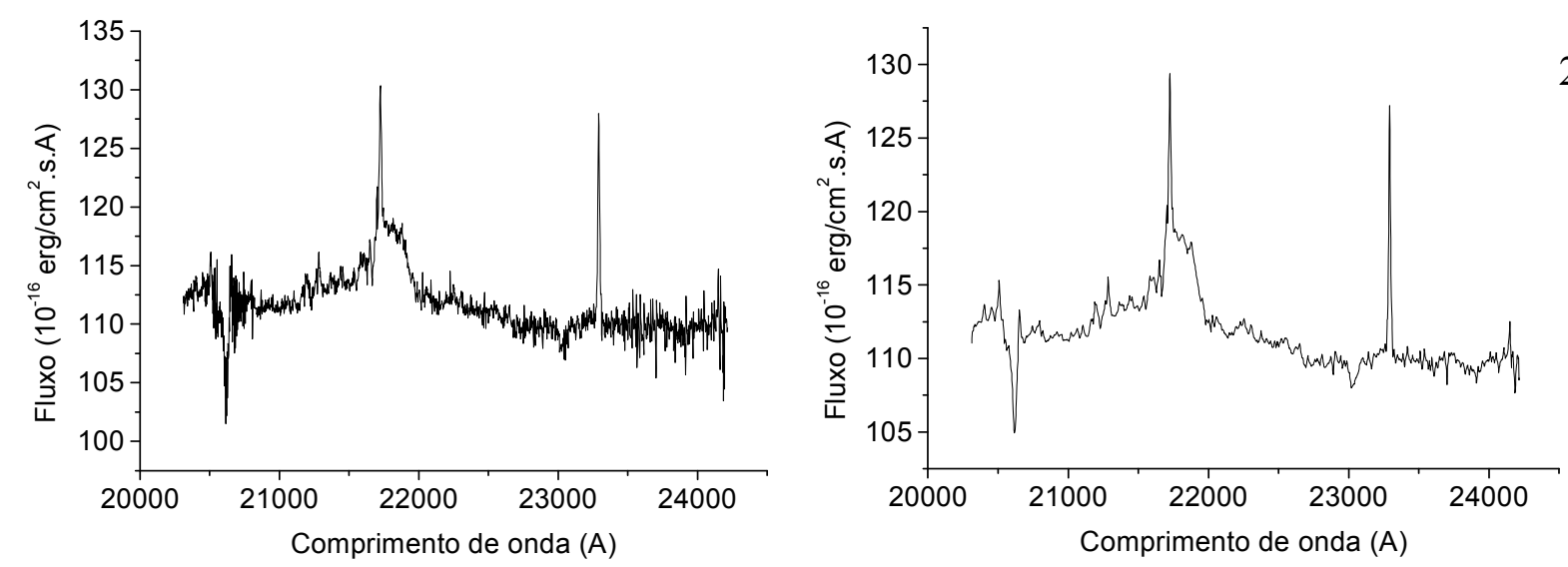

Figura 5.6 - (esquerda) Espectro extraído de uma região circular central do cubo de dados de NGC 4151, antes da aplicação do "de-noising”; (direita) Espectro extraído de uma região circular central do cubo de dados de NGC 4151, após a aplicação do "de-noising”.

Observando-se a figura 5.6, pode-se notar a grande diminuição do ruído espectral que o processo do de-noising proporcionou. Também se pode notar que os efeitos negativos sobre estruturas como linhas de emissão foram mínimos.

Em seguida, passou-se para a etapa da deconvolução de Richardson-Lucy. Para se obter uma imagem representativa da PSF, aplicou-se a Tomografia PCA ao cubo de dados de NGC 4151 e verificou-se que o autovetor 1 representava o AGN contido nesse objeto, com pouca contaminação das emissões provenientes das populações estelares ao redor. O tomograma associado a esse autovetor estava, assim, fortemente relacionado à BLR e, consequentemente, representava uma boa estimativa da PSF da observação, conforme explicado em 3.9. Dessa forma, utilizou-se esse tomograma como PSF para a deconvolução de Richardson-Lucy no cubo de dados. O procedimento foi aplicado utilizando-se 10 iterações. A figura 5.7 mostra a soma de todas as imagens e o espectro médio do cubo de dados final, obtido após a aplicação da deconvolução de Richardson-Lucy.
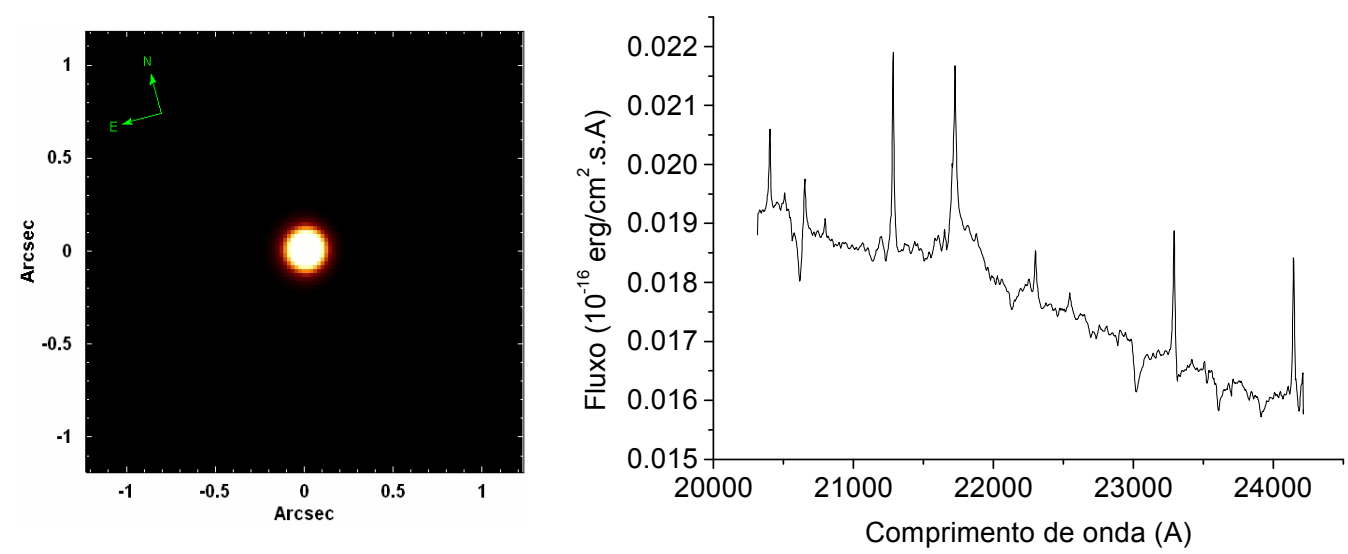

Figura 5.7 - (esquerda) Soma de todas as imagens do cubo de dados final de NGC 4151, obtido após todo o processamento; (direita) Espectro médio do cubo de dados final de NGC 4151, obtido após todo o processamento. 


\section{3 - Aplicação da Tomografia PCA ao cubo de dados de}

\section{NGC 4151 com o contínuo estelar}

Após todo o processamento descrito na seção 5.2, aplicou-se a Tomografia PCA ao cubo de dados de NGC 4151. Os principais auto-espectros e respectivos tomogramas obtidos encontram-se a seguir.
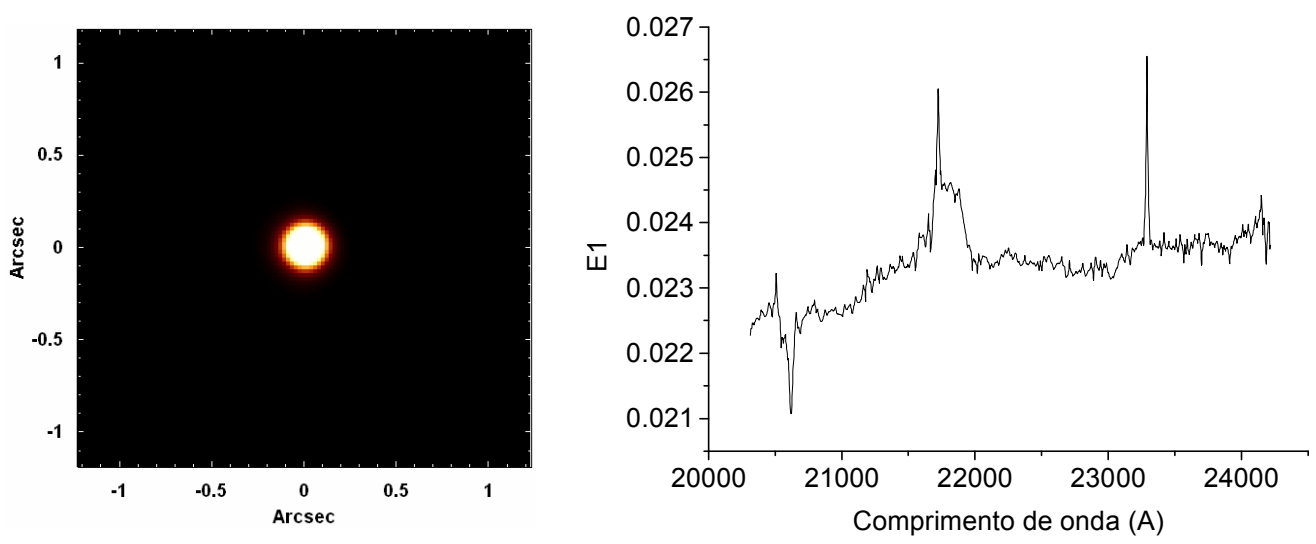

Figura 5.8 - Tomograma e auto-espectro correspondentes ao autovetor E1, obtido com a Tomografia PCA do cubo de dados de NGC 4151 com o contínuo estelar.
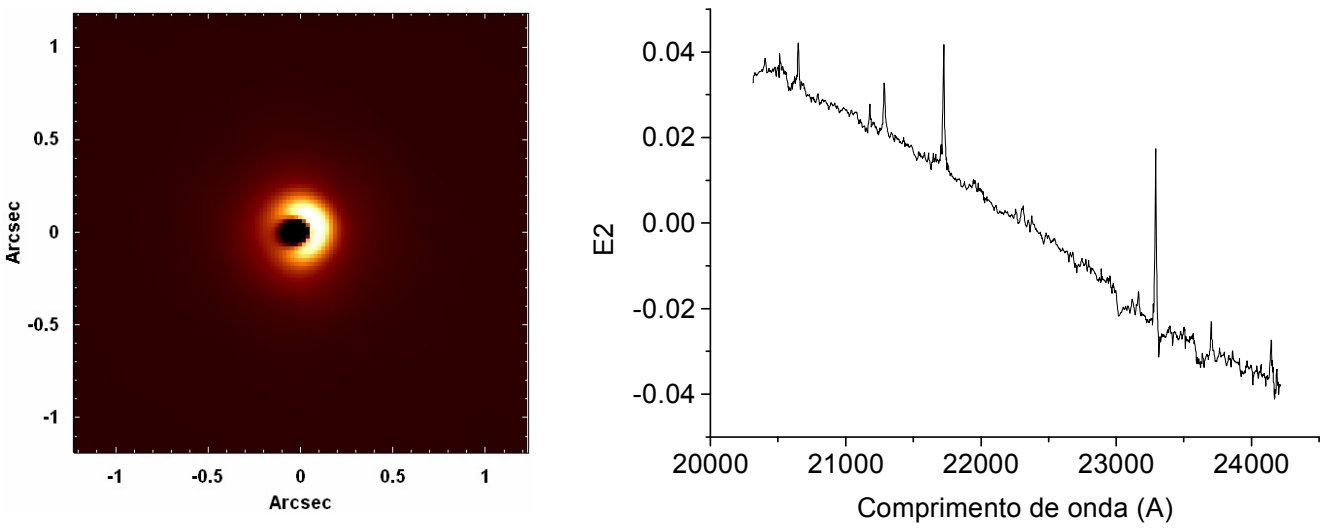

Figura 5.9 - Tomograma e auto-espectro correspondentes ao autovetor E2, obtido com a Tomografia PCA do cubo de dados de NGC 4151 com o contínuo estelar. 

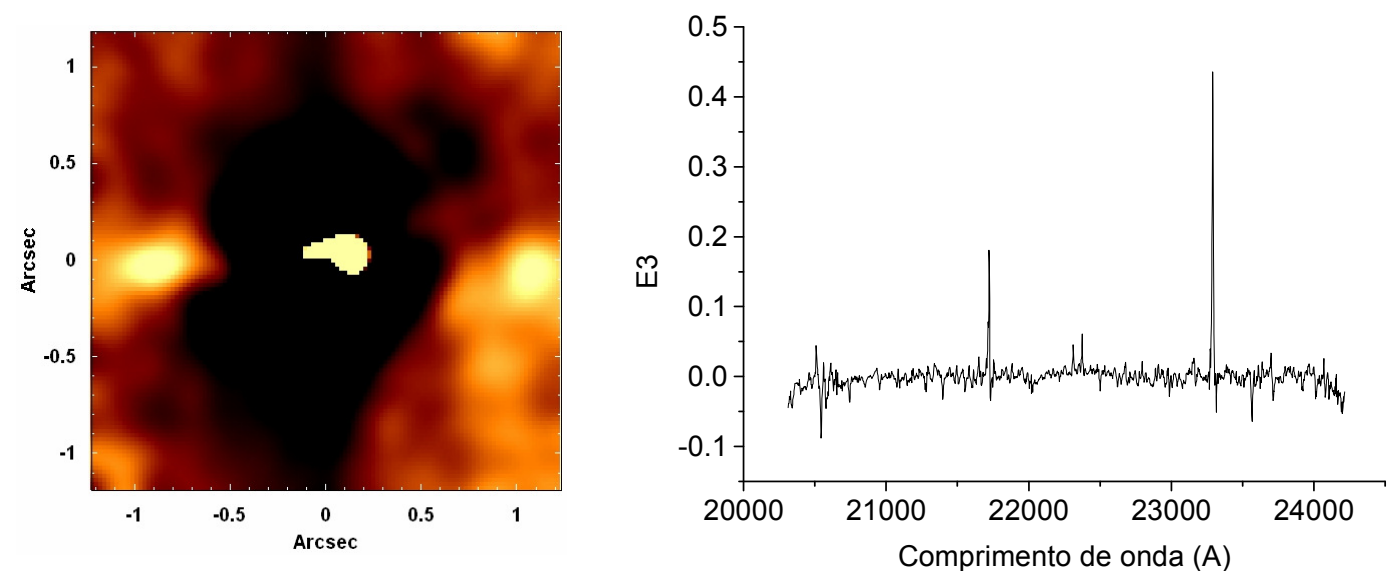

Figura 5.10 - Tomograma e auto-espectro correspondentes ao autovetor E3, obtido com a Tomografia PCA do cubo de dados de NGC 4151 com o contínuo estelar.
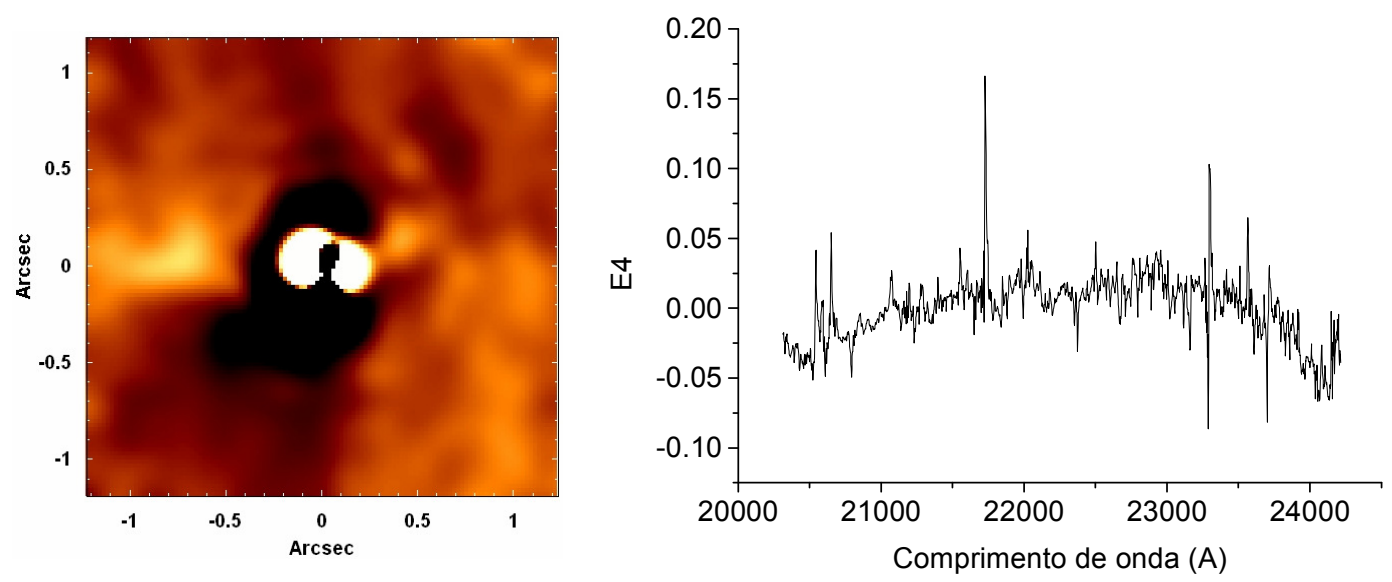

Figura 5.11 - Tomograma e auto-espectro correspondentes ao autovetor E4, obtido com a Tomografia PCA do cubo de dados de NGC 4151 com o contínuo estelar.
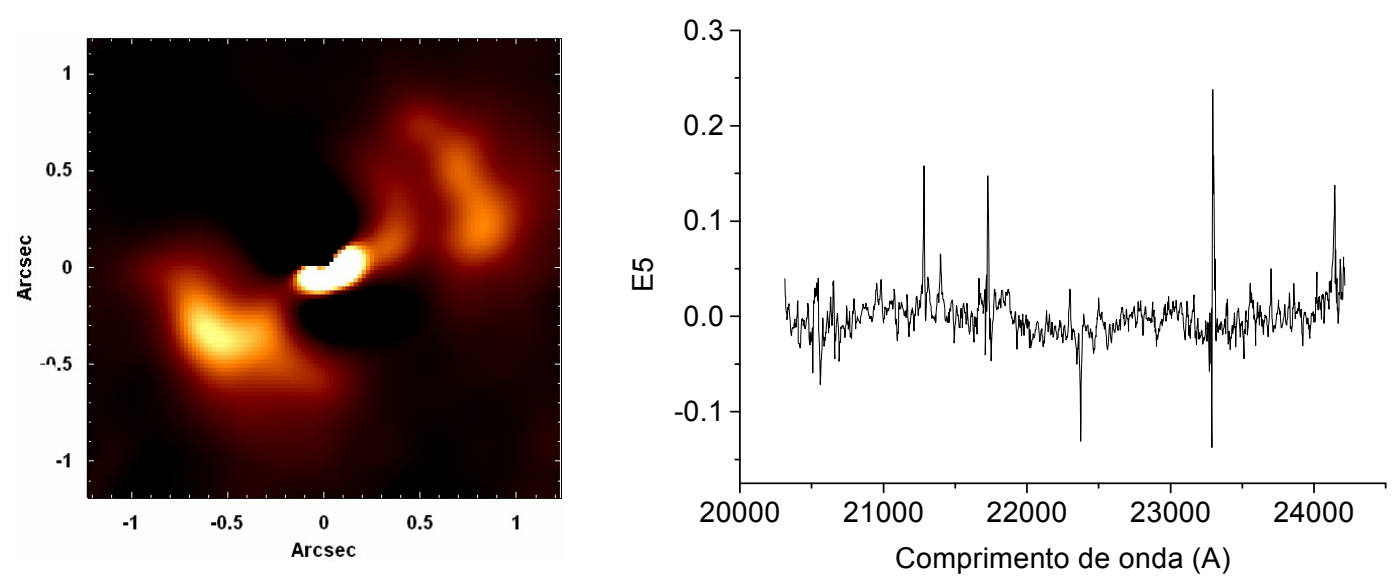

Figura 5.12 - Tomograma e auto-espectro correspondentes ao autovetor E5, obtido com a Tomografia PCA do cubo de dados de NGC 4151 com o contínuo estelar. 

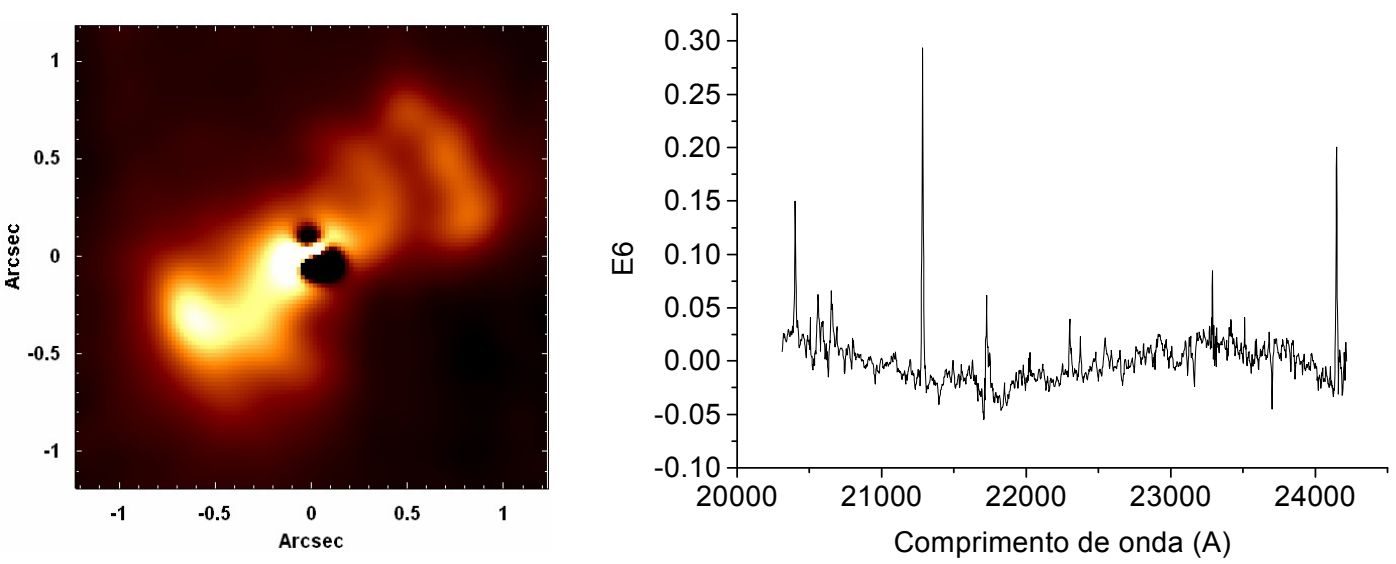

Figura 5.13 - Tomograma e auto-espectro correspondentes ao autovetor E6, obtido com a Tomografia PCA do cubo de dados de NGC 4151 com o contínuo estelar.
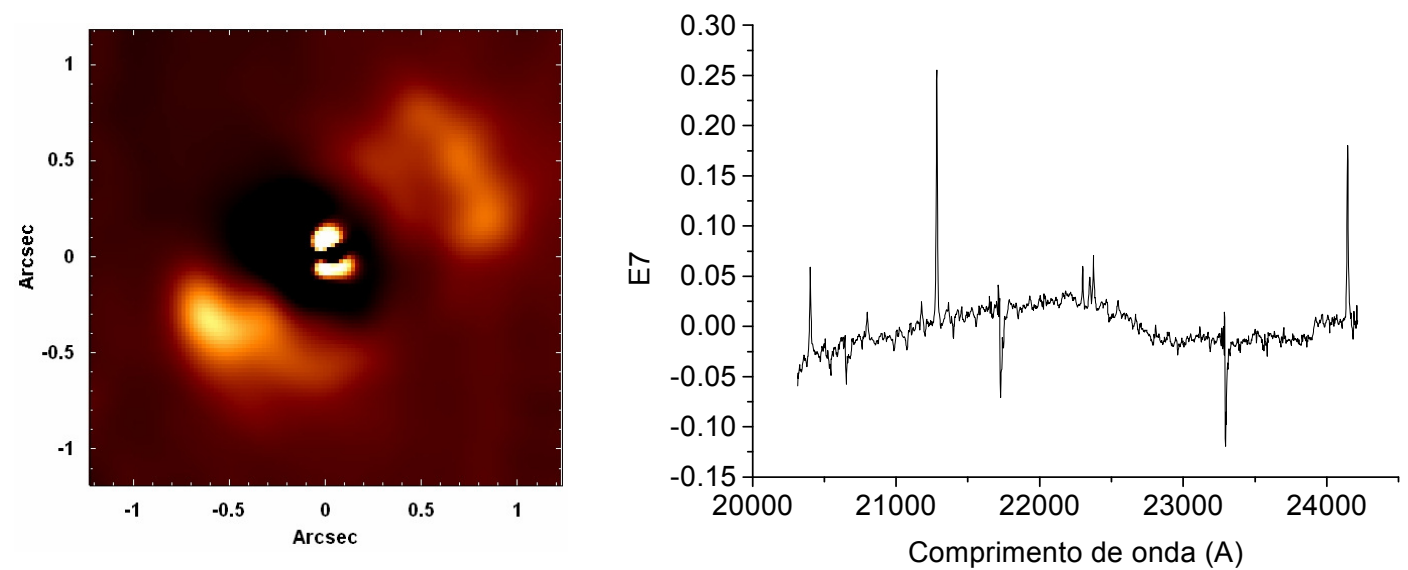

Figura 5.14 - Tomograma e auto-espectro correspondentes ao autovetor E7, obtido com a Tomografia PCA do cubo de dados de NGC 4151 com o contínuo estelar.
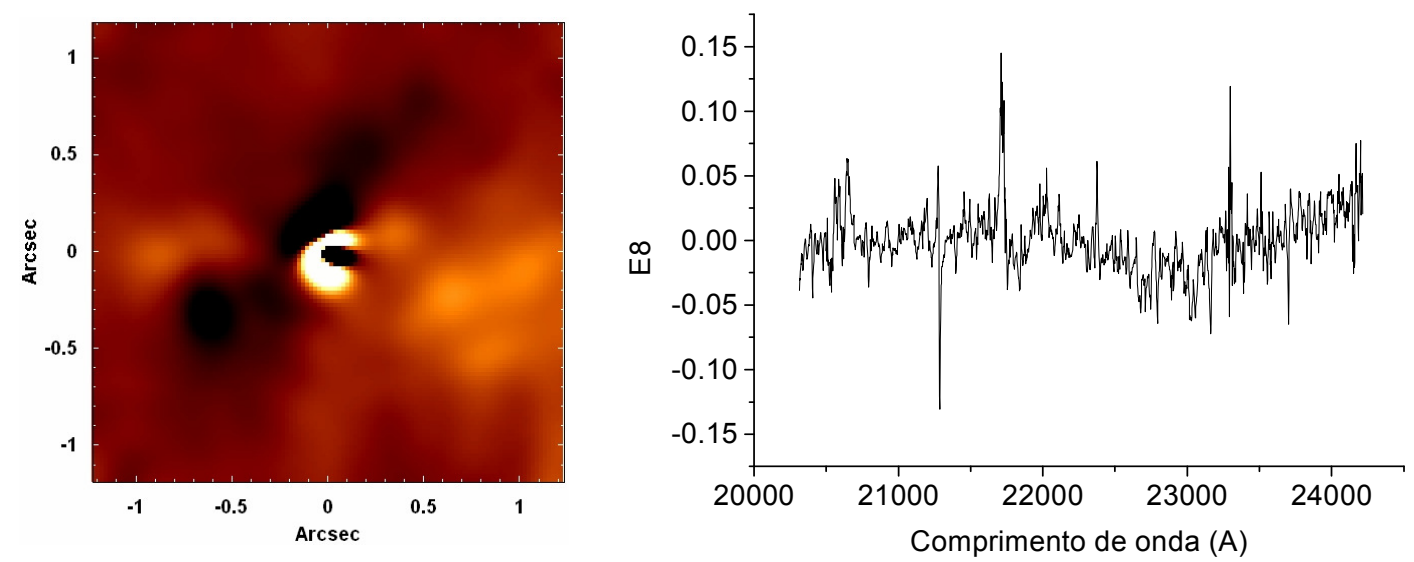

Figura 5.15 - Tomograma e auto-espectro correspondentes ao autovetor E8, obtido com a Tomografia PCA do cubo de dados de NGC 4151 com o contínuo estelar. 

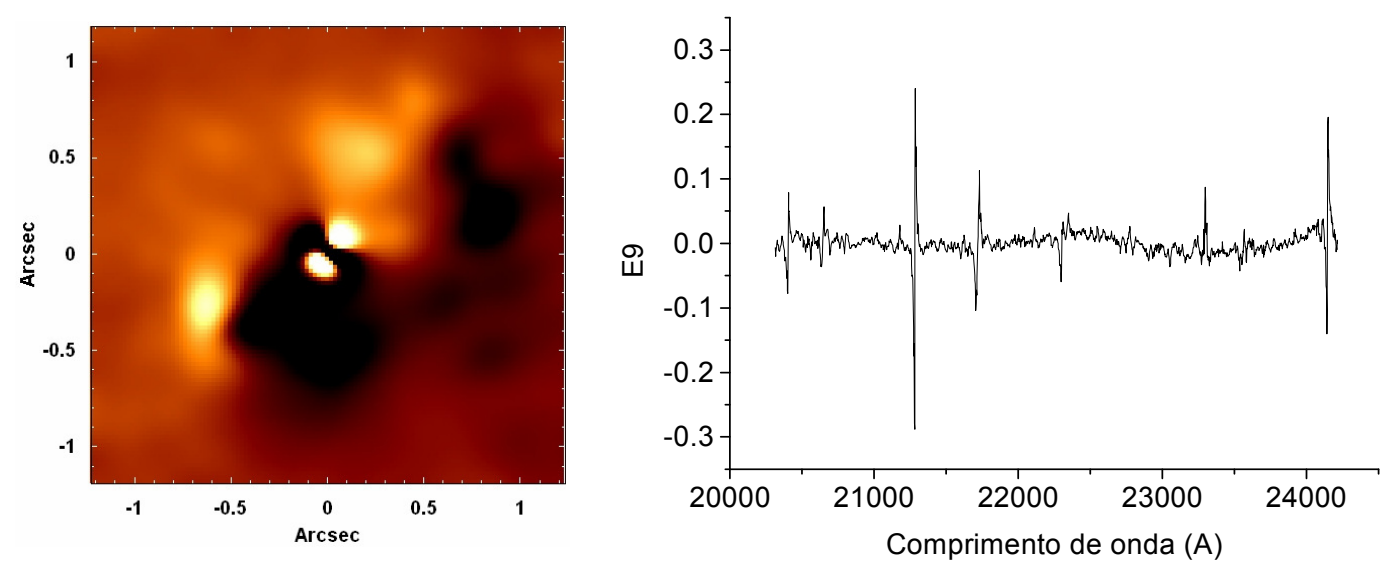

Figura 5.16 - Tomograma e auto-espectro correspondentes ao autovetor E9, obtido com a Tomografia PCA do cubo de dados de NGC 4151 com o contínuo estelar.
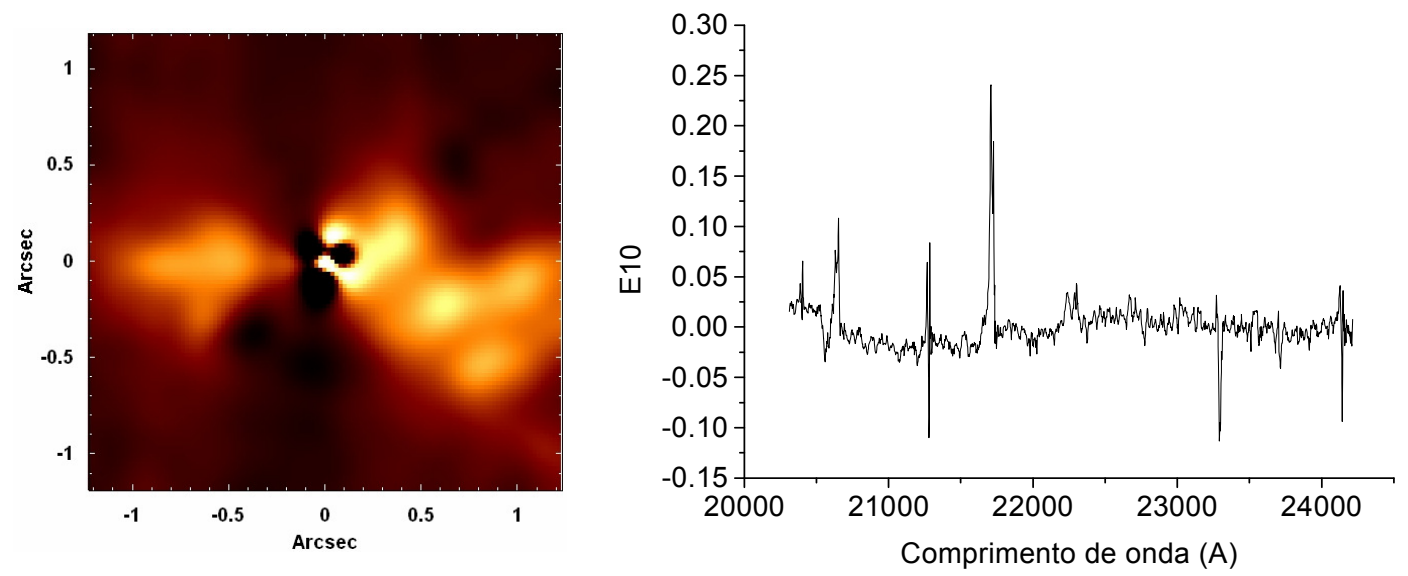

Figura 5.17 - Tomograma e auto-espectro correspondentes ao autovetor E10, obtido com a Tomografia PCA do cubo de dados de NGC 4151 com o contínuo estelar.

\begin{tabular}{|c|c|}
\hline Autovetor & Fração da variância explicada (\%) \\
\hline E1 & 99.91990 \\
\hline E2 & 0.07788 \\
\hline E3 & 0.00094 \\
\hline E4 & 0.00062 \\
\hline E5 & 0.00042 \\
\hline E6 & 0.00035 \\
\hline E7 & 0.00023 \\
\hline E8 & 0.00007 \\
\hline E9 & 0.00005 \\
\hline E10 & 0.00004 \\
\hline
\end{tabular}

Tabela 5.1 - Autovalores obtidos com a Tomografia PCA do cubo de dados de NGC 4151 com o contínuo estelar. 


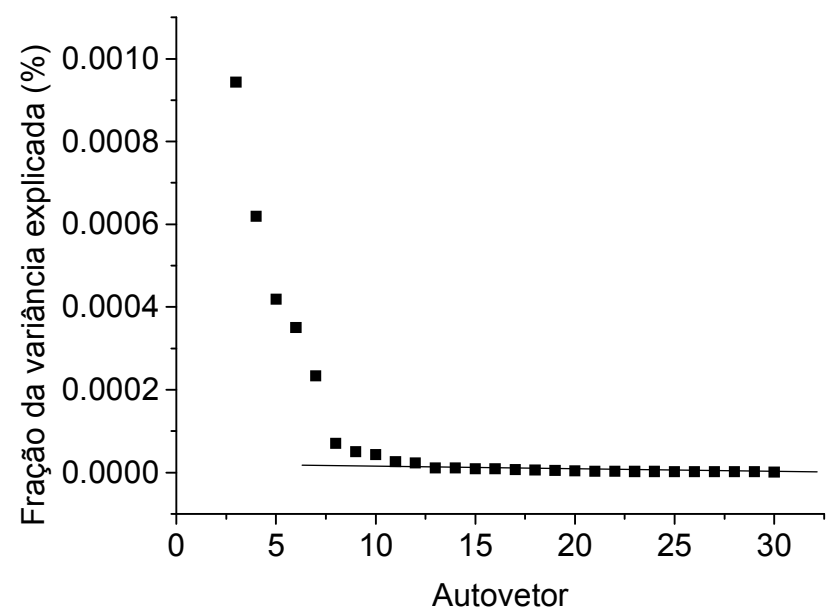

Figura 5.18 - "Scree test" dos autovetores obtidos com a Tomografia PCA do cubo de dados de NGC 4151 com o contínuo estelar.

A figura 5.8 mostra que o auto-espectro E1 apresenta correlações com os comprimentos de onda correspondentes às linhas de $\mathrm{Br} \gamma$ e de [Ca VIII]. Além disso, pode-se notar, ainda, que esse auto-espectro também possui correlações com comprimentos de onda associados a uma componente larga da linha de Bry. Todas essas características indicam que esse autovetor está correlacionado com a emissão proveniente do AGN existente nessa galáxia. Nesse caso, a localização desse AGN corresponderia à área mais clara (correlacionada com o auto-espectro) do tomograma mostrado. O fato do AGN dessa galáxia aparecer tão claramente em E1 está de acordo com o esperado, pois esse autovetor explica a maior parte da variância dos dados $(99.91910 \%)$ e é sabido que esse AGN é bastante intenso e, por isso mesmo, facilmente detectável.

Observando-se a figura 5.9, pode-se notar, primeiramente, que o auto-espectro E2 apresenta uma correlação com a região azul do espectro e uma anti-correlação com a região vermelha do mesmo. Isso, juntamente com a aparência apresentada pelo tomograma associado, parece indicar que esse autovetor estabelece um contraste entre a região mais próxima do núcleo da galáxia, com um contínuo mais vermelho, e as regiões ao redor, com um contínuo mais azul. Outro aspecto que pode ser notado nesse auto-espectro é a presença de estruturas compatíveis com as bandas de CO. Todas essas características sugerem que, nas regiões ao redor do núcleo (áreas claras do tomograma), a emissão parece ter uma considerável componente devida às populações estelares (o que é evidenciado pelo contínuo azul e pelas bandas de CO presentes) e, nas regiões próximas ao núcleo (área escura do tomograma), a emissão parece ser dominada pela poeira quente ao redor do $\mathrm{AGN}$ (o que é evidenciado pelo contínuo mais avermelhado dessa região). O auto-espectro E2 apresenta, ainda, correlações com os comprimentos de onda 
correspondentes às linhas de $\mathrm{Br} \gamma$ e de [Ca VIII], o que parece indicar que esse autovetor também está correlacionado com a emissão proveniente da NLR, que, nesse caso, está localizada entre as áreas claras do tomograma. Por fim, o auto-espectro E2 também possui correlações com os comprimentos de onda associados a várias linhas de $\mathrm{H}_{2}$ do espectro, o que sugere que parte das áreas claras do tomograma também podem representar regiões emissoras de $\mathrm{H}_{2}$. O autovetor E2 explica cerca de 0.07788 \% da variância dos dados.

Uma análise da figura 5.10 mostra que a principal característica do auto-espectro E3 é uma forte correlação com os comprimentos de onda correspondentes à linha de [Ca VIII]. Isso mostra que esse autovetor parece indicar a presença de áreas de mais alta ionização na região central de NGC 4151. Essas regiões correspondem às áreas mais claras do tomograma correspondente. O autovetor E3 explica cerca de 0.00094 \% da variância dos dados. A figura 5.19 mostra uma sobreposição da imagem da emissão em $21 \mathrm{~cm}$ da região central de NGC 4151, obtida a partir do trabalho de Mundell et al. (2003), ao tomograma da figura 5.10.

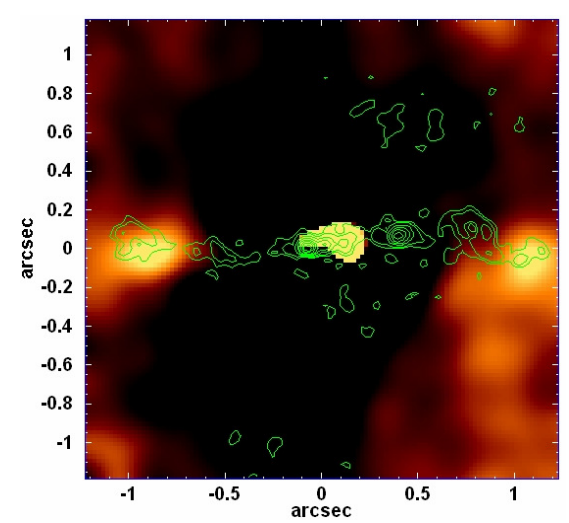

Figura 5.19 - Sobreposição da imagem da emissão em $21 \mathrm{~cm}$ da região central de NGC 4151 (contornos verdes), obtida a partir do trabalho de Mundell et al. (2003), ao tomograma da figura 5.10.

Analisando-se a figura 5.19, nota-se uma aparente associação entre as áreas com alta ionização e algumas regiões com emissão em $21 \mathrm{~cm}$. Uma possível explicação para isso seria a ocorrência de alguma ejeção ao longo da direção correspondente à emissão em rádio, que provocou uma forte ionização do meio, dando origem às regiões emissoras de [Ca VIII] visíveis na figura 5.19. Tais regiões continuaram se afastando do AGN central, entretanto, a correlação dessas áreas com a emissão em $21 \mathrm{~cm}$ ainda é visível. Outro fato interessante que pode ser observado na figura 5.19 é que o ângulo da direção ao longo da qual ocorre a emissão em $21 \mathrm{~cm}$ muda ligeiramente em regiões mais próximas do $\mathrm{AGN}$ do que as áreas emissoras de H I. Isso pode 
indicar que a ocorrência do evento que provocou a ionização do meio, também pode ter gerado alguma alteração na direção correspondente à emissão de H I.

A figura 5.11 revela que o auto-espectro E4 apresenta, primeiramente, uma correlação com os comprimentos de onda correspondentes à linha de Br $\gamma$, o que sugere que esse autovetor está correlacionado com a emissão da NLR desse objeto. Essa emissão seria proveniente das áreas mais claras do tomograma associado. Por outro lado, o auto-espectro E4 também possui uma notável anti-correlação com a região vermelha do espectro. Isso significa que as áreas escuras do tomograma correspondente parecem apresentar um excesso de emissão na região mais vermelha do espectro, o que poderia ser devido à emissão térmica de poeira. $\mathrm{O}$ autovetor E4 explica cerca de $0.00062 \%$ da variância dos dados.

Observando-se as figuras 5.12, 5.13 e 5.14, pode-se notar que os auto-espectros E5, E6 e E7 apresentam fortes correlações com os comprimentos de onda correspondentes a várias linhas de emissão de $\mathrm{H}_{2}$, o que indica que esses autovetores estão relacionados a regiões de emissão molecular de $\mathrm{H}_{2}$ em NGC 4151. Essas regiões correspondem às áreas mais claras dos tomogramas associados. Além disso, as figuras 5.12 e 5.13 mostram que os auto-espectros E5 e E6 apresentam correlações com os comprimentos de onda correspondentes à linha de Bry, o que sugere que esses autovetores também parecem estar associados à NLR do AGN desse objeto. Os auto-espectros E5 e E6 possuem, ainda, correlações com os comprimentos de onda correspondentes à linha de [Ca VIII], ou seja, eles também parecem estar relacionados a áreas de mais alta ionização. Tanto as regiões da NLR quanto as de mais alta ionização estariam entre as áreas claras dos tomogramas associados a E5 e E6. A figura 5.14 mostra que, ao contrário de E5 e E6, o auto-espectro E7 apresenta anti-correlações com os comprimentos de onda correspondentes às linhas de Bry e de [Ca VIII]. Dessa forma, as regiões da NLR e de alta ionização devem corresponder às áreas escuras do tomograma associado a E7. Os autovetores E5, E6 e E7 explicam, respectivamente, cerca de $0.00042 \%, 0.00035 \%$ e $0.00023 \%$ da variância dos dados.

As figuras 5.15 e 5.17 mostram que as principais características dos auto-espectros E8 e E10 são consideráveis correlações com os comprimentos de onda correspondentes à linha de Bry, o que indica que esses dois autovetores parecem estar correlacionados à emissão proveniente da NLR do AGN de NGC 4151. Nesse caso, as nuvens da NLR correspondem às áreas claras dos tomogramas associados a esses dois auto-espectros e pode-se notar, a partir 
dessas imagens, que a NLR apresenta um aspecto similar a um bi-cone, o que está de acordo com o esperado para esse objeto. Comparando-se a morfologia da NLR, mostrada nos tomogramas dos autovetores E8 e E10, com a morfologia das regiões emissoras de $\mathrm{H}_{2}$, mostrada nos tomogramas dos autovetores E5, E6 e E7, pode-se concluir que o bi-cone associado à NLR é aproximadamente perpendicular às regiões emissoras de $\mathrm{H}_{2}$. Os autovetores E8 e E10 explicam, respectivamente, cerca de $0.00007 \%$ e $0.00004 \%$ da variância dos dados.

Finalmente, a figura 5.16 revela que o auto-espectro E9 apresenta correlações com os comprimentos de onda correspondentes às asas vermelhas das principais linhas de emissão e anti-correlações com os comprimentos de onda associados às asas azuis das mesmas. Isso parece indicar algum tipo de fenômeno cinemático e, considerando-se a aparência apresentada pelo tomograma, pode-se concluir que esse autovetor, provavelmente, está revelando a existência de rotação do gás na região central de NGC 4151. Nesse caso, as áreas claras do tomograma correspondem a regiões que apresentam redshift em sua emissão e as áreas escuras estão associadas a regiões com blueshift em sua emissão. O autovetor E9 explica cerca de $0.00005 \%$ da variância dos dados.

O Scree test na figura 5.18 mostra que os valores das variâncias explicadas pelos autovetores decaem bastante até atingir, aproximadamente, o autovetor E11. A partir disso, o decaimento diminui bastante e os valores ficam praticamente constantes, o que mostra que os autovetores de ordem maior do que E10 representam, sobretudo, ruído e, consequentemente, não possuem relevância nessa análise.

Por tudo o que foi dito até aqui, pode-se concluir que essa análise inicial com a Tomografia PCA revelou a presença de uma série de fenômenos na região central de NGC 4151. Primeiramente, esse método isolou consideravelmente bem a emissão proveniente do AGN. Além disso, também foi mostrado que a região mais próxima ao AGN apresenta espectros com um contínuo bem mais avermelhado do que as áreas ao redor, o que, provavelmente, deve ser uma conseqüência da emissão térmica de poeira próxima ao AGN. Tal poeira poderia estar associada a um toro existente nessa região. A Tomografia PCA também conseguiu diferenciar bem as regiões emissoras da NLR (que tomam a forma de um bi-cone) das áreas emissoras de $\mathrm{H}_{2}$, que se distribuem ao longo de uma região aproximadamente perpendicular à NLR. Uma possível explicação para a disposição espacial dessas regiões emissoras é que as moléculas de $\mathrm{H}_{2}$ sejam destruídas na área do cone de ionização, resultando em uma emissão de $\mathrm{H}_{2}$ 
aproximadamente perpendicular ao bi-cone. Foram detectadas regiões com alta ionização razoavelmente afastadas do AGN central, que parecem estar associadas à emissão de H I em 21 $\mathrm{cm}$. Isso parece indicar a ocorrência de alguma ejeção ao longo da direção correspondente à emissão em $21 \mathrm{~cm}$, que teria provocado a ionização do meio. Por fim, essa análise também revelou a presença de um aparente movimento rotacional de $\mathrm{H}_{2}$ em uma região circular mais afastada do AGN central.

\section{4 - Síntese espectral do cubo de dados de NGC 4151 com o}

\section{Starlight}

Depois da análise inicial com a Tomografia PCA, foi feita uma síntese espectral no cubo de dados de NGC 4151 com o software Starlight. Para isso, primeiramente, foi aplicada toda a preparação descrita em 3.12, sendo que a correção da extinção devido à Via Láctea foi feita tomando-se $A_{V}=0.092$ e a passagem dos espectros para o referencial de repouso foi aplicada considerando-se $z=0.003319$. Tanto $A_{V}$ quanto $\mathrm{z}$ foram obtidos a partir do site do NED. Em 3.8 foi mencionado que a aplicação do processo do de-noising aos espectros do cubo de dados pode gerar certas alterações indesejáveis. Embora no caso de NGC 4151 tais alterações tenham sido mínimas, optou-se por fazer a síntese espectral do Starlight em um cubo de dados no qual não havia sido aplicado esse processo.

Como o cubo de dados de NGC 4151 foi obtido na região espectral do infravermelho próximo e há um intenso AGN nessa galáxia, foi preciso levar em conta a emissão térmica de poeira e um featureless continuum na síntese espectral, conforme foi explicado em 3.12. Assim como no caso de NGC 2992, devido às limitações da base utilizada, apenas os mapeamentos mais confiáveis obtidos com a síntese espectral do cubo de dados de NGC 4151 são mostrados nas sessões a seguir.

\subsection{1 - Qualidade dos ajustes}

O mapeamento dos valores do $\chi^{2} / n_{\text {eff }}$ dos ajustes obtidos com a síntese espectral do cubo de dados de NGC 4151 encontra-se a seguir. 


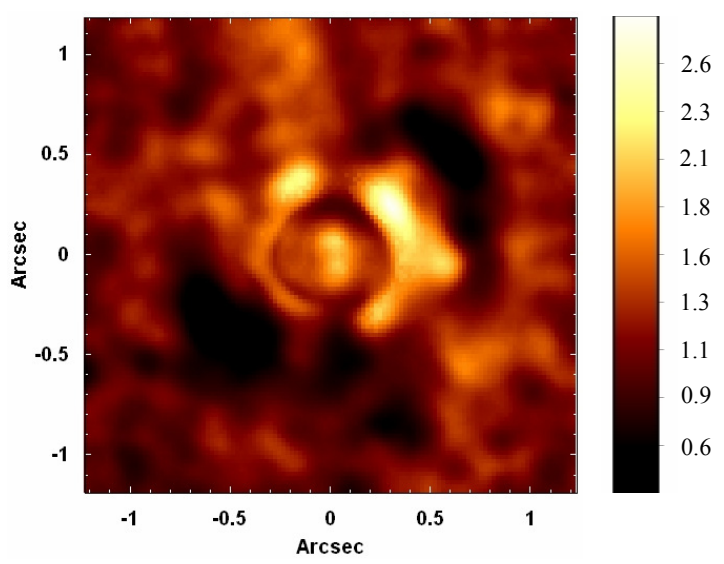

Figura 5.20: Mapeamento dos valores do $\chi^{2} / n_{\text {eff }}$ dos ajustes obtidos pelo "Starlight" para os espectros do cubo de dados de NGC 4151.

Observando-se a figura 5.20, pode-se notar que os melhores ajustes obtidos com o Starlight apresentaram $\chi^{2} / n_{\text {eff }}$ de cerca de 0.4 , ao passo que os piores tiveram $\chi^{2} / n_{\text {eff }}$ de cerca de 2.8, o que ainda pode ser tomado como um indicativo de ajustes com boa qualidade. Dessa forma, pode-se concluir que mesmo os piores ajustes obtidos com o Starlight forneceram resultados que podem ser considerados confiáveis.

\subsection{2 - Populações estelares, poeira e featureless continuum}

Assim como foi discutido no caso de NGC 2992, a partir dos resultados obtidos com a síntese espectral com o Starlight do cubo de dados de NGC 4151, pôde-se construir apenas três mapeamentos de fluxo suficientemente confiáveis para serem mostrados aqui: o mapeamento do fluxo total devido às populações estelares, o mapeamento do fluxo total devido à emissão térmica de poeira e o mapeamento do fluxo devido ao featureless continuum. O procedimento utilizado para se obter esses mapeamentos foi exatamente o mesmo que o usado no caso de NGC 2992. 
278

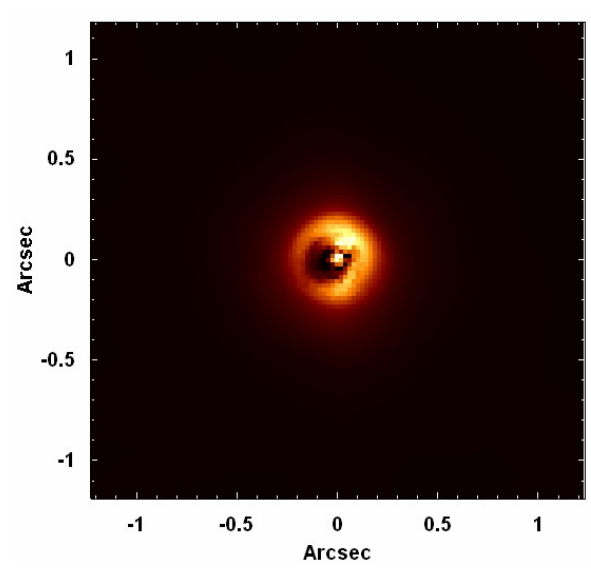

Figura 5.21: Mapeamento do fluxo total devido às populações estelares, obtido com a aplicação do "Starlight" ao cubo de dados de NGC 4151.

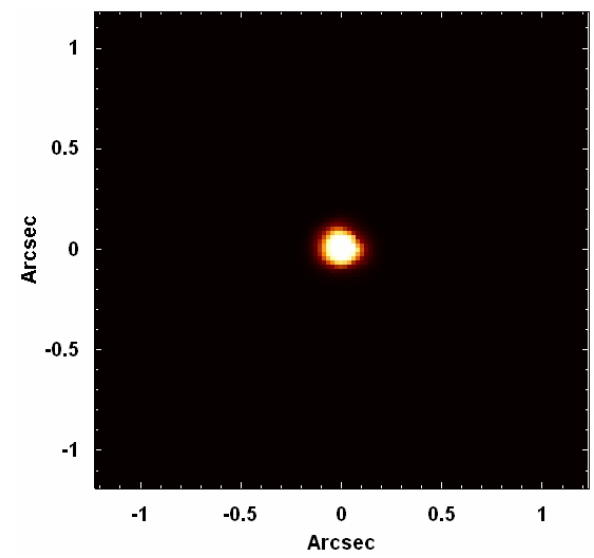

Figura 5.22: Mapeamento do fluxo total devido à emissão térmica de poeira, obtido com a aplicação do "Starlight" ao cubo de dados de NGC 4151.

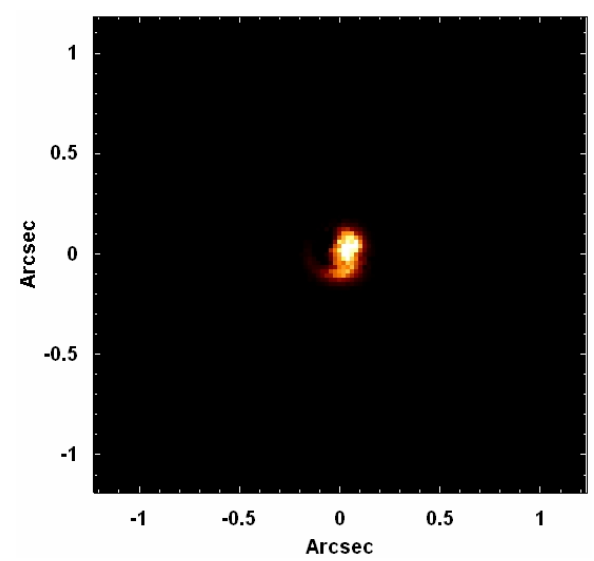

Figura 5.23: Mapeamento do fluxo atribuido ao "featureless continuum" do AGN, obtido com a aplicação do "Starlight" ao cubo de dados de NGC 4151. 
Em seguida, construiu-se um gráfico em colunas contendo as frações de fluxo devidas às populações estelares, à emissão térmica de poeira e ao featureless continumm do AGN, considerando-se todo o campo visual do NIFS. O gráfico obtido encontra-se a seguir.

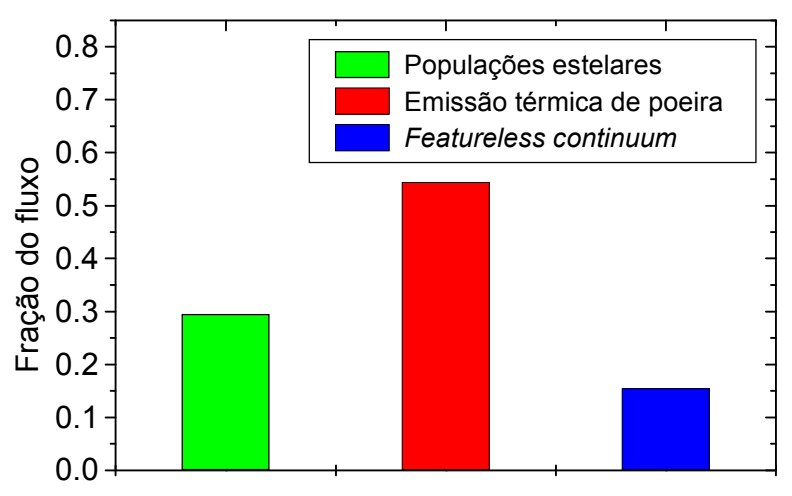

Figura 5.24: Gráfico representativo das frações de fluxo devidas às populações estelares, à emissão térmica de poeira e ao "featureless continuum", considerando-se todo o campo visual do NIFS, obtido com a aplicação do "Starlight" ao cubo de dados de NGC 4151.

As figuras 5.21 e 5.22 revelam que a emissão térmica de poeira está concentrada na região correspondente ao $\mathrm{AGN}$, onde foi detectada pouca luz proveniente de populações estelares. Isso está de acordo com os resultados obtidos anteriormente com a aplicação da Tomografia PCA ao cubo de dados de NGC 4151. Esse resultado também é compatível com o que foi obtido por Riffel et al. (2009), que analisaram esse mesmo cubo de dados. É possível que a emissão térmica de poeira detectada esteja associada a um toro de poeira ao redor do AGN, o que estaria de acordo com o previsto pelo Modelo Unificado. Nas regiões mais afastadas do AGN, o fluxo parece ser essencialmente devido a populações estelares. A ausência de fluxo proveniente de populações estelares nas regiões próximas ao AGN não significa que tais populações não estejam presentes nessa área, mas sim que elas, possivelmente, não foram observadas devido ao fato de a emissão nas regiões bem próximas à posição ocupada pelo AGN ser totalmente dominada pela poeira, o que tornou difícil a detecção de qualquer emissão proveniente de populações estelares. A figura 5.23, por sua vez, mostra que foi detectado algum fluxo atribuído ao featureless continuum na área correspondente ao AGN central, o que está de acordo com o esperado. Para se ter uma melhor visualização geral da morfologia das regiões com espectros dominados pela emissão associada às populações estelares, à poeira e ao featureless continuum, construiu-se uma imagem RGB, que é mostrada na figura 5.25. 


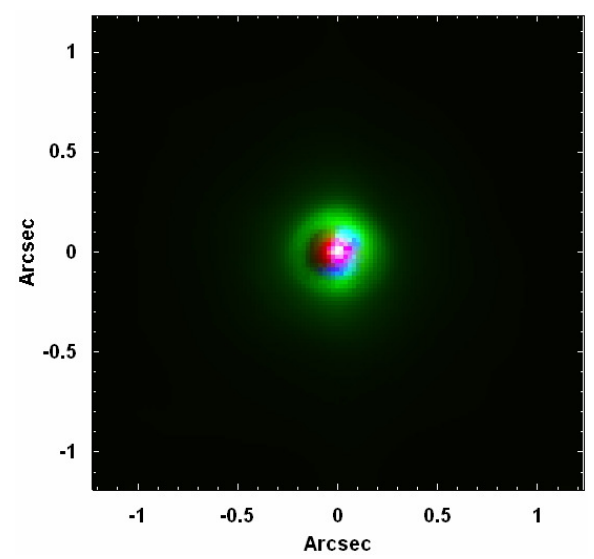

Figura 5.25 - Composição RGB contendo os mapeamentos do fluxo associado às populações estelares (verde), à emissão térmica de poeira (vermelho) e ao "featureless continuum" (azul), obtidos a partir da sintese espectral do cubo de dados de NGC 4151.

Observando-se o gráfico da figura 5.24, pode-se notar que o fluxo devido à emissão térmica de poeira (cerca de $54.4 \%$ do total) é dominante no campo visual do NIFS, o que está de acordo com o esperado, já que o intenso AGN dessa galáxia pode aquecer uma quantidade considerável de poeira ao redor, resultando na emissão térmica detectada. A fração de fluxo devida às populações estelares (cerca de 29.5 \%) também é bastante significativa. Por fim, podese dizer que, embora a fração de fluxo associada ao featureless continuum do AGN (cerca de $15.5 \%)$ ser menor do que as das outras componentes mostradas no gráfico, ela ainda pode ser considerada relevante, o que, sem dúvida, é uma conseqüência do fato desse AGN ser bastante intenso.

\subsection{3 - Valores da razão $S / N$ dos espectros analisados}

O mapeamento dos valores da razão $S / N$ obtidos pelo Starlight no intervalo espectral de $22320 \AA$ até $22609 \AA \AA$ encontra-se a seguir.

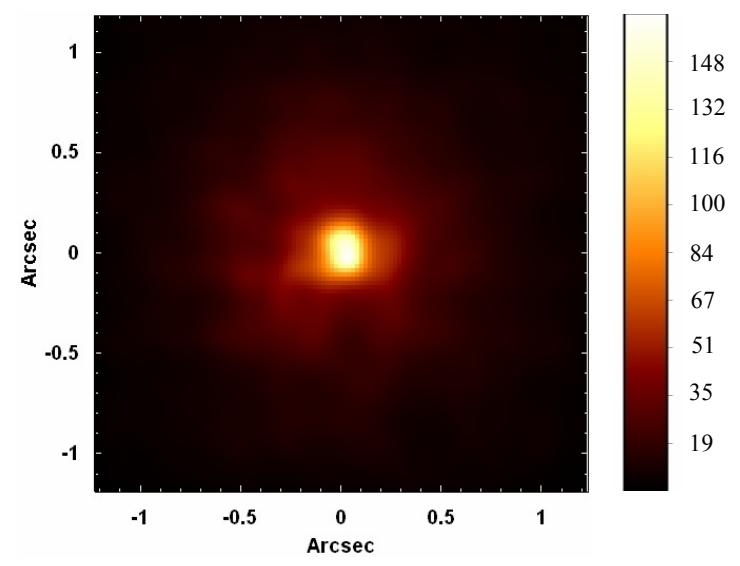

Figura 5.26 - Mapeamentos dos valores da razão $S / N$, obtidos a partir da sintese espectral do cubo de dados de NGC 4151 com o "Starlight". 
A figura 5.26 mostra que os valores mais altos (cerca de 164) para a razão $S / N$ foram obtidos nas regiões mais centrais do campo visual do NIFS, ao passo que os menores valores (cerca de 2.7) foram encontrados nas áreas mais afastadas do centro. Isso está de acordo com o esperado, entretanto, embora a razão $S / N$ seja maior na região correspondente ao AGN central, o Starlight praticamente não conseguiu detectar populações estelares nessa área, devido à forte emissão térmica de poeira, conforme foi mencionado anteriormente.

\section{5 - Aplicação da Tomografia PCA ao cubo de dados de NGC 4151 com o contínuo estelar subtraído}

Utilizando-se os espectros estelares sintéticos obtidos com a síntese espectral com o Starlight, fez-se uma subtração do contínuo estelar de todos os espectros de NGC 4151, obtendo-se, ao final, um cubo de dados contendo, apenas, linhas de emissão. Aplicou-se, então, a Tomografia PCA a esse cubo de dados resultante, a fim de se obter uma análise mais detalhada dos espectros de linhas de emissão dessa galáxia. Os principais auto-espectros e respectivos tomogramas obtidos encontram-se a seguir. Vale lembrar que, como o cubo de dados no qual foi aplicada a síntese espectral com o Starlight não possuía de-noising, o cubo obtido após a subtração do contínuo estelar apresentou valores de $S / N$ inferiores àqueles observados no cubo ao qual se aplicou a Tomografia PCA mostrada na seção 5.3.
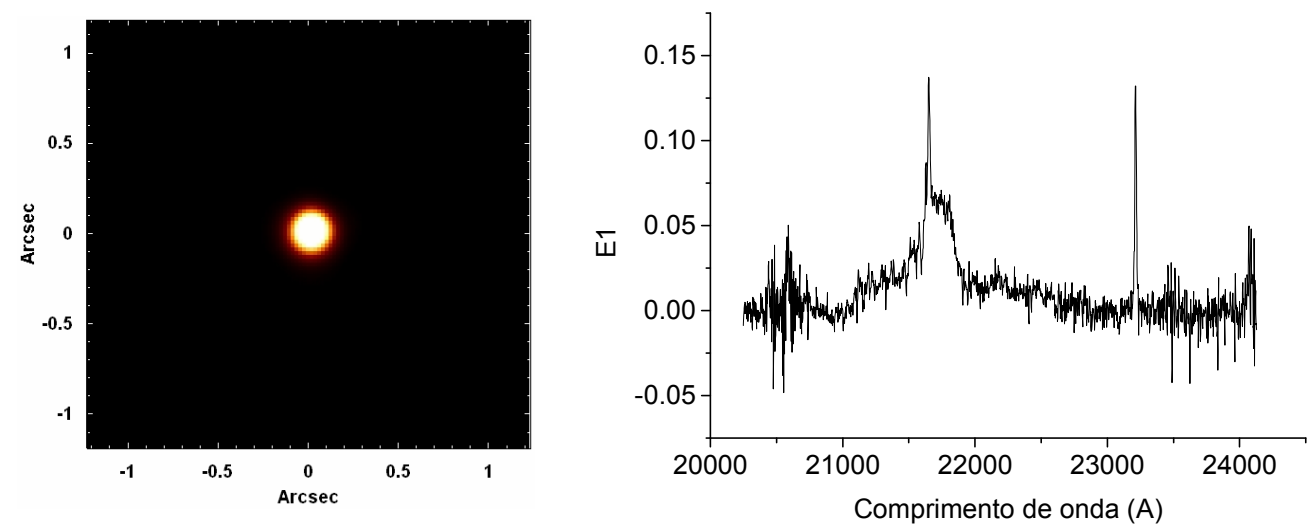

Figura 5.27 - Tomograma e auto-espectro correspondentes ao autovetor E1, obtido com a Tomografia PCA do cubo de dados de NGC 4151 com o contínuo estelar subtraído. 

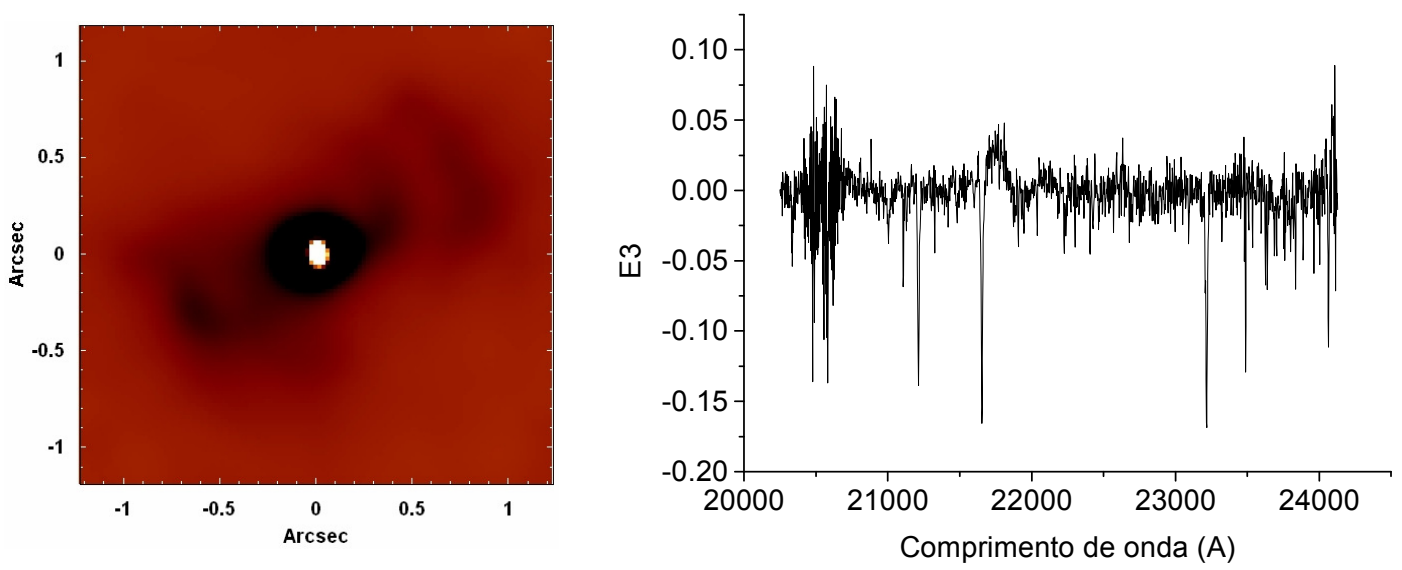

Figura 5.28 - Tomograma e auto-espectro correspondentes ao autovetor E3, obtido com a Tomografia PCA do cubo de dados de NGC 4151 com o contínuo estelar subtraído.
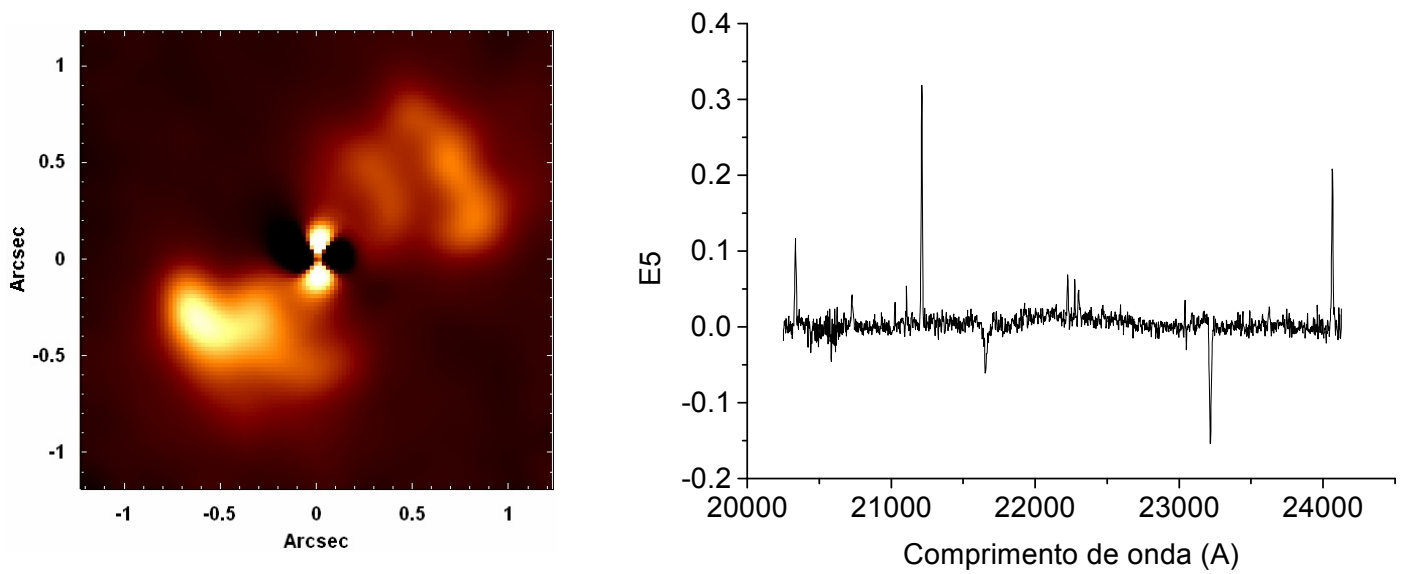

Figura 5.29 - Tomograma e auto-espectro correspondentes ao autovetor E5, obtido com a Tomografia PCA do cubo de dados de NGC 4151 com o contínuo estelar subtraído.
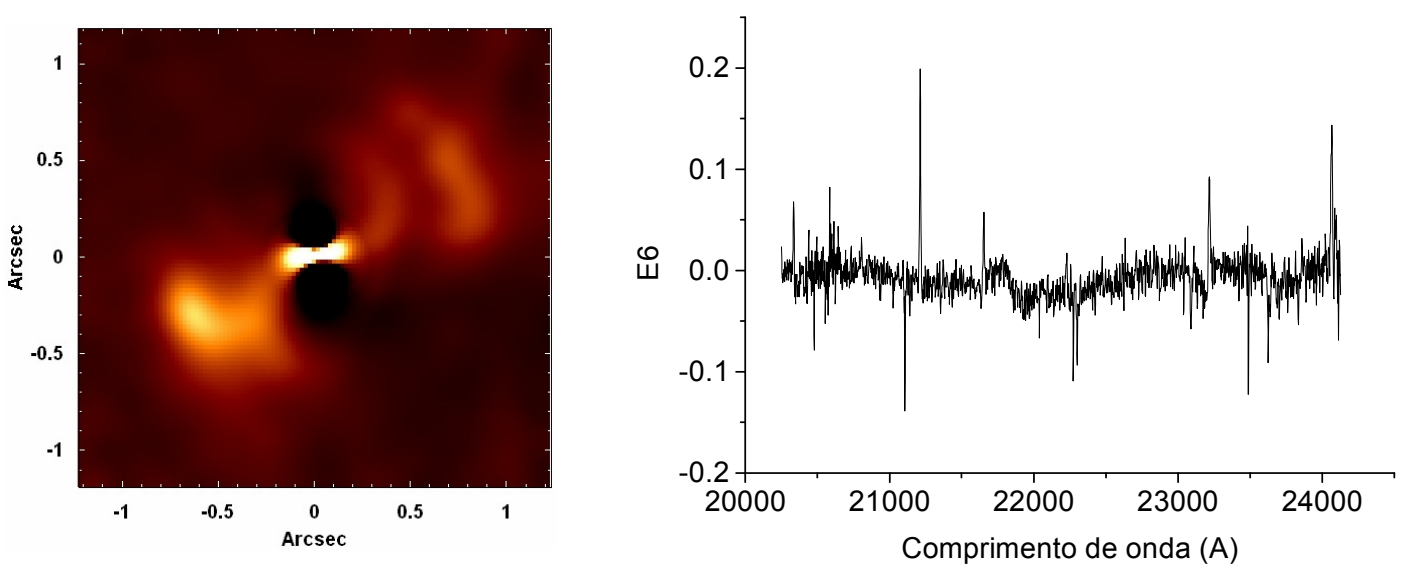

Figura 5.30 - Tomograma e auto-espectro correspondentes ao autovetor E6, obtido com a Tomografia PCA do cubo de dados de NGC 4151 com o contínuo estelar subtraído. 

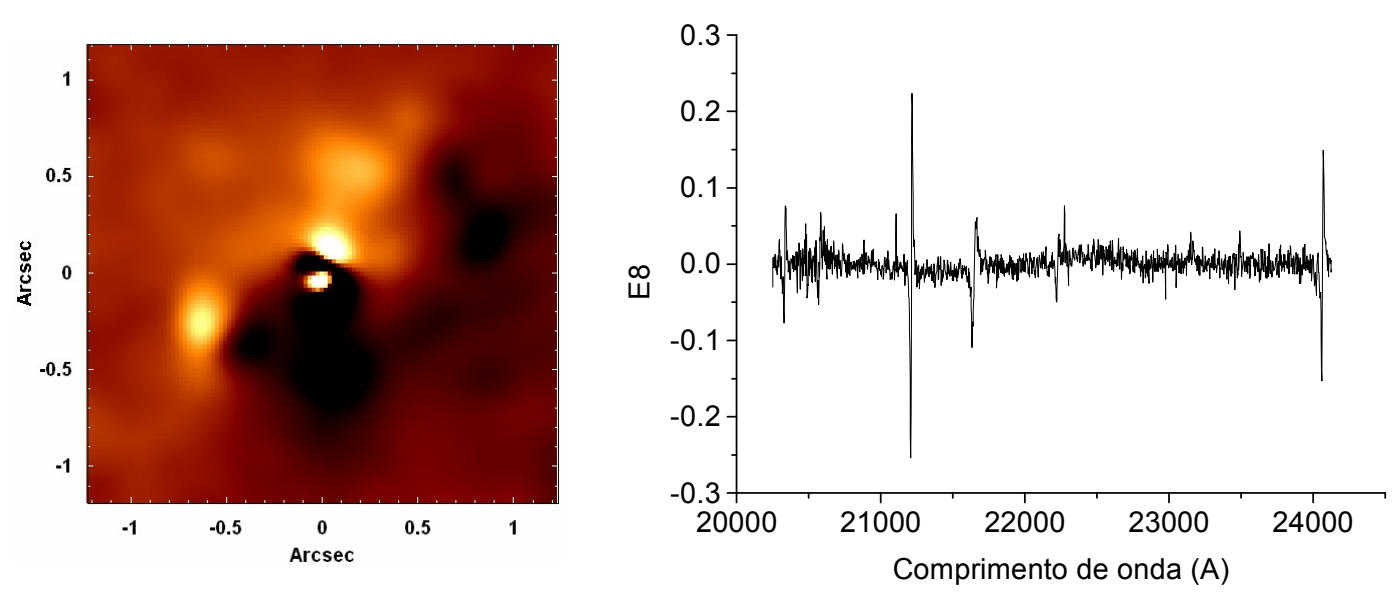

Figura 5.31 - Tomograma e auto-espectro correspondentes ao autovetor E8, obtido com a Tomografia PCA do cubo de dados de NGC 4151 com o contínuo estelar subtraído.
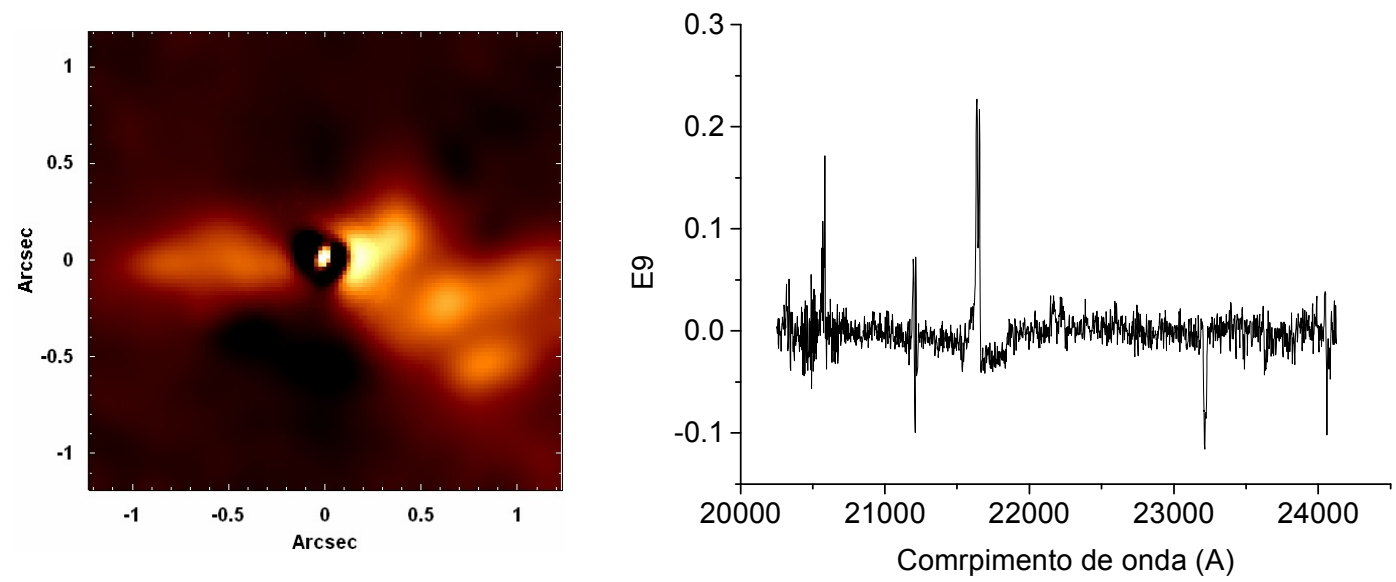

Figura 5.32 - Tomograma e auto-espectro correspondentes ao autovetor E9, obtido com a Tomografia PCA do cubo de dados de NGC 4151 com o contínuo estelar subtraído.
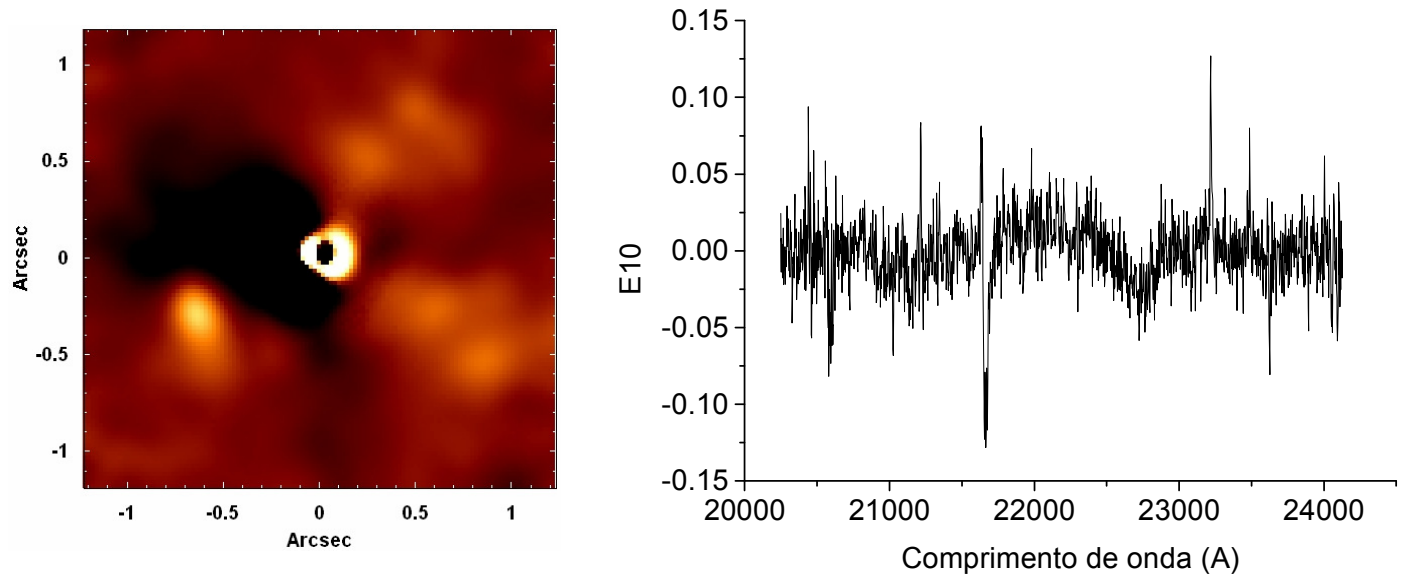

Figura 5.33 - Tomograma e auto-espectro correspondentes ao autovetor E10, obtido com a Tomografia PCA do cubo de dados de NGC 4151 com o contínuo estelar subtraído. 

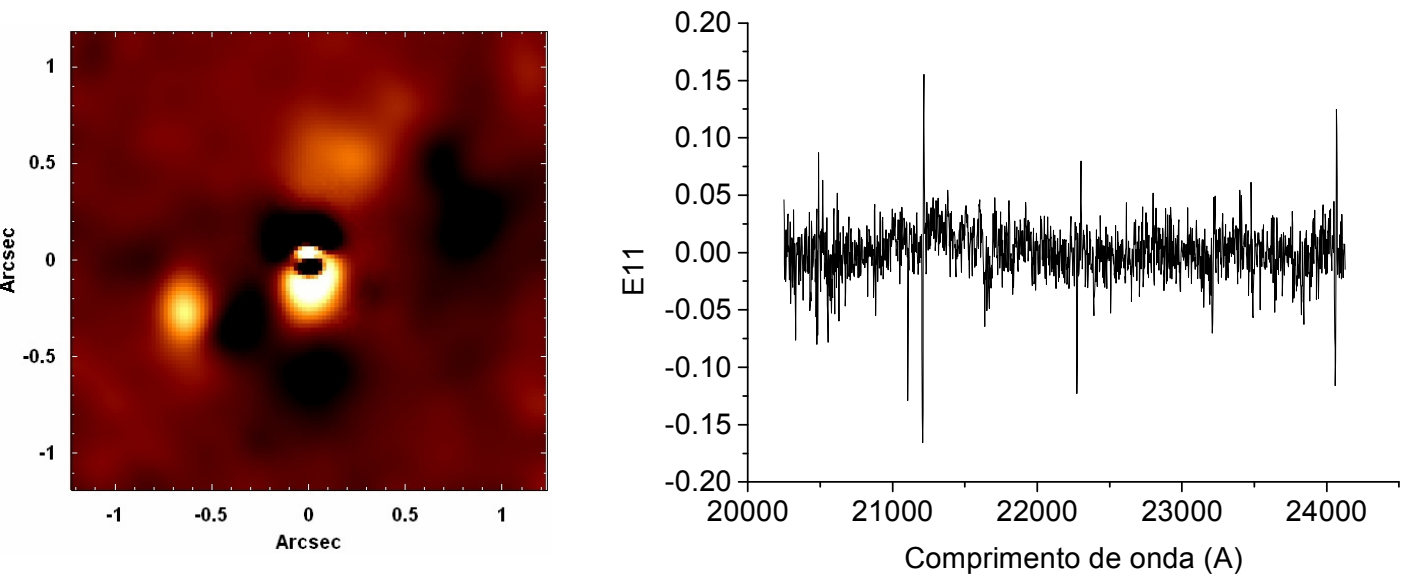

Figura 5.34 - Tomograma e auto-espectro correspondentes ao autovetor E11, obtido com a Tomografia PCA do cubo de dados de NGC 4151 com o contínuo estelar subtraído.
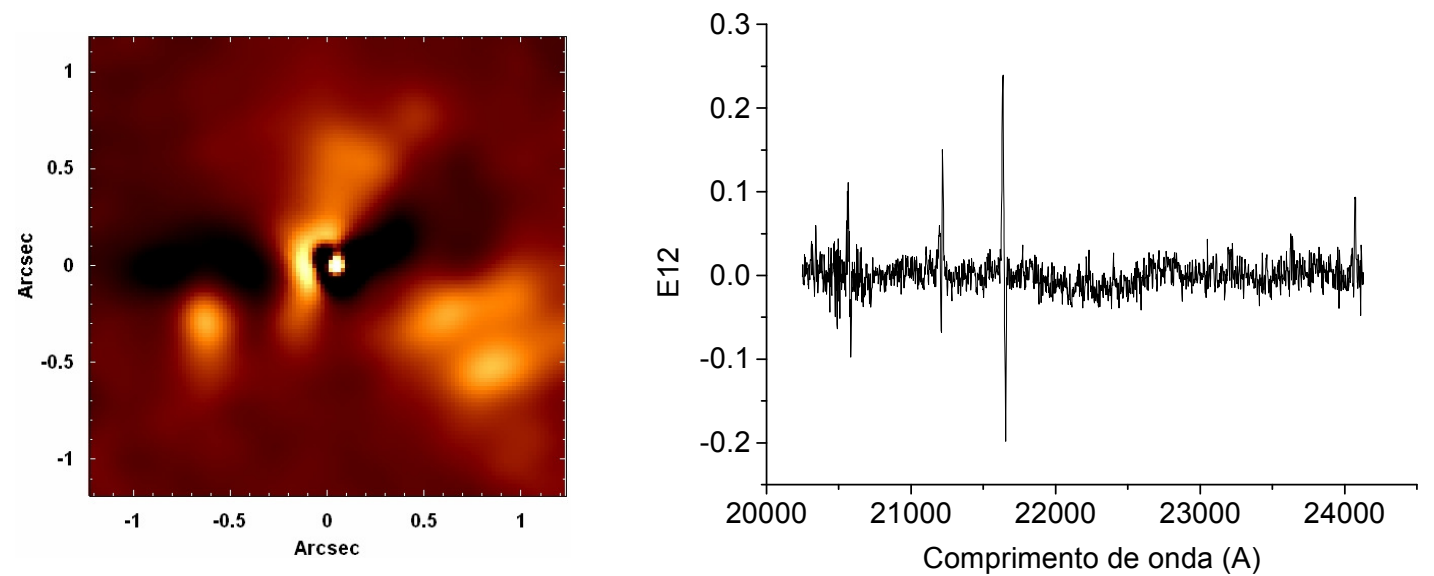

Figura 5.35 - Tomograma e auto-espectro correspondentes ao autovetor E12, obtido com a Tomografia PCA do cubo de dados de NGC 4151 com o contínuo estelar subtraído.

\begin{tabular}{|c|c|}
\hline Autovetor & Fração da variância explicada (\%) \\
\hline E1 & 85.8823 \\
\hline E3 & 2.3617 \\
\hline E5 & 0.7059 \\
\hline E6 & 0.5834 \\
\hline E8 & 0.1323 \\
\hline E9 & 0.0858 \\
\hline E10 & 0.0707 \\
\hline E11 & 0.0498 \\
\hline
\end{tabular}

Tabela 5.2 - Autovalores obtidos com a Tomografia PCA do cubo de dados de NGC 4151 com o contínuo estelar subtraído. 


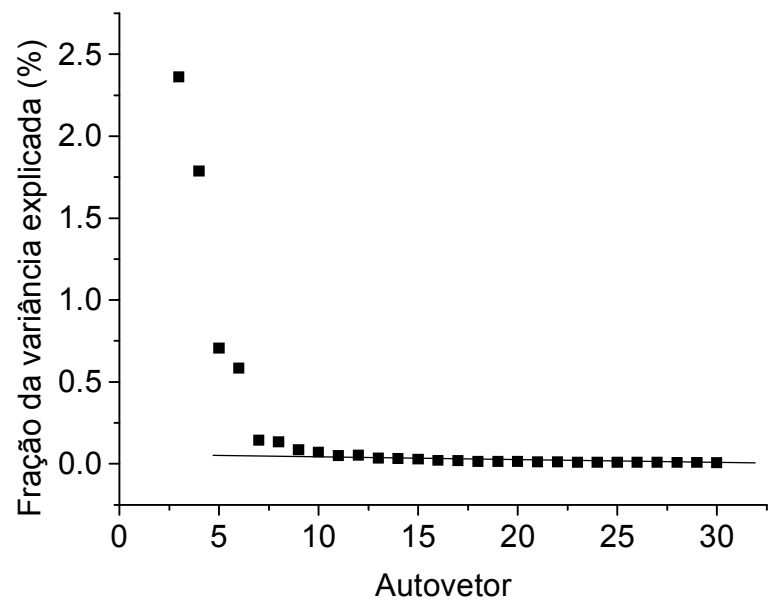

Figura 5.36 - "Scree test" dos autovetores obtidos com a Tomografia PCA do cubo de dados de NGC 4151 com o contínuo estelar subtraído.

Observando-se a figura 5.27, pode-se notar que o auto-espectro E1 apresenta correlações com os comprimentos de onda correspondentes às linhas de emissão de $\mathrm{Br} \gamma$ e de [Ca VIII]. Além disso, também possui correlações com os comprimentos de onda associados a uma componente larga da linha de Bry. Essas características indicam que esse autovetor está correlacionado com a emissão proveniente do AGN central dessa galáxia. Nesse caso, a posição do AGN corresponderia à área mais clara do tomograma associado. Esse resultado é compatível com aquele obtido com o autovetor E1 resultante da Tomografia PCA aplicada ao cubo de dados de NGC 4151 com o contínuo estelar (figura 5.8), entretanto, a remoção do contínuo estelar, aparentemente, permitiu que a emissão proveniente do AGN fosse ligeiramente melhor isolada. Um ponto importante a ser mencionado é que o auto-espectro mostrado na figura 5.27 parece apresentar uma componente extremamente larga da linha de Bry com $F W Z I \approx 27000 \mathrm{~km} / \mathrm{s}$. Tal componente não aparece de maneira clara no autovetor da figura 5.8. O autovetor E1 da figura 5.37 explica a maior parte da variância dos dados $(85.8823 \%)$, o que, assim como no caso do autovetor E1 da figura 5.8, está de acordo com o esperado, já que é sabido que o AGN dessa galáxia é bastante intenso.

A figura 5.28 mostra que o auto-espectro E3 apresenta correlações com os comprimentos de onda associados à componente larga da linha de Bry e anti-correlações com os comprimentos de onda correspondentes às linhas (estreitas) de $\mathrm{H}_{2}, \mathrm{Br} \gamma$ e [Ca VIII]. Isso indica que esse autovetor está correlacionado com a emissão da BLR e anti-correlacionado com a emissão da NLR e de regiões emissoras de $\mathrm{H}_{2}$. Nesse caso, a BLR corresponde à área clara do tomograma associado e a NLR, juntamente com as regiões emissoras de $\mathrm{H}_{2}$, estão entre as áreas escuras do 
mesmo. Isso está de acordo com os resultados obtidos até aqui com as análises anteriores. O autovetor E3 explica cerca de 2.3617 \% da variância dos dados.

As figuras 5.29 e 5.30 revelam que as principais correlações apresentadas pelos autoespectros E5 e E6 são com os comprimentos de onda correspondentes às principais linhas de $\mathrm{H}_{2}$ dessa região espectral. Isso mostra que esses autovetores estão relacionados a regiões emissoras de $\mathrm{H}_{2}$, que correspondem às áreas mais claras dos tomogramas associados. Tal resultado está de acordo com o que foi obtido a partir das análises anteriores. A figura 5.29 mostra, ainda, que o auto-espectro E5 apresenta uma anti-correlação (de intensidade comparável às correlações com as linhas de $\mathrm{H}_{2}$ ) com os comprimentos de onda associados à linha de [Ca VIII]. Isso parece indicar que esse autovetor está anti-correlacionado com a emissão proveniente de regiões de mais alta ionização. Nesse caso, essas regiões de mais alta ionização correspondem às áreas mais escuras do tomograma associado. Os autovetores E5 e E6 explicam, respectivamente, cerca de 0.7059 \% e 0.5834 \% da variância dos dados.

Observando-se as figuras 5.31 e 5.34, pode-se notar que os auto-espectros E8 e E11 apresentam correlações com os comprimentos de onda associados às asas vermelhas das principais linhas de emissão e anti-correlações com os comprimentos de onda correspondentes às asas azuis das mesmas. Isso, juntamente com a aparência apresentada pelos tomogramas associados, parece indicar que esses autovetores estão representando uma rotação do gás na região central de NGC 4151. Nesse caso, as áreas claras dos tomogramas em questão correspondem a regiões que apresentam redshift em sua emissão e as áreas escuras representam regiões com blueshift em sua emissão. Esse resultado é compatível com aquele obtido com o autovetor E9 resultante da Tomografia PCA aplicada ao cubo de dados de NGC $4151 \mathrm{com}$ o contínuo estelar (figura 5.16). Os autovetores E8 e E11 explicam, respectivamente, cerca de $0.1323 \%$ e $0.0498 \%$ da variância dos dados.

A figura 5.32 mostra que a principal característica do auto-espectro E9 é uma forte correlação com os comprimentos de onda correspondentes à linha de Bry. Isso mostra que esse autovetor deve estar relacionado com as regiões emissoras da NLR. Nesse caso, tais regiões correspondem às áreas claras do tomograma. Novamente, esse resultado é compatível com aquele obtido com a Tomografia PCA do cubo de dados de NGC 4151 com o contínuo estelar (conforme se pode notar pelas figuras 5.15 e 5.17, que representam, respectivamente, os autovetores E8 e E10 daquela análise). Da mesma forma que se constatou na seção 5.3, a NLR 
desse objeto apresenta uma disposição similar a um bi-cone, que é aproximadamente perpendicular à direção ao longo da qual se distribuem as regiões emissoras de $\mathrm{H}_{2}$. Tudo isso está de acordo com o esperado para esse objeto. O autovetor E9 explica cerca de $0.0858 \%$ da variância dos dados.

Por fim, as figuras 5.33 e 5.35 revelam que a principal característica dos auto-espectros E10 e E12 é uma correlação com os comprimentos de onda correspondentes à asa azul da linha de Bry e uma anti-correlação com os comprimentos de onda associados à asa vermelha da mesma. Isso parece indicar que esse autovetor está relacionado a algum fenômeno cinemático da NLR. A aparência apresentada pelos tomogramas correspondentes sugere que se trata de um outflow ao longo do eixo da NLR (que possui a forma de um bi-cone). Nesse caso, as áreas claras dos tomogramas em questão representam regiões com blueshift em sua emissão e as áreas escuras estão associadas a regiões com redshift em sua emissão. Um ponto importante a ser mencionado é que a existência desse outflow não havia sido detectada claramente nos resultados obtidos com a aplicação da Tomografia PCA ao cubo de dados de NGC 4151 com o contínuo estelar (seção 5.3), com exceção do caso do autovetor E12 resultante daquela análise, que apresentou certos traços indicativos de um outflow. No entanto, como esse autovetor também estava associado a outros fenômenos cinemáticos simultaneamente, a sua interpretação se tornou bastante complexa e optou-se por nem incluí-lo na seção 5.3. Os autovetores E10 e E12 mostrados nas figuras 5.33 e 5.35 explicam, respectivamente, cerca de $0.0707 \%$ e $0.0510 \%$ da variância dos dados.

O Scree test na figura 5.36 revela que os valores das variâncias explicadas pelos autovetores decaem bastante até, aproximadamente, o autovetor E13. A partir daí o decaimento diminui muito e os valores ficam praticamente constantes. Isso mostra que os autovetores com ordens maiores ou iguais a essa representam, sobretudo, ruído e, consequentemente, não possuem relevância nessa análise.

Pode-se concluir, assim, que a segunda análise com a Tomografia PCA apresentou resultados bastante compatíveis com os obtidos com a primeira análise (seção 5.3). Primeiramente, essa segunda análise conseguiu isolar bem a emissão proveniente do AGN. Entretanto, ao contrário do que ocorreu na análise da seção 5.3, foi detectada uma aparente componente extremamente larga da linha $\mathrm{Br} \gamma \operatorname{com} F W Z I \approx 27000 \mathrm{~km} / \mathrm{s}$. As regiões emissoras associadas à NLR (que tomam a forma de um bi-cone) foram bem diferenciadas das áreas 
emissoras de $\mathrm{H}_{2}$, que apresentam uma disposição espacial aproximadamente perpendicular à NLR. Esses resultados são compatíveis com os obtidos por Storchi-Bergmann et al. (2009) (que analisaram os mesmos dados mostrados aqui) e uma possível explicação para a perpendicularidade entre as regiões emissoras de $\mathrm{H}_{2}$ e a NLR é que as moléculas de $\mathrm{H}_{2}$ sejam destruídas na NLR, resultando em uma emissão aproximadamente perpendicular à NLR. Tal argumento também foi proposto por Storchi-Bergmann et al. (2009). Um aparente movimento rotacional de $\mathrm{H}_{2}$ em uma região com formato quase circular mais afastada do AGN central foi detectado com a mesma clareza com que foi identificado na seção 5.3. Essa segunda análise, entretanto, revelou um aspecto novo, que não havia sido observado claramente com a primeira aplicação da Tomografia PCA a esse cubo de dados: a presença de uma componente cinemática associada a um provável outflow ao longo da NLR. Essas características relacionadas à cinemática do gás na região central de NGC 4151 também foram detectadas por StorchiBergmann et al. (2010). Embora os principais resultados obtidos aqui com as aplicações da Tomografia PCA ao cubo de dados de NGC 4151 sejam compatíveis com o que foi encontrado por Storchi-Bergmann et al. (2009; 2010), as metodologias utilizadas nesse trabalho foram capazes de revelá-los de uma maneira mais clara, com imagens, por exemplo, com uma maior definição.

\section{6 - Switching-off the lights}

Após a aplicação da Tomografia PCA ao cubo de dados de NGC 4151, realizou-se o processo do feature supression and enhacement, explicado em 3.10. As análises nas seções 5.3 e 5.5 revelaram que os resultados obtidos com a aplicação da Tomografia PCA ao cubo de dados de NGC 4151, antes e depois da subtração do contínuo estelar, foram bastante compatíveis entre si, com apenas algumas diferenças na forma com que os diferentes fenômenos presentes foram mostrados. Com base nisso, o processo do feature supression and enhacement poderia ser aplicado em qualquer uma das duas análises. No entanto, como o estudo da seção 5.5 foi feito com um cubo sem de-noising, os auto-espectros obtidos apresentaram uma razão $S / N$ inferior à daqueles resultantes da análise da seção 5.3. Assim, optou-se por aplicar o processo do feature supression and enhacement aos autovetores obtidos com a aplicação da Tomografia PCA ao 
cubo de dados com o contínuo estelar (seção 5.3). Nesse caso, a reconstrução foi feita utilizando-se os 20 primeiros autovetores encontrados, exceto os dois primeiros. Essencialmente, os autovetores E1 e E2 representaram, respectivamente, a emissão do AGN central e das populações estelares ao redor. Esses dois fenômenos são dominantes (sobretudo o primeiro) e, por serem tão intensos, chegam a "ofuscar" fenômenos mais fracos, tornando difícil analisá-los. Dessa forma, reconstruindo-se o cubo de dados sem esses dois primeiros autovetores, foi possível eliminar esses fenômenos dominantes e ressaltar os mais fracos, o que possibilitou uma análise mais detalhada desses últimos. Essa eliminação dos autovetores contendo os fenômenos mais intensos e "ofuscantes" foi chamada aqui de switching-off the lights. Os autovetores de ordem mais elevada do que 20 representam, essencialmente, ruído. Dessa forma, esses autovetores não foram considerados no processo de reconstrução para que esse ruído não fosse incluído no cubo de dados reconstruído. Todo o procedimento foi aplicado de acordo com a expressão (3.98) e, seguindo a notação apresentada em 3.10, o cubo reconstruído é chamado daqui para frente de $I^{\prime}$.

Para se analisar as emissões de $\mathrm{H}_{2}$, foram feitas imagens das principais linhas de $\mathrm{H}_{2}$ do cubo I'. Para cada uma delas, foi feita, também, uma composição RGB, sendo que as cores vermelha, verde e azul corresponderam, respectivamente, às imagens da asa vermelha, da região central e da asa azul da linha de $\mathrm{H}_{2}$ medida. Em seguida, a fim de se construir uma imagem final representativa da emissão molecular de $\mathrm{H}_{2}$, foi calculada uma média ponderada de todas as imagens anteriores, sendo que os pesos utilizados nesse cálculo foram obtidos com base nos fluxos integrados de cada uma das linhas (esse procedimento também foi aplicado para as composições RGBs construídas). A imagem final encontrada, juntamente com a composição RGB correspondente, são mostradas na figura 5.37 . 

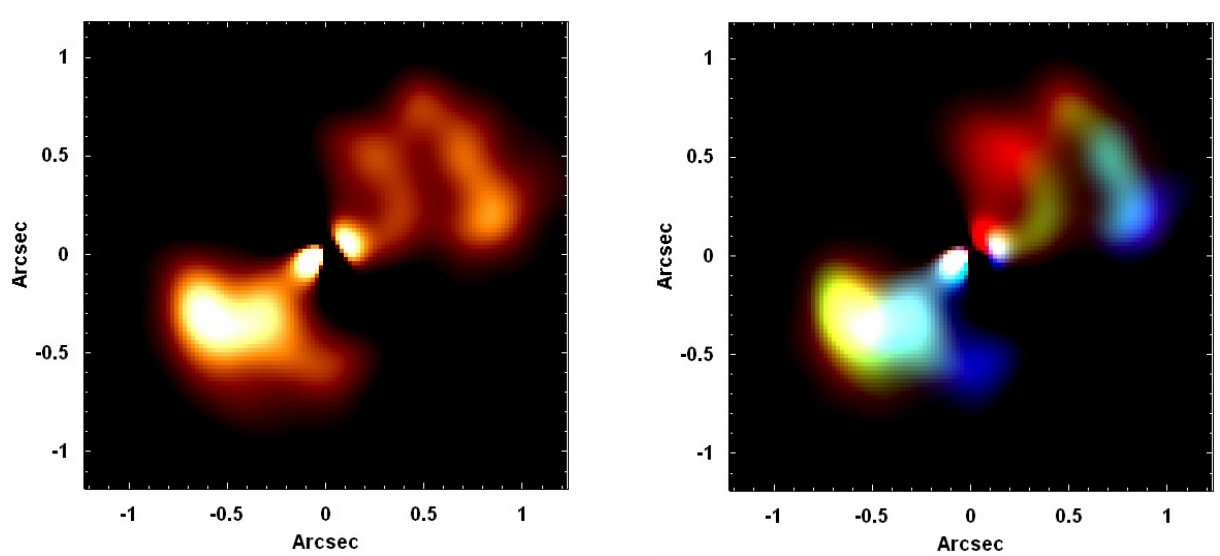

Figura 5.37: (esquerda) Imagem correspondente à média ponderada das imagens das linhas de $\mathrm{H}_{2}$ do cubo de dados I' de NGC 4151; (direita) RGB da imagem da média ponderada à esquerda, sendo que as cores vermelha, azul e verde representam a emissão de $\mathrm{H}_{2}$ em "redshift", "blueshift" e com baixos valores de velocidade radial, respectivamente.

Observando-se a figura 5.37, pode-se concluir que a emissão molecular de $\mathrm{H}_{2}$ na região central de NGC 4151 ocorre em regiões com formatos similares a arcos, em ambos os lados do AGN central. Tal resultado está de acordo com o que já havia sido observado nas análises com a Tomografia PCA aplicada ao cubo de dados de NGC 4151, antes e depois da subtração do contínuo estelar (seções 5.3 e 5.5, respectivamente). Essa mesma configuração das regiões emissoras de $\mathrm{H}_{2}$ também foi observada por Storchi-Bergmann et al. (2009), entretanto, a metodologia utilizada aqui permitiu que tais regiões fossem observadas com mais detalhes e com uma melhor definição. A composição RGB da figura 5.37 mostra que as áreas emissoras de $\mathrm{H}_{2}$ parecem estar dispostas na forma de três canais que se comunicam com o AGN central, sendo que um deles aparece em azul (emissão com blueshift), outro em verde (emissão com pouca componente radial de velocidade e, consequentemente, sem blueshift ou redshift significativos) e outro em vermelho (emissão com redshift). É possível que essas estruturas representem canais de alimentação do AGN central.

A fim de se analisar a emissão da NLR dessa galáxia, fez-se a imagem da linha de Bry do cubo de dados $I^{\prime}$. Assim como no caso das linhas de $\mathrm{H}_{2}$, foi feita também uma composição RGB correspondente. As imagens resultantes, juntamente com uma imagem em [O III] da região central de NGC 4151 obtida com o HST, são mostradas na figura 5.38. 

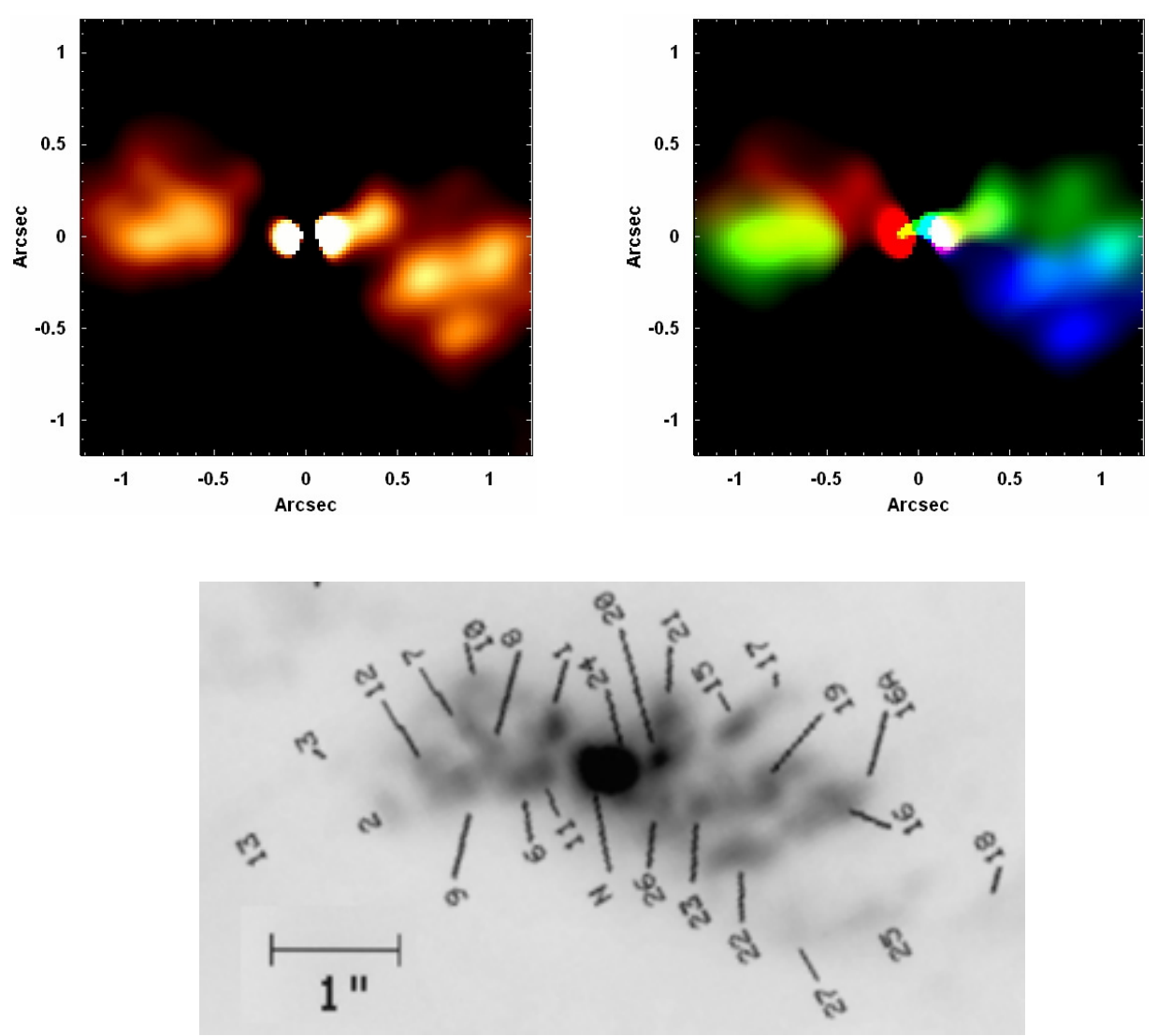

Figura 5.38: (em cima à esquerda) Imagem da linha de Bry do cubo de dados I' de NGC 4151; (em cima à direita) RGB da imagem da linha de Bry à esquerda, sendo que as cores vermelha, azul e verde representam a emissão de Bry em "redshift", "blueshift" e com baixos valores de velocidade radial, respectivamente; (abaixo) Imagem em [O III] da região central de NGC 4151, obtida com o HST, retirada do trabalho de Hutchings et al. (1998).

A figura 5.38 revela que as nuvens que compõem a NLR do AGN dessa galáxia são facilmente identificáveis, tanto nas imagens de Bry quanto na imagem de [O III], obtida com o HST Elas tomam a forma de um aparente bi-cone, o que está de acordo com os resultados obtidos nas seções anteriores. À esquerda do AGN central nota-se que a emissão do material está, predominantemente, em redshift, ao passo que, à direita do AGN, a emissão encontra-se, principalmente, em blueshift. Esse comportamento corresponde a um provável outflow, conforme mencionado na seção 5.5. Assim como no caso das análises das seções 5.3 e 5.5 , todos esses resultados referentes à linha de Bry são compatíveis com os obtidos por Storchi-Bergmann et al. (2009; 2010), mas são revelados de uma maneira mais clara, em conseqüência das metodologias aqui utilizadas para o tratamento e análise dos dados. Essas metodologias não apenas permitiram que fosse obtida uma resolução espacial quase comparável à do HST, mas também suprimiram a emissão do AGN central, o que proporcionou uma visualização mais clara 
das regiões emissoras de Bry. Sem a utilização dessas metodologias, é possível que as áreas emissoras de Bry mais próximas ao AGN não tivessem sido detectadas tão detalhadamente, devido ao ofuscamento causado pelo AGN.

\section{7 - Cinemática estelar do cubo de dados de NGC 4151}

Aplicou-se o processo do pPXF no cubo de dados de NGC 4151, a fim de se obter os seguintes parâmetros relativos à cinemática estelar: velocidade radial estelar, dispersão de velocidades estelar e os coeficientes de Gauss-Hermite $h_{3}$ e $h_{4}$. Os mapeamentos obtidos para os valores desses parâmetros são mostrados na figura 5.39.
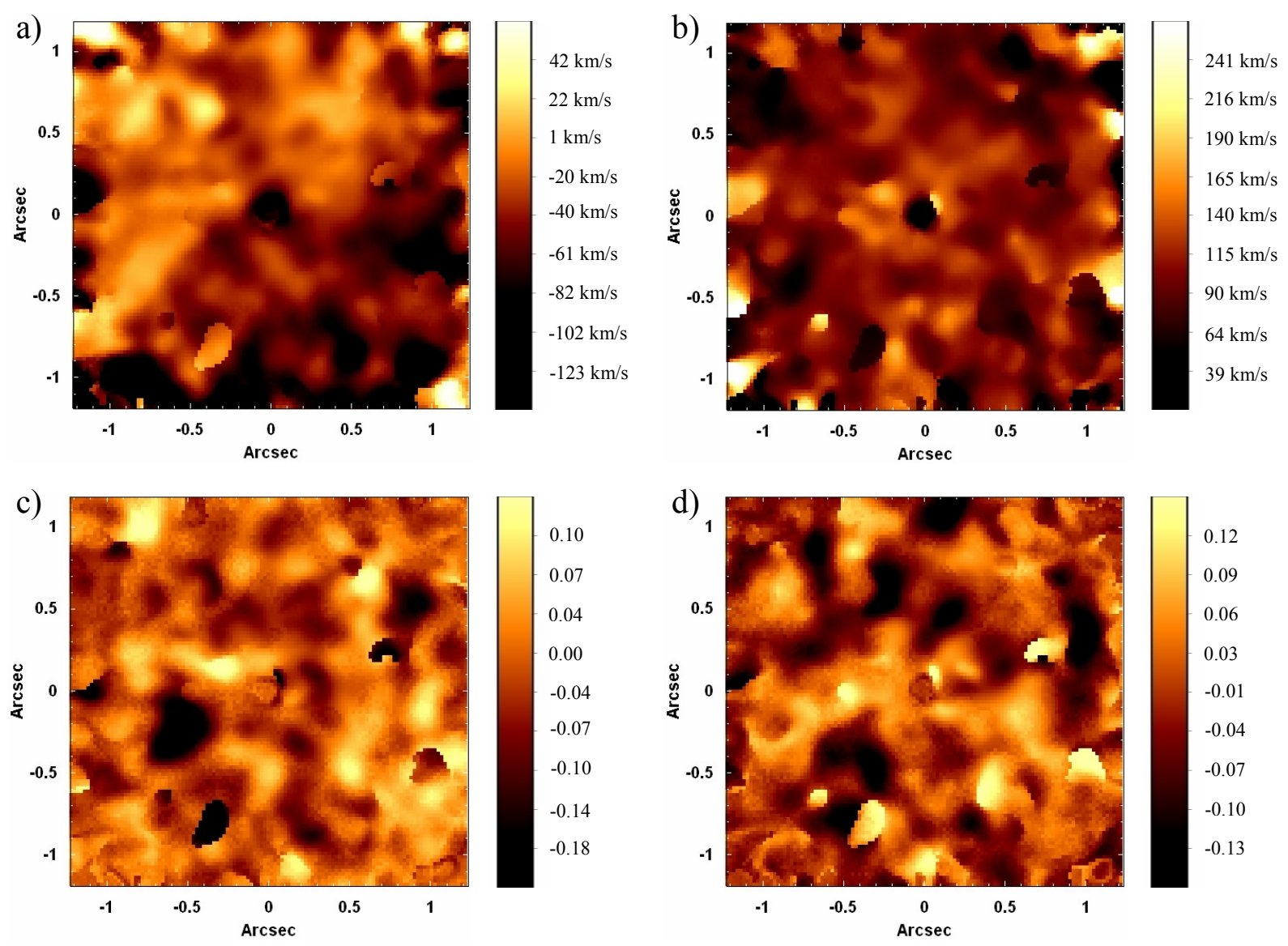

Figura 5.39 - Mapeamentos dos valores (a) da velocidade radial estelar, (b) da dispersão de velocidades estelar, (c) do coeficiente $h_{3} e(d)$ do coeficiente $h_{4}$, obtidos com a aplicação do pPXF ao cubo de dados de NGC 4151. 
Observando-se a figura 5.39 - $a$, pode-se notar a presença do que aparenta ser uma tênue rotação estelar ao redor do núcleo. Esse padrão rotacional parece ser compatível com o que foi detectado para o gás nas seções 5.3 e 5.5 com os resultados da aplicação da Tomografia PCA ao cubo de dados de NGC 4151 com e sem o contínuo estelar (figuras 5.16, 5.31 e 5.34). Esses resultados indicam a presença de uma rotação do gás e das estrelas na região central de NGC 4151, ao redor do núcleo. A escala de valores da velocidade radial estelar na figura 5.39 $a$ revela que a amplitude das velocidades negativas é consideravelmente maior do que a amplitude das velocidades positivas. Entretanto, nota-se que essas velocidades negativas com módulos mais elevados apenas ocorrem em pequenas regiões ao longo do cubo de dados de NGC 4151, o que parece sugerir que elas são geradas por imprecisões dos ajustes e não representam nenhum fenômeno físico. A figura 5.39 - b mostra que o mapeamento dos valores da dispersão de velocidades estelar não apresentou nenhum padrão ou configuração espacial dominante. Entretanto, comparando-se as figuras 5.39 - a e 5.39 - b, pode-se notar que ambas revelaram um decréscimo dos valores na posição correspondente ao AGN. Da mesma forma que no caso de NGC 2992, esse comportamento pode ser explicado pelo fato de, nessa área, o contínuo ser dominado pela emissão térmica de poeira, o que tornou as bandas de CO pouco detectáveis e dificultou os ajustes com o pPXF (que se basearam, essencialmente, nessas bandas). Assim é bem provável que esse decréscimo de valores na região espacial correspondente ao AGN não seja real, mas sim um produto dos problemas de ajuste nessa área.

As figuras $5.39-c$ e $5.39-d$ não revelam comportamentos ou configurações dominantes nos mapeamentos dos valores dos coeficientes $h_{3}$ e $h_{4}$ que possam ser claramente identificados.

Como a rotação estelar detectada na figura 5.39 - $a$ é consideravelmente tênue e tanto esse mapeamento quanto o dos valores da dispersão de velocidades estelar (figura $5.39-b$ ) apresentam várias irregularidades e possíveis zonas com valores não confiáveis (como a posição correspondente ao AGN, que apresenta uma diminuição de valores em ambos os mapeamentos), optou-se por não aplicar nenhum tipo modelagem com o intuito de se determinar a massa do buraco negro central existente nesse objeto. 


\section{8 - Cinemática do gás do cubo de dados de NGC 4151}

Para se obter um maior detalhamento sobre a cinemática do gás molecular e do gás ionizado na região central de NGC 4151, construíram-se os mapas de velocidade das linhas de emissão $\mathrm{H}_{2} \lambda 21218$ e Bry. Assim como no caso de NGC 2992, os valores das velocidades nesses mapeamentos foram obtidos ajustando-se gaussianas nessas linhas em cada um dos espectros do cubo de dados, após a subtração do contínuo estelar. As linhas de $\mathrm{H}_{2} \lambda 21218$ e $\mathrm{Br} \gamma$ foram utilizadas por serem as mais intensas do espectro. Nas regiões mais afastadas do centro do campo de visão do NIFS, a diminuição dos valores da razão $S / N$ tornou difícil o ajuste das gaussianas nessas duas linhas, fazendo com que a determinação das velocidades do gás se tornasse imprecisa. Nessas áreas, os valores foram mascarados. Os mapeamentos construídos são mostrados na figura 5.40 .
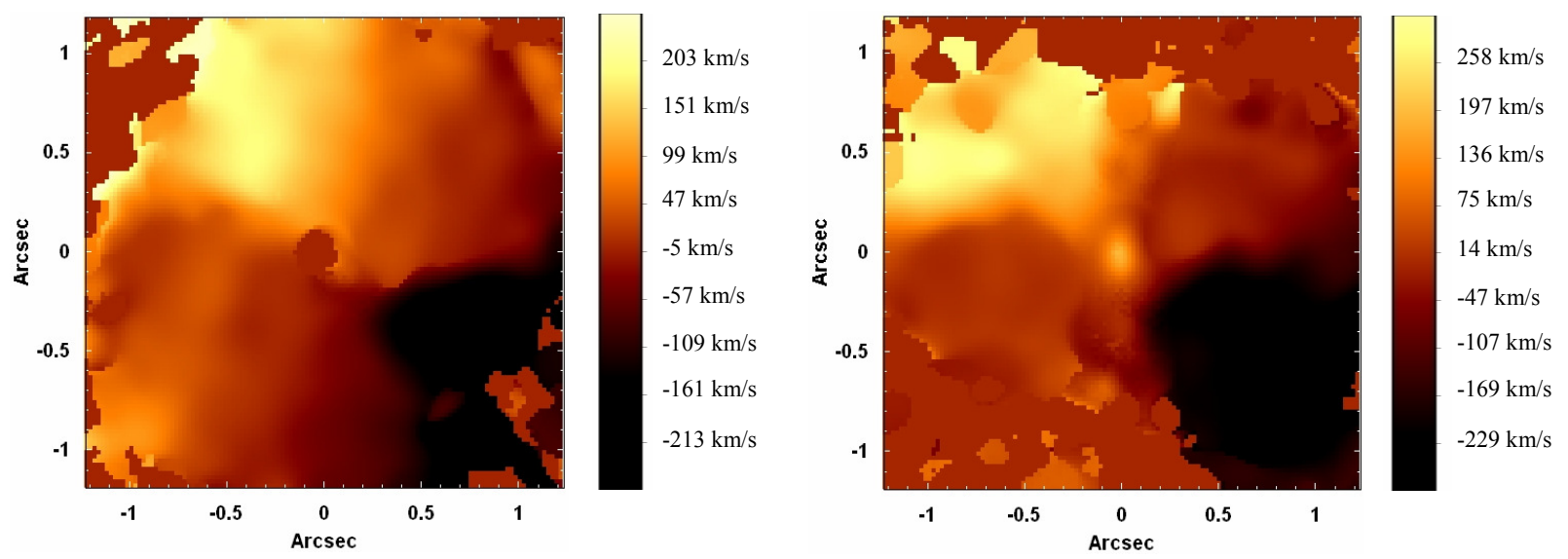

Figura 5.40 - Mapeamentos dos valores de velocidade radial do gás, obtidos (esquerda) com a linha de $\mathrm{H}_{2} \lambda 21218$ e (direita) com a linha de Bry do cubo de dados de NGC 4151.

Os mapeamentos de velocidade da figura 5.40 apresentam uma morfologia compatível tanto com uma rotação quanto com um outflow. Isso está de acordo com o esperado, já que, conforme foi verificado com as aplicações da Tomografia PCA ao cubo de dados de NGC 4151 (sessões 5.3 e 5.5), a região central dessa galáxia apresenta tanto rotação de gás ao redor do núcleo quanto outflows. Assim, é provável que a morfologia observada nos mapeamentos de velocidade radial do gás seja o resultado de uma sobreposição desses dois fenômenos cinemáticos. Uma análise da figura 5.40 também deixa claro que seria bastante difícil separar a rotação do outflow. Um ponto importante a ser discutido é a grande similaridade dos mapas de 
velocidades mostrados na figura 5.40. Isso parece ser contraditório com o fato, mencionado anteriormente, de que a emissão de $\mathrm{H}_{2}$ se dá, principalmente, ao longo de uma região aproximadamente perpendicular à NLR (que possui a forma de um bi-cone). Entretanto, uma análise cuidadosa do cubo de dados de NGC 4151 revelou que, apesar da maior parte da emissão de $\mathrm{H}_{2}$ ocorrer, de fato, em uma área perpendicular à NLR, linhas de $\mathrm{H}_{2}$ mais fracas também podem ser observadas ao longo da região correspondente à NLR. Dessa forma, essa pouca quantidade de $\mathrm{H}_{2}$ que não foi destruído pelo cone de ionização e é co-espacial com a NLR possui a mesma cinemática do gás ionizado (que envolve outflows), o que dá origem à similaridade dos mapas de velocidades observada na figura 5.40. Conforme foi mencionado em 5.1, Das et al. (2005) modelaram a cinemática da NLR de NGC 4151 com um modelo envolvendo outflows bi-cônicos. Um esquema geral do cenário modelado por esses autores é mostrado na figura 5.41 .

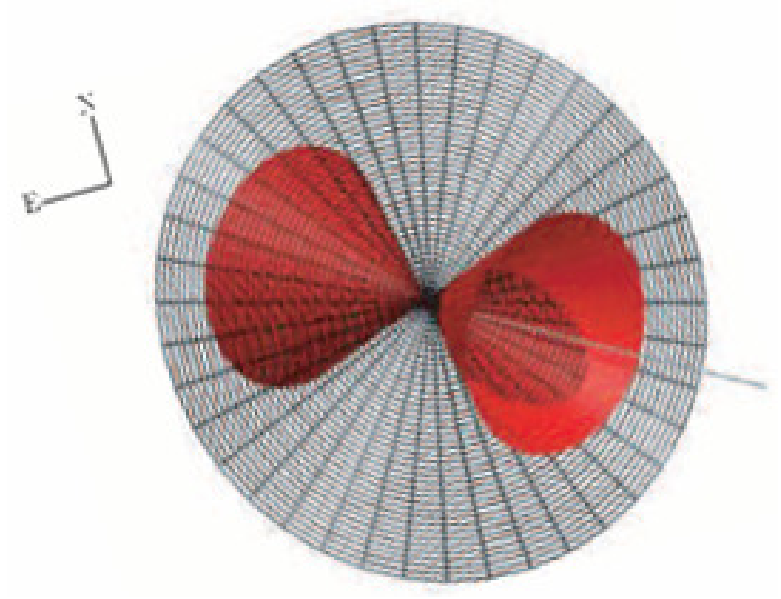

Figura 5.41 - Esquema do "outflow" bi-cônico a partir do AGN de NGC 4151, obtido a partir do trabalho de Das et al. (2005).

Para se tentar modelar os mapas de velocidades do gás mostrados na figura 5.40, seria preciso sobrepor curvas de rotação a outflows. Entretanto, como um dos objetivos desse trabalho envolve, apenas, a simulação de movimentos keplerianos, visando a determinação da massa do buraco negro central existente, e, nesse caso, não é possível separar com precisão a rotação e o outflow existentes no mapeamento de velocidades, optou-se por não fazer essa modelagem aqui. 


\section{9 - Espectro de emissão de $\mathrm{H}_{2}$ do cubo de dados de NGC 4151: razões de linhas e temperaturas de excitação}

A fim de se verificar se a emissão de $\mathrm{H}_{2}$ no cubo de dados de NGC 4151 tem origem térmica ou não térmica, primeiramente, construiu-se um diagrama de diagnóstico com as razões de linhas 1-0 $\mathrm{Q}(1)(\lambda 24066) / 1-0 \quad \mathrm{~S}(1)(221218)$ e 1-0 $\mathrm{S}(2)(\lambda 20338) / 1-0 \mathrm{~S}(0)(\lambda 22235)$, que é mostrado na figura 5.42 .

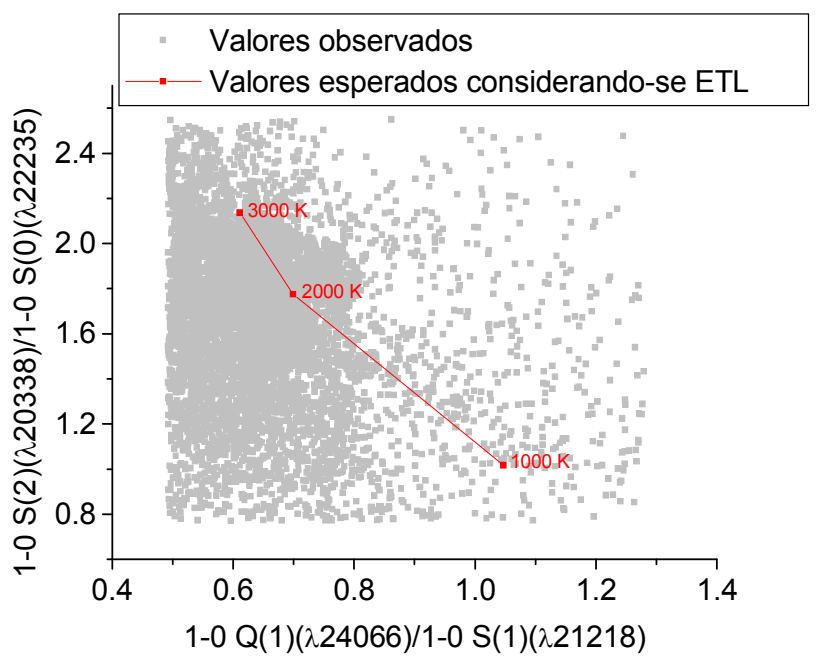

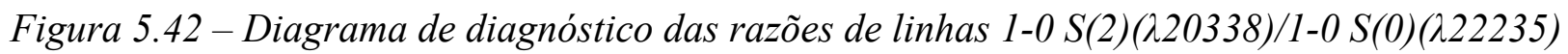
e 1-0 Q(1)(224066)/1-0 S(1)(221218) do cubo de dados de NGC 4151. Os resultados esperados considerando-se ETL são mostrados em vermelho.

Observando-se o diagrama de diagnóstico da figura 5.42, pode-se notar que a aproximação de ETL não parece ser válida na maior parte das regiões espaciais do cubo de dados de NGC 4151. Isso sugere uma origem não térmica para a emissão de $\mathrm{H}_{2}$ nessas áreas. É possível que a existência de outflows na região central de NGC 4151, conforme foi mencionado nas sessões anteriores, crie condições não compatíveis com a aproximação de ETL, o que poderia explicar o resultado aqui obtido.

Para se determinar a temperatura em regiões nas quais o ETL parece ser válido, aplicouse um procedimento análogo ao utilizado no caso de NGC 2992: estimou-se, com base nas flutuações do contínuo nas regiões espectrais próximas às linhas de emissão medidas, uma incerteza de $11 \%$ para as razões de linhas (que, na verdade, corresponde ao mesmo valor obtido no caso de NGC 2992). Após isso, delimitou-se no diagrama da figura 5.42 uma região de 
incerteza englobando valores variando em até $11 \%$ a partir da curva vermelha. Por fim, os valores da temperatura foram calculados para os pontos nessa região, utilizando-se a fórmula (4.4). A figura 5.43 mostra o mapeamento dos valores obtidos para a temperatura, utilizando-se

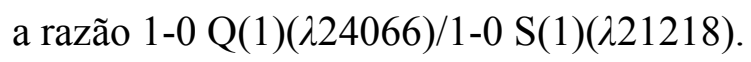

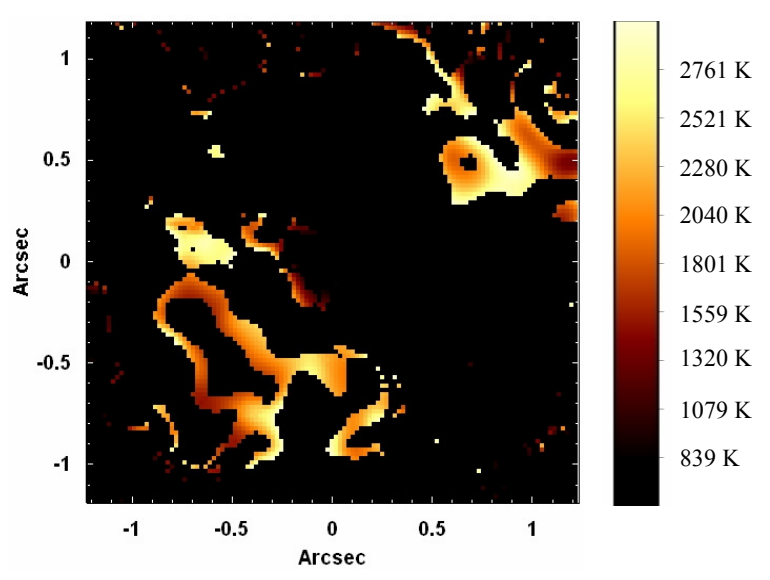

Figura 5.43 - Mapeamento dos valores da temperatura de excitação do cubo de dados de

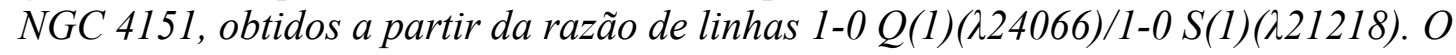
mapeamento foi feito apenas para regiões nas quais a aproximação de ETL é válida.

Uma análise do mapeamento de temperaturas da figura 5.43 deixa claro que a pouca quantidade de regiões mapeadas faz com que não seja possível tirar conclusões relevantes relacionadas à variação dos valores de temperatura nas diferentes áreas do campo de visão do NIFS. Apesar disso, foram detectadas regiões com temperaturas até mais elevadas do que as encontradas em NGC 2992, o que pode sugerir que o mecanismo de aquecimento das nuvens de $\mathrm{H}_{2}$ existentes seja a emissão de raios-x pelo AGN central, assim como foi constatado no caso de NGC 2992.

\section{$5.10-$ Conclusões}

Assim, conclui-se que a análise do cubo de dados de NGC 4151 revelou a existência de uma grande quantidade de fenômenos na região central desse objeto. Primeiramente, as aplicações da Tomografia PCA mostraram que as regiões emissoras de $\mathrm{H}_{2}$ (que apresentam formatos de arcos a uma certa distância do núcleo) se distribuem ao longo de uma área aproximadamente perpendicular à região ocupada pelas nuvens da NLR desse objeto, que, por 
sua vez, assume o formato de um bi-cone. Uma possível explicação para isso é que as moléculas de $\mathrm{H}_{2}$ sejam destruídas pela emissão proveniente da NLR, resultando em uma emissão de $\mathrm{H}_{2}$ muito reduzida nessa área. Com relação aos fenômenos cinemáticos do gás, a Tomografia PCA revelou uma aparente rotação de $\mathrm{H}_{2}$ em uma região circular ao redor núcleo e também um provável outflow ao longo da direção correspondente à NLR. Os mapeamentos de velocidade do gás obtidos a partir das linhas de $\mathrm{H}_{2} \lambda 21218$ e $\mathrm{Br} \gamma$ não permitiram uma diferenciação clara desses dois fenômenos cinemáticos, mas parecem estar de acordo com o modelo de outflow bicônico proposto por Das et al. (2005). Todos esses resultados são compatíveis com os obtidos por Storchi-Bergmann et al. (2009; 2010) (que analisaram os mesmos dados mostrados aqui), mas são revelados de uma maneira mais clara, em conseqüência das metodologias aqui utilizadas para o tratamento e análise dos dados. A utilização da técnica do Switching-off the lights permitiu uma visualização mais detalhada da emissão de $\mathrm{H}_{2}$ e da NLR (com as cinemáticas envolvidas), e mostrou, ainda, a presença de três possíveis canais de alimentação fornecendo gás molecular ao AGN central. As metodologias utilizadas no tratamento e análise do cubo de dados de NGC 4151 (incluindo o Switching-off the lights) fizeram com que várias nuvens emissoras de Br $\gamma$ na NLR fossem detectadas claramente, com uma resolução quase comparável à do HST. O ajuste com o processo do pPXF mostrou a provável existência de um tênue padrão rotacional estelar ao redor do núcleo dessa galáxia. Tanto a aplicação da Tomografia PCA ao cubo de dados de NGC 4151 com contínuo estelar quanto a síntese espectral realizada com o software Starlight evidenciaram a presença de uma provável emissão térmica de poeira na região correspondente ao AGN central. Assim como no caso de NGC 2992, não foi possível fazer um imageamento detalhado dessa área emissora, já que a resolução espacial aqui obtida não foi suficiente para isso. Entretanto, é possível que a emissão térmica de poeira detectada seja proveniente de um toro de poeira ao redor do AGN, o que seria compatível com as previsões do Modelo Unificado. A síntese espectral com o Starlight também mostrou a existência de uma emissão associada a um featureless continuum na região correspondente ao AGN central, o que está de acordo com o esperado, já que se trata de um AGN bastante intenso. As aplicações da Tomografia PCA isolaram consideravelmente bem a emissão proveniente do AGN, sendo que uma proeminente componente larga da linha de Bry pôde ser claramente detectada. A Tomografia PCA do cubo de dados com o contínuo estelar subtraído revelou, 
inclusive, uma aparente componente extremamente larga da linha $\mathrm{Br} \gamma \operatorname{com} F W Z I \approx 27000 \mathrm{~km} / \mathrm{s}$. Uma análise do diagrama de diagnóstico das razões de linhas

1-0 $\mathrm{Q}(1)(\lambda 24066) / 1-0 \quad \mathrm{~S}(1)(\lambda 21218)$ e $1-0 \quad \mathrm{~S}(2)(\lambda 20338) / 1-0 \quad \mathrm{~S}(0)(\lambda 22235)$ revelou que a aproximação de ETL não é válida na maior parte das regiões espaciais no campo de visão do NIFS. O mapa de temperaturas construído para as áreas em ETL não permitiu que fossem tiradas conclusões claras a respeito da variação da temperatura em diferentes regiões, entretanto, foram obtidos alguns valores de temperatura ainda maiores do que no caso de NGC 2992, o que pode indicar que o aquecimento das nuvens moleculares seja devido à emissão de raios-x pelo AGN central. 


\section{$6-$ NGC 3227}

\section{1 - Introdução}

NGC 3227 é uma galáxia espiral de tipo morfológico SAB(s)a pec que se encontra a uma distância de cerca de $18 \mathrm{Mpc}$. Um de seus braços espirais termina na galáxia próxima NGC 3226, que apresenta um tipo morfológico S0 ou E2 (há discordâncias na literatura). Acredita-se que o par NGC 3226/3227 apresente uma interação gravitacional, que poderia explicar, inclusive, as perturbações visíveis nas regiões externas de NGC 3227.

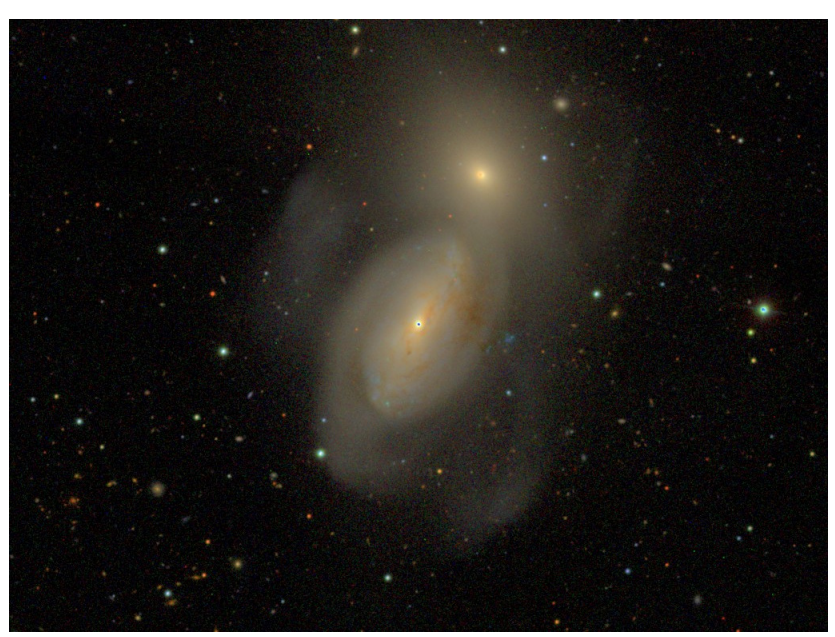

Figura 6.1 - Imagem da galáxia NGC 3227, obtida com o SDSS. A orientação é norte para cima e leste para a esquerda.

Observando-se a figura 6.1, pode-se notar as perturbações nas áreas mais externas de NGC 3227, assim como o braço espiral que conecta essa galáxia à vizinha NGC 3226.

NGC 3227 foi listada como Seyfert 2 por Huchra \& Burg (1992), entretanto, a detecção de componentes largas em algumas linhas de emissão fez com que ela fosse re-classificada como Seyfert 1 (Osterbrock \& Martel 1993). Observações da região nuclear dessa galáxia já foram feitas em todo o espectro eletromagnético. Rubin \& Ford (1968) foram os primeiros a estudar as linhas de emissão ópticas nucleares desse objeto, utilizando espectroscopia long-slit. Os autores observaram que o núcleo de NGC 3227 é composto por várias nuvens discretas emissoras de linhas de hidrogênio. Além disso, foram encontradas evidências de um outflow a partir do núcleo e também da existência de uma grande quantidade de materiais absorvedores 
nessa área. Em anos posteriores, espectros ópticos de mais alta resolução foram obtidos para a região central dessa galáxia (Vrtilek \& Carleton 1985; Whittle 1985; Veilleux 1991) e verificouse que o potencial de ionização e a densidade crítica possuem uma correlação positiva com as larguras das linhas, o que implica que a densidade e/ou o parâmetro de ionização crescem para dentro, à medida que a distância do AGN central diminui.

A emissão nuclear de NGC 3227 apresenta uma grande variabilidade. Os estudos de Rosenblatt et al. (1992) e Salamanca et al. (1994) revelaram que o contínuo óptico e a emissão de linhas largas variam cerca de $20 \%$ em uma escala de tempo de aproximadamente um mês.

Arribas \& Mediavilla (1994) apresentaram espectroscopia bidimensional óptica da região circumnuclear de NGC 3227 e verificaram que a estrutura de ionização é complexa. A análise de um diagrama de diagnóstico de [O III] $\lambda 5007 / \mathrm{H} \beta$ x [N II] $\lambda 6583 / \mathrm{H} \alpha$ mostrou que emissões de tipo LINER e Seyfert estão presentes na região central dessa galáxia. Entretanto, emissão de tipo H II também é encontrada em uma área estendida, a cerca de 300 pc do núcleo óptico. Tudo isso sugere que NGC 3227 é uma galáxia com ionização composta AGN/starburst. Os autores também concluíram que a BLR possui uma posição assimétrica em relação ao centro do mapa de velocidades.

Blitz et al. (1986) detectaram emissão de CO ( $J=1-0)$ na região central de NGC 3227. Posteriormente, Meixner et al.(1990) estudaram novamente essa emissão, utilizando observações de mais alta resolução, e detectaram dois picos não resolvidos e mais uma componente estendida, de aproximadamente 17 " de comprimento, com um formato similar ao de uma barra apontando para a galáxia vizinha NGC 3226. Mundell et al. (1995a) apresentaram observações no óptico e em rádio (contínuo em $6 \mathrm{~cm}$ e em $18 \mathrm{~cm}$ ) da região nuclear de

NGC 3227 e verificaram que a estrutura em rádio é dupla, com as componentes separadas por cerca de 0.4 " em um $P A \sim-10^{\circ}$. Além disso, também foi detectado gás fotoionizado de alta excitação se estendendo por uma área com forma de cunha de cerca de 500 pc de extensão e em um $P A \sim 30^{\circ}$. Utilizando observações de H I, em $21 \mathrm{~cm}$, obtidos com o VLA, Mundell et al. (1995b) verificaram a existência de duas grandes caudas de maré se estendendo $31 \mathrm{kpc}$ para o norte e $70 \mathrm{kpc}$ para o sul, o que é uma forte evidência de que essa galáxia está, de fato, envolvida em uma interação gravitacional. Também foram observadas evidências de uma barra na distribuição de $\mathrm{H}$ I que parece ser uma continuação da barra de $\mathrm{CO}$ detectada por Meixner et al. (1990). Nenhuma emissão de H I proveniente de NGC 3226 foi detectada. A figura 6.2 
mostra uma comparação da barra de H I e da barra de CO observadas por Mundell et al. (1995b) e Meixner et al. (1990), respectivamente.

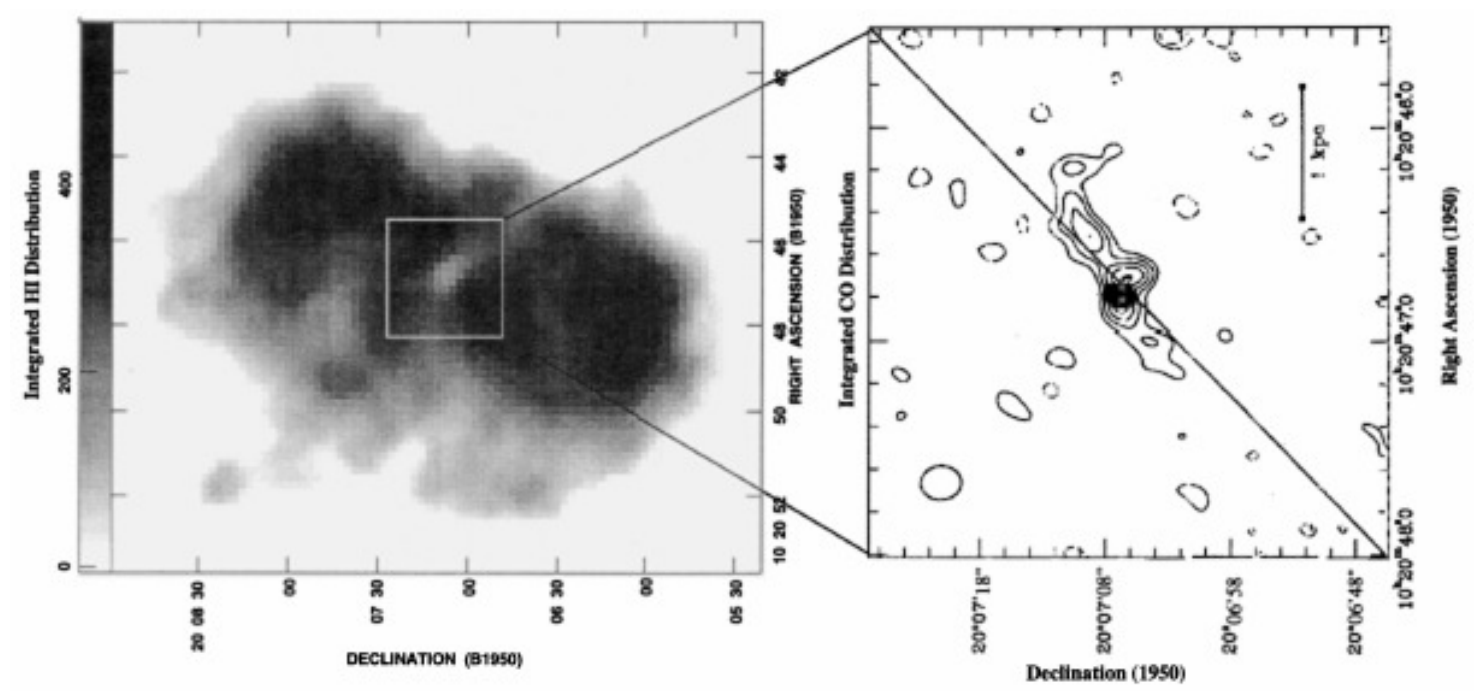

Figura 6.2 - (esquerda) Imagem da emissão em $21 \mathrm{~cm}$ de H I na região central de NGC 3227, obtida a partir do trabalho de Mundell et al. (1995b); (direita) Imagem da emissão de CO na região central de NGC 3227, obtida a partir do trabalho de Meixner et al. (1990).

Schinnerer et al. (2000) analisaram observações interferométricas das linhas de emissão de $\mathrm{CO}$ e $\mathrm{HCN}$ e detectaram a presença de um disco de gás molecular ao redor do núcleo de NGC 3227. Tal disco é provavelmente distorcido (warped). De acordo com o modelo elaborado pelos autores, esse warp começa em um raio externo de 75 pc e se torna perpendicular ao disco externo em um raio de 30 pc. A figura 6.3 mostra o modelo de disco distorcido elaborado por Schinnerer et al. (2000).

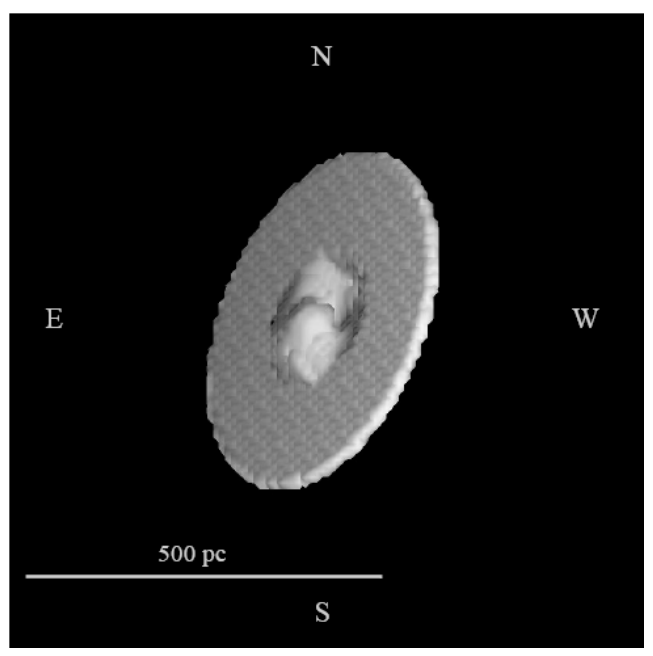

Figura 6.3 - Modelo de disco distorcido para o gás molecular ao redor do AGN central de NGC 3227, elaborado por Schinnerer et al. (2000). 
Utilizando observações em raios-x obtidas com o ASCA, Ptak et al. (1994) detectaram a presença de gás ionizado absorvedor na região central de NGC 3227. Tal resultado está de acordo com o que foi obtido por Rubin \& Ford (1968), que também encontraram evidências da existência de um meio absorvedor nesse objeto. Komossa \& Fink (1997) e George et al. (1998), usando dados obtidos com o ROSAT e com o ASCA, respectivamente, modelaram esse meio absorvedor e concluíram que ele possui uma ionização relativamente baixa, quando comparada ao que é encontrado em outras galáxias Seyfert. Lamer et al. (2003) analisaram dados obtidos com o XMM-Newton numa época em que a fonte central estava passando por um período (de cerca de 3 meses de duração) de forte obscurecimento, devido a uma nuvem de gás compacta bloqueando cerca de $90 \%$ da emissão. Os autores propuseram que essa nuvem obscurecedora deveria estar associada à BLR do AGN.

A emissão infravermelha do núcleo de NGC 3227 é relativamente fraca quando comparada com aquela proveniente da galáxia hospedeira, de acordo com Ward et al. (1989). Os autores interpretaram o crescimento abrupto do fluxo em comprimentos de onda desde $10 \mu \mathrm{m}$ até o infravermelho distante como sendo uma conseqüência da emissão térmica de poeira no disco da galáxia. Chapman et al. (2000) analisaram imagens com alta resolução espacial nas bandas J, H e K, obtidas com o Adaptive Optics Bonnette do CFHT, e, apesar dos artefatos gerados pela óptica adaptativa, identificaram várias estruturas, que se assemelhavam a nós, em um padrão espiral dentro de um raio de 2", o que poderia sugerir que se tratasse de braços espirais embebidos. Essa estrutura espiral também poderia ser o mecanismo de alimentação do AGN.

Davies et al. (2006) analisaram um cubo de dados na banda K da região central de NGC 3227, obtido com o SINFONI do VLT. Os autores detectaram uma estrutura com emissão de $\mathrm{H}_{2}$ geometricamente espessa, com uma extensão espacial de algumas dezenas de parsecs e com uma densidade de coluna de $n_{H}=10^{24}-10^{25} \mathrm{~cm}^{-2}$. Com base em todas essas características os autores concluíram se tratar de um toro molecular obscurecedor ao redor do AGN central. 


\section{2 - Preparação dos cubos de dados de NGC 3227}

Nesse trabalho, foram analisados cubos de dados da região central de NGC 3227, tanto no óptico quanto na banda $\mathrm{K}$ do infravermelho próximo. No óptico, os cubos foram obtidos com o IFU do GMOS do telescópio Gemini-Norte e, no infravermelho próximo, os cubos foram resultantes de observações com o SINFONI do VLT. Os dados no óptico são os mesmos analisados por Barbosa et al. (2006; 2009), ao passo que, no infravermelho, os dados são os mesmos analisados por Davies et al. (2006). Entretanto, aqui foram utilizadas diferentes metodologias de análise.

\subsection{1 - Redução e tratamento dos cubos de dados obtidos com o GMOS}

A redução dos cubos de dados obtidos com o GMOS foi feita em ambiente IRAF, utilizando-se o pacote de tarefas Gemini, conforme explicado em 3.2.1. Ao final desse processo, foram obtidos 2 cubos de dados com pixeis espaciais de 0.05 " de lado.

Após isso, foi aplicada a correção da refração atmosférica diferencial em cada um dos cubos de dados. Em seguida, a fim de se combinar todos os cubos em um só, calculou-se uma média entre eles.

Aplicou-se, então, uma decomposição wavelet no cubo de dados encontrado, obtendo-se, ao final, os cubos $W_{0}, W_{l}, W_{2}, W_{3}, W_{4}$ e $W_{C}$. Utilizou-se $W_{0}$ para se determinar os parâmetros mais adequados para o filtro de Butterworth e, a seguir, esses parâmetros foram usados na filtragem de todas as outras componentes wavelet e também do cubo de dados original. No caso desse objeto, todas as filtragens foram feitas utilizando-se um filtro com forma dada pela expressão (3.67), $n=2$ e freqüência de corte ao longo dos eixos horizontal e vertical de $v_{c}=0.24$ Ny. A figura 6.4 mostra as somas das imagens do cubo de dados, antes e depois da filtragem espacial de Butterworth, assim como a soma das imagens do cubo correspondente à diferença entre esses dois. 

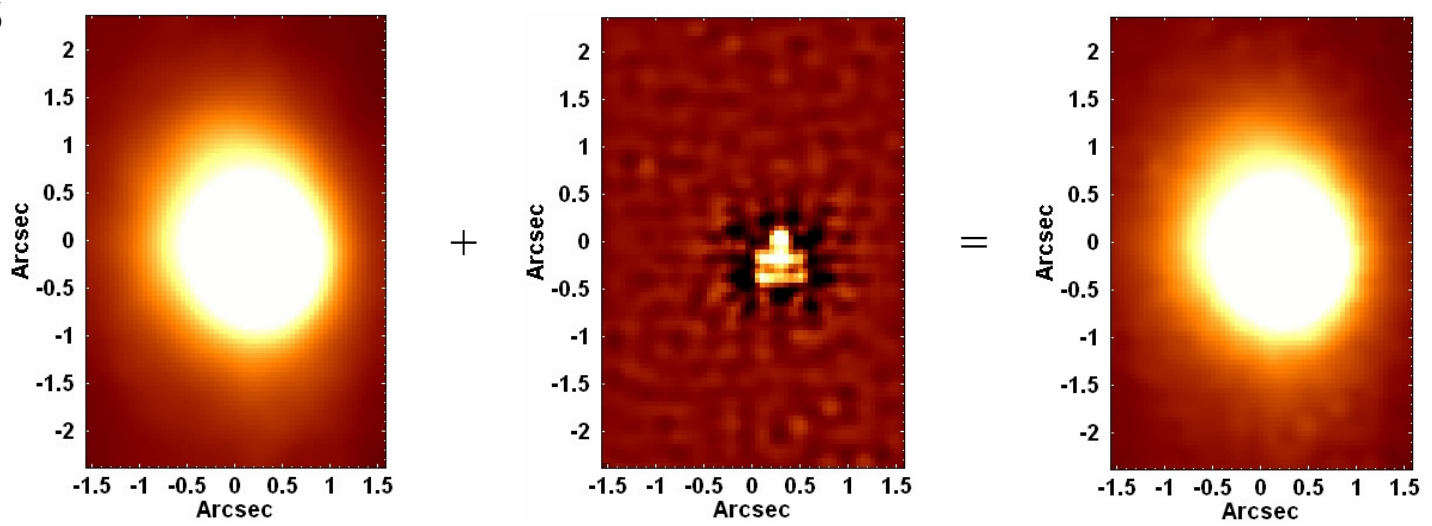

Figura 6.4 - (esquerda) Imagem de um intervalo espectral intermediário colapsado do cubo de dados de NGC 3227 obtido com o GMOS, após a filtragem espacial de Butterworth; (centro) Imagem de um intervalo espectral intermediário colapsado do cubo de dados de NGC 3227 obtido com o GMOS, correspondente à diferença entre o cubo não filtrado e o cubo filtrado; (direita) Imagem de um intervalo espectral intermediário colapsado do cubo de dados de NGC 3227 obtido com o GMOS, antes da filtragem espacial de Butterworth. As imagens à esquerda e à direita estão com a LUT exagerada para facilitar a visualização dos ruídos removidos pela filtragem.

Observando-se a figura 6.4, pode-se notar que a filtragem espacial de Butterworth removeu uma quantidade considerável de ruídos de alta freqüência, o que proporcionou uma melhoria na qualidade das imagens do cubo de dados.

Após a aplicação da filtragem espacial de Butterworth, verificou-se que o cubo de dados ainda apresentava um fingerprint instrumental de baixa freqüência espacial, que tomava a forma de faixas verticais nas imagens. Tal fingerprint também possuía uma assinatura espectral bastante característica. A fim de se remover essa estrutura do cubo de dados, aplicou-se o procedimento descrito em 3.11. A figura 6.5 mostra o tomograma e o auto-espectro correspondentes ao autovetor E4 (que é o que mostra o fingerprint existente de maneira mais clara), resultante da Tomografia PCA do cubo de dados de NGC 3227 obtido com o GMOS, após a remoção das linhas espectrais, assim como o resultado encontrado após o ajuste e a subtração de um spline do auto-espectro. 

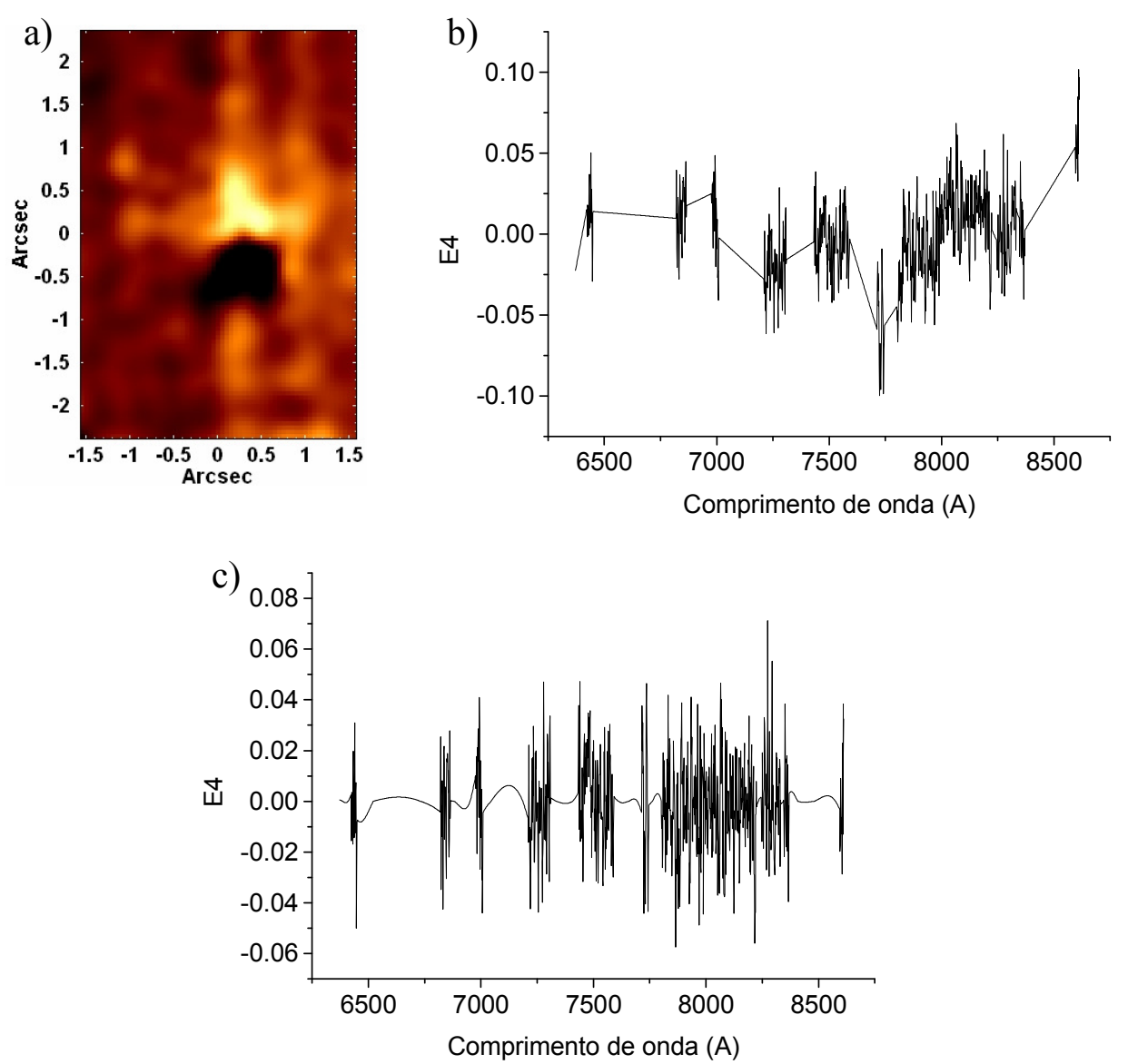

Figura 6.5 - (a) Tomograma correspondente ao autovetor E4, resultante da Tomografia PCA aplicada ao cubo de dados de NGC 3227 obtido com o GMOS, após a remoção das linhas espectrais; (b) Auto-espectro correspondente ao autovetor E4, resultante da Tomografia PCA aplicada ao cubo de dados de NGC 3227 obtido com o GMOS, após a remoção das linhas espectrais; (c) Mesmo auto-espectro mostrado em (b), após a subtração do "spline" ajustado.

Finalmente, passou-se para a etapa da deconvolução de Richardson-Lucy. Esse procedimento foi aplicado utilizando-se uma PSF gaussiana variável com o comprimento de onda, conforme descrito em 3.9.1. Um valor de referência para o $F W H M$ da gaussiana foi estimado a partir da imagem da região espectral correspondente à asa larga da linha $\mathrm{H} \alpha$, e a forma de variação do $F W H M$ com o comprimento de onda foi estimada a partir do cubo de dados da estrela padrão utilizada para a calibração em fluxo. Antes desse processo, entretanto, a filtragem espacial de Butterworth foi aplicada no cubo da estrela padrão. A deconvolução de Richardson-Lucy foi aplicada utilizando-se 10 iterações. A figura 6.6 mostra a soma de todas as imagens e o espectro médio do cubo de dados de NGC 3227 obtido com o GMOS, após a aplicação da deconvolução de Richardson-Lucy. 

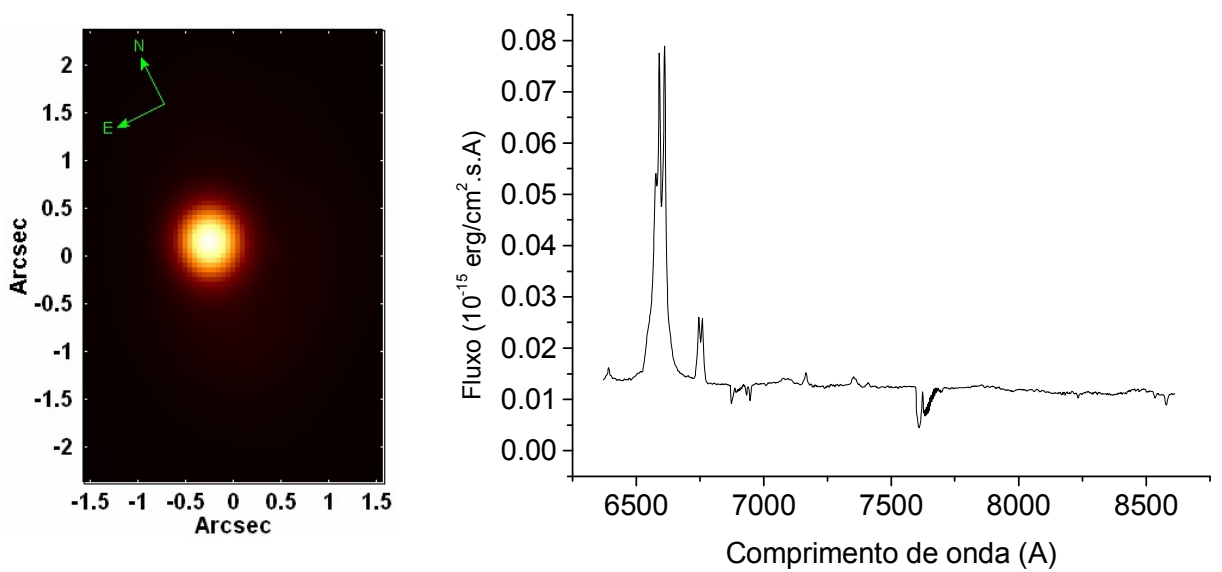

Figura 6.6 - (esquerda) Soma de todas as imagens do cubo de dados de NGC 3227 obtido com o GMOS, após todo o processamento; (direita) Espectro médio do cubo de dados de NGC 3227 obtido com o GMOS, após todo o processamento.

\subsection{2 - Redução e tratamento dos cubos de dados obtidos com SINFONI}

A redução dos cubos de dados de NGC 3227 obtidos com o SINFONI foi feita com o software Gasgano. Entretanto, como a remoção de absorções telúricas e a calibração em fluxo não são feitas com esse software, essas duas etapas da redução foram aplicadas utilizando-se algoritmos escritos em linguagem IRAF. Todo esse procedimento está descrito em maiores detalhes em 3.2.3. Ao final da redução, foram obtidos 9 cubos de dados com pixeis espaciais de $0.0125 \%$ de lado.

Em seguida, foi aplicado o processo de correção da refração atmosférica diferencial em cada um dos cubos de dados. Após isso, a fim de se combinar todos esses cubos em um só, primeiramente, eles foram separados em três grupos. Nomeando os cubos como 1, 2, 3, 4,..,9 (de acordo com a ordem de observação), a separação nos três grupos foi feita da seguinte maneira:

- Grupo 1: cubos 1, 3 e 4

- Grupo 2: cubos 2, 6 e 7

- Grupo 3: cubos 5, 8 e 9 
Os integrantes de cada um desses três grupos foram combinados na forma de mediana, resultando, assim, em três cubos ao final do processo. Calculou-se, então, uma nova mediana desses três cubos de dados para se chegar ao cubo combinado procurado.

Após esse procedimento, aplicou-se uma reamostragem espacial no cubo de dados resultante, a fim de se obter pixeis espaciais de 0.00625 " de lado. A figura 6.7 mostra a soma de todas as imagens do cubo de dados de NGC 3227 obtido com o SINFONI, antes e depois do processo de reamostragem.
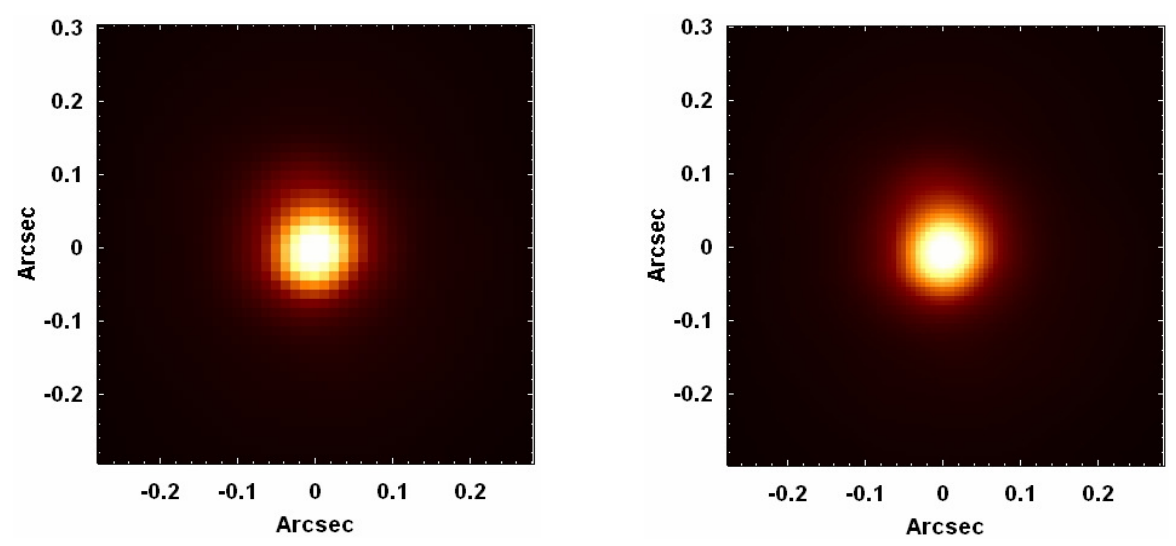

Figura 6.7 - (esquerda) Soma de todas as imagens do cubo de dados de NGC 3227 obtido com o SINFONI, antes da aplicação da reamostragem espacial; (direita) Soma de todas as imagens do cubo de dados de NGC 3227 obtido com o SINFONI, após a aplicação da reamostragem espacial.

A figura 6.7 revela que a aplicação da reamostragem espacial permitiu que as estruturas espaciais presentes no cubo de dados ficassem definidas de uma maneira mais clara. Esse processo, entretanto, também introduziu componentes de alta freqüência espacial, que aparecem, sobretudo, na forma de tênues faixas nas imagens, conforme explicado em 3.5.2. Embora esse efeito colateral não seja claramente visível na figura 6.7, ele afetou significativamente o cubo de dados e precisou ser removido por meio da filtragem espacial de Butterworth.

Aplicou-se uma decomposição wavelet no cubo de dados reamostrado, com a conseqüente obtenção dos cubos $W_{0}, W_{1}, W_{2}, W_{3}, W_{4}$ e $W_{C}$. Utilizou-se $W_{0}$ para se determinar os parâmetros mais adequados para o filtro de Butterworth e, a seguir, esses parâmetros foram usados na filtragem espacial de todas as outras componentes wavelet e também do cubo de dados original. No caso desse objeto, todas as filtragens foram feitas utilizando-se um filtro com forma dada pela expressão (3.67), $n=2$ e freqüência de corte ao longo dos eixos horizontal e vertical de $v_{c}=0.25 \mathrm{Ny}$. A figura 6.8 mostra as somas das imagens do cubo de dados, antes e 
depois da filtragem espacial de Butterworth, assim como a soma das imagens do cubo correspondente à diferença entre esses dois.
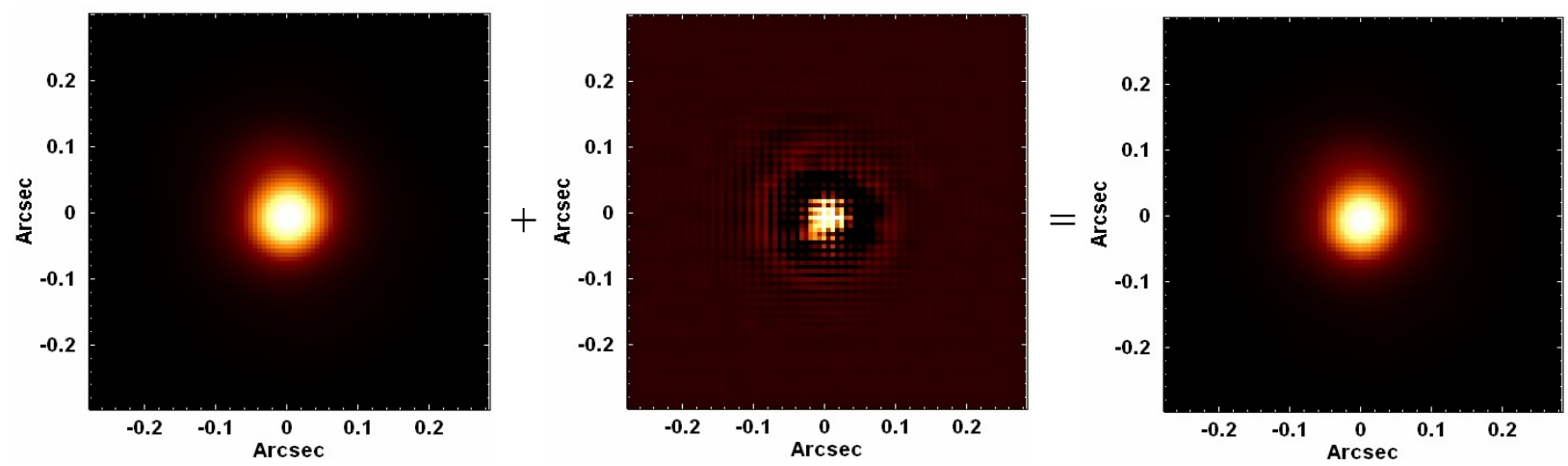

Figura 6.8 - (esquerda) Soma das imagens do cubo de dados de NGC 3227 obtido com o SINFONI, após a filtragem espacial de Butterworth; (centro) Soma das imagens do cubo de dados de NGC 3227 obtido com o SINFONI correspondente à diferença entre o cubo não filtrado e o cubo filtrado; (direita) Soma das imagens do cubo de dados de NGC 3227 obtido com o SINFONI, antes da filtragem espacial de Butterworth.

Observando-se a figura 6.8, pode-se notar que a aplicação da filtragem espacial de Butterworth removeu uma grande quantidade de ruídos de alta freqüência (inclusive as componentes de alta freqüência introduzidas pela reamostragem espacial). Entretanto, também é possível observar que o processo de filtragem espacial de Butterworth provocou uma ligeira degradação da PSF, o que poderia sugerir que freqüências de corte mais elevadas seriam mais adequadas para esse processo de filtragem. Entretanto, verificou-se que maiores freqüências de corte não eliminavam de maneira totalmente eficaz os ruídos espaciais presentes. Considerandose isso e o fato de a degradação da PSF ter sido leve (indicando que poderia ser revertida com a aplicação da deconvolução de Richardson-Lucy), optou-se por manter os valores utilizados para a frequência de corte na filtragem espacial de Butterworth.

Após a filtragem espacial de Butterworth, verificou-se que, assim como ocorreu no caso do cubo de dados de NGC 3227 obtido com o GMOS, um fingerprint instrumental que tomava a forma de largas faixas horizontais na imagem era claramente detectável. Tal fingerprint também possuía uma assinatura espectral bastante característica. A fim de se remover essa estrutura do cubo de dados, aplicou-se o procedimento descrito em 3.11. A figura 6.9 mostra o tomograma e o auto-espectro correspondentes ao autovetor E6 (que é o que mostra o fingerprint existente de maneira mais clara), resultante da Tomografia PCA do cubo de dados de NGC 3227 obtido com 
o SINFONI, após a remoção das linhas espectrais, assim como o resultado encontrado após o ajuste e a subtração de um spline do auto-espectro.
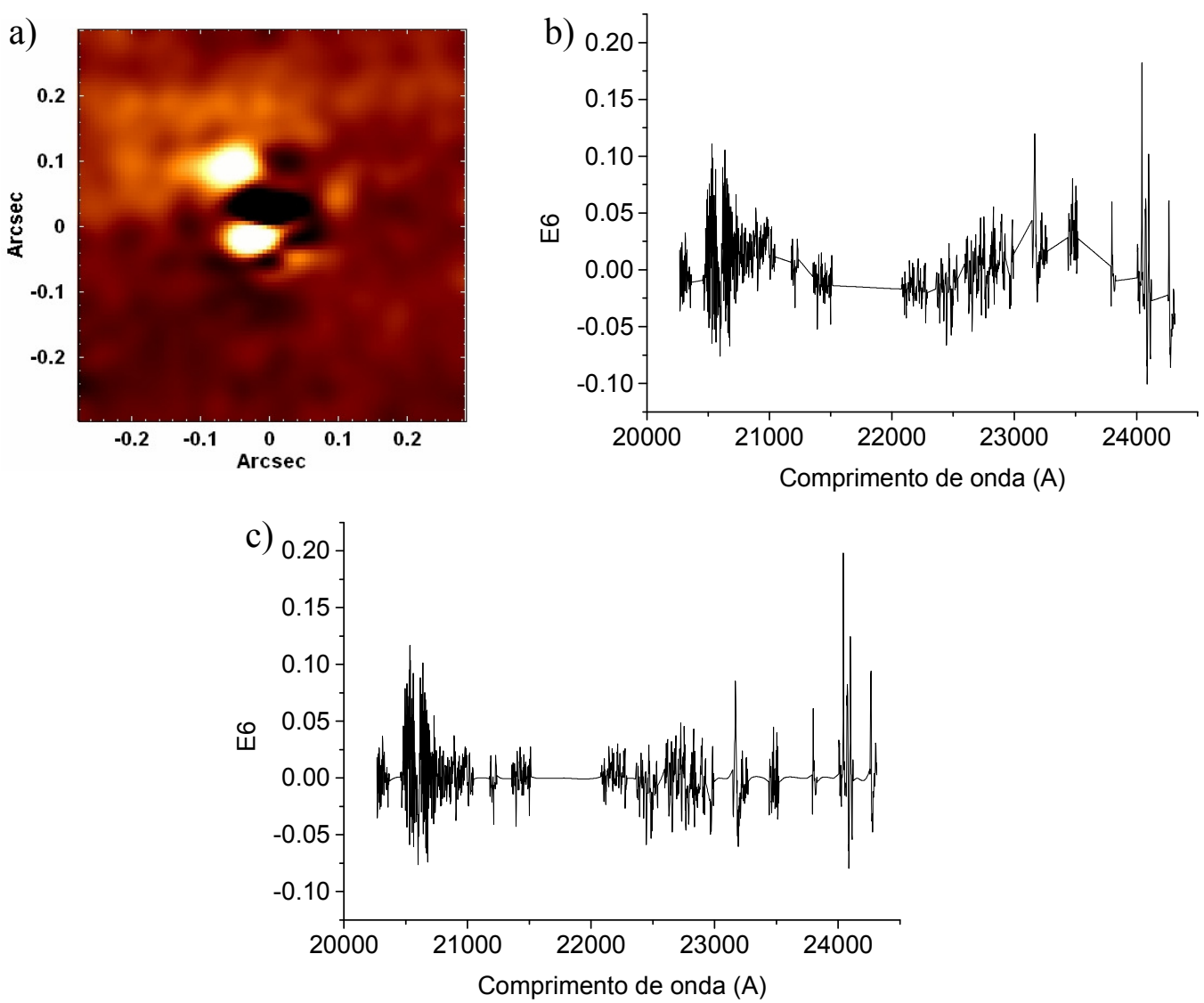

Figura 6.9 - (a) Tomograma correspondente ao autovetor E6, resultante da Tomografia PCA aplicada ao cubo de dados de NGC 3227 obtido com o SINFONI, após a remoção das linhas espectrais; (b) Auto-espectro correspondente ao autovetor E6, resultante da Tomografia PCA aplicada ao cubo de dados de NGC 3227 obtido com o SINFONI, após a remoção das linhas espectrais; (c) Mesmo auto-espectro mostrado em (b), após a subtração do "spline” ajustado.

Por fim, passou-se para a etapa da deconvolução de Richardson-Lucy. Devido ao fato de a imagem da componente larga da linha Br $\gamma$ de NGC 3227 ser consideravelmente ruidosa, não foi possível utilizá-la como estimativa da PSF da observação. Ao invés disso, optou-se por adotar como PSF uma imagem proveniente do cubo de dados da estrela padrão usada no processo de redução dos dados para a remoção das absorções telúricas e para a calibração em fluxo. Para se fazer isso, entretanto, foi preciso aplicar ao cubo de dados dessa estrela padrão o mesmo processamento adotado para o cubo de NGC 3227, ou seja, foi feita a reamostragem espacial e a filtragem espacial de Butterworth desse cubo. Uma vez obtida a imagem 
correspondente à PSF, foi aplicada a deconvolução de Richardson-Lucy no cubo de dados de NGC 3227 utilizando-se 10 iterações. A figura 6.10 mostra a soma de todas as imagens e o espectro médio do cubo de dados final, obtido após a aplicação da deconvolução de RichardsonLucy.
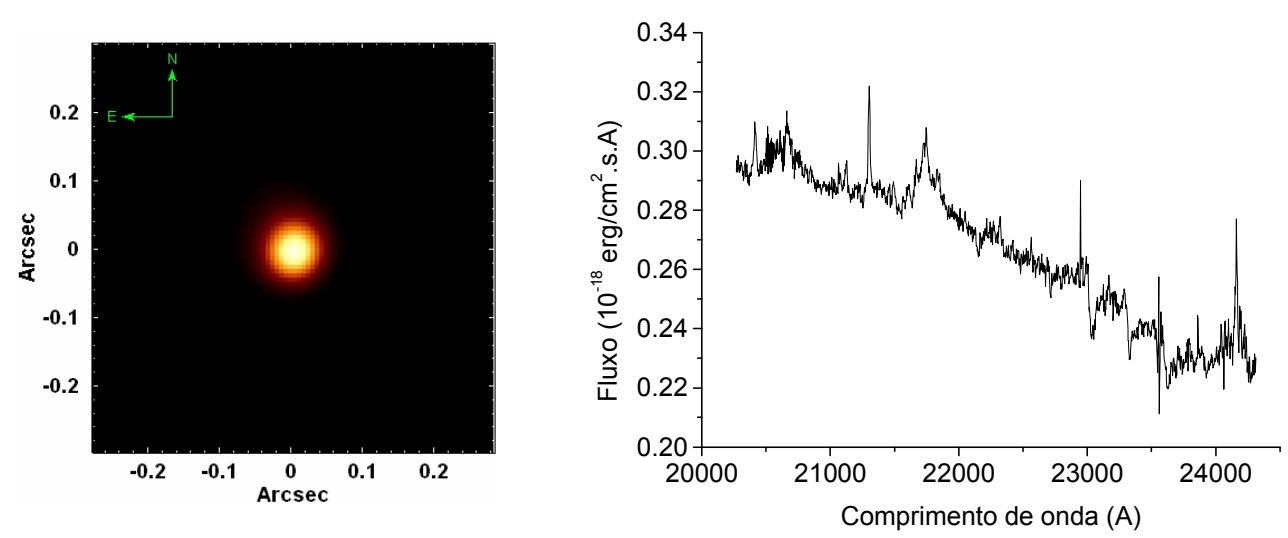

Figura 6.10 - (esquerda) Soma de todas as imagens do cubo de dados de NGC 3227 obtido com o SINFONI, após todo o processamento; (direita) Espectro médio do cubo de dados de NGC 3227 obtido com o SINFONI, após todo o processamento.

\section{3 - Aplicação da Tomografia PCA aos cubos de dados de NGC 3227 com o contínuo estelar}

Após todo o processamento descrito em 6.2, aplicou-se a Tomografia PCA tanto ao cubo de dados de NGC 3227 obtido com o GMOS quanto àquele obtido com o SINFONI, já que as informações reveladas por esses dois cubos são bastante complementares. O cubo proveniente do SINFONI possui uma resolução espacial maior devido ao efeito da óptica adaptativa utilizada, entretanto, a razão $S / N$ de seus espectros é consideravelmente menor do que a apresentada pelos espectros do cubo obtido com o GMOS. Isso faz com que a análise desse último também seja bastante relevante, apesar de sua menor resolução espacial. Assim, pode-se dizer que a aplicação da Tomografia PCA a esses dois cubos de dados permitiu que as informações complementares reveladas por eles fossem igualmente levadas em conta, resultando, assim, numa análise bastante completa e detalhada. 


\subsection{1 - Resultados da Tomografia PCA do cubo de dados de NGC 3227 obtido com o GMOS, com o contínuo estelar}

Os principais auto-espectros e respectivos tomogramas resultantes da Tomografia PCA do cubo de dados de NGC 3227 obtido com o GMOS encontram-se a seguir.
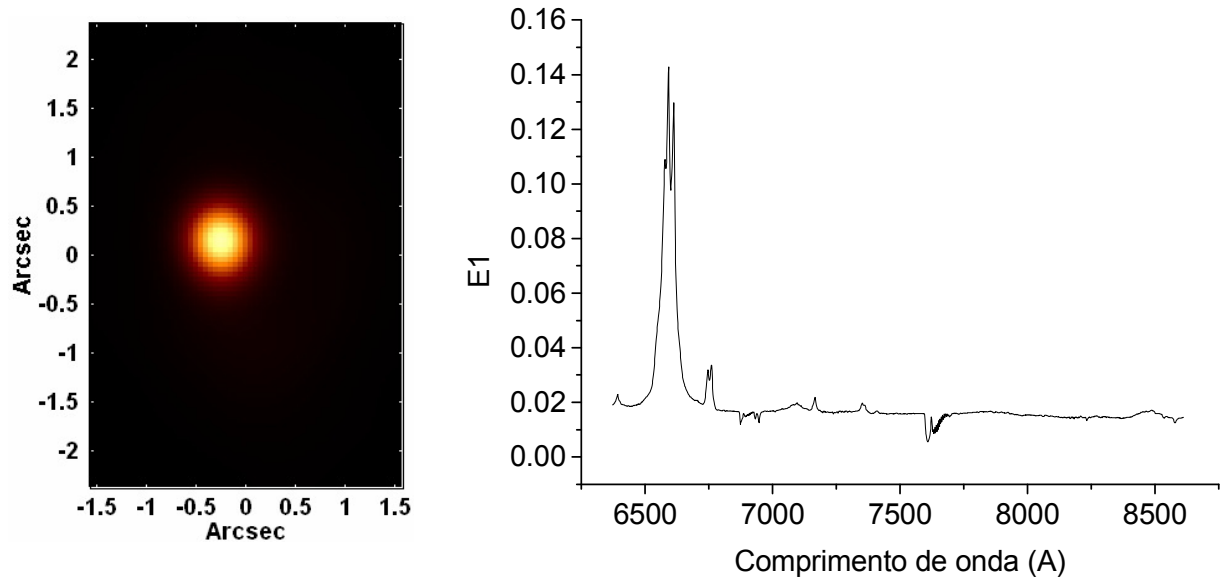

Figura 6.11 - Tomograma e auto-espectro correspondentes ao autovetor E1, resultante da Tomografia PCA do cubo de dados de NGC 3227 obtido com o GMOS, com o contínuo estelar.

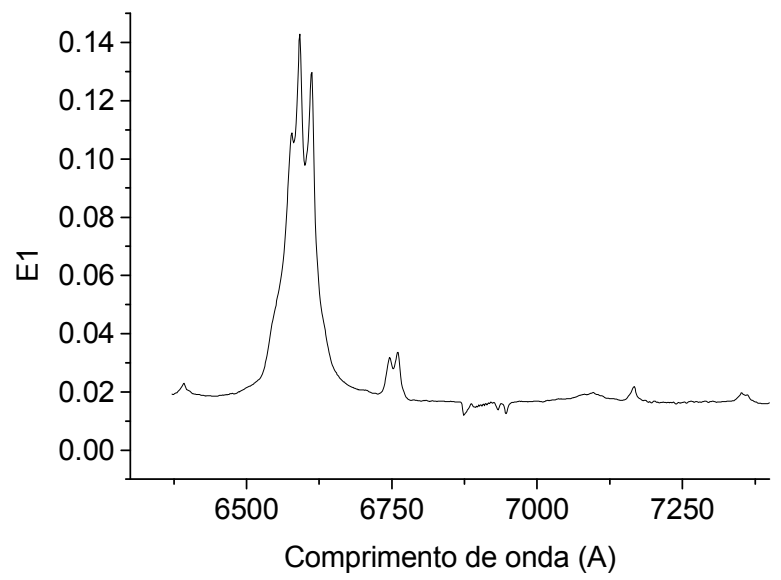

Figura 6.12 - Ampliação na região espectral azul do auto-espectro correspondente ao autovetor E1, resultante da Tomografia PCA do cubo de dados de NGC 3227 obtido com o GMOS, com o contínuo estelar. 
314
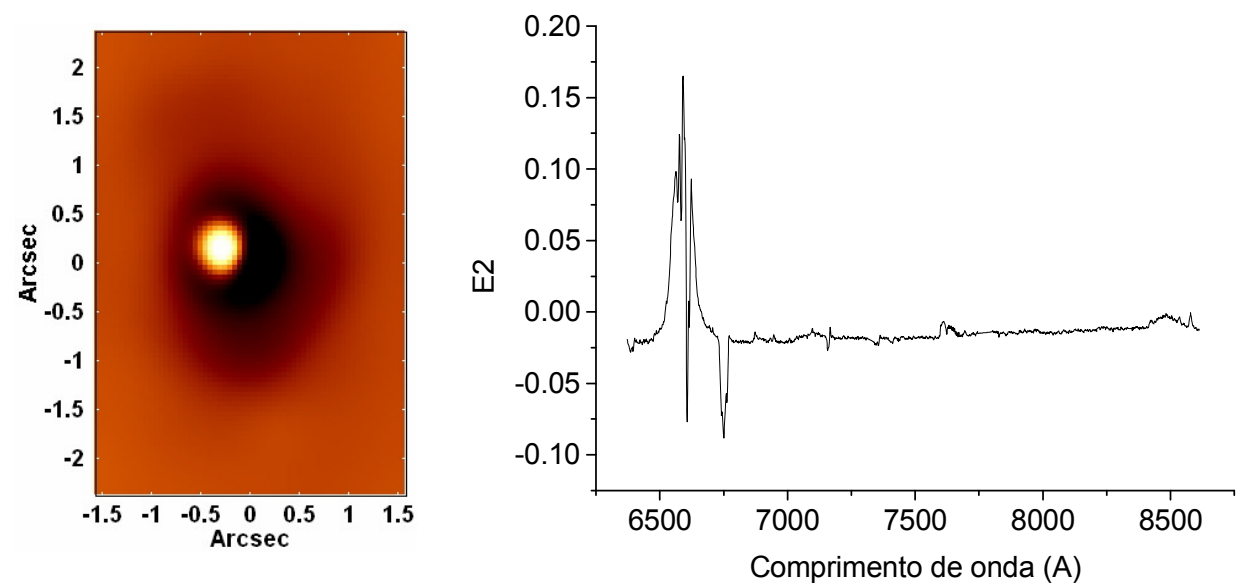

Figura 6.13 - Tomograma e auto-espectro correspondentes ao autovetor E2, resultante da Tomografia PCA do cubo de dados de NGC 3227 obtido com o GMOS, com o contínuo estelar.
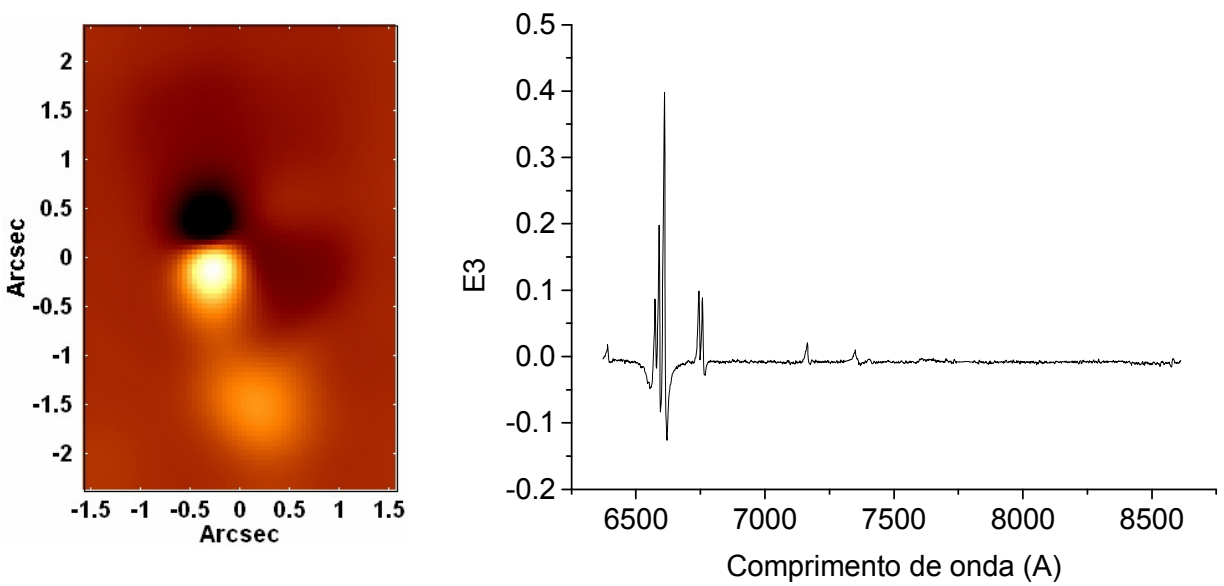

Figura 6.14 - Tomograma e auto-espectro correspondentes ao autovetor E3, resultante da Tomografia PCA do cubo de dados de NGC 3227 obtido com o GMOS, com o contínuo estelar.

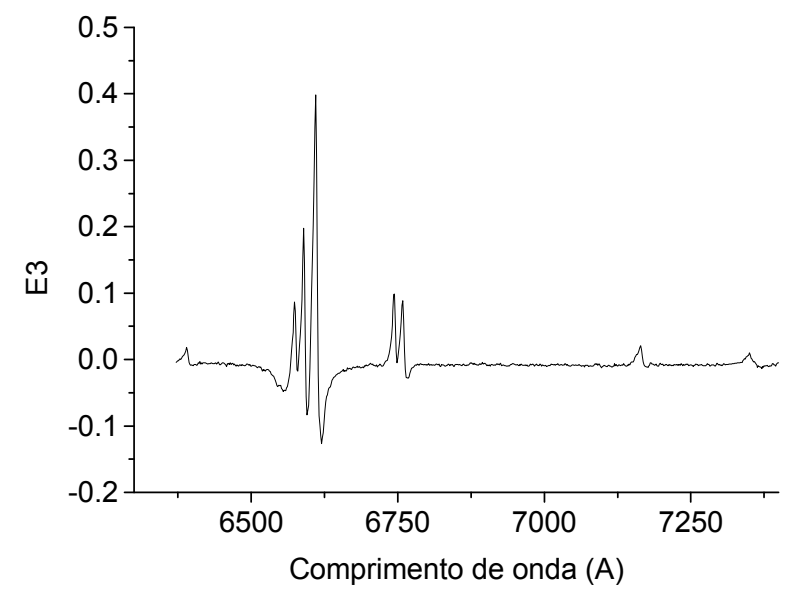

Figura 6.15 - Ampliação na região espectral azul do auto-espectro correspondente ao autovetor E3, resultante da Tomografia PCA do cubo de dados de NGC 3227 obtido com o GMOS, com o contínuo estelar. 

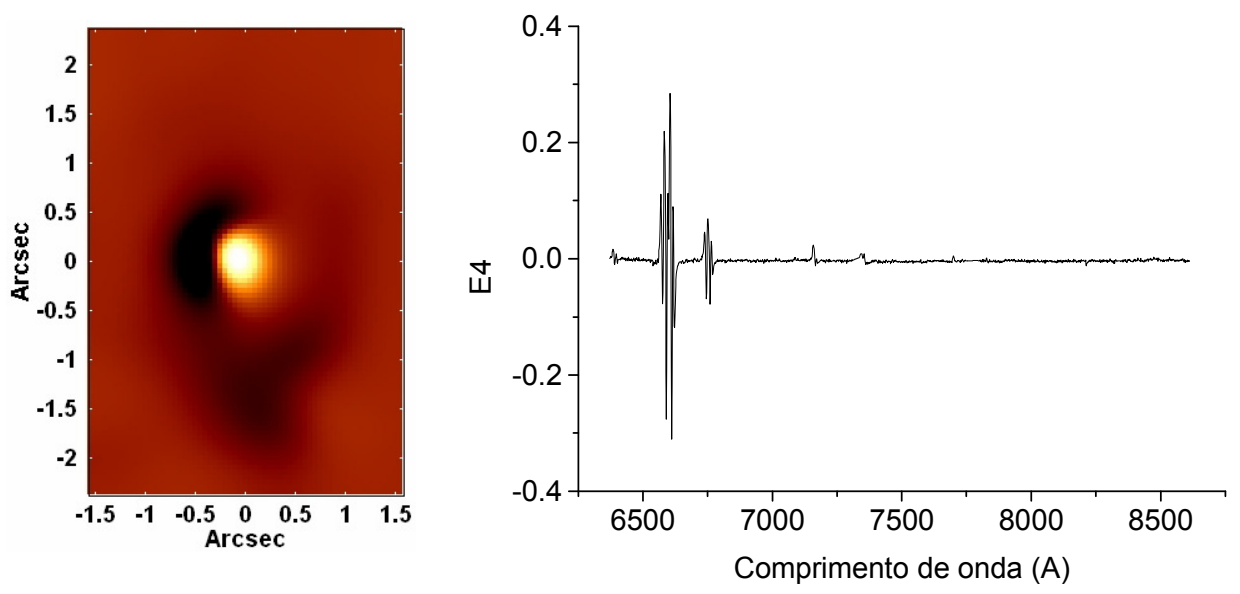

Figura 6.16 - Tomograma e auto-espectro correspondentes ao autovetor E4, resultante da Tomografia PCA do cubo de dados de NGC 3227 obtido com o GMOS, com o contínuo estelar.

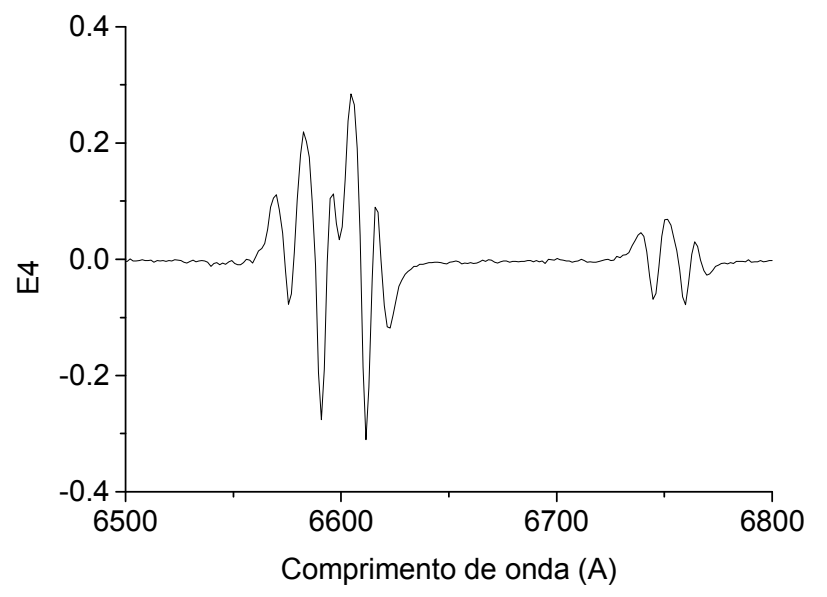

Figura 6.17 - Ampliação na região espectral azul do auto-espectro correspondente ao autovetor E4, resultante da Tomografia PCA do cubo de dados de NGC 3227 obtido com o GMOS, com o contínuo estelar.

\begin{tabular}{|c|c|}
\hline Autovetor & Fração da variância explicada (\%) \\
\hline E1 & 99.3205 \\
\hline E2 & 0.3831 \\
\hline E3 & 0.1640 \\
\hline E4 & 0.0837 \\
\hline
\end{tabular}

Tabela 6.1 - Autovalores encontrados com a Tomografia PCA do cubo de dados de NGC 3227 obtido com o GMOS, com o contínuo estelar. 


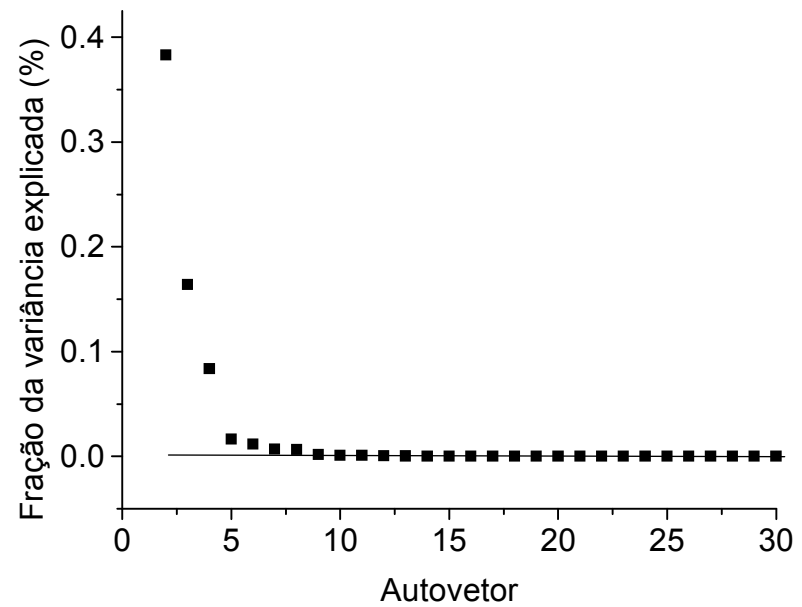

Figura 6.18 - "Scree test" dos autovetores encontrados com a Tomografia PCA do cubo de dados de NGC 3227 obtido com o GMOS, com o contínuo estelar.

As figuras 6.11 e 6.12 mostram que o auto-espectro E1 e o tomograma associado apresentam o aspecto do espectro médio e da soma de todas as imagens do cubo de dados de NGC 3227 obtido com o GMOS (figura 6.6), respectivamente. Isso está de acordo com o esperado, já que esse autovetor explica a maior parte da variância dos dados (98.8843 \%), revelando, portanto, características que já eram claramente detectáveis no cubo de dados do objeto analisado. Um aspecto importante do auto-espectro E1 é que ele apresenta correlações com comprimentos de onda associados às componentes largas das linhas de H $\alpha$ e He I $\lambda 7065$, o que indica que esse autovetor está correlacionado com a emissão proveniente do AGN central, cuja posição deve corresponder à área mais clara do tomograma. A presença da emissão do AGN no autovetor E1 era previsível, já que o AGN desse objeto é de forte intensidade e, por isso mesmo, está associado a uma grande parte da variância dos dados.

Observando-se a figura 6.13, pode-se notar que o auto-espectro E2 apresenta correlações com os comprimentos de onda correspondentes às componentes largas de algumas linhas de emissão do espectro e anti-correlações com os comprimentos de onda associados às componentes estreitas de outras linhas (sendo que certas linhas apresentavam tanto componentes largas quanto estreitas). Isso parece indicar que esse autovetor estabelece uma diferenciação entre regiões com emissão de linhas estreitas (provavelmente representando a NLR do AGN), que estão entre as áreas escuras do tomograma, e regiões emitindo linhas largas (representando a BLR do AGN), que estão entre as áreas claras do tomograma. Nesse caso, obviamente, a posição do AGN é a mesma que a da BLR, ou seja, a área clara do tomograma. Comparando-se 
as figuras 6.11 e 6.13, pode-se notar que as posições encontradas para o AGN são compatíveis. O autovetor E2 explica cerca de 0.3831 \% da variância dos dados.

Uma análise das figuras 6.14 e 6.15 revela que as principais características do autoespectro E3 são correlações com os comprimentos de onda associados à região central de várias linhas de emissão e anti-correlações com os comprimentos de onda correspondentes às asas vermelhas de algumas linhas. Isso indica que esse autovetor está relacionado a algum fenômeno cinemático do gás na região central de NGC 3227. Nesse caso, as áreas claras do tomograma apresentam gás sem componentes radiais de velocidade relevantes e as regiões escuras possuem gás com emissão em redshift. Essas características, juntamente com a morfologia do tomograma em questão, não são compatíveis com o que se esperaria de uma rotação do gás ao redor do núcleo, o que sugere a presença de algum outro fenômeno cinemático, como um outflow, por exemplo. O redshift revelado pelo autovetor E3 indica velocidades radiais bastante apreciáveis, com módulos de mais de $500 \mathrm{~km} / \mathrm{s}$. O autovetor E3 também parece apresentar anti-correlações com os comprimentos de onda associados à componente larga da linha $\mathrm{H} \alpha$. Isso sugere que esse autovetor também está anti-correlacionado com a emissão proveniente da BLR, cuja posição deve estar entre as áreas mais escuras do tomograma. Esse resultado é compatível com o que foi observado nos autovetores discutidos anteriormente. O autovetor E3 explica cerca $0.1640 \%$ da variância dos dados.

Por fim, as figuras 6.16 e 6.17 mostram que o auto-espectro E4 apresenta, primeiramente, correlações com os comprimentos correspondentes às asas azuis de várias linhas de emissão e anti-correlações com os comprimentos de onda associados às asas vermelhas das mesmas. Nesse caso, o blueshift e o redshift revelados por essas correlações e anti-correlações indicam velocidades radiais com módulos relativamente modestos, de pouco mais de $100 \mathrm{~km} / \mathrm{s}$. O auto-espectro E4 também possui correlações com os comprimentos de onda correspondentes às asas vermelhas de algumas linhas de emissão, com redshifts indicativos de velocidades radiais com módulos intermediários, de pouco mais de $300 \mathrm{~km} / \mathrm{s}$. Por fim, o auto-espectro E4 apresenta, ainda, anti-correlações com os comprimentos de onda associados às asas vermelhas de algumas linhas de emissão, com redshifts indicando velocidades radiais com módulos elevados, de mais de $500 \mathrm{~km} / \mathrm{s}$ (os mesmos módulos de velocidade radial presentes no autovetor E3). Todas essas características sugerem que o autovetor E4 revela, de uma maneira mais detalhada que o autovetor E3, a complexa cinemática do gás existente na região central de 
NGC 3227. As correlações e anti-correlações apresentadas pelo autovetor E4, juntamente com a morfologia do tomograma, não são compatíveis com um movimento rotacional do gás ao redor do núcleo, devendo, portanto, estar relacionadas a outro fenômeno cinemático, como um outflow, por exemplo. O autovetor E4 explica cerca de 0.0837 \% da variância dos dados. Um ponto importante a ser mencionado é que as regiões emissoras mostradas nas figuras 6.14 e 6.16, provavelmente, devem estar associadas à NLR e ao cone de ionização do AGN desse objeto.

O Scree test da figura 6.18 revela que os valores das variâncias explicadas pelos autovetores decaem bastante até, aproximadamente, o autovetor E5. A partir daí, a taxa de decaimento diminui bastante, ficando praticamente constante a partir do autovetor E9. Isso indica que autovetores de ordem maior ou igual a 9 representam, sobretudo, ruído e, consequentemente, não possuem relevância nesse estudo. Entretanto, a análise mostrou que autovetores com ordem maior ou igual a 5 apresentavam uma quantidade maior de ruído e uma interpretação menos clara, logo, apenas autovetores com ordem menor do que essa foram

mostrados aqui. É provável que a diminuição da taxa de decaimento dos autovalores a partir do autovetor E5 (mesmo que ela ainda não tenha atingido um valor constante) represente um indicativo da diminuição da significância e um aumento do ruído dos autovetores com ordem maior ou igual a essa.

\subsection{2 - Resultados da Tomografia PCA do cubo de dados de NGC 3227 obtido com o SINFONI, com o contínuo estelar}

Os principais auto-espectros e respectivos tomogramas resultantes da Tomografia PCA do cubo de dados de NGC 3227 obtido com o SINFONI encontram-se a seguir. 

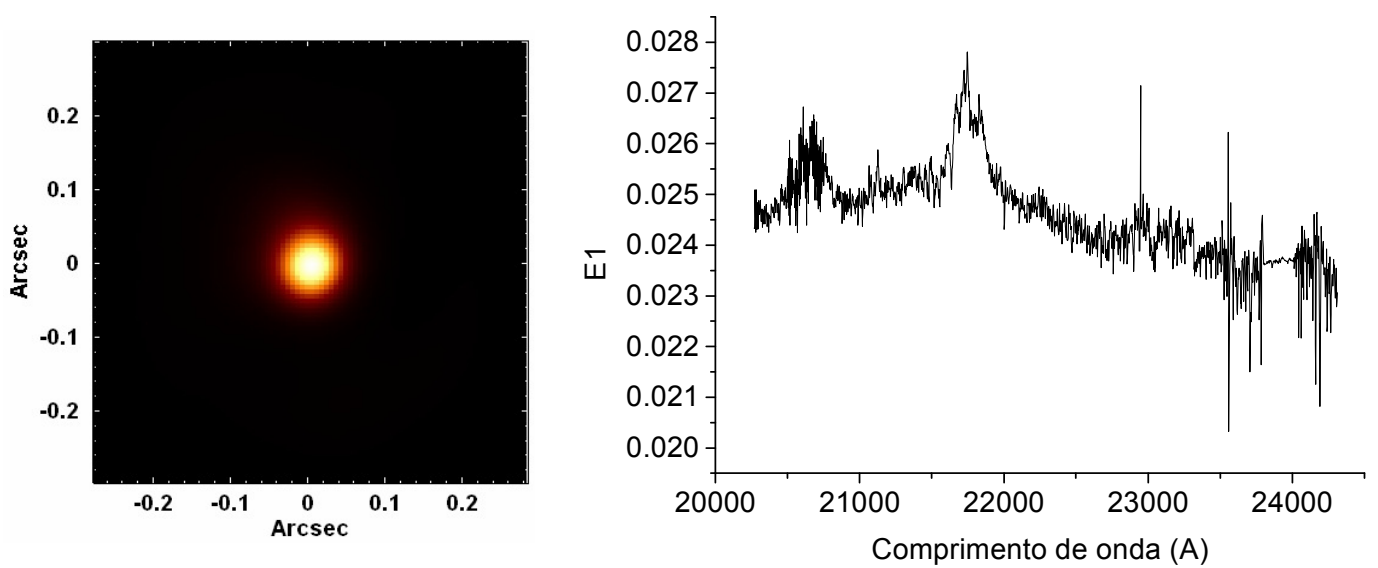

Figura 6.19 - Tomograma e auto-espectro correspondentes ao autovetor E1, resultante da Tomografia PCA do cubo de dados de NGC 3227 obtido com o SINFONI, com o contínuo estelar.
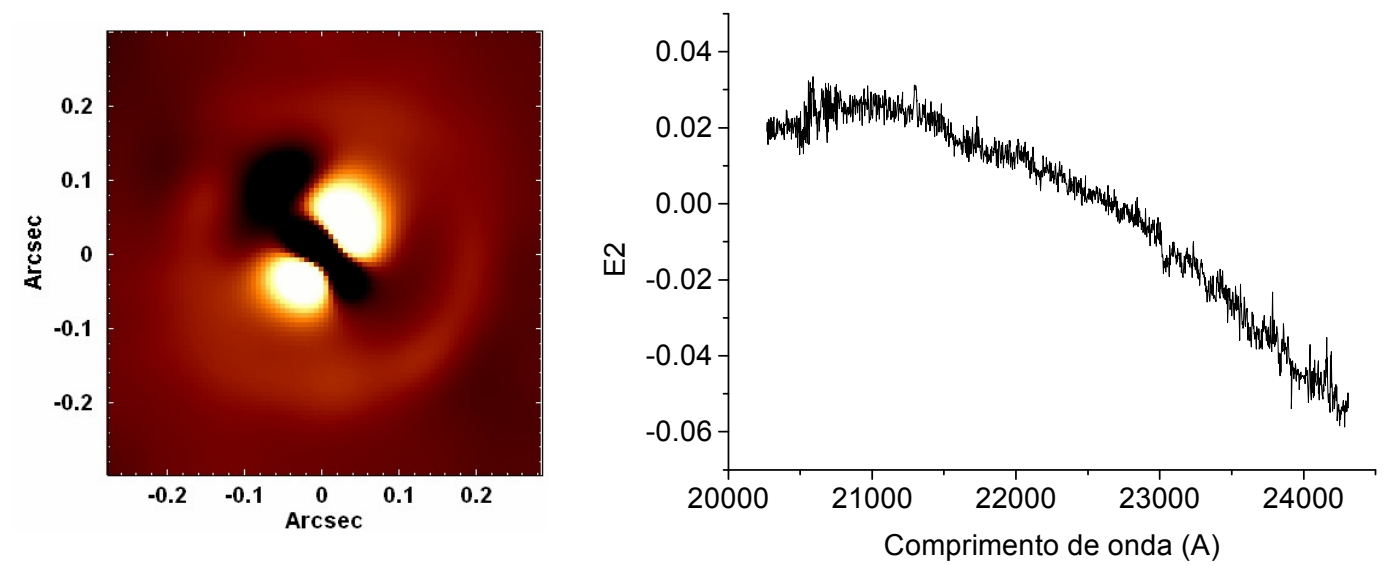

Figura 6.20 - Tomograma e auto-espectro correspondentes ao autovetor E2, resultante da Tomografia PCA do cubo de dados de NGC 3227 obtido com o SINFONI, com o contínuo estelar.
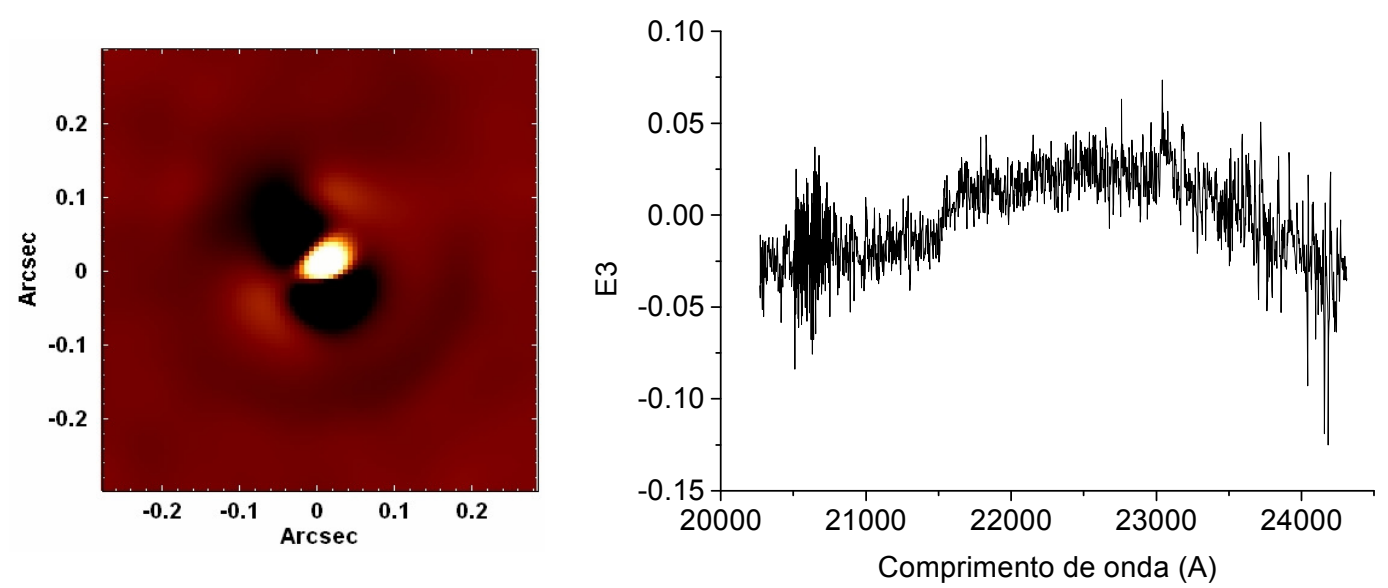

Figura 6.21 - Tomograma e auto-espectro correspondentes ao autovetor E3, resultante da Tomografia PCA do cubo de dados de NGC 3227 obtido com o SINFONI, com o contínuo estelar. 

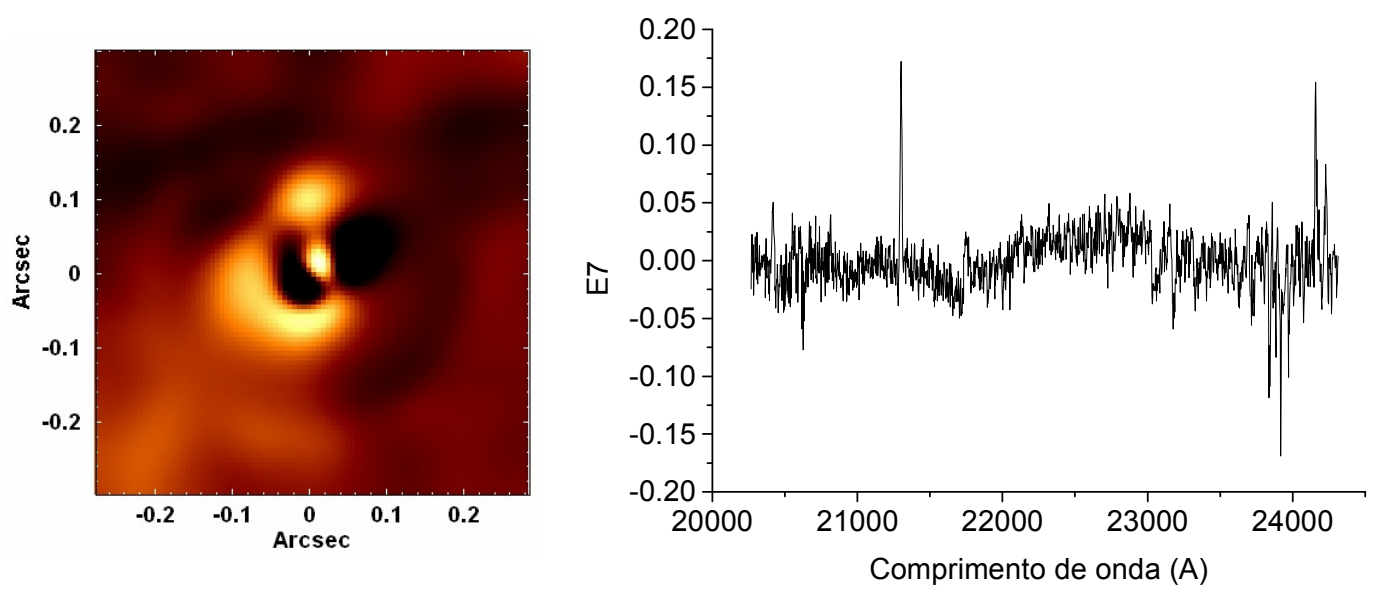

Figura 6.22 - Tomograma e auto-espectro correspondentes ao autovetor E7, resultante da Tomografia PCA do cubo de dados de NGC 3227 obtido com o SINFONI, com o contínuo estelar.
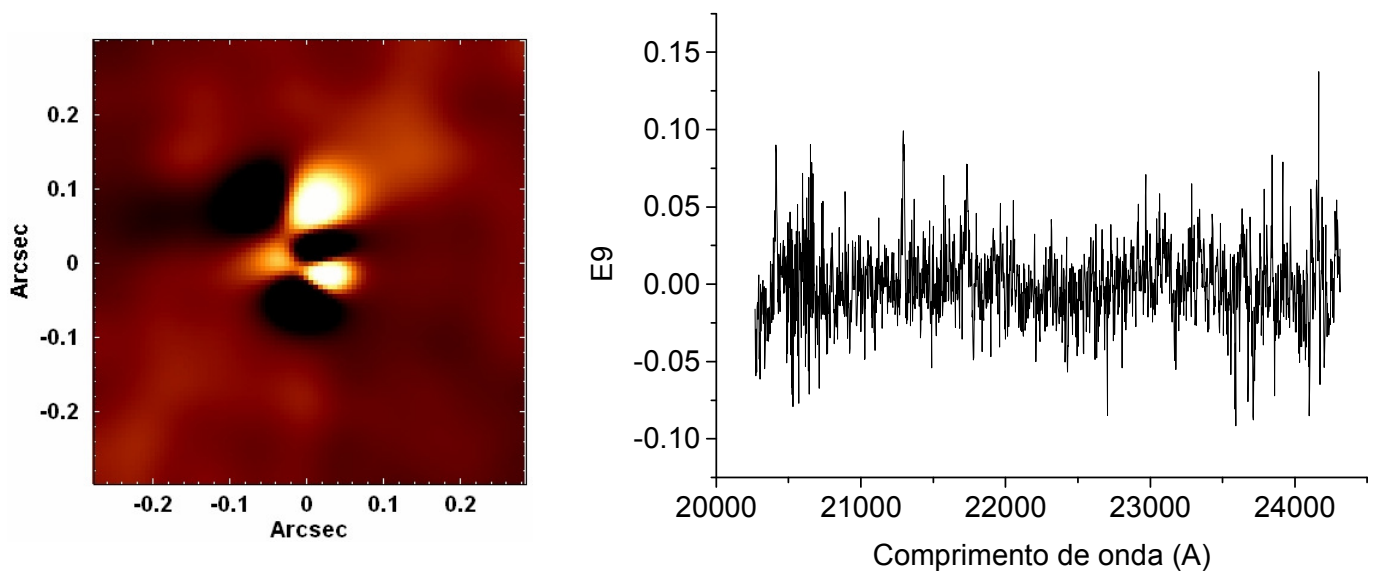

Figura 6.23 - Tomograma e auto-espectro correspondentes ao autovetor E9, resultante da Tomografia PCA do cubo de dados de NGC 3227 obtido com o SINFONI, com o contínuo estelar.
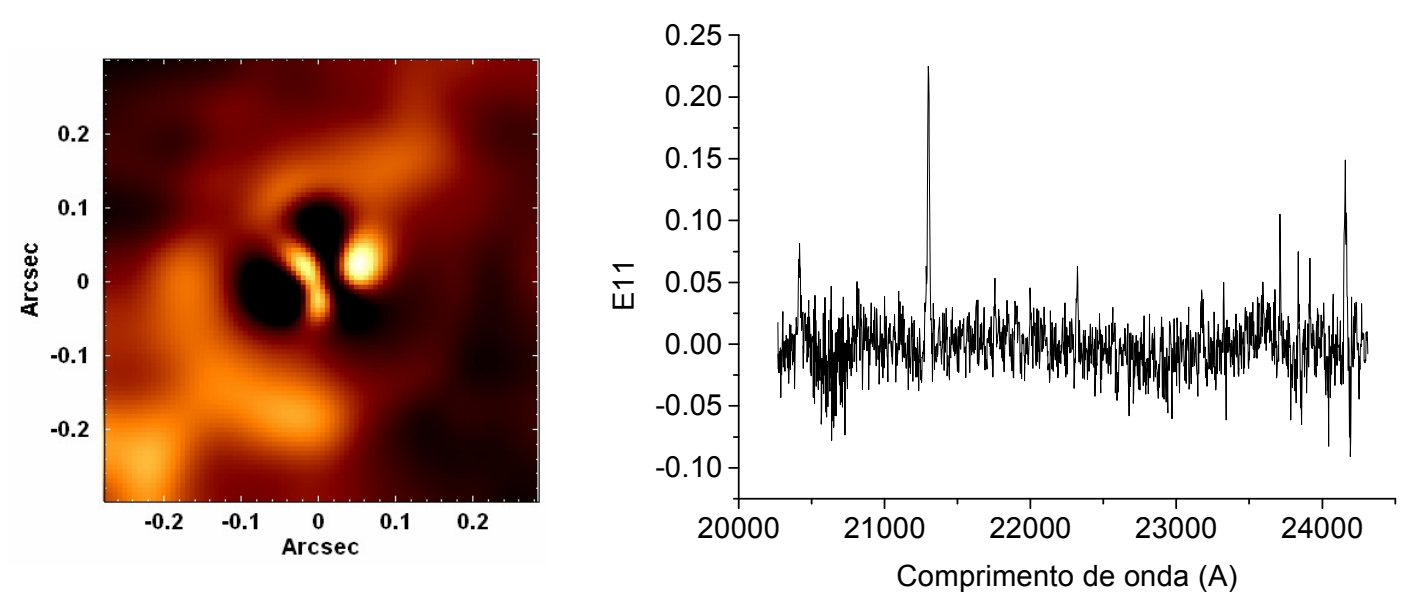

Figura 6.24 - Tomograma e auto-espectro correspondentes ao autovetor E11, resultante da Tomografia PCA do cubo de dados de NGC 3227 obtido com o SINFONI, com o contínuo estelar. 


\begin{tabular}{|c|c|}
\hline Autovetor & Fração da variância explicada (\%) \\
\hline E1 & 99.8834 \\
\hline E2 & 0.0923 \\
\hline E3 & 0.0072 \\
\hline E7 & 0.0009 \\
\hline E9 & 0.0004 \\
\hline E11 & 0.0003 \\
\hline
\end{tabular}

Tabela 6.2 - Autovalores encontrados com a Tomografia PCA do cubo de dados de NGC 3227 obtido com o SINFONI, com o contínuo estelar.

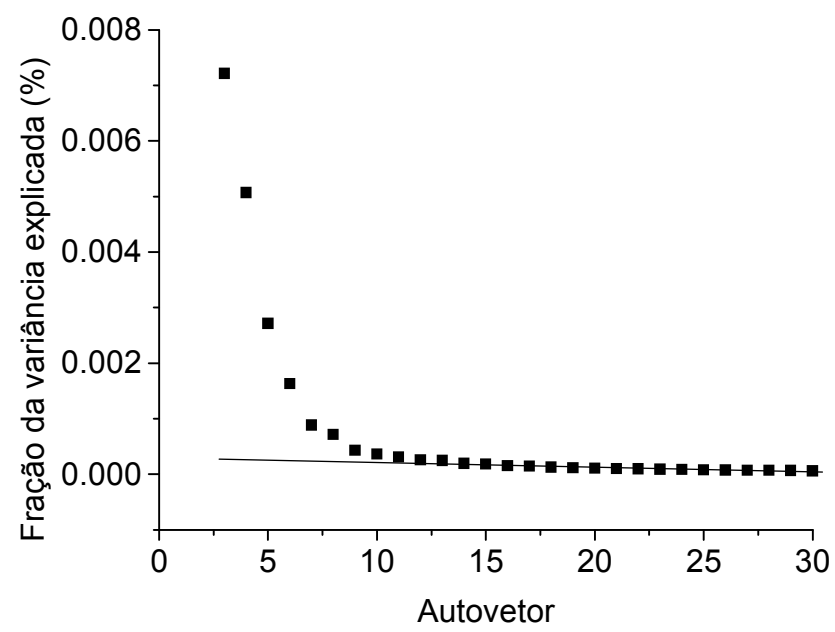

Figura 6.25 - "Scree test" dos autovetores encontrados com a Tomografia PCA do cubo de dados de NGC 3227 obtido com o SINFONI, com o contínuo estelar.

A figura 6.19 mostra que o auto-espectro E1 apresenta correlações com os comprimentos de onda correspondentes à linha de Bry. Pode-se notar, inclusive, correlações com os comprimentos de onda associados à componente larga dessa linha. Isso indica que esse autovetor está correlacionado com a emissão proveniente do AGN existente nessa galáxia. Nesse caso, a localização desse AGN corresponde à área mais clara do tomograma. O fato da emissão do AGN desse objeto aparecer no autovetor E1 está de acordo com o esperado, pois esse autovetor explica a maior parte da variância dos dados (99.8834 \%) e é sabido que o AGN dessa galáxia é de grande intensidade e, consequentemente, facilmente detectável.

Observando-se a figura 6.20, pode-se notar que o auto-espectro E2 apresenta uma correlação com a região azul do espectro, com um pico de correlação próximo a $21000 \AA$ e uma anti-correlação com a região vermelha do mesmo. Isso indica que esse autovetor estabelece um diferencial entre espectros mais avermelhados e espectros mais azulados existentes no cubo de dados desse objeto. Nesse caso, as áreas mais claras do tomograma possuem espectros mais azulados do que as regiões mais escuras. Outro fato a ser mencionado é que esse auto-espectro 
também parece estar correlacionado com algumas bandas de absorção de CO. Todas essas características indicam que, na região escura do tomograma (que possui um aspecto similar a uma pequena faixa diagonal na imagem), o fluxo parece ser devido, principalmente, à emissão térmica de poeira ao redor do AGN (o que é evidenciado pelo contínuo mais avermelhado dessa região) e, nas áreas claras do tomograma, o contínuo parece ser dominado pela emissão proveniente de populações estelares (o que é evidenciado pelo contínuo azul e pelas bandas de $\mathrm{CO}$ existentes). Analisando-se a morfologia desse tomograma, verifica-se que parte das áreas claras tomam a forma de um anel ao redor do núcleo, que, conforme foi discutido anteriormente, deve estar associado às populações estelares presentes. O autovetor E2 explica cerca de 0.0923 \% da variância dos dados.

A figura 6.21 revela que o auto-espectro E3 apresenta uma correlação com a região espectral entre $21500 \AA$ e $23000 \AA$ e uma anti-correlação com a região mais azul do espectro, próxima a $21000 \AA$. Isso sugere que as áreas escuras do tomograma devem possuir uma emissão mais intensa próximo a $21000 \AA$ do que as regiões mais claras. Um pico de emissão similar a esse também foi detectado no autovetor E2 e comparando-se as morfologias dos tomogramas nas figuras 6.20 e 6.21, pode-se notar uma considerável compatibilidade, sobretudo com relação à existência de uma área com formato similar a um anel, que, conforme foi explicado anteriormente, deve apresentar uma emissão dominada pelas populações estelares presentes. As regiões claras do tomograma da figura 6.21 devem possuir espectros mais avermelhados que os das áreas escuras, com uma emissão mais intensa na região espectral entre $21500 \AA$ e $23000 \AA$. É possível que tal emissão seja proveniente de poeira aquecida ao redor do AGN. O autoespectro E3 também apresenta uma anti-correlação com a porção mais vermelha do espectro (com comprimentos maiores do que $23000 \AA$ ). Assim, pelo menos parte das áreas escuras do tomograma devem possuir espectros com uma emissão mais intensa nessa região espectral de maiores comprimentos de onda, o que também poderia ser devido à emissão de térmica de poeira com temperaturas inferiores à daquela com pico de emissão entre $21500 \AA$ e $23000 \AA$. Comparando-se, mais uma vez, os tomogramas das figuras 6.20 e 6.21, nota-se uma certa compatibilidade no que se refere à área escura similar a uma faixa diagonal na imagem. É possível que a emissão térmica de poeira com temperaturas mais elevadas mencionada seja proveniente dessa região escura. O autovetor E3 explica cerca de 0.0072 \% da variância dos dados. 
Uma análise da figura 6.22 mostra que a principal característica do auto-espectro E7 são fortes correlações com os comprimentos de onda correspondentes às regiões centrais e às asas vermelhas das principais linhas de $\mathrm{H}_{2}$ e tênues anti-correlações com os comprimentos de onda associados às asas azuis das mesmas. Isso parece indicar que o autovetor E7 está relacionado a algum fenômeno cinemático do gás molecular existente na região central de NGC 3227. Nesse caso, as áreas claras do tomograma apresentam gás com baixas componentes radiais de velocidade ou redshift e as regiões escuras possuem gás com emissão em blueshift. $\mathrm{O}$ fato de a amplitude das anti-correlações com as asas azuis das linhas de $\mathrm{H}_{2}$ no auto-espectro ser muito menor do que a amplitude das correlações com as regiões centrais e as asas vermelhas das mesmas mostra que esse autovetor parece estar pouco associado com a emissão em blueshift. De qualquer modo, a morfologia do tomograma na figura 6.22 parece ser compatível com uma rotação do gás molecular ao redor do buraco negro central. O autovetor E7 explica cerca de $0.0009 \%$ da variância dos dados.

Por fim, as figuras 6.23 e 6.24 mostram que as principais características dos autoespectros E9 e E11 são correlações com os comprimentos de onda correspondentes às principais linhas de $\mathrm{H}_{2}$ do espectro. Isso mostra que esses autovetores estão correlacionados com a emissão de $\mathrm{H}_{2}$, que deve ser proveniente das áreas claras dos tomogramas associados. Pode-se notar uma considerável compatibilidade entre as morfologias dos tomogramas nas figuras 6.22, 6.23 e 6.24, que revelam que a emissão de $\mathrm{H}_{2}$ na região central de NGC 3227 é proveniente de uma área com um formato similar ao de uma faixa disposta ao longo da diagonal do campo de visão do SINFONI.

O Scree test mostrado na figura 6.25 revela que os as variâncias explicadas pelos autovetores decaem bastante até, aproximadamente, o autovetor E13. A partir daí o decaimento diminui muito e os valores ficam praticamente constantes. Isso mostra que os autovetores com ordens maiores ou iguais a essa representam, sobretudo, ruído e, consequentemente, não possuem relevância nessa análise. Entretanto, vários dos autovetores com ordens menores do que 13 também não apresentam uma interpretação evidente ou são dominados por ruído, logo, não foram analisados aqui. Apenas aqueles com interpretação suficientemente clara foram mostrados anteriormente. Isso revela que, embora o Scree test seja uma boa técnica para se avaliar a partir de que ordem os autovetores deixam conter um sinal significativo e passam a ser 
dominados pelo ruído, há casos em que essa estratégia pode não ser precisa, e uma averiguação detalhada dos autovetores é sempre muito conveniente.

Assim, pode-se dizer que essas análises iniciais com a Tomografia PCA aos cubos de dados de NGC 3227 obtidos com o GMOS e com o SINFONI, primeiramente, isolaram consideravelmente bem a emissão proveniente do AGN central dessa galáxia, sendo que

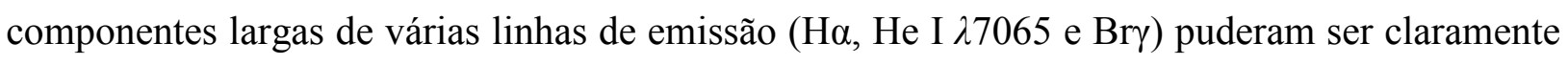
identificadas, o que justifica a classificação desse objeto como tipo 1. A análise no óptico foi capaz de separar a emissão proveniente da NLR e da BLR do AGN dessa galáxia. Além disso, essa mesma análise também revelou a existência de uma cinemática bastante complexa do gás ionizado na região central de NGC 3227, que deve estar associada à NLR e ao cone de ionização do AGN e não parece ser compatível com uma rotação ao redor do buraco negro central. Uma possibilidade muito provável é que se trate de algum outro fenômeno cinemático, como um outflow, por exemplo. A análise no infravermelho, por sua vez, possibilitou a diferenciação entre áreas com o fluxo dominado pela emissão térmica de poeira e regiões com fluxo devido, predominantemente, às populações estelares. Algumas dessas últimas parecem tomar a forma de um anel ao redor do núcleo da galáxia. Também foi possível identificar, nos dados do infravermelho, emissões térmicas de poeira associadas a diferentes temperaturas. Por fim, a análise no infravermelho mostrou, ainda, que a emissão molecular de $\mathrm{H}_{2}$ é proveniente, sobretudo, de uma região com o formato de uma faixa ao longo da diagonal do campo de visão do SINFONI. Tal faixa, inclusive, parece apresentar um padrão rotacional do gás $\mathrm{H}_{2}$ ao redor do núcleo.

\section{4 - Síntese espectral do cubo de dados de NGC 3227 com o}

\section{Starlight}

Após a análise inicial com a Tomografia PCA, passou-se para a etapa da síntese espectral com o software Starlight. Pôde-se notar, entretanto, que o cubo de dados no óptico, obtido com o GMOS, apresentava poucas linhas espectrais associadas a populações estelares. Consequentemente, uma síntese espectral aplicada nesse cubo seria pouco precisa no que se 
refere à determinação de parâmetros relativos às populações estelares presentes. Assim, embora a síntese espectral tenha sido aplicada tanto no cubo de dados do GMOS quanto naquele do SINFONI, apenas os resultados da segunda análise são mostrados aqui.

Para se fazer a síntese espectral no cubo de dados de NGC 3227 obtido com o SINFONI, primeiramente, foi aplicada toda a preparação descrita em 3.12, sendo que a correção da extinção devido à Via Láctea foi feita tomando-se $A_{V}=0.092$ e a passagem dos espectros para o referencial de repouso foi aplicada considerando-se $z=0.003859$. Tanto $A_{V}$ quanto $z$ foram obtidos a partir do site do NED.

Como o cubo de dados de NGC 3227 obtido com o SINFONI contém espectros na região do infravermelho próximo, e há um intenso AGN nessa galáxia, foi preciso levar em conta a emissão térmica de poeira e um featureless continuum na síntese espectral, conforme explicado em 3.12. De acordo com o que foi discutido anteriormente, devido às limitações da base utilizada nesse processo, apenas os mapeamentos mais confiáveis obtidos com a síntese espectral do cubo de dados de NGC 3227 são mostrados nas sessões a seguir.

\subsection{1 - Qualidade dos ajustes}

O mapeamento dos valores do $\chi^{2} / n_{\text {eff }}$ dos ajustes resultantes da síntese espectral do cubo de dados de NGC 3227 obtido com o SINFONI encontra-se a seguir.

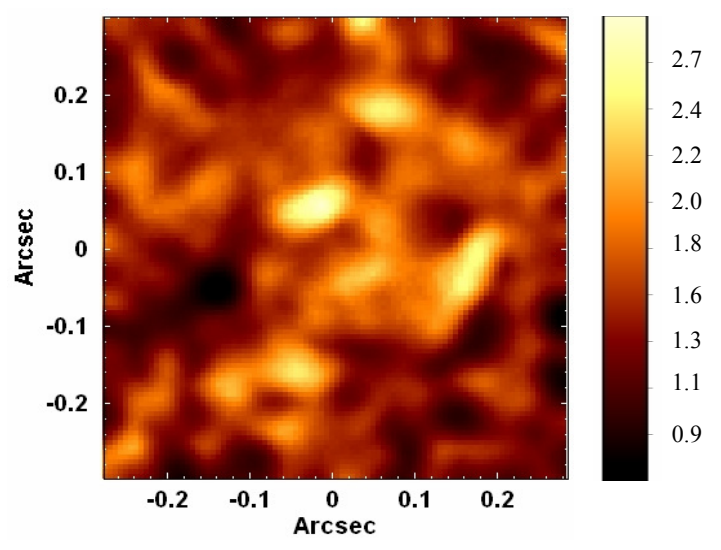

Figura 6.26: Mapeamento dos valores do $\chi^{2} / n_{\text {eff }}$ dos ajustes do "Starlight" para os espectros do cubo de dados de NGC 3227 obtido com o SINFONI.

Observando-se a figura 6.26, verifica-se que os melhores ajustes obtidos com o Starlight apresentaram $\chi^{2} / n_{\text {eff }}$ de cerca de 0.7 , ao passo que os piores tiveram $\chi^{2} / n_{\text {eff }}$ próximo a 2.9 , o que 
ainda pode ser tomado como um indicativo de ajustes com razoável qualidade. Assim, concluise que todos os ajustes feitos com o Starlight nos espectros do cubo de dados desse objeto foram bastante aceitáveis. O mapeamento da figura 6.26 não revelou, claramente, estruturas ou configurações que indicassem áreas com ajustes tendenciosamente melhores do que outras.

\subsection{2 - Populações estelares, poeira e featureless continuum}

Conforme foi mencionado anteriormente, a partir dos resultados obtidos com a síntese espectral com Starlight de um cubo de dados no infravermelho próximo, pode-se construir apenas três mapeamentos de fluxo suficientemente confiáveis: o mapeamento do fluxo total devido às populações estelares, o mapeamento do fluxo total devido à emissão térmica de poeira e o mapeamento do fluxo devido ao featureless continuum. No caso de NGC 3227, entretanto, verificou-se que seria mais apropriado, ao invés de construir apenas uma imagem representativa do fluxo total devido à emissão térmica de poeira, montar duas imagens: uma representando a emissão térmica de poeira com temperaturas entre $700 \mathrm{~K}$ e $1000 \mathrm{~K}$ e a outra mostrando a emissão térmica de poeira com temperaturas entre $1100 \mathrm{~K}$ e $1400 \mathrm{~K}$. Todos os mapeamentos obtidos encontram-se a seguir.
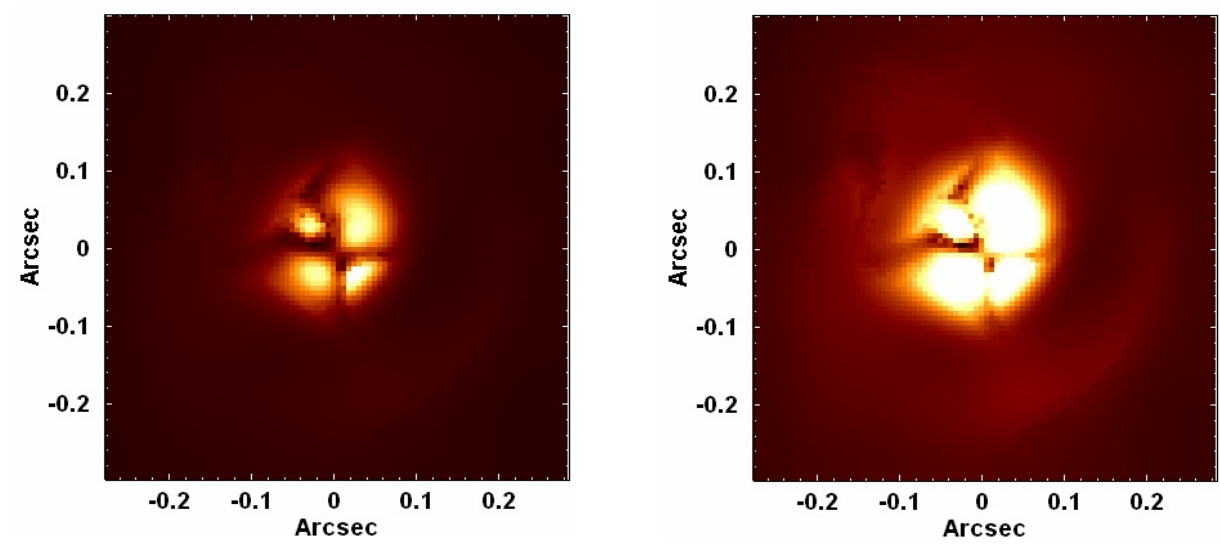

Figura 6.27: (esquerda) Mapeamento do fluxo total devido às populações estelares, resultante da aplicação do "Starlight" ao cubo de dados de NGC 3227 obtido com o SINFONI; (direita) mesmo mapeamento mostrado à esquerda, mas com a LUT "exagerada". 

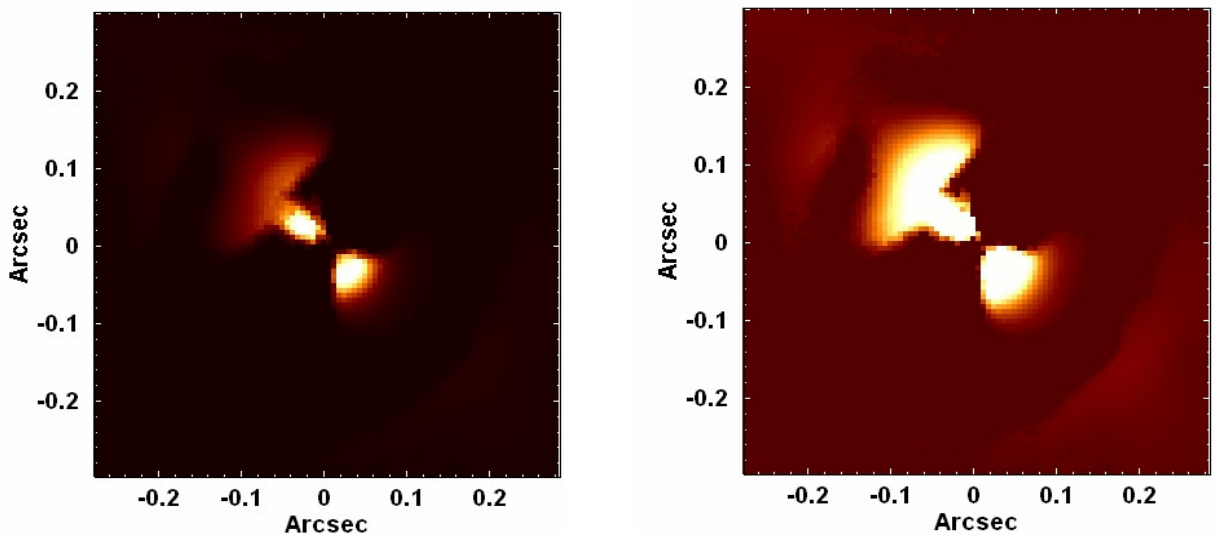

Figura 6.28: (esquerda) Mapeamento do fluxo devido à emissão térmica de poeira com temperaturas entre $700 \mathrm{~K}$ e $1000 \mathrm{~K}$, resultante da aplicação do "Starlight" ao cubo de dados de NGC 3227 obtido com o SINFONI; (direita) mesmo mapeamento mostrado à esquerda, mas com a LUT "exagerada".
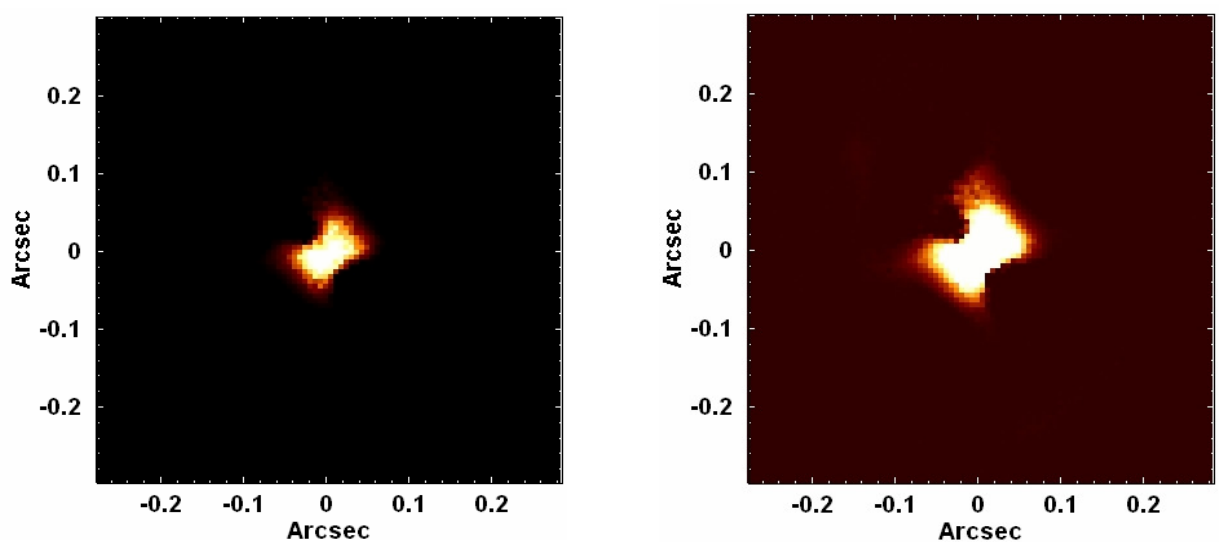

Figura 6.29: (esquerda) Mapeamento do fluxo devido à emissão térmica de poeira com temperaturas entre $1100 \mathrm{~K}$ e $1400 \mathrm{~K}$, resultante da aplicação do "Starlight" ao cubo de dados de NGC 3227 obtido com o SINFONI; (direita) mesmo mapeamento mostrado à esquerda, mas com a LUT "exagerada”.

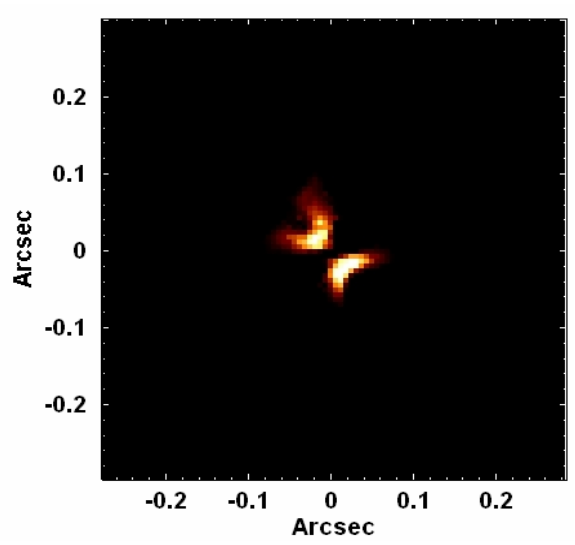

Figura 6.30: Mapeamento do fluxo atribuido ao "featureless continuum" do AGN, resultante da aplicação do "Starlight" ao cubo de dados de NGC 3227 obtido com o SINFONI. 
Em seguida, construiu-se um gráfico em colunas contendo as frações de fluxo devidas às populações estelares, à emissão térmica de poeira e ao featureless continumm do AGN, considerando-se todo o campo visual do SINFONI. O gráfico obtido encontra-se a seguir.

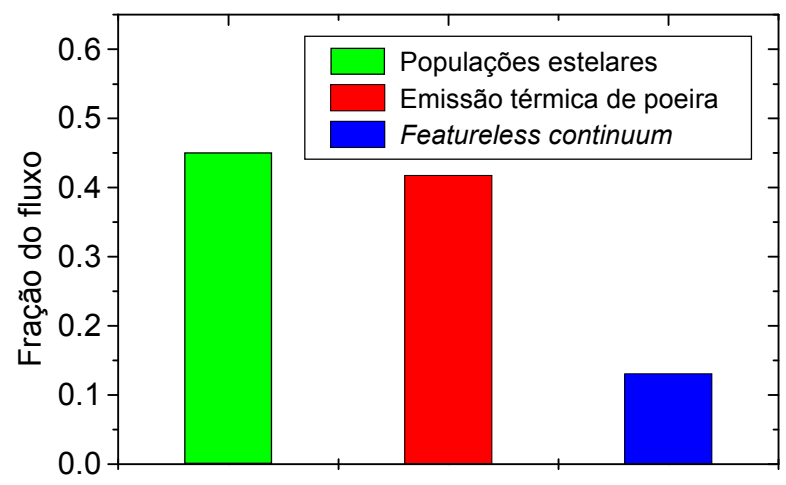

Figura 6.31: Gráfico representativo das frações de fluxo devidas às populações estelares, à emissão térmica de poeira e ao "featureless continuum", considerando-se todo o campo visual do SINFONI, resultante da aplicação do "Starlight" ao cubo de dados de NGC 3227 obtido com o SINFONI.

As figuras 6.27, 6.28 e 6.29 mostram que a síntese espectral com o Starlight foi capaz de diferenciar consideravelmente bem o fluxo proveniente de populações estelares daquele devido à emissão térmica de poeira. Entretanto, ao contrário do que se observou nos casos de NGC 2992 e NGC 4151, foi possível identificar certas configurações espaciais na emissão térmica de poeira. Uma análise das figuras 6.28 e 6.29 deixa claro que a região com emissão de poeira com temperaturas entre $700 \mathrm{~K}$ e $1000 \mathrm{~K}$ é aproximadamente perpendicular àquela com emissão de poeira com temperaturas entre $1100 \mathrm{~K}$ e $1400 \mathrm{~K}$. Essa última, por sua vez, parece alinhada com a faixa com emissão de $\mathrm{H}_{2}$, ao longo da diagonal do campo de visão do SINFONI, que foi detectada anteriormente com a Tomografia PCA. Observando-se, em seguida, a figura 6.30, pode-se notar que o featureless continuum detectado não se concentra na posição correspondente ao AGN central, mas sim se distribui ao longo de duas áreas diametralmente opostas. Essas, por sua vez, são aproximadamente perpendiculares à região com emissão térmica de poeira com maiores temperaturas. Reunindo-se todas essas características, pode-se propor o seguinte cenário para a região central de NGC 3227: a região com emissão térmica de poeira com maiores temperaturas corresponde a um toro de poeira ao redor do AGN central. A faixa emissora de $\mathrm{H}_{2}$ pode ser tomada como uma continuação desse toro de poeira. Nesse caso, o que delimita o início dessa região com emissão molecular é a distância do AGN central a partir da 
qual as moléculas não são mais destruídas pelos fótons energéticos emitidos por ele. Em áreas internas a essa distância mínima, essas moléculas não "sobrevivem" e apenas a emissão térmica de poeira pode ser observada. A análise com a Tomografia PCA em 6.3.2 revelou, inclusive, a existência de um provável movimento rotacional ao redor do núcleo nessa faixa de $\mathrm{H}_{2}$. Tanto essa região emissora de $\mathrm{H}_{2}$ quanto o movimento rotacional associado também foram detectados por Davies et al. (2006) (lembrando que esse autores analisaram os mesmos dados mostrados aqui), que, com base em todas as propriedades observadas, identificaram essa área como sendo um "toro molecular obscurecedor". Considerando-se tudo o que foi dito anteriormente, pode-se concluir que os resultados aqui obtidos são compatíveis com a hipótese proposta por esses autores. Isso porque a aparente continuidade entre a região com emissão térmica de poeira com altas temperaturas e a faixa emissora de $\mathrm{H}_{2}$ sugere uma conexão entre essas duas áreas que, na verdade, seriam apenas partes diferentes de uma estrutura maior, que poderia ser denominada toro obscurecedor. Nesse caso, uma observação da emissão térmica de poeira permitiria a detecção do que poderia ser chamado de toro de poeira, ao passo que uma observação da emissão molecular de $\mathrm{H}_{2}$ levaria à detecção de um toro molecular. A região com emissão térmica de poeira com menores temperaturas está associada a um provável cone de ionização do AGN que, possivelmente, é colimado pelo toro de poeira ao redor do AGN. O featureless continuum emitido pelo AGN é espalhado pelo toro de poeira existente, dando origem à configuração (aproximadamente alinhada com o cone de ionização) mostrada na figura 6.31 . Observando-se a figura 6.28, pode-se notar uma certa similaridade entre as morfologias das populações estelares presentes e da emissão térmica de poeira. Isso pode indicar alguma conexão entre o AGN existente nessa galáxia e a formação de estrelas ao redor. Na figura 6.27, é possível observar, ainda, um anel associado ao fluxo devido às populações estelares presentes, que também foi revelado pela Tomografia PCA do cubo de dados de NGC 3227 obtido com o SINFONI, com o contínuo estelar (figura 6.20 da seção 6.3.2). Para se obter uma melhor visualização de todo o cenário aqui proposto, construiu-se uma imagem RB com as regiões com espectros dominados pela emissão térmica de poeira com temperaturas mais elevadas (entre $1100 \mathrm{~K}$ e $1400 \mathrm{~K}$ ) e mais baixas (entre $700 \mathrm{~K}$ e $1000 \mathrm{~K}$ ). Também foram elaboradas duas imagens RGB. A primeira delas com as regiões com espectros dominados pela emissão associada às populações estelares, à poeira com temperaturas mais elevadas e ao featureless continuum, e a segunda com as regiões com espectros dominados pela emissão térmica de poeira 
com temperaturas mais elevadas, pelo featureless continuum e pela emissão de $\mathrm{H}_{2}$ (o método para a obtenção da imagem da emissão de $\mathrm{H}_{2}$ é descrito em 6.5.2). Os resultados obtidos são mostrados nas figuras $6.32,6.33$ e 6.34 .
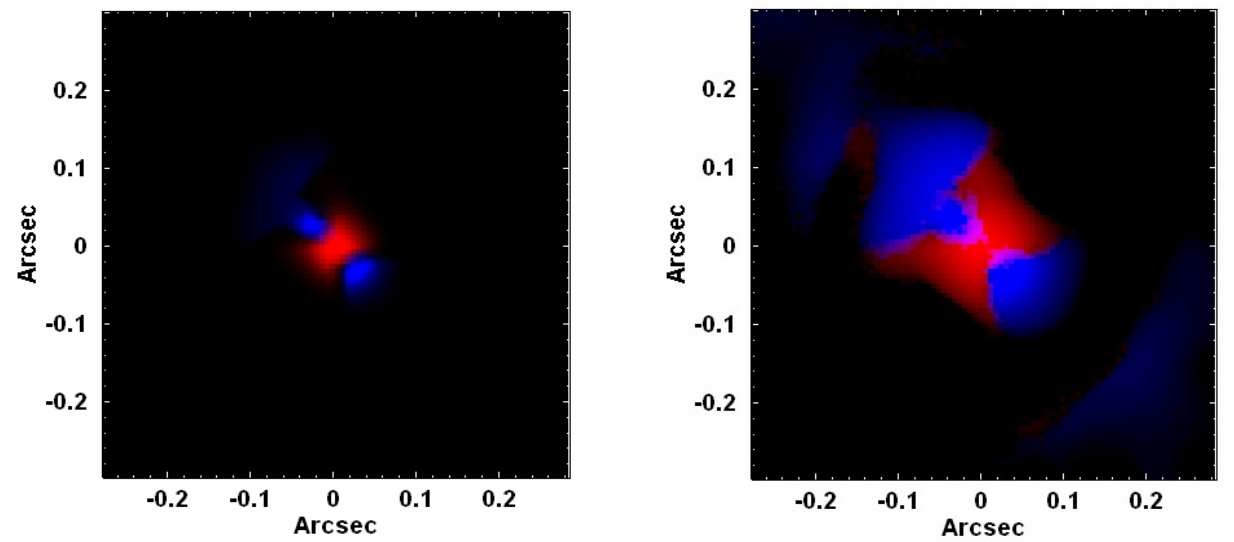

Figura 6.32 - (esquerda) Composição RB contendo os mapeamentos do fluxo associado à emissão térmica de poeira com temperaturas entre $1100 \mathrm{~K}$ e $1400 \mathrm{~K}$ (vermelho) e à emissão térmica de poeira com temperaturas entre $700 \mathrm{~K}$ e $1000 \mathrm{~K}$ (azul), resultantes da sintese espectral do cubo de dados de NGC 3227 obtido com o SINFONI; (direita) Mesma imagem que à esquerda, mas com a LUT "exagerada”.

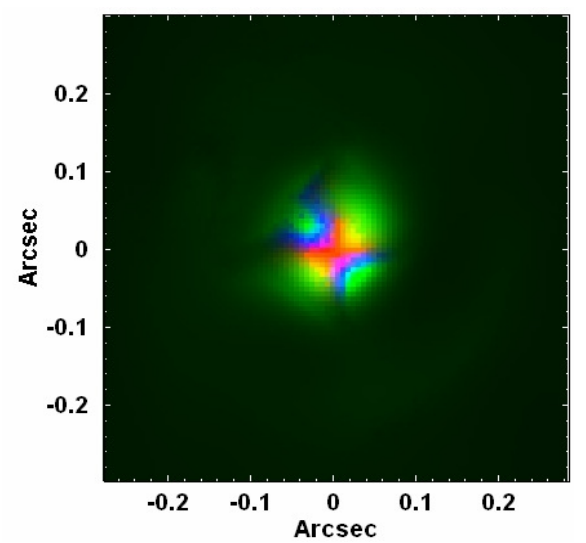

Figura 6.33 - Composição RGB contendo os mapeamentos do fluxo associado às populações estelares (verde), à emissão térmica de poeira com temperaturas entre $1100 \mathrm{~K}$ e $1400 \mathrm{~K}$ (vermelho) e ao "featureless continuum" (azul), resultantes da sintese espectral do cubo de dados de NGC 3227 obtido com o SINFONI. 


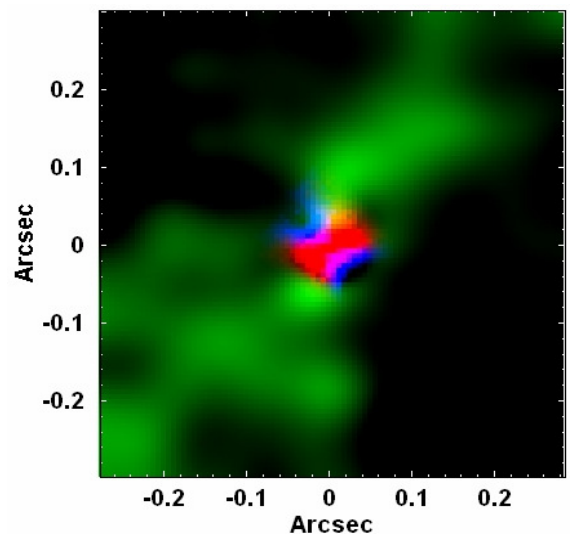

Figura 6.34 - Composição RGB contendo os mapeamentos do fluxo associado à emissão térmica de poeira com temperaturas entre $1100 \mathrm{~K}$ e $1400 \mathrm{~K}$ (vermelho), ao "featureless continuum" (azul) e à emissão de $\mathrm{H}_{2}$ (verde), resultantes da síntese espectral do cubo de dados de NGC 3227 obtido com o SINFONI.

As figuras 6.32, 6.33 e 6.34 facilitam bastante a visualização de tudo o que foi discutido anteriormente. Um ponto importante a ser ressaltado é que, embora as regiões emissoras de linhas detectadas com a aplicação da Tomografia PCA mostrada em 6.3.1 (figuras 6.14 e 6.16) não sejam exatamente perpendiculares ao provável toro obscurecedor detectado, elas também não estão alinhadas com ele. Isso pode ser considerado como estando de acordo com o cenário aqui proposto, que também é compatível com o que é previsto pelo Modelo Unificado.

Observando-se o gráfico da figura 6.31, pode-se notar que o fluxo devido às populações estelares (cerca de $45.1 \%$ do total) é dominante no campo visual do SINFONI. Entretanto, a fração de fluxo associada à emissão térmica de poeira (cerca de $41.8 \%$ ) também é bastante expressiva, o que está de acordo com o esperado, já que o intenso AGN dessa galáxia pode aquecer uma quantidade considerável de poeira ao redor, resultando na emissão térmica detectada. Por fim, pode-se dizer que, apesar da fração de fluxo devida ao featureless continuum do AGN (cerca de $13.1 \%$ ) ser menor do que as das outras componentes mostradas no gráfico, ela ainda pode ser considerada relevante, o que, sem dúvida, é uma conseqüência do fato desse AGN ser bastante intenso.

\subsection{3 - Valores da razão $S / N$ dos espectros analisados}

O mapeamento dos valores da razão $S / N$ obtidos pelo Starlight no intervalo espectral de $22303 \AA$ até $22387 \AA ̊$ encontra-se a seguir. 


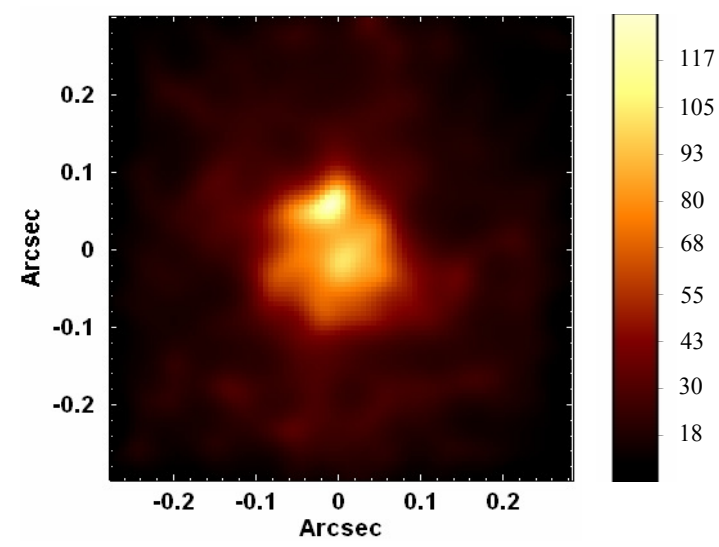

Figura 6.35 - Mapeamentos dos valores da razão $S / N$, resultantes da aplicação do "Starlight" ao cubo de dados de NGC3227 obtido com o SINFONI.

A figura 6.35 revela que os valores mais altos (cerca de 130) para a razão $S / N$ foram obtidos nas regiões mais centrais do campo visual do SINFONI, enquanto que os menores valores (cerca de 6) foram encontrados nas áreas mais afastadas do centro. Isso está de acordo com o esperado, já que o fluxo detectado é muito mais intenso nas regiões mais próximas ao AGN, que, por sua vez, se encontra próximo ao centro do campo de visão do SINFONI.

\section{5 - Aplicação da Tomografia PCA aos cubos de dados de NGC 3227 com o contínuo estelar subtraído}

Utilizando-se os espectros estelares sintéticos obtidos com os ajustes do Starlight, fez-se a subtração do contínuo estelar de todos os espectros dos cubos de dados de NGC 3227 no óptico e no infravermelho. Após isso, aplicou-se a Tomografia PCA aos dois cubos resultantes, a fim de se obter uma análise mais detalhada dos espectros de linhas de emissão dessa galáxia nessas duas regiões espectrais. 


\subsection{1 - Resultados da Tomografia PCA do cubo de dados de NGC 3227 obtido com o GMOS, com o contínuo estelar subtraído}

Os principais auto-espectros e respectivos tomogramas resultantes da aplicação da Tomografia PCA ao cubo de dado de NGC 3227 obtido com o GMOS, após a subtração do contínuo estelar, encontram-se a seguir.
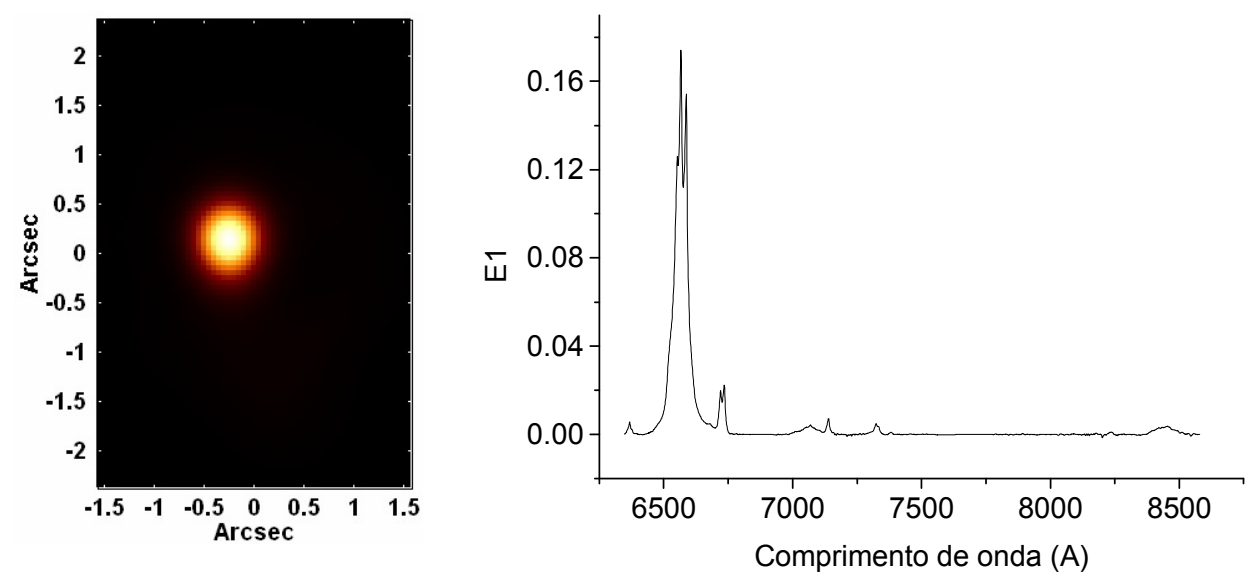

Figura 6.36-Tomograma e auto-espectro correspondentes ao autovetor E1, resultante da Tomografia PCA do cubo de dados de NGC 3227 obtido com o GMOS, com o contínuo estelar subtraído.

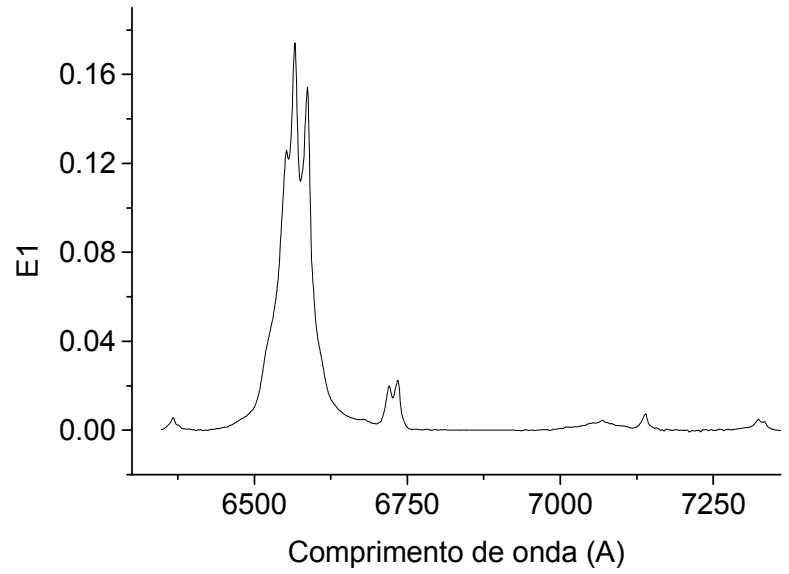

Figura 6.37 - Ampliação na região espectral azul do auto-espectro correspondente ao autovetor E1, resultante da Tomografia PCA do cubo de dados de NGC 3227 obtido com o GMOS, com o contínuo estelar subtraído. 

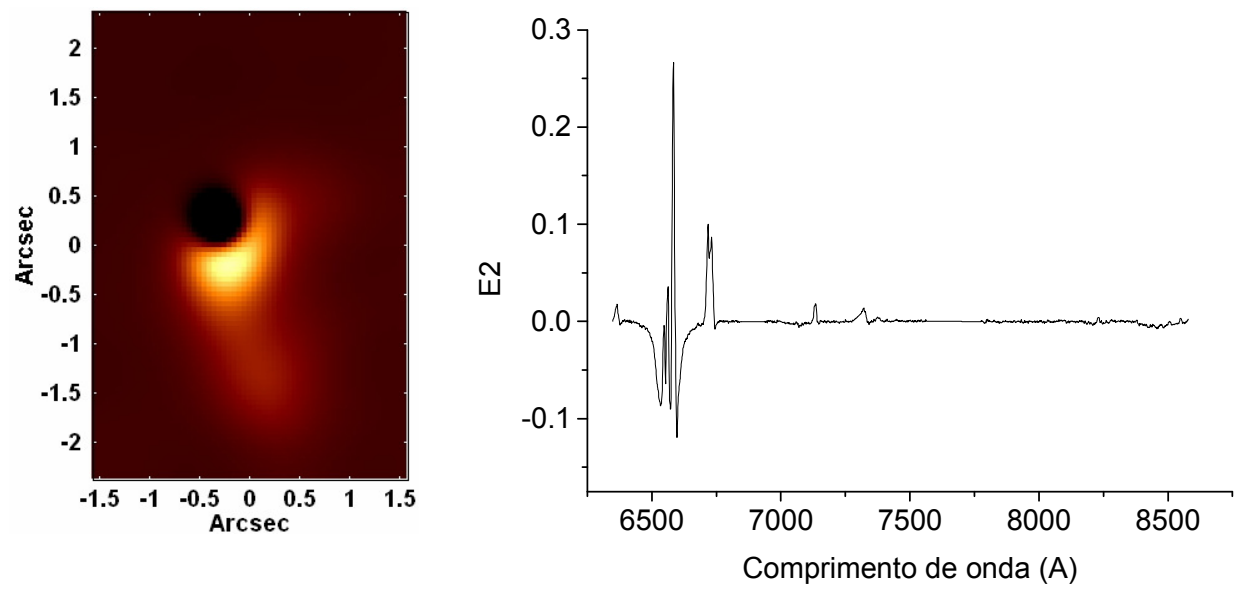

Figura 6.38 - Tomograma e auto-espectro correspondentes ao autovetor E2, resultante da Tomografia PCA do cubo de dados de NGC 3227 obtido com o GMOS, com o contínuo estelar subtraído.

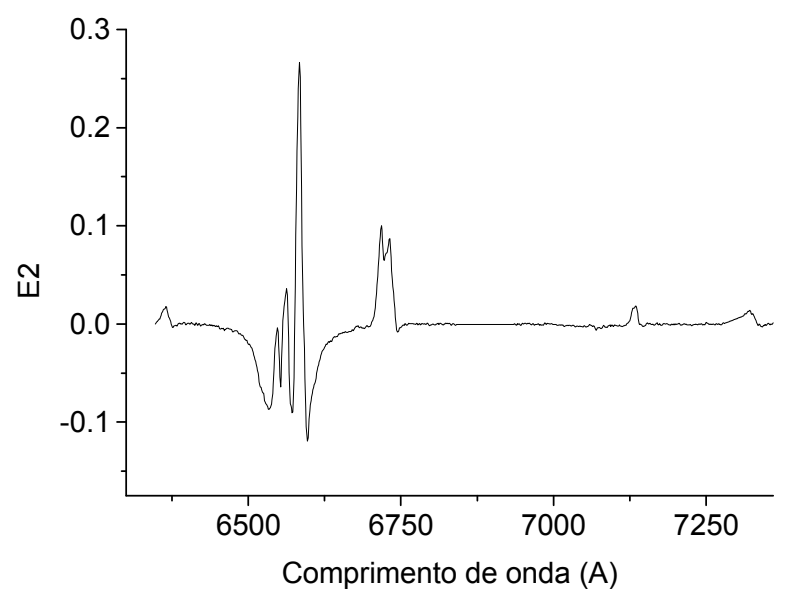

Figura 6.39 - Ampliação na região espectral azul do auto-espectro correspondente ao autovetor E2, resultante da Tomografia PCA do cubo de dados de NGC 3227 obtido com o GMOS, com o contínuo estelar subtraído.
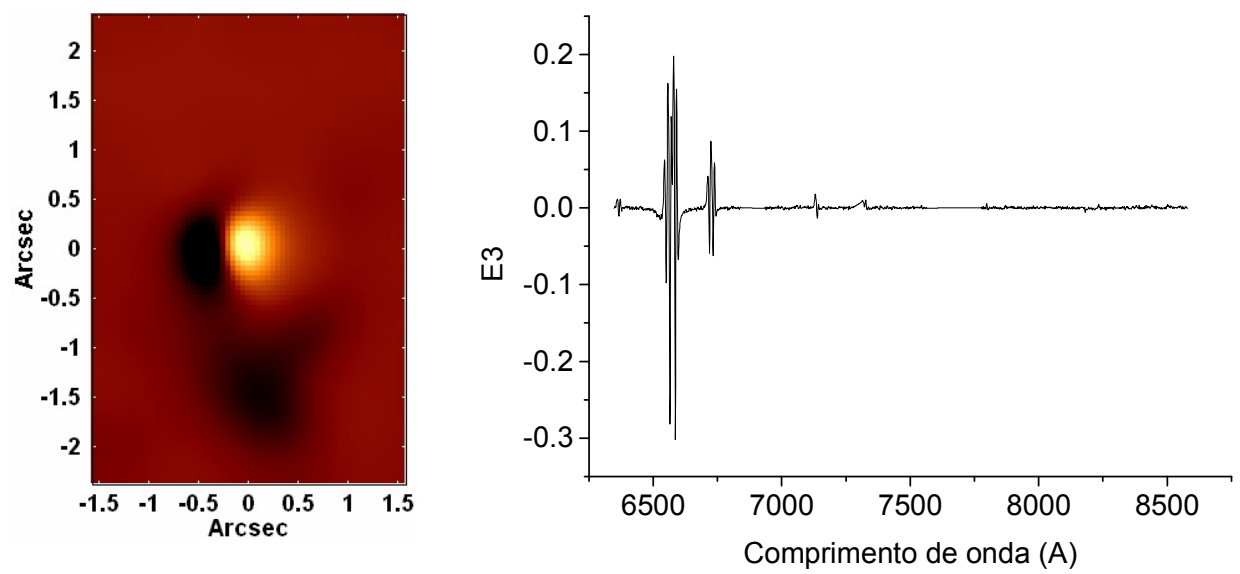

Figura 6.40 - Tomograma e auto-espectro correspondentes ao autovetor E3, resultante da Tomografia PCA do cubo de dados de NGC 3227 obtido com o GMOS, com o contínuo estelar subtraido. 


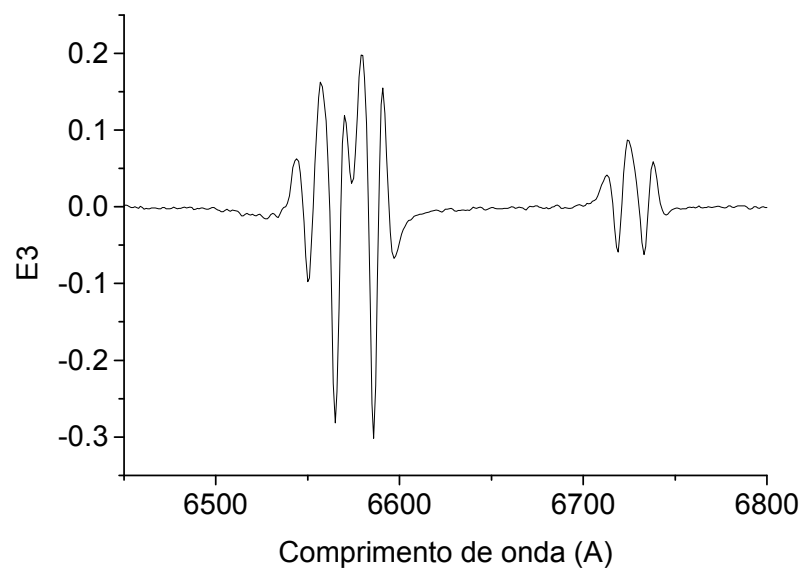

Figura 6.41 - Ampliação na região espectral azul do auto-espectro correspondente ao autovetor E3, resultante da Tomografia PCA do cubo de dados de NGC 3227 obtido com o GMOS, com o contínuo estelar subtraído.

\begin{tabular}{|c|c|}
\hline Autovetor & Fração da variância explicada (\%) \\
\hline E1 & 98.9999 \\
\hline E2 & 0.5788 \\
\hline E3 & 0.2261 \\
\hline
\end{tabular}

Tabela 6.3 - Autovalores encontrados com a Tomografia PCA do cubo de dados de NGC 3227 obtido com o GMOS, com o contínuo estelar subtraído.

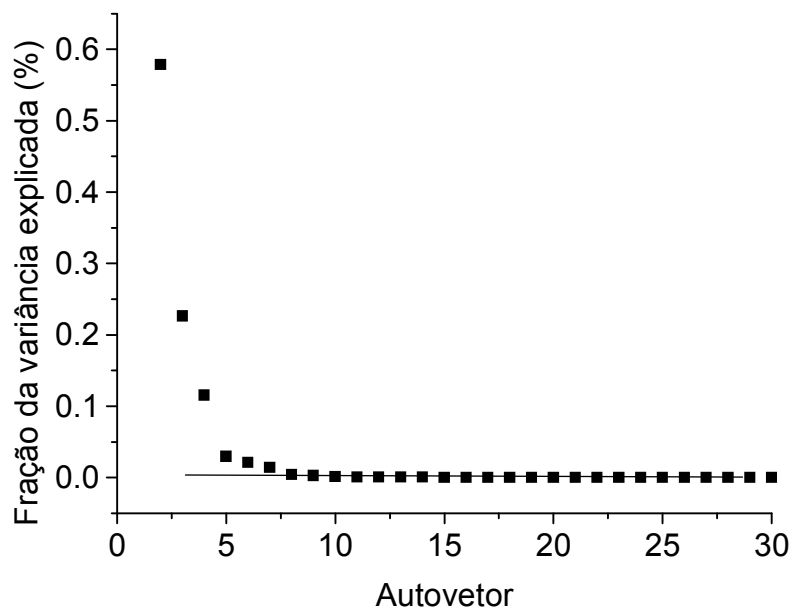

Figura 6.42 - "Scree test" dos autovetores encontrados com a Tomografia PCA do cubo de dados de NGC 3227 obtido com o GMOS, com o contínuo estelar subtraído.

Observando-se as figuras 6.36 e 6.37, pode-se notar que o auto-espectro E1 apresenta correlações com os comprimentos de onda correspondentes às principais linhas de emissão do espectro. Podem ser observadas, inclusive, correlações com os comprimentos de onda associados às componentes largas das linhas de $\mathrm{H} \alpha$ e He I $\lambda 7065$. Isso indica que esse autovetor está correlacionado com a emissão proveniente do AGN central, cuja posição deve corresponder 
à área mais clara do tomograma. Esse resultado é compatível com o encontrado com o autovetor E1 resultante da aplicação da Tomografia PCA ao cubo de dados de NGC 3227 obtido com o GMOS, com o contínuo estelar (figuras 6.11 e 6.12). O fato de a emissão do AGN aparecer no autovetor E1 está de acordo com o esperado, já que esse autovetor explica a maior parte da variância dos dados (cerca de 98.9999 \% do total) e é sabido que o AGN dessa galáxia é bastante intenso e, consequentemente, de fácil detecção.

As figuras 6.38 e 6.39 mostram que o auto-espectro E2 possui fortes correlações com os comprimentos de onda associados à região central de várias linhas de emissão e anti-correlações mais tênues com os comprimentos de onda correspondentes à asa vermelha de algumas linhas. Isso sugere que esse autovetor está relacionado a algum fenômeno cinemático do gás na região central de NGC 3227. Nesse caso, as áreas claras do tomograma apresentam gás sem componentes radiais de velocidade relevantes e as regiões escuras possuem gás com emissão em redshift. O fato de a amplitude das anti-correlações com as asas vermelhas de algumas linhas de emissão no auto-espectro ser muito menor do que a das correlações com as regiões centrais das mesmas mostra que esse autovetor parece estar pouco associado com a emissão em redshift. De qualquer modo, as características desse auto-espectro, juntamente com a morfologia do tomograma, não são compatíveis com o que se esperaria de uma rotação do gás ao redor do núcleo, o que indica a presença de algum outro fenômeno cinemático, como um outflow, por exemplo. O redshift apresentado pelo auto-espectro E3 indica velocidades radiais bastante apreciáveis, com módulos de mais de $500 \mathrm{~km} / \mathrm{s}$. O auto-espectro E3 também parece possuir anticorrelações com os comprimentos de onda correspondentes à componente larga da linha $\mathrm{H} \alpha$. Isso indica que esse autovetor também está anti-correlacionado com a emissão proveniente da BLR, cuja posição deve estar entre as áreas mais escuras do tomograma. Todas as informações reveladas por esse autovetor são compatíveis com o que foi obtido com o autovetor E3 mostrado em 6.3.1 (figuras 6.14 e 6.15). O autovetor E2 explica cerca de 0.5788 \% da variância dos dados.

Finalmente, observando-se as figuras 6.40 e 6.41, pode-se notar que o auto-espectro E3 apresenta, primeiramente, correlações com os comprimentos correspondentes às asas azuis de várias linhas de emissão e anti-correlações com os comprimentos de onda associados às asas vermelhas das mesmas. O blueshift e o redshift relacionados a essas correlações e anticorrelações indicam velocidades radiais com módulos relativamente modestos, de pouco mais 
de $100 \mathrm{~km} / \mathrm{s}$. O auto-espectro E4 também possui correlações com os comprimentos de onda correspondentes a asas vermelhas de algumas linhas de emissão, com redshifts indicativos de velocidades radiais com módulos intermediários, de pouco mais de $300 \mathrm{~km} / \mathrm{s}$. Por fim, o autoespectro E4 apresenta, ainda, anti-correlações com comprimentos de onda associados às asas vermelhas de algumas linhas de emissão, com redshifts indicando velocidades radiais com módulos elevados, de mais de $500 \mathrm{~km} / \mathrm{s}$ (os mesmos módulos de velocidade radial presentes no autovetor E2). Tudo isso sugere que o autovetor E3 revela a complexa cinemática do gás existente na região central de NGC 3227. As correlações e anti-correlações apresentadas pelo auto-espectro E3, juntamente com a morfologia do tomograma, não são compatíveis com um movimento rotacional do gás ao redor do núcleo, devendo, portanto, estar relacionadas a outro fenômeno cinemático, como um outflow, por exemplo. Todas as características do auto-espectro e do tomograma mostrados nas figuras 6.40 e 6.41 são compatíveis com o que foi obtido com o autovetor E4 mostrado em 6.3 .1 (figuras 6.16 e 6.17). O autovetor E3 explica cerca de $0.2261 \%$ da variância dos dados. É provável que as regiões emissoras mostradas nas figuras 6.38 e 6.40 estejam associadas à NLR e ao cone de ionização do AGN desse objeto.

O Scree test da figura 6.42 revela que os valores das variâncias explicadas pelos autovetores decaem bastante até, aproximadamente, o autovetor E8. A partir daí, a taxa de decaimento diminui bastante, ficando praticamente constante. Isso indica que autovetores de ordem maior ou igual a 8 representam, sobretudo, ruído e, consequentemente, não possuem relevância nessa análise. Entretanto, a análise mostrou que autovetores com ordem maior ou igual a 4 apresentavam uma quantidade maior de ruído e uma interpretação não tão clara, logo, apenas autovetores com ordem menor do que essa foram mostrados aqui. Isso revela que, assim como foi mencionado em 6.3.2, embora o Scree test seja uma boa técnica para se avaliar a partir de que ordem os autovetores deixam conter um sinal significativo e passam a ser dominados pelo ruído, há casos em que essa estratégia pode não ser precisa, e uma averiguação detalhada dos autovetores é sempre oportuna. 


\subsection{2 - Resultados da Tomografia PCA do cubo de dados de NGC 3227 obtido com o SINFONI, com o contínuo estelar subtraído}

Os principais auto-espectros e respectivos tomogramas resultantes da aplicação da Tomografia PCA ao cubo de dado de NGC 3227 obtido com o SINFONI, após a subtração do contínuo estelar, encontram-se a seguir.
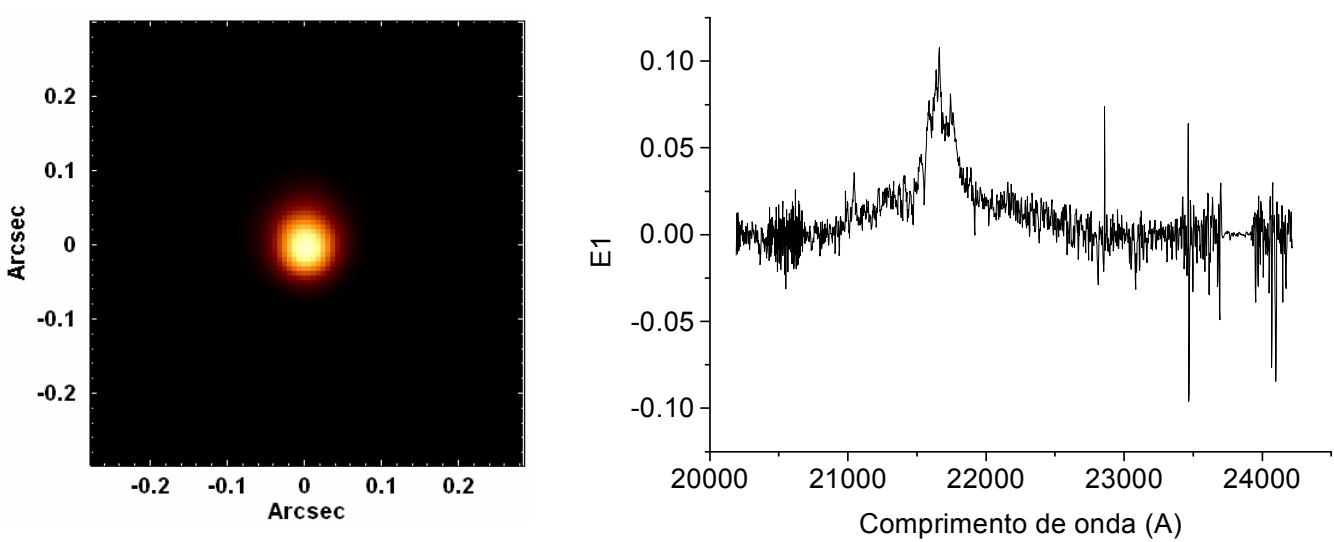

Figura 6.43 - Tomograma e auto-espectro correspondentes ao autovetor E1, resultante da Tomografia PCA do cubo de dados de NGC 3227 obtido com o SINFONI, com o contínuo estelar subtraído.
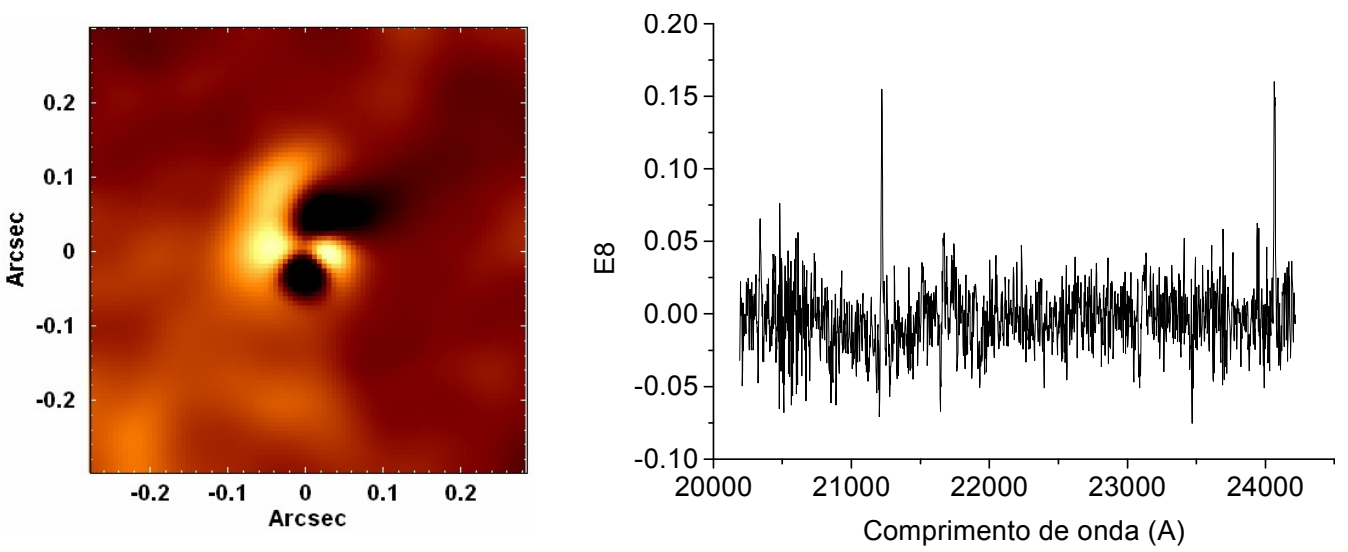

Figura 6.44 - Tomograma e auto-espectro correspondentes ao autovetor E8, resultante da Tomografia PCA do cubo de dados de NGC 3227 obtido com o SINFONI, com o contínuo estelar subtraído. 

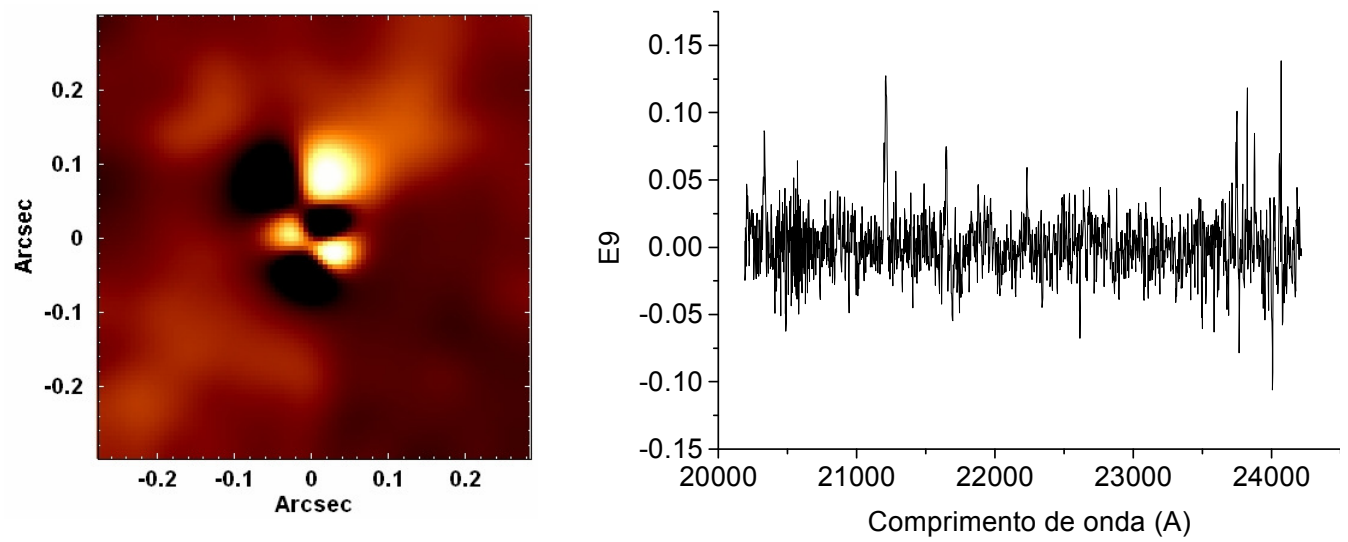

Figura 6.45 - Tomograma e auto-espectro correspondentes ao autovetor E9, resultante da Tomografia PCA do cubo de dados de NGC 3227 obtido com o SINFONI, com o contínuo estelar subtraído.

\begin{tabular}{|c|c|}
\hline Autovetor & Fração da variância explicada (\%) \\
\hline E1 & 83.9421 \\
\hline E8 & 0.4795 \\
\hline E9 & 0.3071 \\
\hline
\end{tabular}

Tabela 6.4 - Autovalores encontrados com a Tomografia PCA do cubo de dados de NGC 3227 obtido com o SINFONI, com o contínuo estelar subtraído.

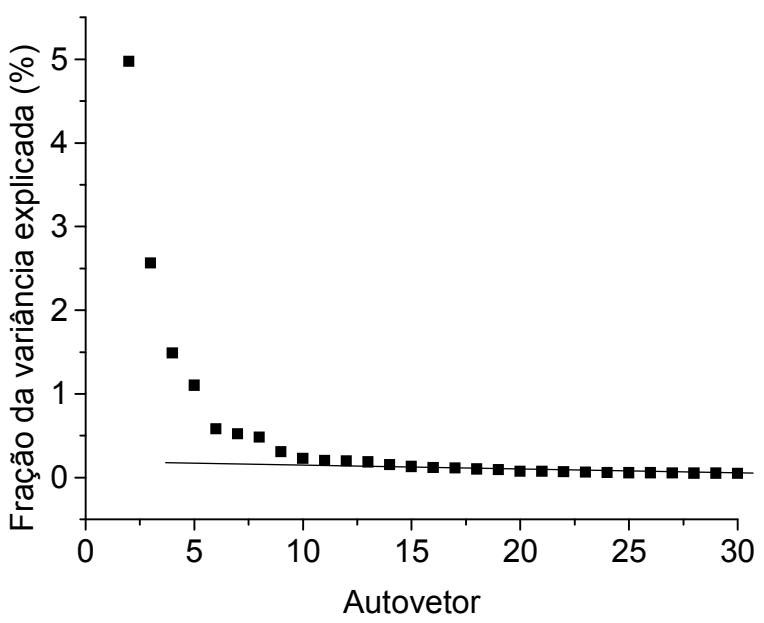

Figura 6.46 - "Scree test" dos autovetores encontrados com a Tomografia PCA do cubo de dados de NGC 3227 obtido com o SINFONI, com o contínuo estelar subtraído.

A figura 6.43 mostra que o auto-espectro E1 apresenta correlações com os comprimentos de onda associados à linha de Bry. Notam-se, inclusive, correlações com os comprimentos de onda correspondentes à componente larga dessa linha. Isso indica que esse autovetor está correlacionado com a emissão proveniente do AGN central, cuja localização corresponde à área mais clara do tomograma. Esse resultado é compatível com o que foi encontrado com o 
autovetor E1 mostrado em 6.3 .2 (figura 6.19), entretanto, a remoção do contínuo estelar, aparentemente, permitiu que a emissão proveniente do AGN fosse ligeiramente melhor isolada. Um ponto importante a ser mencionado é que o auto-espectro mostrado na figura 6.43 parece apresentar uma componente extremamente larga da linha de Br $\gamma \operatorname{com} F W Z I \approx 29000 \mathrm{~km} / \mathrm{s}$. Tal componente não aparece de maneira tão clara no autovetor da figura 6.19. O autovetor E1 explica a maior parte da variância dos dados (cerca de $83.9421 \%$ do total). Novamente, a grande intensidade do AGN existente nessa galáxia explica porque ele aparece nesse autovetor.

Observando-se a figura 6.44, pode-se notar que o auto-espectro E8 apresenta fortes correlações com os comprimentos de onda correspondentes às regiões centrais e às asas vermelhas de algumas linhas de $\mathrm{H}_{2}$ e tênues anti-correlações com os comprimentos de onda associados às asas azuis das mesmas. Isso sugere que o autovetor E8 está relacionado a algum fenômeno cinemático do gás molecular existente na região central de NGC 3227. Nesse caso, as áreas claras do tomograma possuem gás com baixas componentes radiais de velocidade ou redshift e as áreas escuras apresentam gás com emissão em blueshift. O fato de a amplitude das anti-correlações com as asas azuis das linhas de $\mathrm{H}_{2}$ no auto-espectro ser muito menor do que a amplitude das correlações com as regiões centrais e as asas vermelhas das mesmas indica que esse autovetor parece estar pouco relacionado com a emissão em blueshift. Ainda assim, a morfologia do tomograma na figura 6.44 parece ser compatível com uma rotação do gás molecular ao redor do buraco negro central. As características apresentadas por esse autovetor são totalmente compatíveis com o que foi obtido com o autovetor E7 mostrado em 6.3.2 (figura 6.22). O autovetor E8 explica cerca de 0.4795 \% da variância dos dados.

Por fim, a figura 6.45 mostra que o auto-espectro E9 apresenta correlações com os comprimentos de onda correspondentes a algumas linhas de emissão de $\mathrm{H}_{2}$ do espectro. Isso mostra que esse autovetor está correlacionado com a emissão de $\mathrm{H}_{2}$. Nesse caso, as regiões emissoras devem estar entre as áreas claras do tomograma. A morfologia desse último é compatível com as dos tomogramas dos autovetores E9 e E11 mostrados em 6.3.2 (figuras 6.23 e 6.24, respectivamente) e revela que a emissão de $\mathrm{H}_{2}$ na região central de NGC 3227 é proveniente de uma área com um formato similar ao de uma faixa disposta ao longo da diagonal do campo de visão do SINFONI. O autovetor E9 explica cerca de $0.3071 \%$ da variância dos dados. 
Apesar de ambas as aplicações da Tomografia PCA aos cubos de dados de NGC 3227 obtidos com o SINFONI terem revelado a existência de emissão de $\mathrm{H}_{2}$, os valores não tão elevados da razão $S / N$ dos espectros, juntamente com a presença de prováveis resquícios de absorções telúricas não completamente removidas durante a redução dos dados, fizeram com que a morfologia dos tomogramas associados às áreas emissoras não fosse tão clara. A fim de se obter uma visualização mais bem definida da região com emissão de $\mathrm{H}_{2}$, fez-se uma imagem da linha de $\mathrm{H}_{2}$ ג21218, a partir do cubo de dados após a subtração do contínuo estelar. Entretanto, como essa linha estava imersa na componente extremamente larga da linha Bry (revelada pelo auto-espectro E1, mostrado na figura 6.43), aplicou-se o seguinte procedimento: construíram-se imagens de dois intervalos espectrais adjacentes à linha, calculou-se a média entre elas e subtraiu-se o resultado da imagem da linha de $\mathrm{H}_{2}$ 221218. Com isso, removeu-se a contribuição da asa extremamente larga da linha $\mathrm{Br} \gamma$ na imagem da linha de $\mathrm{H}_{2} \lambda 21218$. O resultado obtido está mostrado na figura 6.47 .

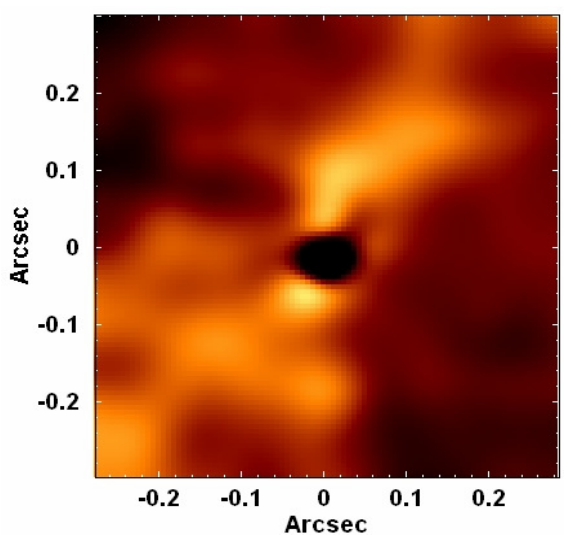

Figura 6.47 - Imagem da linha de $\mathrm{H}_{2} \lambda 21218$ do cubo de dados de NGC 3227 obtido com o SINFONI, com o contínuo estelar subtraído.

A figura 6.47 permite uma melhor visualização da região emissora de $\mathrm{H}_{2}$, entretanto, é compatível com todos os resultados encontrados com as aplicações da Tomografia PCA aos cubos de dados de NGC 3227 obtidos com o SINFONI, antes e após a subtração do contínuo estelar.

O Scree test da figura 6.46 revela que os valores das variâncias explicadas pelos autovetores decaem bastante até, aproximadamente, o autovetor E14. A partir daí, a taxa de decaimento diminui bastante, ficando praticamente constante. Isso indica que autovetores de ordem maior ou igual a 14 representam, sobretudo, ruído e, consequentemente, não possuem 
relevância nessa análise. Entretanto, a análise deixou claro que, dentre os autovetores com ordem menor do que 14, apenas os três discutidos anteriormente possuíam uma interpretação clara (sobretudo devido ao ruído presente). Novamente, isso mostra que, apesar de o Scree test ser uma boa técnica para se avaliar a partir de que ordem os autovetores deixam conter um sinal significativo e passar a ser dominados pelo ruído, esse método não é perfeito e uma averiguação detalhada dos autovetores é sempre conveniente.

Em suma, pode-se dizer que as aplicações da Tomografia PCA aos cubos de dados de NGC 3227 obtidos com o GMOS e com o NIFS, após a subtração do contínuo estelar, revelaram informações bastante compatíveis com as obtidas na seção 6.3. Além disso, certos fenômenos também puderam ser melhor visualizados. Primeiramente, essa segunda análise com a Tomografia PCA, tanto no óptico quanto no infravermelho próximo, isolou muito bem (e de maneira compatível com o que foi obtido em 6.3) a emissão proveniente do AGN central. Componentes largas de várias linhas de emissão, como H $\alpha$, He I $\lambda 7065$ e Br $\gamma$, foram claramente detectadas. Entretanto, a análise no infravermelho revelou a existência de uma provável componente extremamente larga da linha de Bry com $F W Z I \approx 29000 \mathrm{~km} / \mathrm{s}$. Tal estrutura não havia sido detectada, de modo claro, na seção 6.3.2. A Tomografia PCA no óptico foi capaz de separar as emissões provenientes da NLR e da BLR e também revelou a presença de uma complexa cinemática do gás na região central de NGC 3227 (provavelmente associada à NLR e ao cone de ionização do objeto), que não deve ser compatível com uma rotação, mas sim com outro fenômeno cinemático, como um outflow, por exemplo. Os resultados em 6.3.1 levaram a conclusões bastante similares. A análise no infravermelho mostrou que a emissão de $\mathrm{H}_{2}$ se dá, essencialmente, em uma região com o formato de uma faixa ao longo da diagonal do campo de visão do SINFONI. O gás molecular nessa faixa exibe o que aparenta ser uma rotação ao redor do núcleo. Um resultado análogo a esse foi obtido na seção 6.3.2. Essa mesma faixa emissora de $\mathrm{H}_{2}$, juntamente com o seu padrão rotacional, foram detectados por Davies et al. (2006), que identificaram essa estrutura como sendo um toro molecular obscurecedor. Conforme foi mencionado em 6.4.2, os resultados da aplicação da síntese espectral com o Starlight ao cubo de dados de NGC 3227 obtido com o SINFONI parecem estar de acordo com essa hipótese. Um ponto importante a ser mencionado aqui diz respeito à complementaridade das aplicações da Tomografia PCA aos cubos de dados de NGC 3227 obtidos com o GMOS e com o SINFONI. Os dados no infravermelho possuíam uma excelente resolução espacial, gerada pela aplicação da 
óptica adaptativa, entretanto, os valores não tão elevados da razão $S / N$ geraram algumas dificuldades na interpretação de certos auto-espectros obtidos. Por outro lado, apesar de os dados no óptico não possuírem uma resolução espacial tão boa, os seus valores da razão $S / N$ eram consideravelmente maiores. Os dados no infravermelho permitiram que fossem estudados certos fenômenos, como a emissão térmica de poeira, que não podem ser detectados nos dados no óptico, entretanto, esses últimos apresentam uma quantidade bem maior de linhas de emissão, facilitando, assim, o estudo da emissão do gás ionizado. Assim, pode-se concluir que a utilização dos cubos de dados nessas duas bandas espectrais permitiu que se fosse feita uma análise bastante ampla e detalhada do objeto, enfocando-se vários aspectos e propriedades do mesmo.

\section{6 - Cinemática estelar dos cubos de dados de NGC 3227}

Aplicou-se o processo do pPXF nos cubos de dados de NGC 3227 obtidos com o GMOS e com o SINFONI, a fim de se obter os mapeamentos dos valores da velocidade radial estelar, da dispersão de velocidades estelar e dos coeficientes de Gauss-Hermite $h_{3}$ e $h_{4}$.

\subsection{1 - Resultados da aplicação do pPXF ao cubo de dados de NGC 3227 obtido com o GMOS}

Os mapeamentos dos valores dos parâmetros resultantes da aplicação do pPXF ao cubo de dados de NGC 3227 obtido com o GMOS encontram-se a seguir. 

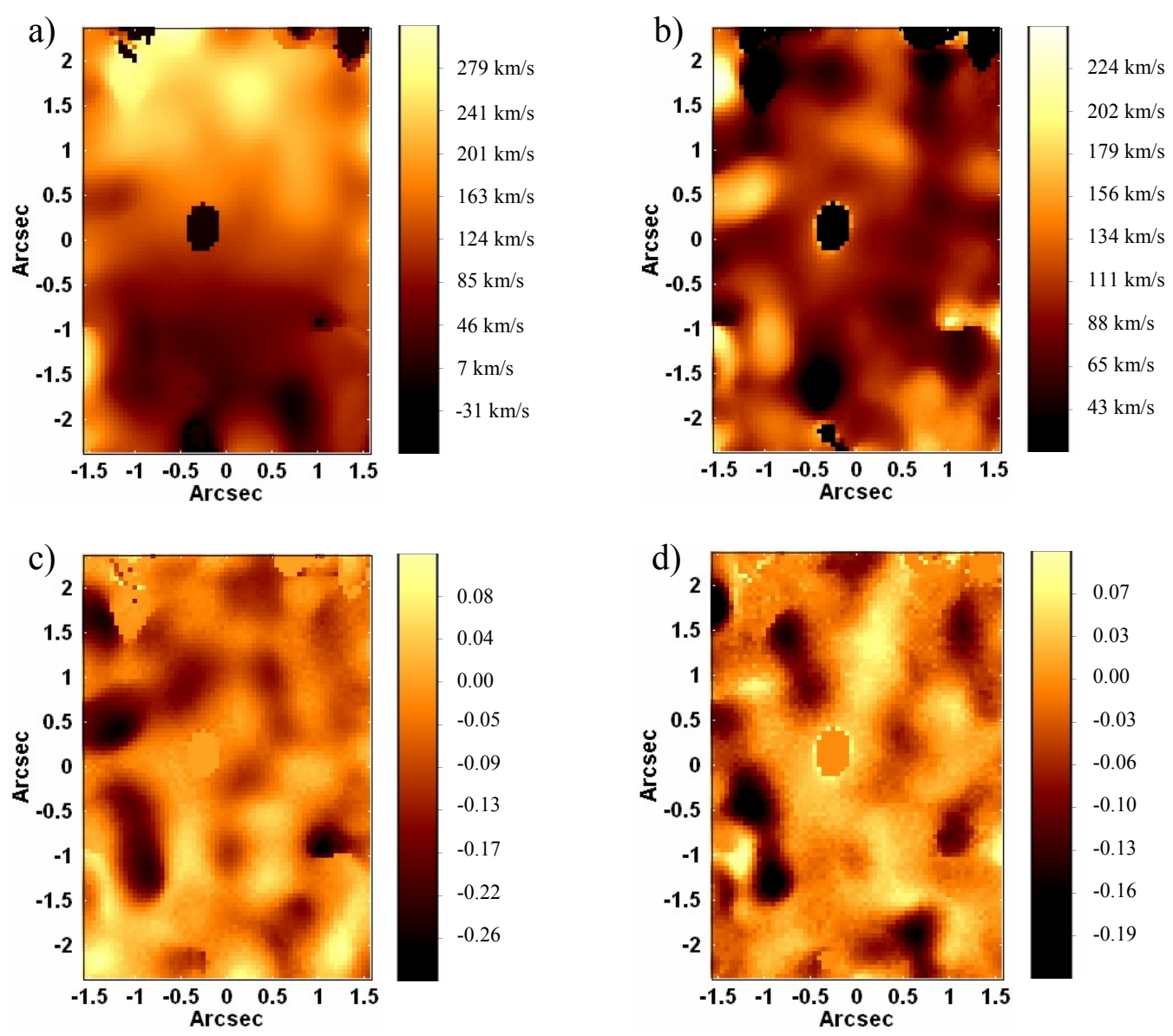

Figura 6.48 - Mapeamentos dos valores (a) da velocidade radial estelar, (b) da dispersão de velocidades estelar, (c) do coeficiente $h_{3} e(d)$ do coeficiente $h_{4}$, resultantes da aplicação do pPXF ao cubo de dados de NGC 3227, obtido com o GMOS.

Observando-se a figura 6.48 - $a$, pode-se notar a presença de uma aparente rotação estelar ao redor do núcleo, que também foi observada por Barbosa et al. (2006; 2009). Embora esse mapa de velocidades apresente várias irregularidades, é possível verificar que esse padrão rotacional não parece ser compatível com o que foi detectado para o gás molecular com as aplicações da Tomografia PCA aos cubos de dados de NGC 3227 obtidos com o SINFONI (figura 6.22 da seção 6.3 .2 e figura 6.44 da seção 6.5.2). Isso mostra que não parece haver qualquer correlação entre as rotações do gás molecular (possivelmente associado a um toro molecular) e estelar (de maior escala) detectadas. Uma outra característica do mapa de velocidades mostrado na figura 6.48 - $a$ é que a amplitude dos valores positivos de velocidade é muito maior que a dos negativos. Isso poderia indicar que, se houver um disco estelar em rotação, então, o mesmo deve apresentar uma excentricidade apreciável, entretanto, essa assimetria na amplitude dos valores positivos e negativos de velocidade também pode ser devida a falhas na calibração em comprimento de onda, durante a redução dos dados, o que geraria 
valores incorretos de velocidade radial. Uma correção imprecisa de redshift (que corresponde à passagem dos espectros para o referencial de repouso) também poderia ocasionar esse tipo de problema. A figura $6.48-b$ mostra que o mapeamento dos valores da dispersão de velocidades estelar não revelou nenhum padrão ou configuração espacial dominante. Entretanto, comparando-se as figuras $6.48-a$ e $6.48-b$, pode-se notar que ambas revelaram problemas para a determinação dos valores na posição correspondente ao AGN central (nas figuras $6.48-a$ e $6.48-b$ os valores foram mascarados e tomados como iguais a 0 ). É provável que isso tenha ocorrido devido ao fato de, nessa região, a emissão do AGN ter "ofuscado" as linhas de absorção estelares presentes, dificultando o ajuste com o pPXF e, consequentemente, a determinação da velocidade radial e da dispersão de velocidades estelar.

As figuras $6.48-c$ e $6.48-d$ não apresentam comportamentos ou configurações dominantes nos mapeamentos dos valores dos coeficientes $h_{3}$ e $h_{4}$. Entretanto, uma análise detalhada da figura $6.48-c$ parece indicar a existência de um tênue padrão compatível com o que foi identificado no mapeamento de velocidades radiais estelares (figura $6.48-a$ ). De qualquer forma, as irregularidades presentes fazem com que não seja possível confirmar essa hipótese. Pode-se notar que os mapeamentos das figuras $6.48-c$ e $6.48-d$ também revelam

problemas para a determinação dos valores na posição correspondente ao AGN central. É provável que a causa disso seja a mesma apresentada anteriormente para o que foi observado nos mapeamentos das figuras $6.48-a$ e $6.48-b$.

Como os mapeamentos das figuras $6.48-a$ e $6.48-b$ apresentam várias irregularidades e regiões com valores não confiáveis (como aqueles que foram mascarados, na posição correspondente ao AGN), optou-se por não aplicar nenhum tipo modelagem com o intuito de se determinar a massa do buraco negro central existente nesse objeto.

\subsection{2 - Resultados da aplicação do pPXF ao cubo de dados de NGC 3227 obtido com o SINFONI}

Os mapeamentos dos valores dos parâmetros resultantes da aplicação do pPXF ao cubo de dados de NGC 3227 obtido com o SINFONI encontram-se a seguir. 
a)

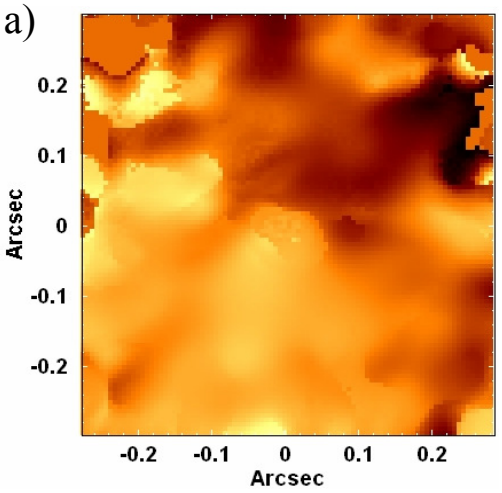

c)

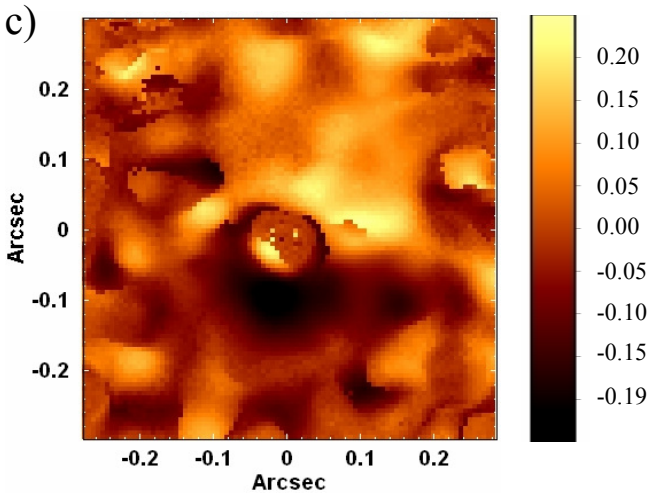

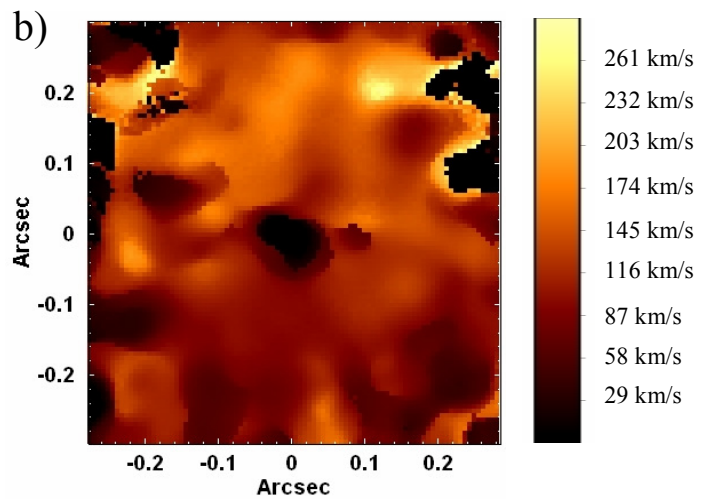

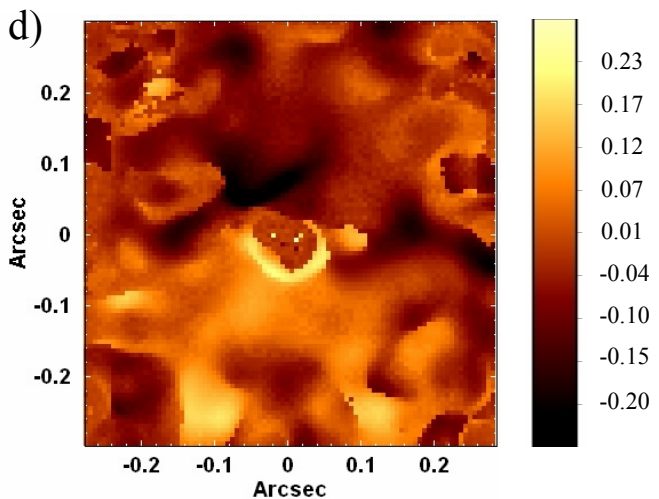

Figura 6.49 - Mapeamentos dos valores (a) da velocidade radial estelar, (b) da dispersão de velocidades estelar, (c) do coeficiente $h_{3} e(d)$ do coeficiente $h_{4}$, resultantes da aplicação do pPXF ao cubo de dados de NGC 3227, obtido com o SINFONI.

A figura 6.49 - a revela a existência de uma aparente rotação ao redor do núcleo de NGC 3227. Entretanto, comparando-se esse mapeamento de velocidades com o mostrado na figura 6.48 - $a$, que possui uma escala bem maior, pode-se notar que eles não são compatíveis. $\mathrm{Na}$ verdade, parece haver uma counter rotation estelar na região mais próxima ao AGN central. Por outro lado, o padrão rotacional observado na figura 6.49 - a parece ser compatível com o que foi detectado para o gás molecular com as aplicações da Tomografia PCA nas seções 6.3.2 e 6.5.2 (figuras 6.22 e 6.44). Isso indica que as estrelas visíveis no campo visual do SINFONI apresentam o mesmo movimento rotacional que o provável toro obscurecedor presente. A figura $6.49-b$, por outro lado, mostra que o mapeamento dos valores da dispersão de velocidades estelar não apresentou um padrão ou configuração espacial dominante. Comparando-se as figuras $6.49-a$ e $6.49-b$, pode-se notar que ambas apresentam valores pouco confiáveis na posição correspondente ao AGN. Assim como nos casos de NGC 2992 e NGC 4151, esse comportamento pode ser explicado pelo fato de, nessa área, o contínuo ser dominado pela emissão térmica de poeira, o que tornou as bandas de $\mathrm{CO}$ pouco detectáveis e dificultou os 
ajustes com o pPXF. Como conseqüência disso, os resultados obtidos para essa região foram pouco confiáveis.

Observando-se as figuras $6.49-c$ e $6.49-d$, pode-se notar que, apesar das irregularidades presentes, ambas parecem revelar algum padrão razoavelmente compatível com o que foi detectado no mapeamento de velocidades da figura $6.49-a$. Isso está de acordo com o esperado, já que, se a sobreposição do movimento rotacional em relação a um fundo com uma distribuição mais aleatória de velocidades é a única responsável por gerar as assimetrias nas asas das linhas (medidas pelo coeficiente $h_{3}$ ) e os desvios em relação a funções gaussianas simples (medidos pelo coeficiente $h_{4}$ ), é natural que haja uma semelhança entre os mapeamentos dos parâmetros em questão. Pode-se notar que as figuras $6.49-c$ e $6.49-d$ também revelam valores pouco confiáveis na posição correspondente ao AGN central. É provável que a causa disso seja a mesma apresentada anteriormente para o que foi observado nos mapeamentos das figuras 6.49 $-a$ e $6.49-b$.

Assim como no caso da seção 6.6.1, como os mapeamentos das figuras 6.49 - $a$ e 6.49 $b$ apresentam várias irregularidades e regiões com valores não confiáveis, optou-se por não aplicar nenhum tipo modelagem com o intuito de se determinar a massa do buraco negro central existente nesse objeto.

\section{7 - Cinemática do gás dos cubos de dados de NGC 3227}

Para se fazer uma análise mais detalhada da cinemática do gás na região central de NGC 3227, construíram-se mapas de velocidade de algumas linhas de emissão dos cubos de dados obtidos com o GMOS e com o SINFONI. Os valores de velocidade desses mapeamentos foram determinados ajustando-se gaussianas nessas linhas em cada um dos espectros do cubo de dados, após a subtração do contínuo estelar. 


\subsection{1 - Mapeamentos da velocidade radial do gás do cubo de dados de NGC 3227 obtido com o GMOS}

No caso do cubo de dados de NGC 3227 obtido com o GMOS, verificou-se que uma das linhas de emissão mais intensas é a de [N II] 26583 , assim, optou-se por utilizá-la para construir um mapeamento da velocidade radial do gás, que é mostrado na figura 6.50. A linha de Ha também apresenta grande intensidade, entretanto, a presença de uma componente larga, juntamente com a proximidade para com as linhas de [N II] $\lambda \lambda 6548 ; 6583$, tornaram difícil o ajuste de uma função gaussiana. Dessa forma, decidiu-se não construir um mapeamento da velocidade radial do gás a partir da linha de $\mathrm{H} \alpha$.

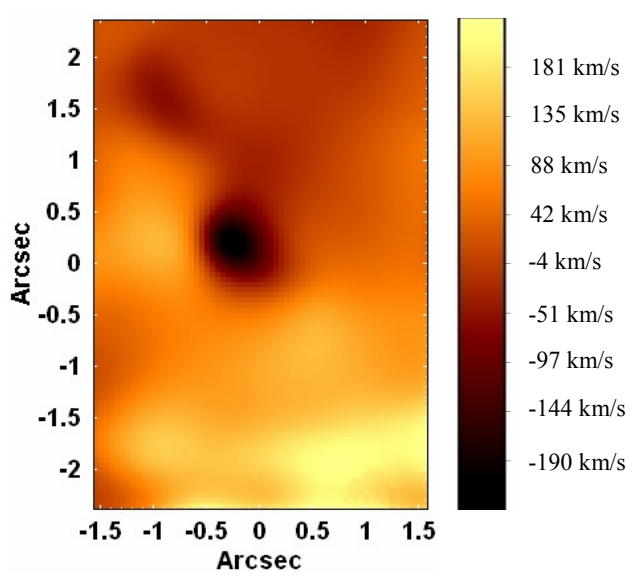

Figura 6.50 - Mapeamento dos valores da velocidade radial do gás, construído com base na linha de [N II] $\lambda 6583$ do cubo de dados de NGC 3227 obtido com o GMOS.

A morfologia apresentada pelo mapeamento da figura 6.50 não parece ser compatível com uma rotação ao redor do núcleo. Dessa forma, deve haver algum outro fenômeno cinemático envolvido, como um outflow, por exemplo. Esse resultado está de acordo com o que foi revelado pelas aplicações da Tomografia PCA aos cubos de dados de NGC 3227 obtidos com o GMOS (seções 6.3.1 e 6.5.1). A possibilidade da existência de um outflow é bastante plausível, já que Rubin \& Ford (1968), por exemplo, também encontraram evidências da existência desse fenômeno na região central de NGC 3227.

Como um dos objetivos desse trabalho envolve a simulação de movimentos keplerianos, visando a determinação da massa do buraco negro central existente, e, nesse caso, não é possível 
detectar claramente um padrão rotacional do gás, nenhuma modelagem da cinemática do gás foi feita para o cubo de dados de NGC 3227 obtido com o GMOS.

\subsection{2 - Mapeamentos da velocidade radial do gás do cubo de dados de NGC 3227 obtido com o SINFONI}

As linhas de emissão mais intensas no cubo de dados de NGC 3227 obtido com o SINFONI eram as de $\mathrm{Br} \gamma$ e de $\mathrm{H}_{2}$ 221218. Entretanto, a presença de uma componente larga na linha de Bry tornou muito difícil o ajuste de uma função gaussiana. Além disso, Bry só é detectada em áreas mais próximas ao AGN central. Assim, optou-se por utilizar, apenas, a linha de $\mathrm{H}_{2} \lambda 21218$ para se construir um mapeamento dos valores da velocidade radial do gás (nesse caso, gás molecular) na região central de NGC 3227. O resultado obtido é mostrado na figura 6.51 .

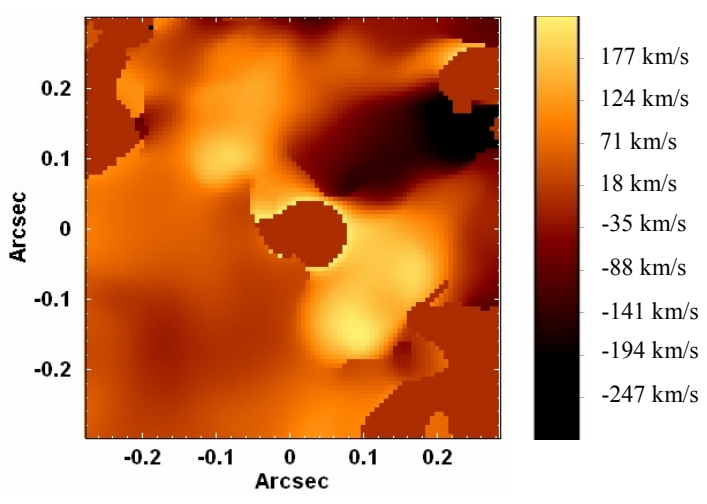

Figura 6.51 - Mapeamento dos valores da velocidade radial do gás, construído com base na linha de $\mathrm{H}_{2} \lambda 21218$ do cubo de dados de NGC 3227 obtido com o SINFONI.

Observando-se a figura 6.51, pode-se notar a existência de uma aparente rotação do gás molecular ao redor do núcleo de NGC 3227. Essa cinemática é compatível com o que foi detectado com as aplicações da Tomografia PCA aos cubos de dados de NGC 3227 obtido com o SINFONI (figura 6.22 da seção 6.3 .2 e figura 6.44 da seção 6.5.2) e ocorre ao longo da direção correspondente à faixa emissora de $\mathrm{H}_{2}$ (figura 6.47). Dessa forma, pode-se concluir que esse padrão rotacional parece estar de acordo com a idéia de que essa região com emissão de $\mathrm{H}_{2}$ corresponda a um toro obscurecedor em rotação ao redor do núcleo. Esse mesmo cenário foi proposto por Davies et al. (2006). Na figura 6.51 também se pode notar a presença de duas 
estruturas com velocidades positivas ao longo de uma direção perpendicular ao provável toro obscurecedor. É possível que tais estruturas estejam associadas a um outflow, o que seria compatível com o que foi constatado por Rubin \& Ford (1968), que, conforme foi mencionado anteriormente, detectaram sinais de um outflow na região central de NGC 3227. É importante mencionar, entretanto, que a linha de $\mathrm{H}_{2} \lambda 21218$ é consideravelmente fraca e apresenta várias irregularidades ao longo da direção perpendicular ao toro obscurecedor. Isso pode ter dificultado o ajuste de uma função gaussiana, tornando os valores de velocidade radial atribuídos para essa região imprecisos. Consequentemente, os elevados valores de velocidade nessa área podem não ser reais, mas sim uma conseqüência de possíveis problemas de ajuste. Assim, embora o cenário de um outflow perpendicular ao toro obscurecedor seja possível, esse modelo precisa ser considerado com muita cautela, devido às incertezas envolvidas.

O mapeamento da figura 6.51 possui uma série de irregularidades e regiões com valores imprecisos, que foram mascaradas. Essas imperfeições foram causadas pelo fato de que, nessas áreas, a linha de $\mathrm{H}_{2}$ era pouco intensa (ou até não era visível), o que dificultou o ajuste de uma função gaussiana. $\mathrm{Na}$ área mais próxima ao $\mathrm{AGN}$, por exemplo, a linha de $\mathrm{H}_{2}$ não é visível, provavelmente devido à destruição das moléculas devido à radiação proveniente do AGN. Consequentemente, não foi possível determinar os valores da velocidade radial do gás molecular nessa região, que precisou ser mascarada no mapeamento da figura 6.51 .

Embora um movimento rotacional possa ser detectado no mapeamento da figura 6.51 , as irregularidades presentes, juntamente com as regiões com valores mascarados, tornaram difícil a elaboração de uma modelagem com o intuito de se determinar a massa do buraco negro central existente nesse objeto. Assim, esse procedimento não foi aplicado nesse cubo de dados. 


\section{8 - Espectro de emissão de $\mathrm{H}_{2}$ do cubo de dados de NGC 3227 obtido com o SINFONI: razões de linhas e temperaturas de excitação}

Para se verificar se a emissão de $\mathrm{H}_{2}$ no cubo de dados de NGC 3227 obtido com o SINFONI tem origem térmica ou não térmica, primeiramente, construiu-se um diagrama de

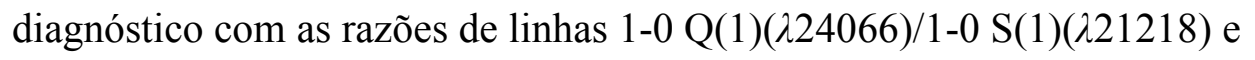
1-0 $\mathrm{S}(2)(\lambda 20338) / 1-0 \mathrm{~S}(0)(\lambda 22235)$, que é mostrado na figura 6.52.

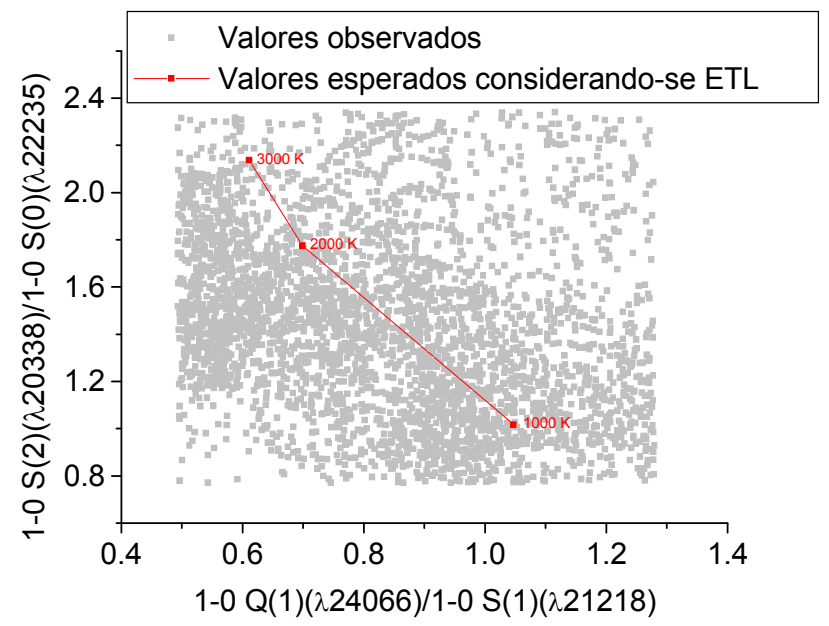

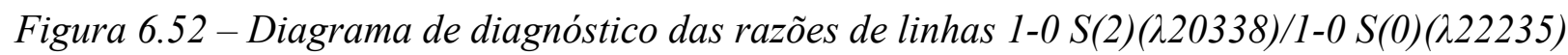

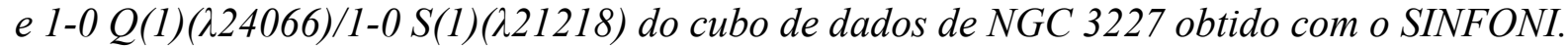

Os resultados esperados considerando-se ETL são mostrados em vermelho.

O diagrama de diagnóstico da figura 6.52 mostra que a aproximação de ETL não parece ser adequada na maior parte das regiões espaciais do cubo de dados de NGC 3227 obtido com o SINFONI. Esse resultado sugere uma origem não térmica para a emissão de $\mathrm{H}_{2}$ nessas áreas. Se a hipótese da existência de outflows na região central dessa galáxia estiver correta, então, é possível que a ocorrência desses fenômenos cinemáticos crie condições não compatíveis com a aproximação de ETL. Isso poderia explicar o comportamento observado no diagrama de diagnóstico da figura 6.52.

Para se determinar a temperatura em regiões nas quais o ETL parece ser válido, aplicouse o mesmo procedimento utilizado para NGC 2992 e NGC 4151. Nesse caso, entretanto, a região de incerteza delimitada no gráfico da figura 6.52 englobou valores variando até $18 \%$ a 
partir da curva vermelha (sendo que essa incerteza para as razões de linhas foi estimada com base nas flutuações do contínuo nas regiões espectrais próximas às linhas de emissão medidas). A figura 6.53 mostra o mapeamento dos valores obtidos para a temperatura, utilizando-se a

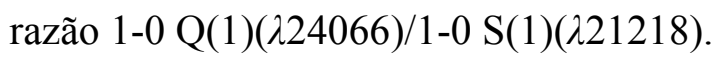

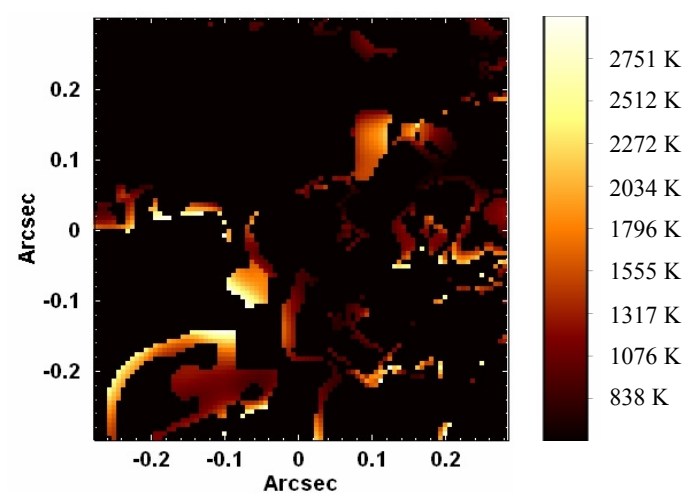

Figura 6.53 - Mapeamento dos valores da temperatura de excitação do cubo de dados de NGC3227 obtido com o SINFONI, construído a partir da razão de linhas

1-0 Q(1)(224066)/1-0 S(1)(221218). O mapeamento foi feito apenas para regiões nas quais a aproximação de ETL é válida.

Observando-se a figura 6.53, nota-se que a pouca quantidade de áreas mapeadas (nas quais a aproximação de ETL é válida) torna muito difícil a análise de possíveis variações dos valores de temperatura nas diferentes regiões espaciais. Mesmo assim, percebe-se que a maioria das áreas nas quais a temperatura pôde ser determinada se localiza ao longo da faixa emissora de $\mathrm{H}_{2}$ detectada anteriormente, que está associada ao suposto toro obscurecedor. Isso, obviamente, está de acordo com o esperado, já que a maior parte da emissão de $\mathrm{H}_{2}$ é proveniente dessa região.

O mapeamento da figura 6.53 também mostra que, em algumas áreas, foram detectadas temperaturas comparáveis às encontradas em NGC 4151, o que pode sugerir que o mecanismo de aquecimento das nuvens de $\mathrm{H}_{2}$ existentes seja a emissão de raios-x pelo AGN central.

\section{$6.9-$ Conclusões}

Em suma, pode-se dizer, primeiramente, que as análises com a Tomografia PCA dos cubos de dados de NGC 3227 obtidos com o GMOS, juntamente com a determinação do mapa 
de velocidades da linha de [N II] $\lambda 6583$, revelaram a existência de uma complexa cinemática do gás ionizado na região central de NGC 3227, que não é compatível com uma rotação ao redor do núcleo. É possível que esse padrão cinemático esteja associado a um outflow, o que estaria de acordo, por exemplo, com as constatações de Rubin \& Ford (1968), que também encontraram evidências da existência de um outflow na região central de NGC 3227. Essa análise no óptico também foi capaz de separar a emissão proveniente da NLR e da BLR do AGN dessa galáxia, sendo que é provável que a cinemática do gás ionizado detectada esteja associada à NLR. As aplicações da Tomografia PCA aos cubos de dados de NGC 3227 obtidos com o GMOS e com o SINFONI isolaram consideravelmente bem a emissão do AGN central, e componentes largas de várias linhas $(\mathrm{H} \alpha$, He I 27065 e Bry) puderam ser claramente identificadas. No caso da Tomografia PCA do cubo de dados de NGC 3227 obtido com o SINFONI, após a subtração do contínuo estelar, foi detectada uma aparente componente extremamente larga da linha de Br $\gamma$ com $F W Z I \approx 29000 \mathrm{~km} / \mathrm{s}$. Um dos maiores achados, entretanto, na análise dos cubos de dados de NGC 3227 foi um aparente toro de poeira ao redor do AGN. A síntese espectral com o Starlight revelou a presença de uma estrutura na posição correspondente ao AGN com emissão térmica de poeira com temperaturas entre $1200 \mathrm{~K}$ e $1400 \mathrm{~K}$, que está alinhada com uma faixa emissora de $\mathrm{H}_{2}$ detectada nas aplicações da Tomografia PCA aos cubos de dados de NGC 3227 obtidos com o SINFONI. A emissão de $\mathrm{H}_{2}$ não é detectada em áreas muito próximas ao AGN. Um possível cenário capaz de explicar esses resultados é que a poeira ao redor do AGN constitua um toro e a faixa emissora de $\mathrm{H}_{2}$ seja, apenas, uma continuação do mesmo (nas regiões mais próximas ao AGN, as moléculas de $\mathrm{H}_{2}$ são destruídas devido à intensa radiação emitida e apenas a emissão térmica de poeira pode ser detectada). Em outras palavras, as áreas com moléculas de $\mathrm{H}_{2}$ e com poeira seriam diferentes partes de um mesmo toro obscurecedor. O movimento rotacional da faixa emissora de $\mathrm{H}_{2}$ ao redor do núcleo, detectado por meio do mapa de velocidades da linha de $\mathrm{H}_{2}$ $\lambda 21218$ e das aplicações da Tomografia PCA aos cubos de dados de NGC 3227 obtidos com o SINFONI, sugere que esse toro obscurecedor está em rotação ao redor do buraco negro central. O mapeamento do featureless continuum emitido pelo AGN, feito com base nos resultados da síntese espectral com o Starlight, sugere a ocorrência de um espalhamento dessa radiação, provavelmente causado pelo toro de poeira existente. A síntese espectral revelou, ainda, a existência de uma emissão térmica de poeira com temperaturas entre $700 \mathrm{~K}$ e $1100 \mathrm{~K}$ ao longo de uma direção aproximadamente perpendicular ao toro de poeira. É possível que essa 
poeira esteja sendo aquecida pela radiação emitida ao longo da NLR e de um cone de ionização do AGN. Todo esse cenário proposto está de acordo com o previsto pelo Modelo Unificado. A rotação estelar detectada a partir da aplicação do processo do pPXF ao cubo de dados de NGC 3227 obtido com o SINFONI parece compatível com o movimento rotacional do gás molecular associado ao provável toro obscurecedor. Isso sugere alguma conexão entre a cinemática do gás e das estrelas nessa região. Entretanto, todo esse padrão rotacional não é compatível com o que foi observado, em maior escala, com a aplicação do pPXF ao cubo de dados no óptico. Na verdade, parece haver uma counter rotation estelar na região próxima ao AGN central. Isso indica que não parece haver qualquer conexão entre o toro obscurecedor detectado e a rotação estelar em maior escala existente. Finalmente, uma análise do diagrama de

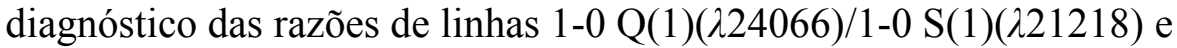

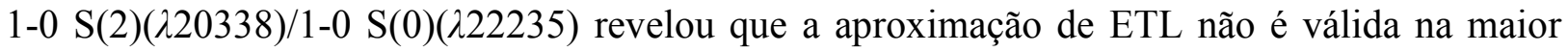
parte das regiões espaciais no campo de visão do SINFONI. O mapa de temperaturas construído para as áreas em ETL não permitiu que fossem tiradas conclusões claras a respeito da variação da temperatura em diferentes regiões, entretanto, foram obtidos alguns valores de temperatura comparáveis aos encontrados no caso de NGC 4151, o que pode indicar que o aquecimento das nuvens moleculares seja devido à emissão de raios-x pelo AGN central. 


\section{7 - NGC 5643}

\section{1 - Introdução}

NGC 5643 é uma galáxia espiral barrada de tipo morfológico $\mathrm{SAB}(\mathrm{rs}) \mathrm{c}$ de baixa inclinação $\left(i \sim 27^{\circ} \pm 5^{\circ}\right)$, sendo, portanto, quase face-on. Seu núcleo apresenta um espectro com linhas de emissão estreitas ( $F W H M \sim 300 \mathrm{~km} / \mathrm{s}$ ) de alta ionização (Sandage 1978), o que fez com que esse objeto fosse classificado como Seyfert 2 de baixa luminosidade por Phillips et al. (1983).

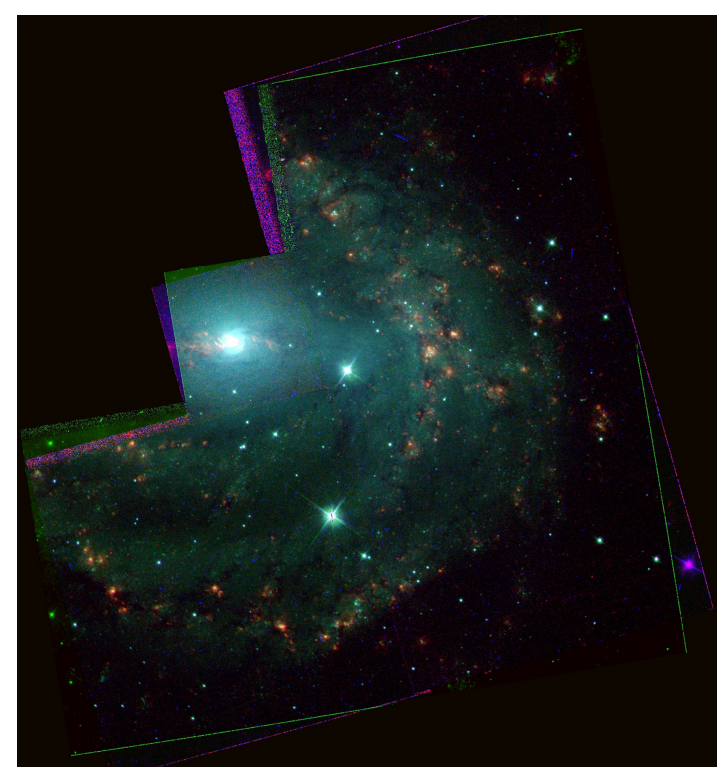

Figura 7.1 - Imagem da galáxia NGC 5643 na banda V, obtida com o HST. A orientação é norte para cima e leste para a esquerda.

Vários estudos têm mostrado que NGC 5643 parece ser um exemplo de um objeto no qual se tem um núcleo ativo obscurecido com escape anisotrópico de radiação, o que o torna compatível com o Modelo Unificado. Morris et al. (1985) analisaram mapas de velocidades de linhas ópticas, obtidos com o espectrômetro Fabri-Perot de imageamento TAURUS, e também mapas de fluxo em $6 \mathrm{~cm}$ e $20 \mathrm{~cm}$, obtidos com o VLA. Uma emissão de linhas ópticas estendida com uma morfologia alongada, aproximadamente ao longo da direção leste-oeste (o que coincide com a direção da barra), foi observada. Além disso, foram encontradas evidências de que o campo de velocidades é similar ao de modelos de fluxo de gás em um potencial barrado. 
Os dados em rádio revelaram, ainda, um núcleo coincidente com o núcleo óptico e com o centro de rotação, com dois lobos (um em cada lado) alongados na mesma direção da emissão óptica. Com base nessas observações, os autores propuseram um modelo simples, no qual o gás flui ao longo da barra, forma um disco ortogonal ao eixo maior da barra e colima a emissão rádio, obscurecendo, também, o contínuo ionizante do gás. Schmitt \& Storchi-Bergmann (1994) analisaram imagens e espectros long-slit, obtidos com o CTIO, e verificaram que as distribuições das razões de intensidade de linhas de emissão estão de acordo com a hipótese de que o contínuo ionizante é colimado dentro de um bi-cone. Simpson et al. (1997) analisaram imagens de alta resolução de NGC 5643 obtidas com o HST e observaram que o mapa de excitação $[\mathrm{O} \mathrm{III}] / \mathrm{H} \alpha$ (figura 7.3) apresenta uma estrutura na forma de $\mathrm{V}$ bem definida, possivelmente a projeção de um cone tridimensional.

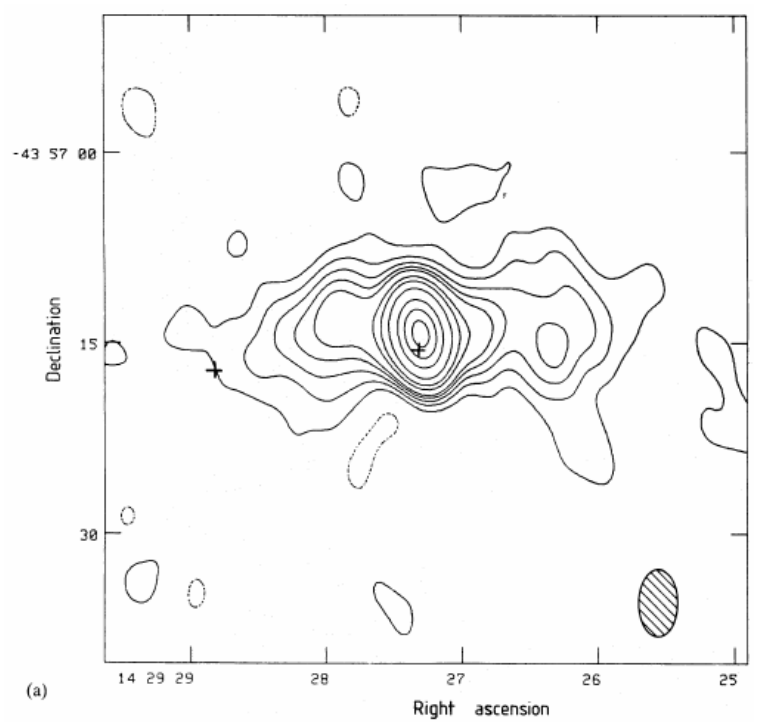

Figura 7.2 - Mapa do contínuo em $6 \mathrm{~cm}$ da região central de NGC 5643, obtido pelo VLA, retirado do trabalho de Morris et al. (1985). A posição do centro óptico está marcada com uma cruz. 


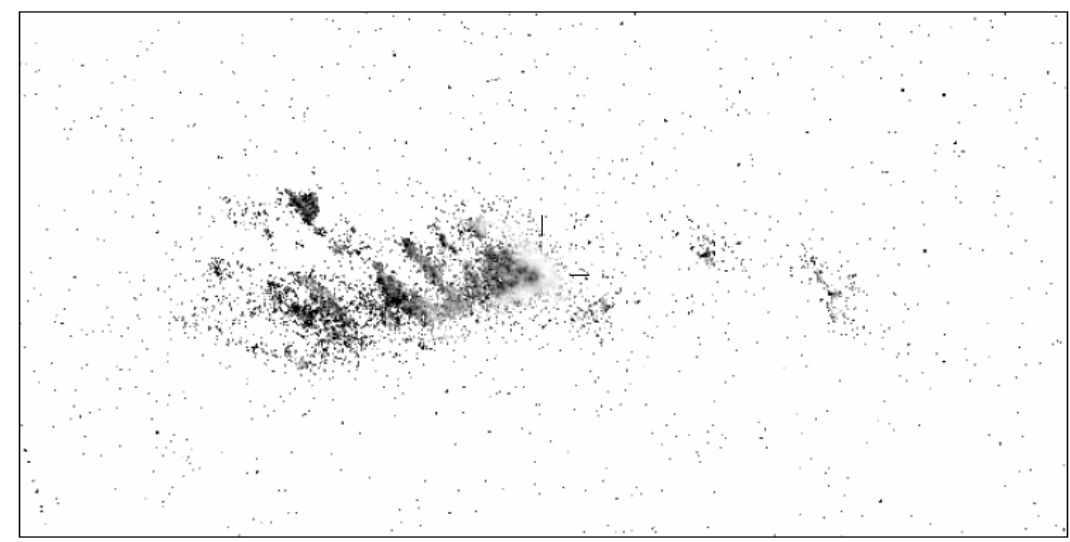

Figura 7.3 - Mapa de excitação [O III]/Ha, obtido a partir de imagens do HST, retirado do trabalho de Simpson et al. (1997). A orientação é norte para cima e leste para a esquerda.

Boller et al. (1992) analisaram observações feitas com o ROSAT e verificaram que NGC 5643 é uma fonte em raios-x, apresentando uma luminosidade de $L_{x}=1.32 \cdot 10^{41} \mathrm{erg} / \mathrm{s}$, em $0.2-4 \mathrm{keV}$.

\section{2 - Preparação do cubo de dados de NGC 5643}

Foram analisados cubos de dados da região central de NGC 5643 obtidos, na banda K do infravermelho próximo, com o SINFONI do VLT. A redução dos cubos de dados foi feita com o software Gasgano e, ao final desse processo, foram obtidos 5 cubos de dados com pixeis espaciais de $0.125 "$ de lado.

Após a redução dos dados, foi aplicada a correção da refração atmosférica diferencial em cada um dos cubos de dados. Em seguida, a fim de se combinar todos esses cubos em um só, primeiramente, eles foram separados em dois grupos. Nomeando-se os cubos como 1, 2, 3, 4 e 5 (de acordo com a ordem de observação), a separação nos dois grupos foi feita da seguinte maneira:

- Grupo 1: cubos 1, 2 e 3

- Grupo 2: cubos 1, 4 e 5 
Os integrantes de cada um desses grupos foram combinados na forma de mediana, resultando, portanto, em dois cubos de dados. Calculou-se, então, a média desses dois cubos, obtendo-se, assim, o cubo combinado procurado.

Após isso, aplicou-se o processo de reamostragem espacial no cubo de dados encontrado, a fim de se obter pixeis espaciais de 0.0625 " de lado. A figura 7.4 mostra a soma de todas as imagens do cubos de dados de NGC 5643, antes e depois do processo de reamostragem.
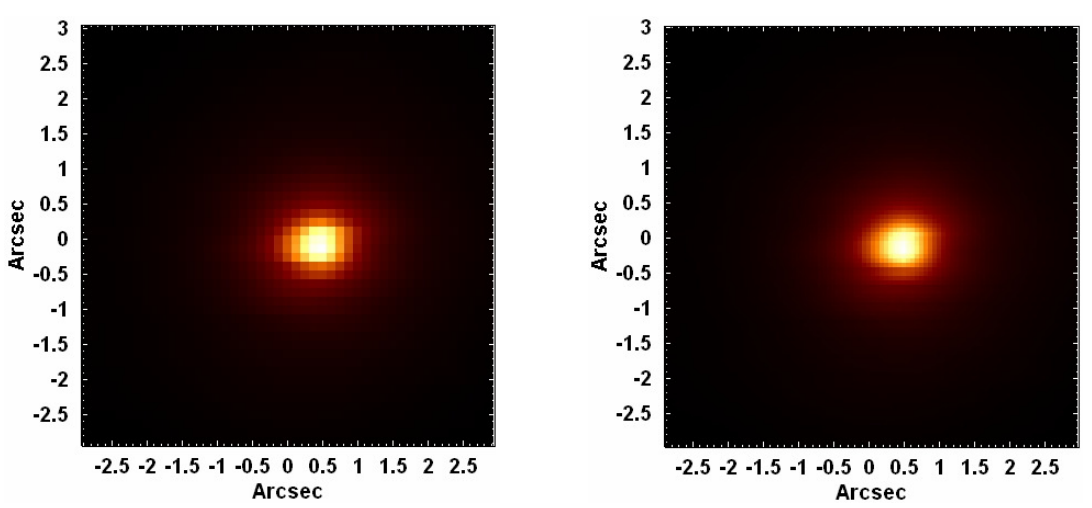

Figura 7.4 - (esquerda) Soma de todas as imagens do cubo de dados de NGC 5643, antes da aplicação da reamostragem espacial; (direita) Soma de todas as imagens do cubo de dados de NGC 5643, após a aplicação da reamostragem espacial.

Uma análise da figura 7.4 revela que a aplicação da reamostragem espacial permitiu que as estruturas espaciais presentes no cubo de dados ficassem definidas de uma maneira mais clara, no entanto, esse procedimento também introduziu componentes de alta freqüência espacial, que aparecem, sobretudo, na forma de faixas horizontais escuras e estreitas na imagem.

Em seguida, aplicou-se uma decomposição wavelet no cubo de dados reamostrado, obtendo-se, assim, os cubos $W_{0}, W_{1}, W_{2}, W_{3}, W_{4}$ e $W_{C}$. Utilizou-se $W_{0}$ para se determinar os parâmetros mais adequados para o filtro de Butterworth e esses parâmetros foram, então, utilizados na filtragem espacial de todas as outras componentes wavelet e também do cubo de dados original. No caso desse objeto, todas as filtragens foram feitas utilizando-se um filtro com forma dada pela expressão (3.67), $n=2$ e freqüência de corte ao longo dos eixos horizontal e vertical de $v_{c}=0.27 \mathrm{Ny}$. A figura 7.5 mostra as somas das imagens do cubo de dados antes e depois da filtragem espacial de Butterworth, assim como a soma das imagens do cubo correspondente à diferença entre esses dois. 

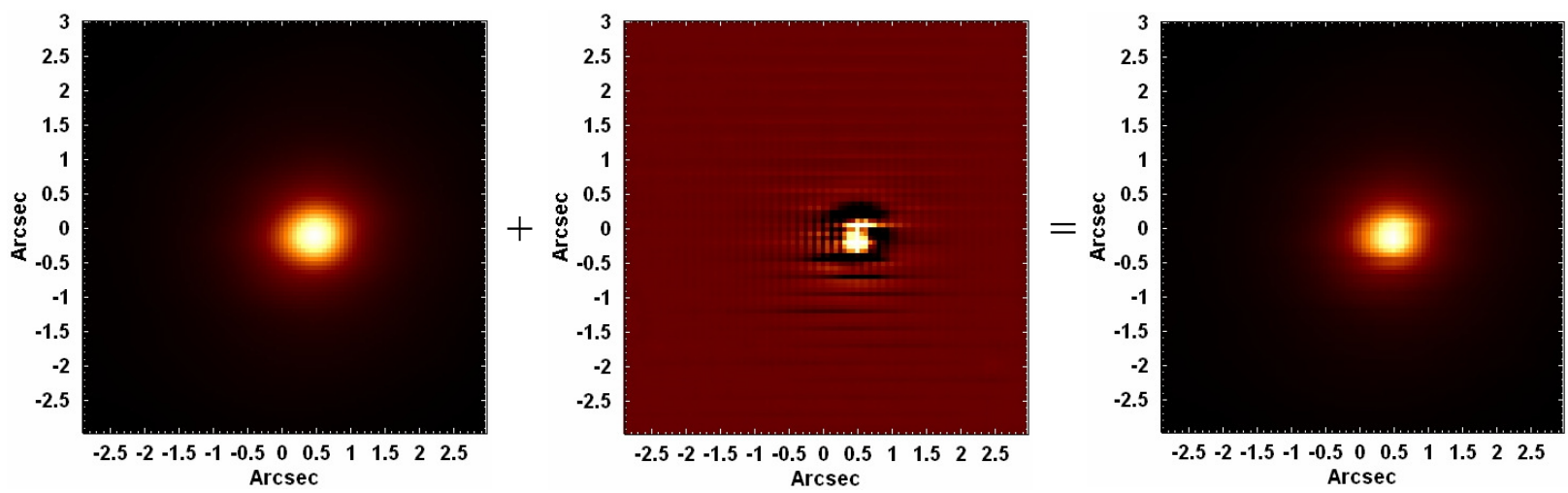

Figura 7.5 - (esquerda) Soma das imagens do cubo de dados de NGC 5643, após a filtragem espacial de Butterworth; (centro) Soma das imagens do cubo de dados de NGC 5643 correspondente à diferença entre o cubo não filtrado e o cubo filtrado; (direita) Soma das imagens do cubo de dados de NGC 5643, antes da filtragem espacial de Butterworth.

Observando-se a figura 7.5, nota-se que a aplicação da filtragem espacial de Butterworth removeu uma grande quantidade de ruídos de alta freqüência (inclusive as componentes de alta freqüência introduzidas pela reamostragem espacial), o que proporcionou uma melhoria na qualidade das imagens do cubo de dados.

Após a aplicação da filtragem espacial de Butterworth, verificou-se que o cubo de dados de NGC 5643 ainda apresentava um fingerprint instrumental de baixa freqüência espacial, que tomava a forma de uma larga faixa horizontal na imagem e possuía uma assinatura espectral característica. A fim de se remover essa estrutura do cubo de dados, aplicou-se o procedimento descrito em 3.11. A figura 7.6 mostra o tomograma e o auto-espectro correspondentes ao autovetor E3 (que é o que mostra o fingerprint existente de maneira mais clara), resultante da Tomografia PCA do cubo de dados de NGC 5643, após a remoção das linhas espectrais, assim como o resultado encontrado após o ajuste e a subtração de um spline do auto-espectro. 

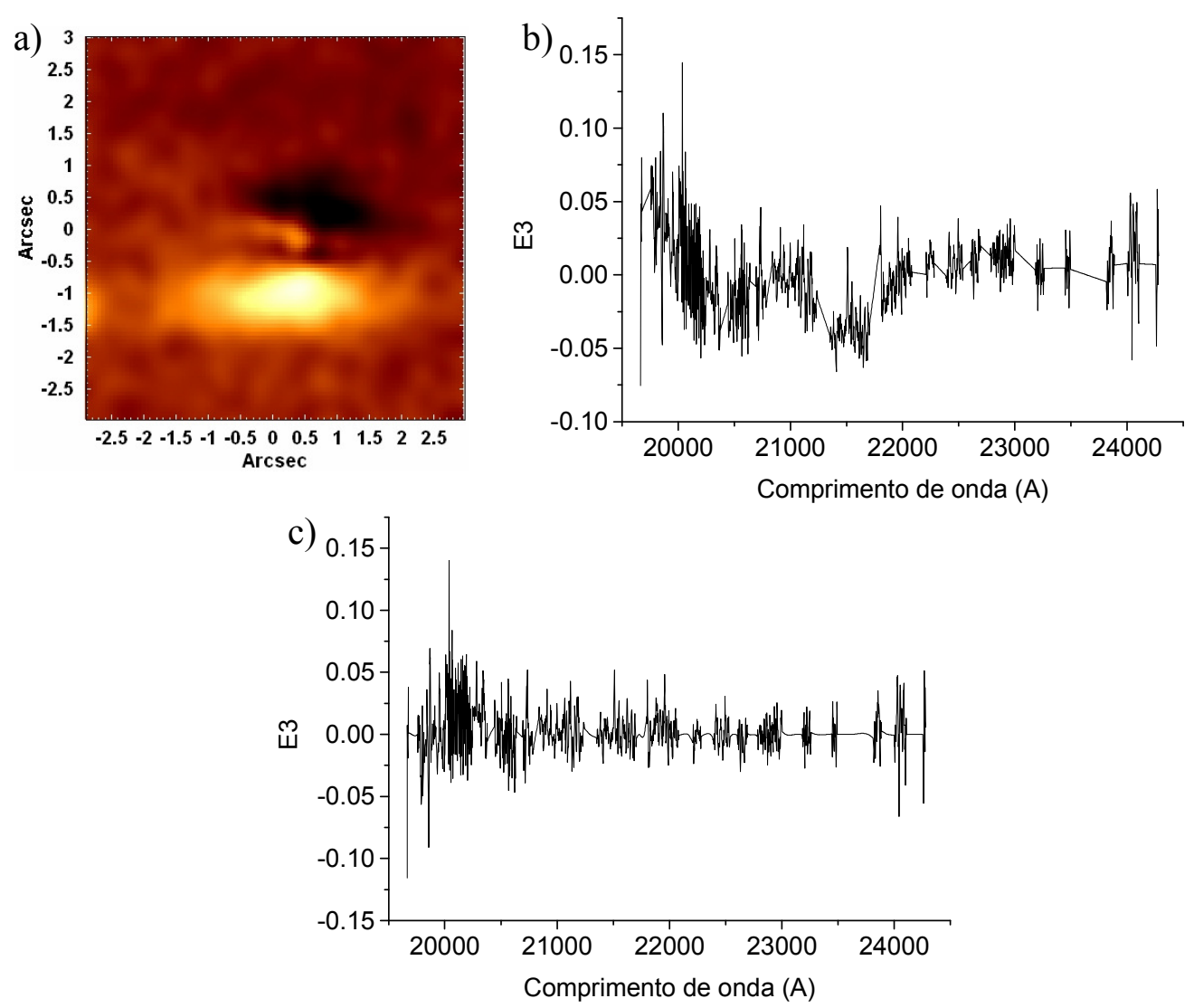

Figura 7.6 - (a) Tomograma correspondente ao autovetor E3, obtido com a Tomografia PCA aplicada ao cubo de dados de NGC 5643, após a remoção das linhas espectrais; (b) Autoespectro correspondente ao autovetor E3, obtido com a Tomografia PCA aplicada ao cubo de dados de NGC 5643, após a remoção das linhas espectrais; (c) Mesmo auto-espectro mostrado em (b), após a subtração do "spline" ajustado.

Finalmente, passou-se para a etapa da deconvolução de Richardson-Lucy. Por se tratar de uma galáxia Seyfert 2, NGC 5643 não possui linhas com uma componente larga visível, logo, não foi possível fazer uma imagem da componente larga de alguma linha espectral. Assim, optou-se por utilizar como PSF uma imagem proveniente do cubo de dados da estrela padrão usada no processo de redução dos dados para a remoção das absorções telúricas e para a calibração em fluxo. Para se fazer isso, entretanto, foi preciso aplicar ao cubo de dados dessa estrela padrão o mesmo processamento utilizado no cubo de NGC 5643, ou seja, foi feita a reamostragem espacial e a filtragem espacial de Butterworth desse cubo. Uma vez obtida a imagem correspondente à PSF, foi aplicada a deconvolução de Richardson-Lucy no cubo de dados de NGC 5643, utilizando-se 10 iterações. A figura 7.7 mostra a soma de todas as imagens e o espectro médio do cubo de dados final, obtido após a aplicação da deconvolução de Richardson-Lucy. 

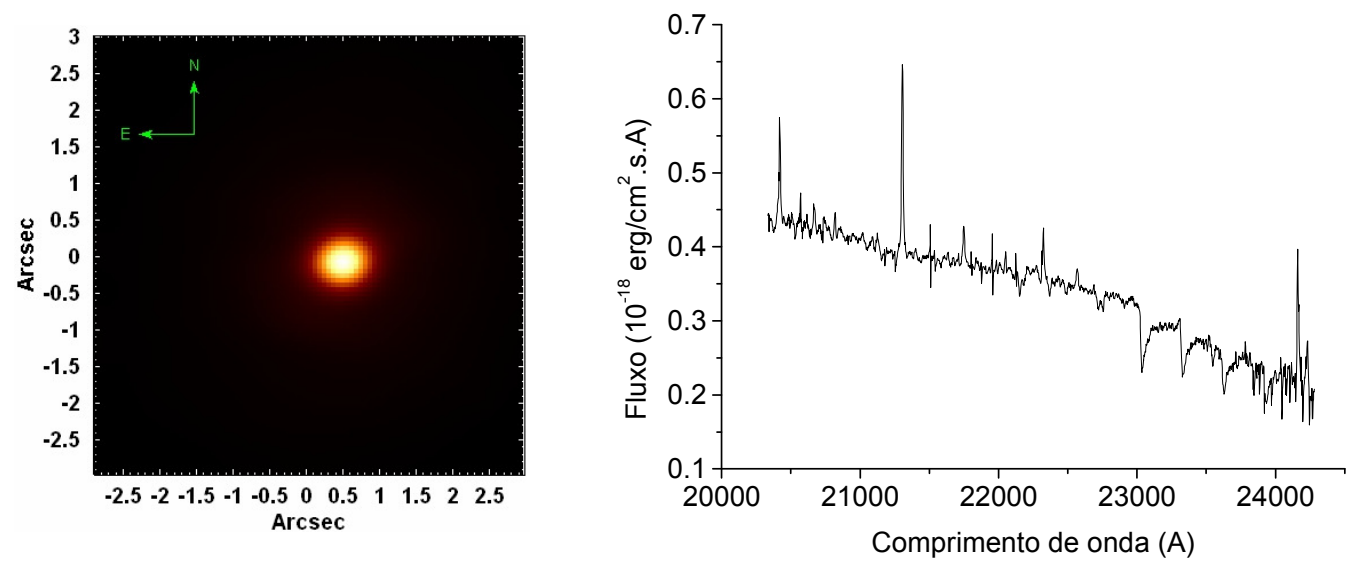

Figura 7.7 - (esquerda) Soma de todas as imagens do cubo de dados final de NGC 5643, obtido após todo o processamento; (direita) Espectro médio do cubo de dados final de

NGC 5643, obtido após todo o processamento.

\section{3 - Aplicação da Tomografia PCA ao cubo de dados de NGC 5643 com o contínuo estelar}

Após todo o processamento descrito na seção 7.2, aplicou-se a Tomografia PCA ao cubo de dados de NGC 5643. Os principais auto-espectros e respectivos tomogramas obtidos encontram-se a seguir.
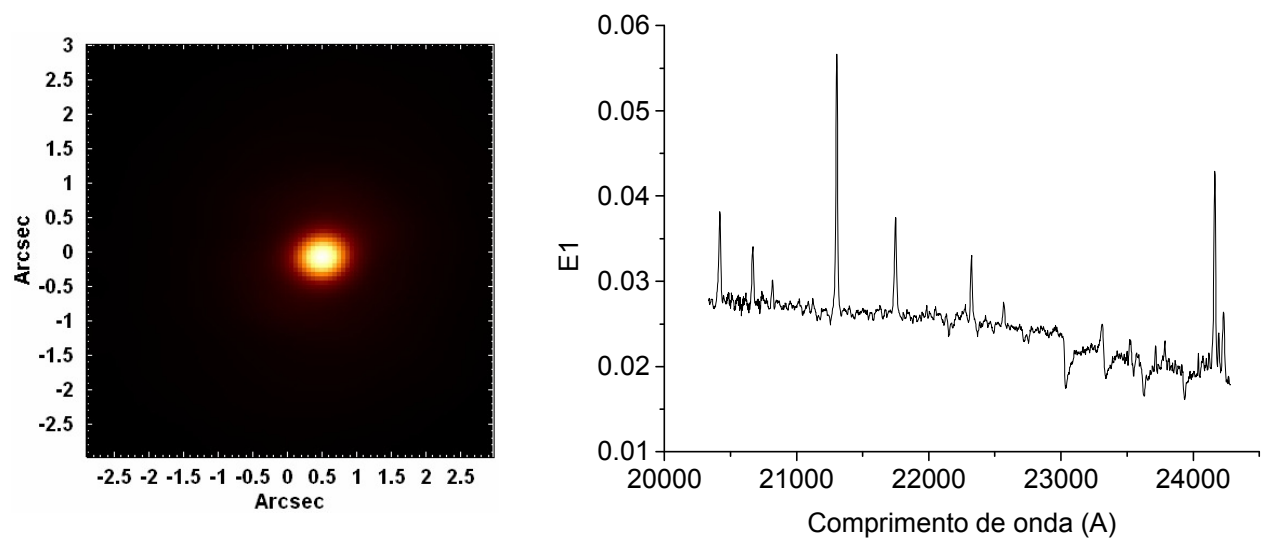

Figura 7.8 - Tomograma e auto-espectro correspondentes ao autovetor E1, obtido com a Tomografia PCA do cubo de dados de NGC 5643 com o contínuo estelar. 

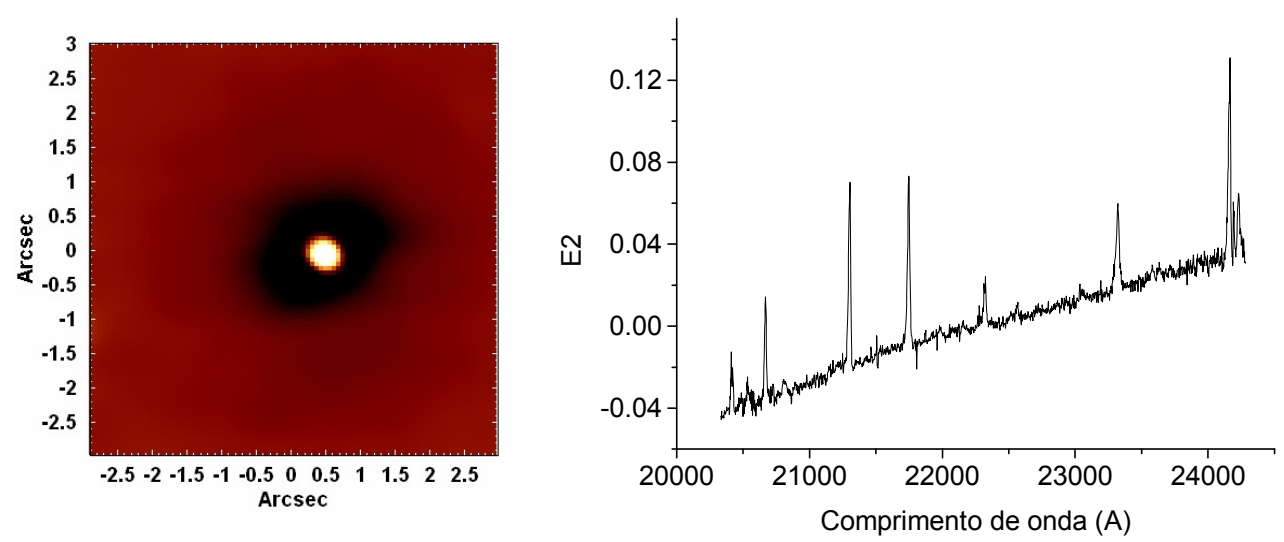

Figura 7.9 - Tomograma e auto-espectro correspondentes ao autovetor E2, obtido com a Tomografia PCA do cubo de dados de NGC 5643 com o contínuo estelar.
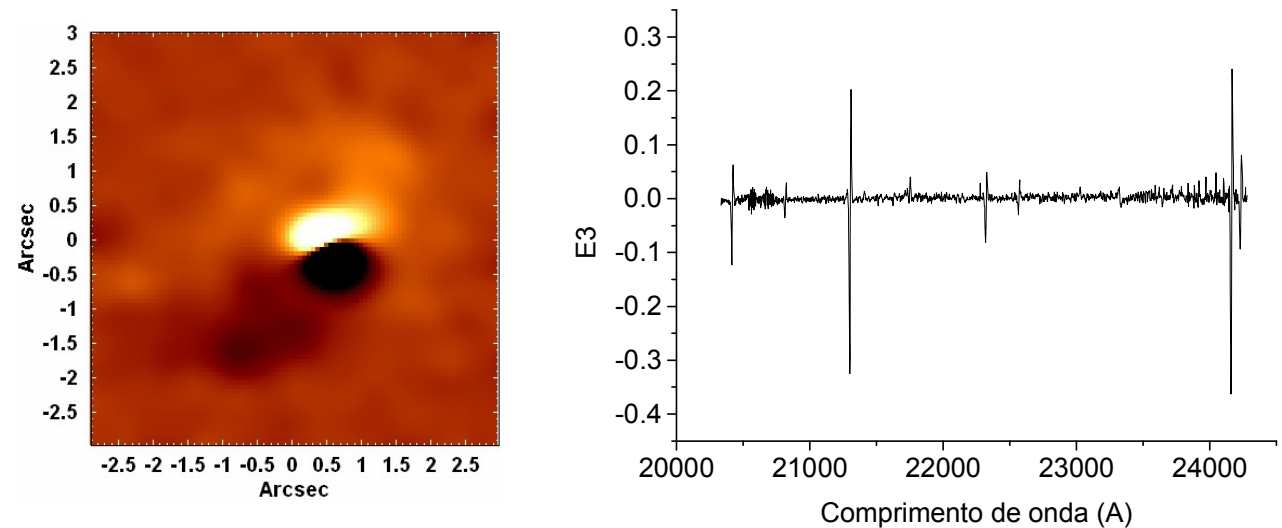

Figura 7.10 - Tomograma e auto-espectro correspondentes ao autovetor E3, obtido com a Tomografia PCA do cubo de dados de NGC 5643 com o contínuo estelar.

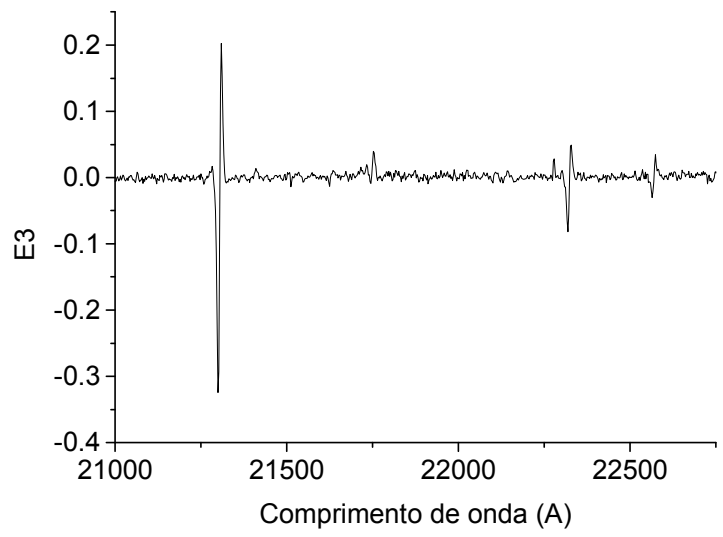

Figura 7.11 - Ampliação do intervalo espectral entre 21000 A e 22750 A do auto-espectro correspondente ao autovetor E3, obtido com a Tomografia PCA do cubo de dados de NGC 5643 com o contínuo estelar. 

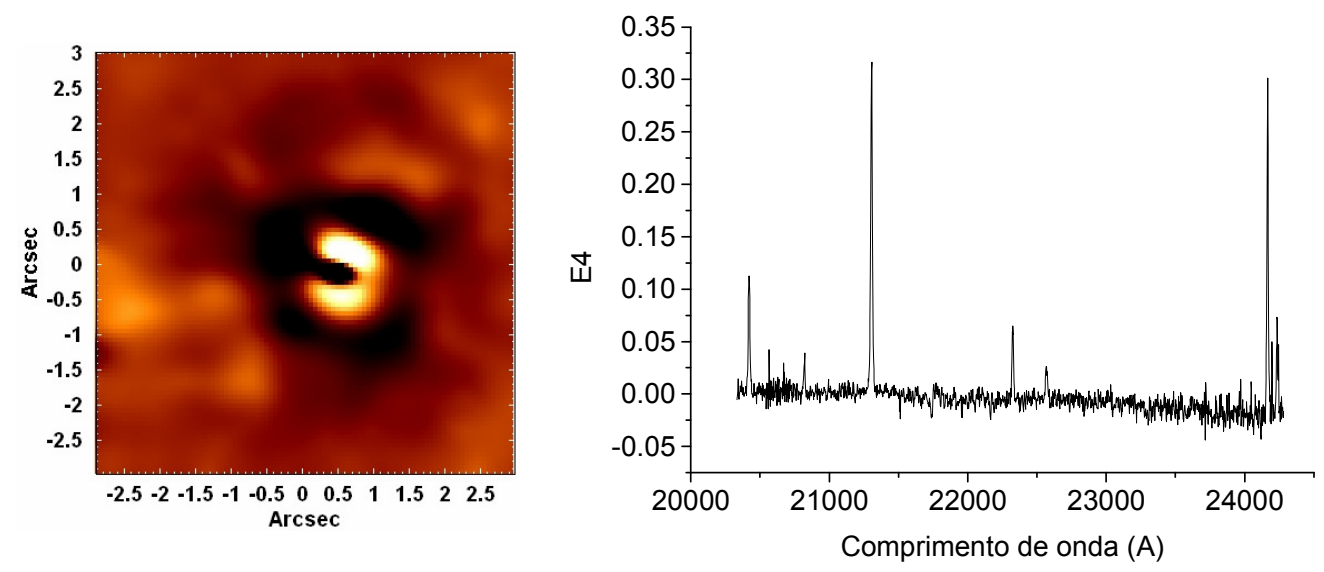

Figura 7.12 - Tomograma e auto-espectro correspondentes ao autovetor E4, obtido com a Tomografia PCA do cubo de dados de NGC 5643 com o contínuo estelar.
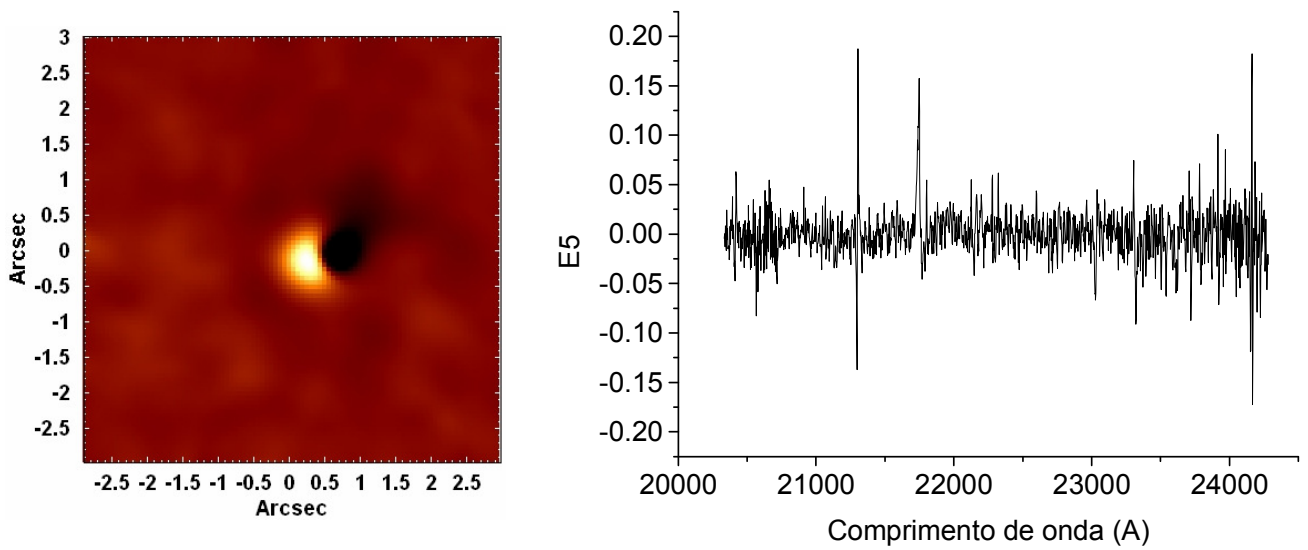

Figura 7.13 - Tomograma e auto-espectro correspondentes ao autovetor E5, obtido com a Tomografia PCA do cubo de dados de NGC 5643 com o contínuo estelar.

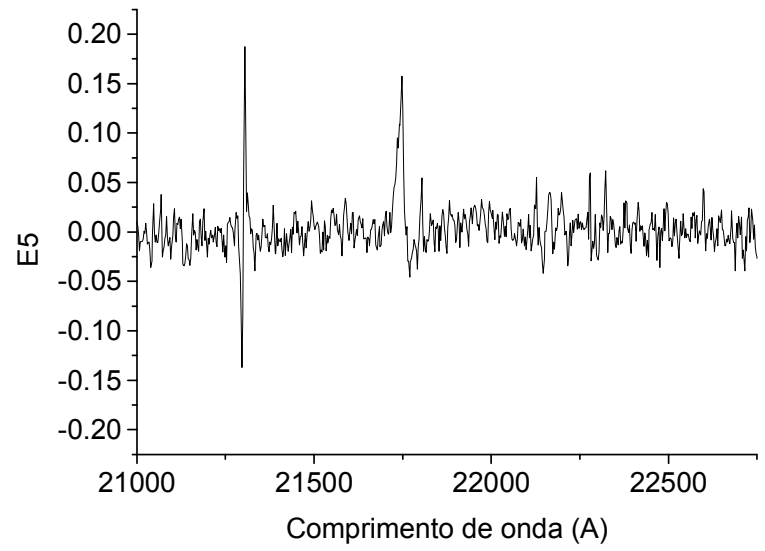

Figura 7.14 - Ampliação do intervalo espectral entre 21000 A e 22750 A do auto-espectro correspondente ao autovetor E5, obtido com a Tomografia PCA do cubo de dados de NGC 5643 com o contínuo estelar. 


\begin{tabular}{|c|c|}
\hline Autovetor & Fração da variância explicada (\%) \\
\hline E1 & 99.6355 \\
\hline E2 & 0.2330 \\
\hline E3 & 0.0423 \\
\hline E4 & 0.0130 \\
\hline E5 & 0.0044 \\
\hline
\end{tabular}

Tabela 7.1 - Autovalores obtidos com a Tomografia PCA do cubo de dados de NGC 5643 com o contínuo estelar.

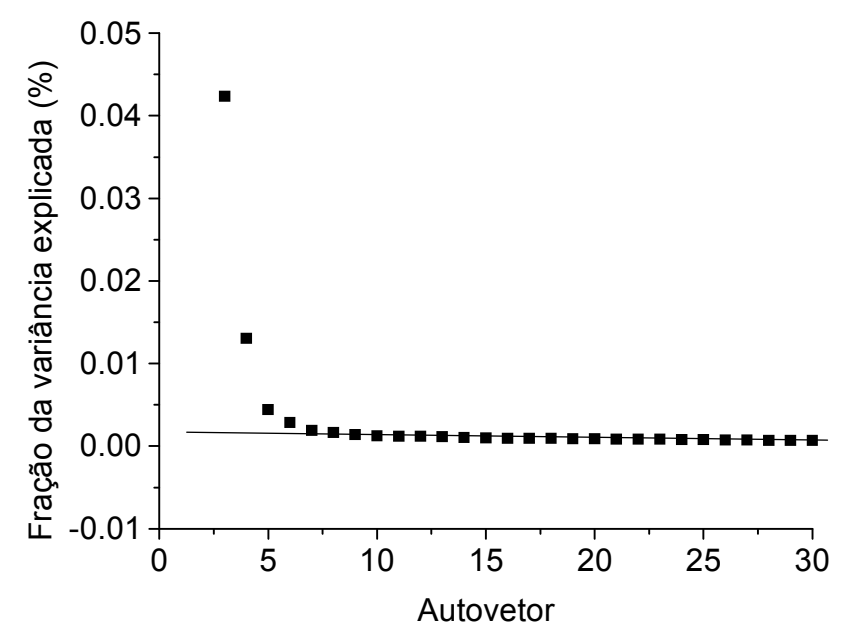

Figura 7.15 - "Scree test" dos autovetores obtidos com a Tomografia PCA do cubo de dados de NGC 5643 com o contínuo estelar.

A figura 7.8 mostra que o auto-espectro E1 apresenta correlações com os comprimentos de onda associados às linhas de $\mathrm{Br} \gamma$, [Ca VIII] e He I 220587 . Isso revela que esse autovetor deve estar correlacionado com a emissão proveniente do AGN existente nessa galáxia. Nesse caso, a posição do AGN deve corresponder à região mais clara do tomograma. Algumas das áreas claras mais afastadas do AGN central podem representar, inclusive, a NLR desse objeto. O fato de a emissão proveniente do AGN ter aparecido no autovetor E1, que explica a maior parte da variância dos dados (cerca de 99.6355 \% do total), está de acordo com o esperado, já que esse AGN é intenso e, consequentemente, facilmente detectável. O auto-espectro E1 apresenta, ainda, correlações com os comprimentos de onda correspondentes às principais linhas de $\mathrm{H}_{2}$ visíveis no espectro. Isso mostra que esse autovetor também está correlacionado com regiões emissoras de $\mathrm{H}_{2}$, que devem estar entre as regiões claras do tomograma. Por fim, uma outra característica que pode ser notada no auto-espectro E1 é a presença de um contínuo possivelmente estelar e de estruturas compatíveis com bandas de absorção de CO. Isso indica 
que esse autovetor está correlacionado com a emissão estelar proveniente da parte central do bojo, que também está representada pelas áreas claras do tomograma.

Observando-se a figura 7.9, pode-se notar que o auto-espectro E2 possui uma correlação com a região vermelha do espectro e uma anti-correlação com a região azul do mesmo, o que indica que esse autovetor estabelece um diferencial entre espectros mais avermelhados e espectros mais azulados existentes no cubo de dados de NGC 5643. Nesse caso, as regiões mais claras do tomograma devem apresentar espectros com um contínuo mais avermelhado e as áreas mais escuras espectros com um contínuo mais azulado. O auto-espectro E2 também possui correlações com comprimentos de onda correspondentes às linhas de $\mathrm{Br} \gamma$, [Ca VIII],

He $\mathrm{I} \lambda 20587$ e às principais linhas de $\mathrm{H}_{2}$ visíveis. Todas essas características sugerem que, na região mais próxima ao AGN central, o fluxo parece ser dominado pela emissão térmica de poeira (o que é evidenciado pelo contínuo mais avermelhado dessa área), além de que linhas de $\mathrm{Br} \gamma$, [Ca VIII] e He I 220587 também estão presentes. Parte da emissão de $\mathrm{H}_{2}$ pode se originar nessa região, entretanto, é pouco provável que as moléculas de $\mathrm{H}_{2}$ consigam "sobreviver" a distâncias muito pequenas do AGN. Na área escura imediatamente ao redor do AGN, a emissão parece ser dominada por populações estelares (o que é evidenciado pelo contínuo mais azulado dessa região). Por fim, nas áreas claras mais afastadas do AGN, parece haver considerável emissão de $\mathrm{H}_{2}$ e possivelmente de linhas como Bry e [Ca VIII] (o que indicaria que parte dessa região pode corresponder à NLR e ao cone de ionização desse objeto). O autovetor E2 explica cerca de $0.2330 \%$ da variância dos dados.

Uma análise das figuras 7.10 e 7.11 revela que as principais características do autoespectro E3 são correlações com os comprimentos de onda correspondentes às asas vermelhas das principais linhas de $\mathrm{H}_{2}$ do espectro e anti-correlações com os comprimentos de onda associados às asas azuis das mesmas. Isso parece indicar que esse autovetor está relacionado a algum fenômeno cinemático do gás $\mathrm{H}_{2}$ na região central de NGC 5643. Nesse caso, as áreas claras do tomograma correspondem a regiões com o gás molecular apresentado uma emissão em redshift e as áreas escuras representam a regiões com o gás possuindo uma emissão em blueshift. A morfologia do tomograma sugere uma cinemática consideravelmente complexa do gás $\mathrm{H}_{2}$, sendo que é possível que mais de um fenômeno cinemático esteja presente. De fato, na área próxima ao AGN, a morfologia do tomograma parece ser compatível com uma rotação do gás molecular ao redor do núcleo. Isso pode ser uma evidência da existência de um toro 
molecular em rotação nessa região. Em áreas mais afastadas do AGN, a morfologia do tomograma pode ser compatível com um fluxo de gás molecular, por exemplo. O autovetor E3 explica cerca de $0.0423 \%$ da variância dos dados.

A figura 7.12 mostra que o auto-espectro E4 apresenta correlações com os comprimentos de onda correspondentes às principais linhas de $\mathrm{H}_{2}$ do espectro, o que indica que esse autovetor está correlacionado com regiões emissoras de $\mathrm{H}_{2}$, que devem estar entre as áreas claras do tomograma. O autovetor $\mathrm{E} 4$ explica cerca de 0.0130 \% da variância dos dados.

Finalmente, as figuras 7.13 e 7.14 revelam que o auto-espectro E5 apresenta correlações com os comprimentos de onda associados às asas azuis das linhas de emissão de Bry e [Ca VIII] e anti-correlações com os comprimentos de onda correspondentes às asas vermelhas das mesmas. Isso parece indicar que o autovetor E5 também está relacionado a algum fenômeno cinemático do gás na região central de NGC 5643, entretanto, nesse caso (ao contrário do que ocorre com autovetor E3), trata-se do gás provavelmente ionizado pelo AGN central. Considerando-se isso, as áreas claras do tomograma representam regiões com gás com emissão em blueshift e as áreas escuras correspondem a regiões com gás com emissão em redshift. Considerando-se a morfologia do tomograma em questão e comparando-o com o mapa de excitação [O III]/Ha dessa galáxia, obtido a partir de imagens do HST (figura 7.3, retirada do trabalho de Simpson et al. 1997), pode-se concluir que o autovetor E5 está provavelmente associado à cinemática do cone de ionização desse objeto. Tal cone de ionização é aproximadamente perpendicular à direção na qual ocorre a suposta rotação do gás molecular detectada no autovetor E3. Isso é compatível com a hipótese de que essa rotação do gás molecular esteja associada a um toro molecular ao redor do núcleo. O auto-espectro E5 também possui correlações com os comprimentos de onda correspondentes às asas vermelhas das principais linhas de $\mathrm{H}_{2}$ do espectro e anti-correlações com os comprimentos de onda associados às asas azuis das mesmas, o que sugere que, apesar da relação com a cinemática do cone de ionização, esse autovetor também parece apresentar alguma "contaminação" por parte da cinemática do gás $\mathrm{H}_{2}$. Nesse caso, as regiões com gás $\mathrm{H}_{2}$ com emissão em redshift devem estar entre as áreas claras do tomograma e as regiões com gás $\mathrm{H}_{2}$ com emissão em blueshift devem estar entre as áreas escuras do tomograma. O autovetor E5 explica cerca de $0.0044 \%$ da variância dos dados. 
Analisando-se o Scree test na figura 7.15, pode-se notar que os valores das variâncias explicadas pelos autovetores decaem bastante até, aproximadamente, o autovetor E7, a partir do qual a taxa de decaimento diminui muito e fica praticamente constante. Isso indica que os autovetores de ordem maior ou igual a 7 representam, sobretudo, ruído e, consequentemente, não possuem relevância nessa análise. Entretanto, dentre os autovetores de ordem menor do que 7, apenas os cinco primeiros apresentavam uma interpretação mais clara e, por essa razão, apenas eles foram mostrados aqui.

Assim, conclui-se que essa análise inicial com a Tomografia PCA revelou uma quantidade considerável de fenômenos na região central de NGC 5643. Primeiramente, a emissão proveniente do AGN (e de sua NLR) foi facilmente detectada. Regiões emissoras de $\mathrm{H}_{2}$ também foram observadas. Além disso, a análise mostrou que as áreas mais próximas ao AGN central apresentam espectros com um contínuo mais avermelhado do que as regiões logo ao redor. Isso pode ser devido ao fato de o contínuo na área mais próxima ao AGN ser dominado pela emissão térmica de poeira e o fluxo nos arredores ser devido, principalmente, a populações estelares. Foi detectada uma cinemática consideravelmente complexa do gás $\mathrm{H}_{2}$ na região central de NGC 5643, com um possível toro molecular em rotação ao redor do núcleo e um fluxo de gás em áreas mais afastadas do AGN. Por fim, a análise também revelou a existência de uma outra cinemática, dessa vez relacionada com o gás provavelmente ionizado pelo AGN. A morfologia observada desse fenômeno é compatível com a do cone de ionização desse objeto, o que pode ser constatado comparando-se as figuras 7.13, que contém o tomograma do autovetor associado à cinemática do gás ionizado, e 7.3, que mostra o mapa de excitação [O III]/H $\alpha$ dessa galáxia, obtido a partir de imagens do HST, retirado do trabalho de Simpson et al. (1997). Esse

cone de ionização é aproximadamente perpendicular ao suposto toro molecular em rotação detectado, mencionado anteriormente.

\section{4 - Síntese espectral do cubo de dados de NGC 5643 com o Starlight}

Depois da análise inicial com a Tomografia PCA, foi aplicada uma síntese espectral no cubo de dados de NGC 5643 com o software Starlight. A preparação dos espectros foi feita 
conforme descrito em 3.12, sendo que a correção da extinção devido à Via Láctea e a passagem dos espectros para o referencial de repouso foram aplicadas considerando-se $A_{V}=0.559$ e $z=$ 0.003999, respectivamente. Tanto $A_{V}$ quanto $\mathrm{z}$ foram obtidos a partir do site do NED.

Como o cubo de dados de NGC 5643 foi obtido na região espectral do infravermelho próximo e há um AGN nessa galáxia, foi preciso levar em conta na síntese espectral a emissão térmica de poeira e um featureless continuum. Assim como nos casos anteriores de sínteses espectrais aplicadas em dados no infravermelho próximo, devido às limitações da base utilizada, apenas os mapeamentos mais confiáveis dos parâmetros obtidos são mostrados nas sessões a seguir.

\subsection{1 - Qualidade dos ajustes}

O mapeamento dos valores do $\chi^{2} / n_{\text {eff }}$ dos ajustes resultantes da síntese espectral do cubo de dados de NGC 5643 encontra-se a seguir.

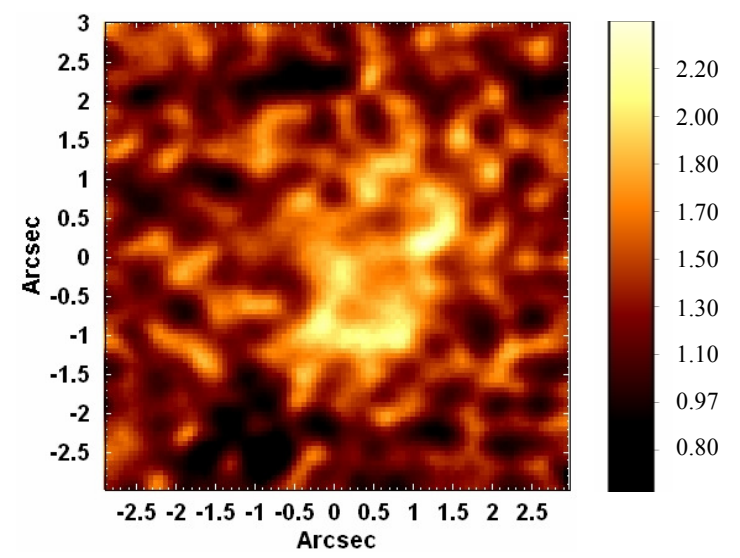

Figura 7.16: Mapeamento dos valores do $\chi^{2} / n_{\text {eff }}$ dos ajustes obtidos pelo "Starlight" para os espectros do cubo de dados de NGC 5643.

Observando-se a figura 7.16, pode-se verificar que os melhores ajustes obtidos com a síntese espectral apresentaram $\chi^{2} / n_{\text {eff }}$ de cerca de 0.6 , ao passo que os piores tiveram $\chi^{2} / n_{\text {eff }}$ de cerca de 2.3. Isso mostra que mesmo os ajustes menos precisos resultantes desse procedimento ainda podem ser considerados suficientemente confiáveis. O mapeamento da figura 7.16 também indica que os valores do $\chi^{2} / n_{\text {eff }}$ nas áreas mais próximas ao AGN central parecem ser consideravelmente maiores do que nos arredores. A razão disso não está clara, mas uma possível explicação é que o featureless continuum emitido pelo AGN, que está sendo detectado nessa 
região, talvez não tenha sido reproduzido com precisão pelo Starlight (possivelmente porque o índice espectral seja diferente do valor de 1.5 utilizado), o que resultou em ajustes com qualidade consideravelmente inferior e maiores valores para $0 \chi^{2} / n_{e f f}$ nessa área.

\subsection{2 - Populações estelares, poeira e featureless continuum}

Assim como nos casos dos capítulos anteriores, a partir dos resultados obtidos com a síntese espectral com Starlight do cubo de dados de NGC 5643, construíram-se três mapeamentos de fluxo (os únicos suficientemente confiáveis, considerando-se que esse cubo de dados contém espectros no infravermelho próximo): o mapeamento do fluxo total devido às populações estelares, o mapeamento do fluxo total devido à emissão térmica de poeira e o mapeamento do fluxo devido ao featureless continuum. Todas essas imagens são mostradas a seguir.

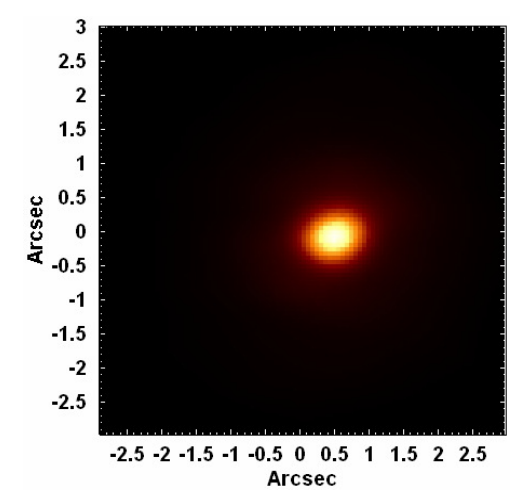

Figura 7.17: Mapeamento do fluxo total devido às populações estelares, obtido com a aplicação do "Starlight" ao cubo de dados de NGC 5643.

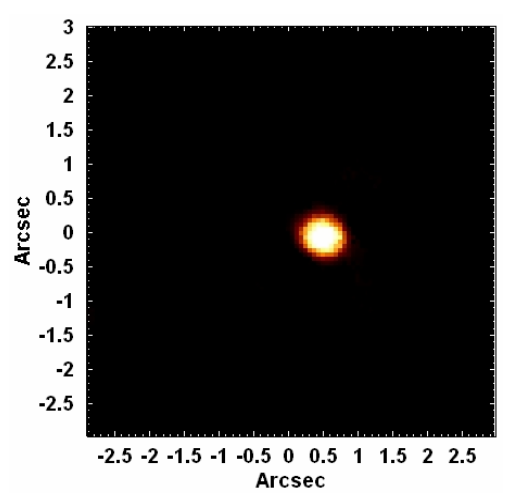

Figura 7.18: Mapeamento do fluxo total devido à emissão térmica de poeira, obtido com a aplicação do "Starlight" ao cubo de dados de NGC 5643. 


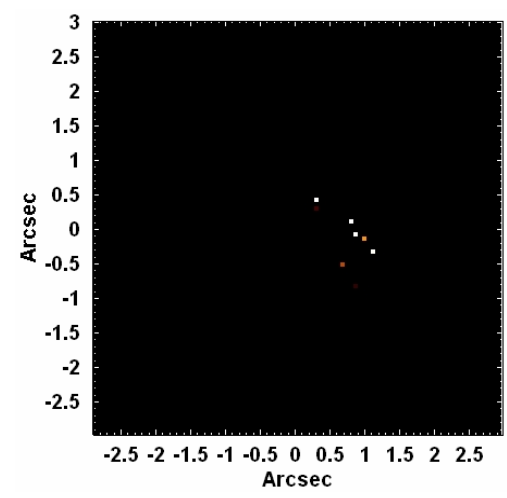

Figura 7.19: Mapeamento do fluxo atribuído ao "featureless continuum" do AGN, obtido com a aplicação do "Starlight" ao cubo de dados de NGC 5643.

Em seguida, construiu-se um gráfico em colunas contendo as frações de fluxo atribuídas às populações estelares, à emissão térmica de poeira e ao featureless continumm do AGN, considerando-se todo o campo visual do SINFONI. O gráfico obtido é mostrado na figura 7.20.
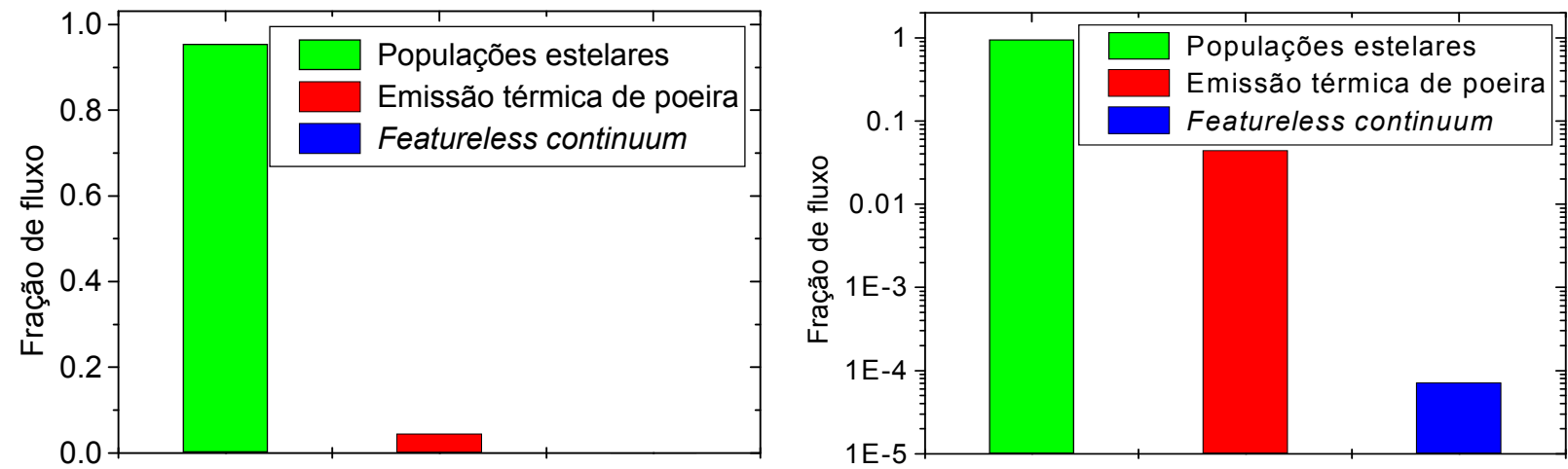

Figura 7.20: (esquerda) Gráfico representativo das frações de fluxo devidas às populações estelares, à emissão térmica de poeira e ao "featureless continuum", considerando-se todo o campo visual do SINFONI, obtido com a aplicação do "Starlight" ao cubo de dados de NGC 5643; (direita) Mesmo gráfico mostrado à esquerda, mas com escala logarítmica no eixo das ordenadas.

Analisando-se as figuras 7.17 e 7.18, pode-se notar que foi detectado fluxo proveniente de populações estelares por todo o campo visual do SINFONI, inclusive na região correspondente ao AGN. A emissão térmica de poeira, por outro lado, somente foi observada na área mais próxima ao AGN. Isso pode ser uma evidência da existência de um toro de poeira ao redor do AGN, o que seria compatível com o que é proposto pelo Modelo Unificado. A existência de emissão térmica de poeira nos arredores do AGN também foi evidenciada pelo autovetor E2 obtido com a Tomografia PCA do cubo de dados de NGC 5643 com o contínuo estelar (figura 7.9). Uma diferença entre os resultados mostrados nas figuras 7.17 e 7.18 e os encontrados nas sínteses espectrais dos cubos de dados de NGC 2992, NGC 4151 e NGC 3227 
(obtido com o SINFONI) é que aqui foi detectado fluxo devido a populações estelares ao longo de todo o campo visual do SINFONI (inclusive na região correspondente ao AGN), ao passo que, nos casos anteriores, tal fluxo não foi observado na área próxima ao AGN. A não detecção de fluxo originário de populações estelares na posição do AGN foi explicada anteriormente como sendo devida ao fato de a forte emissão térmica de poeira nessa região "ofuscar" a emissão estelar, impedindo a sua detecção pelo Starlight. O fato de se ter detectado fluxo de populações estelares na área correspondente ao AGN de NGC 5643 indica que a emissão térmica de poeira nessa galáxia deve ser significativamente mais fraca, já que não foi capaz de “ofuscar” as populações estelares existentes.

A figura 7.19 mostra que praticamente nenhum fluxo atribuído ao featureless continuum do AGN foi detectado. A mínima quantidade observada pode estar associada a imprecisões do ajuste, não sendo, portanto, suficiente para evidenciar qualquer detecção. Existem algumas explicações possíveis para o fato de não se ter detectado nenhum featureless continuum num objeto que, comprovadamente, possui um AGN. Uma delas é que um forte obscurecimento por gás e poeira está impedindo a detecção desse contínuo emitido pelo AGN. De fato, Morris et al. (1985) encontraram evidências da existência de um forte obscurecimento da emissão proveniente do AGN dessa galáxia. Além disso, a emissão térmica de poeira pode estar também "ofuscando" o featureless continuum. Por fim, uma outra explicação é que o contínuo emitido pelo AGN é detectável nessa região espectral, entretanto, possui um índice espectral diferente do que foi utilizado nos ajustes (1.5) e, consequentemente, não pôde ser reproduzido pelo Starlight.

Os gráficos da figura 7.20 revelam que a maior parte do fluxo detectado no campo visual do SINFONI (cerca de $95.54 \%$ do total) foi devida a populações estelares. A fração do fluxo total associada à emissão térmica de poeira, por outro lado, foi significativamente menor (cerca de $4.45 \%$ ). Nos casos de NGC 2992, NGC 4151 e NGC 3227 (considerando o cubo de dados obtido com o SINFONI), as frações do fluxo total associadas à emissão térmica de poeira (cerca de $31.9 \%, 54.4 \%$ e $41.8 \%$, respectivamente) foram consideravelmente maiores. Isso, juntamente com o fato de, nesses casos anteriores, a emissão térmica de poeira ter sido capaz de “ofuscar" o fluxo proveniente das populações estelares (ao contrário do que ocorreu no caso de NGC 5643), parece indicar que os resultados obtidos com a síntese espectral com o Starlight dos cubos de dados de todos esses objetos foram bastante coerentes um com o outro. Entretanto, essa comparação não pode ser feita com precisão, já que o tamanho do campo visual em todos 
esses casos analisados variou consideravelmente. O gráfico da figura 7.20 mostra, ainda, que a fração do fluxo total atribuída ao featureless continuum é extremamente pequena (cerca de 0.01 \%), podendo, inclusive, ser considerada desprezível. Tal ausência de featureless continuum já havia sido constatada por meio do mapeamento da imagem 7.19 e algumas possíveis explicações para esse fato (obscurecimento por gás e poeira, "ofuscamento" por emissão térmica de poeira ou índice espectral diferente de 1.5) também já foram propostas anteriormente.

\subsection{3 - Valores da razão $S / N$ dos espectros analisados}

O mapeamento dos valores da razão $S / N$ obtidos pelo Starlight no intervalo espectral de $22298 \AA$ até $22378 \AA$ encontra-se a seguir.

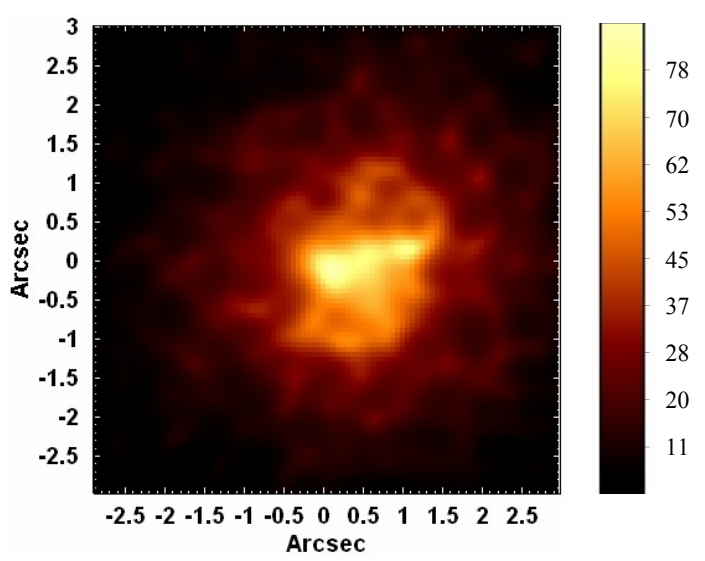

Figura 7.21 - Mapeamentos dos valores da razão $S / N$, obtidos a partir da síntese espectral do cubo de dados de NGC 5643 com o "Starlight".

Observando-se a figura 7.21, pode-se notar que os valores mais altos (até cerca de 86) para a razão $S / N$ foram encontrados nas regiões mais próximas ao centro do campo visual do SINFONI (onde se encontra o AGN), ao passo que os menores valores (até cerca de 3) foram obtidos nas áreas mais afastadas. Isso está de acordo com o esperado, já que o fluxo detectado é mais intenso nas regiões próximas ao $\mathrm{AGN}$, dando origem aos valores mais elevados da razão $S / N$. 


\section{5 - Aplicação da Tomografia PCA ao cubo de dados de NGC 5643 com o contínuo estelar subtraído}

Utilizando-se os espectros estelares sintéticos resultantes da síntese espectral com o Starlight, fez-se uma subtração do contínuo estelar de todos os espectros do cubo de dados de NGC 5643. Aplicou-se, então, a Tomografia PCA ao cubo resultante, contendo apenas linhas de emissão. Os principais auto-espectros e respectivos tomogramas obtidos encontram-se a seguir.
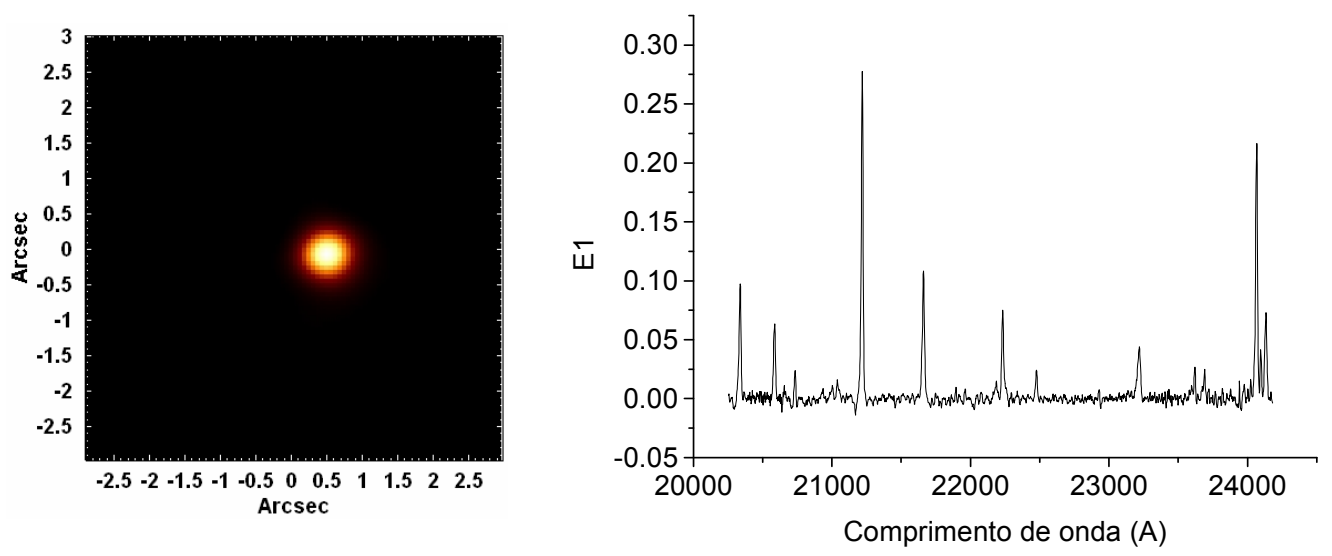

Figura 7.22 - Tomograma e auto-espectro correspondentes ao autovetor E1, obtido com a Tomografia PCA do cubo de dados de NGC 5643 com o contínuo estelar subtraído.
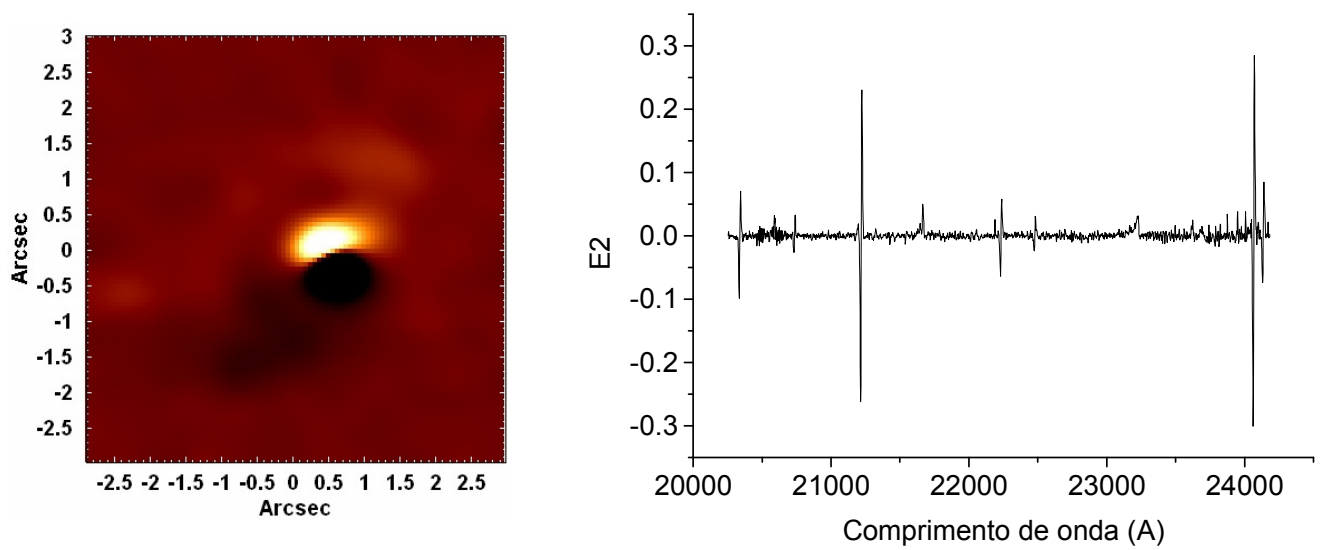

Figura 7.23 - Tomograma e auto-espectro correspondentes ao autovetor E2, obtido com a Tomografia PCA do cubo de dados de NGC 5643 com o contínuo estelar subtraído. 


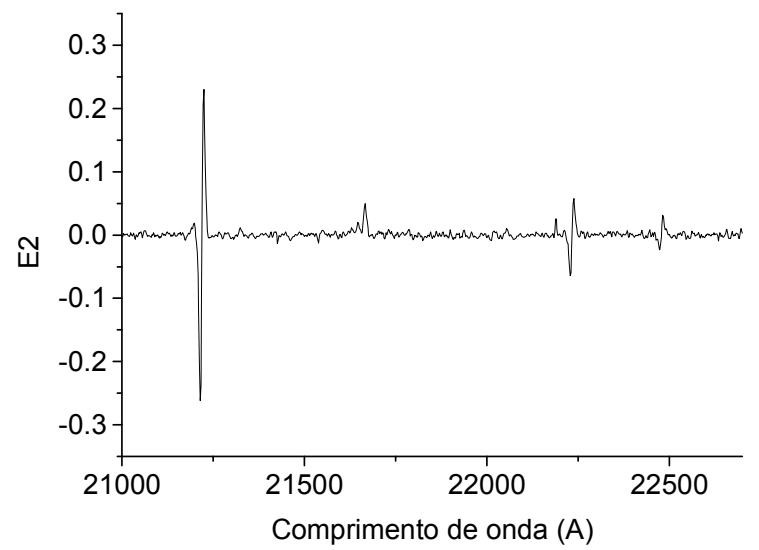

Figura 7.24 - Ampliação do intervalo espectral entre 21000 A e 22700 A do auto-espectro correspondente ao autovetor E2, obtido com a Tomografia PCA do cubo de dados de NGC 5643 com o contínuo estelar subtraído.
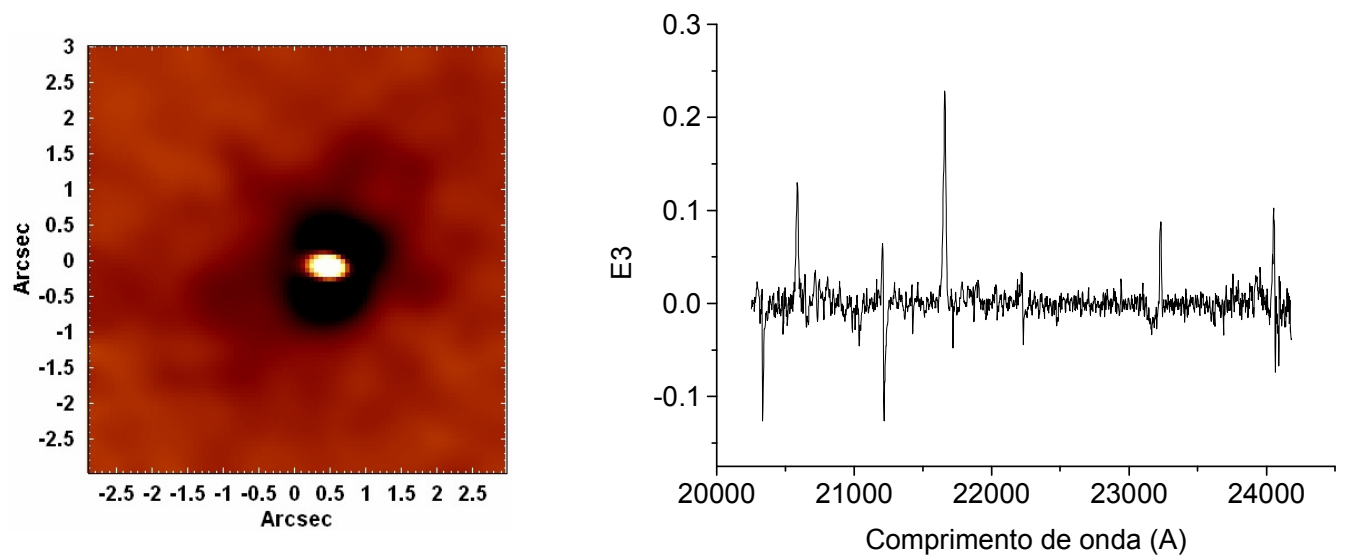

Figura 7.25 - Tomograma e auto-espectro correspondentes ao autovetor E3, obtido com a Tomografia PCA do cubo de dados de NGC 5643 com o contínuo estelar subtraído.
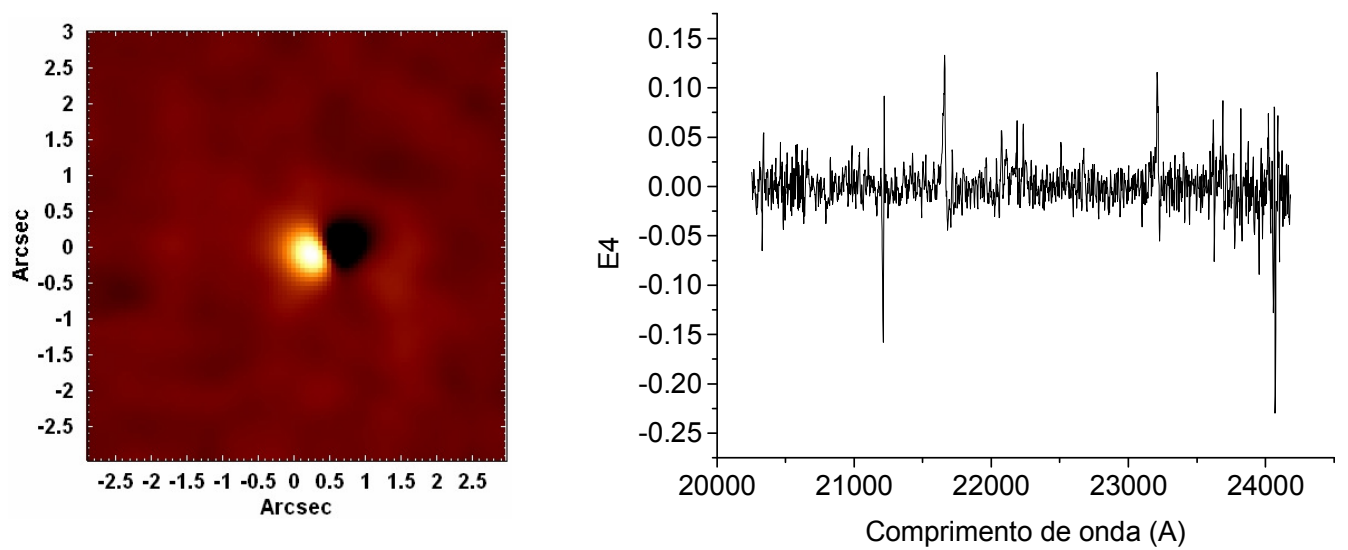

Figura 7.26 - Tomograma e auto-espectro correspondentes ao autovetor E4, obtido com a Tomografia PCA do cubo de dados de NGC 5643 com o contínuo estelar subtraído. 


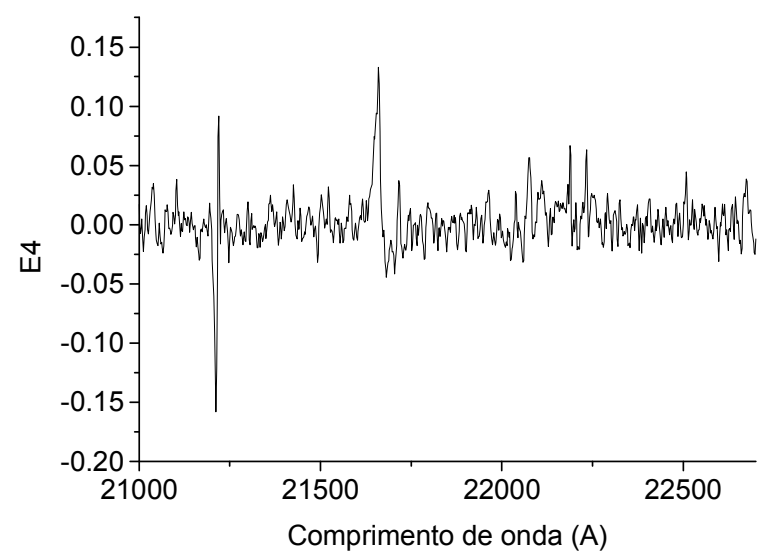

Figura 7.27 - Ampliação do intervalo espectral entre 21000 A e 22700 A do auto-espectro correspondente ao autovetor E4, obtido com a Tomografia PCA do cubo de dados de

NGC 5643 com o contínuo estelar subtraído.

\begin{tabular}{|c|c|}
\hline Autovetor & Fração da variância explicada (\%) \\
\hline E1 & 90.0904 \\
\hline E2 & 3.5838 \\
\hline E3 & 0.8597 \\
\hline E4 & 0.3793 \\
\hline
\end{tabular}

Tabela 7.2 - Autovalores obtidos com a Tomografia PCA do cubo de dados de NGC 5643 com o contínuo estelar subtraído.

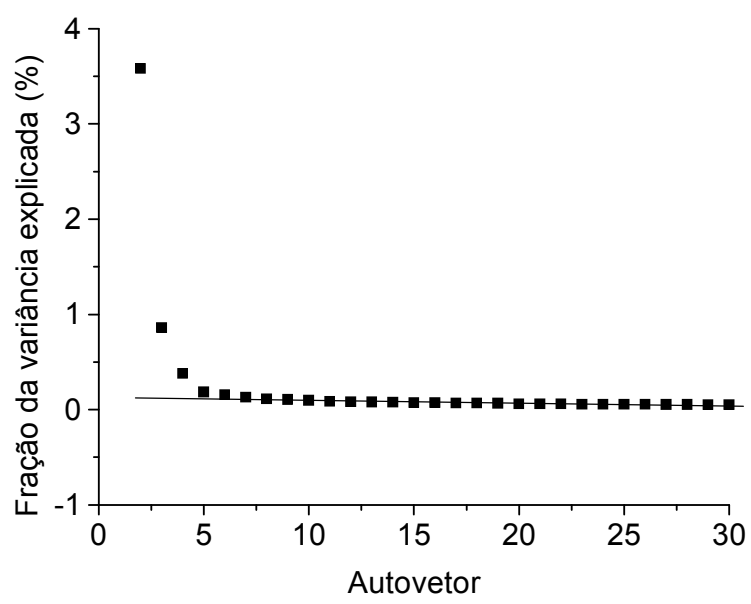

Figura 7.28 - "Scree test" dos autovetores obtidos com a Tomografia PCA do cubo de dados de NGC 5643 com o contínuo estelar subtraído.

A figura 7.22 revela, primeiramente, que o auto-espectro E1 apresenta correlações com os comprimentos de onda associados às linhas de $\mathrm{Br} \gamma$, [Ca VIII] e He I 220587 . Isso indica que esse autovetor deve estar correlacionado com a emissão proveniente do AGN. Nesse caso, a posição do AGN corresponde à região mais clara do tomograma. O fato de a emissão proveniente do AGN ter aparecido no autovetor E1 está de acordo com o esperado, já que ele explica a maior parte da variância dos dados (cerca de 90.0904 \% do total) e é sabido que o 
AGN existente nessa galáxia é intenso e, por conseqüência, facilmente detectável. O autoespectro E1 possui, ainda, correlações com os comprimentos de onda correspondentes às principais linhas de emissão de $\mathrm{H}_{2}$ do espectro. Isso revela que esse autovetor também está correlacionado com regiões emissoras de $\mathrm{H}_{2}$, que devem estar entre as áreas claras do tomograma. Pode-se notar que as informações reveladas por esse autovetor são bastante compatíveis com as mostradas pelo autovetor E1 obtido com a aplicação da Tomografia PCA mostrada na seção 7.3 (figura 7.8), entretanto, a subtração do contínuo estelar facilitou a visualização da emissão do gás existente.

Observando-se as figuras 7.23 e 7.24, nota-se que o auto-espectro E2 apresenta correlações com os comprimentos de onda correspondentes às asas vermelhas das principais linhas de $\mathrm{H}_{2}$ visíveis no espectro e anti-correlações com os comprimentos de onda associados às asas azuis das mesmas. Isso parece indicar que o autovetor E2 está relacionado a algum fenômeno cinemático do gás $\mathrm{H}_{2}$ na região central de NGC 5643. Nesse caso, as áreas claras do tomograma correspondem a regiões com gás molecular apresentando uma emissão em redshift e as áreas escuras representam regiões com gás molecular possuindo uma emissão em blueshift. A morfologia desse tomograma indica alguma complexidade na cinemática do gás $\mathrm{H}_{2}$, com a possibilidade da existência de mais de um fenômeno cinemático. De fato, na área próxima ao AGN, a morfologia do tomograma parece ser compatível com uma rotação do gás molecular ao redor do núcleo, o que pode ser uma evidência da existência de um toro molecular em rotação nessa região. Em áreas mais afastadas do AGN, a morfologia do tomograma pode ser compatível com um fluxo de gás molecular, por exemplo. Todas essas características do autovetor E2 estão de acordo com o que foi observado no autovetor E3 obtido com a aplicação da Tomografia PCA na seção 7.3 (figuras 7.10 e 7.11). O auto-espectro E2 também apresenta correlações e anti-correlações com os comprimentos de onda correspondentes às asas vermelha e azul, respectivamente, da linha de He I $\lambda 20587$, o que mostra que pelo menos parte das regiões emitindo He I possui o comportamento cinemático das áreas emissoras de $\mathrm{H}_{2}$. Um ponto importante a ser mencionado aqui é que o padrão cinemático observado no auto-espectro E2 para as linhas de $\mathrm{H}_{2}$ e para a linha de $\mathrm{He}$ I 220587 não é detectado nas linhas de Bry e de [Ca VIII], o que indica que o fenômeno cinemático revelado pelo autovetor E2 não está relacionado ao gás provavelmente ionizado pelo AGN central. O auto-espectro E2, entretanto, apresenta correlações com os comprimentos de onda correspondentes às linhas de $\mathrm{Br} \gamma \mathrm{e}$ 
[Ca VIII] (sem aspectos cinemáticos envolvidos), o que sugere que esse autovetor também possui alguma correlação com a emissão associada ao AGN. As áreas responsáveis por essa emissão devem estar entre as regiões claras do tomograma. O autovetor E2 explica cerca de 3.5838 \% da variância dos dados.

Analisando-se a figura 7.25, pode-se notar que o auto-espectro E3 apresenta correlações com os comprimentos de onda correspondentes às linhas de Bry, [Ca VIII] e He I 220587 . Isso parece indicar que esse autovetor está correlacionado com a emissão proveniente do AGN, podendo haver, inclusive, uma correlação com as regiões associadas ao cone de ionização existente. Nesse caso, as áreas emissoras dessas linhas devem estar entre as regiões claras do tomograma. Além disso, o auto-espectro E3 apresenta, ainda, correlações com os comprimentos de onda correspondentes às asas azuis das principais linhas de $\mathrm{H}_{2}$ do espectro e anti-correlações com os comprimentos de onda associados às asas vermelhas das mesmas. Isso sugere que o autovetor E3 também possui uma relação com algum fenômeno cinemático do gás $\mathrm{H}_{2}$ na região central de NGC 5643. Nesse caso, as áreas claras do tomograma correspondem a regiões com o gás $\mathrm{H}_{2}$ com uma emissão em blueshift e as áreas escuras representam regiões com o gás $\mathrm{H}_{2}$ com uma emissão em redshift. A morfologia do tomograma em questão não possui as características dos fenômenos cinemáticos detectados até aqui para esse objeto, o que parece indicar que o padrão cinemático revelado pelo auto-espectro E3 não é dominante nesse autovetor. Em outras palavras, pode-se dizer que o autovetor E3 apresenta uma "contaminação" por um fenômeno cinemático, que não é dominante. O autovetor E3 explica cerca de $0.8597 \%$ da variância dos dados.

Por fim, as figuras 7.26 e 7.27 mostram que o auto-espectro E4 apresenta correlações com os comprimentos de onda correspondentes às asas azuis das linhas de emissão de Bry e [Ca VIII] e anti-correlações com os comprimentos de onda associados às asas vermelhas das mesmas. Isso parece indicar que o autovetor E4 também está relacionado a algum fenômeno cinemático do gás na região central de NGC 5643, entretanto, ao contrário do que ocorre no caso do autovetor E2, esse fenômeno envolve o gás ionizado pelo AGN central. Nesse caso, as áreas claras do tomograma correspondem a regiões com o gás com uma emissão em blueshift e as áreas escuras representam regiões com o gás com uma emissão em redshift. Considerando-se a morfologia do tomograma (similar à do mapa de excitação [O III]/H $\alpha$ mostrado na figura 7.3, retirado do trabalho de Simpson et al. 1997), pode-se concluir que o autovetor E4 está 
provavelmente associado à cinemática do cone de ionização desse objeto. Para se obter uma melhor visualização desse cone de ionização e compará-lo com o que é visto no tomograma mostrado na figura 7.26, fez-se uma imagem da linha de Bry do cubo de dados de NGC 5643, após a subtração do contínuo estelar. O resultado obtido é mostrado na figura 7.29.

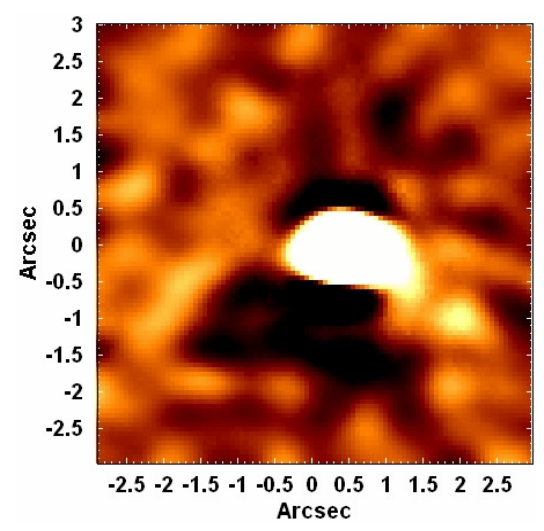

Figura 7.29 - Imagem da linha de Bry do cubo de dados de NGC 5643 com o contínuo estelar subtraido. A imagem apresenta uma LUT "exagerada" para que os detalhes possam ser melhor visualizados.

Analisando-se a figura 7.29, pode-se notar que a emissão de Bry parece se distribuir em uma faixa na direção leste-oeste, o que sugere que o cone de ionização desse objeto se localiza ao longo dessa direção. Isso é compatível com o que é observado na figura 7.3. A estrutura visível na figura 7.29 também está aproximadamente alinhada com a barra dessa galáxia e com os lobos emissores de rádio, o que pode ser constatado comparando-se as figuras 7.29, 7.1 e 7.2. O cone de ionização aqui detectado é aproximadamente perpendicular à direção na qual ocorre a suposta rotação do gás molecular detectada no autovetor E2. Isso está de acordo com a hipótese de que essa rotação do gás molecular esteja associada a um toro molecular ao redor do núcleo. O autoespectro E4 mostrado nas figuras 7.26 e 7.27 apresenta, ainda, correlações com os comprimentos de onda correspondentes às asas vermelhas das principais linhas de $\mathrm{H}_{2}$ do espectro e anti-correlações com os comprimentos de onda associados às asas azuis das mesmas. Isso sugere que esse autovetor também está relacionado à cinemática do gás $\mathrm{H}_{2}$. A morfologia do tomograma, entretanto, não parece ser compatível com a da cinemática do gás $\mathrm{H}_{2}$ que foi detectada nos resultados anteriores, o que indica que esse padrão cinemático do gás $\mathrm{H}_{2}$ não é dominante nesse autovetor, representando o que pode se considerado uma "contaminação" do mesmo. As informações reveladas por esse autovetor são bastante compatíveis com as 
mostradas pelo autovetor E5 obtido com a aplicação da Tomografia PCA na seção 7.3 (figura 7.13). O autovetor E4 explica cerca de $0.3793 \%$ da variância dos dados.

O Scree test na figura 7.28 mostra que os valores das variâncias explicadas pelos autovetores decaem bastante até, aproximadamente, o autovetor E7. A partir daí, a taxa de decaimento diminui muito e fica praticamente constante. Isso indica que os autovetores de ordem maior ou igual a 7 representam, sobretudo, ruído e, consequentemente, não são relevantes nessa análise. Entretanto, dentre os autovetores de ordem menor do que 7, apenas os quatro primeiros apresentavam uma clara interpretação e, por essa razão, apenas eles foram mostrados aqui.

Assim, pode-se dizer que essa segunda análise com a Tomografia PCA, primeiramente, permitiu que a emissão do gás na região central de NGC 5643 (proveniente tanto do AGN quanto de áreas emissoras de $\mathrm{H}_{2}$ ) fosse visualizada de uma maneira um pouco mais clara do que na primeira análise (seção 7.3). Também foi possível fazer uma diferenciação entre regiões com emissão provavelmente devida ao AGN central (incluindo a NLR) e áreas emissoras de $\mathrm{H}_{2}$. Essa segunda análise revelou, ainda, uma complexa cinemática do gás $\mathrm{H}_{2}$ na região central de NGC 5643, com um possível toro molecular em rotação ao redor do núcleo e um fluxo de gás em áreas mais afastadas do AGN. Esse resultado parece estar de acordo com o trabalho de Morris et al. (1985), que propuseram que o gás flui ao longo da barra dessa galáxia, chega á região central e forma um disco ortogonal ao eixo maior da barra. Finalmente, essa análise revelou uma cinemática diferenciada envolvendo as linhas de $\mathrm{Br} \gamma$ e [Ca VIII]. Tal fenômeno, provavelmente, está associado à NLR e ao cone de ionização dessa galáxia, o que pode ser constatado comparando-se o tomograma do autovetor que revelou essa cinemática (figura 7.26) e o mapa de excitação [O III]/H $\alpha$ dessa galáxia, obtido a partir de imagens do HST (figura 7.3, retirada do trabalho de Simpson et al. 1997). A imagem da linha de Bry (figura 7.29) está de acordo com essa hipótese e pode-se notar, inclusive, que o cone de ionização do AGN parece estar alinhado com a barra dessa galáxia (figura 7.1) e com os dois lobos emissores de rádio (figura 7.2). Esse cone de ionização também é aproximadamente perpendicular ao suposto toro molecular em rotação ao redor do núcleo mencionado anteriormente, o que está de acordo com o esperado. Todos os resultados obtidos com essa segunda análise com o Tomografia PCA são compatíveis com os encontrados com a primeira análise (seção 7.3). 


\section{6 - Cinemática estelar do cubo de dados de NGC 5643}

Aplicou-se o processo do pPXF no cubo de dados de NGC 5643, a fim de se obter os seguintes parâmetros relativos à cinemática estelar: velocidade radial estelar, dispersão de velocidades estelar e os coeficientes de Gauss-Hermite $h_{3}$ e $h_{4}$. Verificou-se, entretanto, que a baixa razão $S / N$ nos espectros correspondentes às regiões espaciais mais afastadas do centro do campo visual do SINFONI fez com que a determinação dos parâmetros cinemáticos nessas áreas se tornasse bastante imprecisa. Assim, para se evitar tais imprecisões, os mapeamentos dos parâmetros mencionados foram feitos apenas na região mais central do campo visual do SINFONI. Os resultados obtidos encontram-se a seguir.
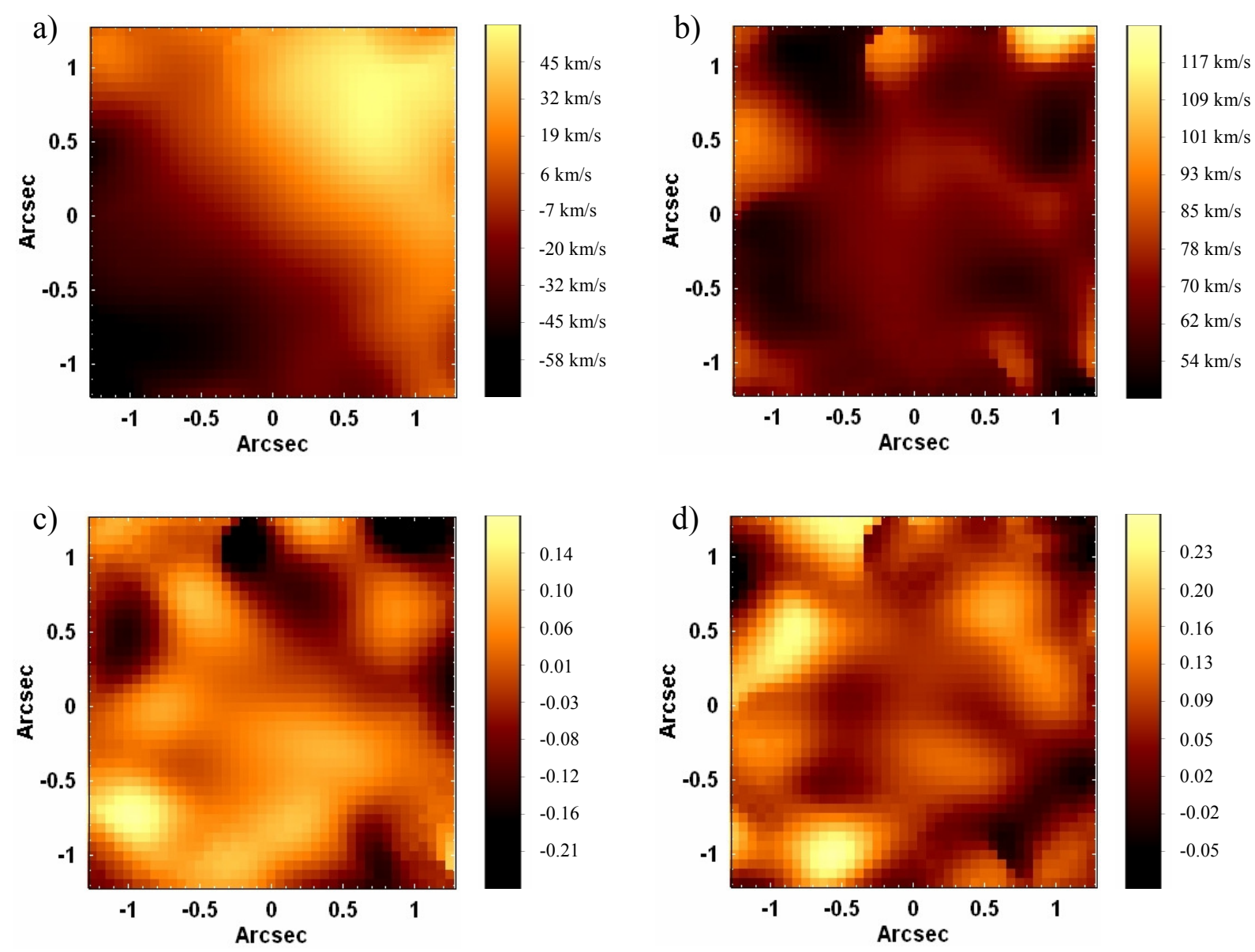

Figura 7.30 - Mapeamentos dos valores (a) da velocidade radial estelar, (b) da dispersão de velocidades estelar, (c) do coeficiente $h_{3}$ e (d) do coeficiente $h_{4}$, obtidos com a aplicação do pPXF ao cubo de dados de NGC 5643. 
Observando-se a figura 7.30 - $a$, pode-se notar a presença de uma clara rotação estelar na região central de NGC 5643. Esse padrão rotacional, entretanto, não é compatível com nenhum dos fenômenos cinemáticos detectados para o gás $\mathrm{H}_{2}$, o que indica que a cinemática estelar na região central dessa galáxia não parece estar associada à cinemática do gás $\mathrm{H}_{2}$. No caso da figura $7.30-b$, nota-se que o mapeamento da dispersão de velocidades não apresentou padrões muito claros, entretanto, pode-se notar um razoável aumento de valores na região próxima ao AGN central. Analisando-se a figura $7.30-c$, verifica-se que o mapeamento dos valores do coeficiente de Gauss-Hermite $h_{3}$ revelou um tênue padrão, que parece estar associado ao que foi detectado no mapeamento da velocidade radial estelar (figura 7.30-a). Pode-se notar que os valores de $h_{3}$ parecem ser ligeiramente menores na região contendo as maiores velocidades radiais estelares e razoavelmente maiores na área contendo as menores velocidades radiais estelares. Considerando que o coeficiente $h_{3}$ revela o grau de assimetria nas linhas de absorção presentes nos espectros analisados, pode-se dizer que a sobreposição de um disco de estrelas em rotação e um fundo com velocidades estelares mais aleatórias poderia, em princípio, dar origem ao comportamento observado dos valores de $h_{3}$. Finalmente, o mapeamento dos valores de $h_{4}$ mostrado na figura $7.30-d$ não revelou padrões ou configurações que pudessem ser identificados claramente.

O mapeamento dos valores da velocidade radial estelar obtido (figura $7.30-a$ ) contém detalhes o suficiente para que possa ser elaborada uma modelagem com o objetivo de se determinar a massa do buraco negro central existente. Tal procedimento foi feito utilizando-se uma implementação do método de Jeans desenvolvida por Cappellari (2008). Esse formalismo, usado para se modelar a cinemática estelar de galáxias, assume uma razão $M / L$ constante e um elipsóide de velocidades alinhado com as coordenadas cilíndricas $(R, z)$ e caracterizado pelo parâmetro de anisotropia $\beta_{z}=1-\frac{\overline{v_{z}^{2}}}{\overline{v_{R}^{2}}}$. Uma descrição mais detalhada de todo esse formalismo é dada no apêndice H. O método de Jeans pode ser utilizado para simular os valores da velocidade radial estelar e do segundo momento de velocidade ao longo da linha de visada, sendo que esse último é uma boa aproximação para a quantidade $V_{r m s}^{2}=V^{2}+\sigma^{2}$, onde $V=$ velocidade radial estelar e $\sigma=$ dispersão de velocidades estelar. No caso de NGC 5643, entretanto, o mapeamento da dispersão de velocidades mostrado na figura $7.30-b$ apresenta muitas irregularidades e 
imprecisões, o que fez com que os valores de $\sigma$ não pudessem ser levados em conta na simulação. Assim, apenas os valores de $V$ foram simulados. As simulações foram feitas utilizando-se um script, elaborado em linguagem IDL por Michele Cappellari (Cappellari 2008), e envolveram o ajuste de 4 parâmetros livres: massa do buraco negro central $\left(M_{b h}\right)$, inclinação do disco de estrelas ao redor do buraco negro $(i)$, razão $M / L$ e a constante $k$, que indica o quanto o modelo do campo de velocidades se assemelha a um rotor isotrópico $(k=1)$ (o parâmetro $k$ é descrito com maiores detalhes no apêndice H). Entretanto, verificou-se que possíveis erros nos valores do parâmetro $M / L$ eram compensados por variações em $k$. Isso fez com que a determinação desses parâmetros não fosse suficientemente confiável e tornou muito difícil a estimativa de qualquer incerteza para eles. Assim, embora $M / L$ e $k$ tenham sido ajustados na modelagem, não foi possível determinar o seu grau de confiabilidade ou lhes atribuir qualquer incerteza. Em todas as simulações, $\beta_{z}$ foi tomado como sendo igual a 0.025 . A razão disso é que vários testes mostraram que, para essa galáxia, quaisquer simulações com $\beta_{z} \neq 0.025 \pm 0.025$ não forneciam resultados compatíveis com o observado. Para se estimar a massa estelar presente, primeiramente, utilizou-se o procedimento do MGE (Multi-Gaussian Expansion) (Cappellari 2002). Isso permitiu que o efeito da projeção no plano do céu fosse removido. Em seguida, os valores de luminosidade encontrados foram multiplicados pela razão $M / L$ fornecida. $\mathrm{O}$ ajuste do MGE foi aplicado na imagem correspondente ao cubo de dados de NGC 5643 integrado ao longo do eixo espectral. O modelo mais adequado para a cinemática estelar foi obtido variandose sequencialmente os 4 parâmetros livres, com o objetivo de se minimizar o $\chi^{2}$, dado pela expressão

$$
\chi^{2}=\sum_{i=1}^{N x} \sum_{j=1}^{N y} \frac{\left(v_{i j}(\text { observada })-v_{i j}(\text { simulada })\right)^{2}}{\sigma_{i j}^{2}}
$$

onde $N_{x}=$ número de pixeis espaciais ao longo do eixo horizontal $N_{y}=$ número de pixeis espaciais ao longo do eixo vertical $\sigma_{i, j}=$ incerteza do valor da velocidade do pixel espacial $(i, j)$ $v_{i, j}($ observada $)=$ velocidade do pixel espacial $(i, j)$ do mapa de velocidades observado $v_{i, j}(\operatorname{simulada})=$ velocidade do pixel espacial $(i, j)$ do mapa de velocidades simulado 
As incertezas dos valores obtidos para os parâmetros $M_{b h}$ e $i$ foram estimadas utilizandose o mesmo método usado por Jardel et al. (2011): primeiramente, construiu-se um gráfico do $\chi^{2}$ em função de cada um desses dois parâmetros. Em seguida, para cada gráfico, traçou-se uma curva passando pelos pontos correspondentes aos menores $\chi^{2}$ obtidos para cada um dos valores de $M_{b h} / i$ considerados no ajuste. Essa curva representou a marginalização dos demais parâmetros. Por fim, a incerteza para o valor de $M_{b h} / i$ foi estimada a partir do ponto ao longo da curva traçada no qual obtinha-se uma variação de $\Delta \chi^{2}=1$ acima do valor mínimo.

Ao se aplicar as simulações, entretanto, verificou-se que o mapa de velocidades da figura 7.30 - $a$ podia ser reproduzido sem que nenhuma massa para o buraco negro central fosse considerada. Isso indica que, no caso dessa galáxia, $M_{b h}$ deve ser consideravelmente pequeno, tendo, portanto, um efeito detectável apenas em regiões muito próximas ao buraco negro central, a uma distância provavelmente inferior à resolução espacial obtida. Para áreas mais distantes, o efeito de $M_{b h}$ é desprezível quando comparado ao da massa estelar presente. Assim, nessa simulação inicial do mapa de velocidades estelares de NGC 5643, não foi considerada nenhuma massa para o buraco negro central. A tabela 7.3 mostra os parâmetros do melhor modelo obtido com as simulações, que apresentou $\chi^{2}=918.06$.

\begin{tabular}{|c|c|}
\hline Parâmetro & $\begin{array}{c}\text { Valor correspondente ao melhor modelo } \\
\text { obtido com as simulações }\end{array}$ \\
\hline$i$ & $55^{\circ} \pm 5^{\mathbf{0}}$ \\
\hline$M / L^{*}$ & 7.5 \\
\hline$k^{*}$ & 2.05 \\
\hline
\end{tabular}

Tabela 7.3 - Parâmetros do melhor modelo obtido com as simulações do mapa dos valores da velocidade radial estelar de NGC 5643, utilizando-se o método de Jeans.

* Parâmetros para os quais não foi possível atribuir uma incerteza

A figura 7.31 mostra uma comparação entre o mapa dos valores da velocidade radial estelar observado, obtido com a aplicação do processo do pPXF, e o mapa correspondente simulado, resultante do melhor modelo elaborado com o método de Jeans. 

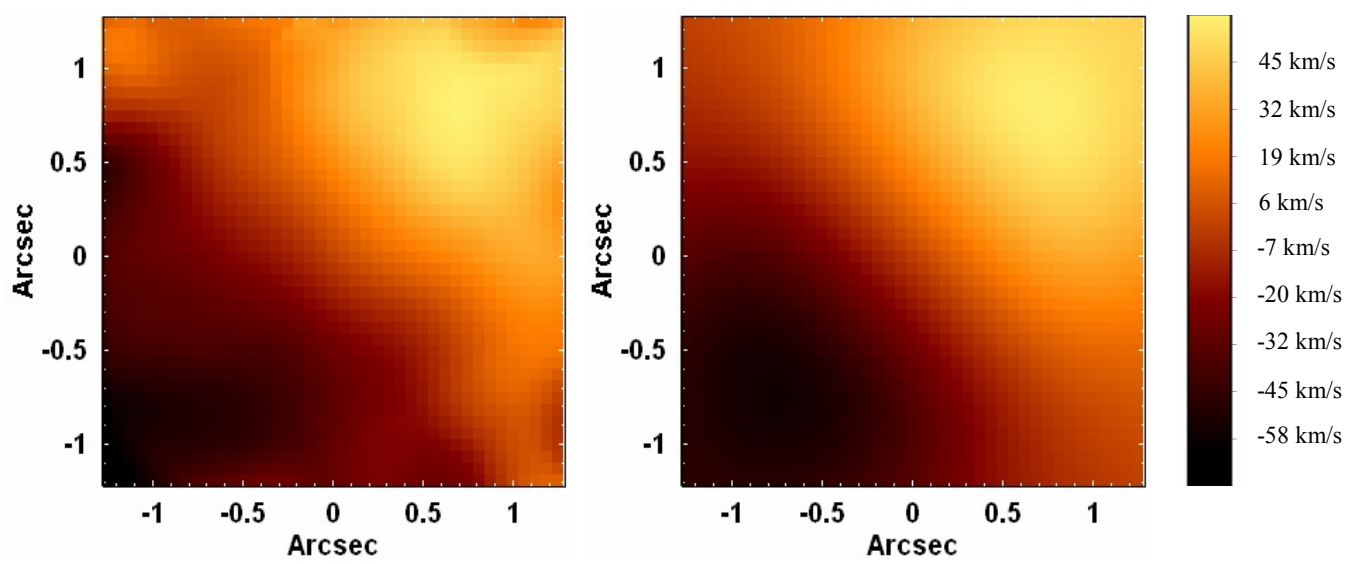

Figura 7.31 - (esquerda) Mapa dos valores da velocidade radial estelar observado, obtido a partir da aplicação do processo do pPXF ao cubo de dados de NGC 5643 (igual ao mostrado na figura 7.30 - a); (direita) Mapa dos valores da velocidade radial estelar, resultante do melhor modelo obtido com as simulações feitas com o método de Jeans.

Verificou-se que a linha de nodos do mapa dos valores da velocidade radial estelar observado apresentava $P A=46.0^{\circ}$. A figura 7.32 mostra uma curva de rotação extraída ao longo da linha de nodos desse mapa de velocidades, juntamente com o resultado do melhor modelo obtido com as simulações com o método de Jeans.

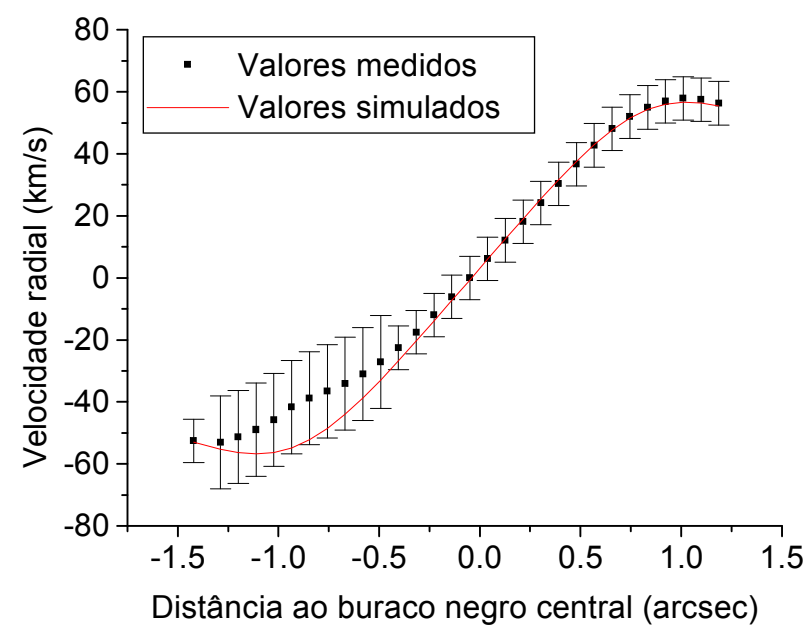

Figura 7.32 - Curva de rotação extraída ao longo da linha de nodos do mapa dos valores da velocidade radial estelar observado, juntamente com o resultado do melhor modelo obtido com as simulações feitas com o método de Jeans.

Uma análise da figura 7.31 revela que o modelo obtido com o método de Jeans reproduz consideravelmente bem o mapa dos valores da velocidade radial estelar observado da região central de NGC 5643. Entretanto, pode-se notar que essa concordância entre os dados e o modelo elaborado é consideravelmente inferior na região com valores negativos de velocidade. 
De fato, o mapa de velocidades observado apresenta várias irregularidades nessa área, que não parecem ser compatíveis com um movimento kepleriano. Duas explicações podem ser propostas para as flutuações observadas nas velocidades negativas: a primeira é que esse comportamento seja devido apenas a falhas nos ajustes feitos com o processo do pPXF, não representando, assim, nenhum fenômeno físico. A segunda explicação é que as irregularidades nos valores da velocidade sejam reais e devidas a possíveis perturbações gravitacionais no movimento rotacional estelar ao redor do buraco negro central. Os dados aqui apresentados não permitem que se avalie qual dessas duas explicações é a mais adequada nessa situação. Independentemente de qual explicação está correta, o método de Jeans não poderia ser capaz de reproduzir esse comportamento atípico observado na região com velocidades negativas, consequentemente, o fato de o ajuste ter apresentado uma qualidade inferior nessa área está de acordo com o esperado.

A figura 7.32 mostra como a curva de rotação extraída ao longo da linha de nodos é consideravelmente bem reproduzida pelo modelo elaborado, sendo que a qualidade do ajuste somente se torna relativamente inferior na região com velocidades negativas, o que está de acordo com o que já foi explicado.

Conforme foi mencionado anteriormente, nessa simulação inicial da cinemática estelar, não foi levada em conta nenhuma massa para o buraco negro central. $O$ fato de, mesmo assim, $o$ modelo ter ajustado consideravelmente bem os dados mostra que $M_{b h}$ deve ser razoavelmente pequeno, tendo um efeito detectável apenas em regiões situadas provavelmente a uma distância do buraco negro inferior à resolução espacial. Nessas circunstâncias, pôde-se estimar, apenas, um limite superior para $M_{b h}$. O procedimento utilizado para isso foi o seguinte: repetiu-se a simulação da curva de rotação mostrada na figura 7.32 aumentando-se progressivamente o valor da massa do buraco negro e mantendo-se todos os demais parâmetros inalterados. Esse processo foi aplicado até que a parte da curva de rotação simulada com os valores positivos de velocidade deixasse de reproduzir os dados observados dentro de 1- $\sigma$. A razão de se adotar esse procedimento foi que a região da curva de rotação com velocidades positivas é a mais confiável, assim, a partir do momento em que o ajuste deixa de reproduzir essa área, pode-se dizer que ele não é mais adequado, o que, nesse caso, indica que a massa do buraco negro central atingiu o limite superior. $\mathrm{O}$ valor obtido para o limite superior da massa do buraco negro central de 
NGC 5643, após aplicar esse processo, foi $M_{b h_{-} \text {sup }}=4.0 \cdot 10^{7} \mathrm{M}_{\odot}$. A figura 7.33 mostra a curva de rotação simulada resultante do modelo feito utilizando-se os mesmos parâmetros dados na tabela 7.3 e $M_{b h}=M_{b h_{-} \text {sup }}$, sobreposta à curva de rotação observada.

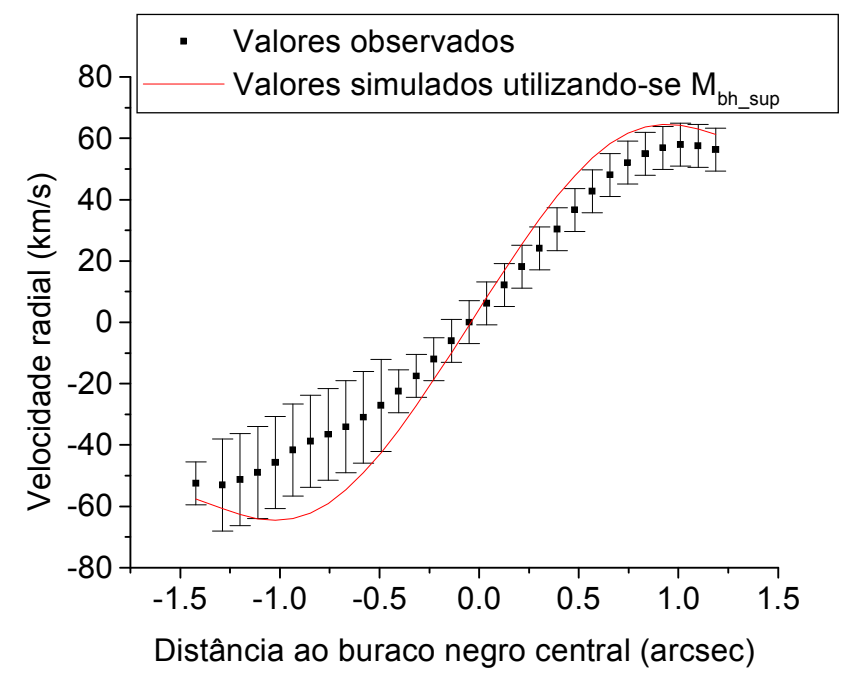

Figura 7.33 - Curva de rotação extraída ao longo da linha de nodos do mapa dos valores da velocidade radial estelar observado, juntamente com o modelo obtido, com o método de Jeans, utilizando-se os mesmos parâmetros dados na tabela 7.3 e $M_{b h}=M_{b h_{-} s u p}=4 \cdot 10^{7} M_{\odot}$.

Assim, pode-se concluir que, embora não tenha sido possível determinar um valor para a massa do buraco negro central de NGC 5643, devido ao fato de ela ser pequena quando comparada à massa estelar presente, pôde-se estimar um limite superior para $M_{b h}$ dado por $M_{b h_{-} \text {sup }}=4 \cdot 10^{7} \mathrm{M}_{\odot}$. As simulações também forneceram a inclinação do disco estelar existente, dada por $i=55^{\circ} \pm 5^{\circ}$.

\section{7 - Cinemática do gás do cubo de dados de NGC 5643}

Para se fazer uma análise mais detalhada da cinemática do gás molecular na região central de NGC 5643, construiu-se o mapa de velocidades (através do ajuste de funções gaussianas) da linha de emissão $\mathrm{H}_{2} \lambda 21218$ do cubo de dados após a subtração do contínuo estelar. A linha de $\mathrm{H}_{2} \lambda 21218$ foi utilizada por ser a mais intensa do espectro. Linhas mais fracas forneceram mapas de velocidades menos precisos, que, por essa razão, não são analisados aqui. $\mathrm{O}$ mapeamento feito a partir da linha de $\mathrm{H}_{2} \lambda 21218$ é mostrado na figura 7.34. 


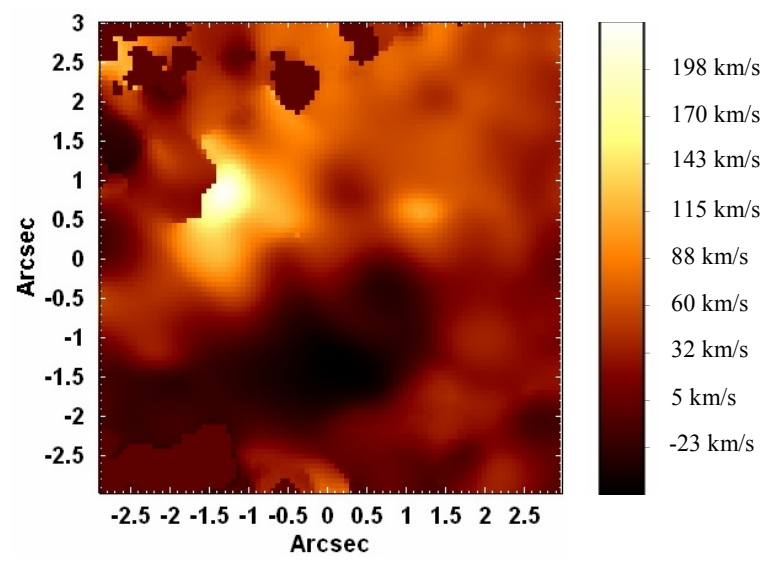

Figura 7.34 - Mapeamento dos valores de velocidade radial do gás molecular, obtido com a linha de $\mathrm{H}_{2} \lambda 21218$ do cubo de dados de NGC 5643.

Analisando-se o mapeamento de velocidades mostrado na figura 7.34, nota-se que ele parece ser compatível com os resultados obtidos com as duas aplicações da Tomografia PCA ao cubo de dados de NGC 5643 (figura 7.10 da seção 7.3 e figura 7.23 da seção 7.5) e revela uma cinemática consideravelmente complexa, com a possível existência de um toro molecular em rotação ao redor do núcleo e um fluxo de gás em áreas mais afastadas. Novamente, tal resultado está de acordo com o esperado, considerando-se o modelo proposto por Morris et al. (1985), que envolve fluxo de gás ao longo da barra de NGC 5643 e formação de um disco na região central. Um ponto importante a ser mencionado é que, observando-se a escala de valores na figura 7.34, pode-se notar que a amplitude dos valores positivos de velocidade é consideravelmente maior do que a dos valores negativos. Entretanto, as velocidades mais elevadas ocorrem em uma região relativamente pequena. Uma análise do cubo de dados de NGC 5643 revelou que, nessa área, a linha de $\mathrm{H}_{2} \lambda 21218$ apresenta várias irregularidades e, em alguns locais específicos, até mesmo picos duplos podem ser notados. Assim, pode-se dizer que é provável que as velocidades obtidas para essa região não sejam precisas e, consequentemente, a elevada amplitude de valores observada pode não ser real. A causa das irregularidades e dos picos duplos observados nos espectros da área em questão não está clara, mas é possível que essas características espectrais sejam geradas pela sobreposição de mais de um fenômeno cinemático existente.

Para se tentar modelar o mapa de velocidades do gás mostrado na figura 7.34, seria preciso considerar a existência de um fluxo de gás, juntamente com um disco de rotação. Entretanto, como o objetivo desse trabalho envolve, apenas, a simulação de movimentos keplerianos visando a determinação da massa do buraco negro central existente e, nesse caso, 
não foi possível separar com precisão os fenômenos cinemáticos na figura 7.34, optou-se por não se fazer essa modelagem aqui.

\section{8 - Espectro de emissão de $\mathrm{H}_{2}$ do cubo de dados de} NGC 5643: razões de linhas e temperaturas de excitação

Construiu-se um diagrama de diagnóstico com as razões de linhas

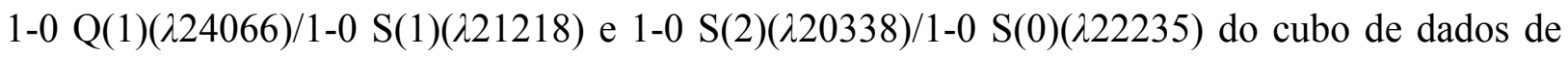
NGC 5643, com o propósito de se avaliar se a emissão de $\mathrm{H}_{2}$ na região central dessa galáxia tem origem térmica ou não térmica. $\mathrm{O}$ resultado obtido é mostrado na figura 7.35.

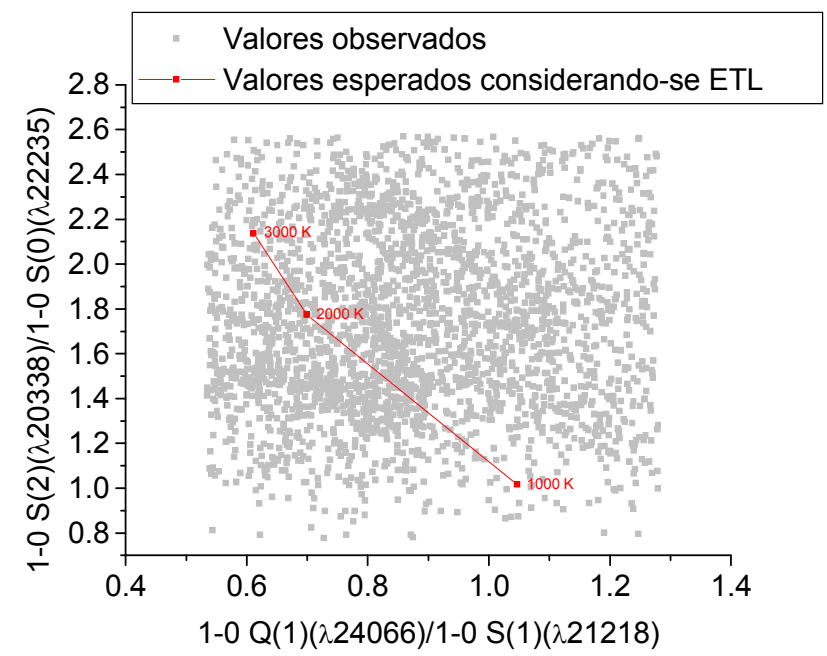

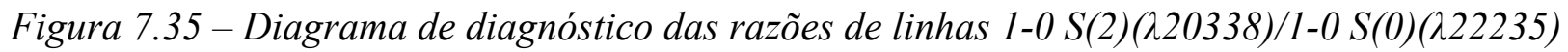
e 1-0 Q(1)(224066)/1-0 S(1)(221218) do cubo de dados de NGC 5643. Os resultados esperados considerando-se ETL são mostrados em vermelho.

O diagrama de diagnóstico da figura 7.35 revela que, assim como em todos os casos analisados nos capítulos anteriores, a aproximação de ETL não parece ser adequada na maior parte das regiões espaciais do cubo de dados de NGC 5643. Nessas áreas, a emissão de $\mathrm{H}_{2}$ deve ter uma origem não térmica.

A fim de se determinar a temperatura em regiões nas quais o ETL parece ser válido, foi aplicado o mesmo procedimento utilizado em todos os casos analisados nos capítulos anteriores. Nesse caso, a região de incerteza delimitada no gráfico da figura 7.35 englobou valores variando 
até $11 \%$ a partir da curva vermelha (essa incerteza para as razões de linhas foi estimada com base nas flutuações do contínuo nas regiões espectrais próximas às linhas de emissão medidas). A figura 7.36 mostra o mapeamento dos valores obtidos para a temperatura, utilizando-se a

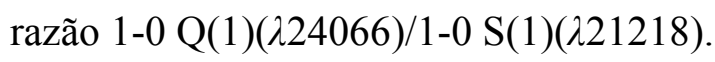

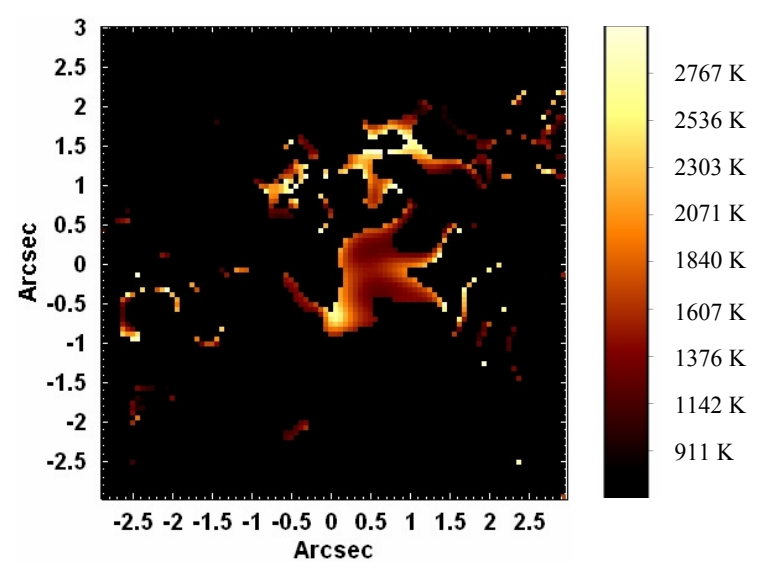

Figura 7.36 - Mapeamento dos valores da temperatura de excitação do cubo de dados de

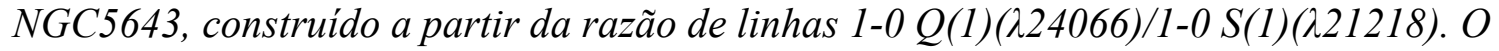
mapeamento foi feito apenas para regiões nas quais a aproximação de ETL é válida.

Uma análise do mapeamento de temperaturas da figura 7.36 revela claramente que, assim como em todos os casos analisados nos capítulos anteriores, a pequena quantidade de regiões mapeadas faz com que não seja possível tirar conclusões relevantes relacionadas à variação dos valores de temperatura nas diferentes áreas do campo de visão do SINFONI. Entretanto, detectaram-se regiões com temperaturas comparáveis às encontradas em NGC 4151 e NGC 3227, o que pode indicar que, assim como nos casos desses objetos, o mecanismo de aquecimento das nuvens de $\mathrm{H}_{2}$ na região central de NGC 5643 seja a emissão de raios-x pelo AGN central.

\section{9 - Conclusões}

Assim, pode-se dizer, primeiramente, que as análises com a Tomografia PCA de NGC 5643 permitiram uma visualização bastante clara da emissão proveniente do AGN central e de sua NLR. Não foi detectada qualquer componente larga em nenhuma das linhas de emissão, o que está de acordo com a classificação dessa galáxia como Seyfert 2. A Tomografia PCA 
também revelou várias áreas emissoras de $\mathrm{H}_{2}$ na região central de $\mathrm{NGC} \mathrm{5643.} \mathrm{Tanto} \mathrm{o} \mathrm{mapa} \mathrm{de}$ velocidades da linha de $\mathrm{H}_{2} \lambda 21218$ quanto as aplicações da Tomografia PCA revelaram uma cinemática consideravelmente complexa do gás molecular no cubo de dados de NGC 5643, com a possível existência de um toro molecular em rotação ao redor do núcleo e um fluxo de gás molecular em áreas mais afastadas. Esse resultado parece ser compatível com o cenário proposto por Morris et al. (1985), que envolve fluxo de gás ao longo da barra dessa galáxia e formação de um disco em rotação na região central. O mapeamento da emissão da linha de Bry mostrou que o cone de ionização existente parece se estender ao longo da direção leste-oeste, estando, portanto, praticamente alinhado com a barra de NGC 5643 e com os lobos emissores em rádio presentes. Isso também está de acordo com o que foi observado no mapa de excitação [O III]/H $\alpha$ dessa galáxia, elaborado por Simpson et al. (1997). Esse cone de ionização é aproximadamente perpendicular ao toro molecular em rotação mencionado anteriormente, o que está de acordo com o esperado. As análises com a Tomografia PCA revelaram, ainda, uma aparente cinemática do gás associada ao cone de ionização. O ajuste com o processo do pPXF mostrou a presença de uma clara rotação estelar na região central de NGC 5643. Uma simulação da cinemática estelar feita com o método de Jeans levou à conclusão de que o disco estelar em rotação ao redor do núcleo apresenta uma inclinação em relação à linha de visada de $i=55^{\circ} \pm 5^{\circ}$. Entretanto, essa simulação também mostrou que o buraco negro central existente deve possui uma massa $\left(M_{b h}\right)$ bem pequena quando comparada à massa estelar presente, já que o melhor modelo para a cinemática estelar foi obtido admitindo-se $M_{b h}=0$. Nessas circunstâncias, foi possível, apenas, determinar um limite superior para a massa do buraco negro central, o que foi feito aumentandose progressivamente o valor de $M_{b h}$, mantendo-se todos os demais parâmetros da simulação inalterados, até que o ajuste da curva de rotação extraída ao longo da linha de nodos do mapa de velocidades estelar deixasse de ser adequado. Ao final desse processo, obteve-se um limite superior para a massa do buraco negro de $M_{b h_{-} \text {sup }}=4 \cdot 10^{7} \mathrm{M}_{\odot}$. Tanto a aplicação da Tomografia PCA ao cubo de dados de NGC 5643 com contínuo estelar quanto a síntese espectral realizada com o software Starlight evidenciaram a presença de uma provável emissão térmica de poeira na área correspondente ao AGN central. Um imageamento detalhado dessa região emissora não pôde ser feito, já que a resolução espacial aqui obtida não foi suficiente para isso. Entretanto, é possível que a emissão térmica de poeira detectada seja proveniente de um toro de poeira ao 
redor do AGN, o que seria compatível com as previsões do Modelo Unificado. Por fim, os valores da temperatura de excitação do gás molecular obtidos a partir da razão de linhas

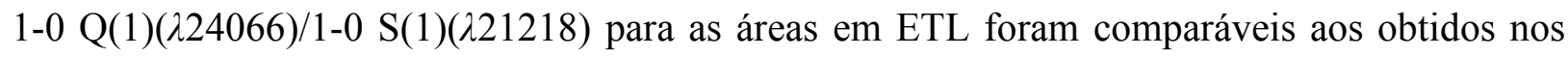
casos de NGC 4151 e NGC 3227, o que sugere que o aquecimento das nuvens moleculares seja devido aos raios-x emitidos pelo AGN central. Entretanto, assim como nos casos analisados nos capítulos anteriores, o mapa de temperaturas construído para as regiões em ETL não permitiu que fossem tiradas conclusões claras a respeito da variação da temperatura em diferentes áreas, já que a quantidade de regiões mapeadas (que estão em ETL) foi bastante pequena. 


\section{$8-$ NGC 1068}

\section{1 - Introdução}

NGC 1068 é uma galáxia de tipo morfológico (R)SA(rs)b que se encontra a uma distância de cerca de 14.4 Mpc. Trata-se de uma das Seyferts 2 mais próximas, que estava, inclusive, na lista de galáxias de Seyfert (1943). Ela recebeu essa classificação por apresentar apenas linhas de emissão estreitas no espectro de sua região nuclear (Khachikian \& Weedman 1974). Essa galáxia possui $7^{\prime}$ 'de diâmetro e, devido à sua grande proximidade e brilho, ela é provavelmente a Seyfert 2 mais estudada até hoje.

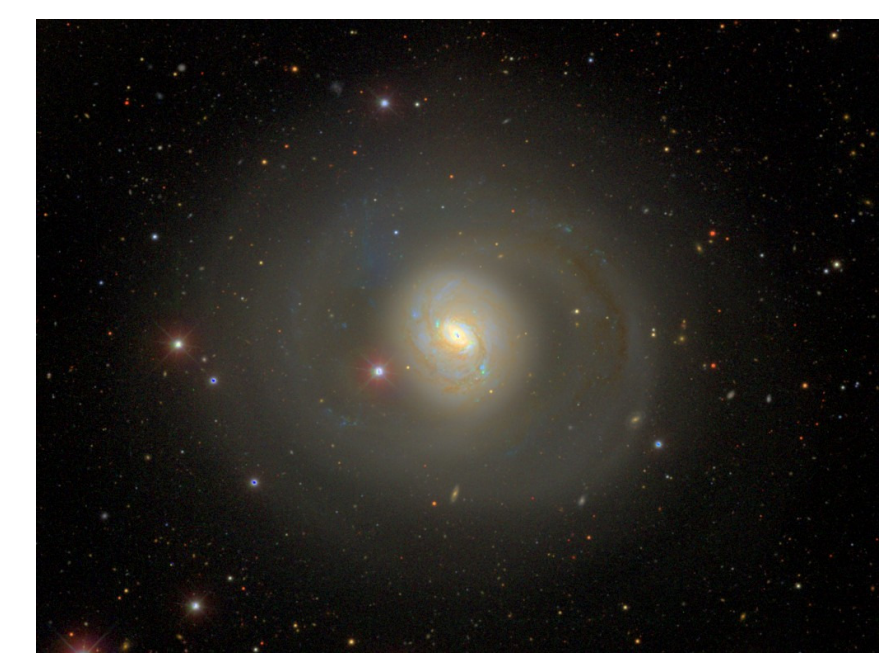

Figura 8.1 - Imagem da galáxia NGC 1068, obtida com o SDSS.

Wilson \& Ulvestad (1983) analisaram observações da região central de NGC 1068, obtidas com o VLA em $4.9 \mathrm{GHz}$ e $15.0 \mathrm{GHz}$, e verificaram que a emissão mais forte coincidente com o núcleo óptico da galáxia é resolvida, em $15.0 \mathrm{GHz}$, em uma estrutura com três pequenas fontes (com a do meio aparentemente associada ao núcleo propriamente dito), com uma extensão total de cerca de 0.7 '. Em $4.9 \mathrm{GHz}$, os autores também observaram a existência de um jato em rádio aproximadamente linear se estendendo a nordeste e a sudoeste, com $P A s \sim 30^{\circ} \mathrm{e}$ $210^{\circ}$, e terminando em dois lobos. A figura 8.2 mostra o mapa em $4.9 \mathrm{GHz}$ da região central de NGC 1068, obtido do trabalho de Wilson \& Ulvestad (1983), juntamente com algumas ampliações resultantes de observações em $15.0 \mathrm{GHz}$. 


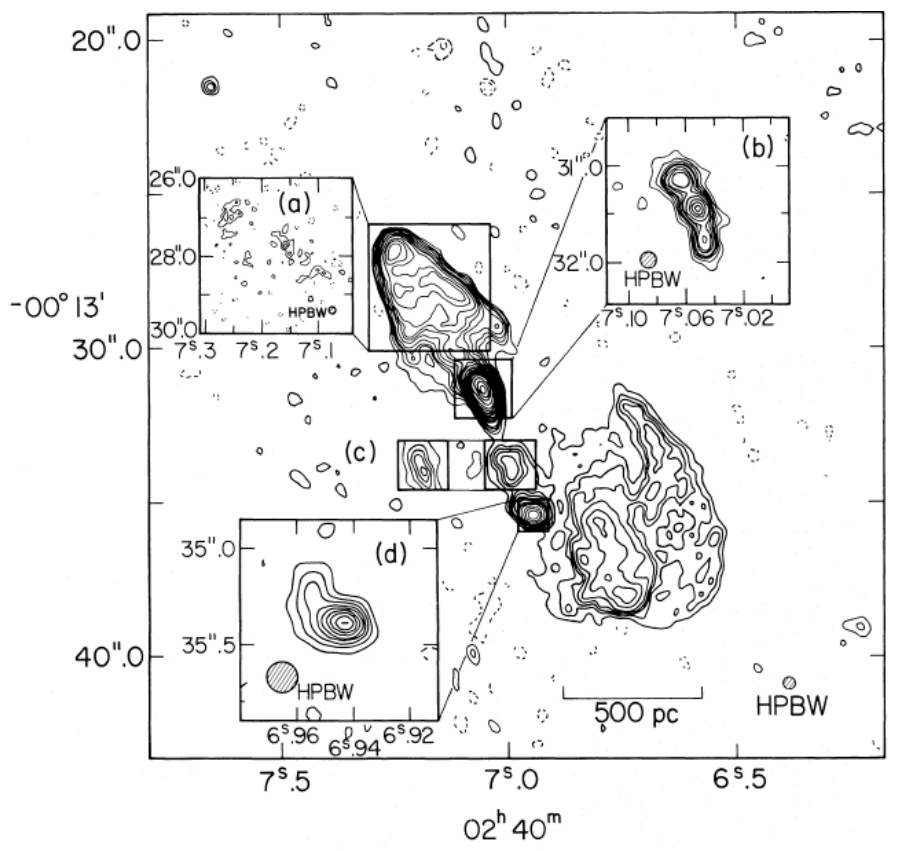

Figura 8.2 - Mapa em $4.9 \mathrm{GHz}$ da região central de NGC 1068, obtido a partir do trabalho de Wilson \& Ulvestad (1983). As ampliações de algumas áreas mostradas são resultantes de observações em $15.0 \mathrm{GHz}$.

Observando-se o mapa e as ampliações mostrados na figura 8.2, pode-se notar claramente a presença do jato, dos lobos e da estrutura tripla correspondente à fonte central mais intensa.

Utilizando dados obtidos em 22.0 GHz com o VLA, Gallimore et al. (2001) analisaram a emissão de masers de $\mathrm{H}_{2} \mathrm{O}$ na região central de $\mathrm{NGC}$ 1068. Os autores detectaram uma variabilidade nessa emissão maser em escalas de tempo de meses a anos, que foi interpretada como sendo uma resposta em reverberação à emissão do AGN. Uma análise da cinemática desses masers de $\mathrm{H}_{2} \mathrm{O}$ revelou que eles, provavelmente, estão localizados em um disco em rotação ao redor do buraco negro central.

Imagens em [O III] dos segundos de arco mais centrais de NGC 1068, obtidas com o HST, foram analisadas por Evans et al. (1991) e Macchetto et al. (1994). A observação de nuvens em escalas de décimos de segundos de arco revelou uma considerável complexidade da NLR do AGN dessa galáxia. Pogge (1988) analisou imagens em [O III] e em [N II] $+\mathrm{H} \alpha$ em uma escala espacial maior e detectou a presença de uma estrutura em formato de cone, coespacial com o jato em rádio, se estendendo a nordeste, que, provavelmente, corresponde ao cone de ionização desse objeto. Um estudo similar também feito com imagens em [O III] por Unger et al. (1992) revelou resultados similares. O fato de apenas uma fraca emissão de [O III] 
ser detectada a sudoeste sugere que, nessa área, o cone de ionização se localiza atrás do plano da galáxia e sofre extinção pela poeira existente. A figura 8.3 mostra uma imagem em [O III] da região central de NGC 1068, obtida a partir do trabalho de Unger et al. (1992), na qual é possível observar o cone de ionização se estendendo para nordeste, mas pouco visível a sudoeste.

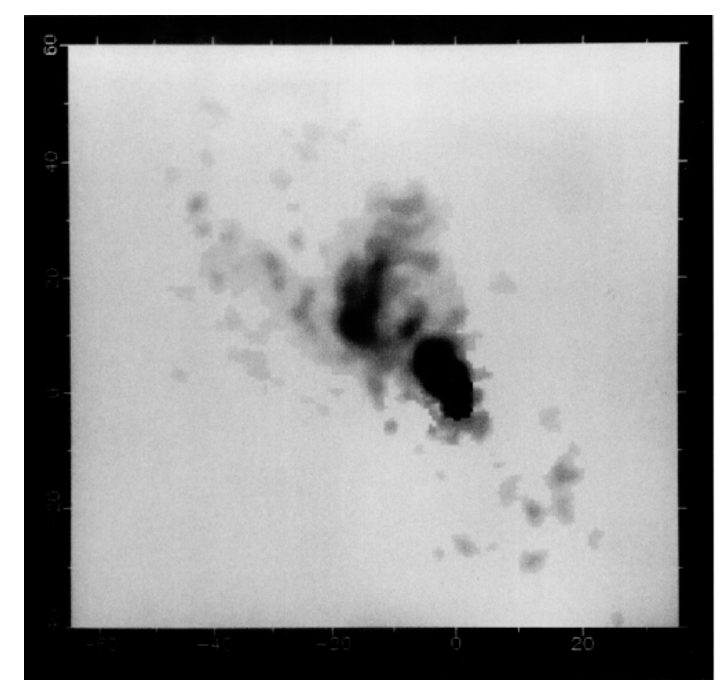

Figura 8.3 - Imagem em [O III] da região central de NGC 1068, obtida a partir do trabalho de Unger et al. (1992). A orientação é norte para cima e leste para a esquerda.

Evidências de outflows radiais na NLR de NGC 1068 foram apresentadas pela primeira vez por Walker (1968) e posteriormente por outros estudos (Arribas et al. 1996; Cecil et al. 2002). Modelagens da cinemática dessa NLR foram feitas por Crenshaw \& Kraemer (2000a), sendo que o modelo elaborado apresentava uma simples geometria de outflow bi-cônico e nuvens tanto em blueshift quanto em redshift foram observadas a nordeste e a sudoeste do núcleo. Das et al. (2006) fizeram modelagens dessa mesma cinemática, utilizando espectros em alta resolução obtidos com o HST, e chegaram e resultados similares.

Desde 2" a sudoeste do núcleo até 4" a nordeste do mesmo, as linhas de emissão observadas nos espectros de NGC 1068 apresentam múltiplas componentes e picos duplos podem ser facilmente observados (Cecil et al. 1990; Crenshaw \& Kraemer 2000b; Axon et al. 1998).

Galliano et al. (2005) analisaram imagens no infravermelho intermediário, em $12.8 \mu \mathrm{m}$, e verificaram que a emissão na região central de NGC 1068, nessa banda espectral, é composta por um núcleo não resolvido e por uma componente estendida. Também foi observado um conjunto de fontes discretas. Martins et al. (2010a) analisaram espectros, no infravermelho 
próximo, se estendendo ao longo das bandas z, J, H e K (desde $0.9 \mu \mathrm{m}$ até $2.4 \mu \mathrm{m}$ ) e verificaram que a região nuclear de NGC 1068 apresenta muitas linhas de emissão com duas componentes: uma no referencial de repouso da galáxia e outra com blueshift no sul e redshift ao norte. Uma emissão bastante estendida de $\mathrm{H}_{2}$ foi observada. Os autores também observaram que a ionização parece ser maior na região mais próxima ao núcleo e modelos simples elaborados mostraram que as razões de linhas podem ser explicadas por pura fotoionização.

Antonucci \& Miller (1985) verificaram que linhas de emissão com larguras típicas da BLR podem ser detectadas em observações de NGC 1068 com luz polarizada, indicando que essa galáxia possui um núcleo Seyfert 1 obscurecido. Essa foi a demonstração mais impactante da validade do Modelo Unificado até então.

Jaffe et al. (2004) analisaram observações interferométricas no infravermelho intermediário e detectaram uma estrutura de poeira de $2.1 \times 3.4 \mathrm{pc}^{2}$, que foi identificada como um toro obscurecedor. Essa foi considerada a primeira detecção direta de um toro de poeira, o que, obviamente, está de acordo com o cenário proposto por Antonucci \& Miller (1985) e com o que é previsto pelo Modelo Unificado. Um estudo inteiramente análogo a esse foi feito por Raban et al. (2009), que conseguiram detectar o toro de poeira de uma maneira ainda mais detalhada.

Em sua região central, NGC 1068 apresenta dois pequenos braços espirais e uma barra estelar, que foram primeiramente detectados, em mapas de emissão em $2 \mu \mathrm{m}$, por Scoville et al. (1988). Schinnerer et al. (2000) analisaram observações interferométricas nas linhas de CO (1-0) e CO (2-1) e verificaram, de maneira bastante clara, a existência dessa barra estelar e dos braços espirais internos. Esses autores também detectaram um disco de gás molecular distorcido (warped) em rotação ao redor do núcleo e concluíram que a causa mais provável desse warping é a pressão do gás do cone de ionização. A figura 8.4 mostra um mapeamento da linha de CO (1-0) na região central de NGC 1068, obtido a partir do trabalho de Schinnerer et al. (2000), no qual é possível observar os braços espirais e a barra estelar interna. 


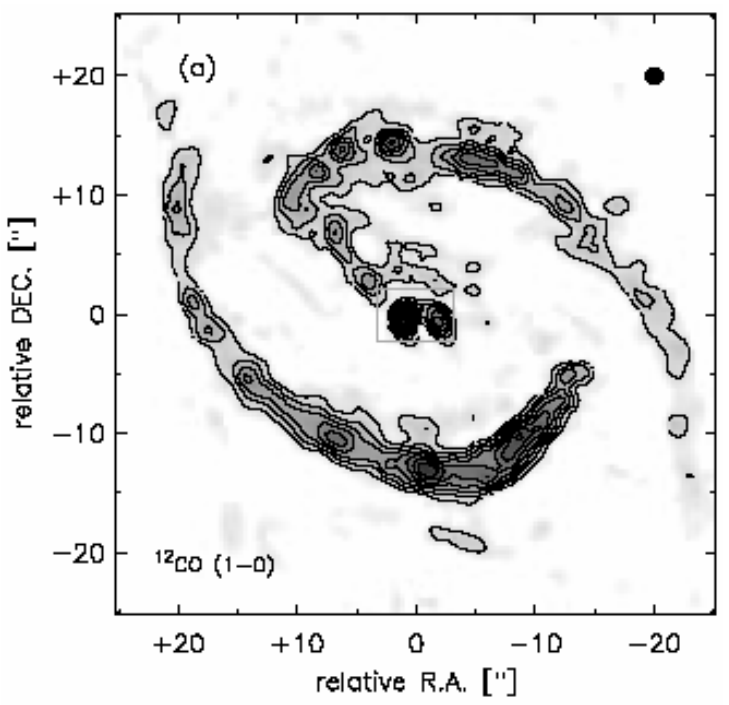

Figura 8.4 - Mapeamento da linha de CO (1-0) da região central de NGC 1068, obtido a partir do trabalho de Schinnerer et al. (2000).

Na região espectral dos raios-x, após as observações pioneiras de NGC 1068 com os satélites Einstein e EXOSAT (Monier \& Halpern 1987; Elvis \& Lawrence 1988), a descoberta, com o GINGA, de uma forte linha de ferro (Koyama et al. 1989) foi interpretada como sendo devida ao reprocessamento de radiação nuclear (nesse caso não detectável, devido ao obscurecimento pelo toro de poeira) pelo material circumnuclear. Isso foi considerado uma confirmação do cenário proposto por Antonucci \& Miller (1985). Observações com o ASCA (Ueno et al. 1994; Iwasawa et al. 1997; Bianchi et al. 2001) mostraram que essa linha de ferro é complexa, implicando em uma reflexão por material tanto neutro quanto ionizado. Esse modelo com dois refletores foi confirmado por observações do contínuo em raios-x duros com o BeppoSAX (Matt et al. 1997). Guainazzi et al. (1999) e Bianchi et al. (2001) demonstraram que a situação é ainda mais complexa, com o espectro em linhas requerendo, pelo menos, três refletores: um neutro (frio), um parcialmente ionizado (morno) e um altamente ionizado (quente). Observações com alta resolução espacial e espectral feitas com o Chandra e com o XMM_Newton confirmaram a complexidade da região circumnuclear de NGC 1068. Uma imagem obtida com o Chandra (Young et al. 2001) revelou, sobretudo em raios-x moles, uma morfologia bastante rica, com o ponto mais brilhante confinado em uma região de 1.5" ao redor do núcleo. A figura 8.5 mostra uma imagem em raios-x do Chandra, $0.25-7.50 \mathrm{keV}$, da região central de NGC 1068, obtida a partir do trabalho de Young et al. (2001). 


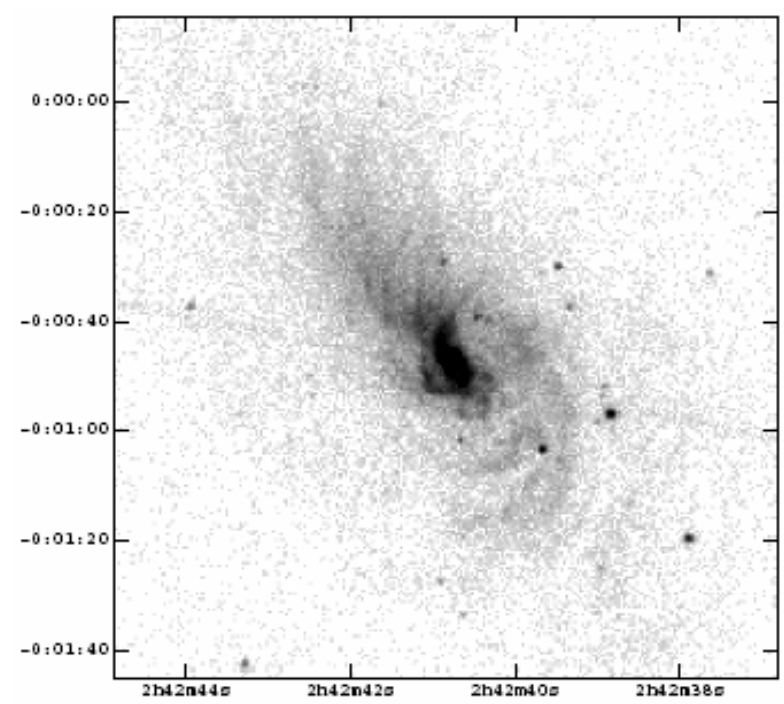

Figura 8.5 - Mapeamento em 0.25 - $7.50 \mathrm{keV}$ da região central de NGC 1068, obtido com o Chandra. Imagem retirada do trabalho de Young et al. (2001).

Atividade de formação estelar já foi detectada em NGC 1068 tanto em grandes (Telesco \& Decher 1988) quanto em pequenas escalas (Macchetto et al. 1994; Thatte et al. 1997). Martins et al. (2010b) aplicaram sínteses espectrais em espectros long-slit, no infravermelho próximo, se estendendo ao longo das bandas z, J, H e K (desde $0.9 \mu \mathrm{m}$ até $2.4 \mu \mathrm{m}$ ) e verificaram que populações estelares de idade intermediária contribuem significativamente para o contínuo nos 200 pc mais internos. Esse resultado parece ser compatível com outras determinações da população estelar em NGC 1068 (Davies et al. 2007; Riffel et al. 2009). A síntese espectral feita por Martins et al. (2010b) revelou, também, que a contribuição do featureless continuum para o fluxo total é de cerca de $25 \%$, o que é esperado para um núcleo Seyfert 1 com espalhamento. Além disso, a cerca de 100 pc do núcleo, foram detectadas populações estelares jovens, assim como picos de featureless continuum. Isso levou os autores a concluir que, a essa distância do núcleo, a interação do jato emitido com o meio interestelar ao redor pode estar formando estrelas. Por fim, essa síntese espectral revelou que a emissão térmica de poeira tem uma importante contribuição na região nuclear de NGC 1068, o que reforça a idéia da presença de um toro denso.

Emsellen et al. (2006) analisaram espectroscopia de campo integrado da região central de NGC 1068, obtida com o SAURON. Foi detectado um desacoplamento cinemático nos 250 pc centrais em relação às regiões ao redor. A cinemática estelar bidimensional observada exibiu características compatíveis com a presença de uma barra. Por outro lado, a cinemática de H $\beta$ e [O III] revelou prováveis fluxos de gás ionizado para dentro. As simulações numéricas 
elaboradas pelos autores sugerem que a barra interna poderia transportar uma quantidade significativa de gás para os 300 pc mais centrais.

Os mecanismos responsáveis pela emissão em linhas na NLR desse objeto tem sido objeto de debate ao longo dos anos. Dopita \& Sutherland (1996) e Bicknell et al. (1998) propuseram que a emissão na NLR pode ser inteiramente causada por choques. Os perfis de pico duplo com os valores de velocidade detectados por Axon et al. (1998) são evidências de que choques velozes existem na região central de NGC 1068. Entretanto, análises de dados mais recentes obtidos com o HST (Crenshaw \& Kraemer 2000a; Cecil et al. 2002; Mazzalay et al. 2007) revelaram que as razões de linhas de emissão observadas são consistentes com fotoionização ao invés de choques. Deve-se mencionar, ainda, que modelos envolvendo fotoionização e choques, simultaneamente, foram necessários para explicar tanto o contínuo quanto as linhas de emissão de várias galáxias ativas (Rodríguez-Ardila et al. 2005).

\section{2 - Preparação do cubo de dados de NGC 1068}

Analisaram-se cubos de dados da região central de NGC 1068, obtidos com o IFU do GMOS do telescópio Gemini-Sul. A redução dos cubos de dados foi feita em ambiente IRAF, utilizando-se o pacote de tarefas Gemini. Ao final desse processo, foram obtidos 3 cubos de dados com pixeis espaciais de $0.05 "$ de lado.

Após a redução, aplicou-se a correção da refração atmosférica diferencial em cada um dos cubos de dados. Em seguida, calculou-se a mediana entre eles, a fim de se combinar todos esses cubos em um só.

Aplicou-se, então, uma decomposição wavelet no cubo de dados encontrado, obtendo-se, ao final, os cubos $W_{0}, W_{l}, W_{2}, W_{3}, W_{4}$ e $W_{C}$. Utilizou-se $W_{0}$ para se determinar os parâmetros mais adequados para o filtro de Butterworth e, a seguir, esses parâmetros foram usados na filtragem de todas as outras componentes wavelet e também do cubo de dados original. No caso desse objeto, todas as filtragens foram feitas utilizando-se um filtro com forma dada pela expressão (3.67), $n=2$ e freqüência de corte ao longo dos eixos horizontal e vertical de $v_{c}=0.18$ Ny. A figura 8.6 mostra as somas das imagens do cubo de dados, antes e depois da filtragem 
espacial de Butterworth, assim como a soma das imagens do cubo correspondente à diferença entre esses dois.
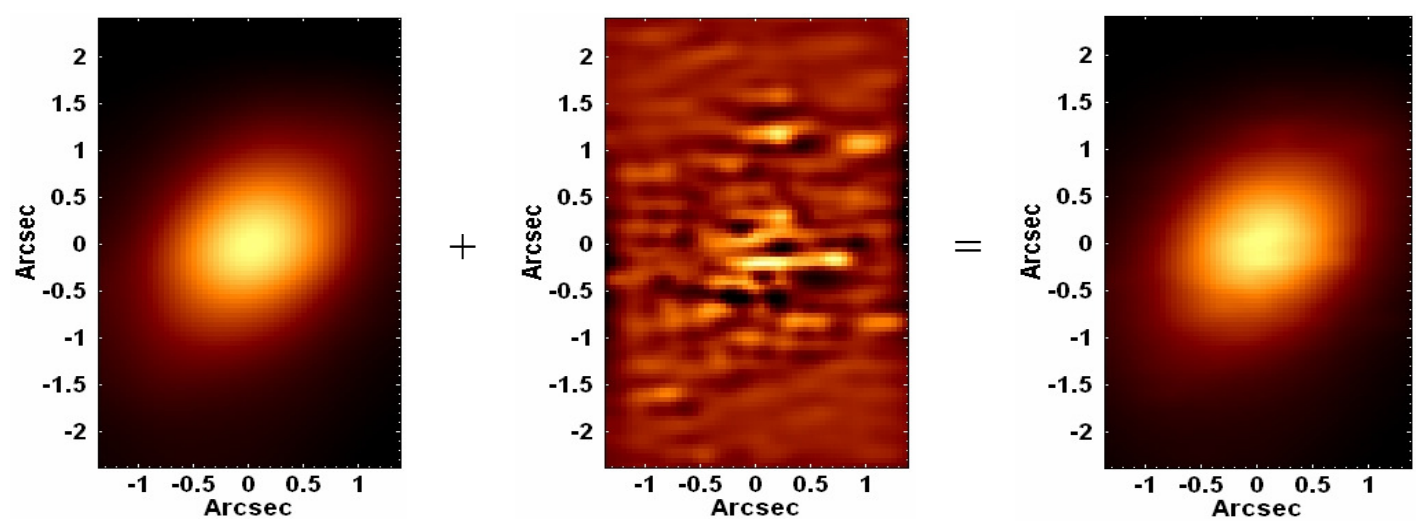

Figura 8.6 - (esquerda) Soma das imagens do cubo de dados de NGC 1068, após a filtragem espacial de Butterworth; (centro) Soma das imagens do cubo de dados de NGC 1068 correspondente à diferença entre o cubo não filtrado e o cubo filtrado; (direita) Soma das imagens do cubo de dados de NGC 1068, antes da filtragem espacial de Butterworth.

Observando-se a figura 8.6, pode-se notar que a filtragem espacial de Butterworth removeu uma grande quantidade de ruídos de alta freqüência, o que proporcionou uma notável melhoria na qualidade das imagens do cubo de dados.

Por fim, passou-se para a etapa da deconvolução de Richardson-Lucy. Esse procedimento foi aplicado utilizando-se uma PSF gaussiana variável com o comprimento de onda, conforme descrito em 3.9.1. Um valor de referência para o $F W H M$ da gaussiana foi estimado a partir de estrelas visíveis na imagem de aquisição da observação, e a forma de variação do $F W H M$ com o comprimento de onda foi determinada a partir do cubo de dados da estrela padrão utilizada para a calibração em fluxo. É importante mencionar que, antes desse processo, a filtragem espacial de Butterworth foi aplicada no cubo da estrela padrão. Foram utilizadas 10 iterações na deconvolução de Richardson-Lucy do cubo de dados de NGC 1068. A figura 8.7 mostra a soma de todas as imagens e o espectro médio do cubo de NGC 1068, após a aplicação da deconvolução de Richardson-Lucy. A figura 8.8, por sua vez, mostra uma ampliação desse espectro médio. 

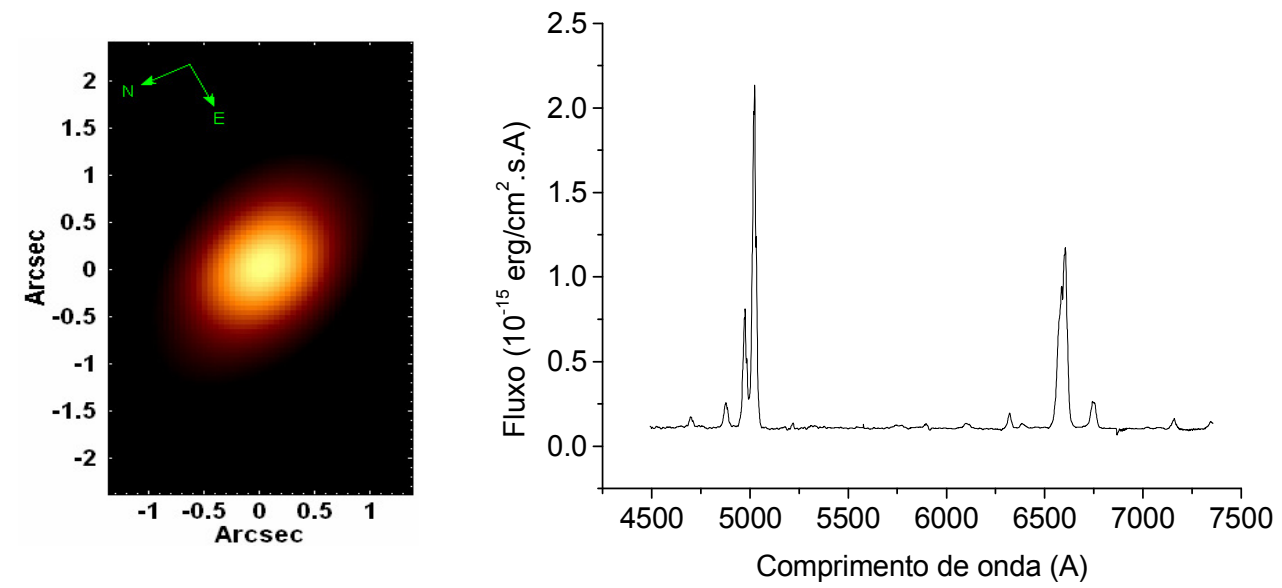

Figura 8.7 - (esquerda) Soma de todas as imagens do cubo de dados de NGC 1068, obtido após todo o processamento; (direita) Espectro médio do cubo de dados de NGC 1068, obtido após todo o processamento.
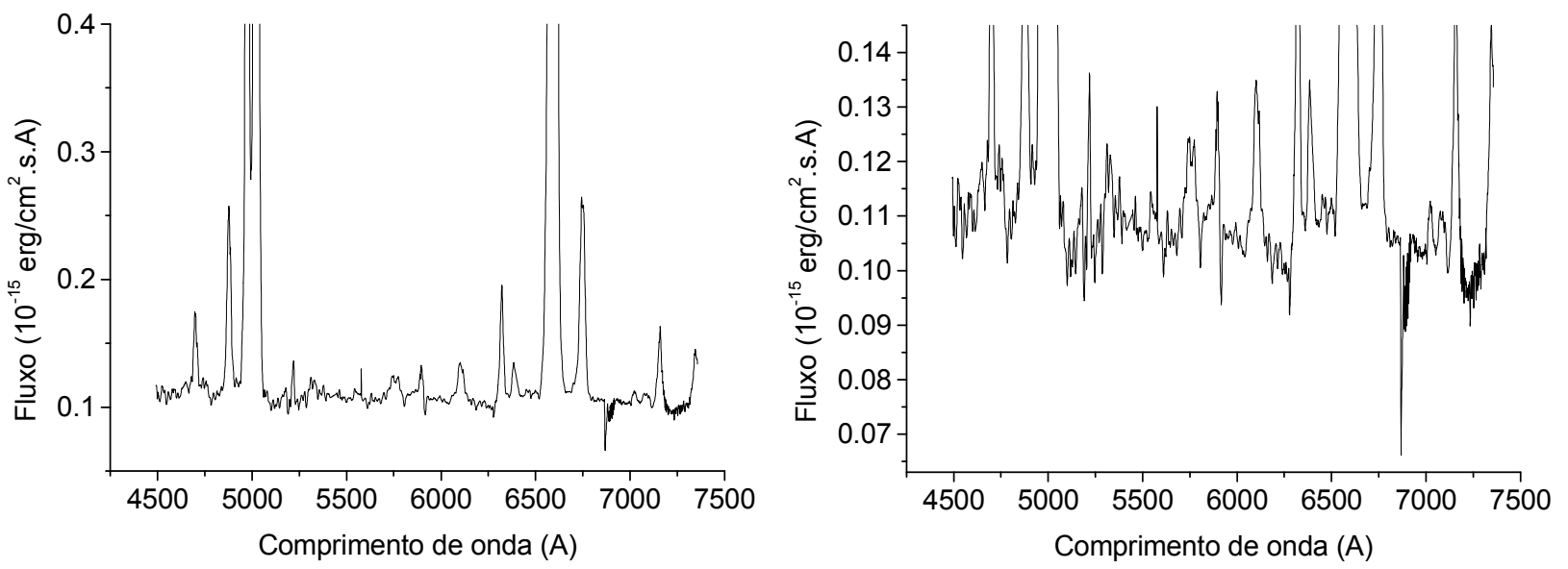

Figura 8.8 - Ampliações do espectro médio do cubo de dados de NGC 1068 mostrado na figura 8.7 .

\section{3 - Aplicação da Tomografia PCA ao cubo de dados de NGC 1068 com o contínuo estelar}

Após todo o processamento descrito na seção 8.2, aplicou-se a Tomografia PCA ao cubo de dados de NGC 1068. Os principais auto-espectros e respectivos tomogramas obtidos encontram-se a seguir. 
402
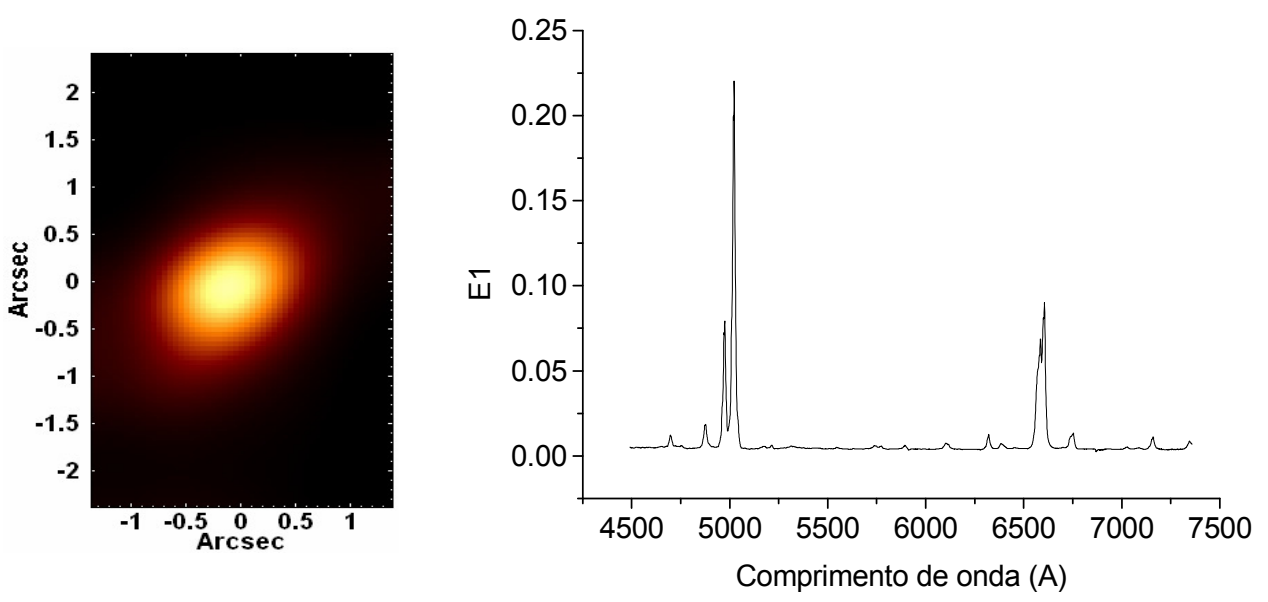

Figura 8.9 - Tomograma e auto-espectro correspondentes ao autovetor E1, obtido com a Tomografia PCA do cubo de dados de NGC 1068 com o contínuo estelar.
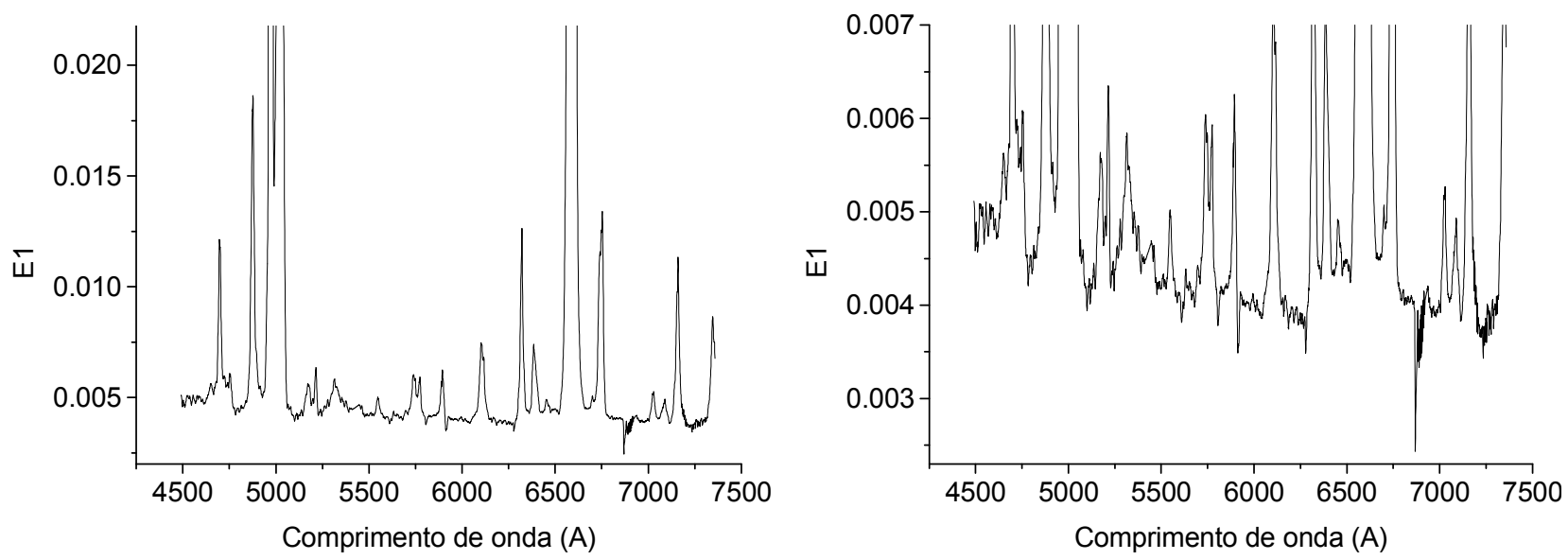

Figura 8.10 - Ampliações do auto-espectro correspondente ao autovetor E1, obtido com a Tomografia PCA do cubo de dados de NGC 1068 com o contínuo estelar.
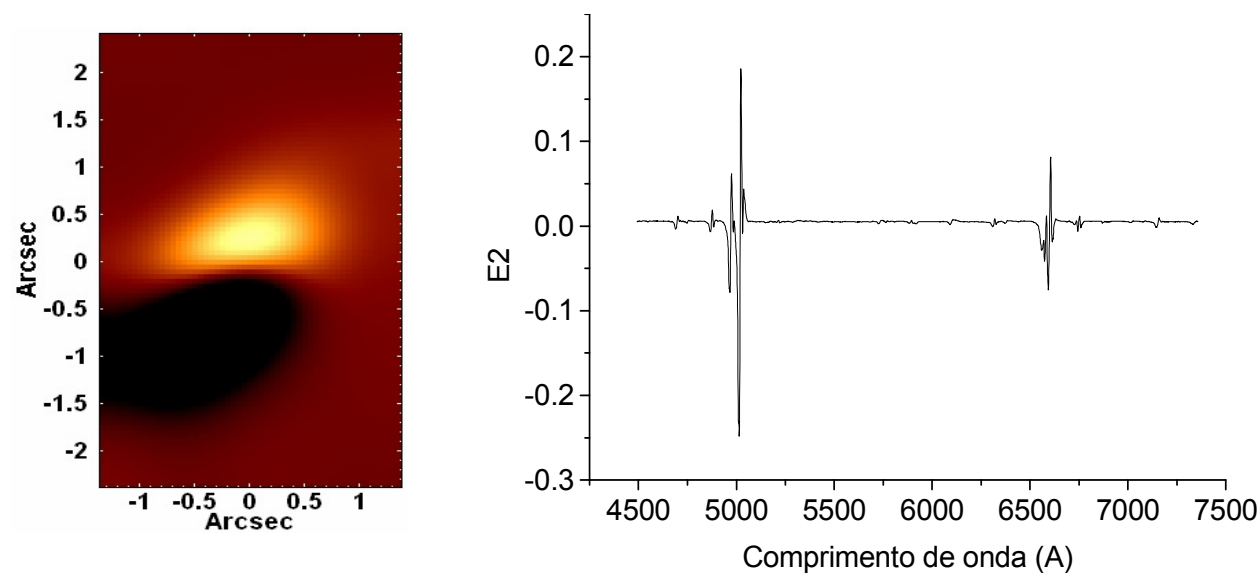

Figura 8.11 - Tomograma e auto-espectro correspondentes ao autovetor E2, obtido com a Tomografia PCA do cubo de dados de NGC 1068 com o contínuo estelar. 


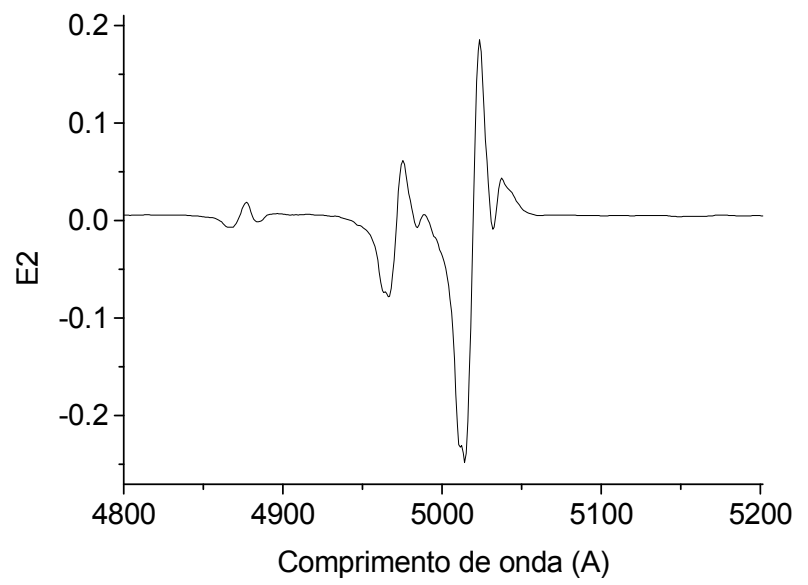

Figura 8.12 - Ampliação na região espectral azul do auto-espectro correspondente ao autovetor E2, obtido com a Tomografia PCA do cubo de dados de NGC 1068 com o contínuo estelar.
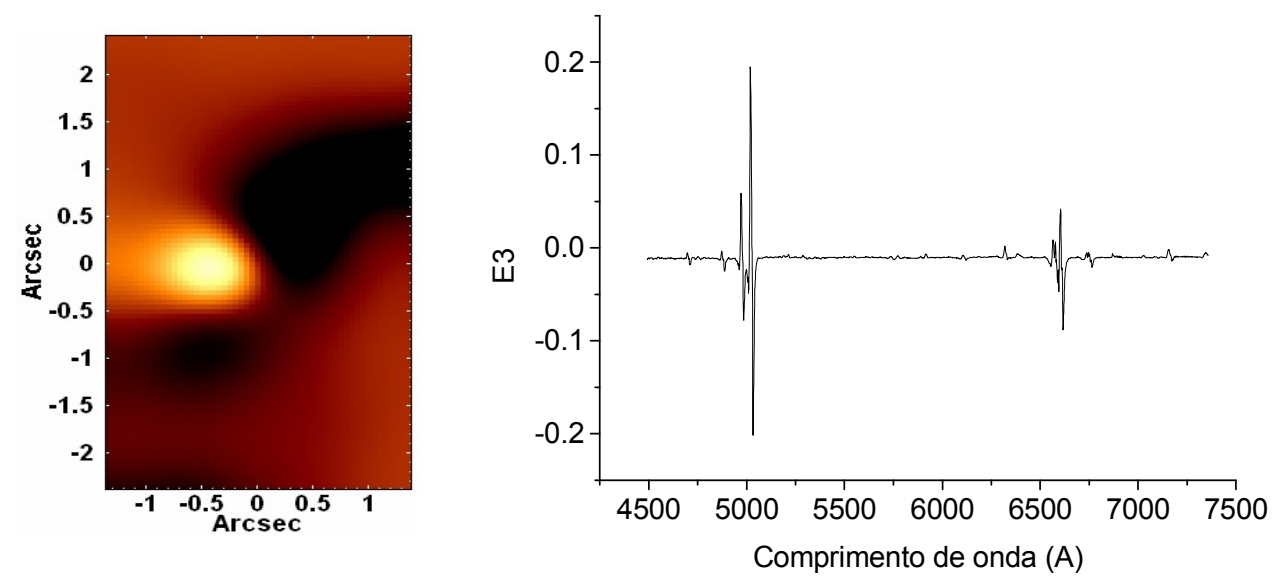

Figura 8.13 - Tomograma e auto-espectro correspondentes ao autovetor E3, obtido com a Tomografia PCA do cubo de dados de NGC 1068 com o contínuo estelar.

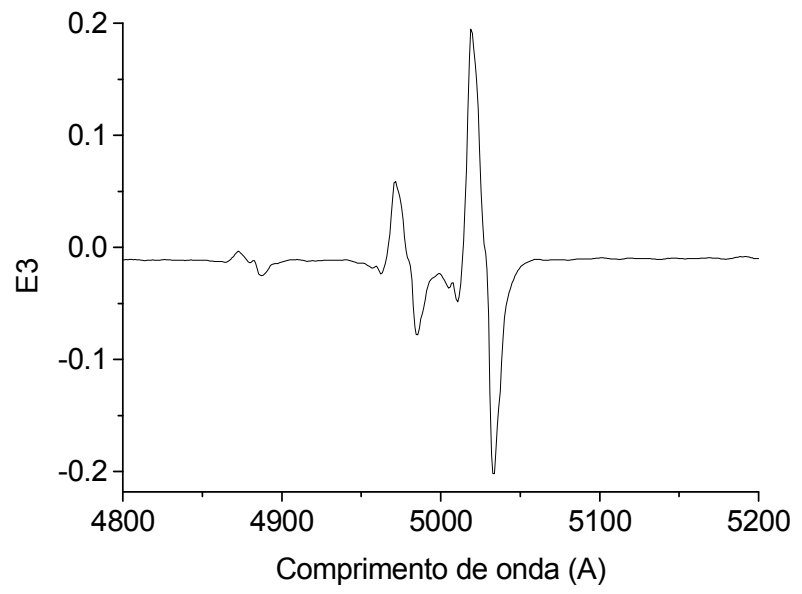

Figura 8.14 - Ampliação na região espectral azul do auto-espectro correspondente ao autovetor E3, obtido com a Tomografia PCA do cubo de dados de NGC 1068 com o contínuo estelar. 

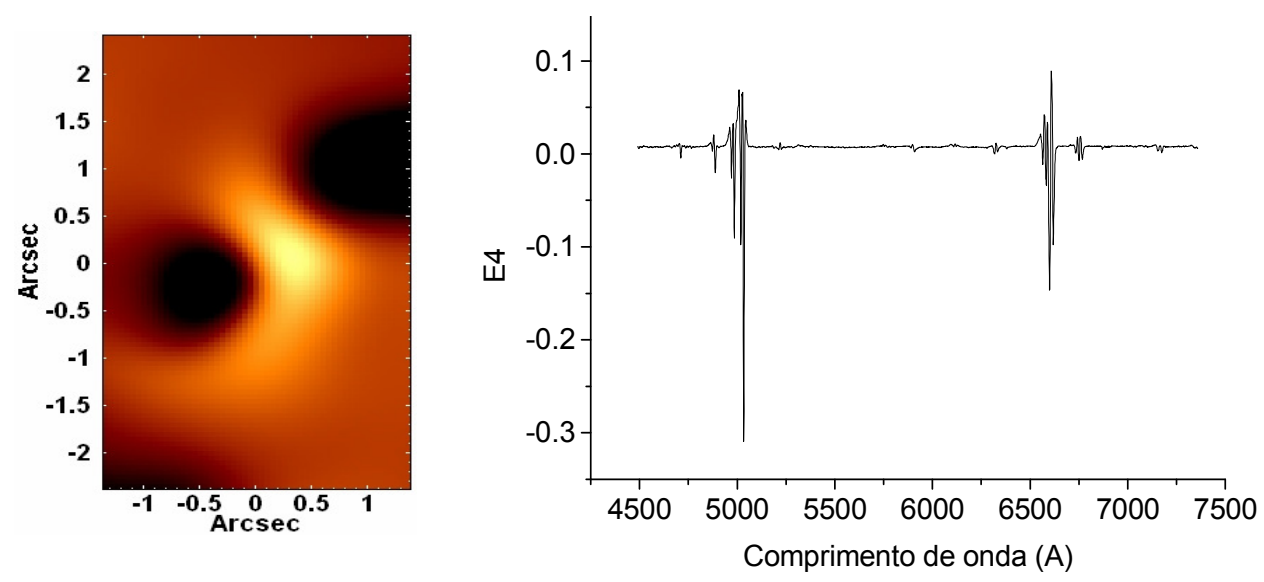

Figura 8.15 - Tomograma e auto-espectro correspondentes ao autovetor E4, obtido com a Tomografia PCA do cubo de dados de NGC 1068 com o contínuo estelar.

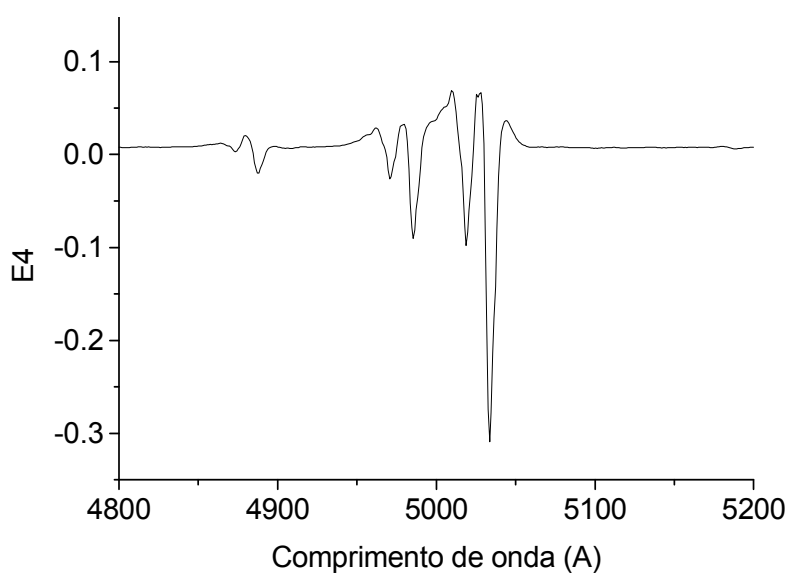

Figura 8.16 - Ampliação na região espectral azul do auto-espectro correspondente ao autovetor E4, obtido com a Tomografia PCA do cubo de dados de NGC 1068 com o contínuo estelar.

\begin{tabular}{|c|c|}
\hline Autovetor & Fração da variância explicada (\%) \\
\hline E1 & 87.9329 \\
\hline E2 & 7.0517 \\
\hline E3 & 2.7077 \\
\hline E4 & 1.1628 \\
\hline
\end{tabular}

Tabela 8.1 - Autovalores obtidos com a Tomografia PCA do cubo de dados de NGC 1068 com o contínuo estelar. 


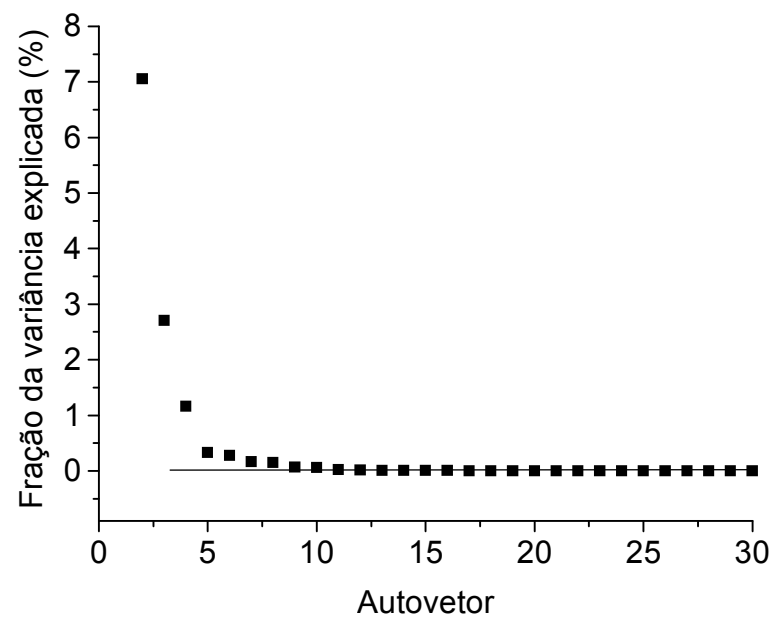

Figura 8.17 - "Scree test" dos autovetores obtidos com a Tomografia PCA do cubo de dados de NGC 1068 com o contínuo estelar.

Observando-se as figuras 8.9 e 8.10, pode-se notar que o auto-espectro E1 e o tomograma associado apresentam o aspecto do espectro médio e da soma de todas as imagens do cubo de dados de NGC 1068 (figuras 8.7 e 8.8), respectivamente. Isso está de acordo com o esperado, pois esse autovetor explica a maior parte da variância dos dados (cerca de 87.9329 \% do total), logo, revela características que já eram claramente detectáveis no cubo de dados do objeto analisado. Pode-se notar que o auto-espectro E1 apresenta correlações com os comprimentos de onda correspondentes a várias linhas espectrais, que devem representar a emissão proveniente do AGN central, cuja posição é dada pela área mais clara do tomograma mostrado. O fato de o autovetor E1 estar relacionado ao AGN existente nessa galáxia também era previsível, já que esse AGN é de forte intensidade e, por isso mesmo, está associado a uma grande parte da variância dos dados. Outra característica importante do auto-espectro E1 é que, embora algumas linhas de emissão visíveis apresentem uma base ligeiramente mais alargada, não foi possível detectar claramente nenhuma componente larga para essas linhas. Isso também está de acordo com o esperado, já que NGC 1068 é classificada como Seyfert 2, não possuindo, portanto, linhas de emissão com componentes largas em seu espectro. Apenas estudos com luz polarizada, como o de Antonucci \& Miller (1985), revelaram a existência de linhas largas nessa galáxia, comprovando que ela contém um núcleo de Seyfert 1 obscurecido.

As figuras 8.11 e 8.12 mostram que o autovetor E2 possui correlações com os comprimentos de onda correspondentes às asas vermelhas de várias linhas de emissão e anticorrelações com os comprimentos de onda associados às asas azuis das mesmas. Isso indica que esse autovetor está relacionado a algum fenômeno cinemático do gás na região central de 
NGC 1068. Nesse caso, as áreas claras do tomograma apresentam gás com emissão em redshift e as regiões escuras possuem gás com emissão em blueshift. Uma análise detalhada do autoespectro E2 mostra que as correlações com as asas vermelhas das linhas indicam velocidades radiais da ordem de $140 \mathrm{~km} / \mathrm{s}$, ao passo que as anti-correlações com as asas azuis revelam velocidades radiais de cerca $-480 \mathrm{~km} / \mathrm{s}$. Assim, pode-se dizer que o tomograma do autovetor E2 "mapeia" tanto regiões com gás apresentando componentes moderadas de velocidade radial no sentido oposto ao do observador quanto áreas com gás possuindo componentes consideravelmente elevadas de velocidade radial no sentido do observador. Por fim, uma observação cuidadosa da ampliação na figura 8.12 indica que o auto-espectro E2 possui correlações praticamente nulas com comprimentos de onda correspondentes a asas vermelhas de linhas associadas a velocidades radiais da ordem de $660 \mathrm{~km} / \mathrm{s}$. Isso deixa bastante claro que esse autovetor não está relacionado a regiões com emissão de gás com componentes tão elevadas de velocidade radial no sentido oposto ao do observador. O autovetor E2 explica cerca de 7.0517 \% da variância dos dados.

Uma análise das figuras 8.13 e 8.14 mostra que o auto-espectro E3 apresenta anticorrelações com os comprimentos de onda correspondentes às asas vermelhas de várias linhas de emissão e correlações com os comprimentos de onda associados às regiões centrais das mesmas. O redshift revelado por esse autovetor indica velocidades radiais de cerca de $720 \mathrm{~km} / \mathrm{s}$. Assim pode-se dizer que esse autovetor também está relacionado a um fenômeno cinemático do gás, sendo que as áreas claras do tomograma correspondem a regiões apresentando gás sem componentes radiais de velocidade elevadas, ao passo que as áreas escuras representam regiões com o gás possuindo componentes radiais de velocidade no sentido oposto ao do observador bastante elevadas. O autovetor E3 explica cerca de 2.7077 \% da variância dos dados.

Finalmente, observando-se as figuras 8.15 e 8.16, nota-se que o auto-espectro E4 apresenta, primeiramente, anti-correlações com os comprimentos de onda correspondentes às asas vermelhas das principais linhas de emissão, com redshifts indicativos de velocidades radiais da ordem de $720 \mathrm{~km} / \mathrm{s}$. Por outro lado esse auto-espectro também possui anti-correlações com os comprimentos de onda associados às asas azuis de várias linhas de emissão, com blueshifts revelando velocidades radiais de cerca de $-180 \mathrm{~km} / \mathrm{s}$. Por fim, o auto-espectro E4 apresenta, ainda, correlações com os comprimentos de onda correspondentes às asas vermelhas de linhas de emissão, com redshifts associados a velocidades radiais próximas a $360 \mathrm{~km} / \mathrm{s}$. Todas essas 
características mostram que o autovetor E4, assim como o E3 e o E2, está relacionado a algum fenômeno cinemático do gás na região central de NGC 1068. Nesse caso, as áreas claras do tomograma correspondem a regiões com o gás apresentando velocidades radiais razoavelmente elevadas $(360 \mathrm{~km} / \mathrm{s})$ no sentido oposto ao do observador, ao passo que as áreas escuras representam regiões com o gás possuindo ou velocidades radiais moderadas $(-180 \mathrm{~km} / \mathrm{s})$ no sentido do observador ou velocidades radiais consideravelmente elevadas $(720 \mathrm{~km} / \mathrm{s})$ no sentido oposto ao do observador. Uma outra possibilidade é que pelo menos parte das áreas escuras apresenta gás com esses dois valores de velocidade radial, o que, provavelmente, indicaria um movimento de expansão ao longo da linha de visada. O autovetor E4 explica cerca de 1.1628 \% da variância dos dados.

Observando-se o Scree test na figura 8.17, pode-se notar que os valores das variâncias explicadas pelos autovetores decaem bastante até, aproximadamente, o autovetor E5. A partir daí, a taxa de decaimento diminui bastante, ficando praticamente constante a partir do autovetor E9. Isso indica que autovetores de ordem maior ou igual a 9 representam, sobretudo, ruído e, consequentemente, não possuem relevância nesse estudo. Entretanto, a análise mostrou que autovetores com ordem maior ou igual a 5 apresentavam uma interpretação menos clara, logo apenas autovetores com ordem menor do que essa foram mostrados aqui. É provável que a diminuição da taxa de decaimento dos autovalores a partir do autovetor E5 (mesmo que ela ainda não tenha atingido um valor constante) represente um indicativo da diminuição da significância e um aumento do ruído dos autovetores com ordem maior ou igual a essa.

Assim, pode-se concluir que essa análise inicial com a Tomografia PCA revelou, primeiramente, uma grande quantidade de linhas de emissão associadas ao AGN central. Nenhuma componente larga dessas linhas pôde ser claramente identificada, o que justifica a classificação dessa galáxia como Seyfert 2. Entretanto, a maior parte dos resultados aqui obtidos com a Tomografia PCA parecem estar relacionados a uma complexa cinemática do gás na região central de NGC 1068. Reunindo-se as informações fornecidas pelos autovetores E2, E3 e E4, tem-se as seguinte situação: a região no extremo nordeste do campo visual do IFU (área escura nos tomogramas das figuras 8.11 e 8.13) apresenta gás com elevados valores de velocidade radial tanto no sentido do observador (até cerca de $-480 \mathrm{~km} / \mathrm{s}$ ) quanto no sentido oposto (até cerca de $720 \mathrm{~km} / \mathrm{s}$ ). Mais ao sudoeste do campo de visão do IFU, tem-se uma região (área clara nos tomogramas das figuras 8.11 e 8.15) com gás com valores moderados de 
velocidade radial (até cerca de $360 \mathrm{~km} / \mathrm{s}$ ) no sentido oposto ao do observador. Por fim, na região no extremo sudoeste do campo visual do IFU (área escura nos tomogramas das figuras 8.13 e 8.15), foi detectado gás com elevadas velocidades radiais (cerca de $720 \mathrm{~km} / \mathrm{s}$ ) no sentido oposto ao do observador. Essa análise inicial, entretanto, não deixou claro se há alguma outra componente de velocidade radial, em blueshift ou em um redshift mais modesto, nessa região no extremo sudoeste do campo visual. Pode-se notar que todos os fenômenos cinemáticos detectados parecem se alinhar desde o sudoeste até o nordeste do campo de visão, o que corresponde à mesma direção apresentada pelo jato em rádio dessa galáxia, conforme foi constatado por Wilson \& Ulvestad (1983). Isso sugere que esse jato pode estar associado a toda essa cinemática do gás, que é analisada em maiores detalhes na seção 8.7.

\section{4 - Síntese espectral do cubo de dados de NGC 1068 com o}

\section{Starlight}

Após a análise com a Tomografia PCA, foi aplicada uma síntese espectral no cubo de dados de NGC 1068 com o software Starlight. A preparação dos espectros foi feita da mesma forma que em todos os casos anteriores, sendo que a correção da extinção devido à Via Láctea foi feita tomando-se $A_{V}=0.112$ e a passagem dos espectros para o referencial de repouso foi aplicada considerando-se $z=0.003793$. Tanto $A_{V}$ quanto $z$ foram obtidos a partir do site do NED.

Como NGC 1068 possui um AGN bastante intenso, foi preciso levar em conta a presença de um featureless continuum na síntese espectral. Como o cubo de dados desse objeto foi obtido no óptico e a base utilizada é bastante precisa nessa região espectral, foi possível construir vários mapeamentos de parâmetros que não puderam ser levados em conta nos capítulos anteriores, devido à pouca confiabilidade dos resultados encontrados. Tais mapeamentos são mostrados nas sessões a seguir.

\subsection{1 - Qualidade dos ajustes}

O mapeamento dos valores do $\chi^{2} / n_{\text {eff }}$ dos ajustes resultantes da síntese espectral do cubo de dados de NGC 1068 encontra-se a seguir. 


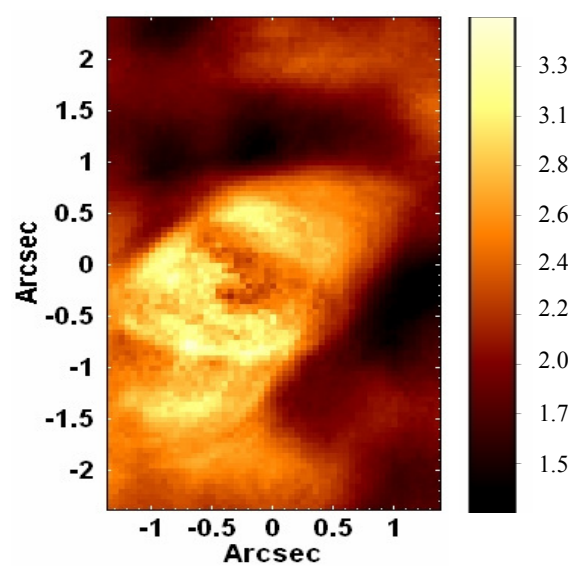

Figura 8.18: Mapeamento dos valores do $\chi^{2} / n_{\text {eff }}$ dos ajustes obtidos pelo "Starlight" para os espectros do cubo de dados de NGC 1068.

Analisando-se a figura 8.18, pode-se notar que os melhores ajustes obtidos com a síntese espectral apresentaram $\chi^{2} / n_{\text {eff }}$ de cerca de 1.3. Por outro lado, os piores tiveram $\chi^{2} / n_{\text {eff }}$ próximo a 3.5 , o que já é considerado um valor razoavelmente alto para o $\chi^{2} / n_{\text {eff }}$ e poderia indicar ajustes menos precisos. Entretanto, uma análise mais detalhada dos espectros correspondentes às áreas mais claras da figura 8.18 revelou que esses valores elevados de $\chi^{2} / n_{\text {eff }}$ ocorreram, sobretudo, em decorrência de um aumento considerável do número de linhas de emissão nessas regiões. As principais linhas de emissão do espectro foram mascaradas na síntese espectral, entretanto, esse processo não pôde ser aplicado a todas elas por duas razões: a primeira é que boa parte dessas linhas somente são visíveis em uma área consideravelmente pequena mais próxima ao AGN. A segunda razão é que mascarar um número tão grande de regiões espectrais (já que o número de linhas é bastante elevado, conforme pode ser notado nos espectros mostrados nas figuras 8.7 e 8.8) teria prejudicado a síntese espectral em várias áreas do cubo de dados (nas quais o número de linhas poderia não ser tão grande). Para evitar problemas de ajuste causados por bad pixeis, raios cósmicos ou mesmo linhas de emissão não mascaradas, o software Starlight possui um sistema de clipping, que exclui certas regiões espectrais (não mascaradas) para as quais não foi possível encontrar nenhum ajuste aceitável. Assim, embora as linhas de emissão adicionais não tenham sido mascaradas para a síntese, o sistema de clipping do Starlight as desconsiderou. Entretanto, esse clipping não é inteiramente eficaz e regiões próximas às asas das linhas de emissão, por exemplo, que obviamente não poderiam ser reproduzidas pelo Starlight, acabaram não sendo excluídas totalmente na síntese espectral desse cubo de dados, o que gerou valores mais elevados do $\chi^{2} / n_{\text {eff. }}$. De qualquer modo, uma inspeção dos ajustes com $\chi^{2} / n_{\text {eff }}$ mais alto revelou que o contínuo dos espectros envolvidos foi consideravelmente bem ajustado, assim, 
mesmo os ajustes com os maiores $\chi^{2} / n_{\text {eff }}$ no mapeamento da figura 8.18 podem ser considerados razoavelmente confiáveis.

\subsection{2 - Parâmetros cinemáticos}

Os mapeamentos dos valores da velocidade radial estelar e da dispersão de velocidades estelar encontram-se a seguir.
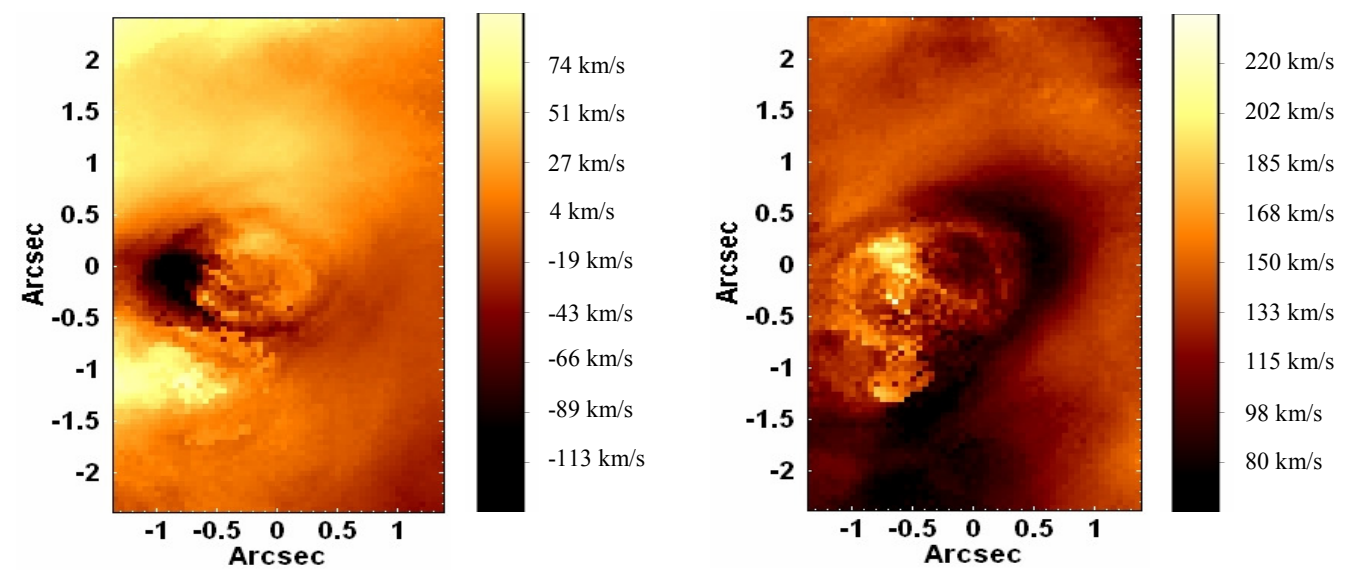

Figura 8.19: Mapeamentos dos valores (esquerda) da velocidade radial estelar e (direita) da dispersão de velocidades estelar, resultantes da aplicação do "Starlight" ao cubo de dados de NGC 1068.

Observando-se a figura 8.19, pode-se notar, primeiramente, a presença de várias irregularidades e assimetrias no mapeamento dos valores da velocidade radial estelar, que não parecem ser compatíveis com uma clara rotação ao redor do núcleo. Entretanto, uma análise mais detalhada desse mapa revela um aparente padrão rotacional bastante tênue, cujo eixo coincide, aproximadamente, com a direção sudoeste-nordeste. Esse resultado é compatível com o que foi encontrado por Emsellem et al. (2006) em uma análise de espectroscopia bidimensional obtida com o SAURON. Entretanto, esses autores também observaram que a rotação estelar em NGC 1068 é mais claramente visível a distâncias maiores do núcleo (da ordem de 10"), sendo que a região central é dominada por várias padrões assimétricos. Assim, mesmo as irregularidades detectadas no mapeamento dos valores da velocidade radial estelar na figura 8.19 também podem ser consideradas como estando de acordo com o esperado. Observando-se a escala de valores da velocidade radial estelar, pode-se notar que a amplitude das velocidades negativas é razoavelmente maior do que a das velocidades positivas. Entretanto, 
verifica-se que essas velocidades negativas com módulos mais elevados apenas ocorrem em uma pequena região próxima ao AGN central, na qual é sabido que o número maior de linhas de emissão pode ter prejudicado os ajustes do Starlight e gerado valores não confiáveis de velocidades radiais. Assim, é provável que essa assimetria observada nos módulos da velocidade radial não seja real, mas sim uma conseqüência de problemas nos ajustes. O mapeamento da dispersão de velocidades estelar revela um considerável aumento dos valores na região mais próxima do AGN central, o que está de acordo com o esperado. Mesmo assim, essa área apresenta várias irregularidades, que também podem ser uma conseqüência de imprecisões nos ajustes.

\subsection{3 - Populações estelares e featureless continuum}

Os mapeamentos do fluxo associado às populações estelares com diferentes idades e metalicidades levadas em conta na síntese espectral, assim como o mapa do fluxo atribuído ao featureless continuum do AGN são mostrados a seguir.
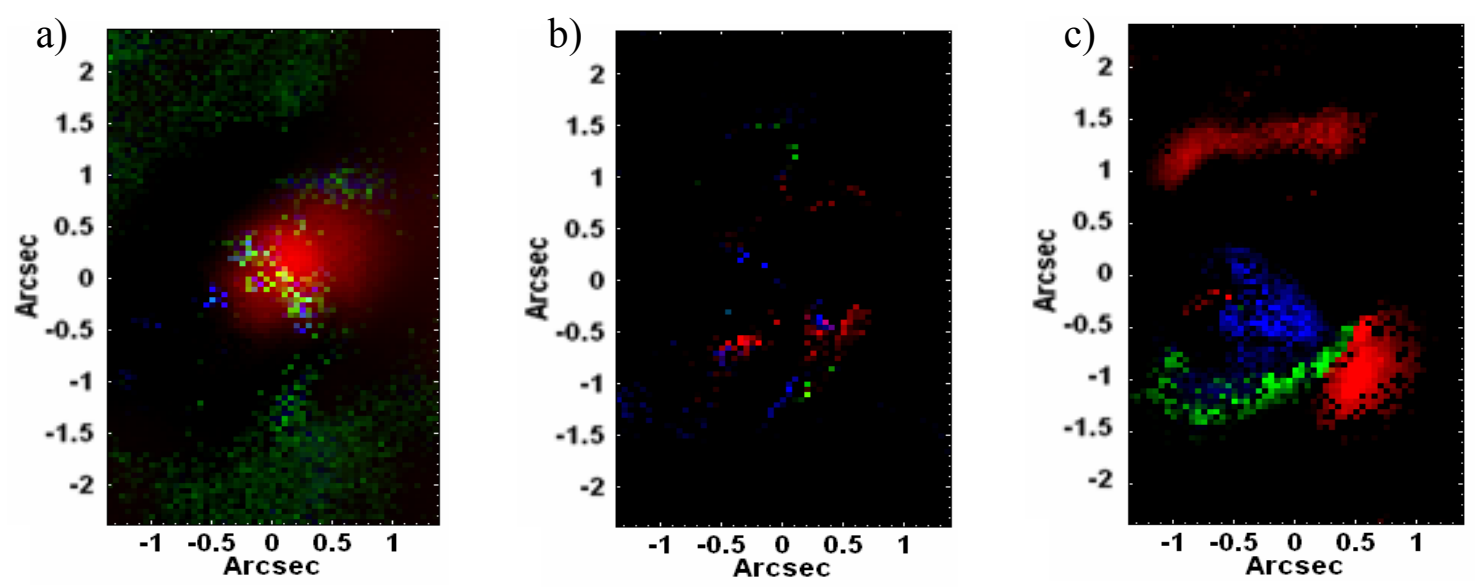

Figura 8.20: a) Composição $R G B$ da população estelar com idade entre $1 \cdot 10^{6}$ e $8.71 \cdot 10^{6}$ anos; b) Composição $R G B$ da população estelar com idade entre $1 \cdot 10^{7}$ e $5.5 \cdot 10^{7}$ anos; c) Composição $R G B$ da população estelar com idade entre $1.02 \cdot 10^{8}$ e 9.05.10 anos; d) Composição $R G B$ da população estelar com idade entre $1.28 \cdot 10^{9}$ e $7.5 \cdot 10^{9}$ anos; e) Composição $R G B$ da população estelar com idade entre $1 \cdot 10^{10}$ e $1.8 \cdot 10^{10}$ anos. Em todas as imagens, obtidas com a sintese espectral do cubo de dados de NGC 1068, a cor azul indica baixa metalicidade $(Z=0.0001$ e $Z=0.0004)$, a cor verde indica metalicidade intermediária $(Z=0.004$ e $Z=0.008)$ e a cor vermelha indica metalicidade mais elevada $(Z=0.02$ e $Z=0.05)$, lembrando que $Z_{\odot}=0.02$. 

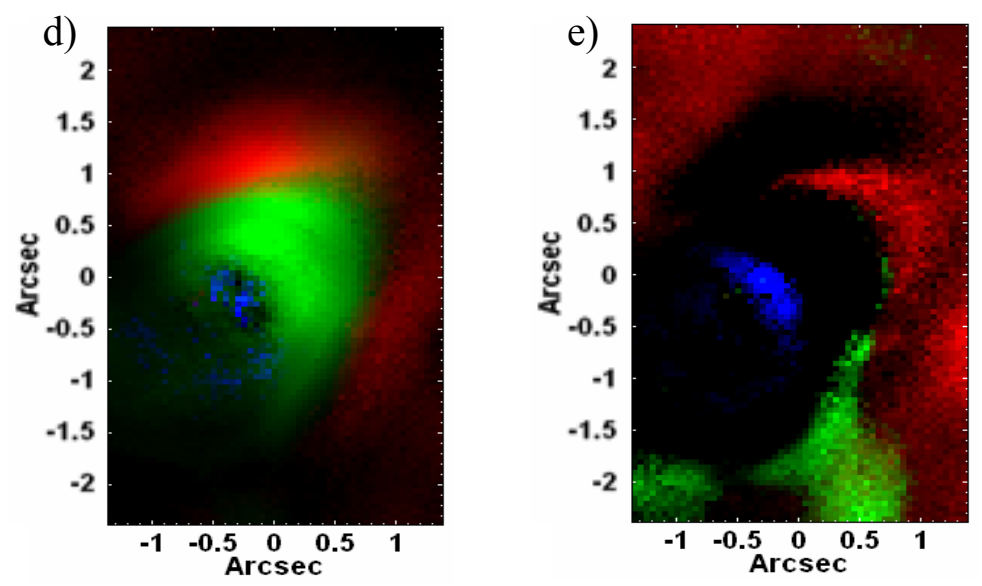

Figura 8.20 (continuação).
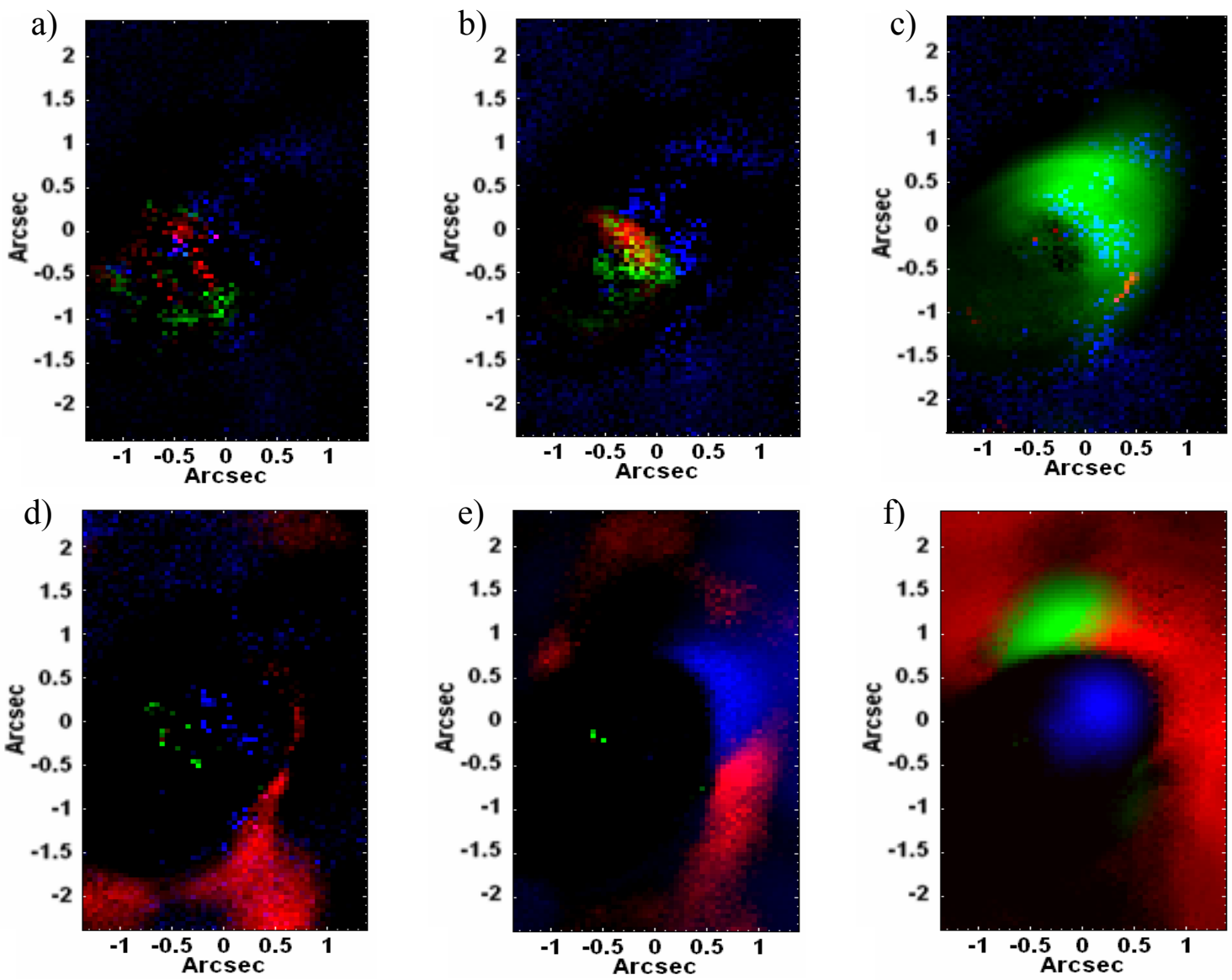

Figura 8.21: a) Composição $R G B$ da população estelar com metalicidade $Z=0.0001$; $b$ ) Composição $R G B$ da população estelar com metalicidade $Z=0.0004$; c) Composição $R G B$ da população estelar com metalicidade $Z=0.004$; d) Composição $R G B$ da população estelar com metalicidade $Z=0.008$; e) Composição $R G B$ da população estelar com metalicidade $Z=0.02$;

f) Composição $R G B$ da população estelar com metalicidade $Z=0.05$. Em todas as imagens, obtidas com a síntese espectral do cubo de dados de NGC 1068, a cor azul indica população estelar jovem (desde $1 \cdot 10^{6}$ anos até $5.5 \cdot 10^{7}$ anos), a cor verde indica população estelar com idade intermediária (desde $1.02 \cdot 10^{8}$ anos até $4.25 \cdot 10^{9}$ anos) e a cor vermelha indica população estelar velha (desde $6.25 \cdot 10^{9}$ anos até $1.8 \cdot 10^{10}$ anos). É importante lembrar que $Z_{\odot}=0.02$. 


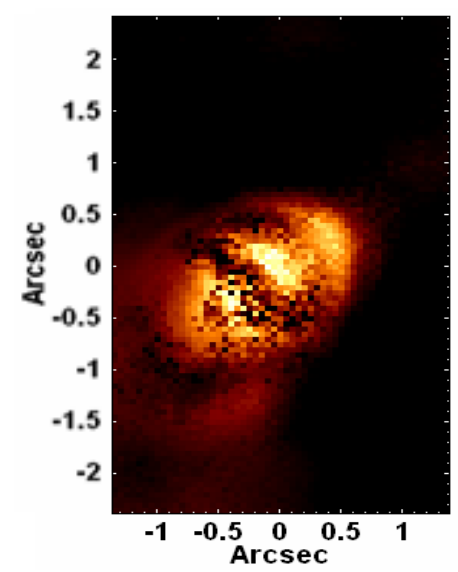

Figura 8.22: Mapeamento do fluxo atribuído ao "featureless continuum" do AGN, obtido com a aplicação do "Starlight" ao cubo de dados de NGC 1068.

A partir dos resultados obtidos com o Starlight, construiu-se um gráfico em colunas contendo as frações de fluxo atribuídas a cada uma das populações estelares e ao featureless continuum, considerando-se todo o campo visual do IFU do GMOS. Utilizando valores apropriados da razão massa/luminosidade, o Starlight também fornece as frações de massa devidas a cada população estelar e, com esses valores, foi possível montar um segundo gráfico, análogo ao anterior, mas contendo frações de massa ao invés de frações de fluxo. Os gráficos construídos encontram-se a seguir.
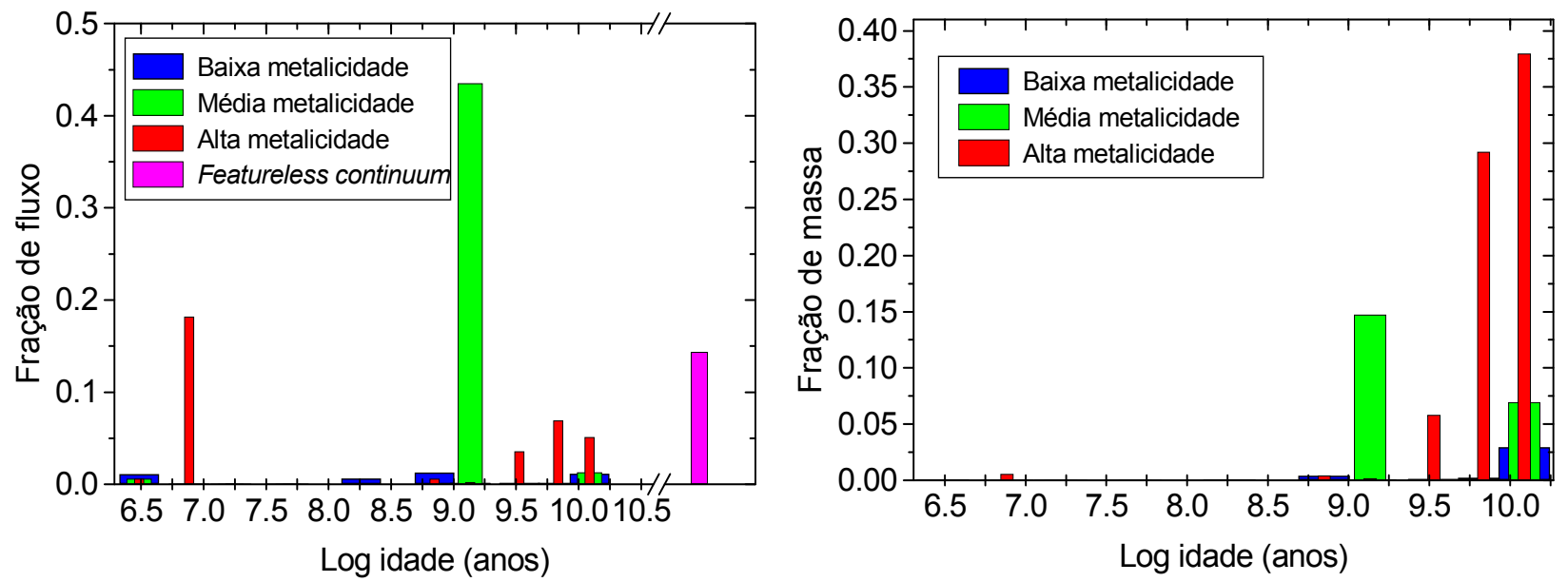

Figura 8.23: Gráficos representativos das frações de (esquerda) fluxo e de (direita) massa devidas às populações estelares (e ao "featureless continuum"), considerando-se todo o campo visual do IFU do GMOS, obtidos com a aplicação do "Starlight" ao cubo de dados de NGC 1068. 
As figuras 8.20 e 8.21 mostram a existência de uma população estelar com idade de cerca de $10^{6}$ anos e metalicidade $Z=0.05$ numa região próxima ao centro do campo visual do IFU do GMOS. Populações com essa mesma idade, mas com metalicidades mais variadas foram detectadas em áreas mais afastadas do centro do campo de visão, entretanto, parecem ter uma contribuição relativamente pequena para o fluxo total. As imagens também revelam poucas populações estelares com idade próxima $10^{8}$ anos e praticamente a ausência de populações com idade da ordem de $10^{7}$ anos. Por outro lado, pode-se observar uma concentração considerável de estrelas com idade de cerca de $10^{9}$ anos e metalicidade $Z=0.004$ numa região próxima ao centro do campo visual do IFU do GMOS, se estendendo ao longo da direção nordeste (área verde da figura $8.20-d$ ). Ainda com uma idade de $10^{9}$ anos, podem ser detectadas populações estelares com alta metalicidade, em áreas mais afastadas do centro do campo de visão. Por fim, as figuras 8.20 e 8.21 revelam a existência de populações estelares com idade da ordem de $10^{10}$ anos e média e alta metalicidade, em regiões também razoavelmente distantes do centro do campo visual do IFU.

Analisando-se a figura 8.22, pode-se notar que foi detectado um featureless continuum em regiões próximas ao AGN, o que, obviamente, parece coerente. Entretanto, esse featureless continumm também pôde ser observado em áreas consideravelmente mais afastadas do AGN. Esse fato pode ser devido a um espalhamento do contínuo emitido pelo AGN por poeira (na forma de um toro, por exemplo) ao redor dele. Isso estaria de acordo com o esperado, já que, conforme foi mencionado na seção 8.1, vários fatos, como a detecção de linhas largas em luz polarizada (Antonucci \& Miller 1985) e estudos interferométricos no infravermelho intermediário (Jaffe et al. 2004), indicam que NGC 1068 possui um núcleo que Seyfert 1 obscurecido por um provável toro de poeira ao seu redor. Trabalhos como os de Jaffe et al. (2004) e Raban et al. (2009) revelaram que esse toro deve se estender ao longo da direção sudeste-noroeste, o que o torna perpendicular ao jato em rádio e ao cone de ionização, conforme o previsto. Seria de se esperar que qualquer espalhamento por poeira também ocorresse perpendicularmente ao toro, ou seja, ao longo da direção sudoeste-nordeste. De fato, observando-se a figura 8.22, nota-se que todo o featureless continuum detectado parece se estender mesmo ao longo dessa direção, o que torna esse resultado bastante significativo e coerente com o cenário proposto para essa galáxia. 
Observando-se os gráficos da figura 8.23, pode-se notar que a maior parte do fluxo (aproximadamente $43.5 \%$ do total) no campo visual do IFU do GMOS é proveniente de populações estelares com idade de cerca de $1.4 \cdot 10^{9}$ anos e média metalicidade, o que pode indicar a ocorrência de um surto de formação estelar (starburst) nesse período. Também é detectada uma fração de fluxo apreciável (por volta de $18.2 \%$ ) associada a populações estelares significativamente mais jovens, com idade de cerca de $7.7 \cdot 10^{6}$ anos, de alta metalicidade. Além disso, podem ser observadas, ainda, frações de fluxo mais modestas (entre $3.5 \%$ e $6.9 \%$ ) relacionadas a populações estelares mais velhas, com idades superiores ou da ordem de $3.4 \cdot 10^{9}$ anos, de alta metalicidade. As frações de fluxo devidas às demais populações estelares são consideravelmente inferiores e, consequentemente, pouco relevantes. Todos esses resultados são compatíveis com o que foi observado nas figuras 8.20 e 8.21. A fração de fluxo associada ao featureless continuum do AGN (cerca de $14.4 \%$ ) é significativa, o que também está de acordo com o que foi observado na figura 8.22. Por fim, a figura 8.23 revela que a maior parte da massa estelar é devida a populações estelares com idades maiores ou próximas a $1.4 \cdot 10^{9}$ anos e médias e altas metalicidades. Isso é coerente com tudo o que foi constatado anteriormente, considerando-se as frações de fluxo mostradas na figura 8.23 e as razões $M / L$ associadas às populações estelares envolvidas.

\subsection{4 - Extinção interestelar}

O mapeamento dos valores de $A_{V}$ fornecidos pelo Starlight é mostrado a seguir. 


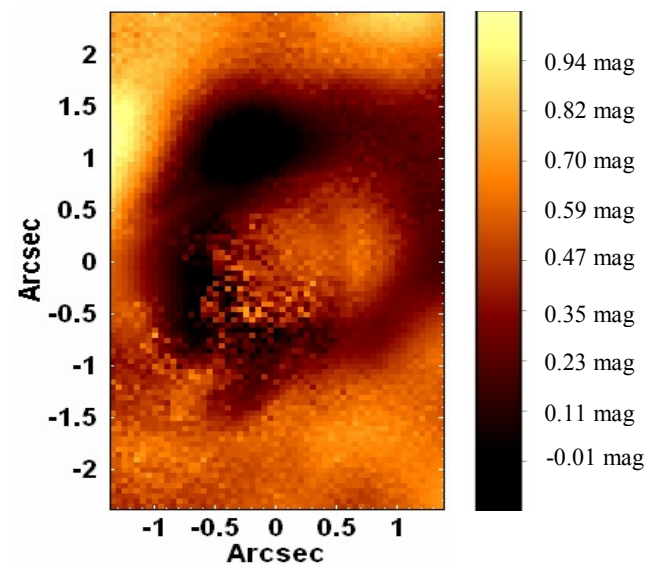

Figura 8.24: Mapeamento dos valores de $A_{V}$, obtido a partir da síntese do cubo de dados de NGC 1068 com o "Starlight".

Analisando-se a figura 8.24, pode-se notar que os menores valores de $A_{V}$ detectados foram de cerca de $-0.13 \mathrm{mag}$, ao passo que os maiores foram próximos a 1.06 mag. Verifica-se um considerável aumento de $A_{V}$ nas regiões mais afastadas do centro do campo visual do IFU do GMOS, o que pode ser um indicativo da existência de uma quantidade considerável de poeira nessas áreas. Pode-se observar um outro razoável aumento de valores na região próxima ao AGN central, o que também sugere a presença de poeira nessa área, que pode estar associada ao toro de poeira mencionado anteriormente. Este, por sua vez, seria responsável pelo obscurecimento do núcleo de Seyfert 1 existente (Antonucci \& Miller 1985) e pelo espalhamento do featureless continuum detectado na figura 8.22. Por fim, nota-se, ainda, que as regiões escuras do mapeamento na figura 8.24 chegam a apresentar valores negativos de $A_{V}$. Tais valores, em geral, encontram-se dentro da incerteza do Starlight e, basicamente, são um indicativo de que a extinção é bem pequena ou nula nessas regiões. É também possível que a correção devido à extinção da Galáxia tenha sido ligeiramente exagerada para algumas áreas de NGC 1068 dentro desse campo de visão, o que pode ter acarretado nos valores negativos observados. 


\subsection{5 - Valores da razão $S / N$ dos espectros analisados}

O mapeamento dos valores da razão $S / N$ obtidos pelo Starlight no intervalo espectral de $5820 \AA$ até $5846 \AA$ encontra-se a seguir.

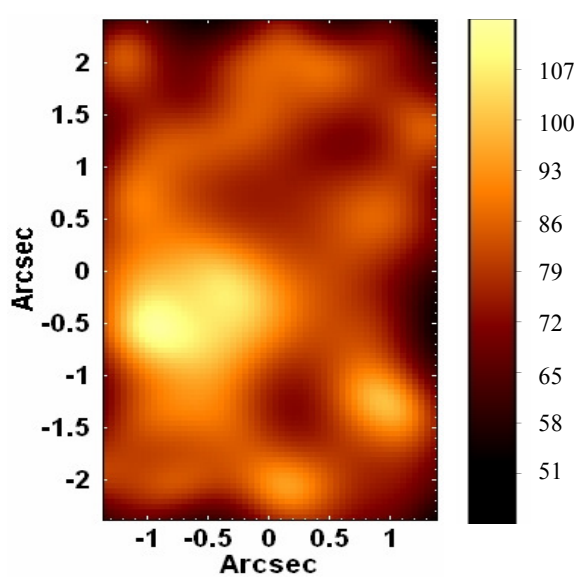

Figura 8.25 - Mapeamentos dos valores da razão $S / N$, obtidos a partir da sintese espectral do cubo de dados de NGC 1068 com o "Starlight".

Observando-se a figura 8.25, pode-se notar que os maiores valores (até cerca de 114) para a razão $S / N$ foram encontrados nas regiões mais próximas ao $\mathrm{AGN}$, ao passo que os menores (até cerca de 44) foram obtidos nas áreas mais afastadas. Isso está de acordo com o esperado, já que o fluxo detectado, inclusive na região do contínuo, é mais intenso em áreas próximas ao $\mathrm{AGN}$, dando origem aos valores mais elevados da razão $S / N$.

\section{5 - Aplicação da Tomografia PCA ao cubo de dados de NGC 1068 com o contínuo estelar subtraído}

Fez-se uma subtração do contínuo estelar de todos os espectros de NGC 1068, utilizando-se os espectros estelares sintéticos resultantes da síntese espectral com o Starlight. Aplicou-se, então, a Tomografia PCA ao cubo de dados resultante, contendo apenas linhas de emissão. Os principais auto-espectros e respectivos tomogramas obtidos encontram-se a seguir 
418
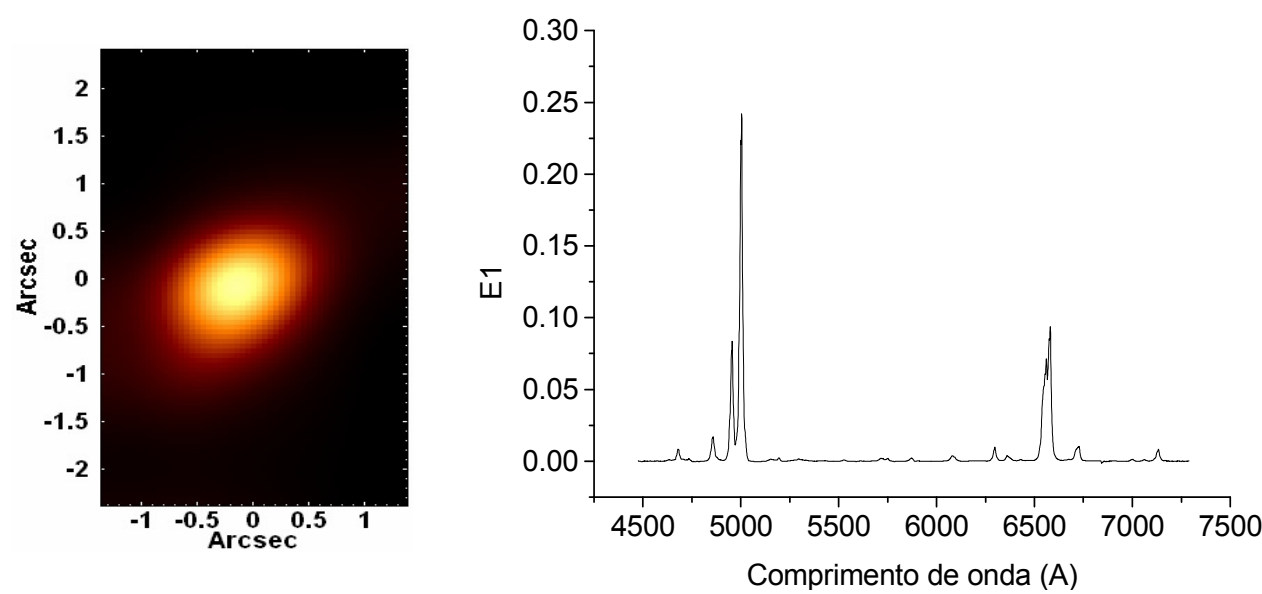

Figura 8.26 - Tomograma e auto-espectro correspondentes ao autovetor E1, obtido com a Tomografia PCA do cubo de dados de NGC 1068 com o contínuo estelar subtraído.
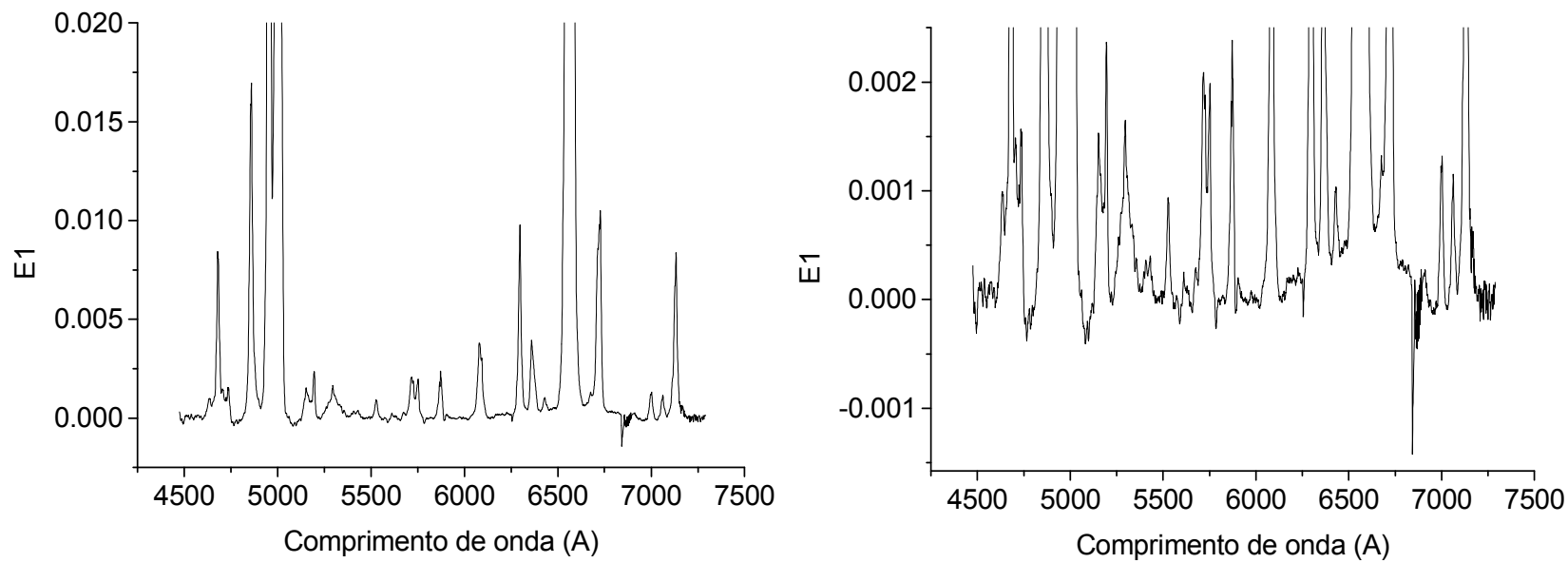

Figura 8.27 - Ampliações do auto-espectro correspondente ao autovetor E1, obtido com a Tomografia PCA do cubo de dados de NGC 1068 com o contínuo estelar subtraído.
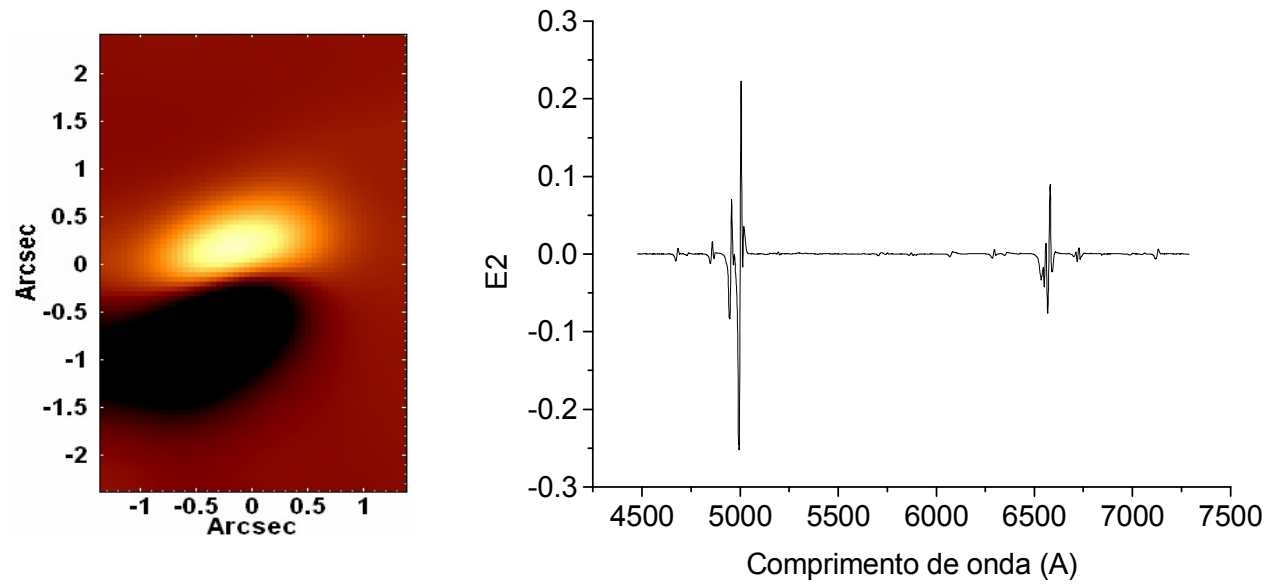

Figura 8.28 - Tomograma e auto-espectro correspondentes ao autovetor E2, obtido com a Tomografia PCA do cubo de dados de NGC 1068 com o contínuo estelar subtraído. 


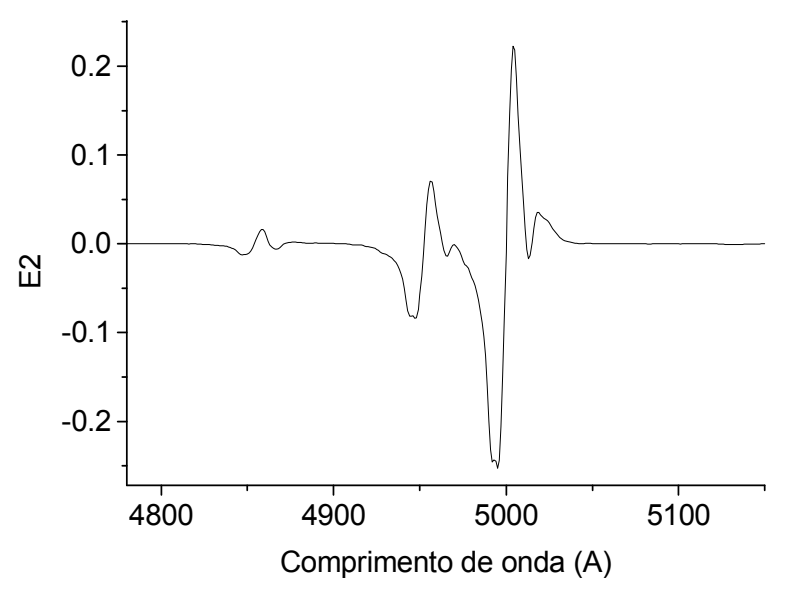

Figura 8.29 - Ampliação na região espectral azul do auto-espectro correspondente ao autovetor E2, obtido com a Tomografia PCA do cubo de dados de NGC 1068 com o contínuo estelar subtraído.
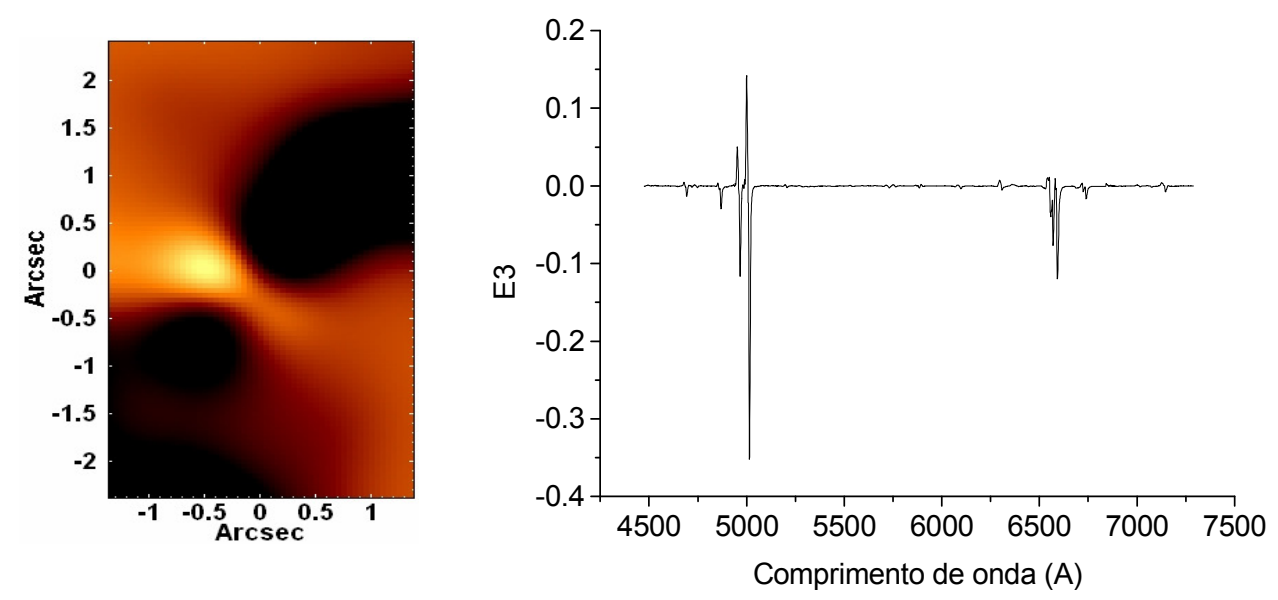

Figura 8.30 - Tomograma e auto-espectro correspondentes ao autovetor E3, obtido com a

Tomografia PCA do cubo de dados de NGC 1068 com o contínuo estelar subtraído.

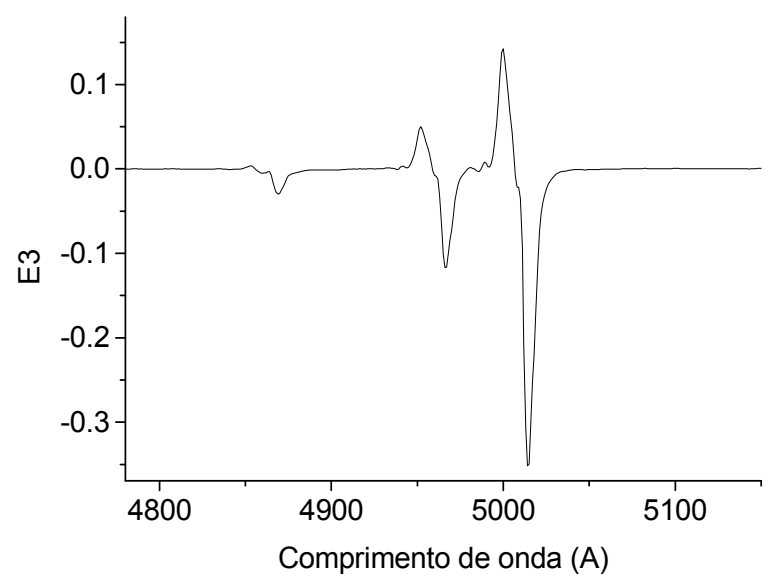

Figura 8.31 - Ampliação na região espectral azul do auto-espectro correspondente ao autovetor E3, obtido com a Tomografia PCA do cubo de dados de NGC 1068 com o contínuo estelar subtraído. 
420
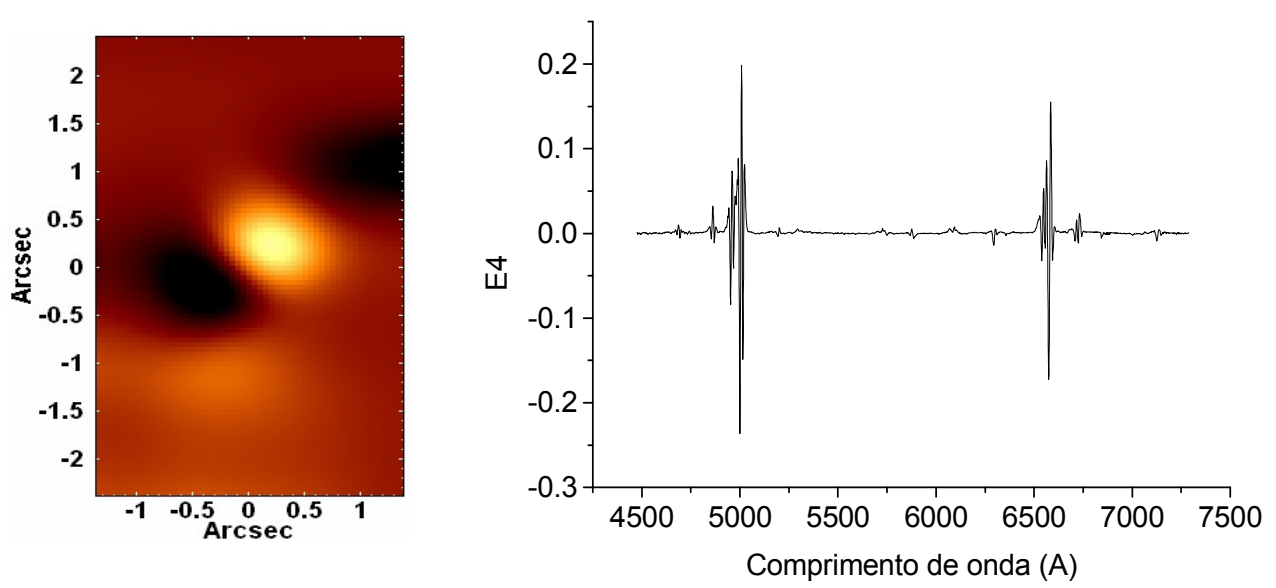

Figura 8.32 - Tomograma e auto-espectro correspondentes ao autovetor E4, obtido com a Tomografia PCA do cubo de dados de NGC 1068 com o contínuo estelar subtraído.

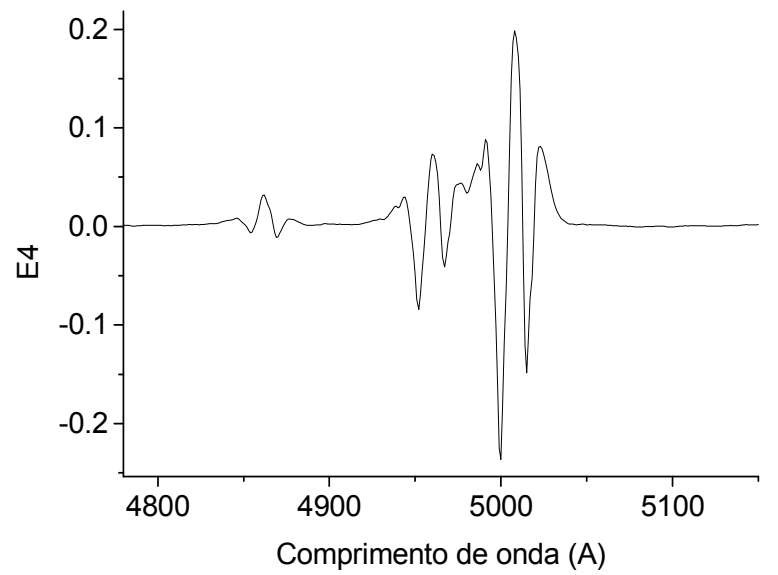

Figura 8.33 - Ampliação na região espectral azul do auto-espectro correspondente ao autovetor E4, obtido com a Tomografia PCA do cubo de dados de NGC 1068 com o contínuo estelar subtraído.

\begin{tabular}{|c|c|}
\hline Autovetor & Fração da variância explicada (\%) \\
\hline E1 & 87.9992 \\
\hline E2 & 8.0111 \\
\hline E3 & 2.1054 \\
\hline E4 & 0.8518 \\
\hline
\end{tabular}

Tabela 8.2 - Autovalores obtidos com a Tomografia PCA do cubo de dados de NGC 1068 com o contínuo estelar subtraído. 


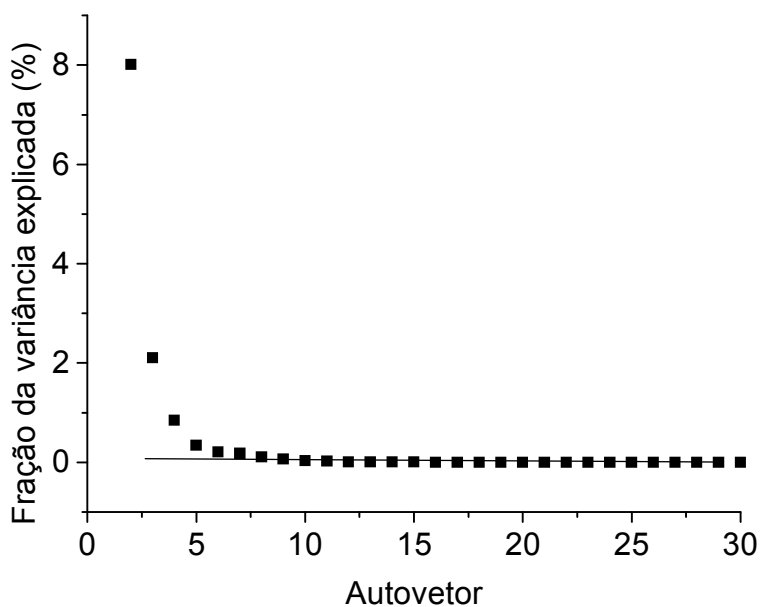

Figura 8.34 - "Scree test" dos autovetores obtidos com a Tomografia PCA do cubo de dados de NGC 1068 com o contínuo estelar subtraído.

As figuras 8.26 e 8.27 mostram que o auto-espectro E1 apresenta correlações com os comprimentos de onda correspondentes a várias linhas espectrais, que devem representar a emissão do AGN central, cuja posição é dada pela área mais clara do tomograma associado. A identificação dessas linhas é mostrada na tabela 8.3.

\begin{tabular}{|c|c|}
\hline Íon & Comprimento de onda $(\AA)$ \\
\hline $\mathrm{N} \mathrm{III}$ & 4640 \\
\hline $\mathrm{He} \mathrm{II}$ & 4686 \\
\hline$[\mathrm{Ar}$ IV] & 4740 \\
\hline $\mathrm{H} \beta$ & 4861 \\
\hline$[\mathrm{O} \mathrm{III}]$ & 4959,5007 \\
\hline$[\mathrm{Fe} \mathrm{VII}]$ & 5158 \\
\hline$[\mathrm{N} \mathrm{I}]$ & 5199 \\
\hline$[\mathrm{Ca} \mathrm{V}]$ & 5309 \\
\hline$[\mathrm{Cl} \mathrm{III}]$ & 5538 \\
\hline$[\mathrm{Fe} \mathrm{VII}]$ & 5721 \\
\hline$[\mathrm{N} \mathrm{II}]$ & 5755 \\
\hline $\mathrm{He} \mathrm{I}$ & 5876 \\
\hline$[\mathrm{Fe} \mathrm{VII}]$ & 6086 \\
\hline$[\mathrm{O} \mathrm{I}]$ & 6300 \\
\hline$[\mathrm{O} \mathrm{I}]$ & 6364 \\
\hline$[\mathrm{N} \mathrm{II}]$ & 6548 \\
\hline $\mathrm{H \alpha}$ & 6563 \\
\hline$[\mathrm{N} \mathrm{II}]$ & 6583 \\
\hline$[\mathrm{S} \mathrm{II}]$ & 6716,6731 \\
\hline $\mathrm{He} \mathrm{I}$ & 7065 \\
\hline$[\mathrm{Ar} \mathrm{III}]$ & 7136 \\
\hline
\end{tabular}

Tabela 8.3 - Identificação das linhas de emissão presentes no auto-espectro E1, mostrado nas figuras 8.25 e 8.26 . 
O fato das características espectrais do AGN terem aparecido no autovetor E1 está de acordo com o esperado, já que ele explica a maior parte da variância dos dados (cerca de 87.9992 \% do total) e é sabido que AGN dessa galáxia é intenso e, consequentemente, facilmente detectável. Comparando-se as figuras 8.9, 8.10, 8.26 e 8.27, pode-se notar uma grande compatibilidade entre os autovetores E1 obtidos a partir das aplicações da Tomografia PCA aos cubos de dados de NGC 1068 antes e depois da subtração do contínuo estelar, que, na verdade, parece ter tido pouco efeito nos resultados dessas análises. Entretanto, uma diferença consideravelmente relevante entre o auto-espectro da figura 8.10 e aquele da figura 8.27 é que o primeiro não mostra, de maneira clara, nenhuma componente larga das linhas de emissão, enquanto que o último parece revelar uma componente larga da linha de H $\alpha$. Esse resultado é bastante relevante, pois nenhuma linha larga havia sido detectada anteriormente no espectro dessa galáxia sem o uso de polarimetria (Antonucci \& Miller 1985). A componente larga de $\mathrm{H} \alpha$ na figura 8.27, entretanto, é bastante fraca quando comparada às demais linhas de emissão, sendo que ela apenas pôde ser observada ampliando-se o auto-espectro associado a E1. A figura 8.35 mostra um espectro extraído de uma região circular, centrada no AGN, do cubo de dados de NGC 1068, após a subtração do contínuo estelar.
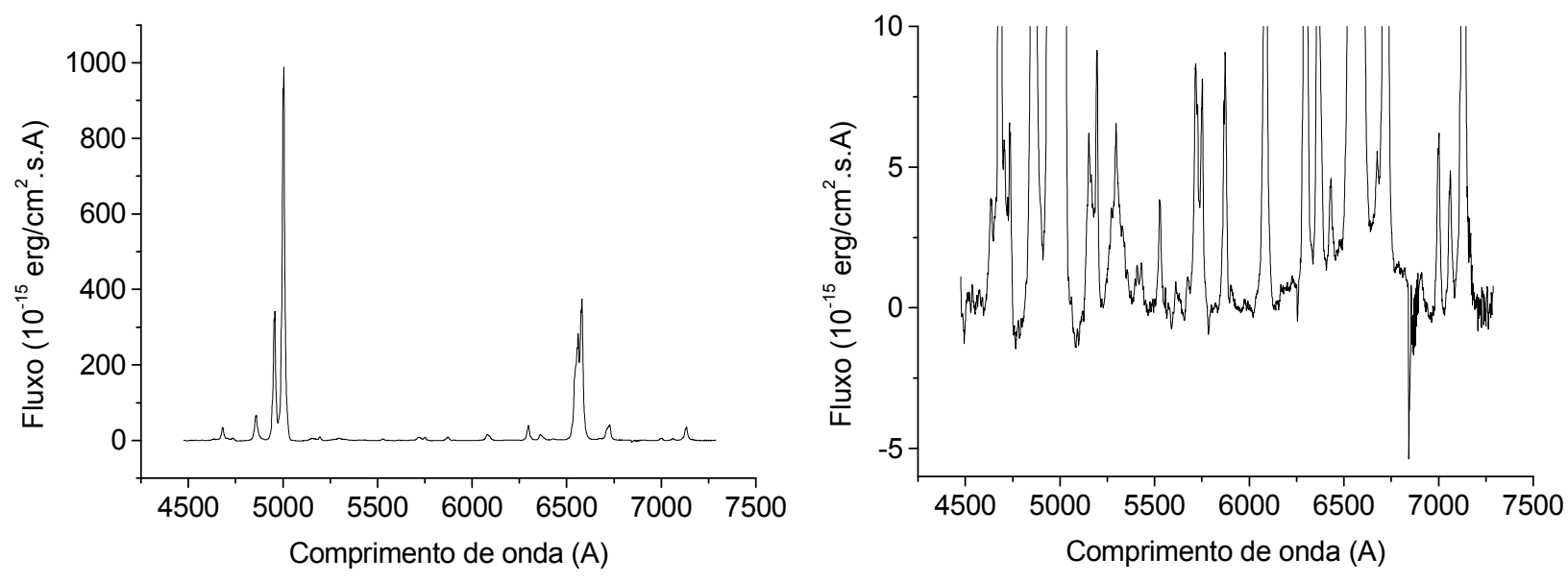

Figura 8.35 - (esquerda) Espectro extraído de uma região circular, centrada no AGN, do cubo de dados de NGC 1068, após a subtração do contínuo estelar; (direita) ampliação do espectro mostrado à esquerda.

A componente larga de $\mathrm{H} \alpha$ revelada pela Tomografia PCA também é claramente visível na ampliação do espectro mostrado na figura 8.35. A detecção dessa estrutura no espectro nuclear de NGC 1068, juntamente com a sua baixa intensidade, pode ser considerada compatível 
com os resultados obtidos em trabalhos anteriores dessa galáxia, confirmando o seguinte cenário: esse objeto possui um núcleo de Seyfert 1 obscurecido por um provável toro de poeira. A grande novidade revelada por esse estudo é que, ao contrário do que se supunha, a absorção por poeira não elimina completamente a componente larga da linha de $H \alpha$, mas sim a torna muito fraca quando comparada às demais linhas, sendo que foi necessária uma cuidadosa subtração do contínuo estelar para revelá-la claramente.

Observando-se as figuras 8.28, 8.29, 8.30, 8.31, 8.32 e 8.33, pode-se notar que os autovetores E2, E3 e E4 são completamente análogos aos obtidos com a aplicação da Tomografia PCA ao cubo de dados de NGC 1068 com o contínuo estelar (seção 8.3), revelando, portanto, o seguinte cenário relativo à cinemática do gás: a região no extremo nordeste do campo visual do IFU apresenta gás com elevados valores de velocidade radial, tanto no sentido do observador (até cerca de $-480 \mathrm{~km} / \mathrm{s}$ ) quanto no sentido oposto (até cerca de $720 \mathrm{~km} / \mathrm{s}$ ). A área no extremo sudoeste do campo de visão do IFU, por outro lado, possui gás com elevadas velocidades radiais (cerca de $720 \mathrm{~km} / \mathrm{s}$ ) no sentido oposto ao do observador, sendo que não foi possível confirmar se há alguma outra componente de velocidade radial, em blueshift ou em um redshift mais modesto, nessa região. Por fim, uma área mais próxima ao centro do campo visual do IFU, porém um pouco a sudoeste do AGN (parte mais clara do tomograma da figura 8.28), apresenta gás com valores moderados de velocidade radial (até cerca de $360 \mathrm{~km} / \mathrm{s}$ ) no sentido oposto ao do observador. Por se distribuírem ao longo de uma região aproximadamente coespacial com o jato em rádio dessa galáxia (Wilson \& Ulvestad 1983), é possível que todos os fenômenos cinemáticos observados estejam associados a esse jato. A cinemática do gás do cubo de dados de NGC 1068 é analisada em maiores detalhes na seção 8.7.

O Scree test na figura 8.34 revela que os valores das variâncias explicadas pelos autovetores decaem bastante até, aproximadamente, o autovetor E5. A partir daí, a taxa de decaimento diminui bastante, ficando praticamente constante a partir do autovetor E10. Isso indica que autovetores de ordem maior ou igual a 10 representam, sobretudo, ruído e, consequentemente, não são de grande importância nesse estudo. Entretanto, a análise mostrou que autovetores com ordem maior ou igual a 5 apresentavam uma interpretação menos clara, logo apenas autovetores com ordem menor do que essa foram mostrados. É provável que a diminuição da taxa de decaimento dos autovalores a partir do autovetor E5 represente um 
indicativo da diminuição da significância e um aumento do ruído dos autovetores com ordem maior ou igual a essa.

Assim, pode-se concluir que essa segunda análise com a Tomografia PCA revelou resultados bastante compatíveis com os obtidos com a primeira aplicação da Tomografia PCA (seção 8.3). Primeiramente, foram observados vários fenômenos cinemáticos do gás, que parecem estar associados ao jato em rádio existente em NGC 1068. No que se refere à emissão do AGN central, foi observada uma fraca componente larga da linha de Ha, que não havia sido detectada na primeira análise com a Tomografia PCA. Isso sugere que, ao contrário do que se imaginava, o obscurecimento pelo toro de poeira não elimina completamente essa estrutura (que

somente pôde ser observada com o uso de polarimetria, conforme foi mostrado por Antonucci \& Miller 1985), mas sim a atenua significativamente, de modo que apenas com uma cuidadosa subtração do contínuo estelar é possível detectá-la.

\section{6 - Cinemática estelar do cubo de dados de NGC 1068}

Aplicou-se o processo do pPXF no cubo de dados de NGC 1068, a fim de se obter os valores da velocidade radial estelar, da dispersão de velocidades estelar e dos coeficientes de Gauss-Hermite $h_{3}$ e $h_{4}$ ao longo de todo o campo visual do IFU do GMOS. Os mapeamentos obtidos são mostrados na figura 8.36 . 

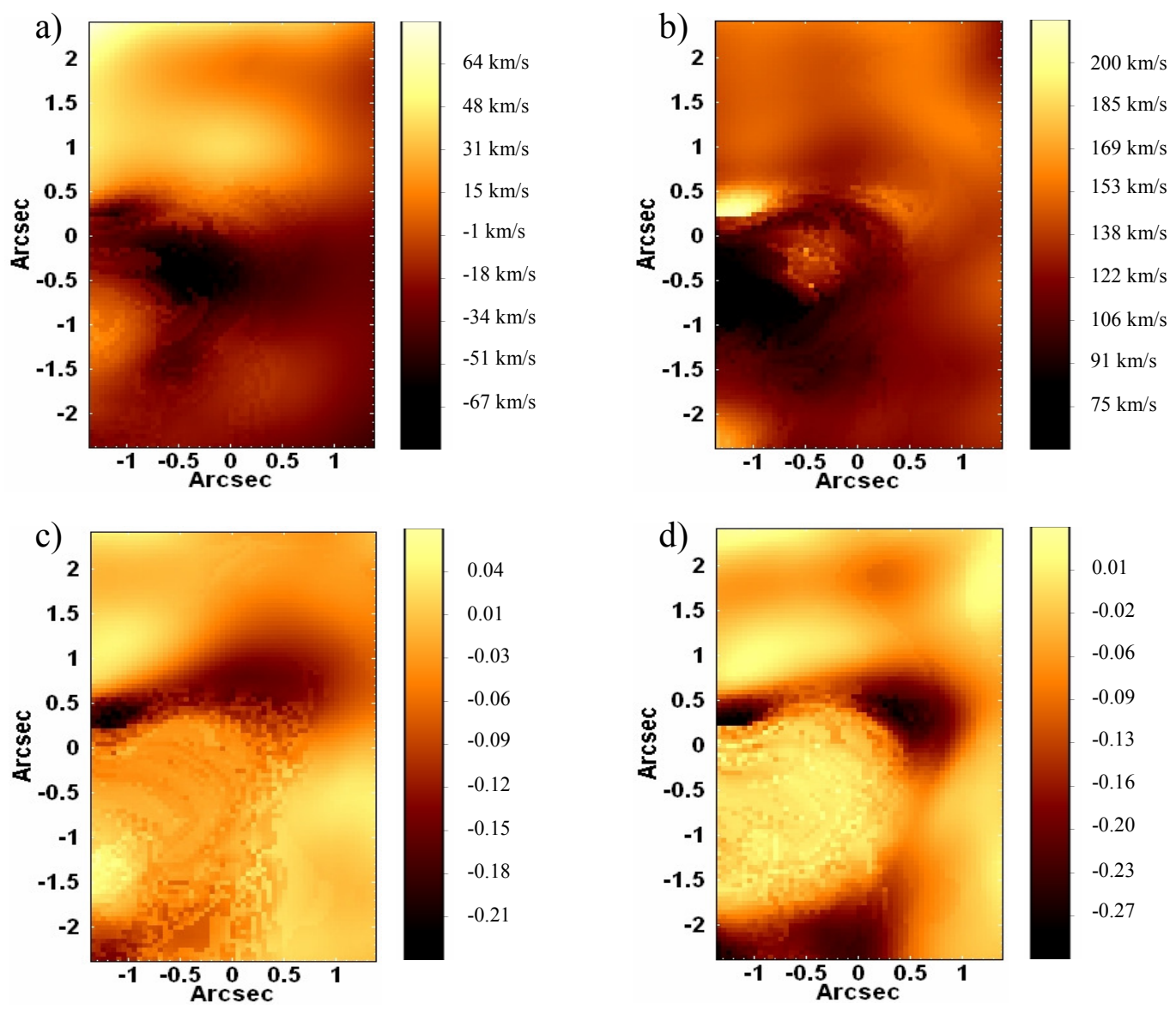

Figura 8.36 - Mapeamentos dos valores (a) da velocidade radial estelar, (b) da dispersão de velocidades estelar, (c) do coeficiente $h_{3} e(d)$ do coeficiente $h_{4}$, obtidos com a aplicação do pPXF ao cubo de dados de NGC 1068.

Observando-se a figura 8.36 - $a$, pode-se notar que, à primeira vista, a morfologia apresentada pelo mapeamento dos valores da velocidade radial estelar não parece indicar uma clara rotação ao redor do núcleo. Entretanto, uma análise mais detalhada permite identificar um tênue padrão rotacional, cujo eixo coincide, aproximadamente, com a direção (sudoestenordeste) do jato em rádio dessa galáxia. Comparando-se os mapas de velocidade radial estelar nas figuras 8.19 e 8.36 - $a$, verifica-se que o primeiro possui uma maior quantidade de irregularidades e estruturas com alta freqüência do que o segundo, que apresenta um aspecto mais "suavizado". É provável que essa maior "suavização" do mapa de velocidades da figura 8.36 - $a$ seja uma conseqüência do processo de penalização utilizado no pPXF. Pode-se notar, também, que a amplitude dos valores negativos no mapeamento de velocidades da figura 8.19 é consideravelmente maior do que no mapa da figura 8.36 - a. Entretanto, conforme já foi mencionado anteriormente, essas velocidades negativas com módulos mais elevados no 
mapeamento da figura 8.19 ocorrem, apenas, em uma pequena região próxima ao AGN central, o que indica que elas podem ser uma conseqüência de problemas de ajustes gerados pelo maior número de linhas de emissão nessa área. Outro ponto a ser mencionado é que os valores da velocidade radial estelar na posição correspondente ao AGN são, em sua maioria, positivos na figura 8.19, mas negativos na figura $8.36-a$, o que, provavelmente, também deve ser devido aos problemas de ajuste gerados pelas linhas de emissão nessa região. Apesar das diferenças mencionadas, esses dois mapeamentos de velocidade apresentam uma morfologia geral bastante similar, sendo que os módulos de velocidades na maior parte das áreas são compatíveis, não apresentando discrepâncias maiores do que cerca de $10 \mathrm{~km} / \mathrm{s}$. Os mapas das figuras $8.36-a$ e 8.19 também estão de acordo com os resultados obtidos por Emsellem et al. (2006) em sua análise de espectroscopia bidimensional, obtida com o SAURON. Conforme foi dito na seção 8.4.2, a rotação estelar detectada por esses autores apresentava várias assimetrias na região próxima ao AGN e somente se tornava mais clara a distâncias maiores (de cerca de 10") do núcleo. Assim, as irregularidades aqui detectadas nos valores da velocidade radial estelar na região central de NGC 1068 eram previsíveis, de acordo com o trabalho de Emsellem et al. (2006).

O mapeamento da dispersão de velocidades estelar na figura $8.36-b$ mostra várias assimetrias, entretanto, pode-se notar um certo aumento dos valores na posição correspondente ao AGN, o que pode ser considerado como estando de acordo com o esperado. Comparando-se os mapas de dispersão das figuras 8.19 e 8.36 - $b$, nota-se que eles possuem uma morfologia geral aproximadamente compatível. Mais uma vez, o mapeamento da figura 8.19 apresenta uma maior quantidade de irregularidades e estruturas com alta freqüência espacial, o que pode ser uma conseqüência de imprecisões nos ajustes do Starlight geradas pelas linhas de emissão existentes. A maior "suavização" do mapa da figura 8.36 - $b$ deve ser devida à penalização usada no pPXF. Uma comparação entre os mapeamentos da dispersão de velocidades estelar na região central de NGC 1068 aqui obtidos e os encontrados por Emsellem et al. (2006) é muito difícil, considerando-se a menor resolução espacial apresentada por esses últimos. Mesmos assim, parece haver uma considerável semelhança no que se refere aos módulos dos valores observados.

Analisando-se os mapeamentos dos coeficientes de Gauss-Hermite $h_{3}$ e $h_{4}$, mostrados nas figuras $8.36-c$ e $8.36-d$, respectivamente, pode-se notar, primeiramente, que a amplitude 
dos valores negativos parece ser consideravelmente maior do que a dos valores positivos. Uma comparação entre esses dois mapas, entretanto, revela que esses coeficientes negativos com módulos mais elevados ocorrem, apenas, em regiões relativamente pequenas (aproximadamente as mesmas regiões nos dois mapeamentos). A razão disso não é clara, mas não se pode descartar a hipótese de que essa assimetria de valores observada nesses mapas não seja real, mas sim uma conseqüência de imprecisões nos ajustes, eventualmente causadas pelas linhas de emissão existentes. A morfologia geral dos mapeamentos dos coeficientes de Gauss-Hermite $h_{3}$ e $h_{4}$ é de considerável complexidade e, consequentemente, de difícil interpretação.

Como o padrão rotacional estelar detectado no mapa da figura $8.36-a$ é bastante tênue e tanto esse mapeamento quanto o dos valores da dispersão de velocidades estelar (figura 8.36 b) apresentam várias irregularidades, assimetrias e possíveis zonas com valores não confiáveis (como a posição correspondente ao AGN), optou-se por não aplicar nenhum tipo modelagem com o intuito de se determinar a massa do buraco negro central existente nesse objeto.

\section{7 - Cinemática do gás do cubo de dados de NGC 1068}

A fim de se fazer uma análise mais detalhada da cinemática do gás na região central de NGC 1068, construiu-se o mapa de velocidades da linha de emissão [O III] $\lambda 5007$ do cubo de dados, após a subtração do contínuo estelar. Essa linha foi utilizada por ser uma das mais intensas do espectro e não estar tão blendada com outras linhas, como H $\alpha$ e [N II] $\lambda \lambda 6548 ; 6583$, por exemplo. O mapeamento feito a partir de [O III] $\lambda 5007$ é mostrado na figura 8.37.

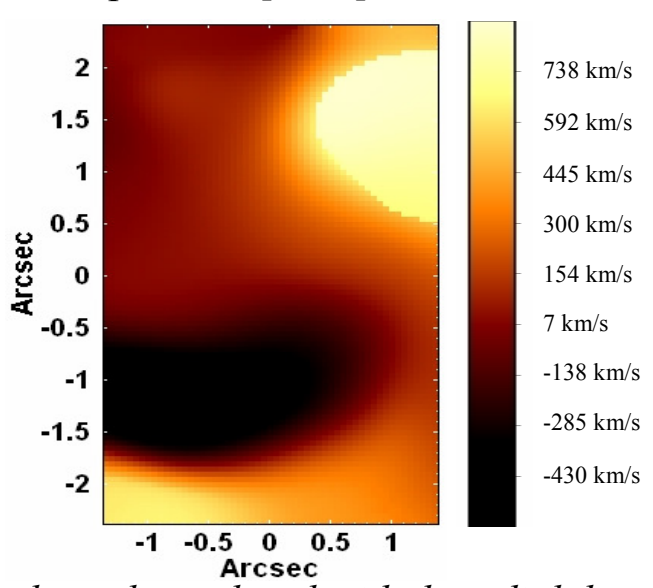

Figura 8.37 - Mapeamento dos valores de velocidade radial do gás, obtido com a linha de [O III] 25007 do cubo de dados de NGC 1068. 
O mapeamento da figura 8.37 revela, primeiramente, uma morfologia que parece ser compatível com os resultados referentes à cinemática do gás obtidos com as aplicações da Tomografia PCA ao cubo de dados de NGC 1068, antes e depois da subtração do contínuo estelar (seções 8.3 e 8.5, respectivamente). Pode-se notar também que a amplitude dos valores negativos de velocidade é consideravelmente menor do que a dos valores positivos. Entretanto, uma análise do cubo de dados de NGC 1068, após a subtração do contínuo estelar, mostrou que as linhas de emissão apresentam picos duplos nas áreas com maiores amplitudes de velocidades (tanto negativas quanto positivas) do mapa da figura 8.37. As figuras 8.38 e 8.39 mostram espectros extraídos de regiões circulares nos extremos nordeste e sudoeste (correspondentes às áreas com maiores amplitudes de velocidades na figura 8.37) do cubo de dados de NGC 1068, após a subtração do contínuo estelar.
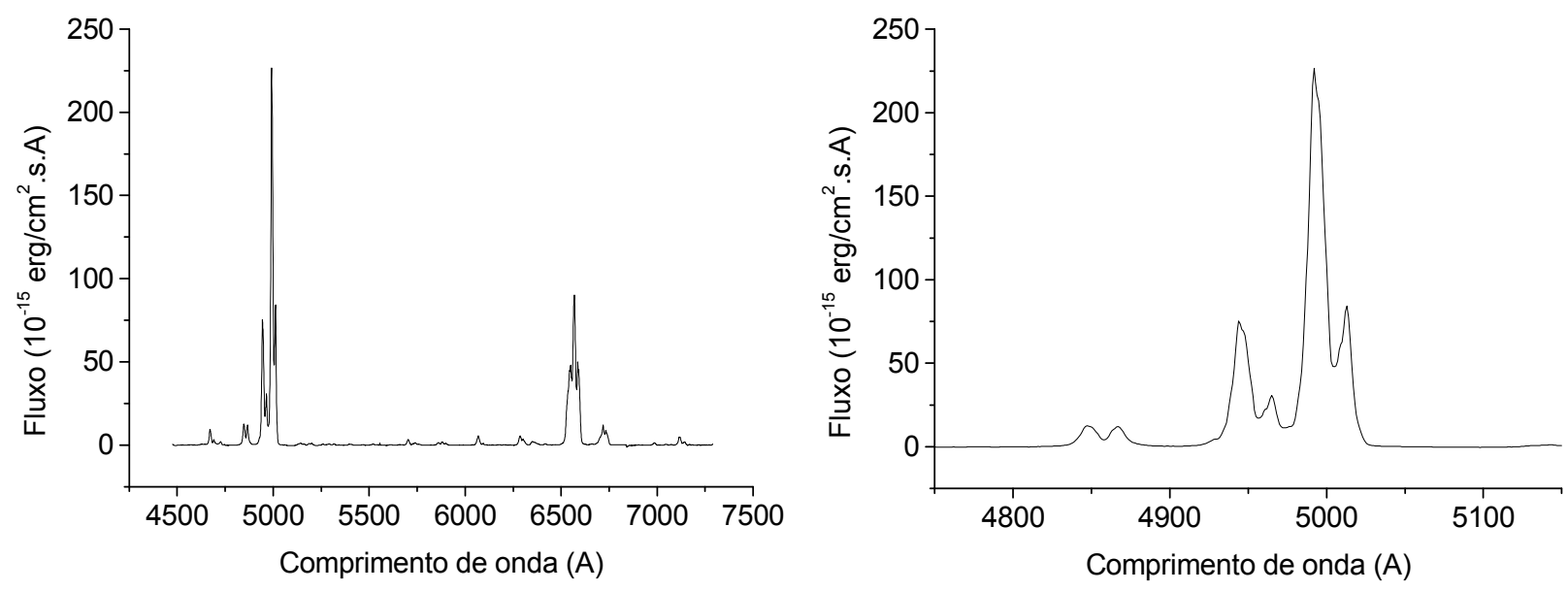

Figura 8.38 - (esquerda) Espectro extraído de uma região circular no extremo nordeste do cubo de dados de NGC 1068, após a subtração do contínuo estelar; (direita) ampliação do espectro mostrado à esquerda. 

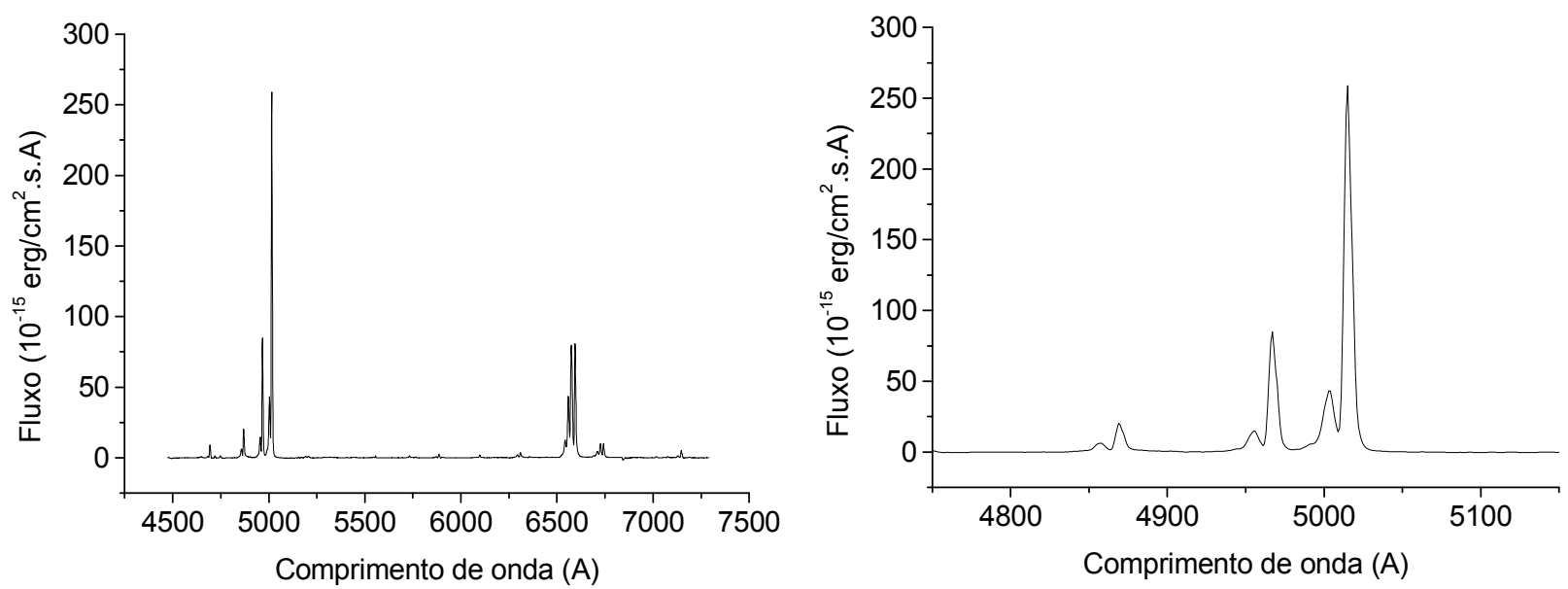

Figura 8.39 - (esquerda) Espectro extraído de uma região circular no extremo sudoeste do cubo de dados de NGC 1068, após a subtração do contínuo estelar; (direita) ampliação do espectro mostrado à esquerda.

A figura 8.40, por sua vez, mostra o espectro extraído de uma região circular do cubo de dados de NGC 1068, após a subtração do contínuo estelar, centrada em uma área mais próxima ao AGN (correspondente à parte clara dos tomogramas nas figuras 8.11 e 8.28).
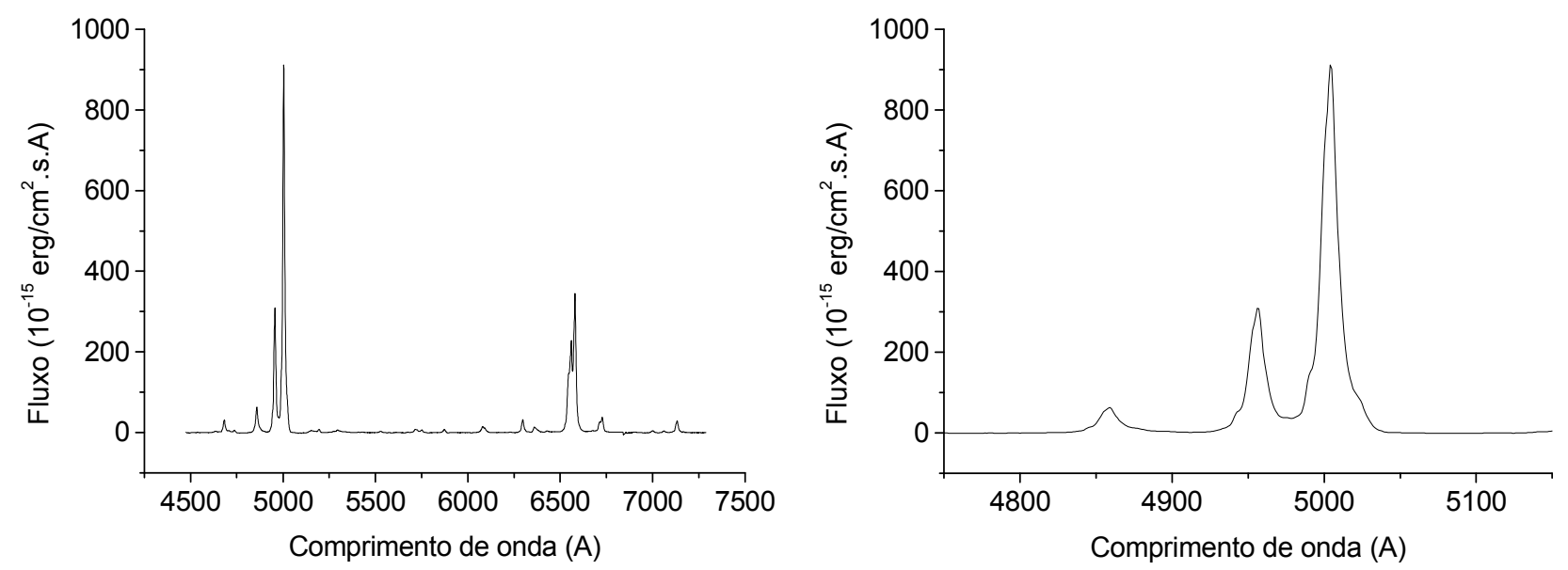

Figura 8.40 - (esquerda) Espectro extraído de uma região circular mais próxima ao AGN (correspondente à área clara dos tomogramas das figuras 8.11 e 8.28) do cubo de dados de NGC 1068, após a subtração do contínuo estelar; (direita) ampliação do espectro mostrado à esquerda.

Observando-se as figuras 8.38 e 8.39, pode-se notar claramente os picos duplos de várias linhas de emissão, incluindo [O III] 25007 , dos espectros nos extremos nordeste e sudoeste do cubo de dados de NGC 1068. Sem dúvida, esse comportamento gerou problemas no ajuste de funções gaussianas para a determinação da velocidade radial do gás. Assim, nesses extremos 
nordeste e sudoeste do campo de visão do IFU do GMOS, os valores de velocidade mostrados no mapeamento da figura 8.37 devem ser consideravelmente imprecisos. A fim de se analisar melhor a cinemática nessas áreas, construíram-se dois novos mapas da velocidade radial do gás a partir da linha de [O III] $\lambda 5007$ : no primeiro, o ajuste das gaussianas foi feito no intervalo entre $4978 \AA$ e $5010 \AA$, ao passo que, no segundo, esse ajuste foi feito no intervalo entre $5009 \AA$ e $5027 \AA$. Em outras palavras, pode-se dizer que o primeiro desses mapeamentos envolveu menores velocidades do gás (incluindo velocidades negativas) e o segundo maiores velocidades. Os dois mapas obtidos são mostrados na figura 8.41 .
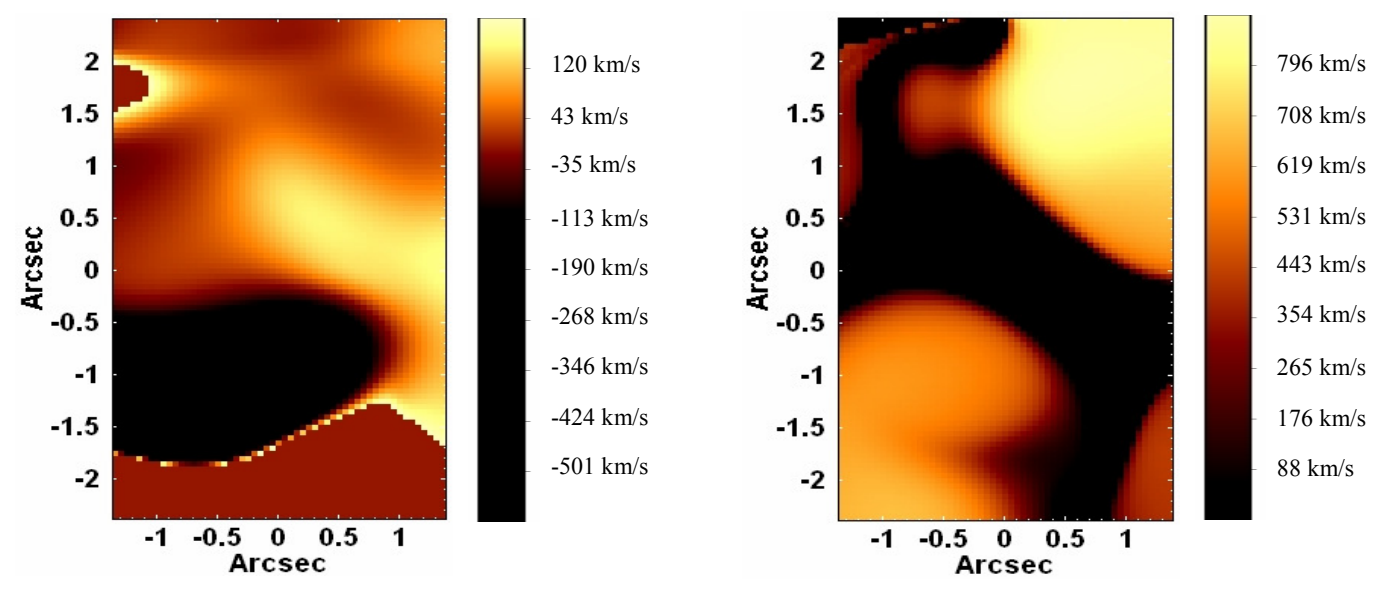

Figura 8.41: Mapeamentos dos valores da velocidade radial estelar obtidos a partir dos intervalos (esquerda) $4978 \AA-5010 \AA$ e (direita) $5009 \AA-5027 \AA$ do cubo de dados de NGC 1068, após a subtração do contínuo estelar.

Analisando-se os mapeamentos da figura 8.41, nota-se que, no extremo nordeste do cubo de dados de NGC 1068, são observados altos valores da velocidade radial do gás, tanto no sentido do observador (até cerca de $-578 \mathrm{~km} / \mathrm{s}$ ) quanto no sentido oposto (até cerca de 620 $\mathrm{km} / \mathrm{s}$ ). No extremo sudoeste do cubo de dados, por sua vez, são detectadas velocidades ainda mais altas no sentido oposto ao do observador (até cerca de $884 \mathrm{~km} / \mathrm{s}$ ), juntamente com velocidades mais baixas (cerca de $40 \mathrm{~km} / \mathrm{s}$ ) nesse mesmo sentido. Na região mais próxima ao AGN, correspondente à área clara nos tomogramas das figuras 8.11 e 8.28, são observados, apenas, valores moderados de velocidade (até cerca de $197 \mathrm{~km} / \mathrm{s}$ ) no sentido oposto ao do observador. Esses resultados são compatíveis com o que se obteve com as aplicações da Tomografia PCA aos cubos de dados de NGC 1068 (seções 8.3 e 8.5). Vale lembrar, também, que todos esses fenômenos cinemáticos são aproximadamente co-espaciais com o jato em rádio 
existente nessa galáxia. Um possível modelo capaz de explicar todo esse cenário envolve a ocorrência de um outflow bi-cônico a partir do AGN: o eixo desse outflow apontaria no sentido do observador no extremo nordeste do cubo de dados de NGC 1068 e no sentido oposto no extremo sudoeste. Isso faria com que, no extremo nordeste, o pico mais intenso das linhas (que possuem pico duplo) fosse aquele em blueshift. Correspondentemente, no extremo sudoeste, o pico mais intenso seria aquele em redshift. De fato, todas essas características são observadas nos espectros das figuras 8.38 e 8.39. A geometria do outflow bi-cônico, com componentes de velocidade tanto no sentido quanto no sentido oposto ao do observador, juntamente com possíveis movimentos de expansão gerados pela sua interação com o meio interestelar presente, dariam origem aos picos duplos observados nas linhas de emissão nos extremos nordeste e sudoeste do cubo de dados. A figura 8.42 mostra um esquema desse outflow bi-cônico, obtido a partir do trabalho de Das et al. (2006).

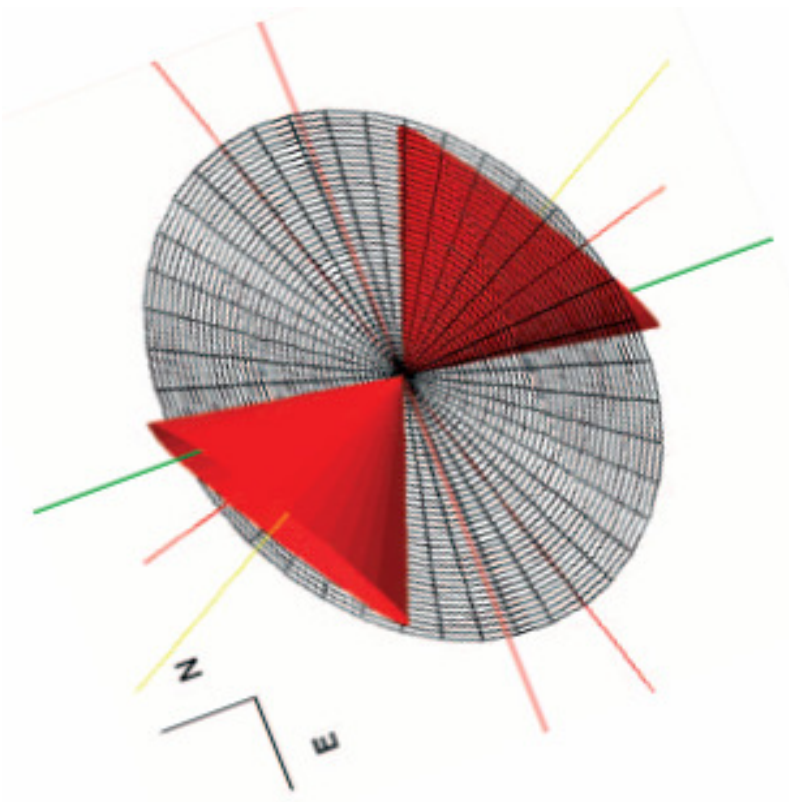

Figura 8.42 - Esquema do "outflow" bi-cônico a partir do AGN de NGC 1068, obtido a partir do trabalho de Das et al. (2006).

Os mecanismos físicos envolvendo o outflow bi-cônico geram um aumento das velocidades do gás a distâncias maiores do AGN. Isso, juntamente com a morfologia associada, faz com que os picos duplos das linhas de emissão somente sejam detectados nos extremos nordeste e sudoeste do cubo de dados de NGC 1068, mas não em áreas mais próximas ao AGN, conforme pode ser notado nos espectros das figuras 8.38, 8.39 e 8.40. Das et al. (2006) 
modelaram a cinemática da NLR de NGC 1068, utilizando um outflow bi-cônico, conforme mostrado na figura 8.42. Os autores concluíram que esse modelo consegue explicar razoavelmente bem os dados observados.

Por fim, um último detalhe a ser mencionado é que a amplitude das velocidades negativas observada nos mapeamentos da figura 8.41 é consideravelmente menor do que a das velocidades positivas. Além disso, no extremo nordeste do cubo de dados é detectada emissão tanto em blueshift quanto em redshift, ao passo que, no extremo sudoeste, apenas componentes em redshift são observadas (uma indicando velocidades muito mais elevadas do que a outra). As causas dessas irregularidades e assimetrias não estão claras, entretanto, não se pode descartar a possibilidade de que parte delas seja devida tanto a possíveis falhas da calibração em comprimento de onda quanto a uma eventual correção imprecisa do redshift da galáxia (lembrando que o valor de z utilizado na correção, antes da aplicação do Starlight, foi obtido a partir do site do NED). Esses dois fatores poderiam, eventualmente, gerar valores de velocidades imprecisas nos mapeamentos mostrados anteriormente. Dependendo da causa exata do problema, seria possível que as velocidades calculadas estivessem corretas a menos de uma constante aditiva.

\section{8 - Conclusões}

Em suma, pode-se dizer, primeiramente, que as aplicações da Tomografia PCA ao cubo de dados de NGC 1068 permitiram uma visualização bastante clara da grande quantidade de linhas de emissão provenientes do AGN central. Após a subtração do contínuo estelar, foi possível visualizar, inclusive, uma fraca componente larga da linha de $\mathrm{H} \alpha$, o que é bastante relevante, pois linhas largas jamais haviam sido detectadas nesse objeto sem o uso de polarimetria. Essa detecção está de acordo com o cenário proposto por Antonucci \& Miller (1985), que diz que essa galáxia possui um núcleo de Seyfert 1 obscurecido por um toro de poeira. Entretanto, o resultado aqui obtido também revela que, ao contrário do que se imaginava, a extinção por poeira não elimina completamente a componente larga da linha de $\mathrm{H} \alpha$, mas sim a torna muito fraca, quando comparada às demais linhas, sendo necessária uma cuidadosa subtração do contínuo estelar para revelá-la. As aplicações da Tomografia PCA também 
mostraram a existência de uma complexa cinemática do gás na região central de NGC 1068. Uma análise mais detalhada, a partir de mapas de velocidade da linha de [O III] $\lambda 5007$, revelou que os fenômenos cinemáticos detectados são compatíveis com a presença de um outflow bicônico aproximadamente co-espacial com o jato em rádio dessa galáxia. A geometria desse outflow, juntamente com possíveis movimentos de expansão do gás gerados pela sua interação com o meio interestelar, dá origem a linhas de pico duplo, que podem ser claramente observadas nos extremos nordeste e sudoeste do cubo de dados de NGC 1068. Esse modelo também foi proposto por Das et al. (2006). O ajuste com o pPXF, juntamente com a síntese espectral do software Starlight, revelaram um tênue padrão rotacional estelar ao redor do núcleo, que é difícil de ser visualizado devido à grande quantidade de assimetrias e irregularidades existentes. De qualquer forma, o resultado obtido parece ser compatível com o encontrado por Emsellem et al. (2006). A síntese espectral com o Starlight mostrou que a maior parte do fluxo no cubo de dados de NGC 1068 é devida a populações estelares com idade de cerca de $1.4 \cdot 10^{9}$ anos e média metalicidade, o que pode indicar, inclusive, a ocorrência de um surto de formação estelar (starburst) nesse período. Foi também detectada uma contribuição significativa de um provável featureless continuum do AGN para o fluxo total no cubo de dados de NGC 1068. Um mapeamento construído mostrou possíveis indícios de um espalhamento desse featureless continuum por poeira, possivelmente associada a um toro. Isso parece estar de acordo com os resultados obtidos por Jaffe et al. (2004), que, utilizando dados interferométricos no infravermelho, conseguiram, pela primeira vez, fazer uma detecção direta de um toro de poeira nessa galáxia. 


\section{9 - NGC 4486 (M87)}

\section{1 - Introdução}

M87 é uma galáxia de tipo morfológico $\mathrm{cD}$ localizada no centro do aglomerado de Virgo, a uma distância de 16 Mpc. Trata-se de uma das rádio-galáxias mais próximas. Desde 1918, quando Heber Curtis observou um curioso raio luminoso a partir do seu núcleo, soube-se que ela possuía um jato óptico brilhante. Seu núcleo é uma fonte de rádio e raios-x bastante estudada. Com base nas razões de linhas de emissão observadas, esse objeto também é classificado como LINER.

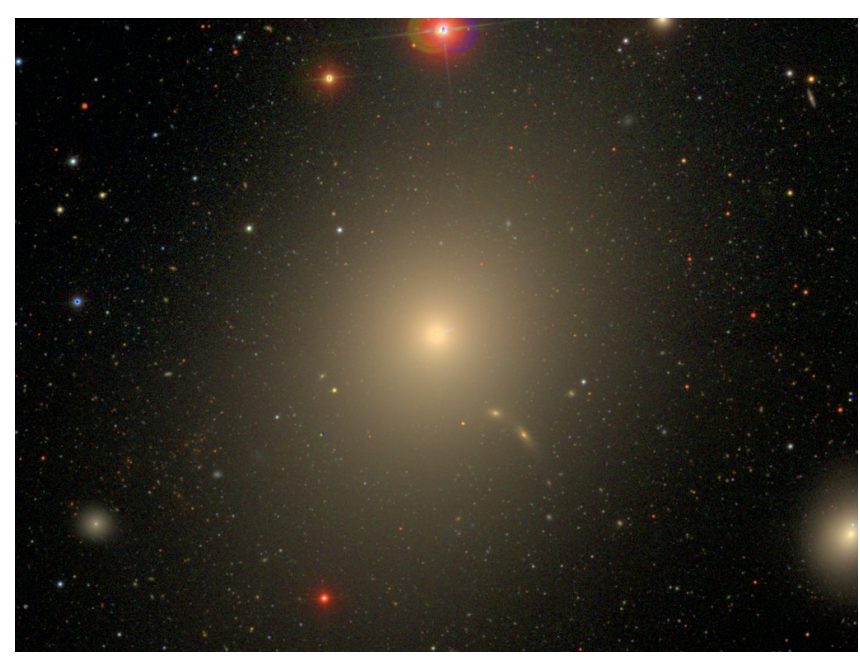

Figura 9.1 - Imagem da galáxia M87, obtida com o SDSS.

Dois estudos publicados em 1978 encontraram evidências da existência de um objeto extremamente massivo no centro de M87. Young et al. (1978) analisaram dados fotométricos dessa galáxia e concluíram que o perfil de brilho não podia ser ajustado por modelos de King ou isotérmicos. Entretanto, um modelo de King com um objeto central com massa de $M \sim 5 \cdot 10^{9} \mathrm{M}_{\odot}$ era capaz de reproduzir o perfil observado. Sargent et al. (1978), por sua vez, analisaram dados espectroscópicos de M87 e também concluíram que um modelo com um objeto central com massa $M \sim 5.10^{9} \mathrm{M}_{\odot}$ conseguia reproduzir os dados observados. Assim, pode-se dizer que ambos os estudos indicaram a presença de um buraco negro supermassivo no núcleo de M87. 
Estudos posteriores, entretanto, contestaram a existência de um buraco negro supermassivo no núcleo dessa galáxia. Dressler (1980) analisou um espectro obtido do spike de luminosidade central de M87 e obteve dados inconsistentes com a presença de tal objeto massivo. Richstone \& Tremaine (1985) utilizaram o método de Schwarzschild para construir modelos esfericamente simétricos para essa galáxia e nenhum desses modelos precisou de um buraco negro supermassivo central para reproduzir os dados observados.

Apesar dessa controvérsia, os trabalhos mais recentes, envolvendo dados obtidos com instrumentos de maior resolução espacial e espectral, têm sustentado a hipótese da presença de um objeto massivo no núcleo de M87. Harms et al. (1994) analisaram espectros da região central dessa galáxia, obtidos com o HST, e detectaram a presença de um disco de gás ionizado com rotação ao redor do núcleo. Os modelos feitos pelos autores indicaram a presença de um buraco negro supermassivo com massa $M=(2.4 \pm 0.7) \cdot 10^{9} \mathrm{M}_{\odot}$. Lauer et al. (1992) analisaram imagens nas bandas V e I, obtidas pelo HST, e constataram que os dados observados estavam de acordo com o modelo do buraco negro supermassivo central com massa $M=2.6 \cdot 10^{9} \mathrm{M}_{\odot}$.

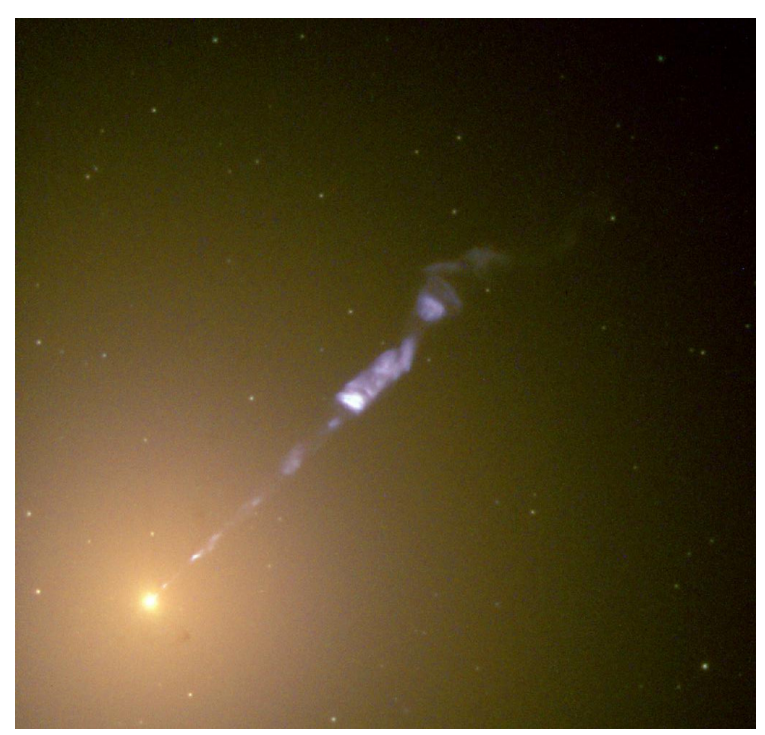

Figura 9.2 - Imagem na banda V da galáxia M87, obtida com o HST.

Observando-se a figura 9.2, pode-se notar a presença do jato óptico a partir do núcleo de M87. Tal jato apresenta uma estrutura em nós e já foi estudado em vários trabalhos (Perlman et al. 2001a; Perlman et al. 2001b; Perlman et al. 2007). A figura 9.3, obtida a partir do trabalho de Perlman et al. (2001b), mostra uma imagem do jato de M87 em $10.8 \mu \mathrm{m}$ e revela a estrutura em nós presente. 


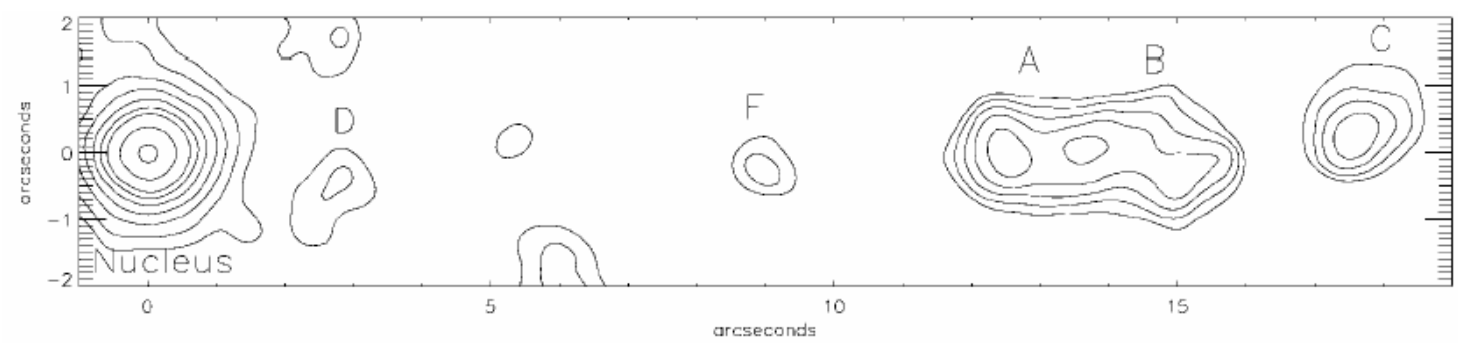

Figura 9.3 - Imagem do jato de M87 em 10.8 um, obtida a partir do trabalho de Perlman et al. (2001b).

Di Matteo et al. (2003) analisaram observações em raios-X de M87 e chegaram à conclusão de que esse objeto é sub-luminoso em relação ao que se esperaria considerando-se uma taxa de acreção de Bondi. A potência total esperada é cerca de 4 vezes maior do que o observado. Se o buraco negro supermassivo existente estiver, de fato, acretando material a uma taxa de Bondi, então, a eficiência da conversão de energia gravitacional em energia térmica deve ser bastante baixa, o que seria compatível, por exemplo, com um modelo de ADAF.

Batcheldor et al. (2010) analisaram imagens dessa galáxia obtidas com o HST e observaram um deslocamento entre o centro fotométrico da galáxia e a posição do buraco negro supermassivo central, sendo a distância projetada de $6.8 \pm 0.8 \mathrm{pc}$. Os autores propuseram quatro explicações possíveis para esse fenômeno: aceleração do buraco negro induzida pelo jato, presença de um buraco negro supermassivo binário, presença de outros perturbadores massivos e a ocorrência do fenômeno do gravitational wave kick. De acordo com os autores, a aceleração por um jato e a ocorrência do gravitational wave kick seriam as explicações mais compatíveis com o observado.

\section{2 - Preparação do cubo de dados de M87}

Foram analisados cubos de dados da região central de M87 obtidos, na banda $\mathrm{K}$ do infravermelho próximo, com o NIFS do telescópio Gemini-Norte. Esses dados são os mesmos analisados por Gebhardt et al. (2011), entretanto, aqui foram utilizadas diferentes metodologias de análise. A redução dos cubos de dados foi feita em ambiente IRAF, utilizando-se o pacote de tarefas Gemini, conforme explicado em 3.2.2. Ao final desse processo, foram obtidos 9 cubos de dados com pixeis espaciais de $0.05 "$ de lado. 
Foi aplicada, então, a correção da refração atmosférica diferencial em cada um dos cubos de dados encontrados. Após isso, a fim de se combinar todos esses cubos em um só, primeiramente, eles foram separados em três grupos. Nomeando-se os cubos como 1, 2, 3, 4,.., 9 (de acordo com a ordem de observação), a separação nos três grupos foi feita da seguinte maneira:

- Grupo 1: cubos 1, 4 e 6

- Grupo 2: cubos 2, 5 e 7

- Grupo 3: cubos 3, 8 e 9

Os integrantes de cada um desses três grupos foram combinados na forma de mediana, resultando, no final do processo, em três cubos. Calculou-se, então, uma nova mediana para esses três últimos cubos, obtendo-se, assim, o cubo combinado procurado.

Em seguida, aplicou-se o processo de reamostragem espacial no cubo de dados encontrado, a fim de se obter pixeis espaciais de 0.021 " de lado. A figura 9.4 mostra as somas de todas as imagens do cubo de dados de M87, antes e depois do processo de reamostragem.
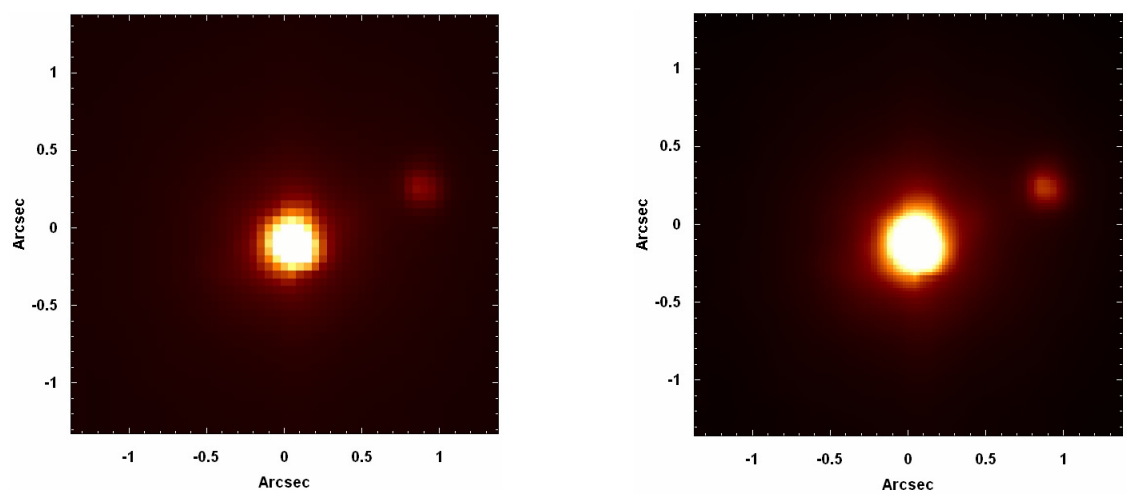

Figura 9.4 - (esquerda) Soma de todas as imagens do cubo de dados de M87, antes da aplicação da reamostragem espacial; (direita) Soma de todas as imagens do cubo de dados de M87, após a aplicação da reamostragem espacial.

Observando-se a figura 9.4, nota-se que a aplicação da reamostragem espacial permitiu que as estruturas espaciais presentes no cubo de dados fossem definidas mais claramente. Esse procedimento, entretanto, também introduziu componentes de alta freqüência espacial, que aparecem tenuamente na forma de estreitas faixas escuras na imagem. 
Após isso, aplicou-se uma decomposição wavelet no cubo de dados reamostrado, obtendo-se, ao final, os cubos $W_{0}, W_{1}, W_{2}, W_{3}, W_{4}$ e $W_{C}$. Utilizou-se, então, $W_{0}$ para se determinar os parâmetros mais adequados para o filtro de Butterworth e, a seguir, esses parâmetros foram utilizados na filtragem espacial de todas as outras componentes wavelet e também do cubo de dados original. No caso desse objeto, todas as filtragens foram feitas utilizando-se um filtro com forma dada pela expressão (3.68), $n=2$ e freqüência de corte ao longo dos eixos horizontal e vertical de $v_{c}=0.27 \mathrm{Ny}$. A figura 9.5 mostra as somas das imagens do cubo de dados, antes e depois da filtragem espacial de Butterworth, assim como a soma das imagens do cubo correspondente à diferença entre esses dois.
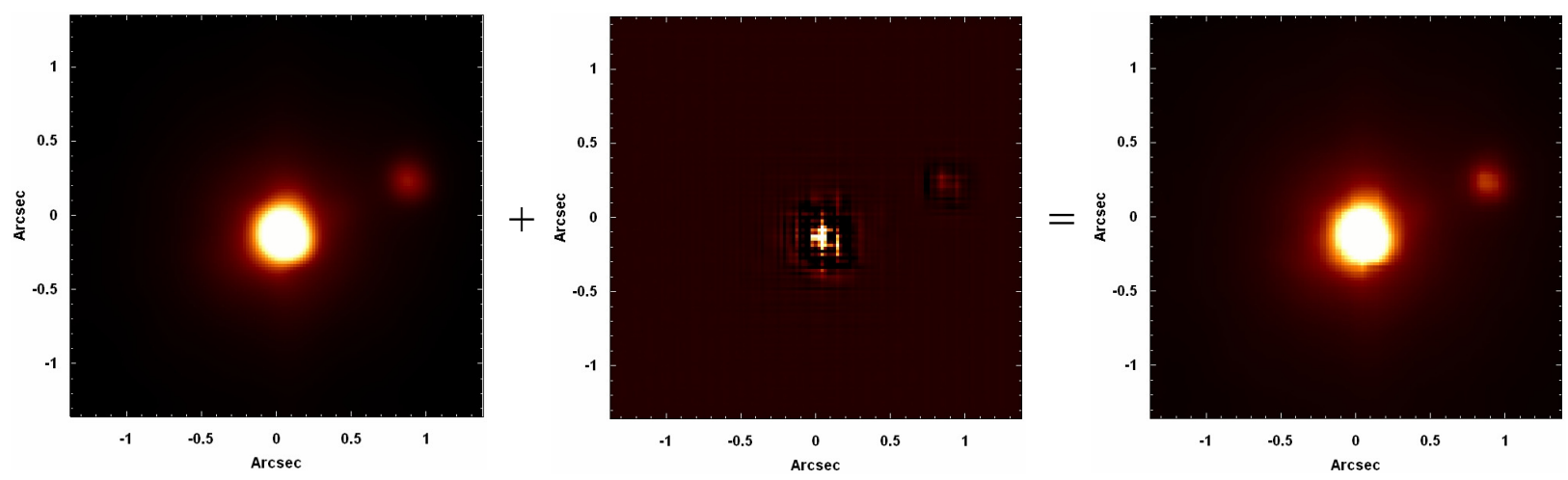

Figura 9.5 - (esquerda) Soma das imagens do cubo de dados de M87, após a filtragem espacial de Butterworth; (centro) Soma das imagens do cubo de dados de M87 correspondente à diferença entre o cubo não filtrado e o cubo filtrado; (direita) Soma das imagens do cubo de dados de M87, antes da filtragem espacial de Butterworth.

A figura 9.5 revela que a aplicação da filtragem espacial de Butterworth proporcionou uma considerável melhoria na aparência das imagens do cubo de dados de M87, já que a maior parte dos ruídos de alta freqüência (introduzidos, inclusive, pelo processo de reamostragem espacial) foi removida. No entanto, pode-se notar que a filtragem espacial de Butterworth também provocou uma leve degradação da PSF, o que poderia indicar que uma maior freqüência de corte seria mais apropriada. Para esse objeto, entretanto, verificou-se que maiores freqüências de corte não eliminavam de maneira totalmente eficaz os ruídos espaciais presentes. Considerando isso e o fato de a degradação da PSF ter sido bastante leve (indicando que poderia ser revertida com a aplicação da deconvolução de Richardson-Lucy), optou-se por manter os valores utilizados para a frequência de corte na filtragem espacial de Butterworth. 
Uma das primeiras características notadas no cubo de dados de M87 foi a quase total ausência de estruturas espectrais. Quase não eram vistas linhas de emissão e as bandas de CO, que são as principais estruturas provenientes de absorção estelar visíveis nessa região espectral, também eram tênues. Dessa forma, apesar do ruído espectral não ser tão grande, a ausência de linhas espectrais fortes fez com que a razão $S / N$ dos espectros ficasse bastante baixa, o que poderia dificultar a utilização da Tomografia PCA a esse cubo de dados. Assim, para diminuir o ruído espectral e aumentar a razão $S / N$, facilitando a análise (sobretudo com a Tomografia PCA), optou-se por aplicar o processo do de-noising a esse cubo de dados. Conforme foi mencionado anteriormente, a utilização desse procedimento apresenta certos riscos, pois pode causar alterações indesejáveis nos espectros do cubo de dados, como, por exemplo, alargamento de linhas de emissão. No caso desse objeto, entretanto, notou-se que os efeitos negativos desse processo eram mínimos e, sem ele, a baixa razão $S / N$ dificultaria muito a utilização da Tomografia PCA, assim, o procedimento foi aplicado. A figura 9.6 mostra o espectro extraído de uma região circular central do cubo de dados de M87, antes e depois da aplicação do denoising.
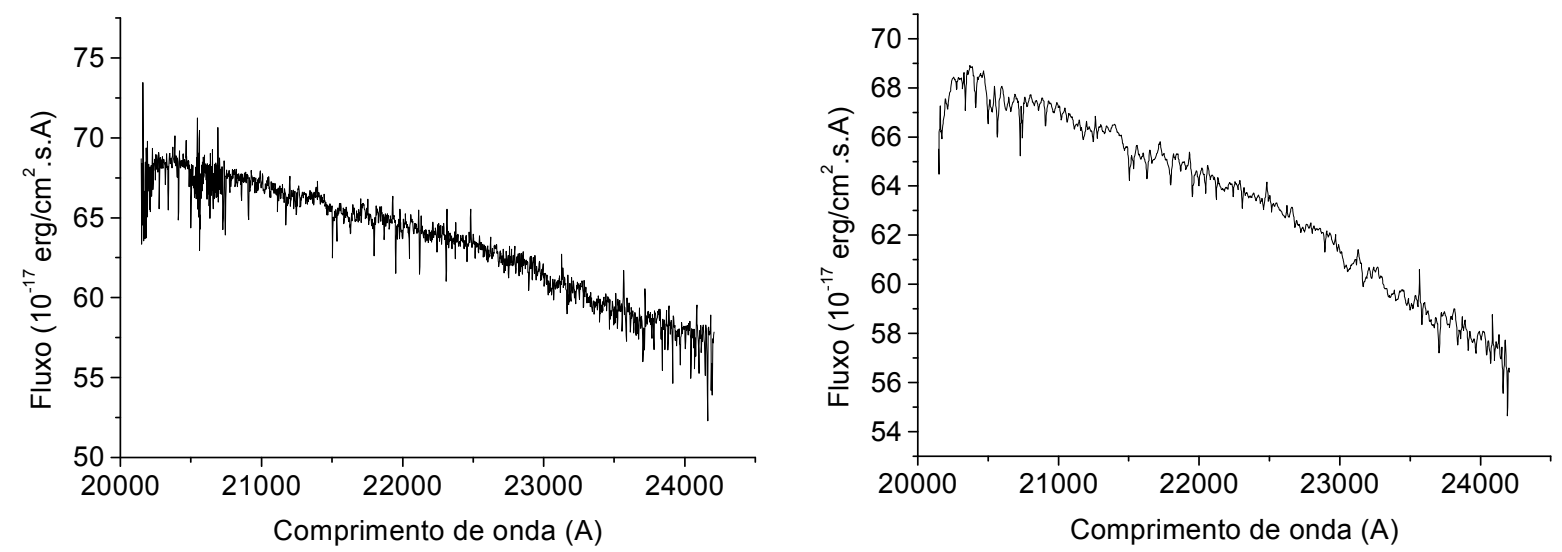

Figura 9.6 - (esquerda) Espectro extraído de uma região circular central do cubo de dados de M87, antes da aplicação do "de-noising”; (direita) Espectro extraído de uma região circular central do cubo de dados de M87, após a aplicação do "de-noising".

Observando-se a figura 9.6, pode-se notar a grande diminuição do ruído espectral que o processo do de-noising proporcionou e também fica claro que os efeitos sobre estruturas como linhas de emissão e absorção foram mínimos. Outra característica bastante evidente é a quase ausência de tais estruturas ao longo do espectro, conforme já foi mencionado anteriormente. 
Finalmente, passou-se para a etapa da deconvolução de Richardson-Lucy. Como o cubo de dados de M87 praticamente não possui estruturas espectrais visíveis, não foi possível fazer uma imagem da componente larga de alguma linha espectral. Assim, utilizou-se como PSF uma imagem proveniente do cubo de dados da estrela padrão utilizada no processo de redução dos dados para a remoção das absorções telúricas e para a calibração em fluxo. Para se fazer isso, entretanto, foi preciso aplicar ao cubo de dados dessa estrela padrão o mesmo processamento utilizado no cubo de M87, ou seja, foi feita a reamostragem espacial e a filtragem espacial de Butterworth desse cubo (não foi preciso aplicar o de-noising, pois tal procedimento não tem efeito significativo sobre o aspecto da PSF). Uma vez obtida a imagem correspondente à PSF, foi feita a deconvolução de Richardson-Lucy no cubo de dados de M87 utilizando-se 10 iterações. A figura 9.7 mostra a soma de todas as imagens e o espectro médio do cubo de dados final, obtido após a aplicação da deconvolução de Richardson-Lucy.
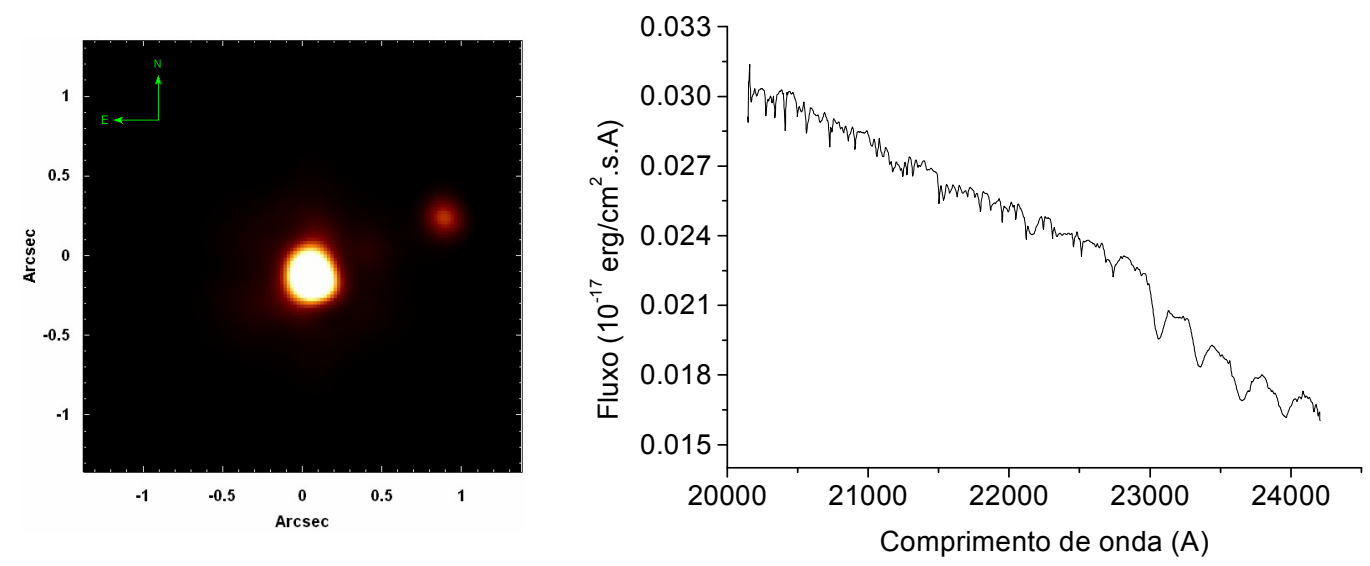

Figura 9.7 - (esquerda) Soma de todas as imagens do cubo de dados final de M87, obtido após todo o processamento; (direita) Espectro médio do cubo de dados final de M87, obtido após todo o processamento.

Uma comparação entre as figuras 9.6 e 9.7 mostra que foi preciso extrair um espectro médio do cubo inteiro para que as bandas de absorção de $\mathrm{CO}$ se tornassem claramente detectáveis, ao passo que linhas de emissão significativas não são visíveis em nenhum dos dois espectros. Isso mostra como esse objeto é desprovido de estruturas intensas nessa região espectral. 


\section{3 - Aplicação da Tomografia PCA ao cubo de dados de M87 com o contínuo estelar}

Após todo o processamento descrito na seção 9.2, verificou-se que o cubo de dados obtido apresentava resquícios de linhas de céu que não foram totalmente eliminadas com o processo de subtração do céu na redução dos dados e nem com o cálculo das medianas dos diferentes cubos de dados. Isso é bastante comum em cubos de dados obtidos nessa região espectral, entretanto, como as linhas espectrais desse objeto eram muito tênues, em vários espectros do cubo, as linhas de céu não subtraídas eram as estruturas mais intensas. Outro detalhe foi que os resquícios de emissão de céu não eram constantes ao longo do cubo, apresentando variância espacial. Tudo isso tornou difícil a aplicação da Tomografia PCA a esse cubo de dados, pois vários dos auto-espectros obtidos apresentaram uma série de correlações e anti-correlações com comprimentos de onda associados a essas linhas de céu remanescentes da redução dos dados. Em outras palavras, vários auto-espectros ficaram "contaminados" pela emissão de céu, o que dificultou a sua interpretação. Assim, para facilitar a interpretação dos resultados da Tomografia PCA, optou-se por remover os resquícios de linhas de céu fazendo-se interpolações com regiões espectrais adjacentes. Após essa remoção, pôde-se, então, aplicar a Tomografia PCA ao cubo de dados. Os auto-espectros e respectivos tomogramas mais relevantes obtidos encontram-se a seguir.
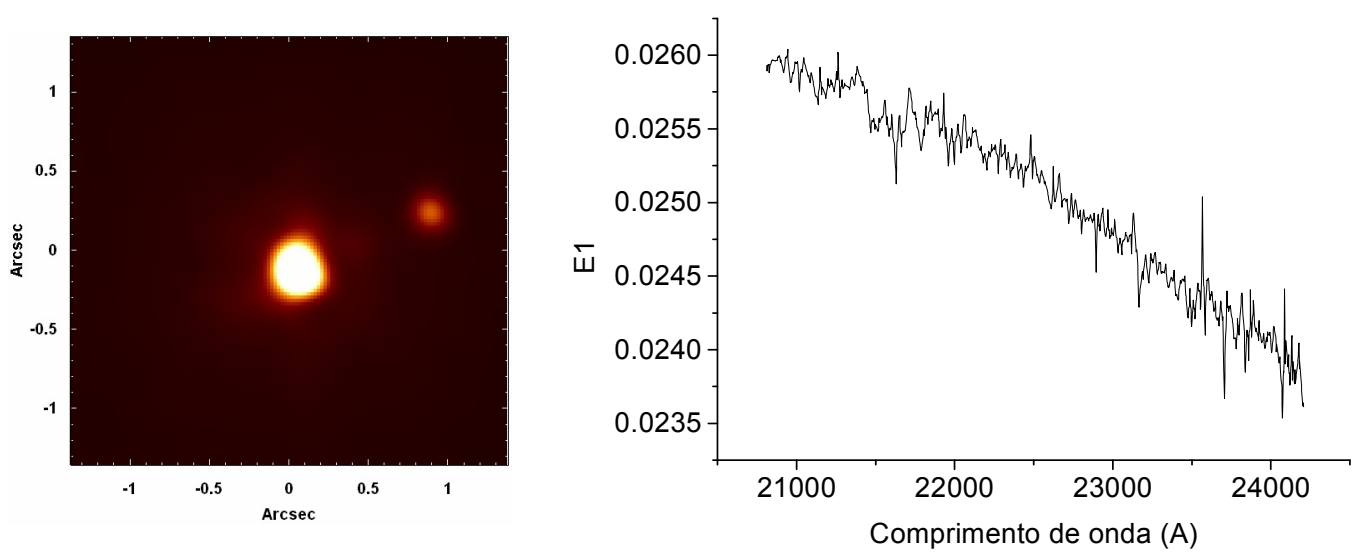

Figura 9.8 - Tomograma e auto-espectro correspondentes ao autovetor E1, obtido com a Tomografia PCA do cubo de dados de M87 com o contínuo estelar. 

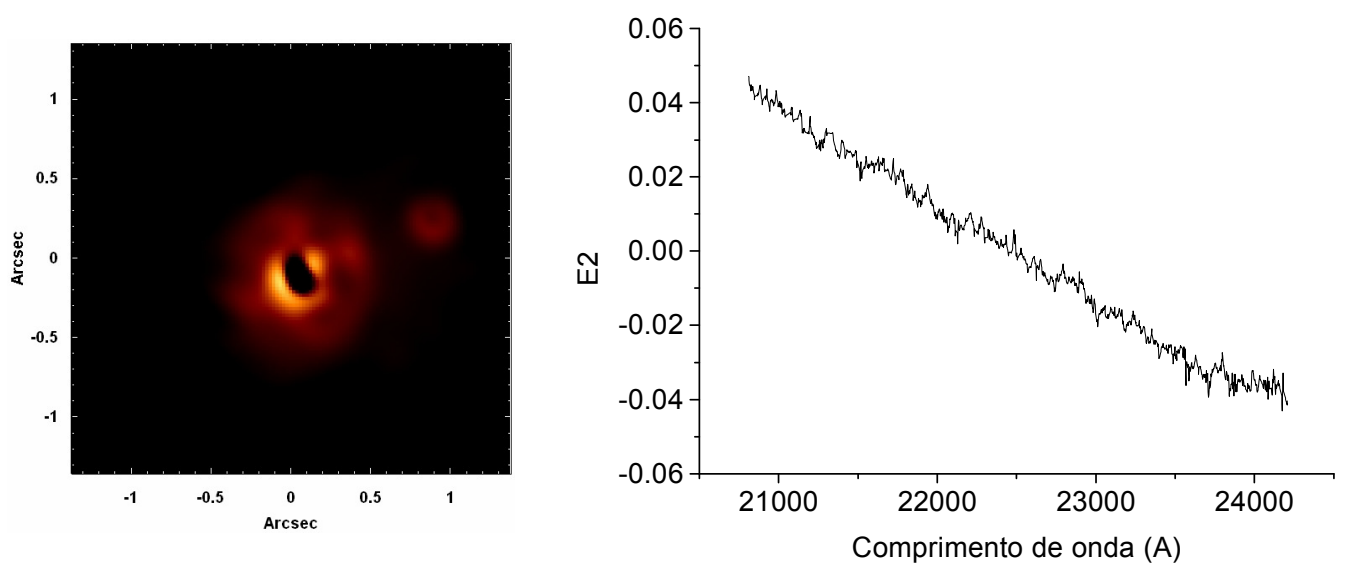

Figura 9.9 - Tomograma e auto-espectro correspondentes ao autovetor E2, obtido com a Tomografia PCA do cubo de dados de M87 com o contínuo estelar.
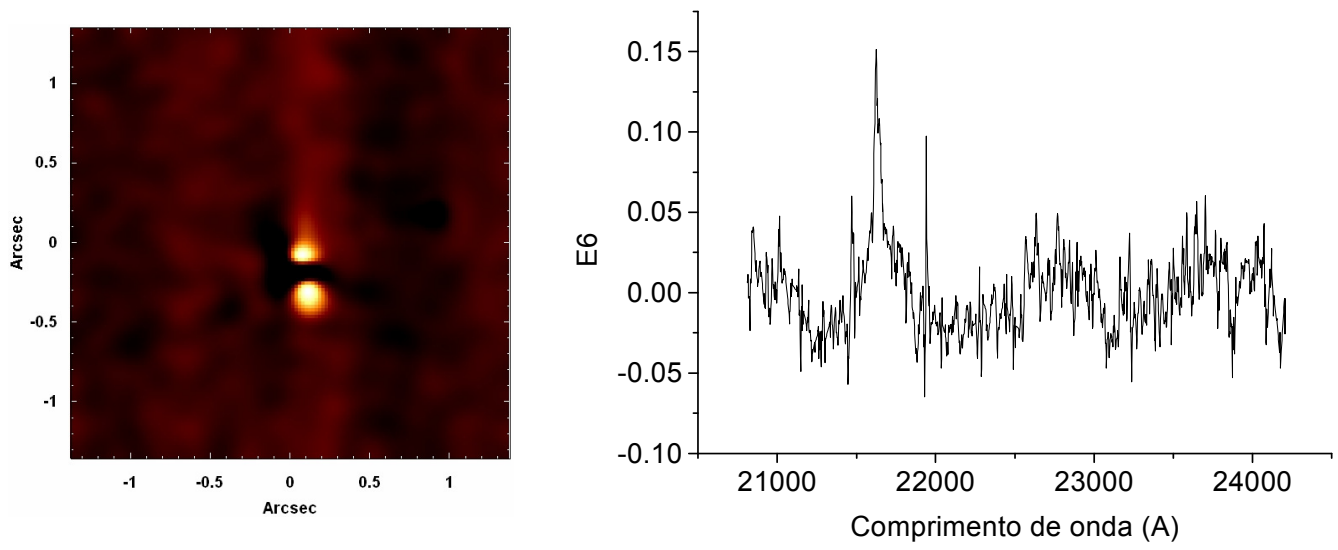

Figura 9.10 - Tomograma e auto-espectro correspondentes ao autovetor E6, obtido com a Tomografia PCA do cubo de dados de M87 com o contínuo estelar.

\begin{tabular}{|c|c|}
\hline Autovetor & Fração da variância explicada (\%) \\
\hline E1 & 99.9546 \\
\hline E2 & 0.0364 \\
\hline E6 & 0.0004 \\
\hline
\end{tabular}

Tabela 9.1 - Autovalores obtidos com a Tomografia PCA do cubo de dados de M87 com o contínuo estelar. 


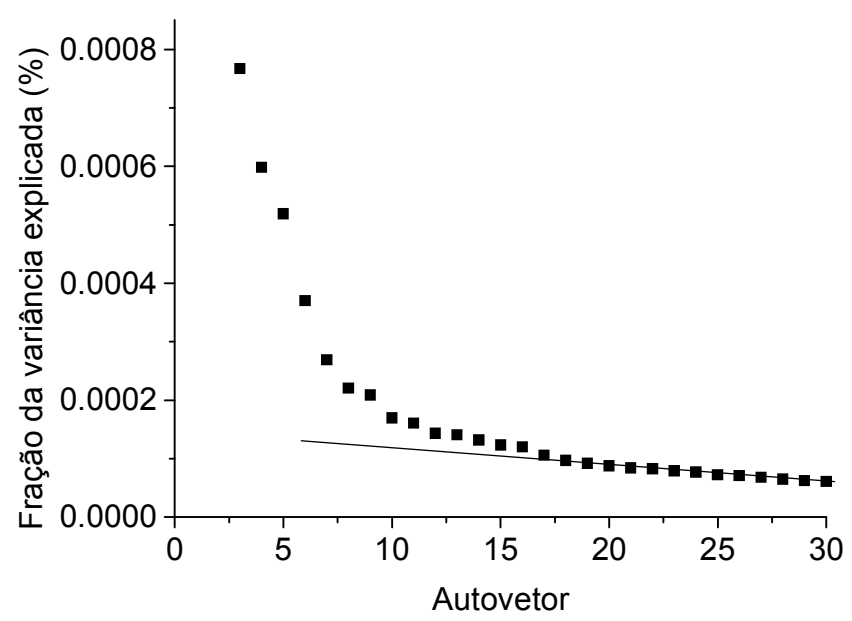

Figura 9.11 - "Scree test" dos autovetores obtidos com a Tomografia PCA do cubo de dados de M87 com o contínuo estelar.

A figura 9.8 revela que o auto-espectro E1 possui uma aparência relativamente similar à do espectro médio do cubo de dados de M87 (figura 9.8), exceto pelo fato de que as bandas de $\mathrm{CO}$ aparecem mais nitidamente no espectro médio do que em E1. Esse auto-espectro apresenta, ainda, correlações com os comprimentos de onda correspondentes à linha de Bry (que não aparece claramente no espectro médio), o que sugere que esse autovetor também está associado à emissão proveniente do AGN existente nesse objeto. O tomograma correspondente a esse autovetor, por sua vez, possui um aspecto similar ao da soma de todas as imagens do cubo de dados de M87 (figura 9.8). A área brilhante próxima ao centro do campo visual do NIFS representa a provável posição do $\mathrm{AGN}$, ao passo que a segunda área brilhante, mais afastada do centro do campo de visão do NIFS, corresponde a um dos nós do jato existente nesse objeto. O fato de o auto-espectro E1 e o tomograma associado serem similares, respectivamente, ao espectro médio e à soma de todas as imagens do cubo de dados de M87 está de acordo com o previsto, já que o autovetor E1 explica a maior parte da variância dos dados $(99.9546$ \%) e, por essa razão, é de se esperar que ele revele características dominantes facilmente detectáveis no cubo de dados.

Observando-se a figura 9.9, pode-se notar que o auto-espectro E2 apresenta uma correlação com a região azul do espectro e uma anti-correlação com a região vermelha do mesmo. Isso, juntamente com a aparência apresentada pelo tomograma, parece indicar que esse autovetor estabelece um contraste entre a região mais próxima do núcleo da galáxia, com um contínuo mais avermelhado, e as áreas ao redor, com um contínuo mais azulado. Nas regiões próximas ao núcleo (áreas escuras do tomograma), é provável que o contínuo mais avermelhado 
seja devido à emissão térmica de poeira ao redor do AGN, ao passo que, nas regiões mais afastadas do núcleo (áreas claras do tomograma), o contínuo mais azulado parece indicar que a emissão possui uma considerável componente devida às populações estelares. Em outras palavras, o autovetor 2 parece diferenciar as regiões com emissão dominada pela poeira (áreas próximas ao $\mathrm{AGN}$ ) das regiões com emissão devida, principalmente, às populações estelares presentes (áreas mais afastadas do AGN), o que está de acordo com o esperado. Analisando-se detalhadamente o tomograma do autovetor E2, pode-se notar que as áreas escuras próximas ao AGN central apresentam um formato "esticado" aproximadamente perpendicular à direção do jato existente, o que, em princípio, pode indicar que se trate de um toro de poeira ao redor do AGN. Isso seria compatível com o previsto pelo Modelo Unificado. Outra característica importante do tomograma correspondente a esse autovetor é a área clara cuja posição parece coincidir com o nó do jato visível no campo do NIFS. Isso mostra que os pixeis dessa região estão positivamente correlacionados com o auto-espectro E2, ou seja, possuem um contínuo consideravelmente azul. Uma observação mais cuidadosa revela que os pixeis na área central do nó estão correlacionados mais fracamente com esse auto-espectro do que os pixeis imediatamente ao redor, ou seja, os espectros na região central do nó parecem ser menos azuis do que aqueles ao redor. Todas essas características, provavelmente, estão relacionadas à emissão synchrotron (que assume a forma de uma lei de potência) proveniente do jato, que já foi analisada em vários estudos (Perlman et al. 2007, por exemplo). Esses detalhes relativos ao jato, entretanto, não são analisados em maiores detalhes aqui. O autovetor E2 explica cerca de 0.0364 \% da variância dos dados.

Uma análise da figura 9.10 mostra que a principal característica do auto-espectro E6 é uma forte correlação com comprimentos de onda correspondentes a uma linha cuja identificação não é clara. Pode-se notar que tal linha apresenta uma considerável componente larga, o que poderia indicar que se trata de Bry, que é a principal linha de emissão nessa região espectral que, em certos casos, possui uma componente larga considerável. Uma medição cuidadosa no autoespectro E6 revela que a suposta linha detectada está situada em um comprimento de onda de cerca de $21625 \AA$, logo, se tal linha fosse, de fato, Bry, então, isso implicaria em um $z=$ -0.00166, ou seja, ela estaria em blueshift. No entanto, é sabido que M87 possui um redshift de $z=0.00436$, o que tornaria o comprimento de onda esperado para a linha de Br $\gamma$ de M87 igual a aproximadamente $21755 \AA$ A. Assim, se a linha detectada no auto-espectro E6 for Bry, então, a 
sua região emissora apresenta uma componente de velocidade radial no sentido do observador. É possível, inclusive, que tal região nem esteja conectada cinematicamente com M87. Observando-se o tomograma do autovetor E6, pode-se notar que a emissão dessa linha parece ser proveniente das duas áreas claras existentes. No entanto, esse tomograma também revela a presença de certas "faixas" verticais ao longo da imagem, o que, aparentemente, parece ser algum tipo de fingerprint instrumental, possivelmente relacionado ao contínuo dos espectros, que não foi eliminado durante o tratamento dos dados, descrito na seção 9.2. A presença desse fingerprint instrumental nesse tomograma representa uma incerteza no que se refere à identificação de estruturas espaciais nessa imagem, ou seja, não é possível garantir que a linha larga visível no auto-espectro E6 seja, de fato, proveniente das duas áreas claras visíveis no tomograma. De qualquer forma, a detecção dessa linha (possivelmente Bry em blueshift) jamais foi conseguida em estudos anteriores, representando, assim, um resultado de considerável importância. O autovetor E6 explica cerca de 0.0004 \% da variância dos dados.

O Scree test da figura 9.11 mostra que os valores das variâncias explicadas pelos autovetores decaem bastante até, aproximadamente, o autovetor E8. A partir daí, a taxa de decaimento diminui bastante, ficando praticamente constante a partir do autovetor E19. Isso indica que autovetores de ordem maior ou igual a 19 representam, sobretudo, ruído e, consequentemente, não possuem relevância nessa análise. Entretanto, vários dos autovetores com ordens menores do que 19 também não apresentam uma interpretação clara ou são dominados por ruído, logo, não foram analisados aqui. Isso mostra que, conforme já foi mencionado anteriormente, embora o Scree test seja uma boa técnica para se avaliar a partir de que ordem os autovetores deixam de conter um sinal significativo e passam a ser dominados pelo ruído, há casos em que essa estratégia pode não ser precisa, e uma averiguação detalhada dos autovetores é sempre recomendada.

Em suma, pode-se dizer que essa primeira análise com a Tomografia PCA estabeleceu um contraste entre espectros com um contínuo mais vermelho (dominado pela emissão térmica de poeira) na região central próxima ao $\mathrm{AGN}$ e espectros com um contínuo mais azul (dominado pela emissão das populações estelares) nas áreas mais afastadas, sendo que a estrutura espacial da região com emissão térmica de poeira parece ser compatível com a de um toro. Também foi identificada, pela primeira vez, a emissão de uma linha espectral possivelmente correspondente 
a Bry em blueshift. Tal emissão pode ser proveniente de alguma estrutura com uma componente de velocidade radial no sentido do observador.

\section{4 - Síntese espectral do cubo de dados de M87 com o Starlight}

Após a análise inicial com a Tomografia PCA, aplicou-se uma síntese espectral no cubo de dados de M87 com o software Starlight. A preparação dos espectros foi feita como nos casos anteriores, sendo que a correção da extinção devido à Via Láctea e a passagem dos espectros para o referencial de repouso foram aplicadas considerando-se $A_{V}=0.074$ e $z=0.00436$, respectivamente. Tanto $A_{V}$ quanto $\mathrm{z}$ foram obtidos a partir do site do NED. Conforme foi dito em 3.8, a aplicação do processo do de-noising aos espectros do cubo de dados pode gerar certas alterações indesejáveis. Embora no caso de M87 tais alterações tenham sido mínimas, optou-se por, assim como foi feito para NGC 4151, fazer a síntese espectral do Starlight em um cubo de dados no qual não havia sido utilizado esse processo.

Como o cubo de dados de M87 foi obtido na região espectral do infravermelho próximo e há um AGN nessa galáxia, foi preciso levar em conta a emissão térmica de poeira e um featureless continuum na síntese espectral. Assim como em todos os casos anteriores de cubos de dados no infravermelho próximo, devido às limitações da base utilizada, apenas os mapeamentos mais confiáveis obtidos com a síntese espectral do cubo de dados de M87 são mostrados nas sessões a seguir.

\subsection{1 - Qualidade dos ajustes}

O mapeamento dos valores do $\chi^{2} / n_{\text {eff }}$ dos ajustes obtidos com a síntese espectral do cubo de dados de M87 encontra-se a seguir. 


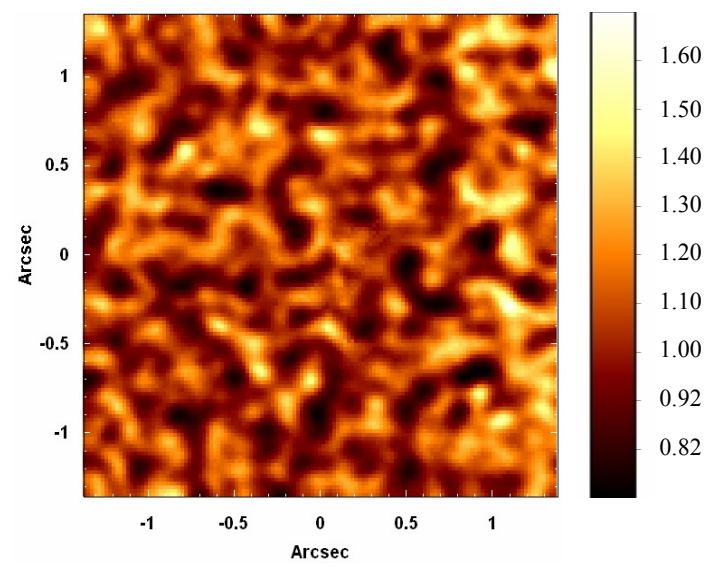

Figura 9.12: Mapeamento dos valores do $\chi^{2} / n_{\text {eff }}$ dos ajustes obtidos pelo "Starlight" para os espectros do cubo de dados de M87.

Observando-se a figura 9.12, pode-se notar que os melhores ajustes obtidos com o Starlight apresentaram $\chi^{2} / n_{\text {eff }}$ de cerca de 0.73 , ao passo que os piores tiveram $\chi^{2} / n_{\text {eff }}$ de cerca de 1.7, o que ainda pode ser tomado como um indicativo de ajustes com boa qualidade. Dessa forma, conclui-se que mesmo os piores ajustes obtidos com o Starlight forneceram resultados que podem ser considerados confiáveis. O mapeamento da figura 9.12, aparentemente, não revelou estruturas ou configurações que indicassem áreas com ajustes tendenciosamente melhores do que outras.

\subsection{2 - Populações estelares, poeira e featureless continuum}

Assim como nos casos anteriores envolvendo cubos de dados no infravermelho próximo, os únicos mapeamentos de fluxo suficientemente confiáveis, obtidos a partir da síntese espectral com o Starlight do cubo de dados de M87, foram os seguintes: o mapeamento do fluxo total devido às populações estelares, o mapeamento do fluxo total devido à emissão térmica de poeira e o mapeamento do fluxo devido ao featureless continuum. Todos esses mapeamentos são mostrados nas figuras a seguir. 


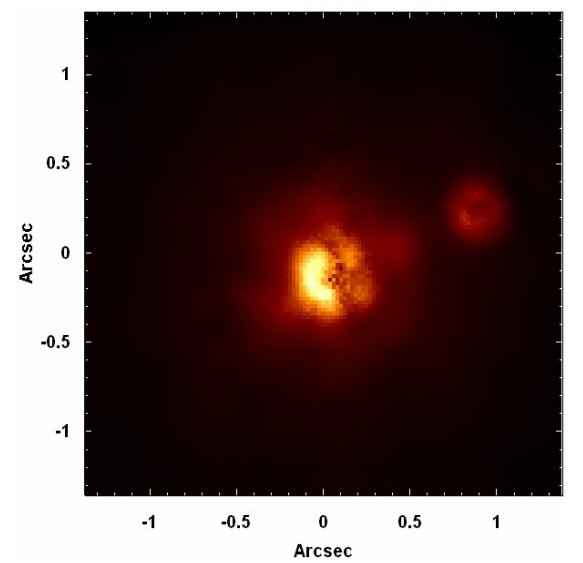

Figura 9.13: Mapeamento do fluxo total devido às populações estelares, obtido com a aplicação do "Starlight" ao cubo de dados de M87.
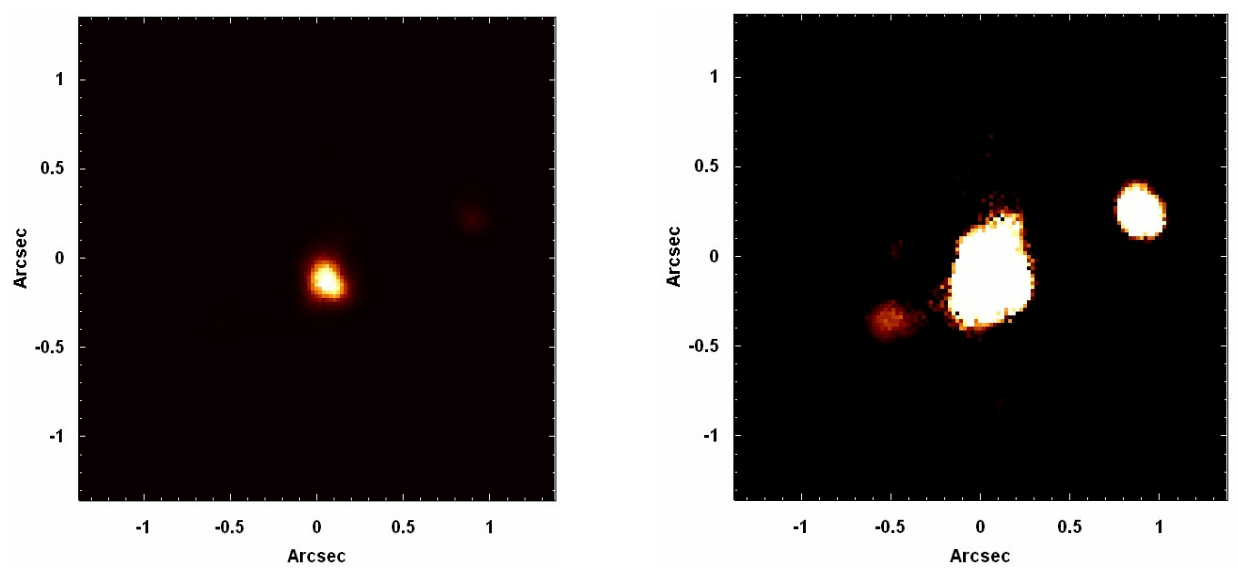

Figura 9.14: (esquerda) Mapeamento do fluxo total devido à emissão térmica de poeira, obtido com a aplicação do "Starlight" ao cubo de dados de M87; (direita) Mesma imagem mostrada à esquerda, mas com a LUT exagerada.

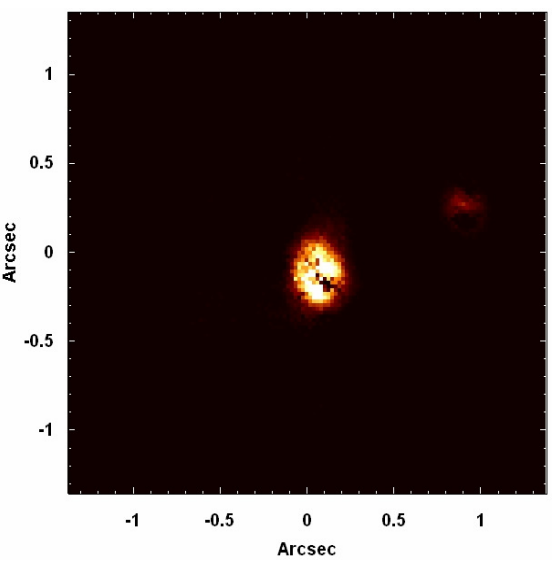

Figura 9.15: Mapeamento do fluxo atribuído ao "featureless continuum" do AGN, obtido com a aplicação do "Starlight" ao cubo de dados de M87. 
Em seguida, construiu-se um gráfico em colunas contendo as frações de fluxo atribuídas às populações estelares, à emissão térmica de poeira e ao featureless continumm do AGN, considerando-se todo o campo visual do NIFS. O gráfico obtido é mostrado na figura 9.16.

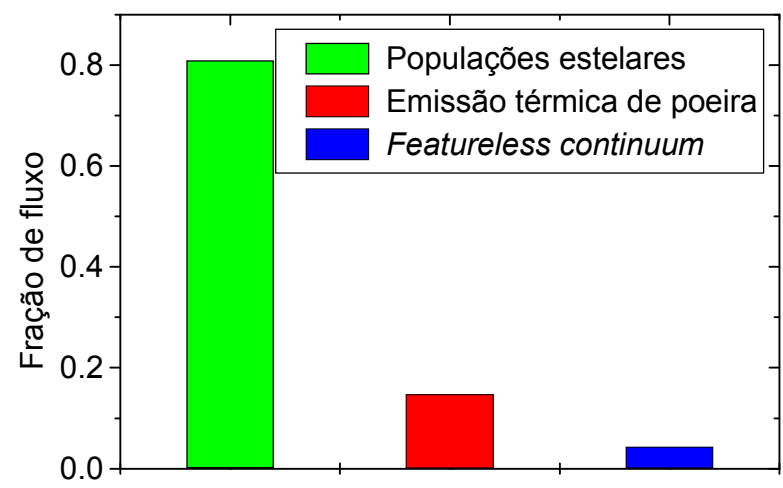

Figura 9.16: Gráfico representativo das frações de fluxo devidas às populações estelares, à emissão térmica de poeira e ao "featureless continuum", considerando-se todo o campo visual do NIFS, obtido com a aplicação do "Starlight" ao cubo de dados de M87.

Analisando-se as figuras 9.13 e 9.14 , pode-se notar que foi detectado fluxo proveniente de populações estelares por todo o campo visual NIFS. A emissão térmica de poeira, por outro lado, somente foi observada em uma área próxima ao AGN com um formato "esticado", aproximadamente perpendicular à direção do jato existente. Isso parece indicar que se trata de um toro de poeira, o que estaria de acordo com o previsto pelo Modelo Unificado. Um resultado similar a esse foi obtido com o autovetor E2 da aplicação da Tomografia PCA ao cubo de dados de M87 com o contínuo estelar (figura 9.9 da seção 9.3). É importante mencionar, entretanto, que não é possível garantir que o suposto formato "esticado" da estrutura observada seja indicativo de um toro, já que o seu tamanho aparente é bastante próximo à resolução espacial do cubo de dados, o que torna difícil a visualização dos detalhes presentes. $\mathrm{O}$ mapeamento da figura 9.14 revela alguma emissão térmica de poeira na posição correspondente ao nó do jato. Esse resultado pode ser real, no entanto, também pode ser apenas uma conseqüência do ajuste realizado pelo Starlight sobre o contínuo da emissão synchrotron proveniente desse nó. Por fim, um resultado bastante relevante que pode ser notado no mapeamento da figura 9.14 com a LUT "exagerada" é uma aparente emissão térmica de poeira em uma área diametralmente oposta ao nó do jato mencionado anteriormente. Embora não seja possível afirmar com segurança se tal emissão está realmente associada à poeira ou é decorrente do ajuste do Starlight sobre algum outro contínuo espectral presente (como uma emissão synchrotron, por exemplo), essa detecção 
pode estar associada a um segundo jato existente nessa galáxia, com um sentido oposto ao primeiro. Esse resultado possui uma considerável importância, pois um segundo jato jamais foi detectado nessa galáxia em estudos anteriores. Os resultados obtidos com a síntese espectral de M87 apresentam uma certa semelhança para com os encontrados com a síntese espectral de NGC 5643, já que, nesses dois casos, foi detectado fluxo devido a populações estelares ao longo de todo o campo visual, inclusive na região correspondente ao AGN. Nos casos de NGC 2992, NGC 4151 e NGC 3227, por outro lado, não foi observado fluxo associado a populações estelares na área próxima ao AGN. Conforme foi mencionado anteriormente, a não detecção de fluxo originário de populações estelares na posição do AGN é provavelmente devida ao "ofuscamento" da emissão estelar pela forte emissão térmica de poeira nessa região. Dessa forma, o fato de se ter detectado fluxo de populações estelares nas áreas próximas aos AGNs de NGC 5643 e M87 indica que a emissão térmica de poeira nessas galáxias deve ser significativamente mais fraca do que nos casos de NGC 2992, NGC 4151 e NGC 3227, já que não foi capaz de "ofuscar" as populações estelares existentes. Pode-se notar o surgimento de um aparente padrão, no qual a emissão térmica de poeira parece ser mais intensa em Seyferts 1 do que em Seyferts 2 ou rádio-galáxias (sendo que M87, na literatura, é classificada tanto como rádio-galáxia quanto como LINER). Entretanto, essa hipótese precisa ser melhor averiguada, já que o pequeno número de objetos aqui analisados não permite que conclusões como essa sejam tiradas de maneira confiável.

A figura 9.15 mostra que a emissão associada ao featureless continuum também é proveniente, sobretudo, da região ocupada pelo AGN central, o que está de acordo com o esperado. Entretanto, uma análise mais detalhada dessa imagem revela que o featureless continuum parece se estender por duas áreas aproximadamente perpendiculares à direção do suposto toro de poeira, correspondente à estrutura "esticada" na figura 9.14. Isso sugere que o contínuo emitido pelo AGN poderia estar sofrendo um espalhamento por poeira ao longo de uma direção aproximadamente perpendicular à do toro, o que estaria de acordo com o esperado. Na figura 9.15, pode-se notar, ainda, alguma emissão proveniente da região correspondente ao nó do jato. É provável que isso seja um produto do ajuste do Starlight sobre a emissão synchrotron proveniente do nó. De fato, a radiação synchrotron é uma das emissões que compõem o featureless continuum dos AGNs e possui um espectro na forma de lei de potência. 
Observando-se o gráfico na figura 9.16, pode-se notar que o fluxo proveniente de populações estelares é dominante no campo visual do NIFS, representando cerca de $80.9 \%$ do total. Por outro lado, a fração de fluxo associada à emissão térmica de poeira (cerca de 14.7 \%), apesar de consideravelmente inferior, ainda é significativa, o que indica que a emissão proveniente do AGN central é capaz de aquecer uma quantidade considerável de poeira ao seu redor. Por fim, a fração de fluxo correspondente ao featureless continuum é bastante pequena (cerca de $4.3 \%$ ), o que pode ser devido tanto a uma menor emissão por parte do AGN (já que se trata de um AGN de menor intensidade do que Seyferts 1 como NGC 2992, NGC 4151 e

NGC 3227) quanto a um obscurecimento pelo possível toro de poeira existente.

\subsection{3 - Valores da razão $S / N$ dos espectros analisados}

O mapeamento dos valores da razão $S / N$ obtidos pelo Starlight no intervalo espectral de $22541 \AA$ até $22752 \AA$ encontra-se a seguir.

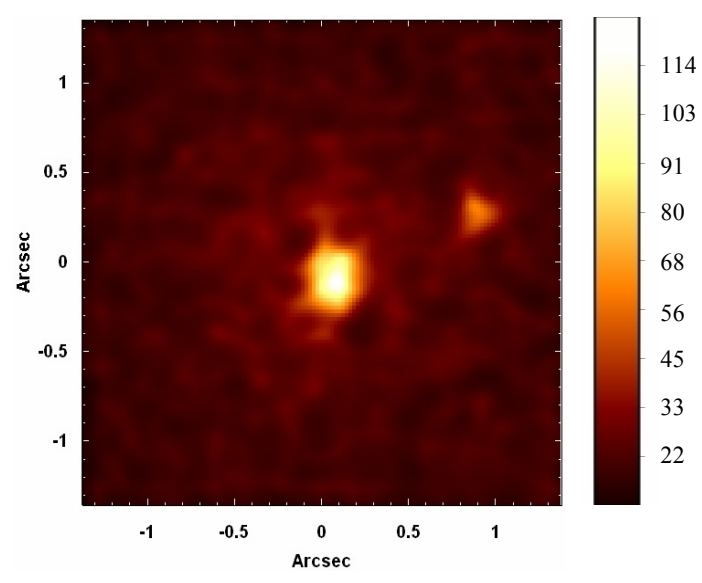

Figura 9.17 - Mapeamentos dos valores da razão $S / N$, obtidos a partir da sintese espectral do cubo de dados de M87 com o "Starlight".

A figura 9.17 revela que os valores mais altos (cerca de 126) para a razão $S / N$ foram obtidos nas regiões centrais do campo visual do NIFS (onde se encontra o AGN), ao passo que os menores (cerca de 10) foram encontrados nas áreas mais afastadas do centro. Isso está de acordo com o esperado, já que o fluxo detectado é mais intenso nas regiões próximas ao AGN, dando origem aos valores mais elevados de $S / N$. Entretanto, pode-se notar, também, um certo 
aumento nos valores da razão $S / N$ na área correspondente ao nó do jato, o que, possivelmente, é devido à considerável emissão synchrotron proveniente dessa região.

\section{5 - Aplicação da Tomografia PCA ao cubo de dados de M87 com o contínuo estelar subtraído}

Utilizando-se os espectros estelares sintéticos resultantes da síntese espectral com o Starlight, fez-se uma subtração do contínuo estelar de todos os espectros de M87. Como o cubo de dados no qual foi aplicada a síntese espectral não possuía de-noising, o resultado obtido após a subtração do contínuo estelar apresentou valores de $S / N$ inferiores àqueles do cubo no qual se aplicou a Tomografia PCA mostrada na seção 9.3. No caso desse objeto, entretanto, a quase ausência de estruturas espectrais tornava os valores de $S / N$ consideravelmente baixos (conforme foi mencionado na seção 9.2), dificultando a interpretação de resultados provenientes da Tomografia PCA. Assim, antes da aplicação da Tomografia PCA ao cubo de dados de M87 com o contínuo estelar subtraído, foi utilizado o de-noising. Também foram eliminados os resquícios de linhas de céu existentes (assim como foi feito na seção 9.3), a fím de se evitar uma possível contaminação dos auto-espectros obtidos com linhas de céu. Após essa preparação, aplicou-se a Tomografia PCA ao cubo de dados resultante. Os principais auto-espectros e respectivos tomogramas encontrados são mostrados a seguir.
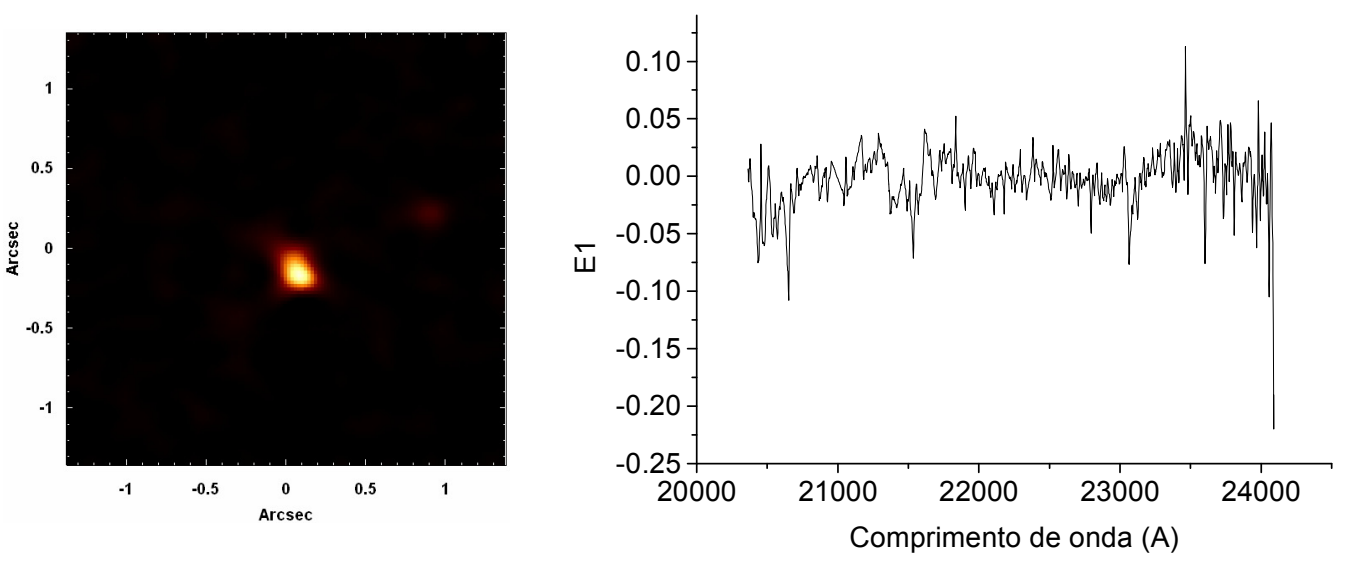

Figura 9.18 - Tomograma e auto-espectro correspondentes ao autovetor E1, obtido com a Tomografia PCA do cubo de dados de M87 com o contínuo estelar subtraído. 

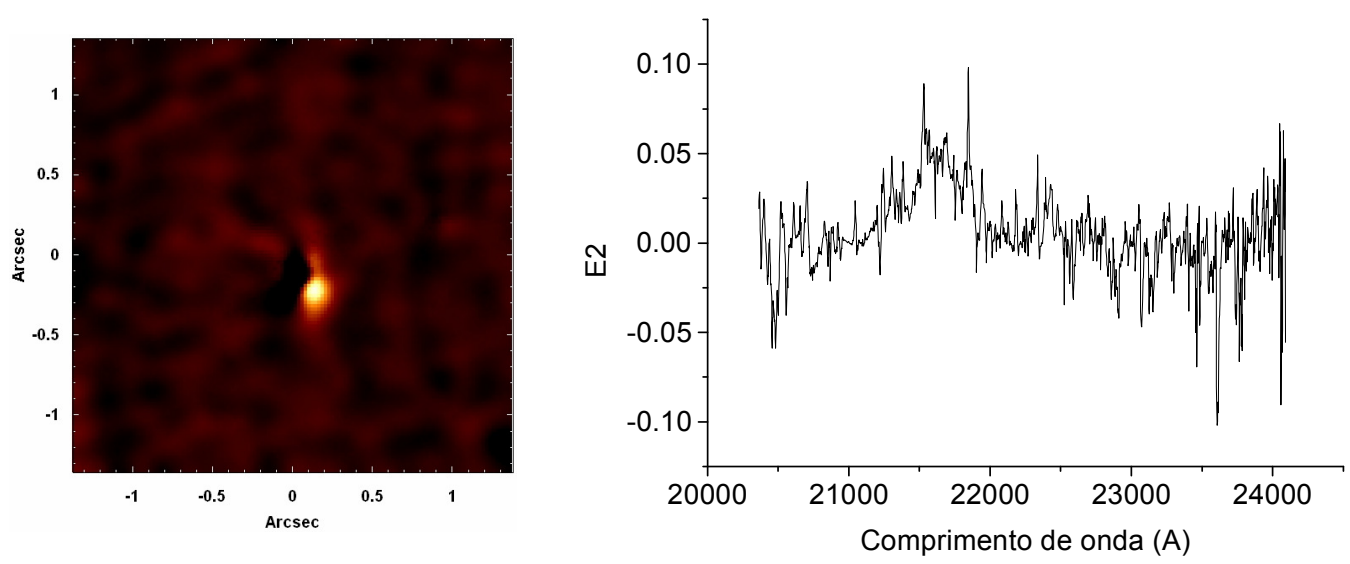

Figura 9.19 - Tomograma e auto-espectro correspondentes ao autovetor E2, obtido com a Tomografia PCA do cubo de dados de M87 com o contínuo estelar subtraído.

\begin{tabular}{|c|c|}
\hline Autovetor & Fração da variância explicada (\%) \\
\hline E1 & 22.9382 \\
\hline E2 & 5.9060 \\
\hline
\end{tabular}

Tabela 9.2 - Autovalores obtidos com a Tomografia PCA do cubo de dados de M87 com o contínuo estelar subtraído.

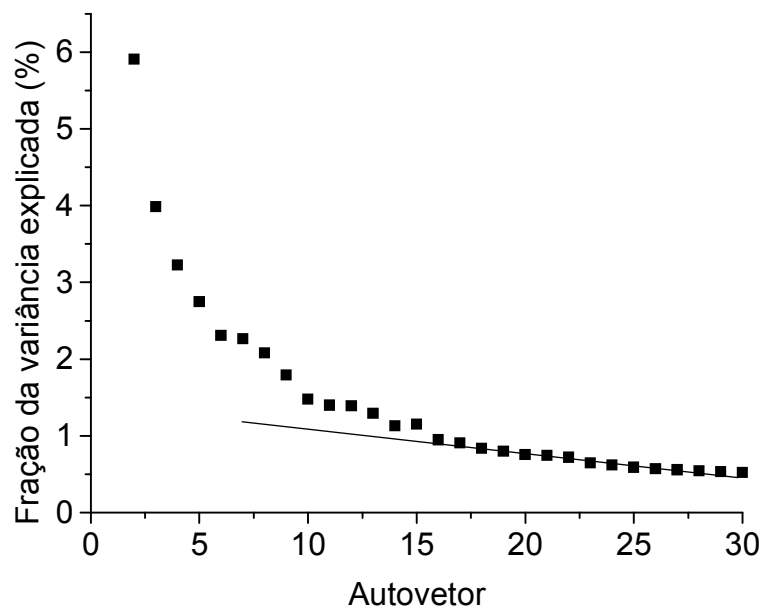

Figura 9.20 - "Scree test" dos autovetores obtidos com a Tomografia PCA do cubo de dados de M87 com o contínuo estelar subtraído.

Observando-se a figura 9.18, pode-se notar, primeiramente, que o auto-espectro E1 apresenta correlações com os comprimentos de onda correspondentes à linha de Bry, o que parece indicar que esse autovetor está relacionado à emissão proveniente do AGN dessa galáxia. Nesse caso, a posição do AGN é representada pela área mais clara central do tomograma, o que está de acordo com os resultados obtidos anteriormente. O fato de a emissão do AGN aparecer no auto-espectro E1 revela que ele é o fenômeno dominante no cubo de dados de M87 com o contínuo estelar subtraído, já que o autovetor E1 explica a maior parte da variância dos dados 
(cerca de $22.9382 \%$ do total). O auto-espectro E1 também possui certas correlações e anticorrelações provavelmente associadas às bandas de absorção de $\mathrm{CO}$, o que mostra que esse autovetor também está revelando resquícios de absorção estelar não totalmente removidos com o processo de subtração dos espectros contínuos sintéticos fornecidos pela síntese espectral com o Starlight. É possível, inclusive, que algumas das ondulações apresentadas pelo auto-espectro E1 correspondam a resquícios do contínuo estelar não removido completamente.

A figura 9.19 mostra que o auto-espectro E2 apresenta correlações com comprimentos de onda associados a uma linha com uma componente larga, cuja identificação é duvidosa. A região emissora dessa suposta linha corresponde à área clara do tomograma. Uma correlação compatível com essa foi detectada no autovetor E6 obtido com a aplicação da Tomografia PCA ao cubo de dados de M87 com o contínuo estelar (figura 9.10), no entanto, na análise da seção 9.3, o tomograma associado a E6 revelava, aparentemente, duas regiões emissoras da linha larga observada, ao passo que o tomograma da figura 9.19 mostra, apenas, uma região emissora. Uma inspeção dos cubos de dados de M87 com e sem o contínuo estelar, entretanto, não revelou qualquer indício de emissão dessa linha larga nos espectros da segunda área clara visível no tomograma do autovetor E6 mostrado na figura 9.10, ao passo que a linha era facilmente detectada nos espectros da outra região clara presente nos tomogramas das figuras 9.10 e 9.19. Isso mostra que é provável que a segunda área clara visível no tomograma da figura 9.10 não esteja relacionada à emissão dessa linha larga, mas sim deve estar associada à "contaminação" daquele autovetor por algum outro fenômeno presente, como o fingerprint instrumental, que aparece na forma de faixas verticais na imagem. No que se refere à região emissora visível tanto no tomograma da figura 9.19 quanto no da figura 9.10, a possibilidade de que a linha larga detectada seja Bry em blueshift (conforme mencionado na seção 9.3) levanta várias questões sobre a natureza da região emissora. O fato de a linha ter uma componente larga parece indicar que se trata da emissão da BLR de um segundo AGN visível no campo visual do NIFS. Esse segundo AGN teria uma componente de velocidade radial no sentido do observador (gerando a emissão com blueshift), no entanto, não é claro se o movimento desse segundo AGN está ou não associado ao primeiro AGN. Uma possibilidade aceitável é que esse segundo objeto esteja em órbita ao redor do AGN central de M87 e seja remanescente de uma galáxia do aglomerado de Virgo "canibalizada" por M87. Essa hipótese é particularmente coerente com o fato de M87 ser uma galáxia elíptica gigante localizada no centro do aglomerado de Virgo. No entanto, também 
é possível que esse segundo objeto não faça parte de M87, estando à frente ou atrás da galáxia. Nesse caso, o que está sendo observado nos tomogramas das figuras 9.10 e 9.19 é, apenas, um efeito de projeção. O auto-espectro E2 da figura 9.10 possui, ainda, correlações com comprimentos de onda (próximos a $21845 \AA$ ) associados a uma aparente linha de emissão estreita, cuja identificação não está clara. O autovetor E2 mostrado na figura 9.19 explica cerca de $5.9060 \%$ da variância dos dados.

Para se obter uma melhor visualização da região emissora da suposta linha de $\mathrm{Br} \gamma$ em blueshift, fez-se uma imagem do intervalo espectral associado à linha e também extraiu-se o espectro de uma região circular, com raio igual a 0.105 ”, centrada na região emissora. Esses dois procedimentos foram aplicados no cubo de dados de M87, após a subtração do contínuo estelar, com os resquícios de linhas de céu removidos, mas sem de-noising, já que esse último, conforme foi mencionado anteriormente, poderia gerar alterações indesejáveis. Os resultados obtidos, juntamente com uma composição RB contendo o tomograma na figura 9.18 e a imagem da região emissora da suposta linha de Bry em blueshift, são mostrados na figura 9.21.
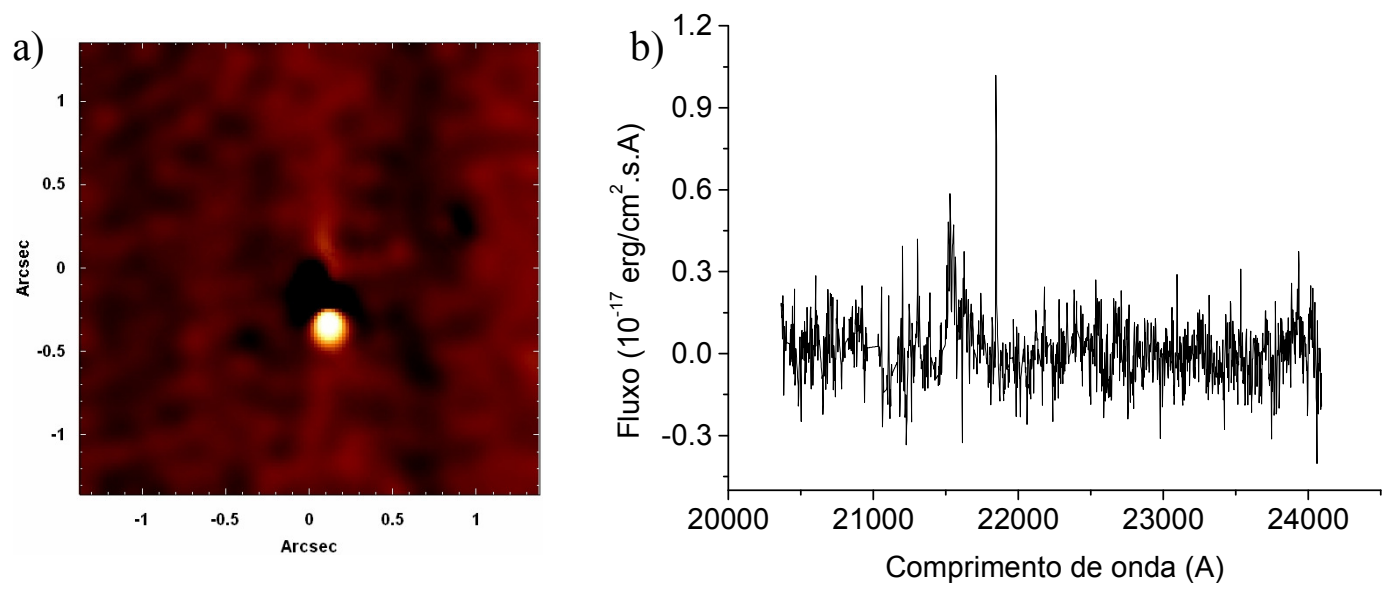

Figura 9.21 - (a) Imagem do intervalo espectral correspondente à região emissora da suposta linha de Bry em "blueshift"; (b) Espectro extraído de uma região circular, com raio igual a 0.105 ”, centrada na região emissora mostrada na figura à esquerda; (c) Composição RB contendo o tomograma mostrado na figura 9.18 (vermelho) e a imagem da região emissora da suposta linha de Bry em "blueshift" (azul). 


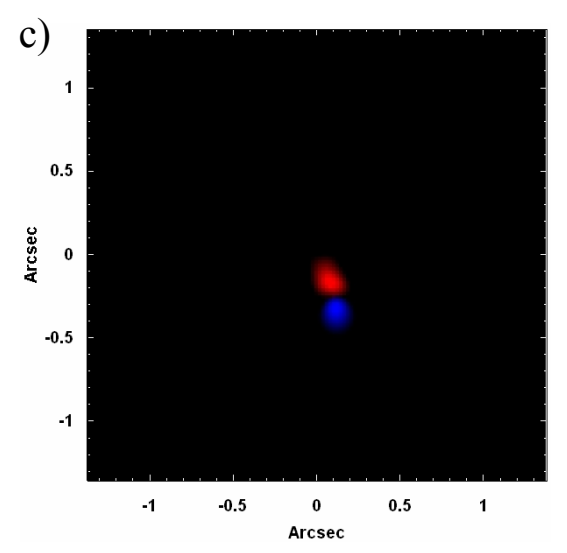

Figura 9.21 (continuação).

Analisando-se a imagem na figura 9.21, pode-se notar que alguns resquícios do fingerprint instrumental, que toma a forma de faixas verticais na imagem, ainda são visíveis (o que indica que esse fingerprint não foi totalmente removido com a subtração do contínuo estelar). Entretanto, isso praticamente não prejudicou a visualização da região emissora, que está localizada a cerca de $0.15 \pm 0.02$ " do AGN central, apresentando $P A=195.9^{\circ}$. Por outro lado, observando-se o espectro na figura 9.21, verifica-se que o ruído existente dificulta uma visualização precisa dos perfis das linhas de emissão presentes. De qualquer modo, a componente larga da suposta linha de Br $\gamma$ pode ser claramente detectada. Se essa linha for, de fato, Bry em blueshift, então, ela apresenta $z=-0.00609$, o que equivale a $v=-1827 \mathrm{~km} / \mathrm{s}$. A luminosidade obtida para essa linha foi de cerca de $3416 \mathrm{~L}_{\odot}$. Os resultados mostrados na figura 9.21 são compatíveis com os encontrados com as aplicações da Tomografia PCA aos cubos de dados de M87, antes e depois da subtração do contínuo estelar (figuras 9.10 e 9.19, respectivamente).

Batcheldor et al. (2010) detectaram a existência de um deslocamento entre o centro fotométrico de M87 e a posição do buraco negro central supermassivo, sendo a distância projetada de $6.8 \pm 0.8 \mathrm{pc}$. Os autores propuseram quatro explicações possíveis para esse fenômeno: aceleração do buraco negro induzida pelo jato, presença de um buraco negro supermassivo binário, existência de outros perturbadores massivos e a ocorrência do fenômeno do gravitational wave kick, conforme já havia sido mencionado na seção 9.1. Embora os autores tenham afirmado que a aceleração por um jato e a ocorrência do gravitational wave kick são as explicações mais compatíveis com o observado, a detecção de um possível segundo AGN pode 
estar relacionada à existência desse deslocamento entre o centro fotométrico de M87 e a posição do buraco negro central supermassivo. Esse segundo AGN poderia representar um perturbador massivo em relação ao buraco negro central, por exemplo. De qualquer modo, essa região emissora de Bry larga em M87 nunca foi detectada em estudos anteriores e representa, portanto, um achado bastante importante.

Observando-se o Scree test da figura 9.20, pode-se notar que os valores das variâncias explicadas pelos autovetores decaem bastante até, aproximadamente, o autovetor E18. A partir daí, a taxa de decaimento diminui bastante, ficando praticamente constante. Isso indica que autovetores de ordem maior ou igual a 18 representam, sobretudo, ruído e, consequentemente, não possuem relevância nessa análise. Entretanto, dentre os autovetores com ordens menores do que 18, apenas os dois primeiros apresentam uma interpretação clara e uma quantidade não tão alta de ruído, logo, apenas eles foram analisados aqui. Novamente, isso mostra que, embora o Scree test seja uma boa técnica para se avaliar a partir de que ordem os autovetores deixam de conter um sinal significativo e passam a ser dominados pelo ruído, há casos em que essa estratégia pode não ser precisa, e uma averiguação detalhada dos autovetores é sempre conveniente.

Assim, pode-se dizer que essa segunda análise com a Tomografia PCA apresentou resultados compatíveis com a primeira análise (seção 9.3) e, ao mesmo tempo, possibilitou que certos fenômenos fossem detectados de uma maneira mais clara. Primeiramente, essa segunda análise permitiu uma boa visualização da emissão proveniente do AGN, sendo que uma linha de Bry pôde ser observada. A primeira análise gerou resultados bastante similares. Além disso, a região emissora de uma suposta linha de Bry larga foi revelada de uma maneira mais precisa do que na análise da seção 9.3. É possível que essa área emissora corresponda a um segundo AGN remanescente de uma galáxia "canibalizada" por M87.

\section{6 - Cinemática estelar do cubo de dados de M87}

O processo do pPXF foi aplicado no cubo de dados de M87, a fim de se obter os valores da velocidade radial estelar, da dispersão de velocidades estelar e dos coeficientes de Gauss- 
Hermite $h_{3}$ e $h_{4}$ ao longo de todo o campo visual do NIFS. Os mapeamentos obtidos são mostrados na figura 9.22.
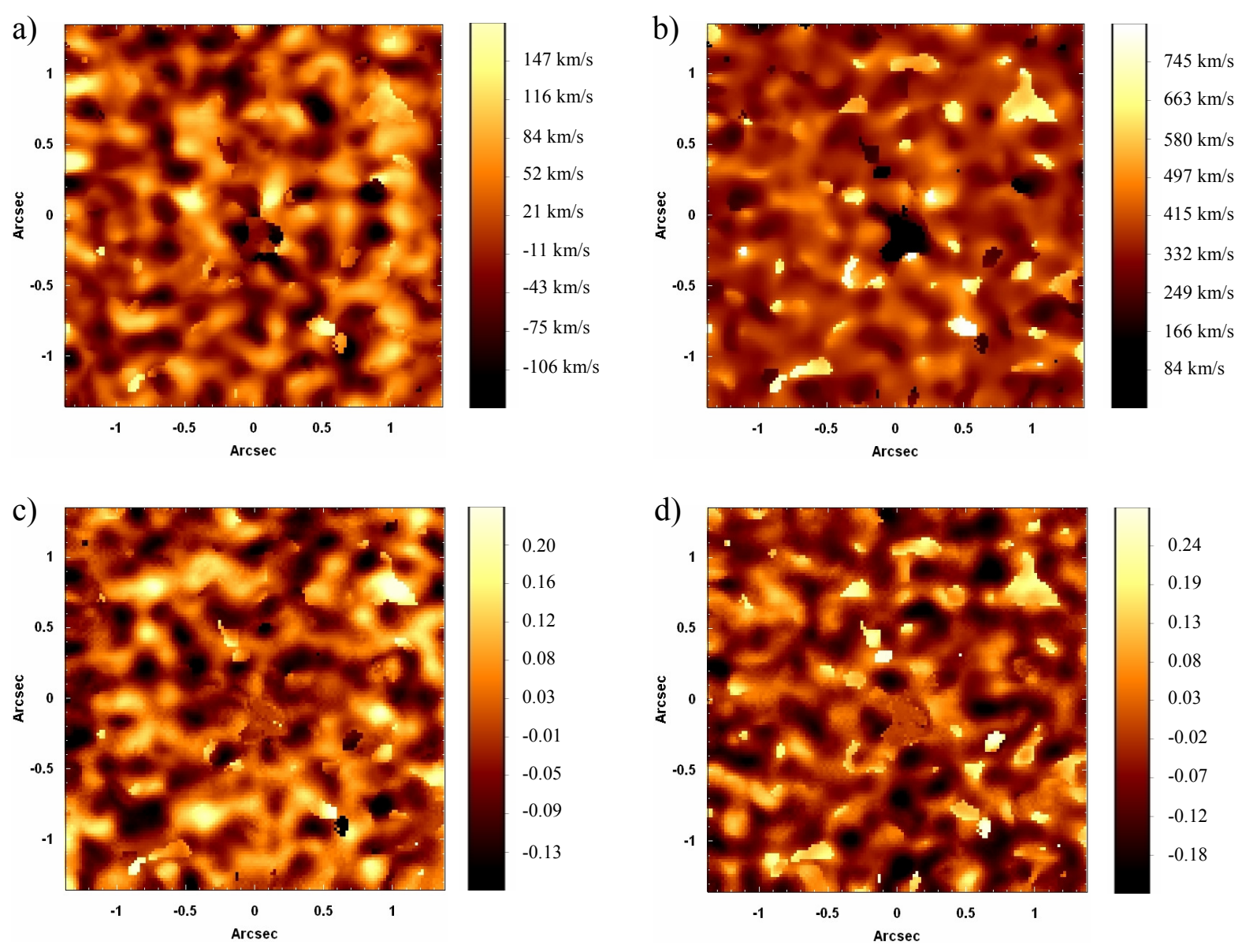

Figura 9.22 - Mapeamentos dos valores (a) da velocidade radial estelar, (b) da dispersão de velocidades estelar, (c) do coeficiente $h_{3} e(d)$ do coeficiente $h_{4}$, obtidos com a aplicação do pPXF ao cubo de dados de M87.

Os mapeamentos na figura 9.22 não revelaram comportamentos ou configurações dominantes nos valores da velocidade radial estelar, da dispersão de velocidades estelar, de $h_{3}$ e de $h_{4}$ que pudessem ser claramente observados. É possível, entretanto, que essa não detecção de padrões ou estruturas seja devida ao fato de as bandas de CO desse cubo serem relativamente tênues, o que, conforme foi discutido anteriormente, pode ter dificultado bastante a aplicação do pPXF. A figura $9.22-b$ revela uma aparente diminuição dos valores da dispersão de velocidades estelar na região correspondente ao AGN central. Entretanto, assim como nos casos de NGC 2992, NGC 4151 e NGC 3227, é provável que isso seja apenas uma conseqüência do fato de o contínuo nessa área ser dominado pela emissão térmica de poeira, o que tornava as 
bandas de $\mathrm{CO}$ mais fracas do que no restante do cubo, dificultando ainda mais o ajuste. Observando-se a escala de valores da dispersão de velocidades estelar, verifica-se que valores consideravelmente elevados, de até $827 \mathrm{~km} / \mathrm{s}$, são atingidos. Entretanto, pode-se notar que essas dispersões de velocidades elevadas apenas ocorrem em pequenas áreas, menores do que a resolução espacial do cubo de dados, ao longo do campo de visão. Isso pode indicar que esses valores elevados não sejam reais, mas sim uma conseqüência de imprecisões nos ajustes, possivelmente geradas pelo fato das bandas de $\mathrm{CO}$ não serem muito intensas.

Como o mapa da figura 9.22 - a não revelou nenhum claro padrão rotacional e, assim como o mapeamento dos valores da dispersão de velocidades estelar na figura $9.22-b$, apresentou uma série de irregularidades e possíveis regiões com valores não confiáveis (como a posição correspondente ao AGN), optou-se por não aplicar nenhum tipo modelagem com o intuito de se determinar a massa do buraco negro central existente em M87. Como o cubo de dados desse objeto praticamente não possui linhas de emissão significativas, também não foi possível fazer qualquer análise relacionada à cinemática do gás.

\section{7 - Conclusões}

Em suma, pode-se dizer, primeiramente, que as análises com a Tomografia PCA permitiram uma boa visualização da emissão proveniente do AGN central de M87, que nesse caso, se resume essencialmente a uma linha de Bry consideravelmente tênue. Fora isso, os cubos de dados desse objeto praticamente não apresentaram linhas de emissão significativas. Tanto a aplicação da Tomografia PCA ao cubo de dados com o contínuo estelar quanto a síntese espectral realizada com o software Starlight mostraram a existência de uma região com emissão térmica de poeira, que apresentava um formato "esticado" ao longo de uma direção aproximadamente perpendicular à do jato em rádio presente. Isso sugere que tal região pode representar um toro de poeira ao redor do AGN, o que estaria de acordo com as previsões do Modelo Unificado. Entretanto, não é possível garantir que o formato “esticado" da estrutura seja realmente um indicativo de um toro, já que o seu tamanho aparente é bastante próximo à resolução espacial do cubo de dados, o que tornou difícil a visualização dos detalhes. A síntese espectral com o Starlight revelou, ainda, a presença de um featureless continuum ao longo de 
duas regiões quase perpendiculares à direção do suposto toro de poeira, correspondente à estrutura "esticada" mencionada anteriormente. Isso sugere que o contínuo emitido pelo AGN pode estar sofrendo um espalhamento por poeira ao longo de uma direção aproximadamente perpendicular à do toro. Sem dúvida, um dos pontos mais importantes nesse estudo sobre M87 foi a detecção, por meio das aplicações da Tomografia PCA, de uma região emissora de uma suposta linha de Bry larga em blueshift, situada a uma distância de cerca de $0.15 \pm 0.02$ " da posição correspondente ao AGN e com $P A=195.9^{\circ}$. Uma segunda linha de emissão, bem mais estreita, também foi detectada no espectro dessa área emissora, entretanto, a sua identificação ainda não está clara. Um imageamento da região espectral correspondente à suposta linha de Br $\gamma$ em blueshift permitiu uma visualização mais clara da área emissora, ao passo que a extração de seu espectro (a partir de uma região circular de raio 0.105 " centrada na área emissora) revelou um fluxo integrado de cerca de $4.27 \cdot 10^{-16} \mathrm{erg} / \mathrm{cm}^{2}$.s para a linha em questão. Uma possível explicação para a emissão proveniente dessa região próxima ao AGN central de M87 é que, na verdade, se trata de um segundo AGN, com uma componente radial de velocidade no sentido do observador. Esse segundo objeto pode tanto estar em movimento ao redor do AGN central quanto pode nem sequer fazer parte de M87 e, nesse caso, o que se vê nos resultados seria, apenas, um efeito de projeção. No caso de se tratar, de fato, de um segundo AGN em movimento ao redor daquele existente no centro de M87, então, é possível que a estrutura detectada represente um remanescente de uma galáxia "canibalizada" por M87, o que seria compatível com o fato dessa última estar localizada no centro do aglomerado de Virgo. Os mapeamentos obtidos com o pPXF, aparentemente, não revelaram quaisquer padrões associados aos valores da velocidade radial estelar, da dispersão de velocidades estelar e dos coeficientes de Gauss-Hermite $h_{3}$ e $h_{4}$. 
462 


\section{0 - NGC 4594 (M104)}

\section{1 - Introdução}

M104 (a galáxia Sombrero) é uma galáxia de tipo SA(s)a altamente inclinada (quase edge-on) que se encontra a uma distância de cerca de $9.2 \mathrm{Mpc}$. Por se tratar de um objeto bastante próximo e brilhante, M104 já foi observada em diversas bandas espectrais. Com base no seu espectro de emissão óptico, o núcleo desse objeto foi classificado como LINER por Heckman (1980).

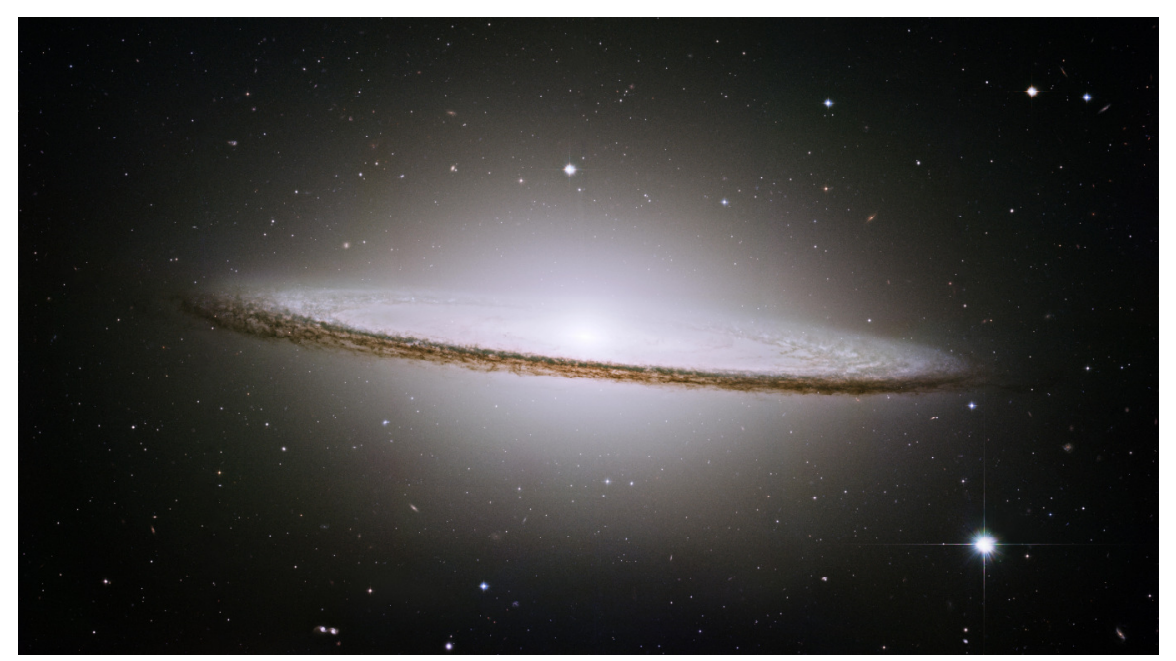

Figura 10.1 - Imagem da galáxia M104 na banda V, obtida com o HST.

Observações feitas em rádio mostraram que essa galáxia possui uma fonte nuclear compacta ( $\leq 1$ pc) nessa região espectral. Hummel et al. (1984), utilizando observações do contínuo em rádio em $2.6 \mathrm{~cm}$ e $20 \mathrm{~cm}$, feitas com o VLA, concluíram que a fonte nuclear desse objeto apresenta um espectro plano e Bajaja et al. (1988), analisando dados em $1.49 \mathrm{GHz}$, também obtidos com o VLA, detectaram um contínuo variável nessa fonte. Essas propriedades são consistentes com o modelo de acreção em um buraco negro central supermassivo. 


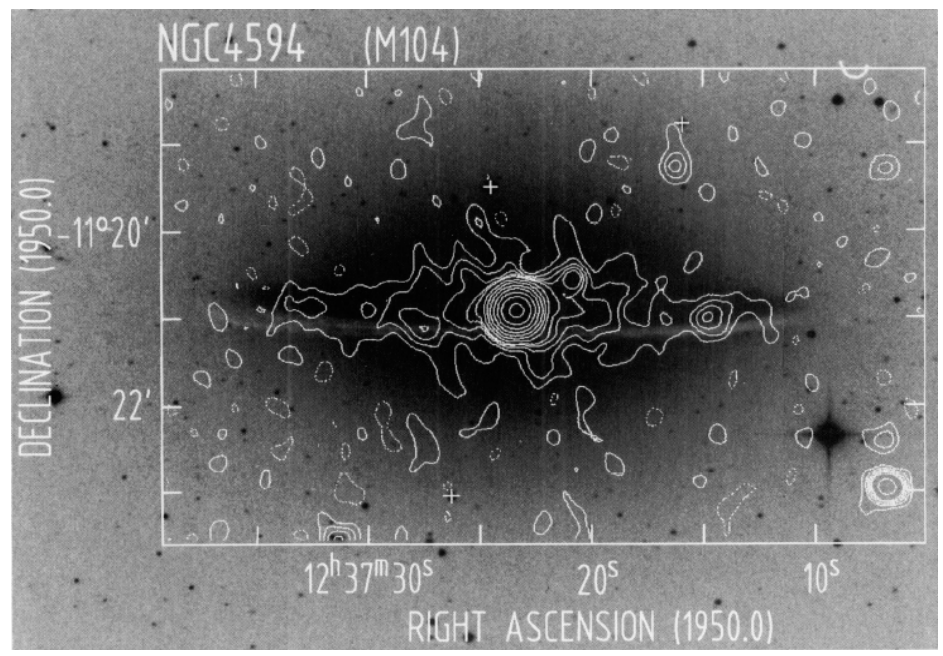

Figura 10.2 - Mapa do contínuo em $1.49 \mathrm{GHz}$ de M104, sobreposto a uma imagem óptica dessa galáxia, obtido a partir do trabalho de Bajaja et al (1988).

$\mathrm{Na}$ região espectral dos raios-X, M104 foi observada por diferentes instrumentos. Fabbiano et al. (1992) analisaram dados de resolução angular de cerca de 50", obtidos pelo observatório Einstein, e determinaram para essa galáxia uma luminosidade de $L_{x}=1.1 \cdot 10^{41}$ erg/s, em 0.2-4 keV. Fabbiano \& Judá (1997) examinaram dados do satélite ROSAT (com uma resolução de cerca de 5", ou seja, consideravelmente melhor do que a do observatório Einstein) e detectaram uma fonte puntual emissora de raios-x com uma luminosidade $L_{x}=3.5 \cdot 10^{40} \mathrm{erg} / \mathrm{s}$ (essa é a luminosidade proveniente dos 15" centrais, $1.5 \mathrm{kpc}$, da galáxia). Pellegrini et al. (2002) analisaram dados obtidos do Beppo SAX e do Chandra e observaram uma fonte puntual de raios-x duros $(>2 \mathrm{keV})$ no núcleo dessa galáxia, com uma luminosidade $L_{x}=1.2-2.3 \cdot 10^{40} \mathrm{erg} / \mathrm{s}$, em 2-10 keV, cujo espectro é bem modelado por uma lei de potência. A figura 10.3 mostra a fonte puntual de raios-x duros detectada pelo Chandra nesse trabalho.

M104 também já foi observada no ultravioleta. Reichert et al. (1993) analisaram dados obtidos com o International Ultraviolet Explorer (IUE) e verificaram que o espectro dessa galáxia apresenta a linha de absorção de Fe II $\lambda 1610$, o que sugere a presença de estrelas supergigantes azuis formadas nos últimos $10^{7}$ a $10^{8}$ anos. Também foi detectada uma possível linha de emissão de C III $\lambda 1909$.

Vários trabalhos também analisaram dados de M104 na região espectral do óptico, obtidos tanto do solo (Ho et al. 1995; 1997) quanto com o HST (Kormendy et al. 1996).

Bendo et al. (2006), utilizando dados no infravermelho de M104, obtidos com o Spitzer e com o JCMT (James Clerk Maxwell Telescope) do SCUBA (Submillimetre Common-User 
Bolometer Array), concluíram que a SED do núcleo dessa galáxia revela a presença de poeira quente. Além disso, o pouco fluxo em $160 \mu \mathrm{m}$ parece indicar que a emissão LINER é uma conseqüência da falta de gás frio necessário para abastecer uma possível atividade Seyfert mais intensa.

Nicholson et al. (1998) analisaram dados do HST e do ASCA e verificaram que o modelo de um AGN de baixa luminosidade (ao invés de um starburst nuclear) é o mais adequado para explicar o espectro de emissão dessa galáxia. O melhor ajuste foi obtido com um modelo de fotoioinzaçào por um AGN com um parâmetro de ionização $U=3.2 \cdot 10^{-4}$. Modelos envolvendo aquecimento por choques foram incompatíveis com os dados observados.

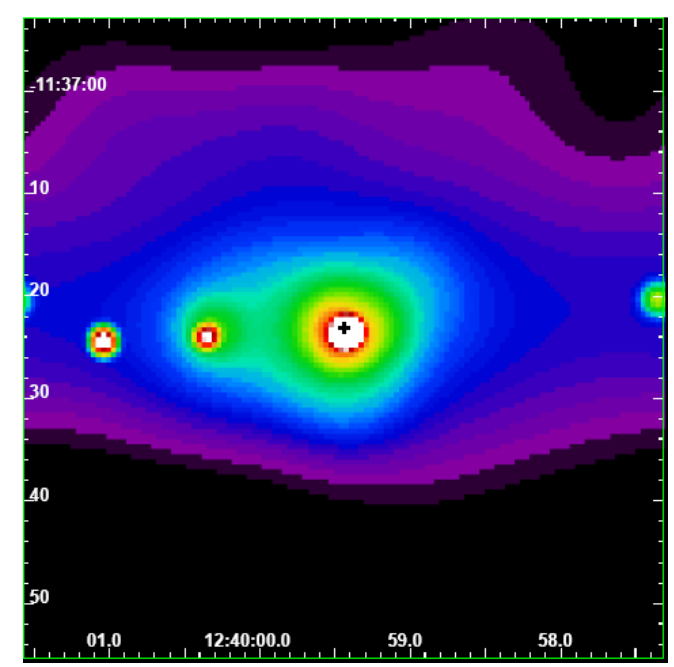

Figura 10.3 - Imagem de 1'x1' da região central de M104, obtida com o Chandra, na região espectral 0.3-7 keV, retirada do trabalho de Pellegrini et al. (2002). A posição de uma fonte em rádio não resolvida, detectada pelo VLA em $8.4 \mathrm{GHz}$ (Thean et al. 2000), é mostrada com uma cruz.

M104 foi uma das primeiras galáxias na qual foi descoberta a presença de um buraco negro supermassivo em seu núcleo. Kormendy (1988), utilizando dados obtidos com o CFHT, encontrou evidências da presença de um buraco negro com massa de cerca de $10^{9} \mathrm{M}_{\odot}$ no núcleo dessa galáxia. Posteriormente, com modelos de Jeans isotrópicos e dados novamente obtidos com o CFHT, Emsellem et al. (1994) também detectaram a presença de um objeto com massa próxima a $10^{9} \mathrm{M}_{\odot}$ no núcleo de M104. Kormendy et al. (1996), utilizando cinemática de alta resolução obtida com o HST, confirmaram a presença do buraco negro com a massa mencionada. Magorrian et al. (1998), usando modelos isotrópicos, fotometria do HST e cinemática obtida a partir de observações no solo, determinaram uma massa de $6.5 \cdot 10^{8} \mathrm{M}_{\odot}$ para 
o buraco negro existente em M104. Finalmente, Jardel et al. (2011), utilizando modelos simétricos de órbitas, determinaram uma massa de $6.6 \cdot 10^{8} \mathrm{M}_{\odot}$ para esse buraco negro.

Utilizando dados fotométricos do CFHT e do HST, juntamente com espectroscopia bidimensional obtida com o espectrógrafo de campo integrado TIGER, Emsellem et al. (1996) concluíram que a distribuição estelar em M104 possui 4 componentes principais: um bojo massivo, que fica ligeiramente mais azul à medida que o raio aumenta, com uma metalicidade central próxima à solar e um halo externo mais pobre em metais; um anel estelar externo, conhecido como o disco principal, sem evidência significativa de gradiente radial de cor ou gradiente de intensidade de linhas, e apenas um pouco mais vermelho do que o bojo interno; um disco interno com rápida rotação, que é significativamente mais vermelho do que os arredores e mais rico em metais; um núcleo puntual (não resolvido).

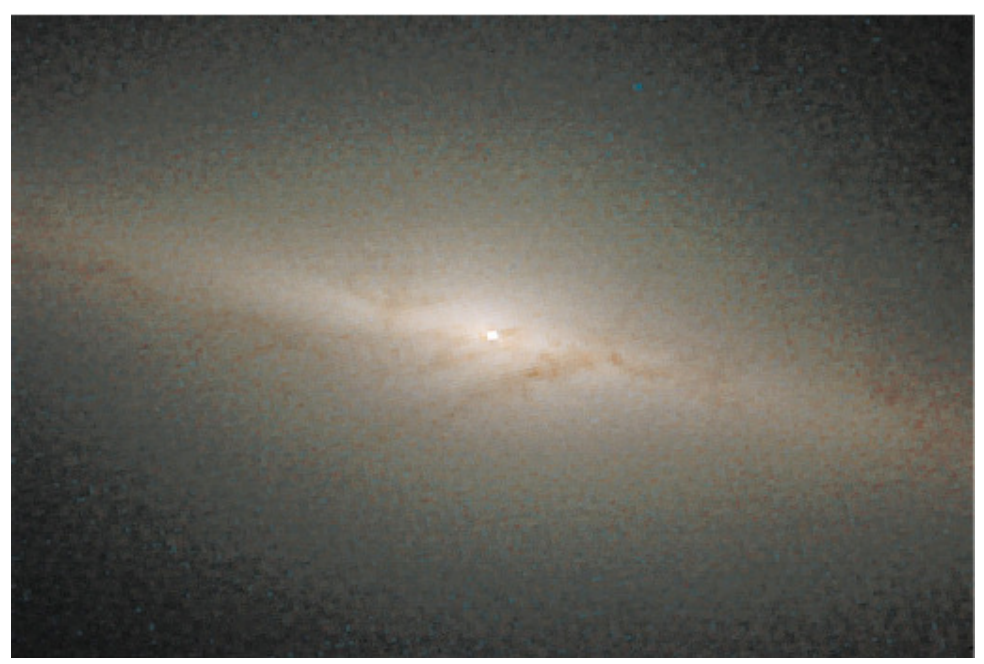

Figura 10.4 - Imagem da região central da galáxia M104, obtida com o HST, retirada do trabalho de Kormendy et al. (1996). A orientação é norte para cima e leste para a esquerda.

\section{2 - Preparação dos cubos de dados de M104}

Nesse trabalho, foram analisados cubos de dados da região central de M104, tanto no óptico quanto na banda $\mathrm{K}$ do infravermelho próximo. No óptico, os cubos foram obtidos com o IFU do GMOS do telescópio Gemini-Sul e, no infravermelho próximo, os cubos foram resultantes de observações com o NIFS do telescópio Gemini-Norte. 


\subsection{1 - Redução e tratamento dos cubos de dados obtidos com o GMOS}

A redução dos cubos de dados obtidos com o GMOS foi feita em ambiente IRAF, utilizando-se o pacote de tarefas Gemini. Ao final desse processo, foram obtidos 3 cubos de dados com pixeis espaciais de $0.05 \%$ de lado.

Depois da redução, aplicou-se a correção da refração atmosférica diferencial em cada um dos cubos de dados. Em seguida, calculou-se a mediana entre eles, a fim de se combinar todos esses cubos em um só.

Aplicou-se, então, uma decomposição wavelet no cubo de dados, obtendo-se, ao final, os cubos $W_{0}, W_{1}, W_{2}, W_{3}, W_{4}$ e $W_{C}$. Utilizou-se $W_{0}$ para se determinar os parâmetros mais adequados para serem utilizados na filtragem espacial de Butterworth, que foi aplicada em todas as outras componentes wavelet e também no cubo de dados original. No caso desse objeto, todas as filtragens foram feitas utilizando-se um filtro com forma dada pela expressão (3.67), $n=2 \mathrm{e}$ freqüência de corte ao longo dos eixos horizontal e vertical de $v_{c}=0.19 \mathrm{Ny}$. A figura 10.5 mostra as somas das imagens do cubo de dados, antes e depois da filtragem espacial de Butterworth, assim como a soma das imagens do cubo correspondente à diferença entre esses dois.
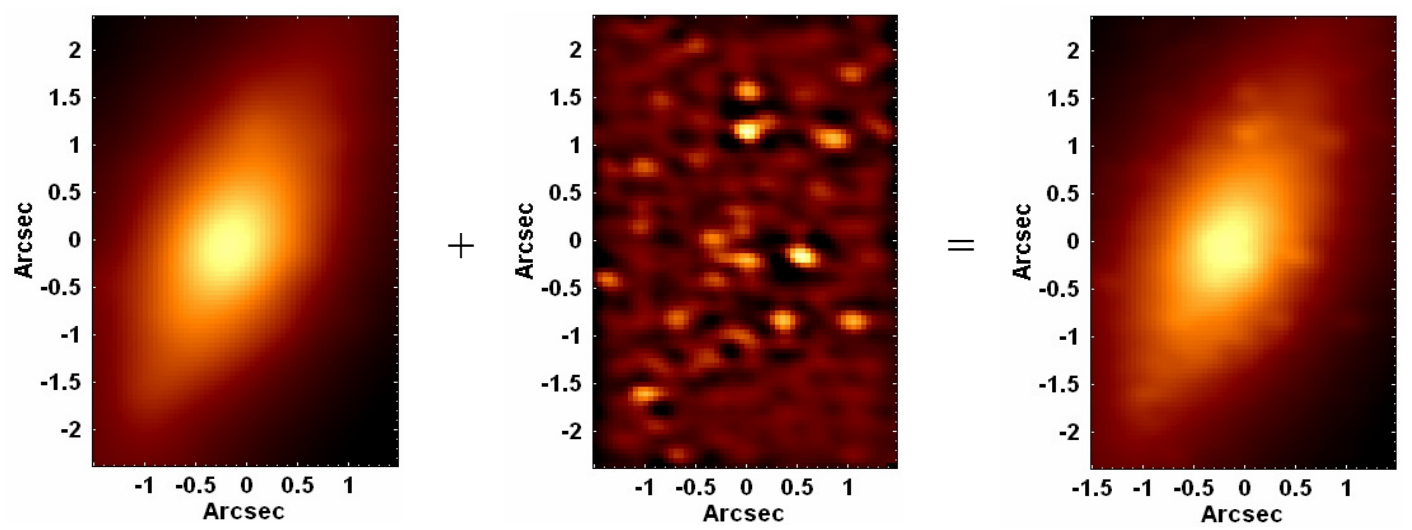

Figura 10.5 - (esquerda) Soma das imagens do cubo de dados de M104 obtido com o GMOS, após a filtragem espacial de Butterworth; (centro) Soma das imagens do cubo de dados de M104 obtido com o GMOS, correspondente à diferença entre o cubo não filtrado e o cubo filtrado; (direita) Soma das imagens do cubo de dados de M104 obtido com o GMOS, antes da filtragem espacial de Butterworth. 
Observando-se a figura 10.5, pode-se notar que a filtragem espacial de Butterworth removeu grande parte dos ruídos de alta freqüência sem afetar o valor da PSF, o que resultou em uma considerável melhoria na qualidade das imagens do cubo de dados.

Após a aplicação da filtragem espacial de Butterworth, verificou-se que o cubo de dados ainda apresentava um fingerprint instrumental de baixa freqüência espacial, que tomava a forma de faixas verticais na imagem e possuía uma assinatura espectral característica. Para se remover essa estrutura do cubo de dados, aplicou-se o procedimento descrito em 3.11. A figura 10.6 mostra o tomograma e o auto-espectro correspondentes ao autovetor E4 (que é o que revela o fingerprint existente de maneira mais clara), resultante da aplicação da Tomografia PCA ao cubo de dados de M104 obtido com o GMOS, após a remoção das linhas espectrais, assim como o resultado encontrado após o ajuste e a subtração de um spline do auto-espectro.
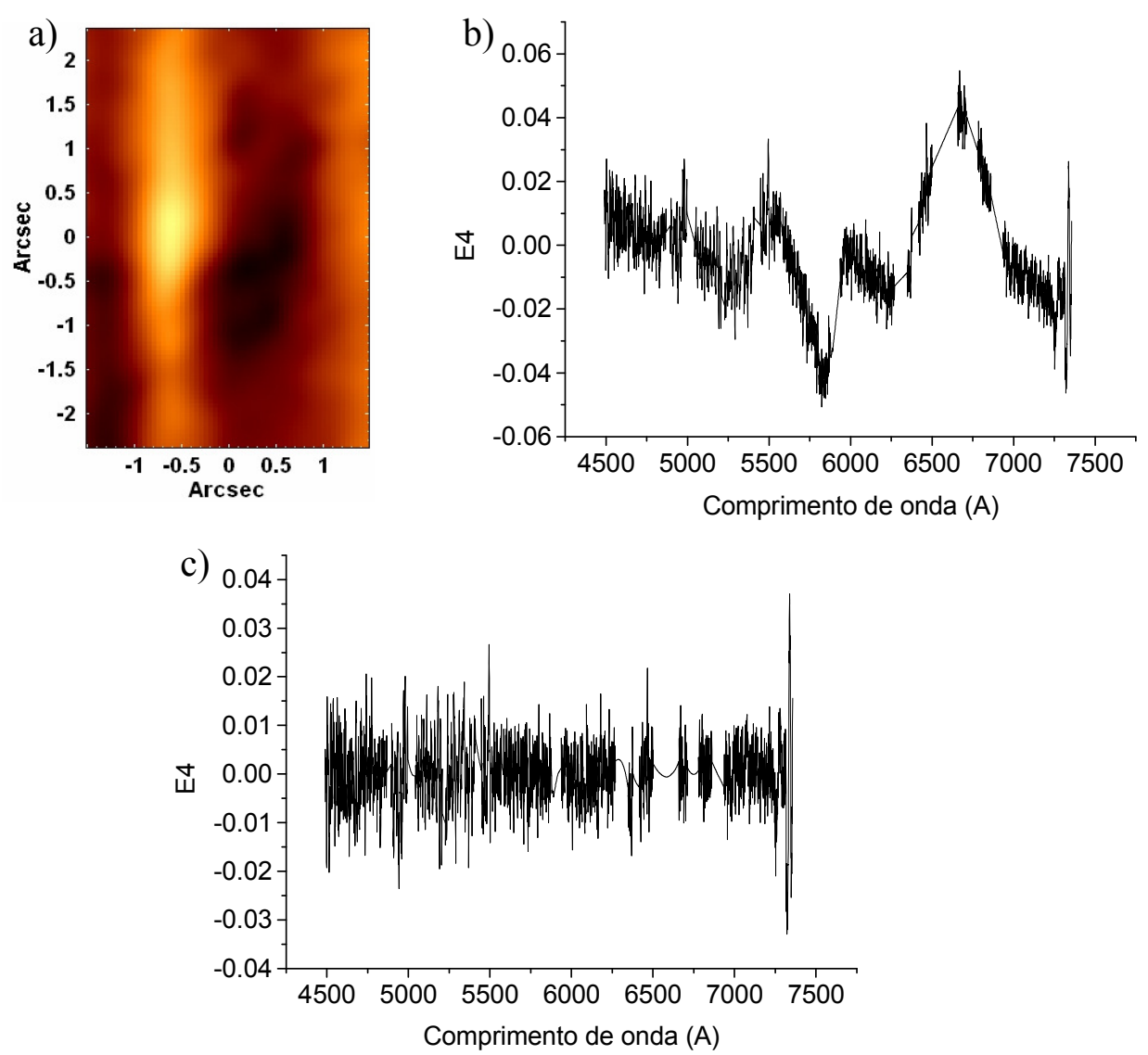

Figura 10.6 - (a) Tomograma correspondente ao autovetor E4, resultante da Tomografia PCA aplicada ao cubo de dados de M104 obtido com o GMOS, após a remoção das linhas espectrais; (b) Auto-espectro correspondente ao autovetor E4, resultante da Tomografia PCA aplicada ao cubo de dados de M104 obtido com o GMOS, após a remoção das linhas espectrais; (c) Mesmo auto-espectro mostrado em (b), após a subtração do "spline" ajustado. 
Por fim, passou-se para a etapa da deconvolução de Richardson-Lucy. Esse procedimento foi aplicado utilizando-se uma PSF gaussiana variável com o comprimento de onda, conforme descrito em 3.9.1, sendo que um valor de referência para o $F W H M$ da gaussiana foi obtido a partir da imagem de aquisição da observação e a forma de variação do $F W H M$ com o comprimento de onda foi estimada a partir do cubo de dados da estrela padrão utilizada para a calibração em fluxo. É importante mencionar que, antes desse processo, a filtragem espacial de Butterworth foi aplicada no cubo da estrela padrão. Foram utilizadas 10 iterações na deconvolução de Richardson-Lucy do cubo de dados de M104 obtido com o GMOS. A figura 10.7 mostra a soma de todas as imagens e o espectro médio do cubo de dados de M104 obtido com o GMOS, após a aplicação da deconvolução de Richardson-Lucy.
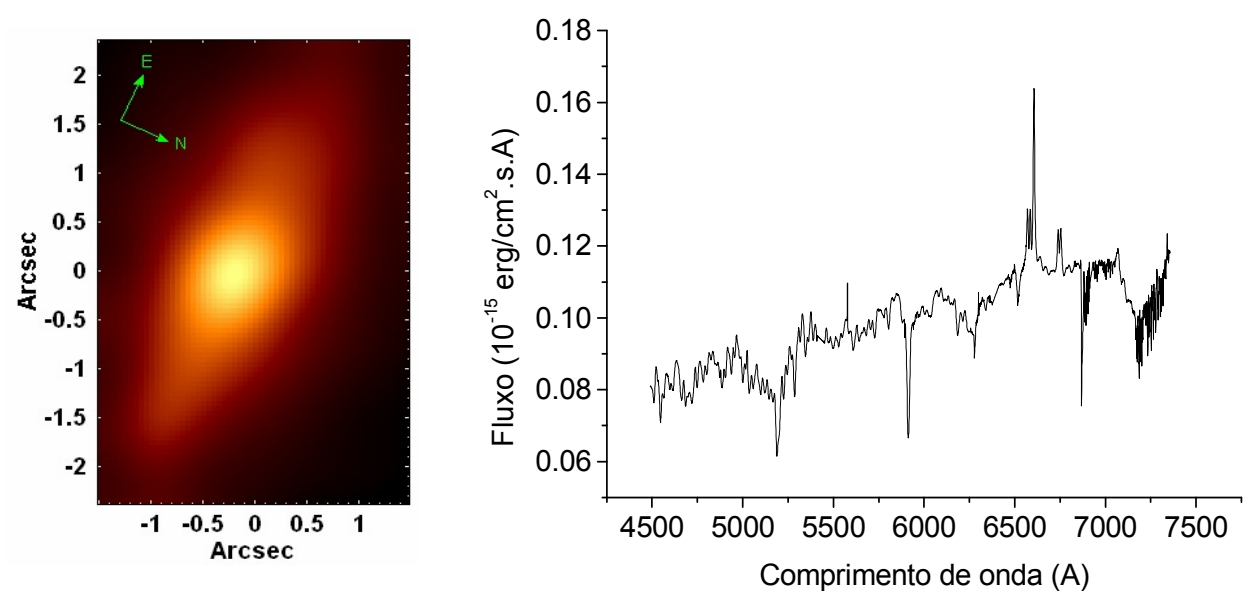

Figura 10.7 - (esquerda) Soma de todas as imagens do cubo de dados de M104 obtido com o GMOS, após todo o processamento; (direita) Espectro médio do cubo de dados de M104 obtido com o GMOS, após todo o processamento.

\subsection{2 - Redução e tratamento dos cubos de dados obtidos com o NIFS}

A redução dos cubos de dados obtidos com o NIFS foi feita em ambiente IRAF, utilizando-se o pacote de tarefas Gemini, conforme explicado em 3.2.2. Ao final desse processo, foram obtidos 5 cubos de dados com pixeis espaciais de 0.05 " de lado.

Após a redução dos dados, foi aplicada a correção da refração atmosférica diferencial em cada um dos cubos de dados. Em seguida, a fim de se combinar todos esses cubos em um só, primeiramente, eles foram separados em dois grupos. Nomeando-se os cubos como 1, 2, 3, 4 e 5 
(de acordo com a ordem de observação), a separação nos dois grupos foi feita da seguinte maneira:

- Grupo 1: cubos 1, 2 e 5

- Grupo 2: cubos 1, 3 e 4

Os integrantes de cada um desses grupos foram combinados na forma de mediana, resultando, portanto, em dois cubos de dados ao final do processo. Calculou-se, então, uma média desses dois cubos de dados, obtendo-se o cubo combinado procurado.

Após esse procedimento, aplicou-se uma reamostragem espacial no cubo de dados encontrado, a fim de se obter pixeis espaciais de 0.021 " de lado. A figura 10.8 mostra a soma de todas as imagens do cubo de dados de M104 obtido com o NIFS, antes e depois do processo de reamostragem.
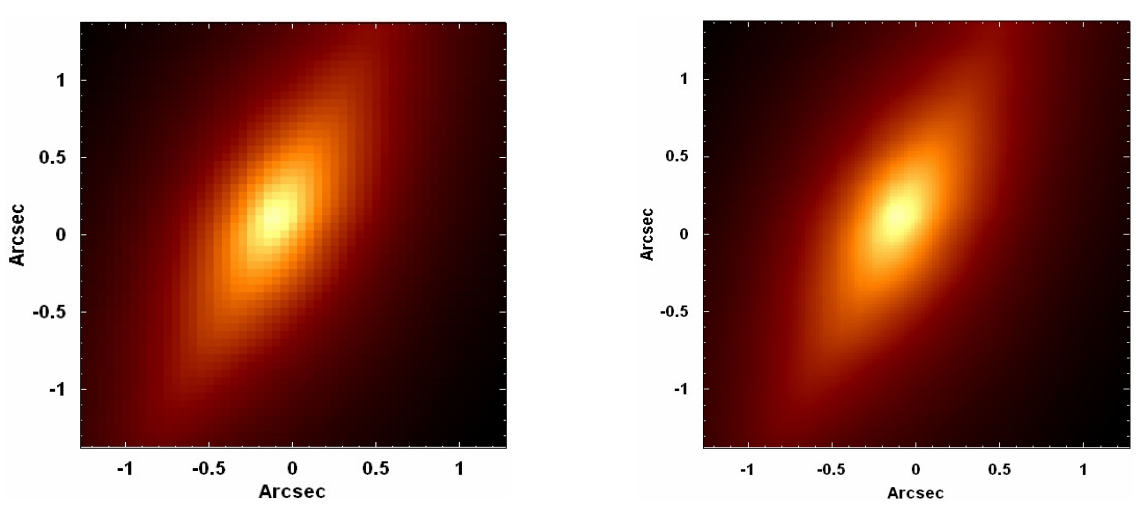

Figura 10.8 - (esquerda) Soma de todas as imagens do cubo de dados de M104 obtido com o NIFS, antes da aplicação da reamostragem espacial; (direita) Soma de todas as imagens do cubo de dados de M104 obtido com o NIFS, após a aplicação da reamostragem espacial.

A figura 10.8 revela que a aplicação da reamostragem espacial fez com que as estruturas espaciais visíveis no cubo de dados ficassem melhor definidas, entretanto, esse processo, também introduziu componentes de alta freqüência espacial, que são visíveis, sobretudo, como tênues estrias ao longo da imagem.

Aplicou-se, então, uma decomposição wavelet no cubo de dados reamostrado, com a conseqüente obtenção dos cubos $W_{0}, W_{1}, W_{2}, W_{3}, W_{4}$ e $W_{C}$. Utilizou-se $W_{0}$ para se determinar os parâmetros mais adequados para o filtro de Butterworth e, a seguir, tais parâmetros foram utilizados na filtragem espacial de todas as outras componentes wavelet e também do cubo de 
dados original. No caso desse objeto, todas as filtragens foram feitas utilizando-se um filtro com forma dada pela expressão (3.68), $n=2$ e freqüência de corte ao longo dos eixos horizontal e vertical de $v_{c}=0.19 \mathrm{Ny}$. A figura 10.9 mostra as somas das imagens do cubo de dados, antes e depois da filtragem espacial de Butterworth, assim como a soma das imagens do cubo correspondente à diferença entre esses dois.
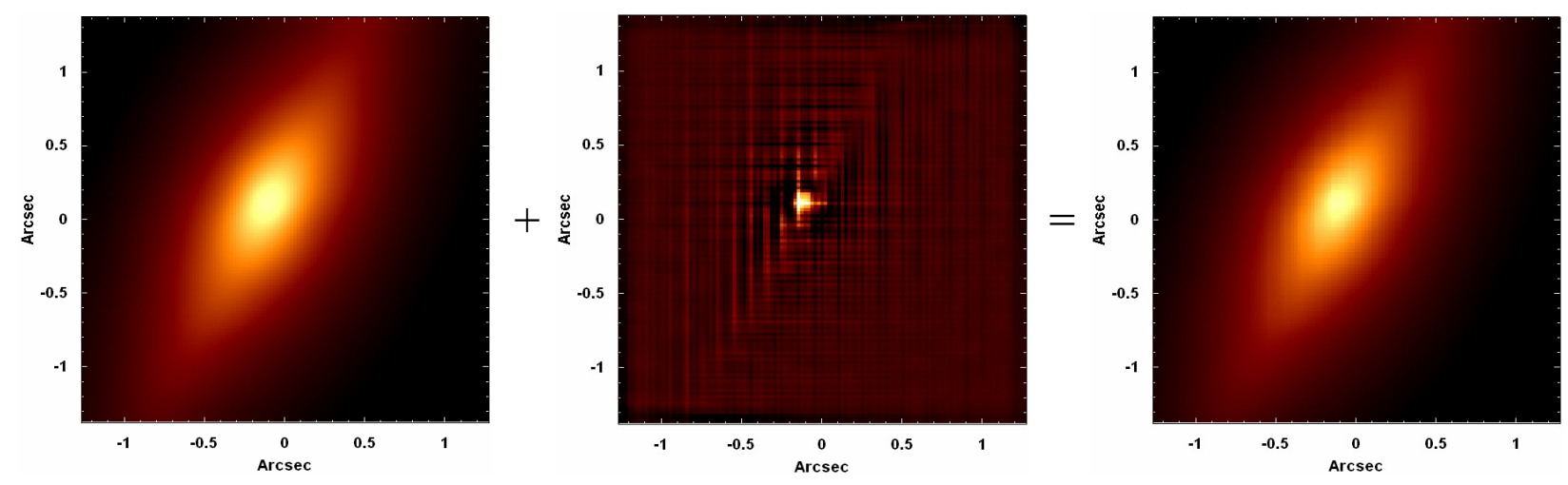

Figura 10.9 - (esquerda) Soma das imagens do cubo de dados de M104 obtido com o NIFS, após a filtragem espacial de Butterworth; (centro) Soma das imagens do cubo de dados de M104 obtido com o NIFS, correspondente à diferença entre o cubo não filtrado e o cubo filtrado; (direita) Soma das imagens do cubo de dados de M104 obtido com o NIFS, antes da filtragem espacial de Butterworth.

Observando-se a figura 10.9, pode-se notar que a aplicação da filtragem espacial de Butterworth removeu uma grande quantidade de ruídos de alta freqüência (inclusive as componentes de alta freqüência introduzidas pela reamostragem espacial), o que proporcionou uma melhoria na qualidade das imagens do cubo de dados.

Após a aplicação da filtragem espacial de Butterworth, verificou-se que, assim como no caso da seção 10.2.1, o cubo de dados de M104 obtido com o NIFS ainda apresentava um fingerprint instrumental, que tomava a forma de uma série de faixas verticais na imagem. Esse fingerprint também possuía uma assinatura espectral bastante característica. A fim de se remover essa estrutura do cubo de dados, aplicou-se o procedimento descrito em 3.11. A figura 10.10 mostra o tomograma e o auto-espectro correspondentes ao autovetor E5 (que é o que revela o fingerprint existente de maneira mais clara), resultante da Tomografia PCA do cubo de dados de M104 obtido com o NIFS, após a remoção das linhas espectrais, assim como o resultado encontrado após o ajuste e a subtração de um spline do auto-espectro. 

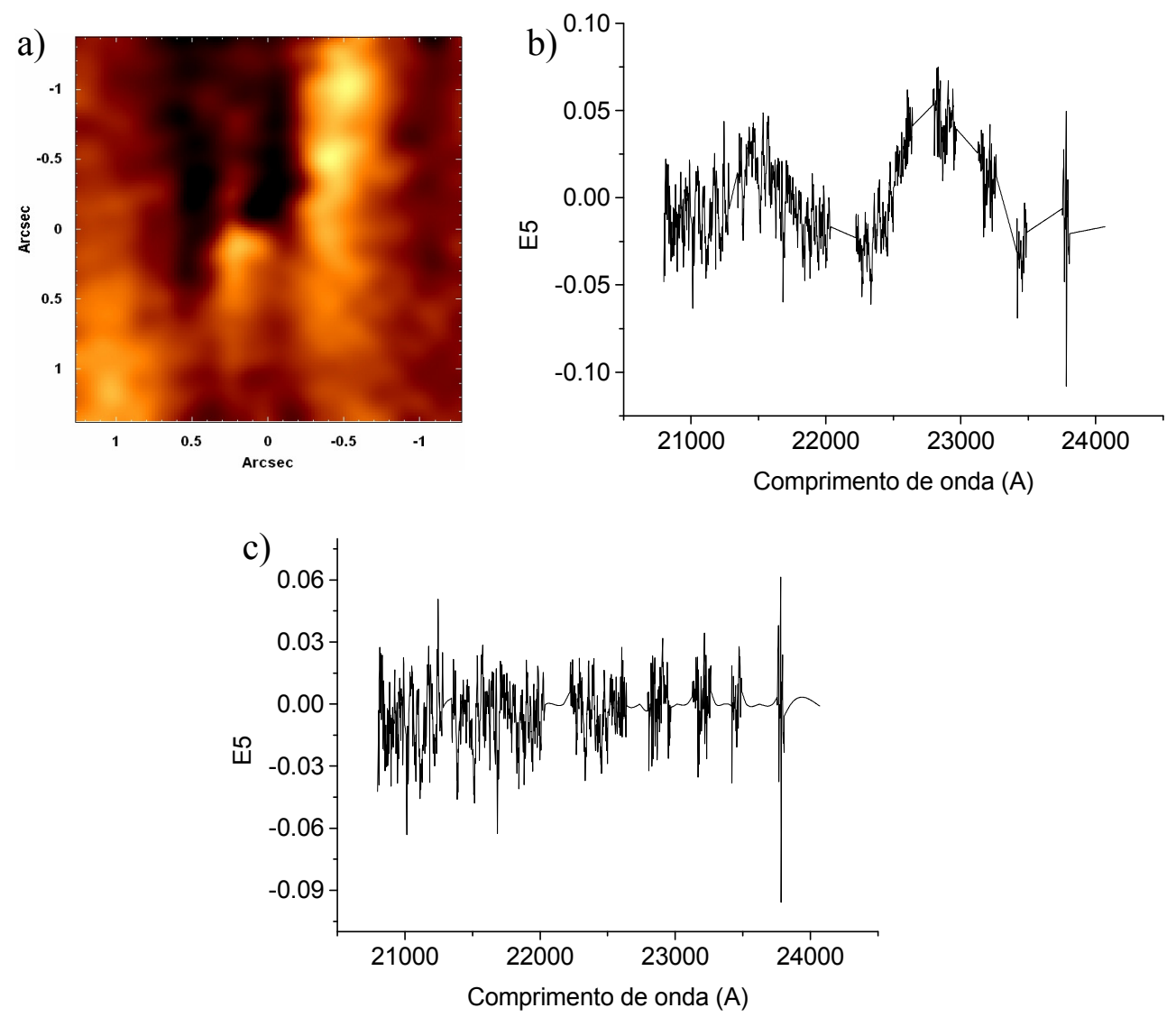

Figura 10.10 - (a) Tomograma correspondente ao autovetor E5, resultante da Tomografia PCA aplicada ao cubo de dados de M104 obtido com o NIFS, após a remoção das linhas espectrais; (b) Auto-espectro correspondente ao autovetor E5, resultante da Tomografia PCA aplicada ao cubo de dados de M104 obtido com o NIFS, após a remoção das linhas espectrais; (c) Mesmo auto-espectro mostrado em (b), após a subtração do "spline” ajustado.

Finalmente, passou-se para a etapa da deconvolução de Richardson-Lucy. Como esse objeto não possui linhas espectrais com uma componente larga visível nessa região espectral, não foi possível utilizar a imagem da asa larga de nenhuma linha como estimativa da PSF. Assim, utilizou-se como PSF uma imagem proveniente do cubo de dados da estrela padrão usada no processo de redução dos dados para a remoção das absorções telúricas e para a calibração em fluxo. Para se fazer isso, entretanto, foi preciso aplicar no cubo de dados dessa estrela padrão o mesmo processamento utilizado no cubo de M104, ou seja, foi feita a reamostragem espacial e a filtragem espacial de Butterworth desse cubo. Uma vez obtida a imagem correspondente à PSF, foi aplicada a deconvolução de Richardson-Lucy no cubo de dados de M104 obtido com o NIFS, utilizando-se 10 iterações. A figura 10.11 mostra a soma de todas as imagens e o espectro médio do cubo de dados final, após a aplicação da deconvolução de Richardson-Lucy. 

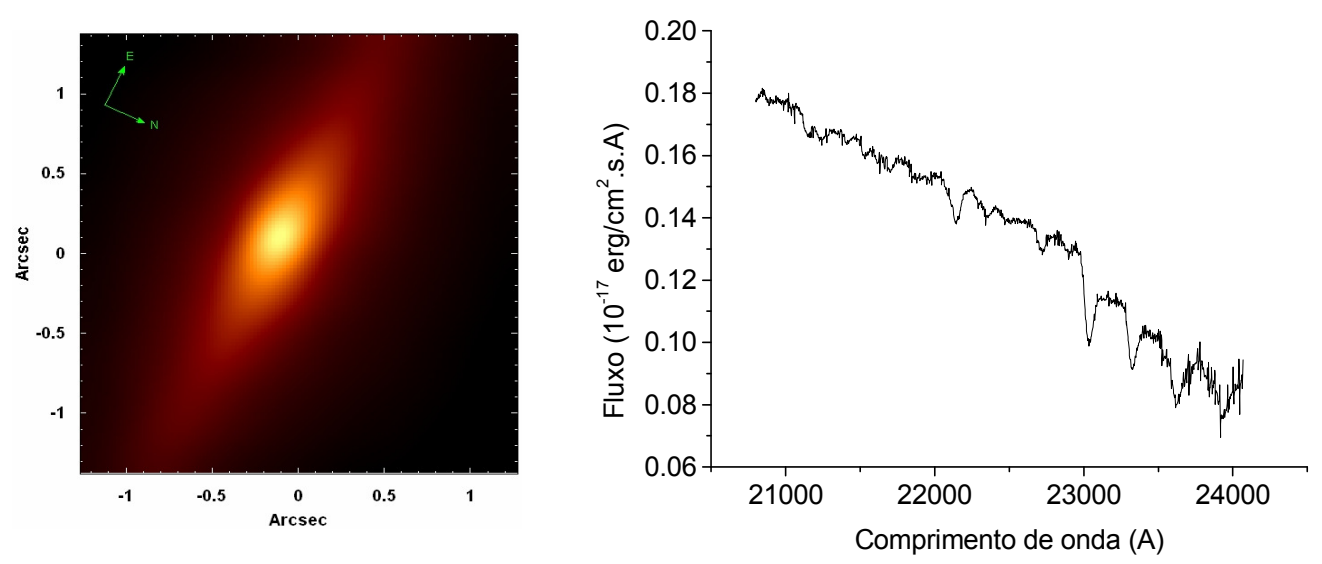

Figura 10.11 - (esquerda) Soma de todas as imagens do cubo de dados de M104 obtido com o NIFS, após todo o processamento; (direita) Espectro médio do cubo de dados de M104 obtido com o NIFS, após todo o processamento.

\section{3 - Aplicação da Tomografia PCA aos cubos de dados de M104 com o contínuo estelar}

Após todo o processamento descrito na seção 10.2, aplicou-se a Tomografia PCA tanto ao cubo de dados de M104 obtido com o GMOS quanto ao cubo obtido com o NIFS, já que as informações reveladas por eles são bastante complementares. O cubo proveniente do NIFS possui uma resolução espacial maior devido ao efeito da óptica adaptativa utilizada, entretanto, M104 quase não possui linhas de emissão nessa região espectral, o que torna muito difícil o estudo da emissão do gás existente na área central dessa galáxia. O cubo obtido com o GMOS, por outro lado, possui uma grande quantidade de linhas de emissão, apesar da sua resolução espacial ser menor. Assim, a aplicação da Tomografia PCA a esses dois cubos de dados permitiu que as informações complementares reveladas por eles fossem igualmente consideradas, resultando, assim, numa análise bastante completa e detalhada.

\subsection{1 - Resultados da Tomografia PCA do cubo de dados de M104 obtido com o GMOS, com o contínuo estelar}

Os principais auto-espectros e respectivos tomogramas resultantes da Tomografia PCA do cubo de dados de M104 obtido com o GMOS encontram-se a seguir. 
474
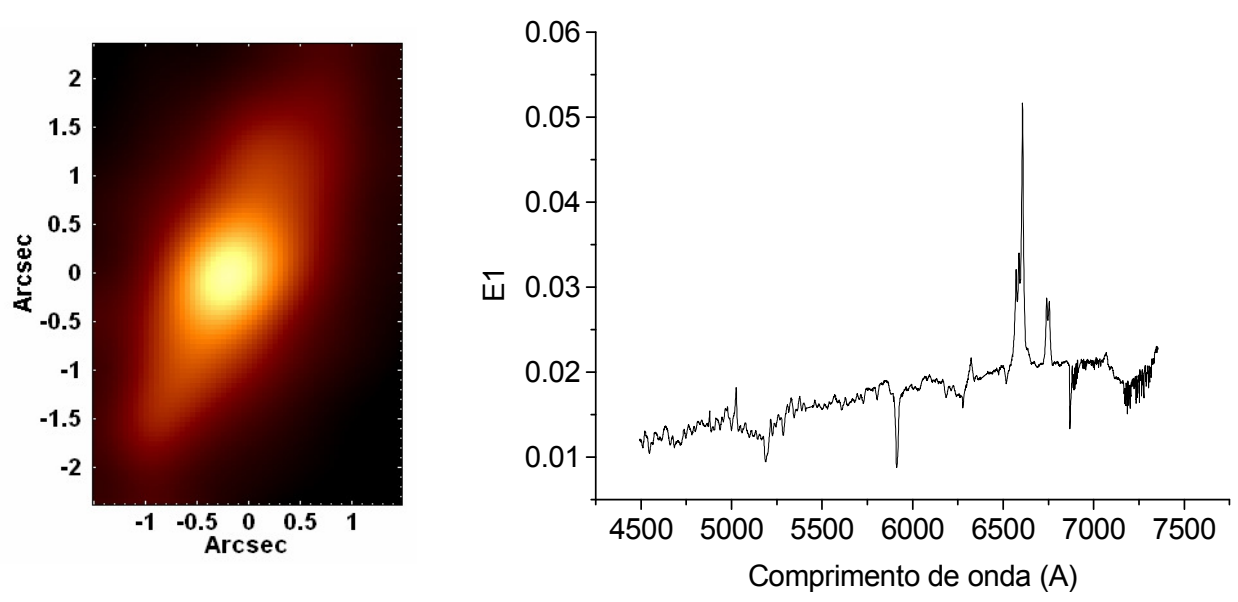

Figura 10.12 - Tomograma e auto-espectro correspondentes ao autovetor E1, resultante da Tomografia PCA do cubo de dados de M104 obtido com o GMOS, com o contínuo estelar.
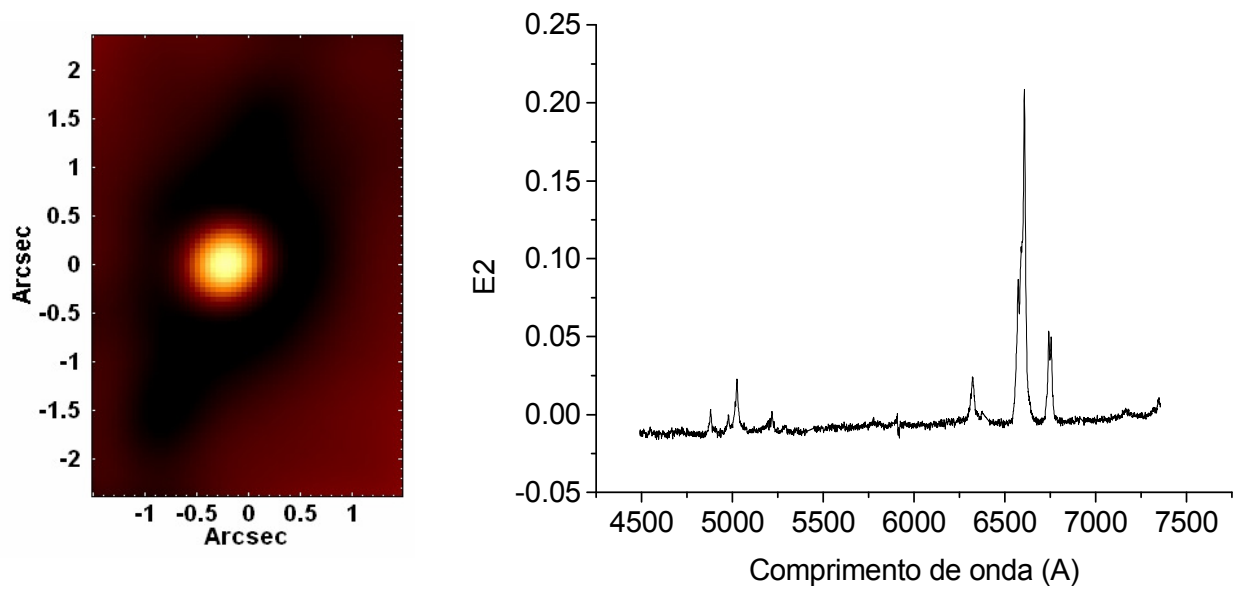

Figura 10.13 - Tomograma e auto-espectro correspondentes ao autovetor E2, resultante da Tomografia PCA do cubo de dados de M104 obtido com o GMOS, com o contínuo estelar.

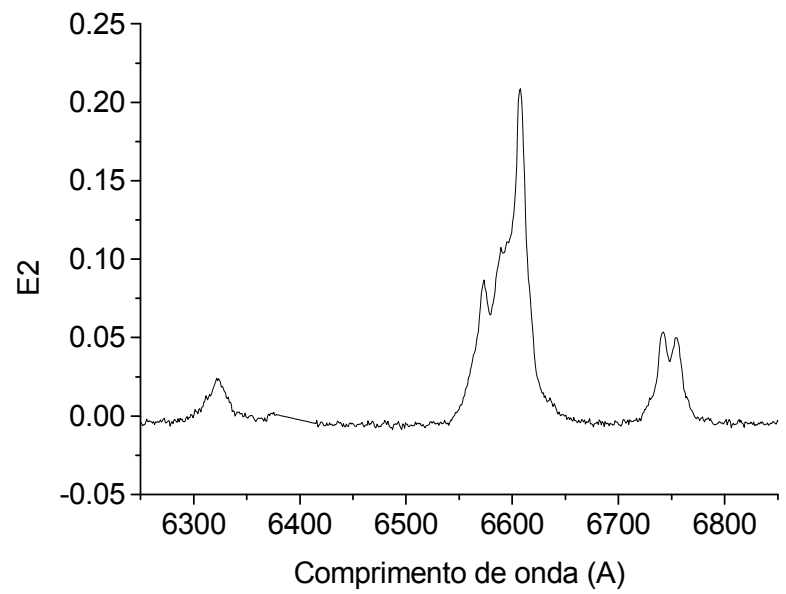

Figura 10.14 - Ampliação na região espectral vermelha do auto-espectro correspondente ao autovetor E2, resultante da Tomografia PCA do cubo de dados de M104 obtido com o GMOS, com o contínuo estelar. 

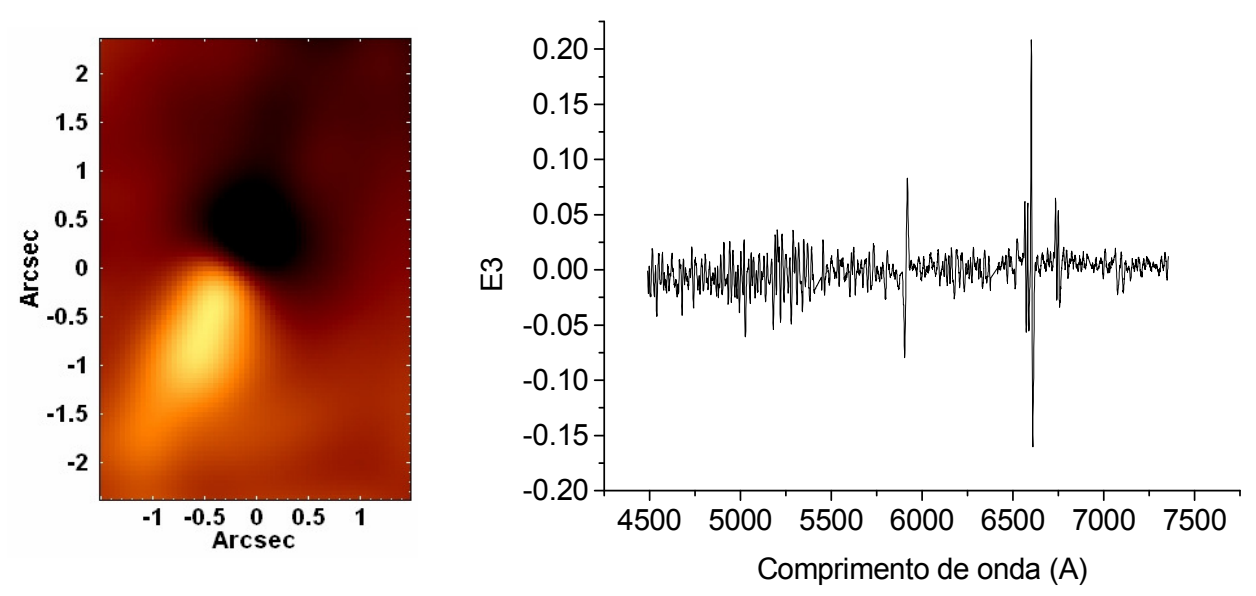

Figura 10.15 - Tomograma e auto-espectro correspondentes ao autovetor E3, resultante da Tomografia PCA do cubo de dados de M104 obtido com o GMOS, com o contínuo estelar.

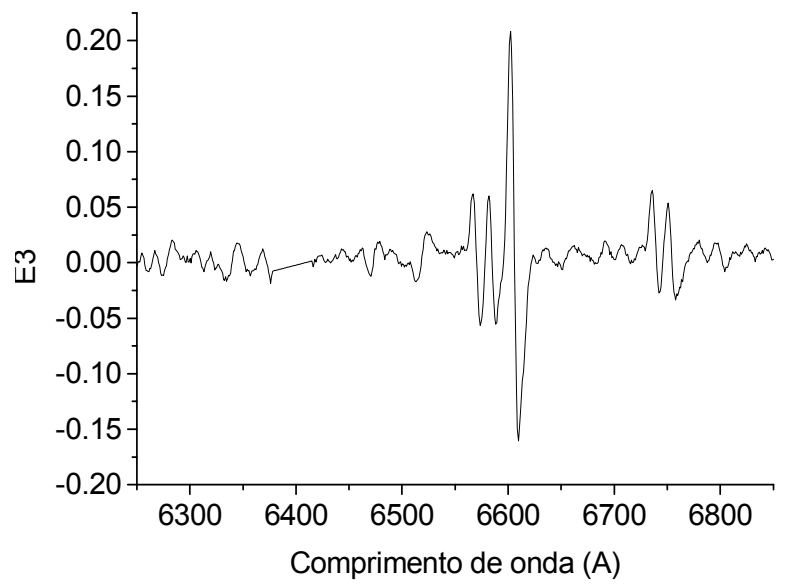

Figura 10.16 - Ampliação na região espectral vermelha do auto-espectro correspondente ao autovetor E3, resultante da Tomografia PCA do cubo de dados de M104 obtido com o GMOS, com o contínuo estelar.
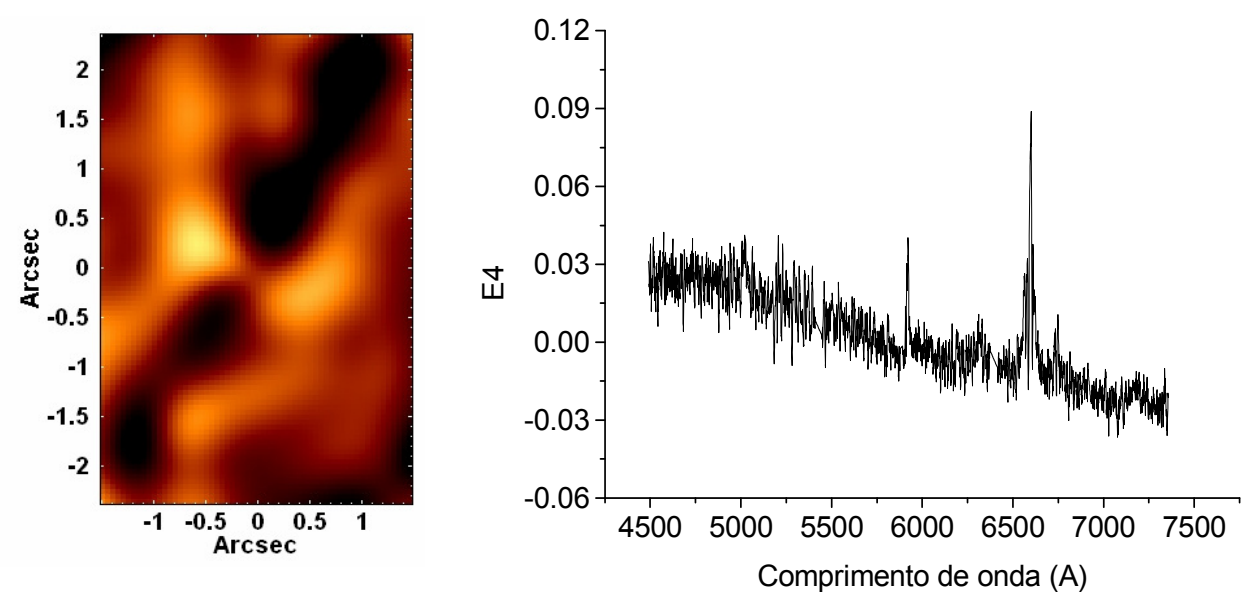

Figura 10.17 - Tomograma e auto-espectro correspondentes ao autovetor E4, resultante da Tomografia PCA do cubo de dados de M104 obtido com o GMOS, com o contínuo estelar. 


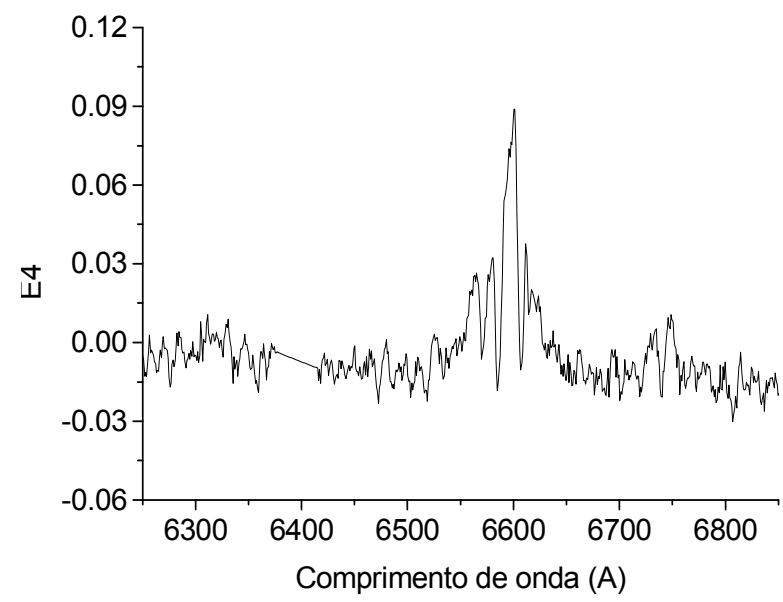

Figura 10.18 - Ampliação na região espectral vermelha do auto-espectro correspondente ao autovetor E4, resultante da Tomografia PCA do cubo de dados de M104 obtido com o GMOS, com o contínuo estelar.
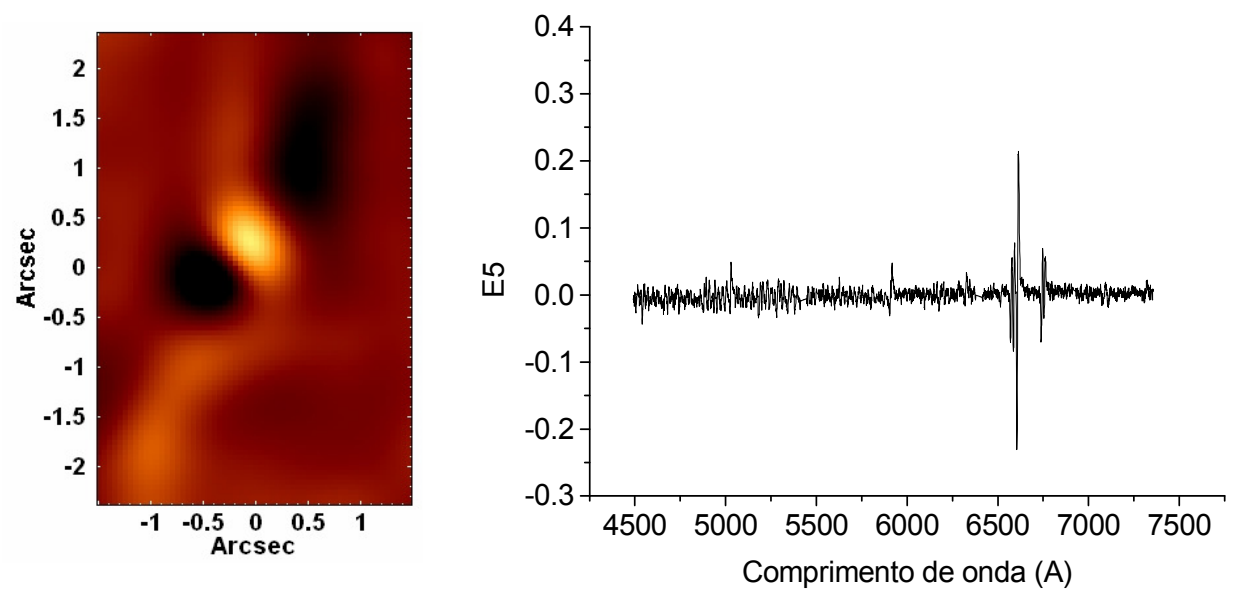

Figura 10.19 - Tomograma e auto-espectro correspondentes ao autovetor E5, resultante da Tomografia PCA do cubo de dados de M104 obtido com o GMOS, com o contínuo estelar.

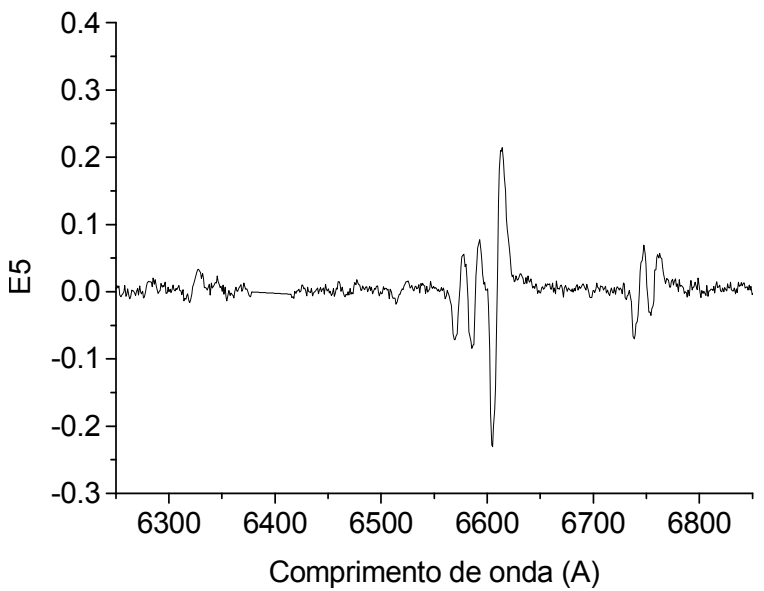

Figura 10.20 - Ampliação na região espectral vermelha do auto-espectro correspondente ao autovetor E5, resultante da Tomografia PCA do cubo de dados de M104 obtido com o GMOS, com o contínuo estelar. 


\begin{tabular}{|c|c|}
\hline Autovetor & Fração da variância explicada (\%) \\
\hline E1 & 98.8843 \\
\hline E2 & 0.7939 \\
\hline E3 & 0.1499 \\
\hline E4 & 0.0507 \\
\hline E5 & 0.0276 \\
\hline
\end{tabular}

Tabela 10.1 - Autovalores encontrados com a Tomografia PCA do cubo de dados de M104 obtido com o GMOS, com o contínuo estelar.

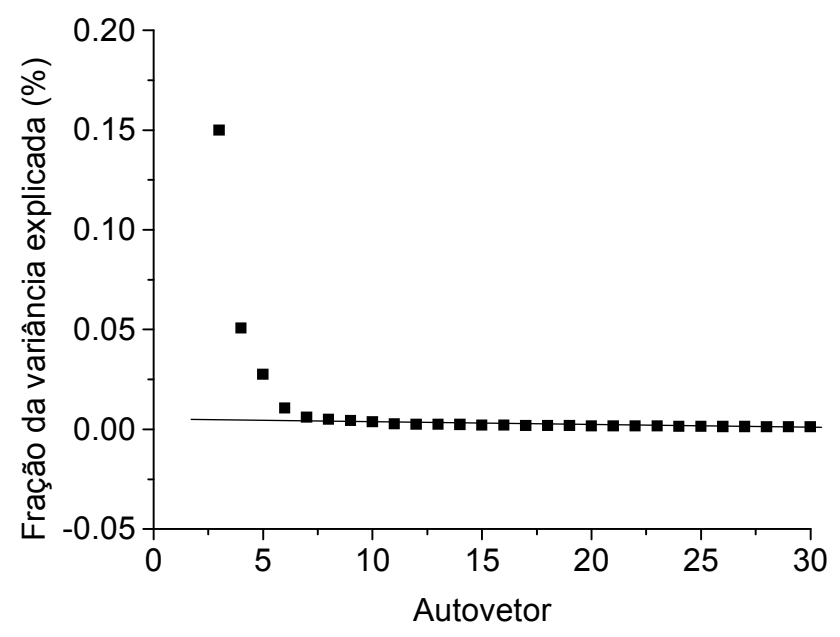

Figura 10.21 - "Scree test" dos autovetores encontrados com a Tomografia PCA do cubo de dados de M104 obtido com o GMOS, com o contínuo estelar.

A figura 10.12 mostra que o auto-espectro E1 e o tomograma associado apresentam o aspecto do espectro médio e da soma de todas as imagens do cubo de dados de M104 obtido com o GMOS (figura 10.7), respectivamente. Isso está de acordo com o esperado, já que esse autovetor explica a maior parte da variância dos dados $(98.8843 \%)$, revelando, portanto, características que já eram claramente detectáveis no cubo de dados do objeto analisado. Um aspecto importante do auto-espectro E1 é que ele possui uma estrutura compatível com uma banda de absorção por volta de $7250 \AA$. Tal banda é típica de estrelas de tipo espectral M, o que indica que a região central de M104 deve apresentar uma população estelar consideravelmente velha.

Observando-se as figuras 10.13 e 10.14, nota-se que o auto-espectro E2 apresenta correlações com os comprimentos de onda correspondentes às principais linhas de emissão visíveis no espectro. Podem ser detectadas, inclusive, correlações com os comprimentos de onda associados a uma possível componente larga da linha de $\mathrm{H} \alpha$ (sobretudo a sua asa vermelha). 
Esse fato parece indicar que esse autovetor está correlacionado com a emissão proveniente do AGN existente nessa galáxia. Nesse caso, a posição do AGN corresponde à área mais clara do tomograma. Além disso, o auto-espectro E2 possui uma correlação com a região vermelha do espectro e uma anti-correlação com a região azul do mesmo. Isso sugere que esse autovetor estabelece um diferencial entre espectros com um contínuo mais avermelhado e espectros com um contínuo mais azulado existentes no cubo de dados. Assim, as áreas claras do tomograma devem apresentar espectros com um contínuo mais avermelhado do que as escuras. Esse comportamento pode ser devido à presença de nuvens de poeira nas regiões claras do tomograma. O autovetor E2 explica cerca de 0.7939 \% da variância dos dados.

As figuras 10.15 e 10.16 revelam que o auto-espectro E3 apresenta correlações com os comprimentos de onda correspondentes às asas azuis das principais linhas de emissão do espectro e anti-correlações com os comprimentos de onda associados às asas vermelhas das mesmas. Além disso, o auto-espectro E3 possui um comportamento oposto no caso das linhas de absorção (correlações com os comprimentos de onda correspondentes às asas vermelhas e anticorrelações com os comprimentos de onda associados às asas azuis). Tudo isso parece indicar que o autovetor E3 está relacionado a algum fenômeno cinemático na região central de M104 envolvendo tanto gás quanto estrelas. Nesse caso, o gás e as estrelas apresentam uma componente radial de velocidade no sentido do observador (blueshift) nas áreas claras do tomograma e uma componente radial de velocidade no sentido oposto ao do observador (redshift) nas regiões escuras. Analisando-se o tomograma, verifica-se que ele possui uma morfologia que parece ser compatível com uma rotação de gás e estrelas, entretanto, algumas pequenas distorções, sobretudo nas áreas mais periféricas da imagem, podem indicar a presença de mais de um fenômeno cinemático (como um outflow de gás, por exemplo). O autovetor E3 explica cerca de 0.1499 \% da variância dos dados.

Uma análise das figuras 10.17 e 10.18 mostra que o auto-espectro E4 apresenta uma correlação com a região azul do espectro e uma anti-correlação com a região vermelha do mesmo. Além disso, esse auto-espectro também possui correlações com os comprimentos de onda correspondentes à componente larga da linha Ha. Com isso, conclui-se que as áreas claras do tomograma possuem um espectro mais azulado do que as regiões escuras e, ao mesmo tempo, revelam uma emissão da linha $\mathrm{H} \alpha$ com uma componente larga. Em princípio, isso parece indicar que as áreas claras em questão apresentam uma emissão proveniente do AGN, sendo que 
o contínuo mais azulado deve corresponder ao featureless continuum do AGN. Entretanto, observando-se o tomograma, nota-se que nenhuma das regiões claras presentes corresponde à posição mais provável do AGN (visível no tomograma da figura 10.13). Na verdade, as áreas claras desse tomograma localizam-se exatamente ao redor do AGN. Uma possível explicação para isso é que o fenômeno revelado pelo autovetor E4 corresponde à emissão do AGN espalhada, sendo que tal espalhamento poderia ser devido à poeira. Uma outra característica do auto-espectro E4 são correlações com os comprimentos de onda correspondentes ao dubleto de linhas de absorção do sódio, ou seja, o autovetor parece estar anti-correlacionado com a absorção de sódio. Isso indica que as regiões escuras do tomograma representam áreas não apenas com um contínuo mais avermelhado, mas também com uma absorção de sódio detectável. Unindo-se todas as características reveladas pelo auto-espectro e pelo tomograma do autovetor E4, chega-se ao seguinte possível cenário: as regiões escuras do tomograma da figura 10.17, associadas a um provável disco de gás e estrelas em rotação (conforme revelado pelo autovetor E3 mostrado nas figuras 10.15 e 10.16), apresentam espectros mais avermelhados, provavelmente devido à extinção por poeira, e com uma absorção estelar detectável, o que confirma a presença de populações estelares nessa área. As regiões claras desse tomograma, por sua vez, revelam uma emissão do AGN (caracterizada pelo contínuo mais azul e pela componente larga da linha $\mathrm{H} \alpha$ ) espalhada, possivelmente, por poeira. O contínuo mais azul dos espectros dessa área não é detectado nas regiões mais escuras, provavelmente, por causa da extinção devida à poeira existente. $\mathrm{O}$ autovetor $\mathrm{E} 4$ explica cerca de 0.0507 \% da variância dos dados.

Finalmente, observando-se as figuras 10.19 e 10.20, pode-se notar que o auto-espectro E5 apresenta correlações com os comprimentos de onda correspondentes às asas vermelhas das principais linhas de emissão do espectro e anti-correlações com os comprimentos de onda associados às asas azuis das mesmas. Isso parece indicar que o autovetor E5 está relacionado a algum fenômeno cinemático do gás na região central de M104. Nesse caso, as áreas claras do tomograma possuem gás com emissão em redshift e as regiões escuras revelam gás com emissão em blueshift. Analisando-se o tomograma em questão, verifica-se que a sua morfologia não parece ser compatível com a de uma rotação, o que sugere a existência de um fenômeno cinemático não rotacional (possivelmente um outflow) na região central de M104. O autoespectro E5 também parece apresentar um comportamento cinemático muito mais tênue 
associado às linhas de absorção do espectro, entretanto, a razão $S / N$ desse auto-espectro não permite uma análise muito mais detalhada desse fenômeno. O autovetor E5 explica cerca de $0.0276 \%$ da variância dos dados.

O Scree test mostrado na figura 10.21 revela que os valores das variâncias explicadas pelos autovetores decaem bastante até, aproximadamente, o autovetor E9, a partir do qual a taxa de decaimento diminui muito e fica praticamente constante. Isso indica que os autovetores de ordem maior ou igual a 9 representam, sobretudo, ruído e, consequentemente, não possuem relevância nessa análise. Entretanto, dentre os autovetores de ordem menor do que 9, apenas os cinco primeiros apresentavam uma interpretação mais clara e, por essa razão, apenas eles foram mostrados aqui.

\subsection{2 - Resultados da Tomografia PCA do cubo de dados de M104 obtido com o NIFS, com o contínuo estelar}

Os principais auto-espectros e respectivos tomogramas resultantes da Tomografia PCA do cubo de dados de M104 obtido com o NIFS encontram-se a seguir.
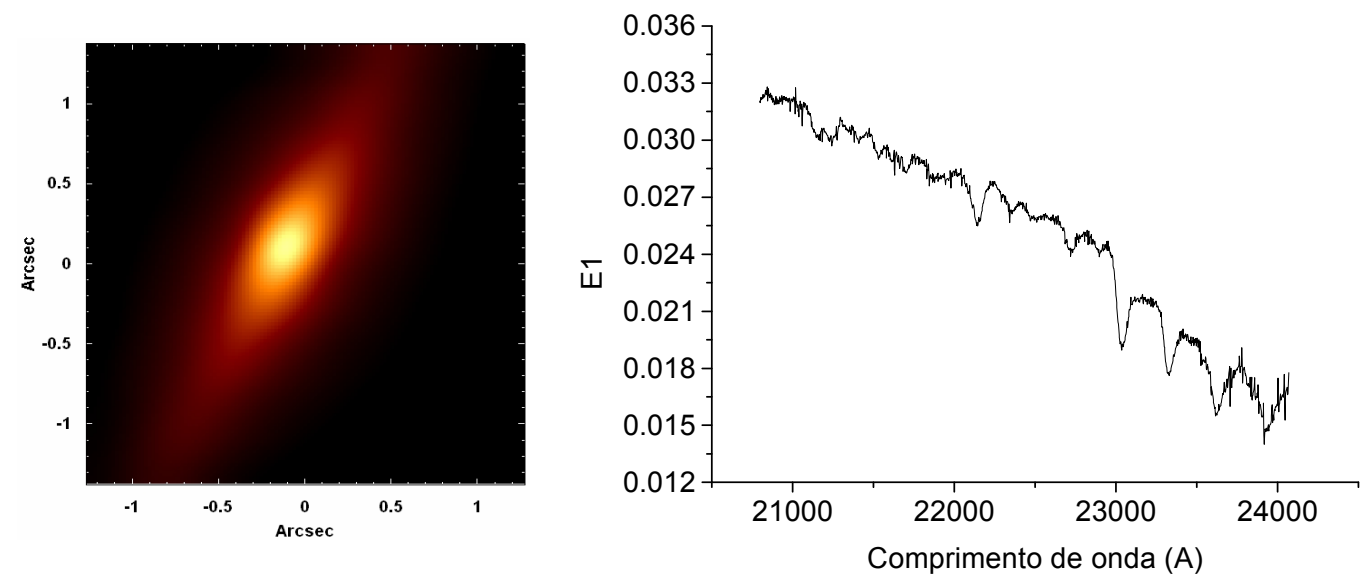

Figura 10.22 - Tomograma e auto-espectro correspondentes ao autovetor E1, resultante da Tomografia PCA do cubo de dados de M104 obtido com o NIFS, com o contínuo estelar. 

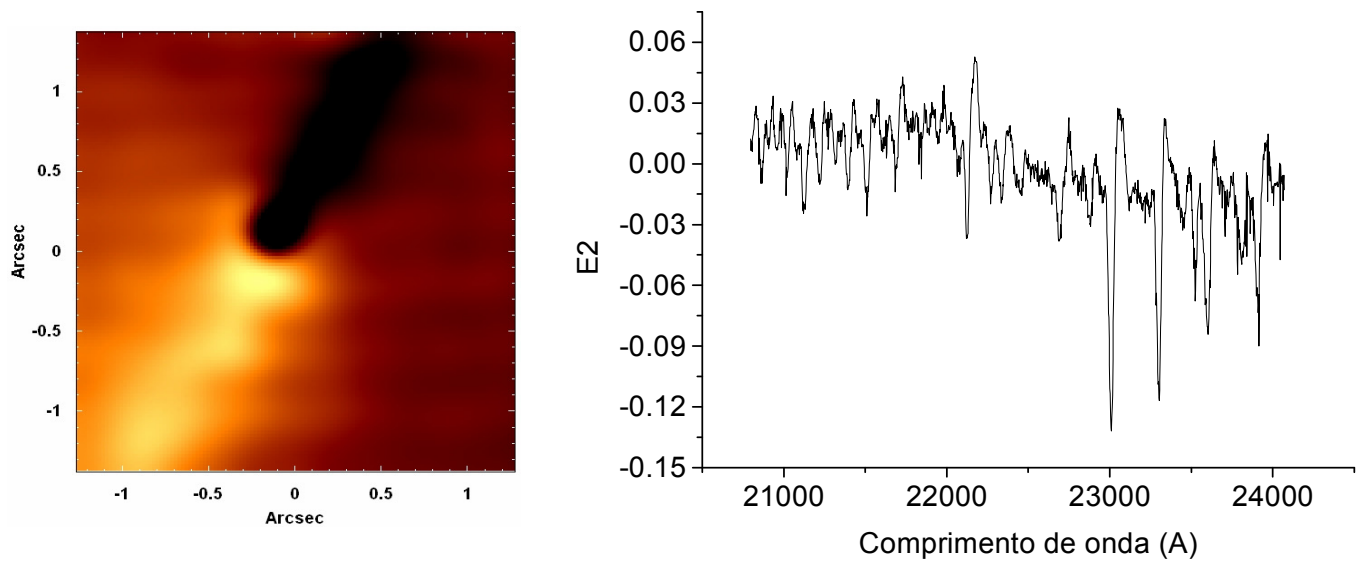

Figura 10.23 - Tomograma e auto-espectro correspondentes ao autovetor E2, resultante da Tomografia PCA do cubo de dados de M104 obtido com o NIFS, com o contínuo estelar.
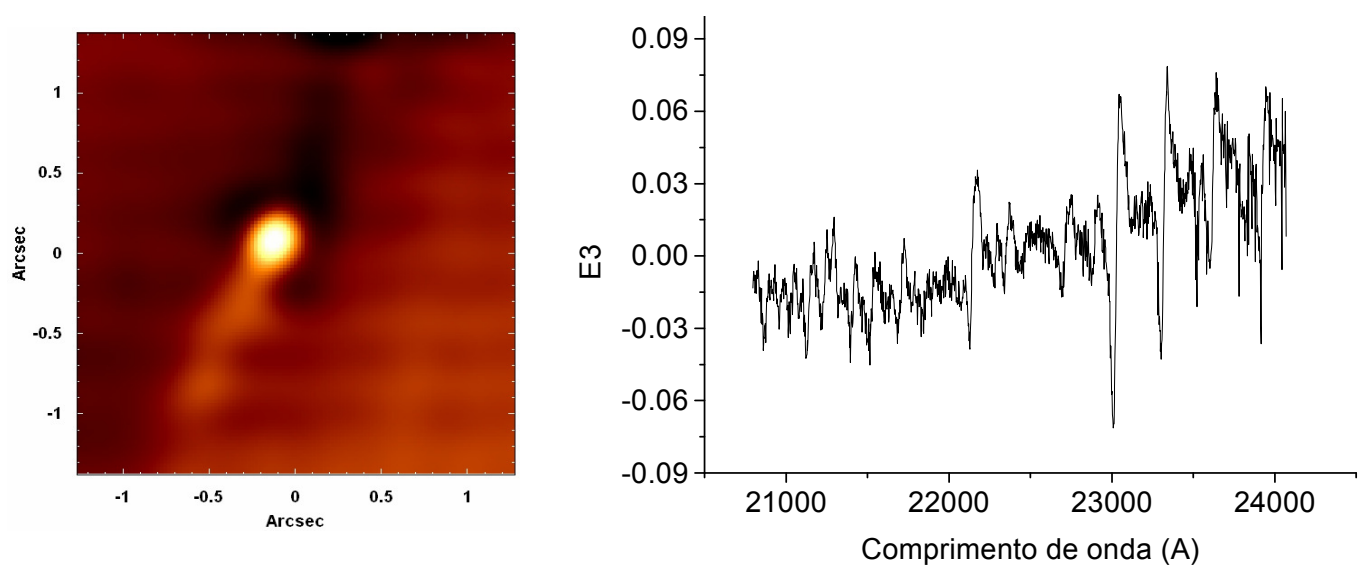

Figura 10.24 - Tomograma e auto-espectro correspondentes ao autovetor E3, resultante da Tomografia PCA do cubo de dados de M104 obtido com o NIFS, com o contínuo estelar.
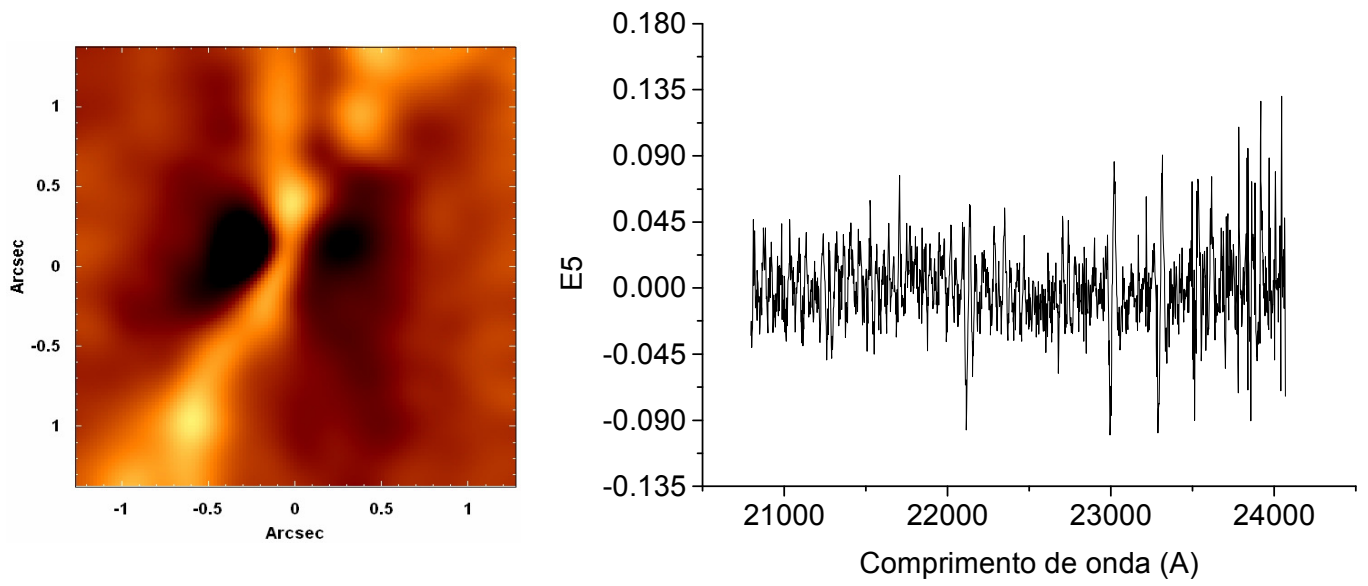

Figura 10.25 - Tomograma e auto-espectro correspondentes ao autovetor E5, resultante da Tomografia PCA do cubo de dados de M104 obtido com o NIFS, com o contínuo estelar. 

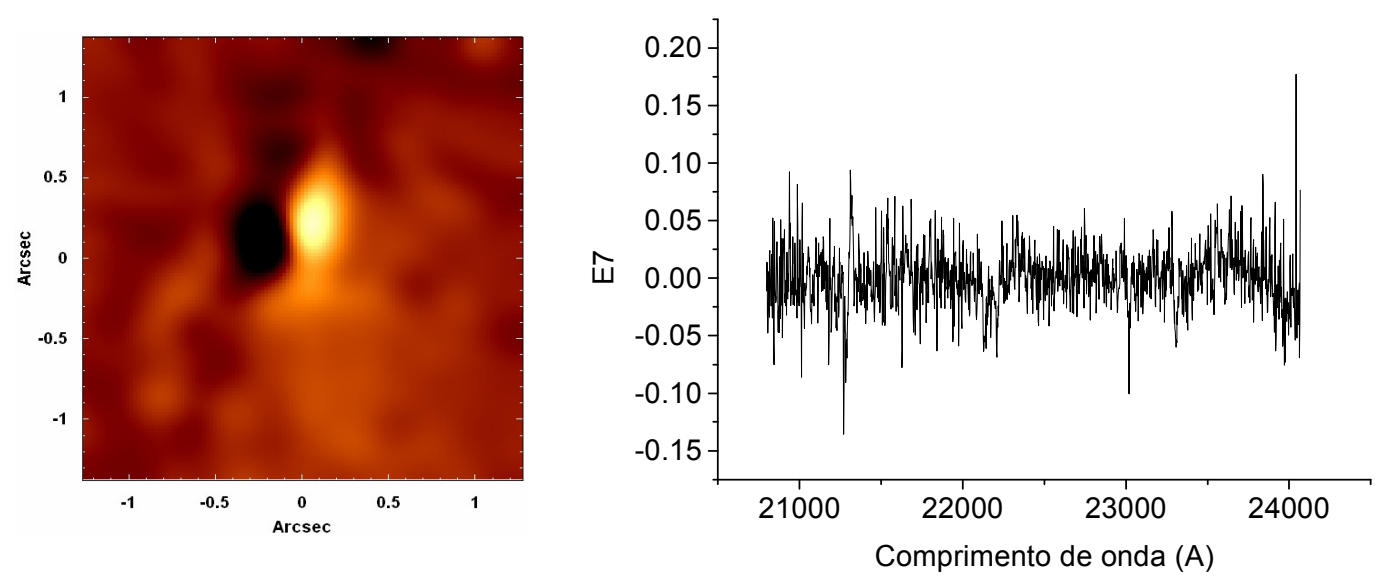

Figura 10.26 - Tomograma e auto-espectro correspondentes ao autovetor E7, resultante da Tomografia PCA do cubo de dados de M104 obtido com o NIFS, com o contínuo estelar.

\begin{tabular}{|c|c|}
\hline Autovetor & Fração da variância explicada (\%) \\
\hline E1 & 99.8797 \\
\hline E2 & 0.0485 \\
\hline E3 & 0.0224 \\
\hline E5 & 0.0024 \\
\hline E7 & 0.0013 \\
\hline
\end{tabular}

Tabela 10.2 - Autovalores encontrados com a Tomografia PCA do cubo de dados de M104 obtido com o NIFS, com o contínuo estelar.

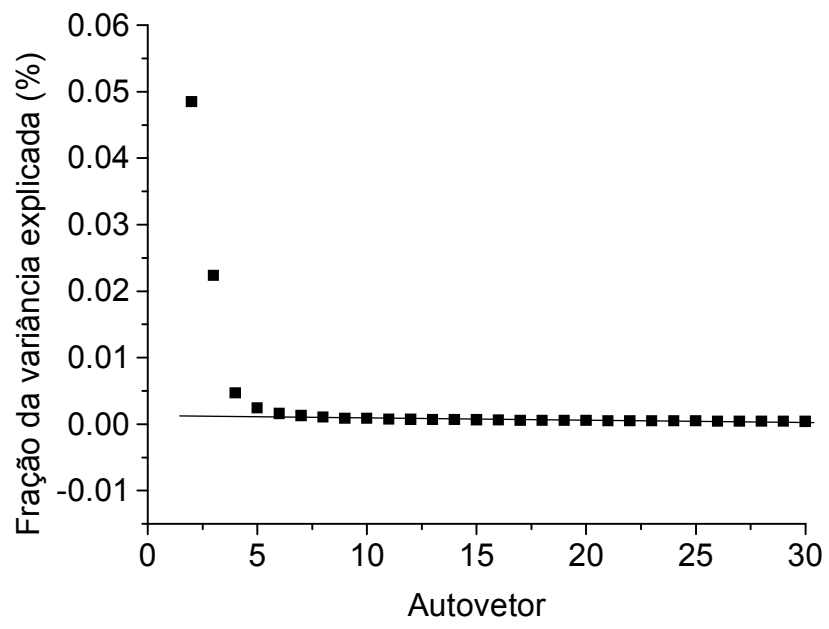

Figura 10.27 - "Scree test" dos autovetores encontrados com a Tomografia PCA do cubo de dados de M104 obtido com o NIFS, com o contínuo estelar.

Observando-se a figura 10.22, pode-se notar que o auto-espectro E1 e o tomograma correspondente a ele apresentam o aspecto do espectro médio e da soma de todas as imagens do cubo de dados de M104 obtido com o NIFS (figura 10.11), respectivamente. Isso está de acordo com o esperado, já que esse autovetor explica a maior parte da variância dos dados $(99.8797$ \%) 
e, consequentemente, revela características que já eram claramente detectáveis no cubo de dados do objeto. Uma característica marcante do auto-espectro E1 (e, consequentemente, do espectro médio da região central dessa galáxia) é a presença de estruturas correspondentes a várias linhas de absorção estelar do espectro (inclusive as bandas de CO), o que indica que o fluxo proveniente de populações estelares é claramente detectável nesse cubo de dados.

A figura 10.23 mostra que o auto-espectro E2 apresenta correlações com os comprimentos de onda correspondentes às asas vermelhas das principais linhas de absorção visíveis no espectro e anti-correlações com os comprimentos de onda associados às asas azuis das mesmas. Isso, juntamente com a morfologia do tomograma, sugere que esse autovetor revela a presença de uma rotação estelar na região central de M104. Nesse caso, as estrelas possuem uma componente radial da velocidade no sentido do observador (blueshift) nas áreas claras do tomograma e uma componente radial da velocidade no sentido oposto (redshift) nas regiões escuras. A rotação estelar detectada no autovetor E2 parece ser compatível com o que foi encontrado com o autovetor E3 da Tomografia PCA do cubo de dados de M104 obtido com o GMOS (figuras 10.15 e 10.16). Um aspecto curioso do autovetor E2 mostrado na figura 10.23 é que o seu tomograma apresenta certas estruturas similares a faixas estreitas horizontais. Aparentemente, esse efeito parece ser devido a algum tipo de fingerprint instrumental que o procedimento de remoção que já foi aplicado nesse cubo de dados não conseguiu eliminar. Embora o auto-espectro E2 apresente um certo comportamento de baixa freqüência espectral que poderia estar associado a esse fingerprint, não se pode descartar a hipótese de que tal comportamento também esteja relacionado a alguma outra característica mais importante do cubo de dados, assim, optou-se por não tentar eliminar esse fingerprint dos dados. $\mathrm{O}$ autovetor E2 explica cerca de 0.0485 \% da variância dos dados.

Analisando-se a figura 10.24, pode-se notar que o auto-espectro E3 apresenta um comportamento bastante similar ao do auto-espectro E2, com correlações com os comprimentos de onda correspondentes às asas vermelhas das principais linhas de absorção e anti-correlações com os comprimentos de onda associados às asas azuis das mesmas. Assim como no caso de E2, esse comportamento parece indicar que o autovetor E3 está relacionado a algum fenômeno cinemático estelar, com as estrelas possuindo uma componente radial da velocidade no sentido do observador nas áreas claras do tomograma e uma componente radial da velocidade no sentido oposto nas regiões escuras. Entretanto, no tomograma em questão, nota-se que, embora haja 
uma certa compatibilidade com o que foi observado no tomograma do autovetor E2 (ou seja, E3 também parece revelar a existência de uma rotação estelar), diferenças apreciáveis são observadas, o que indica que E3 está associado não apenas à rotação estelar, mas também a algum outro fenômeno. De fato, diferentemente do auto-espectro E2, o auto-espectro E3 apresenta uma correlação com a região vermelha do espectro e uma anti-correlação com a região azul, o que sugere que esse autovetor estabelece um diferencial entre espectros com um contínuo mais avermelhado (localizados nas áreas claras do tomograma) e espectros com um contínuo mais azulado (localizados nas regiões escuras do tomograma). A posição do AGN coincide com a área mais clara do tomograma, revelando a presença de espectros mais avermelhados. Isso pode ser conseqüência de uma possível emissão térmica de poeira que está sendo aquecida pelo AGN próximo. O autovetor E3 explica cerca de 0.0224 \% da variância dos dados.

A figura 10.25 revela que o auto-espectro E5 apresenta anti-correlações com os comprimentos de onda correspondentes às asas azuis e vermelhas das principais linhas de absorção do espectro e correlações com os comprimentos de onda associados às regiões centrais das mesmas. Isso indica que o autovetor E5 também está relacionado a algum fenômeno cinemático estelar. Nesse caso, nas áreas claras do tomograma, as estrelas possuem alguma componente radial de velocidade mais expressiva (blueshift ou redshift) e, nas regiões escuras, as estrelas apresentam, apenas, baixas componentes radiais de velocidade. Considerando-se, ainda, o aspecto apresentado pelo tomograma, pode-se dizer que esse autovetor parece estabelecer uma diferenciação entre regiões com rotação estelar e áreas com pouca ou nenhum rotação. Comparando-se as figuras 10.25 e 10.23, pode-se concluir que as informações reveladas pelo autovetor E5 parecem bastante compatíveis com as mostradas pelo autovetor E2. O autovetor E5 explica cerca de $0.0024 \%$ da variância dos dados.

Por fim, a figura 10.26 mostra que o auto-espectro E7 apresenta correlações com os comprimentos de onda correspondentes à asa vermelha da linha de emissão de $\mathrm{H}_{2} \lambda 21218$ e anticorrelações com os comprimentos de onda associados à asa azul da mesma linha. Isso indica que o autovetor E7 está relacionado a algum fenômeno cinemático do gás $\mathrm{H}_{2}$ na região central de M104. Nesse caso, as áreas claras do tomograma possuem gás molecular com uma emissão em redshift e as regiões escuras apresentam gás molecular com uma emissão em blueshift. A morfologia do tomograma parece sugerir que se trata de uma rotação do gás $\mathrm{H}_{2}$, entretanto, outros fenômenos cinemáticos, como outflows, por exemplo, não podem ser descartados. O 
auto-espectro E7 também possui consideráveis correlações na região vermelha do espectro, que, provavelmente, estão associadas a resquícios de linhas telúricas não totalmente removidas. Tais resquícios representam uma "contaminação" desse autovetor e, consequentemente, é possível que a morfologia do fenômeno cinemático mostrada pelo tomograma não seja totalmente confiável, já que ela também pode estar relacionada às "contaminações" desse autovetor. O autovetor E7 explica cerca de $0.0013 \%$ da variância dos dados.

O Scree test na figura 10.27 revela que os valores das variâncias explicadas pelos autovetores decaem bastante até, aproximadamente, o autovetor E7, a partir do qual a taxa de decaimento diminui muito e fica praticamente constante. Esse comportamento sugere que os autovetores de ordem maior ou igual a 7 representam sobretudo ruído, entretanto, a análise revelou que o próprio autovetor E7 apresentava uma interpretação relativamente simples e, por essa razão, ele foi mostrado. Dentre os autovetores de menor ordem, apenas o E1, o E2, o E3 e o E5 possuíam uma interpretação clara e, por isso, somente eles foram analisados aqui.

Em suma, pode-se dizer que essas análises com a Tomografia PCA nos cubos de dados de M104 obtidos com o GMOS e com o NIFS revelaram uma fenomenologia bastante diversificada na região central dessa galáxia. A análise no óptico, primeiramente, mostrou a existência de um AGN de tipo 1 (com uma componente larga da linha H $\alpha$ detectável) nesse objeto. Entretanto, um dos achados mais interessantes obtidos com a análise dos dados no óptico foi a emissão de uma componente larga da linha $\mathrm{H} \alpha$ e de um featureless continuum em regiões afastadas do AGN central, o que sugere que se trata de emissão do AGN espalhada, possivelmente, por poeira. Ambas as análises com a Tomografia PCA revelaram a presença de uma rotação estelar ao redor do núcleo, entretanto, foram encontradas evidências da existência de mais de um fenômeno cinemático associado ao gás. A análise no óptico mostrou que, embora parte do gás apresente um movimento rotacional similar ao estelar, também parece haver um segundo fenômeno cinemático do gás, possivelmente devido a um outflow. No infravermelho, detectou-se um fenômeno cinemático do gás $\mathrm{H}_{2}$, que parece ser compatível com uma rotação, entretanto, outros fenômenos como outflows, por exemplo, não podem ser descartados. Finalmente, ambas as análise com a Tomografia PCA revelaram a existência de diferenciais de inclinação dos contínuos dos espectros. No caso do óptico, a presença de espectros mais avermelhados pode ser devida à extinção por poeira, ao passo que, no infravermelho, tais 
espectros mais avermelhados podem ser uma conseqüência de uma emissão térmica de poeira nos arredores do AGN.

\section{4 - Síntese espectral do cubo de dados de M104 com o}

\section{Starlight}

Depois das análises iniciais com a Tomografia PCA, foram feitas sínteses espectrais dos cubos de dados de M104. Para isso, primeiramente, aplicou-se, tanto no cubo do GMOS quanto no cubo do NIFS, toda a preparação descrita em 3.12, sendo que a correção da extinção devido à Via Láctea foi feita tomando-se $A_{V}=0.17$ e a passagem dos espectros para o referencial de repouso foi aplicada considerando-se $z=0.003416$. Tanto $A_{V}$ quanto $\mathrm{z}$ foram obtidos a partir do site do NED. No caso dos dados no infravermelho, foi preciso levar em conta a emissão térmica de poeira e o featureless continuum do AGN na síntese espectral. Para os dados no óptico, por outro lado, apenas o featureless continuum do AGN precisou ser considerado, já que a emissão térmica de poeira não é relevante na faixa espectral do óptico.

Conforme foi mencionado anteriormente, devido às limitações da base utilizada, a síntese espectral com o Starlight em dados no infravermelho fornece, apenas, três mapeamentos de fluxo suficientemente confiáveis para serem levados em conta na análise: o mapeamento do fluxo total devido às populações estelares, o mapeamento do fluxo total devido à emissão térmica de poeira e o mapeamento do fluxo devido ao featureless continuum. Entretanto, a síntese espectral do cubo de dados de M104 obtido com NIFS não revelou qualquer emissão térmica de poeira ou associada a featureless continuum. Isso tornou esses resultados muito pouco relevantes, já que, nessas circunstâncias, apenas o mapeamento do fluxo total devido às populações estelares seria suficientemente confiável para a análise. Assim, optou-se por não levar em conta aqui o que foi obtido com a síntese espectral do cubo de dados de M104 no infravermelho. Os resultados encontrados a partir do cubo de dados no óptico, por outro lado, são mostrados nas seções a seguir. 


\subsection{1 - Qualidade dos ajustes}

O mapeamento dos valores do $\chi^{2} / n_{\text {eff }}$ dos ajustes resultantes da síntese espectral do cubo de dados de M104 obtido com o GMOS encontra-se a seguir.

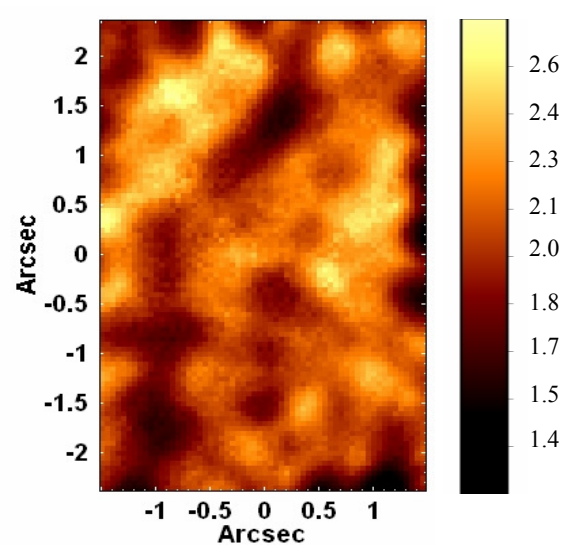

Figura 10.28: Mapeamento dos valores do $\chi^{2} / n_{\text {eff }}$ dos ajustes do "Starlight" para os espectros do cubo de dados de M104 obtido com o GMOS.

Observando-se a figura 10.28, nota-se que os melhores ajustes obtidos com o Starlight apresentaram $\chi^{2} / n_{\text {eff }}$ de cerca de 1.3 , ao passo que os piores tiveram $\chi^{2} / n_{\text {eff }}$ próximo de 2.7 , o que ainda pode ser tomado como um indicativo de ajustes com razoável qualidade. Assim, concluise que todos os ajustes feitos com o Starlight nos espectros do cubo de dados desse objeto foram bastante aceitáveis. Uma outra característica do mapeamento da figura 10.8 é que ele não revelou de maneira muito clara estruturas ou configurações que indicassem áreas com ajustes tendenciosamente melhores do que outras.

\subsection{2 - Parâmetros cinemáticos}

Os mapeamentos dos valores da velocidade radial estelar e da dispersão de velocidades estelar encontram-se a seguir. 

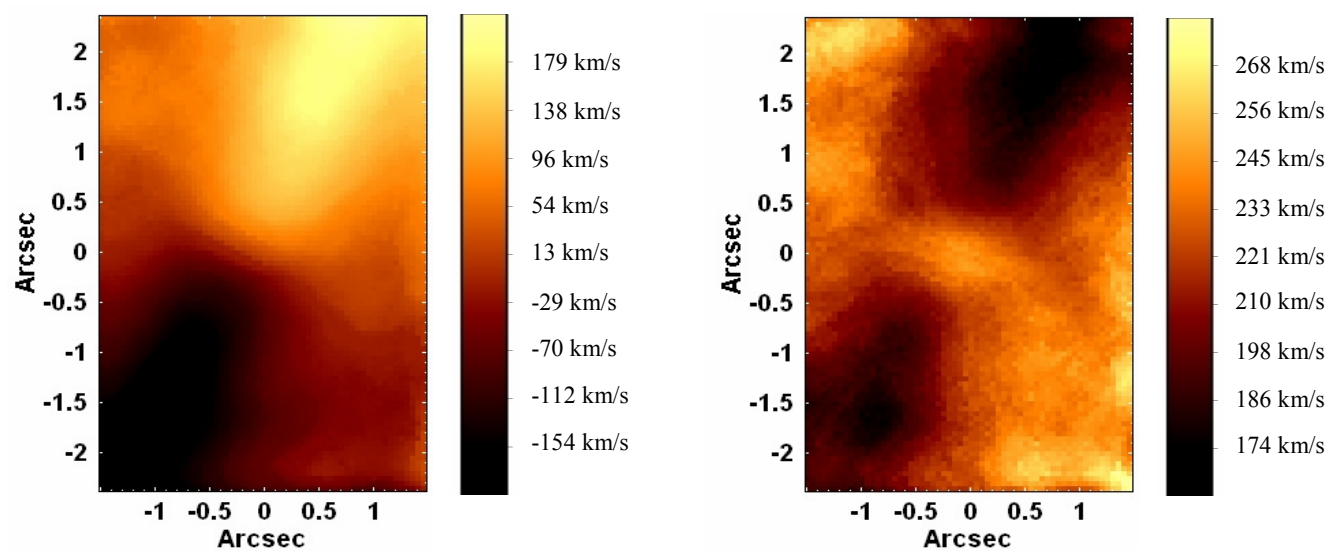

Figura 10.29: Mapeamentos dos valores (esquerda) da velocidade radial estelar e (direita) da dispersão de velocidades estelar, resultantes da aplicação do "Starlight" ao cubo de dados de M104 obtido com o GMOS.

A figura 10.29 mostra, primeiramente, a existência de um aparente disco estelar muito bem definido em rotação ao redor do núcleo de M104. Tal resultado é bastante compatível com os fenômenos cinemáticos detectados com as aplicações da Tomografia PCA aos cubos de dados de M104 obtidos com o GMOS e com o NIFS (figura 10.15 da seção 10.3.1 e figura 10.23 da seção 10.3.2, respectivamente). Por outro lado, a figura 10.29 revela, ainda, que a região correspondente ao disco estelar detectado apresenta valores de dispersão de velocidades consideravelmente menores do que nos arredores. Também se nota a existência de um aumento da dispersão de velocidades na região correspondente ao AGN central. Esses resultados indicam que, na área do disco estelar, a cinemática estelar é dominada pela rotação, resultando em um alto grau de anisotropia e menores valores de dispersão de velocidades. À medida que a distância em relação ao disco aumenta, a cinemática estelar começa a deixar de ser dominada pela rotação e o grau de isotropia aumenta progressivamente, resultando em maiores valores de dispersão de velocidades. O aumento da dispersão de velocidades na área próxima ao AGN, provavelmente, deve estar sendo causada pela presença do buraco negro supermassivo na região.

\subsection{3 - Populações estelares e featureless continuum}

Os mapeamentos do fluxo associado às populações estelares com diferentes idades e metalicidades levadas em conta na síntese espectral, assim como o mapa do fluxo atribuído ao featureless continuum do AGN, são mostrados a seguir. 

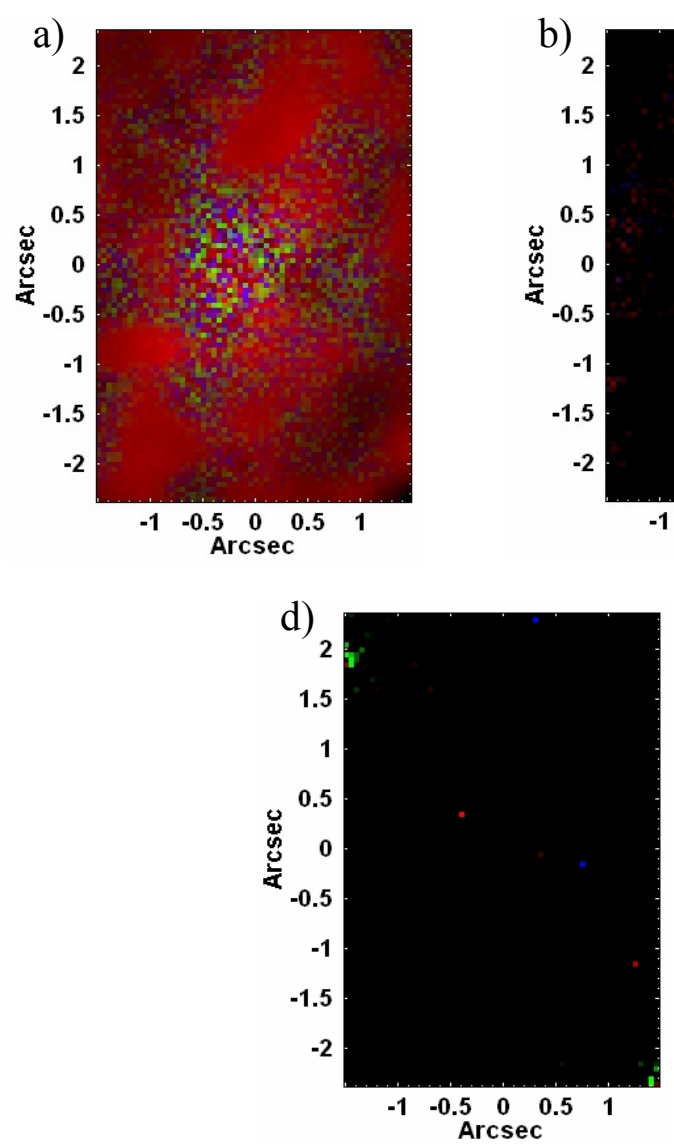
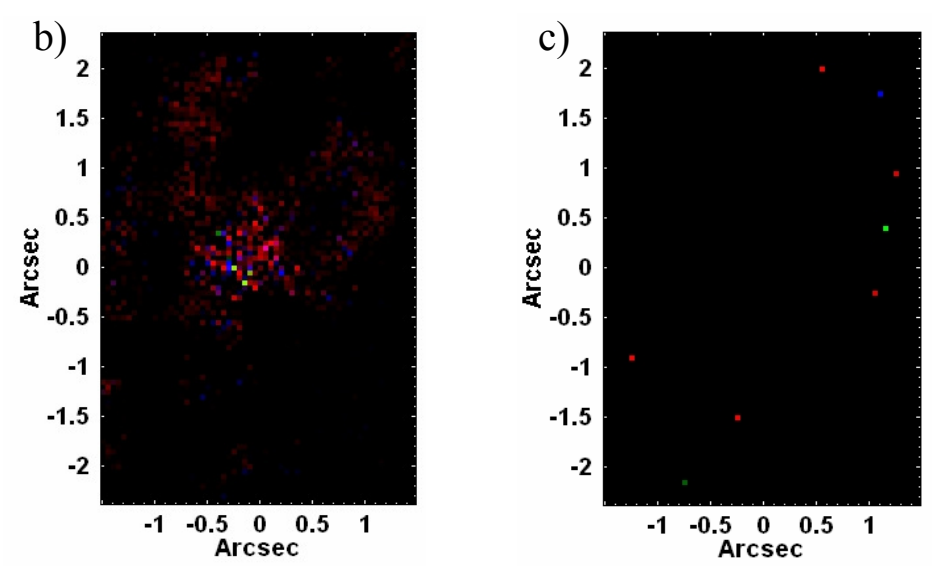

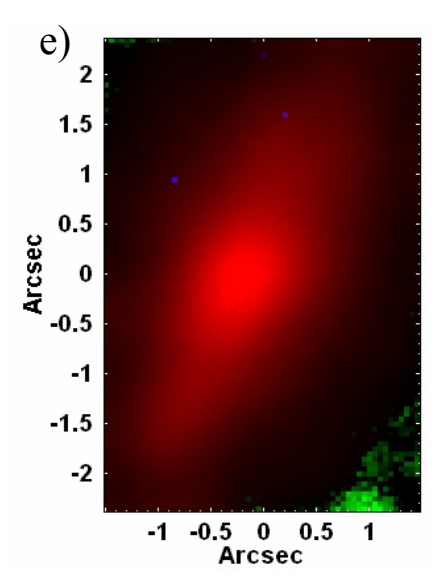

Figura 10.30: a) Composição $R G B$ da população estelar com idade entre $1 \cdot 10^{6}$ e $8.71 \cdot 10^{6}$ anos; b) Composição $R G B$ da população estelar com idade entre $1 \cdot 10^{7}$ e $5.5 \cdot 10^{7}$ anos; c) Composição $R G B$ da população estelar com idade entre $1.02 \cdot 10^{8}$ e 9.05.10 anos; d) Composição $R G B d a$ população estelar com idade entre $1.28 \cdot 10^{9}$ e $7.5 \cdot 10^{9}$ anos; e) Composição RGB da população estelar com idade entre $1 \cdot 10^{10}$ e $1.8 \cdot 10^{10}$ anos. Em todas as imagens, resultantes da síntese espectral do cubo de dados de M104 obtido com o GMOS, a cor azul indica baixa metalicidade $(Z=0.0001$ e $Z=0.0004)$, a cor verde indica metalicidade intermediária $(Z=0.004$ e $Z=$ $0.008)$ e a cor vermelha indica metalicidade mais elevada $(Z=0.02$ e $Z=0.05)$, lembrando que

$$
Z_{\odot}=0.02 \text {. }
$$



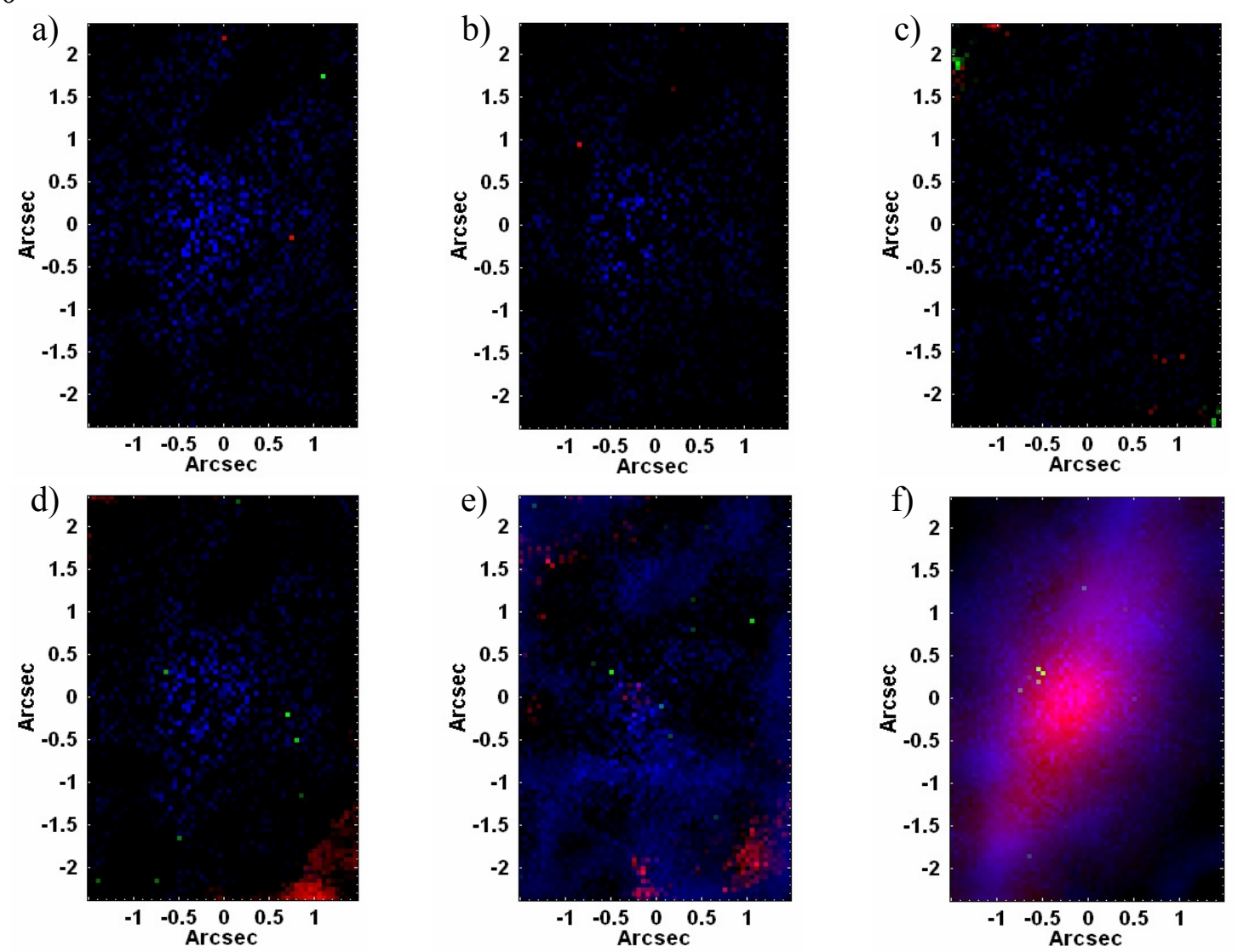

Figura 10.31: a) Composição $R G B$ da população estelar com metalicidade $Z=0.0001$; b) Composição $R G B$ da população estelar com metalicidade $Z=0.0004$; c) Composição $R G B d a$ população estelar com metalicidade $Z=0.004$; d) Composição $R G B$ da população estelar com metalicidade $Z=0.008$; e) Composição $R G B$ da população estelar com metalicidade $Z=0.02$;

f) Composição $R G B$ da população estelar com metalicidade $Z=0.05$. Em todas as imagens, resultantes da sintese espectral do cubo de dados de M104 obtido com o GMOS, a cor azul indica população estelar jovem (desde $1 \cdot 10^{6}$ anos até $5.5 \cdot 10^{7}$ anos ), a cor verde indica população estelar com idade intermediária (desde $1.02 \cdot 10^{8}$ anos até $4.25 \cdot 10^{9}$ anos) e a cor vermelha indica população estelar velha (desde $6.25 \cdot 10^{9}$ anos até $1.8 \cdot 10^{10}$ anos). É importante lembrar que $Z_{\odot}=0.02$.

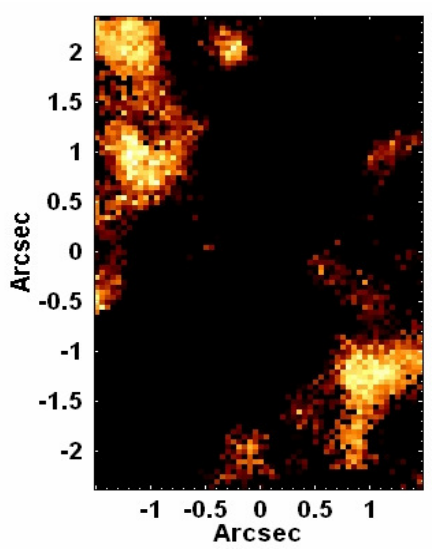

Figura 10.32: Mapeamento do fluxo atribuido ao "featureless continuum" do AGN, resultante da aplicação do "Starlight" ao cubo de dados de M104 obtido com o GMOS. 
A partir dos resultados obtidos com o Starlight, construiu-se um gráfico em colunas contendo as frações de fluxo atribuídas a cada uma das populações estelares e ao featureless continuum, considerando-se todo o campo visual do IFU do GMOS. Montou-se, também, um segundo gráfico, análogo ao anterior, mas contendo as frações de massa devidas a cada uma das populações estelares, calculadas pelo Starlight a partir de valores apropriados da razão $M / L$. Os
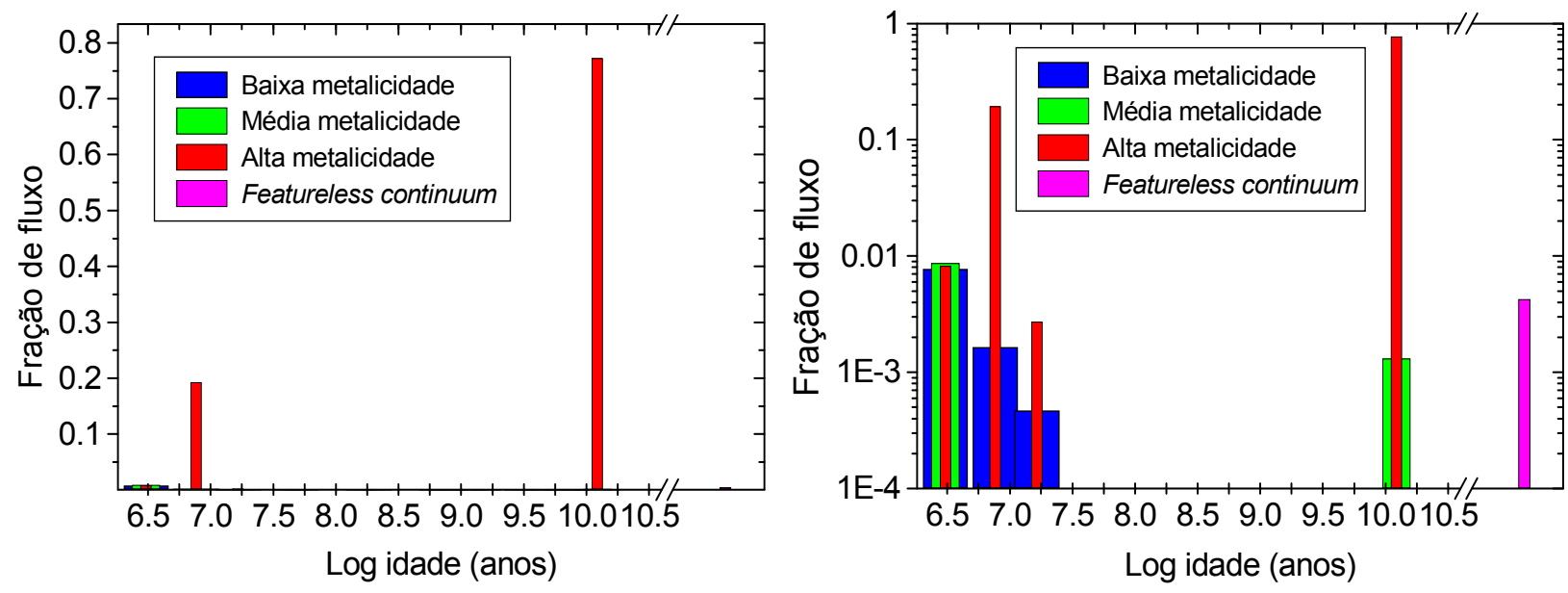

gráficos construídos encontram-se a seguir.

Figura 10.33: (esquerda) Gráfico representativo das frações de fluxo devidas às populações estelares e ao "featureless continuum", considerando-se todo o campo visual do IFU do GMOS, resultante da aplicação do "Starlight" ao cubo de dados de M104 obtido com o GMOS; (direita) Mesmo gráfico mostrado à esquerda, mas com escala logarítmica no eixo das ordenadas.
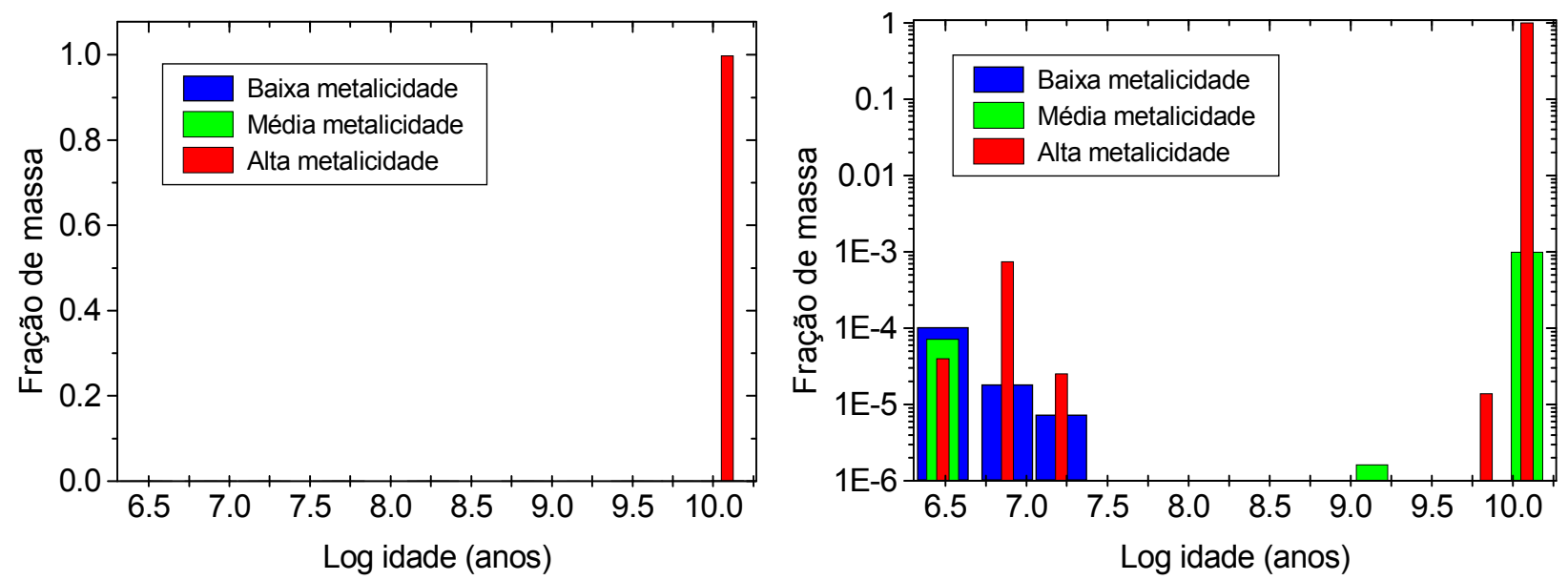

Figura 10.34: (esquerda) Gráfico representativo das frações de massa devidas às populações estelares, considerando-se todo o campo visual do IFU do GMOS, resultante da aplicação do "Starlight" ao cubo de dados de M104 obtido com o GMOS; (direita) Mesmo gráfico mostrado à esquerda, mas com escala logarítmica no eixo das ordenadas. 
Analisando-se as figuras 10.30 e 10.31 , pode-se notar a existência de uma população estelar bastante jovem, com idade de cerca de $10^{6}$ anos, distribuída ao longo de todo o campo visual do IFU do GMOS, sem estruturas ou configurações muito claras. Tal população possui, sobretudo, alta metalicidade, entretanto, componentes com todos os valores de metalicidade considerados no ajuste foram observadas. Também foi detectada uma população com idade de cerca de $10^{7}$ anos e metalicidade variada, um pouco mais concentrada na região central, mas com estruturas similares a filamentos que se estendem até áreas mais afastadas do centro. As figuras 10.30 e 10.31, entretanto, parecem indicar que a maior parte do fluxo é devida a populações estelares velhas, com idade de cerca de $10^{10}$ anos, e com alta metalicidade, $Z=0.05$. Tais populações se distribuem, sobretudo, ao longo do disco estelar, no qual as análises anteriores detectaram a presença de um claro movimento rotacional. Praticamente não foram detectadas populações com idades próximas a $10^{8}$ e a $10^{9}$ anos.

A figura 10.32 mostra que foi detectado featureless continuum no campo visual do IFU do GMOS, porém não na área correspondente ao AGN central. Três possíveis explicações podem ser propostas para isso: a primeira é que o fluxo observado é, de fato, devido ao featureless continuum do AGN, que sofreu um espalhamento por poeira, sendo detectado, por fim, em regiões mais afastadas. Esse featureless continuum não é visível na área correspondente ao AGN devido a um possível obscurecimento por poeira. A segunda explicação é que não foi detectado nenhum featureless continuum emitido pelo AGN e o Starlight utilizou o arquivo de base representativo do featureless continuum para compensar falhas de ajuste. A terceira explicação é que o fluxo no mapeamento da figura 10.32 é devido a populações estelares (talvez sob o efeito de um valor de $A_{V}$ considerável) com um espectro apresentando um contínuo com formato similar ao de uma lei de potência. Nesse caso, o Starlight pode não ter conseguido reproduzir bem o fluxo observado com nenhum dos espectros de base de populações estelares (possivelmente devido a imprecisões da base) e acabou utilizando o arquivo de base representando o featureless continuum. Comparando-se esse resultado com o que foi revelado pelo autovetor E4 resultante da Tomografia PCA do cubo de dados de M104 obtido com o GMOS (figuras 10.17 e 10.18), conclui-se que a primeira interpretação proposta para explicar o que é visto na figura 10.32 parece ser a correta. De fato, o autovetor E4 mencionado revelou a existência de um provável featureless continuum emitido pelo AGN (juntamente com uma componente larga da linha $\mathrm{H} \alpha$ ), que é detectado em áreas bem afastadas do mesmo. Para esse 
autovetor, foi proposto que o featureless continuum sofre um espalhamento por poeira e acaba sendo detectado em regiões mais distantes do AGN. Comparando-se, então, o mapeamento da figura 10.32 com o tomograma mostrado na figura 10.17, conclui-se que eles são consideravelmente compatíveis entre si, sugerindo que o Starlight realmente deve ter detectado o featureless continuum do AGN após sofrer espalhamento.

Observando-se o gráfico da figura 10.33, pode-se notar que a maior parte do fluxo (cerca de $77.2 \%$ do total) no campo visual do IFU do GMOS é proveniente de populações estelares velhas, com idade de cerca de $1.2 \cdot 10^{10}$ anos, e alta metalicidade. Também é detectada uma fração de fluxo considerável (cerca de $19.3 \%$ ) associada a populações bem mais jovens, com idade de cerca de $7.7 \cdot 10^{6}$ anos, e também com alta metalicidade. As frações de fluxo devidas às demais populações estelares são consideravelmente inferiores. No caso do featureless continuum do AGN, pode-se notar que a fração do fluxo associada a ele também é muito reduzida (cerca de $0.4 \%$ ). A figura 10.34, por sua vez, mostra que a maior parte da massa estelar (cerca de $99.8 \%$ do total) é devida a populações estelares velhas, com idade de cerca de $1.2 \cdot 10^{10}$ anos, e com alta metalicidade, o que está de acordo com o esperado, considerando-se as frações de fluxo mostradas nos gráficos da figura 10.33 e as razões $M / L$ associadas às populações estelares envolvidas.

\subsection{4 - Extinção interestelar}

O mapeamento dos valores de $A_{V}$ fornecidos pelo Starlight é mostrado a seguir.

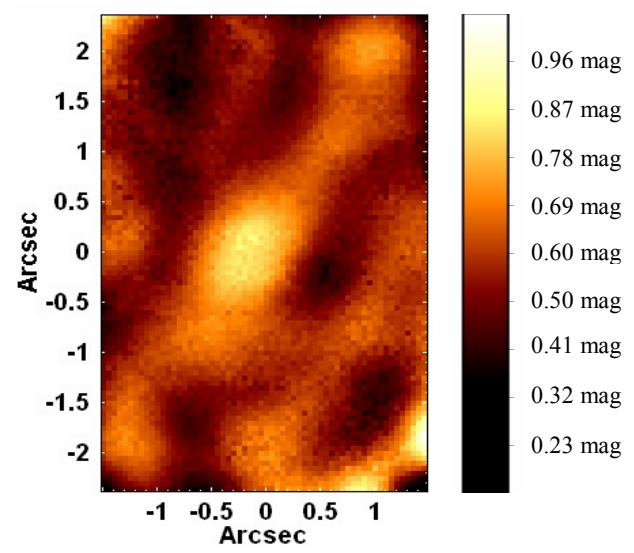

Figura 10.35: Mapeamento dos valores de $A_{V}$, resultante da aplicação do "Starlight" ao cubo de dados de M104 obtido com o GMOS. 
A figura 10.35 revela que os menores valores de $A_{V}$ detectados foram de cerca de 0.14 mag, ao passo que os maiores foram próximos a 1.06 mag. Pode-se notar um certo aumento dos valores na área correspondente ao AGN central, o que indica a presença de uma considerável quantidade de poeira nessa região. Tal poeira pode, inclusive, ser responsável pelo espalhamento do featureless continuum do AGN, que foi detectado nas análises das seções 10.3.1 e 10.4.3.

\subsection{5 - Valores da razão $S / N$ dos espectros analisados}

O mapeamento dos valores da razão $S / N$ obtidos pelo Starlight no intervalo espectral de $5820 \AA$ até $5846 \AA$ encontra-se a seguir.

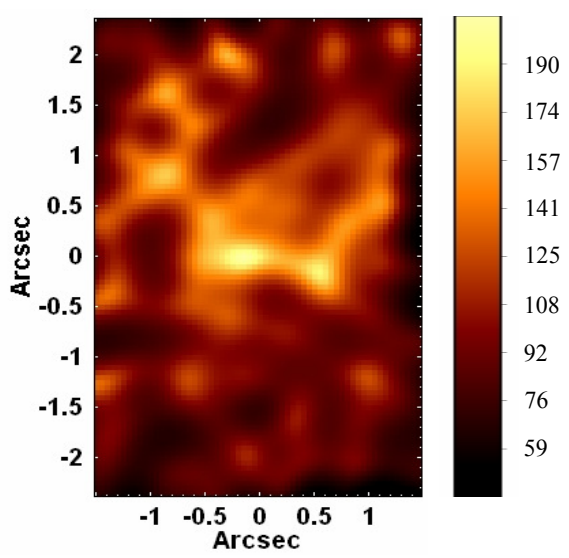

Figura 10.36 - Mapeamentos dos valores da razão $S / N$, resultante da aplicação do "Starlight" ao cubo de dados de M104 obtido com o GMOS.

Observando-se a figura 10.36, nota-se que os valores mais altos (até cerca de 206) para a razão $S / N$ foram encontrados em áreas mais próximas do centro do campo visual do IFU do GMOS, onde se localiza o AGN. Por outro lado, os menores valores (até cerca de 43) foram obtidos nas regiões mais afastadas. Tal comportamento está de acordo com o esperado, já que o fluxo detectado, inclusive na região do contínuo, é mais intenso em áreas próximas ao AGN, dando origem aos valores mais elevados da razão $S / N$. 


\section{5 - Aplicação da Tomografia PCA aos cubos de dados de M104 com o contínuo estelar subtraído}

Utilizando-se os espectros estelares sintéticos obtidos com os ajustes do Starlight, fez-se a subtração do contínuo estelar de todos os espectros dos cubos de dados de M104 no óptico e no infravermelho. Após isso, aplicou-se a Tomografia PCA aos dois cubos resultantes, a fim de se obter uma análise mais detalhada dos espectros de emissão dessa galáxia tanto no óptico quanto no infravermelho.

\subsection{1 - Resultados da Tomografia PCA do cubo de dados de M104 obtido com o GMOS, com o contínuo estelar subtraído}

Os principais auto-espectros e respectivos tomogramas resultantes da aplicação da Tomografia PCA ao cubo de dado de M104 obtido com o GMOS, após a subtração do contínuo estelar, encontram-se a seguir.
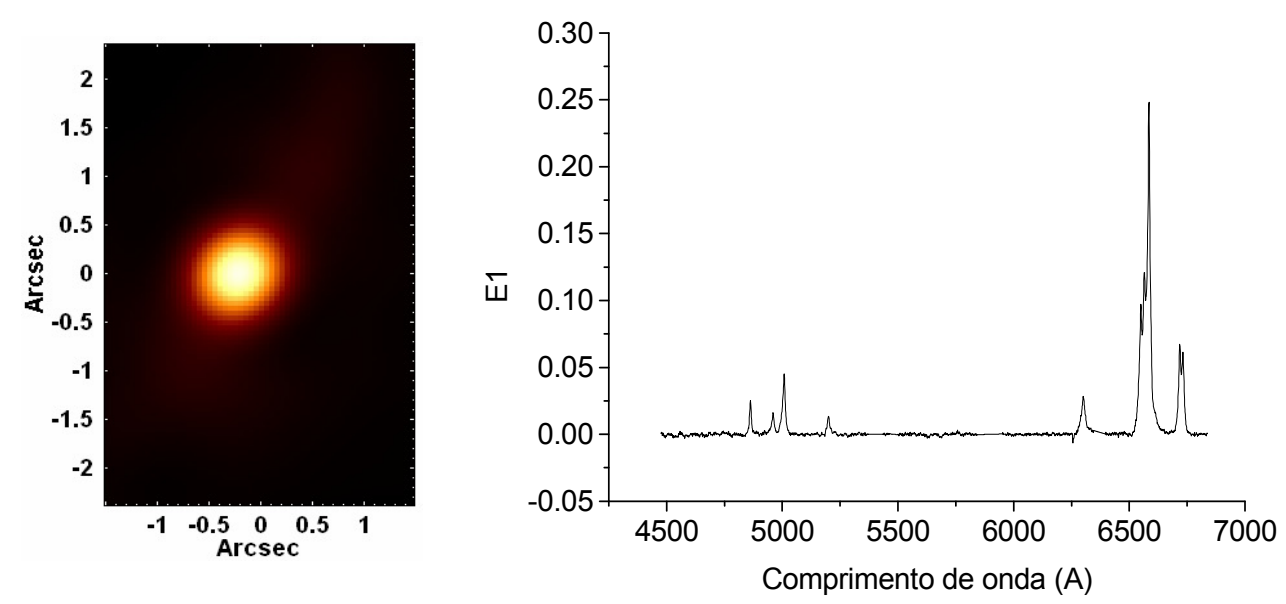

Figura 10.37 - Tomograma e auto-espectro correspondentes ao autovetor E1, resultante da Tomografia PCA do cubo de dados de M104 obtido com o GMOS, com o contínuo estelar subtraído. 


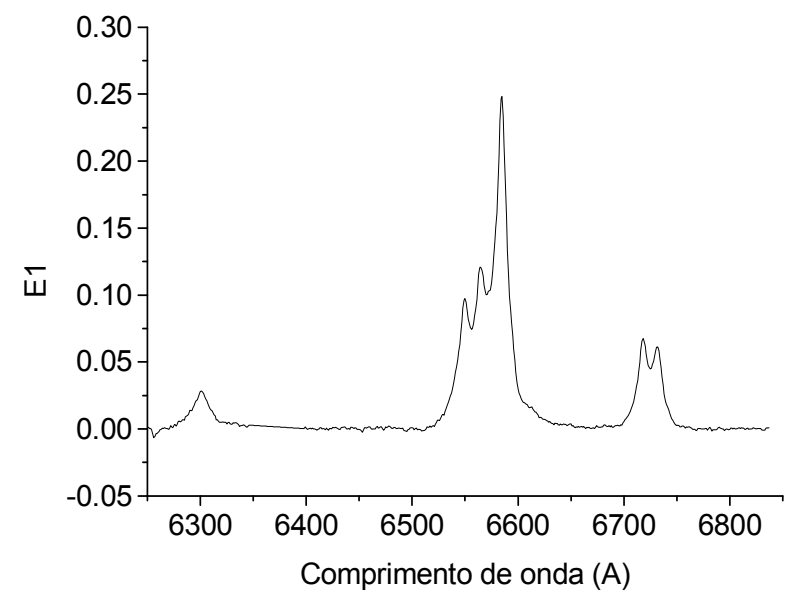

Figura 10.38 - Ampliação na região espectral vermelha do auto-espectro correspondente ao autovetor E1, resultante da Tomografia PCA do cubo de dados de M104 obtido com o GMOS, com o contínuo estelar subtraído.
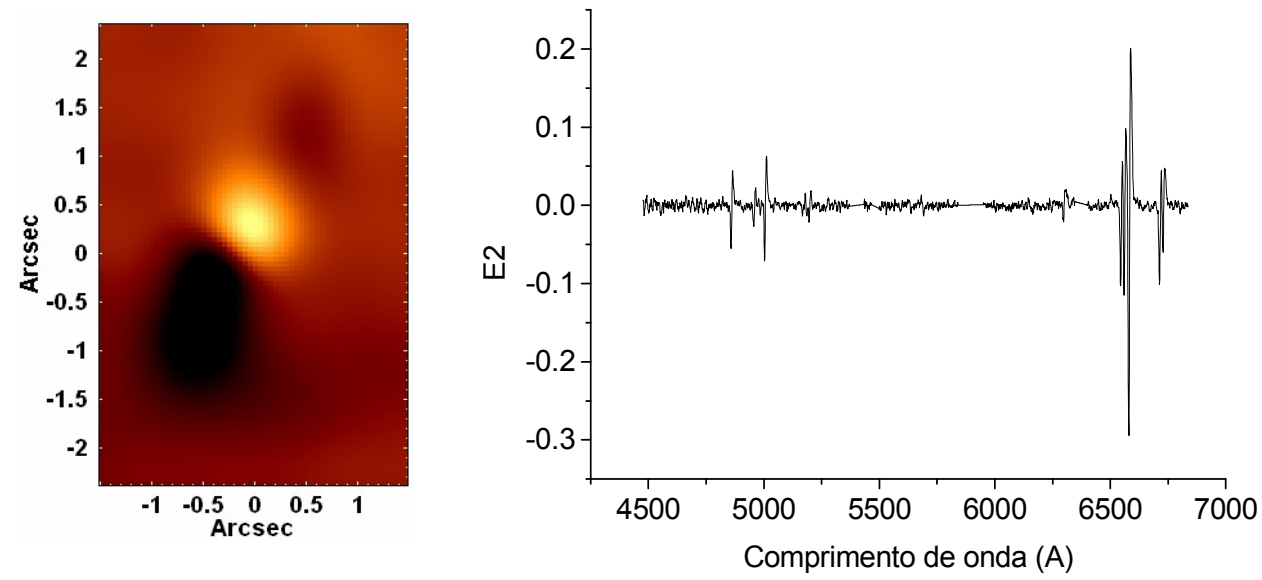

Figura 10.39 - Tomograma e auto-espectro correspondentes ao autovetor E2, resultante da Tomografia PCA do cubo de dados de M104 obtido com o GMOS, com o contínuo estelar subtraído.

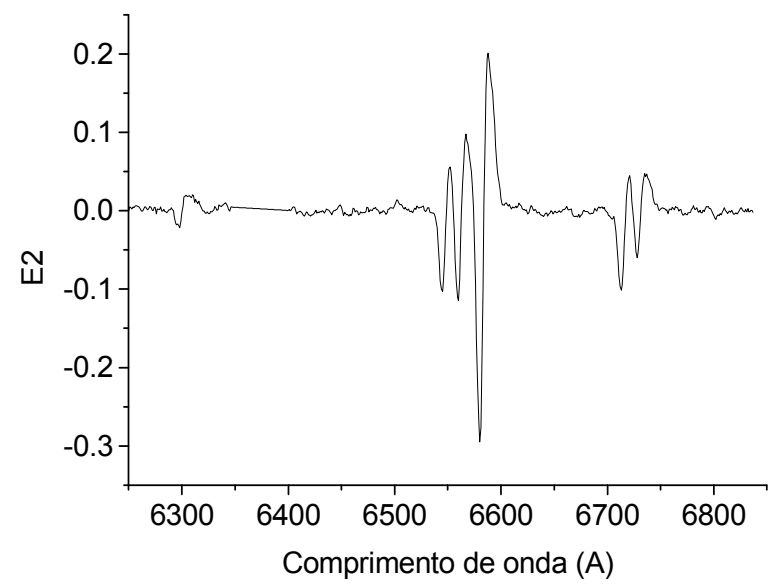

Figura 10.40 - Ampliação na região espectral vermelha do auto-espectro correspondente ao autovetor E2, resultante da Tomografia PCA do cubo de dados de M104 obtido com o GMOS, com o contínuo estelar subtraído. 

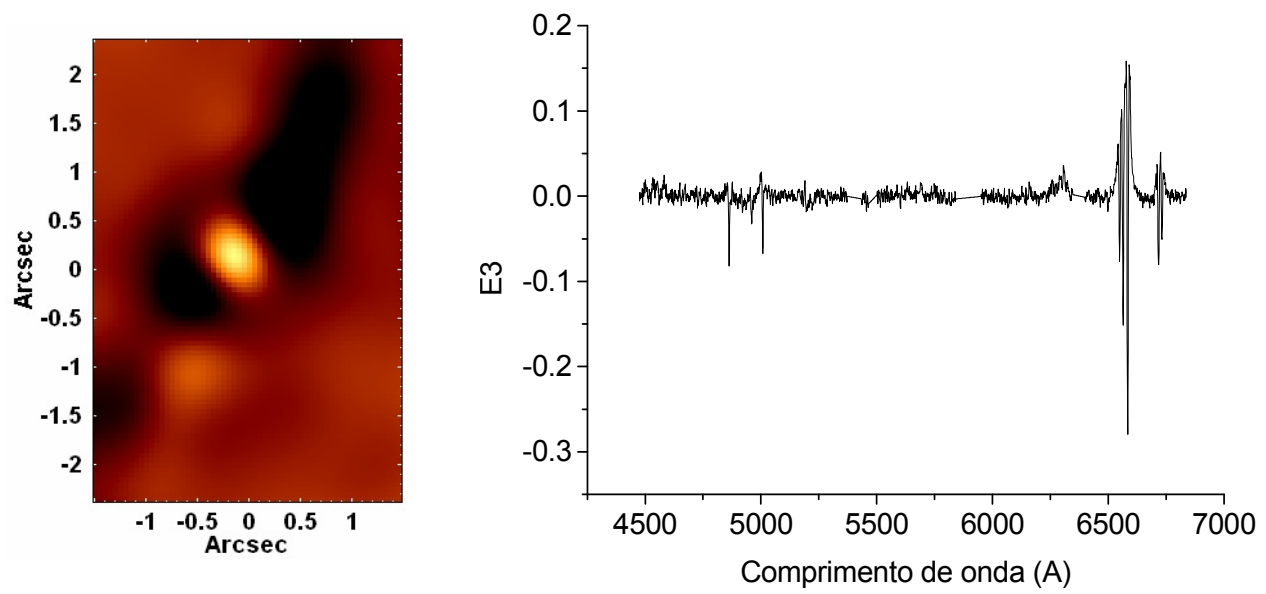

Figura 10.41 - Tomograma e auto-espectro correspondentes ao autovetor E3, resultante da Tomografia PCA do cubo de dados de M104 obtido com o GMOS, com o contínuo estelar subtraído.

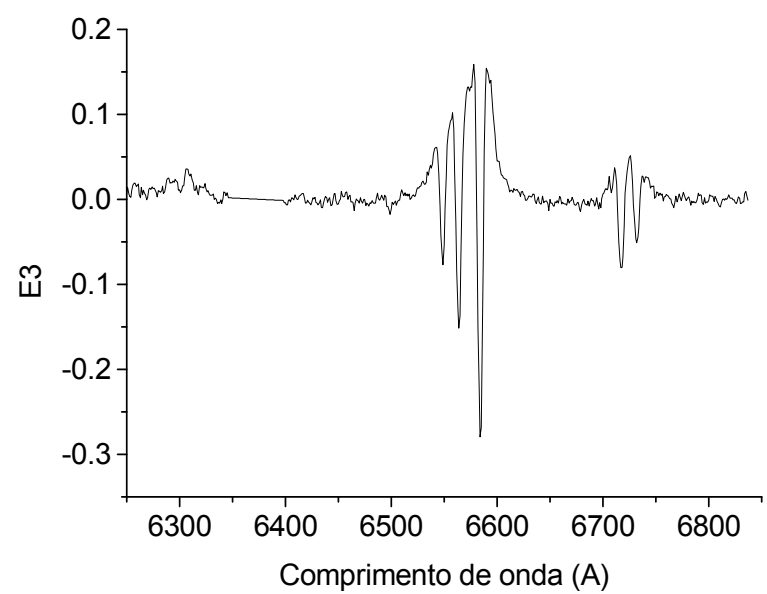

Figura 10.42 - Ampliação na região espectral vermelha do auto-espectro correspondente ao autovetor E3, resultante da Tomografia PCA do cubo de dados de M104 obtido com o GMOS, com o contínuo estelar subtraído.
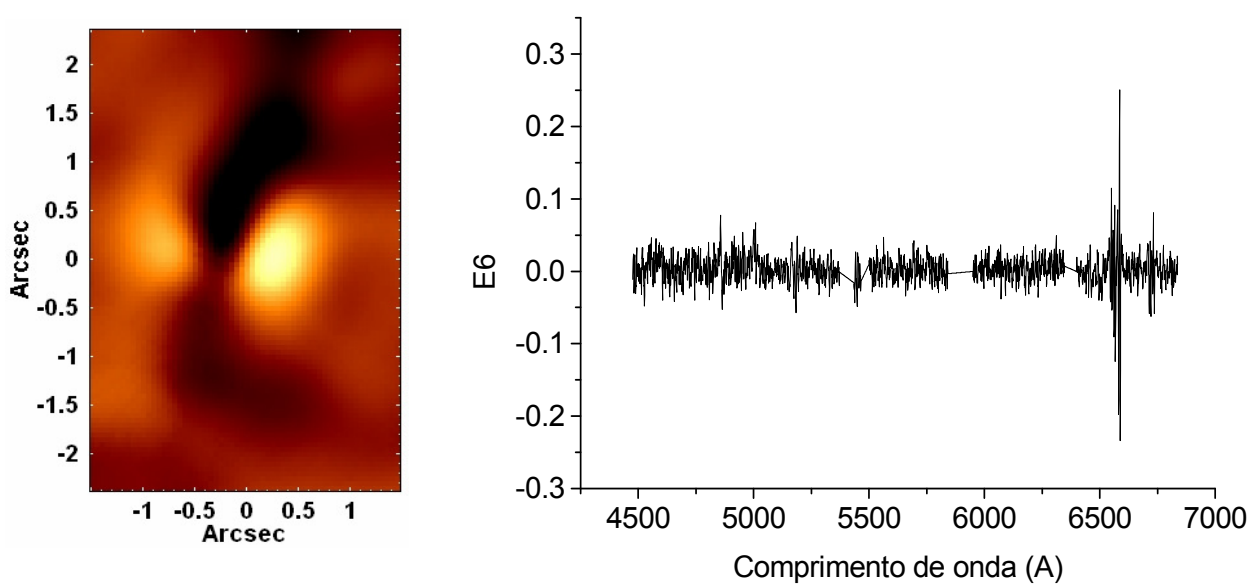

Figura 10.43 - Tomograma e auto-espectro correspondentes ao autovetor E6, resultante da Tomografia PCA do cubo de dados de M104 obtido com o GMOS, com o contínuo estelar subtraído. 


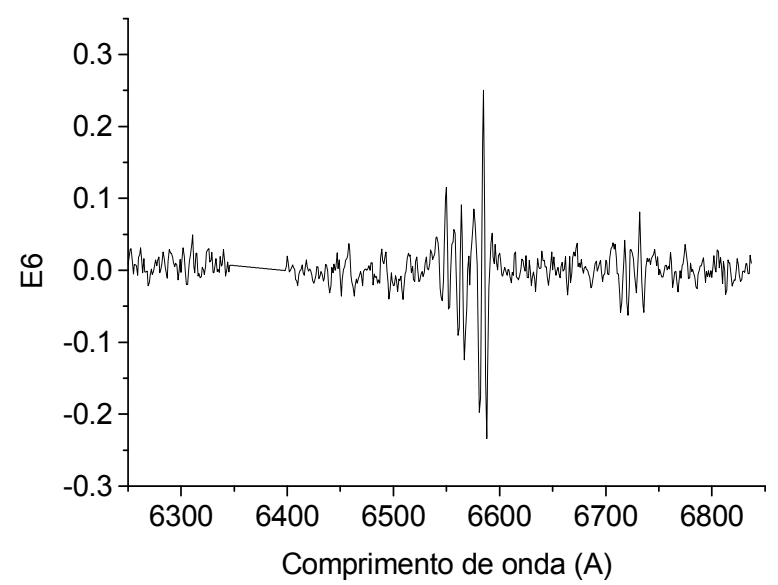

Figura 10.44 - Ampliação na região espectral vermelha do auto-espectro correspondente ao autovetor E6, resultante da Tomografia PCA do cubo de dados de M104 obtido com o GMOS, com o contínuo estelar subtraído.

\begin{tabular}{|c|c|}
\hline Autovetor & Fração da variância explicada (\%) \\
\hline E1 & 92.8589 \\
\hline E2 & 3.5201 \\
\hline E3 & 1.0944 \\
\hline E6 & 0.1246 \\
\hline
\end{tabular}

Tabela 10.3 - Autovalores encontrados com a Tomografia PCA do cubo de dados de M104 obtido com o GMOS, com o contínuo estelar subtraído.

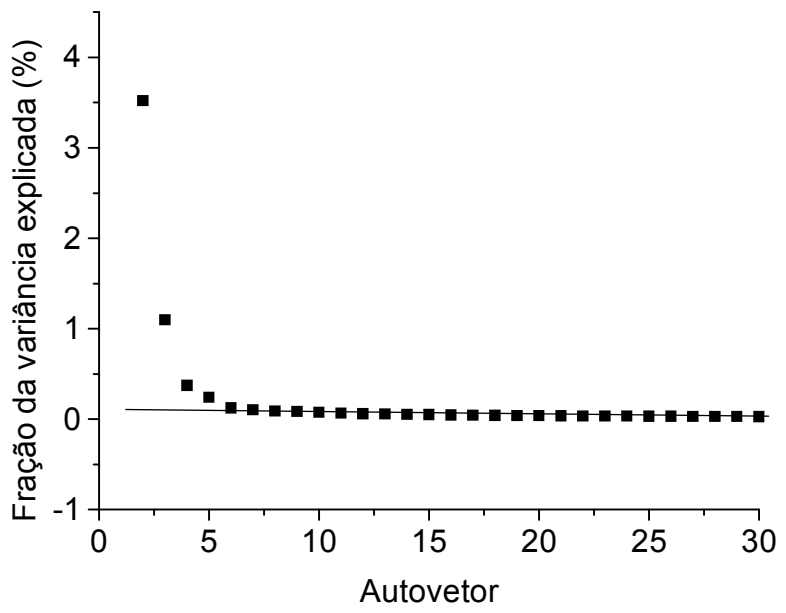

Figura 10.45 - "Scree test" dos autovetores encontrados com a Tomografia PCA do cubo de dados de M104 obtido com o GMOS, com o contínuo estelar subtraído.

As figuras 10.37 e 10.38 mostram que o auto-espectro E1 apresenta correlações com os comprimentos de onda correspondentes às principais linhas de emissão do espectro, sendo que se podem notar, inclusive, correlações com os comprimentos de onda associados a uma provável componente larga da linha $\mathrm{H} \alpha$ (sobretudo a sua asa vermelha). Isso parece indicar que esse 
autovetor está correlacionado com a emissão proveniente do AGN central, cuja posição deve corresponder à área mais clara do tomograma. As informações reveladas por esse autovetor são bastante compatíveis com as mostradas pelo autovetor E2 resultante da aplicação da Tomografia PCA ao cubo de dados de M104 obtido com o GMOS, com o contínuo estelar (figuras 10.13 e 10.14). O autovetor E1 explica cerca de 92.8589 \% da variância dos dados.

Observando-se as figuras 10.39 e 10.40, pode-se notar que o auto-espectro E2 apresenta correlações com os comprimentos de onda correspondentes às asas vermelhas das principais linhas de emissão do espectro e anti-correlações com os comprimentos de onda associados às asas azuis das mesmas. Isso parece indicar que o autovetor E2 está relacionado a algum fenômeno cinemático do gás na região central de M104. Nesse caso, as áreas claras do tomograma possuem gás com emissão em redshift e as regiões escuras revelam gás com emissão em blueshift. Analisando-se o tomograma em questão, nota-se que a sua morfologia sugere a presença de mais de um fenômeno cinemático do gás, como uma rotação e um outflow, por exemplo. Isso é compatível com os resultados obtidos na seção 10.3.1, que também revelaram a provável existência de mais de um fenômeno cinemático do gás na região central de M104. O autovetor E2 explica cerca de $3.5201 \%$ da variância dos dados.

As figuras 10.41 e 10.42, por sua vez, revelam que o auto-espectro E3 apresenta anticorrelações com os comprimentos de onda correspondentes às componentes estreitas das principais linhas de emissão do espectro e correlações com os comprimentos de onda associados às componentes mais alargadas das mesmas. Isso sugere que esse autovetor estabelece uma diferenciação entre regiões emissoras de linhas mais estreitas, que correspondem às áreas escuras do tomograma, e regiões com emissão de linhas mais alargadas, que estão entre as áreas claras do tomograma. É importante mencionar que nem todas as componentes alargadas detectadas por esse autovetor estão associadas necessariamente à BLR do objeto, já que não são largas o suficiente para isso. Algumas das linhas alargadas visíveis nesse auto-espectro, inclusive, nem poderiam ser emitidas em ambientes tão densos como a BLR (como [SII] $\lambda \lambda 6716 ; 6731$ e [NII] $\lambda \lambda 6548 ; 6583$, por exemplo), pois a desexcitação colisional presente impediria tal emissão. É provável que tais linhas estejam sendo emitidas em regiões com densidades intermediárias entre a BLR e a NLR desse objeto. Observando-se o tomograma na figura 10.41, pode-se notar que uma das áreas emissoras de linhas alargadas localiza-se na posição correspondente ao AGN e, consequentemente, à BLR existente, o que está de acordo 
com o esperado. Esse tomograma também mostra a presença de algumas regiões emissoras de linhas alargadas um pouco mais afastadas do AGN central, que, provavelmente, devem corresponder às regiões com densidade intermediária mencionadas. Entretanto, uma das características mais marcantes desse tomograma é que ele revela a presença de áreas emissoras de linhas alargadas muito mais distantes do AGN (na periferia do campo visual do IFU do GMOS, na verdade), que, provavelmente, não apresentam os valores intermediários de densidade mencionados (devido à considerável distância em relação ao AGN e à BLR). Uma possível explicação para isso é que a emissão de linhas alargadas detectada nessas regiões corresponde à emissão do AGN central que foi espalhada por poeira, sendo detectada, por fim, nessas áreas mais afastadas. A presença desse tipo de espalhamento na região central de M104 já foi detectada nas análises das seções 10.3 e 10.4 (figuras 10.17 e 10.32). De fato, comparando-se o tomograma da figura 10.41 com o da figura 10.17 e com o mapeamento da figura 10.32, pode-se notar que eles são razoavelmente compatíveis no que se refere às características das áreas mais periféricas das imagens. Isso sugere que o fenômeno revelado em todas essas figuras é o mesmo. No que se refere às regiões emissoras de linhas estreitas (partes escuras do tomograma da figura 10.41), pode-se dizer que elas se localizam na área correspondente ao disco de gás e estrelas detectado nas análises anteriores (inclusive devido à rotação existente). Parte dessas regiões pode estar associada à NLR desse objeto. O autovetor E3 explica cerca de 1.0944 \% da variância dos dados.

Finalmente, analisando-se as figuras 10.43 e 10.44, nota-se que o auto-espectro E6 apresenta anti-correlações com os comprimentos de onda correspondentes às asas azuis e vermelhas de várias linhas de emissão do objeto e correlações com os comprimentos de onda associados às regiões centrais das mesmas. Isso parece indicar que esse autovetor está estabelecendo um contraste entre áreas com o gás sem nenhuma componente radial de velocidade significativa, correspondentes às regiões claras do tomograma, e áreas com o gás possuindo alguma componente radial de velocidade (blueshift ou redshift), representadas pelas regiões escuras da imagem. Observando-se o tomograma, pode-se notar que o fenômeno cinemático do gás mostrado é compatível com os resultados obtidos anteriormente (figuras 10.15, 10.19 e 10.39). Entretanto, o auto-espectro E6 apresenta, ainda, correlações com comprimentos de onda associados a uma componente larga da linha $\mathrm{H} \alpha$, o que sugere que esse autovetor também está correlacionado com a emissão proveniente da BLR desse objeto. Nesse 
caso, as regiões com essa emissão devem corresponder às áreas claras do tomograma. Entretanto, pode-se notar na figura 10.43 que nenhuma dessas regiões localiza-se na posição do AGN. Uma possível explicação para isso é que (assim como foi o caso do autovetor E3) o que foi observado nesse autovetor corresponde à emissão da BLR do AGN que sofreu um espalhamento por poeira, sendo, por fim, detectada em áreas mais afastadas. Comparando-se o tomograma da figura 10.43 com imagens das análises anteriores também associadas a esse espalhamento (figuras 10.17 e 10.32), pode-se notar uma grande compatibilidade entre elas, o que parece indicar que, de fato, estão relacionadas ao mesmo fenômeno. O autovetor E6 explica cerca de 0.1246 \% da variância dos dados.

O Scree test da figura 10.45 mostra que os valores das variâncias explicadas pelos autovetores decaem bastante até, aproximadamente, o autovetor E8. A partir daí, a taxa de decaimento diminui bastante e fica praticamente constante. Isso indica que os autovetores de ordem maior ou igual a 8 representam, sobretudo, ruído e, consequentemente, não possuem relevância nessa análise. Dentre os autovetores de menor ordem, entretanto, apenas o E1, o E2, o E3 e o E6 apresentavam uma interpretação mais clara e, por isso mesmo, apenas eles foram mostrados aqui.

\subsection{2 - Resultados da Tomografia PCA do cubo de dados de M104 obtido com o NIFS, com o contínuo estelar subtraído}

Os principais auto-espectros e respectivos tomogramas resultantes da aplicação da Tomografia PCA ao cubo de dado de M104 obtido com o NIFS, após a subtração do contínuo estelar, encontram-se a seguir. 

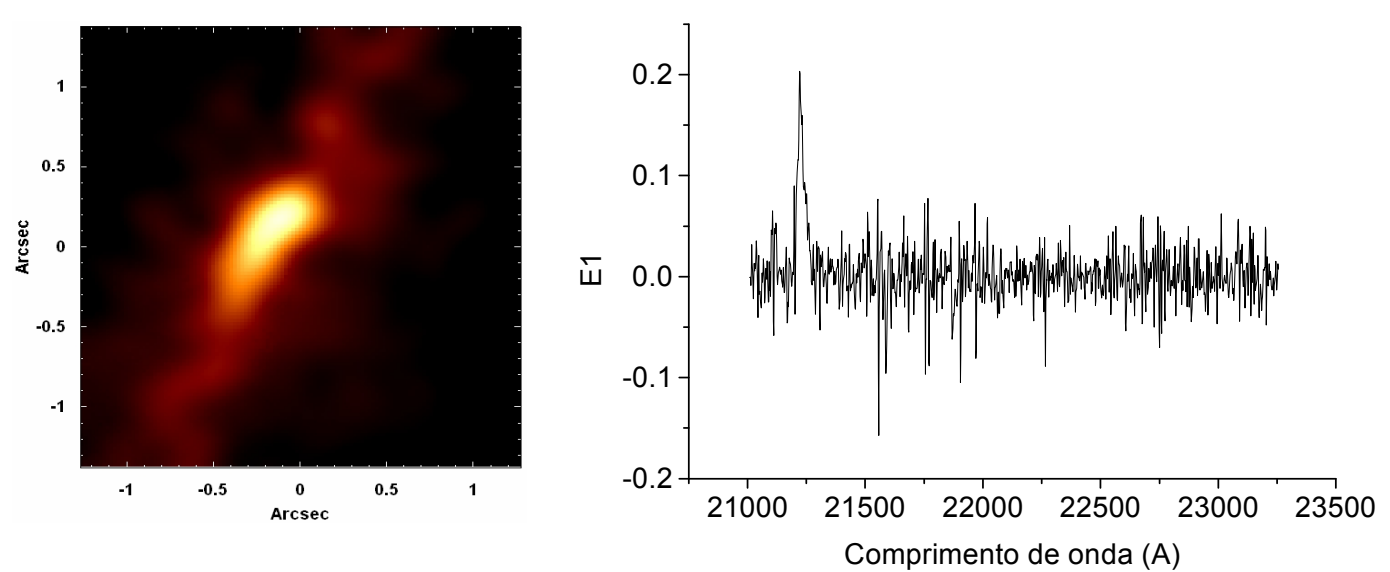

Figura 10.46 - Tomograma e auto-espectro correspondentes ao autovetor E1, resultante da Tomografia PCA do cubo de dados de M104 obtido com o NIFS, com o contínuo estelar subtraído.
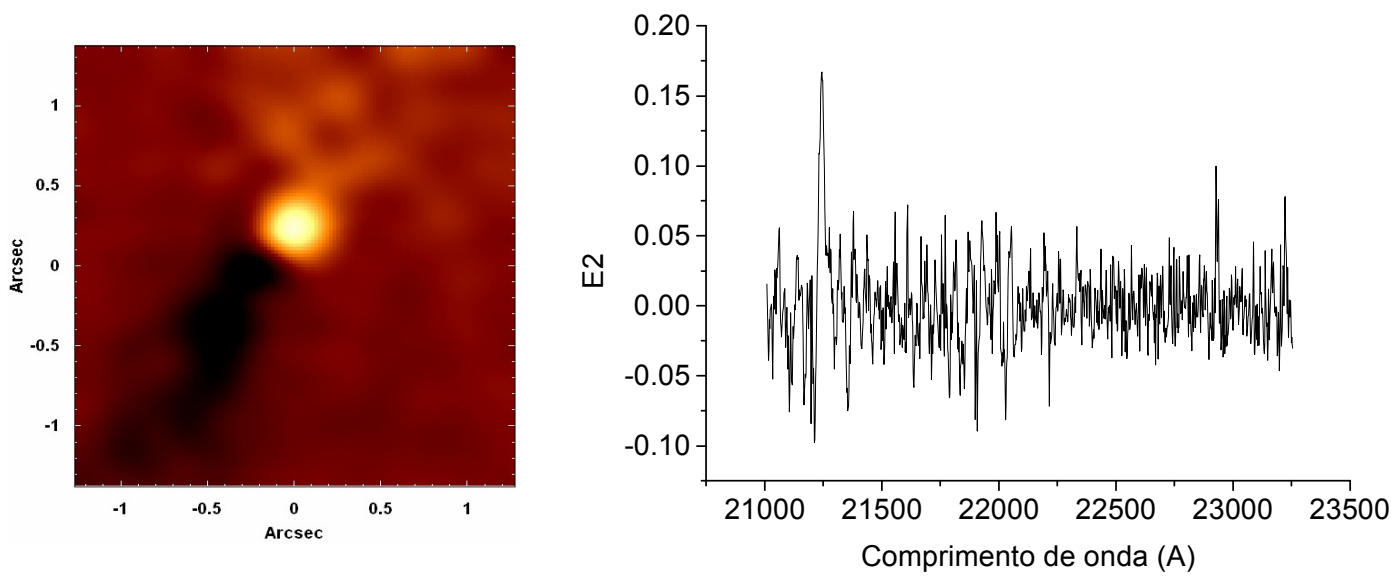

Figura 10.47 - Tomograma e auto-espectro correspondentes ao autovetor E2, resultante da Tomografia PCA do cubo de dados de M104 obtido com o NIFS, com o contínuo estelar subtraído.

\begin{tabular}{|c|c|}
\hline Autovetor & Fração da variância explicada (\%) \\
\hline E1 & 12.7564 \\
\hline E2 & 5.8935 \\
\hline
\end{tabular}

Tabela 10.4 - Autovalores encontrados com a Tomografia PCA do cubo de dados de M104 obtido com o NIFS, com o contínuo estelar subtraído. 


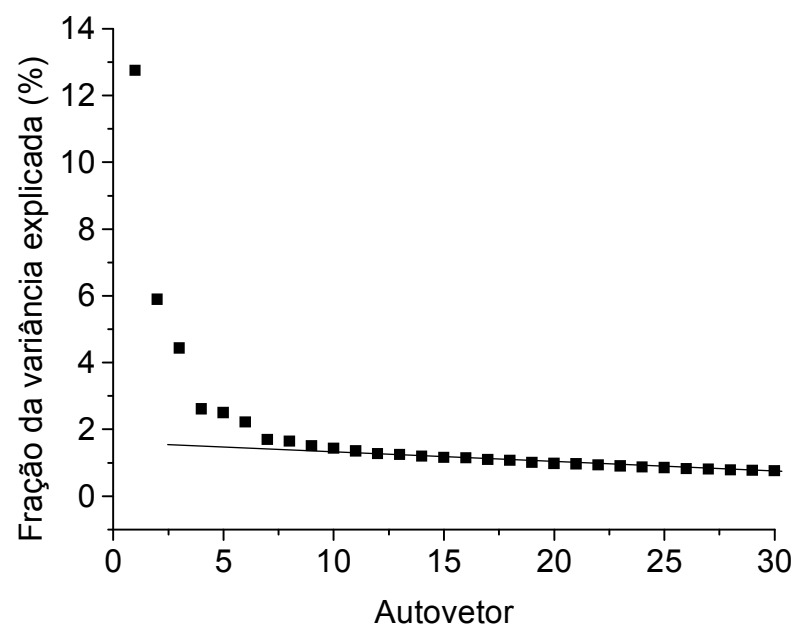

Figura 10.48 - "Scree test" dos autovetores encontrados com a Tomografia PCA do cubo de dados de M104 obtido com o NIFS, com o contínuo estelar subtraído.

Observando-se a figura 10.46, pode-se notar que o auto-espectro E1 apresenta correlações com os comprimentos de onda correspondentes à linha de $\mathrm{H}_{2}$ 221218. Isso mostra que esse autovetor está correlacionado com regiões emissoras de $\mathrm{H}_{2}$, que devem estar entre as áreas claras do tomograma. A morfologia desse último mostra que essas regiões emissoras de $\mathrm{H}_{2}$ estão distribuídas ao longo do disco de gás ao redor do núcleo, que várias análises anteriores detectaram, inclusive, devido à cinemática existente (conforme mostrado pelos autovetores das figuras 10.15 e 10.39, por exemplo). O autovetor E1 explica cerca de 12.7564 \% da variância dos dados.

A figura 10.47 mostra que o auto-espectro E2 apresenta correlações com os comprimentos de onda correspondentes à asa vermelha da linha de $\mathrm{H}_{2} \lambda 21218$ e anti-correlações com os comprimentos de onda associados à asa azul da mesma linha. Isso parece indicar que esse autovetor está relacionado a algum fenômeno cinemático do gás $\mathrm{H}_{2}$ na região central de M104. Nesse caso, as áreas claras do tomograma possuem gás molecular com uma emissão em redshift e as regiões escuras apresentam gás molecular com uma emissão em blueshift. A morfologia do tomograma parece ser compatível com a de uma rotação do gás, entretanto, algumas irregularidades e assimetrias visíveis sugerem que pode haver também um segundo fenômeno cinemático presente, como um outflow, por exemplo. Um fenômeno cinemático relacionado ao gás $\mathrm{H}_{2}$ foi detectado no autovetor E7 resultante da aplicação da Tomografia PCA na seção 10.3.2 (figura 10.26), entretanto, comparando-se o tomograma do autovetor E2 aqui obtido com o tomograma do autovetor E7 mostrado na figura 10.26, nota-se que as morfologias não parecem ser compatíveis. Por outro lado, é possível que as estruturas mostradas pelo 
tomograma da figura 10.26 não sejam totalmente confiáveis, devido ao fato de o auto-espectro associado a ele ter apresentado contaminações, provavelmente devidas a resquícios de absorções telúricas não completamente removidas. Assim, a morfologia do tomograma mostrado na figura 10.47 deve ser a mais confiável. O autovetor E7 explica cerca de 5.8935 \% da variância dos dados.

O Scree test mostrado na figura 10.48 revela que os valores das variâncias explicadas pelos autovetores decaem bastante até, aproximadamente, o autovetor E4. A partir daí, a taxa de decaimento diminui consideravelmente, ficando praticamente constante a partir do autovetor E12. Isso indica que autovetores de ordem maior ou igual a 12 representam essencialmente ruído e, portanto, não possuem relevância nessa análise. Entretanto, dentre os autovetores de menor ordem, apenas os dois primeiros apresentaram uma interpretação clara e, por essa razão, apenas eles foram mostrados aqui.

Assim, pode-se dizer que essas aplicações da Tomografia PCA aos cubos de dados de M104 obtidos com o GMOS e com o NIFS, após a subtração do contínuo estelar, revelaram informações bastante compatíveis com as encontradas na seção 10.3, mas, ao mesmo tempo, permitiram que alguns fenômenos fossem melhor visualizados. Primeiramente, essa segunda análise no óptico isolou consideravelmente bem (e de maneira compatível com a análise da seção 10.3.1) a emissão proveniente do AGN central, que pôde ser classificado como de tipo 1, devido a uma componente larga da linha Ha detectada. A Tomografia PCA no óptico também revelou a existência de um provável espalhamento por poeira da emissão proveniente do AGN. Nesse caso, entretanto, a análise da seção 10.3.1 apresentou resultados mais claros. A razão disso é que, nos resultados aqui obtidos, pôde-se observar apenas o espalhamento da componente larga da linha $\mathrm{H} \alpha$ (proveniente da BLR), já que o contínuo foi subtraído de todos os espectros, entretanto, na seção 10.3.1 foi possível detectar o espalhamento da componente larga de $\mathrm{H} \alpha$ e também do featureless continuum emitido pelo AGN, o que proporcionou uma melhor visualização do fenômeno. Por fim, essa segunda aplicação da Tomografia PCA (assim como a da seção 10.3) revelou a provável existência de mais de um fenômeno cinemático do gás na região central de M104. Tanto no óptico quanto no infravermelho, foi visualizada uma aparente rotação do gás ao redor do núcleo, entretanto, em ambos os casos, foram detectadas evidências da existência de algum outro fenômeno cinemático (como um outflow, por exemplo). 


\section{6 - Cinemática estelar dos cubos de dados de M104}

Aplicou-se o processo do pPXF nos cubos de dados de M104 obtidos com o GMOS e com o NIFS, a fim de se obter os mapeamentos dos valores da velocidade radial estelar, da dispersão de velocidades estelar e dos coeficientes de Gauss-Hermite $h_{3}$ e $h_{4}$.

\subsection{1 - Resultados da aplicação do pPXF ao cubo de dados de M104 obtido com o GMOS}

Os mapeamentos dos valores dos parâmetros resultantes da aplicação do pPXF ao cubo de dados de M104 obtido com o GMOS encontram-se a seguir.
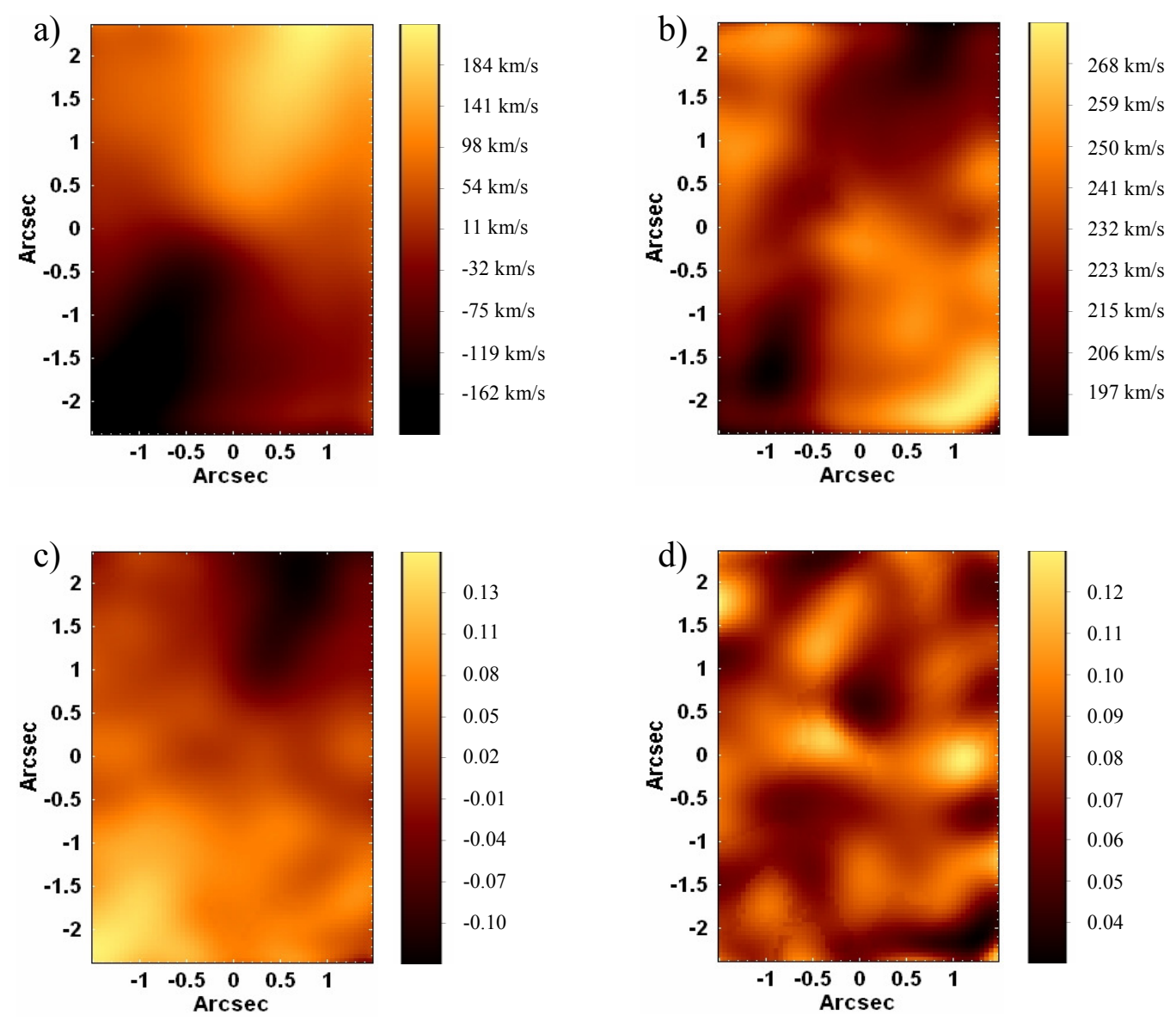

Figura 10.49 - Mapeamentos dos valores (a) da velocidade radial estelar, (b) da dispersão de velocidades estelar, (c) do coeficiente $h_{3}$ e (d) do coeficiente $h_{4}$, resultantes da aplicação do pPXF ao cubo de dados de M104, obtido com o GMOS. 
Observando-se a figura 10.49 - $a$, pode-se notar a presença de um disco estelar bem definido em rotação ao redor do núcleo de M104. Esse achado é compatível não apenas com o mapeamento dos valores da velocidade radial estelar da figura 10.29, mas também com os resultados obtidos com as aplicações da Tomografia PCA da seção 10.3 (figuras 10.15 e 10.23). A figura $10.49-b$, por sua vez, mostra uma diminuição da dispersão de velocidades na região do disco estelar detectado e um aumento da mesma nos arredores. Também se nota um aumento da dispersão de velocidades na área correspondente ao AGN central. Esse resultado é compatível com o que foi obtido com o mapeamento da figura 10.29 e revela que, na região do disco, a cinemática estelar é dominada pela rotação, resultando em um alto grau de anisotropia e menores dispersões de velocidades. Nas áreas fora do disco, a rotação diminui e o grau de isotropia aumenta, resultando em maiores dispersões de velocidades. É provável que o aumento da dispersão de velocidades na região próxima ao AGN deva estar sendo causado pela presença do buraco negro supermassivo.

Analisando-se a figura $10.49-c$, nota-se um claro padrão na disposição dos valores do coeficiente $h_{3}$, que parece estar associado ao que foi detectado no mapeamento da velocidade radial estelar (figura $10.49-a$ ). Percebe-se uma diminuição dos valores de $h_{3}$ nas regiões com maiores velocidades radiais estelares e um aumento dos valores de $h_{3}$ nas áreas com menores velocidades radiais estelares. Considerando-se que o coeficiente $h_{3}$ revela o grau de assimetria nas linhas de absorção presentes nos espectros analisados, pode-se dizer que a sobreposição de um disco de estrelas em rotação a um fundo com valores de velocidades mais aleatórios poderia, em princípio, dar origem ao comportamento de $h_{3}$ observado na figura $10.49-c$. Finalmente, o mapeamento dos valores de $h_{4}$ mostrado na figura $10.49-d$ não revelou padrões ou configurações que pudessem ser identificados claramente.

O mapeamento dos valores da velocidade radial estelar obtido (figura $10.49-a$ ) apresenta detalhes suficientes para que possa ser elaborada uma modelagem com o objetivo de se determinar a massa do buraco negro central existente. Esse procedimento foi aplicado da mesma forma que no caso de NGC 5643, utilizando-se a implementação do método de Jeans desenvolvida por Cappellari (2008). O mapeamento da dispersão de velocidades estelar na figura $10.49-b$ possui uma morfologia que não pôde ser bem reproduzida pelo método de Jeans, assim, analogamente ao que foi feito para NGC 5643, simularam-se, apenas, os valores da velocidade radial $V$, e não os do segundo momento de velocidades, dado por $V_{r m s}^{2}=V^{2}+\sigma^{2}$. A 
modelagem envolveu o ajuste de 4 parâmetros livres: massa do buraco negro central $\left(M_{b h}\right)$, inclinação do disco de estrelas ao redor do buraco negro (i), razão $M / L$ e a constante $k$. Assim como no caso de NGC 5643, não foi possível estimar incertezas para $M / L$ e $k$, e $\beta_{z}$ foi tomado como sendo igual a 0.025 , já que $\beta_{z} \neq 0.025 \pm 0.025$ não fornecia resultados compatíveis com o observado. Para se estimar a massa estelar presente, primeiramente, utilizou-se o procedimento do MGE (Multi-Gaussian Expansion), o que permitiu que o efeito da projeção no plano do céu fosse removido. Em seguida, os valores de luminosidade encontrados foram multiplicados pela razão $M / L$ fornecida. O ajuste do MGE foi aplicado na imagem correspondente ao cubo de dados de M104 obtido com o NIFS, integrado ao longo do eixo espectral. A razão disso é que os dados no infravermelho apresentavam uma melhor resolução espacial (devido à utilização da óptica adaptativa), o que proporcionou um ajuste fotométrico mais preciso. O modelo mais adequado para a cinemática estelar foi obtido variando-se sequencialmente os 4 parâmetros livres, com o objetivo de se minimizar o $\chi^{2}$, dado pela expressão

$$
\chi^{2}=\sum_{i=1}^{N x} \sum_{j=1}^{N y} \frac{w_{i j}\left(v_{i j}(\text { observada })-v_{i j}(\text { simulada })\right)^{2}}{\sigma_{i j}^{2}} .
$$

onde $N_{x}=$ número de pixeis espaciais ao longo do eixo horizontal

$$
N_{y}=\text { número de pixeis espaciais ao longo do eixo vertical }
$$$$
\sigma_{i, j}=\text { incerteza do valor da velocidade do pixel espacial }(i, j)
$$$$
v_{i, j}(\text { observada })=\text { velocidade do pixel espacial }(i, j) \text { do mapa de }
$$
velocidades observado

$v_{i, j}($ simulada $)=$ velocidade do pixel espacial $(i, j)$ do mapa de velocidades simulado

$w_{i, j}=$ peso igual a 1 para regiões próximas à linha de nodos do mapa de velocidades observado e igual a 0 para áreas mais afastadas

As incertezas dos valores encontrados para os parâmetros $M_{b h}$ e $i$ foram estimadas utilizando-se o mesmo método usado no caso de NGC 5643 (Jardel et al. 2011). A tabela 10.5 mostra os parâmetros do melhor modelo obtido com as simulações, que apresentou $\chi^{2}=1706.2$. 


\begin{tabular}{|c|c|}
\hline Parâmetro & $\begin{array}{c}\text { Valor correspondente ao melhor modelo } \\
\text { obtido com as simulações }\end{array}$ \\
\hline$i$ & $82.0 \pm 1.2^{\circ}$ \\
\hline$M_{b h}$ & $(2.0 \pm 0.8) \cdot 10^{8} \mathrm{M}_{\odot}$ \\
\hline$M / L^{*}$ & 6.5 \\
\hline$k^{*}$ & 1.17 \\
\hline
\end{tabular}

Tabela 10.5 - Parâmetros do melhor modelo resultante das simulações do mapa dos valores da velocidade radial estelar do cubo de dados de M104, obtido com o GMOS, utilizando-se o método de Jeans.

* Parâmetros para os quais não foi possivel atribuir uma incerteza

A figura 10.50 mostra uma comparação entre o mapa dos valores da velocidade radial estelar observado, obtido com a aplicação do processo do pPXF, e o mapa correspondente simulado, resultante do melhor modelo elaborado com o método de Jeans.
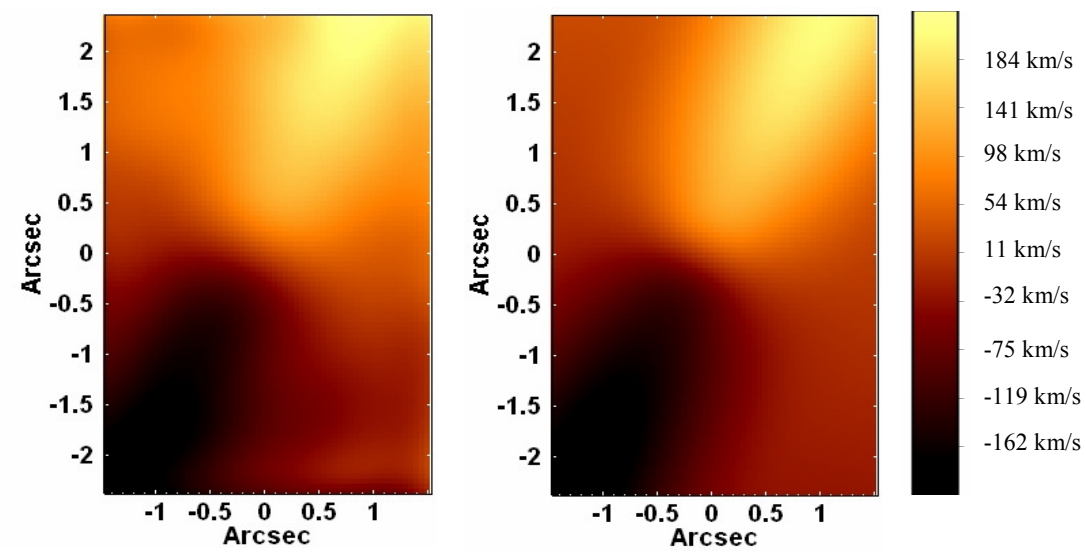

Figura 10.50 - (esquerda) Mapa dos valores da velocidade radial estelar observado, resultante da aplicação do processo do pPXF ao cubo de dados de M104 obtido com o GMOS (igual ao mostrado na figura 10.49-a); (direita) Mapa dos valores da velocidade radial estelar, resultante do melhor modelo obtido com as simulações feitas com o método de Jeans.

Verificou-se que a linha de nodos do mapa dos valores da velocidade radial estelar observado apresenta $P A=88.5^{\circ}$. A figura 10.51 mostra uma curva de rotação extraída ao longo dessa linha de nodos desse mapa de velocidades, juntamente com o resultado do melhor modelo obtido com as simulações com o método de Jeans. 


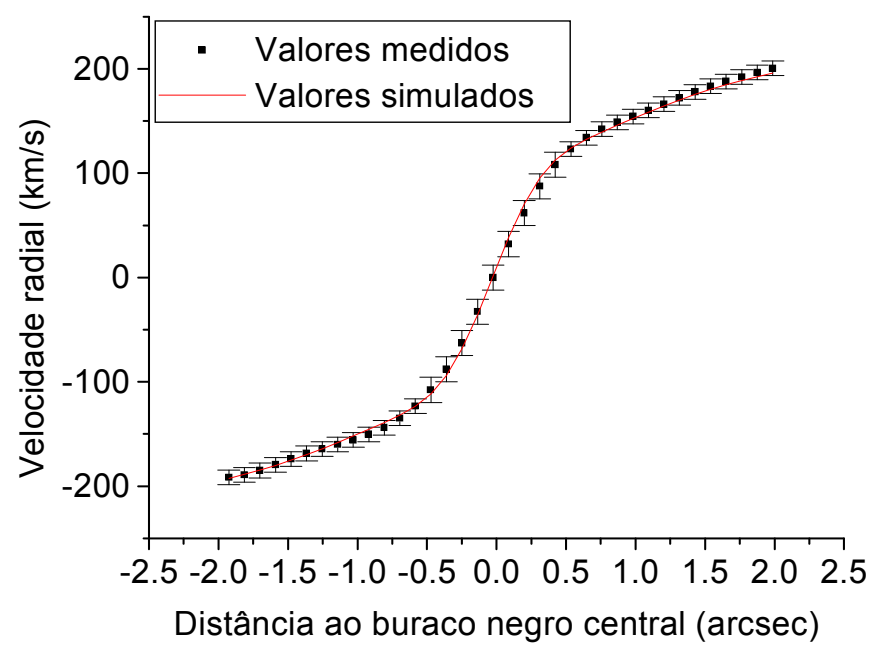

Figura 10.51 - Curva de rotação extraída ao longo da linha de nodos do mapa dos valores da velocidade radial estelar na figura 10.49 - a, juntamente com o resultado do melhor modelo obtido com as simulações feitas com o método de Jeans.

A figura 10.50 revela que o modelo elaborado com o método de Jeans reproduz consideravelmente bem o mapa dos valores da velocidade radial estelar do cubo de dados de M104 obtido com o GMOS. Pela figura 10.51, pode-se notar, inclusive, que o modelo é compatível, em 1- $\sigma$, com todos os valores de velocidade radial estelar ao longo da linha de nodos.

\subsection{2 - Resultados da aplicação do pPXF ao cubo de dados de M104 obtido com o NIFS}

Os mapeamentos dos valores dos parâmetros resultantes da aplicação do pPXF ao cubo de dados de M104 obtido com o NIFS encontram-se a seguir. 

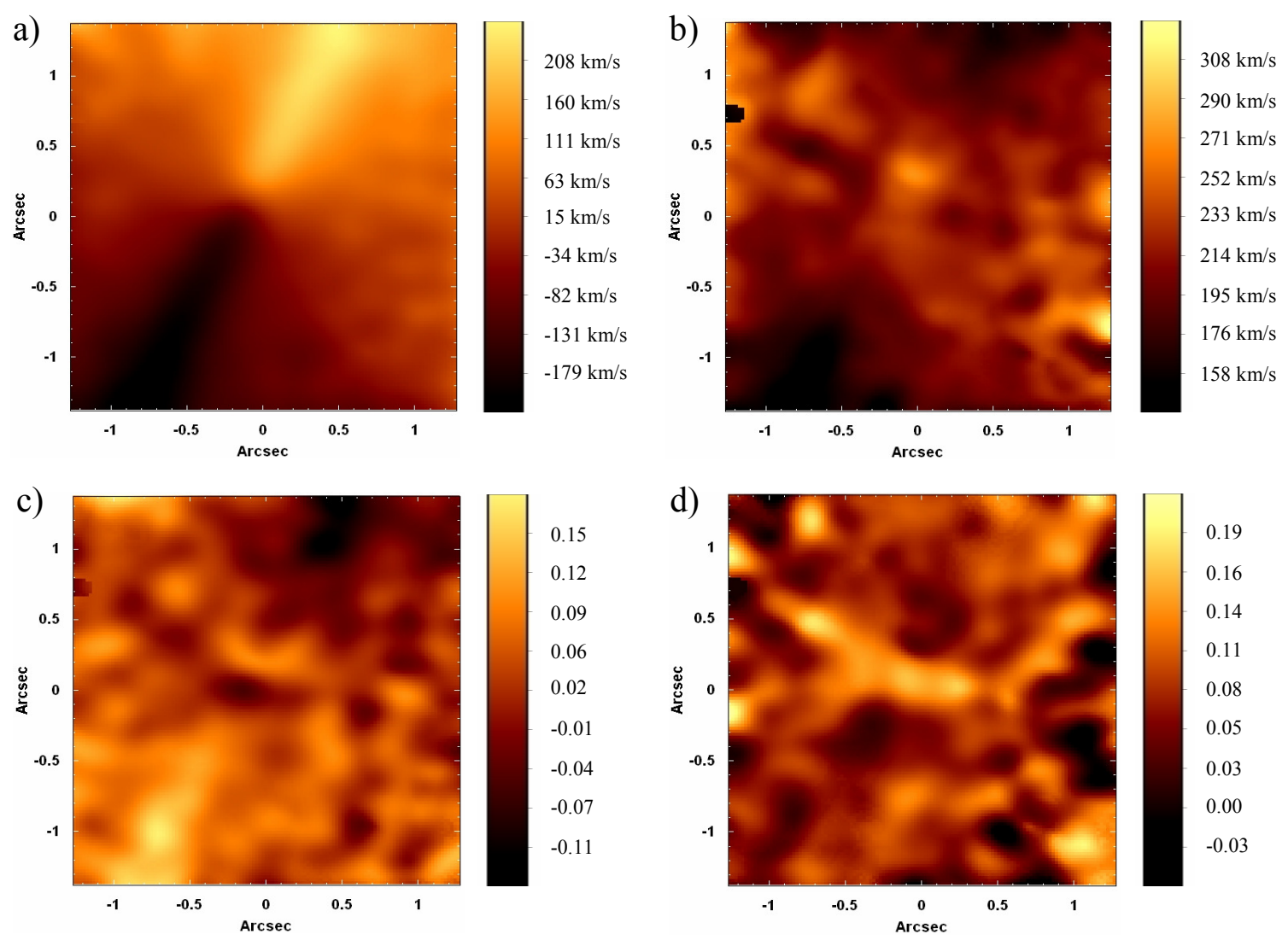

Figura 10.52 - Mapeamentos dos valores (a) da velocidade radial estelar, (b) da dispersão de velocidades estelar, (c) do coeficiente $h_{3} e(d)$ do coeficiente $h_{4}$, resultantes da aplicação do pPXF ao cubo de dados de M104, obtido com o NIFS.

Analisando-se os mapeamentos da figura 10.52, pode-se notar que todos eles são compatíveis com o que se obteve na seção 10.6.1. A figura 10.52 - a mostra a mesma rotação estelar detectada na figura 10.49 - $a$. O comportamento observado no mapeamento da figura 10.52 - b, com uma diminuição da dispersão de velocidades estelar ao longo do disco e o aumento nos arredores, foi o mesmo detectado na figura $10.49-b$. A figura $10.52-c$ revela um padrão na distribuição dos valores do coeficiente $h_{3}$ bastante similar ao que foi observando no mapeamento da velocidade radial estelar da figura $10.52-a$ : o coeficiente $h_{3}$ aumenta nas regiões com menores velocidades e diminui nas áreas com maiores velocidades. Tal associação entre os mapeamentos de $h_{3}$ e da velocidade radial estelar também foi observada nas figuras $10.49-c$ e $10.49-a$. Por fim, o mapeamento do coeficiente $h_{4}$ na figura $10.52-d$, assim como aquele na figura $10.49-d$, não revelou padrões ou configurações que pudessem ser identificados claramente.

Assim como no caso da seção 10.6.1, o mapeamento dos valores da velocidade radial estelar obtido (figura $10.52-a$ ) possui detalhes suficientes para que possa ser elaborada uma 
modelagem, visando a determinação da massa do buraco negro central existente. Entretanto, diferentemente do que foi feito na seção 10.6.1, aqui a simulação envolveu o ajuste de apenas 3 parâmetros livres: massa do buraco negro central $\left(M_{b h}\right)$, inclinação do disco de estrelas ao redor do buraco negro $(i)$ e a constante $k$. Como a imagem utilizada nessa modelagem para a determinação da massa estelar presente foi a mesma da seção 10.6.1 (que corresponde a uma integral ao longo do eixo espectral do cubo de dados de M104 obtido com o NIFS), optou-se por não ajustar novamente o valor de $M / L$, mas sim usar o valor determinado anteriormente $(M / L=$ 6.5). Por razões já mencionadas na seção anterior, o parâmetro $\beta_{z}$ foi tomado como sendo igual a 0.025. Por fim, analogamente ao que ocorreu no caso dos dados no óptico, não foi possível simular os valores do segundo momento de velocidades (dado por $V_{r m s}^{2}=V^{2}+\sigma^{2}$ ), devido à morfologia e também às irregularidades observadas no mapeamento da dispersão de velocidades estelar (figura 10.52 - b). Os três parâmetros livres foram variados sequencialmente com o objetivo de se minimizar o $\chi^{2}$, dado pela expressão (10.1). As incertezas foram estimadas conforme já foi explicado anteriormente. A tabela 10.6 mostra os parâmetros do melhor modelo obtido com as simulações, que apresentou $\chi^{2}=645.1$.

\begin{tabular}{|c|c|}
\hline Parâmetro & $\begin{array}{c}\text { Valor correspondente ao melhor modelo } \\
\text { obtido com as simulações }\end{array}$ \\
\hline$i$ & $82.0 \pm 0.5^{\circ}$ \\
\hline$M_{b h}$ & $(1.0 \pm 0.2) \cdot 10^{8} \mathrm{M}_{\odot}$ \\
\hline$M / L^{*}$ & 6.5 \\
\hline$k^{*}$ & 1.75 \\
\hline
\end{tabular}

Tabela 10.6 - Parâmetros do melhor modelo resultante das simulações do mapa dos valores da velocidade radial estelar do cubo de dados de M104, obtido com o NIFS, utilizando-se o método de Jeans.

* Parâmetros para os quais não foi possível atribuir uma incerteza

A figura 10.53 mostra uma comparação entre o mapa dos valores da velocidade radial estelar observado, obtido com a aplicação do processo do pPXF, e o mapa correspondente simulado, resultante do melhor modelo elaborado com o método de Jeans. 

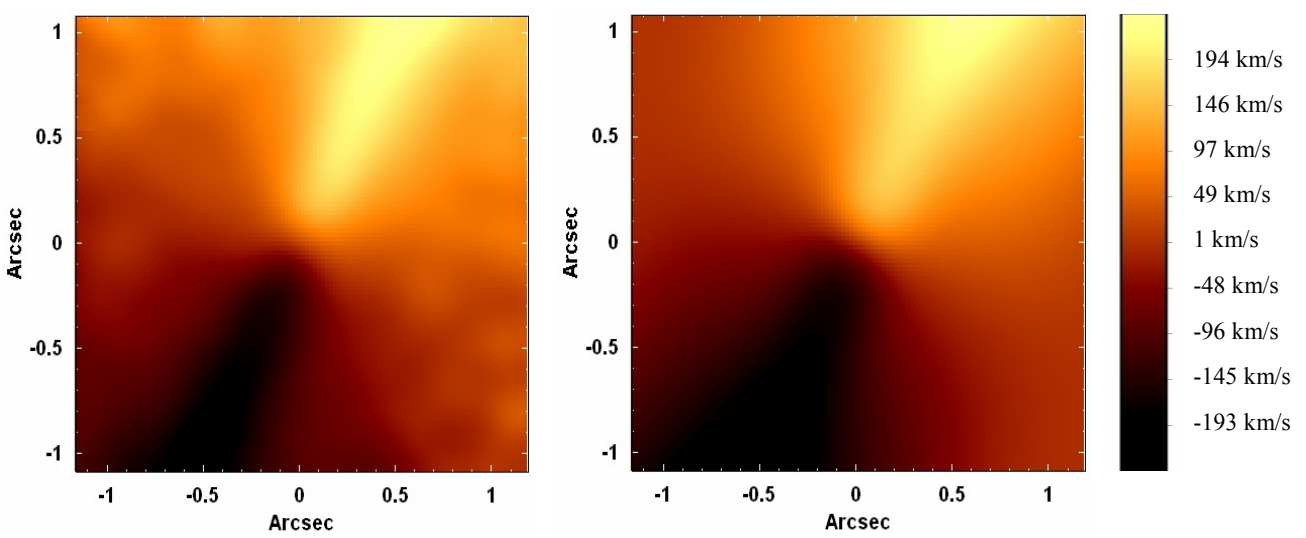

Figura 10.53 - (esquerda) Mapa dos valores da velocidade radial estelar observado, resultante da aplicação do processo do pPXF ao cubo de dados de M104 obtido com o NIFS (igual ao mostrado na figura 10.52 - a); (direita) Mapa dos valores da velocidade radial estelar, resultante do melhor modelo obtido com as simulações feitas com o método de Jeans.

Verificou-se que a linha de nodos do mapa dos valores da velocidade radial estelar observado (figura $10.52-a$ ) apresentava o mesmo $P A\left(88.5^{\circ}\right)$ que aquele na figura $10.49-a$, o que, obviamente, está de acordo com o esperado. A figura 10.54 mostra uma curva de rotação extraída ao longo da linha de nodos do mapa de velocidades da figura $10.52-a$, juntamente com o resultado do melhor modelo obtido com as simulações com o método de Jeans.

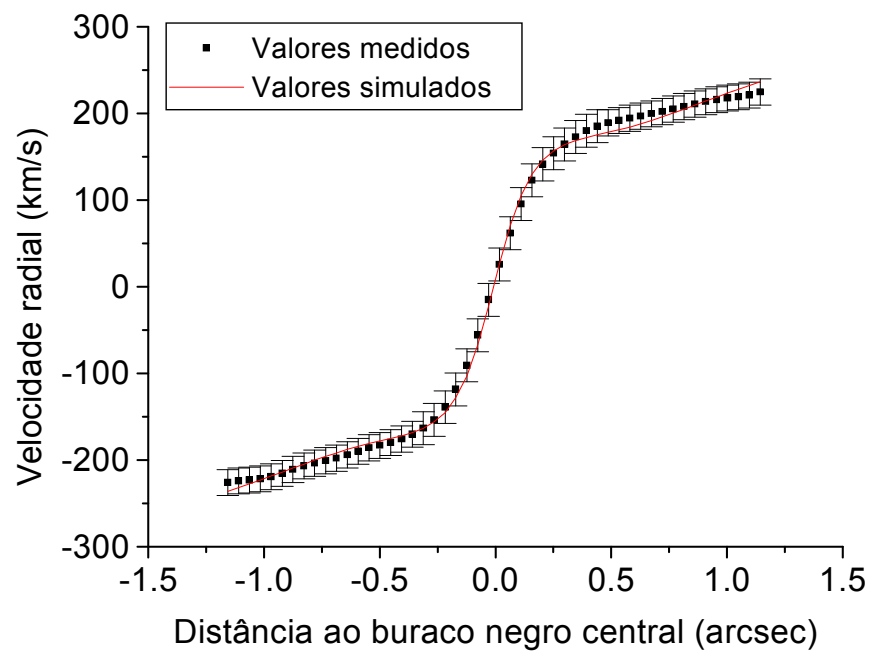

Figura 10.54 - Curva de rotação extraída ao longo da linha de nodos do mapa dos valores da velocidade radial estelar na figura 10.52 - a, juntamente com o resultado do melhor modelo obtido com as simulações feitas com o método de Jeans.

Observando-se a figura 10.53, pode-se notar que o modelo elaborado com o método de Jeans reproduz de maneira bastante satisfatória o mapa da velocidade radial estelar do cubo de 
dados de M104 obtido com o NIFS. A figura 10.54, por sua vez, revela que o modelo é compatível, em 1- $\sigma$, com todos os valores de velocidade radial estelar ao longo da linha de nodos.

Comparando-se as tabelas 10.5 e 10.6 , verifica-se que os valores de $i$ e $M_{b h}$ obtidos na seção 10.6.2 são compatíveis, dentro de 1- $\sigma$, com aqueles na seção 10.6.1. Embora os resultados encontrados para $M_{b h}$ possuam a mesma ordem de grandeza de outras determinações da massa do buraco negro central de M104 feitas em estudos anteriores (Magorrian et al. 1998 obtiveram um valor de $6.5 \cdot 10^{8} \mathrm{M}_{\odot}$ e Jardel et al. 2011 chegaram a $6.6 \cdot 10^{8} \mathrm{M}_{\odot}$ ), essas últimas não são compatíveis, dentro de 3- $\sigma$, com nenhum dos valores aqui obtidos.

Uma comparação entre as figuras 10.51 e 10.54 mostra que o modelo elaborado no infravermelho apresentou mais irregularidades e reproduziu os dados de uma maneira ligeiramente menos precisa. De qualquer forma, ambos os ajustes podem ser considerados bastante satisfatórios. Pode-se notar que as análises no óptico e no infravermelho tiveram um caráter complementar, já que, embora a resolução espacial no infravermelho seja maior, a determinação das velocidades foi mais precisa no óptico.

\section{7 - Cinemática do gás do cubo de dados de M104}

Para se obter informações sobre a cinemática do gás na região central de M104, construíram-se mapas de velocidades de algumas linhas de emissão. No caso do cubo de dados no infravermelho, a única linha de emissão visível era a de $\mathrm{H}_{2}$ 221218, entretanto, as irregularidades dessa linha, associadas à sua baixa intensidade, fizeram com que não fosse possível obter um mapa de velocidades confiável. No cubo de dados no óptico, por outro lado, havia uma série de linhas de emissão visíveis. Optou-se por utilizar a linha de [N II] $\lambda 6583$ para se obter o mapa de velocidades, já que ela era a mais intensa do espectro. Assim como nos casos anteriores, os valores das velocidades foram obtidos a partir do ajuste de funções gaussianas. $\mathrm{O}$ resultado obtido é mostrado na figura 10.55 . 


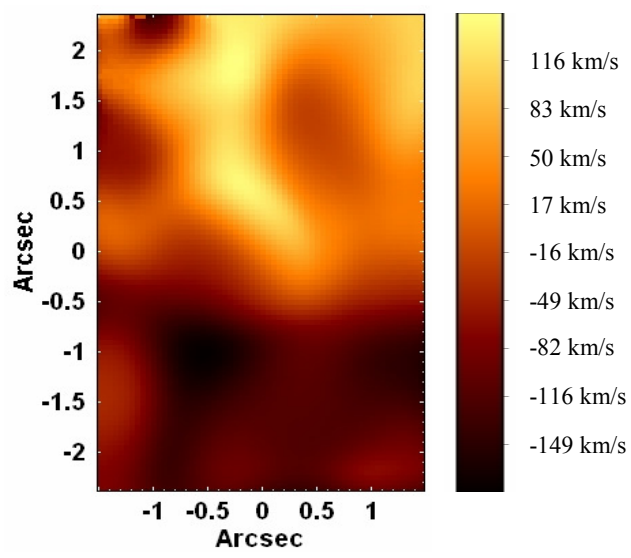

Figura 10.55 - Mapeamento dos valores da velocidade radial do gás, construído com base na linha de [N II] $\lambda 6583$ do cubo de dados de M104 obtido com o GMOS.

Analisando-se o mapeamento de velocidades mostrado na figura 10.55, nota-se que, embora haja indícios da existência de uma rotação do gás, também parece haver um segundo fenômeno cinemático presente, como um outflow, por exemplo. Esse resultado é compatível com o que foi obtido com as aplicações da Tomografia PCA mostradas anteriormente (figura 10.15 da seção 10.3 .1 e figura 10.39 da seção 10.5.1) e revela que a cinemática do gás na região central dessa galáxia parece ser razoavelmente complexa.

Para se tentar modelar o mapa de velocidades mostrado na figura 10.55 , seria preciso considerar os dois fenômenos cinemáticos que, aparentemente, estão presentes. Entretanto, como o objetivo desse trabalho envolve, apenas, a simulação de movimentos keplerianos, visando a determinação da massa do buraco negro central existente, e, nesse caso, não foi possível separar com precisão os fenômenos cinemáticos detectados, optou-se por não fazer essa modelagem aqui.

\section{8 - Espectro de emissão do cubo de dados de M104 obtido com o GMOS: ajustes com o software Cloudy}

A partir do cubo de dados de M104 obtido com o GMOS, após a subtração do contínuo estelar, foi possível medir várias razões de linhas de emissão e, com isso, fazer uma análise envolvendo diagramas de diagnóstico. Para isso, primeiramente, fez-se uma correção da extinção do cubo de dados em questão, utilizando-se os valores de $A_{V}$ fornecidos pela síntese 
espectral com o Starlight (figura 10.35). Em seguida, as intensidades das linhas (e, consequentemente, as razões de intensidade) foram obtidas a partir do ajuste de funções gaussianas. Nesse caso, como o objetivo principal era determinar os mecanismos de excitação e ionização do gás na região mais próxima ao núcleo da galáxia, calcularam-se as razões de linhas apenas de uma área circular, centrada no núcleo, com raio igual a 0.6”. Fizeram-se, então, simulações com o software Cloudy na tentativa de se reproduzir os valores das razões em questão. Em todas as simulações, utilizou-se um contínuo na forma de lei de potência, com índice espectral igual a -1.5 (representando o featureless continuum do AGN), um filling factor de 0.01 e uma densidade eletrônica de $300 \mathrm{~cm}^{-3}$. Para se obter as curvas mostradas nos diagramas a seguir, foram feitas variações do parâmetro de ionização e da metalicidade do gás existente. Além disso, adotaram-se, ainda, diferentes "cortes" inferiores de energia nos contínuos ionizantes (ou seja, foram tomados diferentes valores mínimos de energia emitidos pelos contínuos ionizantes). Os resultados obtidos encontram-se a seguir.
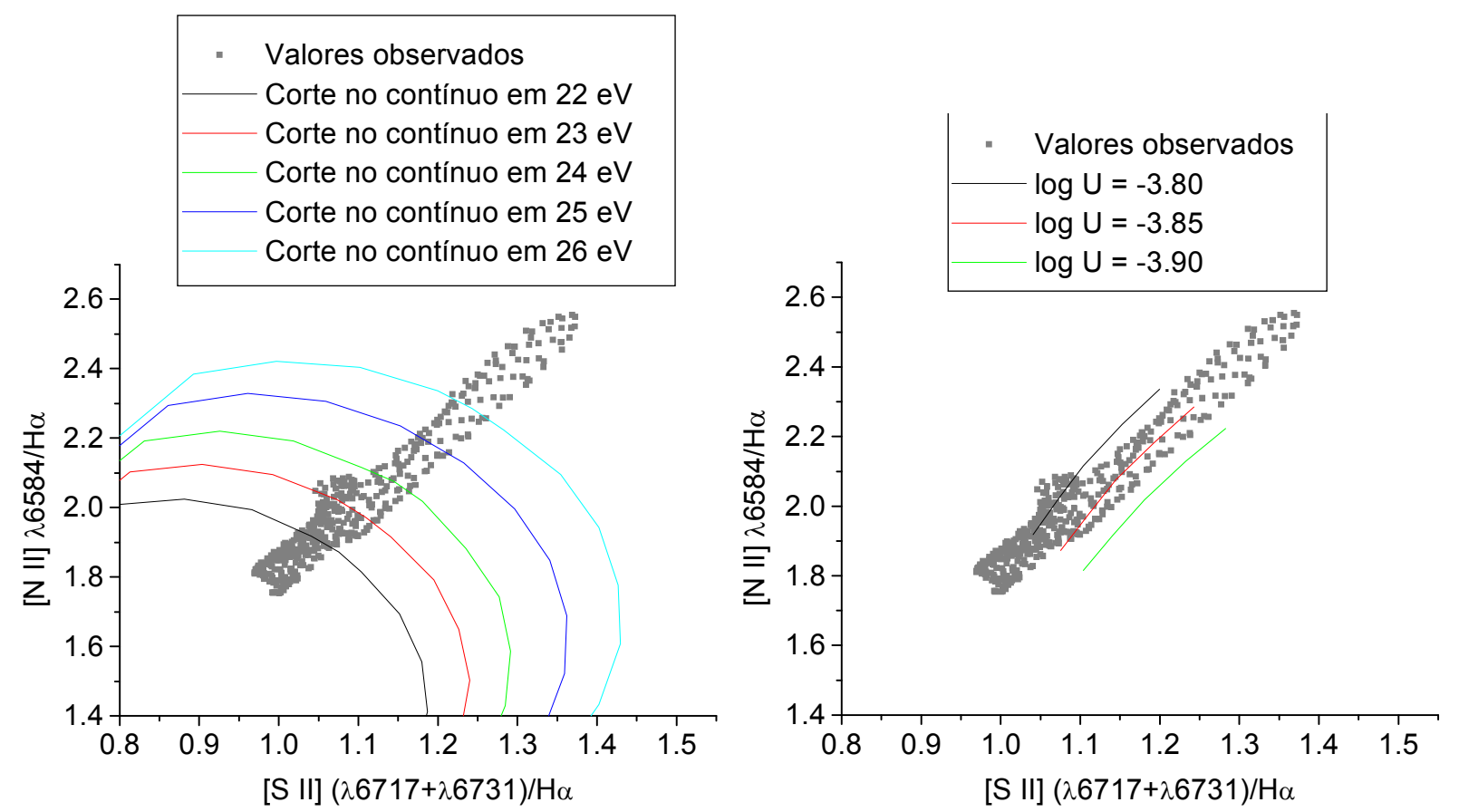

Figura 10.56 - (esquerda) Diagrama de diagnóstico de [N II] $\lambda 6583 / H \alpha \times$ [S II] $(\lambda 6716+\lambda 6731) / H \alpha$, construído a partir do cubo de dados de M104 obtido com o GMOS, após a subtração do contínuo estelar. Sobrepostos aos dados observados estão os ajustes feitos com o software "Cloudy", envolvendo fotoionização por um AGN com parâmetros de ionização com valores entre $10^{-5}$ (região inferior direita) e $10^{-2}$ (região superior esquerda); (direita) Mesmo diagrama mostrado à esquerda, juntamente com os resultados obtidos com o software “Cloudy”, em função dos diferentes parâmetros de ionização considerados no ajuste. 

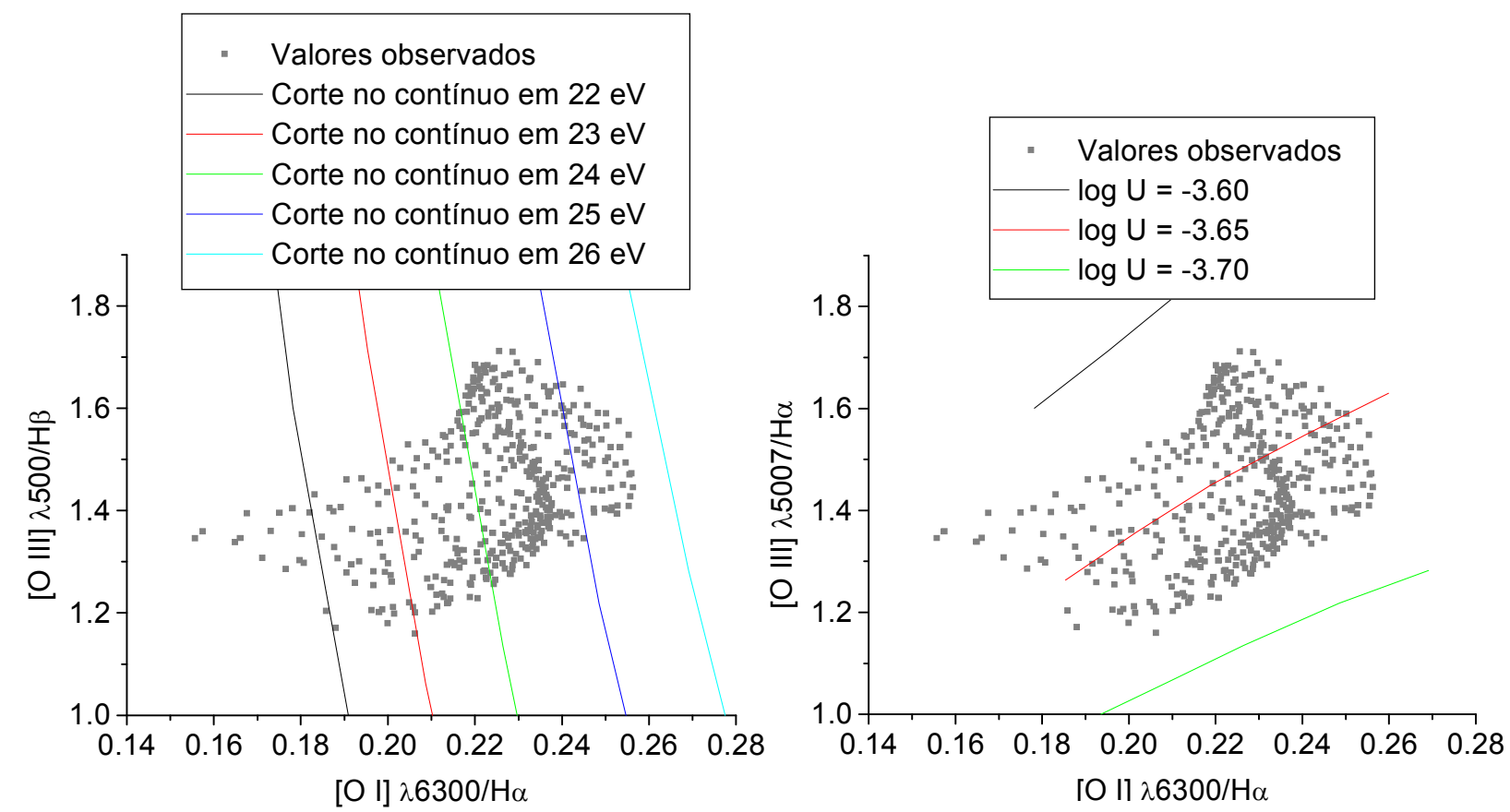

Figura 10.57 - (esquerda) Diagrama de diagnóstico de [O III] $\lambda 5007 / H \beta x$ [O I] $\lambda 6300 / H \alpha$, construído a partir do cubo de dados de M104 obtido com o GMOS, após a subtração do contínuo estelar. Sobrepostos aos dados observados estão os ajustes feitos com o software “Cloudy”, envolvendo fotoionização por um AGN com parâmetros de ionização com valores entre $10^{-5}$ (região inferior direita) e $10^{-2}$ (região superior esquerda); (direita) Mesmo diagrama mostrado à esquerda, juntamente com os resultados obtidos com o software "Cloudy", em função dos diferentes parâmetros de ionização considerados no ajuste.

Observando-se as figuras 10.56 e 10.57, pode-se notar que o mecanismo da fotoionização por um AGN central é capaz de explicar a maior parte das razões de linhas nos diagramas de diagnóstico mostrados. Uma comparação entre essas duas figuras revela que os modelos com corte inferior de energia no contínuo entre $22 \mathrm{eV}$ e $26 \mathrm{eV}$ são os mais adequados. Uma possível explicação para esses cortes de energia seria uma absorção por gás e poeira nas regiões mais próximas ao núcleo da galáxia (como a BLR e um possível toro de poeira, por exemplo). Nesse caso, os fótons com energia inferior a esses cortes seriam absorvidos e apenas os mais energéticos atingiriam a NLR, cujas razões de linhas foram reproduzidas nessa simulação com o Cloudy. A figura 10.56 indica que os modelos mais apropriados para explicar as razões de linhas observadas são aqueles com parâmetros de ionização entre $10^{-3.9}$ e $10^{-3.8}$, ao passo que a figura 10.57 sugere que os modelos mais adequados possuem parâmetros de ionização entre $10^{-3.7}$ e $10^{-3.6}$. Essa leve discrepância entre esses dois intervalos de valores está de acordo com o esperado, já que as regiões emissoras de [O III], [O I], [N II] e [S II] não são 
exatamente as mesmas e é de se esperar que a linha de [O III] $\lambda 5007$ seja produzida em áreas nas quais $U$ é maior, conforme foi observado. Assim, pode-se afirmar que os melhores modelos capazes de reproduzir as razões de linhas observadas devem apresentar parâmetros de ionização no intervalo entre $10^{-3.9}$ e $10^{-3.6}$.

\section{9 - Conclusões}

Em suma, pode-se dizer que as análises com a Tomografia PCA nos cubos de dados de M104 obtidos com o GMOS conseguiram isolar, consideravelmente bem a emissão proveniente do AGN central, que pôde ser classificado como de tipo 1, devido à detecção de uma componente larga da linha $\mathrm{H} \alpha$ (sobretudo a asa vermelha). Um dos maiores resultados, entretanto, obtidos com a Tomografia PCA dos dados no óptico foi a detecção da componente larga da linha $\mathrm{H} \alpha$ e de um featureless continuum em regiões afastadas do AGN. A síntese espectral com o Starlight confirmou a presença de um featureless continuum, com índice espectral igual a -1.5 , nas mesmas áreas distantes do AGN reveladas pela Tomografia PCA. Um cenário capaz de explicar isso envolve o espalhamento por poeira da emissão do AGN, fazendo com que essa última seja detectada em áreas razoavelmente mais afastadas do núcleo. É possível, inclusive, que a poeira responsável pelo espalhamento esteja associada a um toro de poeira, o que seria compatível com o previsto pelo Modelo Unificado. Tanto as aplicações da Tomografia PCA, aos dados no óptico e no infravermelho, quanto o mapeamento de velocidades da linha de [N II] $\lambda 6583$ revelaram uma cinemática razoavelmente complexa do gás na região central de M104, envolvendo uma rotação associada a um provável segundo fenômeno cinemático, como um outflow, por exemplo. Os ajustes com o processo do pPXF nos cubos de dados obtidos com o GMOS e com o NIFS, juntamente com as análises com a Tomografia PCA, mostraram a presença de uma clara rotação estelar ao redor do buraco negro central de M104. Uma modelagem feita com o método de Jeans nos dados no óptico forneceu os valores de $i=$ $82.0 \pm 1.2^{\circ}$ e $M_{b h}=(2.0 \pm 0.8) \cdot 10^{8} \mathrm{M}_{\odot}$ para a inclinação do disco estelar e para a massa do buraco negro central, respectivamente. Uma modelagem análoga nos dados no infravermelho,

por sua vez, resultou em $i=82.0 \pm 0.5^{\circ}$ e $M_{b h}=(1.0 \pm 0.2) \cdot 10^{8} \mathrm{M}_{\odot}$. Esses dois resultados estão de acordo um com o outro, dentro de 1- $\sigma$, entretanto, os valores de $M_{b h}$ encontrados não são 
compatíveis, em 3- $\sigma$, com determinações da massa do buraco negro central de M104 feitas em estudos anteriores (Magorrian et al. 1998; Jardel et al. 2011). A síntese espectral com o Starlight nos dados revelou que a maior parte do fluxo no cubo de dados obtido com GMOS é proveniente de populações estelares velhas, com idade de cerca de $1.2 \cdot 10^{10}$ anos, e alta metalicidade. Além disso, também foi detectado um fluxo considerável proveniente de populações bem mais jovens, com idade de cerca de $7.7 \cdot 10^{6}$ anos, e também com alta metalicidade. Por fim, uma simulação feita com o software Cloudy mostrou que a fotoionização por um AGN é capaz de explicar as razões de linhas de emissão observadas na região mais central do cubo de dados de M104 obtido com o GMOS. Os melhores modelos encontrados para reproduzir as razões de linhas envolveram um featureless continuum com índice espectral igual a -1.5, cortes inferiores de energia no contínuo entre $22 \mathrm{eV}$ e $26 \mathrm{eV}$ e parâmetros de ionização entre $10^{-3.9}$ e $10^{-3.6}$. Esses cortes de energia no contínuo poderiam ser gerados por uma absorção por gás e poeira nas regiões mais próximas ao núcleo da galáxia (como a BLR e um possível toro de poeira, por exemplo). Nesse caso, os fótons com energia inferior a esses cortes seriam absorvidos e apenas os mais energéticos atingiriam a NLR, cujas razões de linhas foram reproduzidas na simulação com o Cloudy. 


\section{$11-$ NGC 224 (M31)}

\section{1 - Introdução}

M31 (a galáxia de Andrômeda) possui tipo morfológico SA(s)b e se encontra a uma distância de $778 \mathrm{kpc}$. Trata-se da galáxia espiral mais próxima e, devido a isso, pode ser observada com uma resolução espacial maior do que qualquer outro objeto no Grupo Local. Graças a essa possibilidade de se obter elevadas resoluções espaciais, muitos resultados importantes, referentes à parte interna do bojo dessa galáxia, foram encontrados.

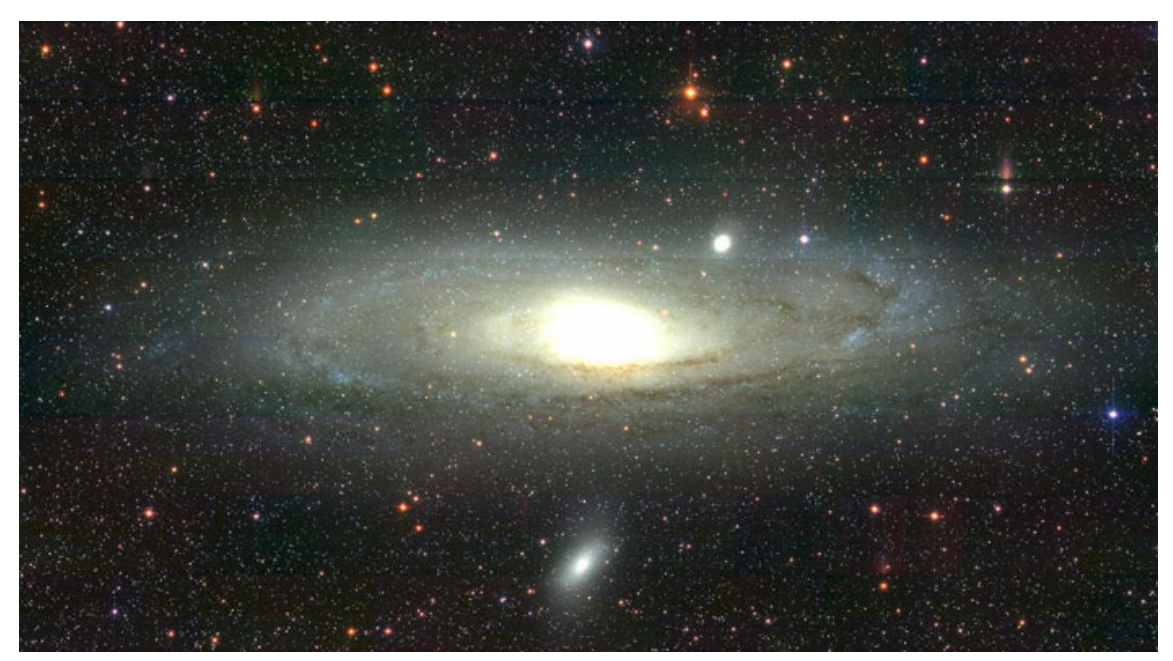

Figura 11.1 - Imagem da galáxia M31, obtida com o SDSS.

Utilizando dados do Stratoscope II, Light et al (1974) observaram uma assimetria na região nuclear de M31, com o núcleo brilhante estando afastado do centro do bojo e do pico da dispersão de velocidades. Através de observações feitas com o HST, Lauer et al. (1993) descobriram que o núcleo dessa galáxia, na verdade, é duplo, sendo que as duas componentes (geralmente chamadas de P1 e P2) estão separadas por 0.49”. P2 coincide com o centro fotométrico do bojo. Trabalhos posteriores (como o de Lauer et al. 1998, por exemplo) revelaram essas duas componentes do núcleo com maiores detalhes.

Lallemand et al. (1960), utilizando dados com uma resolução de cerca de 1", descobriram que o núcleo de M31 está rotacionando rapidamente, com uma curva de rotação bastante compacta que retorna a $0 \mathrm{~km} / \mathrm{s}$ em um raio de 2". Outros estudos como o de Kormendy 
(1988) e o de Dressler \& Richstone (1988) confirmaram tais resultados e, através da elaboração de modelos cinemáticos, revelaram evidências de uma grande concentração de massa central, da ordem de $10^{7} \mathrm{M}_{\odot}$.

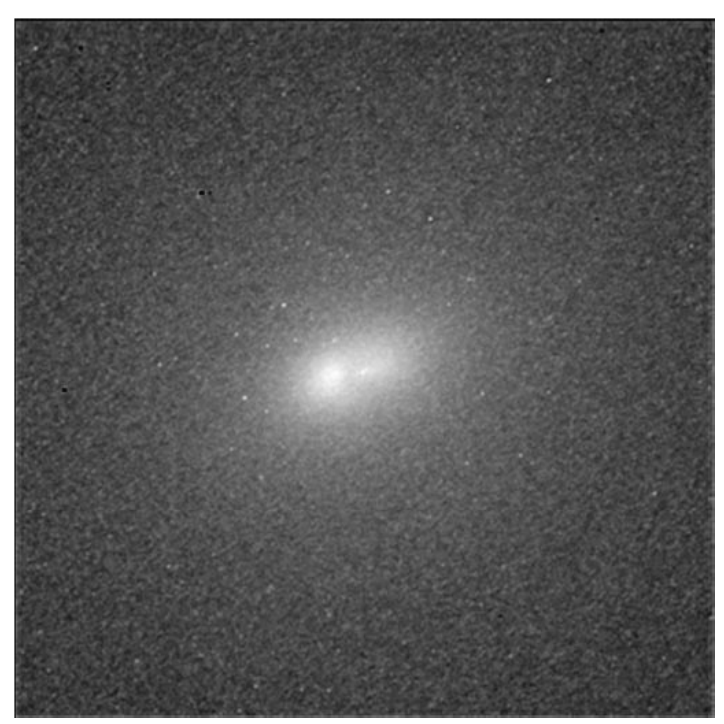

Figura 11.2 - Imagem na banda V do núcleo duplo de M31, obtida com o HST, retirada do trabalho de Lauer et al. (1998).

Observando-se a imagem do núcleo de M31 mostrada na figura 11.2, pode-se notar claramente a existência das componentes P1 e P2. Bacon et al. (1994; 2001) usaram espectroscopia de campo integral para elaborar um mapa dos valores da velocidade radial estelar próximo ao centro de M31. Os autores verificaram que o eixo maior cinemático não coincide com a linha que une P1 e P2. A curva de rotação é simétrica em relação a P2, mas esse não é o ponto da máxima dispersão de velocidades.

Nieto et al. (1986), utilizando dados do CFHT, foram os primeiros a detectar que P2 é mais brilhante do que P1 no ultravioleta, entretanto, os autores não mencionaram nada a respeito. King et al. (1992) confirmaram o excesso no ultravioleta no núcleo de M31, usando dados do HST. Posteriormente, Crane et al. (1993) e Bertola et al. (1995), todos utilizando dados obtidos com o HST, também ilustraram o fato de P2 ser mais brilhante do que P1 no ultravioleta, mas, novamente, não comentaram nada a respeito. Finalmente, King et al. (1995) analisaram com mais detalhes a maior intensidade de P2 no ultravioleta. Os autores concluíram que a luz azulada vem de uma fonte compacta que está embebida em P2. Bender et al. (2005), usando dados do HST, chamaram essa fonte ultravioleta de P3 e verificaram que ela não é 
concêntrica com P2, mas está a 0.03 ” deste, no sentido de P1. Os autores chegaram à conclusão de que P3 deve ser constituído por um aglomerado de estrelas de tipo A.

Para explicar a configuração do núcleo de M31, Tremaine (1995) propôs o que atualmente é considerado o modelo padrão de P1 e P2. De acordo com tal modelo, P1 e P2 são partes de um mesmo disco excêntrico de estrelas. P1 corresponde ao apogeu desse sistema e o buraco negro central é tomando como estando localizado em P2. Trabalhos posteriores, entretanto, verificaram que o buraco negro supermassivo deve estar localizado, mais precisamente, em P3 (Kormendy \& Bender 1999; Bender et al. 2005). O modelo padrão de Tremaine (1995) foi bastante refinado em estudos mais recentes como Salow \& Statler (2001; 2004) e Peiris \& Tremaine (2003).

Até hoje, a massa do buraco negro central de M31 já foi determinada por meio de seis técnicas independentes: (1) modelagem dinâmica padrão que ignora assimetrias, conforme foi feito por Kormendy (1988) e Dressler \& Richstone (1988); (2) o argumento do centro de massa de Kormendy \& Bender (1999), que depende da assimetria de P1+P2; (3) modelo do disco nuclear de Peiris \& Tremaine (2003), que explica a assimetria de P1+P2; (4) modelagem dinâmica completa levando em conta a auto-gravidade do disco de P1+P2, feita por Salow \& Statler (2004); (5) modelagem dinâmica de P3, que é independente de P1+P2, elaborada por Bender et al. (2005); (6) simulação de N corpos, feita por Bacon et al. (2001). Todos os métodos forneceram valores entre $3 \cdot 10^{7} \mathrm{M}_{\odot}$ e $1.4 \cdot 10^{8} \mathrm{M}_{\odot}$. É importante mencionar que vários outros estudos não mencionados aqui também fizeram determinações da massa do buraco negro central de M31, entretanto, utilizaram técnicas similares às citadas acima. O modelo de Peiris \& Tremaine (2003), por exemplo, consiste num refinamento do de Tremaine (1995).

Por se tratar de um objeto tão próximo, M31 já foi observada em várias bandas espectrais. Crane et al. (1992) reportaram uma possível detecção de M31 em rádio, utilizando dados do VLA em $3.6 \mathrm{~cm}$. Garcia et al. (2005) compararam imagens da região central de M31, obtidas com o HST e com o telescópio de raios-x Chandra. Após verificarem que a posição de P2 é coincidente com a da fonte em rádio $\mathrm{M} 31^{*}$, os autores observaram uma área de emissão em raios-X cuja posição também parece ser coincidente com a de P2 e de M31*, dentro de $2.5 \sigma$. 


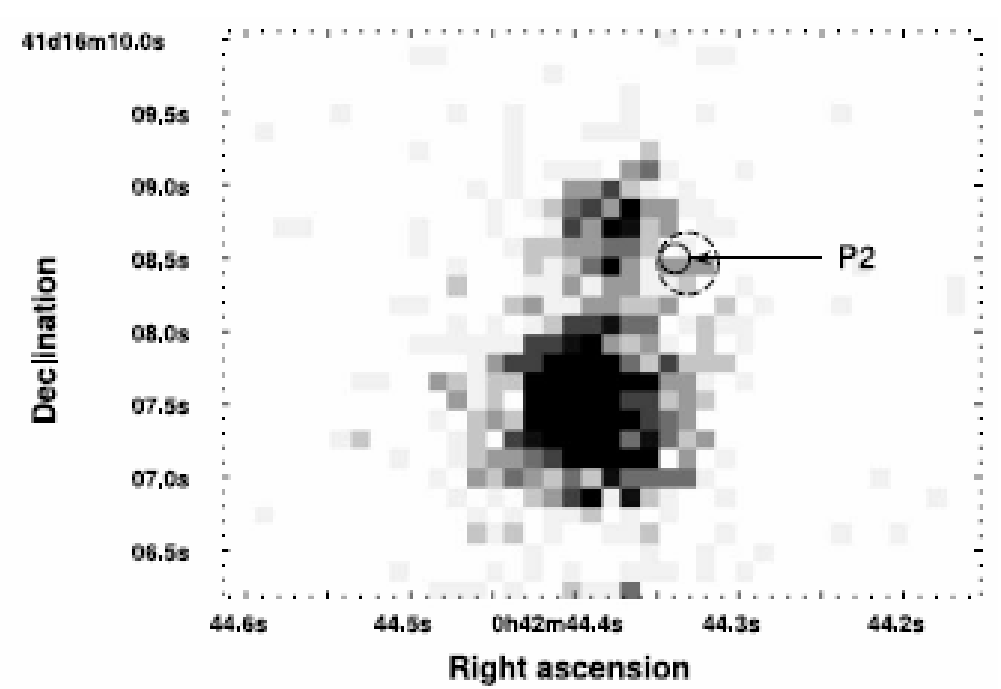

Figura 11.3 - Imagem, obtida com o Chandra, da região nuclear de M31, retirada do trabalho de Garcia et al. (2005). A posição de P2 está marcada com um círculo de linha contínua e a posição da fonte em raios- $x$ detectada na posição coincidente com $P 2$, dentro de $2.5 \sigma$, está marcada por um círculo pontilhado.

A fotometria no infravermelho próximo (Beaton et al. 2007) e no óptico (Walterbos \& Kennicut 1998) mostrou pouco gradiente de cor na região interna do bojo. As cores são típicas de populações estelares velhas e ricas em metais. Há pouca evidência de formação estelar recente nas regiões circumnucleares.

Vários estudos revelaram a presença de emissão de gás ionizado na área próxima ao núcleo de M31 (Rubin \& Ford 1971; Ciardullo et al. 1988). As razões de linhas detectadas sugeriram a presença de um LINER nesse objeto (Heckman 1996). Del Burgo et al. (2000), entretanto, fazendo espectroscopia bidimensional na região central de M31, detectaram que a emissão provém de nuvens de gás isoladas, sendo que nenhuma das posições dessas nuvens coincide com a do núcleo. De fato, a emissão proveniente de algumas dessas nuvens de gás apresenta características espectrais de LINERs e essa pode ter sido a razão de a classificação LINER ter sido atribuída a esse objeto.

\section{2 - Preparação do cubo de dados de M31}

Foram analisados cubos de dados da região central de M31, obtidos com o IFU do GMOS do telescópio Gemini-Norte. A redução dos cubos de dados foi feita em ambiente IRAF, 
utilizando-se o pacote de tarefas Gemini. Ao final desse processo, foram obtidos 3 cubos de dados com pixeis espaciais de $0.05 \%$ de lado.

Após a redução, foi aplicada a correção da refração atmosférica diferencial em cada um dos cubos de dados. Em seguida, calculou-se a mediana entre eles, a fim de se combinar todos esses cubos em um só.

Aplicou-se, então, uma decomposição wavelet no cubo de dados encontrado, obtendo-se, ao final, os cubos $W_{0}, W_{1}, W_{2}, W_{3}, W_{4}$ e $W_{C}$. Utilizou-se $W_{0}$ para se determinar os parâmetros mais adequados para o filtro de Butterworth e, a seguir, esses parâmetros foram usados na filtragem de todas as outras componentes wavelet e também do cubo de dados original. No caso desse objeto, todas as filtragens foram feitas utilizando-se um filtro com forma dada pela expressão (3.67), $n=2$ e freqüência de corte ao longo dos eixos horizontal e vertical de $v_{c}=0.18$ Ny. A figura 11.4 mostra as somas das imagens do cubo de dados, antes e depois da filtragem espacial de Butterworth, assim como a soma das imagens do cubo correspondente à diferença entre esses dois.
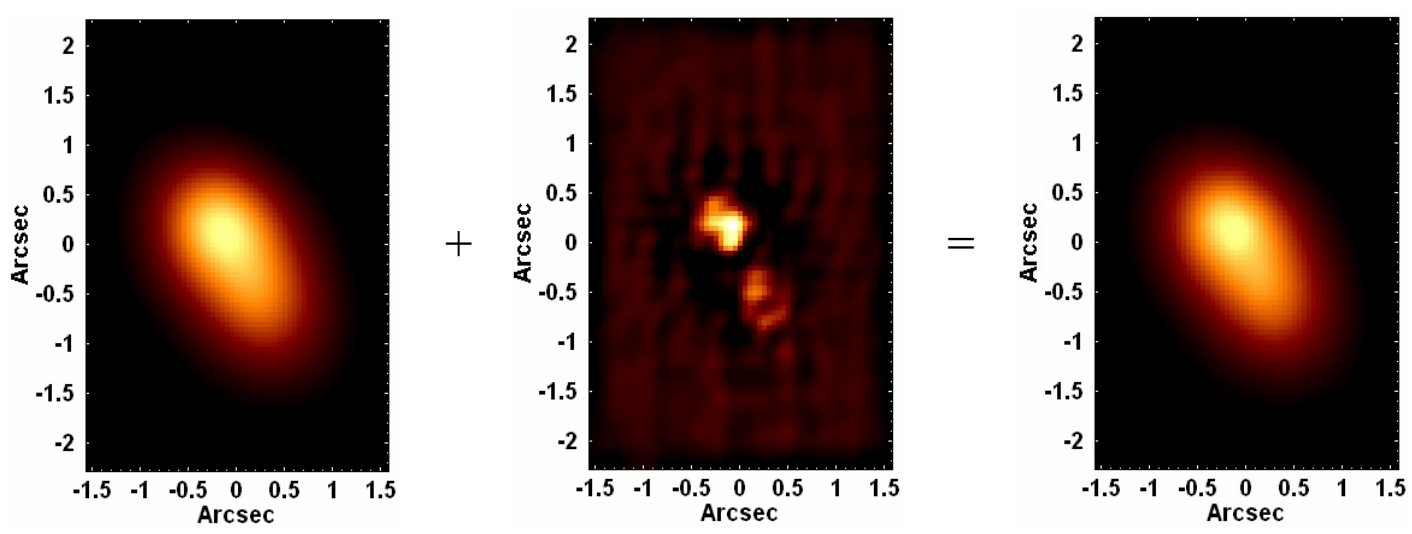

Figura 11.4 - (esquerda) Soma das imagens do cubo de dados de M31, após a filtragem espacial de Butterworth; (centro) Soma das imagens do cubo de dados de M31 correspondente à diferença entre o cubo não filtrado e o cubo filtrado; (direita) Soma das imagens do cubo de dados de M31, antes da filtragem espacial de Butterworth.

Observando-se a figura 11.4, pode-se notar que, à primeira vista, parece não haver grande diferença entre as somas das imagens do cubo de dados de M31, antes e depois da filtragem espacial de Butterworth. No entanto, a imagem no centro da figura 11.4 revela a grande quantidade de ruídos de alta frequência removidos. 
Finalmente, passou-se para a etapa da deconvolução de Richardson-Lucy. Esse procedimento foi aplicado utilizando-se uma PSF gaussiana variável com o comprimento de onda. Um valor de referência para o $F W H M$ da gaussiana foi estimado a partir da imagem de uma região com linhas de emissão, aparentemente puntual, visível no cubo de dados desse objeto. A forma de variação do $F W H M$ com o comprimento de onda, por sua vez, foi determinada a partir do cubo de dados da estrela padrão utilizada para a calibração em fluxo. Antes desse processo, entretanto, a filtragem espacial de Butterworth foi aplicada no cubo da estrela padrão. Foram utilizadas 10 iterações na deconvolução de Richardson-Lucy do cubo de dados de M31. A figura 11.5 mostra a soma de todas as imagens e o espectro médio do cubo de M31, após a aplicação da deconvolução de Richardson-Lucy.
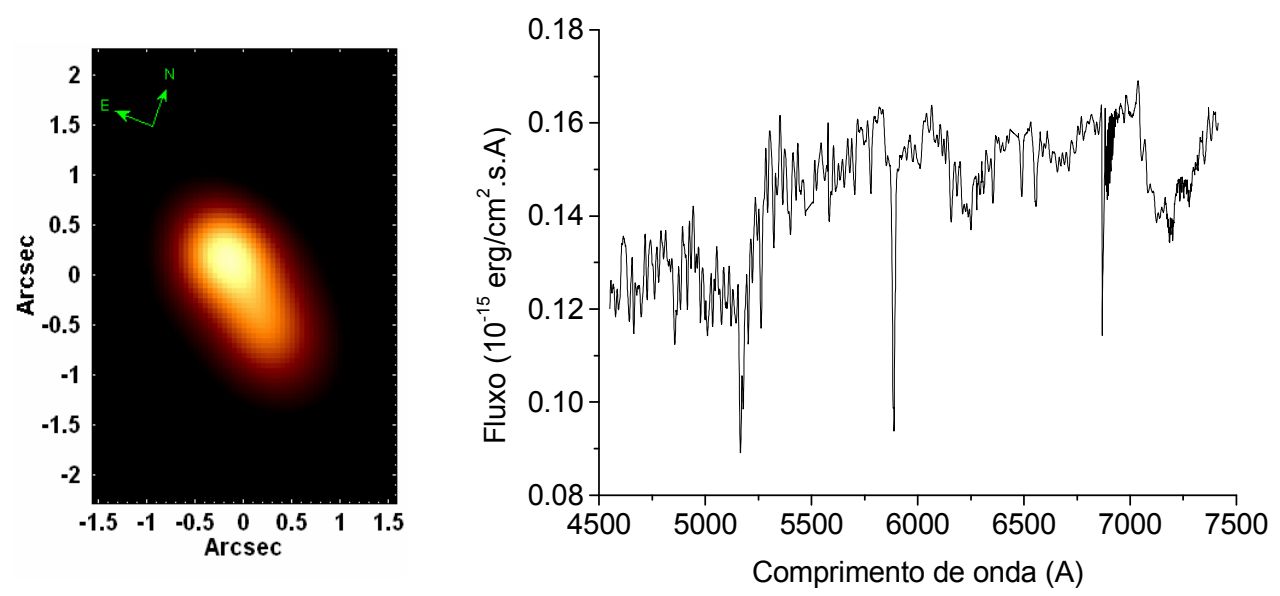

Figura 11.5 - (esquerda) Soma de todas as imagens do cubo de dados de M31, obtido após todo o processamento; (direita) Espectro médio do cubo de dados de M31, obtido após todo o processamento.

\section{3 - Aplicação da Tomografia PCA ao cubo de dados de M31 com o contínuo estelar}

Após todo o processamento descrito na seção 11.2, aplicou-se a Tomografia PCA ao cubo de dados de M31. Os principais auto-espectros e respectivos tomogramas obtidos encontram-se a seguir. 

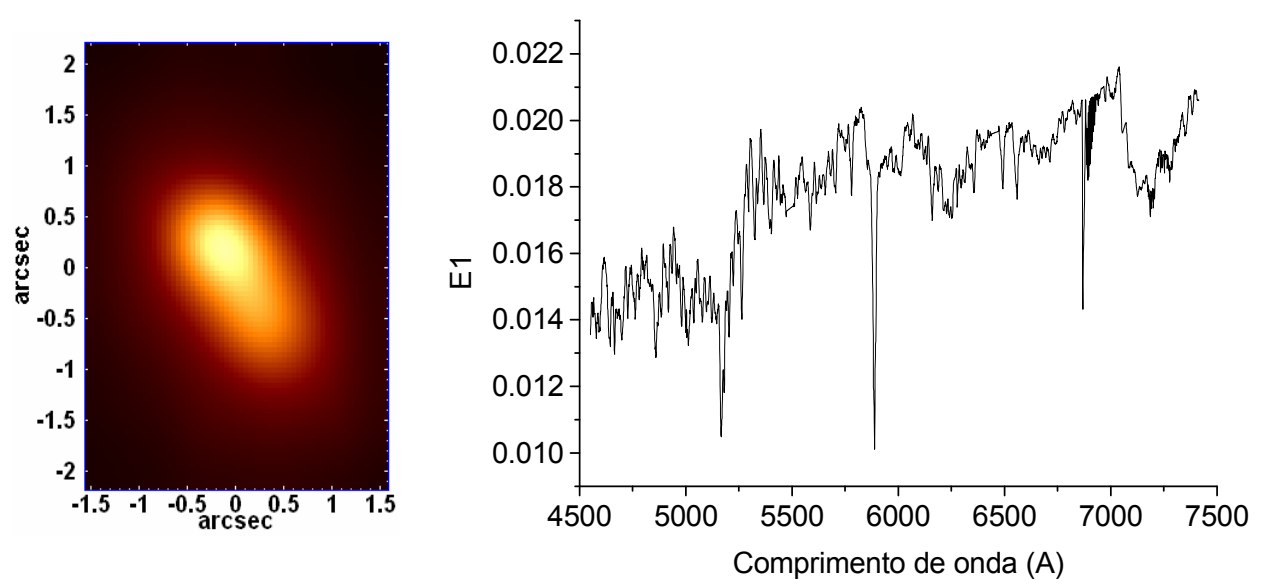

Figura 11.6 - Tomograma e auto-espectro correspondentes ao autovetor E1, obtido com a

Tomografia PCA do cubo de dados de M31 com o contínuo estelar.
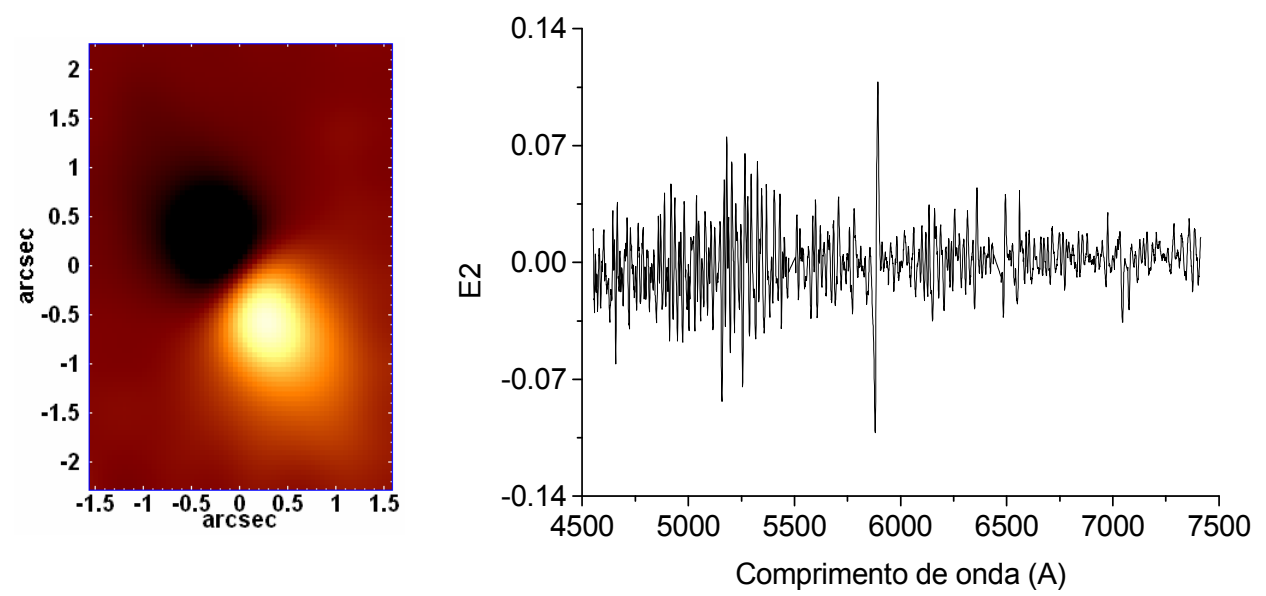

Figura 11.7 - Tomograma e auto-espectro correspondentes ao autovetor E2, obtido com a

Tomografia PCA do cubo de dados de M31 com o contínuo estelar.
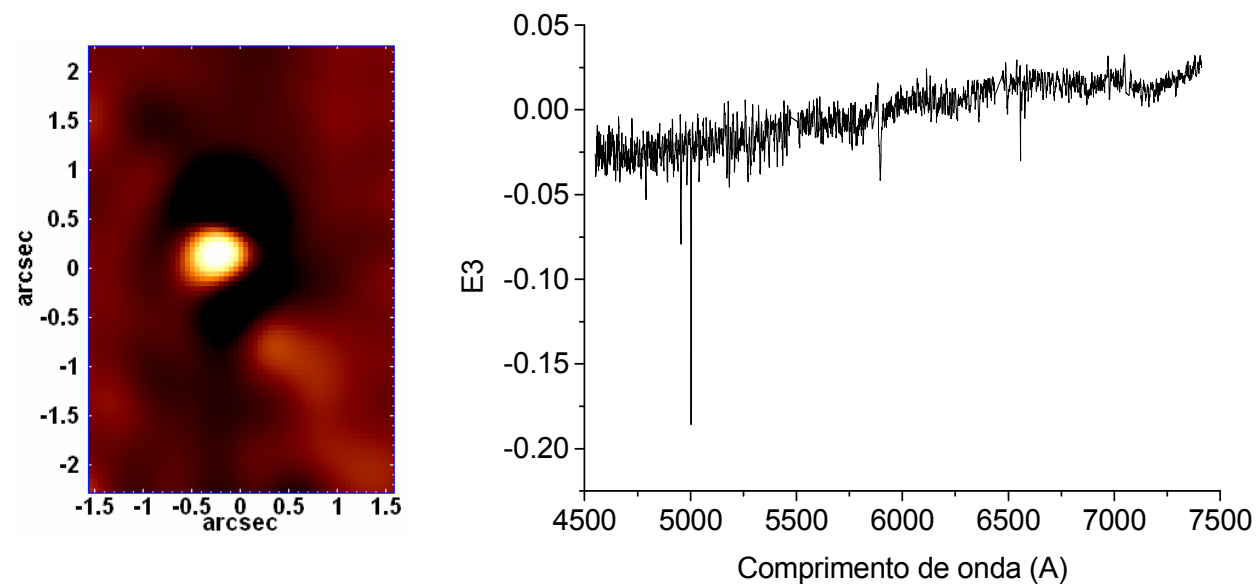

Figura 11.8 - Tomograma e auto-espectro correspondentes ao autovetor E3, obtido com a Tomografia PCA do cubo de dados de M31 com o contínuo estelar. 

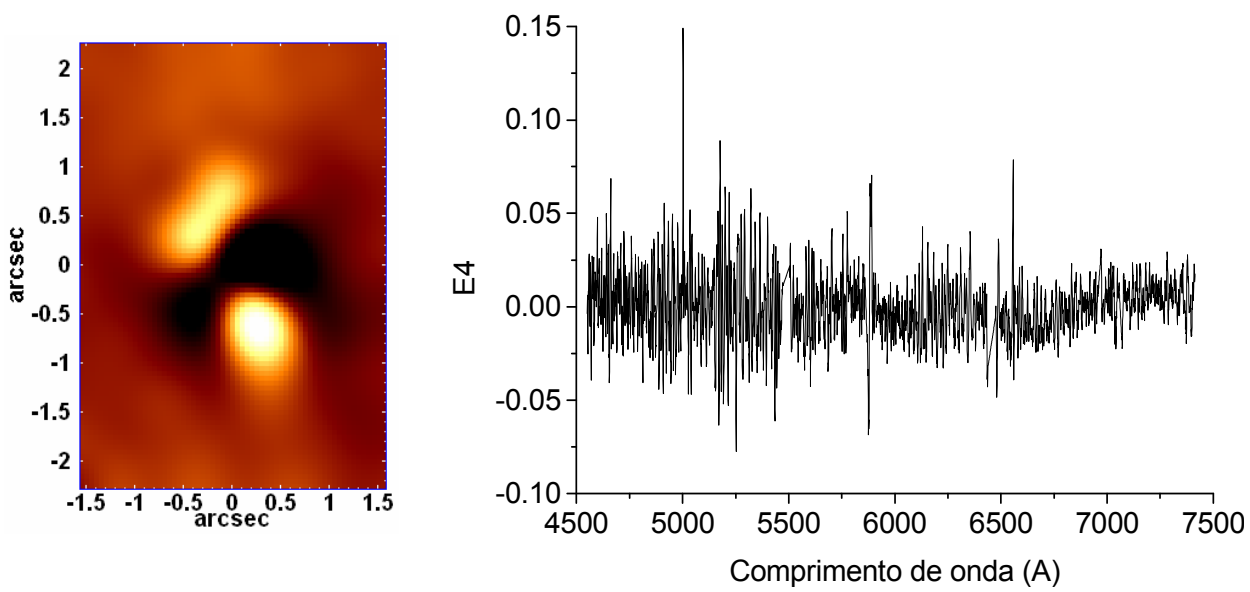

Figura 11.9 - Tomograma e auto-espectro correspondentes ao autovetor E4, obtido com a Tomografia PCA do cubo de dados de M31 com o contínuo estelar.
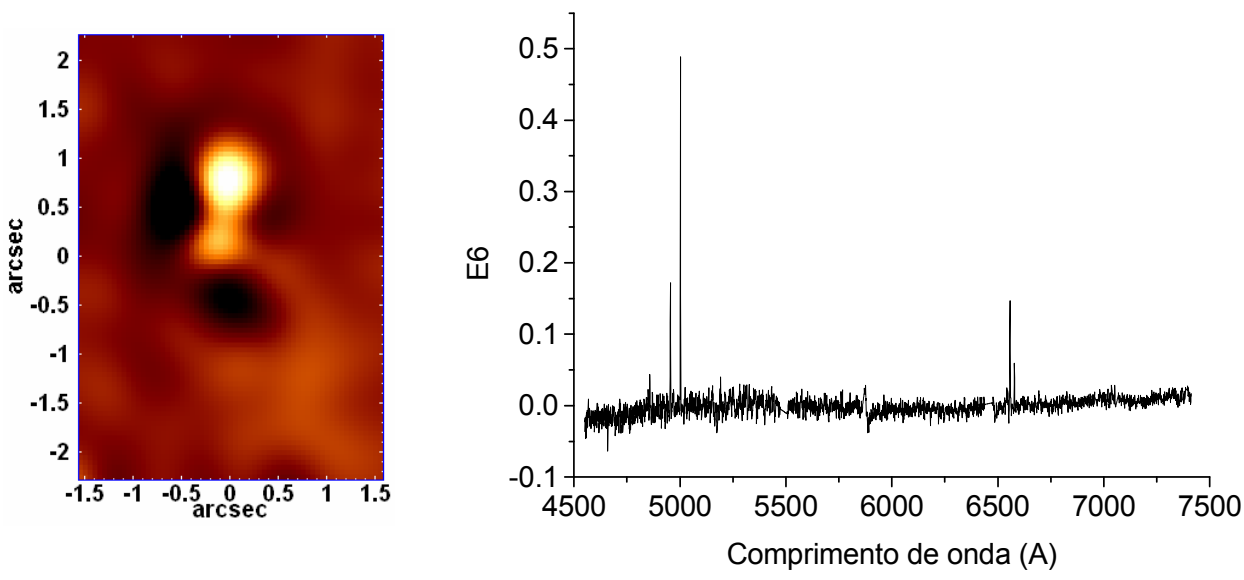

Figura 11.10 - Tomograma e auto-espectro correspondentes ao autovetor E6, obtido com a Tomografia PCA do cubo de dados de M31 com o contínuo estelar.

\begin{tabular}{|c|c|}
\hline Autovetor & Fração da variância explicada (\%) \\
\hline E1 & 99.8356 \\
\hline E2 & 0.0807 \\
\hline E3 & 0.0268 \\
\hline E4 & 0.0082 \\
\hline E6 & 0.0046 \\
\hline
\end{tabular}

Tabela 11.1 - Autovalores obtidos com a Tomografia PCA do cubo de dados de M31 com o contínuo estelar. 


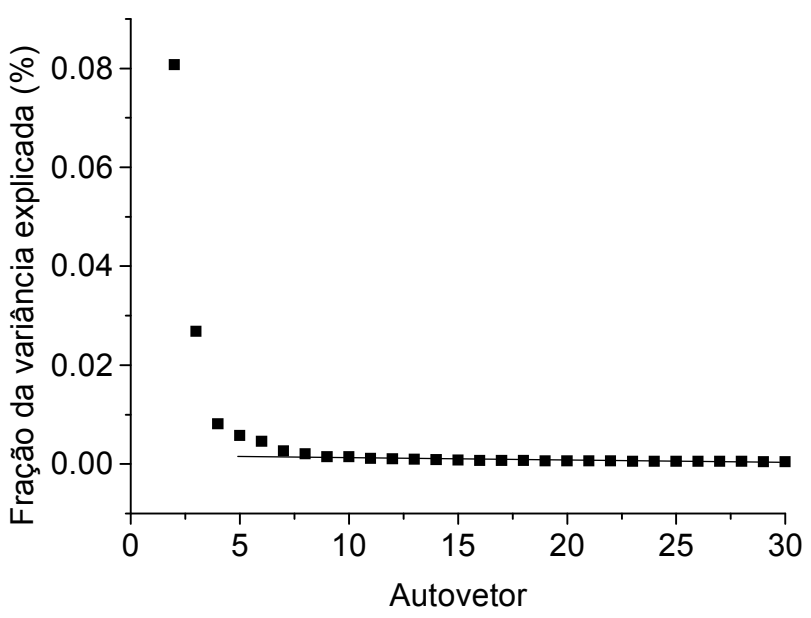

Figura 11.11 - "Scree test" dos autovetores obtidos com a Tomografia PCA do cubo de dados de M31 com o contínuo estelar.

A figura 11.6 mostra que o auto-espectro E1 e o tomograma associado apresentam o aspecto do espectro médio e da soma de todas as imagens do cubo de dados de M31, respectivamente. Isso está de acordo com o esperado, já que esse autovetor explica a maior parte da variância dos dados (cerca de 99.8356 \% do total), logo, revela características que já eram claramente detectáveis no cubo de dados do objeto analisado. Uma característica importante do auto-espectro E1 é que ele apresenta uma estrutura compatível com uma banda de absorção próxima a $7250 \AA$. Essa banda é típica de estrelas do tipo espectral M, o que é um indício de que a região central de M31 deve possuir uma população estelar consideravelmente velha. Outro aspecto relevante do autovetor E1 é que o tomograma associado apresenta um aspecto elíptico para a área próxima ao núcleo de M31, o que está de acordo com o esperado para esse objeto.

Observando-se a figura 11.7, pode-se notar que o auto-espectro E2 apresenta correlações com os comprimentos de onda correspondentes às asas vermelhas de várias linhas de absorção estelares e anti-correlações com os comprimentos de onda associados às asas azuis das mesmas. Isso parece indicar algum tipo de fenômeno cinemático estelar. Levando-se em conta o aspecto do tomograma, pode-se concluir que esse autovetor, provavelmente, está revelando a existência de uma rotação estelar ao redor do núcleo de M31. Nesse caso, as áreas claras do tomograma apresentam uma emissão estelar em blueshift e as regiões escuras possuem uma emissão estelar em redshift. O autovetor E2 explica cerca de 0.0807 \% da variância dos dados.

Uma análise da figura 11.8 mostra que o auto-espectro E3 apresenta anti-correlações com os comprimentos de onda associados às linhas de [O III] $\lambda \lambda 4959 ; 5007$. Assim, pode-se dizer que as áreas escuras no tomograma devem corresponder a regiões emissoras dessas linhas. 
Entretanto, a principal característica do auto-espectro E3 é uma correlação com a região vermelha do espectro e uma anti-correlação com a região azul do mesmo. Isso indica que as áreas claras do tomograma apresentam espectros mais avermelhados do que as escuras. Esse comportamento pode ser devido à presença de nuvens de poeira em regiões localizadas entre as áreas claras do tomograma. O autovetor E3 explica cerca de 0.02683 \% da variância dos dados.

A figura 11.9 revela que o auto-espectro E4 apresenta correlações com os comprimentos de onda correspondentes às asas vermelhas de algumas linhas de absorção e anti-correlações com os comprimentos de onda associados às asas azuis das mesmas. Isso, assim como no caso do autovetor E2, parece indicar algum tipo de fenômeno cinemático estelar, entretanto, observando-se o tomograma, pode-se notar que ele não possui uma morfologia compatível com uma rotação. Logo, é possível que esse autovetor esteja relacionado a algum outro tipo de fenômeno cinemático associado às estrelas. O auto-espectro E4 possui, ainda, correlações com os comprimentos de onda correspondentes a algumas linhas de emissão (como [O III] $\lambda 5007$ e $\mathrm{H} \alpha$ ). As regiões emissoras dessas linhas devem estar entre as áreas claras do tomograma. O autovetor E4 explica cerca de $0.0082 \%$ da variância dos dados.

Finalmente, observando-se a figura 11.10, nota-se que o auto-espectro E6 apresenta correlações com os comprimentos de onda correspondentes a uma série de linhas de emissão. Percebe-se que as mais fortes correlações são com os comprimentos de onda associados às linhas de mais alta ionização, que são as de [O III] $\lambda \lambda 4959 ; 5007$. O tomograma mostra que essas linhas são emitidas na pequena área clara da imagem. Uma comparação desse tomograma com alguns outros mostrados nas figuras anteriores revela que é provável que as linhas de emissão detectadas em outros autovetores também estivessem relacionadas a essa pequena região. Uma inspeção minuciosa do cubo de dados de M31 mostrou que, de fato, a área clara do tomograma correspondente a E6 parece ser a única região com linhas de emissão mais proeminentes. Uma imagem dessa região foi utilizada, inclusive, como estimativa da PSF da observação para a deconvolução de Richardson-Lucy, já que apresentava um aspecto praticamente puntual, conforme foi mencionado em 11.2. O autovetor E6 explica cerca de $0.0046 \%$ da variância dos dados.

O Scree test na figura 11.11 mostra que os valores das variâncias explicadas pelos autovetores decaem bastante até, aproximadamente, o autovetor E9, a partir do qual a taxa de decaimento diminui muito e fica praticamente constante. Isso indica que os autovetores de 
ordem maior ou igual a 9 representam, sobretudo, ruído e, consequentemente, não possuem relevância nessa análise. Entretanto, dentre os autovetores de ordem menor do que 9, apenas os citados anteriormente apresentavam uma interpretação mais clara e, por essa razão, apenas eles foram mostrados aqui.

Assim, pode-se dizer que essa primeira análise com a Tomografia PCA permitiu que vários fenômenos distintos existentes na região nuclear de M31 fossem identificados. Primeiramente, o procedimento evidenciou uma nítida rotação estelar ao redor do núcleo e também revelou o que aparenta ser um segundo fenômeno cinemático existente, cuja natureza não está clara. Foram observadas áreas com espectros mais avermelhados do que outras, o que pode ser devido à presença de nuvens de poeira nessas regiões. Por fim, observou-se a presença de uma pequena região emissora de linhas, com um aspecto praticamente puntual.

Um fato importante a ser notado nos resultados dessa Tomografia PCA é que não foram detectadas linhas de emissão provenientes do núcleo dessa galáxia, ou seja, não foi detectada a presença de um LINER nesse objeto, ao contrário do que a sua classificação indica.

\section{4 - Síntese espectral do cubo de dados de M31 com o Starlight}

Após a análise com a Tomografia PCA, aplicou-se uma síntese espectral no cubo de dados de M31 com o software Starlight. A preparação dos espectros foi feita da mesma forma que em todos os casos anteriores, sendo que a correção da extinção devido à Via Láctea foi feita tomando-se $A_{V}=0.206$ e a passagem dos espectros para o referencial de repouso foi aplicada considerando-se $z=-0.001001$. Tanto $A_{V}$ quanto z foram obtidos a partir do site do NED. Como não há indícios de que M31 possua um AGN detectável, a síntese espectral foi feita com uma base contendo, somente, espectros representativos de populações estelares. A contribuição de um possível featureless continuum de um AGN não foi levada em conta. 


\subsection{1 - Qualidade dos ajustes}

O mapeamento dos valores do $\chi^{2} / n_{\text {eff }}$ dos ajustes obtidos com a síntese espectral do cubo de dados de M31 encontra-se a seguir.

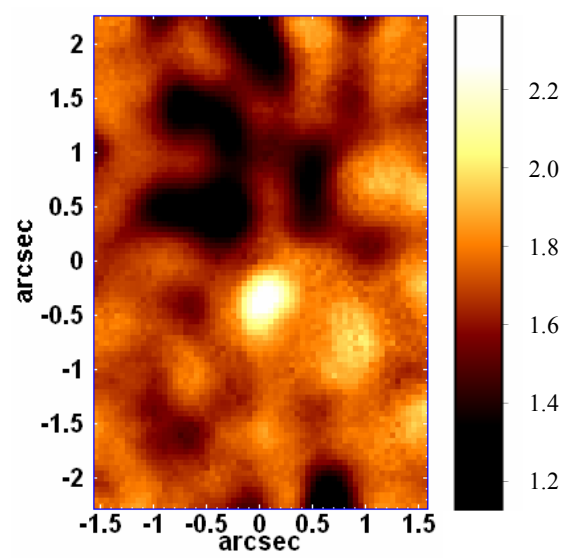

Figura 11.12: Mapeamento dos valores do $\chi^{2} / n_{\text {eff }}$ dos ajustes obtidos pelo "Starlight" para os espectros do cubo de dados de M31.

Observando-se a figura 11.12, pode-se notar que os melhores ajustes resultantes da síntese espectral com o Starlight apresentaram $\chi^{2} / n_{\text {eff }}$ próximo a 1.1 , ao passo que os piores tiveram $\chi^{2} / n_{\text {eff }}$ de cerca de 2.4, o que ainda pode ser tomado como um indicativo de ajustes com razoável qualidade. Um fato interessante a ser notado é que os maiores valores do $\chi^{2} / n_{\text {eff }}$ foram obtidos em uma região espacial próxima à componente P2 do núcleo. Essa má qualidade dos ajustes nessa área pode ser explicada tanto por uma imprecisão na calibração em fluxo quanto por alguma incompleteza na biblioteca de espectros de base utilizados para se fazer o ajuste.

\subsection{2 - Parâmetros cinemáticos}

Os mapeamentos dos valores da velocidade radial estelar e da dispersão de velocidades estelar encontram-se a seguir. 

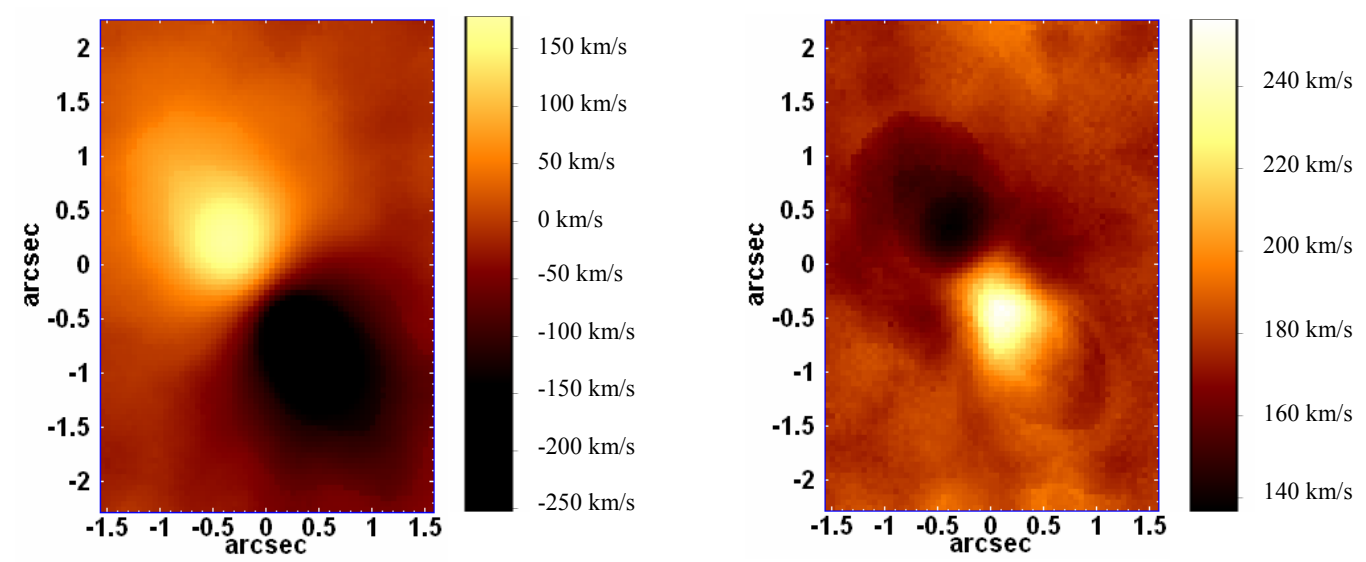

Figura 11.13: Mapeamentos dos valores (esquerda) da velocidade radial estelar e (direita) da dispersão de velocidades estelar, resultantes da aplicação do "Starlight" ao cubo de dados de M31.

Analisando-se o mapeamento dos valores da velocidade radial estelar na figura 11.13, nota-se claramente a existência de uma rotação ao redor do núcleo. A morfologia desse mapa de velocidades é compatível tanto com o que é mostrado pelo tomograma do autovetor E2 na figura 11.7 quanto com mapeamentos de velocidades feitos em estudos anteriores da cinemática estelar na região central de M31 (Bacon et al. 1994; 2001 e del Burgo et al. 2000). O mapa dos valores da dispersão de velocidades estelar na figura 11.13 parece estar associado ao mapa da velocidade radial estelar. Pode-se notar uma diminuição da dispersão de velocidades (sigma drop) numa área onde a velocidade radial é mais elevada e um aumento da dispersão de velocidades numa região onde a velocidade radial é menor. A partir disso, pode-se concluir que o fenômeno da rotação estelar deve estar relacionado à disposição espacial dos valores de dispersão de velocidades detectados. O mapa da dispersão de velocidades na figura 11.13 também é compatível com resultados obtidos em estudos anteriores da cinemática estelar da região central de M31 (Bacon et al. 1994; 2001 e del Burgo et al. 2000). Conforme já foi mencionado na seção 11.1, Tremaine (1995) propôs que o núcleo duplo dessa galáxia é composto por um disco excêntrico espesso de estrelas, em órbitas keplerianas, ao redor de um buraco negro central. Esse modelo é capaz de explicar as morfologias dos mapeamentos cinemáticos na figura 11.13, conforme foi demonstrado por Peiris \& Tremaine (2003), Salow \& Statler (2001; 2004) e Bacon et al. (2001). 


\subsection{3 - Populações estelares}

Os mapeamentos do fluxo associado a populações estelares de diferentes idades são mostrados na figura 11.14. Entretanto, como não foi detectado qualquer fluxo proveniente de populações com $1 \cdot 10^{7}-5.5 \cdot 10^{7}$ anos e $1.02 \cdot 10^{8}-9.05 \cdot 10^{8}$ anos, não foram elaborados mapeamentos para essas faixas de idades.
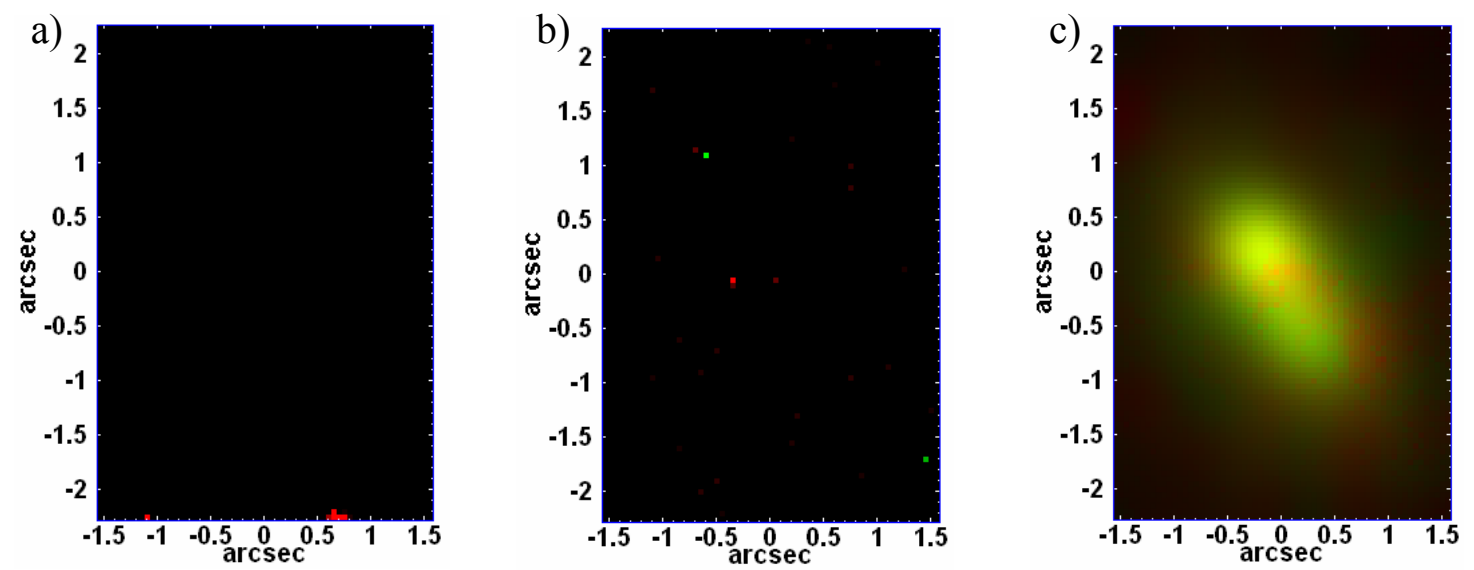

Figura 11.14: a) Imagem em RGB da população estelar com idade entre $1 \cdot 10^{6}$ e $8.71 \cdot 10^{6}$ anos; b) Imagem em $R G B$ da população estelar com idade entre $1.28 \cdot 10^{9}$ e $7.5 \cdot 10^{9}$ anos; c) Imagem em $R G B$ da população estelar com idade entre $1 \cdot 10^{10}$ e $1.8 \cdot 10^{10}$ anos. Em todas as imagens, resultantes da síntese espectral do cubo de dados de M31, a cor azul indica baixa metalicidade

$(Z=0.0001$ e $Z=0.0004)$, a cor verde indica metalicidade intermediária $(Z=0.004$ e $Z=$ $0.008)$ e a cor vermelha indica metalicidade mais elevada $(Z=0.02$ e $Z=0.05)$, lembrando que $Z_{\odot}=0.02$.

Os mapeamentos do fluxo devido a populações estelares com diferentes metalicidades são mostrados na figura 11.15. Como não foi detectado qualquer fluxo proveniente de populações com $Z=0.0001$ e $Z=0.0004$, não foram elaborados mapeamentos associados a essas metalicidades. 

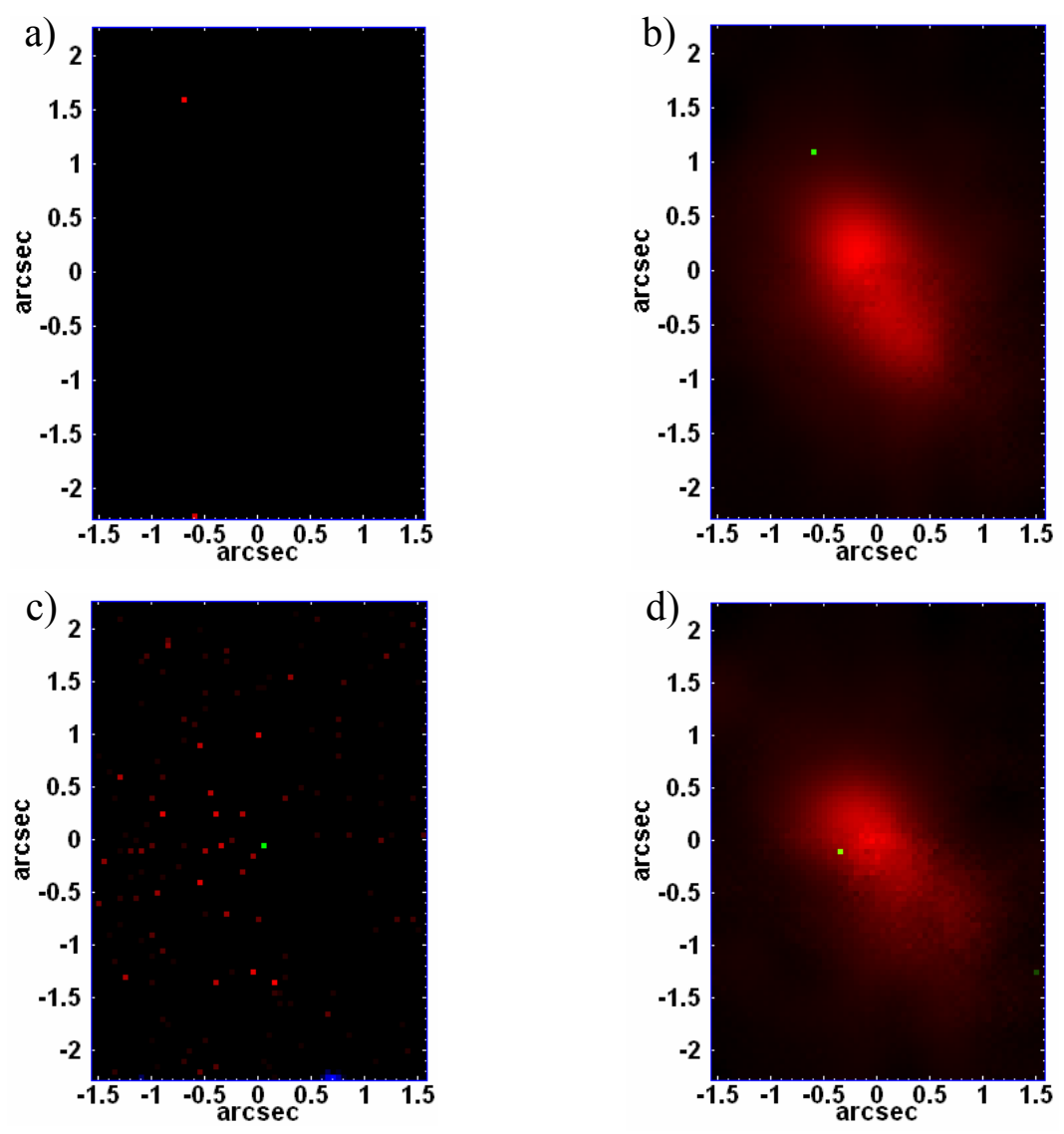

Figura 11.15: a) Imagem em $R G B$ da população estelar com metalicidade $Z=0.004 ; b)$ Imagem em $R G B$ da população estelar com metalicidade $Z=0.008$; c) Imagem em $R G B d a$ população estelar com metalicidade $Z=0.02$; d) Imagem em $R G B$ da população estelar com metalicidade $Z=0.05$. Em todas as imagens, resultantes da síntese espectral do cubo de dados de M31, a cor azul indica população estelar jovem (desde $1 \cdot 10^{6}$ anos até $5.5 \cdot 10^{7}$ anos ), a cor verde indica população estelar com idade intermediária (desde $1.02 \cdot 10^{8}$ anos até $4.25 \cdot 10^{9}$ anos) e a cor vermelha indica população estelar velha (desde $6.25 \cdot 10^{9}$ anos até $1.8 \cdot 10^{10}$ anos). É importante lembrar que $Z_{\odot}=0.02$.

A partir dos resultados obtidos com o Starlight, construiu-se um gráfico em colunas contendo as frações de fluxo atribuídas a cada uma das populações estelares, considerando-se todo o campo visual do IFU do GMOS. Montou-se, também, um segundo gráfico, análogo ao anterior, mas contendo as frações de massa devidas a cada uma das populações estelares, calculadas pelo Starlight a partir de valores apropriados da razão $M / L$. Os gráfícos construídos encontram-se a seguir. 

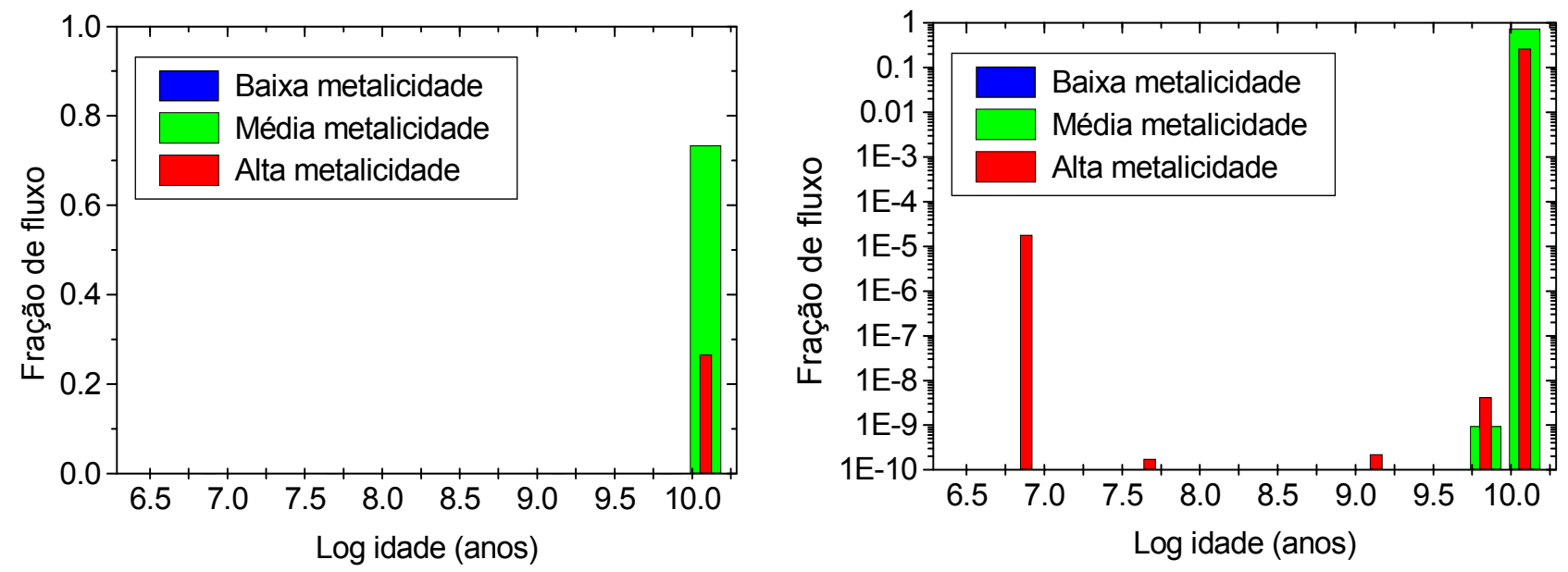

Figura 11.16: (esquerda) Gráfico representativo das frações de fluxo devidas às populações estelares, considerando-se todo o campo visual do GMOS, resultante da aplicação do

"Starlight" ao cubo de dados de M31; (direita) Mesmo gráfico mostrado à esquerda, mas com escala logarítmica no eixo das ordenadas.
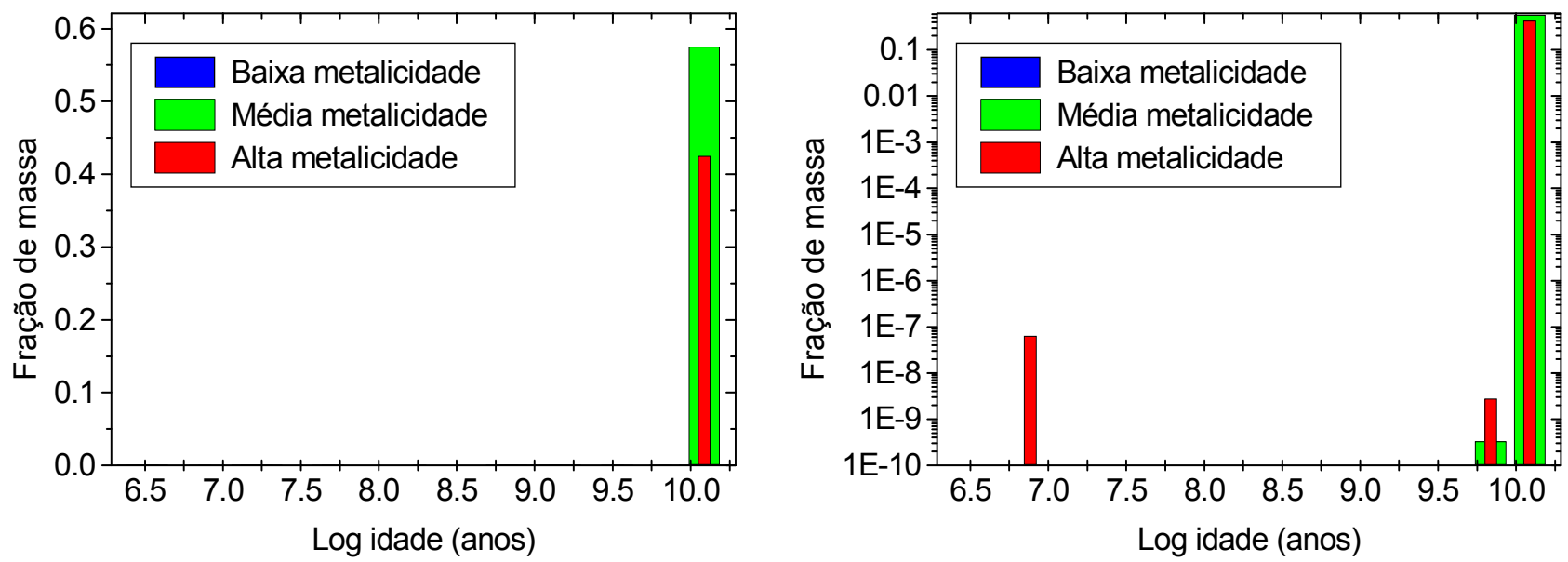

Figura 11.17: (esquerda) Gráfico representativo das frações de massa devidas às populações estelares, considerando-se todo o campo visual do GMOS, resultante da aplicação do "Starlight" ao cubo de dados de M31; (direita) Mesmo gráfico mostrado à esquerda, mas com escala logarítmica no eixo das ordenadas.

A figura 11.14 mostra que as populações estelares na região interna do bojo de M31 apresentam, predominantemente, uma idade próxima a $10^{10}$ anos. A figura 11.15 , por sua vez, revela que a maior parte do fluxo detectado provém de populações estelares com metalicidade $\mathrm{Z}=0.008$ e $\mathrm{Z}=0.05$. Dessa forma, pode-se concluir que a região central do bojo de M31 possui, essencialmente, populações estelares velhas e com metalicidades médias e elevadas.

Observando-se o gráfico da figura 11.16, pode-se notar que a maior parte do fluxo (cerca de $73.4 \%$ do total) no campo visual do IFU do GMOS é proveniente de populações estelares 
velhas, com idade de cerca de $1.2 \cdot 10^{10}$ anos, e média metalicidade. Também é detectada uma fração de fluxo considerável (cerca de 26.6 \%) associada a populações com a mesma idade, mas com alta metalicidade. As frações de fluxo devidas às demais populações estelares são consideravelmente inferiores. A figura 11.17, por sua vez, mostra que a maior parte da massa estelar (cerca de $57.5 \%$ do total) é devida a populações estelares velhas, com idade de cerca de $1.2 \cdot 10^{10}$ anos, e com média metalicidade, ao passo que cerca de $42.5 \%$ da massa estelar está associada a outras populações, com a mesma idade, mas com alta metalicidade. Isso está de acordo com o esperado, considerando-se as frações de fluxo mostradas nos gráficos da figura 11.16 e as razões $M / L$ associadas às populações estelares envolvidas.

\subsection{4 - Extinção interestelar}

O mapeamento dos valores de $A_{V}$ fornecidos pelo Starlight é mostrado a seguir.

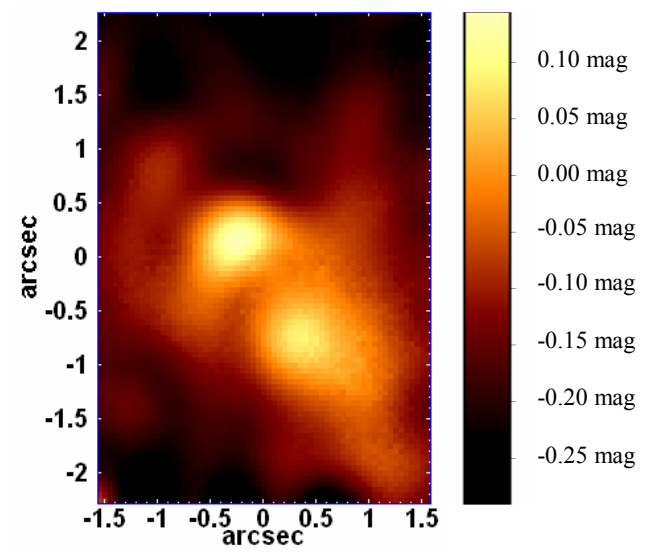

Figura 11.18: Mapeamento dos valores de $A_{V}$, obtido a partir da síntese do cubo de dados de M31 com o "Starlight".

Analisando-se a figura 11.18, pode-se notar que os maiores valores de $A_{V}$ estão concentrados em duas principais regiões (as áreas brilhantes da imagem). É possível que essas duas regiões com elevados valores de $A_{V}$ apresentem nuvens de poeira. Essa imagem está razoavelmente compatível com o tomograma do autovetor E3 obtido com a aplicação da Tomografia PCA ao cubo de dados de M31 com o contínuo estelar (figura 11.8), que também parecia estar associado à presença de nuvens de poeira. A distribuição dessas nuvens de poeira possui uma morfologia relativamente similar à do disco de estrelas ao redor do núcleo (mostrado no mapa de velocidades da figura 11.13). As regiões escuras da imagem acima chegam a 
apresentar valores negativos de $A_{V}$. Esses valores, em geral, encontram-se dentro da incerteza do Starlight e, essencialmente, são um indicativo de que a extinção é bem pequena ou nula nessas áreas. É também possível que a correção devido à extinção da Galáxia tenha sido ligeiramente exagerada para algumas regiões de M31 dentro desse campo de visão, o que pode ter acarretado nos valores negativos observados na imagem acima.

\subsection{5 - Valores da razão $S / N$ dos espectros analisados}

O mapeamento dos valores da razão $S / N$ obtidos pelo Starlight no intervalo espectral de $5610 \AA$ até $5670 \AA ̊$ encontra-se a seguir.

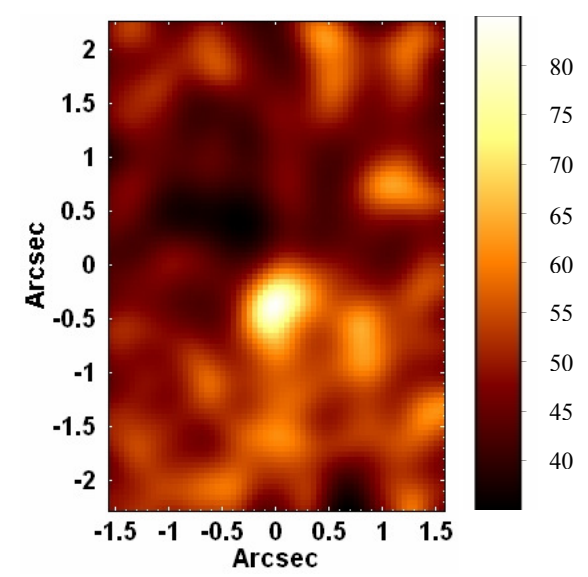

Figura 11.19 - Mapeamentos dos valores da razão $S / N$, obtidos a partir da síntese espectral do cubo de dados de M31 com o "Starlight".

Observando-se a figura 11.19, pode-se notar que os valores mais elevados encontrados para a razão $S / N$ foram próximos 85 , ao passo que os menores foram de cerca de 45 .

\section{5 - Aplicação da Tomografia PCA ao cubo de dados de M31 com o contínuo estelar subtraído}

Fez-se uma subtração do contínuo estelar de todos os espectros de M31, utilizando-se os espectros estelares sintéticos resultantes da síntese espectral com o Starlight. Aplicou-se, então, 
a Tomografia PCA ao cubo de dados resultante, contendo apenas linhas de emissão. Os principais auto-espectros e respectivos tomogramas obtidos encontram-se a seguir.
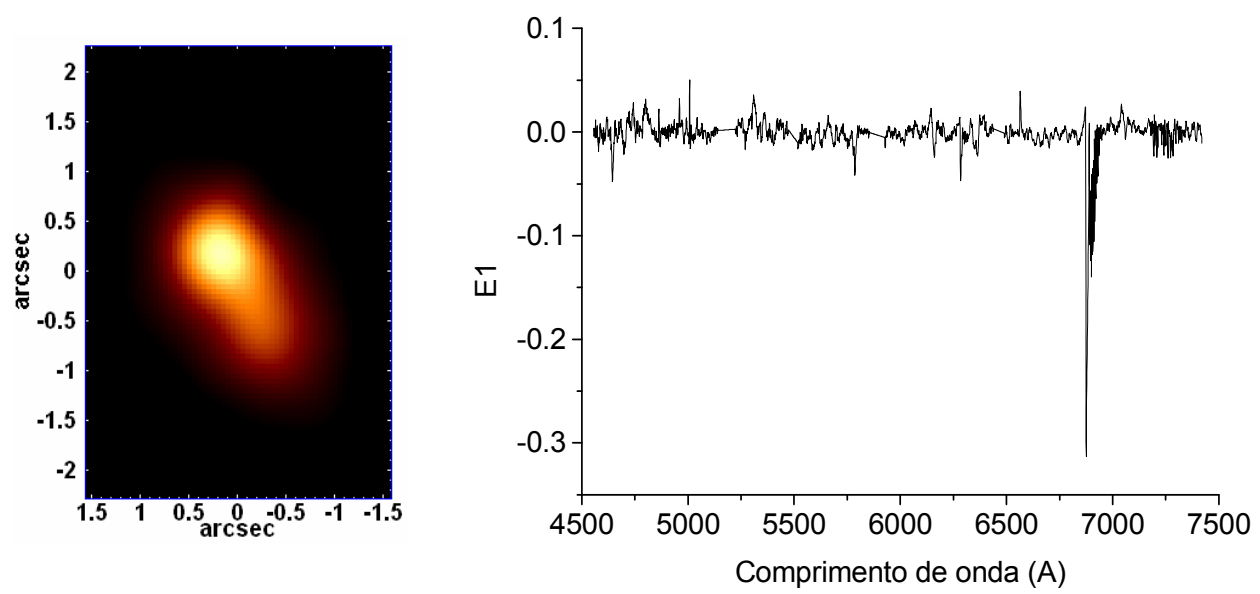

Figura 11.20 - Tomograma e auto-espectro correspondentes ao autovetor E1, obtido com a

Tomografia PCA do cubo de dados de M31 com o contínuo estelar subtraído.

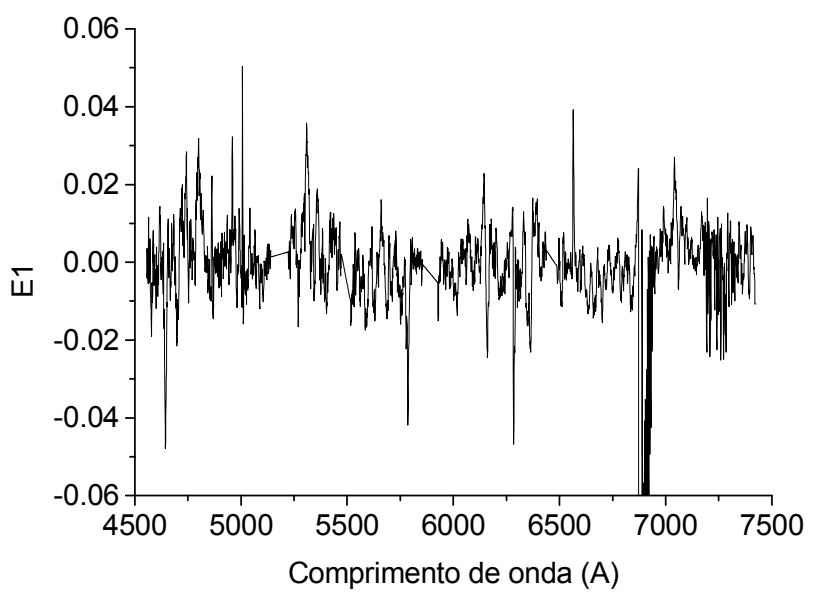

Figura 11.21 - Ampliação do auto-espectro correspondente ao autovetor E1, obtido com a Tomografia PCA do cubo de dados de M31 com o contínuo estelar subtraído.
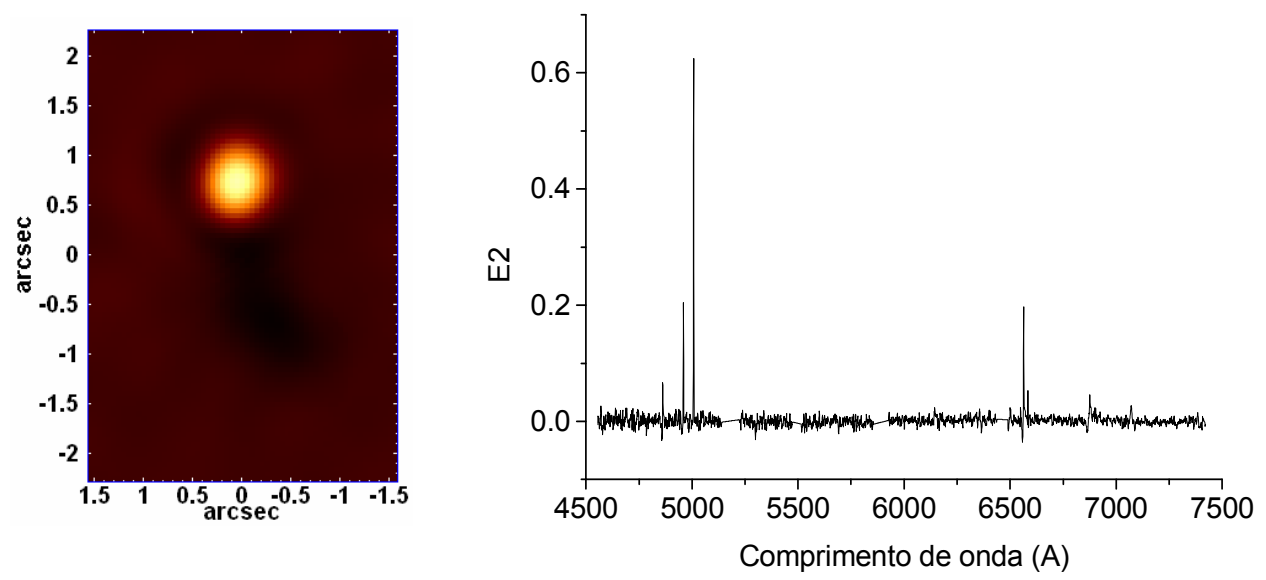

Figura 11.22 - Tomograma e auto-espectro correspondentes ao autovetor E2, obtido com a Tomografia PCA do cubo de dados de M31 com o contínuo estelar subtraído. 


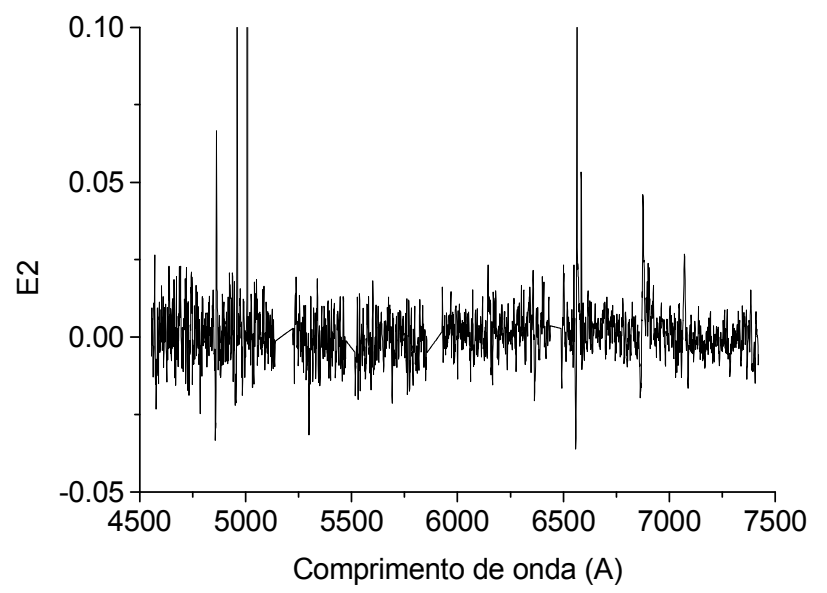

Figura 11.23 - Ampliação do auto-espectro correspondente ao autovetor E2, obtido com a Tomografia PCA do cubo de dados de M31 com o contínuo estelar subtraído.
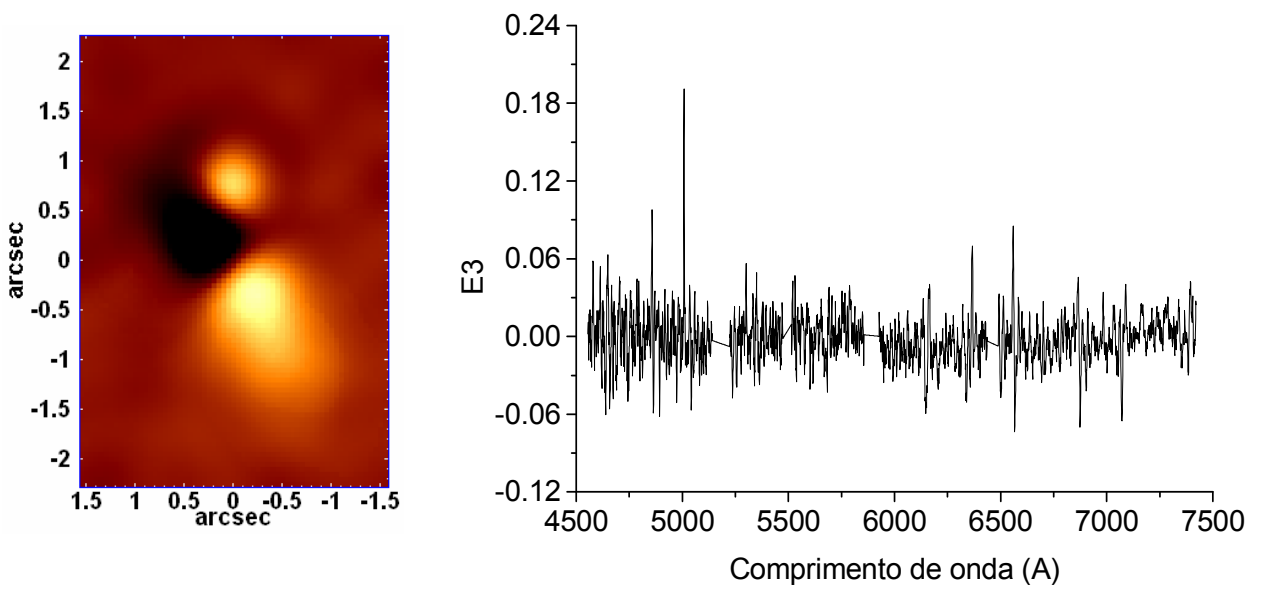

Figura 11.24 - Tomograma e auto-espectro correspondentes ao autovetor E3, obtido com a Tomografia PCA do cubo de dados de M31 com o contínuo estelar subtraído.
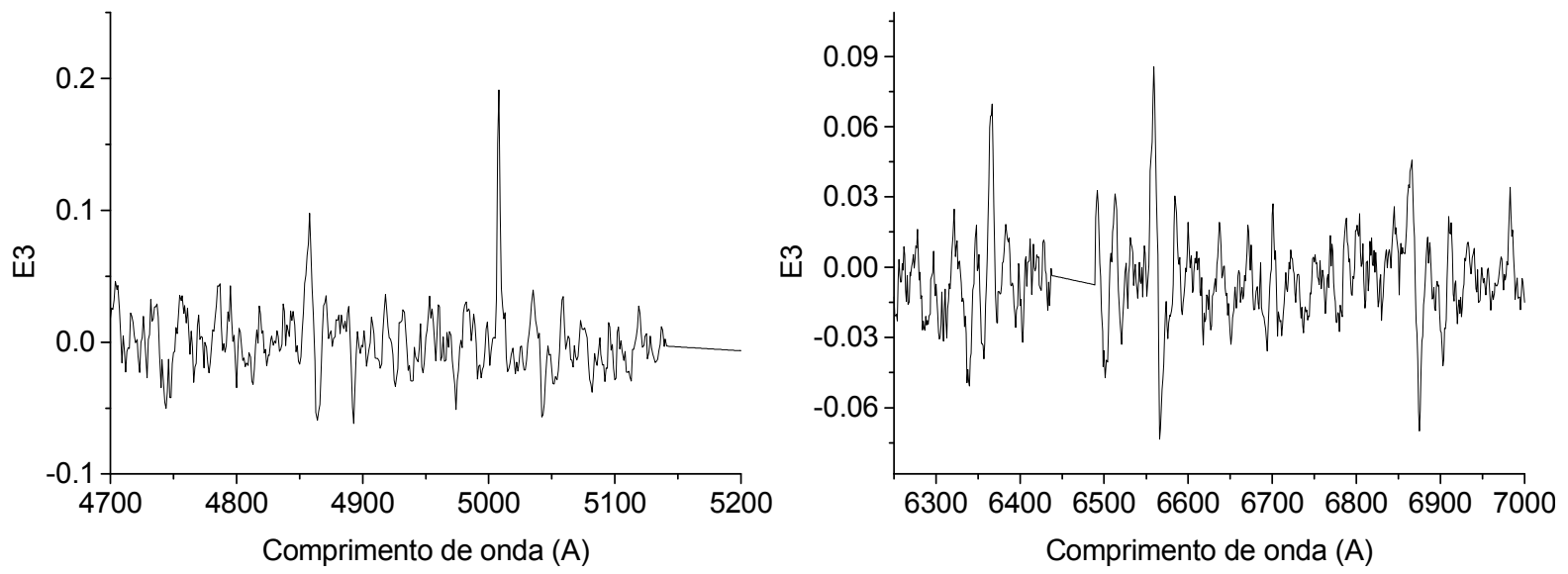

Figura 11.25 - Ampliações nas regiões espectrais (esquerda) azul e (direita) vermelha do autoespectro correspondente ao autovetor E3, obtido com a Tomografia PCA do cubo de dados de M31 com o contínuo estelar subtraído. 


\begin{tabular}{|c|c|}
\hline Autovetor & Fração da variância explicada (\%) \\
\hline E1 & 45.3157 \\
\hline E2 & 9.5948 \\
\hline E3 & 5.0558 \\
\hline
\end{tabular}

Tabela 11.2 - Autovalores obtidos com a Tomografia PCA do cubo de dados de M31 com o contínuo estelar subtraído.

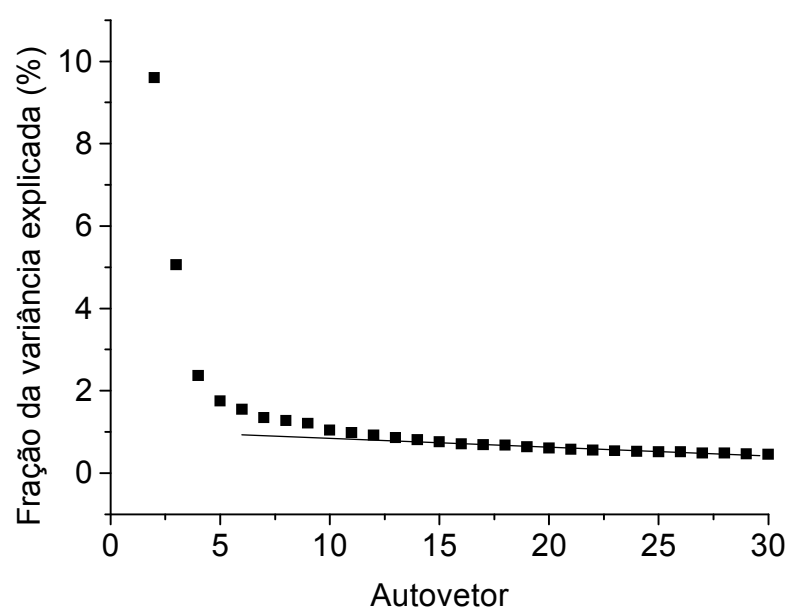

Figura 11.26 - "Scree test" dos autovetores obtidos com a Tomografia PCA do cubo de dados de M31 com o contínuo estelar subtraído.

As figuras 11.20 e 11.21 mostram que o auto-espectro E1 apresenta correlações e anticorrelações que são compatíveis com certas linhas e bandas de absorção estelares que não foram completamente subtraídas após o ajuste com o Starlight. Em outras palavras, pode-se dizer que o autovetor E1 está relacionado, sobretudo, a resíduos da subtração do espectro estelar. Além disso, o auto-espectro E1 também possui anti-correlações com comprimentos de onda próximos a $6800 \AA$, que são compatíveis com uma banda de absorção atmosférica existente nessa região espectral que não foi subtraída após o ajuste com o Starlight, pois esse software não ajusta absorções originárias da atmosfera terrestre. $\mathrm{O}$ tomograma mostrado na figura 11.20 confirma a hipótese de que o autovetor E1 está relacionado a resíduos da subtração do espectro estelar, já que ele apresenta o aspecto das imagens do cubo de dados original de M31. O auto-espectro E1 apresenta, ainda, correlações com os comprimentos de onda correspondentes a algumas linhas de emissão, inclusive $\mathrm{H} \alpha$ e $\mathrm{H} \beta$. Apesar dessas correlações não serem muito intensas, esse é um resultado bastante importante, pois, considerando o aspecto do tomograma, pode-se concluir que esse autovetor parece indicar a existência de linhas de emissão provenientes de várias áreas na 
região central de M31. Tal resultado jamais foi obtido claramente em trabalhos anteriores. O autovetor E1 explica cerca de 45.3157 \% da variância dos dados.

Observando-se as figuras 11.22 e 11.23, pode-se notar que o auto-espectro E2 apresenta correlações com os comprimentos de onda correspondentes a várias linhas de emissão, cuja região emissora é representada pela área clara do tomograma. Tal resultado é compatível com o que foi obtido com o autovetor E6 mostrado na seção 11.3 (figura 11.10). Essa área com linhas de emissão também foi detectada por del Burgo et al. (2000) (e chamada pelos autores de região B). Para se fazer uma análise mais detalhada dessa emissão de linhas no cubo de dados de M31, extraiu-se um espectro de uma região circular, com 0.45 " de raio, centrada na área clara do tomograma da figura 11.22. Além disso, fez-se uma imagem da linha de [O III] $\lambda 5007$, que é a mais intensa emitida pela região emissora detectada. Os resultados obtidos são mostrados na figura 11.27 .
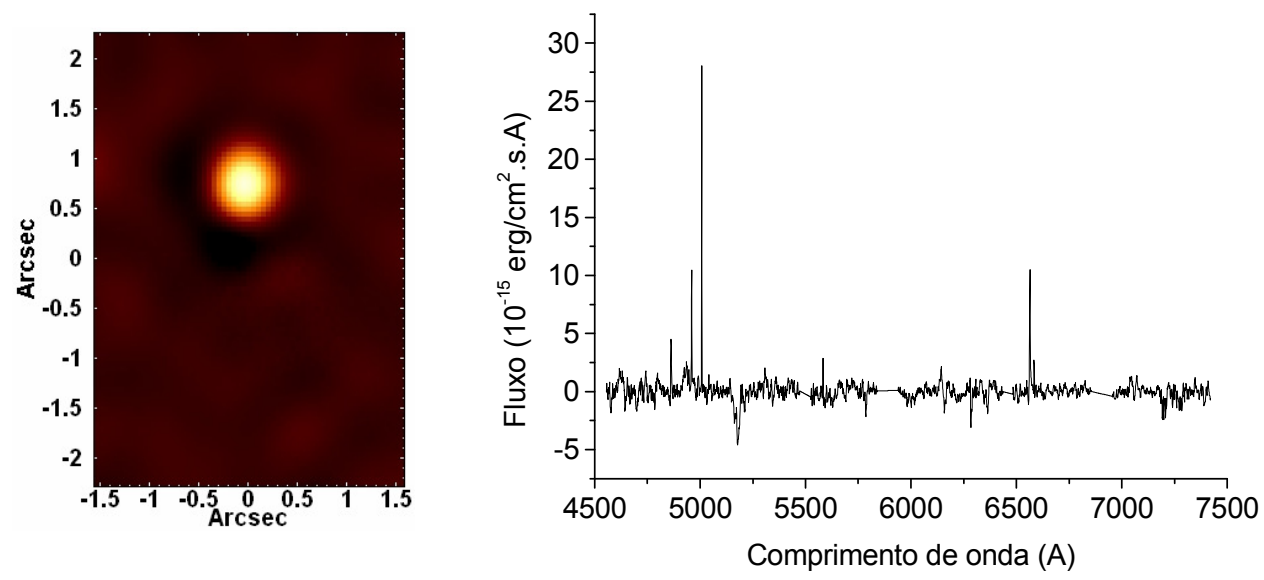

Figura 11.27 - (esquerda) Imagem da linha de [O III] 25007 do cubo de dados de M31, após a subtração do contínuo estelar; (direita) espectro extraído de uma região circular, com 0.45 " de raio, centrada na área clara da figura à esquerda.

Analisando-se a figura 11.27, verifica-se que a imagem da linha de [O III] $\lambda 5007$ e o espectro extraído de uma região circular centrada na área emissora são compatíveis, respectivamente, com o tomograma e o auto-espectro mostrados na figura 11.22 (e também na figura 11.10). O espectro na figura 11.27 apresenta as seguintes razões de linhas: [N II] $\lambda 6583 / \mathrm{H} \alpha=0.21 \mathrm{e}$ [O III] $\lambda 5007 / \mathrm{H} \beta=7.8$. Esses valores são os esperados para uma nebulosa planetária, de acordo com Baldwin et al. (1981). Tal resultado também havia sido constatado por del Burgo et al. (2000). A luminosidade da linha de [O III] $\lambda 5007$ na figura 11.27 é de cerca de 1090 L $\odot$. Uma 
outra característica do auto-espectro E2 na figura 11.22 é que podem ser notadas correlações com os comprimentos de onda correspondentes às asas vermelhas das linhas de $\mathrm{H} \alpha$ e $\mathrm{H} \beta$ e anticorrelações com os comprimentos de onda associados às asas azuis das mesmas. Isso parece indicar que esse autovetor está relacionado a algum fenômeno cinemático dessas linhas de emissão, entretanto, é provável que essa característica não seja dominante. O autovetor E2 explica cerca de 9.5948 \% da variância dos dados.

Por fim, as figuras 11.24 e 11.25 revelam que o auto-espectro E3 apresenta, primeiramente, correlações com os comprimentos de onda correspondentes às linhas de [O III] $\lambda \lambda 4959 ; 5007$, o que indica uma emissão com mais alta ionização. De fato, a região emissora identificada no auto-espectro E2 (figura 11.22), que possui um espectro de mais alta ionização, é visível no tomograma na figura 11.24, assim, é provável que as correlações detectadas com os comprimentos de onda associados às linhas de [O III] $\lambda \lambda 4959 ; 5007$ sejam devidas a essa região. O auto-espectro E3 também apresenta, de forma mais sutil, correlações com os comprimentos de onda associados às asas azuis de algumas linhas de emissão permitidas (como H $\alpha, \mathrm{H} \beta$ e C III $\lambda 6872$ ) e anti-correlações com os comprimentos de onda correspondentes às asas vermelhas das mesmas. Isso indica a presença de algum tipo de fenômeno cinemático relacionado a essas linhas. Considerando-se isso e o aspecto apresentado pelo tomograma, podese concluir que esse autovetor está associado a uma rotação ao redor do núcleo de M31. Nesse caso, as áreas claras do tomograma representam regiões com emissão em blueshift e as áreas escuras correspondem a regiões com emissão em redshift. Em outras palavras, pode-se dizer que o autovetor E3 revela um disco com linhas de emissão em rotação ao redor do núcleo de M31. Uma inspeção minuciosa do cubo de dados revelou resquícios de algumas outras linhas (como [O III] $\lambda 5007$, [N II] $\lambda 6583$ e [S II] $\lambda \lambda 6716 ; 6731)$ nas áreas com emissão em redshift ou blueshift detectadas com esse autovetor, o que sugere que o disco em rotação pode ser gasoso. Entretanto, não se pode descartar a hipótese de que, pelo menos, parte dessa emissão de linhas seja devida a estrelas. O autovetor E3 explica cerca de 5.0558 \% da variância dos dados.

O Scree test na figura 11.26 mostra que os valores das variâncias explicadas pelos autovetores decaem bastante até, aproximadamente, o autovetor E5. A partir disso, a taxa de decaimento diminui, atingindo um valor quase constante a partir do autovetor E15, aproximadamente. Isso indica que autovetores de ordem maior ou igual a 15 representam, sobretudo, ruído e, consequentemente, não possuem relevância nessa análise. Entretanto, dentre 
os autovetores de menor ordem, apenas os três primeiro apresentavam uma interpretação mais clara, assim, somente eles foram mostrados aqui.

Assim, pode-se concluir que essa segunda aplicação da Tomografia PCA forneceu informações compatíveis e também complementares às encontradas com a primeira análise (seção 11.3). Primeiramente, foi observada a presença de uma pequena região emissora de linhas, cujas razões são compatíveis com as de uma nebulosa planetária. Tal região emissora também foi detectada na seção 11.3. Entretanto, o resultado mais relevante obtido com essa segunda aplicação da Tomografia PCA foi a detecção de um disco com linhas de emissão em rotação ao redor do núcleo de M31. Não é possível afirmar com certeza se esse disco é gasoso ou se, pelo menos, parte da emissão tem origem estelar. De qualquer forma, pode-se dizer que esse resultado é de considerável importância, pois um disco em rotação com essas características na região central de M31 jamais havia sido observado em estudos anteriores.

Assim como na seção 11.3, aqui também não foi detectada nenhuma emissão na região nuclear do objeto que indicasse a presença de um LINER, ao contrário do que é afirmado na literatura. Uma possível explicação para isso baseia-se no fato de a classificação desse objeto como LINER ter sido feita a partir de espectros de fenda (long-slit) que apresentaram certas linhas de emissão, cujas razões eram compatíveis com as de um LINER. Como o tamanho aparente de uma região observada com um espectrógrafo de fenda pode ser relativamente grande, é possível que as linhas detectadas tenham sido emitidas por áreas emissoras mais afastadas do núcleo, como as observadas por del Burgo et al. (2000) (de fato, algumas das regiões detectadas pelos autores apresentavam espectros com razões de linhas de um LINER), e não por uma área localizada no núcleo exatamente. Assim, a conseqüência disso pode ter sido a atribuição da classificação LINER, apesar de, aparentemente, não haver nenhum nessa galáxia.

\section{6 - Cinemática estelar do cubo de dados de M31}

Aplicou-se o processo do pPXF no cubo de dados de M31, a fim de se obter os valores da velocidade radial estelar, da dispersão de velocidades estelar e dos coeficientes de GaussHermite $h_{3}$ e $h_{4}$ ao longo de todo o campo visual do IFU do GMOS. Os mapeamentos obtidos são mostrados na figura 11.28. 

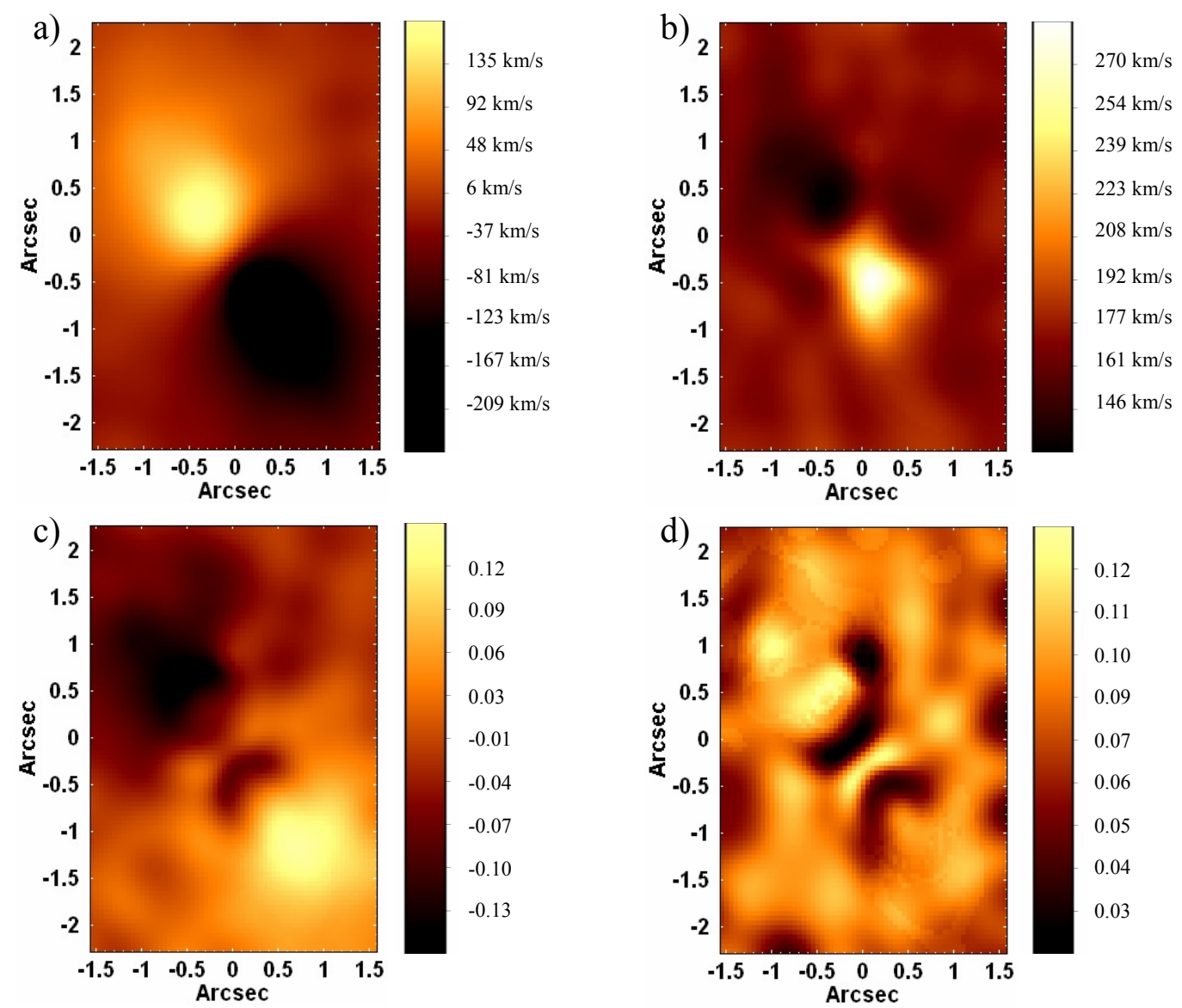

Figura 11.28 - Mapeamentos dos valores (a) da velocidade radial estelar, (b) da dispersão de velocidades estelar, (c) do coeficiente $h_{3} e(d)$ do coeficiente $h_{4}$, obtidos com a aplicação do pPXF ao cubo de dados de M31.

Observando-se a figura 11.28 - $a$, pode-se notar que o mapa dos valores da velocidade radial estelar revela uma clara rotação estelar ao redor do núcleo de M31. Esse mapeamento é compatível com o tomograma do autovetor E2 obtido com a Tomografia PCA na seção 11.3 (figura 11.7) e com o mapa da velocidade radial estelar resultante da síntese espectral com o Starlight (figura 11.3 da seção 11.4.2). Esse resultado também está de acordo com os mapeamentos da velocidade radial estelar na região central de M31 encontrados por Bacon et al. (1994; 2001) e del Burgo et al. (2000). O mapa dos valores da dispersão de velocidades estelar mostrado na figura 11.28 - $b$, por sua vez, também é compatível com o mapeamento obtido a partir da síntese espectral com o Starlight (figura 11.3 da seção 11.4.2) e com os resultados de Bacon et al. (1994; 2001) e del Burgo et al. (2000). Conforme foi mencionado anteriormente, pode-se verificar que o mapa da dispersão de velocidades estelar parece estar associado ao mapa da velocidade radial estelar, já que é observada uma diminuição da dispersão de velocidades (sigma drop) numa área onde a velocidade radial é elevada e um aumento da dispersão de 
velocidades numa região onde a velocidade radial é menor. Comparando-se os mapeamentos das figuras $11.13,11.28-a$ e $11.28-b$, pode-se notar que aqueles na figura 11.13 possuem uma maior quantidade de estruturas com alta freqüência espacial, ao passo que os mapas na figura 11.28 apresentam um aspecto mais "suavizado". É provável que essa maior "suavização" na figura 11.28 seja uma conseqüência do processo de penalização utilizado no pPXF.

A figura $11.28-c$ mostra que o mapeamento dos valores do coeficiente $h_{3}$ apresenta um máximo na região inferior direita da imagem e um mínimo na região superior esquerda. Essa distribuição parece estar relacionada aos mapas de rotação mostrados nas figuras 11.13 e 11.28 - $a$, já que os valores de $h_{3}$ são maiores na área com velocidades negativas e menores na área com velocidades positivas.

O modelo proposto por Tremaine (1995), já mencionado nas seções anteriores, é capaz de explicar as morfologias apresentadas pelos mapeamentos da velocidade radial estelar, da dispersão de velocidades estelar e de $h_{3}$. De fato, uma sobreposição de uma rotação estelar em uma órbita elíptica excêntrica com um fundo de estrelas com valores mais aleatórios de dispersão de velocidades pode dar origem às características observadas.

Finalmente, o mapeamento dos valores do coeficiente $h_{4}$ na figura $11.28-d$ não revelou a presença de estruturas claramente detectáveis.

O mapeamento dos valores da velocidade radial estelar obtido (figura 11.28-a) contém detalhes suficientes para que possa ser elaborada uma modelagem, com o objetivo de se determinar a massa do buraco negro central. Supondo-se a existência de um disco fino de estrelas ao redor do buraco negro central de M31, a modelagem foi feita da seguinte maneira: para a construção de cada um dos mapas de velocidades simulados, inicialmente, calculavam-se, utilizando-se equações keplerianas básicas (apêndice I), as velocidades correspondentes a 41 órbitas elípticas concêntricas que eram, em seguida, projetadas no plano do céu. Fazia-se, então, uma convolução do resultado obtido com uma estimativa da PSF da observação, chegando-se, por fim, ao mapa de velocidades simulado procurado. Em todas as simulações, foram considerados 4 parâmetros livres: a inclinação do disco estelar (i), a excentricidade das órbitas $(e)$, o argumento do periastro $(\omega)$ e a massa do buraco negro central $\left(M_{\bullet}\right)$. A longitude do nodo ascendente $(\Omega)$ pôde ser medida no mapa de velocidades observado $\left(\Omega=126.4^{\circ}\right)$, logo, esse parâmetro foi tomado como fixo nas simulações. O modelo mais adequado foi obtido variandose todos os 4 parâmetros livres a fim de se minimizar o $\chi^{2}$, dado pela expressão (10.1). Todas as 
simulações foram feitas desprezando-se a massa estelar presente, ou seja, a massa total das estrelas foi tomada como sendo muito pequena quando comparada à do buraco negro central. Essa hipótese é discutida em maiores detalhes a seguir. A área simulada englobou uma região se estendendo até 0.8 " do buraco negro central. Regiões mais distantes não foram simuladas devido ao fato de a massa estelar se tornar significativa a essas distâncias mais elevadas. As incertezas dos valores encontrados para os parâmetros das simulações foram estimadas utilizando-se o mesmo método usado nos casos de NGC 5643 e M104 (Jardel et al. 2011). A tabela 11.3 mostra os parâmetros do melhor modelo obtido com as simulações, que apresentou $\chi^{2}=46.1$.

\begin{tabular}{|c|c|}
\hline Parâmetro & $\begin{array}{c}\text { Valor correspondente ao melhor modelo } \\
\text { obtido com as simulações }\end{array}$ \\
\hline$M \bullet$ & $(4.5 \pm 0.1) \cdot 10^{7} \mathrm{M}_{\odot}$ \\
\hline$i$ & $55 \pm 1^{\mathbf{0}}$ \\
\hline$e$ & $0.30 \pm 0.06$ \\
\hline$\Omega$ & $250 \pm 6^{\mathbf{0}}$ \\
\hline
\end{tabular}

Tabela 11.3 - Parâmetros do melhor modelo obtido com as simulações do mapa dos valores da velocidade radial estelar de M31.

A figura 11.29 mostra uma comparação entre o mapa dos valores da velocidade radial estelar observado, obtido com a aplicação do processo do pPXF, e o mapa correspondente simulado, resultante do melhor modelo encontrado com as simulações.
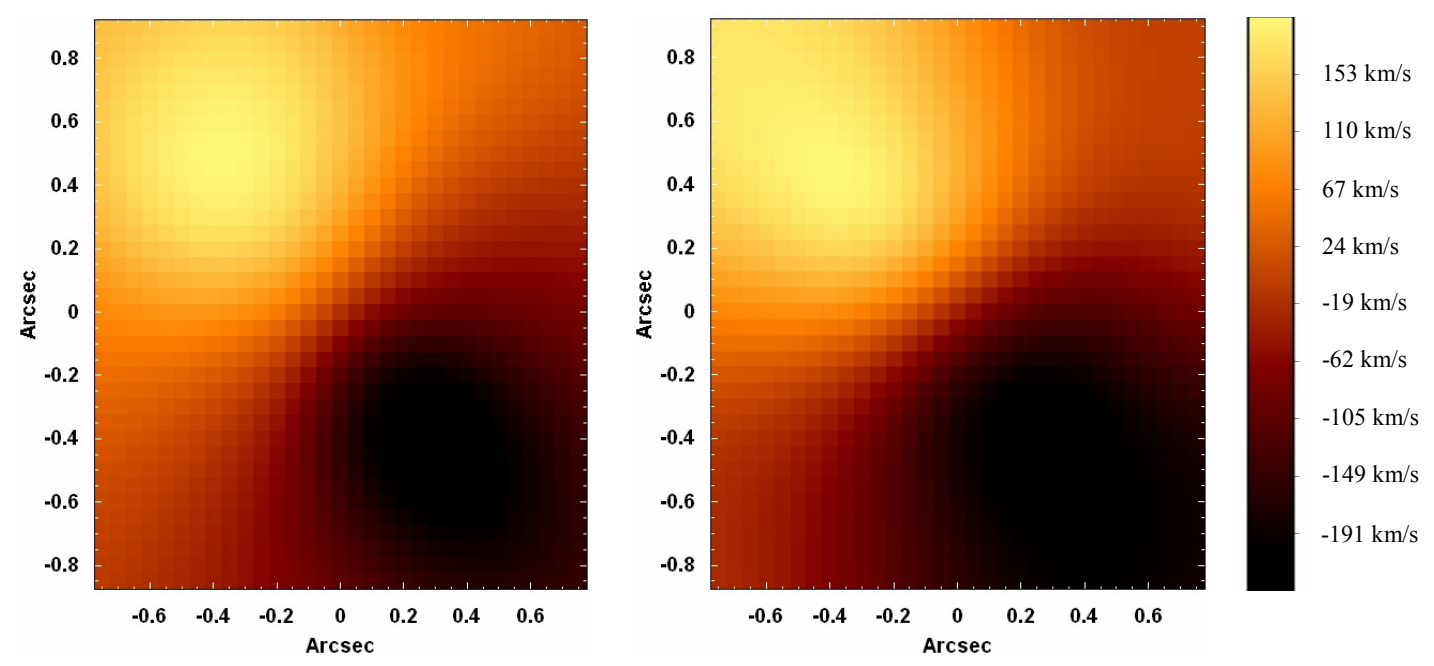

Figura 11.29 - (esquerda) Mapa dos valores da velocidade radial estelar observado, obtido a partir da aplicação do processo do pPXF ao cubo de dados de M31 (igual ao mostrado na figura 11.28 - a, mas englobando apenas a área simulada); (direita) Mapa dos valores da velocidade radial estelar, resultante do melhor modelo obtido com as simulações. 
Verificou-se que a linha de nodos do mapa dos valores da velocidade radial estelar observado apresentava $P A=57.4^{\circ}$. A figura 11.30 mostra uma curva de rotação extraída ao longo da linha de nodos desse mapa de velocidades, juntamente com o resultado do melhor modelo obtido com as simulações.

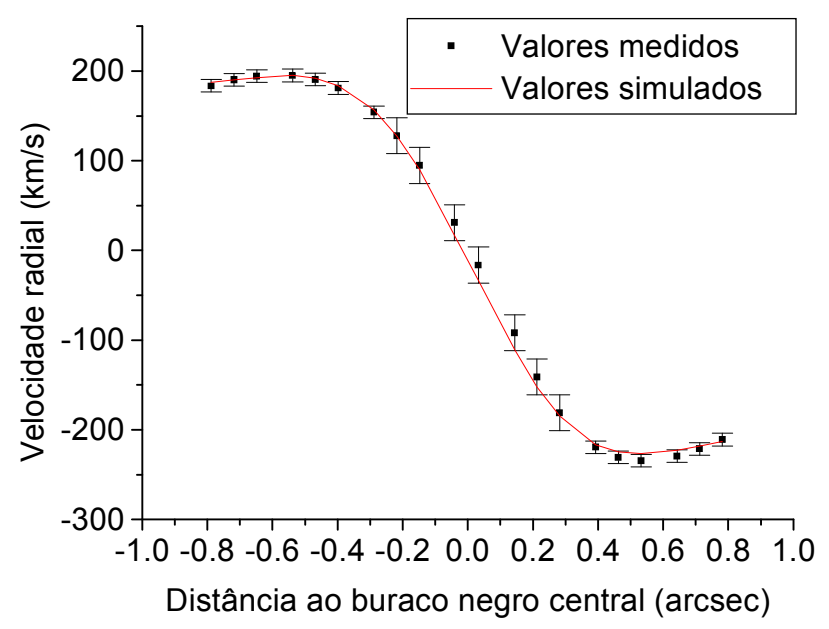

Figura 11.30 - Curva de rotação extraída ao longo da linha de nodos do mapa dos valores da velocidade radial estelar na figura 11.28 - a, juntamente com o resultado do melhor modelo obtido com as simulações.

Analisando-se a figura 11.29, pode-se notar que o modelo obtido com as simulações reproduz consideravelmente bem o mapa dos valores da velocidade radial estelar observado da região central de M31. Entretanto, algumas discrepâncias podem ser observadas. Particularmente, percebe-se que as regiões, ao longo da linha dos nodos, mais afastadas do buraco negro central (áreas superior esquerda e inferior direita das imagens) no mapeamento da velocidade radial observado não são tão bem reproduzidas pelo modelo. É possível que essas imprecisões sejam devidas ao fato de que, a distâncias maiores do buraco negro central, o efeito gravitacional da massa estelar (que foi desconsiderado nas simulações) passa a ser mais significativo, fazendo com que o modelo obtido se torne menos adequado. Também se pode notar uma discrepância na região correspondente à área emissora de linhas detectada com as aplicações da Tomografia PCA ao cubo de dados de M31 (figura 11.10 da seção 11.3 e figuras 11.22 e 11.27 da seção 11.5). Isso sugere que tal área emissora (possivelmente uma nebulosa planetária) não está associada ao disco estelar em rotação ao redor do núcleo. 
A figura 11.30 mostra como a curva de rotação extraída ao longo da linha de nodos é consideravelmente bem reproduzida pelo modelo elaborado. Pode-se notar, inclusive, que o ajuste é compatível, em 1- $\sigma$, com quase todos os valores observados.

Conforme foi mencionado anteriormente, todas as simulações foram feitas considerandose a massa estelar existente desprezível. Para se avaliar a validade dessa hipótese, utilizou-se uma imagem do HST, na banda V, do núcleo de M31, obtida com a Wide Field Planetary Câmera 2 (WFPC2), para se estimar a massa estelar dentro do raio da área simulada. Esse procedimento foi feito da seguinte maneira: primeiramente, a imagem do HST foi decomposta em uma componente assimétrica (contendo o disco estelar ao redor do buraco negro central) e uma componente simétrica (contendo a parte central do bojo estelar). Após isso, foi feita a deprojeção da componente simétrica em relação ao plano do céu, utilizando-se o processo do MGE. Por fim, as massas estelares das duas componentes foram calculadas, usando-se uma razão massa-luminosidade de $M / L_{V}=5.7$ (obtida a partir do trabalho de Peiris \& Tremaine 2003). Os valores obtidos foram $M_{\text {simétrica }}=1.14 \cdot 10^{6} \mathrm{M}_{\odot}$ e $M_{\text {assimétrica }}=1.02 \cdot 10^{7} \mathrm{M}_{\odot}$. Dessa forma, pode-se concluir que a massa estelar total dentro do raio (igual a 0.8 ”) da área simulada é de $M_{\text {estelar_total }}=1.13 \cdot 10^{7} \mathrm{M}_{\odot}$, o que equivale a cerca de $25 \%$ da massa do buraco negro central (M•) obtida com as simulações (de acordo com o que é mostrado na tabela 11.3). Isso significa que esse valor de $M_{\bullet}$ pode estar, no máximo, $25 \%$ superestimado, devido ao fato de não se ter levado em conta a massa estelar nas simulações. Introduzindo esse resultado na incerteza calculada previamente para $M_{\bullet}$, obtém-se um valor final para a massa do buraco negro central de $M_{b h}=4.5_{-1.1}^{+0.1} \cdot 10^{7} \mathrm{M}_{\odot}$.

A massa aqui obtida para o buraco negro central de M31 está dentro do intervalo de valores encontrados em vários estudos anteriores (Kormendy 1988; Dressler \& Richstone 1988; Peiris \& Tremaine 2003; Bender et al. 2005; Bacon et al. 2001) e é compatível, em 2- $\sigma$, com a medição feita por Salow \& Statler (2004) $\left(5.62 \pm 0.66 \cdot 10^{7} \mathrm{M}_{\odot}\right)$, que corresponde ao estudo mais detalhado da cinemática estelar na região central de M31 feito até hoje. Boa parte dos modelos elaborados para reproduzir o disco estelar em rotação ao redor do núcleo dessa galáxia não assumiram uma única excentricidade, inclinação ou argumento do periastro para todo o disco. Entretanto, os valores obtidos com o modelo aqui elaborado estão na faixa daqueles encontrados em vários estudos anteriores (Salow \& Statler 2004; Peiris \& Tremaine 2003). 


\section{7 - Cinemática da linha $\mathrm{H} \alpha$ do cubo de dados de M31}

Para se fazer uma análise mais detalhada da cinemática do disco com linhas de emissão detectado no autovetor E3 mostrado na seção 11.5 (figura 11.24), construiu-se o mapa de velocidades (através do ajuste de funções gaussianas) da linha de emissão Ha. Essa linha foi escolhida por ser a mais intensa do espectro, após a subtração do contínuo estelar. Linhas mais fracas geraram resultados menos precisos que, por essa razão, não são analisados aqui. A linha de emissão $\mathrm{H} \alpha$ possui uma luminosidade de cerca de $1082 \mathrm{~L}_{\odot}$, dentro de uma região circular centrada no núcleo com 0.7 "de raio. Isso equivale a uma largura equivalente de aproximadamente $-0.07 \AA$, enquanto que a largura equivalente da componente de absorção da linha $\mathrm{H} \alpha$ é de cerca de $2.07 \AA$. Dessa forma, pode-se concluir que a linha de emissão H $\alpha$ é consideravelmente menos intensa do que a componente de absorção, o que justifica o fato de ela jamais ter sido detectada em estudos anteriores. O mapeamento de velocidades da linha de emissão Ha foi feito apenas para a região mais central do campo visual do IFU do GMOS, já que a emissão em áreas mais afastadas é muito mais fraca e, consequentemente, não forneceu valores de velocidade confiáveis. O resultado obtido é mostrado na figura 11.31.

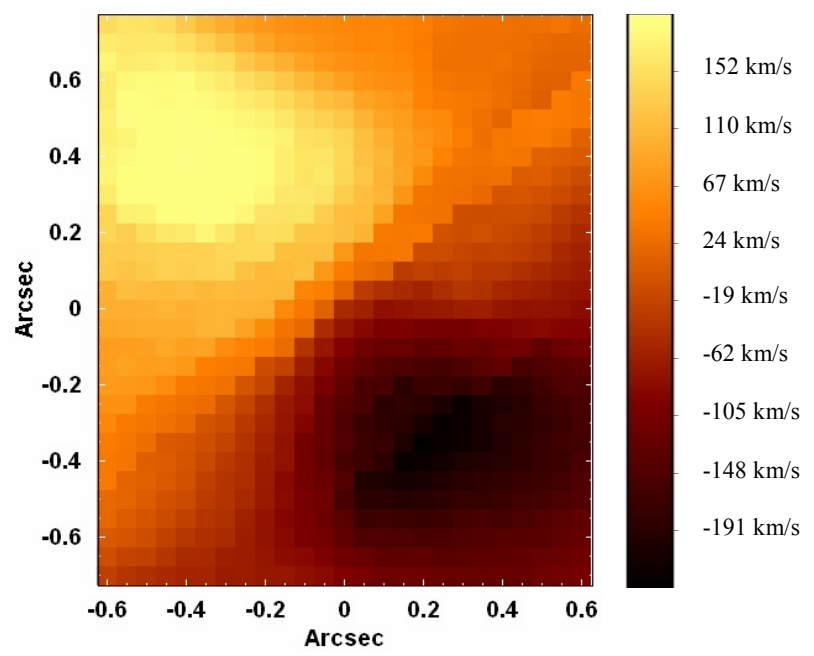

Figura 11.31 - Mapeamento dos valores de velocidade radial, obtido com a linha de emissão Ha do cubo de dados de M31, após a subtração do contínuo estelar.

Observando-se a figura 11.31, pode-se notar a existência de um disco emissor de $\mathrm{H} \alpha \mathrm{em}$ rotação ao redor do núcleo de M31, compatível com o que foi observado no autovetor E3 mostrado na seção 11.5 (figura 11.24). A morfologia apresentada por esse disco também é 
razoavelmente similar à do disco estelar analisado na seção 11.6. No mapeamento da figura 11.31, pode-se observar, ainda, algumas irregularidades e estruturas com alta freqüência espacial. É provável que essas características tenham sido geradas por instabilidades nos ajustes das funções gaussianas, devido às baixas intensidades das linhas de Ha. Conforme já foi mencionado anteriormente, a detecção desse disco com linhas de emissão na região central de M31 é inédita e, consequentemente, possui grande importância.

Apesar das irregularidades presentes, o mapeamento da figura 11.31 possui detalhes suficientes para que possa ser elaborada uma modelagem, com o objetivo de se determinar a massa do buraco negro central. Esse procedimento foi aplicado de uma maneira inteiramente análoga à da seção 11.6. Nesse caso, entretanto, foram utilizadas 33 órbitas elípticas superpostas para simular o disco. A longitude do nodo ascendente $(\Omega)$ medida no mapa de velocidades observado foi de $\Omega=128.28^{\circ}$, logo, não foi a mesma encontrada no caso do mapeamento das velocidades radiais estelares (figura $11.28-a$ ). A área simulada englobou uma região se estendendo até 0.7 " do buraco negro central, já que, em áreas mais distantes, a emissão de H $\alpha$ é fraca demais para que os valores de velocidade medidos possam ser considerados confiáveis. Além disso, como a massa estelar presente foi desprezada nos cálculos (de maneira análoga à da seção 11.6), simular regiões mais afastadas do núcleo seria arriscado, já que o efeito da massa estelar poderia não ser desprezível. As incertezas dos parâmetros das simulações foram, novamente, estimadas de acordo com o método utilizado por Jardel et al. (2011). O modelo mais adequado foi obtido variando-se todos os 4 parâmetros livres $\left(i, e, \omega\right.$ e $M_{\bullet}$ ), a fim de se minimizar o $\chi^{2}$, dado pela expressão (10.1). A tabela 11.4 mostra os parâmetros do melhor modelo obtido com as simulações, que apresentou $\chi^{2}=244.7$.

\begin{tabular}{|c|c|}
\hline Parâmetro & $\begin{array}{c}\text { Valor correspondente ao melhor modelo } \\
\text { obtido com as simulações }\end{array}$ \\
\hline$M_{\bullet}$ & $(5.0 \pm 0.3) \cdot 10^{7} \mathrm{M}_{\odot}$ \\
\hline$i$ & $45 \pm 4^{\mathbf{0}}$ \\
\hline$e$ & $0.35 \pm 0.03$ \\
\hline$\omega$ & $115 \pm 5^{\circ}$ \\
\hline
\end{tabular}

Tabela 11.4 - Parâmetros do melhor modelo obtido com as simulações do mapa dos valores da velocidade radial associada à linha de Ha de M31. 
A figura 11.32 mostra uma comparação entre o mapa dos valores da velocidade radial da linha $\mathrm{H} \alpha$ observado e o mapa correspondente simulado, resultante do melhor modelo encontrado com as simulações.
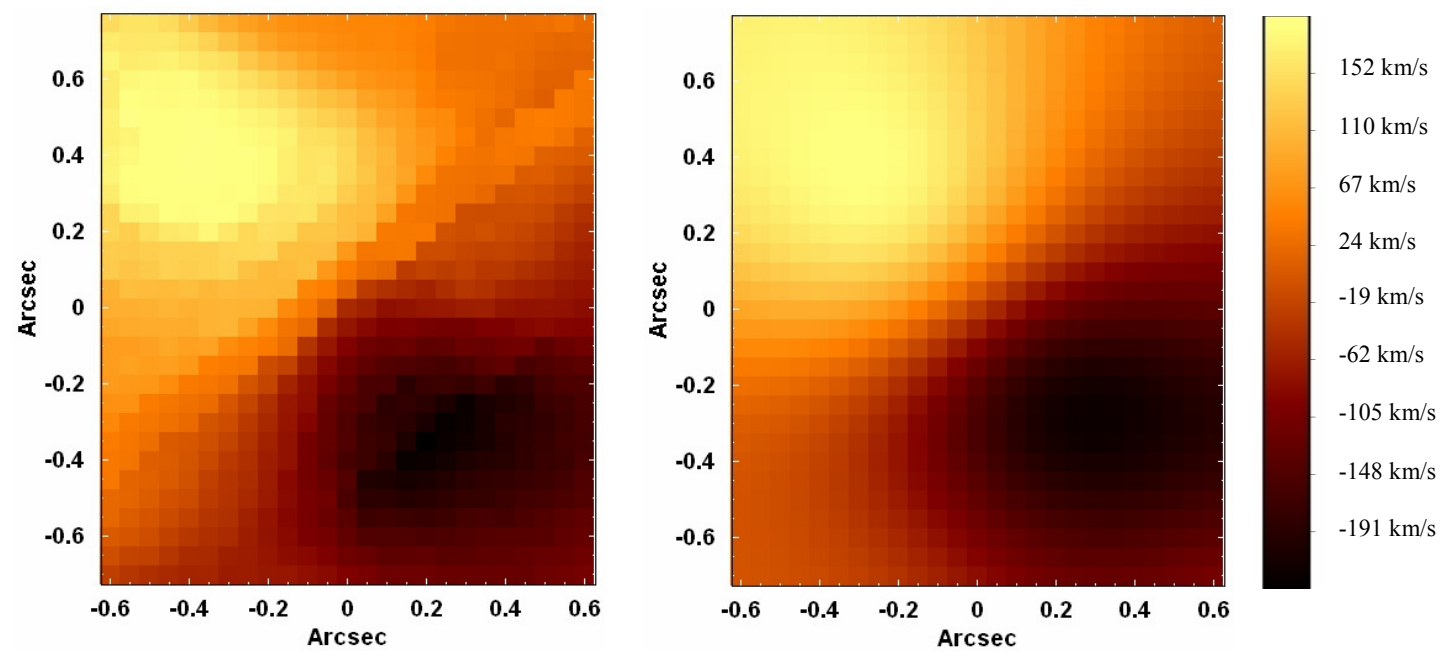

Figura 11.32 - (esquerda) Mapa dos valores da velocidade radial da linha Ha observado, obtido a partir do cubo de dados de M31, após a subtração do contínuo estelar (igual ao mostrado na figura 11.31); (direita) Mapa dos valores da velocidade radial da linha Ha, resultante do melhor modelo obtido com as simulações.

Verificou-se que a linha de nodos do mapa dos valores da velocidade radial da linha $\mathrm{H} \alpha$ observado apresentava $P A=59.3^{\circ}$. A figura 11.33 mostra uma curva de rotação extraída ao longo da linha de nodos desse mapa de velocidades, juntamente com o resultado do melhor modelo obtido com as simulações.

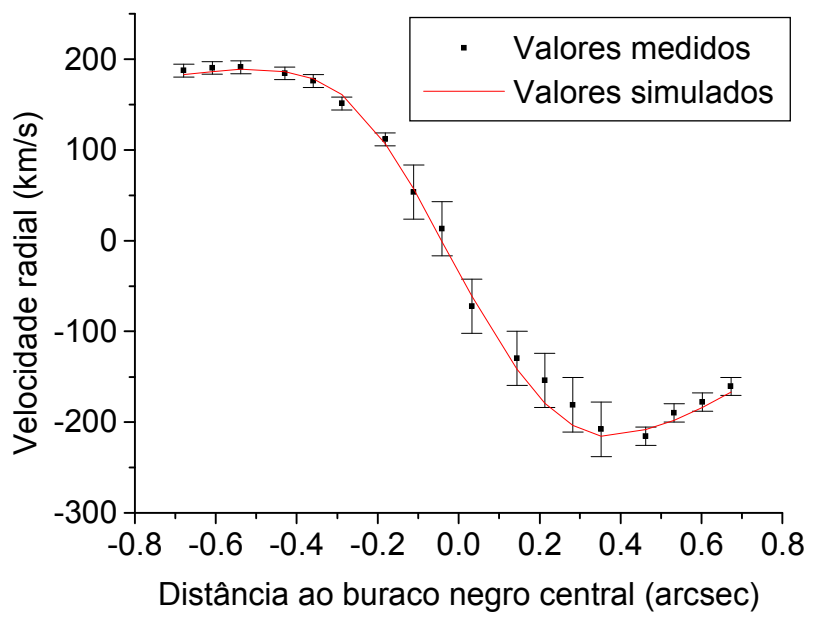

Figura 11.33 - Curva de rotação extraída ao longo da linha de nodos do mapa dos valores da velocidade radial da linha Ha na figura 11.31, juntamente com o resultado do melhor modelo obtido com as simulações. 
A figura 11.32 revela que o modelo obtido com as simulações reproduz razoavelmente bem o mapa dos valores da velocidade radial da linha $\mathrm{H} \alpha$ observado na região central de M31. Entretanto, algumas discrepâncias podem ser notadas. Assim como no caso da seção 11.6, a região correspondente à área emissora de linhas detectada com as aplicações da Tomografia PCA ao cubo de dados de M31 (figura 11.10 da seção 11.3 e figuras 11.22 e 11.27 da seção 11.5) não foi bem ajustada pelo modelo. Analogamente ao que foi dito anteriormente, isso sugere que essa área emissora (possivelmente uma nebulosa planetária) não está associada ao disco com linhas de emissão em rotação ao redor do núcleo.

Observando-se a figura 11.33, nota-se que a curva de rotação extraída ao longo da linha de nodos é bem reproduzida pelo modelo. Assim como no caso da seção 11.6, o ajuste é compatível, em 1- $\sigma$, com praticamente todos os valores observados.

A partir das imagens das componentes simétrica e assimétrica da região central de M31, que foram construídas conforme foi explicado anteriormente, obtiveram-se os seguintes valores das massas estelares dentro do raio (igual a 0.7 ") da área aqui simulada: $M_{\text {simétrica }}=8.65 \cdot 10^{5} \mathrm{M}_{\odot}$ e $M_{\text {assimétrica }}=8.70 \cdot 10^{6} \mathrm{M}_{\odot}$. Assim, a massa estelar total dentro da área simulada é de $M_{\text {estelar_total }}$ $=9.57 \cdot 10^{6} \mathrm{M}_{\odot}$, o que equivale a cerca de $19 \%$ de $M_{\bullet}$. Dessa forma, esse valor de $M_{\bullet}$ pode estar, no máximo, 19 \% superestimado, já que a massa estelar não foi levada em conta na simulação. Introduzindo esse resultado na incerteza calculada para $M_{\bullet}$, analogamente ao que foi feito na seção 11.6 , obtém-se um valor final para a massa do buraco negro central de $M_{b h}=5.0_{-1.0}^{+0.3} \cdot 10^{7}$ $\mathrm{M}_{\odot}$

A massa aqui encontrada para o buraco negro central está dentro do intervalo de valores encontrados em vários estudos, já mencionados na seção 11.6 (Kormendy 1988; Dressler \& Richstone 1988; Peiris \& Tremaine 2003; Bender et al. 2005; Bacon et al. 2001). Além disso, esse resultado também é compatível, em 1- $\sigma$, com a medição de Salow \& Statler (2004) $\left(5.62 \pm 0.66 \cdot 10^{7} \mathrm{M}_{\odot}\right)$. Os valores obtidos para os parâmetros $e$, $i$ e $\omega$ estão na faixa daqueles encontrados em vários estudos anteriores (Salow \& Statler 2004; Peiris \& Tremaine 2003).

Comparando-se os valores de $\mathrm{M}_{\mathrm{bh}}$ encontrados nas seções 11.6 e 11.7, nota-se que eles são compatíveis em 1- $\sigma$, o que, obviamente, está de acordo com o esperado. Os parâmetros $e$ e $i$ obtidos nas duas seções são compatíveis em 1- $\sigma$ e $2-\sigma$, respectivamente. Isso indica que os discos estelar e com linhas de emissão devem apresentar excentricidades e inclinações consideravelmente próximas. Por outro lado, os parâmetros $\omega$ encontrados são totalmente 
discrepantes, o que corresponde uma diferença considerável entre os discos estelar e com linhas de emissão.

\section{8 - Conclusões}

Em suma, pode-se dizer, primeiramente, que as aplicações da Tomografia PCA revelaram a existência de uma pequena região com linhas de emissão, relativamente afastada da posição correspondente ao núcleo de M31. Uma análise detalhada do espectro de emissão associado mostrou que as razões de linhas são compatíveis com as de uma nebulosa planetária (Baldwin et al. 1981). Esse resultado está de acordo com o que foi obtido por del Burgo et al. (2000), que identificaram essa área emissora como região B. A Tomografia PCA no cubo de dados de M31 com o contínuo estelar revelou a presença de espectros mais avermelhados em um região central do campo visual, o que sugere a presença de nuvens de poeira nessa área. Essa constatação foi confirmada a partir dos resultados obtidos com a síntese espectral com o Starlight. Nenhuma das aplicações da Tomografia PCA detectou linhas de emissão provenientes do núcleo dessa galáxia que indicassem a presença de um LINER, ao contrário do que é afirmado na literatura. É possível que a classificação desse objeto como LINER tenha sido devida à detecção, em observações long-slit da região central de M31, de linhas de emissão não provenientes exatamente do núcleo, mas sim de outras áreas próximas. De fato, algumas regiões emissoras, afastadas do núcleo, detectadas por del Burgo et al. (2000) possuem linhas de emissão cujas razões de intensidade são compatíveis com as de um LINER. A síntese espectral com o Starlight mostrou que a região interna do bojo dessa galáxia apresenta populações estelares com idade próxima a $10^{10}$ anos e média e alta metalicidade. Tanto a Tomografia PCA do cubo de dados de M31 com o contínuo estelar quanto os mapeamentos da velocidade radial estelar obtidos a partir da síntese espectral com o Starlight e do processo do pPXF revelaram claramente presença de um disco estelar em rotação ao redor do núcleo. Isso está de acordo com os resultados obtidos nos trabalhos de Bacon et al. (1994; 2001) e del Burgo et al. (2000). Uma modelagem da cinemática desse disco estelar forneceu um valor para a massa do buraco negro

central de $M_{b h}=4.5_{-1.1}^{+0.1} \cdot 10^{7} \mathrm{M}_{\odot}$, o que é compatível, em 2- $\sigma$, com a medição feita por Salow \& Statler (2004) $\left(5.62 \pm 0.66 \cdot 10^{7} \mathrm{M}_{\odot}\right)$, que corresponde ao estudo mais detalhado da cinemática estelar na região central de M31 feito até o momento. A Tomografia PCA no cubo de dados de 
M31 com o contínuo estelar subtraído evidenciou a presença de um disco com algumas linhas de emissão (como H $\alpha, H \beta$ e C III 26872) em rotação ao redor do núcleo. Esse resultado é inédito para essa galáxia e, consequentemente, bastante relevante. Um mapeamento dos valores da velocidade radial da linha $\mathrm{H} \alpha$ permitiu uma análise mais detalhada desse disco emissor de linhas. Uma modelagem cinemática desse mapa de velocidades de $\mathrm{H} \alpha$ resultou em $M_{b h}=$ $5.0_{-1.0}^{+0.3} \cdot 10^{7} \mathrm{M}_{\odot}$, que é compatível, em 1- $\sigma$, com o que foi encontrado por Salow \& Statler (2004). Os dois valores aqui obtidos para a massa do buraco negro central são compatíveis um com o outro em 1- $\sigma$ e também estão na faixa de valores encontrados em vários estudos da cinemática estelar na região central de M31 (Kormendy 1988; Dressler \& Richstone 1988; Peiris \& Tremaine 2003; Bender et al. 2005; Bacon et al. 2001). A detecção de um disco com linhas de emissão em rotação ao redor do núcleo dessa galáxia forneceu uma maneira independente para se determinar a massa do buraco negro central existente, logo, essa descoberta possui uma considerável importância nos estudos desse objeto. 
554 


\section{2 - Conclusões}

As aplicações da Tomografia PCA nesse trabalho revelaram uma fenomenologia bastante diversificada nos cubos de dados analisados. Em todas as galáxias (exceto M31), a emissão proveniente do AGN central pôde ser consideravelmente bem visualizada por essa metodologia, sendo que, em alguns casos (como NGC 2992, NGC 4151, NGC 3227 e M104), componentes largas de algumas linhas de emissão foram claramente detectadas. Sem dúvida, uma das maiores utilidades da Tomografia PCA nesse trabalho foi a detecção de uma série de fenômenos cinemáticos associados ao gás ou às estrelas dos bojos. Uma clara rotação de um disco estelar ao redor do núcleo, por exemplo, foi observada em M104 (no óptico e no infravermelho) e M31, ao passo que uma aparente rotação de gás foi detectada em NGC 3227 no infravermelho (para gás molecular) e em M104 no óptico (para gás ionizado). Em NGC 1068, toda a cinemática do gás observada estava provavelmente relacionada à NLR do objeto. Nos casos de NGC 2992 e NGC 3227 no óptico, o que se observou foram características cinemáticas do gás (molecular ou ionizado), em um mesmo autovetor, associadas a provavelmente mais de um fenômeno cinemático (como uma rotação e um outflow), o que tornou difícil a diferenciação de tais fenômenos. Os resultados da Tomografia PCA relacionados à cinemática do gás em NGC 4151 e NGC 5643, por outro lado, foram consideravelmente peculiares. Em NGC 4151, foram encontradas evidências, em autovetores separados, tanto de outflows quanto de uma rotação ao redor do núcleo. Em NGC 5643, observou-se uma cinemática associada ao cone de ionização do objeto e, em um diferente autovetor, uma rotação de gás molecular ao redor do núcleo e um possível fluxo de gás também molecular. Apesar desses dois últimos fenômenos estarem sobrepostos em um mesmo autovetor, foi possível diferenciá-los razoavelmente. Outro importante uso da Tomografia PCA evidenciado nesse trabalho foi a detecção de diferenciais de inclinação nos espectros dos cubos de dados. No infravermelho, essa função da Tomografia PCA possibilitou separar regiões com o fluxo dominado pela emissão térmica de poeira (com espectros mais avermelhados) de áreas com o fluxo devido, principalmente, a populações estelares presentes (com espectros mais azulados). Em todos os casos, a emissão térmica de

poeira foi detectada principalmente na região correspondente ao AGN central, indicando a existência de um possível toro de poeira, o que estaria de acordo com o Modelo Unificado. Os 
diferenciais de inclinação dos espectros do cubo de dados de M31 no óptico detectados pela Tomografia PCA revelaram possíveis áreas com um maior avermelhamento, provavelmente causado por nuvens de poeira presentes. Ainda no que se refere à capacidade da Tomografia PCA de revelar diferenciais de inclinações dos espectros, pode-se dizer que o resultado obtido na análise do cubo de dados de M104 no óptico com o contínuo estelar foi bastante relevante. Foram observadas áreas com espectros mais azulados e com uma componente larga da linha $\mathrm{H} \alpha$ afastadas da posição correspondente ao AGN central. Isso foi interpretado como sendo devido a um espalhamento da emissão do AGN por poeira ao seu redor. As aplicações da Tomografia PCA aos cubos de dados analisados nesse trabalho também foram capazes de separar regiões com diferentes graus de ionização. No infravermelho, foi possível diferenciar áreas com maior ionização, normalmente associadas às NLRs dos AGNs, de regiões menos ionizadas, com uma emissão geralmente dominada por $\mathrm{H}_{2}$. Em NGC 4151, por exemplo, foram observadas nuvens de mais alta ionização ao longo do cone de ionização do AGN (que, na verdade, possui a forma de um bi-cone) e também áreas com uma considerável emissão de $\mathrm{H}_{2}$, que chegam a formar três possíveis canais de alimentação do AGN. Em NGC 5643, a Tomografia PCA pôde separar a emissão provavelmente associada ao cone de ionização daquela proveniente de áreas emissoras de $\mathrm{H}_{2}$ que, aparentemente, dão origem a uma estrutura em rotação ao redor do AGN (talvez um toro molecular). Em NGC 3227, foi detectada uma faixa emissora de $\mathrm{H}_{2}$ em rotação ao redor do núcleo que pode constituir um toro molecular ao redor do AGN. Em M104, observou-se uma considerável emissão de $\mathrm{H}_{2}$ ao longo de uma região correspondente à parte interna do disco dessa galáxia. Por fim, em M87, foi detectada uma pequena região relativamente próxima ao AGN central, com uma linha de emissão com uma considerável componente larga. Essa área jamais havia sido observada em estudos anteriores. Supondo-se que a linha de emissão observada seja Bry em blueshift, foi proposto que a região emissora detectada corresponda a um segundo AGN em interação gravitacional com o AGN principal. É possível que esse segundo AGN seja o que restou de uma galáxia canibalizada por M87. No óptico, a Tomografia PCA de M31 revelou uma região, com tamanho inferior à resolução espacial da observação, com um espectro de emissão de mais alta ionização (essencialmente, a única área com linhas de emissão razoavelmente intensas no cubo de dados de M31). As razões de linhas dessa região emissora são compatíveis com as de uma nebulosa planetária. 
A síntese espectral com o Starlight nos cubos de dados no infravermelho foi capaz de detectar consideravelmente bem regiões com o fluxo devido às populações estelares, à emissão térmica de poeira e ao featureless continuum. Em todas as galáxias analisadas, foi observada emissão térmica de poeira na área correspondente ao AGN, o que pode indicar que a poeira emissora está associada a um toro ao redor do AGN. Em vários casos (NGC 2992, NGC 4151, NGC 5643), a região com emissão térmica de poeira apresentou um tamanho aparente inferior à resolução espacial da observação. Entretanto, no cubo de dados de NGC 3227 no infravermelho, verificou-se que a poeira emissora está disposta em áreas com estruturas claramente visíveis. Foi possível separar, inclusive, regiões com poeira com temperaturas entre $700 \mathrm{~K}$ e $1000 \mathrm{~K}$ de áreas com poeira com temperaturas entre $1100 \mathrm{~K}$ e $1400 \mathrm{~K}$. Com base nisso e em outras características observadas no cubo de dados desse objeto, foi proposto que a região com poeira mais quente corresponde a um toro de poeira ao redor do AGN. Esse toro, entretanto, representa apenas a parte interna de uma estrutura maior emissora de $\mathrm{H}_{2}$, com rotação ao redor do núcleo, que poderia ser chamada de toro molecular. A área com poeira mais fria por outro lado, está associada ao cone de ionização do AGN dessa galáxia. O mapeamento do fluxo devido ao featureless continuum em NGC 3227, obtido com a síntese espectral com o Starlight, parece ser compatível com a ocorrência de um espalhamento causado pelo toro de poeira mencionado anteriormente. Todo esse cenário está de acordo com o previsto pelo Modelo Unificado. Em M87, observou-se que a região com emissão térmica de poeira parece se estender ao longo de uma direção perpendicular ao jato existente, o que, sem dúvida, parece compatível com a idéia de um toro. Entretanto, não se pode tirar conclusões muito significativas nesse caso, pois a área com emissão de poeira possui um tamanho aparente muito próximo à resolução espacial da observação, o que tornou difícil uma observação detalhada. Nesse mesmo objeto, foi detectada emissão térmica de poeira na região correspondente ao nó do jato visível no campo visual do NIFS. Além disso, alguma emissão térmica de poeira também foi observada numa área diametralmente oposta ao nó do jato em questão. Isso pode ser um indicativo de que essa segunda detecção esteja associada ao segundo jato de M87 (no sentido oposto ao do observador). Tal resultado possui uma importância considerável, já que um segundo jato jamais foi observado em estudos anteriores dessa galáxia. Em NGC 2992, não foi detectado featureless continuum na posição correspondente ao $\mathrm{AGN}$, mas apenas ao seu redor, o que pode ser uma evidência de espalhamento por poeira. Em M87, o featureless continuum observado parece se 
estender ao longo de duas regiões aproximadamente perpendiculares ao suposto toro de poeira mencionado anteriormente, o que também constitui um indício de espalhamento do contínuo emitido pelo AGN pela poeira presente no toro. Por fim, em NGC 5643, praticamente não foi detectado featureless continuum do AGN. Três possíveis explicações podem ser propostas para isso: uma é que o featureless continum sofre um forte obscurecimento por poeira, tornando difícil a sua detecção. Outra explicação é que o featureless continuum não pode ser detectado devido ao "ofuscamento" pela emissão térmica de poeira. Além disso, também é possível que o featureless continuum existente possua um índice espectral diferente do valor 1.5, utilizado nas sínteses espectrais. No óptico, as aplicações da síntese espectral com o Starlight revelaram informações bastante relevantes associadas às populações estelares presentes. Em M104, verificou-se que a maior parte do fluxo no cubo de dados é devido a populações estelares velhas, com idade de cerca de $1.2 \cdot 10^{10}$ anos, e alta metalicidade. Entretanto, também foi detectado um fluxo considerável associado a populações estelares jovens, com idade próxima a $7.7 \cdot 10^{6}$ anos, e alta metalicidade. A síntese espectral do cubo de dados de M104 no óptico evidenciou, ainda, a presença de um featureless continuum em áreas consideravelmente afastadas. Isso indica um espalhamento do contínuo emitido pelo AGN por poeira, o que está de acordo com os resultados obtidos com a Tomografia PCA desse cubo de dados, mencionados anteriormente. Em M31, constatou-se que a maior parte do fluxo no cubo de dados é proveniente de populações estelares velhas, com idade de cerca de $10^{10}$ anos, e com metalicidades $Z=0.008$ e $Z=0.05$. Finalmente, em NGC 1068, a síntese espectral com o Starlight mostrou que a maior parte do fluxo é devida a populações estelares com idade próxima a $1.4 \cdot 10^{9}$ anos e média metalicidade. Também foi constatado que o featureless continuum nessa galáxia se estende ao longo da direção correspondente ao jato em rádio (e perpendicular ao toro de poeira), o que, sem dúvida, sugere a ocorrência de um espalhamento do contínuo do AGN pela poeira no toro.

A subtração do contínuo estelar a partir dos espectros sintéticos fornecidos pelo Starlight, em alguns casos, possibilitou que fenômenos menos intensos, e muitas vezes indetectáveis, relacionados ao espectro de emissão dos objetos fossem observados. No caso de NGC 1068, por exemplo, a subtração do contínuo estelar permitiu que uma componente larga da linha $\mathrm{H} \alpha$, jamais detectada anteriormente sem o uso de polarimetria, fosse observada. Em M31, a subtração do contínuo estelar revelou a existência de fracas linhas de emissão (H $\alpha, \mathrm{H} \beta$ e 
C III 26872) em áreas ao redor do núcleo. A aplicação da Tomografia PCA ao cubo de dados de M31 com o contínuo estelar subtraído mostrou que essas linhas de emissão são emitidas por um disco em rotação ao redor do núcleo. Uma inspeção minuciosa do cubo de dados revelou resquícios de algumas outras linhas de emissão (como [O III] $\lambda 5007$, [N II] $\lambda 6583$ e [S II] $\lambda \lambda 6716 ; 6731)$, o que sugere que esse disco em rotação pode ser gasoso. Entretanto, não se pode descartar a hipótese de que, pelo menos, parte dessa emissão de linhas seja devida a estrelas. De qualquer forma essa descoberta possui uma considerável importância, já que um disco com linhas de emissão ao redor do núcleo de M31 jamais havia sido detectado.

Com relação à cinemática estelar, pode-se dizer que a aplicação do processo do pPXF revelou a existência de uma aparente rotação estelar ao redor do núcleo em todos os casos analisados, exceto M87. Em NGC 2992, NGC 4151 e NGC 3227 no infravermelho, entretanto, não foi possível fazer qualquer modelagem com o objetivo de se determinar a massa do buraco negro central, devido às irregularidades e regiões com valores pouco confiáveis nos mapeamentos da velocidade radial. Um problema que pôde ser observado nos quatro casos mencionados foi a presença de valores de velocidades imprecisos na posição correspondente ao AGN central. Isso pode ser explicado pelo fato de que, nessa área, o contínuo era dominado pela emissão térmica de poeira e as bandas de CO praticamente não eram detectáveis. Como os ajustes com o pPXF se basearam, essencialmente, nas bandas de CO (que são as estruturas espectrais provenientes de absorção estelar mais relevantes nessa faixa espectral), eles acabaram sendo prejudicados nessa região do cubo, gerando resultados não confiáveis. No óptico de NGC 3227 e em NGC 1068, também não foi possível fazer modelagens para se determinar a massa do buraco negro central, devido às irregularidades presentes nos mapas de velocidades. Analogamente ao que se observou nas análises no infravermelho, nesses dois casos os valores das velocidades na posição do AGN foram imprecisos. Entretanto, é provável que, nesses objetos, esse problema tenha sido causado pelo fato de a própria emissão do AGN (incluindo o featureless continuum e as linhas espectrais) ter "ofuscado" as linhas de absorção estelares necessárias para o ajuste com o pPXF, o que gerou valores de velocidade incorretos. Em NGC 5643, a rotação estelar detectada apresentou detalhes suficientes para que fosse elaborada uma modelagem, com o método de Jeans, para se determinar a massa do buraco negro $\left(M_{b h}\right)$. Nesse caso, entretanto, verificou-se que o valor de $M_{b h}$ era muito pequeno quando comparado à massa estelar, o que fez com que o mapa de velocidades pudesse ser consideravelmente bem 
simulado sem que qualquer massa fosse atribuída para o buraco negro. Nessa simulação, verificou-se que o disco estelar possui uma inclinação de $i=55 \pm 5^{\circ}$. Pôde-se estimar um limite superior para $M_{b h}$ aumentando-se progressivamente o valor da massa do buraco negro nas simulações, com todos os demais parâmetros constantes (e iguais aos obtidos na melhor simulação com $M_{b h}=0$ ). Ao final, obteve-se $M_{b h_{-} \text {sup }}=4.0 \cdot 10^{7} \mathrm{M}_{\odot}$. Em M104, a rotação estelar observada nos dados no óptico e no infravermelho também foi suficientemente detalhada para que modelagens com o método de Jeans pudessem ser feitas. No óptico, os parâmetros correspondentes ao melhor modelo obtido para o disco estelar foram $i=82.0 \pm 1.2^{\circ}$ e $M_{b h}=$ $(2.0 \pm 0.8) \cdot 10^{8} \mathrm{M}_{\odot}$. No infravermelho, por sua vez, os parâmetros do melhor modelo foram $i=$ $82.0 \pm 0.5^{\circ}$ e $M_{b h}=(1.0 \pm 0.2) \cdot 10^{8} \mathrm{M}_{\odot}$. Pode-se notar que esses resultados são compatíveis uns com os outros, em 1- $\sigma$. Por fim, em M31, o mapeamento da velocidade radial estelar revelou uma rotação estelar bastante clara, o que favoreceu uma modelagem. Nesse caso, entretanto, as simulações foram feitas utilizando-se equações keplerianas básicas e a massa estelar presente foi desprezada. Os parâmetros obtidos para o disco estelar ao redor do núcleo dessa galáxia, levando-se em conta a massa estelar desprezada, foram: $M_{b h}=4.5_{-1.1}^{+0.1} \cdot 10^{7} \mathrm{M}_{\odot}, i=55 \pm 1^{\mathrm{o}}, e=$ $0.30 \pm 0.06$ e $\omega=250 \pm 6^{\circ}$.

No que se refere à cinemática do gás molecular (obtida a partir de dados no infravermelho), detectou-se uma considerável complexidade nos mapas de velocidades de NGC 2992, NGC 4151 e NGC 5643, com a provável presença de mais de um fenômeno cinemático (como uma rotação e um outflow, por exemplo). Isso fez com que não fosse possível elaborar quaisquer modelagens nesses casos. A cinemática do gás ionizado observada em NGC 4151, NGC 3227 no óptico e M104 no óptico também foi relativamente complexa (com a possível presença de mais de um fenômeno cinemático), apesar de, no último caso, uma rotação ao redor do núcleo ser razoavelmente clara. Isso também acarretou na impossibilidade de se fazer modelagens para esse cubos de dados, com o objetivo de se determinar a massa do buraco negro central. Em NGC 3227 no infravermelho, embora tenham sido detectados indícios de outflows, uma clara rotação do gás molecular era bastante evidente. Mesmo assim, as imprecisões e irregularidades do mapa de velocidades em questão tornaram impossível a elaboração de modelagens. Também não foi feita qualquer simulação da cinemática do gás ionizado em NGC 1068, já que não foi observada nenhuma rotação ao redor do núcleo (mas apenas uma cinemática associada à NLR do AGN dessa galáxia) no cubo de dados desse objeto. 
Finalmente, em M31, o mapa de velocidades da linha de emissão $\mathrm{H} \alpha$ revelou uma rotação ao redor do núcleo suficientemente detalhada para que fosse feita uma modelagem. Analogamente ao que foi feito no caso da rotação estelar, todas as simulações foram elaboradas utilizando-se equações keplerianas básicas e desprezando-se a massa estelar presente. Ao final, os parâmetros obtidos para o disco com linhas de emissão, levando-se em conta a massa estelar desprezada, foram: $M_{b h}=5.0_{-1.0}^{+0.3} \cdot 10^{7} \mathrm{M}_{\odot}, i=45 \pm 4^{\mathrm{o}}, e=0.35 \pm 0.03$ e $\omega=115 \pm 5^{\circ}$. Pode-se notar que os valores de $M_{b h}$ obtidos a partir dos discos estelar e com linhas de emissão ao redor do núcleo de M31 são compatíveis em 1- $\sigma$. Os parâmetros $e$ e $i$ encontrados com essas duas simulações, por sua vez, são compatíveis em $1-\sigma$ e $2-\sigma$, respectivamente. Isso revela que a excentricidade e a inclinação do disco estelar na região central de M31 são similares às do disco com linhas de emissão. Os valores obtidos nessas simulações para $\omega$, por outro lado, são totalmente discrepantes, o que representa uma diferença considerável entre os discos em questão. Mais uma vez é importante lembrar que não é possível afirmar com segurança se o disco com linhas de emissão na região central de M31 é gasoso ou, pelo menos em parte, originado por emissão estelar. De qualquer forma, a sua descoberta representou uma maneira independente para se determinar a massa do buraco negro central nessa galáxia. Um ponto relevante a ser mencionado aqui é que, embora M31 tenha sido classificada como LINER, nenhuma das análises aqui aplicadas nessa galáxia revelou qualquer emissão desse tipo. É possível que a classificação desse objeto como LINER tenha sido devida à detecção, em observações long-slit da região central de M31, de linhas de emissão não provenientes exatamente do núcleo, mas sim de outras áreas próximas, o que gerou uma classificação errônea desse objeto.

$\mathrm{O}$ estudo das razões de linhas de $\mathrm{H}_{2}$ no infravermelho revelou que a aproximação de ETL parece não ser válida na maior parte das regiões espaciais dos cubos de dados analisados (NGC 2992, NGC 4151, NGC 3227, NGC 5643). Nas áreas onde o ETL é uma boa aproximação, as temperaturas de excitação mais elevadas obtidas para o gás são compatíveis com um aquecimento das nuvens moleculares por raios-X provavelmente emitidos pelo AGN central. Em M104 no óptico, a simulação feita com o software Cloudy mostrou que a fotoionização por um AGN é capaz de explicar as razões de linhas de emissão observadas na região mais central do cubo de dados. Os melhores modelos encontrados para reproduzir as razões de linhas envolveram um featureless continuum com índice espectral igual a -1.5 , cortes inferiores de energia no contínuo entre $22 \mathrm{eV}$ e $26 \mathrm{eV}$ e parâmetros de ionização entre $10^{-3.9}$ e 
$10^{-3.6}$. Esses cortes de energia no contínuo poderiam ser gerados por uma absorção por gás e poeira nas regiões mais próximas ao núcleo da galáxia (como a BLR e um possível toro de poeira, por exemplo). Nesse caso, os fótons com energia inferior a esses cortes seriam absorvidos e apenas os mais energéticos atingiriam a NLR, cujas razões de linhas foram reproduzidas na simulação com o Cloudy.

Um aspecto extremamente importante desse trabalho foi a utilização de uma série de metodologias de tratamento e análise de dados. Sem isso, é provável que a qualidade das análises tivesse sido consideravelmente inferior. É possível, inclusive, que parte dos resultados relevantes mostrados anteriormente nem tivessem sido obtidos. Alguns dos cubos de dados estudados nesse trabalho (NGC 2992, NGC 4151 e NGC 3227 no infravermelho) também foram analisados por outros autores, entretanto, as metodologias aqui utilizadas possibilitaram a obtenção de resultados de melhor qualidade e até mesmo não detectados anteriormente.

É importante mencionar que várias análises mostradas ao longo desse trabalho podem ser mais aprofundadas em trabalhos futuros. A síntese espectral no infravermelho, por exemplo, poderia gerar resultados mais detalhados em relação às populações estelares detectadas se fosse feita ao longo de uma maior extensão espectral (incluindo as bandas J, H e K, por exemplo) e, possivelmente, com uma base de espectros mais confiável do que a utilizada nesse trabalho. A aplicação da síntese espectral no infravermelho em maiores extensões espectrais também poderia permitir, em princípio, detectar emissões térmicas associadas à poeira com diferentes temperaturas. A análise da cinemática estelar e do gás nos arredores dos núcleos das galáxias pode ser bastante refinada. A utilização de métodos mais robustos, como o método de Schwarzschild, por exemplo, poderia permitir que a cinemática estelar fosse reproduzida com maiores detalhes. Mesmo o método que envolve, apenas, um disco excêntrico em rotação redor do buraco negro central (que foi um dos métodos utilizados nesse trabalho) poderia ser aprimorado, levando em conta, por exemplo, órbitas com diferentes inclinações e excentricidades. Por fim, as simulações da cinemática do gás poderiam ser aplicadas em um número bem maior de situações, se fossem considerados fenômenos cinemáticos não keplerianos, como outflows, por exemplo. 


\section{Referências Bibliográficas}

Adams, T. F. 1977, ApJS, 33, 19

Antonucci, R. 1993, ARA\&A, 31, 473

Antonucci, R. R. J. \& Miller, J. S. 1985, ApJ, 297, 621

Arribas, S. \& Mediavilla, E. 1994, ApJ, 437, 149

Arribas, S., Mediavilla, E. \& Garcia-Lorenzo, B. 1996, ApJ, 463, 509

Axon, D. J., Marconi, A., Capetti, A., Maccetto, F. D., Schreier, E. \& Robinson, A. 1998, ApJ, 496, L75

Bacon, R., Emsellem, E., Combes, F., Copin, Y., Monnet, G. \& Martin, P. 2001, A\&A, 371,409

Bacon, R., Emsellem, E., Monnet, G. \& Nieto, J. L. 1994, A\&A, 281, 691

Baldwin, J. A., Phillips, M. M. \& Terlevich, R. 1981, PASP, 93, 5

Bajaja, E., Dettmar, R. J., Hummel, E. \& Wielbinski, R. 1988, A\&A, 202, 35

Barbosa, F. K. B., Storchi-Bergmann, T., Cid Fernandes, R., Winge, C. \& Schmitt, H. 2006, MNRAS, 371, 170

Barbosa, F. K. B., Storchi-Bergmann, T., Cid Fernandes, R., Winge, C. \& Schmitt, H. 2009, MNRAS, 396, 2

Barrel, H. 1951, Journal of the Optical Society of America (1917-1983), 41, 295

Barthel, P. D. 1989, ApJ, 336, 606

Barvainis, R. 1987, ApJ, 320. 537

Bassani, L., Dadina, M., Maiolino, R., Salvat, M., Risalti, G., Della Ceca, R., Matt, G. \& Zamorani, G. 1999, ApJS, 121, 473

Batcheldor, D., Robinson, A., Axon, D. J., Perlman, E. S. \& Merritt, D. 2010, ApJ, 717, L6

Beaton, R. L., Majewski, S. R., Guhathakurta, P., Skrutskie, M. F., Cutri, R. M., Good, J., Patterson, R. J., Athanassoula, E. \& Bureau, M. 2007, AJ, 658, L91

Beckmann, V., Barthelmy, S. D., Courvoisier, T. J. -L., Gehrels, N., Soldi, S., Tueller, J. \& Wendt, G. 2007, A\&A, 475, 827 
Bender, R., Kormendy, J., Bower, G., Green, R., Thomas, J., Danks, A. C., Gull, T., Hutchings, J. B., Joseph, C. L., Kaiser, M. E., Lauer, T. R., Nelson, C. H., Richstone, D., Weistrop, D. \& Woodgate, B. 2005, ApJ, 631, 280

Bendo, G. J., Buckalew, B. A., Dale, D. A., Draine, B. T., Joseph, R. D., Kennicutt Jr, R. C., Sheth, K., Smith, J. D. T., Walter, F., Calzetti, D., Cannon, J. M., Engelbracht, C. W., Gordon, K. D., Helou, G., Hollenbach, D., Murphy, E. J. \& Roussel, H. 2006, ApJ, 645, 134

Bertola, F., Bressan, A., Burstein, D., Buson, L. M., Chiosi, C. \& di Serego Alighieri, S. 1995, ApJ, 438, 680

Bianchi, S., Matt, G. \& Iwasawa, K. 2001, MNRAS, 322, 669

Bicknell, G. V. Dopita, M. A. Tsvetanov, Z. I. \& Sutherland, R. S. 1998, ApJ, 495, 680

Binette, L., Magris, C. G., Stasinska, G. \& Bruzual, A. G. 1994, A\&A, 292, 13

Binney J. \& Tremaine S. D. 1987, Galactic Dynamics, Princeton Univ. Press, Princeton, NJ

Black, J. H. \& van Dishoeck, E. F. 1987, ApJ, 322, 412

Blandford, R. \& Eichler, D. 1987, PhR, 154, 1

Blitz, L., Mathieu, R. D. \& Bally, J. 1986, ApJ, 311, 142

Brand, P. W. J. L., Toner, M. P., Geballe, T. R., Webster, A. S., Williams, P. M. \& Burton, M. G. 1989, MNRAS, 236, 929

Cappellari, M. 2002, MNRAS, 333, 400

Cappellari, M. 2008, MNRAS, 390, 71

Cappellari, M. \& Emsellem, E. 2004, PASP, 116, 138

Cardelli, J. A., Clayton, G. C. \& Mathis, J. S. 1989, ApJ, 345, 245

Carral, P., Turner, J. L. \& Ho, P. T. P. 1990, ApJ, 362, 434

Cecil, G., Bland, J. \& Tully, R. B. 1990, ApJ, 355, 70

Cecil, G., Dopita, M. A., Groves, B., Wilson, A. S., Ferruit, P., Pécontal, E. \& Binnette, L. 2002, ApJ, 568, 627

Chapman, S. C., Morris, S. L., Alonso-Herrero, A. \& Falcke, H. 2000, MNRAS, 314, 263

Chapman, S. C., Morris, S. L. \& Walker, G. A. H. 2000, MNRAS, 319, 666

Ciardullo, R., Rubin, V. C., Jacoby, G. H., Ford, H C. \& Ford, W. K. Jr. 1988, AJ, 95, 438 
Cid Fernandes, R., Mateus, A., Sodré, L., Stasinska, G. \& Gomes, J. M. 2005, MNRAS, 358,363

Code, A. D., Meade, M. R., Anderson, C. M., Nordsieck, K. H., Clayton, G. C., Whitney, B. A., Magalhaes, A. M., Babler, B., Bjorkman, K. S., Schulte-Ladbeck, R. E. \& Taylor, M. 1993, ApJ, 403, L63

Cohen, R. D. 1983, ApJ, 273, 489

Colbert, E. J. M., Baum, S. A., O’Dea, C. P. \& Villeux, S. 1998, ApJ, 496, 786

Coleman, C.D., Bozman, W.R. \& Meggers, W.F. 1960, Table of Wave numbers, Washington, U.S. Dept. of Commerce, National Bureau of Standards

Colina, L., Fricke, K. J., Kollatschny, W. \& Perryman, M. A. C. 1987, A7A, 178, 51

Crane, P. C., Dickel, J. R. \& Cowan, J. J. 1992, ApJ, 390, L9

Crane, P. C., Cowan, J. J., Dickel, J. R. \& Roberts, D. A. 1993, ApJ, 417, L61

Crenshaw, D. M. \& Kraemer, S. B. 2000a, ApJ, 532, L101

Crenshaw, D. M. \& Kraemer, S. B. 2000b, ApJ, 532, 247

Crenshaw, D. M., Kraemer, S. B., Hutchings, J. B., Bradley II, J. D., Gull, T. R., Kaiser, M. E., Nelson, C. H., Ruiz, J. R. \& Weistrop, D. 2000, ApJ, 120, 1731

Das, V., Crenshaw, D. M., Hutchings, J. B., Deo, R. P., Kraemer, S. B., Gull, T. R., Kaiser, M. E., Nelson, C. H. \& Weistrop, D. 2005, ApJ, 130, 945

Das, V., Crenshaw, D. M., Kraemer, S. B. \& Deo, R. P. 2006, ApJ, 132, 620

Davies, E. D. 1973, MNRAS, 161, 25

Davies, R. I., Müller Sánchez, F., Genzel, R., Tacconi, L. J., Hicks, E. K. S., Friedrich, S. \& Sternberg, A. 2007, ApJ, 671, 1388

Davies, R. I., Thomas, J., Genzel, R., Müller, S. F., Tacconi, L. J., Sternberg, A., Eisenhauer, F., Abuter, R., Saglia, R. \& Bender, R. 2006, ApJ, 646, 754

Decaux, V., Beiersdorfer, P., Kahn, S. M. \& Jacobs, V. L. 1997, ApJ, 482, 1076

del Burgo, C., Mediavilla, E. \& Arribas, S. 2000, 540, 741

Di Matteo, T. Allen, S. W., Fabian, A. C., Wilson, A. S. \& Young, A. J. 2003, ApJ, 582, 133

Dopita, M. A., Koratkar, A. P., Evans, I. N., Allen, M., Bicknell, G. V., Sutherland, R. S., Hawley, J. F. \& Sadler, E. 1996, ASPC, 103, 44 
Dopita, M. A. \& Sutherland, R. S. 1995, ApJ, 455, 468

Dopita, M. A. \& Sutherland, R. S. 1996, ApJS, 102, 161

Draine, B. T. \& Lee, H. M. 1984, ApJ, 285, 89

Draine, B. T. \& Woods, D. T. 1990, ApJ, 363, 464

Dressler, A. 1980, ApJ, 240, L11

Dressler, A. \& Richstone, D. O. 1988, ApJ, 324, 701

Edelson, R. A. \& Malkan, M. A. 1986, ApJ, 308, 59

Edlén, B. 1953, Journal of the Optical Society of America (1917-1983), 43, 339

Elitzur, M. 2007, ASPC, 373, 415

Elitzur, M. 2008, NewAR, 52, 274

Elvis, M. \& Lawrence, A. 1988, ApJ, 331, 161

Emsellem, E., Bacon, R., Monnet, G. \& Poulain, P. 1996, A\&A, 312, 777

Emsellem, E., Fathi, K., Wozniak, H., Ferruit, P. Mundell, C. G. \& Schinnerer, E. 2006, MNRAS, 365, 367

Emsellem, E., Monnet, G. \& Bacon, R. 1994, A\&A, 285, 723

Emsellem, E., Monnet, G., Bacon, R. \& Nieto, J. L. 1994, A\&A, 285, 739

Evans, I. N., Ford, H. C., Kinney, A. L., Antonucci, R. R. J., Armus, L. \& Caganoff, S. 1991, ApJ, 369, L27

Evans, I. N., Tsvetanov, Z., Kriss, G. A., Ford, H. C., Caganoff, S. \& Koratkar, A. P. 1993, ApJ, 417, 82

Fabbiano, G. \& Juda, J. Z. 1997, ApJ, 476, 666

Fabbiano, G., Kim, D. W. \& Trinchieri, G. 1992, ApJS, 80, 531

Fanaroff, B. L. \& Riley, J. M. 1974, MNRAS, 167, 31

Ferland, G. J. \& Netzer, H. 1983, ApJ, 264, 105

Fermi, E. 1949, PhRv, 75, 1169

Francis, P. J., Hewett, P. C., Foltz, C. B., Chaffee, F. H., Weymann, R. J. \& Morris, S. L. 1991, ApJ, 373, 465

Friedrich, S., Davies, R. I., Hicks, E. K. S., Engel, H., Müller-Sánchez, F., Genzel, R. \& Tacconi, L. J. 2010, 519, 79 
Fukunaga, K. 1990, Statistical Pattern Recongnition $-2^{\text {nd }}$ ed., Academic Press Inc

Galliano, E., Pantin, E., Alloin, D. \& Lagage, P. O. 2005, MNRAS, 363, L1

Gallimore, J. F., Henkel, C., Baum, S. A., Glass, I. S., Claussen, M. J., Prieto, M. A. \& Von Kap-Herr, A. 2001, ApJ, 556, 694

Garcia, M. R., Williams, B. F., Yuan, F., Kong, A. K. H., Primini, F. A., Barmby, P., Kaaret, P. \& Murray, S. S. 2005, ApJ, 632, 1042

Gebhardt, K., Adams, J., Richstone, D., Lauer, T. R., Faber, S. M., Gültekin, K., Murphy, J. \& Tremaine, S. 2011, ApJ, 729, 119

George, I. M., Mushotzky, R., Turner, T. J., Yaqoob, T., Ptak, A., Nandra, K. \& Netzer, H. 1998, ApJ, 509, 146

Gerhard, O. E. 1993, MNRAS, 265, 213

Gerhard, O. E. \& Binney, J. J. 1996, MNRAS, 279, 993

Glass, I. S. 1997, MNRAS, 292, L50

Gonzalez, R.C. \& Woods, R.E. 2002, Digital Image Processing - $2^{\text {nd }}$ ed., Prentice-Hall Inc

Granato, G. L. \& Danese, L. 1994, MNRAS, 268, 235

Granato, G. L., Danese, L. \& Franceschini, A. 1997, ApJ, 486, 147

Guainazzi, M., Matt, G., Antonelli, L. A., Bassani, L. Fabian, A. C., Maiolino, R., Marconi, A., Fiore, F. Iwasawa, K. \& Piro, L. 1999, MNRAS, 310, 10

Haardt, F. \& Maraschi, L. 1993, ApJ, 413, 507

Halpern, J. P. \& Steiner, J. E. 1983, ApJ, 269, L37

Hao, L., Strauss, M. A., Fan, X., Tremonti, C. A., Schlegel, D. J., Heckman, T. M., Kauffmann, G., Blanton, M. R., Gunn, J. E., Hall, P. B., Ivezic, Z., Knapp, G. R., Krolik, J. H., Lupton, R. H., Richards, G. T., Schneider, D. P., Strateva, I. V., Zakamska, N. L., Brinkmann, J. \& Szokoly, G. P. 2005, AJ, 129, 1795

Harms, R. J., Ford, H. C., Tsvetanov, Z. I., Hartig, G. F., Dressel, L. L., Kriss, G. A., Bohlin, R., Davidsen, A. F., Margon, B. \& Kochhar, A. K. 1994, ApJ, 435, L35

Heckman, T. M. 1978, PASP, 90, 24

Heckman, T. M. 1980, A\&A, 87, 152

Heckman, T. M. 1996, ASP Conf. Ser., 103, 241

Heckman, T. M., Armus, L. \& Miley, G. K. 1990, ApJS, 74, 833 
Heckman, T. M., Butcher, H. R., Miley, G. K. \& van Breugel, W. J. M. 1981, ApJ, 247, 403

Hilditch, R. W. 2001, An Introduction to Close Binary Stars, Cambridge University

Press

Ho, L. C. 2008, ARA\&A, 46, 475

Ho, L. C., Filippenko, A. V. \& Sargent, W. L. W. 1995, ApJS, 98, 477

Ho, L. C., Filippenko, A. V. \& Sargent, W. L. W. 1997, ApJS, 112, 315

Huchra, J. \& Burg, R. 1992, ApJ, 393, 90

Hummel, E., van der Hulst, J. M. \& Dickey, J. M. 1984, A\&A, 134, 207

Hutchings, J. B., Crenshaw, D. M., Kaiser, M. E., Kraemer, S. B., Weistrop, D., Baum, S., Bowers, C. W., Feinberg, L. D., Green, R. F., Gull, T. R., Hartig, G. F., Hill, G. \& Lindler, D. J. 1998, ApJ, 492, L115

Iwasawa, K., Fabian, A. C. \& Matt, G. 1997, MNRAS, 289, 443

Jaffe, W., Meisenheimer, K., Röttgering, H. J. A., Leinert, Ch., Richichi, A., Chesneau, O., Fraix-Burnet, D., Glazenborg-Kluttig, A., Granato, G. L., Graser, U., Heijligers, B., Köhler, R., Malbet, F., Miley, G. K., Paresce, F., Pel, J. W., Perrin, G., Przygodda, F., Schoeller, M., Sol, H., Waters, L. B. F. M., Weigelt, G., Woillez, J. \& de Zeeuw, P. T. 2004, Nature, 429, 47

Jannuzi, B. T., Elston, R., Schmidt, G. D., Smith, P. S. \& Stockman, H. S. 1994, ApJ, 429, L49

Jardel, J. R., Gebhardt, K., Shen, J., Fisher, D. B., Kormendy, J., Kinzler, J., Lauer, T. R., Richstone, D. \& Gültekin, K. 2011, ApJ, 739, 21

Johnson, P. A., Mastichiadis, A., Protheroe, R. J., Stanev, T. S. \& Szabo, A. P. 1994, $\mathrm{JPhG}, 20,979$

Johnston, K. J., Elvis, M., Kjer, D. \& Shen, B. S. P. 1982, ApJ, 262, 61

Jones, F. C. \& Ellison, D. C. 1991, SSRv, 58, 259

Kauffmann, G., Heckman, T. M., Tremonti, C., Brinchmann, J., Charlot, S., White, S. D. M., Ridgway, S. E., Brinkmann, J., Fukugita, M., Hall, P. B., Ivezic, Z., Richards, G. T. \& Schneider, D. P. 2003, MNRAS, 346, 1055

Kawara, K., Gregory, B. \& Nishida, M. 1987, ApJ, 321, L35

Kawara, K., Nishida, M. \& Gregory, B. 1990, ApJ, 352, 433

Khachikian, E. Y. \& Weedman, D. W. 1974, ApJ, 192, 581

Kellermann, K. I. \& Pauliny-Toth, I. I. K. 1969, ApJ, 155, L71 
Kewley, L. J., Dopita, M. A., Sutherland, R. S., Heisler, C. A. \& Trevena, J. 2001, ApJ, 556,121

King, I. R., Deharveng, J. M., Albrecht, R., Barbieri, C., Blades, J. C., Boksenberg, A., Crane, P., Disney, M. J., Jakobsen, P., Kamperman, T. M., Macchetto, F., Mackay, C. D., Paresce, F., Weigelt, G., Baxter, D., Greenfield, P., Jedrzejewski, R., Nota, A., Sparks, W. B. \& Stanford, S. A. 1992, ApJ, 397, L35

King, I. R., Stanford, S. A. \& Crane, P. 1995, AJ, 109, 164

Kinkhabwala, A., Sako, M., Behar, E., Kahn, S. M., Paerels, F., Brinkman, A. C., Kaastra, J. S., Gu, M. F. \& Liedahl, D. A. 2002, ApJ, 575, 732

Knop, R. A., Armus, L., Larkin, J. E., Matthews, K., Shupe, D. L. \& Soifer, B. T. 1996, AJ, 112, 81

Kochanek, C. S. \& Rybicki, G. B. 1996, MNRAS, 280, 1257

Komossa, S. \& Fink, H. 1997, A\&A, 327, 483

Kormendy, J. 1988, ApJ, 325, 128

Kormendy, J. 1988, ApJ, 335, 40

Kormendy, J. \& Bender, R. 1999, ApJ, 522, 772

Kormendy, J., Bender, R., Ajhar, E. A., Dressler, A., Faber, S. M., Gebhardt, K., Grillmair, C., Lauer, T. R., Richstone, D. \& Tremaine, S. 1996, ApJ, 473, L91

Koyama, K., Inoue, H., Tanaka, Y., Awaki, H., Takano, S., Ohashi, T. \& Matsuoka, M. 1989, PASJ, 41, 731

Krolik, J. H. \& Begelman, M. C. 1988, ApJ, 329, 702

Lallemand, A., Duchesne, M. \& Walker, M. F. 1960, Pub.A.S.P., 72, 76

Lamer, G., Uttley, P. \& McHardy, I. M. 2003, MNRAS, 342, L41

Lauer, T. R., Faber, S. M., Ajhar, E. A., Grillmair, C. J. \& Scowen, P. A. 1998, 116, 2263

Lauer, T. R., Faber, S. M., Groth, E. J., Shaya, E. J., Campbell, B., Code, A., Currie, D. G., Baum, W. A., Ewald, S. P., Hester, J. J., Holtzman, J. A., Kristian, J. \& Light, R. M. 1993, AJ, 106, 1436

Lauer, T. R., Faber, S. M., Lynds, C. R., Baum, W. A., Ewald, S. P., Groth, E. J., Hester, J. J., Holtzman, J. A., Kristian, J., Light, R. M., O’Neil Jr, E. J., Schneider, D. P., Shaya, E. J. \& Westphal, J. A. 1992, AJ, 103, 703

Lawson, C. L., \& Hanson, R. 1995, Solving Least Squares Problems $-2^{\text {nd }}$ ed., Englewood Cliffs, NJ: Prentice-Hall 
Lepp, S. \& McCray, R. 1983, ApJ, 269, 560

Light, E. S., Danielson, R. E. \& Schwarzschild, M. 1974, ApJ, 194, 257

Macchetto, F., Capetti, A., Sparks, W. B., Axon, D. J. \& Boksenberg, A. 1994, 435, L15

Magorrian, J. 1999, MNRAS, 302, 530

Magorrian, J., Tremaine, S., Richstone, D., Bender, R., Bower, G., Dressler, A., Faber, S. M., Gebhardt, K., Green, R., Grillmair, C., Kormendy, J. \& Lauer, T. 1998, AJ, 115,2285

Malkan, M. 1989, tad. conf, 19

Márquez, I., Boisson, C., Durret, F. \& Petitjean, P. 1998, A\&A, 333, 459

Martins, L. P., Rodríguez-Ardila, A., de Souza, R. \& Gruenwald, R. 2010a, MNRAS, 406, 2168

Martins, L. P., Riffel, R., Rodríguez-Ardila, A., Gruenwald, R. \& de Souza, R. 2010b, MNRAS, 406, 2185

Matt, G., Guainazzi, M., Frontera, F., Bassani, L., Brandt, W. N., Fabian, A. C., Fiore, F., Haardt, F., Iwasawa, K., Maiolino, R., Malaguti, G., Marconi, A., Matteuzzi, A., Molendi, S., Perola, G. C., Piraino, S. \& Piro, L. 1997, A\&A, 325, L13

Mazzalay, X. \& Rodríguez-Ardila, A. 2007, A\&A, 463, 445

Meixner, M., Puchalsky, R., Blitz, L., Wright, M. \& Heckman, T. 1990. ApJ, 354, 158

Miller, J. S. \& Goodrich, R. W. 1990, ApJ, 355, 456

Miller, J. S., Goodrich, R. W. \& Mathews, W. G. 1991, ApJ, 378, 47

Mo, H., van den Bosch, F. \& White, S. 2010, Galaxy Formation and Evolution, Cambridge University Press

Monier, R. \& Halpern, J. P. 1987, ApJ, 315, L17

Monnet, G., Bacon, R. \& Emsellem, E. 1992, A\&A, 253, 366

Moorwood, A. F. M. \& Oliva, E. 1990, A\&A, 239, 78

Moré, J. J., Garbow, B. S. \& Hillstrom, K. E. 1980, User Guide for MINPACK-1, Argonne National Laboratory Report ANL-80-74

Morris, S., Ward, M., Whittle, M., Wilson, A. S. \& Taylor, K. 1985, MNRAS, 216, 193

Mouri, H. 1994, ApJ, 427, 777

Mundell, C. G., Holloway, A. J., Pedlar, A., Meaburn, J., Kukula, M. J. \& Axon, D. J. 
1995a, MNRAS, 275, 67

Mundell, C. G., Pedlar, A., Axon, D. J., Meaburn, J. \& Unger, S. W. 1995b, MNRAS, 277,641

Mundell, C. G., Pedlar, A., Baum, S. A., O’Dea, C. P., Gallimore, J. F. \& Brinks, E. 1995, MNRAS, 272, 355

Mundell, C. G. \& Shone, D. L. 1999, MNRAS, 304, 475

Mundell, C. G., Wrobel, J. M., Pedlar, A. \& Gallimore, J. F. 2003, ApJ, 583, 192

Murtagh, F. \& Heck, A. 1987, Multivariate Data Analysis, Reidel Publishing Company, Dordrecht, Holland

Mushotzky, R. F., Boldt, E. A., Holt, S. S. \& Serlemitsos, P. J. 1980, BAAS, 12, 873

Nandra, K. \& Pounds, K. A. 1994, MNRAS, 268, 405

Narayan, R. \& Yi, I. 1994, ApJ, 428, L13

Navarro, J. F., Frenk, C. S. \& White, S. D. M. 1996, ApJ, 462, 563

Nenkova, M., Sirocky, M. M., Nikutta, R., Ivezic, Z. \& Elitzur, M. 2008a, ApJ, 685, 160

Nenkova, M., Sirocky, M. M., Ivezic, Z. \& Elitzur, M. 2008b, ApJ, 685, 147

Neugebauer, G., Oke, J. B., Becklin, E. E. \& Matthews, K. 1979, ApJ, 230, 79

Nicholson, K. L., Reichert, G. A., Mason, K. O., Puchnarewicz, E. M., Ho, L. C., Shields, J. C. \& Filippenko, A. V. 1998, MNRAS, 300, 893

Nieto, J. L., Macchetto, F. D., Perryman, M. A. C., di Serego Alighieri, S. \& Lelièvre, G. 1986, A\&A, 165, 189

Osterbrock, D. E. 1978, PNAS, 75, 540

Osterbrock, D. E. 1981, ApJ, 249, 462

Osterbrock, D. E. \& Ferland, G. J. 2006, Astrophysics of Gaseous Nebulae and Active Galactic Nucle $i-2^{\text {nd }}$ ed., University Science Books

Osterbrock, D. E. \& Koski, A. T. 1976, MNRAS, 176, 61

Osterbrock, D. E. \& Martel, A. 1993, ApJ, 414, 552

Padovani, P. \& Urry, C. M. 1992, ApJ, 387, 449

Pedlar, A., Kukula, M. J., Longley, D. P. T., Muxlow, T. W. B., Axon, D. J., Baum, S., O’Dea, C. \& Unger, S. W. 1993, MNRAS, 263, 471

Peiris, H. V. \& Tremaine, S. 2003, ApJ, 599, 237 
Pellegrini, S., Fabbiano, G., Fiore, F., Trinchieri, G. \& Antonelli, A. 2002, A\&A, 383, 1

Perlman, E. S., Biretta, J. A., Sparks, W. B., Macchetto, F. D. \& Leahy, J. P. 2001a, ApJ, 551, 206

Perlman, E. S., Mason, R. E., Packham, C., Levenson, N. A., Elitzur, M., Schaefer, J. J., Imanishi, M., Sparks, W. B. \& Radomski, J. 2007, ApJ, 663, 808

Perlman, E. S., Sparks, W. B., Radomski, J., Packham, C., Fisher, R. S., Piña, R. \& Biretta, J. A. 2001b, ApJ, 561, L51

Peterson, B. M. 1997, An introduction to active galactic nuclei, Cambridge University Press

Phillips, M. M., Charles, P. A. \& Baldwin, J. A. 1983, ApJ, 266, 485

Phinney, E. S. 1985, Astrophysics of Active Galaxies and Quasi-Stellar Objects, University Science Books: Mill Valley

Pier, E. A. \& Krolik, J. H. 1992, ApJ, 401, 99

Pier, E. A. \& Krolik, J. H. 1993, ApJ, 418, 673

Ptak, A., Yaqoob, T., Serlemitsos, P. J., Mushotzky, R. Otani, C. 1994, ApJ, 436, L31

Pogge, R. W. 1988, ApJ, 328, 519

Raban, D., Jaffe, W., Röttgerin, H., Meisenheimer, K. \& Tristram, K. R. W. 2009, MNRAS, 394, 1325

Reichert, G. A., Puchnarewiez, E. M., Filippenko, A. V., Mason, K. O., BranduardiRaymont, G. \& Wu, C. C. 1993, The Nearest Active Galaxies, CSIC, Madrid

Reyes, R., Zakamska, N. L., Strauss, M. A., Green, J., Krolik, J. H., Shen, Y., Richards, G. T., Anderson, S. F. \& Schneider, D. P. 2008, AJ, 136, 2373

Richstone, D. O. \& Tremaine, S. 1985, ApJ, 296, 370

Riffel, R. A., Storchi-Bergmann, T. \& McGregor, P. J. 2009, ApJ, 698, 1767

Riffel, R., Pastoriza, M. G., Rodríguez-Ardila, A. \& Bonatto, C. 2009, MNRAS, 400, 273

Riffel, R., Rodríguez-Ardila, A. \& Pastoriza, M. G. 2006, A\&A, 457, 61

Risaliti, G., Elvis, M. \& Nicastro, F. 2002, ApJ, 571, 234

Robson, E. I., Gear, W. K., Brown, L. M. J., Courvoisier, T. J. L. \& Smith, M. G. 1986, Nature, 323, 134

Rodríguez-Ardila, A., Riffel, R. \& Pastoriza, M. G. 2005, MNRAS, 364, 1041 
Romanowsky, A. J. \& Kochanek, C. S. 1997, MNRAS, 287, 35

Rosenblatt, E. E., Malkan, M. A., Sargent, W. L. W. \& Readhead, A. C. S. 1992, ApJS, 81,59

Rubin, V. C. \& Ford, W. K. Jr. 1968, ApJ, 154, 431

Rubin, V. C. \& Ford, W. K. Jr. 1971, ApJ, 170, 25

Rybicki G. B. 1987, Structure and Dynamics of Elliptical Galaxies, Vol. 127 of IAU Symposium, Deprojection of Galaxies - how much can BE Learned

Salamanca, I., Alloin, D., Baribaud, T., Axon, D., de Bruyn, G., Goad, M., Gondhalekar, P., van Groningen, E., Jackson, N., Kollatschny, W., Laurikainen, E., Lawrence, A., Masegosa, J., O’Brien, P., Pelat, D., Penston, M. V., Perez, E., PerezFournon, I., Robinson, A., Santos-Lleo, M., Stirpe, G. M., Tadhunter, C., Terlevich, R., Unger, S., Wagner, S. \& Wanders, I. 1994, A\&A, 282, 742

Salow, R. M. \& Statler, T. S. 2001, ApJ, 551, L49

Salow, R. M. \& Statler, T. S. 2004, ApJ, 611, 245

Sánchez-Blázquez, P., Peletier, R. F., Jiménez-Vicente, J., Cardiel, N., Cenarro, A. J., Falcón-Barroso, J., Gorgas, J., Selam, S. \& Vazdekis, A. 2006, MNRAS, 371, 703

Sandage, A. 1978, AJ, 83, 904

Sargent, W. L. W., Young, P. J., Boksenberg, A., Shortridge, K., Lynds, C. R. \& Hardwick, F. D. A. 1978, ApJ, 221, 731

Schinnerer, E., Eckart, A. \& Tacconi, L. J. 2000, ApJ, 533, 826

Schinnerer, E., Eckart, A., Tacconi, L. J. \& Genzel, R. 2000, ApJ, 533, 850

Schmidt, M. \& Green, R. F. 1983, ApJ, 269, 352

Schmitt, H. R., Antonucci, R. R. J., Ulvestad, J. S., Kinney, A. L., Vlarke, C. J. \& Pringle, J. E. 2001, ApJ, 555, 663

Schmitt, H. R. \& Storchi-Bergmann, T. 1994, ApJ, 423, 237

Scoville, N. Z., Matthews, K., Carico, D. P. \& Sanders, D. B. ApJ, 327, L61

Seyfert, C. K. 1943, ApJ, 97, 28

Shakura, N. I. \& Sunyaev, R. A. 1973, A\&A, 24, 337

Shields, J. C. 1992, ApJ, 399, L27

Shull, J. M. \& Beckwith, S. 1982, ARA\&A, 20, 163

Simpson, C., Wilson, A. S., Bower, G., Heckman, T. M., Krolik, J. H. \& Miley, G. K. 
1997, ApJ, 474, 121

Smart, W.M. 1977, Textbook on Spherical Astronomy, Cambridge University Press

Smith, L.I. 2002 - http://kybele.psych.cornell.edu/ edelman/Psych-465-Spring-

2003/PCA-tutorial.pdf

Starck, J.L. \& Murtagh, F. 2006, Astronomical Image and Data Analysis - $2^{\text {nd }}$ ed., Springer-Verlag Berlin Heidelberg

Steiner, J. E., Menezes, R. B., Ricci, T. V. \& Oliveira, A. S. 2009, MNRAS, 396, 788

Sternberg, A. \& Dalgarno, A. 1989, ApJ, 338, 197

Storchi-Bergmann, T., Simões-Lopes, R. D., McGregor, P. J., Riffel, R. A., Beck, T. \& Martini, P. 2010, MNRAS, 402, 819

Storchi-Bergmann, T., McGregor, P. J., Riffel, R. A., Simões Lopes, R., Beck, T. \& Dopita, M. 2009, MNRAS, 394, 1148

Suganuma, M., Yoshii, Y., Kobayashi, Y., Minezaki, T., Enya, K., Tomita, H., Aoki, T., Koshida, S. \& Peterson, B. A. 2006, ApJ, 639, 46

Tanaka, M., Hasegawa, T., Hayashi, S. S., Brand, P. W. J. L. \& Gatley, I. 1989, ApJ, 336, 207

Tananbaum, H., Avni, Y., Branduardi, G., Elvis, M., Fabbiano, G., Feigelson, E., Giacconi, R., Henry, J. P., Pye, J. P., Soltan, A. \& Zamorani, G. 1979, ApJ, 234, L9

Taniguchi, Y., Shioya, Y. \& Murayama, T. 2000, AJ, 120, 1265

Telesco, C. M. \& Decher, R. 1988, ApJ, 334, 573

Terlevich, R. \& Melnick, J. 1985, MNRAS, 213, 841

Thatte, N., Quirrenbach, A., Genzel, R., Maiolino, R. \& Tecza, M. 1997, ApJ, 490, 238

Thean, A., Pedlar, A., Kukula, M. J., Baum, S. A. \& O’Dea, C. P. 2000, MNRAS, 314, 573

Tran, H. D., Miller, J. S. \& Kay, L. E. 1992, ApJ, 397, 452

Tremaine, S. 1995, AJ, 110, 628

Tristram, K. R. W., Meisenheimer, K., Jaffe, W., Schartmann, M., Rix, H. W., Leinert, Ch., Morel, S., Wittkowski, M., Röttgering, H., Perrin, G., Lopez, B., Raban, D., Cotton, W. D., Graser, U., Paresce, F. \& Henning, Th. 2007, A\&A, 474, 837

Ueno, S., Mushotzky, R. F., Koyama, K., Iwasawa, K., Awaki, H. \& Hayashi, I. 1994, PASJ, 46, L71

Ulrich, M. H. 1973, ApJ, 181, 51 
Ulvestad, J. S. \& Wilson, A. S. 1984, ApJ, 285, 439

Unger, S. W., Lewis, J. R., Pedlar, A. \& Axon, D. J. 1992, MNRAS, 258, 371

Urry, C. M. \& Padovani, P. 1995, PASP, 107, 803

Urry, C. M., Padovani, P. \& Stickel, M. 1991, ApJ, 382, 501

van den Bosch, F. C. 1997, MNRAS, 287, 543

van der Marel, R. P. \& Franx, M. 1993, ApJ, 407, 525

Veilleux, S. 1991, ApJ, 369, 331

Vrtilek, J. M. \& Carleton, N. P. 1985, ApJ, 294, 106

Walker, M. F. 1968, ApJ, 151, 71

Walterbos, R. A. M. \& Kennicutt, R. C. Jr 1998, A\&A, 198, 61

Ward, M., Elvis, M., Fabbiano, G., Carleton, N. P., Willner, S. P. \& Lawrence, A. 1989, ApJ, 315, 74

Ward, M. J., Penston, M. V., Elvis, M., Maccacaro, T. \& Tritton, K. P. 1980, MNRAS, 193,563

Wehrle, A. E. \& Morris, M. 1988, AJ, 95, 1689

Whittle, M. 1985, MNRAS, 213, 1

Wilson, A. S. \& Ulvestad, J. S. 1982, ApJ, 263, 576

Wilson, A. S. \& Ulvestad, J. S. 1983, ApJ, 275, 8

Winge, C., Axon, D. J., Macchetto, F. D. \& Capetti, A. 1997, ApJ, 487, L121

Winge, C., Riffel, R. A. \& Storchi-Bergmann, T. 2009, ApJS, 185, 186

Young, P. J., Westphal, J. A., Kristian, J. \& Wilson, C. P. 1978, ApJ, 221, 721

Young, A. J., Wilson, A. S. \& Shopbell, P. L. 2001, ApJ, 556, 6

Zakamska, N. L., Strauss, M. A., Krolik, J. H., Collinge, M. J., Hall, P. B., Hao, L., Heckman, T. M., Ivezic, Z., Richards, G. T., Schlegel, D. J., Schneider, D. P., Strateva, I., Vanden Berk, D. E., Anderson, S. F. \& Brinkmann, J. 2003, AJ, 126, 2125

Zheng, W., Kriss, G. A., Davidsen, A. F., Lee, G., Code, A. D., Bjorkman, K. S., Smith, P. S., Weistrop, D., Malkan, M. A., Baganoff, F. K. \& Peterson, B. M. 1995, ApJ, 444,632 
576 


\section{Apêndice A}

\section{A taxa de acreção de Eddington}

Tomando-se um AGN emitindo uma luminosidade $L$, sabe-se que, para que o sistema seja estável, é preciso que a força exercida pela pressão da radiação emitida seja balanceada pela força gravitacional. O fluxo a uma distância $r$ da fonte central pode ser dado por

$$
F=\frac{L}{4 \pi r^{2}}
$$

Sabendo-se que o momento associado a um fóton com energia $E=h v$ pode ser dado por $p=E / c$, tem-se que o fluxo de momento, ou pressão de radiação, fica dado por

$$
P_{\text {rad }}=\frac{F}{c}=\frac{L}{4 \pi r^{2} c} .
$$

Considerando-se que o ambiente contenha apenas hidrogênio totalmente ionizado, temse que a força de radiação sobre cada elétron presente pode ser obtida multiplicando-se a pressão de radiação pela seção de choque correspondente à interação de um fóton com um elétron (seção de choque de Thomson):

$$
F_{\text {rad }}=\frac{L}{4 \pi r^{2} c} \sigma_{e}
$$

Para que o sistema permaneça estável, é preciso que a força gravitacional seja maior ou igual do que a força de radiação. Assim, tem-se que

$$
F_{\text {rad }} \leq F_{\text {grav }}
$$




$$
\frac{L \sigma_{e}}{4 \pi r^{2} c} \leq \frac{G M\left(m_{p}+m_{e}\right)}{r^{2}} .
$$

onde $m_{p}=$ massa do próton

$$
\begin{aligned}
& m_{e}=\text { massa do elétron } \\
& M=\text { massa do buraco negro central } \\
& \sigma_{e}=\text { seção de choque de Thomson }=\frac{8 \pi}{3}\left(\frac{e^{2}}{m_{e} c^{2}}\right)^{2}=6.65 \cdot 10^{-25} \mathrm{~cm}^{2}
\end{aligned}
$$

Assumindo-se que $m_{p}>>m_{e}$, obtém-se que

$$
\begin{aligned}
& \frac{L \sigma_{e}}{4 \pi r^{2} c} \leq \frac{G M m_{p}}{r^{2}} \\
& L \leq \frac{4 \pi G c m_{p}}{\sigma_{e}} M .
\end{aligned}
$$

A partir da equação acima, pode-se dizer que, para uma dada luminosidade $L$, há uma massa mínima, $M_{E}$ (massa de Eddington), para que o sistema permaneça estável. Olhando de outro modo, para uma dada massa $M$, há um valor máximo para a luminosidade emitida. Esse valor é chamado de luminosidade de Eddington e, pela equação anterior, pode ser dado por

$$
L_{E}=\frac{4 \pi G c m_{p}}{\sigma_{e}} M .
$$

Com base no que foi dito até aqui, pode-se calcular a taxa de acreção de Eddington, que corresponde a taxa de acreção necessária para manter o AGN emitindo com uma luminosidade igual à de Eddington (em outras palavras, pode-se dizer que a taxa de acrsção de Eddington corresponde ao maior valor possível da taxa de acreção para que o sistema permaneça estável). Com base na equação (2.2), tem-se que a taxa de acreção de Eddington pode ser dada por 


$$
\begin{gathered}
\dot{M}_{E}=\frac{L_{E}}{\eta c^{2}} \\
\dot{M}_{E}=\frac{4 \pi G c m_{p} M}{\sigma_{e} \eta c^{2}} .
\end{gathered}
$$

Colocando-se a expressão acima em unidades apropriadas e tomando-se $\eta=0.1$ (conforme foi demonstrado na seção 2.2), obtém-se

$$
\dot{M}_{E}=2.2 M_{8} M_{O} / \text { ano }
$$




\section{Apêndice B}

\section{Espectro de um disco de acreção na aproximação de corpo negro}

Se um disco de acreção emite como um corpo negro, então, seu espectro é dado pela lei de Planck

$$
B_{v}=\frac{2 h v^{3}}{c^{2}} \frac{1}{\left(e^{\frac{h v}{k T(r)}}-1\right)}
$$

$$
\begin{aligned}
\text { onde } T(r)= & \text { temperatura do disco a uma } \\
& \text { distância } r \text { do centro }
\end{aligned}
$$

$T(r)$ pode ser dada pela equação (2.12), a qual, para $r>R_{\text {in }}$ (o raio interno do disco de acreção), pode ser aproximada por

$$
T(r) \approx\left(\frac{3 G M \dot{M}}{8 \pi \sigma r^{3}}\right)^{\frac{1}{4}}=\left[\frac{3 G M \dot{M}}{8 \pi \sigma R_{S}^{3}}\right]^{\frac{1}{4}}\left(\frac{r}{R_{S}}\right)^{-\frac{3}{4}}
$$

$$
\text { onde } R_{S}=\text { raio de Schwarzschild }
$$

Tomando-se $T_{*}=\left(\frac{3 G M \dot{M}}{8 \pi \sigma R_{S}^{3}}\right)^{\frac{1}{4}}$, a expressão (B.2) pode ser re-escrita como

$$
T(r)=T_{*}\left(\frac{r}{R_{S}}\right)^{-\frac{3}{4}}
$$


O fluxo na superfície do disco é dado por $F_{v}=\pi B_{v}$. Assumindo-se, então, um disco geometricamente fino e opticamente espesso, a luminosidade de um anel de largura $d r$ em um raio $r$ é dada por

$$
d L_{v}(r)=2 \pi r \cos (i) \pi B_{v} d r
$$

onde $i=$ inclinação do disco em relação ao plano do céu

Para se obter, então, a luminosidade total do disco, integra-se ao longo do raio:

$$
L_{v}=\frac{4 \pi^{2} h v^{3} \cos (i)}{c^{2}} \int_{R_{\text {in }}}^{R_{\text {out }}} \frac{r d r}{e^{\frac{h v}{k T(r)}}-1} .
$$

onde $R_{\text {out }}=$ raio externo do disco de acreção

Para baixas freqüências, $h v<<k T\left(R_{\text {out }}\right)$, o disco todo emite segundo a lei de RayleighJeans, que corresponde à lei de Planck no limite de baixas frequências:

$$
\begin{gathered}
B_{v}(\text { Rayleigh }- \text { Jeans })=\lim _{\frac{h v}{k T(r)} \rightarrow 0} \frac{2 h v^{3}}{c^{2}} \frac{1}{\left(e^{\frac{h v}{k T(r)}}-1\right)}= \\
=\frac{2 h v^{3}}{c^{2}} \frac{1}{\left(1+\frac{h v}{k T(r)}-1\right)}= \\
=\frac{2 k T(r) v^{2}}{c^{2}} .
\end{gathered}
$$

Assim, a luminosidade do disco fica dada por 


$$
L_{v} \propto v^{2}
$$

Para altas freqüências, por outro lado, a emissão de corpo negro segue a lei de Wien, que é dada por

$$
\begin{aligned}
B_{v}(\text { Wien }) & =\lim _{\frac{h v}{k T(r)} \rightarrow \infty} \frac{2 h v^{3}}{c^{2}} \frac{1}{\left(e^{\frac{h v}{k T(r)}}-1\right)}= \\
& =\frac{2 h v^{3}}{c^{2}} \frac{1}{\left(e^{\frac{h v}{k T(r)}}\right)}= \\
& =\frac{2 h v^{3}}{c^{2}} e^{-\frac{h v}{k T(r)}} .
\end{aligned}
$$

Nesse caso, devido ao corte exponencial, o espectro de todo o disco de acreção pode ser tomado como sendo aproximadamente igual ao das regiões mais quentes, ou seja, a luminosidade do disco fica dada por

$$
L_{v} \propto v^{3} e^{-\frac{h v}{k T\left(R_{i n}\right)}} .
$$

Finalmente, para frequências intermediárias, pode-se obter uma aproximação para o espectro do disco de acreção de uma maneira razoavelmente simples. Supondo-se que haja uma faixa considerável de temperaturas ao longo do disco, tem-se que $R_{\text {out }}>>R_{i n}$. Nesse caso, considerase, apenas, uma faixa intermediária de freqüências $k T\left(R_{\text {out }}\right) / h<<v<<k T\left(R_{\text {in }}\right) / h$. Usando-se, então, a substituição (incluindo a equação B.3)

$$
x=\frac{h v}{k T(r)}=\frac{h v}{k T_{*}}\left(\frac{r}{R_{S}}\right)^{\frac{3}{4}}
$$


e reparando-se que, para $r=R_{\text {in }} \approx R_{S}, x<<1$ (já que $h v<<k T\left(R_{\text {in }}\right)$ ) e, para $r \rightarrow R_{\text {out }}, x \rightarrow \infty$ (já que $\left.h v>>k T\left(R_{\text {out }}\right)\right)$, a equação (B.5) fica

$$
\begin{gathered}
L_{v}=\frac{16 \pi^{2} R_{S}^{2} h v^{3} \cos (i)}{3 c^{2}}\left(\frac{k T_{*}}{h v}\right)^{\frac{8}{3}} \int_{0}^{\infty} \frac{x^{\frac{5}{3}} d x}{e^{x}-1}= \\
=2.4 \cdot 10^{-18} R_{S}^{2} \cos (i) T_{*}^{\frac{8}{3}} v^{\frac{1}{3}} \propto v^{\frac{1}{3}} .
\end{gathered}
$$




\section{Apêndice C}

\section{Tratamento teórico do fenômeno da refração atmosférica}

A maneira mais simples de se analisar o fenômeno da refração atmosférica é considerar a atmosfera da Terra como sendo formada por $n+1$ camadas esféricas, cada uma com o seu próprio índice de refração $\mu_{i}$. Considerando-se apenas pequenas distâncias zenitais, as curvaturas dessas camadas não precisam ser levadas em conta, de modo que elas podem ser consideradas paralelas. Ao passar pelo plano divisório entre cada uma dessas camadas, a luz sofre um desvio devido ao efeito da refração. A figura C.1 mostra um esquema do cenário considerado para um raio de luz $S$ incidindo na atmosfera com uma distância zenital $z$.

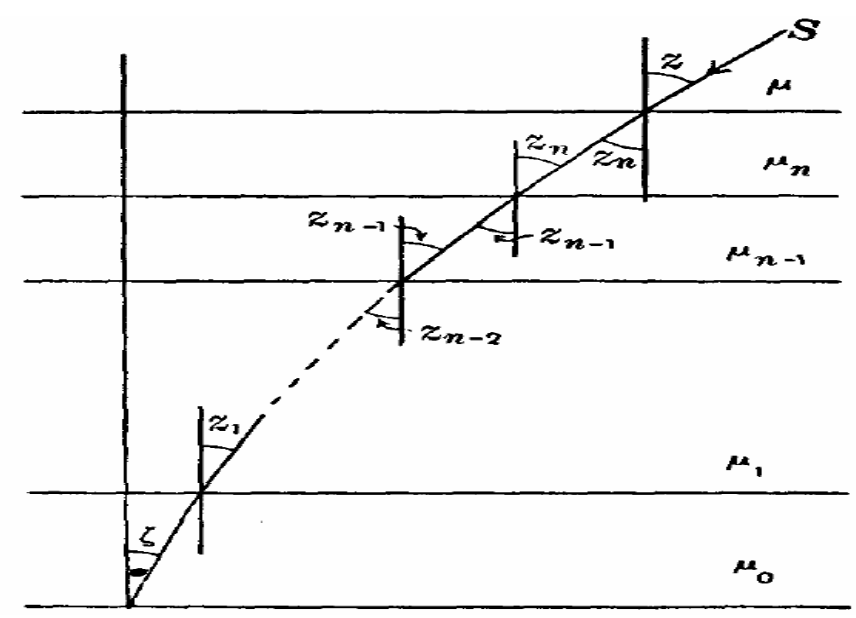

Figura C.1: Modelo considerado para um raio de luz $S$ atravessando a atmosfera terrestre (formada por $n+1$ camadas). Figura obtida de Smart (1977).

Aplicando-se a Lei de Snell na superfície divisória entre o vácuo e a camada atmosférica mais elevada, tem-se que

$$
\mu \cdot \operatorname{sen} z=\mu_{n} \cdot \operatorname{sen} z_{n}
$$

mas, como o índice de refração do vácuo é $\mu=1$, a equação (C.1) pode ser escrita como 


$$
\operatorname{sen} z=\mu_{n} \cdot \operatorname{sen} z_{n}
$$

Aplicando-se, então, a Lei de Snell nas superfícies divisórias entre as demais camadas obtém-se:

$$
\begin{aligned}
& \mu_{n} \cdot \operatorname{sen} z_{n}=\mu_{n-1} \cdot \operatorname{sen} z_{n-1} \\
& \mu_{n-1} \cdot \operatorname{sen} z_{n-1}=\mu_{n-2} \cdot \operatorname{sen} z_{n-2} \\
& \text { - } \\
& \text { - } \\
& \mu_{1} \operatorname{sen} z_{1}=\mu_{0} \cdot \operatorname{sen} \zeta
\end{aligned}
$$

onde $\zeta=$ distância zenital observada

$$
\mu_{0}=\text { índice de refração próximo à superfície da Terra }
$$

A partir das expressões (C.2) e (C.3), pode-se concluir que

$$
\operatorname{sen} z=\mu_{0} \cdot \operatorname{sen} \zeta
$$

Como a densidade do meio aumenta conforme a altitude diminui, conclui-se que os valores dos índices de refração $\mu_{\mathrm{i}}$ também crescem com a proximidade da superfície terrestre. Pelas equações anteriores, esse fato implica que $\zeta<z$, ou seja, o objeto emissor do raio de luz $S$ na figura C.1 é visto mais próximo ao zênite do que se não existisse o efeito da refração atmosférica. O ângulo $z$ - $\zeta$ é chamado de ângulo de refração e daqui por diante será denotado por $R$. Com isso, a equação (C.4) fica

$$
\begin{gathered}
\operatorname{sen}(R+\zeta)=\mu_{0} \cdot \operatorname{sen} \zeta \\
\operatorname{sen} R \cdot \cos \zeta+\operatorname{sen} \zeta \cdot \cos R=\mu_{0} \cdot \operatorname{sen} \zeta .
\end{gathered}
$$

Admitindo-se apenas valores de $R$ pequenos, pode-se considerar $\operatorname{sen}(R) \approx R$ e $\cos (R) \approx 1, \operatorname{logo}$, a expressão (C.5) fica 


$$
\begin{gathered}
R \cdot \cos \zeta+\operatorname{sen} \zeta=\mu_{0} \cdot \operatorname{sen} \zeta \\
R=\left(\mu_{0}-1\right) \cdot \tan \zeta .
\end{gathered}
$$

Convertendo-se a equação (C.6) para segundos de arco, obtém-se

$$
R=206265 \cdot\left(\mu_{0}-1\right) \cdot \tan \zeta
$$

A expressão (C.7) corresponde à fórmula da refração para pequenas distâncias zenitais. Quando essas são maiores, entretanto, as curvaturas das camadas que formam a atmosfera não podem ser desprezadas e a análise do efeito da refração atmosférica torna-se mais complexa, já que envolve uma quantidade bem maior de parâmetros. Por conta desse grau de dificuldade, esse tipo de tratamento detalhado do fenômeno da refração atmosférica com maiores valores de distâncias zenitais não é tratado aqui.

É importante mencionar que o valor de $\mu_{0}$ na fórmula (C.7) depende do comprimento de onda considerado. Ao nível do mar (com pressão $P=760 \mathrm{mmHg}$ e temperatura $T=15^{\circ} \mathrm{C}$ ), $\mathrm{o}$ índice de refração do ar com pouca umidade pode ser dado por (Edlén 1953; Coleman, Bozman \& Meggers 1960)

$$
\left(\mu(\lambda)_{15,760}-1\right) \cdot 10^{6}=64.328+\frac{29498.1}{146-\left(\frac{1}{\lambda}\right)^{2}}+\frac{255.4}{41-\left(\frac{1}{\lambda}\right)^{2}} .
$$

onde $\lambda=$ comprimento de onda (em microns)

Entretanto, a maior parte dos observatórios está localizada em elevadas altitudes, assim, os índices de refração mais apropriados para essas localidades devem ser calculados para valores mais baixos de temperatura e pressão. De acordo com Barrell (1951), a expressão para o índice de refração nessas condições fica dada por 


$$
\left(\mu(\lambda)_{T, P}-1\right)=\left(\mu(\lambda)_{15,760}-1\right) \cdot \frac{P\left[1+(1.049-0.0157 T) \cdot 10^{-6} P\right]}{720.883(1+0.003661 T)}
$$

$$
\text { onde } \begin{aligned}
P & =\text { pressão }(\mathrm{em} \mathrm{mmHg}) \\
T & =\text { temperatura }\left(\mathrm{em}^{\circ} \mathrm{C}\right)
\end{aligned}
$$

Na presença de vapor de água na atmosfera, o valor $(n-1) \cdot 10^{6}$ é reduzido por um fator

$$
\frac{0.0624-\frac{0.000680}{\lambda^{2}}}{1+0.003661 T} f
$$

onde $f$ = pressão do vapor de água (em $\mathrm{mmHg})$

A equação (C.7) mostra que os cálculos referentes ao efeito da refração atmosférica envolvem o conhecimento da distância zenital do objeto observado. Tomando-se um triângulo esférico com os vértices no objeto observado, no zênite e no pólo celeste apropriado, e aplicando-se a lei dos senos, obtém-se a expressão

$$
\frac{\operatorname{sen} \eta}{\operatorname{sen}\left(\frac{\pi}{2}-\phi\right)}=\frac{\operatorname{senh}}{\operatorname{sen} \zeta}
$$

$$
\begin{gathered}
\text { onde } \begin{aligned}
\eta & =\text { ângulo paralático do objeto } \\
h & =\text { ângulo horário do objeto } \\
\phi & =\text { latitude do observador }
\end{aligned}
\end{gathered}
$$

A equação (C.11) é uma forma útil de se expressar a distância zenital em função de outros parâmetros (geralmente conhecidos), mas também é equivalente à expressão

$$
\operatorname{sen} \eta=\frac{\operatorname{senh} \cdot \cos \phi}{\left[1-(\operatorname{sen} \phi \cdot \operatorname{sen} \delta+\cos \phi \cdot \cos \delta \cdot \cosh )^{2}\right]^{\frac{1}{2}}} .
$$


A partir da fórmula (C.7), pode-se dizer que a variação sofrida pelo ângulo de refração quando o comprimento de onda varia de $\lambda_{1}$ e $\lambda_{2}$ (mantendo-se $\zeta$ constante) pode ser dada por

$$
\begin{gathered}
\Delta R=R\left(\lambda_{2}\right)-R\left(\lambda_{1}\right) \\
\Delta R=206265 \cdot\left[\mu_{0}\left(\lambda_{2}\right)-\mu_{0}\left(\lambda_{1}\right)\right] \tan \zeta
\end{gathered}
$$




\title{
Apêndice D
}

\section{Algoritmo para correção de refração atmosférica diferencial}

\author{
J.E. Steiner
}

O centroide do perfil de uma estrela (ou núcleo de galáxia) guia pode ser descrita por duas equações de segundo grau

$x=a 1+b 1 \cdot \lambda+c 1 \cdot \lambda^{2}+d 1 \cdot \lambda^{3}$

$y=a 2+b 2 \cdot \lambda+c 2 \cdot \lambda^{2}+d 2 \cdot \lambda^{3}$

onde $x, y$ são números reais (parte inteira mais fracionária), em pixels. Definindo-se estas grandezas em parte inteira, $(i, j)$ e em parte fracionaria $(F i, F j)$, tem-se que

$\operatorname{delta} x=i+F i$

delta $y=j+F j$

Portanto $(i, j)$ são números inteiros de pixels e $(F i, F j)$ são números fracionários de pixels. Os valores $(i, j)$ são definidos como zero $(0,0)$ para o extremo do espectro. O objetivo é calcular a intensidade corrigida no pixel $(m, n), I c(m, n)$, que pode ser expressa como

$I c(m, n)=I(m+i+F i ; n+j+F j)$.

Para calcular esse valor, é preciso achar em que quadrante de $(F i, F j)$ o cálculo é feito, para esse pixel espectral.

Se $F i>0.5$ e $F j>0.5$, tem-se que 
592

$I c(m, n)=I(m+i+F i ; n+j+F j)=I(m+i ; n+j)(1.5-F i)(1.5-F j)+I(m+i+1 ; n+j)(F i-0.5)(1.5-F j)++$ $I(m+I ; n+j+1)(F j-0.5)(1.5-F i)+I(m+i+1 ; n+j+1)(F i-0.5)(F j-0.5)$.

Se $F i>0.5$ e $F j<0.5$,

$I c(m, n)=I(m+i+F i ; n+j+F j)=I(m+i ; n+j)(1.5-F i)(F j+0.5)+I(m+i, n+j-1)(0.5-F j)(1.5-F i)+$ $+I(m+i+1 ; n+j)(F i-0.5)(0.5+F j)+I(m+i+1 ; n+j-1)(0.5-F j)(F i-0.5)$.

Se $F i<0.5$ e $F j>0.5$,

$I c(m, n)=I(m+i+F i ; n+j+F j)=I(m+i ; n+j)(F i+0.5)(1.5-F j)+I(m+i-1 ; n+j)(0.5-F i)(1.5-F j)+$ $+I(m+i ; n+j+1)(F j-0.5)(0.5+F i)+I(m+i-1 ; n+j+1)(F j-0.5)(0.5-F i)$.

Se $F i<0.5$ e $F j<0.5$,

$I c(m, n)=I(m+i+F i ; n+j+F j)=I(m+i ; n+j)(F i+0.5)(F j+0.5)+I(m+i-1 ; n+j)(0.5-F i)(0.5+F j)+$ $+I(m+j ; n+j-1)(0.5-F j)(0.5+F i)+I(m+i-1 ; n+j-1)(0.5-F i)(0.5-F j)$. 


\section{Apêndice E}

\section{O algoritmo Fast Fourier Transform - FFT}

A transformada de Fourier bidimensional discreta se tornou uma importante ferramenta de análise de imagens nos últimos anos. Uma das razões do sucesso desse método foi o desenvolvimento do algoritmo Fast Fourier Transform, que permite o cálculo da transformada de Fourier bidimensional discreta utilizando-se menos operações (adições e multiplicações) do que a equação (3.13) e, consequentemente, com uma economia de tempo. Para se compreender

esse algoritmo, primeiramente, considera-se a transformada de Fourier discreta de uma função unidimensional. Tomando-se

$$
W_{M}=e^{\frac{-i 2 \pi}{M}}
$$

a equação (3.7) pode ser reescrita como

$$
F(u)=\frac{1}{M} \sum_{x=0}^{M-1} f(x) \cdot W_{M}^{u x}
$$

Admitindo-se, ainda, que

$$
M=2^{n}
$$

onde $n$ é um número inteiro positivo

então, conclui-se que $M$ pode ser, também, expresso por 


$$
M=2 K
$$

onde $K$ é um número inteiro positivo

Substituindo-se (E.4) em (E.2), obtém-se:

$$
F(u)=\frac{1}{2 K} \sum_{x=0}^{2 K-1} f(x) \cdot W_{2 K}^{u x}=\frac{1}{2}\left[\frac{1}{K} \sum_{x=0}^{K-1} f(2 x) \cdot W_{2 K}^{u(2 x)}+\frac{1}{K} \sum_{x=0}^{K-1} f(2 x+1) \cdot W_{2 K}^{u(2 x+1)}\right]
$$

Entretanto, pela equação (E.1), tem-se que:

$$
W_{2 K}^{2 u x}=e^{\frac{-i 2 \pi 2 u x}{2 K}}=e^{\frac{-i 2 \pi u x}{K}}=W_{K}^{u x} .
$$

Assim, com base na expressão (E.6), pode-se dizer que a equação (E.5) pode ser reescrita como

$$
F(u)=\frac{1}{2}\left[\frac{1}{K} \sum_{x=0}^{K-1} f(2 x) \cdot W_{K}^{u x}+\frac{1}{K} \sum_{x=0}^{K-1} f(2 x+1) \cdot W_{K}^{u x} \cdot W_{2 K}^{u}\right] .
$$

Definindo-se, então,

$$
\begin{array}{r}
F_{\text {par }}(u)=\frac{1}{K} \sum_{x=0}^{K-1} f(2 x) \cdot W_{K}^{u x} \\
\qquad \operatorname{para} u=0,1,2, \ldots, K-1
\end{array}
$$




$$
F_{\text {impar }}(u)=\frac{1}{K} \sum_{x=0}^{K-1} f(2 x+1) \cdot W_{K}^{u x}
$$

$$
\text { para } u=0,1,2, \ldots, K-1
$$

a expressão (E.7) pode ser escrita como

$$
F(u)=\frac{1}{2}\left[F_{\text {par }}(u)+F_{\text {impar }}(u) \cdot W_{2 K}^{u}\right] .
$$

Entretanto, pode-se verificar que

$$
W_{K}^{u+K}=e^{\frac{-i 2 \pi(u+K)}{K}}=e^{\frac{-i 2 \pi u}{K}} \cdot e^{\frac{-i 2 \pi K}{K}}=e^{\frac{-i 2 \pi u}{K}} \cdot e^{-i 2 \pi}=e^{\frac{-i 2 \pi u}{K}}=W_{K}^{u}
$$

e

$$
W_{2 K}^{u+K}=e^{\frac{-i 2 \pi(u+K)}{2 K}}=e^{\frac{-i 2 \pi u}{2 K}} \cdot e^{\frac{-i 2 \pi K}{2 K}}=e^{\frac{-i 2 \pi u}{2 K}} \cdot e^{-i \pi}=-e^{\frac{-i 2 \pi u}{2 K}}=-W_{2 K}^{u} \cdot
$$

Aplicando-se, então, as equações (E.11) e (E.12) em (E.8), (E.9) e (E.10), obtém-se:

$$
F(u+K)=\frac{1}{2}\left[F_{p a r}(u)-F_{\text {impar }}(u) \cdot W_{2 K}^{u}\right] .
$$

Analisando-se as expressões anteriores, pode-se notar que uma transformada de Fourier de $M$ pontos pode ser calculada dividindo-se a equação original em duas partes, como mostram as expressões (E.10) e (E.13). Para se calcular a primeira metade de $F(u)$, é preciso calcular $F_{\text {par }}(u)$ e $F_{\text {impar }}(u)$ e substituir os resultados em (E.10), para $u=0,1,2, \ldots,(M / 2-1)$. A outra metade de $F(u)$ pode, então, ser obtida diretamente de (E.13), sem a necessidade do cálculo de novas transformadas. Esse procedimento para se obter $F(u)$ corresponde à Fast Fourier 
Transform (FFT) e apresenta grandes vantagens computacionais. O cálculo direto de uma transformada de Fourier discreta de $M$ pontos, utilizando-se a equação (3.7), exige cerca $M^{2}$ adições e multiplicações. Entretanto, utilizando-se as expressões acima, pode-se mostrar que o número de multiplicações $(m(n))$ e de adições $(a(n))$ necessários, para um determinado $\mathrm{n}$ (lembrando que $M=2^{n}$ ), podem ser dados por

$$
m(n)=2 m(n-1)+2^{n-1}, \text { para } \mathrm{n} \geq 1
$$

$\mathrm{e}$

$$
a(n)=2 a(n-1)+2^{n}, \text { para } \mathrm{n} \geq 1 .
$$

É possível também mostrar que as equações (E.14) e (E.15) são equivalentes a

$$
m(n)=\frac{1}{2} M \log _{2} M
$$

$\mathrm{e}$

$$
a(n)=M \log _{2} M
$$

A vantagem computacional desse método pode ser, então, dada, aproximadamente, pela razão

$$
C(M)=\frac{M^{2}}{M \log _{2} M}=\frac{M}{\log _{2} M} .
$$

Como $M=2^{n}$, conclui-se que a expressão anterior também pode ser escrita como

$$
C(M)=\frac{2^{n}}{n} .
$$


A equação (E.19) mostra a grande vantagem computacional que o método da FFT apresenta. Tomando-se $n=10$, por exemplo, a expressão (E.19) revela que a FFT é cerca de 102 vezes mais rápida do que o cálculo padrão mostrado na equação (3.7). Além disso, pode-se notar que quanto maior for o valor de $n$, maior será a vantagem computacional da FFT. Por essa razão, a FFT se tornou um método bastante utilizado para o cálculo de transformadas de Fourier.

Todo o procedimento aqui descrito refere-se à transformada de Fourier de uma função unidimensional. Entretanto, conforme foi explicado na seção 3.4, uma transformada de Fourier bidimensional pode ser calculada através de sucessivas transformadas unidimensionais, assim, a extensão do cálculo da FFT, mostrado anteriormente, para funções bidimensionais é bastante simples. Atualmente, existem algoritmos que também conseguem executar a FFT em funções com um número $M$ de pontos ímpar. 
598 


\section{Apêndice F}

\section{Tratamento matemático da Análise em Componentes Principais (Principal Component Analysis - PCA)}

Conforme foi mencionado na seção 3.10, a transformação matemática correspondente ao PCA pode ser representada, matricialmente, pela expressão

$T=E \cdot X$

onde $X=$ matriz contendo os dados originais

$E=$ matriz cujas linhas correspondem aos

autovetores (ou Componentes Principais)

mencionados na seção 3.10

$T=$ matriz contendo os dados no novo sistema de

Coordenadas

De acordo com o que também está explicado na seção 3.10, na fórmula anterior, cada linha da matriz $X$ corresponde a uma variável diferente (ou seja, a uma dimensão diferente) e cada coluna a um observável diferente. Além disso, a matriz $E$, que passa os dados para o novo sistema de coordenadas, é definida de modo que suas linhas correspondam aos autovetores da matriz de covariância, que pode ser dada pela expressão

$$
C_{X}=\frac{X \cdot X^{T}}{n-1} \text {. }
$$

onde $n=$ número de observáveis

Pela maneira como foi construída, a matriz de covariância possui algumas propriedades que devem ser mencionadas. Uma delas é que essa matriz é simétrica, ou seja, 


$$
C_{X}^{T}=C_{X} .
$$

Além disso, os elementos da diagonal principal de $C_{X}$ correspondem às variâncias de cada uma das variáveis envolvidas na análise, ao passo que os elementos fora da diagonal principal representam as covariâncias entre todas essas variáveis (as definições matemáticas de variância e covariância encontram-se no apêndice G).

A partir do que foi mencionado, pode-se dizer que a matriz de covariância, como o próprio nome diz, revela o grau de covariância existente entre todos os pares de variáveis possíveis. Valores elevados na diagonal principal dessa matriz correspondem a altas variâncias nas variáveis, ao passo altos valores fora da diagonal principal indicam altas covariâncias existentes entre as variáveis.

Como o objetivo do PCA é passar os dados originais para um novo sistema de coordenadas não correlacionadas, conclui-se que a matriz de covariância ideal para os dados nesse novo sistema de coordenadas $\left(C_{T}\right)$ deve ser diagonal (ou seja, a covariância entre as variáveis deve ser nula). Assim, pode-se dizer que a execução do PCA consiste na determinação da matriz $E$, que satisfaça a equação (F.1) e tal que $C_{T}$ seja diagonal. Para se determinar como essa matriz pode ser obtida, toma-se

$$
C_{T}=\frac{T \cdot T^{T}}{n-1} .
$$

Substituindo-se (F.1) em (F.4), obtém-se:

$$
\begin{gathered}
C_{T}=\frac{E \cdot X \cdot(E \cdot X)^{T}}{n-1} \\
C_{T}=\frac{E \cdot X \cdot X^{T} \cdot E^{T}}{n-1} \\
C_{T}=\frac{E \cdot\left(X \cdot X^{T}\right) \cdot E^{T}}{n-1} \\
C_{T}=E \cdot C_{X} \cdot E^{T} .
\end{gathered}
$$


Conforme já foi mencionado, a matriz de covariância $C_{X}$ é simétrica, por outro lado, de acordo com os teoremas 2 e 3 (também enunciados no Apêndice D), uma matriz simétrica pode ser diagonalizada por uma matriz ortogonal formada por seus autovetores. Assim, para $C_{X}$, tem-se que

$$
C_{X}=F \cdot D \cdot F^{T}
$$

onde $D=$ matriz diagonal, cujos elementos da diagonal principal correspondem aos autovalores dos autovetores que compoem $F$

$F=$ matriz formada pelos autovetores de $C_{X}$ (colocados em colunas)

Agora, tomando-se a matriz $E$ procurada como sendo formada pelos autovetores de $C_{X}$ colocados em linhas, ou seja,

$$
E=F^{T}
$$

e substituindo-se (F.7) em (F.6), obtém-se

$$
C_{X}=E^{T} \cdot D \cdot E
$$

Em seguida, substituindo-se (F.8) em (F.5) e levando-se em conta que $E^{-1}=E^{T}$ (teorema 1 do Apêndice D), obtém-se

$$
\begin{gathered}
C_{T}=E \cdot\left(E^{T} \cdot D \cdot E\right) \cdot E^{T} \\
C_{T}=\left(E \cdot E^{T}\right) \cdot D \cdot\left(E \cdot E^{T}\right) \\
C_{T}=\left(E \cdot E^{-1}\right) \cdot D \cdot\left(E \cdot E^{-1}\right) \\
C_{T}=D .
\end{gathered}
$$

Assim, pode-se dizer que essa escolha de $E$ diagonaliza $C_{T}$, ou seja, para que a matriz $E$ em questão satisfaça as condições desejadas, ela deve ter suas linhas constituídas pelos 
autovetores de $C_{X}$. Além disso, os elementos da diagonal principal de $C_{T}$ correspondem não apenas às variâncias associadas a cada um dos autovetores (que compõem o novo sistema de coordenadas), mas também aos seus próprios autovalores. Em outras palavras, pode-se dizer que toda a demonstração realizada mostra que a variância explicada por cada um dos autovetores é dada pelos seus respectivos autovalores. 


\section{Apêndice G}

\section{Definições de variância e covariância}

Tomando-se um conjunto de $n$ observáveis, tem-se que a sua variância referente a uma coordenada $X$ pode ser dada por

$$
\operatorname{var}(X)=\frac{\sum_{i=1}^{n}\left(X_{i}-\bar{X}\right)^{2}}{n-1} .
$$

onde $\bar{X}=$ valor médio da variável $X$

Por outro lado, a covariância entre as coordenadas $X$ e $Y$ desse mesmo conjunto de observáveis pode ser dada por

$$
\operatorname{cov}(X, Y)=\frac{\sum_{i=1}^{n}\left(X_{i}-\bar{X}\right) \cdot\left(Y_{i}-\bar{Y}\right)}{n-1}
$$

onde $\bar{Y}=$ valor médio da variável $Y$

\section{Teoremas de Álgebra Linear relevantes na Análise em Componentes Principais}

1 - A inversa de uma matriz ortogonal é igual à sua transposta

2 - Uma matriz $A$ é simétrica se e somente se ela for ortogonalmente diagonalizável, ou seja, se e somente se existir uma matriz $E$ ortogonal tal que 
604

$$
A=E \cdot D \cdot E^{T}
$$

onde $D=$ matriz ortogonal

3 - Uma matriz simétrica pode ser diagonalizada por uma matriz formada por seus autovetores ortonormais. 


\section{Apêndice H}

\section{$\mathrm{O}$ método de Jeans}

As posições $\boldsymbol{x}$ e as velocidades $\boldsymbol{v}$ de um grande conjunto de estrelas podem ser descritas por uma função de distribuição (FD) $f(\boldsymbol{x}, \boldsymbol{v})$. Quando o sistema se encontra em um estado estacionário sob a influência gravitacional de um potencial $\Phi$, a FD deve satisfazer a equação fundamental da dinâmica estelar, a equação de Boltzmann não colisional de estado estacionário (Binney \& Tremaine 1987, daqui para frente BT):

$$
\sum_{i=1}^{3}\left(v_{i} \frac{\partial f}{\partial x_{i}}-\frac{\partial \Phi}{\partial x_{i}} \frac{\partial f}{\partial v_{i}}\right)=0
$$

Como $f$ é uma função de seis variáveis, a equação (H.1) possui uma enorme quantidade de soluções. Assim, hipóteses adicionais são necessárias para que (H.1) possa ser utilizada de uma maneira prática.

Reescrevendo-se a expressão (H.1) em coordenadas cilíndricas $(R, z, \varphi)$ e assumindo-se simetria axial $\left(\frac{\partial \Phi}{\partial \varphi}=\frac{\partial f}{\partial \varphi}=0\right)$, obtém-se

$$
v_{R} \frac{\partial f}{\partial R}+v_{z} \frac{\partial f}{\partial z}+\left(\frac{v_{\varphi}^{2}}{R}-\frac{\partial \Phi}{\partial R}\right) \frac{\partial f}{\partial v_{R}}-\frac{\partial \Phi}{\partial z} \frac{\partial f}{\partial v_{z}}-\frac{v_{R} v_{\varphi}}{R} \frac{\partial f}{\partial v_{\varphi}}=0
$$

Multiplicando-se a equação (H.2) por $v_{R}$ e por $v_{z}$ e integrando-se em todas as velocidades, obtém-se as duas equações de Jeans

$$
\frac{\eta \overline{v_{R}^{2}}-\eta \overline{v_{\varphi}^{2}}}{R}+\frac{\partial\left(\eta \overline{v_{R}^{2}}\right)}{\partial R}+\frac{\partial\left(\eta \overline{v_{R} v_{z}}\right)}{\partial z}=-\eta \frac{\partial \Phi}{\partial R}
$$


606

$$
\frac{\eta \overline{v_{R} v_{z}}}{R}+\frac{\partial\left(\eta \overline{v_{z}^{2}}\right)}{\partial z}+\frac{\partial\left(\eta \overline{v_{R} v_{z}}\right)}{\partial R}=-\eta \frac{\partial \Phi}{\partial z}
$$

onde foi usada a notação

$$
\eta \overline{v_{k} v_{j}}=\int v_{k} v_{j} d^{3} v
$$

Nas equações anteriores $\eta$ representa a densidade de luminosidade. Se $\Phi$ é conhecido, então, (H.3) e (H.4) são funções de 4 variáveis: $\overline{v_{R}^{2}}, \overline{v_{z}^{2}}, \overline{v_{\varphi}^{2}}$ e $\overline{v_{R} v_{z}}$. Consequentemente, essas equações ainda não possuem uma única solução. Uma forma de se obter uma única solução a partir das equações de Jeans é especificar o formato e a orientação da intersecção do elipsóide de velocidades com o plano meridional. A elipse de dispersão de velocidades possui um eixo maior em um ângulo $\theta$ com o plano equatorial dado por

$$
\tan (2 \theta)=\frac{2 \overline{v_{R} v_{z}}}{\overline{v_{R}^{2}}-\overline{v_{z}^{2}}}
$$

e uma razão axial, $0 \leq q \leq 1$, de

$$
q^{2}=\frac{\overline{v_{R}^{2}}+\overline{v_{z}^{2}}-\sqrt{\left(\overline{v_{R}^{2}}-\overline{v_{z}^{2}}\right)^{2}+4\left(\overline{v_{R} v_{z}}\right)^{2}}}{\overline{v_{R}^{2}}+\overline{v_{z}^{2}}+\sqrt{\left(\overline{v_{R}^{2}}-\overline{v_{z}^{2}}\right)^{2}+4\left(\overline{v_{R} v_{z}}\right)^{2}}} .
$$

Assumindo-se (i) que o elipsóide de velocidades está alinhado com o sistema de coordenadas cilíndricas $(R, z, \varphi)$ e (ii) que a anisotropia é constante e dada pelo parâmetro de anisotropia 


$$
\beta_{z}=1-\frac{\overline{v_{z}^{2}}}{\overline{v_{R}^{2}}}=1-\frac{1}{b} \Rightarrow \overline{v_{R}^{2}}=b \overline{v_{z}^{2}},
$$

as equações de Jeans (H.3) e (H.4) podem ser re-escritas como

$$
\begin{gathered}
\frac{b \eta \overline{v_{z}^{2}}-\eta \overline{v_{\varphi}^{2}}}{R}+\frac{\partial\left(b \eta \overline{v_{z}^{2}}\right)}{\partial R}=-\eta \frac{\partial \Phi}{\partial R} \\
\frac{\partial\left(\eta \overline{v_{z}^{2}}\right)}{\partial z}=-\eta \frac{\partial \Phi}{\partial z} .
\end{gathered}
$$

Com a condição de contorno $\eta \overline{v_{z}^{2}}=0$, quando $z \rightarrow \infty$, as equações ficam

$$
\begin{gathered}
\eta \overline{v_{z}^{2}}(R, z)=\int_{z}^{\infty} \eta \frac{\partial \Phi}{\partial z} d z \\
\eta \overline{v_{\varphi}^{2}}(R, z)=b\left[R \frac{\partial\left(\eta \overline{v_{z}^{2}}\right)}{\partial R}+\eta \overline{v_{z}^{2}}\right]+R \eta \frac{\partial \Phi}{\partial R} .
\end{gathered}
$$

Para determinar as soluções das equações de Jeans, é preciso adotar uma parametrização para a densidade estelar e para a densidade total (que inclui a matéria escura e o buraco negro central). Nesse caso, é utilizada, para essa função, a parametrização Multi Gaussian Expansion (MGE) de Emsellem et al. (1994), devido à sua precisão na reprodução da fotometria de galáxias (Cappellari 2002). De acordo com esse método, se o eixo x está alinhado com o eixo maior fotométrico da galáxia, o brilho superficial $\Sigma$ em um ponto $\left(x^{\prime}, y^{\prime}\right)$ no plano do céu é dado por

$$
\Sigma\left(x^{\prime}, y^{\prime}\right)=\sum_{k=1}^{N} \frac{L_{k}}{2 \pi \sigma_{k}^{2} q_{k}^{\prime}} \exp \left[-\frac{1}{2 \sigma_{k}^{2}}\left(x^{\prime 2}+\frac{y^{\prime 2}}{q_{k}^{\prime 2}}\right)\right],
$$


onde $N$ corresponde ao número de componentes gaussianas, cada uma com uma luminosidade total $L_{k}$, uma razão axial $0 \leq q^{\prime}{ }_{k} \leq 1$ e uma dispersão $\sigma_{k}$ ao longo do eixo maior.

A de-projeção do brilho superficial para se obter a densidade de luminosidade intrínseca não é única, a não ser que a galáxia com simetria axial seja vista edge-on $\left(i=90^{\circ}\right)$ (Rybicki 1987; Kochanek \& Rybicki 1996). A degenerecência torna-se particularmente severa quando a galáxia é vista com baixas inclinações (Gerhard \& Binney 1996; Romanowsky \& Kochanek 1997; van den Bosch 1997; Magorrian 1999). O método da MGE fornece uma escolha simples para a de-projeção (Monnet et al. 1992). A densidade de luminosidade oblata de-projetada $\eta$, de acordo com a MGE, pode ser dada por

$$
\eta(R, z)=\sum_{k=1}^{N} \frac{L_{k}}{\left(\sqrt{2 \pi} \sigma_{k}\right)^{3} q_{k}} \exp \left[-\frac{1}{2 \sigma_{k}^{2}}\left(R^{2}+\frac{z^{2}}{q_{k}^{2}}\right)\right]
$$

onde as componentes individuais possuem a mesma luminosidade $L_{k}$ e dispersão $\sigma_{k}$ que no caso projetado (equação H.13). Após a de-projeção, a razão axial intrínseca de cada gaussiana tornase

$$
q_{k}=\frac{\sqrt{q_{k}^{\prime 2}-\cos ^{2}(i)}}{\operatorname{sen}(i)}
$$

A densidade total $\rho$ pode ser geralmente descrita por um grupo diferente de $M$ gaussianas

$$
\rho(R, z)=\sum_{j=1}^{M} \frac{M_{j}}{\left(\sqrt{2 \pi} \sigma_{j}\right)^{3} q_{j}} \exp \left[-\frac{1}{2 \sigma_{j}^{2}}\left(R^{2}+\frac{z^{2}}{q_{j}^{2}}\right)\right] .
$$

No caso auto-consistente, as gaussianas nas equações (H.14) e (H.16) são as mesmas e tem-se $M$ $=N, \sigma_{j}=\sigma_{k}, q_{j}=q_{k}$ e $M_{j}=\Gamma_{k} L_{k}$, onde $\Gamma_{k}$ corresponde à razão massa-luminosidade, que pode ser diferente para cada componente gaussiana. No caso não auto-consistente, a densidade total pode ser descrita pela soma de dois conjuntos de funções gaussianas: o primeiro é obtido deprojetando o brilho superficial com a expressão (H.14) e o segundo corresponde ao que é 
encontrado com um modelo MGE aplicado em alguma parametrização da matéria escura (Navarro et al. 1996).

O potencial gravitacional gerado pela densidade total na equação (H.16) é dado por (Emsellem et al. 1994)

$$
\Phi(R, z)=-\sqrt{\frac{2}{\pi}} G \int_{0}^{1} \sum_{j=1}^{M} \frac{M_{j} H_{j}(u)}{\sigma_{j}} d u,
$$

onde $G$ é a constante gravitacional e

$$
H_{j}(u)=\frac{\exp \left\{-\frac{u^{2}}{2 \sigma_{j}^{2}}\left[R^{2}+\frac{z^{2}}{1-\left(1-q_{j}^{2}\right) u^{2}}\right]\right\}}{\sqrt{1-\left(1-q_{j}^{2}\right) u^{2}}} .
$$

Um buraco negro supermassivo pode ser modelado através da adição de um potencial kepleriano

$$
\Phi .(R, z)=-\frac{G M}{\sqrt{R^{2}+z^{2}}}
$$

à expressão (H.17). Entretanto, conforme foi discutido por Emsellem et al. (1994), uma estratégia ainda mais simples para modelar o efeito de um buraco negro supermassivo consiste em adicionar uma pequena gaussiana à equação (H.17), com $M_{j}=M_{\bullet}, q_{j}=1$ e $3 \sigma_{j} \leq r_{m i n}$, onde $r_{\text {min }}$ corresponde à menor distância a partir do buraco negro central que precisa ser modelada com precisão. Essa foi a estratégia utilizada ao longo desse trabalho.

Aplica-se, então, o formalismo MGE na solução das equações de Jeans. Para manter uma generalidade, essa solução é obtida para cada uma das $N$ componentes gaussianas. Substituindose as expressões (H.14) e (H.17) nas equações (H.11) e (H.12), chega-se a

$$
\left[\eta \overline{v_{R}^{2}}\right]_{k}=b_{k}\left[\eta \overline{v_{z}^{2}}\right]_{k}
$$




$$
\begin{gathered}
{\left[\eta \overline{v_{z}^{2}}\right]_{k}=4 \pi G \int_{0}^{1} \sum_{j=1}^{M} \frac{\sigma_{k}^{2} q_{k}^{2} \eta_{k} q_{j} \rho_{0 j} H_{j}(u) u^{2}}{1-C u^{2}}} \\
{\left[\eta \overline{v_{\varphi}^{2}}\right]_{k}=b_{k}\left[\eta \overline{v_{z}^{2}}\right]_{k}+4 \pi G \int_{0}^{1} \sum_{j=1}^{M} \frac{\eta_{k} q_{j} \rho_{0 j} H_{j}(u) u^{2}}{1-C u^{2}} D R^{2} d u=4 \pi G \int_{0}^{1} \sum_{j=1}^{M} \frac{\eta_{k} q_{j} \rho_{0 j} H_{j}(u) u^{2}}{1-C u^{2}}\left(D R^{2}+b_{k} \sigma_{k}^{2} q_{k}^{2}\right) d u}
\end{gathered}
$$

onde foi definido $\eta_{k}=\eta_{k}(R, z), \rho_{0 j}=\rho_{j}(0,0) \mathrm{e}$

$$
\begin{gathered}
C=1-q_{j}^{2}-\frac{\sigma_{k}^{2} q_{k}^{2}}{\sigma_{j}^{2}} \\
D=1-b_{k} q_{k}^{2}-\left[\left(1-b_{k}\right) C+\left(1-q_{j}^{2}\right) b_{k}\right] u^{2} .
\end{gathered}
$$

Em todas as equações, o índice $k$ se refere aos parâmetros, ou à anisotropia, das gaussianas descrevendo a densidade de luminosidade da galáxia, enquanto que o índice $j$ se refere aos parâmetros das gaussianas descrevendo a massa total, a partir da qual o potencial é calculado. Para se obter os mapas de velocidades observados, é preciso integrar as grandezas obtidas com as equações anteriores ao longo da linha de visada. Esse processo apresenta uma considerável complexidade e não é tratado aqui. Mais detalhes podem ser obtidos em Cappellari (2008). 


\section{Apêndice I}

\section{Equações keplerianas para a simulação de órbitas}

Os parâmetros utilizados no cálculo das órbitas nas simulações descritas nas seções 11.6 e 11.7 são mostrados a seguir.

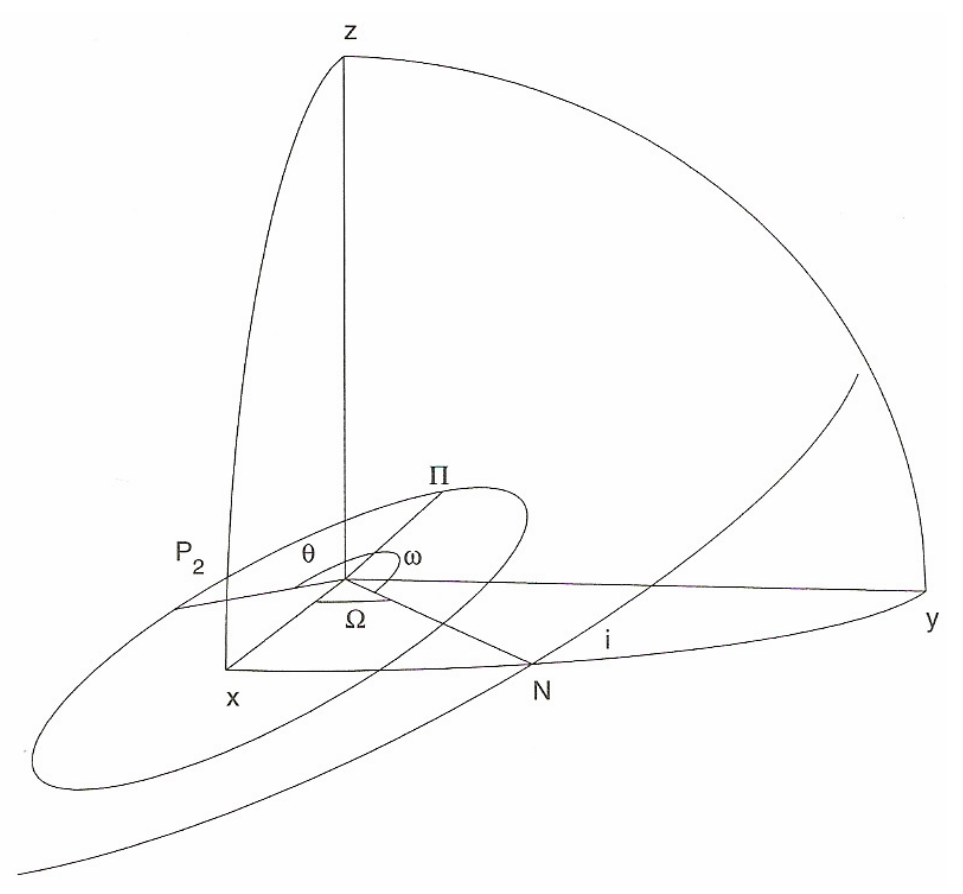

Figura I.1 - Esquema com os parâmetros orbitais levados em conta nas simulações das seções 11.6 e 11.7. O plano tangente ao céu é denotado por xNy e o observador visualiza o sistema ao longo da direção z, a partir da parte inferior da figura. Figura retirada de Hilditch (2001).

Na figura H.1, $i$ = inclinação do disco, $\omega=$ argumento do periastro, $e=$ excentricidade das órbitas e $\Omega=$ longitude do nodo ascendente. A velocidade radial em um ponto qualquer das órbitas é dada por 


$$
V_{\text {rad }}=\operatorname{sen}(i)\left(\frac{G M}{a\left(1-e^{2}\right)}\right)^{\frac{1}{2}}[\cos (\theta+\omega)+e \cos (\omega)]
$$

onde $M=$ massa total interna á órbita

$$
\begin{aligned}
a & =\text { semi-eixo maior da órbita } \\
G & =\text { Constante da Gravitação Universal }
\end{aligned}
$$

As coordenadas $x$ e $y$ projetadas no plano do céu podem ser dadas por

$$
\begin{aligned}
& x=\frac{a\left(1-e^{2}\right)}{(1+e \cos (\theta))}[\cos (\Omega) \cos (\theta+\omega)-\operatorname{sen}(\Omega) \operatorname{sen}(\theta+\omega) \cos (i)] \\
& y=\frac{a\left(1-e^{2}\right)}{(1+e \cos (\theta))}[\operatorname{sen}(\Omega) \cos (\theta+\omega)+\cos (\Omega) \operatorname{sen}(\theta+\omega) \cos (i)]
\end{aligned}
$$

Todas as equações anteriores são demonstradas com detalhes em Hilditch (2001). 